\title{
MULTI-AGENCY
}

\section{RADIATION SURVEY}

\section{AND SITE}

INVESTIGATION

MANUAL

(MARSSIM)

REQFIVD

FFA 10 100

OSTI

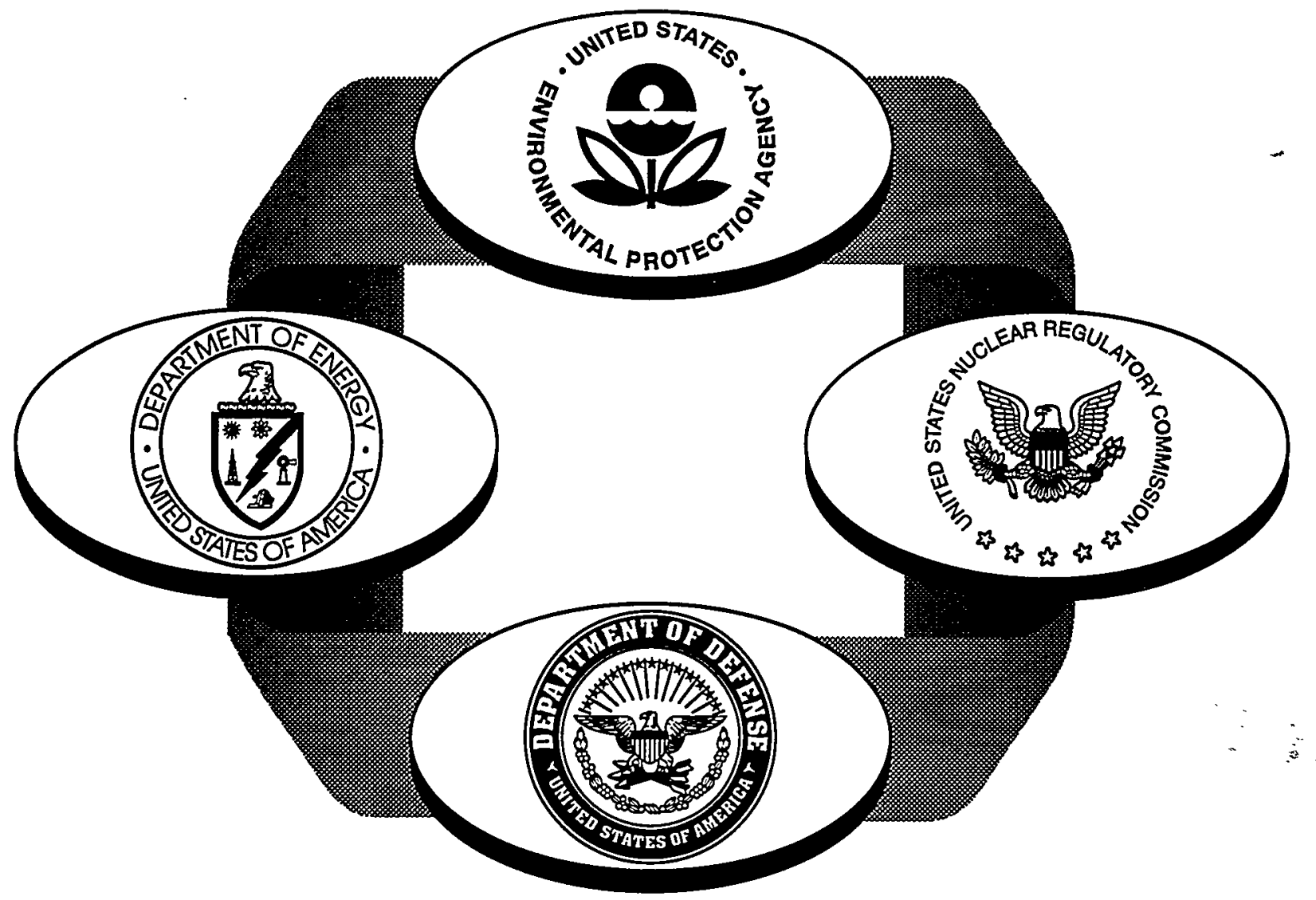

Final

December 1997 


\section{AVAILABILITY NOTICE}

\section{Availability of Reference Materials Cited in This Publication}

Most documents cited in this publication will be available from one of the following sources:

1. Federal agency information resource centers, libraries, and public document rooms such as the Department of Energy Library, 1000 Independence Ave S.W. (Room GA-138), Washington DC 20585; the EPA Information Resources Center, Waterside Mall, 401 M Street, S.W., Washington D.C. 20460; or the NRC Public Document Room, 2120 L Street, N.W., Lower Level, Washington, DC 20555-0001.

2. The Superintendent of Documents, U.S. Government Printing Office, P. O. Box 37082, Washington, DC 20402-9328

3. The National Technical Information Service (NTIS), Springfield, VA 22161-0002

Although the listing that follows represents the majority of documents cited in this publication, it is not intended to be exhaustive. Documents may also be available through the Internet at:

http://www.epa.gov/radiation/marssim or through links with the NRC and DOE home pages, respectively, at: http://www.nrc.gov or http://www.doe.gov.

Referenced documents available for inspection and copying from the NRC and EPA Public Document Rooms, libraries, or dockets generally include rulemaking information; advisory board or committee reports; correspondence and internal memoranda; bulletins, circulars, information notices, inspection and investigation notices; NRC Commission papers; and licensing and permitting reports, documents and correspondence. Copying may require a fee.

The documents available for purchase from the Government Printing Office generally include formal NRC staff and contractor reports, NRC-sponsored conference proceedings, international agreement reports, and NRC booklets and brochures. Also available are regulatory guides, Federal regulations in the Code of Federal Regulations, and Nuclear Regulatory Commission Issuances.

Documents available for purchase from the National Technical Information Service include NUREG-series reports, EPA guidance documents, technical reports prepared by Federal agencies and reports prepared by the Atomic Energy Commission, a forerunner agency that had its authority distributed among the NRC, DOE, DOD, and EPA.

Documents available from public and special technical libraries include all open literature items, such as books, journal articles, and transactions. Federal Register notices, Federal and State legislation, and congressional reports can usually be obtained from these libraries.

Documents such as theses, dissertations, foreign reports, translations, and non-federal conference proceedings are available for purchase from the organization sponsoring the publication cited.

Single copies of NRC draft reports are available free, to the extent of supply, upon written request to the Office of Administration, Distribution and Mail Services Section, U.S. Nuclear Regulatory Commission, Washington DC 20555-0001. Copies of many EPA reports can be obtained from or located through the National Center for Environmental Publications and Information at 1-800-490-9198 or the Office of Research and Development publications office at 1-513-569-7566.

Copies of industry codes and standards used in a substantive manner in the NRC regulatory process are maintained at libraries such as the NRC Library, Two White Flint North, 11545 Rockville Pike, Rockville, MD 20852-2738, for use by the public. Codes and standards are usually copyrighted and may be purchased from the originating organization or, if they are American National Standards, from the American National Standards Institute, 1430 Broadway, New York, NY 10018-3308.

Members of the public are invited to submit written comments arising from the review or use of MARSSIM to EITHER the U.S. Environmental Protection Agency, ATTN: Air and Radiation Docket, Mail Stop 6102, Air Docket No. A-96-44, Room M1500, First Floor Waterside Mall, 401 M Street, S.W., Washington D.C. 20460 or the Chief, Rules and Directives Branch, Division of Administrative Services, U. S. Nuclear Regulatory Commission, Washington DC 20555-0001. As appropriate, revised pages of MARSSIM will be posted on the Internet at: http://www.epa.gov/radiation/marssim. 


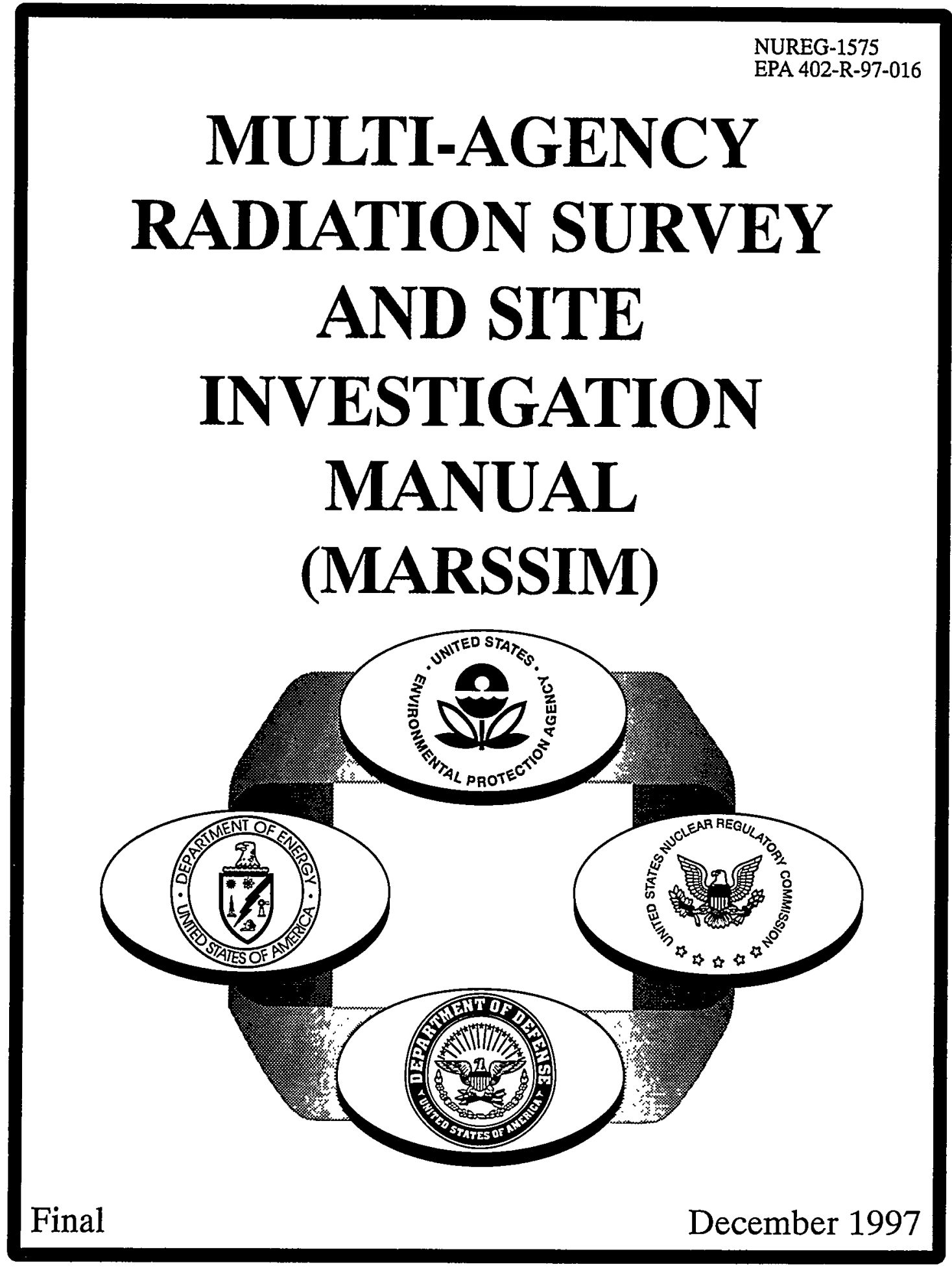

IMTPIBUTION OF THIS DOCUMEAT IS UNLIMTRES 


\section{DISCLAIMER}

Portions of this document may be illegible electronic image products. Images are produced from the best available original document. 


\begin{abstract}
The MARSSIM provides information on planning, conducting, evaluating, and documenting building surface and surface soil final status radiological surveys for demonstrating compliance with dose or risk-based regulations or standards. The MARSSIM is a multi-agency consensus document that was developed collaboratively by four Federal agencies having authority and control over radioactive materials: Department of Defense (DOD), Department of Energy (DOE), Environmental Protection Agency (EPA), and Nuclear Regulatory Commission (NRC). The MARSSIM's objective is to describe a consistent approach for planning, performing, and assessing building surface and surface soil final status surveys to meet established dose or riskbased release criteria, while at the same time encouraging an effective use of resources.
\end{abstract}




\section{DISCLAIMER}

This manual was prepared by four agencies of the United States Government. Neither the United States Government nor any agency or branch thereof, or any of their employees, makes any warranty, expressed or implied, or assumes any legal liability of responsibility for any third party's use, or the results of such use, of any information, apparatus, product, or process disclosed in this manual, or represents that its use by such third party would not infringe on privately owned rights.

References within this manual to any specific commercial product, process, or service by trade name, trademark, or manufacturer does not constitute an endorsement or recommendation by the United States Government. 


\section{CONTENTS}

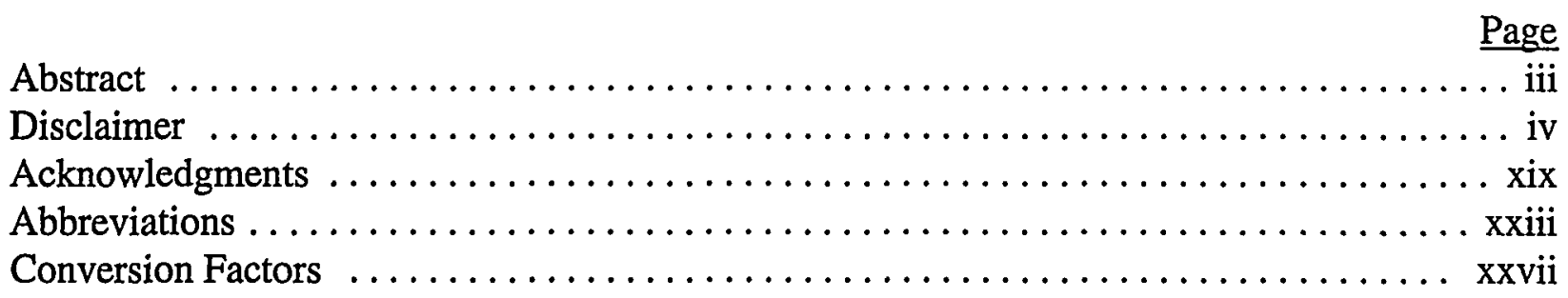

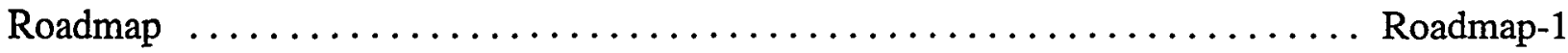

1. Introduction $\ldots \ldots \ldots \ldots \ldots \ldots \ldots \ldots \ldots \ldots \ldots \ldots \ldots \ldots \ldots \ldots \ldots \ldots \ldots \ldots \ldots, 1$

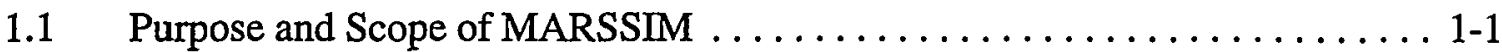

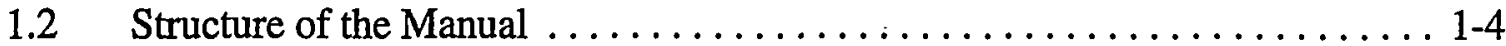

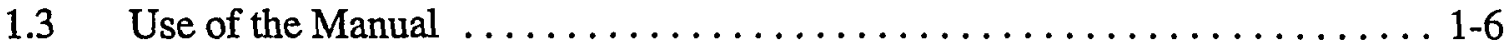

1.4 Missions of the Federal Agencies Producing MARSSIM . . . . . . . . . . 1-7

1.4.1 Environmental Protection Agency . . . . . . . . . . . . . . . 1-7

1.4.2 Nuclear Regulatory Commission ..................... 1-7

1.4.3 Department of Energy . . . . . . . . . . . . . . . . . . . . . $1-7$

1.4.4 Department of Defense $\ldots \ldots \ldots \ldots \ldots \ldots \ldots \ldots \ldots \ldots \ldots \ldots \ldots \ldots \ldots \ldots, 1-8$

2. Overview of the Radiation Survey and Site Investigation Process $\ldots \ldots \ldots \ldots \ldots .2-1$

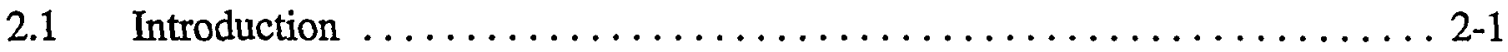

$2.2 \quad$ Understanding Key MARSSIM Terminology $\ldots \ldots \ldots \ldots \ldots \ldots \ldots \ldots 2-2$

2.3 Making Decisions Based on Survey Results $\ldots \ldots \ldots \ldots \ldots \ldots \ldots \ldots . .6 .6$

2.3.1 Planning Effective Surveys-Planning Phase $\ldots \ldots \ldots \ldots \ldots \ldots .2-8$

2.3.2 Estimating the Uncertainty in Survey Results-

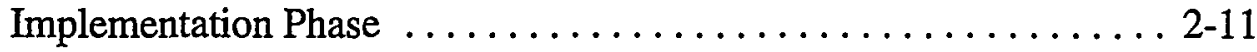

2.3.3 Interpreting Survey Results—Assessment Phase $\ldots \ldots \ldots \ldots \ldots . . \ldots 2-11$

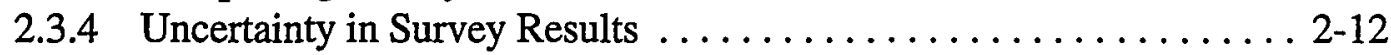

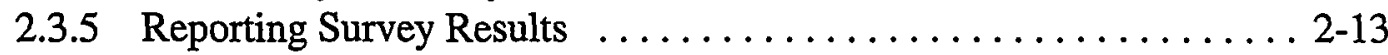

2.4 Radiation Survey and Site Investigation Process $\ldots \ldots \ldots \ldots \ldots \ldots \ldots .2-14$

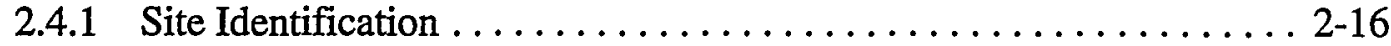

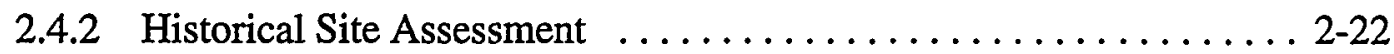

2.4 .3 Scoping Survey $\ldots \ldots \ldots \ldots \ldots \ldots \ldots \ldots \ldots \ldots \ldots \ldots \ldots \ldots \ldots \ldots \ldots \ldots, 22$

2.4.4 Characterization Survey .............................. 2-23

2.4.5 Remedial Action Support Survey $\ldots \ldots \ldots \ldots \ldots \ldots \ldots \ldots . . \ldots \ldots$

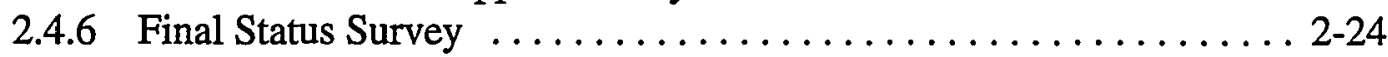

2.4.7 Regulatory Agency Confirmation and Verification .......... 2-25

2.5 Demonstrating Compliance With a Dose-Based Regulation . . . . . . . . . 2-25

2.5.1 The Decision To Use Statistical Tests . . . . . . . . . . . . 2-25

2.5.2 Classification ............................ 2-28

2.5.3 Design Considerations for Small Areas of Elevated Activity . . . . . 2-29 


\section{CONTENTS}

2.5.4 Design Considerations for Relatively Uniform

$\underline{\text { Page }}$

Distributions of Contamination ................... 2-30

2.5.5 Developing an Integrated Survey Design $\ldots \ldots \ldots \ldots \ldots \ldots \ldots .2-31$

2.6 Flexibility in Applying MARSSIM Guidance $\ldots \ldots \ldots \ldots \ldots \ldots \ldots .2-33$

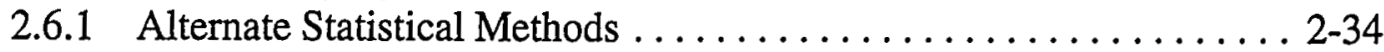

2.6.2 Alternate Null Hypothesis . . . . . . . . . . . . . . . . . . 2-39

2.6.3 Integrating MARSSIM with Other Survey Designs $\ldots \ldots \ldots \ldots .2-39$

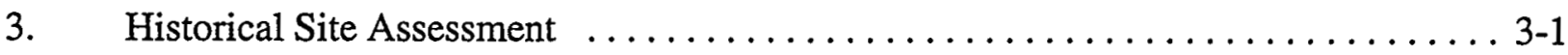

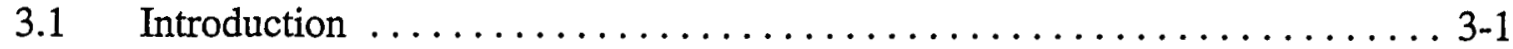

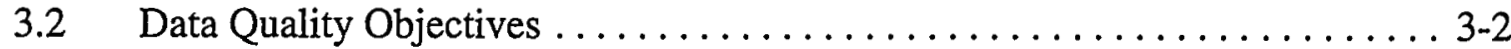

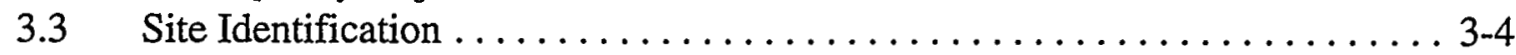

3.4 Preliminary Historical Site Assessment Investigation . . . . . . . . . . . . 3-4

3.4.1 Existing Radiation Data ......................... 3-7

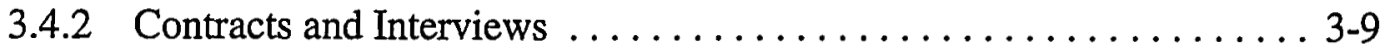

3.5 Site Reconnaissance ............................ 3-9

3.6 Evaluation of Historical Site Assessment Data . . . . . . . . . . . . 3-10

3.6.1 Identify Potential Contaminants $\ldots \ldots \ldots \ldots \ldots \ldots \ldots \ldots, 3-11$

3.6.2 Identify Potentially Contaminated Areas ............... 3-12

3.6.3 Identify Potentially Contaminated Media $\ldots \ldots \ldots \ldots \ldots \ldots . . \ldots \ldots$

3.6.4 Develop a Conceptual Model of the Site . . . . . . . . . . . . . 3-21

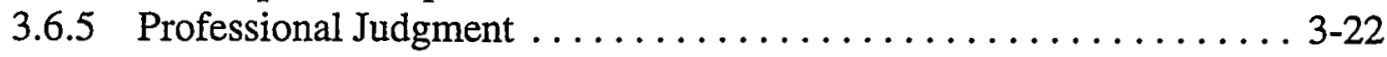

3.7 Determining the Next Step in the Site Investigation Process . . . . . . . . . 3-24

3.8 Historical Site Assessment Report ......................... . 3-24

3.9 Review of the Historical Site Assessment . . . . . . . . . . . . . . 3-25

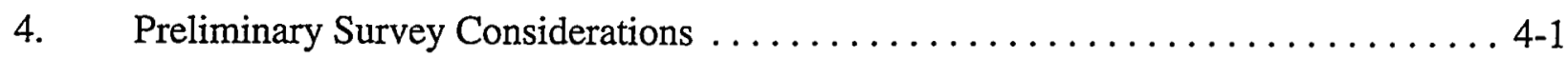

4.1 Introduction $\ldots \ldots \ldots \ldots \ldots \ldots \ldots \ldots \ldots \ldots \ldots \ldots \ldots, \ldots, \ldots, 1$

4.2 Decommissioning Criteria $\ldots \ldots \ldots \ldots \ldots \ldots \ldots \ldots \ldots \ldots \ldots .4 .1$

4.3 Identify Contaminants and Establish Derived Concentration Guideline Levels 4-3

4.3.1 Direct Application of DCGLs . .................. 4-4

4.3.2 DCGLs and the Use of Surrogate Measurements ........... 4-4

4.3.3 Use of DCGLs for Sites With Multiple Radionulcides .......... 4-8

4.3.4 Integrated Surface and Soil Contamination DCGLs ........... 4-8

4.4 Classify Areas by Contamination Potential . . . . . . . . . . . . . . 4-11

4.5 Select Background Reference Areas $\ldots \ldots \ldots \ldots \ldots \ldots \ldots \ldots \ldots .4 .13$

4.6 Identify Survey Units $\ldots \ldots \ldots \ldots \ldots \ldots \ldots \ldots \ldots \ldots \ldots \ldots \ldots \ldots \ldots \ldots \ldots \ldots, 14$ 


\section{CONTENTS}

4.7 Select Instruments and Survey Techniques $\ldots \ldots \ldots \ldots \ldots \ldots \ldots \ldots . \frac{\text { Page }}{4-16}$

4.7.1 Selection of Instruments $\ldots \ldots \ldots \ldots \ldots \ldots \ldots \ldots \ldots \ldots, 4-16$

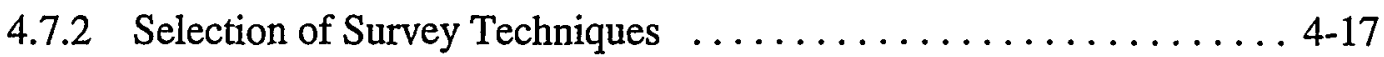

4.7.3 Criteria for Selection of Sample Collection and

Direct Measurement Methods ........................ 4-19

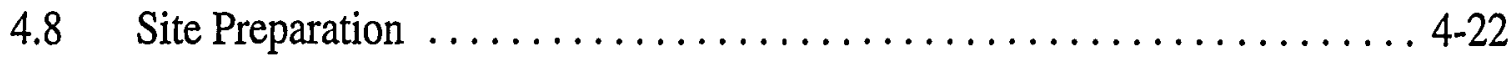

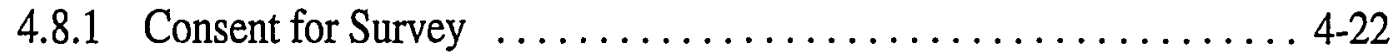

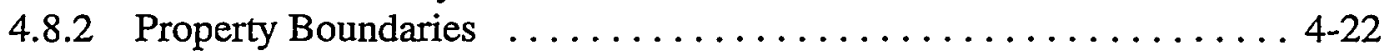

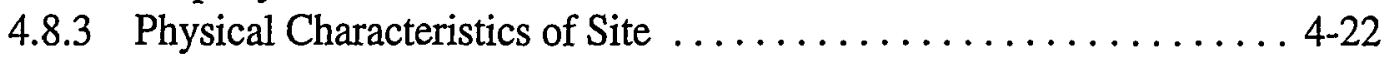

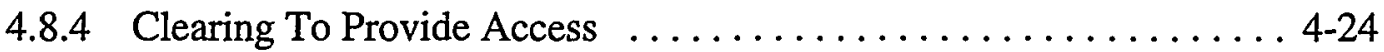

4.8.5 Reference Coordinate System $\ldots \ldots \ldots \ldots \ldots \ldots \ldots \ldots \ldots .4 .27$

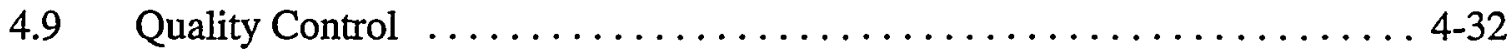

4.9.1 Precision and Systematic Errors (Bias) $\ldots \ldots \ldots \ldots \ldots \ldots \ldots .4 .33$

4.9.2 Number of Quality Control Measurements ............. 4-34

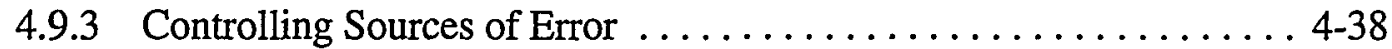

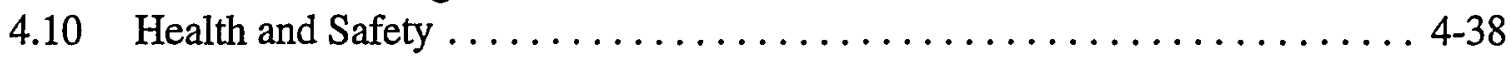

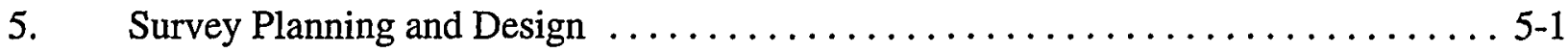

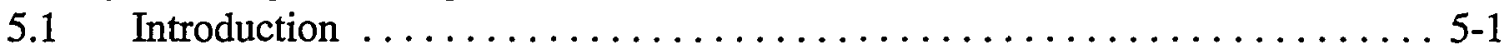

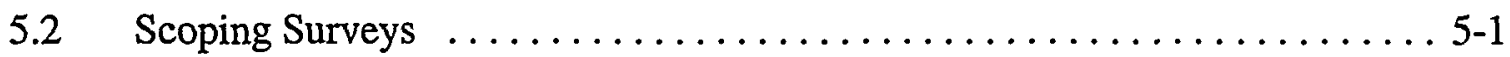

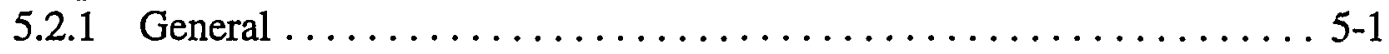

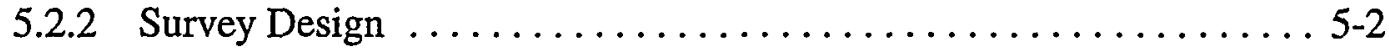

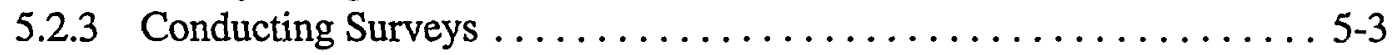

5.2 .4 Evaluating Survey Results $\ldots \ldots \ldots \ldots \ldots \ldots \ldots \ldots \ldots \ldots \ldots \ldots \ldots \ldots \ldots$

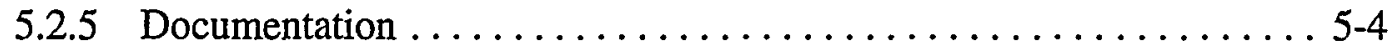

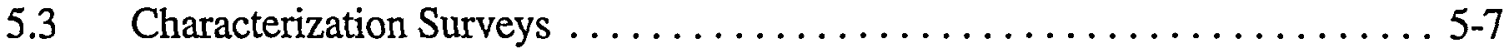

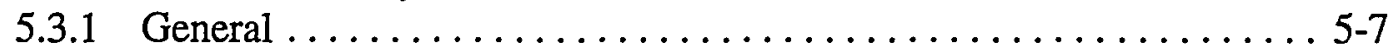

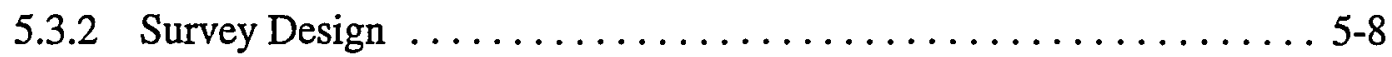

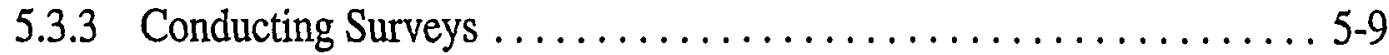

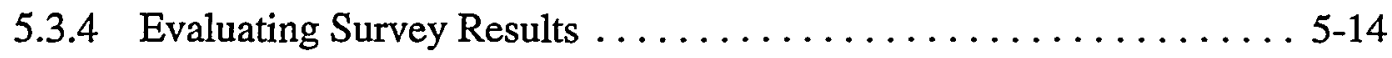

5.3.5 Documentation .............................. 5-15

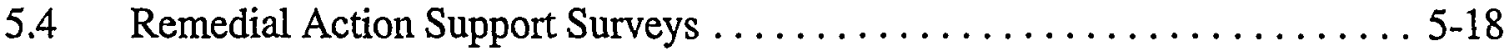

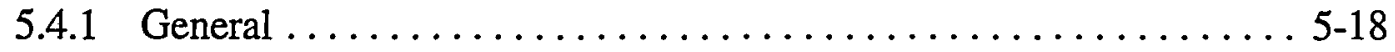

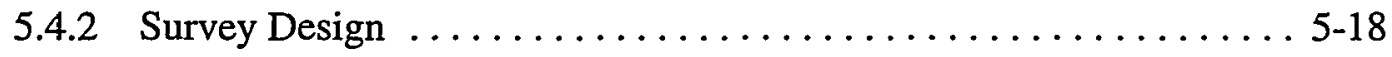

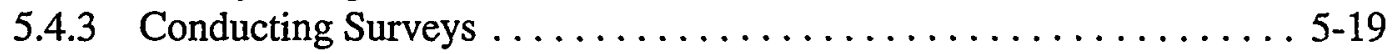

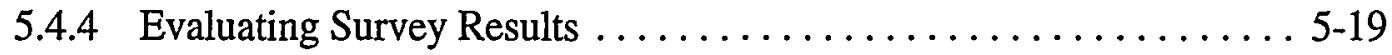

5.4.5 Documentation ............................ 5-19 


\section{CONTENTS}

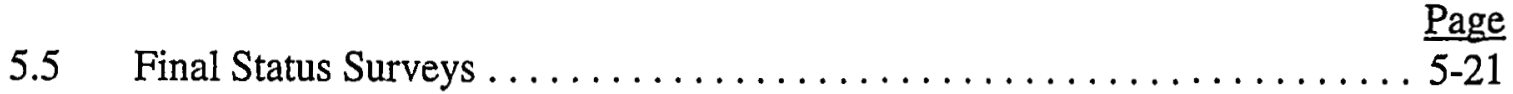

5.5 .1 General $\ldots \ldots \ldots \ldots \ldots \ldots \ldots \ldots \ldots \ldots \ldots \ldots \ldots \ldots, 21$

5.5 .2 Survey Design $\ldots \ldots \ldots \ldots \ldots \ldots \ldots \ldots \ldots \ldots \ldots \ldots, 5-21$

5.5.3 Developing an Integrated Survey Strategy $\ldots \ldots \ldots \ldots \ldots \ldots . . \ldots$ 5-46

5.5 .4 Evaluating Survey Results ..................... 5-52

5.5.5 Documentation ............................ 5-52

6. Field Measurement Methods and Instrumentation $\ldots \ldots \ldots \ldots \ldots \ldots \ldots \ldots 6.1$

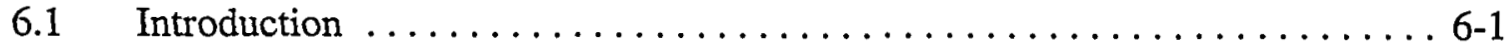

6.2 Data Quality Objectives $\ldots \ldots \ldots \ldots \ldots \ldots \ldots \ldots \ldots \ldots \ldots, 6,2$

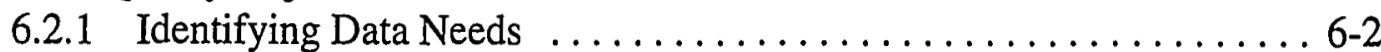

6.2.2 Data Quality Indicators ....................... 6-3

6.3 Selecting a Service Provider to Perform Field Data Collection Activities . . . 6-8

6.4 Measurement Methods ................................ 6-10

6.4.1 Direct Measurements ..........................6 6-10

6.4 .2 Scanning Surveys $\ldots \ldots \ldots \ldots \ldots \ldots \ldots \ldots \ldots \ldots \ldots, 6,13$

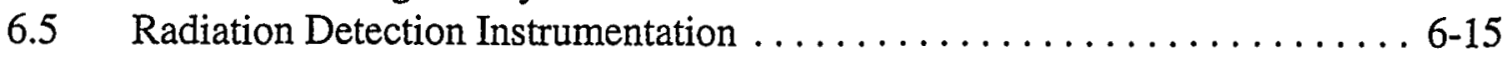

6.5 .1 Radiation Detectors $\ldots \ldots \ldots \ldots \ldots \ldots \ldots \ldots \ldots \ldots, 6-15$

6.5.2 Display and Recording Equipment $\ldots \ldots \ldots \ldots \ldots \ldots \ldots, 6-17$

6.5 .3 Instrument Selection $\ldots \ldots \ldots \ldots \ldots \ldots \ldots \ldots \ldots \ldots \ldots, \ldots, 18$

6.5 .4 Instrument Calibration $\ldots \ldots \ldots \ldots \ldots \ldots \ldots \ldots \ldots \ldots, 6-20$

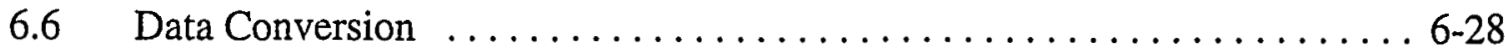

6.6 .1 Surface Activity .............................. 6-29

6.6.2 Soil Radionuclide Concentration and Exposure Rates ........ 6-31

6.7 Detection Sensitivity $\ldots \ldots \ldots \ldots \ldots \ldots \ldots \ldots \ldots \ldots \ldots \ldots .6 .6 \ldots \ldots$

6.7.1 Direct Measurement Sensitivity $\ldots \ldots \ldots \ldots \ldots \ldots \ldots \ldots .6 .6 .32$

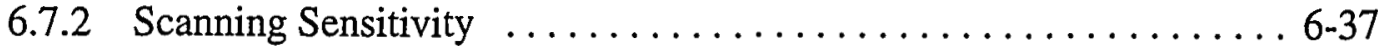

6.8 Measurement Uncertainty (Error) . . . . . . . . . . . . . . . . . . . . . 6-49

6.8.1 Systematic and Random Uncertainties $\ldots \ldots \ldots \ldots \ldots \ldots \ldots .6 .6-50$

6.8 .2 Statistical Counting Uncertainty $\ldots \ldots \ldots \ldots \ldots \ldots \ldots \ldots, 6-52$

6.8 .3 Uncertainty Propagation $\ldots \ldots \ldots \ldots \ldots \ldots \ldots \ldots \ldots .6 .6 .52$

6.8.4 Reporting Confidence Intervals . . . . . . . . . . . . . . . . . . . 6-53

6.9 Radon Measurements . . . . . . . . . . . . . . . . . . . . . . . . 6-55

6.9.1 Direct Radon Measurements . . . . . . . . . . . . . . . . . 6-58

6.9.2 Radon Progeny Measurements . . . . . . . . . . . . . . . . . . 6-59

6.9 .3 Radon Flux Measurements $\ldots \ldots \ldots \ldots \ldots \ldots \ldots \ldots \ldots .6 .60$

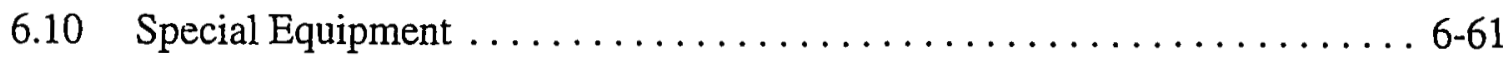

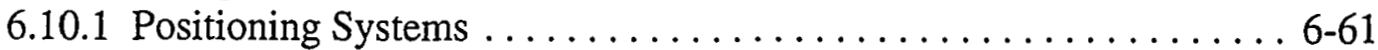

6.10.2 Mobile Systems with Integrated Positioning Systems . . . . . . . 6-62

6.10.3 Radar, Magnetometer, and Electromagnetic Sensors . . . . . . . . 6-63

6.10 .4 Aerial Radiological Surveys $\ldots \ldots \ldots \ldots \ldots \ldots \ldots \ldots \ldots .6 .66$ 


\section{CONTENTS}

7. Sampling and Preparation for Laboratory Measurements $\ldots \ldots \ldots \ldots \ldots \ldots \ldots . \ldots \ldots$ Page

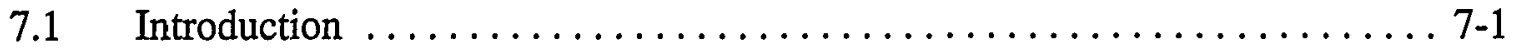

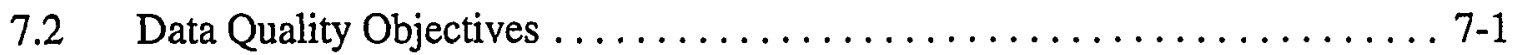

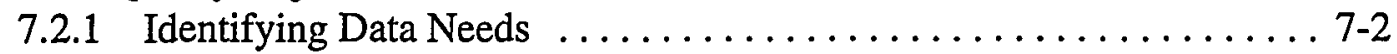

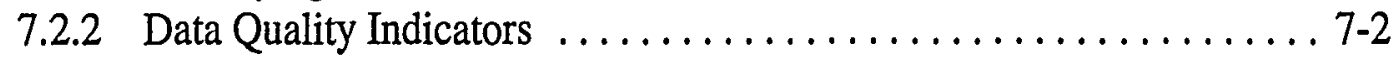

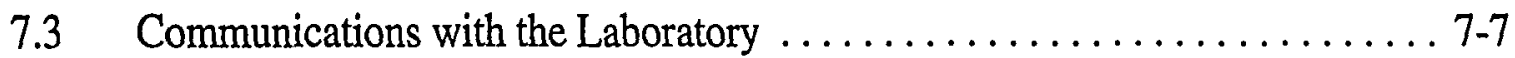

7.3.1 Communications During Survey Planning $\ldots \ldots \ldots \ldots \ldots \ldots \ldots .7-8$

7.3.2 Communications Before and During Sample Collection ......... 7-8

7.3.3 Communications During Sample Analysis . .............. 7-9

7.3.4 Communications Following Sample Analysis . . . . . . . . . . 7-9

7.4 Selecting a Radioanalytical Laboratory $\ldots \ldots \ldots \ldots \ldots \ldots \ldots \ldots \ldots . \ldots \ldots$

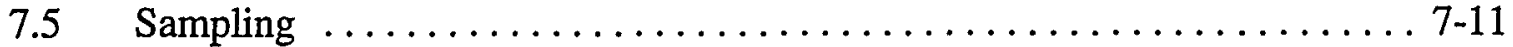

7.5.1 Surface Soil $\ldots \ldots \ldots \ldots \ldots \ldots \ldots \ldots \ldots \ldots \ldots \ldots \ldots \ldots \ldots \ldots \ldots \ldots \ldots \ldots, 12$

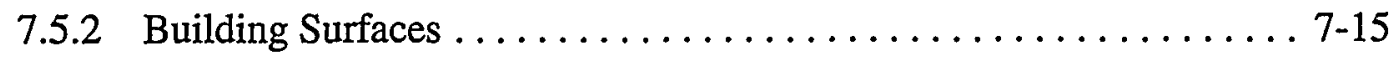

7.5.3 Other Media ............................. 7-16

7.6 Field Sample Preparation and Preservation $\ldots \ldots \ldots \ldots \ldots \ldots \ldots \ldots \ldots .7-16$

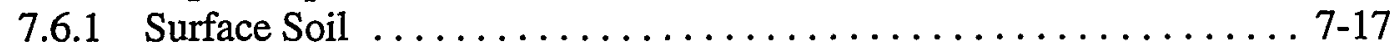

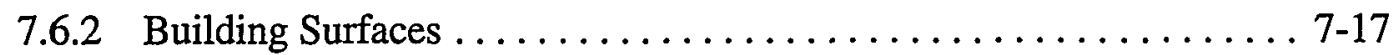

7.6.3 Other Media ................................ $7-17$

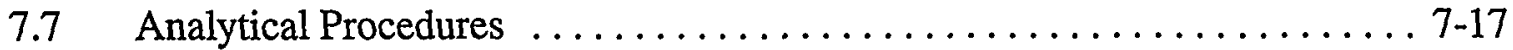

7.7.1 Photon Emitting Radionuclides $\ldots \ldots \ldots \ldots \ldots \ldots \ldots \ldots \ldots \ldots \ldots \ldots \ldots \ldots .21$

7.7.2 Beta Emitting Radionuclides .................... 7-21

7.7.3 Alpha Emitting Radionuclides ..................... 7-22

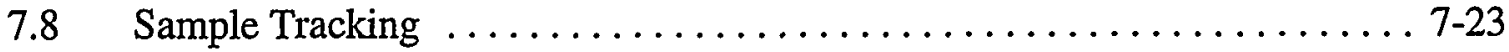

7.8.1 Field Tracking Considerations . . . . . . . . . . . . .

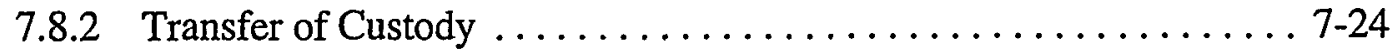

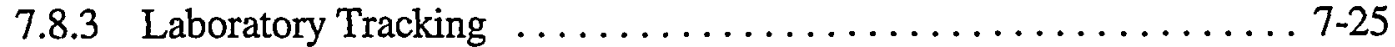

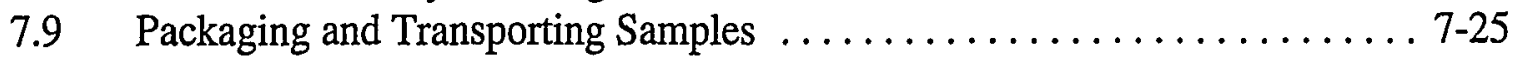

7.9.1 U.S. Nuclear Regulatory Commission Regulations ............ 7-27

7.9.2 U.S. Department of Transportation Regulations . . . . . . . . . . 7-27

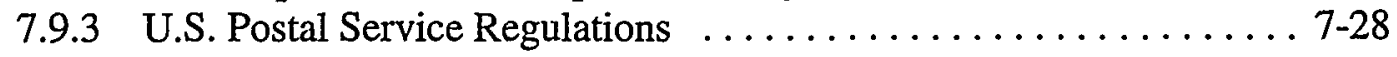

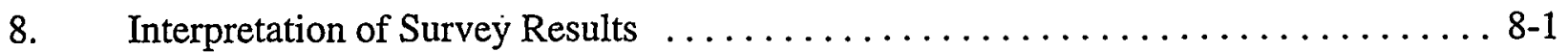

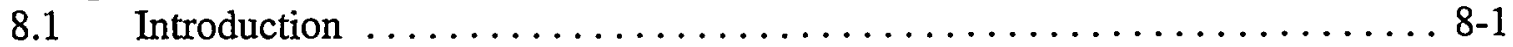

8.2 Data Quality Assessment $\ldots \ldots \ldots \ldots \ldots \ldots \ldots \ldots \ldots \ldots \ldots \ldots .1$

8.2.1 Review the Data Quality Objectives and Sampling

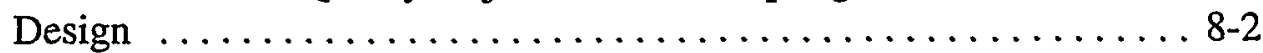

8.2.2 Conduct a Preliminary Data Review $\ldots \ldots \ldots \ldots \ldots \ldots \ldots \ldots . . .6$. 8

8.2.3 Select the Tests $\ldots \ldots \ldots \ldots \ldots \ldots \ldots \ldots \ldots \ldots \ldots . \ldots \ldots$ 


\section{CONTENTS}

8.2 .4 Venify the Assumptions of

8.2.4 Verify the Assumptions of the Tests $\ldots \ldots \ldots \ldots \ldots \ldots \ldots$ 8-7

8.2.5 Draw Conclusions From the Data . . . . . . . . . . . . . . 8-8

8.2 .6 Example .......................... 8-10

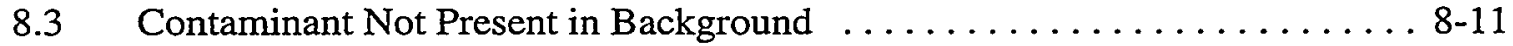

8.3.1 One-Sample Statistical Test . . . . . . . . . . . . . . . . . 8-11

8.3.2 Applying the Sign Test $\ldots \ldots \ldots \ldots \ldots \ldots \ldots \ldots \ldots \ldots .12$

8.3.3 Sign Test Example: Class 2 Exterior Soil Survey Unit . . . . . . . . 8-12

8.3.4 Sign Test Example: Class 3 Exterior Soil Survey Unit . . . . . . . . 8 8-14

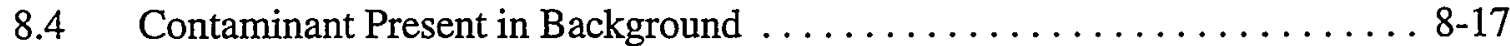

8.4.1 Two-Sample Statistical Test $\ldots \ldots \ldots \ldots \ldots \ldots \ldots \ldots \ldots$ 8-17

8.4.2 Applying the Wilcoxon Rank Sum Test ............ 8-18

8.4.3 Wilcoxon Rank Sum Test Example:

Class 2 Interior Drywall Survey Unit $\ldots \ldots \ldots \ldots \ldots \ldots$. . . . . . . .

8.4.4 Wilcoxon Rank Sum Test Example:

Class 1 Interior Concrete Survey Unit . . . . . . . . . . . . 8-21

8.4.5 Multiple Radionuclides $\ldots \ldots \ldots \ldots \ldots \ldots \ldots \ldots \ldots \ldots \ldots . \ldots . \ldots \ldots$ 8-21

8.5 Evaluating the Results: The Decision ................. 8-21

8.5.1 Elevated Measurement Comparison . . . . . . . . . . . 8-21

8.5.2 Interpretation of Statistical Test Results $\ldots \ldots \ldots \ldots \ldots \ldots \ldots$ 8-23

8.5.3 If the Survey Unit Fails $\ldots \ldots \ldots \ldots \ldots \ldots \ldots \ldots \ldots \ldots . \ldots \ldots . \ldots \ldots$

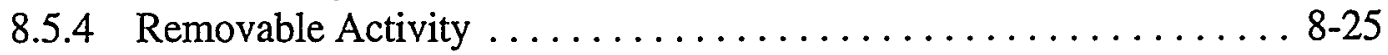

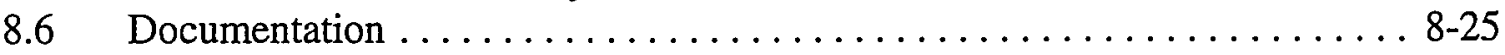

9. ' Quality Assurance and Quality Control ..................... 9-1

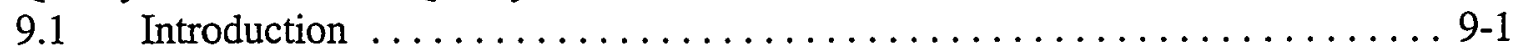

9.2 Development of a Quality Assurance Project Plan .............. 9-3

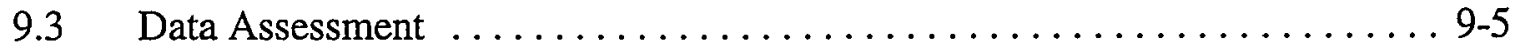

9.3.1 Data Verification ......................... 9-6

9.3.2 Data Validation ............................ 9-7

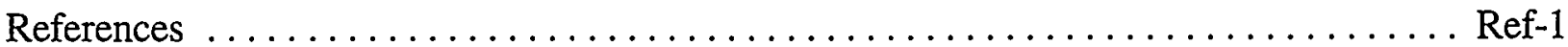

Appendix A Example of MARSSIM Applied to a Final Status Survey $\ldots \ldots \ldots \ldots$. . A-1

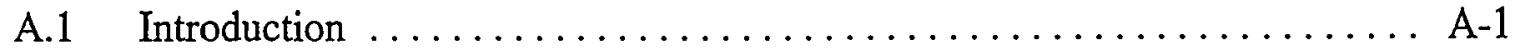

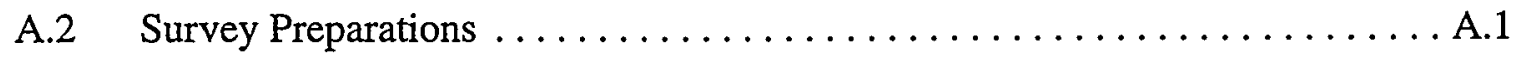

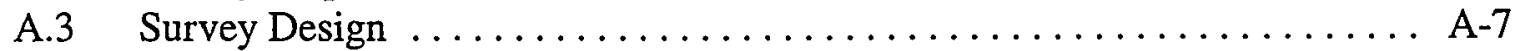

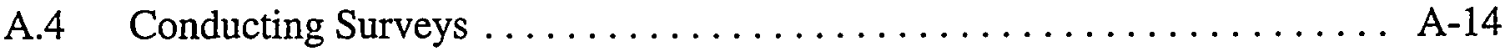

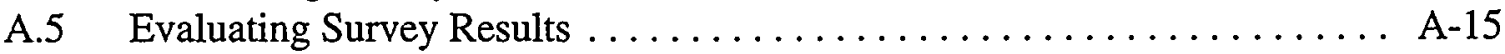




\section{CONTENTS}

Appendix B Simplified Procedure for Certain Users of Sealed Sources, Short

$\underline{\text { Page }}$

Half-Life Materials, and Small Quantities . . . . . . . . . . . . . B-1

Appendix C Site Regulations and Requirements Associated With Radiation

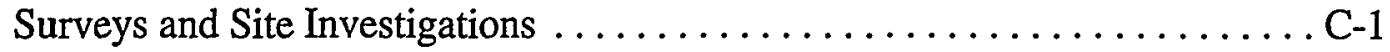

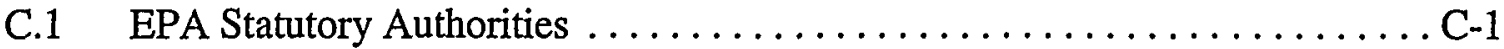

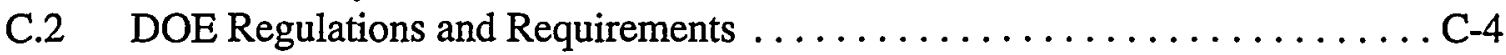

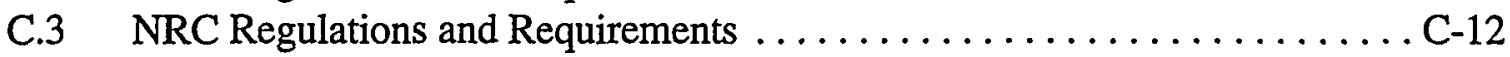

C.4 DOD Regulations and Requirements .................... 15

C.5 State and Local Regulations and Requirements $\ldots \ldots \ldots \ldots \ldots \ldots \ldots$ C-20

Appendix D The Planning Phase of the Data Life Cycle $\ldots \ldots \ldots \ldots \ldots \ldots \ldots \ldots$ D-1

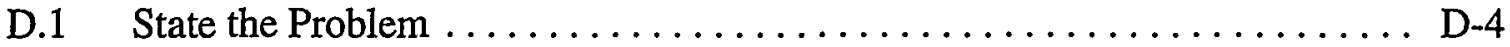

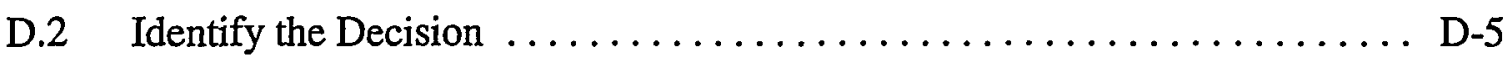

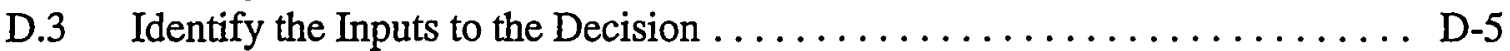

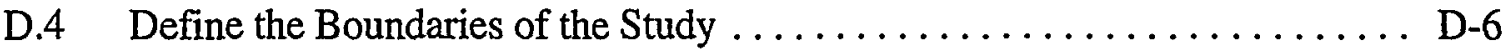

D.5 Develop a Decision Rule ......................... D-8

D. 6 Specify Limits on Decision Errors ...................... D-13

D.7 Optimize the Design for Collecting Data $\ldots \ldots \ldots \ldots \ldots \ldots \ldots \ldots$ D-28

Appendix E The Assessment Phase of the Data Life Cycle $\ldots \ldots \ldots \ldots \ldots \ldots \ldots \ldots$ E-1

E.1 Review DQOs and Survey Design ......................

E.2 Conduct a Preliminary Data Review $\ldots \ldots \ldots \ldots \ldots \ldots \ldots \ldots \ldots \ldots \ldots \ldots \ldots \ldots$

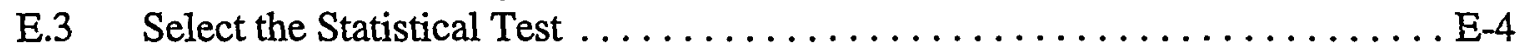

E.4 Verify the Assumptions of the Statistical Test $\ldots \ldots \ldots \ldots \ldots \ldots \ldots$ E-4

E.5 Draw Conclusions from the Data $\ldots \ldots \ldots \ldots \ldots \ldots \ldots \ldots \ldots \ldots \ldots \ldots$

Appendix F The Relationship Between the Radiation Survey and Site Investigation Process, the CERCLA Remedial or Removal Process, and the RCRA Correction Action Process . . . . . . . . . . . . . . . F-1

Appendix G Historical Site Assessment Information Sources . . . . . . . . . . . . G-1

Appendix $\mathrm{H}$ Description of Field Survey and Laboratory Analysis Equipment $\ldots \ldots \ldots$ H-1

H.1 Introduction $\ldots \ldots \ldots \ldots \ldots \ldots \ldots \ldots \ldots \ldots \ldots \ldots \ldots \ldots, \mathrm{H}-3$

H.2 Field Survey Equipment $\ldots \ldots \ldots \ldots \ldots \ldots \ldots \ldots \ldots \ldots \ldots \ldots \ldots \ldots \ldots, \mathrm{H}-5$

H.3 Laboratory Instruments $\ldots \ldots \ldots \ldots \ldots \ldots \ldots \ldots \ldots \ldots \ldots \ldots \ldots \ldots \ldots \ldots \ldots$ 


\section{CONTENTS}

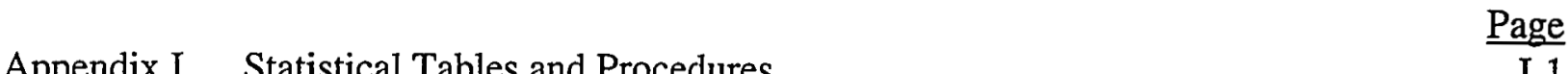

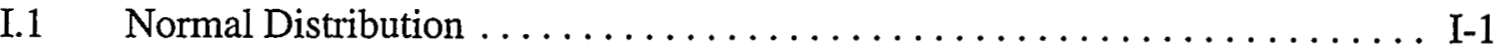

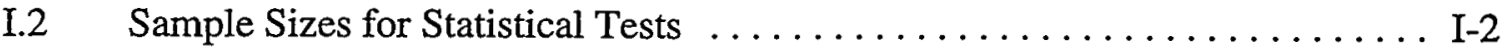

I.3 Critical Values for the Sign Test $\ldots \ldots \ldots \ldots \ldots \ldots \ldots \ldots \ldots \ldots \ldots \ldots$

I.4 Critical Values for the WRS Test $\ldots \ldots \ldots \ldots \ldots \ldots \ldots \ldots \ldots \ldots \ldots$

I.5 Probability of Detecting an Elevated Area $\ldots \ldots \ldots \ldots \ldots \ldots \ldots \ldots$ I-11

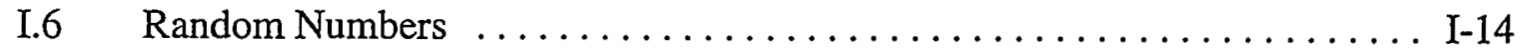

I.7 Stem and Leaf Display . . . . . . . . . . . . . . . . . . . . .

I.8 Quantile Plots ............................... $\ldots \ldots$

I.9 Power Calculations for the Statistical Tests $\ldots \ldots \ldots \ldots \ldots \ldots \ldots \ldots$ I-25

I.10 Spreadsheet Formulas for the Wilcoxon Rank Sum Test ........... I-30

I.11 Multiple Radionuclides . ..................... I-31

Appendix J Derivation of Alpha Scanning Equations Presented in Section 6.7.2.2 . . . . . J-1

Appendix K Comparison Tables Between Quality Assurance Documents . . . . . . . K K-1

Appendix $L \quad$ Regional Radiation Program Managers $\ldots \ldots \ldots \ldots \ldots \ldots \ldots \ldots \ldots \ldots$. $\ldots \ldots$

L.1 Department of Energy . . . . . . . . . . . . . . . . . . . . . L-2

L.2 Environmental Protection Agency $\ldots \ldots \ldots \ldots \ldots \ldots \ldots \ldots \ldots \ldots \ldots$

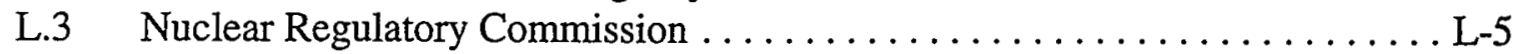

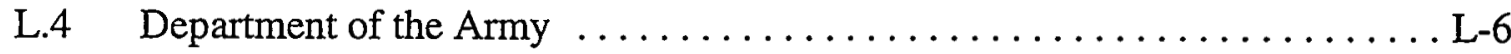

L.5 Department of the Navy ..........................

L.6 Department of the Air Force $\ldots \ldots \ldots \ldots \ldots \ldots \ldots \ldots \ldots \ldots \ldots \ldots$

Appendix M Sampling Methods: A List of Sources $\ldots \ldots \ldots \ldots \ldots \ldots \ldots \ldots \ldots \ldots$

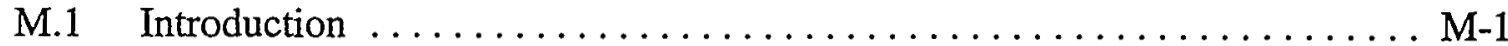

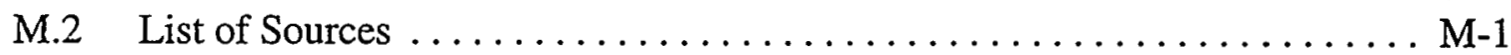

Appendix $N \quad$ Data Validation Using Data Descriptors $\ldots \ldots \ldots \ldots \ldots \ldots \ldots \ldots \ldots$

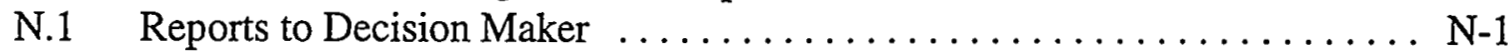

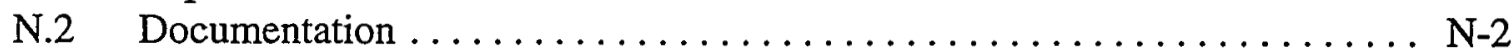

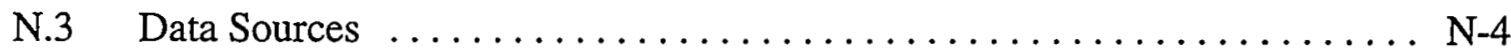

N.4 Analytical Method and Detection Limit $\ldots \ldots \ldots \ldots \ldots \ldots \ldots \ldots$. . . . . . .

N.5 Data Review ................................

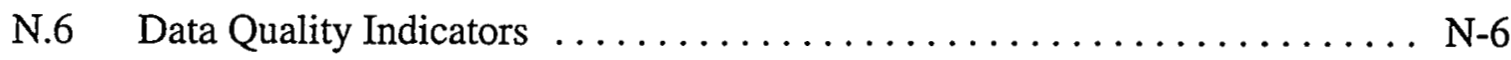

Glossary $\ldots \ldots \ldots \ldots \ldots \ldots \ldots \ldots \ldots \ldots \ldots \ldots \ldots \ldots \ldots \ldots \ldots \ldots \ldots \ldots \ldots$

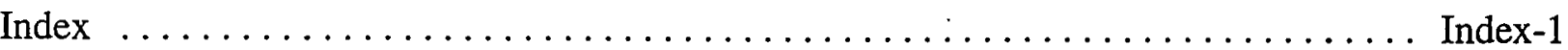




\section{CONTENTS}

\section{LIST OF TABLES}

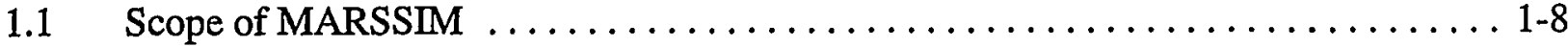

2.1 The Data Life Cycle used to Support the Radiation Survey and

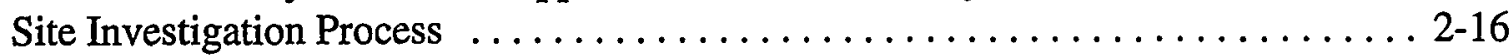

2.2 Recommended Conditions for Demonstrating Compliance Based on Survey Unit Classification for a Final Status Survey $\ldots \ldots \ldots \ldots \ldots \ldots \ldots \ldots \ldots \ldots \ldots \ldots \ldots \ldots .2-32$

2.3 Examples of Alternate Statistical Tests . . . . . . . . . . . . . . . . . .

3.1 Questions Useful for the Preliminary HSA Investigation $\ldots \ldots \ldots \ldots \ldots \ldots . . \ldots$

4.1 Selection of Direct Measurement Techniques Based on Experience $\ldots \ldots \ldots \ldots$. 4-20

4.2 Example of DQO Planning Considerations . . . . . . . . . . . . . . .

4.3 Upper Confidence Limits for the True Variance as a Function of the Number of QC Measurements used to Determine the Estimated Variance ............ 4-36

5.1 Values of $\mathrm{P}_{\mathrm{r}}$ for Given Values of the Relative Shift, $\Delta / \sigma$, when the Contaminant is Present in Background $\ldots \ldots \ldots \ldots \ldots \ldots \ldots \ldots \ldots \ldots \ldots, 5-28$

5.2 Percentiles Represented by Selected Values of $\alpha$ and $\beta \ldots \ldots \ldots \ldots \ldots \ldots .5-28$

5.3 Values of $N / 2$ for Given Values of the Relative Shift $(\Delta / \sigma), \alpha$, and $\beta$ when the Contaminant is Present in Background ....................... 5-30

5.4 Values of Sign $p$ for Given Values of the Relative Shift, $\Delta / \sigma$, when the Contaminant is Not Present in Background .................... 5-32

5.5 Values of $\mathrm{N}$ for Given Values of the Relative Shift $(\Delta / \sigma), \alpha$, and $\beta$ when the Contaminant is Not Present in Background .................... 5-34

5.6 Illustrative Examples of Outdoor Area Dose Factors $\ldots \ldots \ldots \ldots \ldots \ldots \ldots \ldots .5-37$

5.7 Illustrative Examples of Indoor Area Dose Factors $\ldots \ldots \ldots \ldots \ldots \ldots \ldots . . \ldots . . \ldots .37$

5.8 Example Final Status Survey Investigation Levels $\ldots \ldots \ldots \ldots \ldots \ldots \ldots \ldots .5-45$

5.9 Recommended Survey Coverage for Structures and Land Areas ........... 5-47

6.1 Radiation Detectors With Applications for Alpha Surveys . . . . . . . . . . . 6-20

6.2 Radiation Detectors With Applications for Beta Surveys . . . . . . . . . . . . 6-21

6.3 Radiation Detectors With Applications for Gamma Surveys ............. 6-22

6.4 Examples of Estimated Detection Sensitivities for Alpha and Beta Survey

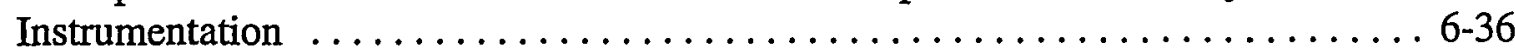

6.5 Values of $d^{\prime}$ for Selected True Positive and False Positive Proportions . . . . . . . 6-40

6.6 Scanning Sensitivity (MDCR) of the Ideal Observer for Various Background Levels . ................................ 6-41 


\section{LIST OF TABLES}

6.7 $\mathrm{NaI}(\mathrm{TI})$ Scintillation Detector Scan MDCs for Common Radiological

Page

Contaminants ................................... 6-47

6.8 Probability of Detecting $300 \mathrm{dpm} / 100 \mathrm{~cm}^{2}$ of Alpha Activity While Scanning with Alpha Detectors Using an Audible Output . ..................... 6-49

6.9 Areas Under Various Intervals About the Mean of a Normal Distribution . . . . . . . 6-54

6.10 Radiation Detectors with Applications to Radon Surveys .............. 6-57

6.11 Typical Radar Penetration Depths for Various Geologic Materials .......... . 6-64

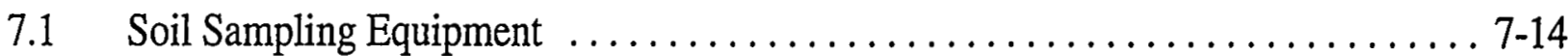

7.2 Examples of Sources for Routine Analytical Methods .............. 7-18

7.3 Typical Measurement Sensitivities for Laboratory Radiometric Procedures . . . . . 7-20

8.1 Methods for Checking the Assumptions of Statistical Tests . . . . . . . . . . . . 8-8

8.2 Summary of Statistical Tests $\ldots \ldots \ldots \ldots \ldots \ldots \ldots \ldots \ldots \ldots \ldots \ldots \ldots .6 \ldots \ldots$

8.3 Final Status Survey Parameters for Example Survey Units $\ldots \ldots \ldots \ldots \ldots \ldots$ 8-10

8.4 Example Sign Analysis: Class 2 Exterior Soil Survey Unit $\ldots \ldots \ldots \ldots \ldots \ldots \ldots$ 8-14

8.5 Sign Test Example Data for Class 3 Exterior Survey Unit $\ldots \ldots \ldots \ldots \ldots \ldots \ldots$ 8 16

8.6 WRS Test for Class 2 Interior Drywall Survey Unit $\ldots \ldots \ldots \ldots \ldots \ldots \ldots$ 8-20

9.1 The Elements of a Quality System Related to the Data Life Cycle ........... 9-2

9.2 Examples of QAPP Elements for Site Surveys and Investigations . . . . . . . . 9-4

9.3 Suggested Content or Consideration, Impact if Not Met, and Corrective Actions for Data Descriptors . . . . . . . . . . . . . . . . . . . .

A.1 Class 1 Interior Concrete Survey Unit and Reference Area Data . . . . . . . . . A-15

A.2 Stem and Leaf Displays for Class 1 Interior Concrete Survey Unit $\ldots \ldots \ldots \ldots$ A-16

A.3 WRS Test for Class 1 Interior Concrete Survey Unit $\ldots \ldots \ldots \ldots \ldots \ldots \ldots$ A-18

C.1 DOE Authorities, Orders and Regulations Related to Radiation Protection . . . . . . C-5

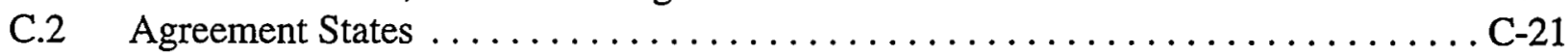

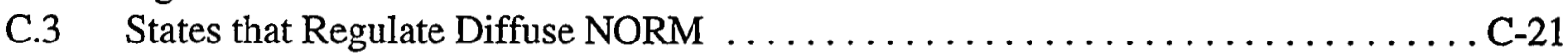

D.1 Example Representation of Decision Errors for a Final Status Survey ......... D-15

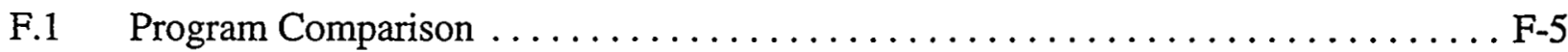

F.2 Data Elements for Site Visits . . . . . . . . . . . . . . . . . . . . . . F-10

F.3 Comparison of Sampling Emphasis Between Remedial Site Assessment

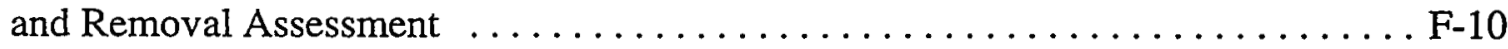

G.1 Site Assessment Information Sources (Organized by Information Needed) . . . . . . G-2

G.2 Site Assessment Information Sources (Organized by Information Source) $\ldots \ldots \ldots$. G-7 


\section{LIST OF TABLES}

Page

H.1 Radiation Detectors with Applications to Alpha Surveys $\ldots \ldots \ldots \ldots \ldots \ldots \ldots$ H-50

H.2 Radiation Detectors with Applications to Beta Surveys $\ldots \ldots \ldots \ldots \ldots \ldots \ldots$ H-52

H.3 Radiation Detectors with Applications to Gamma Surveys $\ldots \ldots \ldots \ldots \ldots \ldots$. -53

H.4 Radiation Detectors with Applications to Radon Surveys $\ldots \ldots \ldots \ldots \ldots \ldots$ H-55

H.5 Systems that Measure Atomic Mass or Emissions $\ldots \ldots \ldots \ldots \ldots \ldots \ldots$ H-56

I.1 Cumulative Normal Distribution Function $\Phi(\mathrm{z}) \ldots \ldots \ldots \ldots \ldots \ldots \ldots \ldots \ldots \ldots \ldots \ldots$

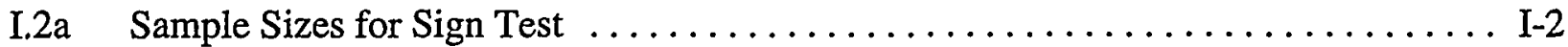

I.2b Sample Sizes for Wilcoxon Rank Sum Test $\ldots \ldots \ldots \ldots \ldots \ldots \ldots \ldots \ldots \ldots \ldots \ldots \ldots \ldots$

I.3 Critical Values for the Sign Test Statistic S+ $\ldots \ldots \ldots \ldots \ldots \ldots \ldots \ldots \ldots \ldots \ldots \ldots \ldots \ldots \ldots$

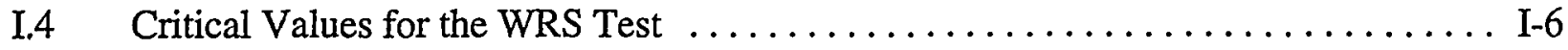

I.5 Risk that an Elevated Area with Length $\mathrm{L} / \mathrm{G}$ and Shape $\mathrm{S}$ will not be Detected and the Area (\%) of the Elevated Area Relative to a

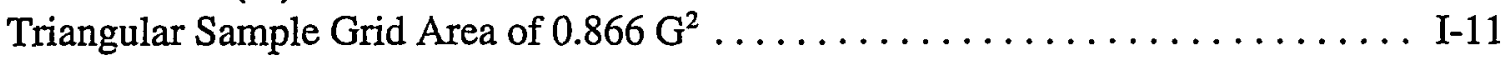

I.6 1,000 Random Numbers Uniformly Distributed between Zero and One . . . . . . . I-14

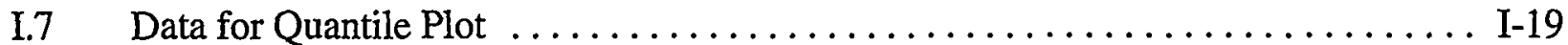

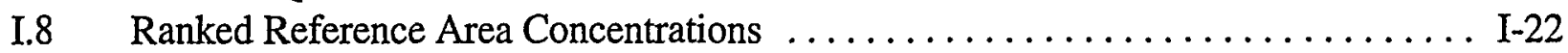

I.9 Interpolated Ranks for Survey Unit Concentrations I-23

I.10 Values of $P_{r}$ and $p_{2}$ for Computing the Mean and Variance of $W_{M W} \ldots \ldots \ldots \ldots$ I-28

I.11 Spreadsheet Formulas Used in Table $8.7 \ldots \ldots \ldots \ldots \ldots \ldots \ldots \ldots \ldots \ldots$ I-30

I.12 Example WRS Test for Two Radionuclides $\ldots \ldots \ldots \ldots \ldots \ldots \ldots \ldots \ldots$ I-35

K.1 Comparison of EPA QA/R-5 and EPA QAMS-005/80 $\ldots \ldots \ldots \ldots \ldots \ldots \ldots$ K-2

K.2 Comparison of EPA QA/R-5 and ASME NQA-1 $\ldots \ldots \ldots \ldots \ldots \ldots \ldots \ldots \ldots, \mathrm{K}-3$

K.3 Comparison of EPA QA/R-5 and DOE Order $5700.6 \mathrm{c} \ldots \ldots \ldots \ldots \ldots \ldots \ldots$ K-4

K.4 Comparison of EPA QA/R-5 and MIL-Q-9858A $\ldots \ldots \ldots \ldots \ldots \ldots \ldots \ldots \ldots$ K-5

K.5 Comparison of EPA QA/R-5 and ISO $9000 \ldots \ldots \ldots \ldots \ldots \ldots \ldots \ldots \ldots \ldots \ldots \ldots$

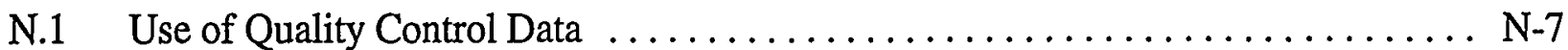

N.2 Minimum Considerations for Precision, Impact if Not Met,

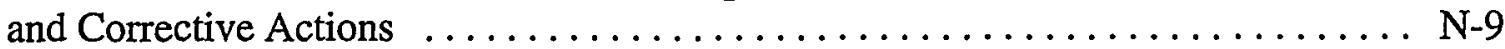

N.3 Minimum Considerations for Bias, Impact if Not Met,

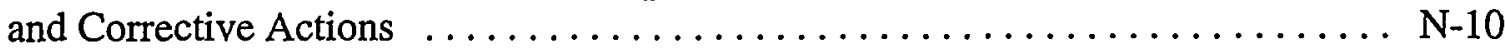

N.4 Minimum Considerations for Representativeness, Impact if Not Met,

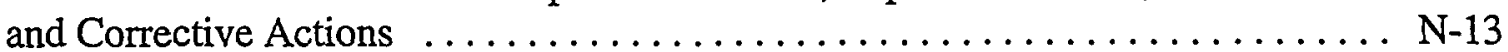

N.5 Minimum Considerations for Comparability, Impact if Not Met,

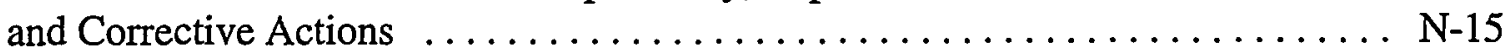

N.6 Minimum Considerations for Completeness, Impact if Not Met, and Corrective Actions 


\section{CONTENTS}

\section{LIST OF FIGURES}

1.1 Page

Compliance Demonstration..$\ldots \ldots \ldots \ldots \ldots \ldots \ldots \ldots \ldots \ldots \ldots \ldots \ldots \ldots \ldots$

2.1 The Data Life Cycle $\ldots . \ldots \ldots \ldots \ldots \ldots \ldots \ldots \ldots \ldots \ldots \ldots \ldots \ldots . \ldots \ldots$

2.2 The Data Quality Objectives Process $\ldots \ldots \ldots \ldots \ldots \ldots \ldots \ldots \ldots \ldots \ldots \ldots \ldots$

2.3 The Assessment Phase of the Data Life Cycle . . . . . . . . . . . . . . . 2-12

2.4 The Radiation Survey and Site Investigation Process

in Terms of Area Classification . . . . . . . . . . . . . . . . . . . 2-17

2.5 The Historical Site Assessment Portion of the

Radiation Survey and Site Investigation Process $\ldots \ldots \ldots \ldots \ldots \ldots \ldots \ldots$ 2-18

2.6 The Scoping Survey Portion of the Radiation Survey and

Site Investigation Process . . . . . . . . . . . . . . . . . . . . 2-19

2.7 The Characterization and Remedial Action Support Survey Portion of the

Radiation Survey and Site Investigation Process . . . . . . . . . . . . . 2-20

2.8 The Final Status Survey Portion of the Radiation Survey and

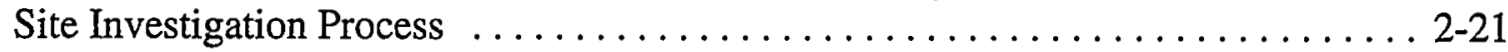

3.1 Example Showing How a Site Might Be Classified Prior to Cleanup

Based on the Historical Site Assessment . . . . . . . . . . . . . . . . . . 3-23

3.2 Example of a Historical Site Assessment Report Format . . . . . . . . . . . 3-26

4.1 Sequence of Preliminary Activities Leading to Survey Design . . . . . . . . . . 4-2

4.2 Flow Diagram for Selection of Field Survey Instrumentation for

Direct Measurements and Analysis of Samples . . . . . . . . . . . . . 4-18

4.3 Indoor Grid Layout With Alphanumeric Grid Block Designation . . . . . . . . . 4-28

4.4 Example of a Grid System for Survey of Site Grounds Using Compass Directions .. 4-29

4.5 Example of a Grid System for Survey of Site Grounds Using Distances

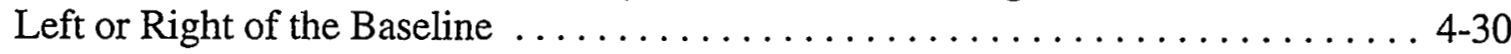

5.1 Flow Diagram Illustrating the Process for Identifying Measurement Locations . . . 5-22

5.2 Flow Diagram for Identifying the Number of Data Points, N, for Statistical Tests . . 5-23

5.3 Flow Diagram for Identifying Data Needs for Assessment of Potential Areas of

Elevated Activity in Class 1 Survey Units . . . . . . . . . . . . . . . . . . 5-24

5.4 Example of a Random Measurement Pattern . . . . . . . . . . . . . . 5-41

5.5 Example of a Random-Start Triangular Grid Measurement Pattern . . . . . . . . . 5-43

6.1 The Physical Probe Area of a Detector . . . . . . . . . . . . . . . . . . . . . . . 6-29

6.2 Graphically Represented Probabilities for Type I and Type II Errors in Detection

Sensitivity for Instrumentation With a Background Response . . . . . . . . . 6-33 


\section{LIST OF FIGURES}

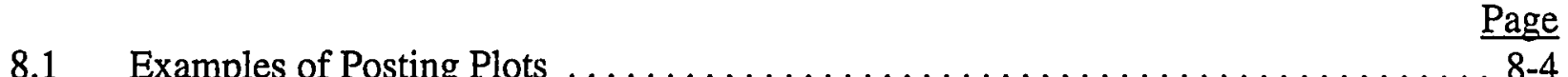

8.2 Example of a Frequency Plot $\ldots \ldots \ldots \ldots \ldots \ldots \ldots \ldots \ldots \ldots . \ldots \ldots$

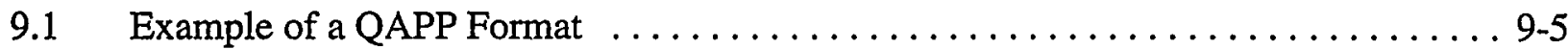

A.1 Plot Plan for the Specialty Source Manufacturing Company $\ldots \ldots \ldots \ldots \ldots$ A-3

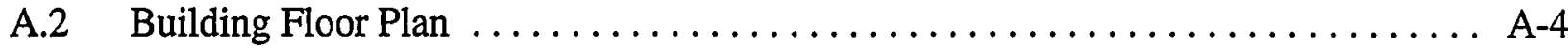

A.3 Examples of Scanning Patterns for Each Survey Unit Classification .......... A-6

A.4 Reference Coordinate System for the Class 1 Interior Concrete Survey Unit . . . . . A A-8

A.5 Power Chart for the Class 1 Interior Concrete Survey Unit ................ A-9

A.6 Prospective Power Curve for the Class 1 Interior Concrete Survey Unit . . . . . . . A A-12

A.7 Measurement Grid for the Class 1 Interior Concrete Survey Unit . ........... A-13

A.8 Quantile-Quantile Plot for the Class 1 Interior Concrete Survey Unit .......... A-17

A.9 Retrospective Power Curve for the Class 1 Interior Concrete Survey Unit ....... A-20

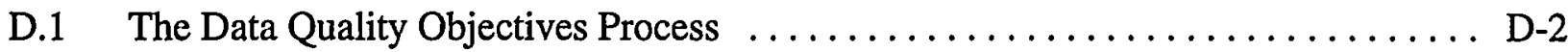

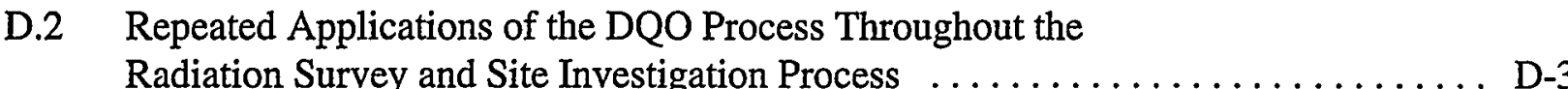

D.3 Example of the Parameter of Interest for the 1-Sample Case $\ldots \ldots \ldots \ldots \ldots \ldots$ D-11

D.4 Example of the Parameter of Interest for the 2-Sample Case ............. D-12

D.5 Possible Statement of the Null Hypothesis for the Final Status Survey

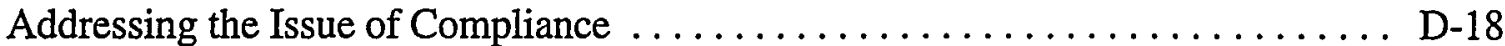

D.6 Possible Statement of the Null Hypothesis for the Final Status Survey

Addressing the Issue of Indistinguishability from Background . . . . . . . . . D 19

D.7 Geometric Probability of Sampling at Least One Point of an

Area of Elevated Activity as a Function of Sample Density with

Either a Square or Triangular Sampling Pattern $\ldots \ldots \ldots \ldots \ldots \ldots \ldots \ldots$ D-24

D.8 Example of a Power Chart Illustrating the Decision Rule for the

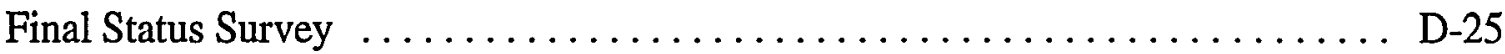

D.9 Example of an Error Chart Illustrating the Decision Rule for the

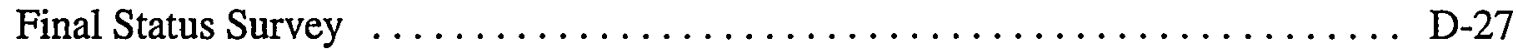

E.1 The Assessment Phase of the Data Life Cycle $\ldots \ldots \ldots \ldots \ldots \ldots \ldots \ldots \ldots$ E-2

F.1 Comparison of the Radiation Survey and Site Investigation Process with the CERCLA Superfund Process and the RCRA Corrective Action Process ......... F-2 


\section{LIST OF FIGURES}

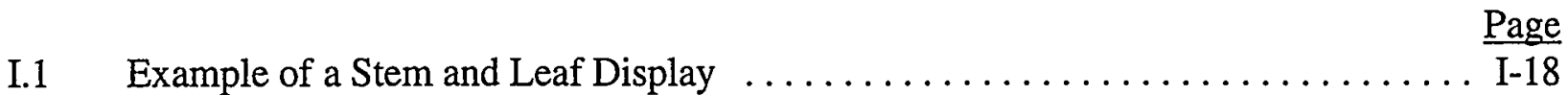

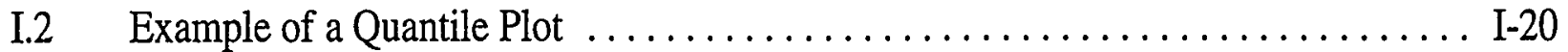

I.3 Quantile Plot for Example Class 2 Exterior Survey Unit of Section 8.3.3 . . . . . . I-21

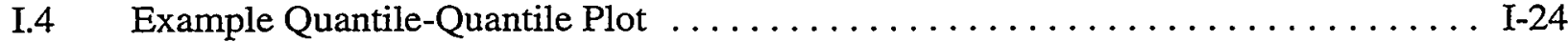

I.5 Retrospective Power Curve for Class 3 Exterior Survey Unit $\ldots \ldots \ldots \ldots \ldots \ldots$ I-26

I.6 Retrospective Power Curve for Class 2 Interior Drywall Survey Unit . . . . . . . . . I-29

J.1 Probability (P) of Getting One or More Counts When Passing Over a $100 \mathrm{~cm}^{2}$ Area Contaminated at $500 \mathrm{dpm} / 100 \mathrm{~cm}^{2}$ Alpha .................. J-5

J.2 Probability $(\mathrm{P})$ of Getting One or More Counts When Passing Over a $100 \mathrm{~cm}^{2}$ Area Contaminated at $1,000 \mathrm{dpm} / 100 \mathrm{~cm}^{2}$ Alpha ................. J-6

J.3 Probability (P) of Getting One or More Counts When Passing Over a $100 \mathrm{~cm}^{2}$ Area Contaminated at $5,000 \mathrm{dpm} / 100 \mathrm{~cm}^{2}$ Alpha ................. J-7

J.4 Probability (P) of Getting Two or More Counts When Passing Over a $100 \mathrm{~cm}^{2}$ Area Contaminated at $500 \mathrm{dpm} / 100 \mathrm{~cm}^{2}$ Alpha $\ldots \ldots \ldots \ldots \ldots \ldots \ldots . . . . .6$

J.5 Probability (P) of Getting Two or More Counts When Passing Over a $100 \mathrm{~cm}^{2}$ Area Contaminated at $1,000 \mathrm{dpm} / 100 \mathrm{~cm}^{2}$ Alpha .................. J-9

J.6 Probability (P) of Getting Two or More Counts When Passing Over a $100 \mathrm{~cm}^{2}$ Area Contaminated at $5,000 \mathrm{dpm} / 100 \mathrm{~cm}^{2}$ Alpha $\ldots \ldots \ldots \ldots \ldots \ldots \ldots \ldots . \ldots . . .10$

N.1 Measurement Bias and Random Measurement Uncertainty $\ldots \ldots \ldots \ldots \ldots$ N-11 


\section{ACKNOWLEDGMENTS}

The Multi-Agency Radiation Survey and Site Investigation Manual (MARSSIM) came about as a result of individuals-at the management level-within the Environmental Protection Agency (EPA), Nuclear Regulatory Commission (NRC), Department of Energy (DOE), and Department of Defense (DOD) who recognized the necessity for a standardized guidance document for investigating radioactively contaminated sites. The creation of the MARSSIM was facilitated by the cooperation of subject matter specialists from these agencies with management's support and a willingness to work smoothly together toward reaching the common goal of creating a workable and user-friendly guidance manual. Special appreciation is extended to Robert A. Meck of the NRC and Anthony Wolbarst of EPA for developing the concept of a multi-agency work group and bringing together representatives from the participating agencies.

The MARSSIM could not have been possible without the technical work group members who contributed their time, talent, and efforts to develop this consensus guidance document:

CDR Colleen F. Petullo, U.S. Public Health Service, EPA, Chair

EPA: Mark Doehnert

Anthony Wolbarst, Ph.D.

H. Benjamin Hull

Sam Keith, CHP*

Jon Richards

NRC: Robert A. Meck, Ph.D.

Anthony Huffert

George E. Powers, Ph.D.

David Fauver, CHP

Cheryl Trottier
DOE: Hal Peterson, CHP

Kenneth Duvall

Andrew Wallo III
DOD: David Alberth, CHP (Army)

LCDR Lino Fragoso, Ph.D. (Navy)

Lt. Col. Donald Jordan (Air Force)

Capt. Kevin Martilla (Air Force)

Capt. Julie Coleman (Air Force)

Special mention is extended to the Federal agency contractors for their assistance in developing the MARSSIM:

EPA: Scott Hay (S. Cohen \& Associates, Inc.)

Todd Peterson, Ph.D. (S. Cohen \& Associates, Inc.)

Harry Chmelynski, Ph.D. (S. Cohen \& Associates, Inc.)

Ralph Kenning, CHP (S. Cohen \& Associates, Inc.)

NRC: Eric Abelquist, CHP (Oak Ridge Institute of Science and Education)

James Berger (Auxier \& Associates)

Carl Gogolak, Ph.D. (DOE/EML, under contract with NRC)

* Formerly with EPA National Air and Radiation Environmental Laboratory (NAREL). Currently with the Agency for Toxic Substances and Disease Registry (ATSDR). 


\section{ACKNOWLEDGMENTS}

DOE: Robert Coleman, CHP (Oak Ridge National Laboratory)

John Kirk Williams (Oak Ridge National Laboratory)

Romance Carrier (Oak Ridge National Laboratory)

A special thank you is extended to Emilio Braganza (EPA), Gregory Budd (EPA), Mary Clark, Ph.D. (EPA), Brian Littleton (EPA), John Karhnak (EPA), Sarah Seeley (EPA), Rett Sutton (EPA/SEE), Juanita Beeson (NRC), Stephen A. McGuire, Ph.D. (NRC), Walter Oliu (NRC), LT James Coleman (Navy), CDR David E. Farrand (U.S Navy), CAPT David George (Navy), CDR Garry Higgins (Navy), CAPT James Malinoski (Navy), Harlan Keaton (State of Florida), J. Michael Beck, J.D. (EMS), Tom McLaughlin, Ph.D. (SC\&A), Kevin Miller, Ph.D. (DOE/EML), and the members of the EPA's Science Advisory Board (SAB) for their assistance in developing the manual.

The membership of the SAB Radiation Advisory Committee's Review Subcommittee that conducted an extensive peer review of the MARSSIM includes:

Chair

James E. Watson, Jr., Ph.D., University of North Carolina at Chapel Hill

Members

William Bair, Ph.D., (Retired), Battelle Pacific Northwest Laboratory

Stephen L. Brown, Ph.D., R2C2 (Risks of Radiation and Chemical Compounds)

June Fabryka-Martin, Ph.D., Los Alamos National Laboratory

Thomas F. Gesell, Ph.D., Idaho State University

F. Owen Hoffman, Ph.D., SENES Oak Ridge, Inc.

Janet Johnson, Ph.D., Shepherd Miller, Inc.

Bernd Kahn, Ph.D., Georgia Institute of Technology

Ellen Mangione, M.D., Colorado Department of Health

Paul J. Merges, Ph.D., New York State Department of Environmental Conservation

\section{$\underline{\text { SAB Consultants }}$}

Michael E. Ginevan, Ph.D., M.E. Ginevan \& Associates

David G. Hoel, Ph.D., University of South Carolina

David E. McCurdy, Ph.D., Yankee Atomic Electric Company

Frank L. Parker, Ph.D., Vanderbilt University [Liaison from Environmental Management Advisory Board, U.S. Department of Energy]

Science Advisory Board Staff

K. Jack Kooyoomjian, Ph.D., Designated Federal Official, EPA

Mrs. Diana L. Pozun, Staff Secretary, EPA 


\section{ACKNOWLEDGMENTS}

The work group meetings were open to the public, and the following people attended meetings as technical experts at the request of the work group or as observers:

$\begin{array}{llll}\text { K. Allison } & \text { A.T. Kearney } & \text { N. Lailas } & \text { EPA } \\ \text { L. Abramson } & \text { NRC } & \text { H. Larson } & \text { NRC } \\ \text { R. Abu-Eid } & \text { NRC } & \text { G. Lindsey } & \text { International Atomic } \\ \text { W. Beck } & \text { Oak Ridge Institute of } & & \text { Energy Agency } \\ & \text { Science and Education } & \text { J. Lux } & \text { Kerr-McGee Corporation } \\ \text { A. Boerner } & \text { Oak Ridge Institute of } & \text { M. Mahoney } & \text { Army } \\ & \text { Science and Education } & \text { J. Malaro } & \text { NRC } \\ \text { Lt. E. Bonano } & \text { Air Force } & \text { H. Morton } & \text { Morton Associates } \\ \text { M. Boyd } & \text { EPA } & \text { H. Mukhoty } & \text { EPA } \\ \text { J. Buckley } & \text { NRC } & \text { A.J. Nardi } & \text { Westinghouse } \\ \text { B. Burns } & \text { Army } & \text { D. Ottlieg } & \text { Westinghouse Hanford } \\ \text { W. Cottrell } & \text { Oak Ridge } & & \text { Company } \\ & \text { National Laboratory } & \text { V. Patania } & \text { Oak Ridge } \\ \text { D. Culberson } & \text { Nuclear Fuel Services, } & & \text { National Laboratory } \\ & \text { Inc. } & \text { C.L. Pittiglio } & \text { NRC } \\ \text { M.C. Daily } & \text { NRC } & \text { C. Raddatz } & \text { NRC } \\ \text { M. Eagle } & \text { EPA } & \text { L. Ralston } & \text { SC\&A, Inc. } \\ \text { M. Frank } & \text { Booz, Allen \& Hamilton } & \text { P. Reed } & \text { NRC } \\ \text { F. Galpin } & \text { RAE Corp. } & \text { R. Rodriguez } & \text { Oak Ridge } \\ \text { R. Gilbert } & \text { Pacific Northwest } & & \text { National Laboratory } \\ & \text { Laboratory } & \text { N. Rohnig } & \\ \text { J.E. Glenn } & \text { NRC } & \text { R. Schroeder } & \text { Army } \\ \text { J. Hacala } & \text { Booz, Allen \& Hamilton } & \text { C. Simmons } & \text { Kilpatrick \& Cody } \\ \text { L. Hendricks } & \text { Nuclear Environmental } & \text { E. Stamataky } & \text { EPA } \\ & \text { Services } & \text { R. Story } & \text { Foster Wheeler } \\ \text { K. Hogan } & \text { EPA } & \text { E. Temple } & \text { EPA } \\ \text { R. Hutchinson } & \text { National Institute of } & \text { D. Thomas } & \text { Air Force } \\ & \text { Standards and } & \text { S. Walker } & \text { EPA } \\ \text { G. Jablonowski } & \text { EPA } & \text { P. White } & \text { EPA } \\ & & \text { R. Wilhelm } & \text { EPA } \\ & & & \end{array}$




\section{ABBREVIATIONS}

\begin{tabular}{|c|c|}
\hline AEA & Atomic Energy Act \\
\hline AEC & Atomic Energy Commission \\
\hline AFI & Air Force Instructions \\
\hline ALARA & as low as reasonably achievable \\
\hline AMC & Army Material Command \\
\hline ANSI & American National Standards Institute \\
\hline AR & Army Regulations \\
\hline ASTM & American Society of Testing and Materials \\
\hline ATSDR & Agency for Toxic Substances and Disease Registry \\
\hline CAA & Clean Air Act \\
\hline Capt. & Captain (Air Force) \\
\hline CAPT & Captain (Navy) \\
\hline CDR & Commander \\
\hline CEDE & committed effective dose equivalent \\
\hline CERCLA & Comprehensive Environmental Response, Compensation, and Liability Act \\
\hline CERCLIS & $\begin{array}{l}\text { Comprehensive Environmental Response, Compensation, and Liability } \\
\text { Information System }\end{array}$ \\
\hline CFR & Code of Federal Regulations \\
\hline CHP & Certified Health Physicist \\
\hline CPM & counts per minute \\
\hline DARA & Department of the Army Radioactive Material Authorization \\
\hline DCF & dose conversion factor \\
\hline DCGL & derived concentration guideline level \\
\hline DEFT & Decision Error Feasibility Trials \\
\hline DLC & Data Life Cycle \\
\hline DOD & Department of Defense \\
\hline DOE & Department of Energy \\
\hline DOT & Department of Transportation \\
\hline DQA & Data Quality Assessment \\
\hline DQO & Data Quality Objectives \\
\hline EERF & Eastern Environmental Radiation Facility \\
\hline Ehf & human factors efficiency \\
\hline EMC & elevated measurement comparison \\
\hline EML & Environmental Measurements Laboratory \\
\hline EMMI & Environmental Monitoring Methods Index \\
\hline EPA & Environmental Protection Agency \\
\hline EPIC & Environmental Photographic Interpretation Center \\
\hline ERAMS & Environmental Radiation Ambient Monitoring System \\
\hline
\end{tabular}




\begin{tabular}{|c|c|}
\hline FEMA & Federal Emergency Management Agency \\
\hline FIRM & Flood Insurance Rate Maps \\
\hline FRDS & Federal Reporting Data System \\
\hline FSP & Field Sampling Plan \\
\hline FWPCA & Federal Water Pollution Control Act \\
\hline FUSRAP & Formerly Utilized Sites Remedial Action Program \\
\hline GEMS & Geographical Exposure Modeling System \\
\hline GM & Geiger-Mueller \\
\hline GPS & global positioning system \\
\hline GRIDS & Geographic Resources Information Data System \\
\hline GWSI & Ground Water Site Inventory \\
\hline $\mathrm{H}_{0}$ & null hypothesis \\
\hline $\mathrm{H}_{\mathrm{a}}$ & alternative hypothesis \\
\hline HSA & Historical Site Assessment \\
\hline HSWA & Hazardous and Solid Waste Amendments \\
\hline ISI & Information System Inventory \\
\hline $\mathrm{L}_{\mathrm{C}}$ & critical level \\
\hline $\mathrm{L}_{\mathrm{D}}$ & detection limit \\
\hline LBGR & lower bound of the gray region \\
\hline LCDR & Lieutenant Commander \\
\hline LLRWPA & Low Level Radioactive Waste Policy Act as Amended \\
\hline LT & Lieutenant \\
\hline MARLAP & Multi-Agency Radiation Laboratory Analytical Protocols (Manual) \\
\hline MARSSIM & Multi-Agency Radiation Survey and Site Investigation Manual \\
\hline $\mathrm{MCA}$ & multichannel analyzer \\
\hline MDC & minimum detectable concentration \\
\hline MDCR & minimum detectable count rate \\
\hline MED & Manhattan Engineering District \\
\hline NARM & naturally occurring or accelerator produced radioactive material \\
\hline NCAPS & National Corrective Action Prioritization System \\
\hline NCRP & National Council on Radiation Protection and Measurements \\
\hline NCP & National Contingency Plan \\
\hline NIST & National Institute of Standards and Technology \\
\hline NORM & naturally occurring radioactive material \\
\hline NPDC & National Planning Data Corporation \\
\hline
\end{tabular}




\section{ABBREVIATIONS}

NPDES

NRC

NWPA

NWWA

ODES

ORNL

ORISE

PERALS

PIC

QA

QAPP

QC

QMP

RASP

RAGS/HHEM

RC

RCRA

RCRIS

RI/FS

ROD

RODS

RSSI

SARA

SAP

SDWA

SFMP

SOP

STORET

TEDE

TLD

TRU

TSCA
National Pollutant Discharge Elimination System

Nuclear Regulatory Commission

Nuclear Waste Policy Act

National Water Well Association

Ocean Data Evaluation System

Oak Ridge National Laboratory

Oak Ridge Institute for Science and Education

photon electron rejecting alpha liquid scintillator

pressurized ionization chamber

quality assurance

Quality Assurance Project Plan

quality control

Quality Management Plan

Radiological Affairs Support Program

Risk Assessment Guidance for Superfund/Human Health Evaluation Manual release criterion

Resource Conservation and Recovery Act

Resource Conservation and Recovery Information System

Remedial Investigation/Feasibility Study

Record of Decision

Records of Decision System

Radiation Survey and Site Investigation

Superfund Amendments and Reauthorization Act

Sampling and Analysis Plan

Safe Drinking Water Act

Surplus Facilities Management Program

Standard Operating Procedures

Storage and Retrieval of U.S. Waterways Parametric Data

total effective dose equivalent

thermoluminescence dosimeter

transuranic

Toxic Substances Control Act 


\[ \text { ABBREVIATIONS } \]
Uranium Mill Tailings Radiation Control Act
United States Geological Survey
United States Public Health Service
Ultrasonic Ranging and Data System
National Water Data Storage and Retrieval System
working level
Wilcoxon rank sum
Wilcoxon signed ranks
Wilcoxon test

UMTRCA

USGS

USPHS

USRADS

WATSTORE National Water Data Storage and Retrieval System

WL

WRS

WSR

WT

\author{
Wilcoxon test \\ Uranium Mill Tailings Radiation Control Act \\ United States Public Health Service \\ working level \\ Wilcoxon signed ranks
}


CONVERSION FACTORS

\begin{tabular}{|c|c|c|c|c|c|}
\hline $\begin{array}{l}\text { To Convert } \\
\text { From }\end{array}$ & To & Multiply By & $\begin{array}{l}\text { To Convert } \\
\text { From }\end{array}$ & To & Multiply By \\
\hline \multirow[t]{2}{*}{ acre } & $\begin{array}{l}\text { hectare } \\
\text { sq. meter }\left(\mathrm{m}^{2}\right)\end{array}$ & $\begin{array}{l}0.405 \\
4,050\end{array}$ & meter $(\mathrm{m})$ & $\begin{array}{l}\text { inch } \\
\text { mile }\end{array}$ & $\begin{array}{l}39.4 \\
0.000621\end{array}$ \\
\hline & sq. feet $\left(\mathrm{ft}^{2}\right)$ & 43,600 & \multirow[t]{2}{*}{ sq. meter $\left(\mathrm{m}^{2}\right)$} & acre & 0.000247 \\
\hline becquerel $(\mathrm{Bq})$ & $\begin{array}{l}\text { curie }(\mathrm{Ci}) \\
\mathrm{dps} \\
\mathrm{pCi}\end{array}$ & $\begin{array}{l}2.7 \times 10^{-11} \\
1 \\
27\end{array}$ & & $\begin{array}{l}\text { hectare } \\
\text { sq. feet }\left(\mathrm{ft}^{2}\right) \\
\text { sq. mile }\end{array}$ & $\begin{array}{l}0.0001 \\
10.8 \\
3.86 \times 10^{-7}\end{array}$ \\
\hline $\mathrm{Bq} / \mathrm{kg}$ & $\mathrm{pCi} / \mathrm{g}$ & 0.027 & $\mathrm{~m}^{3}$ & liter & 1,000 \\
\hline $\mathrm{Bq} / \mathrm{m}^{2}$ & $\mathrm{dpm} / 100 \mathrm{~cm}^{2}$ & 1.67 & mrem & $\mathrm{mSv}$ & 0.01 \\
\hline \multirow[t]{2}{*}{$\mathrm{Bq} / \mathrm{m}^{3}$} & $\mathrm{~Bq} / \mathrm{L}$ & 0.001 & $\mathrm{mrem} / \mathrm{y}$ & $\mathrm{mSv} / \mathrm{y}$ & 0.01 \\
\hline & $\mathrm{pCi} / \mathrm{L}$ & 0.027 & $\mathrm{mSv}$ & mrem & 100 \\
\hline centimeter $(\mathrm{cm})$ & inch & 0.394 & $\mathrm{mSv} / \mathrm{y}$ & mrem/y & 100 \\
\hline \multirow[t]{2}{*}{$\mathrm{Ci}$} & $\mathrm{Bq}$ & $3.70 \times 10^{10}$ & ounce (oz) & liter $(\mathrm{L})$ & 0.0296 \\
\hline & $\mathrm{pCi}$ & $1 \times 10^{12}$ & $\mathrm{pCi}$ & $\begin{array}{l}\mathrm{Bq} \\
\mathrm{dpm}\end{array}$ & $\begin{array}{l}0.037 \\
0.45 \\
\end{array}$ \\
\hline \multirow[t]{2}{*}{ dps } & dpm & 0.0167 & $\mathrm{pCi} / \mathrm{g}$ & $\mathrm{Bq} / \mathrm{kg}$ & 37 \\
\hline & $\mathrm{pCi}$ & 27 & $\mathrm{pCi} / \mathrm{L}$ & $\mathrm{Bq} / \mathrm{m}^{3}$ & 37 \\
\hline \multirow[t]{2}{*}{$\mathrm{dpm}$} & dps & 60 & $\mathrm{rad}$ & Gy & 0.01 \\
\hline & & 2.22 & \multirow[t]{3}{*}{ rem } & mrem & 1,000 \\
\hline gray (Gy) & $\mathrm{rad}$ & 100 & & $\mathrm{mSv}$ & 10 \\
\hline hectare & acre & 2.47 & & Sv & 0.01 \\
\hline liter (L) & $\begin{array}{l}\mathrm{cm}^{3} \\
\mathrm{~m}^{3} \\
\text { ounce (fluid) }\end{array}$ & $\begin{array}{l}1000 \\
0.001 \\
33.8 \\
\end{array}$ & seivert (Sv) & $\begin{array}{l}\text { mrem } \\
\mathrm{mSv} \\
\text { rem }\end{array}$ & $\begin{array}{l}100,000 \\
1,000 \\
100\end{array}$ \\
\hline
\end{tabular}




\section{ROADMAP}

\section{Introduction to MARSSIM}

The Multi-Agency Radiation Survey and Site Investigation Manual (MARSSIM) provides detailed guidance for planning, implementing, and evaluating environmental and facility radiological surveys conducted to demonstrate compliance with a dose- or risk-based regulation. The MARSSIM guidance focuses on the demonstration of compliance during the final status survey following scoping, characterization, and any necessary remedial actions.

The process of planning the survey, implementing the survey plan, and assessing the survey results prior to making a decision is called the Data Life Cycle. MARSSIM Chapter 2 and Appendix D provide detailed guidance on developing appropriate survey designs using the Data Quality Objectives (DQO) Process to ensure that the survey results are of sufficient quality and quantity to support the final decision. The survey design process is described in MARSSIM Chapters 3, 4, and 5. Guidance on selecting appropriate measurement methods (i.e., scan surveys, direct measurements, samples) and measurement systems (i.e., detectors, instruments, analytical methods) is provided in MARSSIM Chapters 6 and 7 and Appendix H. Data Quality Assessment (DQA) is the process of assessing the survey results, determining that the quality of the data satisfies the objectives of the survey, and interpreting the survey results as they apply to the decision being made. The DQA process is described in MARSSIM Chapter 2 and Appendix E and is applied in MARSSIM Chapter 8. Quality Assurance and Quality Control (QA/QC) procedures are developed and recorded in survey planning documents, such as a Quality Assurance Project Plan (QAPP) which is described in MARSSIM Chapter 9

MARSSIM does not provide guidance for translating the release criterion into derived concentration guideline levels (DCGLs). MARSSIM discusses contamination of surface soil and building surfaces in detail. If other media (e.g., ground water, surface water, subsurface soil, equipment, vicinity properties) are potentially contaminated at the time of the final status survey, modifications to the MARSSIM survey design guidance and examples may be required.

\section{The Goal of the Roadmap}

The goal of the roadmap is to present a summary of the major steps in the design, implementation, and assessment of a final status survey and to identify where guidance on these steps is located in MARSSIM. A brief description of each step is included in the roadmap along with references to the sections of MARSSIM that provide more detailed guidance.

This roadmap provides the user with basic guidance from MARSSIM combined with "rules of thumb" (indicated by for performing compliance demonstration surveys. The roadmap is not designed to be a stand-alone document, but to be used as a quick reference to MARSSIM for 
users already familiar with the process of planning and performing surveys. Roadmap users will also find flow charts summarizing the major steps in the Radiation Survey and Site Investigation Process, combined with references to sections in MARSSIM where detailed guidance may be found. In addition, the roadmap serves as an overview and example for applying MARSSIM guidance at sites with radioactive contamination of surface soil and building surfaces. The roadmap assumes a working knowledge of MARSSIM terminology. If such knowledge is lacking, the user may refer to Section 2.2 of MARSSIM for definitions of key terms. In addition, a complete set of definitions is provided in the Glossary.

\section{Data Life Cycle}

Compliance demonstration is simply a decision as to whether or not a survey unit meets the release criterion. For most sites, this decision is supported by statistical tests based on the results of one or more surveys. The initial assumption used in MARSSIM is that each survey unit is contaminated above the release criterion until proven otherwise. The surveys are designed to provide the information needed to reject this initial assumption. MARSSIM recommends using the Data Life Cycle as a framework for planning, implementing, and evaluating survey results prior to making a decision. Figure 1 summarizes the major activities associated with each phase of the Data Life Cycle.

\section{Planning Stage}

The survey design is developed and documented using the Data Quality Objectives (DQO) Process (Section 2.3.1, Appendix D). The DQOs for the project are established and preliminary surveys (e.g., scoping, characterization) are performed to provide information necessary to design the final status survey for compliance demonstration. The DQOs for the project are re-evaluated for each of the preliminary surveys. The preliminary surveys may provide information for purposes other than compliance demonstration that are not discussed in MARSSIM. For example, a characterization survey may provide information to support evaluation of remedial alternatives. In addition, any of the preliminary surveys may be designed to demonstrate compliance with the release criterion as one of the survey objectives. These alternate survey designs are developed based on site-specific considerations (Section 2.6). The planning phase of the Data Life Cycle produces a final status survey design that is used for demonstrating compliance with the release criterion. This design is recorded in planning documents, such as a Quality Assurance Project Plan (QAPP) described in Section 9.2. 


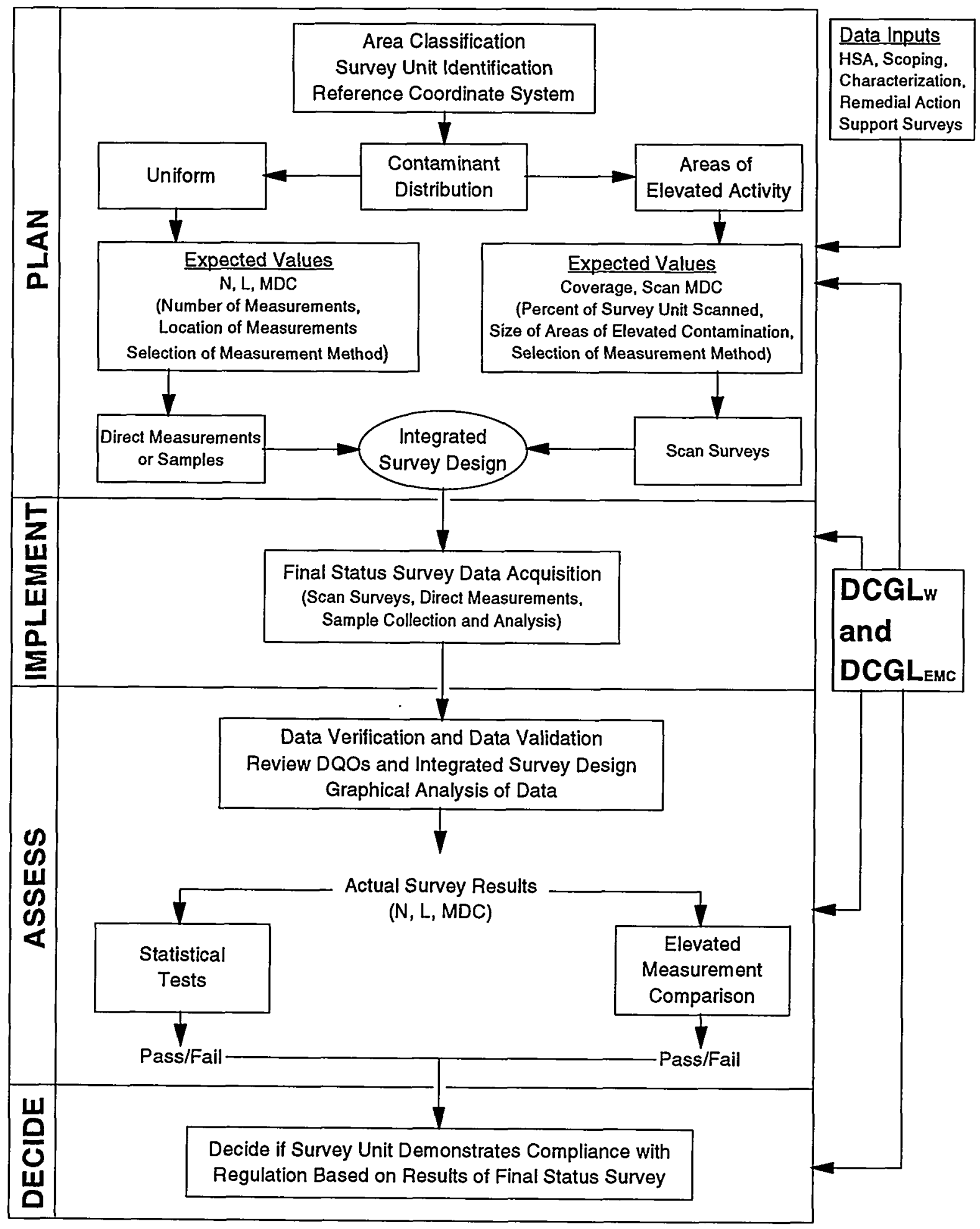

Figure 1 The Data Life Cycle Applied to a Final Status Survey

December 1997

Roadmap-3

MARSSIM 


\section{MARSSIM Roadmap}

A minimum amount of information is needed from the preliminary surveys to develop an effective final status survey design. This includes

- sufficient information to justify classification and specification of boundaries for survey units (the default is Class 1 which results in the highest level of survey effort)

- an estimate of the variability of the contaminant concentration in the survey unit $\left(\sigma_{s}\right)$ and the reference area $\left(\sigma_{\mathrm{r}}\right)$ if necessary

After the preliminary surveys are completed, the final status survey design can be developed. Figure 2 presents the major steps in the development of a survey design that integrates scanning surveys with direct measurements and sampling. Most of the steps are easy to understand and references to appropriate sections of MARSSIM are included in the flowchart. Several of these steps are important enough to justify additional discussion in this guide. These steps are

- Classify Areas by Contamination Potential

- Group/Separate Areas into Survey Units

- Determine Number of Data Points

- Select Instrumentation

- Develop an Integrated Survey Design

\section{Classify Areas by Contamination Potential (Section 4.4)}

Classification is a critical step in survey design because it determines the level of survey effort based on the potential for contamination. Overestimating the potential for contamination results in an unnecessary increase in the level of survey effort. Underestimating the potential for contamination greatly increases the probability of failing to demonstrate compliance based on the survey results. There are two key decisions made when classifying areas: 1) is the average activity in the area likely to exceed the $\mathrm{DCGL}_{\mathrm{W}}$, and 2) is the contamination present in small areas of elevated activity or is the contamination distributed relatively homogeneously across the area. Each of these decisions is considered separately when designing the survey and then combined into an integrated survey design. Class 1 areas, prior to remediation, are impacted areas with concentrations of residual radioactivity that exceed the DCGL $\mathrm{w}_{\mathrm{w}}$. Class 2 areas are impacted areas concentrations of residual activity that exceed the DCGL $\mathrm{w}_{\mathrm{w}}$ are not expected. Class 3 areas are impacted areas that have a low probability of containing areas with residual radioactivity. The information obtained from the preliminary surveys is crucial for classifying areas (see Figure 2.4).

Area classification considers both the level of contamination relative to the $\mathrm{DCGL}_{\mathrm{W}}$ and the distribution of the contamination. The contamination may be uniformly distributed or present as small areas of elevated activity. 


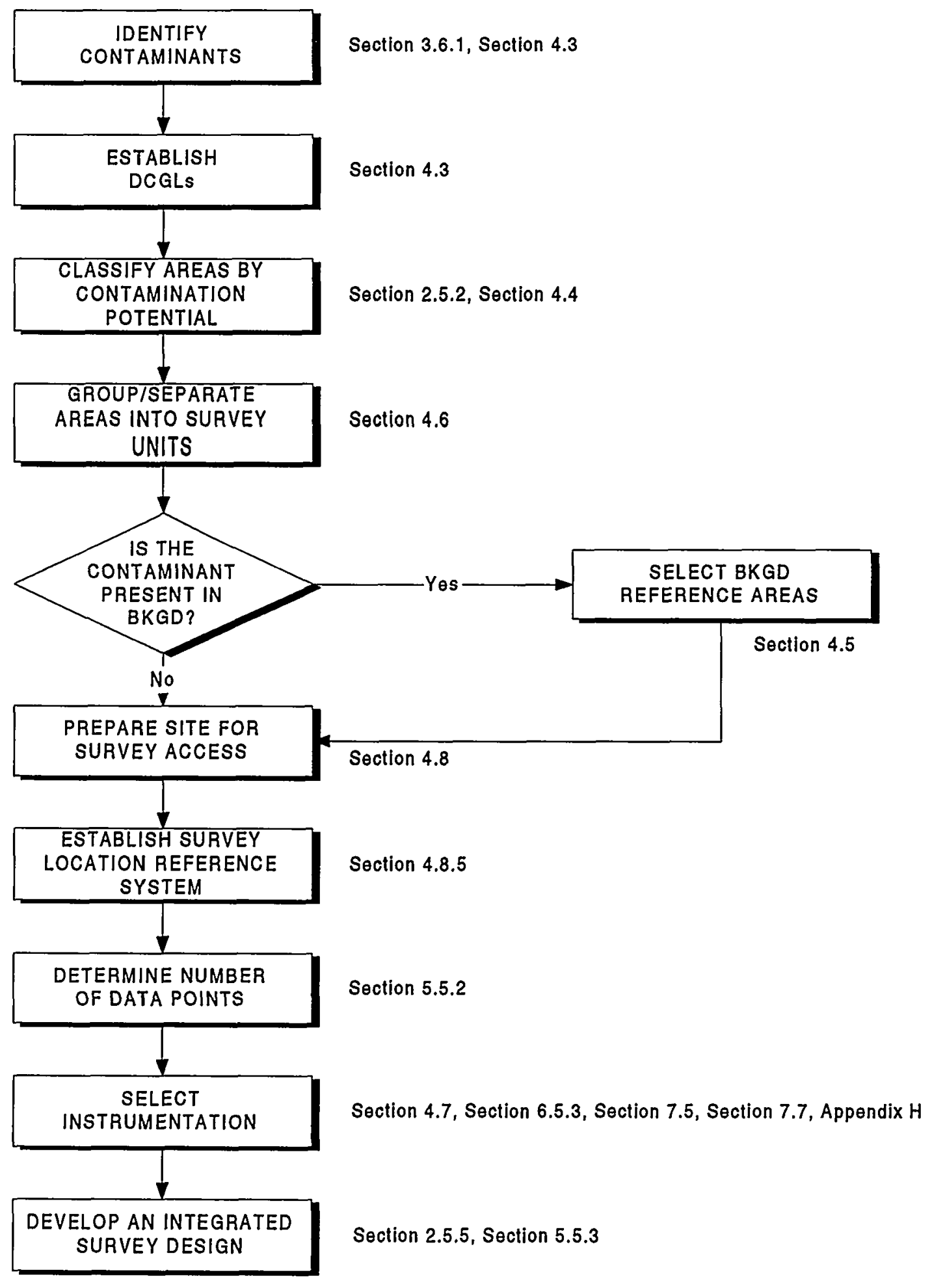

Figure 2 Flow Diagram for Designing a Final Status Survey 


\section{Group/Separate Areas into Survey Units (Section 4.6)}

Survey units are limited in size based on classification, exposure pathway modeling assumptions, and site-specific conditions. Table 1 provides suggested survey unit areas based on area classification. The rationale for selecting a larger survey unit area should be developed using the DQO Process and fully documented.

Table 1 Suggested Survey Unit Areas

\begin{tabular}{|c|c|}
\hline Classification & Suggested Area \\
\hline Class 1 & \\
\hline Structures & up to $100 \mathrm{~m}^{2}$ \\
\hline Land Areas & up to $2,000 \mathrm{~m}^{2}$ \\
\hline Class 2 & \\
\hline Structures & 100 to $1,000 \mathrm{~m}^{2}$ \\
\hline Land Areas & 2,000 to $10,000 \mathrm{~m}^{2}$ \\
\hline Class 3 & \\
\hline Structures & no limit \\
\hline Land Areas & no limit \\
\hline
\end{tabular}

Survey unit areas should be consistent with exposure pathway modeling assumptions used to develop DCGLs.

\section{Determine Number of Data Points (Section 5.5.2)}

The number of data points is determined based on the selection of a statistical test, which in turn is based on whether or not the contaminant is present in background. Figure 3 presents a flow chart for determining the number of data points.

The first step in determining the number of data points is to specify the acceptable decision error rates, $\alpha$ and $\beta$. Decision error rates are site-specific and selected using the DQO Process. Changes in the values of $\alpha$ and $\beta$ may result from successive iterations of the DQO Process.

Values for $\alpha$ and $\beta$ are site-specific and selected using the DQO Process. 


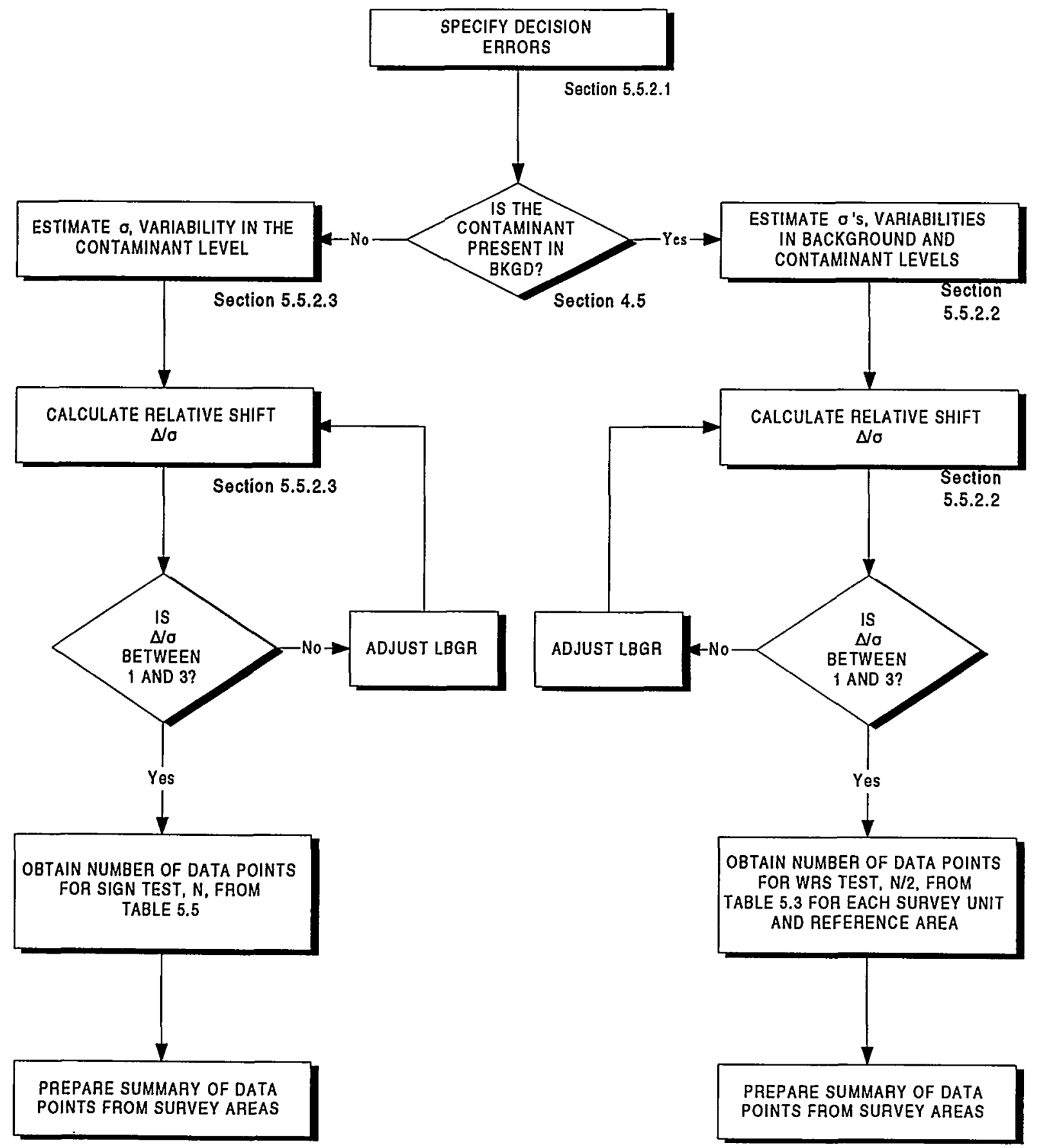

Section 5.5.2.3

Section 5.5.2.2

Figure 3 Flow Diagram for Determining the Number of Data Points 


\section{MARSSIM Roadmap}

The next step, after determining whether or not the contaminant is present in background, is to estimate the variability of the contaminant concentration, $\sigma$. The standard deviation of the contaminant concentration determined from the preliminary survey results should provide an appropriate estimate of $\sigma$. If the contaminant is present in background, the variability in the survey unit $\left(\sigma_{\mathrm{s}}\right)$ and the variability in the reference area $\left(\sigma_{\mathrm{r}}\right)$ should both be estimated. The larger of the two values should be selected for determining the number of data points. Underestimating $\sigma$ can underestimate the number of measurements needed to demonstrate compliance with the regulation, which increases the probability the survey unit will fail the statistical test. Overestimating $\sigma$ can result in collecting more data than is necessary to demonstrate compliance.

It is better to overestimate values of $\sigma_{s}$ and $\sigma_{r}$

When $\sigma_{\mathrm{s}}$ and $\sigma_{\mathrm{r}}$ are different, select the larger of the two values.

The third step is to calculate the relative shift, $\Delta / \sigma$. The variability of the contaminant concentration, $\sigma$, was determined in the previous step. The shift, $\Delta$, is equal to the width of the gray region. The upper bound of the gray region is defined as the DCGL $\mathrm{W}_{\mathrm{w}}$. The lower bound of the gray region (LBGR) is a site-specific parameter, adjusted to provide a value for $\Delta / \sigma$ between one and three. $\Delta / \sigma$ can be adjusted using the following steps:

- Initially select LBGR to equal one half the DCGL ${ }_{\mathrm{W}}$. This means $\Delta$ (DCGL $_{\mathrm{W}}-\mathrm{LBGR}$ ) also equals one half the DCGL $\mathrm{w}_{\mathrm{w}}$. Calculate $\Delta / \sigma$.

- If $\Delta / \sigma$ is between one and three, obtain the appropriate number of data points from Table 5.3 or Table 5.5 .

- If $\Delta / \sigma$ is less than one, select a lower value for LBGR. Continue to select lower values for LBGR until $\Delta / \sigma$ is greater than or equal to one, or until LBGR equals zero.

- If $\Delta / \sigma$ is greater than three, select a higher value for LBGR. Continue to select higher values for LBGR until $\Delta / \sigma$ is less than or equal to three.

Alternatively, $\Delta / \sigma$ can be adjusted by solving the following equation and calculating $\Delta / \sigma$ :

$$
L B G R=D C G L_{W}-\sigma
$$

If LBGR is less than zero, $\Delta / \sigma$ can be calculated as DCGL $_{W} / \sigma$.

Adjust the LBGR to provide a value for $\Delta / \sigma$ between one and three. 
The final step in determining the number of data points is to obtain the appropriate value from Table 5.3 or Table 5.5. Table 5.3 provides the number of data points for each survey unit and each reference area when the contaminant is present in background (N/2). Table 5.5 provides the number of data points for each survey unit when the contaminant is not present in background $(\mathrm{N})$.

\section{Select Instrumentation (Section 4.7, Section 6.5.3, Section 7.5, Section 7.7, Appendix H)}

Instrumentation or measurement techniques should be selected based on detection sensitivity to provide technically defensible results that meet the objectives of the survey. Because of the uncertainty associated with interpreting scanning results, the detection sensitivity of the selected instruments should be as far below the DCGL as possible. For direct measurements and sample analyses, minimum detectable concentrations (MDCs) less than 10\% of the DCGL are preferable while MDCs up to $50 \%$ of the DCGL are acceptable.

10

Estimates of the MDC that minimize potential decision errors should be used for planning surveys.

\section{Develop an Integrated Survey Design (Section 5.5.3)}

The integrated survey design combines scanning surveys with direct measurements and sampling. The level of survey effort is determined by the potential for contamination as indicated by the survey unit classification. This is illustrated in Figure 4. Class 3 survey units receive judgmental scanning and randomly located measurements. Class 2 survey units receive scanning over a portion of the survey unit based on the potential for contamination combined with direct measurements and sampling performed on a systematic grid. Class 1 survey units receive scanning over $100 \%$ of the survey unit combined with direct measurements and sampling performed on a systematic grid. The grid spacing is adjusted to account for the scan MDC (Section 5.5.2.4).

Table 2 provides a summary of the recommended survey coverage for structures and land areas. Modifications to the example survey designs may be required to account for other contaminated media (e.g., ground water, subsurface soil).

\section{Implementation Phase}

The objectives outlined in the QAPP are incorporated into Standard Operating Procedures (SOPs). The final status survey design is carried out in accordance with the SOPs and the QAPP resulting in the generation of raw data. Chapter 6, Chapter 7, and Appendix H provide information on measurement techniques. 


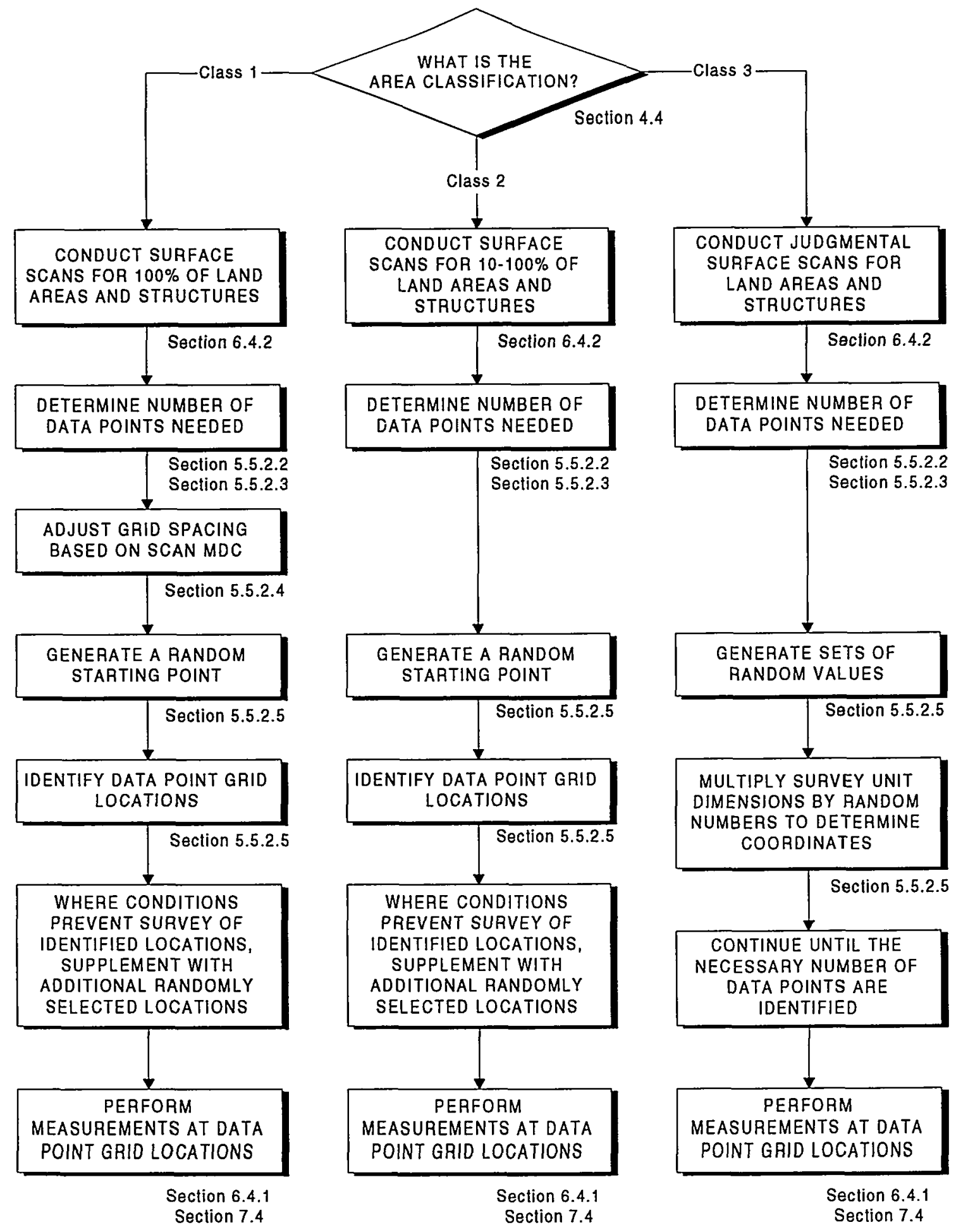

Figure 4 Flow Diagram for Developing an Integrated Survey Design 


\section{Table 2 Recommended Survey Coverage for Structures and Land Areas}

\begin{tabular}{|c|c|c|c|c|}
\hline \multirow[b]{2}{*}{$\begin{array}{c}\text { Area } \\
\text { Classification }\end{array}$} & \multicolumn{2}{|c|}{ Structures } & \multicolumn{2}{|c|}{ Land Areas } \\
\hline & $\begin{array}{c}\text { Surface } \\
\text { Scans } \\
\end{array}$ & $\begin{array}{l}\text { Surface Activity } \\
\text { Measurements }\end{array}$ & $\begin{array}{l}\text { Surface } \\
\text { Scans }\end{array}$ & $\begin{array}{c}\text { Surface Soil } \\
\text { Measurements }\end{array}$ \\
\hline Class 1 & $100 \%$ & $\begin{array}{l}\text { Number of data points } \\
\text { from statistical tests } \\
\text { (Sections 5.5.2.2 and } \\
5.5 .2 .3 \text { ); additional } \\
\text { direct measurements } \\
\text { and samples may be } \\
\text { necessary for small } \\
\text { areas of elevated } \\
\text { activity (Section } \\
5.5 .2 .4 \text { ) }\end{array}$ & $100 \%$ & $\begin{array}{l}\text { Number of data points } \\
\text { from statistical tests } \\
\text { (Sections 5.5.2.2 and } \\
5.5 .2 .3 \text { ); additional } \\
\text { direct measurements } \\
\text { and samples may be } \\
\text { necessary for small } \\
\text { areas of elevated } \\
\text { activity (Section } \\
5.5 .2 .4 \text { ) }\end{array}$ \\
\hline Class 2 & $\begin{array}{l}10 \text { to } 100 \% \\
\text { (10 to } 50 \% \text { for upper } \\
\text { walls and ceilings) } \\
\text { Systematic and } \\
\text { Judgmental }\end{array}$ & $\begin{array}{l}\text { Number of data points } \\
\text { from statistical tests } \\
\text { (Sections 5.5.2.2 and } \\
5.5 .2 .3 \text { ) }\end{array}$ & $\begin{array}{l}10 \text { to } 100 \% \\
\text { Systematic } \\
\text { and } \\
\text { Judgmental }\end{array}$ & $\begin{array}{l}\text { Number of data points } \\
\text { from statistical tests } \\
\text { (Sections 5.5.2.2 and } \\
\text { 5.5.2.3) }\end{array}$ \\
\hline Class 3 & Judgmental & $\begin{array}{l}\text { Number of data points } \\
\text { from statistical tests } \\
\text { (Sections 5.5.2.2 and } \\
\text { 5.5.2.3) }\end{array}$ & Judgmental & $\begin{array}{l}\text { Number of data points } \\
\text { from statistical tests } \\
\text { (Sections 5.5.2.2 and } \\
\text { 5.5.2.3) }\end{array}$ \\
\hline
\end{tabular}

\section{Assessment Phase}

The assessment phase of the Data Life Cycle includes verification and validation of the survey results combined with an assessment of the quantity and quality of the data. As previously stated, both the average level of contamination in the survey unit and the distribution of the contamination within the survey unit are considered during area classification. For this reason, the assessment phase includes a graphical review of the data to provide a visual representation of the radionuclide distribution, an appropriate statistical test to demonstrate compliance for the average concentration of a uniformly distributed radionuclide, and the elevated measurement comparison (EMC) to demonstrate compliance for small areas of elevated activity.

The survey data are verified to ensure that SOPs specified in the survey design were followed and that the measurement systems were performed in accordance with the criteria specified in the QAPP (Section 9.3.1). The data are validated to ensure that the results support the objectives of the survey, as documented in the QAPP, or permit a determination that these objectives should 
be modified (Section 9.3.2). The Data Quality Assessment (DQA) process is then applied using the verified and validated data to determine if the quality of the data satisfies the data user's needs. DQA is described in Appendix $E$ and is applied in Chapter 8.

The first step in DQA is to review the DQOs and survey design to ensure that they are still applicable. For example, if the data suggest that a survey unit is misclassified, the DQOs and survey design would be modified for the new classification.

The next step is to conduct a preliminary data review to learn about the structure of the data and to identify patterns, relationships, or potential anomalies. This review should include calculating basic statistical quantities (i.e., mean, standard deviation, median) and graphically presenting the data using at least a histogram and a posting plot. The results of the preliminary data review are also used to verify the assumptions of the tests. Some of the assumptions and possible methods for assessing them are summarized in Table 3. Information on diagnostic tests is provided in Section 8.2 and Appendix I.

Table 3 Methods for Checking the Assumptions of Statistical Tests

\begin{tabular}{||l|l|}
\hline \multicolumn{1}{|c|}{ Assumption } & \multicolumn{1}{|c|}{} \\
\hline Spatial Independence & Posting Plot (Figure 8.1) \\
\hline Symmetry & $\begin{array}{l}\text { Histogram (Figure 8.2) } \\
\text { Quantile Plot (Figure I.2) }\end{array}$ \\
\hline Data Variance & Sample Standard Deviation (Section 8.2) \\
\hline Power is Adequate & $\begin{array}{l}\text { Retrospective Power Chart } \\
\text { (Sign Test, Figure I.5) } \\
\text { (WRS Test, Figure I.6) }\end{array}$ \\
\hline
\end{tabular}

The final step in interpreting the data is to draw conclusions from the data. Table 4 summarizes the statistical tests recommended in MARSSIM. Section 8.3 provides guidance on performing the Sign test when the contaminant is not present in background. Section 8.4 provides guidance on performing the Wilcoxon Rank Sum (WRS) test when the contaminant is present in background. 


\section{Table 4 Summary of Statistical Tests}

Radionuclide not in background and radionuclide-specific measurements made:

\begin{tabular}{|l|l||}
\hline \multicolumn{1}{|c|}{ Survey Result } & \multicolumn{1}{|c|}{} \\
\hline All measurements less than $\mathrm{DCGL}_{\mathrm{W}}$ & Survey unit meets release criterion \\
\hline Average greater than $\mathrm{DCGL}_{\mathrm{W}}$ & Survey unit does not meet release criterion \\
\hline $\begin{array}{l}\text { Any measurement greater than } \mathrm{DCGL}_{\mathrm{W}} \text { and the average } \\
\text { less than } \mathrm{DCGL}_{\mathrm{W}}\end{array}$ & $\begin{array}{l}\text { Conduct Sign test and elevated measurement } \\
\text { comparison }\end{array}$ \\
\hline
\end{tabular}

Radionuclide in background or radionuclide non-specific (gross) measurements made:

\begin{tabular}{||l|l||}
\hline \multicolumn{1}{|c|}{ Survey Result } & \multicolumn{1}{|c|}{ Conclusion } \\
\hline $\begin{array}{l}\text { Difference between maximum survey unit measurement } \\
\text { and minimum reference area measurements is less than } \\
\text { DCGL }_{\mathrm{W}}\end{array}$ & Survey unit meets release criterion \\
\hline $\begin{array}{l}\text { Difference of survey unit average and reference area } \\
\text { average is greater than DCGL }\end{array}$ & Survey unit does not meet release criterion \\
\hline $\begin{array}{l}\text { Difference between any survey unit measurement and any } \\
\text { reference area measurement greater than } \text { DCGL }_{\mathrm{W}} \text { and the } \\
\text { difference of survey unit average and reference area } \\
\text { average is less than DCGL }\end{array}$ & $\begin{array}{l}\text { Conduct WRS test and elevated measurement } \\
\text { comparison }\end{array}$ \\
\hline
\end{tabular}

Table 5 provides examples of final status survey investigation levels for each survey unit classification and type of measurement. For a Class 1 survey unit, measurements above the DCGL $_{\mathrm{w}}$ are not necessarily unexpected. However, a measurement above the $\mathrm{DCGL}_{\mathrm{W}}$ at one of the discrete measurement locations might be considered unusual if it were much higher than all of the other discrete measurements. Thus, any discrete measurement that is above both the DCGL $_{\mathrm{w}}$ and the statistical-based parameter for the measurements should be investigated further. Any measurement, either at a discrete location or from a scan, that is above the DCGL $\mathrm{EMC}_{\text {should }}$ be flagged for further investigation.

In Class 2 or Class 3 areas, neither measurements above the DCGL $_{W}$ nor areas of elevated activity are expected. Any measurement at a discrete location exceeding the $\mathrm{DCGL}_{\mathrm{w}}$ in these areas should be flagged for further investigation. Because the survey design for Class 2 and Class 3 survey units is not driven by the EMC, the scanning MDC might exceed the DCGL $\mathrm{w}_{\mathrm{w}}$. In this case, any indication of residual radioactivity during the scan would warrant further investigation. 
MARSSIM Roadmap

Table 5 Summary of Investigation Levels

\begin{tabular}{||l|l|l||}
\hline \multicolumn{1}{|c|}{$\begin{array}{c}\text { Survey Unit } \\
\text { Classification }\end{array}$} & Flag Direct Measurement or Sample Result When: & $\begin{array}{c}\text { Flag Scanning Measurement } \\
\text { Result When: }\end{array}$ \\
\hline Class 1 & $\begin{array}{l}>\mathrm{DCGL}_{\mathrm{EMC}} \text { or } \\
>\mathrm{DCGL}_{\mathrm{W}} \text { and }>\text { a statistical-based parameter value }\end{array}$ & $>\mathrm{DCGL}_{\mathrm{EMC}}$ \\
\hline Class 2 & $>\mathrm{DCGL}_{\mathrm{W}}$ & $>\mathrm{DCGL}_{\mathrm{w}}$ or $>\mathrm{MDC}$ \\
\hline Class 3 & $>$ fraction of $\mathrm{DCGL}_{\mathrm{W}}$ & $>\mathrm{DCGL}_{\mathrm{W}}$ or $>\mathrm{MDC}$ \\
\hline
\end{tabular}

Because there is a low expectation for residual radioactivity in a Class 3 area, it may be prudent to investigate any measurement exceeding even a fraction of the $\mathrm{DCGL}_{\mathrm{w}}$. The level one chooses here depends on the site, the radionuclides of concern, and the measurement and scanning methods chosen. This level should be set using the DQO Process during the survey design phase of the Data Life Cycle. In some cases, the user may also decide to follow this procedure for Class 2 and even Class 1 survey units.

Both the measurements at discrete locations and the scans are subject to the EMC. The result of the EMC does not in itself lead to a conclusion as to whether the survey unit meets or exceeds the release criterion, but is a flag or trigger for further investigation. The investigation may involve taking further measurements in order to determine that the area and level of the elevated residual radioactivity are such that the resulting dose or risk meets the release criterion. ${ }^{1}$ The investigation should also provide adequate assurance that there are no other undiscovered areas of elevated residual radioactivity in the survey unit that might result in a dose exceeding the release criterion. This could lead to a re-classification of all or part of a survey unit-that is, unless the results of the investigation indicate that reclassification is not necessary.

\section{Decision Making Phase}

A decision is made, in coordination with the responsible regulatory agency, based on the conclusions drawn from the assessment phase. The results of the EMC are used to demonstrate compliance with the dose- or risk-based regulation for small areas of elevated activity, while the nonparametric statistical tests are used to demonstrate that the average radionuclide concentration in the survey unit complies with the release criterion. The objective is to make technically defensible decisions with a specified level of confidence.

${ }^{1}$ Rather than, or in addition to, taking further measurements, the investigation may involve assessing the adequacy of the exposure pathway model used to obtain the DCGLs and area factors, and the consistency of the results obtained with the Historical Site Assessment and the scoping, characterization, and remedial action support surveys. 
The EMC consists of comparing each measurement from the survey unit with the investigation levels in Table 5. The EMC is performed for measurements obtained from the systematic or random sample locations as well as locations flagged by scanning surveys. Any measurement from the survey unit that is equal to or greater than the investigation level indicates an area of relatively higher concentration and is investigated, regardless of the outcome of the nonparametric statistical tests.

$\infty \quad$ Any measurement from the survey unit that is equal to or greater than the investigation level indicates an area of relatively higher concentration and is investigated, regardless of the outcome of the nonparametric statistical tests.

The result of the Sign test or the WRS test is the decision to reject or not to reject the null hypothesis that the survey unit is contaminated above the $\mathrm{DCGL}_{\mathrm{W}}$. Provided that the results of any investigations triggered by the EMC have been resolved, a rejection of the null hypothesis leads to the decision that the survey unit meets the release criterion. If necessary, the amount of residual radioactivity in the survey unit can be estimated so that dose or risk calculations can be made. In most cases, the average concentration is the best estimate for the amount of residual radioactivity.

\section{Summary}

The roadmap presents a summary of the planning, implementation, assessment, and decision making phases for a final status survey and identifies where guidance on these phases is located in MARSSIM. Each step in the process is described briefly along with references to the sections of MARSSIM to which the user may refer for more detailed guidance. Flow charts are provided to summarize the major steps in the Radiation Survey and Site Investigation Process, again citing appropriate sections of MARSSIM. In addition to providing the user with basic guidance from MARSSIM, the roadmap also includes "rules of thumb" for performing compliance demonstration surveys. 


\section{INTRODUCTION}

\subsection{Purpose and Scope of MARSSIM}

Radioactive materials have been produced, processed, used, and stored at thousands of sites throughout the United States. Many of these sites-ranging in size from Federal weaponsproduction facilities covering hundreds of square kilometers to the nuclear medicine departments of small hospitals-were at one time or are now radioactively contaminated.

The owners and managers of a number of sites would like to determine if these sites are contaminated, clean them up if contaminated, and release them for restricted use or for unrestricted public use. The Environmental Protection Agency (EPA), the Nuclear Regulatory Commission (NRC), and the Department of Energy (DOE) are responsible for the release of sites following cleanup. These responsibilities apply to facilities under the control of Federal agencies, such as the DOE and Department of Defense (DOD), and to sites licensed by the NRC and its Agreement States. Some States have responsibilities for similar sites under their control.

The Multi-Agency Radiation Survey and Site Investigation Manual (MARSSIM) provides a nationally consistent consensus approach to conducting radiation surveys and investigations at potentially contaminated sites. This approach should be both scientifically rigorous and flexible enough to be applied to a diversity of site cleanup conditions. MARSSIM's title includes the term "survey" because it provides information on planning and conducting surveys, and includes the term "site investigation" because the process outlined in the manual allows one to begin by investigating any site (i.e., by gathering data or information) that may involve radioactive contamination.

The decommissioning that follows remediation will normally require a demonstration to the responsible Federal or State agency that the cleanup effort was successful and that the release criterion (a specific regulatory limit) was met. In MARSSIM, this demonstration is given the name "final status survey." This manual assists site personnel or others in performing or assessing such a demonstration. (Generally, MARSSIM may serve to guide or monitor remediation efforts whether or not a release criterion is applied.)

As illustrated in Figure 1.1, the demonstration of compliance with respect to conducting surveys is comprised of three interrelated parts:

I. Translate: Translating the cleanup/release criterion (e.g., $\mathrm{mSv} / \mathrm{y}, \mathrm{mrem} / \mathrm{y}$, specific risk) into a corresponding derived contaminant concentration level $(e . g ., \mathrm{Bq} / \mathrm{kg}$ or pCi/g in soil) through the use of environmental pathway modeling. 


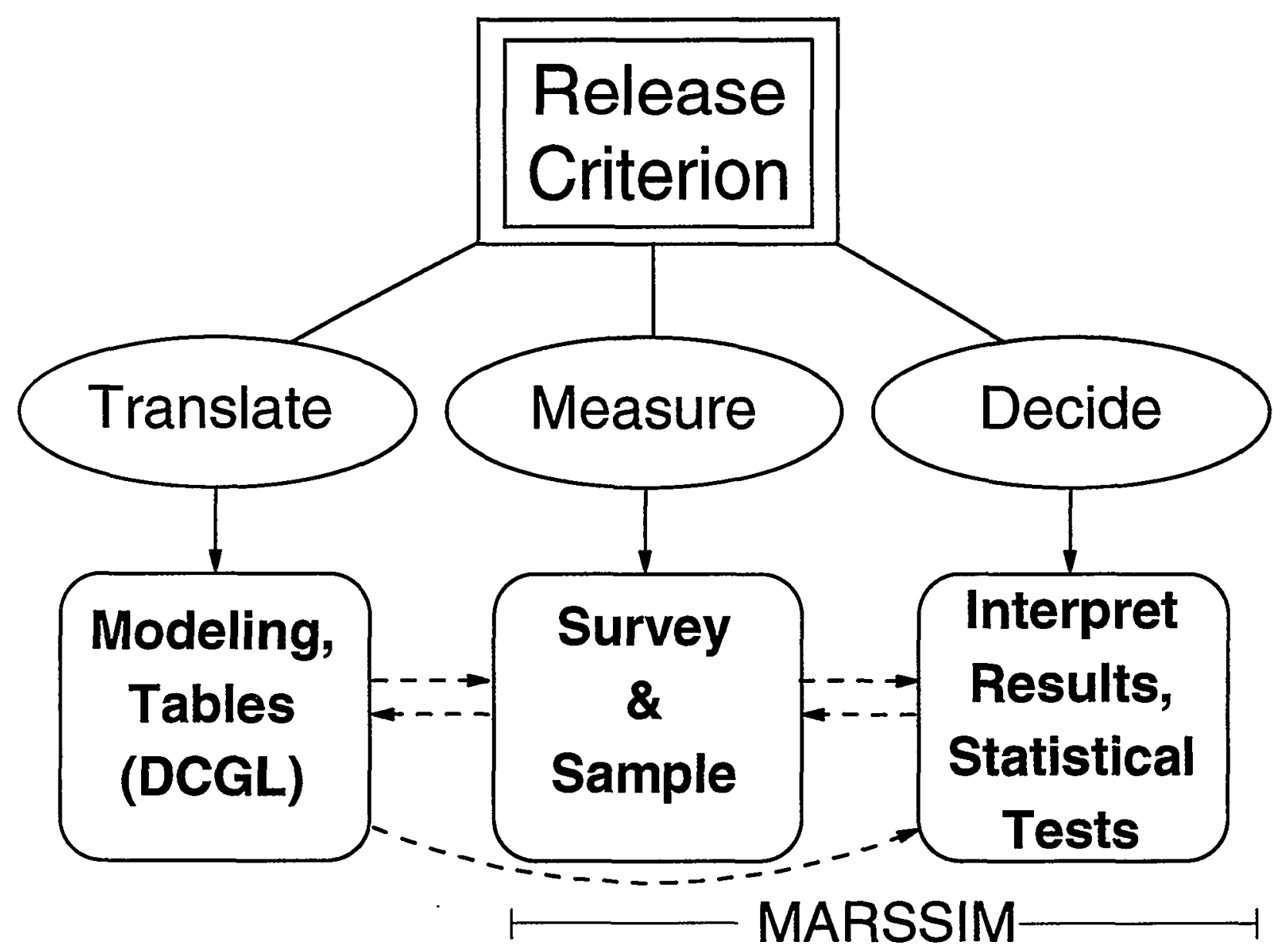

Figure 1.1 Compliance Demonstration

II. Measure: Acquiring scientifically sound and defensible site-specific data on the levels and distribution of residual contamination, as well as levels and distribution of radionuclides present as background, by employing suitable field and/or laboratory measurement techniques. ${ }^{1}$

III. Decide: Determining that the data obtained from sampling does support the assertion that the site meets the release criterion, within an acceptable degree of uncertainty, through application of a statistically based decision rule.

\footnotetext{
${ }^{1}$ Measurements include field and laboratory analyses, however, MARSSIM leaves detailed discussions of laboratory sample analyses to another manual (i.e., a companion document, the Multi-Agency Radiation Laboratory Analytical Protocols (MARLAP) manual that is currently under development).
} 
MARSSIM presents comprehensive guidance-specifically for II and III above-for contaminated soil and buildings. This guidance describes a performance-based approach for demonstrating compliance with a dose- or risk-based regulation. This approach includes processes that identify data quality needs and may reveal limitations that enter into conducting a survey. The data quality needs stated as Data Quality Objectives (DQOs) include performance measures and goals in relation to a specific intended use of the data (EPA 1997).

DQOs must be developed on a site-specific basis. However, because of the large variability in the types of radiation sites, it is impossible to provide criteria that apply to every situation. As an example, MARSSIM presents a method for planning, implementing, assessing, and making decisions about regulatory compliance at sites with radioactive contaminants in surface soil and on building surfaces. In particular, MARSSIM describes generally acceptable approaches for:

- $\quad$ planning and designing scoping, characterization, remediation-support, and final status surveys for sites with surface soil and building surface contamination

- Historical Site Assessment (HSA)

- QAVQC in data acquisition and analysis

- conducting surveys

- field and laboratory methods and instrumentation, and interfacing with radiation laboratories

- statistical hypothesis testing, and the interpretation of statistical data

- documentation

Thus, MARSSIM provides standardized and consistent approaches for planning, conducting, evaluating, and documenting environmental radiological surveys, with a specific focus on the final status surveys that are carried out to demonstrate compliance with cleanup regulations. These approaches may not meet the DQOs at every site, so other methods may be used to meet site-specific DQOs, as long as an equivalent level of performance can be demonstrated.

Table 1.1, at the end of Chapter 1, summarizes the scope of MARSSIM. Several issues related to releasing sites are beyond the scope of MARSSIM. These include translation of dose or risk standards into radionuclide specific concentrations, or demonstrating compliance with ground water or surface water regulations. MARSSIM can be applied to surveys performed at vicinity properties- those not under government or licensee control-but the decision to apply the MARSSIM at vicinity properties is outside the scope of MARSSIM. Other contaminated media (e.g., sub-surface soil, building materials, ground water) and the release of contaminated components and equipment are also not addressed by MARSSIM. With MARSSIM's main focus on final status surveys, this manual continues a process of following remediation activities that are intended to remove below-surface contaminants. Therefore, some of the reasons for limiting the scope of the guidance to contaminated surface soils and building surfaces include: 1) contamination is limited to these media for many sites following remediation, 2) since many 
sites have surface soil and building surface contamination as the leading source of contamination, existing computer models used for calculating the concentrations based on dose or risk generally consider only surface soils or building surfaces as a source term, and 3) MARSSM was written in support of cleanup rulemaking efforts for which supporting data are mostly limited to contaminated surface soil and building surfaces.

MARSSIM also recognizes that there may be other factors, such as cost or stakeholder concerns, that have an impact on designing surveys. Guidance on how to address these specific concerns is outside the scope of MARSSIM. Unique site-specific cases may arise that require a modified approach beyond what is presently described in MARSSIM. This includes examples such as: 1) the release of sites contaminated with naturally occurring radionuclides in which the concentrations corresponding to the release criteria are close to the variability of the background and 2) sites where a reference background cannot be established. However, the process of planning, implementing, assessing, and making decisions about a site described in MARSSIM is applicable to all sites, even if the examples in this manual do not meet a site's specific objectives.

Of MARSSIM's many topics, the Data Quality Objective (DQO) approach to data acquisition and analysis and the Data Quality Assessment (DQA) for determining that data meet stated objectives are two elements that are a consistent theme throughout the manual. The DQO Process and DQA approach, described in Chapter 2, present a method for building common sense and the scientific method into all aspects of designing and conducting surveys, and making best use of the obtainable information. This becomes a formal framework for systematizing the planning of data acquisition surveys so that the data sought yield the kind of information actually needed for making important decisions - such as whether or not to release a particular site following remediation.

\subsection{Structure of the Manual}

MARSSIM begins with the overview of the Radiation Survey and Site Investigation Process in Chapter 2-Figures 2.4 through 2.8 are flowcharts that summarize the steps and decisions taken in the process. Chapter 3 provides instructions for performing an Historical Site Assessment (HSA) - a detailed investigation to collect existing information on the site or facility and to develop a conceptual site model. The results of the HSA are used to plan surveys, perform measurements, and collect additional information at the site. Chapter 4 covers issues that arise in all types of surveys. Detailed information on performing specific types of surveys is included in Chapter 5. Guidance on selecting the appropriate instruments and measurement techniques for each type of measurement is in Chapters 6 and 7. Chapter 6 discusses direct measurements and scanning surveys, and Chapter 7 discusses sampling and sample preparation for laboratory measurements. The interpretation of survey results is described in Chapter 8. Chapter 9 provides guidance on data management, quality assurance (QA), and quality control (QC). Information on specific subjects related to radiation site investigation can be found in the appendices. 
MARSSIM contains several appendices to provide additional guidance on specific topics. Appendix A presents an example of how to apply the MARSSIM guidance to a specific site. Appendix B describes a simplified procedure for compliance demonstration that may be applicable at certain types of sites. Appendix $\mathrm{C}$ summarizes the regulations and requirements associated with radiation surveys and site investigations for each of the agencies involved in the development of MARSSIM. Detailed guidance on the DQO Process is in Appendix D, and Appendix $\mathrm{E}$ has guidance on DQA. Appendix F describes the relationships among MARSSIM, the Comprehensive Environmental Response, Compensation, and Liability Act (CERCLA), and the Resource Conservation and Recovery Act (RCRA). Sources of information used during site assessment are listed in Appendix G. Appendix $\mathrm{H}$ describes field survey and laboratory analysis equipment that may be used for radiation surveys and site investigations. Appendix I offers tables of statistical data and supporting information for interpreting survey results described in Chapter 8. The derivation of the alpha scanning detection limit calculations used in Chapter 6 is described in Appendix J. Comparison tables for QA documents are in Appendix K. Appendix L lists the regional radiation program managers for each of the agencies participating in the development of MARSSIM. Appendix M lists publications that serve as resources describing sampling methods. Information on data validation is provided in Appendix $\mathrm{N}$.

MARSSIM is presented in a modular format, with each module containing guidance on conducting specific aspects of, or activities related to, the survey process. Followed in order, each module leads to the generation and implementation of a complete survey plan. Although this approach may involve some overlap and redundancy in information, it also allows many users to concentrate only on those portions of the manual that apply to their own particular needs or responsibilities. The procedures within each module are listed in order of performance and options are provided to guide a user past portions of the manual that may not be specifically applicable to the user's area of interest. Where appropriate, checklists condense and summarize major points in the process. The checklists may be used to verify that every suggested step is followed or to flag a condition in which specific documentation should explain why a step was not needed.

Also included in the manual is a section titled Roadmap. The roadmap is designed to be used with MARSSIM as a quick reference for users already familiar with the process of planning and performing radiation surveys. The roadmap gives the user basic guidance, rules of thumb, and references to sections in the manual containing detailed guidance.

MARSSIM, which is based on a graded approach, also contains a simplified procedure (see Appendix B) that many users of radioactive materials may - with the approval of the responsible regulatory agency — be able to employ to demonstrate compliance with the release criterion. Sites that may qualify for simplified release procedures are those in which the radioactive materials used were 1) of relatively short half-life (e.g., $\mathrm{t}_{1 / 2} \leq 120$ days) and have since decayed to insignificant quantities, 2) kept only in small enough quantities so as to be exempted or not 
Introduction

requiring a specific license from a regulatory authority, 3) used or stored only in the form of nonleaking sealed sources, or 4) combinations of the above.

\subsection{Use of the Manual}

Potential users of this manual are Federal, State, and local government agencies having authority for control of radioactive environmental contamination; their contractors; and other parties, such as organizations with licensed authority to possess and use radioactive materials. The manual is intended for a technical audience having knowledge of radiation health physics and an understanding of statistics as well as experience with the practical applications of radiation protection. An understanding of instrumentation and methodologies and expertise in planning, approving, and implementing surveys of environmental levels of radioactive material is assumed. This manual has been written so that individuals responsible for planning, approving, and implementing radiological surveys will be able to understand and apply the guidance provided here. Certain situations and sites may require consultation with more experienced personnel.

MARSSIM provides guidance for conducting radiation surveys and site investigations. MARSSIM uses the word "should" as a recommendation, that ought not be interpreted as a requirement. The reader need not expect that every recommendation in this manual will be taken literally and applied at every site. Rather, it is expected that the survey planning documentation will address how the guidance will be applied on a site-specific basis.

As previously stated, MARSSIM supports implementation of dose- or risk-based regulations. The translation of the regulatory dose limit to a corresponding concentration level is not addressed in MARSSIM, so the guidance in this manual is applicable to a broad range of regulations, including risk- or concentration-based regulations. The terms dose and dose-based regulation are used throughout the manual, but these terms are not intended to limit the use of the manual.

Note that Federal or State agencies that can approve a demonstration of compliance may support requirements that differ from what is presented in this version of MARSSIM . It is essential, therefore, that the persons carrying out the surveys, whether they are conducting surveys in accordance with the simplified approach of Appendix B or the full MARSSIM process, remain in close communication with the proper Federal or State authorities throughout the compliance demonstration process. 
Introduction

\subsection{Missions of the Federal Agencies Producing MARSSIM}

MARSSIM is the product of a multi-agency workgroup with representatives from EPA, NRC, DOE, and DOD. This section briefly describes the missions of the participating agencies. Regulations and requirements governing site investigations for each of the agencies associated with radiation surveys and site investigations are presented in Appendix C.

\subsubsection{Environmental Protection Agency}

The mission of the U.S. Environmental Protection Agency (EPA) is to improve and preserve the quality of the environment, on both national and global levels. The EPA's scope of responsibility includes implementing and enforcing environmental laws, setting guidelines, monitoring pollution, performing research, and promoting pollution prevention. EPA Headquarters maintains overall planning, coordination, and control of EPA programs, and EPA's ten regional offices are responsible for executing EPA's programs within the boundaries of each region. EPA also coordinates with, and supports research and development of, pollution control activities carried out by State and local governments.

\subsubsection{Nuclear Regulatory Commission}

The mission of the U.S. Nuclear Regulatory Commission (NRC) is to ensure adequate protection of public health and safety, the common defense and security, and the environment in the use of certain radioactive materials in the United States. The NRC's scope of responsibility includes regulation of commercial nuclear power reactors; non-power research, test, and training reactors; fuel cycle facilities; medical, academic, and industrial uses of nuclear materials; and the transport, storage, and disposal of nuclear materials and waste. The Energy Reorganization Act of 1974 and the Atomic Energy Act of 1954, as amended, provide the foundation for regulation of the Nation's commercial use of radioactive materials.

\subsubsection{Department of Energy}

The mission of the Department of Energy (DOE) is to develop and implement a coordinated national energy policy to ensure the availability of adequate energy supplies and to develop new energy sources for domestic and commercial use. In addition, DOE is responsible for the development, construction and testing of nuclear weapons for the U.S. Military. DOE is also responsible for managing the low- and high-level radioactive wastes generated by past nuclear weapons and research programs and for constructing and maintaining a repository for civilian radioactive wastes generated by the commercial nuclear reactors. DOE has the lead in decontaminating facilities and sites previously used in atomic energy programs. 
Introduction

\subsubsection{Department of Defense}

The global mission of the Department of Defense (DOD) is to provide for the defense of the United States. In doing this, DOD is committed to protecting the environment. Each military service has specific regulations addressing the use of radioactive sources and the development of occupational health programs and radiation protection programs. The documents describing these regulations are used as guidance in developing environmental radiological surveys within DOD and are discussed in Appendix C.

Table 1.1 Scope of MARSSIM

\begin{tabular}{|c|c|c|c|}
\hline \multicolumn{2}{|c|}{ Within Scope of MARSSU } & \multicolumn{2}{|c|}{ 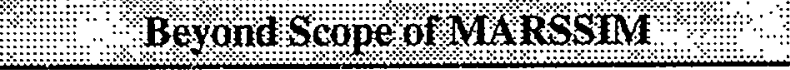 } \\
\hline Guidance & $\begin{array}{l}\text { MARSSIM provides technical } \\
\text { guidance on conducting radiation } \\
\text { surveys and site investigations. }\end{array}$ & Regulation & $\begin{array}{l}\text { MARSSIM does not set new } \\
\text { regulations or non-technical issues } \\
\text { (e.g., legal or policy) for site } \\
\text { cleanup. Release criterion will be } \\
\text { provided rather than calculated using } \\
\text { MARSSIM. }\end{array}$ \\
\hline Tool Box & $\begin{array}{l}\text { MARSSIM can be thought of as an } \\
\text { extensive tool box with many } \\
\text { components-some within the text } \\
\text { of MARSSIM, others by reference. }\end{array}$ & Tool Box & $\begin{array}{l}\text { Many topics are beyond the scope of } \\
\text { MARSSIM, for example: } \\
\text {-a public participation program } \\
\text {-packaging and transportation of } \\
\text { wastes for disposal } \\
\text {-decontamination and stabilization } \\
\text { techniques } \\
\text {-training }\end{array}$ \\
\hline Measurement & $\begin{array}{l}\text { The guidance given in MARSSIM is } \\
\text { performance-based and directed } \\
\text { towards acquiring site-specific data. }\end{array}$ & Procedure & $\begin{array}{l}\text { The approaches suggested in } \\
\text { MARSSIM vary depending on the } \\
\text { various site data needs-there are no } \\
\text { set procedures for sample collection, } \\
\text { measurement techniques, storage and } \\
\text { disposal established in MARSSIM. }\end{array}$ \\
\hline Modeling & $\begin{array}{l}\text { The interface between environmental } \\
\text { pathway modeling and MARSSIM is } \\
\text { an important survey design } \\
\text { consideration addressed in } \\
\text { MARSSIM. }\end{array}$ & Modeling & $\begin{array}{l}\text { Environmental pathway modeling } \\
\text { and ecological endpoints in } \\
\text { modeling are beyond the scope of } \\
\text { MARSSIM. }\end{array}$ \\
\hline
\end{tabular}


Table 1.1 Scope of MARSSIM (continued)

\begin{tabular}{|c|c|c|c|}
\hline \multicolumn{2}{|c|}{ 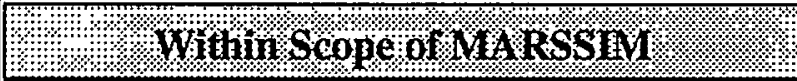 } & \multicolumn{2}{|c|}{ 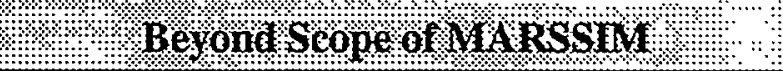 } \\
\hline $\begin{array}{l}\text { Soil and } \\
\text { Buildings }\end{array}$ & $\begin{array}{l}\text { The two main media of interest in } \\
\text { MARSSIM are contaminated surface } \\
\text { soil and building surfaces. }\end{array}$ & Other Media & $\begin{array}{l}\text { MARSSIM does not cover other } \\
\text { media, including construction } \\
\text { materials, equipment, subsurface } \\
\text { soil, surface or subsurface water, } \\
\text { biota, air, sewers, sediments or } \\
\text { volumetric contamination. }\end{array}$ \\
\hline $\begin{array}{l}\text { Final Status } \\
\text { Survey }\end{array}$ & $\begin{array}{l}\text { The focus of MARSSIM is on } \\
\text { the final status survey as this is the } \\
\text { deciding factor in judging if the site } \\
\text { meets the release criterion. }\end{array}$ & $\begin{array}{l}\text { Materials or } \\
\text { Equipment }\end{array}$ & $\begin{array}{l}\text { MARSSIM does not recommend } \\
\text { the use of any specific materials or } \\
\text { equipment-there is too much } \\
\text { variability in the types of radiation } \\
\text { sites-this information will be in } \\
\text { other documents. }\end{array}$ \\
\hline Radiation & $\begin{array}{l}\text { MARSSIM only considers } \\
\text { radiation-derived hazards. }\end{array}$ & Chemicals & $\begin{array}{l}\text { MARSSIM does not deal with any } \\
\text { hazards posed by chemical } \\
\text { contamination. }\end{array}$ \\
\hline $\begin{array}{l}\text { Remediation } \\
\text { Method }\end{array}$ & $\begin{array}{l}\text { MARSSIM assists users in } \\
\text { determining when sites are ready for } \\
\text { a final status survey and provides } \\
\text { guidance on how to determine if } \\
\text { remediation was successful. }\end{array}$ & $\begin{array}{l}\text { Remediation } \\
\text { Method }\end{array}$ & $\begin{array}{l}\text { MARSSIM does not discuss } \\
\text { selection and evaluation of remedial } \\
\text { alternatives, public involvement, } \\
\text { legal considerations, policy decisions } \\
\text { related to planning }\end{array}$ \\
\hline $\begin{array}{l}\text { DQO } \\
\text { Process }\end{array}$ & $\begin{array}{l}\text { MARSSIM presents a systemized } \\
\text { approach for designing surveys to } \\
\text { collect data needed for making } \\
\text { decisions such as whether or not to } \\
\text { release a site. }\end{array}$ & $\begin{array}{l}D Q O \\
\text { Process }\end{array}$ & $\begin{array}{l}\text { MARSSIM does not provide } \\
\text { prescriptive or default values of } \\
\text { DQOs. }\end{array}$ \\
\hline$D Q A$ & $\begin{array}{l}\text { MARSSIM provides a set of } \\
\text { statistical tests for evaluating data } \\
\text { and lists alternate tests that may be } \\
\text { applicable at specific sites. }\end{array}$ & $D Q A$ & $\begin{array}{l}\text { MARSSIM does not prescribe a } \\
\text { statistical test for use at all sites. }\end{array}$ \\
\hline
\end{tabular}




\section{OVERVIEW OF THE RADIATION SURVEY AND SITE INVESTIGATION PROCESS}

\subsection{Introduction}

This chapter provides a brief overview of the Radiation Survey and Site Investigation (RSSI) Process, several important aspects of this Process, and its underlying principles. The concepts introduced here are discussed in detail throughout the manual.

The purpose of MARSSIM is to provide a standardized approach to demonstrating compliance with a dose- or risk-based regulation. Since most of the manual is based on general technical and statistical concepts, much of the guidance can still be applied to other types of regulations or standards. The purpose of this chapter is to provide the overview information required to understand the rest of this manual.

Section 2.2 introduces and defines key terms used throughout the manual. Some of these terms may be familiar to the MARSSIM user, while others are new terms developed specifically for this manual.

Section 2.3 describes the flow of information used to decide whether or not a site or facility complies with a regulation. The section describes the framework that is used to demonstrate compliance with a regulation, and is the basis for all guidance presented in this manual. The decision-making process is broken down into four phases: 1) planning, 2) implementation, 3) assessment, and 4) decision making.

Section 2.4 introduces the Radiation Survey and Site Investigation Process, which can be used for compliance demonstration at many sites. The section describes a series of surveys that combine to form the core of this process. Each survey has specified goals and objectives to support a final decision on whether or not a site or facility complies with the appropriate regulations. Flow diagrams showing how the different surveys support the overall process are provided, along with descriptions of the information provided by each type of survey.

Section 2.5 presents major considerations that relate to the decision-making and survey-design processes. This section, as well as the exanuples discussed in detail throughout the manual, focuses on residual radioactive contamination in surface soils and on building surfaces.

Recommended survey designs for demonstrating compliance are presented along with the rationale for selecting these designs.

Section 2.6 recognizes that the methods presented in MARSSIM may not represent the optimal survey design at all sites. Some alternate methods for applying the Radiation Survey and Site Investigation process are discussed. Different methods for demonstrating compliance that are technically defensible may be developed with the approval of the responsible regulatory agency. 
Overview of the Radiation Survey and Site Investigation Process

MARSSIM provides an approach that is technically defensible and flexible enough to be applied to a variety of site-specific conditions. Applying this guidance to a dose- or risk-based regulation provides a consistent approach to protecting human health and the environment. The manual's performance-based approach to decision making provides the flexibility needed to address compliance demonstration at individual sites.

\subsection{Understanding Key MARSSIM Terminology}

The first step in understanding the Radiation Survey and Site Investigation (RSSI) Process is accomplished by understanding the scope of this manual, the terminology, and the concepts set forth. Some of the terms used in MARSSIM were developed for the purposes of this manual, while other commonly used terms are also adopted for use in MARSSIM. This section explains some of the terms roughly in the order of their presentation in the manual.

The process described in MARSSIM begins with the premise that a release criterion has already been provided in terms of a measurement quantity. The methods presented in MARSSM are generally applicable and are not dependent on the value of the release criterion.

A release criterion is a regulatory limit expressed in terms of dose (mSv/y or mrem/y) or risk (cancer incidence or cancer mortality). The terms release limit or cleanup standard are also used to describe this term. A release criterion is typically based on the total effective dose equivalent (TEDE), the committed effective dose equivalent (CEDE), risk of cancer incidence (morbidity), or risk of cancer death (mortality) and generally cannot be measured directly. Exposure pathway modeling is used to calculate a radionuclide-specific predicted concentration or surface area concentration of specific nuclides that could result in a dose (TEDE or CEDE) or specific risk equal to the release criterion. In this manual, such a concentration is termed the derived concentration guideline level (DCGL). Exposure pathway modeling is an analysis of various exposure pathways and scenarios used to convert dose or risk into concentration. In many cases DCGLs can be obtained from responsible regulatory agency guidance based on default modeling input parameters, while other users may elect to take into account site-specific parameters to determine DCGLs. In general, the units for the DCGL are the same as the units for measurements performed to demonstrate compliance $\left(e . g\right.$., $\mathrm{Bq} / \mathrm{kg}$ or $\mathrm{pCi} / \mathrm{g}, \mathrm{Bq} / \mathrm{m}^{2}$ or $\mathrm{dpm} / 100$ $\mathrm{cm}^{2}$ ). This allows direct comparisons between the survey results and the DCGL. A discussion of the uncertainty associated with using DCGLs to demonstrate compliance is included in Appendix D, Section D.6.

An investigation level is a radionuclide-specific level based on the release criterion that, if exceeded, triggers some response such as further investigation or remediation. An investigation level may be used early in decommissioning to identify areas requiring further investigation, and may also be used as a screening tool during compliance demonstration to identify potential problem areas. A DCGL is an example of a specific investigation level. 
While the derivation of DCGLs is outside the scope of MARSSIM, it is important to understand the assumptions that underlie this derivation. The derivation assumptions must be consistent with those used for planning a compliance demonstration survey. One of the most important assumptions used for converting a dose or risk limit into a media-specific concentration is the modeled area of contamination. Other considerations include sample depth, composition, modeling parameters, and exposure scenarios. MARSSIM defines two potential DCGLs based on the area of contamination.

- If the residual radioactivity is evenly distributed over a large area, MARSSIM looks at the average activity over the entire area. The $D C G L_{W}{ }^{1}$ (the DCGL used for the statistical tests, see Section 2.5.1.2) is derived based on an average concentration over a large area.

- If the residual radioactivity appears as small areas of elevated activity ${ }^{2}$ within a larger area, typically smaller than the area between measurement locations, MARSSIM considers the results of individual measurements. The DCGL $L_{E M C}$ (the DCGL used for the elevated measurement comparison (EMC), see Section 2.5.3 and Section 2.5.4) is derived separately for these small areas and generally from different exposure assumptions than those used for larger areas.

A site is any installation, facility, or discrete, physically separate parcel of land, or any building or structure or portion thereof, that is being considered for survey and investigation.

Area is a very general term that refers to any portion of a site, up to and including the entire site.

Decommissioning is the process of safely removing a site from service, reducing residual radioactivity through remediation to a level that permits release of the property, and termination of the license or other authorization for site operation. Although only part of the process, the term decommissioning is used in this sense for the Radiation Survey and Site Investigation (RSSI) Process, and is used this way throughout MARSSIM.

\footnotetext{
'The "W" in DCGL ${ }_{W}$ stands for Wilcoxon Rank Sum test, which is the statistical test recommended in MARSSIM for demonstrating compliance when the contaminant is present in background. The Sign test recommended for demonstrating compliance when the contaminant is not present in background also uses the DCGL $_{\mathrm{w}}$.

${ }^{2}$ A small area of elevated activity, or maximum point estimate of contamination, might also be referred to as a "hot spot." This term has been purposefully omitted from MARSSIM because the term often has different meanings based on operational or local program concerns. As a result, there may be problems associated with defining the term and reeducating MARSSIM users in the proper use of the term. Because these implications are inconsistent with MARSSIM concepts, the term is not used.
} 
A survey unit is a physical area consisting of structure or land areas of specified size and shape for which a separate decision will be made as to whether or not that area exceeds the release criterion. This decision is made as a result of the final status survey-the survey in the RSSI Process used to demonstrate compliance with the regulation or standard. The size and shape of the survey unit are based on factors, such as the potential for contamination, the expected distribution of contamination, and any physical boundaries (e.g., buildings, fences, soil type, surface water body) at the site.

For MARSSIM, measurement is used interchangeably to mean: 1) the act of using a detector to determine the level or quantity of radioactivity on a surface or in a sample of material removed from a media being evaluated, or 2) the quantity obtained by the act of measuring. Direct measurements are obtained by placing a detector near the media being surveyed and inferring the radioactivity level directly from the detector response. Scanning is a measurement technique performed by moving a portable radiation detector at a constant speed above a surface to semiquantitatively detect areas of elevated activity. Sampling is the process of collecting a portion of an environmental medium as being representative of the locally remaining medium. The collected portion, or aliquot, of the medium is then analyzed to identify the contaminant and determine the concentration. The word sample may also refer to a set of individual measurements drawn from a population whose properties are studied to gain information about the entire population. This second definition of sample is primarily used for statistical discussions.

To make the best use of resources for decommissioning, MARSSIM places greater survey efforts on areas that have, or had, the highest potential for contamination. This is referred to as a graded approach. The final status survey uses statistical tests to support decision making. These statistical tests are performed using survey data from areas with common characteristics, such as contamination potential, which are distinguishable from other areas with different characteristics. Classification is the process by which an area or survey unit is described according to radiological characteristics. The significance of survey unit classification is that this process determines the final status survey design and the procedures used to develop this design. Preliminary area classifications, made earlier in the MARSSIM Process, are useful for planning subsequent surveys.

Areas that have no reasonable potential for residual contamination are classified as non-impacted areas. These areas have no radiological impact from site operations and are typically identified early in decommissioning. Areas with some potential for residual contamination are classified as impacted areas.

Impacted areas are further divided into one of three classifications: 
- Class 1 Areas: Areas that have, or had prior to remediation, a potential for radioactive contamination (based on site operating history) or known contamination (based on previous radiation surveys) above the DCGL $\mathrm{w}_{\mathrm{w}}$. Examples of Class 1 areas include: 1) site areas previously subjected to remedial actions ${ }^{3}, 2$ ) locations where leaks or spills are known to have occurred, 3) former burial or disposal sites, 4) waste storage sites, and 5) areas with contaminants in discrete solid pieces of material and high specific activity.

- Class 2 Areas: Areas that have, or had prior to remediation, a potential for radioactive contamination or known contamination, but are not expected to exceed the DCGL ${ }_{\mathrm{w}}$. To justify changing the classification from Class 1 to Class 2, there should be measurement data that provides a high degree of confidence that no individual measurement would exceed the DCGL $\mathrm{w}_{\mathrm{w}}$. Other justifications for reclassifying an area as Class 2 may be appropriate, based on site-specific considerations. Examples of areas that might be classified as Class 2 for the final status survey include: 1) locations where radioactive materials were present in an unsealed form, 2) potentially contaminated transport routes, 3) areas downwind from stack release points, 4) upper walls and ceilings of buildings or rooms subjected to airborne radioactivity, 5) areas handling low concentrations of radioactive materials, and 6) areas on the perimeter of former contamination control areas.

- Class 3 Areas: Any impacted areas that are not expected to contain any residual radioactivity, or are expected to contain levels of residual radioactivity at a small fraction of the DCGL $\mathrm{w}_{\mathrm{w}}$, based on site operating history and previous radiation surveys. Examples of areas that might be classified as Class 3 include buffer zones around Class 1 or Class 2 areas, and areas with very low potential for residual contamination but insufficient information to justify a non-impacted classification.

Class 1 areas have the greatest potential for contamination and therefore receive the highest degree of survey effort for the final status survey using a graded approach, followed by Class 2 , and then by Class 3. Non-impacted areas do not receive any level of survey coverage because they have no potential for residual contamination. Non-impacted areas are determined on a sitespecific basis. Examples of areas that would be non-impacted rather than impacted usually include residential or other buildings that have or had nothing more than smoke detectors or exit signs with sealed radioactive sources.

\footnotetext{
${ }^{3}$ Remediated areas are identified as Class 1 areas because the remediation process often results in less than $100 \%$ removal of the contamination, even though the goal of remediation is to comply with regulatory standards and protect human health and the environment. The contamination that remains on the site after remediation is often associated with relatively small areas with elevated levels of residual radioactivity. This results in a non-uniform distribution of the radionuclide and a Class 1 classification. If an area is expected to have no potential to exceed the $D C G L_{w}$ and was remediated to demonstrate the residual radioactivity is as low as reasonably achievable (ALARA), the remediated area might be classified as Class 2 for the final status survey.
} 
If the radionuclide of potential concern is present in background, or if the measurement system used to determine concentration in the survey unit is not radionuclide-specific, background measurements are compared to the survey unit measurements to determine the level of residual radioactivity. The background reference area is a geographical area from which representative reference measurements are performed for comparison with measurements performed in specific survey units. The background reference area is defined as an area that has similar physical, chemical, radiological, and biological characteristics as the survey unit(s) being investigated but has not been contaminated by site activities (i.e., non-impacted).

The process of planning the survey, implementing the survey plan, and assessing the survey results prior to making a decision is called the Data Life Cycle. Survey planning uses the Data Quality Objectives ( $D Q O)$ Process to ensure that the survey results are of sufficient quality and quantity to support the final decision. Quality Assurance and Quality Control (QAVQC) procedures are performed during implementation of the survey plan to collect information necessary to evaluate the survey results. Data Quality Assessment (DQA) is the process of assessing the survey results, determining that the quality of the data satisfies the objectives of the survey, and interpreting the survey results as they apply to the decision being made.

A systematic process and structure for quality should be established to provide confidence in the quality and quantity of data collected to support decision making. The data used in decision making should be supported by a planning document that records how quality assurance and quality control are applied to obtain type and quality of results that are needed and expected. There are several terms used to describe a variety of planning documents, some of which document only a small part of the survey design process. MARRSIM uses the term Quality Assurance Project Plan (QAPP) to describe a single document that incorporates all of the elements of the survey design. This term is consistent with consensus guidance ANSU/ASQC E41994 (ASQC 1995) and EPA guidance (EPA 1994c; EPA 1997), and is recommended to promote consistency. The use of the term QAPP in MARSSIM does not exclude the use of other terms (e.g., Decommissioning Plan, Sampling and Analysis Plan, Field Sampling Plan) to describe survey documentation provided the information included in the documentation supports the objectives of the survey.

\subsection{Making Decisions Based on Survey Results}

Compliance demonstration is simply a decision as to whether or not a survey unit meets the release criterion. For most sites this decision is based on the results of one or more surveys. When survey results are used to support a decision, the decision maker ${ }^{4}$ needs to ensure that the

\footnotetext{
${ }^{4}$ The term decision maker is used throughout this section to describe the person, team, board, or committee responsible for the final decision regarding disposition of the survey unit.
} 
data will support that decision with satisfactory confidence. Usually a decision maker will make a correct decision after evaluating the data. However, since uncertainty in the survey results is unavoidable, the possibility of errors in decisions supported by survey results is unavoidable. For this reason, positive actions must be taken to manage the uncertainty in the survey results so that sound, defensible decisions may be made. These actions include proper survey planning to control known causes of uncertainty, proper application of quality control (QC) procedures during implementation of the survey plan to detect and control significant sources of error , and careful analysis of uncertainty before the data are used to support decision making. These actions describe the flow of data throughout each type of survey, and are combined in the Data Life Cycle as shown in Figure 2.1.

There are four phases of the Data Life Cycle:

- Planning Phase. The survey design is developed and documented using the Data Quality Objectives (DQO) Process. Quality assurance and quality control (QA/QC) procedures are developed and documented in the Quality Assurance Project Plan (QAPP). The QAPP is the principal product of the planning process which incorporates the DQOs as it integrates all technical and quality aspects for the life cycle of the project, including planning, implementation, and assessment. The QAPP documents planning results for survey operations and provides a specific format for obtaining the type and quality of data needed for decision making. The QAPP elements are presented in an order corresponding to the Data Life Cycle by grouping them into two types of elements: 1) project management; and 2) collection and evaluation of environmental data (ASQC 1995). The DQO process is described in Appendix D, and applied in Chapters 3, 4 , and 5 of this manual. Development of

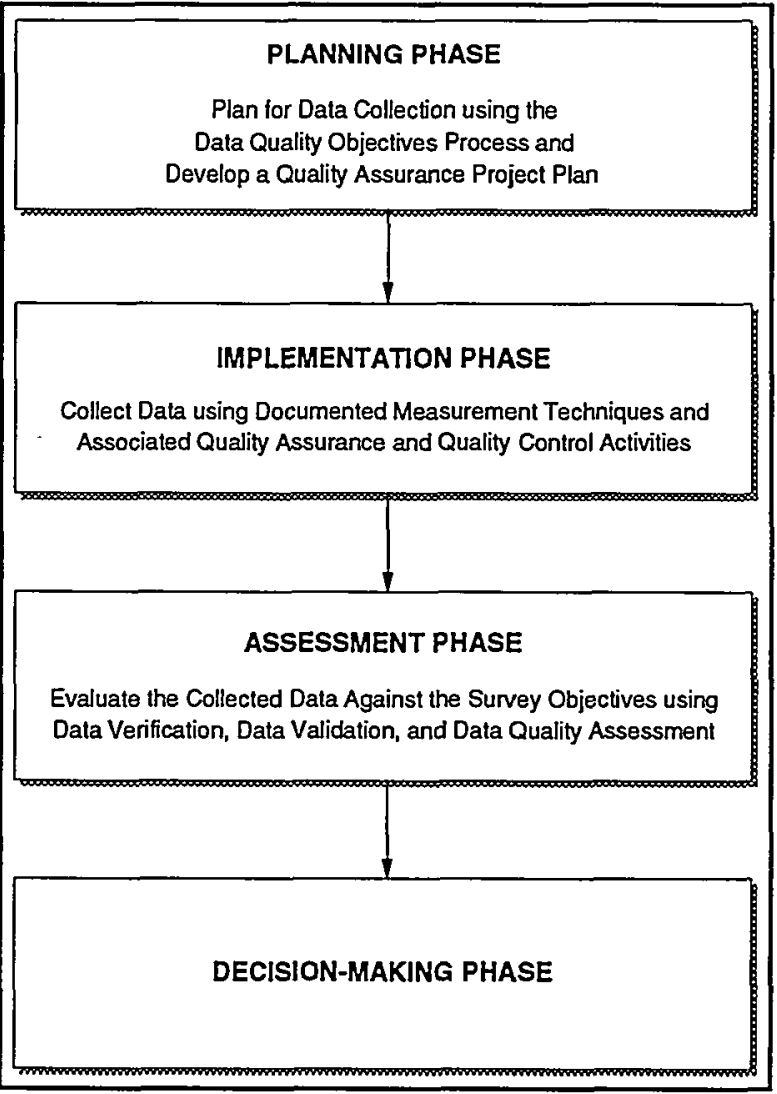

Figure 2.1 The Data Life Cycle the QAPP is described in Section 9.2 and applied throughout decommissioning. 
- Implementation Phase. The survey design is carried out in accordance with the SOPs and QAPP, resulting in the generation of raw data. Chapter 6, Chapter 7, and Appendix $\mathrm{H}$ provide information on the selection of data collection techniques. The QA and QC measurements, discussed in Chapter 6 and Chapter 7, also generate data and other important information that will be used during the Assessment Phase.

- Assessment Phase. The data generated during the Implementation Phase are first verified to ensure that the SOPs specified in the QAPP were actually followed and that the measurement systems performed in accordance with the criteria specified in the QAPP. Then the data are validated to ensure that the results of data collection activities support the objectives of the survey as documented in the QAPP, or permit a determination that these objectives should be modified. The data quality assessment (DQA) process is then applied using the validated data to determine if the quality of the data satisfies the data user's needs. Data verification and validation are described in Section 9.3. The DQA process is described in Appendix $\mathrm{E}$ and is applied in Chapter 8.

- Decision-Making Phase. A decision is made, in coordination with the responsible regulatory agency, based on the conclusions drawn from the assessment process. The ultimate objective is to make technically defensible decisions with a specified level of confidence (Chapter 8 ).

\subsubsection{Planning Effective Surveys-Planning Phase}

The first step in designing effective surveys is planning. The DQO Process is a series of planning steps based on the scientific method for establishing criteria for data quality and developing survey designs (ASQC 1995, EPA 1994a, EPA 1987b, EPA 1987c). Planning radiation surveys using the DQO Process improves the survey effectiveness and efficiency, and thereby the defensibility of decisions. This minimizes expenditures related to data collection by eliminating unnecessary, duplicative, or overly precise data. Using the DQO Process ensures that the type, quantity, and quality of environmental data used in decision making will be appropriate for the intended application. MARSSIM supports the use of the DQO Process to design surveys for input to both evaluation techniques (elevated measurement comparison and the statistical test). The DQO Process provides systematic procedures for defining the criteria that the survey design should satisfy, including what type of measurements to perform, when and where to perform measurements, the level of decision errors for the survey, and how many measurements to perform.

The level of effort associated with planning a survey is based on the complexity of the survey. Large, complicated sites generally receive a significant amount of effort during the planning phase, while smaller sites may not require as much planning. This graded approach defines data quality requirements according to the type of survey being designed, the risk of making a 
decision error based on the data collected, and the consequences of making such an error. This approach provides a more effective survey design combined with a basis for judging the usability of the data collected.

DQOs are qualitative and quantitative statements derived from the outputs of the DQO Process that:
- $\quad$ clarify the study objective
- define the most appropriate type of data to collect
- determine the most appropriate conditions for collecting the data
- $\quad$ specify limits on decision errors which will be used as the basis for establishing the quantity and quality of data needed to support the decision

The DQO Process consists of seven steps, as shown in Figure 2.2. Each step is discussed in detail in Appendix D. While all of the outputs of the DQO Process are important for designing efficient surveys, there are some that are referred to throughout the manual. These DQOs are mentioned briefly here, and are discussed in detail throughout MARSSIM and in Appendix D.

The minimum information (outputs) required from the DQO Process to proceed with the methods described in MARSSIM are:

- classify and specify boundaries of survey units: this can be accomplished at any time, but must be finalized during final status survey planning (Section 4.4, Section 4.6)

- $\quad$ state the null hypothesis $\left(\mathrm{H}_{0}\right)$ : the residual radioactivity in the survey unit exceeds the release criterion (Section 2.5, Appendix D, Section D.6)

- $\quad$ specify a gray region where the consequences of decision errors are relatively minor: the upper bound of the gray region is defined as the $\mathrm{DCGL}_{\mathrm{W}}$, and the lower bound of the gray region (LBGR) is a site-specific variable generally initially selected to equal one half the $\mathrm{DCGL}_{\mathrm{w}}$ and adjusted to provide an acceptable value for the relative shift (Section 5.5.2.2, Section 5.5.2.3, Appendix D, Section D.6)

- define Type I and Type II decision errors and assign probability limits for the occurrence of these errors: the probability of making a Type I decision error $(\alpha)$ or a Type II decision error ( $\beta$ ) are site-specific variables (Section 5.5.2.2, Section 5.5.2.3, Appendix D, Section D.6)

- estimate the standard deviation of the measurements in the survey unit: the standard deviation $(\sigma)$ is a site-specific variable, typically estimated from preliminary survey data (Section 5.5.2.2, Section 5.5.2.3)

- $\quad$ specify the relative shift: the shift $(\Delta)$ is equal to the width of the gray region (DCGL $L_{w}$ - LBGR), and the relative shift is defined as $\Delta / \sigma$, which is generally designed to have a value between one and three (Section 5.5.2.2, Section 5.5.2.3) 


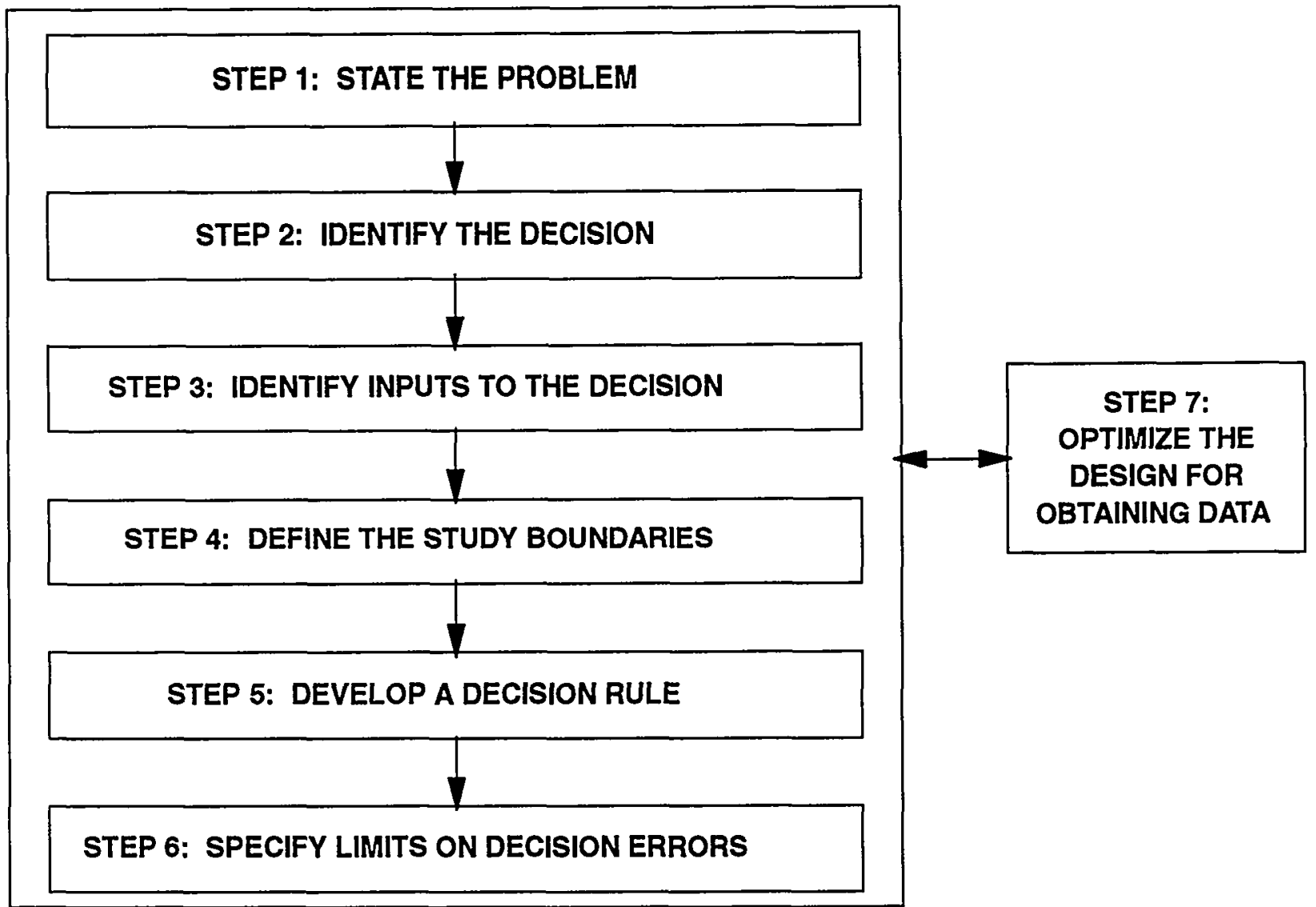

Figure 2.2 The Data Quality Objectives Process

- specify the detection limit for all measurement techniques (scanning, direct measurement, and sample analysis) specified in the QAPP: the minimum detectable concentration (MDC) is unique for each measurement system (Section 6.7)

- $\quad$ calculate the estimated number of measurements $(\mathrm{N})$ and specify the measurement locations required to demonstrate compliance: the number of measurements depends on the relative shift $(\Delta / \sigma)$, Type I and Type II decision error rates ( $\alpha$ and $\beta$ ), the potential for small areas of elevated activity, and the selection and classification of survey units (Section 5.5.2.2, Section 5.5.2.3)

- $\quad$ specify the documentation requirements for the survey, including survey planning documentation: documentation supporting the decision on whether or not the site complies with the release criterion is determined on a site-specific basis (Appendix N, Section N.2) 
In addition to DQOs, values for the Data Quality Indicators (DQIs) should also be established and recorded during the planning stage. Where DQOs include performance measures and goals in relation to a specific intended use of the data, DQIs quantify the amount of error in the data collection process and the analytical measurement system regardless of how the data may be used (EPA 1997). Precision, bias, accuracy, representativeness, comparability, and completeness are the DQIs recommended for quantifying the amount of error for survey data. These DQIs are discussed in detail in Appendix N, Section N.6.

\subsubsection{Estimating the Uncertainty in Survey Results-Implementation Phase}

To encourage flexibility and the use of optimal measurement techniques for a specific site, MARSSIM does not provide detailed guidance on specific techniques. Instead, MARSSIM encourages the decision maker to evaluate available techniques based on the survey objectives. Guidance on evaluating these objectives, such as detection limit, is provided.

QC programs can both lower the chances of making an incorrect decision and help the data user understand the level of uncertainty that surrounds the decision (EPA 1997). As discussed previously, QC data are collected and analyzed during implementation to provide an estimate of the uncertainty associated with the survey results. QC measurements (scans, direct measurements, and samples) are technical activities performed to measure the attributes and performance of the survey. During any survey, a certain number of measurements should be taken for QC purposes.

\subsubsection{Interpreting Survey Results—Assessment Phase}

Assessment of environmental data is used to evaluate whether the data meet the objectives of the survey and whether the data are sufficient to determine compliance with the DCGL (EPA 1992a, EPA 1992b, EPA 1996a). The assessment phase of the Data Life Cycle consists of three phases: data verification, data validation, and Data Quality Assessment (DQA).

Data verification is used to ensure that the requirements stated in the planning documents are implemented as prescribed (see Section 9.3). Data validation is used to ensure that the results of the data collection activities support the objectives of the survey as documented in the QAPP, or permit a determination that these objectives should be modified (see Section 9.3 and Appendix N). Data quality assessment (DQA) is the scientific and statistical evaluation of data to determine if the data are of the right type, quality, and quantity to support their intended use (EPA 1996a). DQA helps complete the Data Life Cycle by providing the assessment needed to determine that the planning objectives are achieved (see Section 8.2). Figure 2.3 illustrates where data verification, data validation, and DQA fit into the Assessment Phase of the Data Life Cycle. 
Overview of the Radiation Survey and Site Investigation Process

There are five steps in the DQA Process:

- $\quad$ Review the DQOs and Survey Design

- Conduct a Preliminary Data Review

- $\quad$ Select the Statistical Test

- Verify the Assumptions of the Statistical Test

- Draw Conclusions from the Data

The strength of DQA is its design that progresses in a logical and efficient manner to promote an understanding of how well the data meet the intended use. The Assessment Phase is described in more detail in Appendix E. Section 2.6 discusses the flexibility of the Data Life Cycle and describes the use of survey designs other than those described later in MARSSIM.

\subsubsection{Uncertainty in Survey Results}

Uncertainty in survey results arises primarily from two sources: survey design errors and measurement errors. Survey design errors occur when the survey design is unable to capture the complete extent of variability that

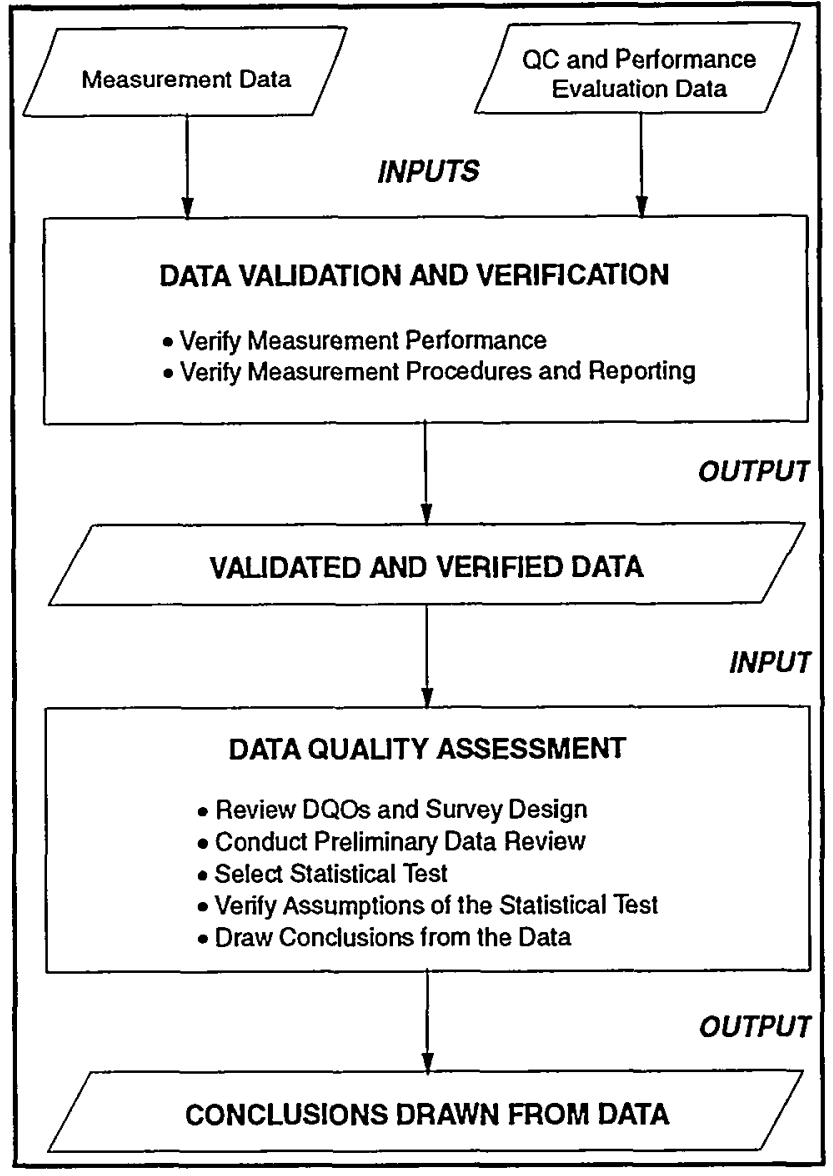

Figure 2.3 The Assessment Phase of the Data Life Cycle exists for the radionuclide distribution in a survey unit. Since it is impossible in every situation to measure the residual radioactivity at every point in space and time, the survey results will be incomplete to some degree. It is also impossible to know with complete certainty the residual radioactivity at locations that were not measured, so the incomplete survey results give rise to uncertainty. The greater the natural or inherent variation in residual radioactivity, the greater the uncertainty associated with a decision based on the survey results. The unanswered question is: "How well do the survey results represent the true level of residual radioactivity in the survey unit?"

Measurement errors create uncertainty by masking the true level of residual radioactivity and may be classified as random or systematic errors. Random errors affect the precision of the measurement system, and show up as variations among repeated measurements. Systematic errors show up as measurements that are biased to give results that are consistently higher or lower than the true value. Measurement uncertainty is discussed in Section 6.8. 
MARSSIM uses the Data Life Cycle to control and estimate the uncertainty in the survey results on which decisions are made. Adequate planning should minimize known sources of uncertainty. QC data collected during implementation of the survey plan provide an estimate of the uncertainty. Statistical hypothesis testing during the assessment phase provides a level of confidence for the final decision. There are several levels of decisions included within each survey type. Some decisions are quantitative, based on the numerical results of measurements performed during the survey. Other decisions are qualitative based on the available evidence and best professional judgment. The Data Life Cycle can and should be applied consistently to both types of decisions.

\subsubsection{Reporting Survey Results}

The process of reporting survey results is an important consideration in planning the survey. Again, the level of effort for reporting should be based on the complexity of the survey. A simple survey with relatively few results may specify a single report, while a more complicated survey may specify several reports to meet the objectives of the survey. Reporting requirements for individual surveys should be developed during planning and clearly documented in the QAPP. These requirements should be developed with cooperation from the people performing the analyses (e.g., the analytical laboratory should be consulted on reporting results for samples). The Health Physics Society has developed several suggestions for reporting survey results (EPA 1980c). These suggestions include:

- Report the actual result of the analysis. Do not report data as "less than the detection limit." Even negative results and results with large uncertainties can be used in the statistical tests to demonstrate compliance. Results reported only as " $\angle M D C$ " cannot be fully used and, for example, complicate even such simple analyses as calculating an average. While the nonparametric tests described in Section 8.3 and Section 8.4 can accommodate as much as $40 \%$ of the results as non-detects, it is better to report the actual results and avoid the possibility of exceeding this limit.

- Report results using the correct units and the correct number of significant digits. The choice of reporting results using SI units (e.g., $\mathrm{Bq} / \mathrm{kg}, \mathrm{Bq} / \mathrm{m}^{2}$ ) or conventional units (e.g., $\mathrm{pCi} / \mathrm{g}, \mathrm{dpm} / 100 \mathrm{~cm}^{2}$ ) is made on a site-specific basis. Generally, MARSSIM recommends that all results be reported in the same units as the DCGLs. Sometimes the results may be more convenient to work with as counts directly from the detector. In these cases the user should decide what the appropriate units are for a specific survey based on the survey objectives. The user should also report the correct number of significant digits as described in EPA 1980c. 
- Report the measurement uncertainty for every analytical result or series of results, such as for a measurement system. This uncertainty, while not directly used for demonstrating compliance with the release criterion, is used for survey planning and data assessment throughout the Radiation Survey and Site Investigation Process. In addition, the uncertainty is used for evaluating the performance of measurement systems using QC measurement results (as described in Section 6.2 for scans and direct measurements, and in Section 7.2 for laboratory analysis of samples). The uncertainty is also used for comparing individual measurements to the action level, which is especially important in the early stages of decommissioning (scoping, characterization, and remedial action support surveys described in Section 2.4) when decisions are made based on a limited number of measurements. Section 6.8 discusses methods for calculating the measurement uncertainty.

- Report the minimum detectable concentration (MDC) for the measurement system as well as the method used to calculate the MDC. The MDC is an a priori estimate of the capability for detecting an activity concentration with a specific measurement system (EPA 1980c). As such, this estimate is valuable for planning and designing radiation surveys. Optimistic estimates of the MDC (calculated using ideal conditions that may not apply to actual measurements) overestimate the ability of a technique to detect residual radioactivity, especially when scanning for alpha or low-energy beta radiations. This can invalidate survey results, especially for scanning surveys. Using a more realistic MDC, as described in Section 6.7, during scoping and characterization surveys helps in the proper classification of survey units for final status surveys and minimizes the possibility of designing and performing subsequent surveys because of errors in classification. Estimates of the MDC that minimize potential decision errors should be used for planning surveys.

Reporting requirements for individual surveys should be developed during planning and clearly documented in the QAPP.

\subsection{Radiation Survey and Site Investigation Process}

The Data Life Cycle discussed in Section 2.3 is the basis for the performance-based guidance in MARSSIM. As a framework for collecting the information required for demonstrating compliance identified using the DQO Process, MARSSIM recommends using a series of surveys. The Radiation Survey and Site Investigation (RSSI) Process is an example of a series of surveys designed to demonstrate compliance with a dose- or risk-based regulation for sites with radioactive contamination. 
Overview of the Radiation Survey and Site Investigation Process

There are six principal steps in the RSSI Process:

$\begin{array}{ll}- & \text { Site Identification } \\ - & \text { Historical Site Assessment } \\ - & \text { Scoping Survey } \\ - & \text { Characterization Survey } \\ - & \text { Femedial Action Support Survey } \\ \text { - } & \text { Final Status Survey }\end{array}$

Table 2.1 provides a simplified overview of the principal steps in the RSSI process and how the Data Life Cycle can be used in an iterative fashion within the process. Each of these steps is briefly described in the Sections 2.4.1 through 2.4.6, and described in more detail in Chapter 3 and Chapter 5. In addition, there is a brief description of regulatory agency confirmation and verification (see Section 2.4.7). Because MARSSIM focuses on demonstrating compliance with a release criterion, specifically through the use of a final status survey, these surveys have additional objectives that are not fully discussed in MARSSIM (e.g., health and safety of workers, supporting selection of values for exposure pathway model parameters).

Figure 2.4 illustrates the Radiation Survey and Site Investigation Process in terms of area classification, and lists the major decision to be made for each type of survey. The flowchart demonstrates one method for quickly estimating the survey unit classification early in the MARSSIM Process based on limited information. While this figure shows the relationship between area classification and survey unit classification along with the major decision points that determine classification, this illustration is not designed to comprehensively consider every possibility that may occur at individual survey units. As such, it is a useful tool for visualizing the classification process, but there are site-specific characteristics that may cause variation from this scheme.

The flowchart, illustrated in Figures 2.5 through 2.8, presents the principal steps and decisions in the site investigation process and shows the relationship of the survey types to the overall assessment process. As shown in these figures, there are several sequential steps in the site investigation process and each step builds on information provided by its predecessor. Properly applying each sequential step in the RSSI Process should provide a high degree of assurance that the release criterion has not been exceeded. 
Overview of the Radiation Survey and Site Investigation Process

Table 2.1 The Data Life Cycle used to Support the Radiation Survey and Site Investigation Process

\begin{tabular}{|c|c|c|c|}
\hline RSSIOIEOCesS & \multicolumn{2}{|c|}{ 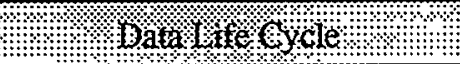 } & 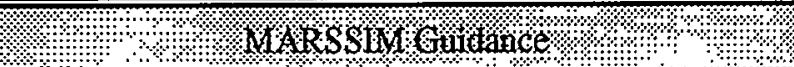 \\
\hline Site Identification & & & $\begin{array}{l}\text { Provides information on identifying potential radiation } \\
\text { sites (Section 3.3) }\end{array}$ \\
\hline $\begin{array}{l}\text { Historical Site } \\
\text { Assessment }\end{array}$ & $\begin{array}{l}\text { Historical Site } \\
\text { Assessment } \\
\text { Data Life Cycle }\end{array}$ & $\begin{array}{l}\text { Plan } \\
\text { Implement } \\
\text { Assess } \\
\text { Decide }\end{array}$ & $\begin{array}{l}\text { Provides information on collecting and assessing } \\
\text { existing site data (Sections } 3.4 \text { through 3.9) and } \\
\text { potential sources of information (Appendix G) }\end{array}$ \\
\hline Scoping Survey & $\begin{array}{l}\text { Scoping Data } \\
\text { Life Cycle }\end{array}$ & $\begin{array}{l}\text { Plan } \\
\text { Implement } \\
\text { Assess } \\
\text { Decide }\end{array}$ & $\begin{array}{l}\text { Discusses the purpose and general approach for } \\
\text { performing scoping surveys, especially as sources of } \\
\text { information when planning final status surveys (Section } \\
5.2 \text { ) }\end{array}$ \\
\hline $\begin{array}{l}\text { Characterization } \\
\text { Survey }\end{array}$ & $\begin{array}{l}\text { Characterization } \\
\text { Data Life Cycle }\end{array}$ & $\begin{array}{l}\text { Plan } \\
\text { Implement } \\
\text { Assess } \\
\text { Decide }\end{array}$ & $\begin{array}{l}\text { Discusses the purpose and general approach for } \\
\text { performing characterization surveys, especially as } \\
\text { sources of information when planning final status } \\
\text { surveys (Section 5.3) }\end{array}$ \\
\hline $\begin{array}{l}\text { Remedial Action } \\
\text { Support Survey }\end{array}$ & $\begin{array}{l}\text { Remedial } \\
\text { Action Data } \\
\text { Life Cycle }\end{array}$ & $\begin{array}{l}\text { Plan } \\
\text { Implement } \\
\text { Assess } \\
\text { Decide }\end{array}$ & $\begin{array}{l}\text { Discusses the purpose and general approach for } \\
\text { performing remedial action support surveys, especially } \\
\text { as sources of information when planning final status } \\
\text { surveys (Section 5.4) }\end{array}$ \\
\hline Final Status Survey & $\begin{array}{l}\text { Final Status } \\
\text { Data Life Cycle }\end{array}$ & $\begin{array}{l}\text { Plan } \\
\text { Implement } \\
\text { Assess } \\
\text { Decide }\end{array}$ & $\begin{array}{l}\text { Provides detailed guidance for planning final status } \\
\text { surveys (Chapter } 4 \text { and Section } 5.5 \text { ), selecting } \\
\text { measurement techniques (Chapter } 6 \text {, Chapter } 7 \text {, and } \\
\text { Appendix H), and assessing the data collected during } \\
\text { final status surveys (Chapter } 8 \text { and Chapter 9) }\end{array}$ \\
\hline
\end{tabular}

\subsubsection{Site Identification}

The identification of known, likely, or potential sites is generally easily accomplished, and is typically performed before beginning decommissioning. Any facility preparing to terminate an NRC or agreement state license would be identified as a site. Formerly terminated NRC licenses may also become sites for the EPA Superfund Program. Portions of military bases or DOE facilities may be identified as sites based on records of authorization to possess or handle radioactive materials. In addition, information obtained during the performance of survey activities may identify additional potential radiation sites related to the site being investigated. Information on site identification is provided in Section 3.3. 
Overview of the Radiation Survey and Site Investigation Process

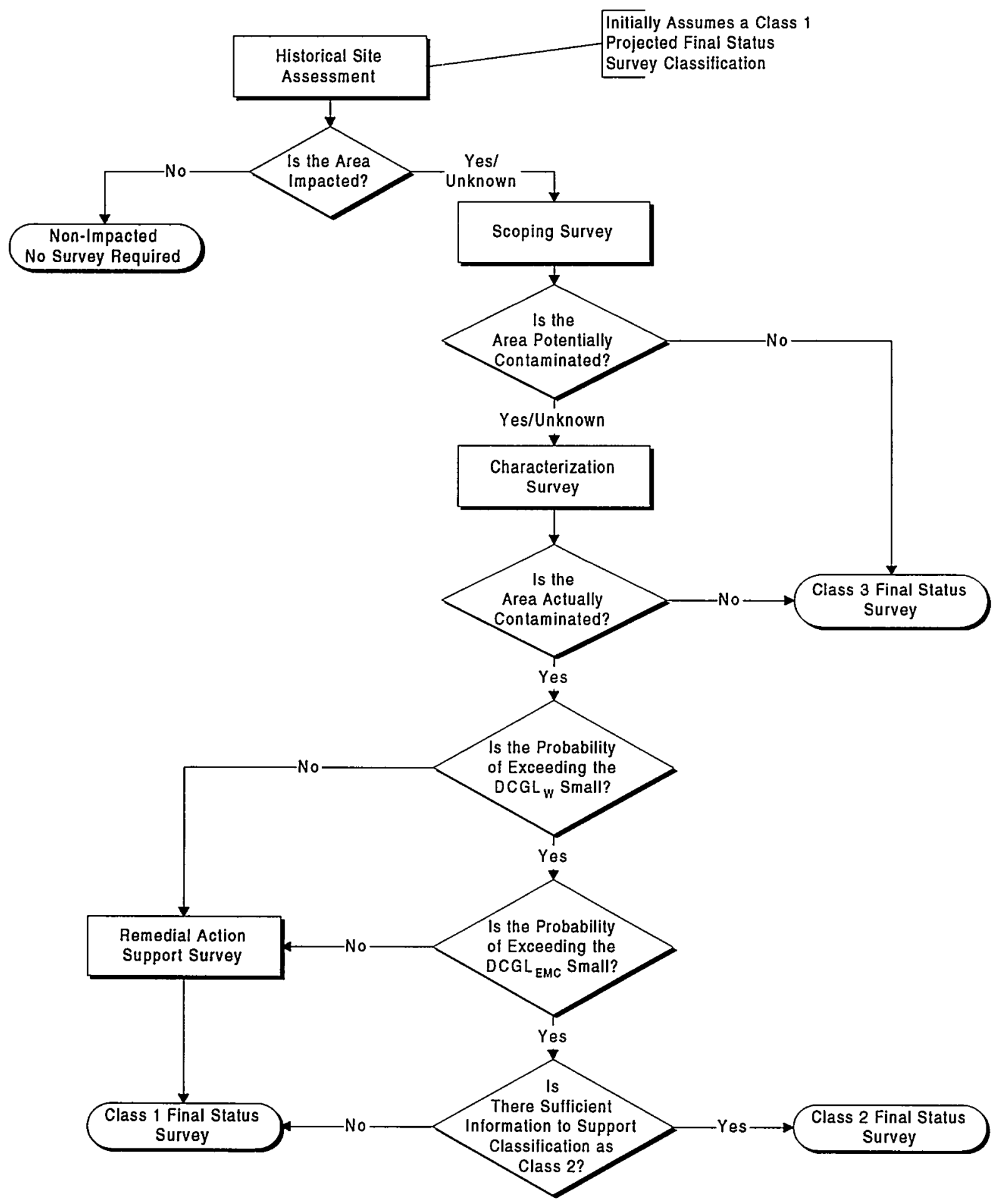

Figure 2.4 The Radiation Survey and Site Investigation Process in Terms of Area Classification 
Overview of the Radiation Survey and Site Investigation Process

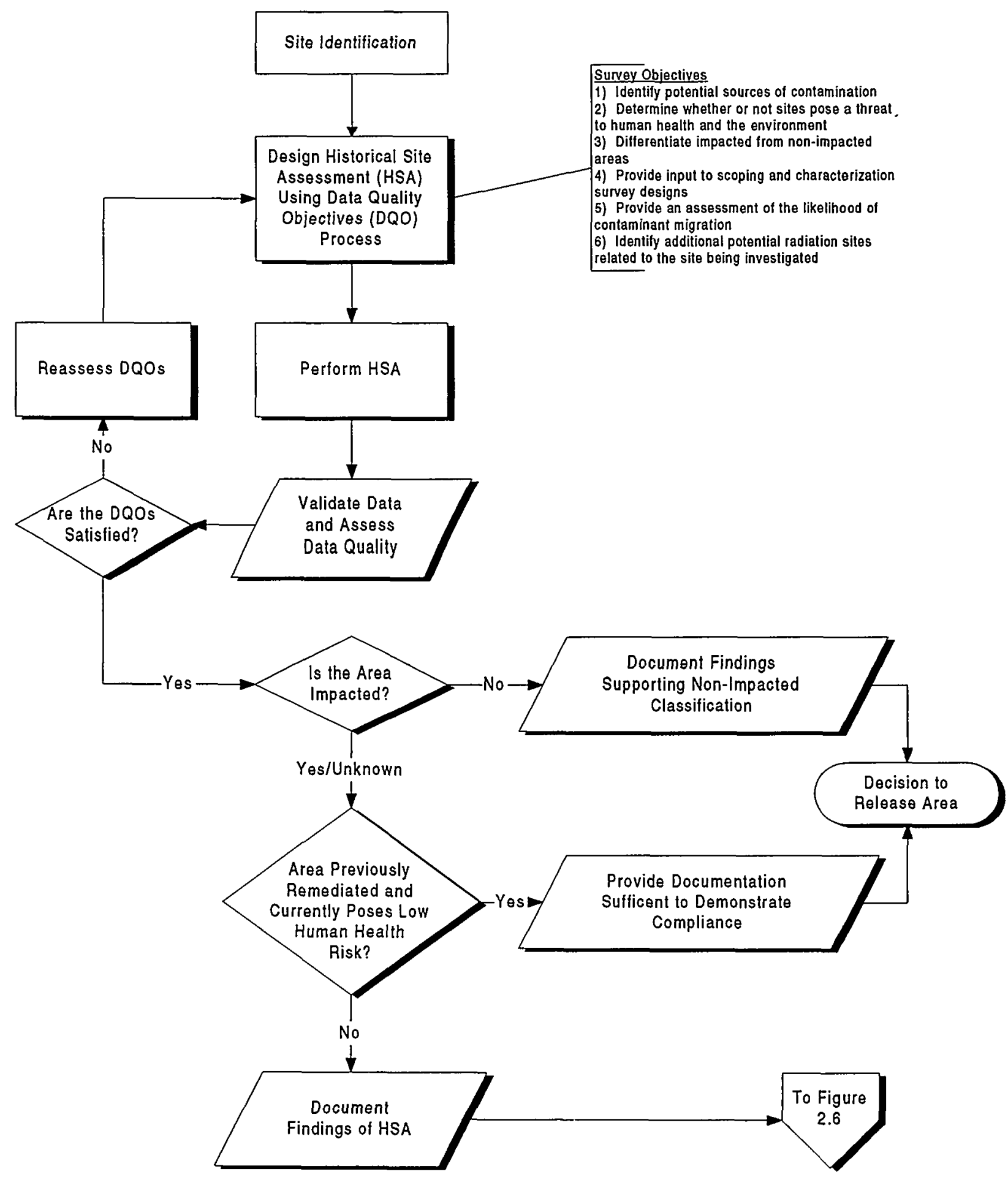

Figure 2.5 The Historical Site Assessment Portion of the Radiation Survey and Site Investigation Process 
Overview of the Radiation Survey and Site Investigation Process

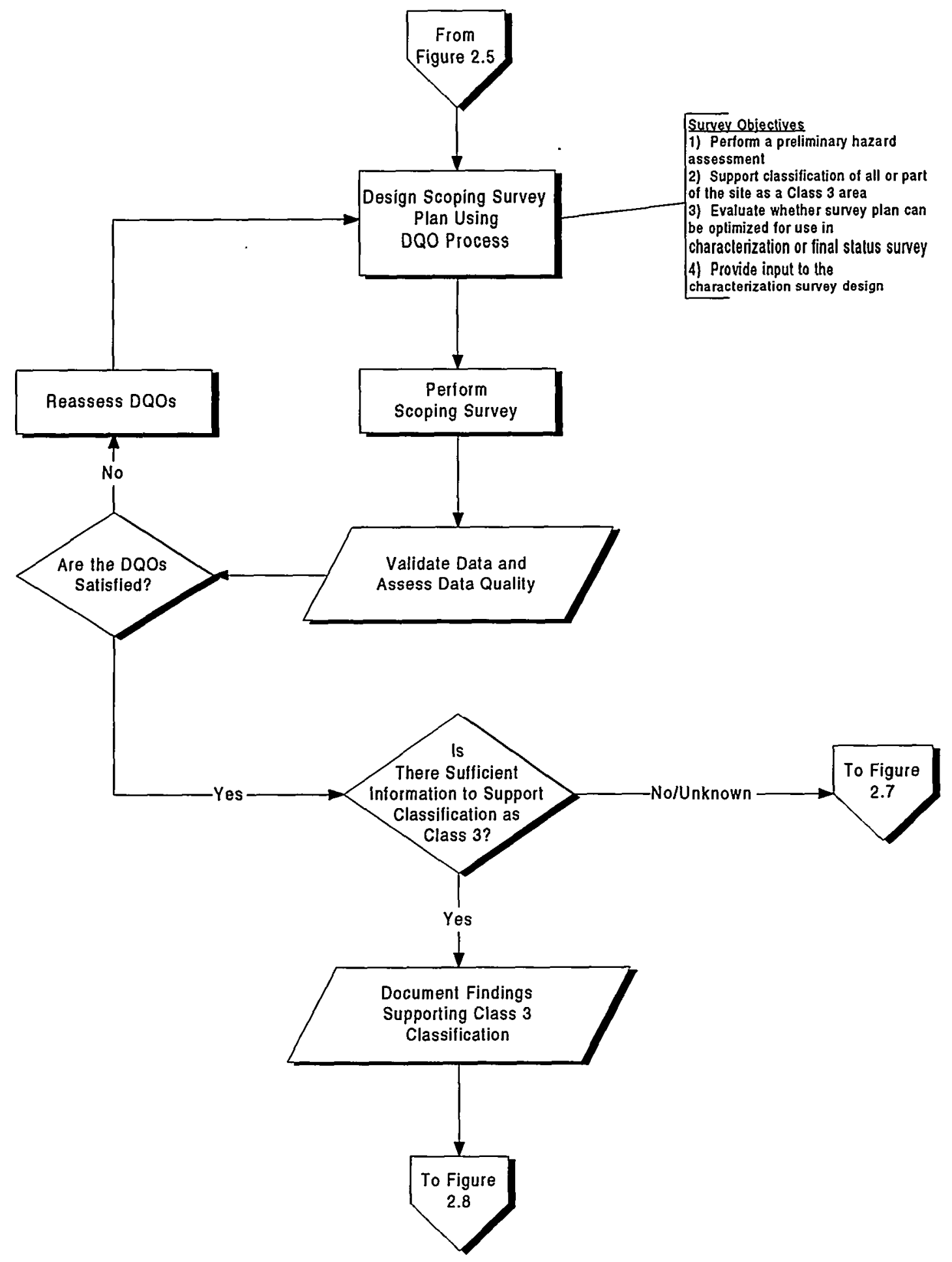

Figure 2.6 The Scoping Survey Portion of the Radiation Survey and Site Investigation Process 
Overview of the Radiation Survey and Site Investigation Process

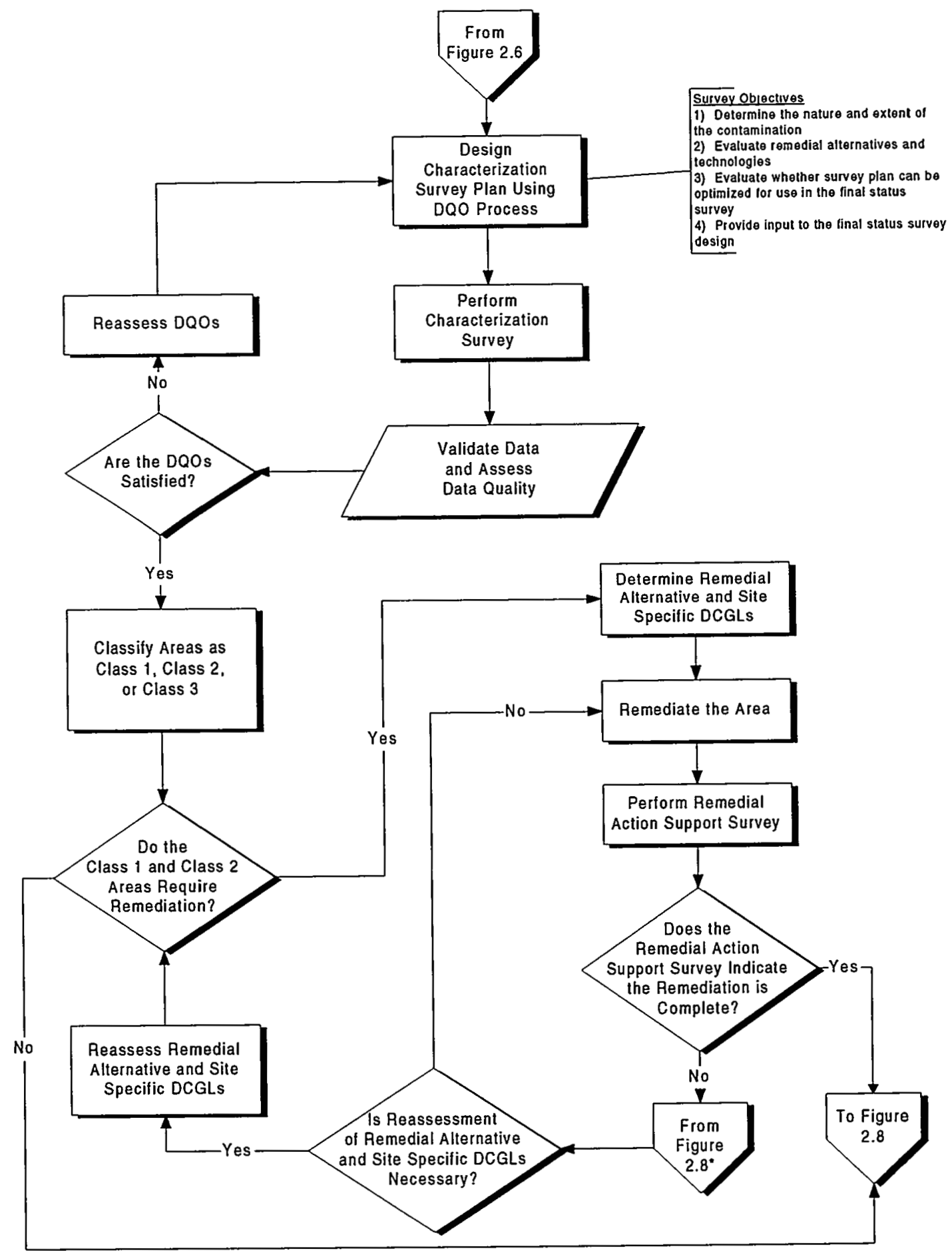

* The point where survey units that fail to demonstrate compliance in the final status survey in Figure 2.8 re-enter the process

Figure 2.7 The Characterization and Remedial Action Support Survey Portion of the Radiation Survey and Site Investigation Process 
Overview of the Radiation Survey and Site Investigation Process

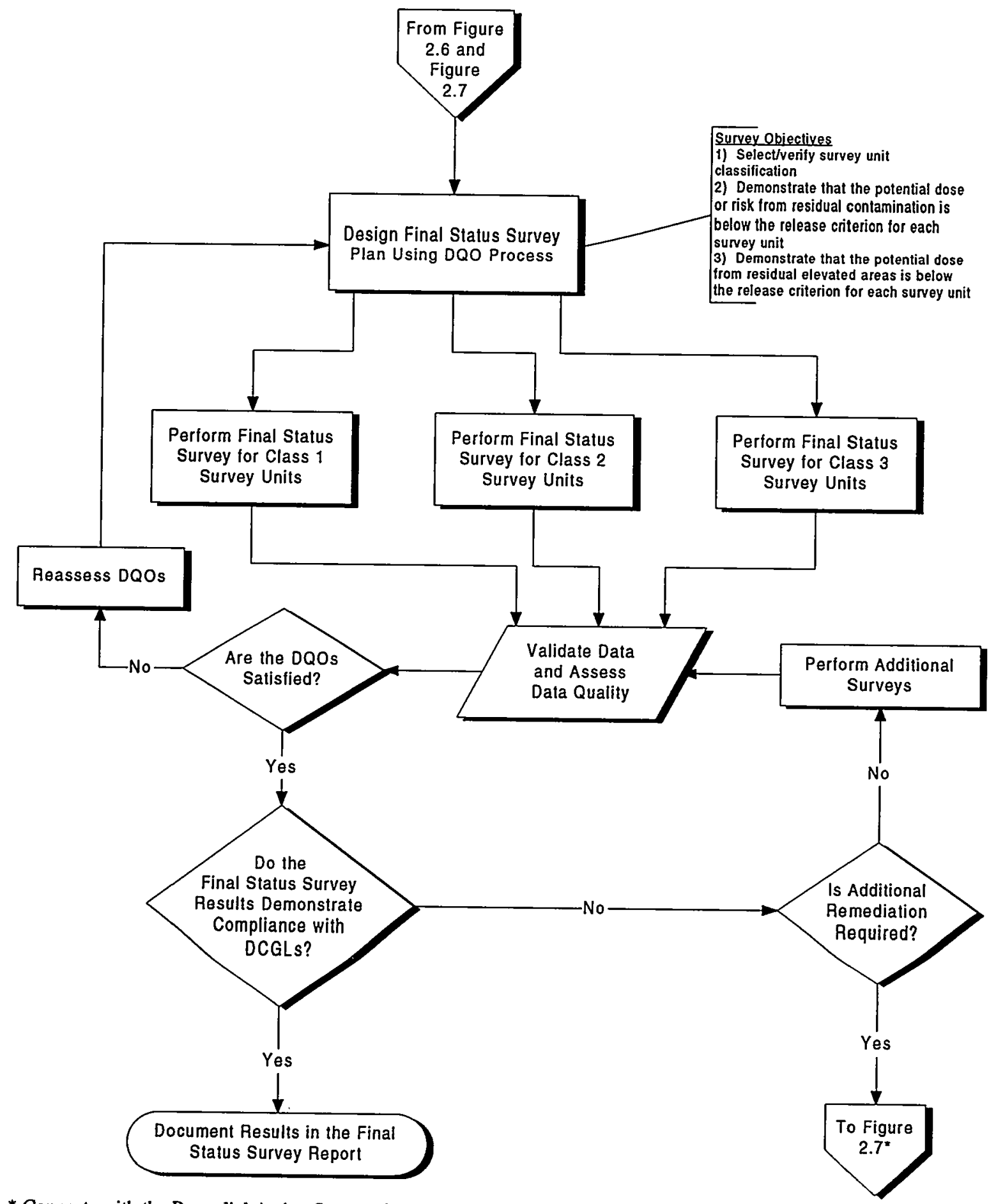

* Connects with the Remedial Action Support Survey portion of the process in Figure 2.7

Figure 2.8 The Final Status Survey Portion of the Radiation Survey and Site Investigation Process 
Overview of the Radiation Survey and Site Investigation Process

\subsubsection{Historical Site Assessment}

The primary purpose of the Historical Site Assessment (HSA) is to collect existing information concerning the site and its surroundings.

The primary objectives of the HSA are to:

- identify potential sources of contamination

- determine whether or not sites pose a threat to human health and the environment

- differentiate impacted from non-impacted areas

- $\quad$ provide input to scoping and characterization survey designs

- $\quad$ provide an assessment of the likelihood of contaminant migration

- identify additional potential radiation sites related to the site being investigated

The HSA typically consists of three phases: identification of a candidate site, preliminary investigation of the facility or site, and site visits or inspections. The HSA is followed by an evaluation of the site based on information collected during the HSA.

\subsubsection{Scoping Survey}

If the data collected during the HSA indicate an area is impacted, a scoping survey could be performed. Scoping surveys provide site-specific information based on limited measurements.

The primary objectives of a scoping survey are to:

- $\quad$ perform a preliminary hazard assessment

- $\quad$ support classification of all or part of the site as a Class 3 area

- evaluate whether the survey plan can be optimized for use in the characterization or final status surveys

- provide data to complete the site prioritization scoring process (CERCLA and RCRA sites only)

- provide input to the characterization survey design if necessary

Scoping surveys are conducted after the HSA is completed and consist of judgment measurements based on the HSA data. If the results of the HSA indicate that an area is Class 3 and no contamination is found, the area may be classified as Class 3 and a Class 3 final status survey is performed. If the scoping survey locates contamination, the area may be considered as Class 1 (or Class 2) for the final status survey and a characterization survey is typically performed. Sufficient information should be collected to identify situations that require immediate radiological attention. For sites where the Comprehensive Environmental Response, Compensation, and Liability Act (CERCLA) requirements are applicable, the scoping survey 
should collect sufficient data to complete the Hazard Ranking System (HRS) scoring process. For sites where the Resource Conservation and Recovery Act (RCRA) requirements are applicable, the scoping survey should collect sufficient data to complete the National Corrective Action Prioritization System (NCAPS) scoring process. Sites that meet the National Contingency Plan (NCP) criteria for a removal should be referred to the Superfund removal program (EPA 1988c). A comparison of MARSSIM guidance to CERCLA and RCRA requirements is provided in Appendix $\mathrm{F}$.

\subsubsection{Characterization Survey}

If an area could be classified as Class 1 or Class 2 for the final status survey, based on the HSA and scoping survey results, a characterization survey is warranted. The characterization survey is planned based on the HSA and scoping survey results. This type of survey is a detailed radiological environmental characterization of the area.

The primary objectives of a characterization survey are to:

- determine the nature and extent of the contamination

- collect data to support evaluation of remedial alternatives and technologies

- evaluate whether the survey plan can be optimized for use in the final status survey

- support Remedial Investigation/Feasibility Study requirements (CERCLA sites only) or Facility Investigation/Corrective Measures Study requirements (RCRA sites only)

- provide input to the final status survey design

The characterization survey is the most comprehensive of all the survey types and generates the most data. This includes preparing a reference grid, systematic as well as judgment measurements, and surveys of different media (e.g., surface soils, interior and exterior surfaces of buildings). The decision as to which media will be surveyed is a site-specific decision addressed throughout the Radiation Survey and Site Investigation Process.

\subsubsection{Remedial Action Support Survey}

If an area is adequately characterized and is contaminated above the derived concentration guideline levels (DCGLs), a decontamination plan should be prepared. A remedial action support survey is performed while remediation is being conducted, and guides the cleanup in a real-time mode.

Remedial action support surveys are conducted to:

- $\quad$ support remediation activities

- determine when a site or survey unit is ready for the final status survey 
Overview of the Radiation Survey and Site Investigation Process

- $\quad$ provide updated estimates of site-specific parameters used for planning the final status survey

This manual does not provide guidance on the routine operational surveys used to support remediation activities. The determination that a survey unit is ready for a final status survey following remediation is an important step in the RSSI Process. In addition, remedial activities result in changes to the distribution of contamination within the survey unit. For most survey units, the site-specific parameters used during final status survey planning (e.g., variability in the radionuclide concentration, probability of small areas of elevated activity) will need to be reestablished following remediation. Obtaining updated values for these critical parameters should be considered when planning a remedial action support survey.

\subsubsection{Final Status Survey}

The final status survey is used to demonstrate compliance with regulations. This type of survey is the major focus of this manual.

The primary objectives of the final status survey are to:

- select/verify survey unit classification

- demonstrate that the potential dose or risk from residual contamination is below the release criterion for each survey unit

- demonstrate that the potential dose or risk from small areas of elevated activity is below the release criterion for each survey unit

The final status survey provides data to demonstrate that all radiological parameters satisfy the established guideline values and conditions.

Although the final status survey is discussed as if it were an activity performed at a single stage of the site investigation process, this does not have to be the case. Data from other surveys conducted during the Radiation Survey and Site Investigation Process-such as scoping, characterization, and remedial action support surveys - can provide valuable information for planning a final status survey provided they are of sufficient quality.

Professional judgment and biased sampling are important for locating contamination and characterizing the extent of contamination at a site. However, the MARSSIM focus is on planning the final status survey which utilizes a more systematic approach to sampling. Systematic sampling is based on rules that endeavor to achieve the representativeness in sampling consistent with the application of statistical tests. 
Overview of the Radiation Survey and Site Investigation Process

\subsubsection{Regulatory Agency Confirmation and Verification}

The regulatory agency responsible for the site often confirms whether the site is acceptable for release. This confirmation may be accomplished by the agency or an impartial party. Although some actual measurements may be performed, much of the work required for confirmation and verification will involve evaluation and review of documentation and data from survey activities. The evaluation may include site visits to observe survey and measurement procedures or splitsample analyses by the regulatory agency's laboratory. Therefore, accounting for confirmation and verification activities during the planning stages is important to each type of survey. In some cases, post-remedial sampling and analysis may be performed by an impartial party. The review of survey results should include verifying that the data quality objectives are met, reviewing the analytical data used to demonstrate compliance, and verifying that the statistical test results support the decision to release the site. Confirmation and verification are generally ongoing processes throughout the Radiation Survey and Site Investigation (RSSI) Process.

\subsection{Demonstrating Compliance With a Dose- or Risk-Based Regulation}

MARSSIM presents a process for demonstrating compliance with a dose- or risk-based regulation. The RSSI Process provides flexibility in planning and performing surveys based on site-specific considerations. A dose- or risk-based regulation usually allows one to take into account radionuclide and site-specific differences.

The final status survey is designed to demonstrate compliance with the release criterion. The earlier surveys in the RSSI Process are performed to support decisions and assumptions used in the design of the final status survey. These preliminary surveys (e.g., scoping, characterization) may have other objectives in addition to compliance demonstration that need to be considered during survey planning that are not fully discussed in this manual. For this reason MARSSIM focuses on final status survey design. To allow maximum flexibility in the survey design, MARSSIM provides guidance on designing a survey using the RSSI Process. This allows users with few resources available for planning to develop an acceptable survey design. The rationale for the development of the guidance in MARSSIM is presented in the following sections. Users with available planning resources are encouraged to investigate alternate survey designs for sitespecific applications using the information provided in Section 2.6.

\subsubsection{The Decision to Use Statistical Tests}

The objective of compliance demonstration is to provide some level of confidence that the release criterion is not exceeded. As previously stated, $100 \%$ confidence in a decision cannot be proven because the data always contain some uncertainty. The use of statistical methods is necessary to provide a quantitative estimate of the probability that the release criterion is not 
Overview of the Radiation Survey and Site Investigation Process

exceeded at a particular site. Statistical methods provide for specifying (controlling) the probability of making decision errors and for extrapolating from a set of measurements to the entire site in a scientifically valid fashion (EPA 1994b).

Clearly stating the null hypothesis is necessary before a statistical test can be performed. The null hypothesis recommended for use in MARSSIM is: "The residual radioactivity in the survey unit exceeds the release criterion." This statement directly addresses the issue of compliance demonstration for the regulator and places the burden of proof for demonstrating compliance on the site owner or responsible party. The statistical tests are only applied at sites that were subjected to an Historical Site Assessment (HSA). At this point, the results of the HSA have been reviewed and the site is determined to be impacted based on existing data and professional judgment as described in Chapter 3. An impacted site, by definition, is expected to contain areas of contamination, so this statement of the null hypothesis is reasonable for these sites.

The information needed to perform a statistical test is determined by the assumptions used to develop the test. MARSSIM recommends the use of nonparametric statistical tests because these tests use fewer assumptions, and consequently require less information to verify these assumptions. The tests described in MARSSIM (see Chapter 8 ) are relatively easy to understand and implement compared to other statistical tests.

Site conditions can also affect the selection of statistical tests. The distribution of contamination is of particular concern at sites with residual radioactivity. Is the contamination distributed uniformly, or is it located in small areas of elevated activity? Is the residual radioactivity present as surface, volumetric, or subsurface contamination? To demonstrate the use of the RSSI Process at radiation sites, MARSSIM addresses only surface soil and building surfaces for the final status survey to demonstrate compliance. This represents a situation that is expected to commonly occur at sites with radioactive contamination, and allows the survey design to take into account the ability to directly measure surface radioactivity using scanning techniques. Other contaminated media may be identified during the HSA or preliminary surveys (i.e., scoping, characterization, remedial action support). If other contaminated media (e.g., subsurface contamination, volumetric contamination of building materials) are identified, methodologies for demonstrating compliance other than those described in this manual may need to be developed or evaluated. Situations where scanning techniques may not be effective (e.g., volumetric or subsurface contamination) are discussed in existing guidance (EPA 1989a, EPA 1994b, EPA 1994d). 


\subsubsection{Small Areas of Elevated Activity}

While the development of DCGLs is outside the scope of MARSSIM, this manual assumes that DCGLs will be developed using exposure pathway models which in turn assume a relatively uniform distribution of contamination. While this represents an ideal situation, small areas of elevated activity are a concern at many sites.

MARSSIM addresses the concern for small areas of elevated activity by using a simple comparison to an investigation level as an alternative to statistical methods. Using the elevated measurement comparison (EMC) represents a conservative approach, in that every measurement needs to be below the action level. The investigation level for this comparison is called the DCGL $_{\mathrm{EMC}}$, which is the $\mathrm{DCGL}_{\mathrm{w}}$ modified to account for the smaller area. This area factor correction (discussed in Section 5.5.2.4) is considered to be a defensible modification because the exposure assumptions (e.g., exposure time and duration) are the same as those used to develop the DCGL $\mathrm{w}_{\mathrm{W}}$. In the case of multiple areas of elevated activity in a survey unit, a posting plot (discussed in Section 8.2.2.2) or similar representation of the distribution of activity in the survey unit can be used to determine any pattern in the location of these areas.

If elevated levels of residual radioactivity are found in an isolated area, in addition to residual radioactivity distributed relatively uniformly across the survey unit, the unity rule (Section 4.3.3) can be used to ensure that the total dose or risk meets the release criterion. If there is more than one of these areas, a separate term should be included in the calculation for each area of elevated activity. As an alternative to the unity rule, the dose or risk due to the actual residual radioactivity distribution can be calculated if there is an appropriate exposure pathway model available. Note that these considerations generally only apply to Class 1 survey units, since areas of elevated activity should not be present in Class 2 or Class 3 survey units.

\subsubsection{Relatively Uniform Distribution of Contamination}

As discussed previously, the development of a DCGL starts with the assumption of a relatively uniform distribution of contamination. Some variability in the measurements is expected. This is primarily due to a random spatial distribution of contamination and uncertainties in the measurement process. The arithmetic mean of the measurements taken from such a distribution would represent the parameter of interest for demonstrating compliance.

Whether or not the radionuclide of concern is present in background determines the form of the statistical test. The Wilcoxon Rank Sum (WRS) test is recommended for comparisons of survey unit radionuclide concentrations with background. When the radionuclide of concern is not present in background, the Sign test is recommended. Instructions on performing these tests are provided in Section 8.3 and Section 8.4. 
Overview of the Radiation Survey and Site Investigation Process

The WRS and Sign tests are designed to determine whether or not the level of residual activity uniformly distributed throughout the survey unit exceeds the DCGL ${ }_{\mathrm{W}}$. Since these methods are based on ranks, the results are generally expressed in terms of the median. When the underlying measurement distribution is symmetric, the mean is equal to the median. When the underlying distribution is not symmetric, these tests are still true tests of the median but only approximate tests of the mean. However, numerous studies show that this is a fairly good approximation (Hardin and Gilbert, 1993). The assumption of symmetry is less restrictive than that of normality because the normal distribution is itself symmetric. If, however, the measurement distribution is skewed to the right, the average will generally be greater than the median. In severe cases, the

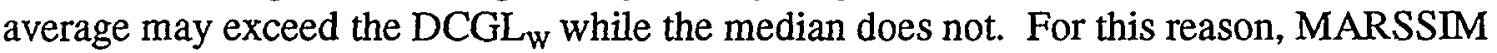
recommends comparing the arithmetic mean of the survey unit data to the DCGL $_{\mathrm{W}}$ as a first step in the interpretation of the data (see Section 8.2.2.1).

The WRS test is a two-sample test that compares the distribution of a set of measurements in a survey unit to that of a set of measurements in a reference area. The test is performed by first adding the value of the DCGL to each measurement in the reference area. The combined set of survey unit data and adjusted reference area data are listed, or ranked, in increasing numerical order. If the ranks of the adjusted reference site measurements are significantly higher than the ranks of the survey unit measurements, the survey unit demonstrates compliance with the release criterion.

The Sign test is a one-sample test that compares the distribution of a set of measurements in a survey unit to a fixed value, namely the DCGL $\mathrm{W}_{\mathrm{W}}$. First, the value for each measurement in the survey unit is subtracted from the DCGL ${ }_{\mathrm{w}}$. The resulting distribution is tested to determine if the center of the distribution is greater than zero. If the adjusted distribution is significantly greater than zero, the survey unit demonstrates compliance with the release criterion.

Guidance on performing the statistical tests and presenting graphical representations of the data is provided in Chapter 8 and Appendix I.

\subsubsection{Classification}

Classifying a survey unit is crucial to the survey design because this step determines the level of survey effort based on the potential for contamination. Areas are initially classified as impacted or non-impacted based on the results of the HSA. Non-impacted areas have no reasonable potential for residual contamination and require no further evidence to demonstrate compliance with the release criterion. When planning the final status survey, impacted areas may be further divided into survey units. If a survey unit is classified incorrectly, the potential for making decision errors increases. For this reason, all impacted areas are initially assumed to be Class 1 . Class 1 areas require the highest level of survey effort because they are known to have contaminant concentrations above the $\mathrm{DCGL}_{\mathrm{W}}$, or the contaminant concentrations are unknown. 
Information indicating the potential or known contaminant concentration is less than the $\mathrm{DCGL}_{\mathrm{w}}$ can be used to support re-classification of an area or survey unit as Class 2 or Class 3.

There is a certain amount of information necessary to demonstrate compliance with the release criterion. The amount of this information that is available and the level of confidence in this information is reflected in the area classification. The initial assumption for affected areas is that none of the necessary information is available. This results in a default Class 1 classification. This corresponds with the statement of the null hypothesis that the survey unit is contaminated, and represents the most efficient case for the regulator. For this reason, the recommendations for a Class 1 final status survey represent the minimal amount of information necessary to demonstrate compliance.

Not all of the information available for an area will have been collected for purposes of compliance demonstration. For example, data are collected during characterization surveys to determine the extent, and not necessarily the amount, of contamination. This does not mean that the data do not meet the objectives of compliance demonstration, but may mean that statistical tests would be of little or no value because the data have not been collected using appropriate protocols or design. Rather than discard potentially valuable information, MARSSIM allows for a qualitative assessment of existing data (Chapter 3). Non-impacted areas represent areas where all of the information necessary to demonstrate compliance is available from existing sources. For these areas, no statistical tests are considered necessary. A classification as Class 2 or Class 3 indicates that some information on describing the potential for contamination is available for that survey unit. The data collection recommendations are modified to account for the information already available, and the statistical tests are performed on the data collected during the final status survey.

As previously stated, the conservative assumption that an area receive a classification of Class 1 is only applied to impacted sites. The HSA (described in Chapter 3 ) is used to provide an initial classification for the site of impacted or non-impacted based on existing data and professional judgment.

\subsubsection{Design Considerations for Small Areas of Elevated Activity}

Scanning surveys are typically used to identify small areas of elevated activity. The size of the area of elevated activity that the survey is designed to detect affects the DCGL EMC $_{\text {, which in turn }}$ determines the ability of a scanning technique to detect these areas. Larger areas have a lower $\mathrm{DCGL}_{\mathrm{EMC}}$ and are more difficult to detect than smaller areas.

The percentage of the survey unit to be covered by scans is also an important consideration. $100 \%$ coverage means that the entire surface area of the survey unit has been covered by the field of view of the scanning instrument. $100 \%$ scanning coverage provides a high level of confidence 
that all areas of elevated activity have been identified. If the available information concerning the survey unit provides information demonstrating that areas of elevated activity may not be present, the survey unit may be classified as Class 2 or Class 3 . Because there is already some level of confidence that areas of elevated activity are not present, $100 \%$ coverage may not be necessary to demonstrate compliance. The scanning survey coverage may be adjusted based on the level of confidence supplied by the existing data. If there is evidence providing a high level of confidence that areas of elevated activity are not present, $10 \%$ scanning coverage may meet the objectives of the survey. If the existing information provides a lower level of confidence, the scanning coverage may be adjusted between 10 and 100\% based on the level of confidence and the objectives of the survey. A general recommendation is to always err to minimize the decision error. In general, scanning the entire survey unit is less expensive than finding areas of elevated activity later in the survey process. Finding such areas will lead to performing additional surveys due to survey unit misclassification.

Another consideration for scanning surveys is the selection of scanning locations. This is not an issue when $100 \%$ of the survey unit is scanned. Whenever less than $100 \%$ of the survey unit is scanned, a decision must be made on what areas are scanned. The general recommendation is that when large amounts of the survey unit are scanned (e.g., $>50 \%)$, the scans should be systematically performed along transects of the survey unit. When smaller amounts of the survey unit are scanned, selecting areas based on professional judgment may be more appropriate and efficient for locating areas of elevated activity (e.g., drains, ducts, piping, ditches). A combination of $100 \%$ scanning in portions of the survey unit selected based on professional judgement and less coverage (e.g., 20-50\%) for all remaining areas may result in an efficient scanning survey design for some survey units.

\subsubsection{Design Considerations for Relatively Uniform Distributions of Contamination}

The survey design for areas with relatively uniform distributions of contamination is primarily controlled by classification and the requirements of the statistical test. Again, the recommendations provided for Class 1 survey units are designed to minimize the decision error. Recommendations for Class 2 or Class 3 surveys may be appropriate based on the existing information and the level of confidence associated with this information.

The first consideration is the identification of survey units. The identification of survey units may be accomplished early (e.g., scoping) or late (e.g., final status) in the survey process, but must be accomplished prior to performing a final status survey. Early identification of survey units can help in planning and performing surveys throughout the RSSI Process. Late identification of survey units can prevent misconceptions and problems associated with reclassification of areas based on results of subsequent surveys. The area of an individual survey unit is determined based on the area classification and modeling assumptions used to develop the DCGL $_{\mathrm{w}}$. Identification of survey units is discussed in Section 4.6. 
Another consideration is the estimated number of measurements to demonstrate compliance using the statistical tests. Section 5.5.2 describes the calculations used to estimate the number of measurements. These calculations use information that is usually available from planning or from preliminary surveys (i.e., scoping, characterization, remedial action support).

The information needed to perform these calculations is: 1) acceptable values for the probabilities of making Type $I(\alpha)$ or Type $\Pi(\beta)$ decision errors, 2$)$ the estimates of the measurement variability in the survey unit $\left(\sigma_{s}\right)$ and the reference area $\left(\sigma_{r}\right)$ if necessary, and 3$)$ the $\operatorname{shift}(\Delta)$.

MARSSIM recommends that site-specific values be determined for each of these parameters. To assist the user in selecting site-specific values for decision error rates and $\triangle$, MARSSIM recommends that an initial value be selected and adjusted to develop a survey design that is appropriate for a specific site. An arbitrary initial value of one half the $\mathrm{DCGL}_{\mathrm{W}}$ is selected for the lower bound of the gray region. This value is adjusted to provide a relative shift $(\Delta / \sigma)$ value between one and three as described in Section 5.5.2. For decision error rates a value that minimizes the risk of making a decision error is recommended for the initial calculations. The number of measurements can be recalculated using different decision error rates until an optimum survey design is obtained. A prospective power curve (see Appendix D, Section D.6 and Appendix I, Section I.9) that considers the effects of these parameters can be very helpful in designing a survey and considering alternative values for these parameters, and is highly recommended.

To ensure that the desired power is achieved with the statistical test and to account for uncertainties in the estimated values of the measurement variabilities, MARSSIM recommends that the estimated number of measurements calculated using the formulas in Section 5.5.2.2 and 5.5.2.3 be increased by $20 \%$. Insufficient numbers of measurements may result in failure to achieve the DQO for power and result in increased Type $I$ decision errors, where survey units below the release criterion fail to demonstrate compliance.

Once survey units are identified and the number of measurements is determined, measurement locations should be selected. The statistical tests assume that the measurements are taken from random locations within the survey unit. A random survey design is used for Class 3 survey units, and a random starting point for the systematic grid is used for Class 2 and Class 1 survey units.

\subsubsection{Developing an Integrated Survey Design}

To account for assumptions used to develop the DCGL $\mathrm{W}_{\mathrm{W}}$ and the realistic possibility of small areas of elevated activity, an integrated survey design should be developed to include all of the design considerations. An integrated survey design combines a scanning survey for areas of 
Overview of the Radiation Survey and Site Investigation Process

elevated activity with random measurements for relatively uniform distributions of contamination. Table 2.2 presents the recommended conditions for demonstrating compliance for a final status survey based on classification.

\section{Table 2.2 Recommended Conditions for Demonstrating Compliance Based on Survey Unit Classification for a Final Status Survey}

\begin{tabular}{|c|c|c|c|c|c|}
\hline \multicolumn{2}{|c|}{$\begin{array}{l}\text { Survey Unit } \\
\text { Classification }\end{array}$} & $\begin{array}{c}\text { Statistical } \\
\text { Test }\end{array}$ & $\begin{array}{l}\text { Elevated Measuremeent } \\
\text { Comparison }\end{array}$ & $\begin{array}{l}\text { Sampling and/or } \\
\text { Direct-Measurements }\end{array}$ & Scanning \\
\hline \multirow[t]{3}{*}{ Impacted } & Class 1 & Yes & Yes & Systematic & $100 \%$ Coverage \\
\hline & Class 2 & Yes & Yes & Systematic & $10-100 \%$ Systematic \\
\hline & Class 3 & Yes & Yes & Random & Judgmental \\
\hline \multicolumn{2}{|c|}{ Non-Impacted } & No & No & No & None \\
\hline
\end{tabular}

Random measurement patterns are used for Class 3 survey units to ensure that the measurements are independent and meet the requirements of the statistical tests. Systematic grids are used for Class 2 survey units because there is an increased probability of small areas of elevated activity. The use of a systematic grid allows the decision maker to draw conclusions about the size of any potential areas of elevated activity based on the area between measurement locations, while the random starting point of the grid provides an unbiased method for determining measurement locations for the statistical tests. Class 1 survey units have the highest potential for small areas of elevated activity, so the areas between measurement locations are adjusted to ensure that these areas can be identified by the scanning survey if the area of elevated activity is not detected by the direct measurements or samples.

The objectives of the scanning surveys are different. Scanning is used to identify locations within the survey unit that exceed the investigation level. These locations are marked and receive additional investigations to determine the concentration, area, and extent of the contamination.

For Class 1 areas, scanning surveys are designed to detect small areas of elevated activity that are not detected by the measurements using the systematic grids. For this reason, the measurement locations and the number of measurements may need to be adjusted based on the sensitivity of the scanning technique (see Section 5.5.2.4). This is also the reason for recommending $100 \%$ coverage for the scanning survey.

Scanning surveys in Class 2 areas are also performed primarily to find areas of elevated activity not detected by the measurements using the systematic pattern. However, the measurement 
locations are not adjusted based on sensitivity of the scanning technique, and scanning is only performed in portions of the survey unit. The level of scanning effort should be proportional to the potential for finding areas of elevated activity: in Class 2 survey units that have residual radioactivity close to the release criterion a larger portion of the survey unit would be scanned, but for survey units that are closer to background scanning a smaller portion of the survey unit may be appropriate. Class 2 survey units have a lower probability for areas of elevated activity than Class 1 survey units, but some portions of the survey unit may have a higher potential than others. Judgmental scanning surveys would focus on the portions of the survey unit with the highest probability for areas of elevated activity. If the entire survey unit has an equal probability for areas of elevated activity, or the judgmental scans don't cover at least $10 \%$ of the area, systematic scans along transects of the survey unit or scanning surveys of randomly selected grid blocks are performed.

Class 3 areas have the lowest potential for areas of elevated activity. For this reason, MARSSIM recommends that scanning surveys be performed in areas of highest potential (e.g., corners, ditches, drains) based on professional judgment. This provides a qualitative level of confidence that no areas of elevated activity were missed by the random measurements or that there were no errors made in the classification of the area.

Note that the DCGL itself is not free of error. The assumptions made in any model used to develop DCGLs for a site should be examined carefully. The results of this examination should determine if the use of site-specific parameters result in large changes in the DCGLs, or whether a site-specific model should be developed to obtain DCGLs more relevant to the exposure conditions at the site. Appendix D, Section D.6 provides additional information about the uncertainty associated with the DCGL and other considerations for developing an integrated survey design using the DQO Process.

\subsection{Flexibility in Applying MARSSIM Guidance}

Section 2.5 describes an example that applies the performance-based guidance presented in Section 2.3 and Section 2.4 to design a survey for a site with specific characteristics (i.e., surface soil and building surface contamination). Obviously this design cannot be uniformly applied at every site with radioactive contamination, so flexibility has been provided in the form of performance-based guidance. This guidance encourages the user to develop a site-specific survey design to account for site-specific characteristics. It is expected that most users will adopt the portions of the MARSSIM guidance that apply to their site. In addition, changes to the overall survey design that account for site-specific differences would be presented as part of the survey plan. The plan should also demonstrate that the extrapolation from measurements performed at specific locations to the entire site or survey unit is performed in a technically defensible manner. 
Where Section 2.5 describes the development of a generic survey design that will be applicable at most radiation sites, this section describes the flexibility available within the MARSSIM for designing a site-specific survey design. Alternate methods for accomplishing the demonstration of compliance are briefly described and references for obtaining additional information on these alternate methods are provided.

\subsubsection{Alternate Statistical Methods}

MARSSIM encourages the use of statistics to provide a quantitative estimate of the probability that the release criterion is not exceeded at a site. While it is unlikely that any site will be able to demonstrate compliance with a dose- or risk-based regulation without at least considering the use of statistics, MARSSIM recognizes that the use of statistical tests may not always provide the most effective method for demonstrating compliance. For example, MARSSIM recommends a simple comparison to an investigation level to evaluate the presence of small areas of elevated activity in place of complicated statistical tests. At some sites a simple comparison of each measurement result to the $\mathrm{DCGL}_{\mathrm{w}}$, to demonstrate that all the measurement results are below the release criterion, may be more effective than statistical tests for the overall demonstration of compliance with the regulation provided an adequate number of measurements are performed.

MARSSIM recommends the use of nonparametric statistical tests for evaluating environmental data. There are two reasons for this recommendation: 1) environmental data is usually not normally distributed, and 2) there are often a significant number of qualitative survey results (e.g., less than MDC). Either one of these conditions means that parametric statistical tests may not be appropriate. If one can demonstrate that the data are normally distributed and that there are a sufficient number of results to support a decision concerning the survey unit, parametric tests will generally provide higher power (or require fewer measurements to support a decision concerning the survey unit). The tests to demonstrate that the data are normally distributed generally require more measurements than the nonparametric tests. EPA provides guidance on selecting and performing statistical tests to demonstrate that data are normally distributed (EPA 1996a). Guidance is also available for performing parametric statistical tests (NRC 1992, EPA 1989a, EPA 1994b, EPA 1996a).

There are a wide variety of statistical tests designed for use in specific situations. These tests may be preferable to the generic statistical tests recommended in MARSSIM when the underlying assumptions for these tests can be verified. Table 2.3 lists several examples of statistical tests that may be considered for use at individual sites or survey units. A brief description of the tests and references for obtaining additional information on these tests are also listed in the table. Applying these tests may require consultation with a statistician. 
Table 2.3 Examples of Alternate Statistical Tests

\begin{tabular}{|c|c|c|c|c|c|}
\hline $\begin{array}{l}\text { Alternate } \\
\text { Tests }\end{array}$ & $\begin{array}{c}\text { Probability } \\
\text { Model Assumed }\end{array}$ & Type of Test & Reference & $\therefore$ Advantages & Disadvantages \\
\hline \multicolumn{6}{|c|}{ Alternate 1-Sample Tests (no reference area measurements) } \\
\hline Student's t Test & Normal & $\begin{array}{l}\text { Parametric test for } \\
\mathrm{H}_{0}: \text { Mean }<\mathrm{L}\end{array}$ & $\begin{array}{l}\text { Guidance for Data } \\
\text { Quality Assessment, } \\
\text { EPA QA/G-9, } \\
\text { p. 3.2-2. }\end{array}$ & $\begin{array}{l}\text { Appropriate if data } \\
\text { appears to be normally } \\
\text { distributed and } \\
\text { symmetric. }\end{array}$ & $\begin{array}{l}\text { Relies on a non-robust } \\
\text { estimator for } \mu \text { and } \sigma \text {. } \\
\text { Sensitive to outliers and } \\
\text { departures from } \\
\text { normality. }\end{array}$ \\
\hline $\begin{array}{l}\text { t Test Applied To } \\
\text { Logarithms }\end{array}$ & Lognormal & $\begin{array}{l}\text { Parametric test for } \mathrm{H}_{\mathrm{o}} \text { : } \\
\text { Median }<\mathrm{L}\end{array}$ & $\begin{array}{l}\text { Guidance for Data } \\
\text { Quality Assessment, } \\
\text { EPA QA/G-9, } \\
\text { p. 3.2-2 }\end{array}$ & $\begin{array}{l}\text { This is a well-known } \\
\text { and easy-to-apply test. } \\
\text { Useful for a quick } \\
\text { summary of the } \\
\text { situation if the data is } \\
\text { skewed to right. }\end{array}$ & $\begin{array}{l}\text { Relies on a non-robust } \\
\text { estimator for } \sigma . \\
\text { Sensitive to outliers and } \\
\text { departures from } \\
\text { lognormality. }\end{array}$ \\
\hline $\begin{array}{l}\text { Minimum } \\
\text { Variance } \\
\text { Unbiased } \\
\text { Estimator For } \\
\text { Lognormal Mean }\end{array}$ & Lognormal & $\begin{array}{l}\text { Parametric estimates } \\
\text { for mean and variance } \\
\text { of lognormal } \\
\text { distribution }\end{array}$ & $\begin{array}{l}\text { Gilbert, Statistical } \\
\text { Methods for } \\
\text { Environmental } \\
\text { Pollution } \\
\text { Monitoring, p. 164, } \\
\text { 1987. } \\
\end{array}$ & $\begin{array}{l}\text { A good parametric test } \\
\text { to use if the data is } \\
\text { lognormal. }\end{array}$ & $\begin{array}{l}\text { Inappropriate if the data } \\
\text { is not lognormal. }\end{array}$ \\
\hline Chen Test & $\begin{array}{l}\text { Skewed to right, } \\
\text { including } \\
\text { Lognormal }\end{array}$ & $\begin{array}{l}\text { Parametric test for } \\
\mathrm{H}_{0}: \text { Mean }>0\end{array}$ & $\begin{array}{l}\text { Journal of the } \\
\text { American Statistical } \\
\text { Association (90), } \\
\text { p. } 767,1995 .\end{array}$ & $\begin{array}{l}\text { A good parametric test } \\
\text { to use if the data is } \\
\text { lognormal. }\end{array}$ & $\begin{array}{l}\text { Applicable only for } \\
\text { testing } \mathrm{H}_{\mathrm{o}} \text { : "survey unit } \\
\text { is clean." Survey unit } \\
\text { must be significantly } \\
\text { greater than } 0 \text { to fail. } \\
\text { Inappropriate if the data } \\
\text { is not skewed to the } \\
\text { right. }\end{array}$ \\
\hline
\end{tabular}


Table 2.3 (continued)

\begin{tabular}{|c|c|c|c|c|c|}
\hline $\begin{array}{c}\text { Alternative } \\
\text { Tests }\end{array}$ & $\begin{array}{c}\text { Probability } \\
\text { Model Assumed }\end{array}$ & Type of Test & Reference & Advantages & Disadvantages \\
\hline \multicolumn{6}{|c|}{ Alternate 1-Samples Tests (no reference area measurements) } \\
\hline Bayesian Approaches & $\begin{array}{l}\text { Varies, but a } \\
\text { family of } \\
\text { probability } \\
\text { distributions } \\
\text { must be selected. }\end{array}$ & $\begin{array}{l}\text { Parametric test for } \\
\mathrm{H}_{\mathrm{o}}: \text { Mean }<\mathrm{L}\end{array}$ & $\begin{array}{l}\text { DeGroot, Optimal } \\
\text { Statistical Decisions, } \\
\text { p. } 157,1970 .\end{array}$ & $\begin{array}{l}\text { Permits use of } \\
\text { subjective "expert } \\
\text { judgment" in } \\
\text { interpretation of data. }\end{array}$ & $\begin{array}{l}\text { Decisions based on } \\
\text { expert judgment may be } \\
\text { difficult to explain and } \\
\text { defend. }\end{array}$ \\
\hline Bootstrap & No restriction & $\begin{array}{l}\text { Nonparametric. Uses } \\
\text { resampling methods to } \\
\text { estimate sampling } \\
\text { variance. }\end{array}$ & $\begin{array}{l}\text { Hall, Annals of } \\
\text { Statistics (22), p. } \\
\text { 2011-2030, 1994. }\end{array}$ & $\begin{array}{l}\text { Avoids assumptions } \\
\text { concerning the type of } \\
\text { distribution. }\end{array}$ & $\begin{array}{l}\text { Computer intensive } \\
\text { analysis required. } \\
\text { Accuracy of the results } \\
\text { can be difficult to } \\
\text { assess. }\end{array}$ \\
\hline $\begin{array}{l}\text { Lognormal } \\
\text { Confidence Intervals } \\
\text { Using Bootstrap }\end{array}$ & Lognormal & $\begin{array}{l}\text { Uses resampling } \\
\text { methods to estimate } \\
\text { one-sided confidence } \\
\text { interval for lognormal } \\
\text { mean. }\end{array}$ & $\begin{array}{l}\text { Angus, The } \\
\text { Statistician (43), p. } \\
\text { 395, } 1994 .\end{array}$ & $\begin{array}{l}\text { Nonparametric method } \\
\text { applied within a } \\
\text { parametric lognormal } \\
\text { model. }\end{array}$ & $\begin{array}{l}\text { Computer intensive } \\
\text { analysis required. } \\
\text { Accuracy of the results } \\
\text { can be difficult to } \\
\text { assess. }\end{array}$ \\
\hline
\end{tabular}




\begin{tabular}{|c|c|c|c|c|c|}
\hline \multicolumn{6}{|c|}{ Table 2.3 (continued) } \\
\hline $\begin{array}{c}\text { Alternative } \\
\text { Tests }\end{array}$ & $\begin{array}{c}\text { Probability } \\
\text { Model Assumed }\end{array}$ & Type of Test & Reference & Advantages & Disadvantages \\
\hline \multicolumn{6}{|c|}{ Alternate 2-Sample Tests (reference area measurements are required) } \\
\hline Student's t Test & Symmetric, normal & $\begin{array}{l}\text { Parametric test for } \\
\text { difference in means } \\
\mathrm{H}_{\mathrm{o}}: \mu_{\mathrm{x}}<\mu_{\mathrm{y}}\end{array}$ & $\begin{array}{l}\text { Guidance for Data } \\
\text { Quality Assessment, } \\
\text { EPA QA/G-9, } \\
\text { p. 3.3-2 }\end{array}$ & $\begin{array}{l}\text { Easy to apply. } \\
\text { Performance for non- } \\
\text { normal data is } \\
\text { acceptable. }\end{array}$ & $\begin{array}{l}\text { Relies on a non-robust } \\
\text { estimator for } \sigma \text {, } \\
\text { therefore test results are } \\
\text { sensitive to outliers. }\end{array}$ \\
\hline Mann-Whitney Test & No restrictions & $\begin{array}{l}\text { Nonparametric test } \\
\text { difference in location } \\
\mathrm{H}_{0}: \mu_{\mathrm{x}}<\mu_{\mathrm{y}}\end{array}$ & $\begin{array}{l}\text { Hollander and } \\
\text { Wolfe, } \\
\text { Nonparametric } \\
\text { Statistical Methods, } \\
\text { p. } 71,1973 \text {. }\end{array}$ & $\begin{array}{l}\text { Equivalent to the WRS } \\
\text { test, but used less } \\
\text { often. Similar to } \\
\text { resampling, because } \\
\text { test is based on set of } \\
\text { all possible differences } \\
\text { between the two data } \\
\text { sets. }\end{array}$ & $\begin{array}{l}\text { Assumes that the only } \\
\text { difference between the } \\
\text { test and reference areas } \\
\text { is a shift in location. }\end{array}$ \\
\hline $\begin{array}{l}\text { Kolmogorov- } \\
\text { Smirnov }\end{array}$ & No restrictions & $\begin{array}{l}\text { Nonparametric test for } \\
\text { any difference between } \\
\text { the } 2 \text { distributions }\end{array}$ & $\begin{array}{l}\text { Hollander and } \\
\text { Wolfe, } \\
\text { Nonparametric } \\
\text { Statistical Methods, } \\
\text { p. } 219,1973 .\end{array}$ & $\begin{array}{l}\text { A robust test for } \\
\text { equality of two sample } \\
\text { distributions against all } \\
\text { alternatives. }\end{array}$ & $\begin{array}{l}\text { May reject because } \\
\text { variance is high, } \\
\text { although mean is in } \\
\text { compliance. }\end{array}$ \\
\hline $\begin{array}{l}\text { Bayesian } \\
\text { Approaches }\end{array}$ & $\begin{array}{l}\text { Varies, but a } \\
\text { family of } \\
\text { probability } \\
\text { distributions must } \\
\text { be selected }\end{array}$ & $\begin{array}{l}\text { Parametric tests for } \\
\text { difference in means or } \\
\text { difference in variance. }\end{array}$ & $\begin{array}{l}\text { Box and Tiao, } \\
\text { Bayesian Inference } \\
\text { in Statistical } \\
\text { Analysis, Chapter 2, } \\
1973 \text {. }\end{array}$ & $\begin{array}{l}\text { Permits use of "expert } \\
\text { judgment" in the } \\
\text { interpretation of data. }\end{array}$ & $\begin{array}{l}\text { Decisions based on } \\
\text { expert judgement may } \\
\text { be difficult to explain } \\
\text { and defend. }\end{array}$ \\
\hline
\end{tabular}


Table 2.3 (continued)

\begin{tabular}{|c|c|c|c|c|c|}
\hline $\begin{array}{l}\text { Alternative } \\
\text { Tests }\end{array}$ & $\begin{array}{c}\text { Probability Model } \\
\text { Assumed }\end{array}$ & Type of Test & Reference & Advantages & Disadvantages \\
\hline \multicolumn{6}{|c|}{ Alternate 2-Sample Tests (reference area measurements are required) } \\
\hline $\begin{array}{l}\text { 2-Sample } \\
\text { Quantile Test }\end{array}$ & No restrictions & $\begin{array}{l}\text { Nonparametric test for } \\
\text { difference in shape and } \\
\text { location. }\end{array}$ & $\begin{array}{l}\text { EPA, Methods for } \\
\text { Evaluating the } \\
\text { Attainment of } \\
\text { Cleanup Standards, } \\
\text { Vol. 3, p. } 7.1,1992 .\end{array}$ & $\begin{array}{l}\text { Will detect if survey } \\
\text { unit distribution } \\
\text { exceeds reference } \\
\text { distribution in the } \\
\text { upper quantiles. }\end{array}$ & $\begin{array}{l}\text { Applicable only for } \\
\text { testing } \mathrm{H}_{\mathrm{o}} \text { : "survey unit } \\
\text { is clean." Survey unit } \\
\text { must be significantly } \\
\text { greater than } 0 \text { to fail. }\end{array}$ \\
\hline $\begin{array}{l}\text { Simultaneous } \\
\text { WRS and Quantile } \\
\text { Test }\end{array}$ & No restrictions & $\begin{array}{l}\text { Nonparametric test for } \\
\text { difference in shape and } \\
\text { location. }\end{array}$ & $\begin{array}{l}\text { EPA, Methods for } \\
\text { Evaluating the } \\
\text { Attainment of } \\
\text { Cleanup Standards, } \\
\text { Vol. 3, p. } 7.17,1992 .\end{array}$ & $\begin{array}{l}\text { Additional level of } \\
\text { protection provided by } \\
\text { using two tests. Has } \\
\text { advantages of both } \\
\text { tests. }\end{array}$ & $\begin{array}{l}\text { Cannot be combined } \\
\text { with the WRS test that } \\
\text { uses } \mathrm{H}_{\mathrm{o}} \text { : "survey unit is } \\
\text { not clean." Should only } \\
\text { be combined with WRS } \\
\text { test for } \mathrm{H}_{\mathrm{o}} \text { : "survey unit } \\
\text { is clean." }\end{array}$ \\
\hline $\begin{array}{l}\text { Bootstrap and } \\
\text { Other Resampling } \\
\text { Methods }\end{array}$ & No restrictions & $\begin{array}{l}\text { Nonparametric. Uses } \\
\text { resampling methods to } \\
\text { estimate sampling } \\
\text { variance. }\end{array}$ & $\begin{array}{l}\text { Hall, Annals of } \\
\text { Statistics (22), } \\
\text { p. 2011, 1994. }\end{array}$ & $\begin{array}{l}\text { Avoids assumptions } \\
\text { concerning the type of } \\
\text { distribution. Generates } \\
\text { informative resampling } \\
\text { distributions for } \\
\text { graphing. }\end{array}$ & $\begin{array}{l}\text { Computer intensive } \\
\text { analysis required. }\end{array}$ \\
\hline \multicolumn{6}{|c|}{ Alternate to Statistical Tests } \\
\hline Decision Theory & No restrictions & $\begin{array}{l}\text { Incorporates loss } \\
\text { function in the } \\
\text { decision theory } \\
\text { approach. }\end{array}$ & $\begin{array}{l}\text { DOE, Statistical and } \\
\text { Cost-Benefit } \\
\text { Enhancements to the } \\
\text { DQO Process for } \\
\text { Characterization } \\
\text { Decisions, } 1996 .\end{array}$ & $\begin{array}{l}\text { Combines elements of } \\
\text { cost-benefit analysis } \\
\text { and risk assessment } \\
\text { into the planning } \\
\text { process. }\end{array}$ & $\begin{array}{l}\text { Limited experience in } \\
\text { applying the method to } \\
\text { compliance } \\
\text { demonstration and } \\
\text { decommissioning. } \\
\text { Computer intensive } \\
\text { analysis required. }\end{array}$ \\
\hline
\end{tabular}


Overview of the Radiation Survey and Site Investigation Process

\subsubsection{Alternate Null Hypothesis}

The selection of the null hypothesis in MARSSIM is designed to be protective of human health and the environment as well as consistent with current methods used for demonstrating compliance with regulations. MARSSIM also acknowledges that site-specific conditions (e.g., high variability in background, lack of measurement techniques with appropriate detection sensitivity) may preclude the use of the null hypothesis that the survey unit is assumed to be contaminated. Similarly, a different null hypothesis and methodology could be used for different survey units (e.g., Class 3 survey units). NUREG 1505 (NRC 1997b) provides guidance on determining when background variability might be an issue, designing surveys based on the null hypothesis that the survey unit concentration is indistinguishable from the concentration in the reference area, and performing statistical tests to demonstrate that the survey unit is indistinguishable from background.

\subsubsection{Integrating MARSSIM with Other Survey Designs}

\subsubsection{Accelerated Cleanup Models}

There are a number of approaches designed to expedite site cleanups. These approaches can save time and resources by reducing sampling, preventing duplication of effort, and reducing inactive time periods between steps in a cleanup process. Although Section 2.4 describes the RSSI Process recommended in MARSSIM as one with six principal steps, MARSSIM is not intented to be a serial process that would slow site cleanups. Rather, MARSSIM supports existing programs and encourages approaches to expedite site cleanups. Part of the significant emphasis on planning in MARSSIM is meant to promote saving time and resources.

There are many examples of accelerated cleanup approaches. The Superfund Accelerated Cleanup Model (SACM), which includes a module called integrated site assessment, has as its objectives increased efficiency and shorter response times (EPA 1992f, EPA 1993c, EPA 1997b).

Sandia National Laboratories (SNL) uses the Observational Approach. This approach uses an iterative process of sample collection and real-time data evaluation to characterize a site. This process allows early field results to guide later data collection in the field. Data collection is limited to only that required for selecting a unique remedy for a site. ${ }^{5}$

At DOE's Hanford Site, the parties to the Tri-Party Agreement negotiated a method to implement the CERCLA process in order to 1) accelerate the assessment phase, and 2) coordinate RCRA

\footnotetext{
${ }^{5}$ Information on the Observational Approach recommended by Sandia National Laboratories is available on the internet at http://www.em.doe.gov/tie/strechar.html.
} 
and CERCLA requirements whenever possible, thereby resulting in cost savings. The Hanford Past Practice Strategy (HPPS) was developed in 1991 to accelerate decisionmaking and initiation of remediation through activities that include maximizing the use of existing data consistent with data quality objectives. ${ }^{6}$

The adaptive sampling programs at the Environmental Assessment Division (EAD) of Argonne National Laboratory quantitatively fuse soft data (for example, historical records, aerial photos, nonintrusive geophysical data) with hard sampling results to estimate contaminant extent, measure the uncertainty associated with these estimates, determine the benefits from collecting additional samples, and assist in siting new sample locations to maximize the information gained. $^{7}$

\subsubsection{Superfund Soil Screening Guidance}

The goal of the Soil Screening Guidance (EPA 1996b, EPA 1996c) is to help standardize and accelerate the evaluation and cleanup of contaminated soils at sites on the National Priorities List (NPL) designated for future residential land use. The guidance provides a methodology for calculating risk-based, site-specific, soil screening levels for chemical contaminants in soil that may be used to identify areas needing further investigation at NPL sites. While the Soil Screening Guidance was not developed for use with radionuclides, the methodology used is comparable to the MARSSIM guidance for demonstrating compliance using DCGLs. The Soil Screening Guidance assumes that there is a low probability of contamination, and does not account for small areas of elevated activity. These assumptions correlate to a Class 3 area in MARSSIM. Because the Soil Screening Guidance is designed as a screening tool instead of a final demonstration of compliance, the specific values for decision error levels, the bounds of the gray region, and the number and location of measurements are developed to support these objectives. However, MARSSIM guidance can be integrated with the survey design in the Soil Screening Guidance using this guidance as an alternate MARSSIM survey design.

The Soil Screening Guidance survey design is based on collecting samples, so scan surveys and direct measurements are not considered. To reduce analytical costs the survey design recommends compositing samples and provides a statistical test for demonstrating compliance. Compositing samples provides an additional source of uncertainty and prevents the detection of small areas of elevated activity.

\footnotetext{
${ }^{6}$ Information on the Hanford Past Practice Strategy is available on the internet at http://www.bhi-erc.com/map/sec5.html.

7 Information on the Argonne National Laboratory adaptive sampling programs can be obtained on the internet at http://www.ead.anl.gov/ web/newead/prgprj/proj/adaptive/adaptive.html.
} 


\section{HISTORICAL SITE ASSESSMENT}

\subsection{Introduction}

The Radiation Survey and Site Investigation (RSSI) Process uses a graded approach that starts with the Historical Site Assessment (HSA) and is later followed by other surveys that lead to the final status survey. The HSA is an investigation to collect existing information describing a site's complete history from the start of site activities to the present time. The necessity for detailed information and amount of effort to conduct an HSA depend on the type of site, associated historical events, regulatory framework, and availability of documented information. For example, some facilities-such as Nuclear Regulatory Commission (NRC) licensees that routinely maintain records throughout their operations-already have HSA information in place. Other facilities, such as Comprehensive Environmental Response, Compensation, and Liability Act (CERCLA) or Resource Conservation and Recovery Act (RCRA) sites, may initiate a comprehensive search to gather HSA information (also see Appendix F for comparison of MultiAgency Radiation Survey and Site Investigation Manual (MARSSIM), CERCLA, and RCRA). In the former case, the HSA is essentially complete and a review of the following sections ensures that all information sources are incorporated into the overall investigation. In still other cases, where sealed sources or small amounts of radionuclides are described by the HSA, the site may qualify for a simplified decommissioning procedure (see Appendix B).

The HSA

- identifies potential, likely, or known sources of radioactive material and radioactive contamination based on existing or derived information

- identifies sites that need further action as opposed to those posing no threat to human health

- provides an assessment for the likelihood of contaminant migration

- provides information useful to scoping and characterization surveys

- $\quad$ provides initial classification of the site or survey unit ${ }^{1}$ as impacted or non-impacted

The HSA may provide information needed to calculate derived concentration guideline levels (DCGLs, initially described in Section 2.2) and furthermore provide information that reveals the magnitude of a site's DCGLs. This information is used for comparing historical data to potential DCGLs and determining the suitability of the existing data as part of the assessment of the site. The HSA also supports emergency response and removal activities within the context of the

${ }^{1}$ Refer to Section 4.6 for a discussion of survey units. 
EPA's Superfund program, fulfills public information needs, and furnishes appropriate information about the site early in the Site Investigation process. For a large number of sites (e.g. currently licensed facilities), site identification and reconnaissance may not be needed. For certain response activities, such as reports concerning the possible presence of radioactivity, preliminary investigations may consist more of a reconnaissance and a scoping survey in conjunction with efforts to gather historical information.

The HSA is typically described in three sections: identification of a candidate site (Section 3.3), preliminary investigation of the facility or site (Section 3.4), and site reconnaissance (Section 3.5). The reconnaissance however is not a scoping survey. The HSA is followed by an evaluation of the site based on information collected during the HSA.

\subsection{Data Quality Objectives}

The Data Quality Objectives (DQO) Process assists in directing the planning of data collection activities performed during the HSA. Information gathered during the HSA supports other DQOs when this process is applied to subsequent surveys.

Three HSA-DQO results are expected:

- identifying an individual or a list of planning team members-including the decision maker (DQO Step 1, Appendix D, Section D.1)

- $\quad$ concisely describing the problem (DQO Step 1, Appendix D, Section D.1)

- initially classifying site and survey unit as impacted or non-impacted (DQO Step 4, Appendix D, Section D.4)

Other results may accompany these three, and this added information may be useful in supporting subsequent applications of the DQO process.

The planning team clarifies and defines the DQOs for a site-specific survey. This multidisciplinary team of technical experts offers the greatest potential for solving problems when identifying every important aspect of a survey. Including a stakeholder group representative is an important consideration when assembling this team. Once formed, the team can also consider the role of public participation for this assessment and the possible surveys to follow. The number of team members is directly related to the scope and complexity of the problem. For a small site or simplified situations, planning may be performed by the site owner. For other specific sites (e.g., CERCLA), a regulatory agency representative may be included. 
The representative's role facilitates survey planning - without direct participation in survey plan development-by offering comments and information based on past precedent, current guidance, and potential pitfalls. For a large, complex facility, the team may include technical project managers, site managers, scientists, engineers, community and local government representatives, health physicists, statisticians, and regulatory agency representatives. A reasonable effort should be made to include other individuals - that is, specific decision makers or data users-who may use the study findings sometime in the future.

The planning team is generally led by a member who is referred to as the decision maker. This individual is often the person with the most authority over the study and may be responsible for assigning the roles and responsibilities to planning team members. Overall, the decision-making process arrives at final decisions based on the planning team's recommendations.

The problem or situation description provides background information on the fundamental issue to be addressed by the assessment (see EPA 1994a). The following steps may be helpful during DQO development:

- describe the conditions or circumstances regarding the problem or situation and the reason for undertaking the survey

- describe the problem or situation as it is currently understood by briefly summarizing existing information

- conduct literature searches and interviews, and examine past or ongoing studies to ensure that the problem is correctly defined

- if the problem is complex, consider breaking it into more manageable pieces

Section 3.4 provides guidance on gathering existing site data and determining the usability of this data.

The initial classification of the site involves developing a conceptual model based on the existing information collected during the preliminary investigation. Conceptual models describe a site or facility and its environs and present hypotheses regarding the radionuclides for known and potential residual contamination (EPA 1987b, 1987c). The classification of the site is discussed in Section 3.6, Evaluation of Historical Site Assessment Data.

Several results of the DQO Process may be addressed initially during the HSA. This information or decision may be based on limited or incomplete data. As the site assessment progresses and as decisions become more difficult, the iterative nature of the DQO Process allows for re-evaluation of preliminary decisions. This is especially important for classification of sites and survey units where the final classification is not made until the final status survey is planned. 
Historical Site Assessment

\subsection{Site Identification}

A site may already be known for its prior use and presence of radioactive materials. Elsewhere, potential radiation sites may be identified through the following:

- records of authorization to possess or handle radioactive materials (e.g., NRC or NRC Agreement State License, DOE facility records, Naval Radioactive Materials Permit, USAF Master Materials License, Army Radiation Authorization, State Authorization for Naturally Occurring and Accelerator Produced Radioactive Material (NARM))

- notification to government Agencies of possible releases of radioactive substances

- citizens filing a petition under section 105(d) of the Superfund Amendments and Reauthorization Act of 1986 (SARA; EPA 1986)

- ground and aerial radiological surveys

- contacts with knowledge of the site

- review of EPA's Environmental Radiation Ambient Monitoring System (ERAMS) database (Appendix G)

Once identified, the name, location, and current legal owner or custodian (where available) of the site should be recorded.

\subsection{Preliminary HSA Investigation}

This limited-scope investigation serves to collect readily available information concerning the facility or site and its surroundings. The investigation is designed to obtain sufficient information to provide initial classification of the site or survey unit as impacted or nonimpacted. Information on the potential distribution of radioactive contamination may be used for classifying each site or survey unit as Class 2 or Class 1 and is useful for planning scoping and characterization surveys.

Table 3.1 provides a set of questions that can be used to assist in the preliminary HSA investigation. Apart from obvious cases (e.g., NRC licensees), this table focuses on characteristics that identify a previously unrecognized or known but undeclared source of potential contamination. Furthermore, these questions may identify confounding factors for selecting reference sites. 
Table 3.1 Questions Useful for the Preliminary HSA Investigation

\begin{abstract}
1. Was the site ever licensed for the manufacture, use, or distribution of radioactive materials under Agreement State Regulations, NRC licenses, or Armed Services permits, or for the use of $91 \mathrm{~B}$ material?
\end{abstract}

2. Did the site ever have permits to dispose of, or incinerate, radioactive material onsite?

$$
\text { Is there evidence of such activities? }
$$

3. Has the site ever had deep wells for injection or permits for such?

4. Did the site ever have permits to perform research with radiation generating devices or radioactive materials except medical or dental $\mathrm{x}$-ray machines?

5. As a part of the site's radioactive materials license were there ever any Soil Moisture Density Gauges (Americium-Beryllium or Plutonium-Beryllium sources), or Radioactive Thickness Monitoring Gauges stored or disposed of onsite?

6. Was the site used to create radioactive material(s) by activation?

7. Were radioactive sources stored at the site?

8. Is there evidence that the site was involved in the Manhattan Project or any Manhattan Engineering District (MED) activities (1942-1946)?

9. Was the site ever involved in the support of nuclear weapons testing (1945-1962)?

10. Were any facilities on the site used as a weapons storage area? Was weapons maintenance ever performed at the site?

11. Was there ever any decontamination, maintenance, or storage of radioactively contaminated ships, vehicles, or planes performed onsite?
Indicates a higher probability that the area is impacted.

Evidence of radioactive material disposal indicates a higher probability that the area is impacted.

Indicates a higher probability that the area is impacted.

Research that may have resulted in the release of radioactive materials indicates a higher probability that the area is impacted.

Leak test records of sealed sources may indicate whether or not a storage area is impacted. Evidence of radioactive material disposal indicates a higher probability that the area is impacted.

Indicates a higher probability that the area is impacted.

Leak test records of sealed sources may indicate whether or not a storage area is impacted.

Indicates a higher probability that the area is impacted.

Indicates a higher probability that the area is impacted.

Indicates a higher probability that the area is impacted.

Indicates a higher probability that the area is impacted. 
Table 3.1 Questions Useful for the Preliminary HSA Investigation (continued)

12. Is there a record of any aircraft accident at or near the site (e.g., depleted uranium counterbalances, thorium alloys, radium dials)?

13. Was there ever any radiopharmaceutical manufacturing, storage, transfer, or disposal onsite?

14. Was animal research ever performed at the site?

15. Were uranium, thorium, or radium compounds (NORM) used in manufacturing, research, or testing at the site, or were these compounds stored at the site?

16. Has the site ever been involved in the processing or production of Naturally Occurring Radioactive Material (e.g., radium, fertilizers, phosphorus compounds, vanadium compounds, refractory materials, or precious metals) or mining, milling, processing, or production of uranium?

17. Were coal or coal products used onsite?

If yes, did combustion of these substances leave ash or ash residues onsite?

If yes, are runoff or production ponds onsite?

18. Was there ever any onsite disposal of material known to be high in naturally occurring radioactive materials (e.g., monazite sands used in sandblasting)?

19. Did the site process pipe from the oil and gas industries?

20. Is there any reason to expect that the site may be contaminated with radioactive material (other than previously listed)?
May include other considerations such as evidence of radioactive materials that were not recovered.

Indicates a higher probability that the area is impacted.

Evidence that radioactive materials were used for animal research indicates a higher probability that the area is impacted.

Indicates a higher probability that the area is impacted or results in a potential increase in background variability.

Indicates a higher probability that the area is impacted or results in a potential increase in background variability.

May indicate other considerations such as a potential increase in background variability.

May indicate other considerations such as a potential increase in background variability.

Indicates a higher probability that the area is impacted or results in a potential increase in background variability.

See Section 3.6.3.

Appendix $\mathrm{G}$ of this document provides a general listing and cross-reference of information sources-each with a brief description of the information contained in each source. The Site Assessment Information Directory (EPA 1991e) contains a detailed compilation of data sources, including names, addresses, and telephone numbers of agencies that can provide HSA information. 


\subsubsection{Existing Radiation Data}

Site files, monitoring data, former site evaluation data, Federal, State, or local investigations, or emergency actions may be sources of useful site information. Existing site data may provide specific details about the identity, concentration, and areal distribution of contamination. However, these data should be examined carefully because:

- Previous survey and sampling efforts may not be compatible with HSA objectives or may not be extensive enough to characterize the facility or site fully.

- $\quad$ Measurement protocols and standards may not be known or compatible with HSA objectives (e.g., Quality Assurance/Quality Control (QA/QC) procedures, limited analysis rather than full-spectrum analysis) or may not be extensive enough to characterize the facility or site fully.

- Conditions may have changed since the site was last sampled (i.e., substances may have been released, migration may have spread the contamination, additional waste disposal may have occurred, or decontamination may have been performed).

Existing data can be evaluated using the Data Quality Assessment (DQA) process described in Appendix E. (Also see DOE 1987 and EPA 1980c, 1992a, 1992b, 1996a for additional guidance on evaluating data.)

\subsubsection{Licenses, Site Permits, and Authorizations}

The facility or site radioactive materials license and supporting or associated documents are potential sources of information for licensed facilities. If a license does not exist, there may be a permit or other document that authorized site operations involving radioactivity. These documents may specify the quantities of radioactive material authorized for use at the site, the chemical and physical form of the materials, operations for which the materials are (or were) used, locations of these operations at the facility or site, and total quantities of material used at the site during its operating lifetime.

EPA and State agencies maintain files on a variety of environmental programs. These files may contain permit applications and monitoring results with information on specific waste types and quantities, sources, type of site operations, and operating status of the facility or site. Some of these information sources are listed in Appendix G (e.g., Comprehensive Environmental Response, Compensation, and Liability Information System (CERCLIS), Resource Conservation and Recovery Information System (RCRIS), Ocean Data Evaluation System (ODES)). 


\subsubsection{Operating Records}

Records and other information sources useful for site evaluations include those describing onsite activities; current and past contamination control procedures; and past operations involving demolition, effluent releases, discharge to sewers or onsite septic systems, production of residues, land filling, waste and material storage, pipe and tank leaks, spills and accidental releases, release of facilities or equipment from radiological controls, and onsite or offsite radioactive and hazardous waste disposal. Some records may be or may have been classified for National Security purposes and means should be established to review all pertinent records. Past operations should be summarized in chronological order along with information indicating the type of permits and approvals that authorized these operations. Estimates of the total activity disposed of or released at the site and the physical and chemical form of the radioactive material should also be included. Records on waste disposal, environmental monitoring, site inspection reports, license applications, operational permits, waste disposal material balance and inventory sheets, and purchase orders for radioactive materials are useful-for estimating total activity. Information on accidents, such as fires, flooding, spills, unintentional releases, or leakage, should be collected as potential sources of contamination. Possible areas of localized contamination should be identified.

Site plats or plots, blueprints, drawings, and sketches of structures are especially useful to illustrate the location and layout of buildings on the site. Site photographs, aerial surveys, and maps can help verify the accuracy of these drawings or indicate changes following the time when the drawings were prepared. Processing locations-plus waste streams to and from the site as well as the presence of stockpiles of raw materials and finished product-should be noted on these photographs and maps. Buildings or outdoor processing areas may have been modified or reconfigured such that former processing areas were converted to other uses or configurations. The locations of sewers, pipelines, electric lines, water lines, etc., should also be identified. This information facilitates planning the Site Reconnaissance and subsequent surveys, developing a site conceptual model, and increasing the efficiency of the survey program.

Corporate contract files may also provide useful information during subsequent stages of the Radiation Survey and Site Investigation Process. Older facilities may not have complete operational records, especially for obsolete or discontinued processes. Financial records may also provide information on purchasing and shipping that in turn help to reconstruct a site's operational history.

While operating records can be useful tools during the HSA, the investigator should be careful not to place too much emphasis on this type of data. These records are often incomplete and lack information on substances previously not considered hazardous. Out-of-date blueprints and drawings may not show modifications made during the lifetime of a facility. 


\subsubsection{Contacts and Interviews}

Interviews with current or previous employees are performed to collect first-hand information about the site or facility and to verify or clarify information gathered from existing records. Interviews to collect first-hand information concerning the site or facility are generally conducted early in the data-gathering process. Interviews cover general topics, such as radioactive waste handling procedures. Results of early interviews are used to guide subsequent data collection activities.

Interviews scheduled late in the data gathering process may be especially useful. This activity allows questions to be directed to specific areas of the investigation that need additional information or clarification. Photographs and sketches can be used to assist the interviewer and allow the interviewees to recall information of interest. Conducting interviews onsite where the employees performed their tasks often stimulates memories and facilitates information gathering. In addition to interviewing managers, engineers, and facility workers, interviews may be conducted with laborers and truck drivers to obtain information from their perspective. The investigator should be cautious in the use of interview information. Whenever possible, anecdotal evidence should be assessed for accuracy and results of interviews should be backed up with supporting data. Steps that ensure specific information is properly recorded may include hiring trained investigators and taking affidavits.

\subsection{Site Reconnaissance}

The objective of the Site Reconnaissance or Site Visit is to gather sufficient information to support a decision regarding further action. Reconnaissance activity is not a risk assessment, a scoping survey, or a study of the full extent of contamination at a facility or site. The reconnaissance offers an opportunity to record information concerning hazardous site conditions as they apply to conducting future survey work. In this regard, information describing physical hazards, structural integrity of buildings, or other conditions, defines potential problems that may impede future work. This section is most applicable to sites with less available information and may not be necessary at other sites having greater amounts of data, such as Nuclear Regulatory Commission (NRC) licensed facilities.

To prepare for the Site Reconnaissance, begin by reviewing what is known about the facility or site and identify data gaps. Given the site-specific conditions, consider whether or not a Site Reconnaissance is necessary and practical. This type of effort may be deemed necessary if a site is abandoned, not easily observed from areas of public access, or discloses little information during file searches. These same circumstances may also make a Site Reconnaissance risky for health and safety reasons-in view of the many unknowns-and may make entry difficult. This investigative step may be practical, but less critical, for active facilities whose operators grant 
access and provide requested information. Remember to arrange for proper site access and prepare an appropriate health and safety plan, if required, before initiating the Site Reconnaissance.

Investigators should acquire signed consent forms from the site or equipment owner to gain access to the property to conduct the reconnaissance. Investigators are to determine if State and Federal officials, and local individuals, should be notified of the reconnaissance schedule. If needed, local officials should arrange for public notification. Guidance on obtaining access to sites can be found in Entry and Continued Access Under CERCLA (EPA 1987d).

A study plan should be prepared before the Site Reconnaissance to anticipate every reconnaissance activity and identify specific information to be gathered. This plan should incorporate a survey of the site's surroundings and provide details for activities that verify or identify the location of: nearby residents, worker populations, drinking water or irrigation wells, foods, and other site environs information.

Preparing for the Site Reconnaissance includes initially gathering necessary materials and equipment. This includes a camera to document site conditions, health and safety monitoring instruments including a radiation detection meter for use during the site visit, and extra copies of topographic maps to mark target locations, water distribution areas, and other important site features. A logbook is critical to keeping a record of field activities and observations as they occur. For documentation purposes MARSSIM recommends that the logbook be completed in waterproof ink, preferably by one individual. Furthermore, each page of the logbook should be signed and dated, including the time of day, after the last entry on the page. Corrections should be documented and approved.

\subsection{Evaluation of Historical Site Assessment Data}

The main purpose of the Historical Site Assessment (HSA) is to determine the current status of the site or facility, but the data collected may also be used to differentiate sites that need further action from those that pose little or no threat to human health and the environment. This screening process can serve to provide a site disposition recommendation or to recommend additional surveys. Because much of the data collected during HSA activities is qualitative or is analytical data of unknown quality, many decisions regarding a site are the result of professional judgment.

There are three possible recommendations that follow the HSA:

- An emergency action to reduce the risk to human health and the environment-this alternative is applicable to Superfund removal actions, which are discussed in detail by EPA (EPA 1988c). 
- The site or area is impacted and further investigation is needed before a decision regarding final disposition can be made. The area may be Class 1, Class 2, or Class 3 , and a scoping survey or a characterization survey should be performed. Information collected during the HSA can be very useful in planning these subsequent survey activities.

- The site or area is non-impacted. There is no possibility or an extremely low probability of residual radioactive materials being present at the site. The site or area can be released.

Historical analytical data indicating the presence of contamination in environmental media (surface soil, subsurface soil, surface water, ground water, air, or buildings) can be used to support the hypothesis that radioactive material was released at the facility or site. A decision that the site is contaminated can be made regardless of the quality of the data, its attribution to site operations, or its relationship to background levels. In such cases, analytical indications are sufficient to support the hypothesis-it is not necessary to definitively demonstrate that a problem exists. Conversely, historical analytical data can also be used to support the hypothesis that no release has occurred. However, these data should not be the sole basis for this hypothesis. Using historical analytical data as the principal reason for ruling out the occurrence of contamination forces the data to demonstrate that a problem does not exist.

In most cases it is assumed there will be some level of process knowledge available in addition to historical analytical data. If process knowledge suggests that no residual contamination should be present and the historical analytical data also suggests that no residual contamination is present, the process knowledge provides an additional level of confidence and supports classifying the area as non-impacted. However, if process knowledge suggests no residual contamination should be present but the historical analytical data indicate the presence of residual contamination, the area will probably be considered impacted.

The following sections describe the information recommended for assessing the status of a site. This information is needed to accurately and completely support a site disposition recommendation. If some of the information is not available, it should be identified as a data need for future surveys. Data needs are collected during Step 3 of the Data Quality Objective (DQO) process (Identify Inputs to the Decision) as described in Appendix D, Section D.3. Section 3.6.5 provides information on professional judgment and how it may be applied to the decision making process.

\subsubsection{Identify Potential Contaminants}

An efficient HSA gathers information sufficient to identify the radionuclides used at the site-including their chemical and physical form. The first step in evaluating HSA data is to estimate the potential for residual contamination by these radionuclides. 
Site operations greatly influence the potential for residual contamination (NRC 1992a). An operation that only handled encapsulated sources is expected to have a low potential for contamination-assuming that the integrity of the sources was not compromised. A review of leak-test records for such sources may be adequate to demonstrate the low probability of residual contamination. A chemical manufacturing process facility would likely have contaminated piping, ductwork, and process areas, with a potential for soil contamination where spills, discharges, or leaks occurred. Sites using large quantities of radioactive ores-especially those with outside waste collection and treatment systems-are likely to have contaminated grounds. If loose dispersible materials were stored outside or process ventilation systems were poorly controlled, then windblown surface contamination may be possible.

Consider how long the site was operational. If enough time elapsed since the site discontinued operations, radionuclides with short half-lives may no longer be present in significant quantities. In this case, calculations demonstrating that residual activity could not exceed the DCGL may be sufficient to evaluate the potential residual contaminants at the site. A similar consideration can be made based on knowledge of a contaminant's chemical and physical form. Such a determination relies on records of radionuclide inventories, chemical and physical forms, total amounts of activity in waste shipments, and purchasing records to document and support this decision. However, a number of radionuclides experience significant decay product ingrowth, which should be included when evaluating existing site information.

\subsubsection{Identify Potentially Contaminated Areas}

Information gathered during the HSA should be used to provide an initial classification of the site areas as impacted or non-impacted.

Impacted areas have a potential for radioactive contamination (based on historical data) or contain known radioactive contamination (based on past or preliminary radiological surveillance). This includes areas where 1) radioactive materials were used and stored; 2) records indicate spills, discharges, or other unusual occurrences that could result in the spread of contamination; and 3) radioactive materials were buried or disposed. Areas immediately surrounding or adjacent to these locations are included in this classification because of the potential for inadvertent spread of contamination.

Non-impacted areas-identified through knowledge of site history or previous survey information-are those areas where there is no reasonable possibility for residual radioactive contamination. The criteria used for this segregation need not be as strict as those used to demonstrate final compliance with the regulations. However, the reasoning for classifying an area as non-impacted should be maintained as a written record. Note that-based on accumulated survey data-an impacted area's classification may change as the RSSI Process progresses. 
All potential sources of radioactivity in impacted areas should be identified and their dimensions recorded (in 2 or 3 dimensions - to the extent they can be measured or estimated). Sources can be delineated and characterized through visual inspection during the site reconnaissance, interviews with knowledgeable personnel, and historical information concerning disposal records, waste manifests, and waste sampling data. The HSA should address potential contamination from the site whether it is physically within or outside of site boundaries. This approach describes the site in a larger context, but as noted in Chapter 1, MARSSIM's scope concerns releasing a site and not areas outside a site's boundaries.

\subsubsection{Identify Potentially Contaminated Media}

The next step in evaluating the data gathered during the HSA is to identify potentially contaminated media at the site. To identify media that may and media that do not contain residual contamination supports both preliminary area classification (Section 4.4) and planning subsequent survey activities.

This section provides guidance on evaluating the likelihood for release of radioactivity into the following environmental media: surface soil, subsurface soil, sediment, surface water, ground water, air, and buildings. While MARSSIM's scope is focused on surface soils and building surfaces, this section makes note of still other media to provide a starting place to identify and address all possible media. The evaluation will result in either a finding of "Suspected Contamination" or "No Suspected Contamination," which may be based on analytical data, professional judgment, or a combination of the two.

Subsequent sections describe the environmental media and pose questions pertinent to each type. Each question is accompanied by a commentary. Carefully consider the questions within the context of the site and the available data. Avoid spending excessive amounts of time answering each question because answers to every question are unlikely to be available at each site. Questions that cannot be answered based on existing data can be used to direct future surveys of the site. Also, keep in mind the numerous differences in site-specific circumstances and that the questions do not identify every characteristic that might apply to a specific site. Additional questions or characteristics identified during a specific site assessment should be included in the HSA report (Section 3.8; EPA 1991f).

\subsubsection{Surface Soil}

Surface soil is the top layer of soil on a site that is available for direct exposure, growing plants, resuspension of particles for inhalation, and mixing from human disturbances. Surface soil may also be defined as the thickness of soil that can be measured using direct measurement or scanning techniques. Typically, this layer is represented as the top $15 \mathrm{~cm}(6 \mathrm{in}$ ) of soil (40 CFR 192). Surface sources may include gravel fill, waste piles, concrete, or asphalt paving. For many 
sites where radioactive materials were used, one first assumes that surface contamination exists and the evaluation is used to identify areas of high and low probability of contamination (Class 1 , Class 2 or Class 3 areas).

- Were all radiation sources used at the site encapsulated sources?

A site where only encapsulated sources were used would be expected to have a low potential for contamination. A review of the leak-test records and documentation of encapsulated source location may be adequate for a finding of "No Suspected Contamination."

- Were radiation sources used only in specific areas of the site?

Evidence that radioactive materials were confined to certain areas of the site may be helpful in determining which areas are impacted and which are non-impacted.

- Was surface soil regraded or moved elsewhere for fill or construction purposes?

This helps to identify additional potential radiation sites.

\subsubsection{Subsurface Soil and Media}

Subsurface soil and media are defined as any solid materials not considered to be surface soil. The purpose of these investigations is to locate and define the vertical extent of the potential contamination. Subsurface measurements can be expensive, especially for beta- or alphaemitting radionuclides. Removing areas from consideration for subsurface measurements or defining areas as non-impacted for subsurface sampling conserves limited resources and focuses the site assessment on areas of concern.

- Are there areas of known or suspected surface soil contamination?

Surface soil contamination can migrate deeper into the soil. Surface soil sources should be evaluated based on radionuclide mobility, soil permeability, and infiltration rate to determine the potential for subsurface contamination. Computer modeling may be helpful for evaluating these types of situations.

- Is there a ground-water plume without an identifiable source?

Contaminated ground water indicates that a source of contamination is present. If no source is identified during the HSA, subsurface contamination is a probable source. 
- Is there potential for enhanced mobility of radionuclides in soils?

Radionuclide mobility can be enhanced by the presence of solvents or other volatile chemicals that affect the ion-exchange capacity of soil.

- Is there evidence that the surface has been disturbed?

Recent or previous excavation activities are obvious sources of surface disturbance. Areas with developed plant life (forested or old growth areas) may indicate that the area remained undisturbed during the operating life of the facility. Areas where vegetation is removed during previous excavation activity may be distinct from mature plant growth in adjacent areas. If a site is not purposely replanted, vegetation may appear in a sequence starting with grasses that are later replaced by shrubs and trees. Typically, grasslands recover within a few years, sagebrush or low ground cover appears over decades, while mature forests may take centuries to develop.

- Is there evidence of subsurface disturbance?

Non-intrusive, non-radiological measurement techniques may provide evidence of subsurface disturbance. Magnetometer surveys can identify buried metallic objects, and ground-penetrating radar can identify subsurface anomalies such as trenches or dump sites. Techniques involving special equipment are discussed in Section 6.10.

\section{- Are surface structures present?}

Structures constructed at a site-during the operational history of that site-may cover belowground contamination. Some consideration for contaminants that may exist beneath parking lots, buildings, or other onsite structures may be warranted as part of the investigation. There may be underground piping, drains, sewers, or tanks that caused contamination.

\subsubsection{Surface Water}

Surface waters include streams and rivers, lakes, coastal tidal waters, and oceans. Note that certain ditches and intermittently flowing streams qualify as surface water. The evaluation determines whether radionuclides are likely to migrate to surface waters or their sediments. Where a previous release is not suspected, the potential for future release depends on the distance to surface water and the flood potential at the site. With regard to the two preceding sections, one can also consider an interaction between soil and water in relation to seasonal factors including soil cracking due to freezing, thawing, and dessication that influence the dispersal or infiltration of radionuclides. 
Historical Site Assessment

- Is surface water nearby?

The proximity of a contaminant to local surface water is essentially determined by runoff and radionuclide migration through the soil. The definition for nearby depends on site-specific conditions. If the terrain is flat, precipitation is low, and soils are sandy, nearby may be within several meters. If annual precipitation is high or occasional rainfall events are high, within 1,200 meters (3/4 mile) might be considered nearby. In general, sites need not include the surface water pathway where the overland flow distance to the nearest surface water is more than 3,200 meters (2 miles).

- Is the waste quantity particularly large?

Depending on the physical and chemical form of the waste and its location, large is a relative term. A small quantity of liquid waste may be of more importance-i.e., a greater risk or hazard-than a large quantity of solid waste stored in water tight containers.

- Is the drainage area large?

The drainage area includes the area of the site itself plus the upgradient area that produces runoff flowing over the site. Larger drainage areas generally produce more runoff and increase the potential for surface water contamination.

- Is rainfall heavy?

If the site and surrounding area are flat, a combination of heavy precipitation and low infiltration rate may cause rainwater to pool on the site. Otherwise, these characteristics may contribute to high runoff rates that carry radionuclides overland to surface water. Total annual rainfall exceeding one meter (40 inches), or a once in two-year-24-hour precipitation exceeding five cm (two inches) might be considered "heavy."

Rainfall varies for locations across the continental United States from high (e.g., 89 in./y, Mt. Washington, $\mathrm{NH}$ ) to low values (e.g., 4.2 in./y, Las Vegas, NV). Precipitation rates will vary during the year at each location due to seasonal and geographic factors. A median value for rainfall within the United States, as found in van der Leeden et al. 1990, is about 26 in./y as is observed for Minneapolis, MN.

- Is the infiltration rate low?

Infiltration rates range from very high in gravelly and sandy soils to very low in fine silt and clay soils. Paved sites prevent infiltration and generate runoff. 
- Are sources of contamination poorly contained or prone to runoff?

Proper containment which prevents radioactive material from migrating to surface water generally uses engineered structures such as dikes, berms, run-on and runoff control systems, and spill collection and removal systems. Sources prone to releases via runoff include leaks, spills, exposed storage piles, or intentional disposal on the ground surface. Sources not prone to runoff include underground tanks, above-ground tanks, and containers stored in a building.

- Is a runoff route well defined?

A well defined runoff route-along a gully, trench, berm, wall, etc.-will more likely contribute to migration to surface water than a poorly defined route. However, a poorly defined route may contribute to dispersion of contamination to a larger area of surface soil.

- Has deposition of waste into surface water been observed?

Indications of this type of activity will appear in records from past practice at a site or from information gathered during personal interviews.

- Is ground water discharge to surface water probable?

The hydrogeology and geographical information of the area around and inside the site may be sufficiently documented to indicate discharge locations.

- Does analytical or circumstantial evidence suggest surface water contamination?

Any condition considered suspicious - and that indicates a potential contamination problem-can be considered circumstantial evidence.

- Is the site prone to flooding?

The Federal Emergency Management Agency (FEMA) publishes flood insurance rate maps that delineate 100-year and 500-year flood plains. Ten-year floodplain maps may also be available. Generally, a site on a 500-year floodplain is not considered prone to flooding.

\subsubsection{Ground Water}

Proper evaluation of ground water includes a general understanding of the local geology and subsurface conditions. Of particular interest is descriptive information relating to subsurface stratigraphy, aquifers, and ground water use. 
Historical Site Assessment

- Are sources poorly contained?

Proper containment which prevents radioactive material from migrating to ground water generally uses engineered structures such as liners, layers of low permeability soil (e.g., clay), and leachate collection systems.

- Is the source likely to contaminate ground water?

Underground tanks, landfills, ${ }^{2}$ surface impoundments and lagoons are examples of sources that are likely to release contaminants that migrate to ground water. Above ground tanks, drummed solid wastes, or sources inside buildings are less likely to contribute to ground-water contamination.

- Is waste quantity particularly large?

Depending on the physical and chemical form of the waste and its location, large is a relative term. A small quantity of liquid waste may be of more importance-i.e., greater risk or hazard-than a large quantity of solid waste stored in water tight containers.

- Is precipitation heavy?

If the site and surrounding area are flat, a combination of heavy precipitation and low infiltration rate may cause rainwater to pool on the site. Otherwise, these characteristics may contribute to high runoff rates that carry radionuclides overland to surface water. Total annual rainfall exceeding one meter (40 in.), or a once in two-year-24-hour precipitation exceeding five $\mathrm{cm}$ (two in.) might be considered "heavy."

Rainfall varies for locations across the continental United States from high (e.g., 89 in./y, Mt. Washington, NH) to low values (e.g., $4.2 \mathrm{in./y,} \mathrm{Las} \mathrm{Vegas,} \mathrm{NV).} \mathrm{Precipitation} \mathrm{rates} \mathrm{will} \mathrm{vary}$ during the year at each location due to seasonal and geographic factors. A median value for rainfall within the United States, as found in van der Leeden et al. 1990, is about 26 in./y as is observed for Minneapolis, $\mathrm{MN}$.

- Is the infiltration rate high?

Infiltration rates range from very high in gravelly and sandy soils to very low in fine silt and clay soils. Unobstructed surface areas are potential candidates for further examination to determine infiltration rates.

\footnotetext{
${ }^{2}$ Landfills can affect the geology and hydrogeology of a site and produce heterogeneous conditions. It may be necessary to consult an expert on landfills and the conditions they generate.
} 
- Is the site located in an area of karst terrain?

In karst terrain, ground water moves rapidly through channels caused by dissolution of the rock material (usually limestone) that facilitates migration of contaminants.

- Is the subsurface highly permeable?

Highly permeable soils favor downward movement of water that may transport radioactive materials. Well logs, local geologic literature, or interviews with knowledgeable individuals may help answer this question.

- What is the distance from the surface to an aquifer?

The shallower the source of ground water, the higher the threat of contamination. It is difficult to determine whether an aquifer may be a potential source of drinking water in the future (e.g., next 1,000 years). This generally applies to the shallowest aquifer below the site.

- Are suspected contaminants highly mobile in ground water?

Mobility in ground water can be estimated based on the distribution coefficient $\left(\mathrm{K}_{\mathrm{d}}\right)$ of the radionuclide. Elements with a high $\mathrm{K}_{\mathrm{d}}$, like thorium $\left(e . g ., \mathrm{K}_{\mathrm{d}}=3,200 \mathrm{~cm}^{3} / \mathrm{g}\right)$, are not mobile while elements with a low $\mathrm{K}_{\mathrm{d}}$, like hydrogen $\left(e . g ., \mathrm{K}_{\mathrm{d}}=0 \mathrm{~cm}^{3} / \mathrm{g}\right.$ ), are very mobile. The NRC (NRC 1992b) and Department of Energy (DOE) (Yu, et al., 1993) provide a compilation of $\mathrm{K}_{\mathrm{d}}$ values. These values can be influenced by site-specific considerations such that site-specific $\mathrm{K}_{d}$ values need to be evaluated or determined. Also, the mobility of a radionuclide can be enhanced by the presence of a solvent or volatile chemical.

- Does analytical or circumstantial evidence suggest ground water contamination?

Evidence for contamination may appear in current site data; historical, hydrogeological, and geographical information systems records; or as a result of personal interviews.

\subsubsection{Air}

Evaluation of air is different than evaluation of other potentially contaminated media. Air is rarely the source of contamination. Air is evaluated as a pathway for resuspending and dispersing radioactive contamination as well as a contaminated media. 
Historical Site Assessment

- Were there observations of contaminant releases into the air?

Direct observation of a release to the air might occur where radioactive materials are suspected to be present in particulate form (e.g., mine tailings, waste pile) or adsorbed to particulates (e.g., contaminated soil), and where site conditions favor air transport (e.g., dry, dusty, windy).

- Does analytical or circumstantial evidence suggest a release to the air?

Other evidence for releases to the air might include areas of surface soil contamination that do not appear to be caused by direct deposition or overland migration of radioactive material.

- For radon exposure only, are there elevated amounts of radium $\left({ }^{226} \mathrm{Ra}\right)$ in the soil or water that could act as a source of radon in the air?

The source, ${ }^{226} \mathrm{Ra}$, decays to ${ }^{222} \mathrm{Rn}$, which is radon gas. Once radon is produced, the gas needs a pathway to escape from its point of origin into the air. Radon is not particularly soluble in water, so this gas is readily released from water sources which are open to air. Soil, however, can retain radon gas until it has decayed (see Section 6.9). The rate that radon is emitted by a solid, i.e. radon flux, can be measured directly to evaluate potential sources of radon.

- Is there a prevailing wind and a propensity for windblown transport of contamination?

Information pertaining to geography, ground cover (e.g., amount and types of local vegetation), meteorology (e.g., windspeed at 7 meters above ground level) for and around the site, plus sitespecific parameters related to surface soil characteristics enter into calculations used to describe particulate transport. Mean annual windspeed can be obtained from the National Weather Service surface station nearest to the site.

\subsubsection{Structures}

Structures used for storage, maintenance, or processing of radioactive materials are potentially contaminated by these materials. The questions presented in Table 3.1 help to determine if a building might be potentially contaminated. The questions listed in this section are for identifying potentially contaminated structures, or portions of structures, that might not be identified using Table 3.1. Section 4.8.3.1 also presents useful information on identifying structural contamination. 
- Were adjacent structures used for storage, maintenance, or processing of radioactive materials?

Adjacent is a relative term for this question. A processing facility with a potential for venting radioactive material to the air could contaminate buildings downwind. A facility with little potential for release outside of the structures handling the material would be less likely to contaminate nearby structures.

- Is a building or its addition or a new structure located on a former radioactive waste burial site or contaminated land?

Comparing past and present photographs or site maps and retrieving building permits or other structural drawings and records in relation to historical operations information will reveal site locations where structures may have been built over buried waste or contaminated land.

- Was the building constructed using contaminated material?

Building materials such as concrete, brick, or cinder block may have been formed using contaminated material.

- Does the potentially non-impacted portion of the building share a drainage system or ventilation system with a potentially contaminated area?

Technical and architectural drawings for site structures along with visual inspections are required to determine if this is a concern in terms of current or past operations.

- Is there evidence that previously identified areas of contamination were remediated by painting or similar methods of immobilizing contaminants?

Removable sources of contamination immobilized by painting may be more difficult to locate, and may need special consideration when planning subsequent surveys.

\subsubsection{Develop a Conceptual Model of the Site}

Starting with project planning activities, one gathers and analyzes available information to develop a conceptual site model. The model is essentially a site diagram showing locations of known contamination, areas of suspected contamination, types and concentrations of radionuclides in impacted areas, potentially contaminated media, and locations of potential reference (background) areas. The diagram should include the general layout of the site including buildings and property boundaries. When possible, produce three dimensional diagrams. The conceptual site model will be upgraded and modified as information becomes 
available throughout the RSSI Process. The process of developing this model is also briefly described in Attachment A of EPA 1996b.

The model is used to assess the nature and the extent of contamination, to identify potential contaminant sources, release mechanisms, exposure pathways, human and/or environmental receptors, and to develop exposure scenarios. Further, this model helps to identify data gaps, determine media to be sampled, and assists staff in developing strategies for data collection. Site history and preliminary survey data generally are extremely useful sources of information for developing this model. The conceptual site model should include known and suspected sources of contamination and the types of contaminants and affected media. Such a model can also illustrate known and potential routes of migration and known or potential human and environmental receptors.

The site should be classified or initially divided into similar areas. Classification may be based on the operational history of the site or observations made during the Site Reconnaissance (see Section 3.5.2). After the site is classified using current and past site characteristics, further divide the site or facility based on anticipated future use. This classification can help to a) assign limited resources to areas that are anticipated to be released without restrictions, and b) identify areas with little or no possibility of unrestricted release. Figure 3.1 shows an example of how a site might be classified in this manner. Further classification of a site may be possible based on site disposition recommendations (unrestricted vs. release with passive controls).

\subsubsection{Professional Judgment}

In some cases, traditional sources of information, data, models, or scientific principles are unavailable, unreliable, conflicting, or too costly or time consuming to obtain. In these instances professional judgment may be the only practical tool available to the investigator. Professional judgment is the expression of opinion, that is documented in written form and based on technical knowledge and professional experience, assumptions, algorithms, and definitions, as stated by an expert in response to technical problems (NRC 1990). For general applications, this type of judgment is a routine part of scientific investigation where knowledge is incomplete. Professional judgment can be used as an independent review of historical data to support decision making during the HSA. Professional judgment should only be used in situations where data are not reasonably obtainable by collection or experimentation.

The process of recruiting professionals should be documented and as unbiased as possible. The credentials of the selected individual or individuals enhance the credibility of the elicitation, and the ability to communicate their reasoning is a primary determinant of the quality of the results. Qualified professionals can be identified by different sources, including the planning team, professional organizations, government agencies, universities, consulting firms, and public interest groups. The selection criteria for the professionals should include potential conflict of interest (economic or personal), evidence of expertise in a required topic, objectiveness, and availability. 
Historical Site Assessment

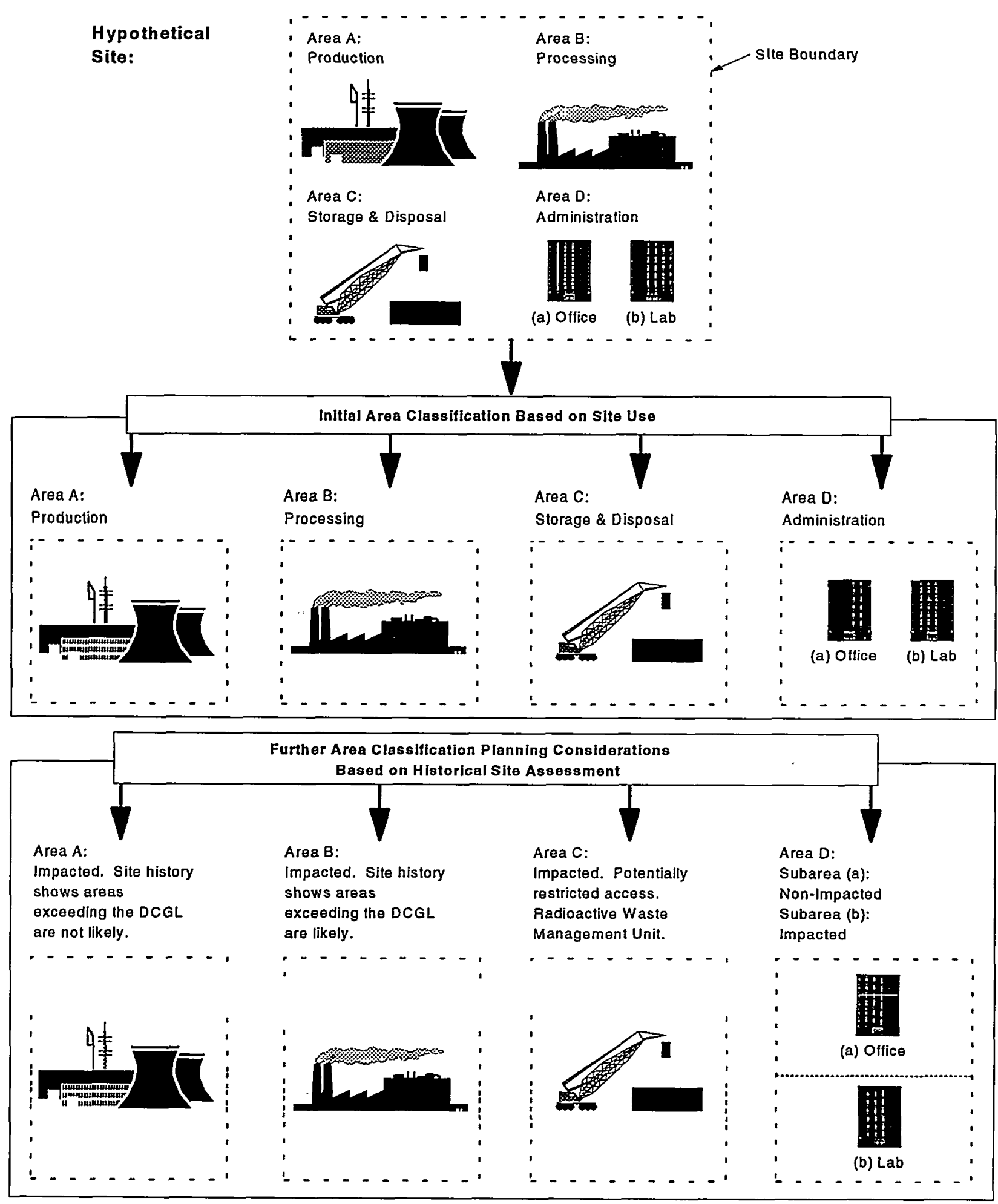

Figure 3.1 Example Showing how a Site Might be Classified Prior to Cleanup Based on the Historical Site Assessment 


\subsection{Determining the Next Step in the Site Investigation Process}

As stated in Section 1.1, the purpose of this manual is to describe a process-oriented approach for demonstrating compliance with the release criterion for residual radioactivity. The highest probability of demonstrating compliance can be obtained by sequentially following each step in the RSSI Process. In some cases, however, performing each step in the process is not practical or necessary. This section provides guidance on how the results of the HSA can be used to determine the next step in the process.

The best method for determining the next step is to review the purpose for each type of survey described in Chapter 5. For example, a scoping survey is performed to provide sufficient information for determining 1 ) whether present contamination warrants further evaluation and 2) initial estimates of the level of effort for decontamination and preparing a plan for a more detailed survey. If the HSA demonstrates that this information is already available, do not perform a scoping survey. On the other hand, if the information obtained during the HSA is limited, a scoping survey may be necessary to narrow the scope of the characterization survey.

The exception to conducting additional surveys before a final status survey is the use of HSA results to release a site. Generally, the analytical data collected during the HSA are not adequate to statistically demonstrate compliance for impacted areas as described in Chapter 8. This means that the decision to release the site will be based on professional judgment. This determination will ultimately be decided by the responsible regulatory agency.

\subsection{Historical Site Assessment Report}

A narrative report is generally a useful product for an HSA. Use this report to summarize what is known about the site, what is assumed or inferred, activities conducted during the HSA, and all researched information. Cite a supporting reference for each factual statement given in the report. Attach copies of references (i.e., those not generally available to the public) to the report. The narrative portion of the report should be written in plain English and avoid the use of technical terminology.

To encourage consistency in the content of HSA narratives, both the structure and content of each report should follow the outline shown in Figure 3.2. Additional information not identified in the outline may be requested by the regulatory agency at its discretion. The level of effort to produce the report should reflect the amount of information gathered during the HSA. 


\subsection{Review of the HSA}

The planning team should ensure that someone (a first reviewer) conducts a detailed review of the HSA report for internal consistency and as a quality-control mechanism. A second reviewer with considerable site assessment experience should then examine the entire information package to assure consistency and to provide an independent evaluation of the HSA conclusions. The second reviewer also evaluates the package to determine if special circumstances exist where radioactivity may be present but not identified in the HSA. Both the first reviewer and a second independent reviewer should examine the HSA written products to ensure internal consistency in the report's information, summarized data, and conclusions. The site review ensures that the HSA's recommendations are appropriate.

An important quality assurance objective is to find and correct errors. A significant inconsistency indicating either an error or a flawed conclusion, if undetected, could contribute to an inappropriate recommendation. Identifying such a discrepancy directs the HSA investigator and site reviewers to reexamine and resolve the apparent conflict.

Under some circumstances, experienced investigators may have differing interpretations of site conditions and draw differing conclusions or hypotheses regarding the likelihood of contamination. Any such differences should be resolved during the review. If a reviewer's interpretations contradict those of the HSA investigator, the two should discuss the situation and reach a consensus. This aspect of the review identifies significant points about the site evaluation that may need detailed explanation in the HSA narrative report to fully support the conclusions. Throughout the review, the HSA investigator and site reviewers should keep in mind the need for conservative judgments in the absence of definitive proof to avoid underestimating the presence of contamination, which could lead to an inappropriate HSA recommendation. 


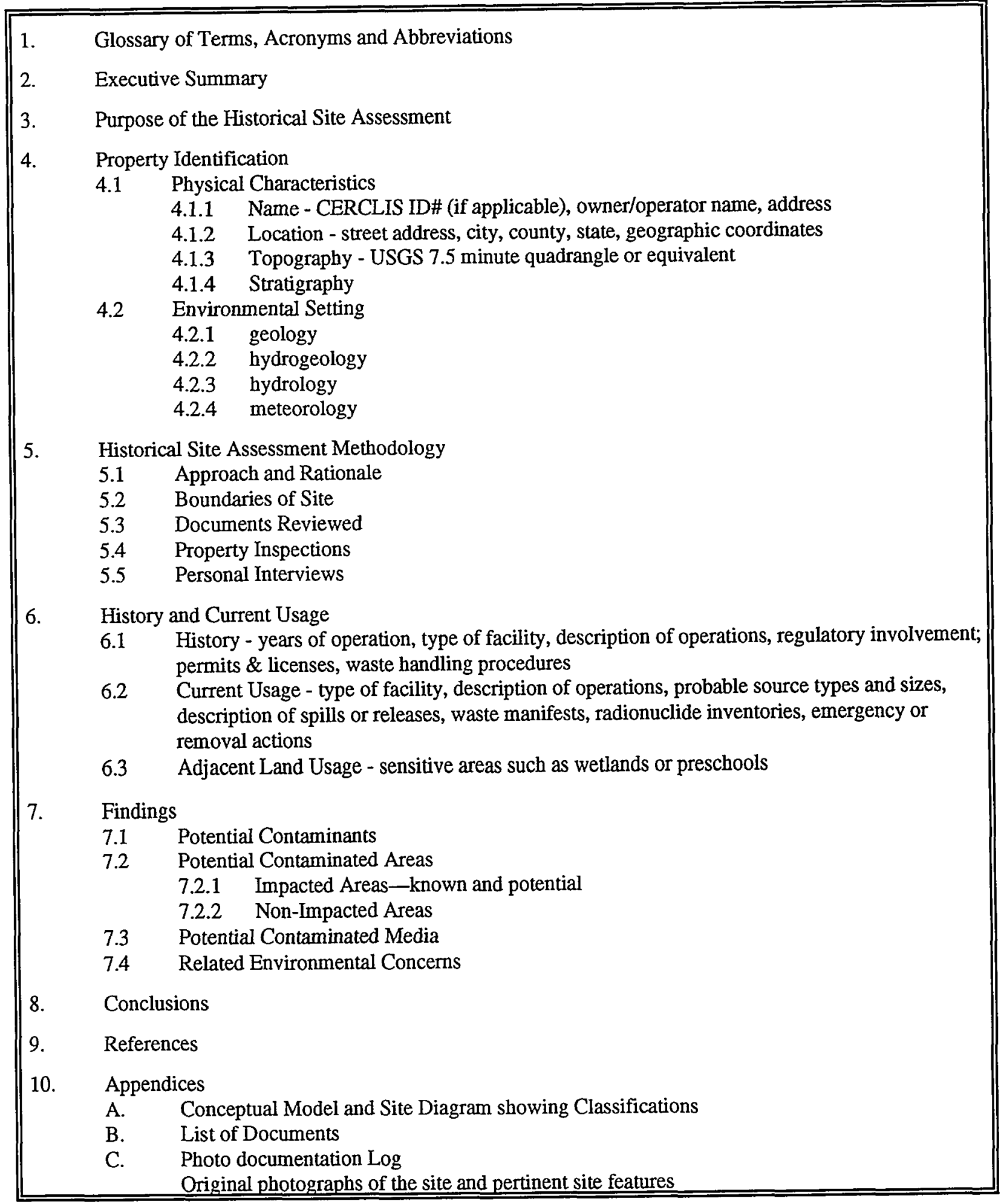

Figure 3.2 Example of a Historical Site Assessment Report Format 


\section{PRELIMINARY SURVEY CONSIDERATIONS}

\subsection{Introduction}

This chapter assists the MARSSIM user in designing a survey plan by presenting areas of consideration common to radiation surveys and site investigations in support of decommissioning. The topics discussed here should be addressed during the planning stages of each survey. Figure 4.1 illustrates the sequence of preliminary activities described in this chapter and their relationship to the survey design process.

Conducting radiological surveys in support of decommissioning serves to answer several basic questions, including:

- Is there residual radioactive contamination present from previous uses?

- What is the character (qualitative and quantitative) of the residual activity?

- Is the average residual activity level below the established derived concentration guideline level?

- Are there small localized areas of residual activity in excess of the investigation level?

The survey methods used to evaluate radiological conditions and develop answers to these questions depend on a number of factors including: contaminants, contaminant distribution, acceptable contaminant levels established by the regulatory agency, future site use, and physical characteristics of the site.

\subsection{Decommissioning Criteria}

The decommissioning process assures that residual radioactivity will not result in individuals being exposed to unacceptable levels of radiation or radioactive materials. Regulatory agencies establish radiation dose standards based on risk considerations and scientific data relating dose to risk. Residual levels of radioactive material that correspond to allowable radiation dose standards are calculated (derived) by analysis of various pathways and scenarios (direct radiation, inhalation, ingestion, etc.) through which exposures could occur. These derived levels, known as derived concentration guideline levels (DCGLs), are presented in terms of surface or mass activity concentrations. DCGLs usually refer to average levels of radiation or radioactivity above appropriate background levels. DCGLs applicable to building or other structural and miscellaneous surfaces are expressed in units of activity per surface area (typically $\mathrm{Bq} / \mathrm{m}^{2}$ or $\mathrm{dpm} / 100 \mathrm{~cm}^{2}$ ). When applied to soil and induced activity from neutron irradiation, DCGLs are expressed in units of activity per unit of mass (typically $\mathrm{Bq} / \mathrm{kg}$ or $\mathrm{pCi} / \mathrm{g}$ ). 
Preliminary Survey Considerations

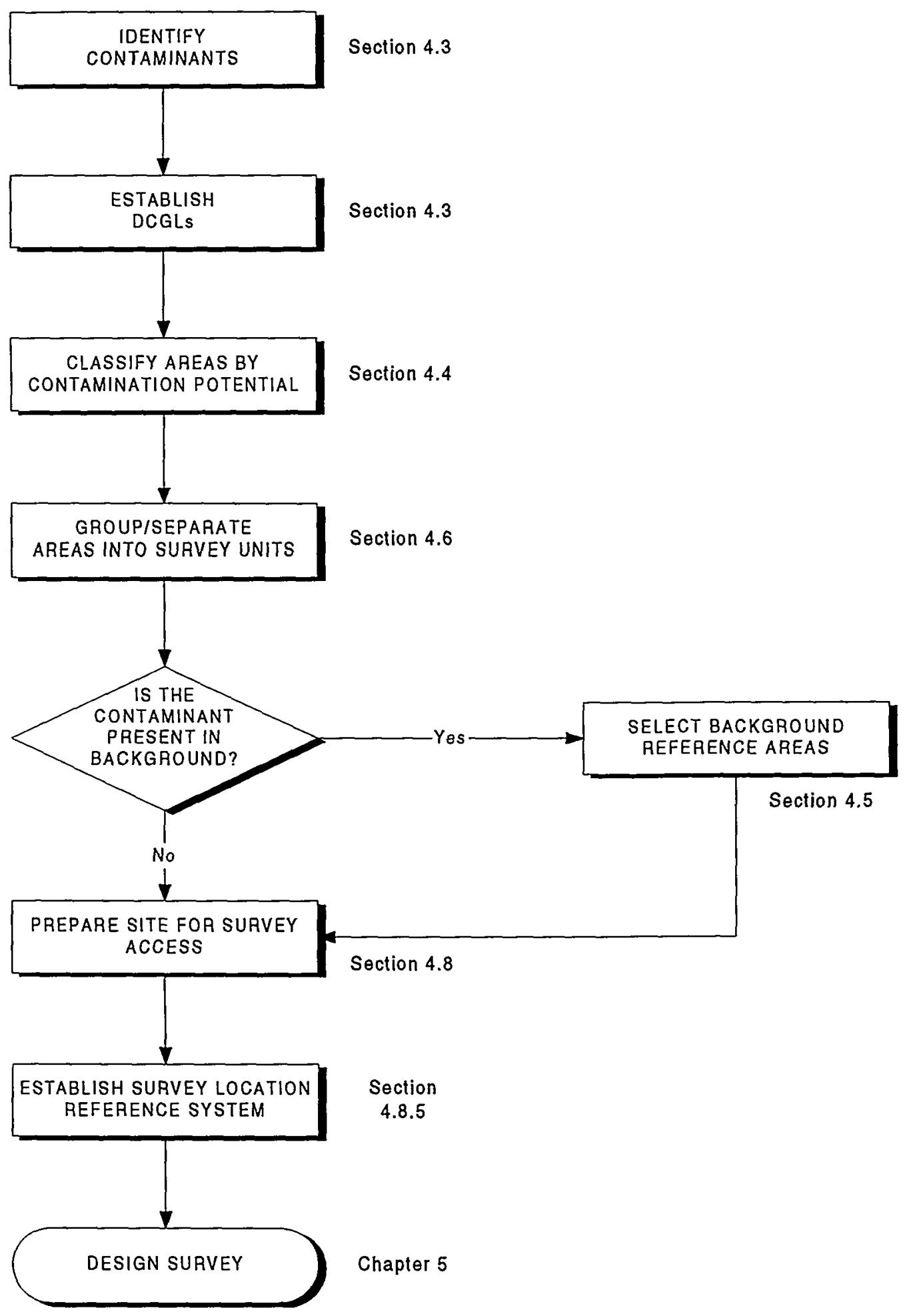

Figure 4.1 Sequence of Preliminary Activities Leading to Survey Design 
The DCGL $\mathrm{W}_{\mathrm{w}}$, based on pathway modeling, is the uniform residual radioactivity concentration level within a survey unit that corresponds to the release criterion (e.g., regulatory limit in terms of dose or risk). Note that for the majority of MARSSIM users, the DCGL will simply be obtained using regulatory agency guidance based on default parameters - other users may elect to perform site-specific pathway modeling to determine DCGLs. In both cases, the DCGL is based on the spatial distribution of the contaminant, and each derivation can produce different values depending on the specific radionuclide distribution and pathway modeling.

In addition to the numerical DCGLs, criteria include conditions for implementing those guideline levels. Conditions applicable to satisfying decommissioning objectives described in Chapter 5 are as follows:

- The uniform residual contamination above background is below the DCGL

- Individual measurements or samples, representing small areas of residual radioactivity, do not exceed the DCGL $\mathrm{EMC}_{\mathrm{E}}$ for areas of elevated residual radioactivity. These small areas of residual radioactivity may exceed the $\mathrm{DCGL}_{\mathrm{W}}$ established for average residual radioactivity levels in a survey unit, provided these areas of residual radioactivity satisfy the criteria of the responsible regulatory agency.

The manner in which a DCGL is applied should be clearly documented in the survey plans and reports.

\subsection{Identify Contaminants and Establish DCGLs}

Some objectives of the scoping and characterization surveys, as discussed in Chapter 5, include identifying site contaminants, determining relative ratios of contaminants, and establishing DCGLs and conditions for the contaminants which satisfy the requirements of the responsible agency. Identification of potential radionuclide contaminants at the site is generally performed through laboratory analyses, such as alpha and gamma spectrometry. These analyses are used to determine the relative ratios of the identified contaminants, as well as isotopic ratios for common contaminants like uranium and thorium. This information is essential in establishing and applying the DCGLs for the site. DCGLs provide the goal for essentially all aspects of designing, implementing, and evaluating the final status survey. The DCGLs discussed in this manual are limited to structure surfaces and soil contamination; the user should consult the responsible regulatory agency if it is necessary to establish DCGLs for other environmental media (e.g., ground water, and other water pathways). This section contains information regarding the selection and application of DCGLs. 
The development of DCGLs is often an iterative process, where the DCGLs selected or developed early in the Radiation Survey and Site Investigation (RSSI) Process are modified as additional site-specific information is obtained from subsequent surveys. One example of the iterative nature of DCGLs is the development of final cleanup levels in EPA's Superfund program. Soil Screening Levels ${ }^{1}$ (SSLs; EPA 1996b, EPA 1996c) are selected or developed at a point early in the process, usually corresponding to the scoping survey in MARSSIM. An SSL can be further developed, based on site-specific information, to become a preliminary remediation goal (PRG; EPA 1991h), usually at a point corresponding to the characterization survey. If the PRG is found to be acceptable during the characterization survey, it is documented as the final cleanup level in the Record of Decision (ROD) for the site. The ROD is typically in place prior to any remedial action, because the remedy is also documented in the ROD. Additional information on the Superfund program can be found in Appendix $F$.

\subsubsection{Direct Application of DCGLs}

In the simplest case, the DCGLs may be applied directly to survey data to demonstrate compliance. This involves assessing the surface activity levels and volumetric concentrations of radionuclides and comparing measured values to the appropriate DCGL. For example, consider a site that used only one radionuclide, such as ${ }^{90} \mathrm{Sr}$ throughout its operational lifetime. The default DCGL for ${ }^{90} \mathrm{Sr}$ on building surfaces and in soil may be obtained from the responsible agency. Survey measurements and samples are then compared to the surface and volume activity concentration DCGLs for ${ }^{90} \mathrm{Sr}$ directly to demonstrate compliance. While seemingly straightforward, this approach is not always possible $(e . g .$, when more than one radionuclide is present).

\subsubsection{DCGLs and the Use of Surrogate Measurements}

For sites with multiple contaminants, it may be possible to measure just one of the contaminants and still demonstrate compliance for all of the contaminants present through the use of surrogate measurements. Both time and resources can be saved if the analysis of one radionuclide is simpler than the analysis of the other. For example, using the measured ${ }^{137} \mathrm{Cs}$ concentration as a surrogate for ${ }^{90} \mathrm{Sr}$ reduces the analytical costs because wet chemistry separations do not have to be performed for ${ }^{90} \mathrm{Sr}$ on every sample. In using one radionuclide to measure the presence of others, a sufficient number of measurements, spatially separated throughout the survey unit, should be made to establish a "consistent" ratio. The number of measurements needed to determine the ratio is selected using the Data Quality Objectives (DQO) Process and based on the chemical, physical, and radiological characteristics of the nuclides and the site. If consistent

\footnotetext{
${ }^{1}$ Soil Screening Levels are currently available for chemical contaminants and are not designed for use at sites with radioactive contamination.
} 
radionuclide ratios cannot be determined during the Historical Site Assessment (HSA) based on existing information, MARSSIM recommends that one of the objectives of scoping or characterization be a determination of the ratios rather than attempting to determine ratios based on the final status survey. If the ratios are determined using final status survey data, MARSSIM recommends that at least $10 \%$ of the measurements (both direct measurements and samples) include analyses for all radionuclides of concern.

In the use of surrogates, it is often difficult to establish a "consistent" ratio between two or more radionuclides. Rather than follow prescriptive guidance on acceptable levels of variability for the surrogate ratio, a more reasonable approach may be to review the data collected to establish the ratio and to use the DQO process to select an appropriate ratio from that data. An example is provided to illustrate the application of surrogate measurements.

Ten soil samples within the survey unit were collected and analyzed for ${ }^{137} \mathrm{Cs}$ and ${ }^{90} \mathrm{Sr}$ to establish a surrogate ratio. The ratios of ${ }^{90} \mathrm{Sr}$ to ${ }^{137} \mathrm{Cs}$ were as follows: $6.6,5.7,4.2,7.9,3.0,3.8$, 4.1, 4.6, 2.4, and 3.3. An assessment of this example data set results in an average ${ }^{90} \mathrm{Sr}$ to ${ }^{137} \mathrm{Cs}$ surrogate ratio of 4.6, with a standard deviation of 1.7. There are various approaches that may be used to develop a surrogate ratio from this data-but each must consider the variability and level of uncertainty in the data. One may consider the variability in the surrogate ratio by selecting the $95 \%$ upper bound of the surrogate ratio (to yield a conservative value of ${ }^{90} \mathrm{Sr}$ from the measured ${ }^{137} \mathrm{Cs}$ ), which is 8.0 in this case. Similarly, one may select the most conservative value from the data set (7.9). The DQO process should be used to assess the use of surrogates. The benefit of using the surrogate approach is the reduced cost of not having to perform costly wet chemistry analyses on each sample. This benefit should be considered relative to the difficulty in establishing the surrogate ratio, as well as the potential consequence of unnecessary investigations that result from the error in using a "conservative" surrogate ratio. Selecting a conservative surrogate ratio ensures that potential exposures from individual radionuclides are not underestimated. The surrogate method can only be used with confidence when dealing with the same media in the same surroundings-for example, soil samples with similar physical and geological characteristics. The MARSSIM user will need to consult with the responsible regulatory agency for concurrence on the approach used to determine the surrogate ratio.

Once an appropriate surrogate ratio is determined, one needs to consider how compliance will be demonstrated using surrogate measurements. That is, the user must modify the DCGL of the measured radionuclide to account for the inferred radionuclide. Continuing with the above example, the modified DCGL for ${ }^{137} \mathrm{Cs}$ must be reduced according to the following equation:

$$
D C G L_{C s, \bmod }=D C G L_{C s} \times \frac{D C G L_{S r}}{\left[\left(C_{S r} / C_{C s}\right) \times D C G L_{C s}\right]+D C G L_{S r}}
$$

where $\mathrm{C}_{\mathrm{Sr}} / \mathrm{C}_{\mathrm{Cs}}$ is the surrogate ratio of ${ }^{90} \mathrm{Sr}$ to ${ }^{137} \mathrm{Cs}$. 
Preliminary Survey Considerations

Assuming that the $\mathrm{DCGL}_{\mathrm{S}_{\mathrm{r}}}$ is $15 \mathrm{~Bq} / \mathrm{kg}$, the $\mathrm{DCGL}_{\mathrm{Cs}}$ is $10 \mathrm{~Bq} / \mathrm{kg}$, and the surrogate ratio is 8 (as derived previously), the modified DCGL for ${ }^{137} \mathrm{Cs}\left(\mathrm{DCGL}_{\mathrm{Cs} \text {, mod }}\right)$ can be calculated using Equation 4-1:

$$
D C G L_{C s, \bmod }=10 \times \frac{15}{[8 \times 10]+15}=1.6 \mathrm{~Bq} / \mathrm{kg}
$$

This modified DCGL is then used for survey design purposes described in Chapter 5.

The potential for shifts or variations in the radionuclide ratios means that the surrogate method should be used with caution. Physical or chemical differences between the radionuclides may produce different migration rates, causing the radionuclides to separate and changing the radionuclide ratios. Remediation activities have a reasonable potential to alter the surrogate ratio established prior to remediation. MARSSIM recommends that when the ratio is established prior to remediation, additional post-remediation samples should be collected to ensure that the data used to establish the ratio are still appropriate and representative of the existing site condition. If these additional post-remediation samples are not consistent with the pre-remediation data, surrogate ratios should be re-established.

Compliance with surface activity DCGLs for radionuclides of a decay series (e.g., thorium and uranium) that emit both alpha and beta radiation may be demonstrated by assessing alpha, beta, or both radiations. However, relying on the use of alpha surface contamination measurements often proves problematic due to the highly variable level of alpha attenuation by rough, porous, and dusty surfaces. Beta measurements typically provide a more accurate assessment of thorium and uranium contamination on most building surfaces because surface conditions cause significantly less attenuation of beta particles than alpha particles. Beta measurements, therefore, may provide a more accurate determination of surface activity than alpha measurements.

The relationship of beta and alpha emissions from decay chains or various enrichments of uranium should be considered when determining the surface activity for comparison with the DCGL $_{\mathrm{w}}$ values. When the initial member of a decay chain has a long half-life, the radioactivity associated with the subsequent members of the series will increase at a rate determined by the individual half-lives until all members of the decay chain are present at activity levels equal to the activity of the parent. This condition is known as secular equilibrium.

Consider an example where the average surface activity DCGL $_{\mathrm{W}}$ for natural thorium is 1,000 $\mathrm{Bq} / \mathrm{m}^{2}\left(600 \mathrm{dpm} / 100 \mathrm{~cm}^{2}\right)$, and all of the progeny are in secular equilibrium-that is, for each disintegration of ${ }^{232} \mathrm{Th}$ there are six alpha and four beta particles emitted in the thorium decay 
series. Note that in this example, the surface activity DCGL $\mathrm{w}_{\mathrm{W}}$ of $1,000 \mathrm{~Bq} / \mathrm{m}^{2}$ is assumed to apply to the total activity from all members of the decay chain. In this situation, the corresponding alpha activity DCGL $\mathrm{W}_{\mathrm{W}}$ should be adjusted to $600 \mathrm{~Bq} / \mathrm{m}^{2}\left(360 \mathrm{dpm} / 100 \mathrm{~cm}^{2}\right)$, and the corresponding beta activity DCGL ${ }_{\mathrm{w}}$ to $400 \mathrm{~Bq} / \mathrm{m}^{2}\left(240 \mathrm{dpm} / 100 \mathrm{~cm}^{2}\right)$, in order to be equivalent to $1,000 \mathrm{~Bq} / \mathrm{m}^{2}$ of natural thorium surface activity. For a surface activity $\mathrm{DCGL}_{\mathrm{W}}$ of $1,000 \mathrm{~Bq} / \mathrm{m}^{2}$, the beta activity $\mathrm{DCGL}_{\mathrm{W}}$ is calculated as follows:

$$
\frac{\left(\frac{1,000 \mathrm{~Bq} \text { of chain }}{\mathrm{m}^{2}}\right) \times\left(\frac{4 \beta}{\text { dis of } T h-232}\right)}{\frac{10 \text { Bq of chain }}{1 B q \text { of } T h-232}}=\frac{400 \beta \mathrm{Bq}}{\mathrm{m}^{2}}
$$

To demonstrate compliance with the beta activity $\mathrm{DCGL}_{\mathrm{W}}$ for this example, beta measurements (in cpm) must be converted to activity using a weighted beta efficiency that accounts for the energy and yield of each beta particle. For decay chains that have not achieved secular equilibrium, the relative activities between the different members of the decay chain can be determined as previously discussed for surrogate ratios.

Another example for the use of surrogates involves the measurement of exposure rates, rather than surface or volume activity concentrations, for radionuclides that deliver the majority of their dose through the direct radiation pathway. That is, instead of demonstrating compliance with soil or surface contamination DCGLs derived from the direct radiation pathway, compliance is demonstrated by direct measurement of exposure rates. To implement this surrogate method, Historical Site Assessment (HSA) documentation should provide reasonable assurance that no radioactive materials are buried at the site and that radioactive materials have not seeped into the soil or groundwater. This surrogate approach may still be possible for sites that contain radionuclides that do not deliver the majority of their dose through the direct radiation pathway. This requires that a consistent relative ratio for the radionuclides that do deliver the majority of their dose through the direct radiation pathway can be established. The appropriate exposure rate limit in this case accounts for the radionuclide(s) that do not deliver the majority of their dose to the direct radiation pathway. This is accomplished by determining the fraction of the total activity represented by radionuclide(s) that do deliver the majority of their dose through the direct radiation pathway, and weighting the exposure rate limit by this fraction. Note that the considerations for establishing consistent relative ratios discussed above apply to this surrogate approach as well. The responsible regulatory agency should be consulted prior to implementing this surrogate approach. 
Preliminary Survey Considerations

\subsubsection{Use of DCGLs for Sites with Multiple Radionuclides}

Typically, each radionuclide DCGL corresponds to the release criterion (e.g., regulatory limit in terms of dose or risk). However, in the presence of multiple radionuclides, the total of the DCGLs for all radionuclides would exceed the release criterion. In this case, the individual DCGLs need to be adjusted to account for the presence of multiple radionuclides contributing to the total dose. One method for adjusting the DCGLs is to modify the assumptions made during exposure pathway modeling to account for multiple radionuclides. The surrogate measurements discussed in the previous section describe another method for adjusting the DCGL to account for multiple radionuclides. Other methods include the use of the unity rule and development of a gross activity DCGL for surface activity to adjust the individual radionuclide DCGLs.

The unity rule, represented in the expression below, is satisfied when radionuclide mixtures yield a combined fractional concentration limit that is less than or equal to one:

$$
\frac{C_{1}}{D C G L_{1}}+\frac{C_{2}}{D C G L_{2}}+\ldots \frac{C_{n}}{D C G L_{n}} \leq 1
$$

where

$$
\begin{array}{ll}
\mathrm{C}= & \text { concentration } \\
\mathrm{DCGL}= & \text { guideline value for each individual radionuclide }(1,2, \ldots, \mathrm{n})
\end{array}
$$

For sites that have a number of significant radionuclides, a higher sensitivity will be needed in the measurement methods as the values of $\mathrm{C}$ become smaller. Also, this is likely to affect statistical testing considerations-specifically by increasing the numbers of data points necessary for statistical tests.

\subsubsection{Integrated Surface and Soil Contamination DCGLs}

Surface contamination DCGLs apply to the total of fixed plus removable surface activity. For cases where the surface contamination is due entirely to one radionuclide, the DCGL for that radionuclide is used for comparison to measurement data (Section 4.3.1).

For situations where multiple radionuclides with their own DCGLs are present, a gross activity DCGL can be developed. This approach enables field measurement of gross activity, rather than determination of individual radionuclide activity, for comparison to the DCGL. The gross activity DCGL for surfaces with multiple radionuclides is calculated as follows: 
1. Determine the relative fraction (f) of the total activity contributed by the radionuclide.

2. Obtain the DCGL for each radionuclide present.

3. Substitute the values of $f$ and DCGL in the following equation.

$$
\text { Gross Activity } D C G L=\frac{1}{\left(\frac{f_{1}}{D C G L_{1}}+\frac{f_{2}}{D C G L_{2}}+\ldots \frac{f_{n}}{D C G L_{n}}\right)}
$$

\section{Example}

Assume that $40 \%$ of the total surface activity was contributed by a radionuclide with a DCGL of $8,300 \mathrm{~Bq} / \mathrm{m}^{2}\left(5000 \mathrm{dpm} / 100 \mathrm{~cm}^{2}\right) ; 40 \%$ by a radionuclide with a DCGL of $1,700 \mathrm{~Bq} / \mathrm{m}^{2}\left(1000 \mathrm{dpm} / 100 \mathrm{~cm}^{2}\right)$; and $20 \%$ by a radionuclide with a DCGL of $830 \mathrm{~Bq} / \mathrm{m}^{2}$ (500 dpm/100 $\mathrm{cm}^{2}$ ). Using Equation 4-4,

$$
\text { Gross Activity DCGL } \begin{aligned}
& =\frac{1}{\frac{0.40}{8,300}+\frac{0.40}{1,700}+\frac{0.20}{830}} \\
& =1,900 \mathrm{~Bq} / \mathrm{m}^{2}
\end{aligned}
$$

Note that Equation 4-4 may not work for sites exhibiting surface contamination from multiple radionuclides having unknown or highly variable concentrations of radionuclides throughout the site. In these situations, the best approach may be to select the most conservative surface contamination DCGL from the mixture of radionuclides present. If the mixture contains radionuclides that cannot be measured using field survey equipment, laboratory analyses of surface materials may be necessary.

Because gross surface activity measurements are not nuclide-specific, they should be evaluated by the two-sample nonparametric tests described in Chapter 8 to determine if residual contamination meets the release criterion. Therefore, gross surface activity measurements should be performed for both the survey units being evaluated and for background reference areas. The background reference areas for surface activity typically involve building surfaces and construction materials that are considered free of residual radioactivity (see Section 4.5). The total surface activity due to residual contamination should not exceed the gross activity DCGL calculated above. 
For soil contamination, it is likely that specific radionuclides, rather than gross activity, will be measured for demonstrating compliance. For radionuclides that are present in natural background, the two-sample nonparametric test described in Section 8.4 should be used to determine if residual soil contamination exceeds the release criterion. The soil contamination due to residual activity should not exceed the DCGL. To account for multiple background radionuclides, the DCGL should be adjusted in a manner similar to the gross activity DCGL described above. For a known mixture of these radionuclides, each having a fixed relative fraction of the total activity, the site-specific DCGLs for each radionuclide may be calculated by first determining the gross activity DCGL and then multiplying that gross DCGL by the respective fractional contribution of each radionuclide. For example, if ${ }^{238} \mathrm{U}$, ${ }^{226} \mathrm{Ra}$, and ${ }^{232} \mathrm{Th}$ have DCGLs of $190 \mathrm{~Bq} / \mathrm{kg}(5.0 \mathrm{pCi} / \mathrm{g}), 93 \mathrm{~Bq} / \mathrm{kg}(2.5 \mathrm{pCi} / \mathrm{g})$, and $37 \mathrm{~Bq} / \mathrm{kg}(1.0 \mathrm{pCi} / \mathrm{g})$ and activity ratios of $40 \%, 40 \%$, and $20 \%$, respectively, Equation $4-4$ can be used to calculate the gross activity DCGL.

$$
\text { Gross Activity DCGL } \begin{aligned}
\frac{1}{\frac{0.40}{190}+\frac{0.40}{93}+\frac{0.20}{37}} \\
=85 \mathrm{~Bq} / \mathrm{kg}
\end{aligned}
$$

The adjusted DCGLs for each of the contributory radionuclides, when present in the given activity ratios, are then $34 \mathrm{~Bq} / \mathrm{kg}(0.40 \times 85)$ for ${ }^{238} \mathrm{U}, 34 \mathrm{~Bq} / \mathrm{kg}(0.40 \times 85)$ for ${ }^{226} \mathrm{Ra}$, and 17 $\mathrm{Bq} / \mathrm{kg}(0.20 \times 85)$ for ${ }^{232} \mathrm{Th}$. Determining gross activity DCGLs to demonstrate compliance enables an evaluation of site conditions based on analysis for only one of the contributory contaminants (surrogate approach), provided the relative ratios of the contaminants do not change.

For situations where the background radionuclides occurring in background have unknown or variable relative concentrations throughout the site, it may be necessary to perform the twosample nonparametric tests separately for each radionuclide present. The unity rule should be used to determine that the sum of each radionuclide concentration divided by its DCGL is less than or equal to one.

Therefore, at each measurement location calculate the quantity:

$$
\frac{C_{1}}{D C G L_{1}}+\frac{C_{2}}{D C G L_{2}}+\ldots+\frac{C_{n}}{D C G L_{n}}
$$

where $\mathrm{C}$ is the radionuclide concentration. 
The values of $\mathrm{C}$ are the data to be used in the statistical tests to determine if the average over the survey unit exceeds one.

The same approach applies for radionuclides that are not present in background, with the exception that the one-sample nonparametric statistical test described in Section 8.3 is used in place of the two-sample nonparametric test (see Section 5.5.2.3). Again, for multiple radionuclides either the surrogate approach or the unity rule should be used to demonstrate compliance, if relative ratios are expected to change.

\subsection{Classify Areas by Contamination Potential}

All areas of the site will not have the same potential for residual contamination and, accordingly, will not need the same level of survey coverage to achieve the established release criteria. The process will be more efficient if the survey is designed so areas with higher potential for contamination (based in part on results of the HSA in Chapter 3) will receive a higher degree of survey effort.

Classification is a critical step in the survey design process.' The working hypothesis of MARSSIM is that all impacted areas being evaluated for release have a potential for radioactive contamination above the DCGL. This initial assumption means that all areas are initially considered Class 1 areas unless some basis for reclassification as non-impacted, Class 3, or Class 2 is provided.

Areas that have no reasonable potential for residual contamination do not need any level of survey coverage and are designated as non-impacted areas. These areas have no radiological impact from site operations and are typically identified during the HSA (Chapter 3). Background reference areas are normally selected from non-impacted areas (Section 4.5).

Impacted areas are areas that have some potential for containing contaminated material. They can be subdivided into three classes:

- Class 1 areas: Areas that have, or had prior to remediation, a potential for radioactive contamination (based on site operating history) or known contamination (based on previous radiological surveys). Examples of Class 1 areas include: 1) site areas previously subjected to remedial actions, 2) locations where leaks or spills are known to have occurred, 3) former burial or disposal sites, 4) waste storage sites, and 5) areas with contaminants in discrete solid pieces of material high specific activity. Note that areas containing contamination in excess of the $\mathrm{DCGL}_{\mathrm{w}}$ prior to remediation should be classified as Class 1 areas. 
- $\quad$ Class 2 areas: These areas have, or had prior to remediation, a potential for radioactive contamination or known contamination, but are not expected to exceed the DCGL ${ }_{\mathrm{W}}$. To justify changing an area's classification from Class 1 to Class 2, the existing data (from the HSA, scoping surveys, or characterization surveys) should provide a high degree of confidence that no individual measurement would exceed the DCGL $\mathrm{W}_{\mathrm{W}}$. Other justifications for this change in an area's classification may be appropriate based on the outcome of the DQO process. Examples of areas that might be classified as Class 2 for the final status survey include: 1) locations where radioactive materials were present in an unsealed form (e.g., process facilities), 2) potentially contaminated transport routes, 3) areas downwind from stack release points, 4) upper walls and ceilings of some buildings or rooms subjected to airborne radioactivity, 5) areas where low concentrations of radioactive materials were handled, and 6) areas on the perimeter of former contamination control areas.

- Class 3 areas: Any impacted areas that are not expected to contain any residual radioactivity, or are expected to contain levels of residual radioactivity at a small fraction of the DCGL $\mathrm{W}_{\mathrm{W}}$, based on site operating history and previous radiological surveys. Examples of areas that might be classified as Class 3 include buffer zones around Class 1 or Class 2 areas, and areas with very low potential for residual contamination but insufficient information to justify a non-impacted classification.

Class 1 areas have the greatest potential for contamination and, therefore, receive the highest degree of survey effort, followed by Class 2 and then Class 3 areas.

The criteria used for designating areas as Class 1,2 , or 3 should be described in the final status survey plan. Compliance with the classification criteria should be demonstrated in the final status survey report. A thorough analysis of HSA findings (Chapter 3) and the results of scoping and characterization surveys provide the basis for an area's classification. As a survey progresses, reevaluation of this classification may be necessary based on newly acquired survey data. For example, if contamination is identified in a Class 3 area, an investigation and reevaluation of that area should be performed to determine if the Class 3 area classification is appropriate. Typically, the investigation will result in part or all of the area being reclassified as Class 1 or Class 2. If survey results identify residual contamination in a Class 2 area exceeding the DCGL or suggest that there may be a reasonable potential that contamination is present in excess of the DCGL, an investigation should be initiated to determine if all or part of the area should be reclassified to Class 1 . More information on investigations and reclassifications is provided in Section 5.5.3. 
Preliminary Survey Considerations

\subsection{Select Background Reference Areas}

Certain radionuclides may also occur at significant levels as part of background in the media of interest (soil, building material, etc.). Examples include members of the naturally-occurring uranium, thorium, and actinium series; ${ }^{40} \mathrm{~K} ;{ }^{14} \mathrm{C}$; and tritium. ${ }^{137} \mathrm{Cs}$ and other radionuclides are also present in background as a result of nuclear weapons fallout (Wallo, et al., 1994).

Establishing background concentrations that describe a distribution of measurement data is necessary to identify and evaluate contributions attributable to site operations. Determining background levels for comparison with the conditions determined in specific survey units entails conducting surveys in one or more reference areas to define the radiological conditions of the site. NUREG-1505 (NRC 1997a) provides additional information on background reference areas.

A site background reference area should have similar physical, chemical, geological, radiological, and biological characteristics as the survey unit being evaluated. Background reference areas are normally selected from non-impacted areas, but are not limited to natural areas undisturbed by human activities. In some situations, a reference area may be associated with the survey unit being evaluated, but cannot be potentially contaminated by site activities. For example, background measurements may be taken from core samples of a building or structure surface, pavement, or asphalt. This option should be discussed with the responsible regulatory agency during survey planning. Generally, reference areas should not be part of the survey unit being evaluated.

Reference areas provide a location for background measurements which are used for comparisons with survey unit data. The radioactivity present in a reference area would be ideally the same as the survey unit had it never been contaminated. If a site includes physical, chemical, geological, radiological, or biological variability that is not represented by a single reference background area, selecting more than one reference area may be necessary.

It may be difficult to find a reference area within an industrial complex for comparison to a survey unit if the radionuclides of potential concern are naturally occurring. Background may vary greatly due to different construction activities that have occurred at the site. Examples of construction activities that change background include: leveling; excavating; adding fill dirt; importing rocks or gravel to stabilize soil or underlay asphalt; manufacturing asphalt with different matrix rock; using different pours of asphalt or concrete in a single survey unit; layering asphalt over concrete; layering different thicknesses of asphalt, concrete, rock, or gravel; and covering or burying old features such as railroad beds or building footings. Background variability may also increase due to the concentration of fallout in low areas of parking lots where runoff water collects and evaporates. Variations in background of a factor of five or more can occur in the space of a few hectares. 
There are a number of possible actions to address these concerns. Reviewing and reassessing the selection of reference areas may be necessary. Selecting different reference areas to represent individual survey units is another possibility. More attention may also be needed in selecting survey units and their boundaries with respect to different areas of potential or actual background variability. More detailed scoping or characterization surveys may be needed to better understand background variability. Using radionuclide-specific measurement techniques instead of gross radioactivity measurement techniques may also be necessary. If a background reference area that satisfies the above recommendations is not available, consultation and negotiation with the responsible regulatory agency is recommended. Alternate approaches may include using published studies of radionuclide distributions.

Verifying that a particular background reference area is appropriate for a survey can be accomplished using the techniques described or referenced in Chapter 8. Verification provides assurance that assumptions used to design the survey are appropriate and defensible. This approach can also prevent decision errors that may result from selecting an inappropriate background reference area.

If the radionuclide contaminants of interest do not occur in background, or the background levels are known to be a small fraction of the $\mathrm{DCGL}_{\mathrm{w}}(e . g .,<10 \%)$, the survey unit radiological conditions may be compared directly to the specified DCGL and reference area background surveys are not necessary. If the background is not well defined at a site, and the decision maker is willing to accept the increased probability of incorrectly failing to release a survey unit (Type II error), the reference area measurements can be eliminated and a one-sample statistical test performed as described in Section 8.3.

\subsection{Identify Survey Units}

A survey unit is a physical area consisting of structures or land areas of specified size and shape for which a separate decision will be made as to whether or not that area exceeds the release criterion. This decision is made as a result of the final status survey. As a result, the survey unit is the primary entity for demonstrating compliance with the release criterion.

To facilitate survey design and ensure that the number of survey data points for a specific site are relatively uniformly distributed among areas of similar contamination potential, the site is divided into survey units that share a common history or other characteristics, or are naturally distinguishable from other portions of the site. A site may be divided into survey units at any time before the final status survey. For example, HSA or scoping survey results may provide sufficient justification for partitioning the site into Class 1, 2, or 3 areas. Note, however, that dividing the site into survey units is critical only for the final status survey-scoping, characterization, and remedial action support surveys may be performed without dividing the site into survey units. 
A survey unit should not include areas that have different classifications. The survey unit's characteristics should be generally consistent with exposure pathway modeling that is used to convert dose or risk into radionuclide concentrations. For indoor areas classified as Class 1, each room may be designated as a survey unit. Indoor areas may also be subdivided into several survey units of different classification, such as separating floors and lower walls from upper walls and ceilings (and other upper horizontal surfaces) or subdividing a large warehouse based on floor area.

Survey units should be limited in size based on classification, exposure pathway modeling assumptions, and site-specific conditions. The suggested areas for survey units are as follows:

$\begin{array}{ll}\text { Classification } & \text { Suggested Area } \\ \text { Class 1 } & \text { up to } 100 \mathrm{~m}^{2} \text { floor area } \\ \text { Structures } & \text { up to } 2,000 \mathrm{~m}^{2} \\ \text { Land areas } & \\ \text { Class 2 } & 100 \text { to } 1,000 \mathrm{~m}^{2} \\ \text { Structures } & 2,000 \text { to } 10,000 \mathrm{~m}^{2} \\ \text { Land areas } & \text { no limit } \\ \text { Class 3 } & \text { no limit } \\ \text { Structures } & \end{array}$

The limitation on survey unit size for Class 1 and Class 2 areas ensures that each area is assigned an adequate number of data points. The rationale for selecting a larger survey unit area should be developed using the DQO Process (Section 2.3) and fully documented. Because the number of data points (determined in Sections 5.5.2.2 or 5.5.2.3) is independent of the survey unit size, disregarding locating small areas of elevated activity, the survey coverage in an area is determined by dividing the fixed number of data points obtained from the statistical tests by the survey unit area. That is, if the statistical test estimates that 20 data points are necessary to demonstrate compliance, then the survey coverage is determined by dividing 20 by the area over which the data points are distributed.

Special considerations may be necessary for survey units with structure surface areas less than $10 \mathrm{~m}^{2}$ or land areas less than $100 \mathrm{~m}^{2}$. In this case, the number of data points obtained from the statistical tests is unnecessarily large and not appropriate for smaller survey unit areas. Instead, some specified level of survey effort should be determined based on the DQO process and with the concurrence of the responsible regulatory agency. The data generated from these smaller survey units should be obtained based on judgment, rather than on systematic or random design, and compared individually to the DCGLs. 


\subsection{Select Instruments and Survey Techniques}

Based on the potential radionuclide contaminants, their associated radiations, and the types of residual contamination categories (e.g., soil, structure surfaces) to be evaluated, the detection sensitivities of various instruments and techniques are determined and documented. Instruments should be identified for each of the three types of measurements: 1) scans, 2) direct measurements, and 3) laboratory analysis of samples. In some cases, the same instrument (e.g., sodium iodide detector) or same type of instrument (e.g., gas-flow proportional counter) may be used for performing several types of measurements. Once the instruments are selected, appropriate survey techniques and standard operating procedures (SOPs) should be developed and documented. The survey techniques describe how the instrument will be used to perform the required measurements.

Chapter 6 of this manual, NRC report NUREG-1507 (NRC 1997b), and draft NRC report NUREG-1506 (NRC 1995) discuss the concept of detection sensitivities and provide guidance on determining sensitivities and selecting appropriate measurement methods. Chapter 6 also discusses instruments and survey techniques for scans and direct measurements, while Chapter 7 provides guidance on sampling and laboratory analysis. Appendix $\mathrm{H}$ describes typical field and laboratory equipment plus associated cost and instrument sensitivities.

\subsubsection{Selection of Instruments}

Choose reliable instruments that are suited to the physical and environmental conditions at the site and capable of detecting the radiations of concern to the appropriate minimum detectable concentration (MDC). During survey design, it is generally considered good practice to select a measurement system with an MDC between 10-50\% of the DCGL. Sometimes this goal may not be achievable based on site-specific conditions (e.g., best available technology, cost restrictions).

The MDC is calculated based on an hypothesis test for individual measurements (see Section 6.7), and results below the MDC are variable and lead to a high value for $\sigma$ of the measured values in the survey unit or reference area. This high value for $\sigma$ can be accounted for using the statistical tests described in Chapter 8 for the final status survey, but a large number of measurements are needed to account for the variability. $\sigma$ is defined as the standard deviation of the measurements in the survey unit.

Early in decommissioning, during scoping and characterization, low MDCs help in the identification of areas that can be classified as non-impacted or Class 3 areas. These decisions are usually based on fewer numbers of samples, and each measurement is evaluated individually. Using an optimistic estimation of the MDC (see Section 2.3.5) for these surveys may result in the misclassification of a survey unit and cleaning up an uncontaminated area or performing a final status survey in a contaminated area. Selecting a measurement technique with a well defined 
MDC or a conservative estimate of the MDC ensures the usefulness of the data for making decisions for planning the final status survey. For these reasons, MARSSIM recommends that a realistic or conservative estimate of the MDC be used instead of an optimistic estimate. A conservative estimate of the MDC uses reasonably conservative values for parameters with a high level of uncertainty, and results in a MDC value that is higher than a non-conservative or optimistic estimate.

The instrument should be calibrated for the radiations and energies of interest at the site. This calibration should be traceable to an accepted standards organization such as the National Institute of Science and Technology (NIST). Routine operational checks of instrument performance should be conducted to assure that the check source response is maintained within acceptable ranges and that any changes in instrument background are not attributable to contamination of the detector. If the radionuclide contaminants cannot be detected at desired levels by direct measurement (Section 6.7), the portion of the survey dealing with measurements at discrete locations should be designed to rely primarily on sampling and laboratory analysis (Chapter 7).

Assuming the contaminants can be detected, either directly or by measuring a surrogate radionuclide in the mixture, the next decision point depends on whether the radionuclide being measured is present in background. Gross measurement methods will likely be more appropriate for measuring surface contamination in structures, scanning for locations of elevated activity, and determining exposure rates. Nuclide-specific measurement techniques, such as gamma spectrometry, provide a marked increase in detection sensitivity over gross measurements because of their ability to screen out contributions from other sources. Figure 4.2 illustrates the sequence of steps in determining if direct measurement techniques can be applied at a particular site, or if laboratory analysis is more appropriate. Scanning surveys are typically performed at all sites. The selection of appropriate instruments for scanning, direct measurement, and sampling and analysis should be survey specific.

\subsubsection{Selection of Survey Techniques}

In practice, the DQO process is used to obtain a proper balance among the use of various measurement techniques. In general, there is an inverse correlation between the cost of a specific measurement technique and the detection levels being sought. Depending on the survey objectives, important considerations include survey costs and choosing the optimum instrumentation and measurement mix.

A certain minimum number of direct measurements or samples will be needed to demonstrate compliance with the release criterion based on the nonparametric statistical tests (see Section 5.5.2). In addition, the potential for areas of elevated contamination will have to be considered for designing scanning surveys. Areas of elevated activity may also affect the number of measurements; however, scanning with survey instruments should generally be sufficient to 


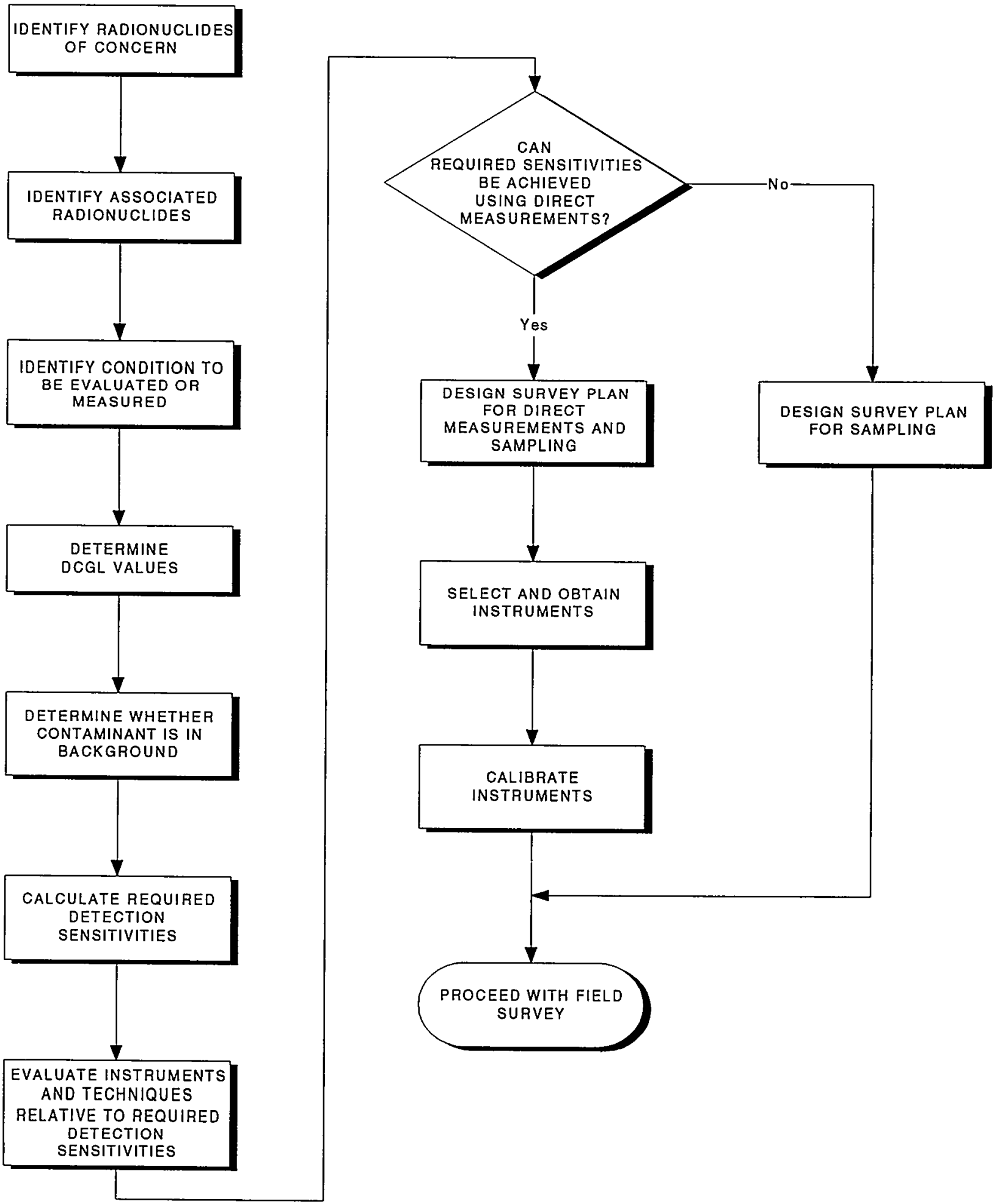

Figure 4.2 Flow Diagram for Selection of Field Survey Instrumentation for Direct Measurements and Analysis of Samples (Refer to Section 4.7) 
ensure that no areas with unusually high levels of radioactivity are left in place. Some measurements may also provide information of a qualitative nature to supplement other measurements. An example of such an application is in situ gamma spectrometry to demonstrate the absence (or presence) of specific contaminants.

Table 4.1 presents a list of common contaminants along with recommended survey methods that have proven to be effective based on past survey experience in the decommissioning industry. This table provides a general indication of the detection capability of commercially-available instruments. As such, Table 4.1 may be used to provide an initial evaluation of instrument capabilities for some common radionuclides at the example DCGLs listed in the table. For example, consider the contamination of a surface with ${ }^{241} \mathrm{Am}$. Table 4.1 indicates that ${ }^{241} \mathrm{Am}$ is detectable at the example DCGLs, and that viable direct measurement instruments include gasflow proportional ( $\alpha$ mode) and alpha scintillation detectors. Table 4.1 should not be interpreted as providing specific values for an instrument's detection sensitivity, which is discussed in Section 6.7. In addition, NRC draft report NUREG-1506 (NRC 1995) provides further information on factors that may affect survey instrumentation selection.

\subsubsection{Criteria for Selection of Sample Collection and Direct Measurement Methods}

Sample characteristics such as sample depth, volume, area, moisture level, and composition, as well as sample preparation techniques which may alter the sample, are important planning considerations for Data Quality Objectives. Sample preparation may include, but is not limited to, removing extraneous material, homogenizing, splitting, drying, compositing, and final preparation of samples. As is the case for determining survey unit characteristics, the physical sample characteristics and sampling method should be consistent with the dose or risk pathway modeling that is used to determine radionuclide DCGL's. If a direct measurement method is used, it should also be consistent with the pathway modeling.

For example, a sample depth of $15 \mathrm{~cm}$ (6 in.) for soil samples might be specified during the DQO process for a final status survey because this corresponds to the soil mixing or plow depth in several environmental pathway models (Yu et al., 1993, NRC 1992b). If contamination exists at a depth less than this, a number of models uniformly mix it throughout this depth to simulate the soil mixing associated with plowing. Similarly, models may be based on dry weight, which may necessitate either drying samples or data transformation to account for dry weight.

The DQOs and subsequent direction to the laboratory for analysis might include removal of material not relevant for characterizing the sample, such as pieces of glass, twigs, or leaves. Table 4.2 provides examples of how a particular field soil composition of fine-, medium-, and coarse-grained materials might determine laboratory analysis DQOs for particular radionuclides. Fine materials consist of clay (less than $0.002 \mathrm{~mm}$ ) and silt $(0.002$ to $0.062 \mathrm{~mm})$. Medium materials consist of sand, which can be further divided into very fine, fine, medium, coarse, and very coarse sand. Coarse materials consist of gravel, which is composed of pebbles ( 2 to 64 $\mathrm{mm}$ ), cobbles (64 to $256 \mathrm{~mm}$ ), and boulders (greater than $256 \mathrm{~mm}$ ) (Friedman 1978). 
Preliminary Survey Considerations

Table 4.1 Selection of Direct Measurement Techniques Based on Experience

\begin{tabular}{|c|c|c|c|c|c|c|c|}
\hline \multirow[b]{2}{*}{ Nuclide } & \multicolumn{2}{|c|}{ Structure Surfaces } & \multicolumn{2}{|c|}{ Land Areas } & \multicolumn{3}{|c|}{ Direct Measurement Instruments ${ }^{2}$} \\
\hline & $\begin{array}{l}\text { Example } \\
\text { DCGL } \\
\left(\mathbf{B g} / \mathbf{m}^{2}\right) \\
\end{array}$ & Detectable & $\begin{array}{l}\text { Example } \\
\text { DCGL } \\
\text { (Bq/kg) }\end{array}$ & Detectable & $\begin{array}{l}\text { Surface } \\
\text { Activity }\end{array}$ & $\begin{array}{c}\text { Soil } \\
\text { Activity }\end{array}$ & $\begin{array}{l}\text { Exposure } \\
\text { Rate }\end{array}$ \\
\hline${ }^{3} \mathrm{H}$ & $1.6 \times 10^{6}$ & No & $1.5 \times 10^{4}$ & No & $\mathrm{ND}^{6}$ & $\mathrm{ND}$ & ND \\
\hline${ }^{14} \mathrm{C}$ & $4.7 \times 10^{5}$ & Yes & $1.4 \times 10^{3}$ & No & GPB & ND & ND \\
\hline${ }^{54} \mathrm{Mn}$ & $1.3 \times 10^{4}$ & Yes & 450 & Yes & $\mathbf{G P B}^{7}, \mathrm{GM}$ & $\gamma \mathrm{S}, \mathrm{IS} \gamma$ & PIC, $\gamma \mathrm{S}, \mathrm{IS} \gamma$ \\
\hline${ }^{55} \mathrm{Fe}$ & $1.8 \times 10^{6}$ & No & $4.1 \times 10^{5}$ & $\mathrm{No}^{5}$ & ND & $\mathrm{ND}(\mathrm{IS} \gamma)$ & $\mathrm{ND}(\mathrm{IS} \gamma)$ \\
\hline${ }^{60} \mathrm{Co}$ & $3.1 \times 10^{3}$ & Yes & 110 & Yes & GPß,GM & $\gamma \mathrm{S}, \mathrm{IS} \gamma$ & PIC, $\gamma \mathrm{S}, \mathrm{IS} \gamma$ \\
\hline${ }^{63} \mathrm{Ni}$ & $1.5 \times 10^{6}$ & Yes & $2.8 \times 10^{5}$ & No & GPB & ND & ND \\
\hline${ }^{90} \mathrm{Sr}$ & $6.0 \times 10^{3}$ & Yes & 420 & $\mathrm{No}^{5}$ & GPß,GM & $\begin{array}{c}\mathrm{ND} \\
(\mathrm{GM}, \mathrm{GPB})\end{array}$ & ND \\
\hline${ }^{99} \mathrm{Tc}$ & $6.4 \times 10^{5}$ & Yes & $1.9 \times 10^{3}$ & No & GPB,GM & ND & ND \\
\hline${ }^{137} \mathrm{Cs}$ & $8.2 \times 10^{3}$ & Yes & 400 & Yes & GPB,GM & $\gamma \mathrm{S}, \mathrm{IS} \gamma$ & $\mathrm{PIC}, \gamma \mathrm{S}, \mathrm{IS} \gamma$ \\
\hline${ }^{152} \mathrm{Eu}$ & $6.6 \times 10^{3}$ & Yes & 240 & Yes & GPß,GM & $\gamma \mathrm{S}, \mathrm{IS} \gamma$ & PIC, $\gamma \mathrm{S}, \mathrm{IS} \gamma$ \\
\hline${ }^{226} \mathrm{Ra}(\mathrm{C})^{3}$ & 970 & Yes & 210 & Yes & $\mathbf{G P} \alpha, \alpha \mathbf{S}$ & $\gamma \mathrm{S}, \mathrm{IS} \gamma$ & PIC, $\gamma$ S,IS $\gamma$ \\
\hline${ }^{232} \mathrm{Th}(\mathrm{C})^{3}$ & 340 & Yes & 320 & Yes & $\mathrm{GP} \alpha, \alpha \mathrm{S}, \mathbf{G P B}$ & $\gamma \mathrm{S}, \mathrm{IS} \gamma$ & PIC, $\gamma$ S,IS $\gamma$ \\
\hline $\mathrm{U}^{4}$ & 560 & Yes & 710 & Yes & $\begin{array}{l}\text { GP } \alpha, \alpha S, G P B \\
\text { IS } \gamma\end{array}$ & $\begin{array}{c}\gamma S, \mathbf{I S} \gamma \\
\text { GPB }\end{array}$ & $\mathrm{PIC}, \gamma \mathrm{S}, \mathrm{IS} \gamma$ \\
\hline $\begin{array}{l}{ }^{239} \mathrm{Pu}, \\
{ }^{241} \mathrm{Pu}, \\
\mathrm{Pu}\end{array}$ & 120 & Yes & 70 & $\mathrm{No}^{5}$ & $\mathbf{G P} \alpha, \alpha \mathbf{S}$ & $\mathrm{ND}(\mathrm{IS} \gamma)$ & $\mathrm{ND}$ \\
\hline${ }^{241} \mathrm{Am}$ & 110 & Yes & 70 & Yes & $\mathbf{G P} \alpha, \alpha \mathbf{S}$ & $\gamma$ S,IS $\gamma$ & PIC, $\gamma$ S,IS $\gamma$ \\
\hline
\end{tabular}

${ }^{1}$ Example DCGLs based on values given in NRC draft report NUREG-1500 (NRC 1994c).

${ }^{2} \mathrm{GP} \alpha=$ Gas-flow proportional counter ( $\alpha$ mode)

$\mathrm{GM}=$ Geiger-Mueller survey meter

$\mathrm{GPB}=$ Gas-flow proportional counter $(\beta$ mode $)$

$\mathrm{PIC}=$ Pressurized ionization chamber

$\alpha S=$ Alpha scintillation survey meter

$\gamma S=$ gamma scintillation (gross)

IS $\gamma=$ in situ gamma spectrometry

${ }^{3}$ For decay chains having two or more radionuclides of significant half-life that reach secular equilibrium.

The notation "(c)" indicates the direct measurement techniques assume the presence of progeny in the chain.

${ }^{4}$ Depleted, natural, and enriched.

${ }^{5}$ Possibly detectable at limits for areas of elevated activity.

${ }^{6}$ Not detectable.

${ }^{7}$ Bold indicates the preferred method where alternative methods are available. 


\section{Table 4.2 Example of DQO Planning Considerations}

Separate out and evaluate fine-grain material because resuspension is associated with the fine grain fraction for the air pathway.

If contamination resides on sand, pebbles, and cobbles, analyze these materials for direct exposure pathway and analyze the fine-grain fraction for the air pathway.

Separation and homogenization are not necessary for analyses because direct exposure pathway depends upon the average concentration and presence of cobbles will usually not impact laboratory analysis.

Determine if pathway modeling considered the presence of cobbles.

Separate, homogenize, and evaluate fine-grain material because plant root uptake is associated with the fine-grain fraction for the plant ingestion pathway.

Separate, homogenize, and evaluate fine-grain materials because of their relevance for the contaminant source term for contaminant migration to the sub-surface for the water pathway.

Both sample depth and area are considerations in determining appropriate sample volume, and sample volume is a key consideration for determining the laboratory MDC. The depth should also correlate with the conceptual model developed in Chapter 3 and upgraded throughout the Radiation Survey and Site Investigation (RSSI) Process. For example, if data collected during the Historical Site Assessment indicate contamination may exist to a depth of greater than $15 \mathrm{~cm}$ (6 in.), then samples should be deep enough to support the survey objectives, such as for the scoping or characterization survey. Taking samples as a function of depth might also be a survey design objective, such as for scoping, characterization, or remediation support.

The depth and area of the sample should be recorded as well as any observations, such as the presence of materials noted during sampling. Chapter 6 and Chapter 7 present more detail regarding the application of these survey planning considerations. 
Preliminary Survey Considerations

\subsection{Site Preparation}

Site preparation involves obtaining consent for performing the survey, establishing the property boundaries, evaluating the physical characteristics of the site, accessing surfaces and land areas of interest, and establishing a reference coordinate system. Site preparation may also include removing equipment and materials that restrict access to surfaces. The presence of furnishings or equipment will restrict access to building surfaces and add additional items that the survey should address.

\subsubsection{Consent for Survey}

When facilities or sites are not owned by the organization performing the surveys, consent from the site or equipment owner should be obtained before conducting the surveys. All appropriate local, State, and Federal officials as well as the site owner and other affected parties should be notified of the survey schedule. Section 3.5 discusses consent for access, and additional guidance based on the CERCLA program is available from EPA (EPA 1987d).

\subsubsection{Property Boundaries}

Property boundaries may be determined from property survey maps furnished by the owners or from plat maps obtained from city or county tax maps. Large-area properties and properties with obscure boundaries or missing survey markers may require the services of a professional land surveyor.

If the radiological survey is only performed inside buildings, a tax map with the buildings accurately located will usually suffice for site/building location designation.

\subsubsection{Physical Characteristics of Site}

The physical characteristics of the site will have a significant impact on the complexity, schedule, and cost of a survey. These characteristics include the number and size of structures, type of building construction, wall and floor penetrations, pipes, building condition, total area, topography, soil type, and ground cover. In particular, the accessibility of structures and land areas (Section 4.8.4) has a significant impact on the survey effort. In some cases survey techniques (e.g., in situ gamma spectrometry discussed in Chapter 6) can preclude or reduce the need to gain physical access or use intrusive techniques. This should be considered during survey planning. 


\subsubsection{Structures}

Building design and condition will have a marked influence on the survey efforts. The time involved in conducting a survey of building interior surfaces is essentially directly proportional to the total surface area. For this reason the degree of survey coverage decreases as the potential for residual activity decreases. Judgment measurements and sampling, which are performed in addition to the measurements performed for the nonparametric tests, are recommended in areas likely to have accumulated deposits of residual activity. As discussed in Section 5.5.3.3 and Section 8.5 , judgment measurements and samples are compared directly to the appropriate DCGL.

The condition of surfaces after decontamination may affect the survey process. Removing contamination that has penetrated a surface usually involves removing the surface material. As a result, the floors and walls of decontaminated facilities are frequently badly scarred or broken up and are often very uneven. Such surfaces are more difficult to survey because it is not possible to maintain a fixed distance between the detector and the surface. In addition, scabbled or porous surfaces may significantly attenuate radiations-particularly alpha and low-energy beta particles. Use of monitoring equipment on wheels is precluded by rough surfaces, and such surfaces also pose an increased risk of damage to fragile detector probe faces. These factors should be considered during the calibration of survey instruments; NRC report NUREG-1507 (NRC 1997b) provides additional information on how to address these surface conditions. The condition of the building should also be considered from a safety and health standpoint before a survey is conducted. A structural assessment may be needed to determine whether the structure is safe to enter.

Expansion joints, stress cracks, and penetrations into floors and walls for piping, conduit, and anchor bolts, etc., are potential sites for accumulation of contamination and pathways for migration into subfloor soil and hollow wall spaces. Drains, sewers, and septic systems can also become contaminated. Wall/floor interfaces are also likely locations for residual contamination. Coring, drilling, or other such methods may be necessary to gain access for survey. Intrusive surveying may require permitting by local regulatory authorities. Suspended ceilings may cover areas of potential contamination such as ventilation ducts and fixtures.

Exterior building surfaces will typically have a low potential for residual contamination, however, there are several locations that should be considered during survey planning. If there are roof exhausts, roof accesses that allow for radioactive material movement, or the facility is proximal to the air effluent discharge points, the possibility of roof contamination should be considered. Because roofs are periodically resurfaced, contaminants may be trapped in roofing material, and sampling this material may be necessary. Roof drainage points such as driplines along overhangs, downspouts, and gutters are also important survey locations. Wall penetrations for process equipment, piping, and exhaust ventilation are potential locations for exterior 
Preliminary Survey Considerations

contamination. Window ledges and outside exits (doors, doorways, landings, stairways, etc.) are also building exterior surfaces that should be addressed.

\subsubsection{Land Areas}

Depending upon site processes and operating history, the radiological survey may include varying portions of the land areas. Potentially contaminated open land or paved areas to be considered include storage areas (e.g., equipment, product, waste, and raw material), liquid waste collection lagoons and sumps, areas downwind (based on predominant wind directions on an average annual basis, if possible) of stack release points, and surface drainage pathways. Additionally, roadways and railways that may have been used for transport of radioactive or contaminated materials that may not have been adequately contained could also be potentially contaminated.

Buried piping, underground tanks, sewers, spill areas, and septic leach fields that may have received contaminated liquids are locations of possible contamination may necessitate sampling of subsurface soil (Section 7.5.3). Information regarding soil type (e.g., clay, sand) may provide insight into the retention or migration characteristics of specific radionuclides. The need for special sampling by coring or split-spoon equipment should be anticipated for characterization surveys.

If radioactive waste has been removed, surveys of excavated areas will be necessary before backfilling. If the waste is to be left in place, subsurface sampling around the burial site perimeter to assess the potential for future migration may be necessary.

Additionally, potentially contaminated rivers, harbors, shorelines, and other outdoor areas may require survey activities including environmental media (e.g., sediment, marine biota) associated with these areas.

\subsubsection{Clearing to Provide Access}

In addition to the physical characteristics of the site, a major consideration is how to address inaccessible areas that have a potential for residual radioactivity. Inaccessible areas may need significant effort and resources to adequately survey. This section provides a description of common inaccessible areas that may have to be considered. The level of effort expended to access these difficult-to-reach areas should be commensurate with the potential for residual activity. For example, the potential for the presence of residual activity behind walls should be established before significant effort is expended to remove drywall. 


\subsubsection{Structures}

Structures and indoor areas should be sufficiently cleared to permit completion of the survey. Clearing includes providing access to potentially contaminated interior surfaces (e.g., drains, ducting, tanks, pits, ceiling areas, and equipment) by removing covers, disassembly, or other means of producing adequate openings.

Building features such as ceiling height, construction materials, ducts, pipes, etc., will determine the ease of accessibility of various surfaces. Scaffolding, cranes, lifts, or ladders may be necessary to reach some surfaces, and dismantling portions of the building may be required.

The presence of furnishings and equipment will restrict access to building surfaces and add additional items that the survey should address. Remaining equipment indirectly involved in the process may need to be dismantled in order to evaluate the radiological status, particularly of inaccessible parts of the equipment. Removing or relocating certain furnishings, such as lab benches and hoods, to obtain access to potentially contaminated floors and walls may also be necessary. The amount of effort and resources dedicated to such removal or relocation activities should be commensurate with the potential for contamination. Where the potential is low, a few spot-checks may be sufficient to provide confidence that covered areas are free of contamination. In other cases, complete removal may be warranted.

Piping, drains, sewers, sumps, tanks, and other components of liquid handling systems present special difficulties because of the inaccessibility of interior surfaces. Process information, operating history, and preliminary monitoring at available access points will assist in evaluating the extent of sampling and measurements included in the survey.

If the building is constructed of porous materials (e.g., wood, concrete) and the surfaces were not sealed, contamination may be found in the walls, floors, and other surfaces. It may be necessary to obtain cores of these surfaces for laboratory analysis.

Another accessibility problem is the presence of contamination beneath tile or other floor coverings. This often occurs because the covering was placed over contaminated surfaces, or the joints in tile were not sealed to prevent penetration. The practice in some facilities has been to "fix" contamination (particularly alpha emitters) by painting over the surface of the contaminated area. Thus, actions to obtain access to potentially contaminated surfaces, such as removing wall and floor coverings (including paint, wax, or other sealer) and opening drains and ducts, may be necessary to enable representative measurements of the contaminant. If alpha radiation or very low energy beta radiation is to be measured, the surface should be free of overlying material, such as dust and water, which may significantly attenuate the radiations. 


\subsubsection{Land Areas}

If ground cover needs to be removed or if there are other obstacles that limit access by survey personnel or necessary equipment, the time and expense of making land areas accessible should be considered. In addition, precautionary procedures need to be developed to prevent spreading surface contamination during ground cover removal or the use of heavy equipment.

Removal or relocation of equipment and materials that may entail special precautions to prevent damage or maintain inventory accountability should be performed by the property owner whenever possible. Clearing open land of brush and weeds will usually be performed by a professional land-clearing organization under subcontract arrangements. However, survey personnel may perform minor land-clearing activities as needed.

An important consideration prior to clearing is the possibility of bio-uptake and consequent radiological contamination of the material to be cleared. Special precautions to avoid exposure of personnel involved in clearing activities may be necessary. Initial radiological screening surveys should be performed to ensure that cleared material or equipment is not contaminated.

The extent of site clearing in specific areas depends primarily on the potential for radioactive contamination existing in those areas where: 1) the radiological history or results of previous surveys do not indicate potential contamination of an area (it may be sufficient to perform only minimum clearing to establish a reference coordinate system); 2) contamination is known to exist or a high potential for contamination necessitates completely clearing an area to provide access to all surfaces; and 3) new findings as the survey progresses may indicate that additional clearing be performed.

Open land areas may be cleared by heavy machinery (e.g., bulldozers, bushhogs, and hydroaxes). However, care should be exercised to prevent relocation of surface contamination or damage to site features such as drainage ditches, utilities, fences, and buildings. Minor land clearing may be performed using manually operated equipment such as brushhooks, power saws, knives, and string trimmers. Brush and weeds should be cut to the minimum practical height necessary to facilitate measurement and sampling activities (approximately $15 \mathrm{~cm}$ ). Care should be exercised to prevent unnecessary damage to or removal of mature trees or shrubs.

Potential ecological damage that might result from an extensive survey should be considered. If a survey is likely to result in significant or permanent damage to the environment, appropriate environmental analyses should be conducted prior to initiating the survey. In addition, environmental hazards such as poison ivy, ticks carrying Lyme disease, and poisonous snakes, spiders, or insects should be noted. These hazards can affect the safety and health of the workers as well as the schedule for performing the survey. 


\subsubsection{Reference Coordinate System}

Reference coordinate systems are established at the site to:

- $\quad$ facilitate selection of measurement and sampling locations

- provide a mechanism for referencing a measurement to a specific location so that the same survey point can be relocated

A survey reference coordinate system consists of a grid of intersecting lines, referenced to a fixed site location or benchmark. Typically, the lines are arranged in a perpendicular pattern, dividing the survey location into squares or blocks of equal area; however, other types of patterns (e.g., three-dimensional, polar) have been used.

The reference coordinate system used for a particular survey should provide a level of reproducibility consistent with the objectives of the survey. For example, a commercially available global positioning system will locate a position within tens of meters, while a differential global positioning system (DGPS) provides precision on the order of a few centimeters (see Section 6.10.1.1). On the other hand, a metal bar can be driven into the ground to provide a long-term reference point for establishing a local reference coordinate system.

Reference coordinate system patterns on horizontal surfaces are usually identified numerically on one axis and alphabetically on the other axis or in distances in different compass directions from the grid origin. Examples of structure interior and land area grids are shown in Figures 4.3 through 4.5. Grids on vertical surfaces may include a third designator, indicating position relative to floor or ground level. Overhead measurement and sampling locations (e.g., ceiling and overhead beams) are referenced to corresponding floor grids.

For surveys of Class 1 and Class 2 areas, basic grid patterns at 1 to 2 meter intervals on structure surfaces and at 10 to 20 meter intervals of land areas may be sufficient to identify survey locations with a reasonable level of effort, while not being prohibitive in cost or difficulty of installation. Gridding of Class 3 areas may also be necessary to facilitate referencing of survey locations to a common system or origin but, for practical purposes, may typically be at larger intervals-e.g., 5 to 10 meters for large structural surfaces and 20 to 50 meters for land areas.

Reference coordinate systems on structure surfaces are usually marked by chalk line or paint along the entire grid line or at line intersections. Land area reference coordinate systems are usually marked by wooden or metal stakes, driven into the surface at reference line intersections. The selection of an appropriate marker depends on the characteristics and routine uses of the surface. Where surfaces prevent installation of stakes, the reference line intersection can be marked by painting. 
Preliminary Survey Considerations
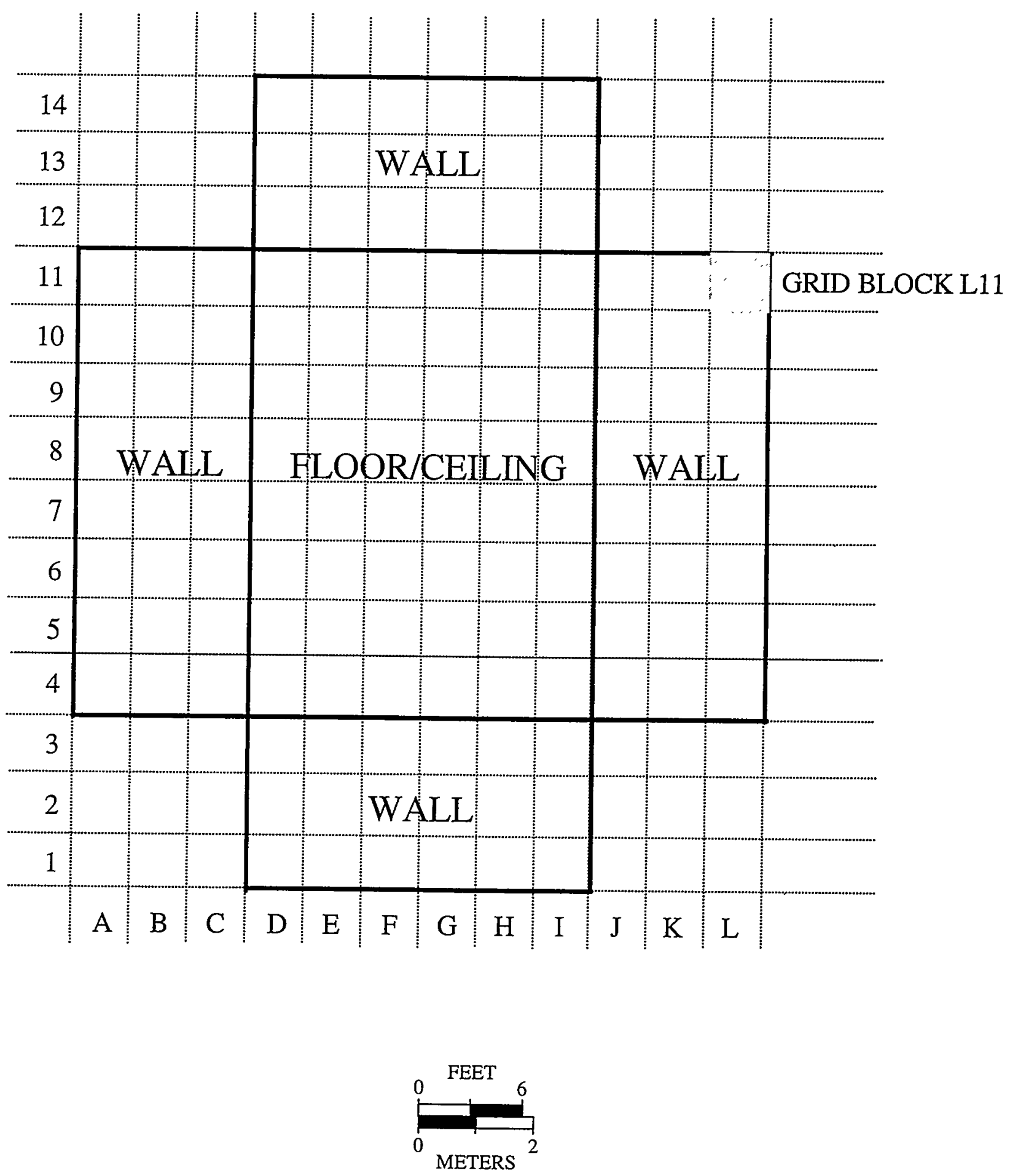

Figure 4.3 Indoor Grid Layout with Alphanumeric Grid Block Designation: Walls and Floors are Diagramed as Though They Lay Along the Same Horizontal Plane 


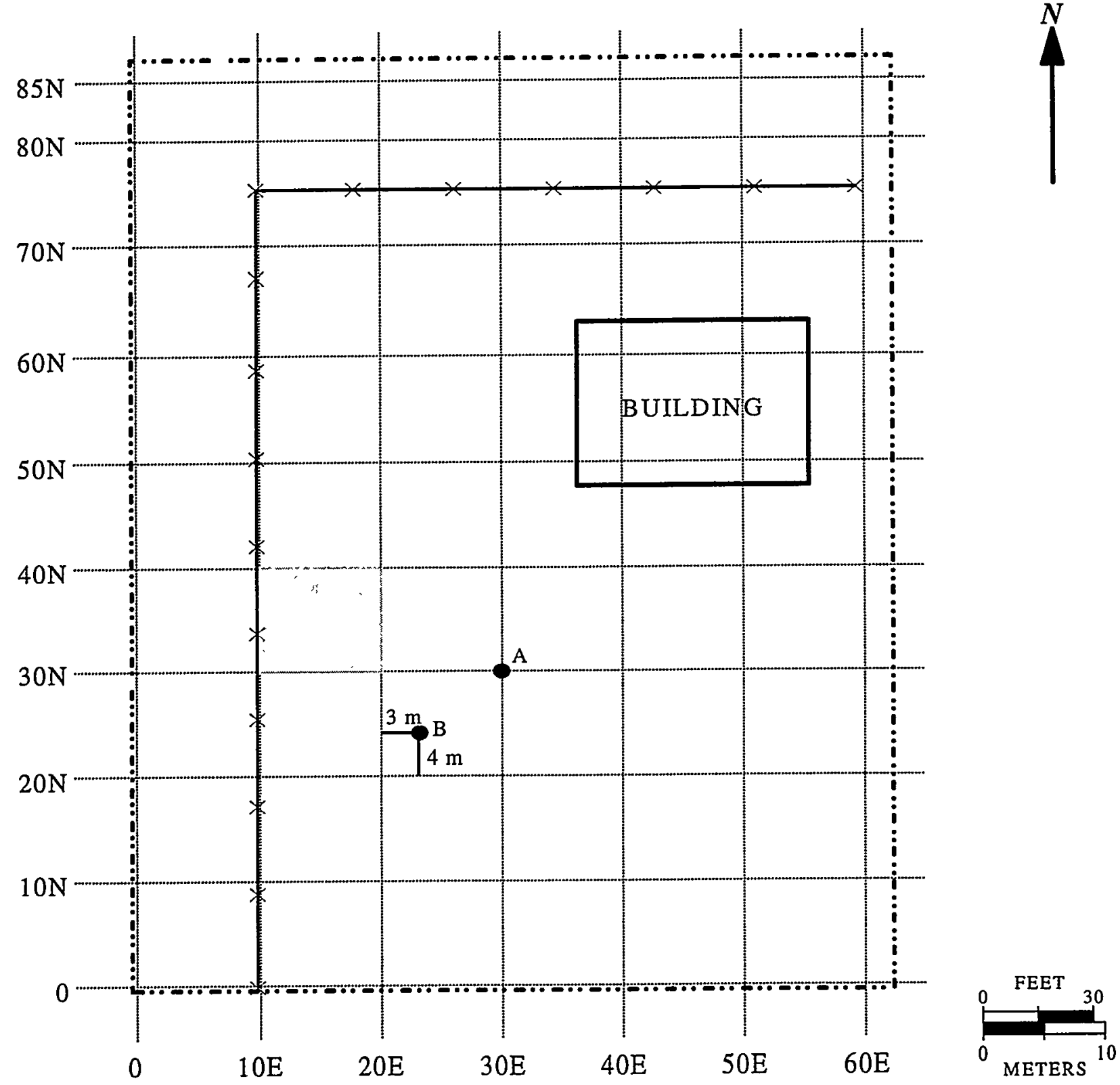

POINT A GRID COORDINATES 30E, 30N

POINT B GRID COORDINATES 23E, 24N

SHADED BLOCK GRID COORDINATES 10E, 30N

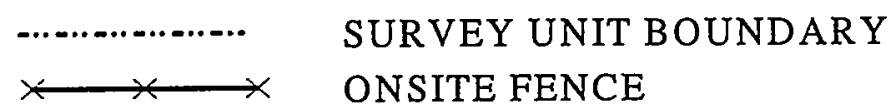

Figure 4.4 Example of a Grid System for Survey of Site Grounds Using Compass Directions 


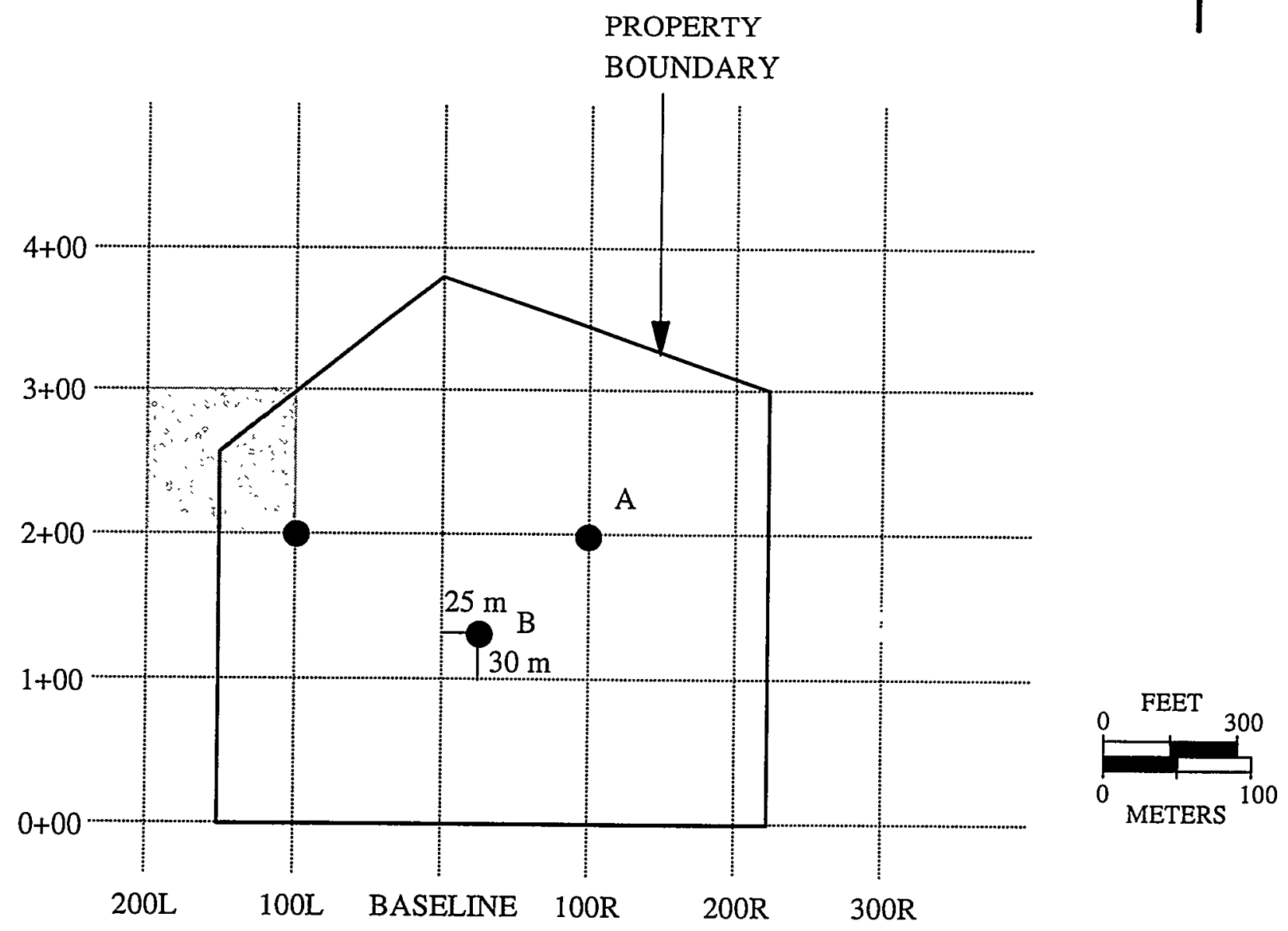

POINT A GRID COORDINATES 100R, 2+00

POINT B GRID COORDINATES 25R, $1+30$

SHADED BLOCK GRID COORDINATES 200L, 2+00

Figure 4.5 Example of a Grid System for Survey of Site Grounds Using Distances Left or Right of the Baseline 
Three basic coordinate systems are used for identifying points on a reference coordinate system. The reference system shown in Figure 4.3 references grid locations using numbers on the vertical axis and letters on the horizontal axis. The reference system shown on Figure 4.4 references distances from the 0,0 point using the compass directions $\mathrm{N}$ (north), $\mathrm{S}$ (south), $\mathrm{E}$ (east), and W (west). The reference system shown in Figure 4.5 references distances along and to the $\mathrm{R}$ (right) or L (left) of the baseline. In addition, a less frequently used reference system is the polar coordinate system, which measures distances along transects from a central point. Polar coordinate systems are particularly useful for survey designs to evaluate effects of stack emissions, where it may be desirable to have a higher density of samples collected near the stack and fewer samples with increasing distance from the stack.

Figure 4.5 shows an example grid system for an outdoor land area. The first digit or set of digits includes an $\mathrm{L}$ or $\mathrm{R}$ (separated from the first set by a comma) to indicate the distance from the baseline in units (meters) and the direction (left or right) from the baseline. The second digit or set of digits refers to the perpendicular distance from the 0,0 point on the baseline and is measured in hundreds of units. Point $A$ in the example of a reference coordinate system for survey of site grounds, Figure 4.5, is identified 100R, 2+00 (i.e., $200 \mathrm{~m}$ from the baseline and $100 \mathrm{~m}$ to the right of the baseline). Fractional distances between reference points are identified by adding the distance beyond the reference point and are expressed in the same units used for the reference coordinate system dimensions. Point $B$ on Figure 4.5 is identified $25 R, 1+30$.

Open land reference coordinate systems should be referenced to a location on an existing State or local reference system or to a U.S. Geological Survey (USGS) bench mark. (This may require the services of a professional land surveyor.) Global positioning systems (GPS) are capable of locating reference points in terms of latitude and longitude (Section 6.10 .1 provides descriptions of positioning systems).

Following establishment of the reference coordinate system, a drawing is prepared by the survey team or the land surveyor. This drawing indicates the reference lines, site boundaries, and other pertinent site features and provides a legend showing the scale and a reference compass direction. The process used to develop the reference coordinate system should be recorded in the survey planning documentation (e.g., the Quality Assurance Project Plan or QAPP). An deviations from the requirements developed during planning should be documented when the reference coordinate system is established.

It should be noted that the reference coordinate systems described in this section are intended primarily for reference purposes and do not necessarily dictate the spacing or location of survey measurements or samples. Establishment of a measurement grid to demonstrate compliance with the DCGL is discussed in Section 5.5.2.5 and Chapter 8. 


\subsection{Quality Control}

Site surveys should be performed in a manner that ensures results are accurate and sources of uncertainty are identified and controlled. This is especially the case for final status surveys that are vital to demonstrating a facility satisfies pre-established release criteria. Quality control (QC) and quality assurance (QA) are initiated at the start of a project and integrated into all surveys as DQOs are developed. This carries over to the writing of a Quality Assurance Project Plan (QAPP), which applies to each aspect of a survey. Section 9.2 provides guidance on developing a QAPP. Data quality is routinely a concern throughout the RSSI Process, and one should recognize that QA/QC procedures will change as data are collected and analyzed, and as DQOs become more rigorous for the different types of surveys that lead up to a final status survey.

In general, surveys performed by trained individuals are conducted with approved written procedures and properly calibrated instruments that are sensitive to the suspected contaminant. However, even the best approaches for properly performing measurements and acquiring accurate data need to consider QC activities. QC activities are necessary to obtain additional quantitative information to demonstrate that measurement results have the required precision and are sufficiently free of errors to accurately represent the site being investigated. The following two questions are the main focus of the rationale for the assessment of errors in environmental data collection activities (EPA 1990).

- How many and what type of measurements are required to assess the quality of data from an environmental survey?

- How can the information from the quality assessment measurements be used to identify and control sources of error and uncertainties in the measurement process?

These questions are introduced as part of guidance that also includes an example to illustrate the planning process for determining a reasonable number of quality control (QC) measurements. This guidance also demonstrates how the information from the process may be used to document the quality of the measurement data. This process was developed in terms of soil samples collected in the field and then sent to a laboratory for analysis (EPA 1990). For MARSSIM, these questions may be asked in relation to measurements of surface soils and building surfaces both of which include sampling, scanning, and direct measurements.

Quality control may be thought of in three parts: 1) determining the type of QC samples needed to detect precision or bias; 2) determining the number of samples as part of the survey design; and 3) scheduling sample collections throughout the survey process to identify and control sources of error and uncertainties. Section 4.9.1 introduces the concepts of precision and bias related to survey measurements and briefly discusses the types of QC measurements needed to detect and quantify precision and bias. Section 6.2 and Section 7.2 provide more detailed 
guidance on the types of QC measurements. The number of QC measurements is addressed in Section 4.9.2, while Section 4.9.3 and Section 9.3 contain information on identifying and controlling sources of uncertainty. Overall, survey activities associated with MARSSIM include obtaining the additional information related to QA of both field and laboratory activities.

\subsubsection{Precision and Systematic Errors (Bias)}

Precision is a measure of agreement among repeated measurements. Precision is discussed further in Appendix N in statistical terms. Table N.2 presents the minimum considerations, impacts of not meeting these considerations, and corrective actions associated with assessing precision. Systematic errors, also called bias, accumulate during the measurement process and result from faults in sampling designs and procedures, analytical procedures, sample contamination, losses, interactions with containers, deterioration, inaccurate instrument calibration, and other sources. Bias causes the mean value of the sample data to be consistently higher or lower than the true mean value. Appendix $\mathrm{N}$ also discusses bias, and Table N.3 presents the minimum considerations associated with assessing bias, the impacts if the considerations are not met, and related corrective actions. Laboratories typically introduce QC samples into their sample load to assess possible bias. In simplest terms, spikes, repeated measurements, and blanks are used to assess precision, bias, and contamination, respectively. See Section 6.2 for further discussion of specific measurements for determining precision and bias for scans and direct measurements and Section 7.2 for further discussion of specific measurements for determining precision and bias for samples.

Field work using scanning or direct measurements eliminates some sources of error because samples are not removed, containerized, nor transported to another location for analysis. The operator's technique or field instrument becomes the source of bias. In this case, detecting bias might incorporate field replicates (see Section 7.2.2.1) by having a second operator to revisit measurement locations and following the same procedure with the same instrument as was used by the first operator. This is an approach used to assess precision of measurements. A field instrument's calibration can also be checked by one or more operators during the course of a survey and recorded on a control chart. Differences in set up or handling of instruments by different operators may reveal a significant source of bias that is quite different from sources of bias associated with laboratory work.

The following factors should be considered when evaluating sources of bias, error, and uncertainty. Contamination is an added factor to consider for each of the following items.

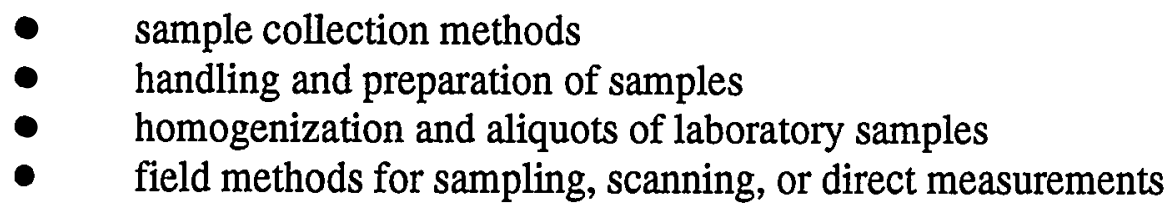


- laboratory analytical process

- total bias contributed by all sources

The magnitude of the measurement system variability should be evaluated to determine if the variability approaches or exceeds the true but unknown variability in the population of interest. Errors, bias, or data variability may accumulate to the point of rendering data unusable to achieve survey objectives. Systematic investigations of field or laboratory processes can be initiated to assess and identify the extent of errors, bias, and data variability and to determine if the DQOs are achieved. An important aspect of each QC determination is the representative nature of a sample or measurement (see Appendix $\mathrm{N}$ for a description of representativeness). If additional samples or measurements are not taken according to the appropriate method, the resulting QC information will be invalid or unusable. For example, if an inadequate amount of sample is collected, the laboratory analytical procedure may not yield a proper result. The QC sample must represent the sample population being studied. Misrepresentation itself creates a bias that if undetected leads to inaccurate conclusions concerning an analysis. At the very least, misrepresentation leads to a need for additional QA investigation.

\subsubsection{Number of Quality Control Measurements}

The number of QC measurements is determined by the available resources and the degree to which one needs assurance that a measurement process is adequately controlled. The process is simplified, for example, when the scope of a survey is narrowed to a single method, one sampling crew, and a single laboratory to analyze field samples. Increasing the number of samples and scheduling sample collections and analyses over time or at different laboratories increases the level of difficulty and necessitates increasing the number of QC measurements. The number of QC measurements may also be driven upward as the action level approaches a given instrument's detection limit. This number is determined on a case-by-case basis, where the specific contaminant and instruments are assessed for detecting a particular radionuclide.

A widely used standard practice is to collect a set percentage, such as 5\% (EPA 1987b), of samples for QA purposes. However, this practice has disadvantages. For example, it provides no real assessment of the uncertainties for a relatively small sample size. For surveys where the required number of measurements increases, there may be a point beyond which there is little added value in performing additional QC measurements. Aside from cost, determining the appropriate number of QC measurements essentially depends on site-specific factors. For example, soil may present a complex and variable matrix requiring many more QC measurements for surface soils than for building surfaces.

A performance based alternative (EPA 1990) to a set percentage or rule of thumb can be implemented. First, potential sources of error or uncertainty, the likelihood of occurrence, and the consequences in the context of the DQOs should be determined. Then, the appropriate type 
and number of QC measurements based on the potential error or uncertainty are determined. For example, field replicate samples (i.e., a single sample that is collected, homogenized, and split into equivalent fractions in the field) are used to estimate the combined contribution of several sources of variation. Hence, the number of field replicate samples to be obtained in the study should be dictated by how precise the estimate of the total measurement should be.

Factors influencing this estimate include the

- number of measurements

- number and experience of personnel involved

- current and historical performance of sampling and analytical procedures used

- the variability of survey unit and background reference area radioactivity measurement systems used

- number of laboratories used

- the level of radioactivity in the survey unit (which for a final status survey should be low)

- how close an action level (e.g., DCGL) is to a detection limit (which may represent a greater concern after reducing or removing radionuclide concentrations by remediation)

The precision of an estimate of the "true" variance for precision or bias within a survey design depends on the number of QC measurements performed to provide the estimate. Table 4.3 provides the one-sided upper confidence limits for selected numbers of QC measurements assuming the results of the measurements are normally distributed. Confidence limits are provided for $90,95,97.5$, and 99 percent confidence levels. At the stated level of confidence, the "true" variance of the estimate of precision or bias for a specified number of QC measurements will be between zero and the multiple of the estimated variance listed in Table 4.3. For example, for five field replicate samples one would be $90 \%$ confident that the true variance for precision falls between zero and 3.10 times the estimated variance based on the results of the five samples.

When planning surveys, the number of each type of QC measurement can be obtained from Table 4.3. For example, if the survey objective is to estimate the variance in the bias for a specific measurement system between zero and two times the estimated variance at a $95 \%$ confidence level, 15 measurements of a material with known concentration (e.g., performance evaluation samples) would be indicated. MARSSIM recommends that the survey objective be set such that the true variance falls between zero and two times the estimated variance. The level of confidence is then determined on a site-specific basis to adjust the number of each type of QC measurement to the appropriate level (i.e., 10, 15, 20 or 30 measurements). The results of the QC measurements are evaluated during the assessment phase of the data life cycle (see Section 9.3 and Appendix N). 
Preliminary Survey Considerations

Table 4.3 Upper Confidence Limits for the True Variance as a Function of the Number of QC Measurements Used to Determine the Estimated Variance

\begin{tabular}{|c|c|c|c|c||}
\hline \multirow{2}{*}{$\begin{array}{c}\text { Number of QC } \\
\text { Measurements }\end{array}$} & \multicolumn{3}{|c|}{ Level of Confidence (\%) } \\
\cline { 2 - 5 } & 90 & 95 & 97.5 & 99 \\
\hline 2 & 9.49 & 19.49 & 39.21 & 99.50 \\
\hline 5 & 3.10 & 6.01 & 6.02 & 9.02 \\
\hline 10 & 2.05 & 2.54 & 3.08 & 3.91 \\
\hline 15 & 1.76 & 2.07 & 2.40 & 2.87 \\
\hline 20 & 1.61 & 1.84 & 2.08 & 2.42 \\
\hline 25 & 1.52 & 1.71 & 1.91 & 2.17 \\
\hline 30 & 1.46 & 1.62 & 1.78 & 2.01 \\
\hline 40 & 1.38 & 1.51 & 1.64 & 1.80 \\
\hline 50 & 1.33 & 1.44 & 1.61 & 1.68 \\
\hline 100 & 1.21 & 1.28 & 1.35 & 1.43 \\
\hline
\end{tabular}

Example:

A site is contaminated with ${ }^{60} \mathrm{Co}$ and consists of four Class 1 interior survey units, nine Class 2 interior survey units, two Class 3 interior survey units, and one Class 3 exterior survey unit. Three different measurement systems are specified in the survey design for performing scanning surveys, one measurement system is specified for performing direct measurements for interior survey units, and one measurement system is specified for measuring samples collected from the exterior survey unit.

Repeated measurements are used to estimate precision. For scan surveys there is not a specified number of measurements. $10 \%$ of the scans in each Class 1 survey unit were repeated as replicates to measure operator precision (see Section 6.2.2.1) within 24 hours of the original scan survey. $5 \%$ of each Class 2 and Class 3 survey unit were similarly repeated as replicates to measure operator precision. The results of the repeated scans were evaluated based on professional judgment. For direct measurements and sample collection activities, a 95\% confidence level was selected as consistent with the objectives of the survey. Using Table 4.3, it was determined that 15 repeated measurements were required for both the direct measurement technique and the sample collection and laboratory measurement technique. Because 72 direct measurements would be performed in Class 1 survey units, 99 in Class 2 survey units, and 20 in Class 3 survey units, it was anticipated that at least 15 direct measurements would have sufficient 
activity above background to perform repeated measurements and obtain usable results (see Section 5.5.2 for guidance on determining the number of measurements and Appendix A for a more detailed discussion of the example site). The 15 direct measurement locations to be repeated would be selected based on the results of the direct measurements and would represent the entire usable range of activity found in the survey units rather than measuring the 15 locations with the highest activities. (The usable range of activity includes the highest measurement result in the survey unit and the lowest measurement result with an acceptable measurement uncertainty compared to the desired level of precision.) The repeated measurements would be performed by different operators using the same equipment, but they would not know the results of the original survey. To ensure that the measurements would be valid, the QC measurements to check for contamination would be performed at the same time. Because the laboratory's QA program called for periodic checks on the precision of the laboratory instruments, the total survey design precision for laboratory measurements was measured. Because the only samples collected would come from a Class 3 area, the sample activities were expected to be close to or below the measurement system MDC. This meant that field replicate samples would not provide any usable information. Also, QC samples for bias were repeated to obtain a usable estimate of precision for the survey design.

Measurements of materials with known concentrations above background (e.g., performance evaluation samples) and known concentrations at or below background (e.g., field blanks) are used to estimate bias. For scan surveys, the repeated scanning performed to estimate precision would also serves as a check for contamination using blanks. Because there was no appropriate material of known concentration on which to perform bias measurements, the calibration checks were used to demonstrate that the instruments were reading properly during the surveys. A control chart was developed using the instrument response for an uncalibrated check source. Measurements were obtained using a specified source-detector alignment that could be easily repeated. Measurements were obtained at several times during the day over a period of several weeks prior to taking the instruments into the field. Calibration checks were performed before and after each survey period in the field and the results immediately plotted on the control chart to determine if the instrument was performing properly. This method was also adopted for the direct measurement system. 20 samples were required by the survey design for the Class 3 exterior survey unit. To ensure that the samples were truly blind for the laboratory, samples three times the requested volume were collected. These samples were sent to a second laboratory for preparation. Each sample was weighed, dried, and reweighed to determine the moisture content. Then each sample was ground to a uniform particle size of $1 \mathrm{~mm}$ (approximately $16 \mathrm{mesh}$ ) and divided into three separate aliquots (each aliquot was the same size). For each sample one aliquot was packaged for transport to the laboratory performing the analysis. After these samples were packaged, 15 of the samples had both of the remaining aliquots spiked with the same level of activity using a 
source solution traceable to the National Institute of Science and Technology (NIST). The 15 samples each had a different level of activity within a range that was accepted by the laboratory performing the analysis. These 30 samples were also packaged for transport to the laboratory. In addition, 15 samples of a soil similar to the soil at the site were prepared as blanks to check against contamination. The 20 samples, 30 spikes, and 15 blanks were transported to the laboratory performing the analyses in a single shipment so that all samples were indistinguishable from each other except by the sample identification.

\subsubsection{Controlling Sources of Error}

During the performance of a survey, it is important to identify sources of error and uncertainty early in the process so that problems can be resolved. The timing of the $\mathrm{QC}$ measurements within the survey design can be very important. In order to identify problems as early as possible, it may be necessary to perform a significant number of QC measurements early in the survey. This can be especially important for surveys utilizing an innovative or untested survey design. Survey designs that have been used previously and produced reliable results may be able to space the QC measurement evenly throughout the survey, or even wait to have samples analyzed at the end of the survey, as long as the objectives of the survey are achieved.

For example, a survey design requires a new scanning method to be used for several survey units when there are little performance data available for this technique. To ensure that the technique is working properly, the first few survey units are re-scanned to provide an initial estimate of the precision and bias. After the initial performance of the techniques has been verified, a small percentage of the remaining survey units is re-scanned to demonstrate that the technique is operating properly for the duration of the survey.

Identifying sources of error and uncertainty is only the first step. Once the sources of uncertainty have been identified, they should be minimized and controlled for the rest of the survey. Section 9.3 discusses the assessment of survey data and provides guidance on corrective actions that may be appropriate for controlling sources of error or uncertainty after they have been identified.

\subsection{Health and Safety}

Consistent with the approach for any operation, activities associated with the radiological surveys should be planned and monitored to assure the health and safety of the worker and other personnel, both onsite and offsite, are adequately protected. At the stage of determining the final status of the site, residual radioactivity is expected to be below the DCGL values; therefore, the final status survey should not include radiation protection controls. However, radiation protection controls may be necessary when performing scoping or characterization surveys where the potential for significant levels of residual radioactivity is unknown. 
Significant health and safety concerns during any radiological survey include the potential industrial hazards commonly found at a construction site, such as exposed electrical circuitry, excavations, enclosed work spaces, hazardous atmospheres, insects, poisonous snakes, plants, and animals, unstable surfaces (e.g., wet or swamp soil), heat and cold, sharp objects or surfaces, falling objects, tripping hazards, and working at heights. The survey plan should incorporate objectives and procedures for identifying and eliminating, avoiding, or minimizing these potential safety hazards. 


\section{SURVEY PLANNING AND DESIGN}

\subsection{Introduction}

This chapter is intended to assist the user in planning a strategy for conducting a final status survey, with the ultimate objective being to demonstrate compliance with the derived concentration guideline levels (DCGLs). The survey types that make up the Radiation Survey and Site Investigation (RSSI) Process include scoping, characterization, remedial action support, and final status surveys. Although the scoping, characterization, and remedial action support surveys have multiple objectives, this manual focuses on those aspects related to supporting the final status survey and demonstrating compliance with DCGLs. In general, each of these survey types expands upon the data collected during the previous survey (e.g., the characterization survey is planned with information collected during the scoping survey) up through the final status survey. The purpose of the final status survey is to demonstrate that the release criterion established by the regulatory agency has not been exceeded. This final release objective should be kept in mind throughout the design and planning phases for each of the other survey types. For example, scoping surveys may be designed to meet the objectives of the final status survey such that the scoping survey report is also the final status survey report. The survey and analytical procedures referenced in this chapter are described in Chapter 6, Chapter 7, and Appendix H. An example of a final status survey, as described in Section 5.5, appears in Appendix A. In addition, example checklists are provided for each type of survey to assist the user in obtaining the necessary information for planning a final status survey.

\subsection{Scoping Surveys}

\subsubsection{General}

If the data collected during the Historical Site Assessment (HSA) indicate that a site or area is impacted, a scoping survey could be performed. The objective of this survey is to augment the HSA for sites with potential residual contamination. Specific objectives may include:

1) performing a preliminary risk assessment and providing data to complete the site prioritization scoring process (CERCLA and RCRA sites only), 2) providing input to the characterization survey design, if necessary, 3 ) supporting the classification of all or part of the site as a Class 3 area for planning the final status survey, 4) obtaining an estimate of the variability in the residual radioactivity concentration for the site, and 5) identifying non-impacted areas that may be appropriate for reference areas and estimating the variability in radionuclide concentrations when the radionuclide of interest is present in background.

Scoping survey information needed when conducting a preliminary risk assessment (as noted above for CERCLA and RCRA sites) includes the general radiation levels at the site and gross levels of residual contamination on building surfaces and in environmental media. If unexpected 
Survey Planning and Design

conditions are identified that prevent the completion of the survey, the MARSSIM user should contact the responsible regulatory agency for further guidance. Sites that meet the National Contingency Plan criteria for a removal should be referred to the Superfund Removal program (EPA 1988c).

If the HSA indicates that contamination is likely, a scoping survey could be performed to provide initial estimates of the level of effort for remediation and information for planning a more detailed survey, such as a characterization survey. Not all radiological parameters need to be assessed when planning for additional characterization because total surface activity or limited sample collection may be sufficient to meet the objectives of the scoping survey.

Once a review of pertinent site history indicates that an area is impacted, the minimum survey coverage at the site will include a Class 3 area final status survey prior to the site being released. For scoping surveys with this objective, identifying radiological decision levels is necessary for selecting instruments and procedures with the necessary detection sensitivities to demonstrate compliance with the release criterion. A methodology for planning, conducting, and documenting scoping surveys is described in the following sections.

\subsubsection{Survey Design}

Planning a scoping survey involves reviewing the HSA (Chapter 3 ). This process considers available information concerning locations of spills or other releases of radioactive material. Reviewing the radioactive materials license or similar documentation provides information on the identity, locations, and general quantities of radioactive material used at the site. This information helps to determine which areas are likely to contain residual radioactivity and, thus, areas where scoping survey activities will be concentrated. The information may also identify one or more non-impacted areas as potential reference areas when radionuclides of concern are present in background (Section 4.5). Following the review of the HSA, DCGLs that are appropriate for the site are selected. The DCGLs may be adjusted later if a determination is made to use site-specific information to support the development of DCGLs.

If residual radioactivity is identified during the scoping survey, the area may be classified as Class 1 or Class 2 for final status survey planning (refer to Section 4.4 for guidance on initial classification), and a characterization survey is subsequently performed. For scoping surveys that are designed to provide input for characterization surveys, measurements and sampling may not be as comprehensive or performed to the same level of sensitivity necessary for final status surveys. The design of the scoping survey should be based on specific data quality objectives (DQOs; see Section 2.3.1 and Appendix D) for the information to be collected.

For scoping surveys that potentially serve to release the site from further consideration, the survey design should consist of sampling based on the HSA data and professional judgment. If 
residual radioactivity is not identified during judgment sampling, it may be appropriate to classify the area as Class 3 and perform a final status survey for Class 3 areas. Refer to Section 5.5 for a description of final status surveys. However, collecting additional information during subsequent surveys (e.g., characterization surveys) may be necessary to make a final determination as to area classification.

\subsubsection{Conducting Surveys}

Scoping survey activities performed for preliminary risk assessment or to provide input for additional characterization include a limited amount of surface scanning, surface activity measurements, and sample collection (smears, soil, water, vegetation, paint, building materials, subsurface materials). In this case, scans, direct measurements, and samples are used to examine areas likely to contain residual radioactivity. These activities are conducted based on HSA data, preliminary investigation surveys, and professional judgment.

Background activity and radiation levels for the area should be determined, including direct radiation levels on building surfaces and radionuclide concentrations in media. Survey locations should be referenced to grid coordinates, if appropriate, or fixed site features. It may be considered appropriate to establish a reference coordinate system in the event that contamination is detected above the DCGLs (Section 4.8.5). Samples collected as part of a scoping survey should consider any sample tracking requirements, including chain of custody, if required (Section 7.8).

Scoping surveys that are expected to be used as Class 3 area final status surveys should be designed following the guidance in Section 5.5. These surveys should also include judgment measurements and sampling in areas likely to have accumulated residual radioactivity (Section 5.5.3).

\subsubsection{Evaluating Survey Results}

Survey data are converted to the same units as those in which DCGLs are expressed (Section 6.6). Identification of potential radionuclide contaminants at the site is performed using direct measurements or laboratory analysis of samples. The data are compared to the appropriate regulatory DCGLs.

For scoping survey activities that provide an initial assessment of the radiological hazards at the site, or provide input for additional characterization, the survey data are used to identify locations and general extent of residual radioactivity. Scoping surveys that are expected to be used as Class 3 area final status surveys should follow the methodology presented in Chapter 8 to determine if the release criterion has been exceeded. 


\subsubsection{Documentation}

How the results of the scoping survey are documented depends on the specific objectives of the survey. For scoping surveys that provide additional information for characterization surveys, the documentation should provide general information on the radiological status of the site. Survey results should include identification of the potential contaminants (including the methods used for radionuclide identification), general extent of contamination (e.g., activity levels, area of contamination, and depth of contamination), and possibly even relative ratios of radionuclides to facilitate DCGL application. A narrative report or a report in the form of a letter may suffice for scoping surveys used to provide input for characterization surveys. Sites being released from further consideration should provide a level of documentation consistent with final status survey reports. 


\section{EXAMPLE SCOPING SURVEY CHECKLIST}

\section{SURVEY DESIGN}

Enumerate DQOs: State the objectives of the survey; survey instrumentation capabilities should be appropriate for the specified survey objectives.

Review the Historical Site Assessment for:

Operational history (e.g., problems, spills, releases, or notices of violation) and available documentation (e.g., radioactive materials license).

Other available resources—site personnel, former workers, residents, etc.

Types and quantities of materials that were handled and where radioactive materials were stored, handled, moved, relocated, and disposed.

Release and migration pathways.

Areas that are potentially affected and likely to contain residual contamination. Note: Survey activities will be concentrated in these areas.

Types and quantities of materials likely to remain onsite-consider radioactive decay.

Select separate DCGLs for the site based on the HSA review. (It may be necessary to assume appropriate regulatory DCGLs in order to permit selection of survey methods and instrumentation for the expected contaminants and quantities.)

\section{CONDUCTING SURVEYS}

Follow the survey design documented in the QAPP. Record deviations from the stated objectives or documented SOPs and document additional observations made when conducting the survey.

Select instrumentation based on the specific DQOs of the survey. Consider detection capabilities for the expected contaminants and quantities.

Determine background activity and radiation levels for the area; include direct radiation levels on building surfaces, radionuclide concentrations in media, and exposure rates. 
Survey Planning and Design

Record measurement and sample locations referenced to grid coordinates or fixed site features.

For scoping surveys that are conducted as Class 3 area final status surveys, follow guidance for final status surveys.

Conduct scoping survey, which involves judgment measurements and sampling based on HSA results:

___ Perform investigatory surface scanning.

Conduct limited surface activity measurements.

Perform limited sample collection (smears, soil, water, vegetation, paint, building materials, subsurface materials).

Maintain sample tracking.

\section{EVALUATING SURVEY RESULTS}

Compare survey results with the DQOs.

Identify radionuclides of concern.

Identify impacted areas and general extent of contamination.

Estimate the variability in the residual radioactivity levels for the site.

Adjust DCGLs based on survey findings (the DCGLs initially selected may not be appropriate for the site).

Determine the need for additional action (e.g., none, remediate, more surveys)

Prepare report for regulatory agency (determine if letter report is sufficient). 


\subsection{Characterization Surveys}

\subsubsection{General}

Characterization surveys may be performed to satisfy a number of specific objectives. Examples of characterization survey objectives include: 1 ) determining the nature and extent of radiological contamination, 2) evaluating remediation alternatives (e.g., unrestricted use, restricted use, onsite disposal, off-site disposal, etc.), 3) input to pathway analysis/dose or risk assessment models for determining site-specific DCGLs ( $\left.\mathrm{Bq} / \mathrm{kg}, \mathrm{Bq} / \mathrm{m}^{2}\right)$, 4) estimating the occupational and public health and safety impacts during decommissioning, 5) evaluating remediation technologies, 6) input to final status survey design, and 7) Remedial Investigation/Feasibility Study requirements (CERCLA sites only) or RCRA Facility Investigation/Corrective Measures Study requirements (RCRA sites only).

The scope of this manual precludes detailed discussions of characterization survey design for each of these objectives, and therefore, the user should consult other references for specific characterization survey objectives not covered. For example, the Decommissioning Handbook (DOE 1994) is a good reference for characterization objectives that are concerned with evaluating remediation technologies or unrestricted/restricted use alternatives. Other references (EPA 1988b, 1988c, 1994a; NRC 1994) should be consulted for planning decommissioning actions, including decontamination techniques, projected schedules, costs, and waste volumes, and health and safety considerations during decontamination. Also, the types of characterization data needed to support risk or dose modeling should be determined from the specific modeling code documentation.

This manual concentrates on providing information for the final status survey design, with limited coverage on determining the specific nature and extent of radionuclide contamination. The specific objectives for providing information to the final status survey design include: 1) estimating the projected radiological status at the time of the final status survey, in terms of radionuclides present, concentration ranges and variances, spatial distribution, etc., 2) evaluating potential reference areas to be used for background measurements, if necessary, 3) reevaluating the initial classification of survey units, 4) selecting instrumentation based on the necessary MDCs, and 5) establishing acceptable Type I and Type II errors with the regulatory agency (Appendix D provides guidance on establishing acceptable decision error rates). Many of these objectives are satisfied by determining the specific nature and extent of contamination of structures, residues, and environmental media. Additional detail on the performance of characterization surveys designed to determine the general extent of contamination can be found in the NRC's Draft Branch Technical Position on Site Characterization for Decommissioning (NRC 1994a) and EPA's RI/FS guidance (EPA 1988b; EPA 1993c). 
Results of the characterization survey should include: 1) the identification and distribution of contamination in buildings, structures, and other site facilities; 2) the concentration and distribution of contaminants in surface and subsurface soils; 3 ) the distribution and concentration of contaminants in surface water, ground water, and sediments, and 4) the distribution and concentration of contaminants in other impacted media such as vegetation or paint. The characterization should include sufficient information on the physical characteristics of the site, including surface features, meteorology and climatology, surface water hydrology, geology, demography and land use, and hydrogeology. This survey should also address environmental conditions that could affect the rate and direction of contaminant transport in the environment, depending on the extent of contamination identified above.

The following sections describe a method for planning, conducting, and documenting characterization surveys. Alternative methodologies may also be acceptable to the regulatory agencies.

\subsubsection{Survey Design}

The design of the site characterization survey is based on the specific DQOs for the information to be collected, and is planned using the HSA and scoping survey results. The DQO Process ensures that an adequate amount of data with sufficient quality are collected for the purpose of characterization. The site characterization process typically begins with a review of the HSA, which includes available information on site description, operational history, and the type and extent of contamination (from the scoping survey, if performed). The site description, or conceptual site model as first developed in Section 3.6.4, consists of the general area, dimensions, and locations of contaminated areas on the site. A site map should show site boundaries, roads, hydrogeologic features, major structures, and other features that could affect decommissioning activities.

The operational history includes records of site conditions prior to operational activities, operational activities of the facility, effluents and on-site disposal, and significant incidents-including spills or other unusual occurrences-involving the spread of contamination around the site and on areas previously released from radiological controls. This review should include other available resources, such as site personnel, former workers, residents, etc. Historic aerial photographs and site location maps may be particularly useful in identifying potential areas of contamination.

The types and quantities of materials that were handled and the locations and disposition of radioactive materials should be reviewed using available documentation (e.g., the radioactive materials license). Contamination release and migration pathways should be identified, as well as areas that are potentially affected and are likely to contain residual contamination. The types and quantities of materials likely to remain onsite, considering radioactive decay, should be determined. 
The characterization survey should clearly identify those portions of the site (e.g., soil, structures, and water) that have been affected by site activities and are potentially contaminated. The survey should also identify the portions of the site that have not been affected by these activities. In some cases where no remediation is anticipated, results of the characterization survey may indicate compliance with DCGLs established by the regulatory agency. When planning for the potential use of characterization survey data as part of the final status survey, the characterization data must be of sufficient quality and quantity for that use (see Section 5.5). There are several processes that are likely to occur in conjunction with characterization. These include considering and evaluating remediation alternatives, and calculating site-specific DCGLs.

The survey should also provide information on variations in the contaminant distribution in the survey area. The contaminant variation in each survey unit contributes to determining the number of data points based on the statistical tests used during the final status survey (Section 5.5.2). Additionally, characterization data may be used to justify reclassification for some survey units (e.g., from Class 1 to Class 2).

Note that because of site-specific characteristics of contamination, performing all types of measurements described here may not be relevant at every site. For example, detailed characterization data may not be needed for areas with contamination well above the DCGLs that clearly require remediation. Judgment should be used in determining the types of characterization information needed to provide an appropriate basis for decontamination decisions.

\subsubsection{Conducting Surveys}

Characterization survey activities often involve the detailed assessment of various types of building and environmental media, including building surfaces, surface and subsurface soil, surface water, and ground water. The HSA data should be used to identify the potentially contaminated media onsite (see Section 3.6.3). Identifying the media that may contain contamination is useful for preliminary survey unit classification and for planning subsequent survey activities. Selection of survey instrumentation and analytical techniques are typically based on a knowledge of the appropriate DCGLs, because remediation decisions are made based on the level of the residual contamination as compared to the DCGL. Exposure rate measurements may be needed to assess occupational and public health and safety. The location of underground utilities should be considered before conducting a survey to avoid compounding the problems at the site. 
Survey Planning and Design

\subsubsection{Structure Surveys}

Surveys of building surfaces and structures include surface scanning, surface activity measurements, exposure rate measurements, and sample collection (e.g., smears, subfloor soil, water, paint, and building materials). Both field survey instrumentation (Chapter 6) and analytical laboratory equipment and procedures (Chapter 7) are selected based on their detection capabilities for the expected contaminants and their quantities. Field and laboratory instruments are described in Appendix $\mathrm{H}$.

Background activity and radiation levels for the area should be determined from appropriate background reference areas. Background assessments include surface activity measurements on building surfaces, exposure rates, and radionuclide concentrations in various media (refer to Section 4.5).

Measurement locations should be documented using reference system coordinates, if appropriate, or fixed site features. A typical reference system spacing for building surfaces is 1 meter. This is chosen to facilitate identifying survey locations, evaluating small areas of elevated activity, and determining survey unit average activity levels.

Scans should be conducted in areas likely to contain residual activity, based on the results of the HSA and scoping survey.

Both systematic and judgment surface activity measurements are performed. Judgment direct measurements are performed at locations of elevated direct radiation, as identified by surface scans, to provide data on upper ranges of residual contamination levels. Judgment measurements may also be performed in sewers, air ducts, storage tanks, septic systems and on roofs of buildings, if necessary. Each surface activity measurement location should be carefully recorded on the appropriate survey form.

Exposure rate measurements and media sampling are performed as necessary. For example, subfloor soil samples may provide information on the horizontal and vertical extent of contamination. Similarly, concrete core samples are necessary to evaluate the depth of activated concrete in a reactor facility. Note that one type of radiological measurement may be sufficient to determine the extent of contamination. For example, surface activity measurements alone may be all that is needed to demonstrate that decontamination of a particular area is necessary; exposure rate measurements would add little to this determination.

Lastly, the measuring and sampling techniques should be commensurate with the intended use of the data, as characterization survey data may be used to supplement final status survey data, provided that the data meet the selected DQOs. 


\subsubsection{Land Area Surveys}

Characterization surveys for surface and subsurface soils and media involve employing techniques to determine the lateral and vertical extent and radionuclide concentrations in the soil. This may be performed using either sampling and laboratory analyses, or in situ gamma spectrometry analyses, depending on the detection capabilities of each methodology for the expected contaminants and concentrations. Note that in situ gamma spectrometry analyses or any direct surface measurement cannot easily be used to determine vertical distributions of radionuclides. Sample collection followed by laboratory analysis introduces several additional sources of uncertainty that need to be considered during survey design. In many cases, a combination of direct measurements and samples is required to meet the objectives of the survey.

Radionuclide concentrations in background soil samples should be determined for a sufficient number of soil samples that are representative of the soil in terms of soil type, soil depth, etc. It is important that the background samples be collected in non-impacted areas. Consideration should be given to spatial variations in the background radionuclide concentrations as discussed in Section 4.5 and NRC draft report NUREG-1501 (NRC 1994b).

Sample locations should be documented using reference system coordinates (see Section 4.8.5), if appropriate, or fixed site features. A typical reference system spacing for open land areas is 10 meters (NRC 1992a). This spacing is somewhat arbitrary and is chosen to facilitate determining survey unit locations and evaluating areas of elevated radioactivity.

Surface scans for gamma activity should be conducted in areas likely to contain residual activity. Beta scans may be appropriate if the contamination is near the surface and represents the prominent radiation emitted from the contamination. The sensitivity of the scanning technique should be appropriate to meet the DQOs.

Both surface and subsurface soil and media samples may be necessary. Subsurface soil samples should be collected where surface contamination is present and where subsurface contamination is known or suspected. Boreholes should be constructed to provide samples representing subsurface deposits.

Exposure rate measurements at 1 meter above the sampling location may also be appropriate. Each surface and subsurface soil sampling and measurement location should be carefully recorded. 


\subsubsection{Other Measurements/Sampling Locations}

Surface Water and Sediments. Surface water and sediment sampling may be necessary depending on the potential for these media to be contaminated. The contamination potential depends on several factors, including the proximity of surface water bodies to the site, size of the drainage area, total annual rainfall, and spatial and temporal variability in surface water flow rate and volume. Refer to Section 3.6.3.3 for further consideration of the necessity for surface water and sediment sampling.

Characterizing surface water involves techniques that determine the extent and distribution of contaminants. This may be performed by collecting grab samplesof the surface water in a wellmixed zone. At certain sites, it may be necessary to collect stratified water samples to provide information on the vertical distribution of contamination. Sediment sampling should also be performed to assess the relationship between the composition of the suspended sediment and the bedload sediment fractions (i.e., suspended sediments compared to deposited sediments). When judgment sampling is used to find radionuclides in sediments, contaminated sediments are more likely to be accumulated on fine-grained deposits found in low-energy environments (e.g., deposited silt on inner curves of streams).

Radionuclide concentrations in background water samples should be determined for a sufficient number of water samples that are upstream of the site or in areas unaffected by site operations. Consideration should be given to any spatial or temporal variations in the background radionuclide concentrations.

Sampling locations should be documented using reference system coordinates, if appropriate, or scale drawings of the surface water bodies. Effects of variability of surface water flow rate should be considered. Surface scans for gamma activity may be conducted in areas likely to contain residual activity (e.g., along the banks) based on the results of the document review and/or preliminary investigation surveys.

Surface water sampling should be performed in areas of runoff from active operations, at plant outfall locations, both upstream and downstream of the outfall, and any other areas likely to contain residual activity (see Section 3.6.3.3). Measurements of radionuclide concentrations in water should include gross alpha and gross beta assessments, as well as any necessary radionuclide-specific analyses. Non-radiological parameters, such as specific conductance, $\mathrm{pH}$, and total organic carbon may be used as surrogate indicators of potential contamination, provided that a specific relationship exists between the radionuclide concentration and the level of the indicator (e.g., a linear relationship between $\mathrm{pH}$ and the radionuclide concentration in water is found to exist, then the $\mathrm{pH}$ may be measured such that the radionuclide concentration can be calculated based on the known relationship rather than performing an expensive nuclide-specific analysis). The use of surrogate measurements is discussed in Section 4.3.2. 
Each surface water and sediment sampling location should be carefully recorded on the appropriate survey form. Additionally, surface water flow models may be used to illustrate contaminant concentrations and migration rates.

Ground Water. Ground-water sampling may be necessary depending on the local geology, potential for subsurface contamination, and the regulatory framework. Because different agencies handle ground water contamination situations in different ways (e.g., EPA's Superfund program and some States require compliance with maximum contaminant levels specified in the Safe Drinking Water Act), the responsible regulatory agency should be contacted if ground water contamination is expected. The need for ground-water sampling is described in Section 3.6.3.4.

If ground-water contamination is identified, the responsible regulatory agency should be contacted at once because: 1) ground water release criteria and DCGLs should be established by the appropriate agency (Section 4.3), and 2) the default DCGLs for soil may be inappropriate since they are usually based on initially uncontaminated ground water.

Characterization of ground-water contamination should determine the extent and distribution of contaminants, rates and direction of ground water migration, and the assessment of potential effects of ground water withdrawal on the migration of ground water contaminants. This may be performed by designing a suitable monitoring well network. The actual number and location of monitoring wells depends on the size of the contaminated area, the type and extent of the contaminants, the hydrogeologic system, and the objectives of the monitoring program.

When ground-water samples are taken, background should be determined by sufficient sampling and analysis of ground-water samples collected from the same aquifer upgradient of the site. The background samples should not be affected by site operations and should be representative of the quality of the ground water that would exist if the site had not been contaminated. Consideration should be given to any spatial or temporal variations in the background radionuclide concentrations.

Sampling locations should be referenced to grid coordinates, if appropriate, or to scale drawings of the ground-water monitoring wells. Construction specifications on the monitoring wells should also be provided, including elevation, internal and external dimensions, types of casings, type of screen and its location, borehole diameter, and other necessary information on the wells.

In addition to organic and inorganic constituents, ground-water sampling and analyses should include all significant radiological contaminants. Measurements in potential sources of drinking water should include gross alpha and gross beta assessments, as well as any other radionuclidespecific analyses. Non-radiological parameters, such as specific conductance, $\mathrm{pH}$, and total organic carbon may be used as surrogate indicators of potential contamination, provided that a specific relationship exists between the radionuclide concentration and the level of the indicator. 
Each ground-water monitoring well location should be carefully recorded on the appropriate survey form. Additionally, contaminant concentrations and sources should be plotted on a map to illustrate the relationship among contamination, sources, hydrogeologic features and boundary conditions, and property boundaries (EPA 1993b).

Other Media. Air sampling may be necessary at some sites depending on the local geology and the radionuclides of potential concern. This may include collecting air samples or filtering the air to collect resuspended particulates. Air sampling is often restricted to monitoring activities for occupational and public health and safety and is not required to demonstrate compliance with risk- or dose-based regulations. Section 3.6.3.5 describes examples of sites where air sampling may provide information useful to designing a final status survey. At some sites, radon measurements may be used to indicate the presence of radium, thorium, or uranium in the soil. Section 6.9 and Appendix $\mathrm{H}$ provide information on this type of sampling.

In rare cases, vegetation samples may be collected as part of a characterization survey to provide information in preparation for a final status survey. Because most risk- and dose-based regulations are concerned with potential future land use that may differ from the current land use, vegetation samples are unsuitable for demonstrating compliance with regulations. There is a relationship between radionuclide concentrations in plants and those in soil (the soil-to-plant transfer factor is used in many models to develop DCGLs) and the plant concentration could be used as a surrogate measurement of the soil concentration. In most cases, a measurement of the soil itself as the parameter of interest is more appropriate and introduces less uncertainty in the result.

\subsubsection{Evaluating Survey Results}

Survey data are converted to the same units as those in which DCGLs are expressed (Section 6.6). Identification of potential radionuclide contaminants at the site is performed through laboratory and in situ analyses. Appropriate regulatory DCGLs for the site are selected and the data are then compared to the DCGLs. For characterization data that are used to supplement final status survey data, the statistical methodology in Chapter 8 should be followed to determine if a survey unit satisfies the release criteria.

For characterization data that are used to help guide remediation efforts, the survey data are used to identify locations and general extent of residual activity. The survey results are first compared with DCGLs. Surfaces and environmental media are then differentiated as exceeding DCGLs, not exceeding DCGLs, or not contaminated, depending on the measurement results relative to the DCGL value. Direct measurements indicating areas of elevated activity are further evaluated and the need for additional measurements is determined. 


\subsubsection{Documentation}

Documentation of the site characterization survey should provide a complete and unambiguous record of the radiological status of the site. In addition, sufficient information to characterize the extent of contamination, including all possible affected environmental media, should be provided in the report. This report should also provide sufficient information to support reasonable approaches or alternatives to site decontamination. 
Survey Planning and Design

\section{EXAMPLE CHARACTERIZATION SURVEY CHECKLIST}

\section{SURVEY DESIGN}

Enumerate DQOs: State objective of the survey; survey instrumentation capabilities should be appropriate for the specific survey objective.

Review the Historical Site Assessment for:

Operational history (e.g., any problems, spills, or releases) and available documentation (e.g., radioactive materials license).

Other available resources-site personnel, former workers, residents, etc.

Types and quantities of materials that were handled and where radioactive materials were stored, handled, and disposed of.

Release and migration pathways.

Information on the potential for residual radioactivity that may be useful during area classification for final status survey design. Note: Survey activities will be concentrated in Class 1 and Class 2 areas.

Types and quantities of materials likely to remain on-siteconsider radioactive decay.

\section{CONDUCTING SURVEYS}

Select instrumentation based on detection capabilities for the expected contaminants and quantities and a knowledge of the appropriate DCGLs.

Determine background activity and radiation levels for the area; include surface activity levels on building surfaces, radionuclide concentrations in environmental media, and exposure rates.

Establish a reference coordinate system. Prepare scale drawings for surface water and ground-water monitoring well locations. 
Perform thorough surface scans of all potentially contaminated areas, (e.g., indoor areas include expansion joints, stress cracks, penetrations into floors and walls for piping, conduit, and anchor bolts, and wall/floor interfaces); outdoor areas include radioactive material storage areas, areas downwind of stack release points, surface drainage pathways, and roadways that may have been used for transport of radioactive or contaminated materials.

Perform systematic surface activity measurements.

Perform systematic smear, surface and subsurface soil and media, sediment, surface water and groundwater sampling, if appropriate for the site.

Perform judgment direct measurements and sampling of areas of elevated activity of residual radioactivity to provide data on upper ranges of residual contamination levels.

Document survey and sampling locations.

Maintain chain of custody of samples when necessary.

Note: One category of radiological data (e.g., radionuclide concentration, direct radiation level, or surface contamination) may be sufficient to determine the extent of contamination; other measurements may not be necessary (e.g., removable surface contamination or exposure rate measurements).

Note: Measuring and sampling techniques should be commensurate with the intended use of the data because characterization survey data may be used to supplement final status survey data.

EVALUATING SURVEY RESULTS

Compare survey results with DCGLs. Differentiate surfaces/areas as exceeding DCGLs, not exceeding DCGLs, or not contaminated.

Evaluate all locations of elevated direct measurements and determine the need for additional measurements/samples.

Prepare site characterization survey report. 
Survey Planning and Design

\subsection{Remedial Action Support Surveys}

\subsubsection{General}

Remedial action support surveys are conducted to 1) support remediation activities, 2) determine when a site or survey unit is ready for the final status survey, and 3) provide updated estimates of site-specific parameters to use for planning the final status survey. This manual does not discuss the routine operational surveys (e.g., air sampling, dose rate measurements, environmental sampling) conducted to support remediation activities.

A remedial action support survey serves to monitor the effectiveness of decontamination efforts that are intended to reduce residual radioactivity to acceptable levels. This type of survey guides the cleanup in a real-time mode. The remedial action support survey typically relies on a simple radiological parameter, such as direct radiation near the surface, as an indicator of effectiveness. The investigation level (the level below which there is an acceptable level of assurance that the established DCGLs have been attained) is determined and used for immediate, in-field decisions (Section 5.5.2.6). Such a survey is intended for expediency and cost effectiveness and does not provide thorough or accurate data describing the radiological status of the site. Note that this survey does not provide information that can be used to demonstrate compliance with the DCGLs and is an interim step in the compliance demonstration process. Areas that are determined to satisfy the DCGLs on the basis of the remedial action support survey will then be surveyed in detail by the final status survey. Alternatively, the remedial action support survey can be designed to meet the objectives of a final status survey as described in Section 5.5. DCGLs may be recalculated based on the results of the remediation process as the regulatory program allows or permits.

Remedial activities result in changes to the distribution of contamination within a survey unit. The site-specific parameters used during final status survey planning (e.g., variability in the radionuclide concentration within a survey unit or probability of small areas of elevated activity) will change during remediation. For most survey units, values for these parameters will need to be re-established following remediation. Obtaining updated values for these critical planning parameters should be considered when designing a remedial action support survey.

\subsubsection{Survey Design}

The objective of the remedial action support survey is to detect the presence of residual activity at or below the DCGL criteria. Although the presence of small areas of elevated radioactivity may satisfy the elevated measurement criteria, it may be more efficient to design the remedial

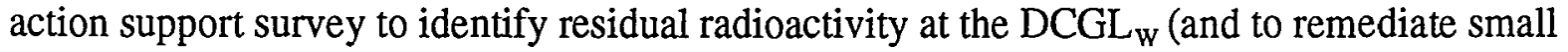
areas of elevated activity that may potentially satisfy the release criteria). Survey instrumentation and techniques are therefore selected based on the detection capabilities for the known or suspected contaminants and DCGLs to be achieved. 
There will be radionuclides and media that cannot be evaluated at the $\mathrm{DCGL}_{\mathrm{w}}$ using field monitoring techniques. For these cases, it may be feasible to collect and analyze samples by methods that are quicker and less costly than radionuclide-specific laboratory procedures. Field laboratories and screening techniques may be acceptable alternatives to more expensive analyses. Reviewing remediation plans may be required to get an indication of the location and amount of remaining contamination following remediation.

\subsubsection{Conducting Surveys}

Field survey instruments and procedures are selected based on their detection capabilities for the expected contaminants and their quantities. Survey methods typically include scans of surfaces followed by direct measurements to identify residual radioactivity. The surface activity levels are compared to the DCGLs, and a determination is made on the need for further decontamination efforts.

Survey activities for soil excavations include surface scans using field instrumentation sensitive to beta and gamma activity. Because it is difficult to correlate scanning results to radionuclide concentrations in soil, judgment should be carefully exercised when using scan results to guide the cleanup efforts. Field laboratories and screening techniques may provide a better approach for determining whether or not further soil remediation is necessary.

\subsubsection{Evaluating Survey Results}

Survey data (e.g., surface activity levels and radionuclide concentrations in various media) are converted to standard units and compared to the DCGLs (Section 6.6). If results of these survey activities indicate that remediation has been successful in meeting the DCGLs, decontamination efforts are ceased and final status survey activities are initiated. Further remediation may be needed if results indicate the presence of residual activity in excess of the DCGLs.

\subsubsection{Documentation}

The remedial action support survey is intended to guide the cleanup and alert those performing remedial activities that additional remediation is needed or that the site may be ready to initiate a final survey. Data that indicate an area has been successfully remediated could be used to estimate the variance for the survey units in that area. Information identifying areas of elevated activity that existed prior to remediation may be useful for planning final status surveys. 
Survey Planning and Design

EXAMPLE REMEDIAL ACTION SUPPORT SURVEY CHECKLIST

SURVEY DESIGN

Enumerate DQOs: State the objectives of the survey; survey instrumentation capabilities should be able to detect residual contamination at the DCGL.

Review the remediation plans.

Determine applicability of monitoring surfaces/soils for the radionuclides of concern. Note: Remedial action support surveys may not be feasible for surfaces contaminated with very low energy beta emitters or for soils or media contaminated with pure alpha emitters.

Select simple radiological parameters (e.g., surface activity) that can be used to make immediate in-field decisions on the effectiveness of the remedial action.

\section{CONDUCTING SURVEYS}

Select instrumentation based on its detection capabilities for the expected contaminants.

Perform scanning and surface activity measurements near the surface being decontaminated.

Survey soil excavations and perform field evaluation of samples (e.g., gamma spectrometry of undried/non-homogenized soil) as remedial actions progress.

\section{EVALUATING SURVEY RESULTS}

Compare survey results with DCGLs using survey data as a field decision tool to guide the remedial actions in a real-time mode.

Document survey results. 


\subsection{Final Status Surveys}

\subsubsection{General}

A final status survey is performed to demonstrate that residual radioactivity in each survey unit satisfies the predetermined criteria for release for unrestricted use or, where appropriate, for use with designated limitations. The survey provides data to demonstrate that all radiological parameters do not exceed the established DCGLs. For these reasons, more detailed guidance is provided for this category of survey. For the final status survey, survey units represent the fundamental elements for compliance demonstration using the statistical tests (see Section 4.6). The documentation specified in the following sections helps ensure a consistent approach among different organizations and regulatory agencies. This allows for comparisons of survey results between sites or facilities.

This section describes methods for planning and conducting final status surveys to satisfy the objectives of the regulatory agencies. The MARSSIM approach recognizes that alternative methods may be acceptable to those agencies. Flow diagrams and a checklist to assist the user in planning a survey are included in this section.

\subsubsection{Survey Design}

Figures 5.1 through 5.3 illustrate the process of designing a final status survey. This process begins with development of DQOs. On the basis of these objectives and the known or anticipated radiological conditions at the site, the numbers and locations of measurement and sampling points used to demonstrate compliance with the release criterion are then determined. Finally, survey techniques appropriate to develop adequate data (see Chapters 6 and 7) are selected and implemented.

Planning for the final status survey should include early discussions with the regulatory agency concerning logistics for confirmatory or verification surveys. A confirmatory survey (also known as an independent verification survey), may be performed by the responsible regulatory agency or by an independent third party (e.g., contracted by the regulatory agency) to provide data to substantiate results of the final status survey. Actual field measurements and sampling may be performed. Another purpose of the confirmatory activities may be to identify any deficiencies in the final status survey documentation based on a thorough review of survey procedures and results. Independent confirmatory survey activities are usually limited in scope to spot-checking conditions at selected locations, comparing findings with those of the final status survey, and performing independent statistical evaluations of the data developed from the confirmatory survey and the final status survey. 
Survey Planning and Design

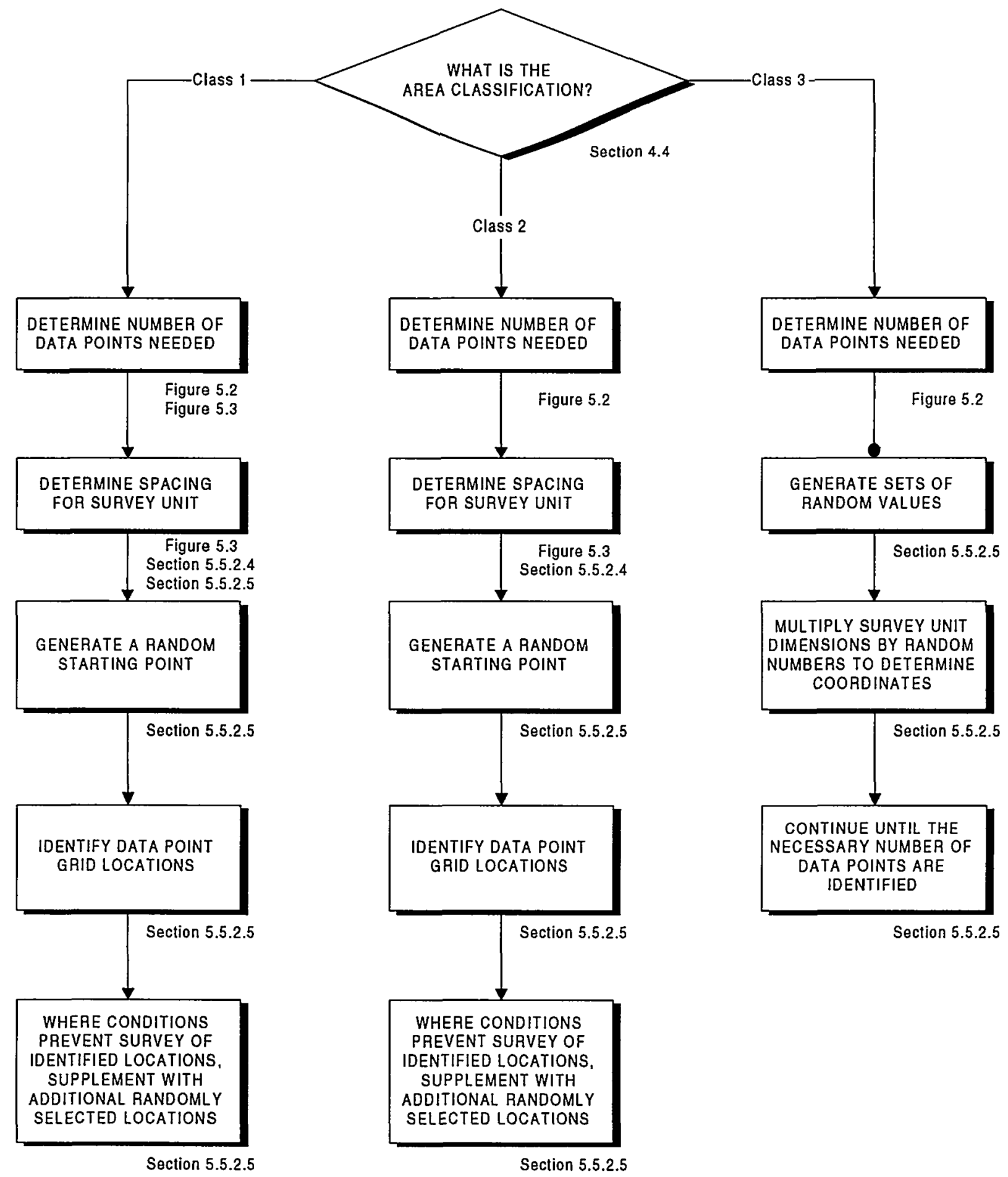

Figure 5.1 Flow Diagram Illustrating the Process for Identifying Measurement Locations (Refer to Section 5.5.2.5) 


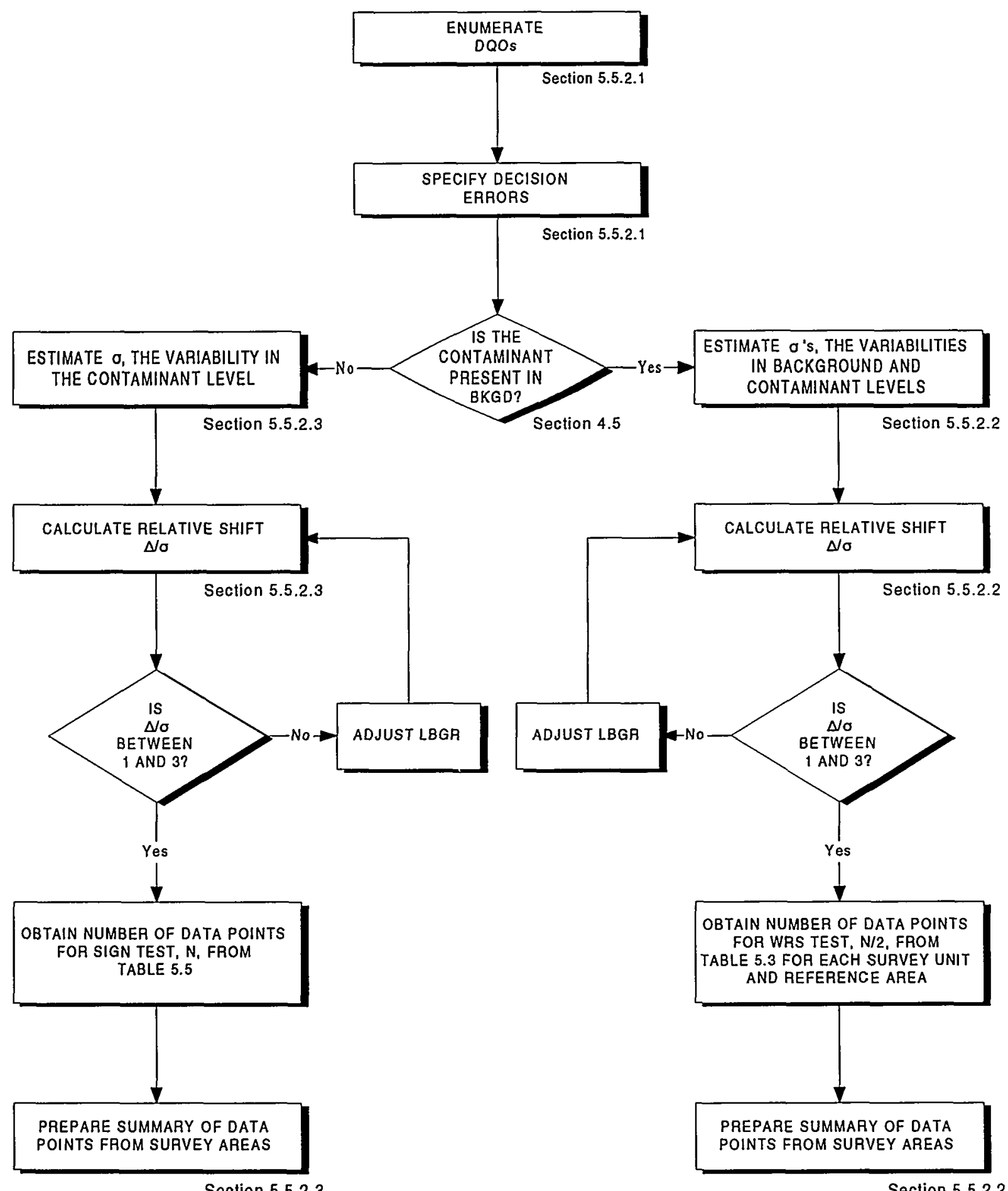

Section 5.5 .2 .3

Section 5.5.2.2

Figure 5.2 Flow Diagram for Identifying the Number of Data Points, $N$, for Statistical Tests 
Survey Planning and Design

CALCULATE AREA FACTOR THAT CORRESPONDS TO THE ACTUAL SCAN MDC (SCAN MDC/AVERAGE DCGL)
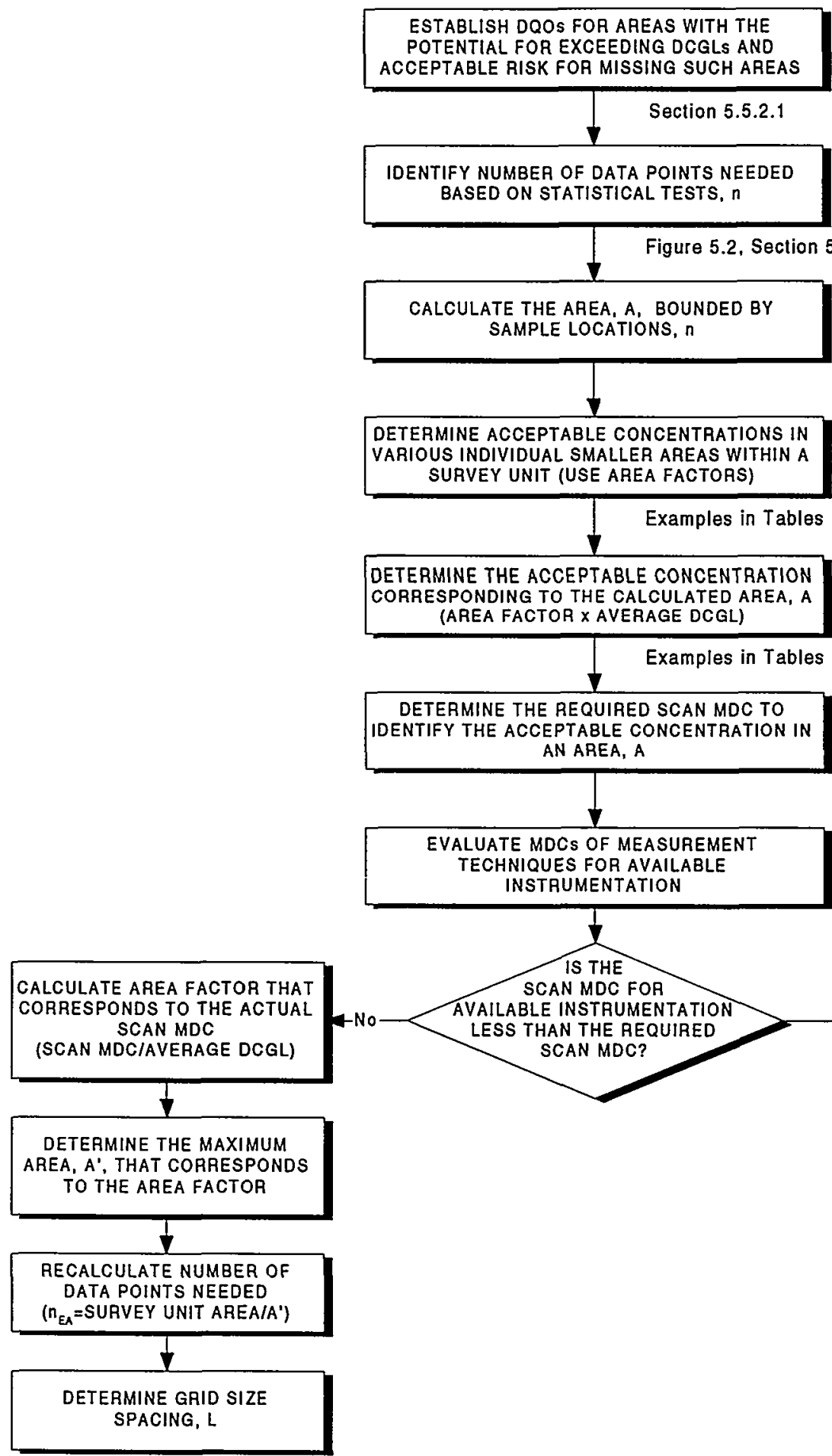

Figure 5.2, Section 5.5.2.2, Section 5.5.2.3

CALCULATE THE AREA, A, BOUNDED BY SAMPLE LOCATIONS, $n$

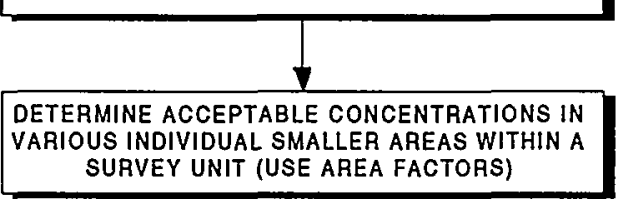

Examples in Tables 5.6 and 5.7 DETERMINE THE ACCEPTABLE CONCENTRATION
CORRESPONDING TO THE CALCULATED AREA, A (AREA FACTOR $\times$ AVERAGE DCGL)

Examples in Tables 5.6 and 5.7

DETERMINE THE REQUIRED SCAN MDC TO IDENTIFY THE ACCEPTABLE CONCENTRATION IN AN AREA, A

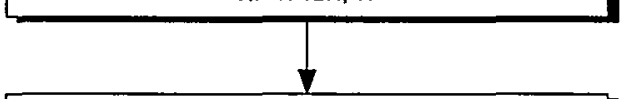

EVALUATE MDCS OF MEASUREMENT TECHNIQUES FOR AVAILABLE INSTRUMENTATION

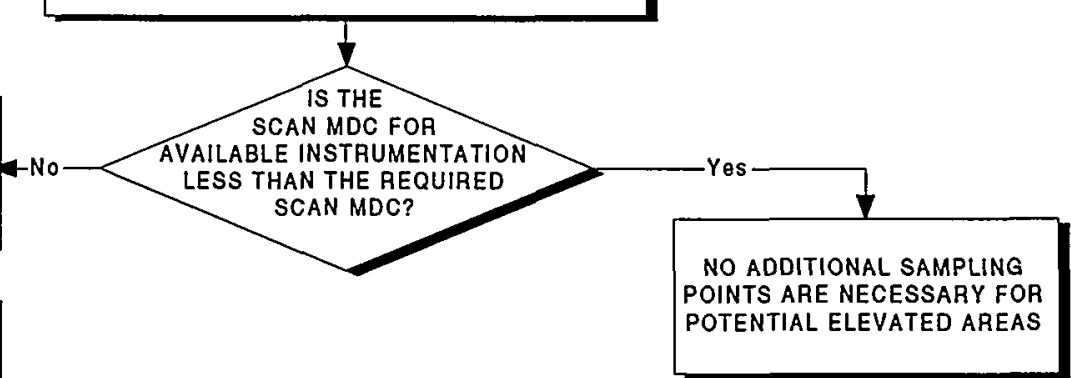

DETERMINE THE MAXIMUM DEA, A', THAT CORRESPOND

\section{$\frac{1}{1}$}

ECALCULATE NUMBER OF

DATA POINTS NEEDED

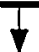

ERMINE GRID SIZ

PACING, $L$

Figure 5.3 Flow Diagram for Identifying Data Needs for Assessment of Potential Areas of Elevated Activity in Class 1 Survey Units (Refer to Section 5.5.2.4) 


\subsubsection{Application of Decommissioning Criteria}

The DQO Process, as it is applied to decommissioning surveys, is described in more detail in Appendix D of this manual and in EPA and NRC guidance documents (EPA 1994, 1987b, 1987c; NRC 1997a). As part of this process, the objective of the survey and the null and alternative hypotheses should be clearly stated. The objective of final status surveys is typically to demonstrate that residual radioactivity levels meet the release criterion. In demonstrating that this objective is met, the null hypothesis $\left(\mathrm{H}_{0}\right)$ tested is that residual contamination exceeds the release criterion; the alternative hypothesis $\left(\mathrm{H}_{2}\right)$ is that residual contamination meets the release criterion.

Two statistical tests are used to evaluate data from final status surveys. For contaminants that are present in background, the Wilcoxon Rank Sum (WRS) test is used. When contaminants are not present in background, the Sign test is used. To determine data needs for these tests, the acceptable probability of making Type I decision errors $(\alpha)$ and Type II decision errors $(\beta)$ should be established (see Appendix D, Section D.6). The acceptable decision error rates are a function of the amount of residual radioactivity and are determined during survey planning using the DQO Process.

The final step of the DQO process includes selecting the optimal design that satisfies the DQOs. For some sites or survey units, the guidance provided in this section may result in a survey design that cannot be accomplished with the available resources. For these situations, the planning team will need to relax one or more of the constraints used to develop the survey design as described in Appendix D. Examples of survey design constraints discussed in this section include:

- increasing the decision error rates, not forgetting to consider the risks associated with making an incorrect decision

- increasing the width of the gray region by decreasing the lower bound of the gray region - changing the boundaries-it may be possible to reduce measurement costs by changing or eliminating survey units that may require different decisions

\subsubsection{Contaminant Present in Background-Determining Numbers of Data Points for Statistical Tests}

The comparison of measurements from the reference area and survey unit is made using the WRS test, which should be conducted for each survey unit. In addition, the elevated measurement comparison (EMC) is performed against each measurement to ensure that the measurement result does not exceed a specified investigation level. If any measurement in the remediated survey unit exceeds the specified investigation level, then additional investigation is recommended, at least locally, regardless of the outcome of the WRS test. 
The WRS test is most effective when residual radioactivity is uniformly present throughout a survey unit. The test is designed to detect whether or not this activity exceeds the DCGL $\mathrm{w}_{\mathrm{W}}$. The advantage of this nonparametric test is that it does not assume the data are normally or log-normally distributed. The WRS test also allows for "less than" measurements to be present in the reference area and the survey units. As a general rule, this test can be used with up to $40 \%$ "less than" measurements in either the reference area or the survey unit. However, the use of "less than" values in data reporting is not recommended. Wherever possible, the actual result of a measurement, together with its uncertainty, should be reported.

This section introduces several terms and statistical parameters that will be used to determine the number of data points needed to apply the nonparametric tests. An example is provided to better illustrate the application of these statistical concepts.

Calculate the Relative Shift. The lower bound of the gray region (LBGR) is selected during the DQO Process along with the target values for $\alpha$ and $\beta$. The width of the gray region, equal to (DCGL - LBGR), is a parameter that is central to the WRS test. This parameter is also referred to as the shift, $\Delta$. The absolute size of the shift is actually of less importance than the relative shift, $\Delta / \sigma$, where $\sigma$ is an estimate of the standard deviation of the measured values in the survey unit. This estimate of $\sigma$ includes both the real spatial variability in the quantity being measured and the precision of the chosen measurement system. The relative shift, $\Delta / \sigma$, is an expression of the resolution of the measurements in units of measurement uncertainty.

The shift $\left(\Delta=\right.$ DCGL $_{\mathrm{W}}$ - LBGR) and the estimated standard deviation in the measurements of the contaminant $\left(\sigma_{\mathrm{r}}\right.$ and $\left.\sigma_{\mathrm{s}}\right)$ are used to calculate the relative shift, $\Delta / \sigma$ (see Appendix D, Section D.6). The standard deviations in the contaminant level will likely be available from previous survey data (e.g., scoping or characterization survey data for unremediated survey units or remedial action support surveys for remediated survey units). If they are not available, it may be necessary to 1 ) perform some limited preliminary measurements (about 5 to 20) to estimate the distributions, or 2) to make a reasonable estimate based on available site knowledge. If the first approach above is used, it is important to note that the scoping or characterization survey data or preliminary measurements used to estimate the standard deviation should use the same technique as that to be used during the final status survey. When preliminary data are not obtained, it may be reasonable to assume a coefficient of variation on the order of $30 \%$, based on experience.

The value selected as an estimate of $\sigma$ for a survey unit may be based on data collected only from within that survey unit or from data collected from a much larger area of the site. Note that survey units are not finalized until the planning stage of the final status survey. This means that there may be some difficulty in determining which individual measurements from a preliminary survey may later represent a particular survey unit. For many sites, the most practical solution is to estimate $\sigma$ for each area classification (i.e., Class 1, Class 2, and Class 3 ) for both interior and exterior survey units. This will result in all exterior Class 3 survey units using the same estimate 
of $\sigma$, all exterior Class 2 survey units using a second estimate for $\sigma$, and all exterior Class 1 survey units using a third estimate for $\sigma$. If there are multiple types of surfaces within an area classification, additional estimates of $\sigma$ may be required. For example, a Class 2 concrete floor may require a different estimate of $\sigma$ than a Class 2 cinder block wall, or a Class 3 unpaved parking area may require a different estimate of $\sigma$ than a Class 3 lawn. In addition, MARSSIM recommends that a separate estimate of $\sigma$ be obtained for every reference area.

The importance of choosing appropriate values for $\sigma_{\mathrm{r}}$ and $\sigma_{\mathrm{s}}$ must be emphasized. If the value is grossly underestimated, the number of data points will be too few to obtain the desired power level for the test and a resurvey may be recommended (refer to Chapter 8). If, on the other hand, the value is overestimated, the number of data points determined will be unnecessarily large.

Values for the relative shift that are less than one will result in a large number of measurements needed to demonstrate compliance. The number of data points will also increase as $\Delta$ becomes smaller. Since the DCGL is fixed, this means that the lower bound of the gray region also has a significant effect on the estimated number of measurements needed to demonstrate compliance. When the estimated standard deviations in the reference area and survey units are different, the larger value should be used to calculate the relative shift $(\Delta / \sigma)$.

Determine $P_{r}$ The probability that a random measurement from the survey unit exceeds a random measurement from the background reference area by less than the $\mathrm{DCGL}_{\mathrm{w}}$ when the survey unit median is equal to the LBGR above background is defined as $P_{r} P_{r}$ is used in Equation 5-1 for determining the number of measurements to be performed during the survey. Table 5.1 lists relative shift values and values for $P_{r}$ Using the relative shift calculated in the preceding section, the value of $\mathrm{P}_{\mathrm{r}}$ can be obtained from Table 5.1. Information on calculating individual values of $P_{r}$ is available in NUREG-1505 (NRC 1997a).

If the actual value of the relative shift is not listed in Table 5.1, always select the next lower value that appears in the table. For example, $\Delta / \sigma=1.67$ does not appear in Table 5.1. The next lower value is 1.6 , so the value of $\mathrm{P}_{\mathrm{r}}$ would be 0.871014 .

Determine Decision Error Percentiles. The next step in this process is to determine the percentiles, $Z_{1-\alpha}$ and $Z_{1-\beta}$, represented by the selected decision error levels, $\alpha$ and $\beta$, respectively (see Table 5.2). $Z_{1-\alpha}$ and $Z_{1-\beta}$ are standard statistical values (Harnett 1975). 
Survey Planning and Design

Table 5.1 Values of $P_{r}$ for Given Values of the Relative Shift, $\Delta / \sigma$, when the Contaminant is Present in Background

\begin{tabular}{|c|c||c|c|}
\hline$\Delta / \sigma$ & $\mathrm{P}_{\mathrm{r}}$ & $\Delta / \mathrm{\sigma}$ & $\mathrm{P}_{\mathrm{r}}$ \\
\hline 0.1 & 0.528182 & 1.4 & 0.838864 \\
\hline 0.2 & 0.556223 & 1.5 & 0.855541 \\
\hline 0.3 & 0.583985 & 1.6 & 0.871014 \\
\hline 0.4 & 0.611335 & 1.7 & 0.885299 \\
\hline 0.5 & 0.638143 & 1.8 & 0.898420 \\
\hline 0.6 & 0.664290 & 1.9 & 0.910413 \\
\hline 0.7 & 0.689665 & 2.0 & 0.921319 \\
\hline 0.8 & 0.714167 & 2.25 & 0.944167 \\
\hline 0.9 & 0.737710 & 2.5 & 0.961428 \\
\hline 1.0 & 0.760217 & 2.75 & 0.974067 \\
\hline 1.1 & 0.781627 & 3.0 & 0.983039 \\
\hline 1.2 & 0.801892 & 3.5 & 0.993329 \\
\hline 1.3 & 0.820978 & 4.0 & 0.997658 \\
\hline
\end{tabular}

If $\Delta / \sigma>4.0$, use $\mathrm{P}_{\mathrm{r}}=1.000000$

Table 5.2 Percentiles Represented by Selected Values of $\alpha$ and $\beta$

\begin{tabular}{|c|c|c|c|}
\hline$\alpha($ or $B)$ & $Z_{\text {La }}\left(\right.$ or $\left.Z_{1-8}\right)$ & $\alpha$ (or $\beta)$ & $Z_{1}\left(\right.$ or $\left.Z_{1-\beta}\right)$ \\
\hline 0.005 & 2.576 & 0.10 & 1.282 \\
\hline 0.01 & 2.326 & 0.15 & 1.036 \\
\hline 0.015 & 2.241 & 0.20 & 0.842 \\
\hline 0.025 & 1.960 & 0.25 & 0.674 \\
\hline 0.05 & 1.645 & 0.30 & 0.524 \\
\hline
\end{tabular}

Calculate Number of Data Points for WRS Test. The number of data points, $N$, to be obtained from each reference area/survey unit pair for the WRS test is next calculated using

$$
N=\frac{\left(Z_{1-\alpha}+Z_{1-\beta}\right)^{2}}{3\left(P_{r}-0.5\right)^{2}}
$$


The value of $N$ calculated using equation 5-1 is an approximation based on estimates of $\sigma$ and $P_{r}$, so there is some uncertainty associated with this calculation. In addition, there will be some missing or unusable data from any survey. The rate of missing or unusable measurements, $R$, expected to occur in survey units or reference areas and the uncertainty associated with the calculation of $\mathrm{N}$ should be accounted for during survey planning. The number of data points should be increased by $20 \%$, and rounded up, over the values calculated using equation 5-1 to obtain sufficient data points to attain the desired power level with the statistical tests and allow for possible lost or unusable data. The value of $20 \%$ is selected to account for a reasonable amount of uncertainty in the parameters used to calculate $\mathrm{N}$ and still allow flexibility to account for some lost or unusable data. The recommended $20 \%$ correction factor should be applied as a minimum value. Experience and site-specific considerations should be used to increase the correction factor if required. If the user determines that the $20 \%$ increase in the number of measurements is excessive for a specific site, a retrospective power curve should be used to demonstrate that the survey design provides adequate power to support the decision (see Appendix 1).

$\mathrm{N}$ is the total number of data points for each survey unit/reference area combination. The $\mathrm{N}$ data points are divided between the survey unit, $\mathrm{n}$, and the reference area, $\mathrm{m}$. The simplest method for distributing the $\mathrm{N}$ data points is to assign half the data points to the survey unit and half to the reference area, so $\mathrm{n}=\mathrm{m}=\mathrm{N} / 2$. This means that $\mathrm{N} / 2$ measurements are performed in each survey unit, and $\mathrm{N} / 2$ measurements are performed in each reference area. If more than one survey unit is associated with a particular reference area, N/2 measurements should be performed in each survey unit and N/2 measurements should be performed in the reference area.

Obtain Number of Data Points for WRS Test from Table 5.3. Table 5.3 provides a list of the number of data points used to demonstrate compliance using the WRS test for selected values of $\alpha, \beta$, and $\Delta / \sigma$. The values listed in Table 5.3 represent the number of measurements to be performed in each survey unit as well as in the corresponding reference area. The values were calculated using Equation 5-1 and increased by $20 \%$ for the reasons discussed in the previous section.

\section{Example:}

A site has 14 survey units and 1 reference area, and the same type of instrument and method is used to perform measurements in each area. The contaminant has a DCGL $_{\mathrm{w}}$ which when converted to cpm equals $160 \mathrm{cpm}$. The contaminant is present in background at a level of $45 \pm 7(1 \sigma) \mathrm{cpm}$. The standard deviation of the contaminant in the survey area is $\pm 20 \mathrm{cpm}$, based on previous survey results for 


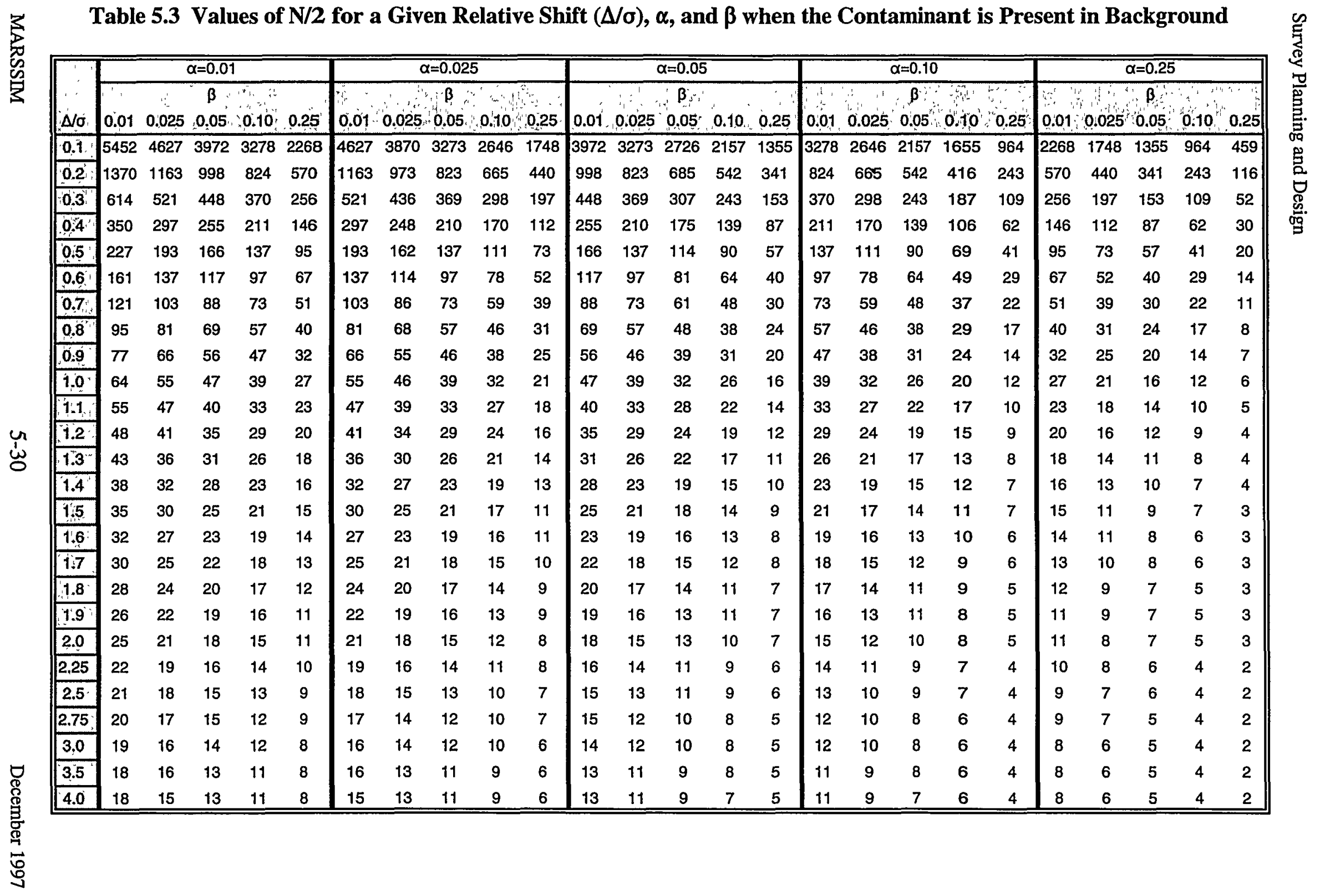


the same or similar contaminant distribution. When the estimated standard deviation in the reference area and the survey units are different, the larger value, $20 \mathrm{cpm}$ in this example, should be used to calculate the relative shift. During the DQO process the LBGR is selected to be one-half the $D_{C G L}(80 \mathrm{cpm})$ as an arbitrary starting point for developing an acceptable survey design, ${ }^{1}$ and Type I and Type $I$ error values ( $\alpha$ and $\beta$ ) of 0.05 have been selected. Determine the number of data points to be obtained from the reference area and from each of the survey units for the statistical tests.

The value of the relative shift for the reference area, $\Delta / \sigma$, is $(160-80) / 20$ or 4 . From Table 5.1, the value of $\mathrm{P}_{\mathrm{r}}$ is 0.997658 . Values of percentiles, represented by the selected decision error levels, are obtained from Table 5.2. In this case $\mathrm{Z}_{1-\alpha}$ (for $\alpha=0.05$ ) is 1.645 and $Z_{1-\beta}(\beta=0.05)$ is also 1.645 .

The number of data points, $\mathrm{N}$, for the WRS test of each combination of reference area and survey units can be calculated using Equation 5-1

$$
N=\frac{(1.645+1.645)^{2}}{3(0.997658-0.5)^{2}}=14.6
$$

Adding an additional $20 \%$ gives 17.5 which is then rounded up to the next even number, 18. This yields 9 data points for the reference area and 9 for each survey unit.

Alternatively, the number of data points can be obtained directly from Table 5.3. For $\alpha=0.05, \beta=0.05$, and $\Delta / \sigma=4.0$ a value of 9 is obtained for $N / 2$. The table value has already been increased by $20 \%$ to account for missing or unusable data.

\subsubsection{Contaminant Not Present in Background—Determining Numbers of Data Points for Statistical Tests}

For the situation where the contaminant is not present in background or is present at such a small fraction of the $\mathrm{DCGL}_{\mathrm{W}}$ as to be considered insignificant, a background reference area is not necessary. Instead, the contaminant levels are compared directly with the DCGL value. The general approach closely parallels that used for the situation when the contaminant is present in background as described in Section 5.5.2.2. However, the statistical tests differ slightly. The one-sample Sign test replaces the two-sample Wilcoxon Rank Sum test described above.

\footnotetext{
1 Appendix D provides more detailed guidance on the selection of the LBGR.
} 
Calculate the Relative Shift. The initial step in determining the number of data points in the one-sample case is to calculate the relative shift, $\Delta / \sigma_{s}=(\mathrm{DCGL}-\mathrm{LBGR}) / \sigma_{s}$, from the DCGL value, the lower bound of the gray region (LBGR), and the standard deviation of the contaminant in the survey unit, $\sigma_{s}$, as described in Section 5.5.2.2. Also as described in Section 5.5.2.2, the value of $\sigma_{s}$ may be obtained from earlier surveys, limited preliminary measurements, or a reasonable estimate. Values of the relative shift that are less than one will result in a large number of measurements needed to demonstrate compliance.

Determine Sign p. Sign $\mathrm{p}$ is the estimated probability that a random measurement from the survey unit will be less than the $\mathrm{DCGL}_{\mathrm{W}}$ when the survey unit median is actually at the LBGR. The Sign $\mathrm{p}$ is used to calculate the minimum number of data points necessary for the survey to meet the DQOs. The value of the relative shift calculated in the previous section is used to obtain the corresponding value of Sign $\mathrm{p}$ from Table 5.4.

Table 5.4 Values of Sign $p$ for Given Values of the Relative Shift, $\Delta / \sigma$, when the Contaminant is Not Present in Background

\begin{tabular}{||c|c|c|c|}
\hline & $\Delta / \sigma$ & $\Delta / \sigma$ & Sign $p$ \\
\hline 0.1 & 0.539828 & 1.2 & 0.884930 \\
\hline 0.2 & 0.579260 & 1.3 & 0.903199 \\
\hline 0.3 & 0.617911 & 1.4 & 0.919243 \\
\hline 0.4 & 0.655422 & 1.5 & 0.933193 \\
\hline 0.5 & 0.691462 & 1.6 & 0.945201 \\
\hline 0.6 & 0.725747 & 1.7 & 0.955435 \\
\hline 0.7 & 0.758036 & 1.8 & 0.964070 \\
\hline 0.8 & 0.788145 & 1.9 & 0.971284 \\
\hline 0.9 & 0.815940 & 2.0 & 0.977250 \\
\hline 1.0 & 0.841345 & 2.5 & 0.993790 \\
\hline 1.1 & 0.864334 & 3.0 & 0.998650 \\
\hline
\end{tabular}

If $\Delta / \sigma>3.0$, use Sign $p=1.000000$

Determine Decision Error Percentiles. The next step in this process is to determine the percentiles, $Z_{1-\alpha}$ and $Z_{1-\beta}$, represented by the selected decision error levels, $\alpha$ and $B$, respectively (see Table 5.2). 
Calculate Number of Data Points for Sign Test. The number of data points, N, to be obtained for the Sign test is next calculated using the following formula:

$$
N=\frac{\left(Z_{1-\alpha}+Z_{1-\beta}\right)^{2}}{4(\operatorname{Sign} P-0.5)^{2}}
$$

Finally, the number of anticipated data points should be increased by at least $20 \%$ as discussed in Section 5.5.2.2 to ensure sufficient power of the tests and to allow for possible data losses.

Obtain Number of Data Points for Sign Test from Table 5.5. Table 5.5 provides a list of the number of data points used to demonstrate compliance using the Sign test for selected values of $\alpha, \beta$, and $\Delta / \sigma$. The values listed in Table 5.5 represent the number of measurements to be performed in each survey unit. These values were calculated using Equation 5-2 and increased by $20 \%$ to account for missing or unusable data and uncertainty in the calculated value of $\mathrm{N}$.

Example:

A site has 1 survey unit. The DCGL level for the contaminant of interest is 140 $\mathrm{Bq} / \mathrm{kg}(3.9 \mathrm{pCi} / \mathrm{g})$ in soil. The contaminant is not present in background; data from previous investigations indicate average residual contamination at the survey unit of $3.7 \pm 3.7(1 \sigma) \mathrm{Bq} / \mathrm{kg}$. The lower bound of the gray region was selected to be $110 \mathrm{~Bq} / \mathrm{kg}$. A value of 0.05 is next selected for the probability of Type I decision errors $(\alpha)$ and a value of 0.01 is selected for the probability of Type II decision errors $(\beta)$ based on the survey objectives. Determine the number of data points to be obtained from the survey unit for the statistical tests.

The value of the shift parameter, $\Delta / \sigma$, is (140-110)/3.7 or 8 . From Table 5.4, the value of Sign $p$ is 1.0. Since $\Delta / \sigma>3$, the width of the gray region can be reduced. If the LBGR is raised to 125 , then $\Delta / \sigma$ is $(140-125) / 3.7$ or 4 . The value of Sign $p$ remains at 1.0. Thus, the number of data points calculated will not change. The probability of a Type II error is now specified at $125 \mathrm{~Bq} / \mathrm{kg}(3.4 \mathrm{pCi} / \mathrm{g})$ rather than $110 \mathrm{~Bq} / \mathrm{kg}(3.0 \mathrm{pCi} / \mathrm{g})$. As a consequence, the probability of a Type II error at $110 \mathrm{~Bq} / \mathrm{kg}(3.0 \mathrm{pCi} / \mathrm{g})$ will be even smaller.

Values of percentiles, represented by the selected decision error levels are obtained from Table 5.2. $Z_{1-\alpha}$ (for $\alpha=0.05$ ) is 1.645 , and $Z_{1-\beta}(\beta=0.01)$ is 2.326 . 


\begin{tabular}{|c|c|c|c|c|c|c|c|c|c|c|c|c|c|c|c|c|c|c|c|c|c|c|c|c|c|}
\hline \multirow[b]{3}{*}{$\Delta / \sigma$} & \multicolumn{5}{|c|}{$\alpha=0.01$} & \multicolumn{5}{|c|}{$\alpha=0.025$} & \multicolumn{5}{|c|}{$\alpha=0.05$} & \multicolumn{5}{|c|}{$\alpha=0.10$} & \multicolumn{5}{|c|}{$\alpha=0.25$} \\
\hline & \multicolumn{5}{|c|}{$\beta$} & \multicolumn{5}{|c|}{$\beta$} & \multicolumn{5}{|c|}{$\beta$} & \multicolumn{5}{|c|}{$\beta$} & \multicolumn{5}{|c|}{$\beta$} \\
\hline & 0.01 & 0.025 & 0.05 & $0.10^{\prime}$ & 0.25 & 0.01 & 0.025 & 0.05 & 0.10 & 0.25 & 0.01 & 0.025 & 0.05 & 0.10 & 0.25 & 0.01 & 0.025 & 0.05 & 0.10 & 0.25 & 0.01 & 0.025 & 0.05 & 0.10 & 0.25 \\
\hline 0.1 & 4095 & 3476 & 2984 & 2463 & 1704 & 3476 & 2907 & 2459 & 1989 & 1313 & 2984 & 2459 & 2048 & 1620 & 1018 & 2463 & 1989 & 1620 & 1244 & 725 & 1704 & 1313 & 1018 & 725 & 345 \\
\hline 0.2 & 1035 & 879 & 754 & 623 & 431 & 879 & 735 & 622 & 503 & 333 & 754 & 622 & 518 & 410 & 258 & 623 & 503 & 410 & 315 & 184 & 431 & 333 & 258 & 184 & 88 \\
\hline 0.3 & 468 & 398 & 341 & 282 & 195 & 398 & 333 & 281 & 227 & 150 & 341 & 281 & 234 & 185 & 117 & 282 & 227 & 185 & 143 & 83 & 195 & 150 & 117 & 83 & 40 \\
\hline 0,4 & 270 & 230 & 197 & 162 & 113 & 230 & 1921 & 162 & 131 & 87 & 197 & 162 & 136 & 107 & 68 & 162 & 131 & 107 & 82 & 48 & 113 & 87 & 68 & 48 & 23 \\
\hline 0.5 & 178 & 152 & 130 & 107 & 75 & 152 & 126 & 107 & 87 & 58 & 130 & 107 & 89 & 71 & 45 & 107 & 87 & 71 & 54 & 33 & 75 & 58 & 45 & 33 & 16 \\
\hline 0.6 & 129 & 110 & 94 & 77 & 54 & 110 & 92 & 77 & 63 & 42 & 94 & 77 & 65 & 52 & 33 & 77 & 63 & 52 & 40 & 23 & 54 & 42 & 33 & 23 & 11 \\
\hline 0.7 & 99 & 83 & 72 & 59 & 41 & 83 & 70 & 59 & 48 & 33 & 72 & 59 & 50 & 40 & 26 & 59 & 48 & 40 & 30 & 18 & 41 & 33 & 26 & 18 & 9 \\
\hline 0.8 & 80 & 68 & 58 & 48 & 34 & 68 & 57 & 48 & 39 & 26 & 58 & 48 & 40 & 32 & 21 & 48 & 39 & 32 & 24 & 15 & 34 & 26 & 21 & 15 & 8 \\
\hline 0.9 & 66 & 57 & 48 & 40 & 28 & 57 & 47 & 40 & 33 & 22 & 48 & 40 & 34 & 27 & 17 & 40 & 33 & 27 & 21 & 12 & 28 & 22 & 17 & 12 & 6 \\
\hline 1.0 & 57 & 48 & 41 & 34 & 24 & 48 & 40 & 34 & 28 & 18 & 41 & 34 & 29 & 23 & 15 & 34 & 28 & 23 & 18 & 11 & 24 & 18 & 15 & 11 & 5 \\
\hline 1.1 & 50 & 42 & 36 & 30 & 21 & 42 & 35 & 30 & 24 & 17 & 36 & 30 & 26 & 21 & 14 & 30 & 24 & 21 & 16 & 10 & 21 & 17 & 14 & 10 & 5 \\
\hline 1.2 & 45 & 38 & 33 & 27 & 20 & 38 & 32 & 27 & 22 & 15 & 33 & 27 & 23 & 18 & 12 & 27 & 22 & 18 & 15 & 9 & 20 & 15 & 12 & 9 & 5 \\
\hline 1.3 & 41 & 35 & 30 & 26 & 17 & 35 & 29 & 24 & 21 & 14 & 30 & 24 & 21 & 17 & 11 & 26 & 21 & 17 & 14 & 8 & 17 & 14 & 11 & 8 & 4 \\
\hline 1.4 & 38 & 33 & 28 & 23 & 16 & 33 & 27 & 23 & 18 & 12 & 28 & 23 & 20 & 16 & 10 & 23 & 18 & 16 & 12 & 8 & 16 & 12 & 10 & 8 & 4 \\
\hline 1.5 & 35 & 30 & 27 & 22 & 15 & 30 & 26 & 22 & 17 & 12 & 27 & 22 & 18 & 15 & 10 & 22 & 17 & 15 & 11 & 8 & 15 & 12 & 10 & 8 & 4 \\
\hline 1.6 & 34 & 29 & 24 & 21 & 15 & 29 & 24 & 21 & 17 & 11 & 24 & 21 & 17 & 14 & 9 & 21 & 17 & 14 & 11 & 6 & 15 & 11 & 9 & 6 & 4 \\
\hline 1.7 & 33 & 28 & 24 & 20 & 14 & 28 & 23 & 20 & 16 & 11 & 24 & 20 & 17 & 14 & 9 & 20 & 16 & 14 & 10 & 6 & 14 & 11 & 9 & 6 & 4 \\
\hline 1.8 & 32 & 27 & 23 & 20 & 14 & 27 & 22 & 20 & 16 & 11 & 23 & 20 & 16 & 12 & 9 & 20 & 16 & 12 & 10 & 6 & 14 & 11 & 9 & 6 & 4 \\
\hline 1.9 & 30 & 26 & 22 & 18 & 14 & 26 & 22 & 18 & 15 & 10 & 22 & 18 & 16 & 12 & 9 & 18 & 15 & 12 & 10 & 6 & 14 & 10 & 9 & 6 & 4 \\
\hline 2.0 & 29 & 26 & 22 & 18 & 12 & 26 & 21 & 18 & 15 & 10 & 22 & 18 & 15 & 12 & 8 & 18 & 15 & 12 & 10 & 6 & 12 & 10 & 8 & 6 & 3 \\
\hline 2.5 & 28 & 23 & 21 & 17 & 12 & 23 & 20 & 17 & 14 & 10 & 21 & 17 & 15 & 11 & 8 & 17 & 14 & 11 & 9 & 5 & 12 & 10 & 8 & 5 & 3 \\
\hline 3.0 & 27 & 23 & 20 & 17 & 12 & 23 & 20 & 17 & 14 & 9 & 20 & 17 & 14 & 11 & 8 & 17 & 14 & 11 & 9 & 5 & 12 & 9 & 8 & 5 & 3 \\
\hline
\end{tabular}


The number of data points, $\mathrm{N}$, for the Sign test can be calculated using Equation 5-2.

$$
N=\frac{(1.645+2.326)^{2}}{4(1.0-0.5)^{2}}=15.85
$$

Adding an additional 20\% gives 19.2 and rounding up yields 20 data points for the survey unit.

Alternatively, the number of data points can be obtained directly from Table 5.5. For $\alpha=0.05, \beta=0.01$, and $\Delta / \sigma>3.0$ a value of 20 is obtained for $N$. The table value has already been increased by $20 \%$ to account for missing or unusable data and uncertainty in the calculated value of $\mathrm{N}$.

\subsubsection{Determining Data Points for Small Areas of Elevated Activity}

The statistical tests described above (also see Chapter 8) evaluate whether or not the residual radioactivity in an area exceeds the $\mathrm{DCGL}_{\mathrm{w}}$ for contamination conditions that are approximately uniform across the survey unit. In addition, there should be a reasonable level of assurance that any small areas of elevated residual radioactivity that could be significant relative to the $\mathrm{DCGL}_{\mathrm{EMC}}$ are not missed during the final status survey. The statistical tests introduced in the previous sections may not successfully detect small areas of elevated contamination. Instead, systematic measurements and sampling, in conjunction with surface scanning, are used to obtain adequate assurance that small areas of elevated radioactivity will still satisfy the release criterion

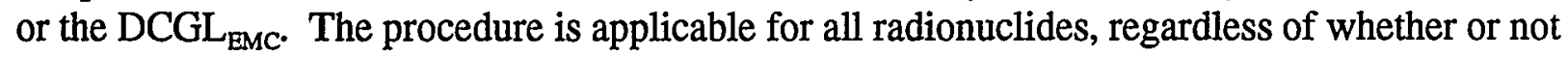
they are present in background, and is implemented for survey units classified as Class 1.

The number of survey data points needed for the statistical tests discussed in Section 5.5.2.2 or 5.5.2.3 is identified (the appropriate section depends on whether the contaminant is present in background or not). These data points are then positioned throughout the survey unit by first randomly selecting a start point and establishing a systematic pattern. This systematic sampling grid may be either triangular or square. The triangular grid is generally more efficient for locating small areas of elevated activity. Appendix D includes a brief discussion on the efficiency of triangular and square grids for locating areas of elevated activity. A more detailed discussion is provided by EPA (EPA 1994b). 
The number of calculated survey locations, $\mathrm{n}$, is used to determine the grid spacing, $\mathrm{L}$, of the systematic sampling pattern (see Section 5.5.2.5). The grid area that is bounded by these survey locations is given by $\mathrm{A}=0.866 \times \mathrm{L}^{2}$ for a triangular grid and $\mathrm{A}=\mathrm{L}^{2}$ for a square grid. The risk of not sampling a circular area-equal to A - of elevated activity by use of a random-start grid pattern is illustrated in Figure D.7 in Appendix D.

One method for determining values for the $\mathrm{DCGL}_{\mathrm{EMC}}$ is to modify the $\mathrm{DCGL}_{\mathrm{w}}$ using a correction factor that accounts for the difference in area and the resulting change in dose or risk. The area factor is the magnitude by which the concentration within the small area of elevated activity can exceed $\mathrm{DCGL}_{\mathrm{w}}$ while maintaining compliance with the release criterion. The area factor is determined based on specific regulatory agency guidance.

Tables 5.6 and 5.7 provide examples of area factors generated using exposure pathway models. The outdoor area factors listed in Table 5.6 were calculated using RESRAD 5.6. For each radionuclide, all exposure pathways were calculated assuming a concentration of $37 \mathrm{~Bq} / \mathrm{kg}$ $(1 \mathrm{pCi} / \mathrm{g})$. The area of contamination in RESRAD 5.6 defaults to $10,000 \mathrm{~m}^{2}$. Other than changing the area (i.e., 1, 3, 10,30,100,300,1,000, or 3,000 $\mathrm{m}^{2}$ ), the RESRAD default values were not changed. The area factors were then computed by taking the ratio of the dose or risk per unit concentration generated by RESRAD for the default $10,000 \mathrm{~m}^{2}$ to that generated for the other areas listed. If the DCGL for residual radioactivity distributed over $10,000 \mathrm{~m}^{2}$ is multiplied by this value, the resulting concentration distributed over the specified smaller area delivers the same calculated dose. The indoor area factors listed in Table 5.7 were calculated in a similar manner using RESRAD-BUILD 1.5. For each radionuclide, all exposure pathways were calculated assuming a concentration of $37 \mathrm{~Bq} / \mathrm{m}^{2}\left(1 \mathrm{pCi} / \mathrm{m}^{2}\right)$. The area of contamination in RESRAD-BUILD 1.5 defaults to $36 \mathrm{~m}^{2}$. The other areas compared to this value were $1,4,9,16$, or $25 \mathrm{~m}^{2}$. Removable surface contamination was assumed to be $10 \%$. No other changes to the default values were made. Note that the use of RESRAD to determine area factors is for illustration purposes only. The MARSSIM user should consult with the responsible regulatory agency for guidance on acceptable techniques to determine area factors.

The minimum detectable concentration (MDC) of the scan procedure-needed to detect an area of elevated activity at the limit determined by the area factor-is calculated as follows:

$$
\text { Scan } M D C \text { (required })=\left(D C G L_{W}\right) \times(\text { Area Factor })
$$

The actual MDCs of scanning techniques are then determined for the available instrumentation (see Section 6.7). The actual MDC of the selected scanning technique is compared to the required scan MDC. If the actual scan MDC is less than the required scan MDC, no additional sampling points are necessary for assessment of small areas of elevated activity. In other words, the scanning technique exhibits adequate sensitivity to detect small areas of elevated activity. 
Table 5.6 Illustrative Examples of Outdoor Area Dose Factors*

\begin{tabular}{|c|c|c|c|c|c|c|c|c|c|}
\hline \multirow{2}{*}{ Nuclide } & \multicolumn{9}{|c|}{ Area Factor } \\
\hline & $1 \mathbf{m}^{2}$ & $3 \mathrm{~m}^{2}$ & $10 \mathrm{~m}^{2}$ & $30 \mathrm{~m}^{2}$ & $100 \mathrm{~m}^{2}$ & $300 \mathrm{~m}^{2}$ & $1000 \mathrm{~m}^{2}$ & $3000 \mathrm{~m}^{2}$ & $10000 \mathrm{~m}^{2}$ \\
\hline Am-241 & 208.7 & 139.7 & 96.3 & 44.2 & 13.4 & 4.4 & 1.3 & 1.0 & 1.0 \\
\hline $\mathrm{Co}-60$ & 9.8 & 4.4 & 2.1 & 1.5 & 1.2 & 1.1 & 1.1 & 1.0 & 1.0 \\
\hline Cs-137 & 11.0 & 5.0 & 2.4 & 1.7 & 1.4 & 1.3 & 1.1 & 1.1 & 1.0 \\
\hline $\mathrm{Ni}-63$ & 1175.2 & 463.7 & 154.8 & 54.2 & 16.6 & 5.6 & 1.7 & 1.5 & 1.0 \\
\hline $\mathrm{Ra}-226$ & 54.8 & 21.3 & 7.8 & 3.2 & 1.1 & 1.1 & 1.0 & 1.0 & 1.0 \\
\hline Th-232 & 12.5 & 6.2 & 3.2 & 2.3 & 1.8 & 1.5 & 1.1 & 1.0 & 1.0 \\
\hline U-238 & 30.6 & 18.3 & 11.1 & 8.4 & 6.7 & 4.4 & 1.3 & 1.0 & 1.0 \\
\hline
\end{tabular}

* The values listed in Table 5.6 are for illustrative purposes only. Consult regulatory guidance to determine area factors to be used for compliance demonstration.

Table 5.7 Illustrative Examples of Indoor Area Dose Factors*

\begin{tabular}{|c|c|c|c|c|c|c|}
\hline \multirow{2}{*}{ Nuclide } & \multicolumn{6}{|c|}{ Area Factor } \\
\hline & $1 \mathrm{~m}^{2}$ & $4 \mathrm{~m}^{2}$ & $9 \mathrm{~m}^{2}$ & $16 \mathrm{~m}^{2}$ & $25 \mathrm{~m}^{2}$ & $36 \mathrm{~m}^{2}$ \\
\hline $\mathrm{Am}-241$ & 36.0 & 9.0 & 4.0 & 2.2 & 1.4 & 1.0 \\
\hline Co-60 & 9.2 & 3.1 & 1.9 & 1.4 & 1.2 & 1.0 \\
\hline Cs-137 & 9.4 & 3.2 & 1.9 & 1.4 & 1.2 & 1.0 \\
\hline Ni-63 & 36.0 & 9.0 & 4.0 & 2.3 & 1.4 & 1.0 \\
\hline $\mathrm{Ra}-226$ & 18.1 & 5.5 & 2.9 & 1.9 & 1.3 & 1.0 \\
\hline Th-232 & 36.0 & 9.0 & 4.0 & 2.2 & 1.4 & 1.0 \\
\hline U-238 & 35.7 & 9.0 & 4.0 & 2.2 & 1.4 & 1.0 \\
\hline
\end{tabular}

* The values listed in Table 5.7 are for illustrative purposes only. Consult regulatory guidance to determine area factors to be used for compliance demonstration.

If the actual scan MDC is greater than the required scan MDC (i.e., the available scan sensitivity is not sufficient to detect small areas of elevated activity), then it is necessary to calculate the area factor that corresponds to the actual scan MDC: 
Survey Planning and Design

$$
\text { Area Factor }=\frac{\text { scan } M D C(\text { actual })}{D C G L}
$$

The size of the area of elevated activity (in $\mathrm{m}^{2}$ ) that corresponds to this area factor is then obtained from specific regulatory agency guidance, and may be similar to those illustrated in Table 5.6 or Table 5.7. The data needs for assessing small areas of elevated activity can then be determined by dividing the area of elevated activity acceptable to the regulatory agency into the survey unit area. For example, if the area of elevated activity is $100 \mathrm{~m}^{2}$ (from Table 5.6) and the survey unit area is $2,000 \mathrm{~m}^{2}$, then the calculated number of survey locations is 20 . The calculated number of survey locations, $\mathrm{n}_{\mathrm{EA}}$, is used to determine a revised spacing, $\mathrm{L}$, of the systematic pattern (refer to Section 5.5.2.5). Specifically, the spacing, L, of the pattern (when driven by the areas of elevated activity) is given by:

$$
\begin{gathered}
L=\sqrt{\frac{A}{0.866 n_{E A}}} \text { for a triangular grid } \\
L=\sqrt{\frac{A}{n_{E A}}} \text { for a square grid }
\end{gathered}
$$

where $\mathrm{A}$ is the area of the survey unit. Grid spacings should generally be rounded down to the nearest distance that can be conveniently measured in the field.

If the number of data points required to identify areas of elevated activity $\left(\mathrm{n}_{\mathrm{EA}}\right)$ is greater than the number of data points calculated using Equation 5-1 (N/2) or Equation 5-2 (N), L should be calculated using Equation 5-5 or Equation 5-6. This value of $\mathrm{L}$ is then used to determine the measurement locations as described in Section 5.5.2.5. If $\mathrm{n}_{\mathrm{EA}}$ is smaller than $\mathrm{N} / 2$ or N, $\mathrm{L}$ is calculated using Equation 5-7 or Equation 5-8 as described in Section 5.5.2.5. The statistical tests are performed using this larger number of data points. Figure 5.3 provides a concise overview of the procedure used to identify data needs for the assessment of small areas of elevated activity. If residual radioactivity is found in an isolated area of elevated activity-in addition to residual radioactivity distributed relatively uniformly across the survey unit-the unity rule (described in Section 4.3.3) can be used to ensure that the total dose or risk does not exceed the release criterion (see Section 8.5.2). If there is more than one elevated area, a separate term should be included for each. As an alternative to the unity rule, the dose or risk due to the actual residual radioactivity distribution can be calculated if there is an appropriate exposure pathway model available. Note that these considerations generally apply only to Class 1 survey units, since areas of elevated activity should not exist in Class 2 or Class 3 survey units. 
When the detection limit of the scanning technique is very large relative to the $\mathrm{DCGL}_{\mathrm{EMC}}$, the number of measurements estimated to demonstrate compliance using the statistical tests may become unreasonably large. In this situation perform an evaluation of the survey objectives and considerations. These considerations may include the survey design and measurement methodology, exposure pathway modeling assumptions and parameter values used to determine the DCGLs, Historical Site Assessment conclusions concerning source terms and radionuclide distributions, and the results of scoping and characterization surveys. In most cases the result of this evaluation is not expected to justify an unreasonably large number of measurements.

Example 1:

A Class 1 land area survey unit of $1,500 \mathrm{~m}^{2}$ is potentially contaminated with ${ }^{60} \mathrm{Co}$. The DCGL $\mathrm{w}_{\mathrm{w}}$ value for ${ }^{60} \mathrm{Co}$ is $110 \mathrm{~Bq} / \mathrm{kg}(3 \mathrm{pCi} / \mathrm{g})$ and the scan sensitivity for this radionuclide has been determined to be $150 \mathrm{~Bq} / \mathrm{kg}$ ( $4 \mathrm{pCi} / \mathrm{g})$. Calculations indicate the number of data points needed for statistical testing is 27 . The distance between measurement locations for this number of data points and the given land area is $8 \mathrm{~m}$. The area encompassed by a triangular sampling pattern of $8 \mathrm{~m}$ is approximately $55.4 \mathrm{~m}^{2}$. From Table 5.6 an area factor of about 1.4 is determined by interpolation. The acceptable concentration in a $55.4 \mathrm{~m}^{2}$ area is therefore $160 \mathrm{~Bq} / \mathrm{kg}(1.4 \times 110 \mathrm{~Bq} / \mathrm{kg})$. Since the scan sensitivity of the procedure to be used is less than the DCGL $\mathrm{w}_{\mathrm{w}}$ times the area factor, no additional data points are needed to demonstrate compliance with the elevated measurement comparison criteria.

Example 2:

A Class 1 land area survey unit of $1500 \mathrm{~m}^{2}$ is potentially contaminated with ${ }^{60} \mathrm{Co}$. The DCGL for ${ }^{60} \mathrm{Co}$ is $110 \mathrm{~Bq} / \mathrm{kg}(3 \mathrm{pCi} / \mathrm{g})$. In contrast to Example 1 , the scan sensitivity for this radionuclide has been determined to be $170 \mathrm{~Bq} / \mathrm{kg}(4.6 \mathrm{pCi} / \mathrm{g}$ ). Calculations indicate the number of data points needed for statistical testing is 15 . The distance between measurement locations for this number of data points and land area is $10 \mathrm{~m}$. The area encompassed by a triangular sampling pattern of $10 \mathrm{~m}$ is approximately $86.6 \mathrm{~m}^{2}$. From Table 5.6 an area factor of about 1.3 is determined by interpolation. The acceptable concentration in a $86.6 \mathrm{~m}^{2}$ area is therefore $140 \mathrm{~Bq} / \mathrm{kg}(1.3 \times 110 \mathrm{~Bq} / \mathrm{kg})$. Since the scan sensitivity of the procedure to be used is greater than the $\mathrm{DCGL}_{\mathrm{W}}$ times the area factor, the data points obtained for the statistical testing may not be sufficient to demonstrate compliance using the elevated measurement comparison. The area multiplier for elevated activity that would have to be achieved is $1.5(170 / 110 \mathrm{~Bq} / \mathrm{kg})$. This is equivalent to an area of $30 \mathrm{~m}^{2}$ (Table 5.6) which would be obtained with a spacing of about $6 \mathrm{~m}$. A triangular pattern of $6 \mathrm{~m}$ spacing includes 50 data points, so 50 measurements should be performed in the survey unit. 


\subsubsection{Determining Survey Locations}

A scale drawing of the survey unit is prepared, along with the overlying planar reference coordinate system or grid system. Any location within the survey area is thus identifiable by a unique set of coordinates. The maximum length, $X$, and width, $Y$, dimensions of the survey unit are then determined. Identifying and documenting a specific location for each measurement performed is an important part of a final status survey to ensure that measurements can be reproduced if necessary. The reference coordinate system described in Section 4.8 .5 provides a method for relating measurements to a specific location within a survey unit.

If the same values for $\alpha, \beta$, and $\Delta / \sigma$ are used in Equations 5-1 or Equation 5-2, the required number of measurements is independent of survey unit classification. This means that the same number of measurements could be performed in a Class 1, Class 2, or Class 3 survey unit. While this is a best case scenario, it points out the importance of identifying appropriate survey units (e.g., size, classification) in defining the level of survey effort. The spacing of measurements is affected by the number of measurements, which is independent of classification. However, the spacing of measurements is also affected by survey unit area, the variability in the contaminant concentration, and the interface with the models used to develop the DCGLs which are dependent on classification.

Land Areas. Measurements and samples in Class 3 survey units and reference areas should be taken at random locations. These locations are determined by generating sets of random numbers ( 2 values, representing the $\mathrm{X}$ axis and $\mathrm{Y}$ axis distances). Random numbers can be generated by calculator or computer, or can be obtained from mathematical tables. Sufficient sets of numbers will be needed to identify the total number of survey locations established for the survey unit. Each set of random numbers is multiplied by the appropriate survey unit dimension to provide coordinates, relative to the origin of the survey unit reference grid pattern. Coordinates identified in this manner, which do not fall within the survey until area or which cannot be surveyed, due to site conditions, are replaced with other survey points determined in the same manner. Figure 5.4 is an example of a random sampling pattern. In this example, 8 data points were identified using the appropriate formula based on the statistical tests (i.e., Equation 5-1 or Equation 5-2). The locations of these points were determined using the table of random numbers found in Appendix I, Table I.6. 

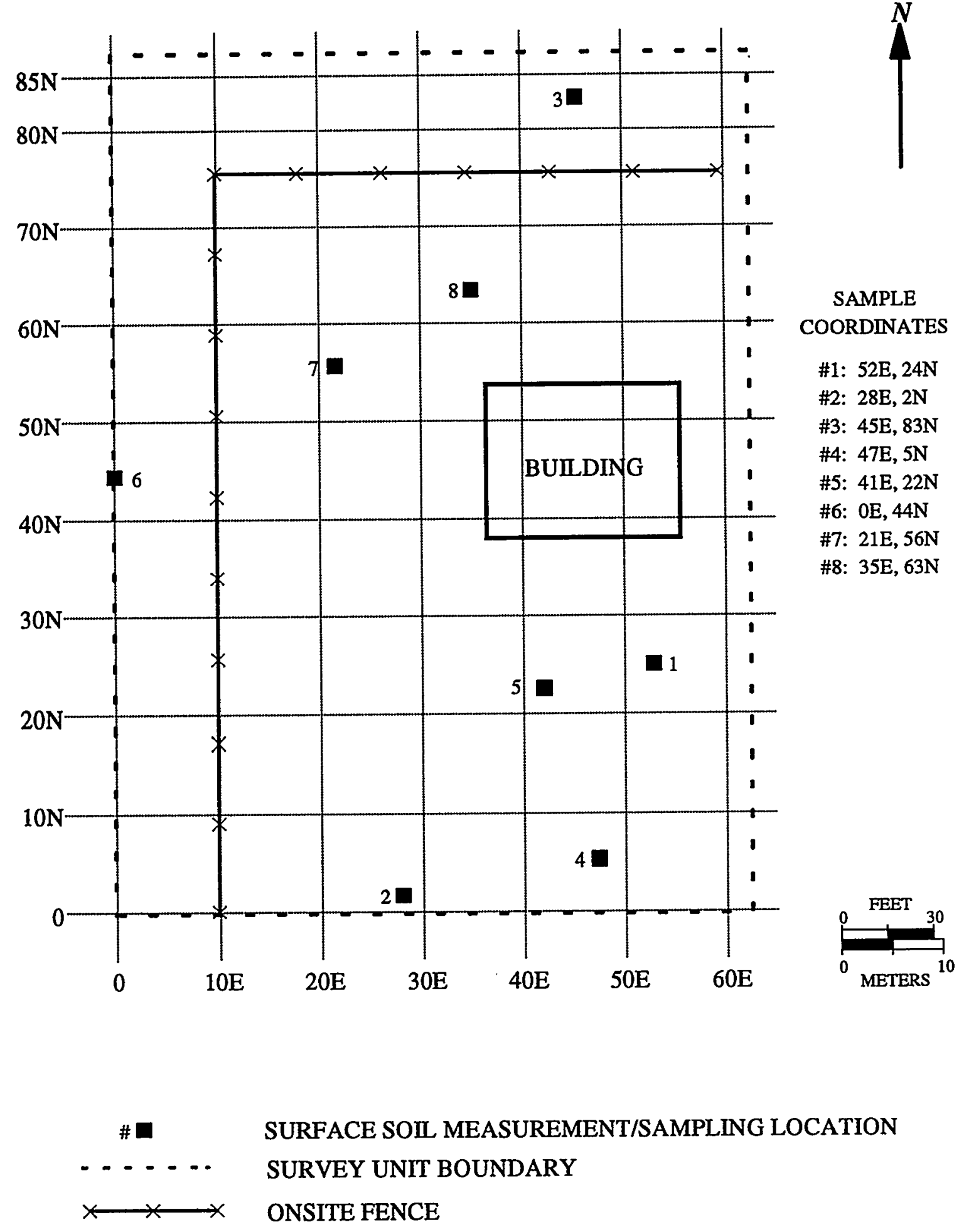

Figure 5.4 Example of a Random Measurement Pattern 
Survey Planning and Design

Class 2 areas are surveyed on a random-start systematic pattern. The number of calculated survey locations, $\mathrm{n}$, based on the statistical tests, is used to determine the spacing, $\mathrm{L}$, of a systematic pattern by:

$$
\begin{gathered}
L=\sqrt{\frac{A}{0.866 n}} \text { for a triangular grid } \\
L=\sqrt{\frac{A}{n}} \text { for a square grid }
\end{gathered}
$$

where $A$-is the area of the survey unit.

After $\mathrm{L}$ is determined, a random coordinate location is identified, as described previously, for a survey pattern starting location. Beginning at the random starting coordinate, a row of points is identified, parallel to the $\mathrm{X}$ axis, at intervals of $\mathrm{L}$.

For a triangular grid, a second row of points is then developed, parallel to the first row, at a distance of $0.866 \times \mathrm{L}$ from the first row. Survey points along that second row are midway (on the $\mathrm{X}$-axis) between the points on the first row. This process is repeated to identify a pattern of survey locations throughout the affected survey unit. If identified points fall outside the survey unit or at locations which cannot be surveyed, additional points are determined using the random process described above, until the desired total number of points is identified.

An example of such a survey pattern is shown in Figure 5.5. In this example, the statistical test calculations estimate 20 samples (Table 5.5, $\alpha=0.01, \beta=0.05, \Delta / \sigma>3.0$ ). The random-start coordinate was 27E, 53N. The grid spacing was calculated using Equation 5-7:

$$
L=\sqrt{\frac{5,100 \mathrm{~m}^{2}}{0.866 \times 20}}=17 \mathrm{~m} .
$$

Two points were identified on a row parallel to the $\mathrm{X}$-axis, each $17 \mathrm{~m}$ from the starting point. The subsequent rows were positioned $0.866 \times \mathrm{L}$, or $15 \mathrm{~m}$, from the initial row. This random-start triangular sampling process resulted in 21 sampling locations, one of which was inaccessible because of the building location, which yields the desired number of data points. 

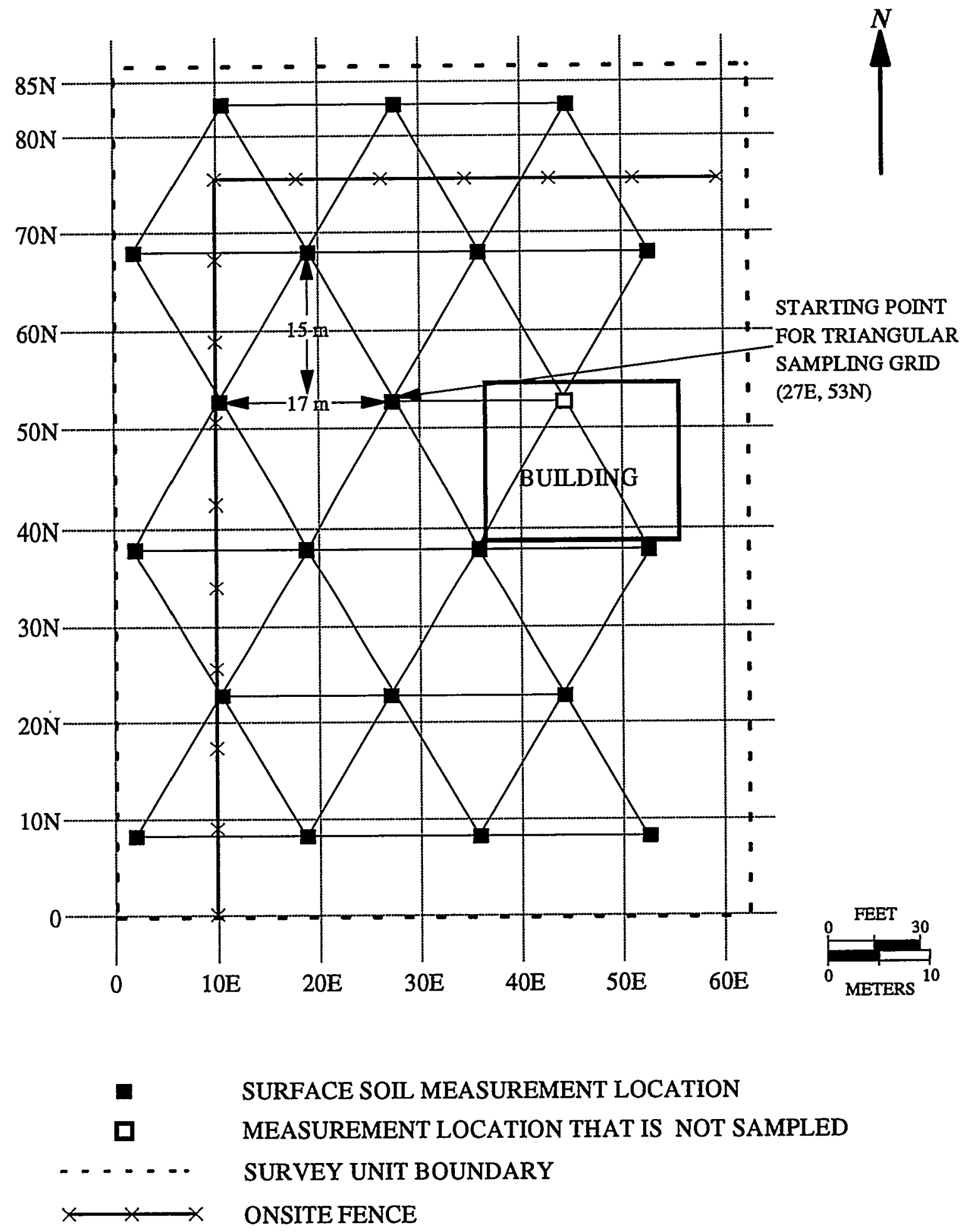

Figure 5.5 Example of a Random-Start Triangular Grid Measurement Pattern 
For Class 1 areas a systematic pattern, having dimensions determined in Section 5.5.2.4, is installed on the survey unit. The starting point for this pattern is selected at random, as described above for Class 2 areas. The same process as described above for Class 2 areas applies to Class 1 , only the estimated number of samples is different.

Structure Surfaces. All structure surfaces for a specific survey unit are included on a single reference grid system for purposes of identifying survey locations. The same methods as described above for land areas are then used to locate survey points for all classifications of areas.

In addition to the survey locations identified for statistical evaluations and elevated measurement comparisons, data will likely be obtained from judgment locations that are selected due to unusual appearance, location relative to contamination areas, high potential for residual activity, general supplemental information, etc. Data points selected based on professional judgment are not included with the data points from the random-start triangular grid for statistical evaluations; instead they are compared individually with the established DCGLs and conditions.

Measurement locations selected based on professional judgment violate the assumption of unbiased measurements used to develop the statistical tests described in Chapter 8.

\subsubsection{Determining Investigation Levels}

An important aspect of the final status survey is the design and implementation of investigation levels. Investigation levels are radionuclide-specific levels of radioactivity used to indicate when additional investigations may be necessary. Investigation levels also serve as a quality control check to determine when a measurement process begins to get out of control. For example, a measurement that exceeds the investigation level may indicate that the survey unit has been improperly classified (see Section 4.4) or it may indicate a failing instrument.

When an investigation level is exceeded, the first step is to confirm that the initial measurement/sample actually exceeds the particular investigation level. This may involve taking further measurements to determine that the area and level of the elevated residual radioactivity are such that the resulting dose or risk meets the release criterion. ${ }^{2}$ Depending on the results of the investigation actions, the survey unit may require reclassification, remediation, and/or resurvey. Table 5.8 illustrates an example of how investigation levels can be developed.

${ }^{2}$ Rather than, or in addition to, taking further measurements the investigation may involve assessing the adequacy of the exposure pathway model used to obtain the DCGLs and area factors, and the consistency of the results obtained with the Historical Site Assessment and the scoping, characterization and remedial action support surveys. 
Table 5.8 Example Final Status Survey Investigation Levels

\begin{tabular}{||l|l|l||}
\hline $\begin{array}{l}\text { Survey Unit } \\
\text { Classification }\end{array}$ & \multicolumn{1}{|c|}{$\begin{array}{c}\text { Flag Direct Measurement or Sample } \\
\text { Result When: }\end{array}$} & Flag Scanning Measurement Result When: \\
\hline Class 1 & $\begin{array}{l}>\mathrm{DCGL}_{\mathrm{EMC}} \text { or } \\
>\mathrm{DCGL}_{\mathrm{W}} \text { and }>\text { a statistical parameter- } \\
\text { based value }\end{array}$ & $>\mathrm{DCGL}_{\mathrm{EMC}}$ \\
\hline Class 2 & $>\mathrm{DCGL}_{\mathrm{W}}$ & $>\mathrm{DCGL}_{\mathrm{W}}$ or $>\mathrm{MDC}$ \\
\hline Class 3 & $>$ fraction of $\mathrm{DCGL}_{\mathrm{W}}$ & $>\mathrm{DCGL}_{\mathrm{W}}$ or $>\mathrm{MDC}$ \\
\hline
\end{tabular}

When determining an investigation level using a statistical-based parameter (e.g., standard deviation) one should consider survey objectives, underlying radionuclide distributions and an understanding of corresponding types (e.g., normal, log normal, non-parametric), descriptors (e.g., standard deviation, mean, median), population stratifications (i.e., are there sub-groups present?), and other prior survey and historical information. For example, a level might be arbitrarily established at the mean $+3 \mathrm{~s}$, where $s$ is the standard deviation of the survey unit, assuming a normal distribution. A higher value might be used if locating discrete sources of higher activity was a primary survey objective. By the time the final status survey is conducted, survey units should be defined. Estimates of the mean, variance, and standard deviation of the radionuclide activity levels within the survey units should also be available.

For a Class 1 survey unit, measurements above the $\mathrm{DCGL}_{\mathrm{W}}$ are not necessarily unexpected. However, a measurement above the $\mathrm{DCGL}_{\mathrm{w}}$ at one of the discrete measurement locations might be considered unusual if it were much higher than all of the other discrete measurements. Thus, any discrete measurement that is both above the $\mathrm{DCGL}_{\mathrm{W}}$ and above the statistical-based parameter for the measurements should be investigated further. Any measurement, either at a discrete location or from a scan, that is above the $\mathrm{DCGL}_{\mathrm{EMC}}$ should be flagged for further investigation.

In Class 2 or Class 3 areas, neither measurements above the $\mathrm{DCGL}_{\mathrm{w}}$ nor areas of elevated activity are expected. Any measurement at a discrete location exceeding the $\mathrm{DCGL}_{\mathrm{w}}$ in these areas should be flagged for further investigation. Because the survey design for Class 2 and Class 3 survey units is not driven by the EMC, the scanning MDC might exceed the DCGL $\mathrm{w}_{\mathrm{w}}$. In this case, any indication of residual radioactivity during the scan would warrant further investigation.

The basis for using the $\mathrm{DCGL}_{\mathrm{EMC}}$ rather than the more conservative criteria for Class 2 and Class 3 areas should be justified in survey planning documents. For example, where there is high uncertainty in the reported scanning $\mathrm{MDC}$, a more conservative criteria would be warranted. 
Survey Planning and Design

Similarly, DQA for scanning may warrant a more conservative flag, as would greater uncertainty from Historical Site Assessment or other surveys on the size of potential areas of elevated activity. In some cases, it may even be necessary to agree in advance with the regulatory agency responsible for the site on which site-specific investigation will be used if other than those presented in Table 5.8 .

Because there is a low expectation for residual radioactivity in a Class 3 area, it may be prudent to investigate any measurement exceeding even a fraction of the DCGL $\mathrm{w}_{\mathrm{w}}$. The level selected in these situations depends on the site, the radionuclides of concern, and the measurement and scanning methods chosen. This level should be set using the DQO Process during the survey design phase of the Data Life Cycle. In some cases, the user may also wish to follow this procedure for Class 2 and even Class 1 survey units.

\subsubsection{Developing an Integrated Survey Strategy}

The final step in survey design is to integrate the survey techniques (Chapter 6) with the number of measurements and measurement spacing determined earlier in this chapter. This integration along with the guidance provided in other portions of this manual produce an overall strategy for performing the survey. Table 5.9 provides a summary of the recommended survey coverage for structures and land areas. This survey coverage for different areas is the subject of this section.

Random measurement patterns are used for Class 3 survey units to ensure that the measurements are independent and support the assumptions of the statistical tests. Systematic grids are used for Class 2 survey units because there is an increased probability of small areas of elevated activity. The use of a systematic grid allows the decision maker to draw conclusions about the size of the potential areas of elevated activity based on the area between measurement locations. The random starting point of the grid provides an unbiased method for obtaining measurement locations to be used in the statistical tests. Class 1 survey units have the highest potential for small areas of elevated activity, so the areas between measurement locations are adjusted to ensure that these areas can be detected by scanning techniques.

The objectives of the scanning surveys are different. Scanning is used to identify locations within the survey unit that exceed the investigation level. These locations are marked and receive additional investigations to determine the concentration, area, and extent of the contamination.

For Class 1 areas, scanning surveys are designed to detect small areas of elevated activity that are not detected by the measurements using the systematic pattern. For this reason the measurement locations, and the number of measurements, may need to be adjusted based on the sensitivity of the scanning technique (Section 5.5.2.4). This is also the reason for recommending $100 \%$ 
Table 5.9 Recommended Survey Coverage for Structures and Land Areas

\begin{tabular}{|c|c|c|c|c|}
\hline \multirow{2}{*}{$\begin{array}{c} \\
\text { Area } \\
\text { Classification }\end{array}$} & \multicolumn{2}{|c|}{ Structures } & \multicolumn{2}{|c|}{ Land Areas } \\
\hline & Surface Scans & $\begin{array}{l}\text { Surface Activity } \\
\text { Measurements }\end{array}$ & Surface Scans & Soil Samples \\
\hline Class 1 & $100 \%$ & $\begin{array}{l}\text { Number of data points } \\
\text { from statistical tests } \\
\text { (Sections 5.5.2.2 and } \\
5.5 .2 .3 \text { ); additional } \\
\text { measurements may be } \\
\text { necessary for small } \\
\text { areas of elevated } \\
\text { activity (Section } \\
5.5 .2 .4 \text { ) }\end{array}$ & $100 \%$ & $\begin{array}{l}\text { Number of data points } \\
\text { from statistical tests } \\
\text { (Sections 5.5.2.2 and } \\
5.5 .2 .3 \text { ); additional } \\
\text { measurements may be } \\
\text { necessary for small } \\
\text { areas of elevated } \\
\text { activity (Section } \\
5.5 .2 .4 \text { ) }\end{array}$ \\
\hline Class 2 & $\begin{array}{c}10 \text { to } 100 \% \\
\text { (10 to } 50 \% \text { for upper } \\
\text { walls and ceilings) } \\
\text { Systematic and } \\
\text { Judgmental }\end{array}$ & $\begin{array}{l}\text { Number of data points } \\
\text { from statistical tests } \\
\text { (Sections 5.5.2.2 and } \\
\text { 5.5.2.3) }\end{array}$ & $\begin{array}{l}10 \text { to } 100 \% \\
\text { Systematic and } \\
\text { Judgmental }\end{array}$ & $\begin{array}{l}\text { Number of data points } \\
\text { from statistical tests } \\
\text { (Sections 5.5.2.2 and } \\
\text { 5.5.2.3) }\end{array}$ \\
\hline Class 3 & Judgmental & $\begin{array}{l}\text { Number of data points } \\
\text { from statistical tests } \\
\text { (Sections 5.5.2.2 and } \\
\text { 5.5.2.3) }\end{array}$ & Judgmental & $\begin{array}{l}\text { Number of data points } \\
\text { from statistical tests } \\
\text { (Sections 5.5.2.2 and } \\
\text { 5.5.2.3) }\end{array}$ \\
\hline
\end{tabular}

coverage for the scanning survey. $100 \%$ coverage means that the entire surface area of the survey unit is covered by the field of view of the scanning instrument. If the field of view is two meters wide, the survey instrument can be moved along parallel paths two meters apart to provide $100 \%$ coverage. If the field of view of the detector is $5 \mathrm{~cm}$, the parallel paths should be $5 \mathrm{~cm}$ apart.

Scanning surveys in Class 2 areas are also primarily performed to find areas of elevated activity not detected by the measurements using the systematic pattern. However, the measurement locations are not adjusted based on sensitivity of the scanning technique and scanning is performed in portions of the survey unit. The level of scanning effort should be proportional to the potential for finding areas of elevated activity based on the conceptual site model developed and refined from Section 3.6.4. A larger portion of the survey unit would be scanned in Class 2 survey units that have residual radioactivity close to the release criterion, but for survey units that are closer to background scanning, a smaller portion of the survey unit may be appropriate. Class 2 survey units have a lower probability for areas of elevated activity than Class 1 survey units, but some portions of the survey unit may have a higher potential than others. Judgmental 
scanning surveys focus on the portions of the survey unit with the highest probability for areas of elevated activity. If the entire survey unit has an equal probability for areas of elevated activity, or the judgmental scans don't cover at least $10 \%$ of the area, systematic scans along transects of the survey unit or scanning surveys of randomly selected grid blocks are performed.

Class 3 areas have the lowest potential for areas of elevated activity. For this reason, scanning surveys are recommended for areas with the highest potential for contamination (e.g., corners, ditches, drains) based on professional judgment. Such recommendations are typically provided by a health physics professional with radiation survey experience. This provides a qualitative level of confidence that no areas of elevated activity were missed by the random measurements or that there were no errors made in the classification of the area.

The sensitivity for scanning techniques used in Class 2 and Class 3 areas is not tied to the area between measurement locations, as they are in a Class 1 area (see Section 5.5.2.4). The scanning techniques selected should represent the best reasonable effort based on the survey objectives. Structure surfaces are generally scanned for alpha, beta, and gamma emitting radionuclides. Scanning for alpha emitters or low-energy $(<100 \mathrm{keV})$ beta emitters for land area survey units is generally not considered effective because of problems with attenuation and media interferences. If one can reasonably expect to find any residual radioactivity, it is prudent to perform a judgmental scanning survey.

If the equipment and methodology used for scanning is capable of providing data of the same quality as direct measurements (e.g., detection limit, location of measurements, ability to record and document results), then scanning may be used in place of direct measurements. Results should be documented for at least the number of locations estimated for the statistical tests. The same logic can be applied for using direct measurements instead of sampling. In addition, some direct measurement systems may be able to provide scanning data.

As previously discussed, investigation levels are determined and used to indicate when additional investigations may be necessary or when a measurement process begins to get out of control. The results of all investigations should be documented in the final status survey report, including the results of scan surveys that may have potentially identified areas of elevated direct radiation.

\subsubsection{Structure Surveys}

Class 1 Areas. Surface scans are performed over $100 \%$ of structure surfaces for radiations which might be emitted from the potential radionuclide contaminants. Locations of direct radiation, distinguishable above background radiation, are identified and evaluated. Results of initial and followup direct measurements and sampling at these locations are recorded and documented in the final status survey report. Measurements of total and removable contamination are performed at locations identified by scans and at previously determined 
locations (Section 5.5.2.5). Where gamma emitting radionuclides are present, in situ gamma spectroscopy may be used to identify the presence of specific radionuclides or to demonstrate compliance with the release criterion.

Direct measurement or sample investigation levels for Class 1 areas should establish a course of action for individual measurements that approach or exceed the DCGL ${ }_{\mathrm{W}}$. Because measurements above the DCGL $_{\mathrm{w}}$ are not necessarily unexpected in a Class 1 survey unit, additional investigation levels may be established to identify discrete measurements that are much higher than the other measurements. Any discrete measurement that is both above the DCGL $\mathrm{W}_{\mathrm{W}}$ and exceeds three times the standard deviation (s) of the mean should be investigated further (Section 5.5.2.6). Any measurement (direct measurement, sample, or scan) that exceeds the $\mathrm{DCGL}_{\mathrm{EMC}}$ should be flagged for further investigation. The results of the investigation and any additional remediation that was performed should be included in the final status survey report. Data are reviewed as described in Section 8.2.2, additional data are collected as necessary, and the final complete data set evaluated as described in Section 8.3 or Section 8.4.

Class 2 Areas. Surface scans are performed over 10 to $100 \%$ of structure surfaces. Generally, upper wall surfaces and ceilings should receive surface scans over 10 to $50 \%$ of these areas. Locations of scanning survey results above the investigation level are identified and investigated. If small areas of elevated activity are confirmed by this investigation, all or part of the survey unit should be reclassified as Class 1 and the survey strategy for that survey unit redesigned accordingly.

Investigation levels for Class 2 areas should establish a course of action for individual measurements that exceed or approach the $\mathrm{DCGL}_{\mathrm{w}}$. The results of the investigation of the positive measurements and basis for reclassifying all or part of the survey unit as Class 1 should be included in the final status survey report. Where gamma emitting radionuclides are contaminants, in situ gamma spectroscopy may be used to identify the presence of specific radionuclides or to demonstrate compliance with the release criterion. Data are reviewed as described in Section 8.2.2, additional data are collected as necessary, and the final complete data set evaluated as described in Section 8.3 or Section 8.4.

Class 3 Areas. Scans of Class 3 area surfaces should be performed for all radiations which might be emitted from the potential radionuclide contaminants. MARSSIM recommends that the surface area be scanned. Locations of scanning survey results above the investigation level are identified and evaluated. Measurements of total and removable contamination are performed at the locations identified by the scans and at the randomly selected locations that are chosen in accordance with Section 5.5.2.5. Identification of contamination suggests that the area may be incorrectly classified. If so, a re-evaluation of the Class 3 area classification should be performed and, if appropriate, all or part of the survey unit should be resurveyed as a Class 1 or Class 2 area. In some cases the investigation may include measurements by in situ gamma spectroscopy at a 
Survey Planning and Design

few locations in each structure in a Class 3 area. A gamma spectroscopy system might even be an appropriate substitution for surface scans.

Because there is a low expectation for residual radioactivity in a Class 3 area, it may be prudent to investigate any measurement exceeding even a fraction of the DCGL $\mathrm{w}_{\mathrm{w}}$. The investigation level selected will depend on the site, the radionuclides of concern, and the measurement and scanning methods chosen. This level should be determined using the DQO Process during survey planning. In some cases, the user may wish to follow this procedure for Class 2 survey units.

The results of the investigation of the measurements that exceed the investigation level and the basis for reclassifying all or part of the survey unit as Class 1 or Class 2 should be included in the final status survey report. The data are tested relative to the preestablished criteria. If additional data are needed, they should be collected and evaluated as part of the entire data set.

\subsubsection{Land Area Surveys}

Class 1 Areas. As with structure surfaces, 100\% scanning coverage of Class 1 land areas is recommended. Locations of scanning survey results above the investigation level are identified and evaluated. Results of initial and followup direct measurements and sampling at these locations are recorded. Soil sampling is performed at locations identified by scans and at previously determined locations (Section 5.5.2.5). Where gamma emitting radionuclides are contaminants, in situ gamma spectroscopy may be used to confirm the absence of specific radionuclides or to demonstrate compliance.

Direct measurement or sample investigation levels for Class 1 areas should establish a course of action for individual measurements that approach or exceed the DCGL $\mathrm{w}_{\mathrm{W}}$. Because measurements above the DCGL $\mathrm{W}_{\mathrm{W}}$ are not necessarily unexpected in a Class 1 survey unit, additional investigation levels may be established to identify discrete measurements that are much higher than the other measurements. Any discrete measurement that is both above the DCGL $\mathrm{W}_{\mathrm{W}}$ and exceeds three standard deviations above the mean should be investigated further (Section 5.5.2.6). Any measurement (direct measurement, sample, or scan) that exceeds the DCGL $\mathrm{EMC}_{\mathrm{E}}$ should be flagged for further investigation. The results of the investigation and any additional remediation that was performed should be included in the final status survey report. Data are reviewed as described in Section 8.2.2, additional data are collected as necessary, and the final complete data set evaluated as described in Section 8.3 or Section 8.4.

Class 2 Areas. Surface scans are performed over 10 to $100 \%$ of open land surfaces. Locations of direct radiation above the scanning survey investigation level are identified and evaluated. If small areas of elevated activity are identified, the survey unit should be reclassified as "Class 1 " and the survey strategy for that survey unit redesigned accordingly. 
If small areas of elevated activity above DCGL values are not identified, direct measurement or soil sampling is performed at previously determined locations (Section 5.5.2.5). Where gamma emitting radionuclides are contaminants, in situ gamma spectroscopy may be used to confirm the absence of specific radionuclides or to demonstrate compliance. Data are reviewed as described in Section 8.2.2, additional data are collected as necessary, and the final complete data set evaluated as described in Section 8.3 or Section 8.4.

Investigation levels for Class 2 areas should establish levels for investigation of individual measurements close to but below the $\mathrm{DCGL}_{\mathrm{w}}$. The results of the investigation of the positive measurements and basis for reclassifying all or part of the survey unit as Class 1 should be included in the final status survey report.

Class 3 Areas. Class 3 areas may be uniformly scanned for radiations from the radionuclides of interest, or the scanning may be performed in areas with the greatest potential for residual contamination based on professional judgment and the objectives of the survey. In some cases a combination of these approaches may be the most appropriate. Locations exceeding the scanning survey investigation level are evaluated, and, if the presence of contamination not occurring in background is identified, reevaluation of the classification of contamination potential should be performed.

Investigation levels for Class 3 areas should be established to identify areas of elevated activity that may indicate the presence of residual radioactivity. Scanning survey locations that exceed the investigation level should be flagged for further investigation. The results of the investigation and basis for reclassifying all or part of the survey unit as Class 1 or Class 2 should be included in the final status survey report. The data are tested relative to the preestablished criteria. If additional data are needed, they should be collected and evaluated as part of the entire data set. Soil sampling is performed at randomly selected locations (Section 5.5.2.5); if the contaminant can be measured at DCGL levels by in situ techniques, this method may be used to replace or supplement the sampling and laboratory analysis approach. For gamma emitting radionuclides, the above data should be supplemented by several exposure rate and/or in situ gamma spectrometry measurements. Survey results are tested for compliance with DCGLs and additional data are collected and tested, as necessary.

\subsubsection{Other Measurement/Sampling Locations}

In addition to the building and land surface areas described above, there are numerous other locations where measurements and/or sampling may be necessary. Examples include items of equipment and furnishings, building fixtures, drains, ducts, and piping. Many of these items or locations have both internal and external surfaces with potential residual radioactivity. Subsurface measurements and/or sampling may also be necessary. Guidance on conducting or evaluating these types of surveys is outside the scope of MARSSIM. 
Special situations may be evaluated by judgment sampling and measurements. Data from such surveys should be compared directly with DCGLs developed for the specific situation. Areas of elevated direct radiation identified by surface scans are typically followed by direct measurements or samples. These direct measurements and samples are not included in the nonparametric tests described in this manual, but rather, should be compared directly with DCGLs developed for the specific situation.

Quality control measurements are recommended for all surveys, as described in Section 4.9, Section 6.2, and Section 7.2. Also, some regulatory programs require removable activity measurements (e.g., NRC Regulatory Guide 1.86; NRC 1974). These additional measurements should be considered during survey planning.

\subsubsection{Evaluating Survey Results}

After data are converted to DCGL units, the process of comparing the results to the DCGLs, conditions, and objectives begins. Individual measurements and sample concentrations are first compared to DCGL levels for evidence of small areas of elevated activity and not to determine if reclassification is necessary. Additional data or additional remediation and resurvey may be necessary. Data are then evaluated using statistical methods to determine if they exceed the release criterion. If the release criterion has been exceeded or if results indicate the need for additional data points, appropriate further actions will be determined by the site management and the responsible regulatory agency. The scope of further actions should be agreed upon and developed as part of the DQO Process before the survey begins (Appendix D). Finally, the results of the survey are compared with the data quality objectives established during the planning phase of the project. Note that Data Quality Objectives may require a report of the semi-quantitative evaluation of removable contamination resulting from the analysis of smears. These results may be used to satisfy regulatory requirements or to evaluate the effectiveness of ALARA procedures. Chapter 8 describes detailed procedures for evaluating survey results.

\subsubsection{Documentation}

Documentation of the final status survey should provide a complete and unambiguous record of the radiological status of the survey unit, relative to the established DCGLs. In addition, sufficient data and information should be provided to enable an independent re-creation and evaluation at some future time. Much of the information in the final status report will be available from other decommissioning documents; however, to the extent practicable, this report should be a stand-alone document with minimum information incorporated by reference. The report should be independently reviewed (see Section 3.9) and should be approved by a designated person (or persons) who is capable of evaluating all aspects of the report prior to release, publication, or distribution. 


\section{EXAMPLE FINAL STATUS SURVEY CHECKLIST}

\section{SURVEY PREPARATIONS}

Ensure that residual radioactivity limits have been determined for the radionuclides present at the site, typically performed during earlier surveys associated with the decommissioning process.

Identify the radionuclides of concern. Determine whether the radionuclides of concern exist in background. This will determine whether one-sample or twosample tests are performed to demonstrate compliance. Two-sample tests are performed when radionuclides are present in the natural background; one-sample tests may be performed if the radionuclide is not present in background.

Segregate the site into Class 1, Class 2, and Class 3 areas, based on contamination potential.

Identify survey units.

Select representative reference (background) areas for both indoor and outdoor survey areas. Reference areas are selected from non-impacted areas and

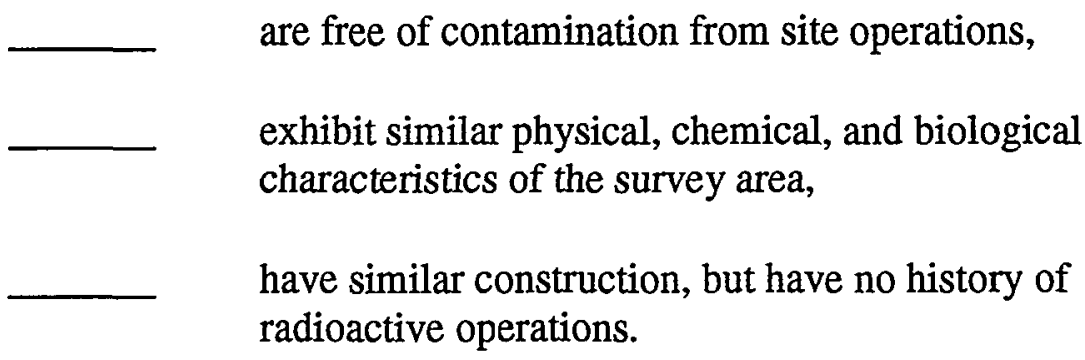

Select survey instrumentation and survey techniques. Determine MDCs (select instrumentation based on the radionuclides present) and match between instrumentation and DCGLs-the selected instruments should be capable of detecting the contamination at $10-50 \%$ of the DCGLs.

Prepare area if necessary—clear and provide access to areas to be surveyed.

Establish reference coordinate systems (as appropriate). 


\section{SURVEY DESIGN}

Enumerate DQOs: State objective of survey, state the null and alternative hypotheses, specify the acceptable decision error rates (Type I $(\alpha)$ and Type II ( $\beta$ )).

Specify sample collection and analysis procedures.

Determine numbers of data points for statistical tests, depending on whether or not the radionuclide is present in background.

Specify the number of samples/measurements to be obtained based on the statistical tests.

Evaluate the power of the statistical tests to determine that the number of samples is appropriate.

Ensure that the sample size is sufficient for detecting areas of elevated activity.

Add additional samples/measurements for QC and to allow for possible loss.

Specify sampling locations.

Provide information on survey instrumentation and techniques. The decision to use portable survey instrumentation or in situ techniques, and/or a combination of both, depends on whether or not the radiation levels are elevated compared to natural background, and whether or not the residual radioactivity is present at some fraction of background levels.

Specify methods of data reduction and comparison of survey units to reference areas.

Provide quality control procedures and QAPP for ensuring validity of survey data:

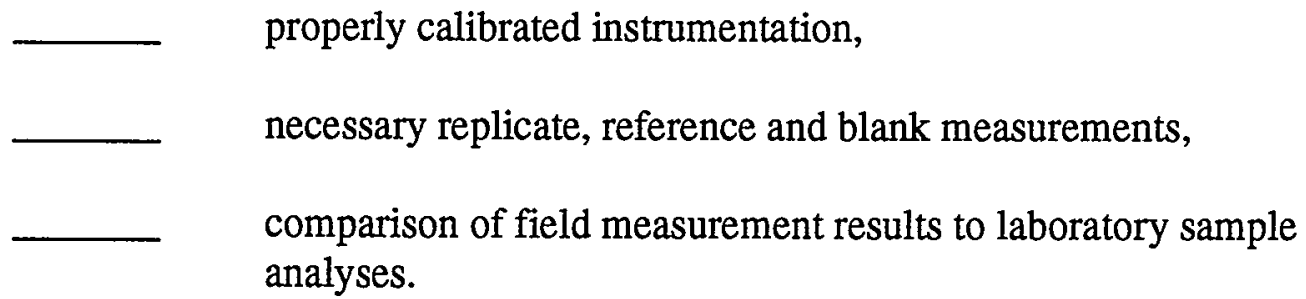

Document the survey plan (e.g., QAPP, SOPs, etc.) 


\section{CONDUCTING SURVEYS}

Perform reference (background) area measurements and sampling.

Conduct survey activities:

Perform surface scans of the Class 1, Class 2, and Class 3 areas.

Conduct surface activity measurements and sampling at previously selected sampling locations.

Conduct additional direct measurements and sampling at locations based on professional judgment.

Perform and document any necessary investigation activities, including survey unit reclassification, remediation, and resurvey.

Document measurement and sample locations; provide information on measurement system MDC and measurement errors.

Document any observations, abnormalities, and deviations from the QAPP or SOPs

\section{EVALUATING SURVEY RESULTS}

Review DQOs.

Analyze samples.

Perform data reduction on survey results.

Verify assumptions of statistical tests.

Compare survey results with regulatory DCGLs:

_ Conduct elevated measurement comparison.

Determine area-weighted average, if appropriate.

Conduct WRS or Sign tests.

Prepare final status survey report.

Obtain an independent review of the report. 


\section{FIELD MEASUREMENT METHODS AND INSTRUMENTATION}

\subsection{Introduction}

Measurement is used in MARSSIM to mean 1) the act of using a detector to determine the level or quantity of radioactivity on a surface or in a sample of material removed from a media being evaluated, or 2) the quantity obtained by the act of measuring. Three methods are available for collecting radiation data while performing a survey-direct measurements, scanning, and sampling. This chapter discusses scanning and direct measurement methods and instrumentation. The collection and analysis of media samples are presented in Chapter 7. Information on the operation and use of individual field and laboratory instruments is provided in Appendix H. Quality assurance and quality control (QA/QC) are discussed in Chapter 9.

Total surface activities, removable surface activities, and radionuclide concentrations in various environmental media (e.g., soil, water, air) are the radiological parameters typically determined using field measurements and laboratory analyses. Certain radionuclides or radionuclide mixtures may necessitate the measurement of alpha, beta, and gamma radiations. In addition to assessing each survey unit as a whole, any small areas of elevated activity should be identified and their extent and activities determined. Due to numerous detector requirements, no single instrument (detector and readout combination) is generally capable of adequately measuring all of the parameters required to satisfy the release criterion or meet all the objectives of a survey.

Selecting instrumentation requires evaluation of both site and radionuclide specific parameters and conditions. Instruments should be stable and reliable under the environmental and physical conditions where they are used, and their physical characteristics (size and weight) should be compatible with the intended application. The instrument and measurement method should be able to detect the type of radiation of interest, and should, in relation to the survey or analytical technique, be capable of measuring levels that are less than the derived concentration guideline level (DCGL). Numerous commercial firms offer a wide variety of instruments appropriate for the radiation measurements described in this manual. These firms can provide thorough information regarding capabilities, operating characteristics, limitations, etc., for specific equipment.

If the field instruments and measurement methods cannot detect radiation levels below the DCGLs, laboratory methods discussed in Chapter 7 are typically used. A discussion of detection limits and detection levels for some typical instruments is presented in Section 6.7. There are certain radionuclides that will be essentially impossible to measure at the DCGLs in situ using current state-of-the-art instrumentation and techniques because of the types, energies, and abundances of their radiations. Examples of such radionuclides include very low energy, pure beta emitters such as ${ }^{3} \mathrm{H}$ and ${ }^{63} \mathrm{Ni}$ and low-energy photon emitters such as ${ }^{55} \mathrm{Fe}$ and ${ }^{125} \mathrm{I}$. Pure alpha emitters dispersed in soil or covered with some absorbing layer may not be detectable because alpha radiation will not penetrate through the media or covering to reach the detector. A 
Field Measurement Methods and Instrumentation

common example of such a condition would be ${ }^{230} \mathrm{Th}$ surface contamination, covered by paint, dust, oil, or moisture. NRC report NUREG-1507 (NRC 1997a) provides information on the extent to which these surface conditions may affect detection sensitivity. In circumstances such as these, the survey design will usually rely on sampling and laboratory analysis to measure residual activity levels.

\subsection{Data Quality Objectives}

The third step of the Data Quality Objectives (DQO) Process involves identifying the data needs for a survey. One decision that can be made at this step is the selection of direct measurements for performing a survey or deciding that sampling methods followed by laboratory analysis are necessary.

\subsubsection{Identifying Data Needs}

The decision maker and the survey planning team need to identify the data needs for the survey being performed, including the:

- type of measurements to be performed (Chapter 5)

- $\quad$ radionuclide(s) of interest (Section 4.3)

- number of direct measurements to be performed (Section 5.5.2)

- area of survey coverage for surface scans based on survey unit classification (Section 5.5.3)

- type and frequency of field QC measurements to be performed (Section 4.9)

- measurement locations and frequencies (Section 5.5.2)

- $\quad$ standard operating procedures (SOPs) to be followed or developed (Chapter 6)

- analytical bias and precision (e.g., quantitative or qualitative) (Appendix N, Section N.6)

- target detection limits for each radionuclide of interest (Section 6.4)

- cost of the methods being evaluated (cost per measurement as well as total cost)

(Appendix H)

- necessary turnaround time

- $\quad$ specific background for the radionuclide(s) of interest (Section 4.5)

- derived concentration guideline level (DCGL) for each radionuclide of interest (Section 4.3)

- measurement documentation requirements

- measurement tracking requirements

Some of this information will be supplied by subsequent steps in the DQO process, and several iterations of the process may be needed to identify all of the data needs. Consulting with a health physicist or radiochemist may be necessary to properly evaluate the information before deciding 
between direct measurements or sampling methods to perform the survey. Many surveys will involve a combination of direct measurements and sampling methods, along with scanning techniques, to demonstrate compliance with the release criterion.

\subsubsection{Data Quality Indicators}

The data quality indicators identified as DQOs in Section 2.3.1 and described in Appendix N should be considered when selecting a measurement method (i.e., scanning, direct measurement, sampling) or a measurement system (e.g., survey instrument, human operator, and procedure for performing measurements). In some instances, the data quality indicator requirements will help in the selection of a measurement system. In other cases, the requirements of the measurement system will assist in the selection of appropriate levels for the data quality indicators.

\subsubsection{Precision}

Precision is a measure of agreement among replicate measurements of the same property, under prescribed similar conditions (ASQC 1995). Precision is determined quantitatively based on the results of replicate measurements (equations are provided in EPA 1990). The number of replicate analyses needed to determine a specified level of precision for a project is discussed in Section 4.9. Determining precision by replicating measurements with results at or near the detection limit of the measurement system is not recommended because the measurement uncertainty is usually greater than the desired level of precision. The types of replicate measurements applied to scanning and direct measurements are limited by the relatively uncomplicated measurement system (i.e., the uncertainties associated with sample collection and preparation are eliminated). However, the uncertainties associated with applying a single calibration factor to a wide variety of site conditions mean these measurements are very useful for assessing data quality.

- Replicates to Measure Operator Precision. For scanning and direct measurements, replicates to measure operator precision provide an estimate of precision for the operator and the Standard Operating Procedure (SOP) or protocol used to perform the measurement. Replicates to measure operator precision are measurements performed using the same instrument at the same location, but with a different operator. Replicates to measure operator precision are usually non-blind or single-blind measurements.

- Replicates to Measure Instrument Precision. For scanning and direct measurements, replicates to measure instrument precision provide an estimate of precision for the type of instrument, the calibration, and the SOP or protocol used to perform the measurement. Replicates to measure instrument precision are measurements performed by the same operator at the same location, but with a different instrument. Replicates to measure instrument precision are usually non-blind or single-blind measurements. 
Field Measurement Methods and Instrumentation

For many surveys a combination of instrument and operator replicates are used to provide an estimate of overall precision for both scanning and direct measurements. Replicates of direct measurements can be compared with one another similar to the analytical results for samples. Results for scanning replicates may be obtained by stopping and recording instrument readings at specific intervals during the scanning survey (effectively performing direct measurements at specified locations). An alternative method for estimating the precision of scanning is to evaluate the effectiveness of the scanning survey for identifying areas of elevated activity. The results of scanning are usually locations that are identified for further investigation. A comparison of the areas identified by the replicate scanning surveys can be performed either quantitatively (using statistical methods) or qualitatively (using professional judgment). Because there is a necessity to evaluate whether the same number of locations were identified by both replicates as well as if the identified locations are the same, there is difficulty in developing precision as a DQO that can be evaluated.

\subsubsection{Bias}

Bias is the systematic or persistent distortion of a measurement process that causes error in one direction (EPA 1997). Bias is determined quantitatively based on the measurement of materials with a known concentration. There are several types of materials with known concentrations that may be used to determine bias for scans and direct measurements.

- Reference Material. Reference material is a material or substance one or more of whose property values are sufficiently homogeneous and well established to be used for the calibration of an apparatus, the assessment of a measurement method, or for assigning values to materials (ISO 1993). A certified reference material is reference material for which each certified property value is accompanied by an uncertainty at a stated level of confidence. Radioactive reference materials may be available for certain radionuclides in soil (e.g., uranium in soil), but reference building materials may not be available.

Because reference materials are prepared and homogenized as part of the certification process, they are rarely available as double-blind samples. When appropriate reference materials are available (i.e., proper matrix, proper radionuclide, proper concentration range) they are recommended for use in determining the overall bias for a measurement system. For scanning and direct measurements a known amount of reference material is sealed in a known geometry. This known material is measured in the field using a specified protocol (e.g., specified measurement time at a specified distance from the reference material) to evaluate the performance of the instrument only.

- Performance Evaluation (PE) Samples. PE samples are used to evaluate the bias of the instrument and detect any error in the instrument calibration. These samples are usually prepared by a third party, using a quantity of analyte(s) which is known to the preparer but unknown to the operator, and always undergo certification analysis. The analyte(s) 
used to prepare the PE sample is the same as the analyte(s) of interest (EPA 1991g). PE samples are recommended for use in determining bias for a measurement system when appropriate reference materials are not available. PE samples are equivalent to matrix spikes prepared by a third party that undergo certification analysis and can be non-blind or single-blind when used to measure bias for scanning and direct measurements.

- $\quad$ Matrix Spike Samples. Matrix spike samples are environmental samples that are spiked in the laboratory with a known concentration of a target analyte(s) to verify percent recoveries. They are primarily used to check sample matrix interferences but can also be used in the field to monitor instrument performance (EPA 1991g). Matrix Spike samples are often replicated to monitor a method's performance and evaluate bias and precision (when four or more pairs are analyzed). These replicates are often collectively referred to as a matrix spike/matrix spike duplicate (MS/MSD).

- Calibration Checks. Calibration checks are measurements performed to verify instrument performance each time an instrument is used (see Section 6.5.4). These checks may be qualitative or quantitative. Operators use qualitative checks to determine if an instrument is operating properly and can be used to perform measurements. Quantitative calibration checks require a specified protocol to measure a calibration source with a known instrument response, and the results are documented to provide a record of instrument precision and bias. The results of quantitative calibration checks are typically recorded on a control chart (see Section 6.2.2.7). Note that the calibration check source does not need to be traceable for qualitative or quantitative calibration checks as long as the instrument response has been adequately established (see Section 6.5.4). Because calibration checks are non-blind measurements they are only recommended when other types of QC measurements are not available.

Quality control measurements can also be used to estimate bias caused by contamination.

- Background Measurement. A background measurement is a measurement performed upgradient of the area of potential contamination (either onsite or offsite) where there is little or no chance of migration of the contaminants of concern (EPA 1991g). Background measurements are performed in the background reference area (Section 4.5), determine the natural composition and variability of the material of interest (especially important in areas with high concentrations of naturally occurring radionuclides), and are considered "clean." They provide a basis for comparison of contaminant concentration levels with measurements performed in the survey unit when the statistical tests described in Chapter 8 are performed. 
Field Measurement Methods and Instrumentation

- Measurement Blanks. Measurement blanks are samples prepared in the laboratory using certified clean sand or soil and brought to the field to monitor contamination for scanning and direct measurements. A measurement blank is used to evaluate contamination error associated with the instrument used to perform measurements in the field. Measurement blanks are recommended for determining bias resulting from contamination of instruments used for scanning and direct measurements.

\subsubsection{Representativeness}

Representativeness is a measure of the degree to which data accurately and precisely represent a characteristic of a population parameter at a sampling point (ASQC 1995) or measurement location. Representativeness is a qualitative term that is reflected in the survey design through the selection of a measurement method (e.g., direct measurement or sampling).

Sample collection and analysis is typically less representative of true radionuclide concentrations at a specific measurement location than performing a direct measurement. This is caused by the additional steps required in collecting and analyzing samples, such as sample collection, field sample preparation, laboratory sample preparation, and radiochemical analysis. However, direct measurement techniques with acceptable detection limits are not always available. The location of the direct measurement is determined in Section 5.5.2.5, where random and systematic survey designs are selected based on survey unit classification. The coverage for a survey unit using scanning techniques is discussed in Section 5.5.3 and is also based primarily on survey unit classification. Because scanning locations are often selected based on professional judgment for survey units with less than $100 \%$ coverage, representativeness of these locations may be a concern. For both scanning and direct measurements the measurement locations and method for performing the measurements should be compared to the modeling assumptions used to develop the DCGLs.

\subsubsection{Comparability}

Comparability is a qualitative term that expresses the confidence that two data sets can contribute to a common analysis and interpolation. Generally, comparability is provided by using the same measurement system for all analyses of a specific radionuclide. Comparability is usually not an issue except in cases where historical data has been collected and is being compared to current analytical results, or when multiple laboratories are used to provide results as part of a single survey design.

\subsubsection{Completeness}

Completeness is a measure of the amount of valid data obtained from the measurement system. This is expressed as a percentage of the number of valid measurements that should have been 
collected. Completeness is of greater concern for laboratory analyses than for direct measurements because the consequences of incomplete data often require the collection of additional data. Completeness is a concern for scanning only if the scanning results are invalidated for some reason. Direct measurements and scans can usually be repeated fairly easily while the personnel performing the measurements are still in the field. For this reason MARSSIM strongly recommends that scanning and direct measurement results be evaluated as soon as possible. Direct measurements performed on a systematic grid to locate areas of elevated activity are also a concern for completeness. If one direct measurement result is not valid, the entire survey design for locating areas of elevated activity may be invalidated.

\subsubsection{Other Data Quality Indicators}

Several additional data quality indicators that influence the final status survey design are identified as DQOs in Section 2.3.1. Many of these (e.g., selection and classification of survey units, decision error rates, variability in the contaminant concentration, lower bound of the gray region) are used to determine the number of measurements and are discussed in detail in Section 5.5.2. The method detection limit is directly related to the selection of a measurement method and a specific measurement system.

Scanning and direct measurement techniques should be capable of measuring levels below the established DCGLs - detection limits of 10-50\% of the DCGL should be the target (see Section 6.7). Cost, time, best available technology, or other constraints may create situations where the above stated sensitivities are deemed impractical. Under these circumstances, higher detection sensitivities may be acceptable. Although service providers and instrument manufacturers will state detection limits, these sensitivities are usually based on ideal or optimistic situations and may not be achievable under site-specific measurement conditions. Detection limits are subject to variation from measurement to measurement, instrument to instrument, operator to operator, and procedure to procedure. This variation depends on geometry, background, instrument calibration, abundance of the radiations being measured, counting time, operator training, operator experience, self-absorption in the medium being measured, and interferences from radionuclides or other materials present in the medium. The detection limit that is achievable in practice should not exceed the DCGL.

\subsubsection{Using Control Charts to Provide Control of Field Measurement Systems}

Control charts are commonly used in radioanalytical laboratories to monitor the performance of laboratory instruments. Control charts are also useful for monitoring the performance of field instruments and can be used to help control field measurement systems.

A control chart is a graphical plot of measurement results with respect to time or sequence of measurement, together with limits within in which the measurement values are expected to lie 
when the system is in a state of statistical control (DOE 1995). Calibration check results are typically plotted on control charts for field measurements. However, control charts may be developed for any measurements where the expected performance is established and documented. A separate set of control charts for monitoring each type of measurement (e.g., calibration check, background, measurement of PE samples) should be developed for each instrument.

The control chart is constructed by preparing a graph showing the arithmetic mean and the control limits as horizontal lines. The recommended control limits are two standard deviations above and below the mean, and three standard deviations above and below the mean. The measurement results in the appropriate units are shown on the $y$-axis and time or sequence is plotted using the $\mathrm{X}$-axis. Detailed guidance on the development and use of control charts is available in Quality Assurance of Chemical Measurements (Taylor 1987) and Statistical Methods for Quality Improvement (Kume 1985).

As the quality control or other measurements are performed, the results are entered on the control chart. If the results are outside the control limits or show a particular trend or tendency, then the process is not in control. The control chart documents the performance of the measurement system during the time period of interest.

Quality control measurements for field instruments may be difficult or expensive to obtain for some surveys. In these cases control charts documenting instrument performance may represent the only determination of precision and bias for the survey. Because control charts are non-blind measurements they are generally not appropriate for estimating precision and bias. However, the control chart documents the performance of the field instruments. Provided the checks for precision and bias fall within the control limits, the results obtained using that instrument should be acceptable for the survey.

\subsection{Selecting a Service Provider to Perform Field Data Collection Activities}

One of the first steps in designing a survey is to select a service provider to perform field data collection activities. MARSSIM recommends that this selection take place early in the planning process so that the service provider can provide information during survey planning and participate in the design of the survey. Service providers may include in-house experts in field measurements and sample collection, health physics companies, or environmental engineering firms among others.

When the service provider is not part of the organization responsible for the site, these services are obtained using some form of procurement mechanism. Examples of procurement mechanisms include purchase orders or contracts. A graded approach should be used in determining the appropriate method for procuring services. 
Field Measurement Methods and Instrumentation

Potential service providers should be evaluated to determine their ability to perform the necessary analyses. For large or complex sites, this evaluation may take the form of a pre-award audit. The results of this audit provide a written record of the decision to use a specific service provider. For less complex sites or facilities, a review of the potential service provider's qualifications is sufficient for the evaluation.

There are six criteria that should be reviewed during this evaluation:

- Does the service provider possess the validated Standard Operating Procedures (SOPs), appropriate instrumentation, and trained personnel necessary to perform the field data collection activities? Field data collection activities (e.g., scanning surveys, direct measurements, and sample collection) are defined by the data needs identified by the DQO process.

- Is the service provider experienced in performing the same or similar data collection activities?

- Does the service provider have satisfactory performance evaluation or technical review results? The service provider should be able to provide a summary of QA audits and QC measurement results to demonstrate proficiency. Equipment calibrations should be performed using National Institute of Standards and Technology (NIST) traceable reference radionuclide standards whenever possible.

- Is there an adequate capacity to perform all field data collection activities within the desired timeframe? This criterion considers the number of trained personnel and quantity of calibrated equipment available to perform the specified tasks.

- Does the service provider conduct an internal quality control review of all generated data that is independent of the data generators?

- $\quad$ Are there adequate protocols for method performance documentation, sample tracking and security (if necessary), and documentation of results?

Potential service providers should have an active and fully documented quality system in place. ${ }^{1}$ This system should enable compliance with the objectives determined by the DQO process in Section 2.3 and Appendix D (see EPA 1994c). The elements of a quality management system are discussed in Section 9.1 (ASQC 1995, EPA 1994f).

\footnotetext{
1 The quality management system is typically documented in one or more documents such as a Quality Management Plan (QMP) or Quality Assurance Manual (QAM). A description of quality systems is included in Section 9.1.
} 
Field Measurement Methods and Instrumentation

\subsection{Measurement Methods}

Measurement methods used to generate field data can be classified into two categories commonly known as scanning surveys and direct measurements. The decision to use a measurement method as part of the survey design is determined by the survey objectives and the survey unit classification. Scanning is performed to identify areas of elevated activity that may not be detected by other measurement methods. Direct measurements are analogous to collecting and analyzing samples to determine the average activity in a survey unit. Section 5.5.3 discusses ' combining scans and direct measurements in an integrated survey design.

\subsubsection{Direct Measurements}

To conduct direct measurements of alpha, beta, and photon surface activity, instruments and techniques providing the required detection sensitivity are selected. The type of instrument and method of performing the direct measurement are selected as dictated by the type of potential contamination present, the measurement sensitivity requirements, and the objectives of the radiological survey. Direct measurements are taken by placing the instrument at the appropriate distance $^{2}$ above the surface, taking a discrete measurement for a pre-determined time interval (e.g., $10 \mathrm{~s}, 60 \mathrm{~s}$, etc.), and recording the reading. A one minute integrated count technique is a practical field survey procedure for most equipment and provides detection sensitivities that are below most DCGLs. However, longer or shorter integrating times may be warranted (see Section 6.4.1 for information dealing with the calculation of direct measurement detection sensitivities).

Direct measurements may be collected at random locations in the survey unit. Alternatively, direct measurements may be collected at systematic locations and supplement scanning surveys for the identification of small areas of elevated activity (see Section 5.5.2.5). Direct measurements may also be collected at locations identified by scanning surveys as part of an investigation to determine the source of the elevated instrument response. Professional judgment may also be used to identify location for direct measurements to further define the areal extent of contamination and to determine maximum radiation levels within an area, although these types of direct measurements are usually associated with preliminary surveys (i.e., scoping, characterization, remedial action support). All direct measurement locations and results should be documented.

\footnotetext{
${ }^{2}$ Measurements at several distances may be needed. Near-surface or surface measurements provide the best indication of the size of the contaminated region and are useful for model implementation. Gamma measurements at $1 \mathrm{~m}$ provide a good estimate of potential direct external exposure.
} 
If the equipment and methodology used for scanning is capable of providing data of the same quality required for direct measurement (e.g., detection limit, location of measurements, ability to record and document results), then scanning may be used in place of direct measurements. Results should be documented for at least the number of locations required for the statistical tests. In addition, some direct measurement systems may be able to provide scanning data, provided they meet the objectives of the scanning survey.

The following sections briefly describe methods used to perform direct measurements in the field. The instruments used to perform these measurements are described in more detail in Section 6.5.3 and Appendix $\mathrm{H}$.

\subsubsection{Direct Measurements for Photon Emitting Radionuclides}

There are a wide variety of instruments available for measuring photons in the field (see Appendix $\mathrm{H}$ ) but all of them are used in essentially the same way. The detector is set up at a specified distance from the surface being measured and data are collected for a specified period of time. The distance from the surface to the detector is generally determined by the calibration of the instrument because photons do not interact appreciably with air. When measuring $x$-rays or low-energy gamma rays, the detector is often placed closer to the surface to increase the counting efficiency. The time required to perform a direct measurement may vary from very short (e.g., 10 seconds) to very long (e.g., several days or weeks) depending on the type of detector and the required detection limit. In general, the lower the required detection limit the longer the time required to perform the measurement. A collimator may be used in areas where activity from adjacent or nearby areas might interfere with the direct measurement. The collimator (usually lead, tungsten, or steel) shields the detector from extraneous photons but allows activity from a specified area of the surface to reach the detector.

\section{Example:}

The portable germanium detector, or in situ gamma spectrometer, can be used to estimate gamma-emitting radionuclide concentrations in the field. As with the laboratory-based germanium detector with multichannel analyzer, in situ gamma spectrometry can discriminate among various radionuclides on the basis of characteristic gamma and $\mathrm{x}$-ray energies to provide a nuclide-specific measurement. A calibrated detector measures the fluence rate of primary photons at specific energies that are characteristic of a particular radionuclide (NRC 1995b). This fluence rate can then be converted to units of concentration. Under certain conditions the fluence rate may be converted directly to dose or risk for a direct comparison to the release criterion rather than to the $\mathrm{DCGL}_{\mathrm{w}}$. Although this conversion is generally made, the fluence rate should be considered the fundamental parameter for assessing the level of radiation at a specific location because it is a directly measurable physical quantity. 
For outdoor measurements, where the contaminant is believed to be distributed within the surface soil, it may be appropriate to assume a uniform depth profile when converting the fluence rate to a concentration. At sites where the soil is plowed or overturned regularly, this assumption is quite realistic because of the effects of homogenization. At sites where the activity was initially deposited on the surface and has gradually penetrated deeper over time, the actual depth profile will have a higher activity at the surface and gradually diminish with depth. In this case, the assumption of a uniform depth profile will estimate a higher radionuclide concentration relative to the average concentration over that depth. In cases where there is an inverted depth proilie (i.e., low concentration at the surface that increase with depth), the assumption of a uniform depth profile will underestimate the average radionuclide concentration over that depth. For this reason, MARSSIM recommends that soil cores be collected to determine the actual depth profile for the site. These soil cores may be collected during the characterization or remedial action support survey to establish a depth profile for planning a final status survey. The cores may also be collected during the final status survey to verify the assumptions used to develop the fluence-to-concentration correction.

For indoor measurements, uncollimated in situ measurements can provide useful information on the low-level average activity across an entire room. The position of the measurement within the room is not critical if the radionuclide of interest is not present in the building materials. A measurement of peak count rate can be converted to fluence rate, which can in turn be related to the average surface activity. The absence of a discernible peak would mean that residual activity could not exceed a certain average level. However, this method will not easily locate small areas of elevated activity. For situations where the activity is not uniformly distributed on the surface, a series of collimated measurements using a systematic grid allows the operator to identify general areas of elevated contamination.

The NRC draft report Measurement Methods for Radiological Surveys in Support of New Decommissioning Criteria (NRC 1995b) provides a detailed description of the theory and implementation of in situ gamma spectrometry. In situ spectrometry is provided as one example of a useful tool for performing direct measurements for particular scenarios, but interpretation of the instrument output in terms of radionuclide distributions is dependent on the assumptions used to calibrate the method site-specifically. The depth of treatment of this technique in this example is not meant to imply that in situ gamma spectrometry is preferred a priori over other appropriate measurement techniques described in this manual. 


\subsubsection{Direct Measurements for Alpha Emitting Radionuclides}

Direct measurements for alpha-emitting radionuclides are generally performed by placing the detector on or near the surface to be measured. The limited range of alpha particles (e.g., about $1 \mathrm{~cm}$ or $0.4 \mathrm{in}$. in air, less in denser material) means that these measurements are generally restricted to relatively smooth, impermeable surfaces such as concrete, metal, or drywall where the activity is present as surface contamination. In most cases, direct measurements of porous (e.g., wood) and volumetric (e.g., soil, water) material cannot meet the objectives of the survey. However, special instruments such as the long range alpha detector (see Appendix $\mathrm{H}$ ) have been developed to measure the concentration of alpha emitting radionuclides in soil under certain conditions. Because the detector is used in close proximity to the potentially contaminated surface, contamination of the detector or damage to the detector caused by irregular surfaces need to be considered before performing direct measurements for alpha emitters.

\subsubsection{Direct Measurements for Beta Emitting Radionuclides}

Direct measurements for beta emitting radionuclides are generally performed by placing the detector on or near the surface to be measured, similar to measurements for alpha emitting radionuclides. These measurements are typically restricted to relatively smooth, impermeable surfaces where the activity is present as surface contamination. In most cases, direct measurements of porous (e.g., wood) and volumetric (e.g., soil, water) material cannot meet the objectives of the survey. However, special instruments such as large area gas-flow proportional counters (see Appendix $\mathrm{H}$ ) and arrays of beta scintillators have been developed to measure the concentration of beta emitting radionuclides in soil under certain conditions. Similar to direct measurements for alpha emitting radionuclides, contamination of the detector and damage to the detector need to be considered before performing direct measurements for beta emitters.

\subsubsection{Scanning Surveys}

Scanning is the process by which the operator uses portable radiation detection instruments to detect the presence of radionuclides on a specific surface (i.e., ground, wall, floor, equipment). The term scanning survey is used to describe the process of moving portable radiation detectors across a suspect surface with the intent of locating radionuclide contamination. Investigation levels for scanning surveys are determined during survey planning to identify areas of elevated activity. Scanning surveys are performed to locate radiation anomalies indicating residual gross activity that may require further investigation or action. These investigation levels may be based on the $\mathrm{DCGL}_{\mathrm{w}}$, the $\mathrm{DCGL}_{\mathrm{EMC}}$, or some other level as discussed in Section 5.5.2.6. 
Small areas of elevated activity typically represent a small portion of the site or survey unit. Thus, random or systematic direct measurements or sampling on the commonly used grid spacing may have a low probability of identifying such small areas. Scanning surveys are often relatively quick and inexpensive to perform. For these reasons, scanning surveys are typically performed before direct measurements or sampling. This way time is not spent fully evaluating an area that may quickly prove to be contaminated above the investigation level during the scanning process. Scans are conducted which would be indicative of all radionuclides potentially present, based on the Historical Site Assessment, surfaces to be surveyed, and survey design objectives. Surrogate measurements may be utilized where appropriate (see Section 4.3.2). Documenting scanning results and observations from the field is very important. For example, a scan that identified relatively sharp increases in instrument response or identified the boundary of an area of increased instrument response should be documented. This information is useful when interpreting survey results.

The following sections briefly describe techniques used to perform scanning surveys for different types of radiation. The instruments used to perform these measurements are described in more detail in Section 6.5.3 and Appendix $\mathrm{H}$.

\subsubsection{Scanning for Photon Emitting Radionuclides}

Sodium iodide survey meters (NaI(Tl) detectors) are normally used for scanning areas for gamma emitters because they are very sensitive to gamma radiation, easily portable and relatively inexpensive. The detector is held close to the ground surface $(\sim 6 \mathrm{~cm}$ or $2.5 \mathrm{in}$.) and moved in a serpentine (i.e., snake like, "S" shaped) pattern while walking at a speed that allows the investigator to detect the desired investigation level. A scan rate of approximately $0.5 \mathrm{~m} / \mathrm{s}$ is typically used for distributed gamma emitting contaminants in soil; however, this rate must be adjusted depending on the expected detector response and the desired investigation level. Discussion of scanning rates versus detection sensitivity for gamma emitters is provided in Section 6.7.2.1.

Sodium iodide survey meters are also used for scanning to detect areas with elevated areas of low-energy gamma and $\mathrm{x}$-ray emitting radionuclides such as ${ }^{241} \mathrm{Am}$ and ${ }^{239} \mathrm{Pu}$. Specially designed detectors, such as the FIDLER (field instrument for the detection of low energy radiation) probe with survey meter, are typically used to detect these types of radionuclides.

\subsubsection{Scanning for Alpha Emitting Radionuclides}

Alpha scintillation survey meters and thin window gas-flow proportional counters are typically used for performing alpha surveys. Alpha radiation has a very limited range and, therefore, instrumentation must be kept close to the surface-usually less than $1 \mathrm{~cm}(0.4$ in.). For this reason, alpha scans are generally performed on relatively smooth, impermeable surfaces (e.g., 
concrete, metal, drywall) and not on porous material (e.g., wood) or for volumetric contamination (e.g., soil, water). In most cases, porous and volumetric contamination cannot be detected by scanning for alpha activity and meet the objectives of the survey because of high detection sensitivities. Under these circumstances, samples of the material are usually collected and analyzed as discussed in Chapter 7 . Determining scan rates when surveying for alpha emitters is discussed in Section 6.7.2.2 and Appendix J.

\subsubsection{Scanning for Beta Emitting Radionuclides}

Thin window gas-flow proportional counters are normally used when surveying for beta emitters, although solid scintillators designed for this purpose are also available. Typically, the beta detector is held less than $2 \mathrm{~cm}$ from the surface and moved at a rate such that the desired investigation level can be detected. Low-energy $(<100 \mathrm{keV})$ beta emitters are subject to the same interferences and self-absorption problems found with alpha emitting radionuclides, and scans for these radionuclides are performed under similar circumstances. Determination of scan rates when surveying for beta emitters is discussed in Section 6.7.2.1.

\subsection{Radiation Detection Instrumentation}

Traditional radiation instruments consist of two components: 1) a radiation detector, and 2) electronic equipment to provide power to the detector and to display or record radiation events. This section identifies and very briefly describes the types of radiation detectors and associated display or recording equipment that are applicable to survey activities in support of environmental assessment or remedial action. Each survey usually requires performing direct field measurements using portable instrumentation and collection of samples for laboratory analysis. The selection and proper use of appropriate instruments for both direct measurements and laboratory analyses will likely be the most critical factors in assuring that the survey accurately determines the radiological status of a site and meets the survey objectives. Chapter 7 provides specific information on laboratory analysis of collected samples. Appendix $\mathrm{H}$ contains instrument specific information for various types of field survey and laboratory analysis equipment currently in use.

\subsubsection{Radiation Detectors}

The particular capabilities of a radiation detector will establish its potential applications in conducting a specific type of survey. Radiation detectors can be divided into four general classes based on the detector material or the application. These categories are: 1) gas-filled detectors, 2) scintillation detectors, 3) solid-state detectors, and 4) passive integrating detectors. 
Field Measurement Methods and Instrumentation

\subsubsection{Gas-Filled Detectors}

Radiation interacts with the fill gas, producing ion-pairs that are collected by charged electrodes. Commonly used gas-filled detectors are categorized as ionization, proportional, or GeigerMueller (GM), referring to the region of gas amplification in which they are operated. The fill gas varies, but the most common are: 1) air, 2) argon with a small amount of organic methane (usually $10 \%$ methane by mass, referred to as P-10 gas), and 3) argon or helium with a small amount of a halogen such as chlorine or bromine added as a quenching agent.

\subsubsection{Scintillation Detectors}

Radiation interacts with a solid or liquid medium causing electronic transitions to excited states in a luminescent material. The excited states decay rapidly, emitting photons that in turn are captured by a photomultiplier tube. The ensuing electrical signal is proportional to the scintillator light output, which, under the right conditions, is proportional to the energy loss that produced the scintillation. The most common scintillant materials are $\mathrm{NaI}(\mathrm{Tl}), \mathrm{ZnS}(\mathrm{Ag}), \mathrm{Cd}(\mathrm{Te})$, and $\mathrm{CsI}(\mathrm{Tl})$ which are used in traditional radiation survey instruments such as the NaI(Tl) detector used for gamma surveys and the $\mathrm{ZnS}(\mathrm{Ag})$ detector for alpha surveys.

\subsubsection{Solid-State Detectors}

Radiation interacting with a semiconductor material creates electron-hole pairs that are collected by a charged electrode. The design and operating conditions of a specific solid-state detector determines the types of radiations (alpha, beta, and/or gamma) that can be measured, the detection level of the measurements, and the ability of the detector to resolve the energies of the interacting radiations. The semiconductor materials currently being used are germanium and silicon which are available in both $\mathrm{n}$ and $\mathrm{p}$ types in various configurations.

Spectrometric techniques using these detectors provide a marked increase in sensitivity in many situations. When a particular radionuclide contributes only a fraction of the total particle or photon fluence, or both, from all sources (natural or manmade background), gross measurements are inadequate and nuclide-specific measurements are necessary. Spectrometry provides the means to discriminate among various radionuclides on the basis of characteristic energies. Insitu gamma spectrometry is particularly effective in field measurements since the penetrating nature of the radiation allows one to "see" beyond immediate surface contamination. The availability of large, high efficiency germanium detectors permits measurement of low abundance gamma emitters such as ${ }^{238} \mathrm{U}$ as well as low energy emitters such as ${ }^{241} \mathrm{Am}$ and ${ }^{239} \mathrm{Pu}$. 
Field Measurement Methods and Instrumentation

\subsubsection{Passive Integrating Detectors}

There is an additional class of instruments that consists of passive, integrating detectors and associated reading/analyzing instruments. The integrated ionization is read using a laboratory or hand-held reader. This class includes thermoluminescence dosimeters (TLDs) and electret ion chambers (EICs). Because these detectors are passive and can be exposed for relatively long periods of time, they can provide better sensitivity for measuring low activity levels such as free release limits or for continuing surveillance. The ability to read and present data onsite is a useful feature and such systems are comparable to direct reading instruments.

The scintillation materials in Section 6.5.1.2 are selected for their prompt fluorescence characteristics. In another class of inorganic crystals, called TLDs, the crystal material and impurities are chosen so that the free electrons and holes created following the absorption of energy from the radiation are trapped by impurities in the crystalline lattice thus locking the excitation energy in the crystal. Such materials are used as passive, integrating detectors. After removal from the exposure area, the TLDs are heated in a reader which measures the total amount of light produced when the energy is released. The total amount of light is proportional to the number of trapped, excited electrons, which in turn is proportional to the amount of energy absorbed from the radiation. The intensity of the light emitted from the thermoluminescent crystals is thus directly proportional to the radiation dose. TLDs come in a large number of materials, the most common of which are $\mathrm{LiF}, \mathrm{CaF}_{2}: \mathrm{Mn}, \mathrm{CaF}_{2}: \mathrm{Dy}, \mathrm{CaSO}_{4}: \mathrm{Mn}, \mathrm{CaSO}_{4}: \mathrm{Dy}$, $\mathrm{Al}_{2} \mathrm{O}_{3}: \mathrm{C}$.

The electret ion chamber consists of a very stable electret (a charged Teflon® disk) mounted inside a small chamber made of electrically charged plastic. The ions produced inside this air filled chamber are collected onto the electret, causing a reduction of its surface charge. The reduction in charge is a function of the total ionization during a specific monitoring period and the specific chamber volume. This change in voltage is measured with a surface potential voltmeter.

\subsubsection{Display and Recording Equipment}

Radiation detectors are connected to electronic devices to 1) provide a source of power for detector operation, and 2) enable measurement of the quantity and/or quality of the radiation interactions that are occurring in the detector. The quality of the radiation interaction refers to the amount of energy transferred to the detector. In many cases, radiation interacts with other material (e.g., air) prior to interacting with the detector, or only partially interacts with the detector (e.g., Compton scattering for photons). Because the energy recorded by the detector is affected, there is an increased probability of incorrectly identifying the radionuclide. 
The most common recording or display device used for portable radiation measurement systems is a ratemeter. This device provides a display on an analog meter representing the number of events occurring over some time period (e.g., counts per minute). Digital ratemeters are also commercially available. The number of events can also be accumulated over a preset time period using a digital scaling device. The resulting information from a scaling device is the total number of events that occurred over a fixed period of time, where a ratemeter display varies with time and represents a short term average of the event rate. Determining the average level on a ratemeter will require judgment by the user, especially when a low frequency of events results in significant variations in the meter reading.

Pulse height analyzers are specialized electronic devices designed to measure and record the number of pulses or events that occur at different pulse height levels. These types of devices are used with detectors which produce output pulses that are proportional in height to the energy deposited within them by the interacting radiation. They can be used to record only those events occurring in a detector within a single band of energy or can simultaneously record the events in multiple energy ranges. In the former case, the equipment is known as a single-channel analyzer; the latter application is referred to as a multichannel analyzer.

\subsubsection{Instrument Selection}

Radiation survey parameters that might be needed for site release purposes include surface activities, exposure rates, and radionuclide concentrations in soil. To determine these parameters, field measurements and laboratory analyses may be necessary. For certain radionuclides or radionuclide mixtures, both alpha and beta radiations may have to be measured. In addition to assessing average radiological conditions, the survey objectives should address identifying small areas of elevated activity and determining the extent and level of residual radioactivity.

Additionally, the potential uses of radiation instruments can vary significantly depending on the specific design and operating criteria of a given detector type. For example, a NaI(Tl) scintillator can be designed to be very thin with a low atomic number entrance window (e.g., beryllium) such that the effective detection capability for low energy photons is optimized. Conversely, the same scintillant material can be fabricated as a thick cylinder in order to optimize the detection probability for higher energy photons. On the recording end of a detection system, the output could be a ratemeter, scaler, or multichannel analyzer as described in Section 6.5.2. Operator variables such as training and level of experience with specific instruments should also be considered.

With so many variables, it is highly unlikely that any single instrument (detector and readout combination) will be capable of adequately measuring all of the radiological parameters necessary to demonstrate that criteria for release have been satisfied. It is usually necessary to select multiple instruments to perform the variety of measurements required. 
Selection of instruments will require an evaluation of a number of situations and conditions. Instruments must be stable and reliable under the environmental and physical conditions where they will be used, and their physical characteristics (size and weight) should be compatible with the intended application. The instrument must be able to detect the type of radiation of interest, and the measurement system should be capable of measuring levels that are less than the DCGL (see Section 6.7).

For gamma radiation scanning, a scintillation detector/ratemeter combination is the usual instrument of choice. A large-area proportional detector with a ratemeter is recommended for scanning for alpha and beta radiations where surface conditions and locations permit; otherwise, an alpha scintillation or thin-window GM detector (for beta surveys) may be used.

For direct gamma measurements, a pressurized ionization chamber or in-situ gamma spectroscopy system is recommended. As an option, a NaI(Tl) scintillation detector may be used if cross-calibrated to a pressurized ion chamber or calibrated for the specific energy of interest. The same alpha and beta detectors identified above for scanning surveys are also recommended for use in direct measurements.

There are certain radionuclides that, because of the types, energies, and abundances of their radiations, will be essentially impossible to measure at the guideline levels, under field conditions, using state-of-the-art instrumentation and techniques. Examples of such radionuclides include very low energy pure beta emitters, such as ${ }^{3} \mathrm{H}$ and ${ }^{63} \mathrm{Ni}$, and low energy photon emitters, such as ${ }^{55} \mathrm{Fe}$ and ${ }^{125} \mathrm{I}$. Pure alpha emitters dispersed in soil or covered with some absorbing layer will not be detectable because the alpha radiation will not penetrate through the media or covering to reach the detector. A common example of such a condition would be ${ }^{230} \mathrm{Th}$ surface contamination covered by paint, dust, oil, or moisture. In such circumstances, sampling and laboratory analysis would be required to measure the residual activity levels unless surrogate radionuclides are present as discussed in Section 4.3.2.

The number of possible design and operating schemes for each of the different types of detectors is too large to discuss in detail within the context of this document. For a general overview, lists of common radiation detectors along with their usual applications during surveys are provided in Tables 6.1 through 6.3. Appendix $\mathrm{H}$ contains specific information for various types of field survey and laboratory analysis equipment currently in use. Continual development of new technologies will result in changes to these listings. 
Field Measurement Methods and Instrumentation

Table 6.1 Radiation Detectors with Applications to Alpha Surveys

\begin{tabular}{|c|c|c|c|}
\hline Detector Type- & Detector Description & Application & Remarks \\
\hline Gas Proportional & $\begin{array}{l}<1 \mathrm{mg} / \mathrm{cm}^{2} \text { window; probe area } \\
50 \text { to } 1000 \mathrm{~cm}^{2} \\
<0.1 \mathrm{mg} / \mathrm{cm}^{2} \text { window; probe area } \\
10 \text { to } 20 \mathrm{~cm}^{2} \\
\text { No window (internal proportional) }\end{array}$ & $\begin{array}{l}\text { Surface scanning; surface } \\
\text { contamination measurement } \\
\text { Laboratory measurement of } \\
\text { water, air, and smear samples } \\
\text { Laboratory measurement of } \\
\text { water, air, and smear samples }\end{array}$ & $\begin{array}{l}\text { Requires a supply } \\
\text { of appropriate fill } \\
\text { gas }\end{array}$ \\
\hline Air Proportional & $\begin{array}{l}<1 \mathrm{mg} / \mathrm{cm}^{2} \text { window; probe area } \\
\sim 50 \mathrm{~cm}^{2}\end{array}$ & $\begin{array}{l}\text { Useful in low humidity } \\
\text { conditions }\end{array}$ & \\
\hline Scintillation & $\begin{array}{l}\mathrm{ZnS}(\mathrm{Ag}) \text { scintillator; probe area } \\
50 \text { to } 100 \mathrm{~cm}^{2} \\
\mathrm{ZnS}(\mathrm{Ag}) \text { scintillator; probe area } \\
10 \text { to } 20 \mathrm{~cm}^{2} \\
\text { Liquid scintillation cocktail } \\
\text { containing sample }\end{array}$ & $\begin{array}{l}\text { Surface contamination } \\
\text { measurements, smears } \\
\text { Laboratory measurement of } \\
\text { water, air, and smear samples } \\
\text { Laboratory analysis, } \\
\text { spectrometry capabilities }\end{array}$ & \\
\hline Solid State & Silicon surface barrier detector & $\begin{array}{l}\text { Laboratory analysis by alpha } \\
\text { spectrometry }\end{array}$ & \\
\hline $\begin{array}{l}\text { Passive, } \\
\text { integrating } \\
\text { electret ion } \\
\text { chamber }\end{array}$ & $\begin{array}{l}<0.8 \mathrm{mg} / \mathrm{cm}^{2} \text { window, also } \\
\text { window-less, window area } 50-180 \\
\mathrm{~cm}^{2} \text {, chamber volume } 50-1,000 \mathrm{ml}\end{array}$ & $\begin{array}{l}\text { Contamination on surfaces, in } \\
\text { pipes and in soils }\end{array}$ & $\begin{array}{l}\text { Useable in high } \\
\text { humidity and } \\
\text { temperature }\end{array}$ \\
\hline
\end{tabular}

\subsubsection{Instrument Calibration}

Calibration refers to the determination and adjustment of the instrument response in a particular radiation field of known intensity. Proper calibration procedures are an essential requisite toward providing confidence in measurements made to demonstrate compliance with cleanup criteria. Certain factors, such as energy dependence and environmental conditions, require consideration in the calibration process, depending on the conditions of use of the instrument in the field. Routine calibration of radiation detection instruments refers to calibration for normal use under typical field conditions. Considerations for the use and calibration of instruments include: 
Table 6.2 Radiation Detectors with Applications to Beta Surveys

\begin{tabular}{|c|c|c|c|}
\hline Detector Type & Detector Description & Application & Remarks \\
\hline Gas Proportional & $\begin{array}{l}<1 \mathrm{mg} / \mathrm{cm}^{2} \text { window; probe area } \\
50 \text { to } 1,000 \mathrm{~cm}^{2} \\
<0.1 \mathrm{mg} / \mathrm{cm}^{2} \text { window; probe } \\
\text { area } 10 \text { to } 20 \mathrm{~cm}^{2} \\
\text { No window (internal } \\
\text { proportional) }\end{array}$ & $\begin{array}{l}\text { Surface scanning; surface } \\
\text { contamination measurement } \\
\text { Laboratory measurement of } \\
\text { water, air, smear, and other } \\
\text { samples } \\
\text { Laboratory measurement of } \\
\text { water, air, smear, and other } \\
\text { samples }\end{array}$ & $\begin{array}{l}\text { Requires a supply } \\
\text { of appropriate fill } \\
\text { gas }\end{array}$ \\
\hline $\begin{array}{l}\text { Ionization } \\
\text { (non-pressurized) }\end{array}$ & $1-7 \mathrm{mg} / \mathrm{cm}^{2}$ window & $\begin{array}{l}\text { Contamination measurements; } \\
\text { skin dose rate estimates }\end{array}$ & \\
\hline Geiger-Mueller & $\begin{array}{l}<2 \mathrm{mg} / \mathrm{cm}^{2} \text { window; probe area } \\
10 \text { to } 100 \mathrm{~cm}^{2} \\
\text { Various window thickness; few } \\
\mathrm{cm}^{2} \text { probe face }\end{array}$ & $\begin{array}{l}\text { Surface scanning; contamination } \\
\text { measurements; laboratory } \\
\text { analyses } \\
\text { Special scanning applications }\end{array}$ & \\
\hline Scintillation & $\begin{array}{l}\text { Liquid scintillation cocktail } \\
\text { containing sample } \\
\text { Plastic scintillator }\end{array}$ & $\begin{array}{l}\text { Laboratory analysis; } \\
\text { spectrometry capabilities } \\
\text { Contamination measurements }\end{array}$ & \\
\hline $\begin{array}{l}\text { Passive, } \\
\text { integrating } \\
\text { electret ion } \\
\text { chamber }\end{array}$ & $\begin{array}{l}7 \mathrm{mg} / \mathrm{cm}^{2} \text { window, also } \\
\text { window-less, window area } 50- \\
180 \mathrm{~cm}^{2} \text {, chamber volume } 50- \\
1,000 \mathrm{ml}\end{array}$ & $\begin{array}{l}\text { Low energy beta including } \mathrm{H}-3 \\
\text { contamination on surfaces and in } \\
\text { pipes }\end{array}$ & $\begin{array}{l}\text { Useable in high } \\
\text { humidity and } \\
\text { temperature }\end{array}$ \\
\hline
\end{tabular}

- use of the instrument for radiation of the type for which the instrument is designed

- use of the instrument for radiation energies within the range of energies for which the instrument is designed

- use under environmental conditions for which the instrument is designed

- use under influencing factors, such as magnetic and electrostatic fields, for which the instrument is designed

- use of the instrument in an orientation such that geotropic effects are not a concern

- use of the instrument in a manner that will not subject the instrument to mechanical or thermal stress beyond that for which it is designed 
Field Measurement Methods and Instrumentation

Table 6.3 Radiation Detectors with Applications to Gamma Surveys

\begin{tabular}{|c|c|c|c|}
\hline Detector Type & Detector Description & Application & Remarks \\
\hline Gas Ionization & $\begin{array}{l}\text { Pressurized ionization } \\
\text { chamber; Non-pressurized } \\
\text { ionization chamber }\end{array}$ & Exposure rate measurements & \\
\hline Geiger-Mueller & $\begin{array}{l}\text { Pancake }\left(<2 \mathrm{mg} / \mathrm{cm}^{2}\right. \\
\text { window) or side window } \\
\left(\sim 30 \mathrm{mg} / \mathrm{cm}^{2}\right)\end{array}$ & $\begin{array}{l}\text { Surface scanning; exposure } \\
\text { rate correlation (side window } \\
\text { in closed position) }\end{array}$ & $\begin{array}{l}\text { Low relative sensitivity to } \\
\text { gamma radiation }\end{array}$ \\
\hline Scintillation & $\begin{array}{l}\text { NaI(Tl) scintillator; up to } \\
5 \mathrm{~cm} \text { by } 5 \mathrm{~cm} \\
\text { NaI(Tl) scintillator; large } \\
\text { volume and "well" } \\
\text { configurations } \\
\text { CsI or NaI(Tl) scintillator; } \\
\text { thin crystal } \\
\text { Organic tissue equivalent } \\
\text { (plastics) }\end{array}$ & $\begin{array}{l}\text { Surface scanning; exposure } \\
\text { rate correlation } \\
\text { Laboratory gamma } \\
\text { spectrometry } \\
\text { Scanning; low-energy gamma } \\
\text { and x-rays } \\
\text { Dose equivalent rate } \\
\text { measurements }\end{array}$ & $\begin{array}{l}\text { High sensitivity; Cross } \\
\text { calibrate with PIC (or } \\
\text { equivalent) or for specific } \\
\text { site gamma energy mixture } \\
\text { for exposure rate } \\
\text { measurements. } \\
\text { Detection of low-energy } \\
\text { radiation }\end{array}$ \\
\hline Solid State & $\begin{array}{l}\text { Germanium semi- } \\
\text { conductor }\end{array}$ & $\begin{array}{l}\text { Laboratory and field gamma } \\
\text { spectrometry and } \\
\text { spectroscopy }\end{array}$ & \\
\hline $\begin{array}{l}\text { Passive, } \\
\text { integrating } \\
\text { electret ion } \\
\text { chamber }\end{array}$ & $\begin{array}{l}7 \mathrm{mg} / \mathrm{cm}^{2} \text { window, also } \\
\text { window-less, window area } \\
50-180 \mathrm{~cm}^{2} \text {, chamber } \\
\text { volume } 50-1,000 \mathrm{ml} \\
\end{array}$ & & $\begin{array}{l}\text { Useable in high humidity } \\
\text { and temperature }\end{array}$ \\
\hline
\end{tabular}

Routine calibration commonly involves the use of one or more sources of a specific radiation type and energy, and of sufficient activity to provide adequate field intensities for calibration on all ranges of concern.

Actual field conditions under which the radiation detection instrument will be used may differ significantly from those present during routine calibration. Factors which may affect calibration validity include: 
Field Measurement Methods and Instrumentation

- the energies of radioactive sources used for routine calibration may differ significantly from those of radionuclides in the field

- the source-detector geometry (e.g., point source or large area distributed source) used for routine calibration may be different than that found in the field

- the source-to-detector distance typically used for routine calibration may not always be achievable in the field

- the condition and composition of the surface being monitored (e.g., sealed concrete, scabbled concrete, carbon steel, stainless steel, and wood) and the presence of overlaying material (e.g., water, dust, oil, paint) may result in a decreased instrument response relative to that observed during routine calibration

If the actual field conditions differ significantly from the calibration assumptions, a special calibration for specific field conditions may be required. Such an extensive calibration need only be done once to determine the effects of the range of field conditions that may be encountered at the site. If responses under routine calibration conditions and proposed use conditions are significantly different, a correction factor or chart should be supplied with the instrument for use under the proposed conditions.

As a minimum, each measurement system (detector/readout combination) should be calibrated annually and response checked with a source following calibration (ANSI 1996). Instruments may require more frequent calibration if recommended by the manufacturer. Re-calibration of field instruments is also required if an instrument fails a performance check or if it has undergone repair or any modification that could affect its response.

The user may decide to perform calibrations following industry recognized procedures (ANSI 1978, DOE Order 5484.1, NCRP 1978, NCRP 1985, NCRP 1991, ISO 1988, HPS 1994a, HPS 1994b), or the user can choose to obtain calibration by an outside service, such as a major instrument manufacturer or a health physics services organization.

Calibration sources should be traceable to the National Institute of Standards and Technology (NIST). Where NIST traceable standards are not available, standards obtained from an industry recognized organization (e.g., the New Brunswick Laboratory for various uranium standards) may be used.

Calibration of instruments for measurement of surface contamination should be performed such that a direct instrument response can be accurately converted to the $4 \pi$ (total) emission rate from the source. An accurate determination of activity from a measurement of count rate above a surface in most cases is an extremely complex task because of the need to determine appropriate chacteristics of the source including decay scheme, geometry, energy, scatter, and selfabsorption. For the purpose of release of contaminated areas from radiological control, measurements must provide sufficient accuracy to ensure that cleanup standards have been 
achieved. Inaccuracies in measurements should be controlled in a manner that minimizes the consequences of decision errors. The variables that affect instrument response should be understood well enough to ensure that the consequences of decision errors are minimized. Therefore, the calibration should account for the following factors (where necessary):

- Calibrations for point and large area source geometries may differ, and both may be necessary if areas of activity smaller than the probe area and regions of activity larger than the probe area are present.

- Calibration should either be performed with the radionuclide of concern, or with appropriate correction factors developed for the radionuclide(s) present based on calibrations with nuclides emitting radiations similar to the radionuclide of concern.

- For portable instrumentation, calibrations should account for the substrate of concern (i.e., concrete, steel) or appropriate correction factors developed for the substrates relative to the actual calibration standard substrate. This is especially important for beta emitters because backscatter is significant and varies with the composition of the substrate. Conversion factors developed during the calibration process should be for the same counting geometry to be used during the actual use of the detector.

For cleanup standards for building surfaces, the contamination level is typically expressed in terms of the particle emission rate per unit time per unit area, normally $\mathrm{Bq} / \mathrm{m}^{2}$ or disintegrations per minute (dpm) per $100 \mathrm{~cm}^{2}$. In many facilities, surface contamination is assessed by converting the instrument response (in counts per minute) to surface activity using one overall total efficiency. The total efficiency may be considered to represent the product of two factors, the instrument (detector) efficiency, and the source efficiency. Use of the total efficiency is not a problem provided that the calibration source exhibits characteristics similar to the surface contamination (i.e., radiation energy, backscatter effects, source geometry, self-absorption). In practice, this is hardly the case; more likely, instrument efficiencies are determined with a clean, stainless steel source, and then those efficiencies are used to determine the level of contamination on a dust-covered concrete surface. By separating the efficiency into two components, the surveyor has a greater ability to consider the actual characteristics of the surface contamination.

The instrument efficiency is defined as the ratio of the net count rate of the instrument and the surface emission rate of a source for a specified geometry. The surface emission rate is defined as the number of particles of a given type above a given energy emerging from the front face of the source per unit time. The surface emission rate is the $2 \pi$ particle fluence that embodies both the absorption and scattering processes that effect the radiation emitted from the source. Thus, the instrument efficiency is determined by the ratio of the net count rate and the surface emission rate. 
The instrument efficiency is determined during calibration by obtaining a static count with the detector over a calibration source that has a traceable activity or surface emission rate. In many cases, a source emission rate is measured by the manufacturer and certified as NIST traceable. The source activity is then calculated from the surface emission rate based on assumed backscatter and self-absorption properties of the source. The maximum value of instrument efficiency is 1 .

The source efficiency is defined as the ratio of the number of particles of a given type emerging from the front face of a source and the number of particles of the same type created or released within the source per unit time. The source efficiency takes into account the increased particle emission due to backscatter effects, as well as the decreased particle emission due to selfabsorption losses. For an ideal source (i.e., no backscatter or self-absorption), the value of the source efficiency is 0.5 . Many real sources will exhibit values less than 0.5 , although values greater than 0.5 are possible, depending on the relative importance of the absorption and backscatter processes.

Source efficiencies may be determined experimentally. Alternatively, ISO-7503-1 (ISO 1988) makes recommendations for default source efficiencies. A source efficiency of 0.5 is recommended for beta emitters with maximum energies above $0.4 \mathrm{MeV}$. Alpha emitters and beta emitters with maximum beta energies between 0.15 and $0.4 \mathrm{MeV}$ have a recommended source efficiency of 0.25 . Source efficiencies for some common surface materials and overlaying material are provided in NUREG-1507 (NRC 1997b).

Instrument efficiency may be affected by detector-related factors such as detector size (probe surface area), window density thickness, geotropism, instrument response time, counting time (in static mode), scan rate (in scan mode), and ambient conditions such as temperature, pressure, and humidity. Instrument efficiency also depends on solid angle effects, which include source-todetector distance and source geometry.

Source efficiency may be affected by source-related factors such as the type of radiation and its energy, source uniformity, surface roughness and coverings, and surface composition (e.g., wood, metal, concrete).

The calibration of gamma detectors for the measurement of photon radiation fields should also provide reasonable assurance of acceptable accuracy in field measurements. Use of these instruments for demonstration of compliance with cleanup standards is complicated by the fact that most cleanup levels produce exposure rates of at most a few $\mu \mathrm{R} / \mathrm{h}$. Several of the portable survey instruments currently available in the United States for exposure rate measurements of $\sim 1 \mu \mathrm{R} / \mathrm{h}$ (often referred to as micro-R meters) have full scale intensities of $\sim 3$ to $5 \mu \mathrm{R} / \mathrm{h}$ on the first range. This is below the ambient background for most low radiation areas and most calibration laboratories. (A typical background dose equivalent rate of $100 \mathrm{mrem} / \mathrm{y}$ gives a 
background exposure rate of about $10 \mu \mathrm{R} / \mathrm{h}$.) Even on the second range, the ambient background in the calibration laboratory is normally a significant part of the range and must be taken into consideration during calibration. The instruments commonly are not energy-compensated and are very sensitive to the scattered radiation that may be produced by the walls and floor of the room or additional shielding required to lower the ambient background.

Low intensity sources and large distances between the source and detector can be used for lowlevel calibrations if the appropriate precautions are taken. Field characterization of low-level sources with traceable transfer standards is difficult because of the poor signal-to-noise ratio in the standard chamber. In order to achieve adequate ionization current, the distance between the standard chamber and the source generally will be as small as possible while still maintaining good geometry ( 5 to 7 detector diameters). Generally it is not possible to use a standard ionization chamber to characterize the field at the distance necessary to reduce the field to the level required for calibration. A high quality GM detector, calibrated as a transfer standard, may be useful at low levels.

Corrections for scatter can be made using a shadow-shield technique in which a shield of sufficient density and thickness to eliminate virtually all the primary radiation is placed about midway between the source and the detector. The dimensions of the shield should be the minimum required to reduce the primary radiation intensity at the detector location to less than $2 \%$ of its unshielded value. The change in reading caused by the shield being removed is attributed to the primary field from the source at the detector position.

In some instruments that produce pulses (GM counters or scintillation counters), the detector can be separated electronically from the readout electronics and the detector output can be simulated with a suitable pulser. Caution must be exercised to ensure that either the high voltage is properly blocked or that the pulser is designed for this application. If this can be accomplished, the instrument can first be calibrated on a higher range that is not affected by the ambient background and in a geometry where scatter is not a problem and, after disconnecting the detector, to provide the pulse-rate from the pulser which will give the same instrument response. The pulse rate can then be related to field strength and reduced to give readings on lower ranges (with the detector disconnected) even below the ambient background. This technique does not take account of any inherent detector background independent of the external background.

Ionization chambers are commonly used to measure radiation fields at very low levels. In order to obtain the sensitivity necessary to measure these radiation levels, the instruments are frequently very large and often pressurized. These instruments have the same calibration problems as the more portable micro-R meters described above. The same precautions (shadow shield) must be taken to separate the response of the instrument to the source and to scattered radiation. Generally, it is not possible to substitute an electronic pulser for the radiation field in these instruments. 
For energy-dependent gamma scintillation instruments, such as NaI(Tl) detectors, calibration for the gamma energy spectrum at a specific site may be accomplished by comparing the instrument response to that of a pressurized ionization chamber, or equivalent detector, at different locations on the site. Multiple radionuclides with various photon energies may also be used to calibrate the system for the specific energy of interest.

In the interval between calibrations, the instrument should receive a performance check prior to use. In some cases, a performance check following use may also provide valuable information. This calibration check is merely intended to establish whether or not the instrument is operating within certain specified, rather large, uncertainty limits. The initial performance check should be conducted following the calibration by placing the source in a fixed, reproducible location and recording the instrument reading. The source should be identified along with the instrument, and the same check source should be used in the same fashion to demonstrate the instrument's operability on a daily basis when the instrument is in use. For analog readout (count rate) instruments, a variation of $\pm 20 \%$ is usually considered acceptable. Optionally, instruments that integrate events and display the total on a digital readout typically provide an acceptable average response range of 2 or 3 standard deviations. This is achieved by performing a series of repetitive measurements (10 or more is suggested) of background and check source response and determining the average and standard deviation of those measurements. From a practical standpoint, a maximum deviation of $\pm 20 \%$ is usually adequate when compared with other uncertainties associated with the use of the equipment. The amount of uncertainty allowed in the response checks should be consistent with the level of uncertainty allowed in the final data. Ultimately the decision maker determines what level of uncertainty is acceptable.

Instrument response, including both the background and check source response of the instrument, should be tested and recorded at a frequency that ensures the data collected with the equipment is reliable. For most portable radiation survey equipment, MARSSIM recommends that a response check be performed twice daily when in use-typically prior to beginning the day's measurements and again following the conclusion of measurements on that same day. Additional checks can be performed if warranted by the instrument and the conditions under which it is used. If the instrument response does not fall within the established range, the instrument is removed from use until the reason for the deviation can be resolved and acceptable response again demonstrated. If the instrument fails the post-survey source check, all data collected during that time period with the instrument must be carefully reviewed and possibly adjusted or discarded, depending on the cause of the failure. Ultimately, the frequency of response checks must be balanced with the stability of the equipment being used under field conditions and the quantity of data being collected. For example, if the instrument experiences a sudden failure during the course of the day's work due to physical harm, such as a punctured probe, then the data collected up until that point is probably acceptable even though a post-use performance check cannot be performed. Likewise, if no obvious failure occurred but the instrument failed the post-use response check, then the data collected with that instrument since 
Field Measurement Methods and Instrumentation

the last response check should be viewed with great skepticism and possibly re-collected or randomly checked with a different instrument. Additional corrective action alternatives are presented in Section 9.3. If re-calibration is necessary, acceptable response ranges must be reestablished and documented.

Record requirements vary considerably and depend heavily on the needs of the user. While Federal and State regulatory agencies all specify requirements, the following records should be considered a minimum.

\section{Laboratory Quality Control}

- $\quad$ records documenting the traceabililty of radiological standards

- records documenting the traceability of electronic test equipment

Records for Instruments to be Calibrated

- date received in the calibration laboratory

- initial condition of the instrument, including mechanical condition (e.g., loose or broken parts, dents, punctures), electrical condition (e.g., switches, meter movement, batteries), and radiological condition (presence or absence of contamination)

- calibrator's records including training records and signature on calibration records

- calibration data including model and serial number of instrument, date of calibration, recommended recalibration date, identification of source(s) used, "as found" calibration results, and final calibration results-“as returned" for use.

In addition, records of instrument problems, failures, and maintenance can be included and are useful in assessing performance and identifying possible needs for altered calibration frequencies for some instruments. Calibration records should be maintained at the facility where the instruments are used as permanent records, and should be available either as hard copies or in safe computer storage.

\subsection{Data Conversion}

This section describes methods for converting survey data to appropriate units for comparison to radiological criteria. As stated in Chapter 4, conditions applicable to satisfying decommissioning requirements include determining that any residual contamination will not result in individuals being exposed to unacceptable levels of radiation and/or radioactive materials.

Radiation survey data are usually obtained in units, such as the number of counts per unit time, that have no intrinsic meaning relative to DCGLs. For comparison of survey data to DCGLs, the survey data from field and laboratory measurements should be converted to DCGL units. 


\subsubsection{Surface Activity}

When measuring surface activity, it is important to account for the physical surface area assessed by the detector in order to make probe area corrections and report data in the proper units (i.e., $\left.\mathrm{Bq} / \mathrm{m}^{2}, \mathrm{dpm} / 100 \mathrm{~cm}^{2}\right)$. This is termed the physical probe area. A common misuse is to make probe area corrections using the effective probe area which accounts for the amount of the physical probe area covered by a protective screen. Figure 6.1 illustrates the difference between the physical probe area and the effective probe area. The physical probe area is used because the reduced detector response due to the screen is accounted for during instrument calibration.

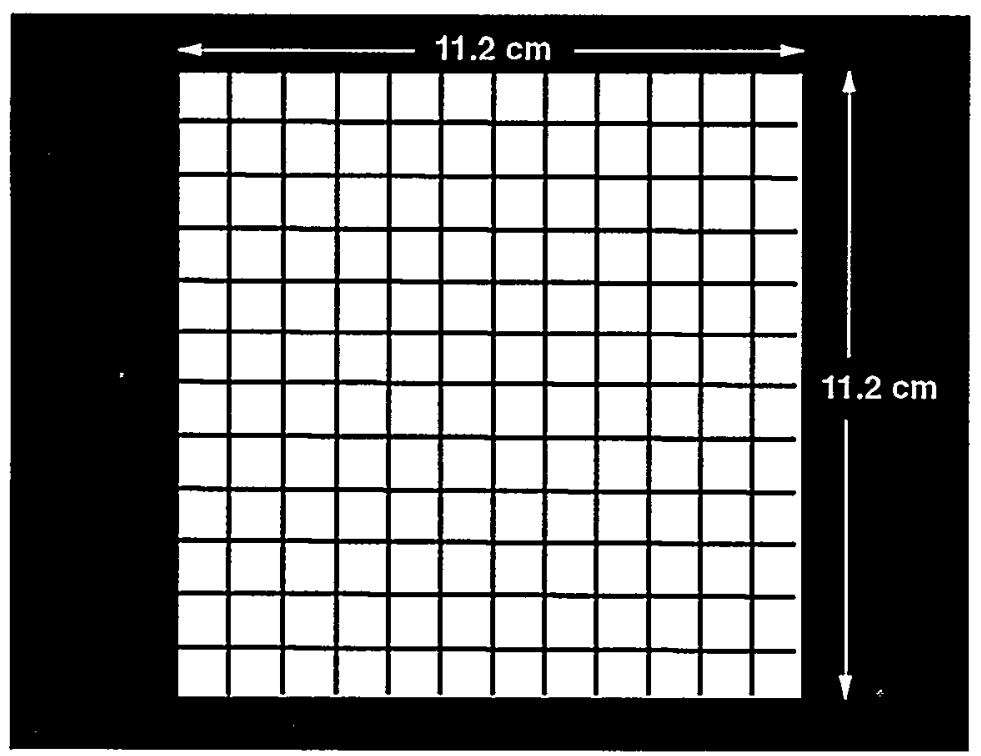

Physical Probe Area $=11.2 \times 11.2=126 \mathrm{~cm}^{2}$ Area of Protective Screen $=26 \mathrm{~cm}^{2}$

Effective Probe Area $=100 \mathrm{~cm}^{2}$

Gas Flow Proportional Detector with Physical Probe Area of $126 \mathrm{~cm}^{2}$

Figure 6.1 The Physical Probe Area of a Detector

The conversion of instrument display in counts to surface activity units is obtained using the following equation.

$$
B q / m^{2}=\frac{\frac{C_{s}}{T_{s}}}{\left(\epsilon_{T} \times A\right)}
$$


where

$\mathrm{C}_{\mathrm{s}}=$ integrated counts recorded by the instrument

$\mathrm{T}_{\mathrm{s}}=$ time period over which the counts were recorded in seconds

$\epsilon_{\mathrm{T}}=$ total efficiency of the instrument in counts per disintegration, effectively the product of the instrument efficiency $\left(\epsilon_{\mathrm{i}}\right)$ and the source efficiency $\left(\epsilon_{\mathrm{s}}\right)$

A $=$ physical probe area in $\mathrm{m}^{2}$

To convert instrument counts to conventional surface activity units, Equation 6-1 can be modified as shown in Equation 6-2.

$$
\frac{d p m}{100 \mathrm{~cm}^{2}}=\frac{\frac{C_{s}}{T_{s}}}{\left(\epsilon_{T}\right) \times(A / 100)}
$$

where $T_{s}$ is recorded in minutes instead of seconds, and $A$ is recorded in $\mathrm{cm}^{2}$ instead of $\mathrm{m}^{2}$.

Some instruments have background counts associated with the operation of the instrument. A correction for instrument background can be included in the data conversion calculation as shown in Equation 6-3. Note that the instrument background is not the same as the measurements in the background reference area used to perform the statistical tests described in Chapter 8.

$$
B q / m^{2}=\frac{\frac{C_{s}}{T_{s}}-\frac{C_{b}}{T_{b}}}{\left(\epsilon_{T} \times A\right)}
$$

where

$\mathrm{C}_{\mathrm{b}}=$ background counts recorded by the instrument

$\mathrm{T}_{\mathrm{b}}=$ time period over which the background counts were recorded in seconds

Equation 6-3 can be modified to provide conventional surface activity units as shown in Equation 6-4.

$$
\frac{d p m}{100 \mathrm{~cm}^{2}}=\frac{\frac{C_{s}}{T_{s}}-\frac{C_{b}}{T_{b}}}{\left(\epsilon_{T}\right) \times(A / 100)}
$$


where $T_{s}$ and $T_{b}$ are recorded in minutes instead of seconds and $A$ is recorded in $\mathrm{cm}^{2}$ instead of $\mathrm{m}^{2}$.

The presence of multiple radionuclides at a site requires additional considerations for demonstrating compliance with a dose- or risk-based regulation. As demonstrated in Section 4.3.2, a gross activity DCGL should be determined. For example, consider a site contaminated with ${ }^{60} \mathrm{Co}$ and ${ }^{63} \mathrm{Ni}$, with ${ }^{60} \mathrm{Co}$ representing $60 \%$ of the total activity. The relative fractions are 0.6 for ${ }^{60} \mathrm{Co}$ and 0.4 for ${ }^{63} \mathrm{Ni}$. If the DCGL for ${ }^{60} \mathrm{Co}$ is $8,300 \mathrm{~Bq} / \mathrm{m}^{2}\left(5,000 \mathrm{dpm} / 100 \mathrm{~cm}^{2}\right)$ and the DCGL for ${ }^{63} \mathrm{Ni}$ is $12,000 \mathrm{~Bq} / \mathrm{m}^{2}\left(7,200 \mathrm{dpm} / 100 \mathrm{~cm}^{2}\right)$, the gross activity DCGL is $9,500 \mathrm{~Bq} / \mathrm{m}^{2}$ $\left(5,700 \mathrm{dpm} / 100 \mathrm{~cm}^{2}\right)$ calculated using Equation 4-4.

When using the gross activity DCGL, it is important to use an appropriately weighted total efficiency to convert from instrument counts to surface activity units using Equations 6-1 through 6-4. In this example, the individual efficiencies for ${ }^{60} \mathrm{Co}$ and ${ }^{63} \mathrm{Ni}$ should be independently evaluated. The overall efficiency is then determined by weighting each individual efficiency by the relative fraction of each radionuclide.

\subsubsection{Soil Radionuclide Concentration and Exposure Rates}

Analytical procedures, such as alpha and gamma spectrometry, are typically used to determine the radionuclide concentration in soil in units of $\mathrm{Bq} / \mathrm{kg}$. Net counts are converted to soil DCGL units by dividing by the time, detector or counter efficiency, mass or volume of the sample, and by the fractional recovery or yield of the chemistry procedure (if applicable). Refer to Chapter 7 for examples of analytical procedures.

Instruments, such as a PIC or micro-R meter, used to measure exposure rate typically read directly in $\mathrm{mSv} / \mathrm{h}$. A gamma scintillation detector (e.g., $\mathrm{NaI}(\mathrm{Tl})$ ) provides data in counts per minute and conversion to $\mathrm{mSv} / \mathrm{h}$ is accomplished by using site-specific calibration factors developed for the specific instrument (Section 6.5.4).

In situ gamma spectrometry data may require special analysis routines before the spectral data can be converted to soil concentration units or exposure rates.

\subsection{Detection Sensitivity}

The detection sensitivity of a measurement system refers to a radiation level or quantity of radioactive material that can be measured or detected with some known or estimated level of confidence. This quantity is a factor of both the instrumentation and the technique or procedure being used. 
The primary parameters that affect the detection capability of a radiation detector are the background count rate, the detection efficiency of the detector and the counting time interval. It is important to use actual background count rate values and detection efficiencies when determining counting and scanning parameters, particularly during final status and verification surveys. When making field measurements, the detection sensitivity will usually be less than what can be achieved in a laboratory due to increased background and, often times, a significantly lower detection efficiency. It is often impossible to guarantee that pure alpha emitters can be detected in situ since the weathering of aged surfaces will often completely absorb the alpha emissions. NRC report NUREG-1507 (NRC 1997b) contains data on many of the parameters that affect detection efficiencies in situ, such as absorption, surface smoothness, and particulate radiation energy.

\subsubsection{Direct Measurement Sensitivity}

Prior to performing field measurements, an investigator must evaluate the detection sensitivity of the equipment proposed for use to ensure that levels below the DCGL can be detected (see Section 4.3). After a direct measurement has been made, it is then necessary to determine whether or not the result can be distinguished from the instrument background response of the measurement system. The terms that are used in this manual to define detection sensitivity for fixed point counts and sample analyses are:

Critical level $\left(\mathrm{L}_{\mathcal{C}}\right)$

Detection limit $\left(\mathrm{L}_{\mathrm{D}}\right)$

Minimum detectable concentration (MDC)

The critical level $\left(\mathrm{L}_{\mathrm{c}}\right)$ is the level, in counts, at which there is a statistical probability (with a predetermined confidence) of incorrectly identifying a measurement system background value as "greater than background." Any response above this level is considered to be greater than background. The detection limit $\left(\mathrm{L}_{\mathrm{D}}\right)$ is an a priori estimate of the detection capability of a measurement system, and is also reported in units of counts. The minimum detectable concentration (MDC) is the detection limit (counts) multiplied by an appropriate conversion factor to give units consistent with a site guideline, such as Bq/kg.

The following discussion provides an overview of the derivation contained in the well known publication by Currie (Currie 1968) followed by a description of how the resulting formulae should be used. Publications by Currie (Currie 1968, NRC 1984) and Altshuler and Pasternack (Altshuler and Pasternak 1963) provide details of the derivations involved.

The two parameters of interest for a detector system with a background response greater than zero are: 
$\mathrm{L}_{\mathrm{C}}$ the net response level, in counts, at which the detector output can be considered "above background"

$\mathrm{L}_{\mathrm{D}}$ the net response level, in counts, that can be expected to be seen with a detector with a fixed level of certainty

Assuming that a system has a background response and that random uncertainties and systematic uncertainties are accounted for separately, these parameters can be calculated using Poisson statistics. For these calculations, two types of decision errors should be considered. A Type I error (or "false positive") occurs when a detector response is considered to be above background when, in fact, only background radiation is present. A Type II error (or "false negative") occurs when a detector response is considered to be background when in fact radiation is present at levels above background. The probability of a Type I error is referred to as $\alpha$ (alpha) and is associated with $L_{c}$; the probability of a Type II error is referred to as $\beta$ (beta) and is associated with $L_{D}$. Figure 6.2 graphically illustrates the relationship of these terms with respect to each other and to a normal background distribution.

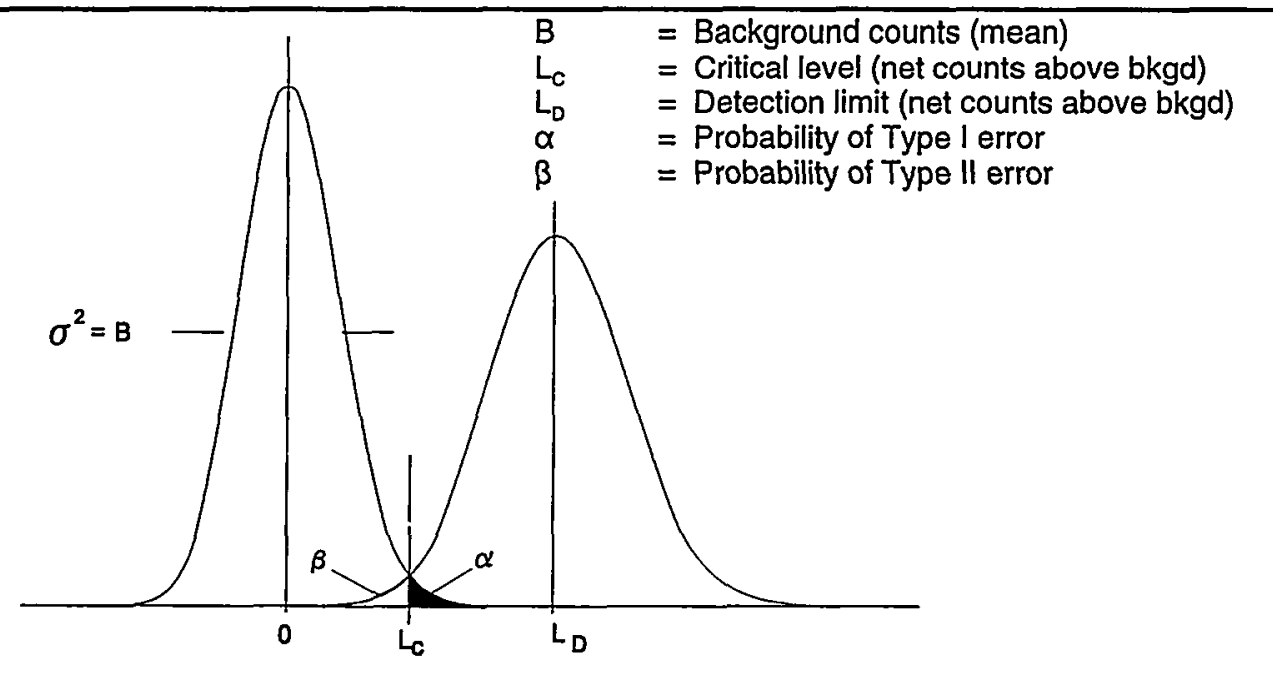

Figure 6.2 Graphically Represented Probabilities for Type I and Type II Errors in Detection Sensitivity for Instrumentation with a Background Response

If $\alpha$ and $\beta$ are assumed to be equal, the variance $\left(\sigma^{2}\right)$ of all measurement values is assumed to be equal to the values themselves. If the background of the detection system is not well known, then the critical detection level and the detection limit can be calculated by using of the following formulae: 
Field Measurement Methods and Instrumentation

$$
\begin{aligned}
& \mathrm{L}_{\mathrm{C}}=\mathrm{k} \sqrt{2 \mathrm{~B}} \\
& \mathrm{~L}_{\mathrm{D}}=\mathrm{k}^{2}+2 \mathrm{k} \sqrt{2 \mathrm{~B}}
\end{aligned}
$$

where

$$
\begin{array}{lll}
\mathrm{L}_{\mathrm{C}} & =\quad \text { critical level (counts) } \\
\mathrm{L}_{\mathrm{D}} & = & \text { detection limit (counts) } \\
\mathrm{k} & = & \text { Poisson probability sum for } \alpha \text { and } \beta \text { (assuming } \alpha \text { and } \beta \text { are equal) } \\
\mathrm{B} & = & \text { number of background counts that are expected to occur while performing } \\
\text { an actual measurement }
\end{array}
$$

The curve to the left in the diagram is the background distribution minus the mean of the background distribution. The result is a Poisson distribution with a mean equal to zero and a variance, $\sigma^{2}$, equal to $B$. Note that the distribution accounts only for the expected statistical variation due to the stochastic nature of radioactive decay. Currie assumed "paired blanks" when deriving the above stated relationships (Currie 1968), which is interpreted to mean that the sample and background count times are the same.

If values of 0.05 for both $\alpha$ and $\beta$ are selected as acceptable, then $k=1.645$ (from Appendix I, Table I.1) and Equation 6-5 can be written as:

$$
\begin{aligned}
& \mathrm{L}_{\mathrm{C}}=2.33 \sqrt{\mathrm{B}} \\
& \mathrm{L}_{\mathrm{D}}=3+4.65 \sqrt{\mathrm{B}}
\end{aligned}
$$

Note: In Currie's derivation, the constant factor of 3 in the $\mathrm{L}_{\mathrm{D}}$ formula was stated as being 2.71, but since that time it has been shown (Brodsky 1992) and generally accepted that a constant factor of 3 is more appropriate. If the sample count times and background count times are different, a slightly different formulation is used.

For an integrated measurement over a preset time, the MDC can be obtained from Equation 6-6 by multiplying by the factor, $\mathrm{C}$. This factor is used to convert from counts to concentration as shown in Equation 6-7:

$$
M D C=C \times(3+4.65 \sqrt{B})
$$

The total detection efficiency and other constants or factors represented by the variable $\mathrm{C}$ are usually not truly constants as shown in Equation 6-7. It is likely that at least one of these factors 
will have a certain amount of variability associated with it which may or may not be significant. These varying factors are gathered together into the single constant, $\mathrm{C}$, by which the net count result will be multiplied when converting the final data. If $C$ varies significantly between measurements, then it might be best to select a value, $C^{\prime}$, from the observed distribution of $C$ values that represents a conservative estimate. For example, a value of $C$ might be selected to ensure that at least $95 \%$ of the possible values of $C$ are less than the chosen value, $C^{\prime}$. The MDC calculated in this way helps assure that the survey results will meet the Data Quality Objectives. This approach for including uncertainties into the MDC calculation is recommended in both NUREG/CR-4007 (NRC 1984) and Appendix A to ANSI N13.30 (ANSI 1996a).

Underestimating an MDC can have adverse consequences, especially if activity is later detected at a level above the stated MDC.

\section{Summary of Direct Measurement Sensitivity Terms}

- The MDC is the a priori net activity level above the critical level that an instrument can be expected to detect $95 \%$ of the time. This value should be used when stating the detection capability of an instrument. The MDC is the detection limit, $\mathrm{L}_{\mathrm{D}}$ multiplied by an appropriate conversion factor to give units of activity. Again, this value is used before any measurements are made and is used to estimate the level of activity that can be detected using a given protocol.

- The critical level, $\mathrm{L}_{C}$, is the lower bound on the $95 \%$ detection interval defined for $\mathrm{L}_{\mathcal{D}}$ and is the level at which there is a 5\% chance of calling a background value "greater than background." This value should be used when actually counting samples or making direct radiation measurements. Any response above this level should be considered as above background (i.e., a net positive result). This will ensure 95\% detection capability for $L_{D}$.

- From a conservative point of view, it is better to overestimate the MDC for a measurement method. Therefore, when calculating $\mathrm{MDC}$ and $\mathrm{L}_{\mathrm{C}}$ values, a measurement system background value should be selected that represents the high end of what is expected for a particular measurement method. For direct measurements, probes will be moved from point to point and, as a result, it is expected that the background will most likely vary significantly due to variations in background, source materials, and changes in geometry and shielding. Ideally, the MDC values should be calculated for each type of area, but it may be more economical to simply select a background value from the highest distribution expected and use this for all calculations. For the same reasons, realistic values of detection efficiencies and other process parameters should be used when possible and should be reflective of the actual conditions. To a great degree, the selection of these parameters will be based on judgment and will require evaluation of site-specific conditions. 
MDC values for other counting conditions may be derived from Equation 6-7 depending on the detector and contaminants of concern. For example, it may be required to determine what level of contamination, distributed over $100 \mathrm{~cm}^{2}$, can be detected with a $500 \mathrm{~cm}^{2}$ probe or what contamination level can be detected with any probe when the contamination area is smaller than the probe active area. Table 6.4 lists several common field survey detectors with estimates of MDC values for ${ }^{238} \mathrm{U}$ on a smooth, flat plane. As such, these represent minimum MDC values and may not be applicable at all sites. Appropriate site-specific MDC values should be determined using the DQO Process.

Table 6.4 Examples of Estimated Detection Sensitivities for Alpha and Beta Survey Instrumentation

(Static one minute counts for ${ }^{238} \mathrm{U}$ calculated using Equations 6-6 and 6-7)

\begin{tabular}{|c|c|c|c|c|c|c|}
\hline \multirow{2}{*}{ 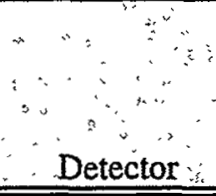 } & \multirow{2}{*}{$\begin{array}{c}\text { Probe area } \\
\left(\mathrm{cm}^{2}\right)\end{array}$} & \multirow{2}{*}{$\begin{array}{c}\ddots \\
\text { Background } \\
\text { (cpm) }\end{array}$} & \multirow{2}{*}{$\begin{array}{l}\text { Efficiency } \\
\text { (cpm/dpm) }\end{array}$} & \multicolumn{3}{|c|}{ Approximate Sensitivity } \\
\hline & & & & $\begin{array}{l}\mathrm{L}_{\mathrm{C}} \\
\text { (counts) }\end{array}$ & $\begin{array}{c}\mathrm{L}_{\mathbf{D}} \\
\text { (counts), }\end{array}$ & $\begin{array}{c}\mathrm{MDC} \\
\left(\mathrm{Bg} / \mathrm{m}^{2}\right)^{\mathrm{a}}\end{array}$ \\
\hline $\begin{array}{l}\text { Alpha } \\
\text { proportional }\end{array}$ & 50 & 1 & 0.15 & 2 & 7 & 150 \\
\hline $\begin{array}{l}\text { Alpha } \\
\text { proportional }\end{array}$ & 100 & 1 & 0.15 & 2 & 7 & 83 \\
\hline $\begin{array}{l}\text { Alpha } \\
\text { proportional }\end{array}$ & 600 & 5 & 0.15 & 5 & 13 & 25 \\
\hline $\begin{array}{l}\text { Alpha } \\
\text { scintillation }\end{array}$ & 50 & 1 & 0.15 & 2 & 7 & 150 \\
\hline $\begin{array}{l}\text { Beta } \\
\text { proportional }\end{array}$ & 100 & 300 & 0.20 & 40 & 83 & 700 \\
\hline $\begin{array}{l}\text { Beta } \\
\text { proportional }\end{array}$ & 600 & 1500 & 0.20 & 90 & 183 & 250 \\
\hline $\begin{array}{l}\text { Beta } \\
\text { GM pancake }\end{array}$ & 15 & 40 & 0.20 & 15 & 32 & 1800 \\
\hline
\end{tabular}

a Assumes that the size of the contamination area is at least as large as the probe area.

Sample Calculation 1:

The following example illustrates the calculation of an $\mathrm{MDC}$ in $\mathrm{Bq} / \mathrm{m}^{2}$ for an instrument with a $15 \mathrm{~cm}^{2}$ probe area when the measurement and background counting times are each one minute: 
B $=40$ counts

C $=(5 \mathrm{dpm} /$ count $)(\mathrm{Bq} / 60 \mathrm{dpm})\left(1 / 15 \mathrm{~cm}^{2}\right.$ probe area $)\left(10,000 \mathrm{~cm}^{2} / \mathrm{m}^{2}\right)$

$=\quad 55.6 \mathrm{~Bq} / \mathrm{m}^{2}-$ counts

The MDC is calculated using Equation 6-7:

$$
M D C=55.6 \times(3+4.65 \sqrt{40})=1,800 \mathrm{~Bq} / \mathrm{m}^{2}\left(3,000 \mathrm{dpm} / 100 \mathrm{~cm}^{2}\right)
$$

The critical level, $\mathrm{L}_{c}$, for this example is calculated from Equation 6-6:

$$
\mathrm{L}_{\mathrm{C}}=2.33 \sqrt{\mathrm{B}}=15 \text { counts }
$$

Given the above scenario, if a person asked what level of contamination could be detected $95 \%$ of the time using this method, the answer would be $1,800 \mathrm{~Bq} / \mathrm{m}^{2}(3,000 \mathrm{dpm} / 100$ $\mathrm{cm}^{2}$ ). When actually performing measurements using this method, any count yielding greater than 55 total counts, or greater than 15 net counts $(55-40=15)$ during a period of one minute, would be regarded as greater than background.

\subsubsection{Scanning Sensitivity}

The ability to identify a small area of elevated radioactivity during surface scanning is dependent upon the surveyor's skill in recognizing an increase in the audible or display output of an instrument. For notation purposes, the term "scanning sensitivity" is used throughout this section to describe the ability of a surveyor to detect a pre-determined level of contamination with a detector. The greater the sensitivity, the lower the level of contamination that can be detected.

Many of the radiological instruments and monitoring techniques typically used for occupational health physics activities may not provide the detection sensitivities necessary to demonstrate compliance with the DCGLs. The detection sensitivity for a given application can be improved (i.e., lower the MDC) by: 1) selecting an instrument with a higher detection efficiency or a lower background, 2) decreasing the scanning speed, or 3) increasing the size of the effective probe area without significantly increasing the background response.

Scanning is usually performed during radiological surveys in support of decommissioning to identify the presence of any areas of elevated activity. The probability of detecting residual contamination in the field depends not only on the sensitivity of the survey instrumentation when used in the scanning mode of operation, but is also affected by the surveyor's ability-i.e., human factors. The surveyor must make a decision whether the signals represent only the 
background activity, or residual contamination in excess of background. The greater the sensitivity, the lower the level of contamination that may be detected by scanning. Accounting for these human factors represents a significant change from the traditionally accepted methods of estimating scanning sensitivities.

An empirical method for evaluating the detection sensitivity for contamination surveys is by actual experimentation or, since it is certainly feasible, by simulating an experimental setup using computer software. The following steps provide a simple example of how one can perform this empirical evaluation:

1) A desired nuclide contamination level is selected.

2) The response of the detector to be used is determined for the selected nuclide contamination level.

3) A test source is constructed which will give a detector count rate equivalent to what was determined in step 2. The count rate is equivalent to what would be expected from the detector when placed on an actual contamination area equal in value to that selected in step 1.

4) The detector of choice is then moved over the source at different scan rates until an acceptable speed is determined.

The most useful aspect of this approach is that the source can then be used to show surveyors what level of contamination is expected to be targeted with the scan. They, in turn, can gain experience with what the expected response of the detector will be and how fast they can survey and still feel comfortable about detecting the target contamination level. The person responsible for the survey can then use this information when developing a fixed point measurement and sampling plan.

The remainder of this section is dedicated to providing the reader with information pertaining to the underlying processes involved when performing scanning surveys for alpha, beta, and gamma emitting radionuclides. The purpose is to provide relevant information that can be used for estimating realistic scanning sensitivities for survey activities.

\subsubsection{Scanning for Beta and Gamma Emitters}

The minimum detectable concentration of a scan survey (scan MDC) depends on the intrinsic characteristics of the detector (efficiency, physical probe area, etc.), the nature (type and energy of emissions) and relative distribution of the potential contamination (point versus distributed source and depth of contamination), scan rate, and other characteristics of the surveyor. Some factors that may affect the surveyor's performance include the costs associated with various outcomes-e.g., fatigue, noise, level of training, experience - and the survey's a priori expectation of the likelihood of contamination present. For example, if the surveyor believes that 
the potential for contamination is very low, as in a Class 3 area, a relatively large signal may be required for the surveyor to conclude that contamination is present. NRC draft report NUREG/CR-6364 (NRC 1997d) provides a complete discussion of the human factors as they relate to the performance of scan surveys.

Signal Detection Theory. Personnel conducting radiological surveys for residual contamination at decommissioning sites must interpret the audible output of a portable survey instrument to determine when the signal ("clicks") exceeds the background level by a margin sufficient to conclude that contamination is present. It is difficult to detect low levels of contamination because both the signal and the background vary widely. Signal detection theory provides a framework for the task of deciding whether the audible output of the survey meter during scanning is due to background or signal plus background levels. An index of sensitivity $(d)$ that represents the distance between the means of the background and background plus signal (refer to Figure 6.2 for determining $L_{D}$ ), in units of their common standard deviation, can be calculated for various decision errors (correct detection and false positive rate). As an example, for a correct detection rate of $95 \%$ (complement of a false negative rate of $5 \%$ ) and a false positive rate of 5\%, $d^{\prime}$ is 3.29 (similar to the static MDC for the same decision error rates). The index of sensitivity is independent of human factors, and therefore, the ability of an ideal observer (theoretical construct), may be used to determine the minimum $d^{\prime}$ that can be achieved for particular decision errors. The ideal observer makes optimal use of the available information to maximize the percent correct responses, providing an effective upper bound against which to compare actual surveyors. Table 6.5 lists selected values of $d$ '.

Two Stages of Scanning. The framework for determining the scan MDC is based on the premise that there are two stages of scanning. That is, surveyors do not make decisions on the basis of a single indication, rather, upon noting an increased number of counts, they pause briefly and then decide whether to move on or take further measurements. Thus, scanning consists of two components: continuous monitoring and stationary sampling. In the first component, characterized by continuous movement of the probe, the surveyor has only a brief "look" at potential sources, determined by the scan speed. The surveyor's willingness to decide that a signal is present at this stage is likely to be liberal, in that the surveyor should respond positively on scant evidence, since the only "cost" of a false positive is a little time. The second component occurs only after a positive response was made at the first stage. This response is marked by the surveyor interrupting his scanning and holding the probe stationary for a period of time, while comparing the instrument output signal during that time to the background counting rate. Owing to the longer observation interval, sensitivity is relatively high. For this decision, the criterion should be more strict, since the cost of a "yes" decision is to spend considerably more time taking a static measurement or a sample. 
Field Measurement Methods and Instrumentation

Table 6.5 Values of $d$ 'for Selected True Positive and False Positive Proportions

\begin{tabular}{||c|c|c|c|c|c|c|c|c||}
\hline \multirow{2}{*}{$\begin{array}{c}\text { False Positive } \\
\text { Proportion }\end{array}$} & $\mathbf{0 . 6 0}$ & $\mathbf{0 . 6 5}$ & $\mathbf{0 . 7 0}$ & $\mathbf{0 . 7 5}$ & $\mathbf{0 . 8 0}$ & $\mathbf{0 . 8 5}$ & $\mathbf{0 . 9 0}$ & $\mathbf{0 . 9 5}$ \\
\hline & $\mathbf{0 . 0 5}$ & 2.02 & 2.16 & 2.32 & 2.48 & 2.68 & 2.92 & 3.28 \\
\hline $\mathbf{0 . 1 0}$ & 1.54 & 1.66 & 1.80 & 1.96 & 2.12 & 2.32 & 2.56 & 2.92 \\
\hline $\mathbf{0 . 1 5}$ & 1.30 & 1.42 & 1.56 & 1.72 & 1.88 & 2.08 & 2.32 & 2.68 \\
\hline $\mathbf{0 . 2 0}$ & 1.10 & 1.22 & 1.36 & 1.52 & 1.68 & 1.88 & 2.12 & 2.48 \\
\hline $\mathbf{0 . 2 5}$ & 0.93 & 1.06 & 1.20 & 1.35 & 1.52 & 1.72 & 1.96 & 2.32 \\
\hline $\mathbf{0 . 3 0}$ & 0.78 & 0.91 & 1.05 & 1.20 & 1.36 & 1.56 & 1.80 & 2.16 \\
\hline $\mathbf{0 . 3 5}$ & 0.64 & 0.77 & 0.91 & 1.06 & 1.22 & 1.42 & 1.66 & 2.02 \\
\hline $\mathbf{0 . 4 0}$ & 0.51 & 0.64 & 0.78 & 0.93 & 1.10 & 1.30 & 1.54 & 1.90 \\
\hline $\mathbf{0 . 4 5}$ & 0.38 & 0.52 & 0.66 & 0.80 & 0.97 & 1.17 & 1.41 & 1.77 \\
\hline $\mathbf{0 . 5 0}$ & 0.26 & 0.38 & 0.52 & 0.68 & 0.84 & 1.04 & 1.28 & 1.64 \\
\hline $\mathbf{0 . 5 5}$ & 0.12 & 0.26 & 0.40 & 0.54 & 0.71 & 0.91 & 1.15 & 1.51 \\
\hline $\mathbf{0 . 6 0}$ & 0.00 & 0.13 & 0.27 & 0.42 & 0.58 & 0.82 & 1.02 & 1.38 \\
\hline
\end{tabular}

Since scanning can be divided into two stages, it is necessary to consider the survey's scan sensitivity for each of the stages. Typically, the minimum detectable count rate (MDCR) associated with the first scanning stage will be greater due to the brief observation intervals of continuous monitoring-provided that the length of the pause during the second stage is significantly longer. Typically, observation intervals during the first stage are on the order of 1 or 2 seconds, while the second stage pause may be several seconds long. The greater value of MDCR from each of the scan stages is used to determine the scan sensitivity for the surveyor.

Determination of MDCR and Use of Surveyor Efficiency. The minimum detectable number of net source counts in the interval is given by $s_{\mathrm{i}}$. Therefore, for an ideal observer, the number of source counts required for a specified level of performance can be arrived at by multiplying the square root of the number of background counts by the detectability value associated with the desired performance (as reflected in $d^{\prime}$ ) as shown in Equation 6-8:

$$
s_{i}=d^{\prime} \sqrt{b_{i}}
$$

where the value of $d$ 'is selected from Table 6.5 based on the required true positive and false positive rates and $b_{i}$ is the number of background counts in the interval. 
For example, suppose that one wished to estimate the minimum count rate that is detectable by scanning in an area with a background of $1,500 \mathrm{cpm}$. Note that the minimum detectable count rate must be considered for both scan stages-and the more conservative value is selected as the minimum count rate that is detectable. It will be assumed that a typical source remains under the probe for 1 second during the first stage, therefore, the average number of background counts in the observation interval is $25\left(b_{i}=1500 \times(1 / 60)\right)$. Furthermore, as explained earlier, it can be assumed that at the first scanning stage a high rate $(e . g ., 95 \%)$ of correct detections is required, and that a correspondingly high rate of false positives (e.g., 60\%) will be tolerated. From Table 6.5 , the value of $d^{\prime}$, representing this performance goal, is 1.38 . The net source counts needed to support the specified level of performance (assuming an ideal observer) will be estimated by multiplying 5 (the square root of 25 ) by 1.38 . Thus, the net source counts per interval, $\mathrm{s}_{\mathrm{j}}$, needed to yield better than $95 \%$ detections with about $60 \%$ false positives is 6.9 . The minimum detectable source count rate, in cpm, may be calculated by:

$$
M D C R=s_{i} \times(60 / i)
$$

For this example, MDCR is equivalent to $414 \mathrm{cpm}$ (1,914 cpm gross). Table 6.6 provides the scan sensitivity for the ideal observer (MDCR) at the first scanning stage for various background levels, based on an index of sensitivity (d) of 1.38 and a 2-second observation interval.

\section{Table 6.6 Scanning Sensitivity (MDCR) of the Ideal Observer for Various Background Levels ${ }^{\mathrm{a}}$}

\begin{tabular}{|c|c|c|}
\hline \hline Background (cpm) & MDCR (net cpm) & Scan Sensitivity (gross cpm) \\
\hline \hline 45 & 50 & 95 \\
\hline 60 & 60 & 120 \\
\hline 260 & 120 & 380 \\
\hline 300 & 130 & 430 \\
\hline 350 & 140 & 490 \\
\hline 400 & 150 & 550 \\
\hline 1,000 & 240 & 1,240 \\
\hline 3,000 & 410 & 3,410 \\
\hline 4,000 & 480 & 4,480 \\
\hline
\end{tabular}

*The sensitivity of the ideal observer during the first scanning stage is based on an index of sensitivity ( $d^{\prime}$ ) of 1.38 and a 2-second observation interval. 
The minimum number of source counts required to support a given level of performance for the final detection decision (second scan stage) can be estimated using the same method. As explained earlier, the performance goal at this stage will be more demanding. The required rate of true positives remains high (e.g., 95\%), but fewer false positives (e.g., 20\%) can be tolerated, such that $d^{\prime}$ (from Table 6.5) is now 2.48. One will assume that the surveyor typically stops the probe over a suspect location for about 4 seconds before making a decision, so that the average number of background counts in an observation interval is $100\left(b_{i}=1,500 \times(4 / 60)\right)$. Therefore, the minimum detectable number of net source counts, $\mathrm{s}_{\mathrm{i}}$, needed will be estimated by multiplying 10 (the square root of 100) by 2.48 (the $d^{\prime}$ value); so $\mathrm{s}_{\mathrm{i}}$ equals 24.8 . The MDCR is calculated by $2.48 \times(60 / 4)$ and equals $372 \mathrm{cpm}$. The value associated with the first scanning stage (this example, $414 \mathrm{cpm}$ ) will typically be greater, owing to the relatively brief intervals assumed.

Laboratory studies using simulated sources and backgrounds were performed to assess the abilities of surveyors under controlled conditions. The methodology and analysis of results for these studies are described in draft NUREG/CR-6364 (NRC 1997d) and NUREG-1507 (NRC 1997b). The surveyor's actual performance as compared with that which is ideally possible (using the ideal observer construct) provided an indication of the efficiency of the surveyors. Based on the results of the confidence rating experiment, this surveyor efficiency (p) was estimated to be between 0.5 and 0.75 .

MARSSIM recommends assuming an efficiency value at the lower end of the observed range (i.e., 0.5) when making MDC estimates. Thus, the required number of net source counts for the surveyor, $\mathrm{MDCR}_{\text {surveyor }}$ is determined by dividing the MDCR by the square root of $\mathrm{p}$. Continuing with this example, the surveyor MDCR is calculated by $414 \mathrm{cpm} / 0.707$, or $585 \mathrm{cpm}(2,085 \mathrm{cpm}$ gross).

Scan MDCs for Structure Surfaces and Land Areas. The survey design for determining the number of data points for areas of elevated activity (see Section 5.5.2.4) depends on the scan MDC for the selected instrumentation. In general, alpha or beta scans are performed on structure surfaces to satisfy the elevated activity measurements survey design, while gamma scans are performed for land areas. Because of low background levels for alpha emitters, the approach described here is not generally applied to determining scan MDCs for alpha contaminantsrather, the reader is referred to Section 6.7.2.2 for an appropriate method for determining alpha scan MDCs for building surfaces. In any case, the data requirements for assessing potential elevated areas of direct radiation depend on the scan MDC of the survey instrument (e.g., floor monitor, GM detector, NaI scintillation detector).

Scan MDCs for Building/Structure Surfaces. The scan MDC is determined from the minimum detectable count rate (MDCR) by applying conversion factors that account for detector and surface characteristics and surveyor efficiency. As discussed above, the MDCR accounts for the background level, performance criteria ( $d$ ), and observation interval. The observation interval 
during scanning is the actual time that the detector can respond to the contamination sourcethis interval depends on the scan speed, detector size in the direction of the scan, and area of elevated activity. Because the actual dimensions of potential areas of elevated activity in the field cannot be known a priori, MARSSIM recommends postulating a certain area (e.g., perhaps 50 to $200 \mathrm{~cm}^{2}$ ), and then selecting a scan rate that provides a reasonable observation interval.

Finally, the scan MDC for structure surfaces may be calculated:

$$
\text { Scan } M D C=\frac{M D C R}{\sqrt{p} \epsilon_{i} \epsilon_{s} \frac{\text { probe area }}{100 \mathrm{~cm}^{2}}}
$$

where

$\begin{array}{lll}\text { MDCR } & = & \text { minimum detectable count rate } \\ \epsilon_{\mathrm{i}} & = & \text { instrument efficiency } \\ \epsilon_{\mathrm{s}} & = & \text { surface efficiency } \\ \mathrm{p} & = & \text { surveyor efficiency }\end{array}$

As an example, the scan MDC (in $\mathrm{dpm} / 100 \mathrm{~cm}^{2}$ ) for ${ }^{99} \mathrm{Tc}$ on a concrete surface may be determined for a background level of $300 \mathrm{cpm}$ and a 2-second observation interval using a handheld gas proportional detector $\left(126 \mathrm{~cm}^{2}\right.$ probe area). For a specified level of performance at the first scanning stage of $95 \%$ true positive rate and $60 \%$ false positive rate (and assuming the second stage pause is sufficiently long to ensure that the first stage is more limiting), $d$ 'equals 1.38 (Table 6.5) and the MDCR is $130 \mathrm{cpm}$ (Table 6.6). Using a surveyor efficiency of 0.5 , and assuming instrument and surface efficiencies of 0.36 and 0.54 , respectively, the scan MDC is calculated using Equation 6-10:

$$
\text { Scan } M D C=\frac{130}{\sqrt{0.5}(0.36)(0.54)(1.26)}=750 \mathrm{dpm} / 100 \mathrm{~cm}^{2}
$$

Additional examples for calculating the scan MDC may be found in NUREG-1507 (NRC 1997b).

Scan MDCs for Land Areas. In addition to the MDCR and detector characteristics, the scan MDC (in pCi/g) for land areas is based on the area of elevated activity, depth of contamination, and the radionuclide (i.e., energy and yield of gamma emissions). If one assumes constant parameters for each of the above variables, with the exception of the specific radionuclide in question, the scan MDC may be reduced to a function of the radionuclide alone. NaI scintillation detectors are generally used for scanning land areas. 
An overview of the approach used to determine scan MDCs for land areas follows. The NaI(Tl) scintillation detector background level and scan rate (observation interval) are postulated, and the MDCR for the ideal observer, for a given level of performance, is obtained. After a surveyor efficiency is selected, the relationship between the surveyor MDCR (MDCR surveyoo $_{\text {) }}$ and the radionuclide concentration in soil (in $\mathrm{Bq} / \mathrm{kg}$ or $\mathrm{pCi} / \mathrm{g}$ )is determined. This correlation requires two steps-first, the relationship between the detector's net count rate to net exposure rate (cpm per $\mu \mathrm{R} / \mathrm{h}$ ) is established, and second, the relationship between the radionuclide contamination and exposure rate is determined.

For a particular gamma energy, the relationship of $\mathrm{NaI}(\mathrm{Tl})$ scintillation detector count rate and exposure rate may be determined analytically (in $\mathrm{cpm}$ per $\mu \mathrm{R} / \mathrm{h}$ ). The approach used to determine the gamma fluence rate necessary to yield a fixed exposure rate $(1 \mu \mathrm{R} / \mathrm{h})$-as a function of gamma energy - is provided in NUREG-1507 (NRC 1997b). The NaI(Tl) scintillation detector response (cpm) is related to the fluence rate at specific energies, considering the detector's efficiency (probability of interaction) at each energy. From this, the NaI(Tl) scintillation detector versus exposure rates for varying gamma energies are determined. Once the relationship between the $\mathrm{NaI}(\mathrm{Tl})$ scintillation detector response (cpm) and the exposure rate is established, the $\mathrm{MDCR}_{\text {surveyor }}$ (in $\mathrm{cpm}$ ) of the $\mathrm{NaI}(\mathrm{Tl})$ scintillation detector can be related to the minimum detectable net exposure rate. The minimum detectable exposure rate is used to determine the minimum detectable radionuclide concentration (i.e., the scan MDC) by modeling a specified small area of elevated activity.

Modeling (using Microshield ${ }^{\mathrm{TM}}$ ) of the small area of elevated activity (soil concentration) is used to determine the net exposure rate produced by a radionuclide concentration at a distance $10 \mathrm{~cm}$ above the source. This position is selected because it relates to the average height of the $\mathrm{NaI}(\mathrm{Tl})$ scintillation detector above the ground during scanning.

The factors considered in the modeling include:

- $\quad$ radionuclide of interest (considering all gamma emitters for decay chains)

- expected concentration of the radionuclide of interest

- $\quad$ areal dimensions of the area of elevated activity

- depth of the area of elevated activity

- location of dose point ( $\mathrm{NaI}(\mathrm{TI})$ scintillation detector height above the surface)

- density of soil

Modeling analyses are conducted by selecting a radionuclide (or radioactive material decay series) and then varying the concentration of the contamination. The other factors are held constant - the areal dimension of a cylindrical area of elevated activity is $0.25 \mathrm{~m}^{2}$ (radius of 28 $\mathrm{cm}$ ), the depth of the area of elevated activity is $15 \mathrm{~cm}$, the dose point is $10 \mathrm{~cm}$ above the surface, and the density of soil is $1.6 \mathrm{~g} / \mathrm{cm}^{3}$. The objective is to determine the radionuclide concentration that is correlated to the minimum detectable net exposure rate. 
As an example, the scan MDC for ${ }^{137} \mathrm{Cs}$ using a 1.5 in. by 1.25 in. NaI(Tl) scintillation detector is considered in detail. Assume that the background level is 4,000 cpm and that the desired level of performance, $95 \%$ correct detections and $60 \%$ false positive rate, results in a $d^{\prime}$ of 1.38 . The scan rate of $0.5 \mathrm{~m} / \mathrm{s}$ provides an observation interval of 1-second (based on a diameter of about 56 $\mathrm{cm}$ for the area of elevated activity). The $\mathrm{MDCR}_{\text {surveyor }}$ may be calculated assuming a surveyor efficiency (p) of 0.5 as follows:

$$
\begin{aligned}
& \text { 1) } \mathrm{b}_{\mathrm{i}}=(4,000 \mathrm{cpm}) \times(1 \mathrm{sec}) \times(1 \mathrm{~min} / 60 \mathrm{sec})=66.7 \mathrm{counts} \\
& \text { 2) } \mathrm{MDCR}=(1.38) \times(\sqrt{66.7}) \times(60 \mathrm{sec} / 1 \mathrm{~min})=680 \mathrm{cpm} \\
& \text { 3) } \mathrm{MDCR}_{\text {surveyor }}=680 / \sqrt{0.5}=960 \mathrm{cpm}
\end{aligned}
$$

The corresponding minimum detectable exposure rate is determined for this detector and radionuclide. The manufacturer of this particular 1.5 in. by 1.25 in. NaI(Tl) scintillation detector quotes a count rate to exposure rate ratio for ${ }^{137} \mathrm{Cs}$ of $350 \mathrm{cpm}$ per $\mu \mathrm{R} / \mathrm{h}$. The minimum detectable exposure rate is calculated by dividing the count rate $(960 \mathrm{cpm})$ by the count rate to exposure rate ratio for the radionuclide of interest $(350 \mathrm{cpm}$ per $\mu \mathrm{R} / \mathrm{h})$. The minimum detectable exposure rate for this example is $2.73 \mu \mathrm{R} / \mathrm{h}$.

Both ${ }^{137} \mathrm{Cs}$ and its short-lived progeny, ${ }^{137 \mathrm{~m}} \mathrm{Ba}$, were chosen from the Microshield ${ }^{\mathrm{TM}}$ library. The source activity and other modeling parameters were entered into the modeling code. The source activity was selected based on an arbitrary concentration of $5 \mathrm{pCi} / \mathrm{g}$. The modeling code performed the appropriate calculations and determined an exposure rate of $1.307 \mu \mathrm{R} / \mathrm{h}$ (which accounts for buildup). Finally, the radionuclide concentrations of ${ }^{137} \mathrm{Cs}$ and ${ }^{137 \mathrm{~m}} \mathrm{Ba}$ (scan MDC) necessary to yield the minimum detectable exposure rate $(2.73 \mu \mathrm{R} / \mathrm{h})$ may be calculated using the following formula.

$$
\text { scan } M D C=\frac{(5 p C i / g)(2.73 \mu R / h)}{1.307 \mu R / h}=10.4 p C i / g
$$

It must be emphasized that while a single scan MDC value can be calculated for a given radionuclide -other scan $\mathrm{MDC}$ values may be equally justifiable depending on the values chosen for the various factors, including the MDCR (background level, acceptable performance criteria, observation interval), surveyor efficiency, detector parameters and the modeling conditions of the contamination. It should also be noted that determination of the scan MDC for radioactive materials-like uranium and thorium - must consider the gamma radiation emitted from the entire decay series. NUREG-1507 (NRC 1997b) provides a detailed example of how the scan MDC can be determined for enriched uranium. 
Table 6.7 provides scan MDCs for common radionuclides and radioactive materials in soil. It is important to note that the variables used in the above examples to determine the scan MDCs for the $1.25 \mathrm{in}$. by $1.5 \mathrm{in}$. $\mathrm{NaI}(\mathrm{Tl})$ scintillation detector-i.e., the $\mathrm{MDCR}_{\text {surveyor }}$ detector parameters (e.g., cpm per $\mu \mathrm{R} / \mathrm{h}$ ), and the characteristics of the area of elevated activity-have all been held constant to facilitate the calculation of scan MDCs provided in Table 6.7. The benefit of this approach is that generally applicable scan MDCs are provided for different radioactive contaminants. Additionally, the relative detectability of different contaminants is evident because the only variable in Table 6.7 is the nature of the contaminant.

As noted above, the scan MDCs calculated using the approach in this section are dependent on several factors. One way to validate the appropriateness of the scan MDC is by tracking the residual radioactivity (both surface activity and soil concentrations) levels identified during investigations performed as a result of scanning surveys. The measurements performed during these investigations may provide an a posteriori estimate of the scan MDC that can be used to validate the a priori scan MDC used to design the survey.

\subsubsection{Scanning for Alpha Emitters}

Scanning for alpha emitters differs significantly from scanning for beta and gamma emitters in that the expected background response of most alpha detectors is very close to zero. The following discussion covers scanning for alpha emitters and assumes that the surface being surveyed is similar in nature to the material on which the detector was calibrated. In this respect, the approach is purely theoretical. Surveying surfaces that are dirty, non-planar, or weathered can significantly affect the detection efficiency and therefore bias the expected MDC for the scan. The use of reasonable detection efficiency values instead of optimistic values is highly recommended. Appendix J contains a complete derivation of the alpha scanning equations used in this section.

Since the time a contaminated area is under the probe varies and the background count rate of some alpha instruments is less than $1 \mathrm{cpm}$, it is not practical to determine a fixed MDC for scanning. Instead, it is more useful to determine the probability of detecting an area of contamination at a predetermined DCGL for given scan rates.

For alpha survey instrumentation with backgrounds ranging from $<1$ to $3 \mathrm{cpm}$, a single count provides a surveyor sufficient cause to stop and investigate further. Assuming this to be true, the probability of detecting given levels of alpha surface contamination can be calculated by use of Poisson summation statistics. 


\section{Table 6.7 NaI(Tl) Scintillation Detector Scan MDCs for Common Radiological Contaminants ${ }^{\mathrm{B}}$}

\begin{tabular}{|c|c|c|c|c|}
\hline \multirow{2}{*}{$\begin{array}{c}\text { Radionuclide/Radioactive } \\
\text { Material }\end{array}$} & \multicolumn{2}{|c|}{1.25 in. by 1.5 in. NaI Detector } & \multicolumn{2}{|c|}{2 in. by 2 in. NaI Detector } \\
\hline & $\begin{array}{l}\text { Scan MDC } \\
\text { (Bq } \mathbf{k g})\end{array}$ & $\begin{array}{l}\text { Weighted } \\
\text { cpm/ } / \mu \mathrm{R} / \mathrm{h}\end{array}$ & $\begin{array}{c}\text { Scan MDC } \\
(\mathbf{B} q / \mathbf{k g})\end{array}$ & $\begin{array}{l}\text { Weighted } \\
\text { cpm/ } \mu \mathbf{R} / \mathbf{h}\end{array}$ \\
\hline Am-241 & 1,650 & 5,830 & 1,170 & 13,000 \\
\hline Co-60 & 215 & 160 & 126 & 430 \\
\hline Cs-137 & 385 & 350 & 237 & 900 \\
\hline Th-230 & 111,000 & 4,300 & 78,400 & 9,580 \\
\hline $\begin{array}{l}\mathrm{Ra}-226 \\
\text { (in equilibrium with progeny) }\end{array}$ & 167 & 300 & 104 & 760 \\
\hline $\begin{array}{l}\text { Th-232 decay series } \\
\text { (Sum of all radionuclides in he } \\
\text { thorium decay series) }\end{array}$ & 1,050 & 340 & 677 & 830 \\
\hline $\begin{array}{l}\text { Th-232 } \\
\text { (In equilibrium with progeny in } \\
\text { decay series) }\end{array}$ & 104 & 340 & 66.6 & 830 \\
\hline $\begin{array}{l}\text { Depleted Uranium } \\
\text { (0.34\% U-235) }\end{array}$ & 2,980 & 1,680 & 2,070 & 3,790 \\
\hline Natural Uranium ${ }^{b}$ & 4,260 & 1,770 & 2,960 & 3,990 \\
\hline 3\% Enriched Uranium ${ }^{\mathrm{b}}$ & 5,070 & 2,010 & 3,540 & 4,520 \\
\hline 20\% Enriched Uranium ${ }^{b}$ & 5,620 & 2,210 & 3,960 & 4,940 \\
\hline 50\% Enriched Uranium ${ }^{b}$ & 6,220 & 2,240 & 4,370 & 5,010 \\
\hline 75\% Enriched Uranium ${ }^{b}$ & 6,960 & 2,250 & 4,880 & 5,030 \\
\hline
\end{tabular}

${ }^{a}$ Refer to text for complete explanation of factors used to calculate scan MDCs. For example, the background level for the $1.25 \mathrm{in}$. by $1.5 \mathrm{in}$. Nal detector was assumed to be $4,000 \mathrm{cpm}$, and $10,000 \mathrm{cpm}$ for the 2 in. by $2 \mathrm{in}$. NaI detector. The observation interval was 1-sec and the level of performance was selected to yield $d^{\prime}$ 'of 1.38 .

${ }^{b}$ Scan MDC for uranium includes sum of ${ }^{238} \mathrm{U},{ }^{235} \mathrm{U}$, and ${ }^{234} \mathrm{U}$. 
Given a known scan rate and a surface contamination DCGL, the probability of detecting a single count while passing over the contaminated area is

$$
P(n \geq 1)=1-e^{\frac{-G E d}{60 v}}
$$

where

$$
\begin{array}{lll}
\mathrm{P}(\mathrm{n} \geq 1) & = & \text { probability of observing a single count } \\
\mathrm{G} & = & \text { contamination activity }(\mathrm{dpm}) \\
\mathrm{E} & = & \text { detector efficiency }(4 \pi) \\
\mathrm{d} & = & \text { width of detector in direction of scan }(\mathrm{cm}) \\
\mathrm{v} & = & \text { scan speed }(\mathrm{cm} / \mathrm{s})
\end{array}
$$

Note: Refer to Appendix J for a complete derivation of these formulas.

Once a count is recorded and the guideline level of contamination is present the surveyor should stop and wait until the probability of getting another count is at least $90 \%$. This time interval can be calculated by

$$
t=\frac{13,800}{\mathrm{CAE}}
$$

where

$$
\begin{array}{lll}
\mathrm{t} & = & \text { time period for static count }(\mathrm{s}) \\
\mathrm{C} & = & \text { contamination guideline }\left(\mathrm{dpm} / 100 \mathrm{~cm}^{2}\right) \\
\mathrm{A} & = & \text { physical probe area }\left(\mathrm{cm}^{2}\right) \\
\mathrm{E} & = & \text { detector efficiency }(4 \pi)
\end{array}
$$

Many portable proportional counters have background count rates on the order of 5 to $10 \mathrm{cpm}$, and a single count should not cause a surveyor to investigate further. A counting period long enough to establish that a single count indicates an elevated contamination level would be prohibitively inefficient. For these types of instruments, the surveyor usually will need to get at least 2 counts while passing over the source area before stopping for further investigation.

Assuming this to be a valid assumption, the probability of getting two or more counts can be calculated by: 
Field Measurement Methods and Instrumentation

$$
\begin{aligned}
\mathrm{P}(\mathrm{n} \geq 2) & =1-\mathrm{P}(\mathrm{n}=0)-\mathrm{P}(\mathrm{n}=1) \\
& =1-\left(1+\frac{(\mathrm{GE}+\mathrm{B}) \mathrm{t}}{60}\right)\left(\mathrm{e}^{-\frac{(\mathrm{GE}+\mathrm{B}) \mathrm{t}}{60}}\right)
\end{aligned}
$$

where

$$
\begin{array}{lll}
\mathrm{P}(\mathrm{n} \geq 2) & = & \text { probability of getting } 2 \text { or more counts during the time interval } t \\
\mathrm{P}(\mathrm{n}=0) & = & \text { probability of not getting any counts during the time interval } t \\
\mathrm{P}(\mathrm{n}=1) & = & \text { probability of getting } 1 \text { count during the time interval } \mathrm{t} \\
\mathrm{B} & = & \text { background count rate }(\mathrm{cpm})
\end{array}
$$

All other variables are the same as for Equation 6-12.

Appendix $\mathrm{J}$ provides a complete derivation of Equations 6-12 through 6-14 and a detailed discussion of the probability of detecting alpha surface contamination for several different variables. Several probability charts are included at the end of Appendix $J$ for common detector sizes. Table 6.8 provides estimates of the probability of detecting $300 \mathrm{dpm} / 100 \mathrm{~cm}^{2}$ for some commonly used alpha detectors.

Table 6.8 Probability of Detecting $300 \mathrm{dpm} / 100 \mathrm{~cm}^{2}$ of Alpha Activity While Scanning with Alpha Detectors Using an Audible Output (calculated using Equation 6-12)

\begin{tabular}{||ccccc|}
\hline $\begin{array}{c}\text { Detector } \\
\text { Type }\end{array}$ & $\begin{array}{c}\text { Detection } \\
\text { Efficiency } \\
\text { cpm/dpm }\end{array}$ & $\begin{array}{c}\text { Probe Dimension } \\
\text { in Direction of Scan } \\
\text { (cm) }\end{array}$ & $\begin{array}{c}\text { Scan Rate } \\
\text { (cm/s) }\end{array}$ & $\begin{array}{c}\text { Probability of } \\
\text { detecting } \\
300 \text { dpm } / 100 \mathrm{~cm}^{2}\end{array}$ \\
\hline \hline Proportional & 0.20 & 5 & 3 & $80 \%$ \\
Proportional & 0.15 & 15 & 5 & $90 \%$ \\
Scintillation & 0.15 & 5 & 3 & $70 \%$ \\
Scintillation & 0.15 & 10 & 3 & $90 \%$ \\
\hline
\end{tabular}

\subsection{Measurement Uncertainty (Error)}

The quality of measurement data will be directly impacted by the magnitude of the measurement uncertainty associated with it. Some uncertainties, such as statistical counting uncertainties, can be easily calculated from the count results using mathematical procedures. Evaluation of other 
Field Measurement Methods and Instrumentation

sources of uncertainty require more effort and in some cases is not possible. For example, if an alpha measurement is made on a porous concrete surface, the observed instrument response when converted to units of activity will probably not exactly equal the true activity under the probe. Variations in the absorption properties of the surface for particulate radiation will vary from point to point and therefore will create some level of variation in the expected detection efficiency. This variability in the expected detector efficiency results in uncertainty in the final reported result. In addition, QC measurement results provide an estimate of random and systematic uncertainties associated with the measurement process.

The measurement uncertainty for every analytical result or series of results, such as for a measurement system, should be reported. This uncertainty, while not directly used for demonstrating compliance with the release criterion, is used for survey planning and data assessment throughout the Radiation Survey and Site Investigation (RSSI) process. In addition, the uncertainty is used for evaluating the performance of measurement systems using QC measurement results. Uncertainty can also be used for comparing individual measurements to the DCGL. This is especially important in the early stages of decommissioning (i.e., scoping, characterization, remedial action support) when decisions are made based on a limited number of measurements.

For most sites, evaluations of uncertainty associated with field measurements is important only for data being used as part of the final status survey documentation. The final status survey data, which is used to document the final radiological status of a site, should state the uncertainties associated with the measurements. Conversely, detailing the uncertainties associated with measurements made during scoping or characterization surveys may or may not be of value depending on what the data will be used for-i.e. the data quality objectives (DQOs). From a practical standpoint, if the observed data are obviously greater than the DCGL and will be eventually cleaned up, then the uncertainty may be relatively unimportant. Conversely, data collected during early phases of a site investigation that may eventually be used to show that the area is below the DCGL-and therefore does not require any clean-up action-will need the same uncertainty evaluation as the final status survey data. In summary, the level of effort needs to match the intended use of the data.

\subsubsection{Systematic and Random Uncertainties}

Measurement uncertainties are often broken into two sub-classes of uncertainty termed systematic (e.g., methodical) uncertainty and random (e.g., stochastic) uncertainty. Systematic uncertainties derive from a lack of knowledge about the true distribution of values associated with a numerical parameter and result in data that is consistently higher (or lower) than the true value. An example of a systematic uncertainty would be the use of a fixed counting efficiency value even though it is known that the efficiency varies from measurement to measurement but without knowledge of the frequency. If the fixed counting efficiency value is higher than the true 
but unknown efficiency—as would be the case for an unrealistically optimistic value-then every measurement result calculated using that efficiency would be biased low. Random uncertainties refer to fluctuations associated with a known distribution of values. An example of a random uncertainty would be a well documented chemical separation efficiency that is known to fluctuate with a regular pattern about a mean. A constant recovery value is used during calculations, but the true value is known to fluctuate from sample to sample with a fixed and known degree of variation.

To minimize the need for estimating potential sources of uncertainty, the sources of uncertainty themselves should be reduced to a minimal level by using practices such as:

- The detector used should minimize the potential uncertainty. For example, when making field surface activity measurements for ${ }^{238} U$ on concrete, a beta detector such as a thinwindow Geiger-Mueller "pancake" may provide better quality data than an alpha detector depending on the circumstances. Less random uncertainty would be expected between measurements with a beta detector such as a pancake since beta emissions from the uranium will be affected much less by thin absorbent layers than will the alpha emissions.

- Calibration factors should accurately reflect the efficiency of a detector being used on the surface material being measured for the contaminant radionuclide or mixture of radionuclides (see Section 6.5.4). For most field measurements, variations in the counting efficiency on different types of materials will introduce the largest amount of uncertainty in the final result.

- Uncertainties should be reduced or eliminated by use of standardized measurement protocols (e.g., SOPs) when possible. Special effort should be made to reduce or eliminate systematic uncertainties, or uncertainties that are the same for every measurement simply due to an error in the process. If the systematic uncertainties are reduced to a negligible level, then the random uncertainties, or those uncertainties that occur on a somewhat statistical basis, can be dealt with more easily.

- Instrument operators should be trained and experienced with the instruments used to perform the measurements.

- $\quad \mathrm{QA} / \mathrm{QC}$ should be conducted as described in Chapter 9.

Uncertainties that cannot be eliminated need to be evaluated such that the effect can be understood and properly propagated into the final data and uncertainty estimates. As previously stated, non-statistical uncertainties should be minimized as much as possible through the use of good work practices. 
Overall random uncertainty can be evaluated using the methods described in the following sections. Section 6.8.2 describes a method for calculating random counting uncertainty. Section 6.8.3 discusses how to combine this counting uncertainty with other uncertainties from the measurement process using uncertainty propagation.

Systematic uncertainty is derived from calibration errors, incorrect yields and efficiencies, nonrepresentative survey designs, and "blunders." It is difficult-and sometimes impossible-to evaluate the systematic uncertainty for a measurement process, but bounds should always be estimated and made small compared to the random uncertainty, if possible. If no other information on systematic uncertainty is available, Currie (NRC 1984) recommends using $16 \%$ as an estimate for systematic uncertainties (1\% for blanks, $5 \%$ for baseline, and $10 \%$ for calibration factors).

\subsubsection{Statistical Counting Uncertainty}

When performing an analysis with a radiation detector, the result will have an uncertainty associated with it due to the statistical nature of radioactive decay. To calculate the total uncertainty associated with the counting process, both the background measurement uncertainty and the sample measurement uncertainty must be accounted for. The standard deviation of the net count rate, or the statistical counting uncertainty, can be calculated by

$$
\sigma_{\mathrm{n}}=\sqrt{\frac{\mathrm{C}_{s+\mathrm{b}}}{\mathrm{T}_{s+\mathrm{b}}^{2}}+\frac{\mathrm{C}_{\mathrm{b}}}{\mathrm{T}_{\mathrm{b}}^{2}}}
$$

where

$$
\begin{array}{lll}
\sigma_{\mathrm{n}} & = & \text { standard deviation of the net count rate result } \\
\mathrm{C}_{\mathrm{stb}} & = & \text { number of gross counts (sample) } \\
\mathrm{T}_{\mathrm{stb}} & = & \text { gross count time } \\
\mathrm{C}_{\mathrm{b}} & = & \text { number of background counts } \\
\mathrm{T}_{\mathrm{b}} & = & \text { background count time }
\end{array}
$$

\subsubsection{Uncertainty Propagation}

Most measurement data will be converted to different units or otherwise included in a calculation to determine a final result. The standard deviation associated with the final result, or the total uncertainty, can then be calculated. Assuming that the individual uncertainties are relatively small, symmetric about zero, and independent of one another, then the total uncertainty for the final calculated result can be determined by solving the following partial differential equation: 


$$
\sigma_{u}=\sqrt{\left(\frac{\partial u}{\partial x}\right)^{2} \sigma_{x}^{2}+\left(\frac{\partial u}{\partial y}\right)^{2} \sigma_{y}^{2}+\left(\frac{\partial u}{\partial z}\right)^{2} \sigma_{z}^{2}+\ldots}
$$

where
$\mathrm{u}$
$=$ function, or formula, that defines the calculation of a final result as $\mathrm{x}, \mathrm{y}, \mathrm{z} . . .$, are assumed to have a measurement uncertainty associated with them and do not include numerical constants
$\sigma_{u} \quad=\quad$ standard deviation, or uncertainty, associated with the final result
$\sigma_{x}, \sigma_{y}, \ldots=$ standard deviation, or uncertainty, associated with the parameters $\mathrm{x}, \mathrm{y}, \mathrm{z}, \ldots$

Equation 6-16, generally known as the error propagation formula, can be solved to determine the standard deviation of a final result from calculations involving measurement data and their associated uncertainties. The solutions for common calculations along with their uncertainty propagation formulas are included below.

Data Calculation

$\mathrm{u}=\mathrm{x}+\mathrm{y}$, or $\mathrm{u}=\mathrm{x}-\mathrm{y}$ :

$\mathrm{u}=\mathrm{x} \div \mathrm{y}$, or $\mathrm{u}=\mathrm{x} \times \mathrm{y}:$

$\mathrm{u}=\mathrm{c} \times \mathrm{x}$, where $\mathrm{c}$ is a positive constant:

$\mathrm{u}=\mathrm{x} \div \mathrm{c}$, where $\mathrm{c}$ is a positive constant: $\quad \sigma_{\mathrm{u}}=\frac{\sigma_{\mathrm{x}}}{\mathrm{c}}$$$
\sigma_{\mathrm{u}}=c \sigma_{\mathrm{x}}
$$

$$
\sigma_{\mathrm{u}}=\frac{\sigma_{\mathrm{x}}}{\mathrm{c}}
$$

\section{Uncertainty Propagation}

$$
\sigma_{u}=\sqrt{\sigma_{x}^{2}+\sigma_{y}^{2}}
$$$$
\sigma_{u}=u \sqrt{\left(\frac{\sigma_{x}}{x}\right)^{2}+\left(\frac{\sigma_{y}}{y}\right)^{2}}
$$

Note: In the above examples, $\mathrm{x}$ and $\mathrm{y}$ are measurement values with associated standard deviations, or uncertainties, equal to $\sigma_{\mathrm{x}}$ and $\sigma_{\mathrm{y}}$ respectively. The symbol "c" is used to represent a numerical constant which has no associated uncertainty. The symbol $\sigma_{u}$ is used to denote the standard deviation, or uncertainty, of the final calculated value $u$.

\subsubsection{Reporting Confidence Intervals}

Throughout Section 6.8, the term "measurement uncertainty" is used interchangeably with the term "standard deviation." In this respect, the uncertainty is qualified as numerically identical to 
the standard deviation associated with a normally distributed range of values. When reporting a confidence interval for a value, one provides the range of values that represent a pre-determined level of confidence (i.e., 95\%). To make this calculation, the final standard deviation, or total uncertainty $\sigma_{\mathrm{u}}$ as shown in Equation 6-16, is multiplied by a constant factor $\mathrm{k}$ representing the area under a normal curve as a function of the standard deviation. The values of $k$ representing various intervals about a mean of normal distributions as a function of the standard deviation is given in Table 6.9. The following example illustrates the use of this factor in context with the propagation and reporting of uncertainty values.

\section{Table 6.9 Areas Under Various Intervals About the Mean of a Normal Distribution}

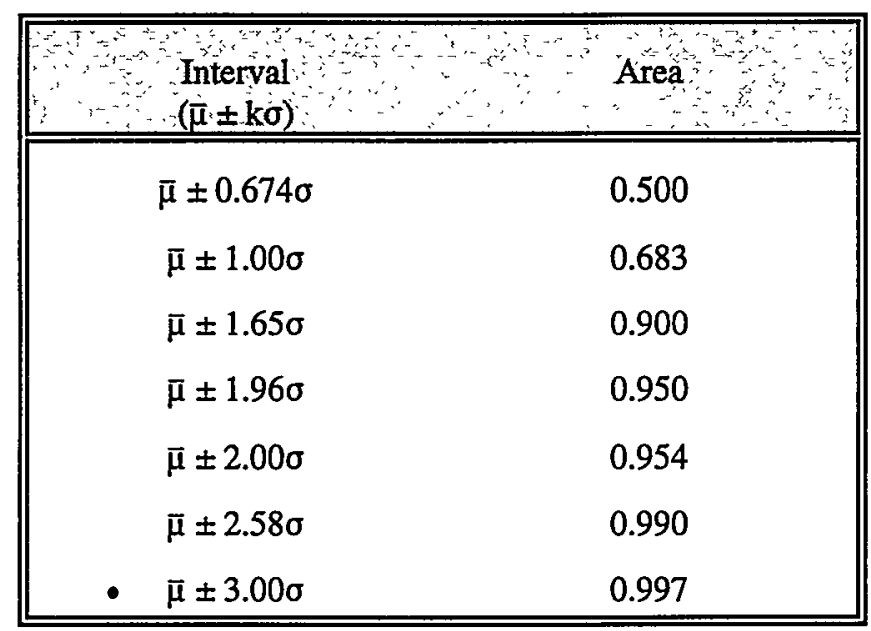

Example:

Uncertainty Propagation and Confidence Interval: A measurement process with a zero background yields a count result of $28 \pm 5$ counts in 5 minutes, where the \pm 5 counts represents one standard deviation about a mean value of 28 counts. The detection efficiency is 0.1 counts per disintegration \pm 0.01 counts per disintegration, again representing one standard deviation about the mean.

Calculate the activity of the sample, in dpm, total measurement uncertainty, and the $95 \%$ confidence interval for the result.

1) The total number of disintegrations is:

$$
\frac{28 \text { counts }}{0.1 \text { cld }}=280
$$


2) Using the equation for error propagation for division, total uncertainty is:

$$
280 \sqrt{\left(\frac{5}{28}\right)^{2}+\left(\frac{0.01}{0.1}\right)^{2}}=57 \text { disintegrations }
$$

3) The activity will then be $280 \div 5$ minutes $=56 \mathrm{dpm}$ and the total uncertainty will be $57 \div 5$ minutes $=11 \mathrm{dpm}$. (Since the count time is considered to have trivial variance, this is assumed to be a constant.)

Referring to Table 6.9 , a $\mathrm{k}$ value of \pm 1.96 represents a confidence interval equal to $95 \%$ about the mean of a normal distribution. Therefore, the $95 \%$ confidence interval would be $1.96 \times 11 \mathrm{dpm}$ $=22 \mathrm{dpm}$. The final result would be $56 \pm 22 \mathrm{dpm}$.

\subsection{Radon Measurements}

There are three radon isotopes in nature: ${ }^{222} \mathrm{Rn}$ (radon) in the ${ }^{238} \mathrm{U}$ decay chain, ${ }^{220} \mathrm{Rn}$ (thoron) in the ${ }^{232} \mathrm{Th}$ chain, and ${ }^{219} \mathrm{Rn}$ (actinon) in the ${ }^{235} \mathrm{U}$ chain. ${ }^{219} \mathrm{Rn}$ is the least abundant of these three isotopes, and because of its short half-life of 4 seconds it has the least probability of emanating into the atmosphere before decaying. ${ }^{220} \mathrm{Rn}$ with a 55 second half-life is somewhat more mobile. ${ }^{222} \mathrm{Rn}$ with a $3.8 \mathrm{~d}$ half-life is capable of migrating through several decimeters of soil or building material and reaching the atmosphere. Therefore, in most situations, ${ }^{222} \mathrm{Rn}$ should be the predominant airborne radon isotope.

Many techniques have been developed over the years for measuring radon (Jenkins 1986) and radon progeny in air. In addition, considerable attention is given by EPA to measurement of radon and radon progeny in homes (EPA 1992d). Radon and radon progeny emit alpha and beta particles and gamma rays. Therefore, numerous techniques can and have been developed for measuring these radionuclides based on detecting alpha particles, beta particles, or gamma rays, independently or in some combination. It is even difficult to categorize the various techniques that are presently in use. This section contains an overview of information dealing with the measurement of radon and radon progeny. The information is focused on the measurement of ${ }^{222} \mathrm{Rn}$, however the information may be adapted for the measurement of ${ }^{219} \mathrm{Rn}$ and ${ }^{220} \mathrm{Rn}$.

Radon concentrations within a fixed structure can vary significantly from one section of the building to another and can fluctuate over time. If a home has a basement, for instance, it is usually expected that a higher radon concentration will be found there. Likewise, a relatively small increase in the relative pressure between the soil and the inside of a structure can cause a significant increase in the radon emanation rate from the soil into the structure. Many factors play a role in these variations, but from a practical standpoint it is only necessary to recognize 
that fluctuations are expected and that they should be accounted for. Long term measurement periods are required to determine a true mean concentration inside a structure and to account for the fluctuations.

Two analytical end points are of interest when performing radon measurements. The first and most commonly used is radon concentration, which is stated in terms of activity per unit volume $\left(\mathrm{Bg} / \mathrm{m}^{3}\right.$ or $\left.\mathrm{pCi} / \mathrm{L}\right)$. Although this terminology is consistent with most federal guidance values, it only infers the potential dose equivalent associated with radon. The second analytical end point is the radon progeny working level. Radon progeny usually attach very quickly to charged aerosols in the air following creation. The fraction that remains unattached is usually quite small (i.e., 5-10\%). Since most aerosol particles carry an electrical charge and are relatively massive $(\geq 0.1 \mu \mathrm{m})$, they are capable of attaching to the surfaces of the lung. Essentially all dose or risk from radon is associated with alpha decays from radon progeny attached to tissues of the respiratory system. If an investigator is interested in accurately determining the potential dose or risk associated with radon in the air of a room, the radon progeny concentration must be known.

Radon progeny concentrations are usually reported in units of working levels (WL), where one working level is equal to the potential alpha energy associated with the radon progeny in secular equilibrium with $100 \mathrm{pCi} / \mathrm{L}$ of radon. One working level is equivalent to $1.28 \times 10^{5} \mathrm{MeV} / \mathrm{L}$ of potential alpha energy. Given a known breathing rate and lung attachment probability, the expected mean lung dose from exposure to a known working level of radon progeny can be calculated.

Radon progeny are not usually found in secular equilibrium with radon indoors due to plating out of the charged aerosols onto walls, furniture, etc. The ratio of ${ }^{222} \mathrm{Rn}$ progeny activity to ${ }^{222} \mathrm{Rn}$ activity usually ranges from 0.2 to as high as 0.8 indoors (NCRP 1988). If only the ${ }^{222} \mathrm{Rn}$ concentration is measured and it is not practical to measure the progeny concentrations, then general practice is to assume a progeny to ${ }^{222} \mathrm{Rn}$ equilibrium ratio of 0.5 for indoor areas. This allows one to estimate the expected dose or risk associated with a given radon concentration.

In general, the following generic guidelines should be followed when performing radon measurements during site investigations:

- The radon measurement method used should be well understood and documented.

- Long term measurements are used to determine the true mean radon concentration.

- The impact of variable environmental conditions (e.g., humidity, temperature, dust loading, and atmospheric pressure) on the measurement process should be accounted for when necessary. Consideration should be given to effects on both the air collection process and the counting system. 
Field Measurement Methods and Instrumentation

- The background response of the detection system should be accounted for.

- If the quantity of interest is the working level, then the radon progeny concentrations should be evaluated. If this is not practical, then the progeny activities can be estimated by assuming they are $50 \%$ of the measured radon activity (NCRP 1988).

For a general overview, a list of common radiation detectors with their usual applications during radon surveys is provided in Table 6.10. Descriptions and costs for specific equipment used for the measurement of radon are contained in Appendix $\mathrm{H}$.

Table 6.10 Radiation Detectors with Applications to Radon Surveys

\begin{tabular}{|c|c|c|c|}
\hline System & Description & Application & Remarks \\
\hline $\begin{array}{l}\text { Large area } \\
\text { activated charcoal } \\
\text { collector }\end{array}$ & $\begin{array}{l}\text { A canister containing activated } \\
\text { charcoal is twisted into the } \\
\text { surface and left for } 24 \text { hours. }\end{array}$ & $\begin{array}{l}\text { Short term radon } \\
\text { flux measurements }\end{array}$ & $\begin{array}{l}\text { The LLD is } 0.007 \mathrm{~Bq} \mathrm{~m}^{-2} \mathrm{~s}^{-1} \\
\left(0.2 \mathrm{pCi} \mathrm{m}^{-2} \mathrm{~s}^{-1}\right) \text {. }\end{array}$ \\
\hline $\begin{array}{l}\text { Continuous radon } \\
\text { monitor }\end{array}$ & $\begin{array}{l}\text { Air pump and scintillation cell } \\
\text { or ionization chamber. }\end{array}$ & $\begin{array}{l}\text { Track the real time } \\
\text { concentration of } \\
\text { radon }\end{array}$ & $\begin{array}{l}\text { Takes } 1 \text { to } 4 \text { hours for system to } \\
\text { equilibrate before starting. The } L L D \\
\text { is } 0.004-0.04 \mathrm{Bg} / \mathrm{L}(0.1-1.0 \mathrm{pCi} / \mathrm{L}) \text {. }\end{array}$ \\
\hline $\begin{array}{l}\text { Activated charcoal } \\
\text { adsorption }\end{array}$ & $\begin{array}{l}\text { Activated charcoal is opened to } \\
\text { the ambient air, then gamma } \\
\text { counted on a gamma } \\
\text { scintillator or in a liquid } \\
\text { scintillation counter. }\end{array}$ & $\begin{array}{l}\text { Measure radon } \\
\text { concentration in } \\
\text { indoor air }\end{array}$ & $\begin{array}{l}\text { Detector is deployed for } 2 \text { to } 7 \text { days. } \\
\text { The } L L D \text { is } 0.007-0.04 \mathrm{~Bq} / \mathrm{L}(0.2 \text { to } \\
1.0 \mathrm{pCi} / \mathrm{L}) \text {. }\end{array}$ \\
\hline $\begin{array}{l}\text { Electret ion } \\
\text { chamber }\end{array}$ & $\begin{array}{l}\text { This is a charged plastic vessel } \\
\text { that can be opened for air to } \\
\text { pass through. }\end{array}$ & $\begin{array}{l}\text { Measure short- } \\
\text { term or long-term } \\
\text { radon } \\
\text { concentration in } \\
\text { indoor air } \\
\end{array}$ & $\begin{array}{l}\text { Must correct reading for gamma } \\
\text { background concentration. Electret is } \\
\text { sensitive to extremes of temperature } \\
\text { and humidity. LLD is } 0.007-0.02 \\
\mathrm{~Bq} / \mathrm{L}(0.2-0.5 \mathrm{pCi} / \mathrm{L}) \text {. }\end{array}$ \\
\hline $\begin{array}{l}\text { Alpha track } \\
\text { detection }\end{array}$ & $\begin{array}{l}\text { A small piece of special plastic } \\
\text { or film inside a small container. } \\
\text { Damage tracks from alpha } \\
\text { particles are chemically etched } \\
\text { and tracks counted. }\end{array}$ & $\begin{array}{l}\text { Measure indoor or } \\
\text { outdoor radon } \\
\text { concentration in air }\end{array}$ & $\begin{array}{l}\text { LLD is } 0.04 \mathrm{~Bq} \mathrm{~L}^{-1} \mathrm{~d}^{-1} \\
\left(1 \mathrm{pCi} \mathrm{L}^{-1} \mathrm{~d}^{-1}\right)\end{array}$ \\
\hline
\end{tabular}

The following provides a general overview of radon sampling and measurement concepts. The intent of this section is to provide an overview of common methods and terminology. 
Field Measurement Methods and Instrumentation

\subsubsection{Direct Radon Measurements}

Direct radon measurements are performed by gathering radon into a chamber and measuring the ionizations produced. A variety of methods have been developed, each making use of the same fundamental mechanics but employing different measurement processes. The first step is to get the radon into a chamber without collecting any radon progeny from the ambient air. A filter is normally used to capture charged aerosols while allowing the radon gas to pass through. Most passive monitors rely on diffusion of the ambient radon in the air into the chamber to establish an equilibrium between the concentrations of radon in the air and in the chamber. Active monitors use some type of air pump system for the air exchange method.

Once inside the chamber, the radon decays by alpha emission to form ${ }^{218} \mathrm{Po}$ which usually takes on a positive charge within thousandths of a second following formation. Some monitor types collect these ionic molecules and subsequently measure the alpha particles emitted by the radon progeny. Other monitor types, such as the electret ion chamber, measure the ionization produced by the decay of radon in the air within the chamber by directly collecting the ions produced inside the chamber. Simple systems measure the cumulative radon during the exposure period based on the total alpha decays that occur. More complicated systems actually measure the individual pulse height distributions of the alpha and/or beta radiation emissions and derive the radon plus progeny isotopic concentration in the air volume.

Care must be taken to accurately calibrate a system and to understand the effects of humidity, temperature, dust loading, and atmospheric pressure on the system. These conditions create a small adverse effect on some systems and a large influence on others.

\subsubsection{Integrating Methods for Radon Measurement}

With integrating methods, measurements are made over a period of days, weeks, or months and the device is subsequently read by an appropriate device for the detector media used. The most common detectors used are activated charcoal adsorbers, electret ion chamber (EIC), and alpha track plastics. Short term fluctuations are averaged out, thus making the measurement representative of average concentration. Results in the form of an average value provide no way to determine the fluctuations of the radon concentration over the measurement interval. Successive short term measurements can be used in place of single long term measurements to gain better insight into the time dependence of the radon concentration.

\subsubsection{Continuous Methods for Radon Measurement}

Devices that measure direct radon concentrations over successive time increments are generally called continuous radon monitors. These systems are more complex than integrating devices in that they measure the radon concentration and log the results to a data recording device on a real 
time basis. Continuous radon measurement devices normally allow the noble gas radon to pass through a filter into a detection chamber where the radon decays and the radon and/or the resulting progeny are measured. The most common detectors used for real time measurements are ion chambers, solid state surface barrier detectors, and $\mathrm{ZnS}(\mathrm{Ag})$ scintillation detectors.

Continuous methods offer the advantage of providing successive, short-term results over long periods of time. This allows the investigator not only to determine the average radon concentration, but also to analyze the fluctuations in the values over time. More complicated systems are available that measure the relative humidity and temperature at the measurement location and log the values along with the radon concentrations to the data logging device. This allows the investigator to make adjustments, if necessary, to the resulting data prior to reporting the results.

\subsubsection{Radon Progeny Measurements}

Radon progeny measurements are performed by collecting charged aerosols onto filter paper and subsequently counting the filter for attached progeny. Some systems pump air through a filter and then automatically count the filter for alpha and/or beta emissions. An equivalent but more labor intensive method is to collect a sample using an air sampling pump and then count the filter in stand alone alpha and/or beta counting systems. The measurement system may make use of any number of different techniques ranging from full alpha and beta spectrometric analysis of the filters to simply counting the filter for total alpha and or beta emissions.

When performing total (gross) counting analyses, the assumption is usually made that the only radioisotopes in the air are due to ${ }^{222} \mathrm{Rn}$ and its progeny. This uncertainty, which is usually very small, can be essentially eliminated when performing manual sampling and analysis by performing a follow up measurement of the filter after the radon progeny have decayed to a negligible level. This value can then be used as a background value for the air. Of course, such a

simple approach is only applicable when ${ }^{222} \mathrm{Rn}$ is the isotope of concern. For ${ }^{219} \mathrm{Rn}$ or ${ }^{220} \mathrm{Rn}$, other methods would have to be used.

Time is a significant element in radon progeny measurements. Given any initial equilibrium condition for the progeny isotopes, an investigator must be able to correlate the sampling and measurement technique back to the true concentration values. When collecting radon progeny, the buildup of total activity on the filter increases asymptotically until the activity on the filter becomes constant. At this point, the decay rate of the progeny atoms on the filter is equal to the collection rate of progeny atoms. This is an important parameter to consider when designing a radon sampling procedure.

Note that the number of charged aerosol particles in the air can affect the results for radon progeny measurements. If the number of particles is few, as is possible when humidity is low and a room is very clean, then most of the progeny will not be attached and can plate out on room 
Field Measurement Methods and Instrumentation

surfaces prior to reaching the sample filter. This is not a problem if the same conditions always exist in the room, however the calculated dose would underestimate the dose that would be received in a higher humidity or dust concentration state with the same radon progeny concentration.

\subsubsection{Radon Flux Measurements}

Sometimes it is desirable to characterize the source of radon in terms of the rate at which radon is emanating from a surface-that is, soil, uranium mill tailings, or concrete. One method used for measuring radon flux is briefly described here.

The measurement of radon flux can be achieved by adsorption onto charcoal using a variety of methods such as a charcoal canister or a large area collector (e.g., $25 \mathrm{~cm}$ PVC end cap). The collector is deployed by firmly twisting the end cap into the surface of the material to be measured. After 24 hours of exposure, the activated charcoal is removed and transferred to plastic containers. The amount of radon adsorbed on the activated charcoal is determined by gamma spectroscopy. Since the area of the surface is well defined and the deployment period is known, the radon flux (in units of $\mathrm{Bq} / \mathrm{m}^{2}-\mathrm{s}$ or $\mathrm{pCi} / \mathrm{m}^{2}-\mathrm{s}$ ) can be calculated.

This method is reliable for measuring radon flux in normal environmental situations. However, care should be taken if an extremely large source of radon is measured with this method. The collection time should be chosen carefully to avoid saturating the canister with radon. If saturation is approached, the charcoal loses its ability to absorb radon and the collection rate decreases. Even transporting and handling of a canister that is saturated with radon can be a problem due to the dose rate from the gamma rays being emitted. One would rarely encounter a source of radon that is so large that this would become a problem; however, it should be recognized as a potential problem. Charcoal can also become saturated with water, which will affect the absorption of radon. This can occur in areas with high humidity.

An alternative method for making passive radon flux measurements has been developed recently using electret ionization chambers (EICs). EIC technology has been widely used for indoor radon measurements. The passive EIC procedure is similar to the procedures used with large area activated charcoal canisters. In order to provide the data for the background corrections, an additional passive monitor is located side by side on a radon impermeable membrane. These data are used to calculate the net radon flux. The Florida State Bureau of Radiation Protection has compared the results from measurements of several phosphogypsum flux beds using the charcoal canisters and EICs and has shown that the two methods give comparable results. The passive method seems to have overcome some of the limitations encountered in the use of charcoal. The measurement periods can be extended from hours to several days in order to obtain a better average, if needed. EIC flux measurements are not affected by environmental conditions such as temperature, humidity, and air flow. The measured sensitivities are 
Field Measurement Methods and Instrumentation

comparable to the charcoal method but, unlike charcoal, EICs do not become saturated by humidity. Intermediate readings can be made if needed.. In view of the low cost of the EIC reading/analyzing equipment, the cost per measurement can be as much as 50\% lower than the charcoal method with additional savings in time.

\subsection{Special Equipment}

Various specialized systems have been developed which can be used during the performance of radiation surveys and site investigations. These range from specially designed quick radiation scanning systems to commercial global positioning systems (GPSs). The equipment may be designed to detect radiation directly, detect and locate materials associated with the contamination (e.g., metal containers), or locate the position where a particular measurement is performed (e.g., GPS). Because these specialized systems are continuously being modified and developed for site-specific applications, it is not possible to provide detailed descriptions of every system. The following sections provide examples of specialized equipment that have been applied to radiation surveys and site investigations.

\subsubsection{Positioning Systems}

As stated in Section 4.8.5, documenting the location of measurements is important for demonstrating the reproducibility of the results. There are a variety of positioning systems available that provide a range of accuracy and precision that can be evaluated during survey planning to determine their applicability to a particular site. These positioning systems can be used to establish a reproducible reference coordinate system or to locate individual measurements using an established reference coordinate system (e.g., longitude and latitude).

\subsubsection{Differential Global Positioning Systems}

A variety of practical and versatile GPSs based on radio signals tracked from satellite beacons are available (e.g., Trimble ${ }^{\mathrm{TM}}$, Novatel ${ }^{\mathrm{TM}}$, Garmin $^{\mathrm{TM}}$ ). These systems are generally used to aid in recording and retrieving location data with precision on the order of tens of meters. With a stationary base station and a separate moving locator, the system is deployed in the "differential global positioning system" (DGPS) mode. DGPSs can record and retrieve location data with a precision in the centimeter range.

DGPS can be used to provide position information on surface features in areas being surveyed, linking the survey results to previously published maps and aerial photographs. In addition, survey results may be positioned using the DGPS readings to accurately and precisely locate the results as well as the results of any subsequent analyses to these same maps or photographs. A process called waypointing uses the DGPS to locate specific points and allows the user to find 
Field Measurement Methods and Instrumentation

predetermined locations and set up gridded locations for measurements based on location data that are tied into local or state coordinate systems.

Limitations on the use of DGPS are related to the number of satellite beacons available to the system. When three or fewer satellites are available the accuracy and precision of the location data will be reduced. There are short periods of time (usually less than one hour even on the worst days) when a limited number of satellites are overhead in the continental United States. Satellites may also be blocked by excess tree cover or tall buildings. Distance between the moving locator and the stationary base station may be several kilometers or may be limited to line-of-sight. This limitation can be mitigated through the strategic use of repeater stations to retransmit the signal between the moving locator and the base station.

\subsubsection{Local Microwave and Sonar Positioning Systems}

Local microwave or sonar beacons and receivers may provide useful location data in small areas and tree-covered locales. One example of a sonar-based system is the ultrasonic ranging and data system (USRADS). With a number of fixed beacons in place, a roving unit can be oriented and provide location data with similar accuracy and precision as the DGPS. If the beacons are located at known points, the resulting positions can be determined using simple calculations based on the known reference locations of the beacons.

The logistics of deploying the necessary number of beacons properly and the short range of the signals are the major limitations of the system. In addition, multipathing of signals within wooded areas can cause jumps in the positioning data.

\subsubsection{Mobile Systems with Integrated Positioning Systems}

In recent years, the advent of new technologies has introduced mobile sensor systems for acquiring data that include fully-integrated positioning systems. Portable and vehicle-based versions of these systems record survey data while moving over surfaces to be surveyed and simultaneously recording the location data from either a roving DGPS receiver or local microwave/sonar receiver. All measurement data are automatically stored and processed with the measurement location for later posting (see Section 8.2.2.2 for a discussion of posting plots) or for mapping the results. These systems are designed with a variety of detectors for different applications. For example, alpha or beta detectors have been mounted on a robot a fixed distance over a smooth surface. The robot moves at a predetermined speed over the surface to provide scanning results, and also records individual direct measurements at predetermined intervals. This type of system not only provides the necessary measurement data, but also reduces the uncertainty associated with human factors. Other systems are equipped with several types of radiation detectors, magnetometers, electromagnetic sensors, or various combinations of multiple sensors. The limitations of each system should be evaluated on a site-specific basis to determine 
if the positioning system, the detector, the transport system, or some combination based on sitespecific characteristics will represent the limits of the system.

\subsubsection{Radar, Magnetometer, and Electromagnetic Sensors}

The number of sensors and sensor systems applicable to the detection and location of buried waste have increased in use and reliability in recent years. These systems are typically applicable to scoping and characterization surveys where the identification of subsurface contamination is a primary concern. However, the results of these surveys may be used during final status survey planning to demonstrate that subsurface contamination is not a concern for a particular site or survey unit. Some of the major technologies are briefly described in the following sections.

\subsubsection{Ground Penetrating Radar}

For most sites, ground penetrating radar (GPR) is the only instrument capable of collecting images of buried objects in situ, as compared to magnetometers (Section 6.10.3.2) and electromagnetic sensors (Section 6.10.3.3) which detect the strength of signals as measured at the ground surface. Additionally, GPR is unique in its ability to detect both metallic and nonmetallic (e.g., plastic, glass) containers.

Subsurface radar detection systems have been the focus of study for locating and identifying buried or submerged objects that otherwise could not be detected. There are two major categories of radar signals: 1) time domain, and 2) frequency domain. Time-domain radar uses short impulses of radar-frequency energy directed into the ground being investigated. Reflections of this energy, based on changes in dielectric properties, are then received by the radar. Frequency-domain radar, on the other hand, uses a continuous transmission where the frequency of the transmission can be varied either stepwise or continuously. The changes in the frequency characteristics due to effects from the ground are recorded. Signal processing, in both cases, converts this signal to represent the location of radar reflectors against the travel time of the return signal. Greater travel time corresponds to a greater distance beneath the surface. Table 6.11 lists the typical penetration depth for various geologic materials (fresh water is included as a baseline for comparison).

Examples of existing GPR technologies currently being applied to subsurface investigations include:

$\begin{array}{ll}\text { - } & \text { narrow-band radar } \\ \text { - } & \text { syntha-wideband radar aperture radar } \\ \text { - } & \text { frequency modulated continuous radar } \\ \text { - } & \text { polarized radar waves }\end{array}$ 
Field Measurement Methods and Instrumentation

\section{Table 6.11 Typical Radar Penetration Depths for Various Geologic Materials}

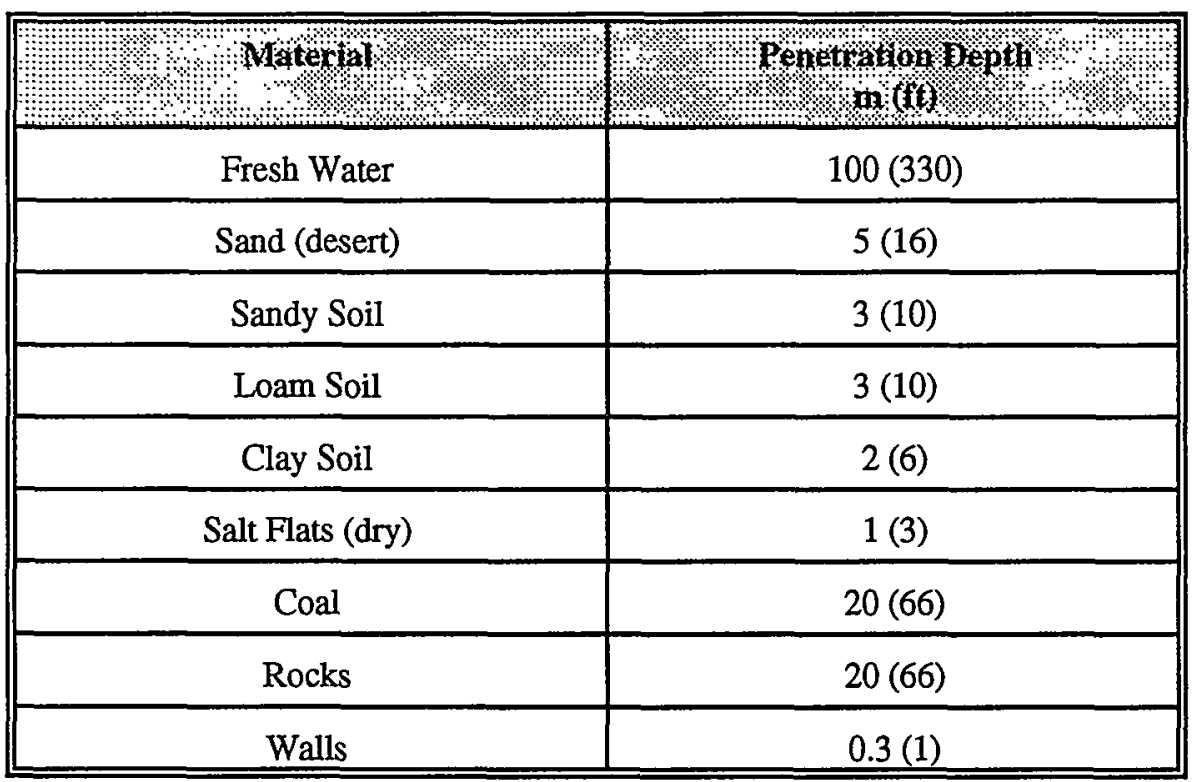

The major limitation to GPR is the difficulty in interpreting the data, which is often provided in the form of hazy, "waterfall-patterned" data images requiring an experienced professional to interpret. Also, GPR can vary depending on the soil type as shown in Table 6.10. Highly conductive clay soils often absorb a large amount of the radar energy, and may even reflect the energy. GPR can be deployed using ground-based or airborne systems.

\subsubsection{Magnetometers}

Although contaminated soil and most radioactive waste possess no ferromagnetic properties, the containers commonly used to hold radioactive waste (e.g., 55-gallon drums) are made from steel. These containers possess significant magnetic susceptibility making the containers detectable using magnetometry.

Magnetometers sense the pervasive magnetic field of the Earth. This field, when encountering an object with magnetic susceptibility, induces a secondary magnetic field in that object. This secondary field creates an increase or decrease in Earth's ambient magnetic field. Magnetometers measure these changes in the expected strength of the ambient magnetic field. Some magnetometers, called "vector magnetometers," can sense the direction as well as the magnitude of these changes. However, for subsurface investigations only the magnitude of the changes are used. 
The ambient magnetic field on Earth averages 55,000 gamma in strength. The variations caused by the secondary magnetic fields typically range from 10 to 1,000 gamma, and average around 100 gamma. Most magnetometers currently in use have a sensitivity in the 0.1 to 0.01 gamma range and are capable of detecting these secondary fields.

An alternate magnetometer survey can be performed using two magnetometers in a gradiometric configuration. This means that the first magnetometer is placed at the ground surface, while the second is mounted approximately 0.5 meters above the first. Data is recorded from both sensors and compared. When the readings from both detectors are nearly the same, it implies that there is no significant disturbance in the Earth's ambient magnetic field or that such disturbances are broad and far away from the gradiometer. When a secondary magnetic field is induced in an object, it affects one sensor more strongly than the other, producing a difference in the readings from the two magnetometers. This approach is similar to the use of a guard detector in anticoincidence mode in a low-background gas-flow proportional counter in a laboratory (see Appendix $\mathrm{H}$ for a description of gas-flow proportional counters). The gradiometric configuration filters out the Earth's ambient magnetic field, large scale variations, and objects located far from the sensor to measure the effects of nearby objects, all without additional data processing.

Fifty-five gallon drums buried 5 to 7 meters below the surface may be detectable using a magnetometer. At many sites, multiple drums have been buried in trenches or pits and detection is straightforward. A single operator carrying a magnetometer with the necessary electronics in a backpack can cover large areas in a relatively small amount of time.

The limitations on the system are related to the size of the objects and their depth below the surface. Objects that are too small or buried too deep will not provide a secondary magnetic field that can be detected at the ground surface.

\subsubsection{Electromagnetic Sensors}

Electromagnetic sensors emit an electromagnetic wave, in either a pulsed or continuous wave mode, and then receive the result of that transmission. The result of the transmission is two signals; quadrature and in-phase. As the wave passes through some material other than air, it is slowed down by a resistive medium or sped up by a conductor through dielectric effects. This produces the quadrature signal. If the electromagnetic wave encounters a highly conductive object it induces a magnetic field in the object. This induced electromagnetic field returns to the sensor as a reflection of the original electromagnetic wave and forms the in-phase signal.

The in-phase signal is indicative of the presence, size, and conductivity of nearby objects (e.g., 55 -gallon drums), while the quadrature signal is a measure of the dielectric properties of the nearby objects such as soil. This means that electromagnetic sensors can detect all metallic objects (including steel, brass, and aluminum), such as the metal in waste containers, and also sample the soil for changes in properties, such as those caused by leaks of contaminants. 
Depths of interest are largely determined by the spacing between the coil used to transmit the primary electromagnetic wave, and the receiver used to receive that transmission. The rule of thumb is that the depth of interest is on the order of the distance between the transmitter and the receiver. A system designed with the transmitter and receiver placed tens of meters apart can detect signals from tens of meters below the surface. A system with the transmitter and receiver collocated can only detect signals from depths on the order of the size of the coil, which is typically about one meter. The limitations of electromagnetic sensors include a lack of clearly defined signals, and decreasing resolution of the signal as the distance below the surface increases.

\subsubsection{Aerial Radiological Surveys}

Low-altitude aerial radiological surveys are designed to encompass large areas and may be useful in:

\footnotetext{
- providing data to assist in the identification of radioactive contaminants and their corresponding concentrations and spatial distributions

- characterizing the nature, extent, and impact of contamination
}

The measurement sensitivity and data processing procedures provide total area coverage and a detailed definition of the extent of gamma-producing isotopes for a specific area. The gamma radiation spectral data are processed to provide a qualitative and quantitative analysis of the radionuclides in the survey area. Helicopter flights establish a grid pattern (e.g., east-west) of parallel lines approximately $61 \mathrm{~m}(200 \mathrm{ft})$ above the ground surface.

The survey consists of airborne measurements of natural and man-made gamma radiation from the terrain surface. These measurements allow for the determination of terrestrial spatial distribution of isotopic concentrations and equivalent gamma exposure rates $\left(e . g .,{ }^{60} \mathrm{Co},{ }^{234 m \mathrm{~Pa}}\right.$, and ${ }^{137} \mathrm{Cs}$ ). The results are reported as isopleths for the isotopes and are usually superimposed on scale maps of the area. 


\section{SAMPLING AND PREPARATION FOR LABORATORY MEASUREMENTS}

\subsection{Introduction}

There are three methods for collecting radiation data while performing a survey. A direct measurement is obtained by placing the detector near'or against the surface or in the media being surveyed and reading the radioactivity level directly. Scanning is an evaluation technique performed by moving a portable radiation detection instrument at a constant speed and distance above the surface to semi-quantitatively detect elevated areas of radiation. These measurement techniques are discussed in Chapter 6 . Sampling is the process of collecting a portion of an environmental medium as representative of the locally remaining medium. The collected portion of the medium is then analyzed to determine the radionuclide concentration. This chapter discusses issues involved in collecting and preparing samples in the field for analysis, and in evaluating the results of these analyses. In addition, a general discussion on laboratory sample preparation and analysis is provided to assist in communications with the laboratory during survey planning.

Samples should be collected and analyzed by qualified individuals using the appropriate equipment and procedures. This manual assumes that the samples taken during the survey will be submitted to a qualified laboratory for analysis. The laboratory should have written procedures that document its analytical capabilities for the radionuclides of interest and a Quality Assurance/Quality Control (QA/QC) program that documents the compliance of the analytical process with established criteria. The method used to assay for the radionuclides of concern should be recognized as a factor affecting analysis time.

Commonly used radiation detection and measuring equipment for radiological survey field applications is described in Chapter 6 and Appendix H. Many of these equipment types are also used for laboratory analyses, usually under more controlled conditions that provide for lower detection limits and greater delineation between radionuclides. Laboratory methods often involve combinations of both chemical and instrument techniques to quantify the low levels expected in the samples. This chapter provides guidance to assist the MARSSIM user in selecting appropriate procedures for collecting and handling samples for laboratory analysis. More detailed information is available in documents listed in the reference section of this manual.

\subsection{Data Quality Objectives}

The survey design is developed and documented using the Data Quality Objectives (DQO) Process (see Appendix D). The third step of the DQO Process involves identifying the data needs for a survey. One decision that can be made at this step is the selection of direct 
Sampling and Preparation for Laboratory Measurements

measurements for performing a survey or deciding that sampling methods followed by laboratory analysis are necessary.

\subsubsection{Identifying Data Needs}

The decision maker and the survey planning team need to identify the data needs for the survey being performed, including the:

- $\quad$ type of samples to be collected or measurements to be performed (Chapter 5)

- $\quad$ radionuclide(s) of interest (Section 4.3)

- $\quad$ number of samples to be collected (Section 5.5.2)

- $\quad$ type and frequency of field QC samples to be collected (Section 4.9)

- $\quad$ amount of material to be collected for each sample (Section 4.7.3 and Section 7.5)

- $\quad$ sampling locations and frequencies (Section 5.5.2)

- $\quad$ standard operating procedures (SOPs) to be followed or developed (Chapter 7)

- analytical bias and precision (e.g., quantitative or qualitative) (Appendix $\mathbf{N}$ )

- target detection limits for each radionuclide of interest (Section 6.4 and Table 7.2)

- $\quad$ cost of the methods being evaluated (cost per analysis as well as total cost) (Appendix $\mathrm{H}$ )

- necessary turnaround time

- $\quad$ sample preservation and shipping requirements (Section 7.6 and Section 7.9)

- $\quad$ specific background for the radionuclide(s) of interest (Section 4.5)

- derived concentration guideline level (DCGL) for each radionuclide of interest (Section 4.3)

- measurement documentation requirements (Section 9.4.2.2)

- $\quad$ sample tracking requirements (Section 7.8)

Some of this information will be supplied by subsequent steps in the DQO process, and several iterations of the process may be needed to identify all of the data needs. Consulting with a radiochemist or health physicist may be necessary to properly evaluate the information before deciding between direct measurements or sampling methods to perform the survey. Surveys may require data from all three collection methods (i.e., sample analysis, direct measurements, and scans) in order to demonstrate compliance with the regulation.

\subsubsection{Data Quality Indicators}

The data quality indicators identified as DQOs in Section 2.3.1 and described in Appendix N, Section N.6, should be considered when selecting a measurement method (i.e., scanning, direct measurement, sampling) or an analytical technique (e.g., radionuclide-specific analytical procedure). In some instances, the data quality indicator requirements will help in the selection of an analytical technique. In other cases, the analytical requirements will assist in the selection of appropriate levels for the data quality indicators. 
Sampling and Preparation for Laboratory Measurements

\subsubsection{Precision}

Precision is a measure of agreement among replicate measurements of the same property under prescribed similar conditions (ASQC 1995). Precision is determined quantitatively based on the results of replicate measurements (equations are provided in EPA 1990). The number of replicate analyses needed to determine a specified level of precision for a project is discussed in Section 4.9. There are several types of replicate analyses available to determine the level of precision, and these replicates are typically distinguished by the point in the sample collection and analysis process where the sample is divided. Determining precision by replicating measurements with results at or near the detection limit of the measurement system is not recommended because the measurement uncertainty is usually greater than the desired level of precision.

- Collocated Samples. Collocated samples are samples collected adjacent to the routine field sample to determine local variability of the radionuclide concentration. Typically, collocated samples are collected about one-half to three feet away from the selected sample location. Analytical results from collocated samples can be used to assess site variation, but only in the immediate sampling area. Collocated samples should not be used to assess variability across a site and are not recommended for assessing error (EPA 1991g). Collocated samples can be non-blind, single-blind, or double-blind.

- Field Replicates. Field replicates are samples obtained from one location, homogenized, divided into separate containers and treated as separate samples throughout the remaining sample handling and analytical processes. These samples are used to assess error associated with sample heterogeneity, sample methodology and analytical procedures. Field replicates are used when determining total error for critical samples with contamination concentrations near the action level. For statistical analysis to be valid in such a case, a minimum of eight replicate samples would be required (EPA 1991g). Field replicates (or field split samples) can be non-blind, single-blind, or double-blind and are recommended for determining the level of precision for a radiation survey or site investigation.

- Analytical Laboratory Replicate. An analytical laboratory replicate is a subsample of a routine sample that is homogenized, divided into separate containers, and analyzed using the same analytical method. It is used to determine method precision, but because it is a non-blind sample, or known to the analyst, it can only be used by the analyst as an internal control tool and not as an unbiased estimate of analytical precision (EPA 1990).

- Laboratory Instrument Replicate. A laboratory instrument replicate is the repeated measurement of a sample that has been prepared for counting (i.e., laboratory sample preparation and radiochemical procedures have been completed). It is used to determine 
Sampling and Preparation for Laboratory Measurements

precision for the instrument (repeated measurements using same instrument) and the instrument calibration (repeated measurements using different instruments, such as two different germanium detectors with multichannel analyzers). A laboratory instrument replicate is generally performed as part of the laboratory QC program and is a non-blind sample. It is typically used as an internal control tool and not as an unbiased estimate of analytical precision.

\subsubsection{Bias}

Bias is the systematic or persistent distortion of a measurement process that causes error in one direction (ASQC 1995). Bias is determined quantitatively based on the analysis of samples with a known concentration. There are several types of samples with known concentrations. QC samples used to determine bias should be included as early in the analytical process as possible.

- Reference Material. A material or substance one or more of whose property values are sufficiently homogeneous and well established to be used for the calibration of an apparatus, the assessment of a measurement method, or for assigning values to materials (ISO 1993). A certified reference material is reference material for which each certified property value is accompanied by an uncertainty at a stated level of confidence. Radioactive reference materials may be available for certain radionuclides in soil (e.g., uranium in soil), but reference building materials may not be available. Because reference materials are prepared and homogenized as part of the certification process, they are rarely available as double-blind samples. When appropriate reference materials are available (i.e., proper matrix, proper radionuclide, proper concentration range), they are recommended for use in determining the overall bias for a measurement system.

- Performance Evaluation (PE) Samples. PE sample are samples that evaluate the overall bias of the analytical laboratory and detect any error in the analytical method used. These samples are usually prepared by a third party, using a quantity of analyte(s) which is known to the preparer but unknown to the laboratory, and always undergo certification analysis. The analyte(s) used to prepare the PE sample is the same as the analyte(s) of interest. Laboratory procedural error is evaluated by the percentage of analyte identified in the PE sample (EPA 1991g). PE samples are recommended for use in determining overall bias for a measurement system when appropriate reference material are not available. PE samples are equivalent to matrix spikes prepared by a third party that undergo certification analysis and can be non-blind, single-blind, or double-blind.

- Matrix Spike Samples. Matrix spike samples are environmental samples that are spiked in the laboratory with a known concentration of a target analyte(s) to verify percent recoveries. They are used primarily to check sample matrix interferences but can also be used to monitor laboratory performance. However, a data set of at least three or more 
- Is there an adequate capacity to perform all analyses within the desired timeframe? This criterion considers whether or not the laboratory possesses a radioactive materials handling license or permit for the samples to be analyzed. Very large survey designs may indicate that more than one analytical laboratory is necessary to meet the survey objectives. $^{2}$

- Does the laboratory provide an internal quality control review of all generated data that is independent of the data generators?

- Are there adequate protocols for method performance documentation and sample security?

Providers of radioanalytical services should have an active and fully documented QA program in place. ${ }^{3}$ This program should comply with the objectives determined by the DQO process in Section 2.3. The QA program should include:

- laboratory organizational structure

- personnel qualifications

- written standard operating procedures and instructions

- inter- and intralaboratory performance analyses

- design control to define the flow of samples through the laboratory

- a corrective action plan

- an internal audit program

Chain-of-Custody requirements and numbers of samples are also specified. The analytical procedures as well as the documentation and reporting requirements should be specified and agreed upon. These topics are discussed in detail in the following sections of this chapter.

\subsection{Sampling}

This section provides guidance on developing appropriate sample collection procedures for surveys designed to demonstrate compliance with a dose- or risk-based regulation. Sample collection procedures are concerned mainly with ensuring that a sample is representative of the sample media, is large enough to provide sufficient material to achieve the desired detection limit, and is consistent with assumptions used to develop the conceptual site model and the DCGLs. Additional considerations for sample collection activities are discussed in Section 4.7.3.

\footnotetext{
2 If several laboratories are performing analyses as part of the survey, the analytical methods used to perform the analyses should be similar to ensure comparability of results (see Appendix N, Section N.6.5).

3 The QA program is typically documented in one or more documents such as a Quality Management Plan, Quality Assurance Manual, or Quality Assurance Project Plan.
} 
Sampling and Preparation for Laboratory Measurements

The presence of radioactive and hazardous chemical wastes (mixed wastes) at a site can influence the survey design. The external exposure rates or radioactivity concentration of a specific sample may limit the time that workers will be permitted to remain in intimate contact with the samples, or may dictate that smaller samples be taken and special holding areas be provided for collected samples prior to shipment. These special handling considerations may conflict with the size specifications for the analytical method, normal sampling procedures, or equipment. There is a potential for biasing sampling programs by selecting samples that can be safely handled or legally shipped to support laboratories. Because final status surveys are performed to demonstrate that a site can be safely released, issues associated with high levels of radioactivity are not expected to be a concern.

\subsubsection{Surface Soil}

The purpose of surface soil sampling is to collect samples that accurately and precisely represent the radionuclides and their concentrations at the location being sampled. In order to do this and plan for sampling, a decision must be made as to the survey design. The selection of a survey design is based on the Historical Site Assessment, results from preliminary surveys (i.e., scoping characterization, remedial action support), and the objectives of the survey developed using the Data Quality Objectives (DQO) Process. The selection between judgmental, random, and systematic survey designs is discussed in Section 5.5.3.

\subsubsection{Sample Volume}

The volume of soil collected should be specified in the sample collection procedure. In general, large volumes of soil are more representative than small volumes of soil. In addition, large samples provide sufficient sample to ensure that required detection limits can be achieved and that sample reanalysis can be done if there is a problem. However, large samples may cause problems with shipping, storage, and disposal. All of these issues should be discussed with the sample collection team and the analytical laboratory during development of sample collection procedures. In general, surface soil samples range in size from $100 \mathrm{~g}$ up to several kilograms.

The sample collection procedure should also make clear if it is more important to meet the volume requirement of the survey design or the surface area the sample represents. Constant volume is related to comparability of the results while surface area is more closely related to the representativeness of the results. Maintaining a constant surface area and depth for samples collected for a particular survey can eliminate problems associated with different depth profiles. The actual surface area included as part of the sample may be important for estimating the probability of locating areas of elevated concentration. 


\subsubsection{Sample Content}

The material present in the field at the sample location may or may not provide a representative sample. Vegetative cover, soil particle size distribution, inaccessibility, or lack of sample material are examples of problems that may be identified during sample collection. All deviations from the survey design as documented in the Standard Operating Procedures (SOPs) should be recorded as part of the field sample documentation.

Sample content is generally defined by the assumptions used to develop the conceptual site model and the DCGLs. A typical agricultural scenario assumes that the top few centimeters of soil are available for resuspension in air, that the top $15 \mathrm{~cm}(6 \mathrm{in}$.) are homogenized by agricultural activities (e.g., plowing), that roots can extend down several meters to obtain water and nutrients depending on the plant, and that external exposure is based on an assumed thickness of contaminated soil (usually at the surface). Depending on the dominant exposure pathways for each radionuclide, this can result in a complicated set of instructions for collecting representative samples. This situation can be further complicated by the fact that the site is not currently being used for agricultural purposes. For this situation it is necessary to look at the analytical results from the preliminary surveys (i.e., scoping, characterization, remedial action support) to determine the expected depth of contamination.

In most situations the vegetative cover is not considered part of the surface soil sample and is removed in the field. For agricultural scenarios where external exposure is not the primary concern, soil particles greater than $2 \mathrm{~mm}(0.08 \mathrm{in}$.) are generally not considered as part of the sample (EPA 1990). Foreign material (e.g., plant roots, glass, metal, or concrete) is also generally not considered part of the sample, but should be reviewed on a site-specific basis. It is important that the sample collection procedure clearly indicate what is and what is not considered part of the sample.

\subsubsection{Sampling Equipment}

The selection of proper sampling equipment is important to ensure that samples are collected effectively and efficiently. Sampling equipment generally consists of a tool to collect the sample and a container to place the collected sample in. Sample tracking begins as soon as the sample is collected, so it may be necessary to consider security of collected samples required by the objectives of the survey.

Sampling tools are selected based on the type of soil, sample depth, number of samples required, and training of available personnel. The selection of a sampling tool may also be based on the expected use of the results. For example, if a soil sample is collected to verify the depth profile used to develop the calibration for in situ gamma spectrometry, it is important to preserve the soil core. Table 7.1 lists several examples of tools used for collecting soil samples, situations where they are applicable, and some advantages and disadvantages involved in their use. 
Table 7.1 Soil Sampling Equipment ${ }^{*}$

\begin{tabular}{|c|c|c|}
\hline Equipment & Application & Advantages/Disadvantages \\
\hline Tier & Soft surface soil & $\begin{array}{l}\text { Inexpensive; easy to use and decontaminate; difficult to } \\
\text { use in stone or dry soil. }\end{array}$ \\
\hline Scoop or trowel & Soft surface soil & $\begin{array}{l}\text { Inexpensive; easy to use and decontaminate; trowels } \\
\text { with painted surfaces should be avoided }\end{array}$ \\
\hline Bulb Planter & $\begin{array}{l}\text { Soft Soil, } 0-15 \mathrm{~cm} \\
(0-6 \mathrm{in} .)\end{array}$ & $\begin{array}{l}\text { Easy to use and decontaminate: uniform diameter and } \\
\text { sample volume; preserves soil core; limited depth } \\
\text { capability; can be difficult to decontaminate }\end{array}$ \\
\hline Soil Coring Device & $\begin{array}{l}\text { Soft soil, } 0-60 \mathrm{~cm} \\
(0-24 \text { in. })\end{array}$ & $\begin{array}{l}\text { Relatively easy to use; preserves soil core; limited depth } \\
\text { capability; can be difficult to decontaminate }\end{array}$ \\
\hline Thin-wall tube sampler & Soft soil, $0-3 \mathrm{~m}(0-10 \mathrm{ft})$ & $\begin{array}{l}\text { easy to use; preserves soil core; easy to decontaminate; } \\
\text { can be difficult to remove cores }\end{array}$ \\
\hline Split spoon sampler & Soil, to bedrock & $\begin{array}{l}\text { Excellent depth range; preserves soil core; useful for } \\
\text { hard soils; often used in conjunction with drill rig for } \\
\text { obtaining deep cores }\end{array}$ \\
\hline Shelby tube sampler & Soft soil, to bedrock & $\begin{array}{l}\text { Excellent depth range; preserves soil core; tube may be } \\
\text { used for shipping core to lab.; may be used in } \\
\text { conjunction with drill rig for obtaining deep cores }\end{array}$ \\
\hline Bucket auger & $\begin{array}{l}\text { Soft soil, } 7.5 \mathrm{~cm}-3 \mathrm{~m} \\
(3 \mathrm{in} .-10 \mathrm{ft})\end{array}$ & $\begin{array}{l}\text { Easy to use; good depth range; uniform diameter and } \\
\text { sample volume; may disrupt and mix soil horizons } \\
\text { greater than } 15 \mathrm{~cm}\end{array}$ \\
\hline $\begin{array}{l}\text { Hand -operated power } \\
\text { auger }\end{array}$ & $\begin{array}{l}\text { Soil, } 15 \mathrm{~cm}-4.5 \mathrm{~m} \\
(6 \mathrm{in} .-15 \mathrm{ft})\end{array}$ & $\begin{array}{l}\text { Good depth range; generally used in conjunction with } \\
\text { bucket auger; destroys soil core; requires two or more } \\
\text { operators; can be difficult to decontaminate }\end{array}$ \\
\hline
\end{tabular}

* Reproduced from EPA $1991 \mathrm{~g}$

Sample containers are generally not a major concern for collecting surface soil samples. Polyethylene bottles with screw caps and wide mouths are recommended. These containers are fairly economical, provide easy access for adding and removing samples, and resist chemicals, breaking, and temperature extremes. Glass containers are also acceptable, but they are fragile and tend to break during shipment. Metal containers are sometimes used, but sealing the container can present a problem and corrosion can be an issue if the samples are stored for a significant length of time. 
Sampling and Preparation for Laboratory Measurements

\subsubsection{Building Surfaces}

Because building surfaces tend to be relatively smooth and the radioactivity is assumed to be on or near the surface, direct measurements are typically used to provide information on contaminant concentrations. Sometimes, however, it is necessary to collect actual samples of the building material surface for analysis in a laboratory.

\subsubsection{Sample Volume}

The sample volume collected from building surfaces is usually a less significant DQO concern than the area from which the sample was collected. This is because building surface DCGLs are usually expressed in terms of activity per unit area. It is still necessary to consider the sample volume to account for sample matrix effects that may reduce the chemical recovery, which in turn has an affect on the detection limit.

\subsubsection{Sample Content}

If residual activity is covered by paint or some other treatment, the underlying surface and the coating itself may be contaminated. If the activity is a pure alpha or low-energy beta emitter, measurements at the surface will probably not be representative of the actual residual activity level. In this case the surface layer is removed from the known area, such as by using a commercial stripping agent or by physically abrading the surface. The removed coating material is analyzed for activity content and the level converted to appropriate units $\left(i . e ., \mathrm{Bq} / \mathrm{m}^{2}\right.$, $\mathrm{dpm} / 100 \mathrm{~cm}^{2}$ ) for comparison with surface activity DCGLs. Direct measurements can be performed on the underlying surface after removal of the coating.

Residual radioactivity may be incorporated into building materials, such as pieces of concrete or other unusual matrices. Development of SOPs for collecting these types of samples may involve consultation with the analytical laboratory to help ensure that the objectives of the survey are achieved.

The thickness of the layer of building surface to be removed as a sample should be consistent with the development of the conceptual site model and the DCGLs. For most sites the surface layer will only be the first few millimeters of the material being sampled.

\subsubsection{Sampling Equipment}

Tools used to provide samples of building surfaces depend on the material to be sampled. Concrete may require chisels, hammers, drills, or other tools specifically designed to remove a thin layer of the surface. Wood surfaces may require using a sander or a saw to collect a sample. Paint may be chemically or physically stripped from the surface. 
Sampling and Preparation for Laboratory Measurements

Sample containers for these samples are generally the same as those recommended for soil samples. If chemicals are used to strip paint or other surface materials, the chemical resistance of the container should be considered.

\subsubsection{Other Media}

Surface soil and building surfaces are the media addressed in MARSSIM during the final status survey design. Other media may be involved and may have been remediated. Data collection activities during preliminary surveys (i.e., scoping, characterization, remedial action support) may involve collecting samples of other media to support the final status survey design. Examples of other media that may be sampled include:

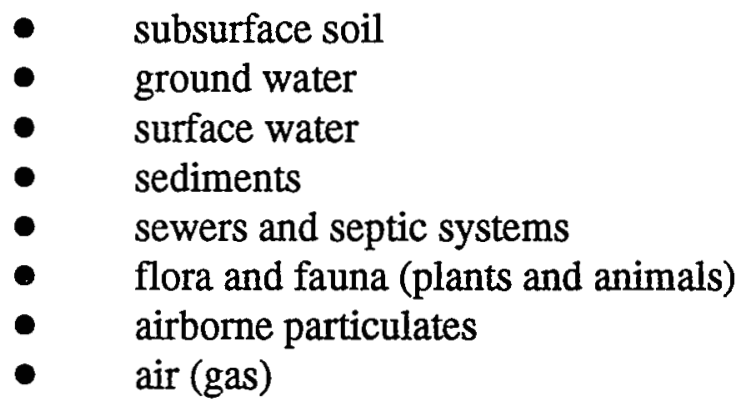

Appendix M provides a list of resources that can be used to develop sample collection procedures for other media that may required by preliminary surveys to support the development of a final status survey design.

\subsection{Field Sample Preparation and Preservation}

Proper sample preparation and preservation are essential parts of any radioactivity sampling program. The sampling objectives should be specified before sampling activities begin. Precise records of sample collection and handling are necessary to ensure that data obtained from different locations or time frames are correctly compared.

The appropriateness of sample preparation techniques is a function of the analysis to be performed (EPA 1992a, 1992b). Field sample preparation procedures are a function of the specified analysis and the objectives of the survey. It is essential that these objectives be clearly established and agreed upon in the early stages of survey planning (see Section 2.3). 
Sampling and Preparation for Laboratory Measurements

\subsubsection{Surface Soil}

Soil and sediment samples, in most protocols, require no field preparation and are not preserved. In some protocols, cooling of soil samples to $4^{\circ} \mathrm{C}$ is required during shipping and storage of soil samples. This is not a practice normally followed for the radiochemical analysis of soil samples.

When replicate samples are prepared in the field, it is necessary to homogenize the sample prior to separation into replicates. There are standard procedures for homogenizing soil in the laboratory (ASTM 1995), but the equipment required for these procedures may not be available in the field. Simple field techniques, such as cone and quarter, or using a riffle splitter to divide the sample may be appropriate if the sample can be dried (ASTM 1993, EPA 1991g). If the sample contains significant amounts of residual water (e.g., forms clumps of soil) and there are no facilities for drying the sample, it is recommended that the homogenization and separation into replicates be performed in a laboratory. It is preferable to use non-blind replicates where the same laboratory prepares and analyzes the replicates rather than use poorly homogenized or heterogeneous samples to prepare replicates samples.

\subsubsection{Building Surfaces}

Field preparation and preservation of building and associated materials, including smear samples, is not generally required. Homogenization of samples to prepare replicates is the same for building surface material and soil.

\subsubsection{Other Media}

Other media may have significant requirements related to field sample preparation and preservation. For example, water samples may need filtering and acidification. Storage at reduced temperatures (i.e., cooling or freezing) to reduce biological activity may be necessary for some samples. Addition of chemical preservatives for specific radionuclides or media may also be required.

\subsection{Analytical Procedures}

The selection of the appropriate radioanalytical methods is normally made prior to the procurement of analytical services and is included in the statement-of-work of the request for proposal. The statement-of-work may dictate the use of specific methods or be performance based. Unless there is a regulatory requirement, such as conformance to the EPA drinking water methods (EPA 1980a), the specification of performance based methodology is encouraged. One reason for this is that a laboratory will usually perform better using the methods routinely employed in its laboratory as contrasted to using other methods with which it has less experience. 
Sampling and Preparation for Laboratory Measurements

The laboratory is also likely to have historical data on performance for methods routinely used by that laboratory. However, the methods employed in a laboratory should be derived from a reliable source, such as those listed in Table 7.2.

Table 7.2 Examples of References for Routine Analytical Methods

\begin{tabular}{|c|}
\hline $\begin{array}{l}\text { Methods of Air Sampling and Analysis (Lodge 1988) } \\
\text { Annual Book of ASTM Standards, Water and Environmental technology. Volume } \\
\text { 11.04, Environmental Assessment; Hazardous Substances and Oil Spill Responses; } \\
\text { Waste Management; Environmental Risk Assessment (ASTM 1997) } \\
\text { Standard Methods for the Examination of Water and Wastewater (APHA 1995) } \\
\text { EML Procedures Manual (DOE 1990b) } \\
\text { Radiochemical Analytical Procedures for Analysis of Environmental Samples (EPA } \\
\text { 1979) } \\
\text { Radiochemistry Procedures Manual (EPA 1984a) } \\
\text { Indoor Radon and Radon Decay Product Measurement Protocols (EPA 1992d) } \\
\text { USAEHA Environmental Sampling Guide (Department of the Army 1993) }\end{array}$ \\
\hline
\end{tabular}

This section briefly describes specific equipment and procedures to be used once the sample is prepared for analysis. The results of these analyses (i.e., the levels of radioactivity found in these samples) are the values used to determine the level of residual activity at a site. In a decommissioning effort, the DCGLs are expressed in terms of the concentrations of certain radionuclides. It is of vital importance, therefore, that the analyses be accurate and of adequate sensitivity for the radionuclides of concern. The selection of analytical procedures should be coordinated with the laboratory and specified in the survey plan.

Analytical methods should be adequate to meet the data needs identified in the DQO process. Consultation with the laboratory performing the analysis is recommended before selecting a course of action. MARSSIM is not intended to limit the selection of analytical procedures, rather all applicable methods should be reviewed to provide results that meet the objectives of the survey. The decision maker and survey planning team should decide whether routine methods will be used at the site or if non-routine methods may be acceptable. 
- Routine analytical methods are documented with information on minimum performance characteristics, such as detection limit, precision and accuracy, and useful range of radionuclide concentrations and sample sizes. Routine methods may be issued by a recognized organization (e.g., Federal or State agency, professional organization), published in a refereed journal, or developed by an individual laboratory. Table 7.2 lists examples of sources for routine methods.

- Non-routine methods address situations with unusual or problematic matrices, low detection limits, or new parameters, procedures or techniques. Non-routine methods include adjustments to routine methods, new techniques published in refereed literature, and development of new methods.

References that provide information on radiochemical methodology and should be considered in the methods review and selection process are available from such organizations as:

- National Council on Radiation Protection and Measurements (NCRP)

- $\quad$ American Society of Testing and Materials (ASTM)

- $\quad$ Radiological and Environmental Sciences Laboratory (RESL), Idaho Falls, Idaho (Operated by the DOE)

- DOE Technical Measurements Center, Grand Junction, CO

- Environmental Measurements Laboratory (EML); formerly the Health and Safety Laboratory of the DOE

Equipment vendor literature, catalogs, and instrument manuals are often a source of useful information on the characteristics of radiation detection equipment. Table 7.3 provides a summary of common laboratory methods with estimated detection limits.

Analytical procedures in the laboratory consist of several parts that are assembled to produce an SOP for a specific project or sample type. These parts include:

- laboratory sample preparation

- sample dissolution

- sample purification

- preparation for counting

- counting

- data reduction 
Table 7.3 Typical Measurement Sensitivities for Laboratory Radiometric Procedures

\begin{tabular}{|c|c|c|c|}
\hline Sample Type & $\begin{array}{l}\text { Radionuclides or Radiation } \\
\text { Measured }\end{array}$ & Procedure & $\begin{array}{l}\text { Approximate } \\
\text { Measurement } \\
\text { Sensitivity }\end{array}$ \\
\hline $\begin{array}{l}\text { Smears (filter } \\
\text { paper) }\end{array}$ & $\begin{array}{l}\text { Gross alpha } \\
\text { Gross beta } \\
\text { Low energy beta } \\
\left({ }^{(} \mathrm{H},{ }^{14} \mathrm{C},{ }^{63} \mathrm{Ni}\right)\end{array}$ & $\begin{array}{l}\text { Gas-flow proportional counter; 5-min count } \\
\text { Alpha scintillation detector with scaler; 5-min count } \\
\text { Gas-flow proportional counter; 5-min count } \\
\text { End window GM with scaler; 5-min count (unshielded detector) } \\
\text { Liquid scintillation spectrometer; 5-min count }\end{array}$ & $\begin{array}{l}5 \mathrm{dpm} \\
20 \mathrm{dpm} \\
10 \mathrm{dpm} \\
80 \mathrm{dpm} \\
30 \mathrm{dpm}\end{array}$ \\
\hline Soil Sediment & $\begin{array}{l}{ }^{137} \mathrm{Cs},{ }^{60} \mathrm{Co},{ }^{226} \mathrm{Ra}\left({ }^{214} \mathrm{Bi}\right){ }^{\mathrm{a}},{ }^{232} \mathrm{Th} \\
\left({ }^{228} \mathrm{Ac}\right),{ }^{235} \mathrm{U} \\
{ }^{234,235,238} \mathrm{U} ;{ }^{238,239,240} \mathrm{Pu} ; \\
\text { e27, 228, 230, 232 } \mathrm{Th} \text {; other alpha } \\
\text { emitters }\end{array}$ & $\begin{array}{l}\text { Germanium detector (25\% relative efficiency) with multichannel analyzer; } \\
\text { pulse height analyzer; } 500-\mathrm{g} \text { sample; } 15 \text {-min analysis } \\
\text { Alpha spectroscopy with multichannel analyzer - pyrosulfate fusion and } \\
\text { solvent extraction; surface barrier detector; pulse height analyzer; } 1 \text {-g } \\
\text { sample; } 16 \text {-hr count }\end{array}$ & $\begin{array}{l}0.04-0.1 \mathrm{~Bq} / \mathrm{g} \\
(1-3 \mathrm{pCi} / \mathrm{g}) \\
0.004-0.02 \mathrm{~Bq} / \mathrm{g} \\
(0.1-0.5 \mathrm{pCi} / \mathrm{g})\end{array}$ \\
\hline Water & $\begin{array}{l}\text { Gross alpha } \\
\text { Gross beta } \\
{ }^{137} \mathrm{Cs},{ }^{60} \mathrm{Co},{ }^{226} \mathrm{Ra}\left({ }^{214} \mathrm{Bi}\right),{ }^{232} \mathrm{Th} \\
\left({ }^{228} \mathrm{Ac}\right),{ }^{235} \mathrm{U} \\
{ }^{234,235,238} \mathrm{U} ;{ }^{238,239,}{ }^{240} \mathrm{Pu} \text {; } \\
\text { emitters } \\
{ }^{3} \mathrm{H}\end{array}$ & $\begin{array}{l}\text { Gas-flow proportional counter; } 100-\mathrm{ml} \text { sample, } 200 \text {-min count } \\
\text { Gas-flow proportional counter; } 100-\mathrm{ml} \text { sample, } 200 \text {-min count } \\
\text { Germanium detector ( } 25 \% \text { relative efficiency) with multichannel analyzer; } \\
\text { pulse height analyzer; } 3.5 \mathrm{~L} \text { sample, } 16 \text {-hr count } \\
\text { Alpha spectroscopy with multichannel analyzer - solvent extraction; } \\
\text { surface barrier detector; pulse height analyzer; } 100 \mathrm{ml} \mathrm{sample,} 30 \mathrm{~min} \\
\text { count } \\
\text { Liquid scintillation spectrometry; } 5 \text {-ml sample, } 30 \text {-min count }\end{array}$ & $\begin{array}{l}0.04 \mathrm{~Bq} / \mathrm{L} \\
(1 \mathrm{pCi} / \mathrm{l}) \\
0.04 \mathrm{~Bq} / \mathrm{L} \\
(1 \mathrm{pCi} / \mathrm{L}) \\
0.4 \mathrm{~Bq} / \mathrm{L} \\
(10 \mathrm{pCi} / \mathrm{L}) \\
\\
0.004-0.02 \mathrm{~Bq} / \mathrm{L} \\
(0.1-0.5 \mathrm{pCi} / \mathrm{L}) \\
100 \mathrm{~Bq} / \mathrm{L} \\
(300 \mathrm{pCi} / \mathrm{L})\end{array}$ \\
\hline
\end{tabular}

\footnotetext{
2 Indicates that a member of the decay series is measured to determine activity level of the parent radionuclide of primary interest.
} 
Sampling and Preparation for Laboratory Measurements

\subsubsection{Photon Emitting Radionuclides}

There is no special sample preparation required for counting samples using a germanium detector or a sodium iodide detector beyond placing the sample in a known geometry for which the detector has been calibrated. The samples can be measured as they arrive at the laboratory, or the sample can be dried, ground to a uniform particle size, and mixed to provide a more homogeneous sample if required by the SOPs.

The samples are typically counted using a germanium detector with a multichannel analyzer or a sodium iodide detector with a multichannel analyzer. Germanium detectors have better resolution and can identify peaks (and the associated radionuclides) at lower concentrations. Sodium iodide detectors often have a higher efficiency and are significantly less expensive than germanium detectors. Low-energy photons (i.e., $\mathrm{x}$-rays and gamma rays below $50 \mathrm{keV}$ ) can be measured using specially designed detectors with an entrance window made from a very light metal, typically beryllium. Descriptions of germanium and sodium iodide detectors are provided in Appendix $\mathrm{H}$.

Data reduction is usually the critical step in measuring photon emitting radionuclides. There are often several hundred individual gamma ray energies detected within a single sample. Computer software is usually used to identify the peaks, associate them with the proper energy, associate the energy with one or more radionuclides, correct for the efficiency of the detector and the geometry of the sample, and provide results in terms of concentrations with the associated uncertainty. It is important that the software be either a well-documented commercial package or thoroughly evaluated and documented before use.

\subsubsection{Beta Emitting Radionuclides}

Laboratory sample preparation is an important step in the analysis of surface soil and other solid samples for beta emitting radionuclides. The laboratory will typically have a sample preparation procedure that involves drying the sample and grinding the soil so that all of the particles are less than a specified size to provide a homogeneous sample. A small portion of the homogenized sample is usually all that is required for the individual analysis.

Once the sample has been prepared, a small portion is dissolved, fused, or leached to provide a clear solution containing the radionuclide of interest. The only way to ensure that the sample is solubilized is to completely dissolve the sample. However, this can be an expensive and timeconsuming step in the analysis. In some cases, leaching with strong acids can consistently provide greater than $80 \%$ recovery of the radionuclide of interest (NCRP 1976a) and may be acceptable for certain applications. Gross beta measurements may be performed on material that has not been dissolved. 
Sampling and Preparation for Laboratory Measurements

After dissolution, the sample is purified using a variety of chemical reactions to remove bulk chemical and radionuclide impurities. The objective is to provide a chemically and radiologically pure sample for measurement. Examples of purification techniques include precipitation, liquid-liquid extraction, ion-exchange chromatography, distillation, and electrodeposition. Gross beta measurements may be performed on material that has not been purified.

After the sample is purified, it is prepared for counting. Beta emitting radionuclides are usually prepared for a specific type of counter in a specified geometry. Solid material is usually precipitated and collected on a filter in a circular geometry to provide a homogeneous sample. Liquid samples are typically converted to the appropriate chemical form and diluted to a specified volume in preparation for counting.

Measurements of solid samples are typically performed using a gas-flow proportional counter. Because total beta activity is measured, it is important that the purification step be performed to remove any interfering radionuclides. Liquid samples are usually diluted using a liquid scintillation cocktail and counted using a liquid scintillation spectrometer. Liquid scintillation spectrometers can be used for low-energy beta emitting radionuclides, such as ${ }^{3} \mathrm{H}$ and ${ }^{63} \mathrm{Ni}$. They also have high counting efficiencies, but often have a high instrument background as well. Gasflow proportional counters have a very low background. Appendix $\mathrm{H}$ provides a description of both the gas-flow proportional counter and the liquid scintillation spectrometer.

Data reduction for beta emitting radionuclides is less complicated than that for photon emitting radionuclides. Since the beta detectors report total beta activity, the calculation to determine the concentration for the radionuclide of interest is straightforward.

\subsubsection{Alpha Emitting Radionuclides}

Laboratory sample preparation for alpha emitting radionuclides is similar to that for beta emitting radionuclides. Sample dissolution and purification tasks are also similar to those performed for beta emitting radionuclides.

Because of the limited penetrating power of alpha particles, the preparation for counting is often a critical step. Gross alpha measurements can be made using small sample sizes with a gas-flow proportional counter, but self-absorption of the alpha particles results in a relatively high detection limit for this technique. Liquid scintillation spectrometers can also be used to measure alpha emitting radionuclides but the resolution limits the usefulness of this technique. Most alpha emitting radionuclides are measured in a vacuum (to limit absorption by air) using alpha spectroscopy. This method requires that the sample be prepared as a virtually weightless mount in a specific geometry. Electrodeposition is the traditional method for preparing samples for counting. This technique provides the highest resolution, but it requires a significant amount of 
training and expertise on the part of the analyst to produce a high quality sample. Precipitation of the radionuclide of interest on the surface of a substrate is often used to prepare samples for alpha spectroscopy. While this technique generally produces a spectrum with lower resolution, the preparation time is relatively short compared to electrodeposition, and personnel can be trained to prepare acceptable samples relatively quickly.

Alpha emitting radionuclides are typically measured using alpha spectroscopy. The data reduction requirements for alpha spectroscopy are greater than those for beta emitting radionuclides, and similar to those for photon emitting radionuclides. Alpha spectroscopy produces a spectrum of alpha particles detected at different energies, but because the sample is purified prior to counting, all of the alpha particles come from radionuclides of a single element. This simplifies the process of associating each peak with a specific radionuclide, but the lower resolution associated with alpha spectroscopy increases the difficulty of identifying the peaks. Although commercial software packages are available for interpreting alpha spectroscopy results, an experienced operator is required to ensure that the software is working properly.

\subsection{Sample Tracking}

Sample tracking refers to the identification of samples, their location, and the individuals responsible for their custody and transfer of the custody. This process covers the entire process from collection of the samples and remains intact through the analysis and final holding or disposal. It begins with the taking of a sample where its identification and designation of the sample are critical to being able to relate the analytical result to a site location.

Tracking samples from collection to receipt at the analytical laboratory is normally done through a Chain of Custody process, and documented on a Chain-of-Custody (COC) record. Once samples are received by the laboratory, internal tracking (e.g., COC) procedures should be in place and codified through SOPs that assure integrity of the samples. Documentation of changes in the custody of a sample(s) is important. This is especially true for samples that may be used as evidence to establish compliance with a release criterion. In such cases, there should be sufficient evidence to demonstrate that the integrity of the sample is not compromised from the time it is collected to the time it is analyzed. During this time, the sample should either be under the positive control of a responsible individual or secured and protected from any activity that could change the true value of the results or the nature of the sample. When this degree of sample handling or custody is necessary, written procedures should be developed for field operations and for interfacing between the field operations and the analytical laboratory. This ensures that a clear transfer of the custodial responsibility is well documented and no questions exist as to who is responsible for the sample at any time. 
Sampling and Preparation for Laboratory Measurements

\subsubsection{Field Tracking Considerations}

- Field personnel are responsible for maintaining field logbooks with adequate information to relate the sample identifier (sample number) to its location and for recording other information necessary to adequately interpret results of sample analytical data.

- The sample collector is responsible for the care and custody of the samples until they are properly transferred or dispatched. This means that samples are in their possession, under constant observation, or secured. Samples may be secured in a sealed container, locked vehicle, locked room, etc.

- Sample labels should be completed for each sample using waterproof ink.

- The survey manager or designee determines whether or not proper custody procedures were followed during the field work, and decides if additional sampling is indicated.

- If photographs are included as part of the sampling documentation, the name of the photographer, date, time, site location, and site description should be entered sequentially in a logbook as the photos are taken. After the photographs are developed, the prints should be serially numbered.

\subsubsection{Transfer of Custody}

- All samples leaving the site should be accompanied by a Chain-of-Custody record. This record documents sample custody transfer from the sampler, often through another person, to the laboratory. The individuals relinquishing the samples should sign and date the record. The record should include a list, including sample designation (number), of the samples in the shipping container and the analysis requested for each sample.

- Shipping containers should be sealed and include a tamper indicating seal that will indicate if the container seal has been disturbed. The method of shipment, courier name, or other pertinent information should be listed in the Chain-of-Custody record.

- The original Chain-of-Custody record should accompany the samples. A copy of the record should be retained by the individual or organization relinquishing the samples.

- Discuss the custody objectives with the shipper to ensure that the objectives are met. For example, if the samples are sent by mail and the originator of the sample requires a record that the shipment was delivered, the package should be registered with return receipt requested. If, on the other hand, the objective is to simply provide a written record of the shipment, a certificate of mailing may be a less expensive and appropriate alternative. The individual receiving the samples should sign and date the record. The condition of the container and the tamper indicating seal should be noted on the Chain-of-Custody record. Any problems with the individual samples, such as a broken container, should be noted on the record. 


\subsubsection{Laboratory Tracking}

When the samples are received by the laboratory they are prepared for radiochemical analyses. This includes the fractionation of the sample into aliquots. The tracking and Chain-of-Custody documentation within the laboratory become somewhat complicated due to the fact that several portions of the original sample may exist in the laboratory at a given time. The use of a computer based Laboratory Information System (LIMS) can greatly assist in tracking samples and fractions through the analytical system.

The minimal laboratory tracking process consists of the following:

- transfer of custody on receipt of the samples (original Chain-of-Custody form is retained by the laboratory and submitted with the data package for the samples)

- documentation of sample storage (location and amount)

- documentation of removal and return of sample aliquots (amount, date and time, person removing or returning, and reason for removal)

- transfer of the samples and residues to the receiving authority (usually the site from which they were taken)

The procedure for accomplishing the above varies from laboratory to laboratory, but the exact details of performing the operations of sample tracking should be contained in a SOP.

\subsection{Packaging and Transporting Samples}

All samples being shipped for radiochemical analysis should be properly packaged and labeled before transport offsite or within the site. The primary concern is the possibility of spills, leaks, or breakage of the sample containers. In addition to resulting in the loss of samples and crosscontamination, the possible release of hazardous material poses a threat to the safety of persons handling and transporting the package.

Suggestions on packaging and shipping radioactive environmental samples are listed below.

1) Review NRC requirements (10 CFR part 71) and Department of Transportation (DOT) requirements (49 CFR parts 170 through 189) for packaging and shipping radioactive environmental samples.

2) Visually inspect each sample container for indication of leaks or defects in the sample container. 
Sampling and Preparation for Laboratory Measurements

a) Liquid samples should be shipped in plastic containers, if possible, and the caps on the containers should be secured with tape. One exception to the use of plastic bottles is samples collected for ${ }^{3} \mathrm{H}$ analyses which may require glass containers.

b) Heavy plastic bags, with sealable tops, can be used to contain solid samples (e.g., soil, sediment, air filters). The zip-lock should be secured with tape. Heavy plastic lawn bags can be used to contain vegetation samples. The tops should be closed with a "tie" that is covered by tape to prevent it from loosening and slipping off.

3) Wipe individual sample containers with a damp cloth or paper towel to remove any exterior contamination. The outer surfaces of containers holding samples collected in a contaminated area should be surveyed with a hand-held instrument(s), appropriate for the suspected type of radioactivity $(\beta / \gamma$ or $\alpha)$.

4) If glass sample containers are used, place sample containers inside individual plastic bags and seal in order to contain the sample in case of breakage.

5) Use packing material (e.g., paper, styrofoam, "bubble wrap") to immobilize and isolate each sample container and buffer hard knocks on the outer container during shipping. This is especially important in cold weather when plastic containers may become brittle and water samples may freeze.

6) When liquid samples are shipped, include a sufficient quantity of an absorbent material (e.g., vermiculite) to absorb all liquid packed in the shipping container in case of breakage. This absorbent material may suffice as the packing material described above in item 5.

7) Include the original, signed and dated, Chain-of-Custody (COC) form, identifying each sample in the package. It is good practice to place the COC form in a plastic bag to prevent it from becoming wet or contaminated in case of a spill during shipment. If possible, avoid having multiple packages of samples covered by a single COC form.

8) Seal closed the package and apply COC tape in such a manner that it must be torn (broken) in order to open the package. The tape should carry the signature of the sender, and the date and time, so that it cannot be removed and replaced undetected.

9) Ice chests, constructed of metal or hard plastic, make excellent shipping containers for radioactive environmental samples. 
If samples are sent offsite for analysis, the shipper is responsible for complying with all applicable Federal, State, and local regulations. Applicable Federal regulations are briefly addressed below. Any State or local regulation will very likely reflect a Federal regulation.

\subsubsection{U.S. Nuclear Regulatory Commission Regulations}

NRC regulations for packaging, preparation, and shipment of licensed material are contained in 10 CFR Part 71: "Packaging and Transportation of Radioactive materials".

Samples containing low levels of radioactivity are exempted as set forth in §§ 71.10. A licensee is exempt from all requirements of Part 71 if the specific activity of the sample being shipped is not greater than $74,000 \mathrm{~Bq} / \mathrm{kg}(2,000 \mathrm{pCi} / \mathrm{g})$.

Low Specific Activity Material (LSAM) is defined in §§ 71.4: "Definitions." Samples classified as LSAM need only meet the requirements of the U.S. Department of Transportation (DOT), discussed below, and the requirements of $\S \S 71.88$ : "Air transport of plutonium." Most environmental samples will fall into this category.

\subsubsection{U.S. Department of Transportation Regulations}

The U.S. Department of Transportation provides regulations governing the transport of hazardous materials under the Hazardous Materials Transportation Act of 1975 (88 Stat. 2156, Public Law 93-633). Applicable requirements of the regulations are found in 49 CFR Parts 170 through 189. Shippers of samples containing radioactivity should be aware of the current rules in the following areas.

- $\quad$ Accident Reporting - 49 CFR 171

- $\quad$ Marking and Labeling Packages for Shipment - 49 CFR 172

- $\quad$ Packaging - 49 CFR 173

- $\quad$ Placarding a Package - 49 CFR 172

- Registration of Shipper/Carrier - 49 CFR 107

- $\quad$ Shipper Required Training - 49 CFR 172

- $\quad$ Shipping Papers \& Emergency Information - 49 CFR 172

- $\quad$ Transport by Air - 49 CFR 175 
Sampling and Preparation for Laboratory Measurements

- Transport by Rail - 49 CFR 174

- Transport by Vessel - 49 CFR 176

- Transport on Public Highway - 49 CFR 177

\subsubsection{U.S. Postal Service Regulations}

Any package containing radioactive materials is nonmailable if required to bear the U.S. Department of Transportation's Radioactive White-1 (49 CFR 172.436), Radioactive Yellow-II (49 CFR 172.438), or Radioactive Yellow-III (49 CFR 172.440) label, or if it contains quantities of radioactive material in excess of those authorized in Publication 6, Radioactive Material, of the U.S. Postal Service. 


\section{INTERPRETATION OF SURVEY RESULTS}

\subsection{Introduction}

This chapter discusses the interpretation of survey results, primarily those of the final status survey. Interpreting a survey's results is most straightforward when measurement data are entirely higher or lower than the $\mathrm{DCGL}_{\mathrm{w}}$. In such cases, the decision that a survey unit meets or exceeds the release criterion requires little in terms of data analysis. However, formal statistical tests provide a valuable tool when a survey unit's measurements are neither clearly above nor entirely below the $\mathrm{DCGL}_{\mathrm{w}}$. Nevertheless, the survey design always makes use of the statistical tests in helping to assure that the number of sampling points and the measurement sensitivity are adequate, but not excessive, for the decision to be made.

Section 8.2 discusses the assessment of data quality. The remainder of this chapter deals with application of the statistical tests used in the decision-making process, and the evaluation of the test results. In addition, an example checklist is provided to assist the user in obtaining the necessary information for interpreting the results of a final status survey.

\subsection{Data Quality Assessment}

Data Quality Assessment (DQA) is a scientific and statistical evaluation that determines if the data are of the right type, quality, and quantity to support their intended use. An overview of the DQA process appears in Section 2.3 and Appendix E. There are five steps in the DQA process:

- Review the Data Quality Objectives (DQOs) and Survey Design

- Conduct a Preliminary Data Review

- $\quad$ Select the Statistical Test

- Verify the Assumptions of the Statistical Test

- Draw Conclusions from the Data

The effort expended during the DQA evaluation should be consistent with the graded approach used in developing the survey design. More information on DQA is located in Appendix E, and the EPA Guidance Document QA/G-9 (EPA 1996a). Data should be verified and validated as described in Section 9.3 prior to the DQA evaluation. 
Interpretation of Survey Results

\subsubsection{Review the Data Quality Objectives (DQOs) and Sampling Design}

The first step in the DQA evaluation is a review of the DQO outputs to ensure that they are still applicable. For example, if the data suggest the survey unit was misclassified as Class 3 instead of Class 1, then the original DQOs should be redeveloped for the correct classification.

The sampling design and data collection documentation should be reviewed for consistency with the DQOs. For example, the review should check that the appropriate number of samples were taken in the correct locations and that they were analyzed with measurement systems with appropriate sensitivity. Example checklists for different types of surveys are given in Chapter 5.

Determining that the sampling design provides adequate power is important to decision making, particularly in cases where the levels of residual radioactivity are near the $\mathrm{DCGL}_{\mathrm{w}}$. This can be done both prospectively, during survey design to test the efficacy of a proposed design, and retrospectively, during interpretation of survey results to determine that the objectives of the design are met. The procedure for generating power curves for specific tests is discussed in Appendix I. Note that the accuracy of a prospective power curve depends on estimates of the data variability, $\sigma$, and the number of measurements. After the data are analyzed, a sample estimate of the data variability, namely the sample standard deviation (s) and the actual number of valid measurements will be known. The consequence of inadequate power is that a survey unit that actually meets the release criterion has a higher probability of being incorrectly deemed not to meet the release criterion.

\subsubsection{Conduct a Preliminary Data Review}

To learn about the structure of the data-identifying patterns, relationships, or potential anomalies-one can review quality assurance (QA) and quality control (QC) reports, prepare graphs of the data, and calculate basic statistical quantities.

\subsubsection{Data Evaluation and Conversion}

Radiological survey data are usually obtained in units, such as the number of counts per unit time, that have no intrinsic meaning relative to DCGLs. For comparison of survey data to DCGLs, the survey data from field and laboratory measurements are converted to DCGL units. Further information on instrument calibration and data conversion is given in Section 6.2.7.

Basic statistical quantities that should be calculated for the sample data set are the:

\footnotetext{
- mean

- standard deviation

- median
} 
Example:

Suppose the following 20 concentration values are from a survey unit:

$90.7,83.5,86.4,88.5,84.4,74.2,84.1,87.6,78.2,77.6$,

$86.4,76.3,86.5,77.4,90.3,90.1,79.1,92.4,75.5,80.5$.

First, the average of the data (83.5) and the sample standard deviation (5.7) should be calculated.

The average of the data can be compared to the reference area average and the DCGL $\mathrm{W}_{\mathrm{w}}$ to get a preliminary indication of the survey unit status. Where remediation is inadequate, this comparison may readily reveal that a survey unit contains excess residual radioactivity-even before applying statistical tests. For example, if the average of the data exceeds the DCGL $\mathrm{W}_{\mathrm{W}}$ and the radionuclide of interest does not appear in background, then the survey unit clearly does not meet the release criterion. On the other hand, if every measurement in the survey unit is below the $\mathrm{DCGL}_{\mathrm{w}}$, the survey unit clearly meets the release criterion. ${ }^{1}$

The value of the sample standard deviation is especially important. If too large compared to that assumed during the survey design, this may indicate an insufficient number of samples were collected to achieve the desired power of the statistical test. Again, inadequate power can lead to unnecessary remediation.

The median is the middle value of the data set when the number of data points is odd, and is the average of the two middle values when the number of data points is even. Thus $50 \%$ of the data points are above the median, and $50 \%$ are below the median. Large differences between the mean and the median would be an early indication of skewness in the data. This would also be evident in a histogram of the data. For the example data above, the median is 84.25 (i.e., $(84.1+84.4) / 2)$. The difference between the median and the mean (i.e., $84.25-83.5=0.75$ ) is a small fraction of the sample standard deviation (i.e., 5.7). Thus, in this instance, the mean and median would not be considered significantly different.

Examining the minimum, maximum, and range of the data may provide additional useful information. The minimum in this example is 74.2 and the maximum is 92.4 , so the range is $92.4-74.2=18.2$. This is only 3.2 standard deviations. Thus, the range is not unusually large. When there are 30 or fewer data points, values of the range much larger than about 4 to 5 standard deviations would be unusual. For larger data sets the range might be wider.

\footnotetext{
${ }^{1}$ It can be verified that if every measurement is below the $\mathrm{DCGL}_{\mathrm{w}}$ the conclusion from the statistical tests will always be that the survey unit does not exceed the release criterion.
} 
Interpretation of Survey Results

\subsubsection{Graphical Data Review}

At a minimum, a graphical data review should consist of a posting plot and a histogram. Quantile plots are also useful diagnostic tools, particularly in the two-sample case, to compare the survey unit and reference area. These are discussed in Appendix I, Section I.8.

A posting plot is simply a map of the survey unit with the data values entered at the measurement locations. This potentially reveals heterogeneities in the data-especially possible patches of elevated residual radioactivity. Even in a reference area, a posting plot can reveal spatial trends in background data that might affect the results of the two-sample statistical tests.

If the data above were obtained using a triangular grid in a rectangular survey unit, the posting plot might resemble the display in Figure 8.1. Figure 8.1a shows no unusual patterns in the data. Figure $8.1 \mathrm{~b}$ shows a different plot of the same values, but with individual results associated with different locations within the survey unit. In this plot there is an obvious trend towards smaller values as one moves from left to right across the survey unit. This trend is not apparent in the simple initial listing of the data. The trend may become more apparent if isopleths are added to the posting plot.

If the posting plot reveals systematic spatial trends in the survey unit, the cause of the trends would need to be investigated. In some cases, such trends could be due to residual radioactivity, but may also be due to inhomogeneities in the survey unit background. Other diagnostic tools for examining spatial data trends may be found in EPA Guidance Document QA/G-9 (EPA

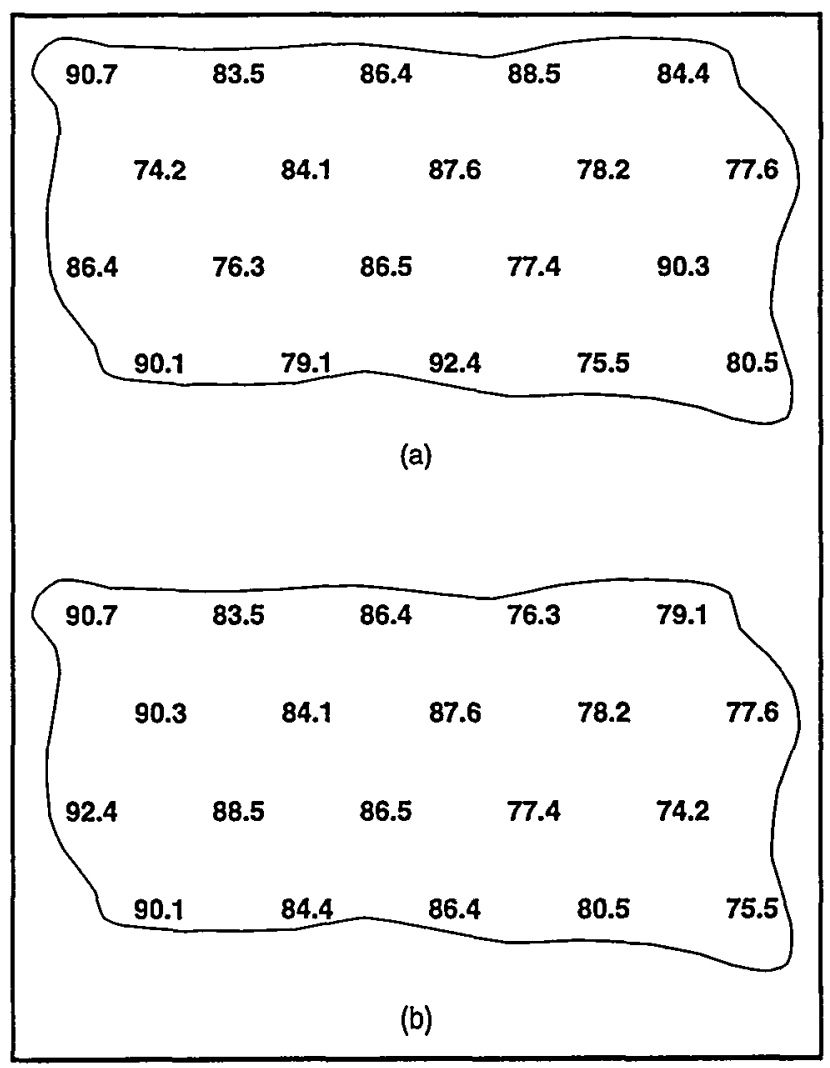

Figure 8.1 Examples of Posting Plots

1996a). The use of geostatistical tools to evaluate spatial data trends may also be useful in some cases (EPA 1989a).

A frequency plot (or a histogram) is a useful tool for examining the general shape of a data distribution. This plot is a bar chart of the number of data points within a certain range of values. A frequency plot of the example data is shown in Figure 8.2). A simple method for generating a 


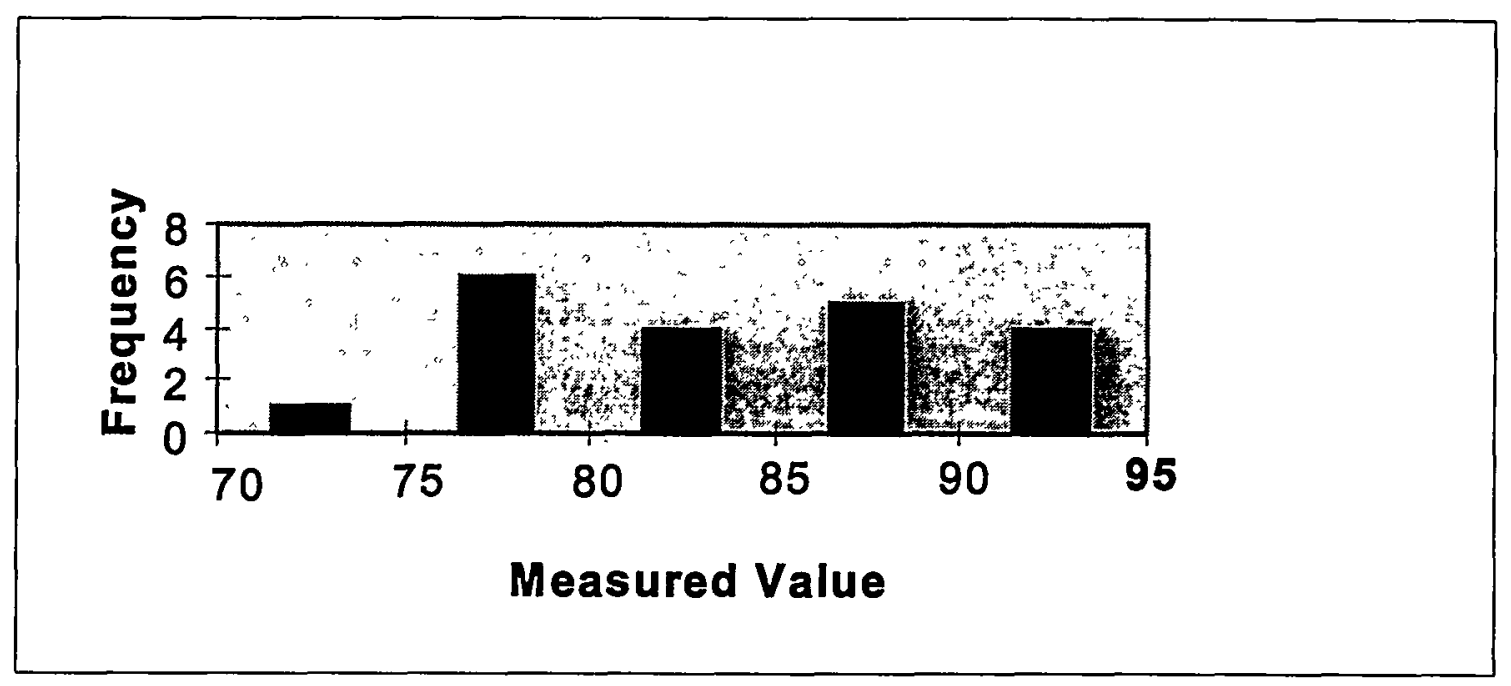

Figure 8.2 Example of a Frequency Plot

rough frequency plot is the stem and leaf display discussed in Appendix I, Section 1.7. The frequency plot will reveal any obvious departures from symmetry, such as skewness or bimodality (two peaks), in the data distributions for the survey unit or reference area. The presence of two peaks in the survey unit frequency plot may indicate the existence of isolated areas of residual radioactivity. In some cases it may be possible to determine an appropriate background for the survey unit using this information. The interpretation of the data for this purpose will generally be highly dependent on site-specific considerations and should only be pursued after a consultation with the responsible regulatory agency.

The presence of two peaks in the background reference area or survey unit frequency plot may indicate a mixture of background concentration distributions due to different soil types, construction materials, etc. The greater variability in the data due to the presence of such a mixture will reduce the power of the statistical tests to detect an adequately remediated survey unit. These situations should be avoided whenever possible by carefully matching the background reference areas to the survey units, and choosing survey units with homogeneous backgrounds.

Skewness or other asymmetry can impact the accuracy of the statistical tests. A data transformation (e.g., taking the logarithms of the data) can sometimes be used to make the distribution more symmetric. The statistical tests would then be performed on the transformed data. When the underlying data distribution is highly skewed, it is often because there are a few high areas. Since the EMC is used to detect such measurements, the difference between using the median and the mean as a measure for the degree to which uniform residual radioactivity remains in a survey unit tends to diminish in importance. 
Interpretation of Survey Results

\subsubsection{Select the Tests}

An overview of the statistical considerations important for final status surveys appears in Section 2.5 and Appendix D. The most appropriate procedure for summarizing and analyzing the data is chosen based on the preliminary data review. The parameter of interest is the mean concentration in the survey unit. The nonparametric tests recommended in this manual, in their most general form, are tests of the median. If one assumes that the data are from a symmetric distribution - where the median and the mean are effectively equal-these are also tests of the mean. If the assumption of symmetry is violated, then nonparametric tests of the median approximately test the mean. Computer simulations (e.g., Hardin and Gilbert, 1993) have shown that the approximation is a good one. That is, the correct decision will be made about whether or not the mean concentration exceeds the DCGL, even when the data come from a skewed distribution. In this regard, the nonparametric tests are found to be correct more often than the commonly used Student's t test. The robust performance of the Sign and WRS tests over a wide range of conditions is the reason that they are recommended in this manual.

When a given set of assumptions is true, a parametric test designed for exactly that set of conditions will have the highest power. For example, if the data are from a normal distribution, the Student's $t$ test will have higher power than the nonparametric tests. It should be noted that for large enough sample sizes (e.g., large number of measurements), the Student's test is not a great deal more powerful than the nonparametric tests. On the other hand, when the assumption of normality is violated, the nonparametric tests can be very much more powerful than the $t$ test. Therefore, any statistical test may be used provided that the data are consistent with the assumptions underlying their use. When these assumptions are violated, the prudent approach is to use the nonparametric tests which generally involve fewer assumptions than their parametric equivalents.

The one-sample statistical test (Sign test) described in Section 5.5.2.3 should only be used if the contaminant is not present in background and radionuclide-specific measurements are made. The one-sample test may also be used if the contaminant is present at such a small fraction of the DCGL $_{\mathrm{w}}$ value as to be considered insignificant. In this case, background concentrations of the radionuclide are included with the residual radioactivity (i.e., the entire amount is attributed to facility operations). Thus, the total concentration of the radionuclide is compared to the release criterion. This option should only be used if one expects that ignoring the background concentration will not affect the outcome of the statistical tests. The advantage of ignoring a small background contribution is that no reference area is needed. This can simplify the final status survey considerably.

The one-sample Sign test (Section 8.3.1) evaluates whether the median of the data is above or below the DCGL $\mathrm{w}_{\mathrm{w}}$. If the data distribution is symmetric, the median is equal to the mean. In cases where the data are severely skewed, the mean may be above the DCGL ${ }_{\mathrm{W}}$, while the median 
is below the $\mathrm{DCGL}$. In such cases, the survey unit does not meet the release criterion regardless of the result of the statistical tests. On the other hand, if the largest measurement is below the DCGL $_{w}$, the Sign test will always show that the survey unit meets the release criterion.

For final status surveys, the two-sample statistical test (Wilcoxon Rank Sum test, discussed in Section 5.5.2.2) should be used when the radionuclide of concern appears in background or if measurements are used that are not radionuclide specific. The two-sample Wilcoxon Rank Sum (WRS) test (Section 8.4.1) assumes the reference area and survey unit data distributions are similar except for a possible shift in the medians. When the data are severely skewed, the value for the mean difference may be above the $\mathrm{DCGL}_{\mathrm{w}}$, while the median difference is below the DCGL $_{\mathrm{w}}$. In such cases, the survey unit does not meet the release criterion regardless of the result of the statistical test. On the other hand, if the difference between the largest survey unit measurement and the smallest reference area measurement is less than the DCGL $\mathrm{w}_{\mathrm{w}}$, the WRS test will always show that the survey unit meets the release criterion.

\subsubsection{Verify the Assumptions of the Tests}

An evaluation to determine that the data are consistent with the underlying assumptions made for the statistical procedures helps to validate the use of a test. One may also determine that certain departures from these assumptions are acceptable when given the actual data and other information about the study. The nonparametric tests described in this chapter assume that the data from the reference area or survey unit consist of independent samples from each distribution.

Spatial dependencies that potentially affect the assumptions can be assessed using posting plots (Section 8.2.2.2). More sophisticated tools for determining the extent of spatial dependencies are also available (e.g., EPA QA/G-9). These methods tend to be complex and are best used with guidance from a professional statistician.

Asymmetry in the data can be diagnosed with a stem and leaf display, a histogram, or a Quantile plot. As discussed in the previous section, data transformations can sometimes be used to minimize the effects of asymmetry.

One of the primary advantages of the nonparametric tests used in this report is that they involve fewer assumptions about the data than their parametric counterparts. If parametric tests are used, (e.g., Student's $t$ test), then any additional assumptions made in using them should be verified (e.g., testing for normality). These issues are discussed in detail in EPA QA/G-9 (EPA 1996a). 
Interpretation of Survey Results

One of the more important assumptions made in the survey design described in Chapter 5 is that the sample sizes determined for the tests are sufficient to achieve the data quality objectives set for the Type $I(\alpha)$ and Type $I(\beta)$ error rates. Verification of the power of the tests $(1-\beta)$ to detect adequate remediation may be of particular interest. Methods for assessing the power are discussed in Appendix I.9. If the hypothesis that the survey unit residual radioactivity exceeds the release criterion is accepted, there should be reasonable assurance that the test is equally effective in determining that a survey unit has residual contamination less than the DCGL $\mathrm{W}_{\mathrm{W}}$. Otherwise, unnecessary remediation may result. For this reason, it is better to plan the surveys cautiously-even to the point of:

- overestimating the potential data variability

- taking too many samples

- overestimating minimum detectable concentrations (MDCs)

If one is unable to show that the DQOs were met with reasonable assurance, a resurvey may be needed. Examples of assumptions and possible methods for their assessment are summarized in Table 8.1.

Table 8.1 Methods for Checking the Assumptions of Statistical Tests

\begin{tabular}{||l|l|}
\hline & \\
\hline Spatial Independence & Posting Plot \\
\hline Symmetry & Histogram, Quantile Plot \\
\hline Data Variance & Sample Standard Deviation \\
\hline Power is Adequate & Retrospective Power Chart \\
\hline
\end{tabular}

\subsubsection{Draw Conclusions from the Data}

The types of measurements that can be made in a survey unit are 1) direct measurements at discrete locations, 2) samples collected at discrete locations, and 3) scans. The statistical tests are only applied to measurements made at discrete locations. Specific details for conducting the statistical tests are given in Sections 8.3 and 8.4. When the data clearly show that a survey unit meets or exceeds the release criterion, the result is often obvious without performing the formal statistical analysis. Table 8.2 describes examples of circumstances leading to specific conclusions based on a simple examination of the data. 
Table 8.2 Summary of Statistical Tests

Radionuclide not in background and radionuclide-specific measurements made:

\begin{tabular}{|l|l|}
\hline Survey Result & Conclusion \\
\hline All measurements less than $\mathrm{DCGL}_{\mathrm{w}}$ & Survey unit meets release criterion \\
\hline Average greater than $\mathrm{DCGL}_{\mathrm{w}}$ & Survey unit does not meet release criterion \\
\hline $\begin{array}{l}\text { Any measurement greater than } \mathrm{DCGL}_{\mathrm{w}} \text { and the average } \\
\text { less than } \mathrm{DCGL}_{\mathrm{w}}\end{array}$ & $\begin{array}{l}\text { Conduct Sign test and elevated measurement } \\
\text { comparison }\end{array}$ \\
\hline
\end{tabular}

Radionuclide in background or radionuclide non-specific (gross) measurements made:

\begin{tabular}{|l|l||}
\hline Survey Result & Conclusion \\
\hline $\begin{array}{l}\text { Difference between largest survey unit measurement and } \\
\text { smallest reference area measurement is less than DCGL }\end{array}$ & Survey unit meets release criterion \\
\hline $\begin{array}{l}\text { Difference of survey unit average and reference area } \\
\text { average is greater than DCGL }\end{array}$ & Survey unit does not meet release criterion \\
\hline $\begin{array}{l}\text { Difference between any survey unit measurement and any } \\
\text { reference area measurement greater than DCGL } \\
\text { difference of survey unit average and reference area } \\
\text { average is less than DCGL }\end{array}$ & $\begin{array}{l}\text { Conduct WRS test and elevated measurement } \\
\text { comparison }\end{array}$ \\
\hline
\end{tabular}

Both the measurements at discrete locations and the scans are subject to the elevated measurement comparison (EMC). The result of the EMC is not conclusive as to whether the survey unit meets or exceeds the release criterion, but is a flag or trigger for further investigation. The investigation may involve taking further measurements to determine that the area and level of the elevated residual radioactivity are such that the resulting dose or risk meets the release criterion. ${ }^{2}$ The investigation should also provide adequate assurance, using the DQO process, that there are no other undiscovered areas of elevated residual radioactivity in the survey unit that might otherwise result in a dose or risk exceeding the release criterion. In some cases, this may lead to re-classifying all or part of a survey unit-unless the results of the investigation indicate that reclassification is not necessary. The investigation level appropriate for each class of survey unit and type of measurement is shown in Table 5.8 and is described in Section 5.5.2.6.

${ }^{2}$ Rather than, or in addition to, taking further measurements the investigation may involve assessing the adequacy of the exposure pathway model used to obtain the DCGLs and area factors, and the consistency of the results obtained with the Historical Site Assessment and the scoping, characterization and remedial action support surveys. 
Interpretation of Survey Results

\subsubsection{Example}

To illustrate the data interpretation process, consider an example facility with 14 survey units consisting of interior concrete surfaces, one interior survey unit with drywall surfaces, and two exterior survey units. The contaminant of concern is ${ }^{60} \mathrm{Co}$. The interior surfaces were measured with a gas-flow proportional counter (see Appendix $\mathrm{H}$ ) with an active surface area of $20 \mathrm{~cm}^{2}$ to determine total beta-gamma activity. Because these measurements are not radionuclide specific, appropriate reference areas were chosen for comparison. The exterior soil was measured with a germanium spectrometer to provide radionuclide-specific results. A reference area is not needed because ${ }^{60} \mathrm{Co}$ does not have a significant background in soil.

The exterior Class 3 survey unit incorporates areas that are not expected to contain residual radioactivity. The exterior Class 2 survey unit is similar to the Class 3 survey unit, but is expected to contain residual radioactivity below the $\mathrm{DCGL}_{\mathrm{w}}$. The Class 1 Interior Concrete survey units are expected to contain small areas of elevated activity that may or may not exceed the DCGL $\mathrm{w}_{\mathrm{w}}$. The Class 2 Interior Drywall survey unit is similar to the Class 1 Interior Concrete survey unit, but the drywall is expected to have a lower background, less measurement variability, and a more uniform distribution of contamination. The Class 2 survey unit is not expected to contain areas of activity above the $\mathrm{DCGL}_{\mathrm{W}}$. Section 8.3 describes the Sign test used to evaluate the survey units where the contaminant is not present in background. Section 8.4 describes the WRS test used to evaluate the survey units where the contaminant is present in background. Section 8.5 discusses the evaluation of the results of the statistical tests and the decision regarding compliance with the release criterion. The survey design parameters and DQOs developed for these survey units are summarized in Table 8.3.

Table 8.3 Final Status Survey Parameters for Example Survey Units

\begin{tabular}{|c|c|c|c|c|c|c|c|}
\hline Surrey & $\therefore$ & D & 0 & $=$ & Estimate & $\begin{array}{l}\text { Standard } \\
\text { ơn, } o\end{array}$ & Tést/Section \\
\hline Unit & Type & $\alpha$ & $\beta$ & DCGL & Survey & Reference & \\
\hline $\begin{array}{l}\text { Interior } \\
\text { Concrete }\end{array}$ & Class 1 & .05 & .05 & $\begin{array}{l}5000 \mathrm{dpm} \\
\text { per } 100 \mathrm{~cm}^{2}\end{array}$ & $\begin{array}{l}625 \mathrm{dpm} \\
\text { per } 100 \mathrm{~cm}^{2}\end{array}$ & $\begin{array}{l}220 \mathrm{dpm} \\
\text { per } 100 \mathrm{~cm}^{2}\end{array}$ & WRS/App. A \\
\hline $\begin{array}{l}\text { Interior } \\
\text { Drywall }\end{array}$ & Class 2 & .025 & .05 & $\begin{array}{l}5000 \mathrm{dpm} \\
\text { per } 100 \mathrm{~cm}^{2}\end{array}$ & $\begin{array}{l}200 \mathrm{dpm} \\
\text { per } 100 \mathrm{~cm}^{2}\end{array}$ & $\begin{array}{l}200 \mathrm{dpm} \\
\text { per } 100 \mathrm{~cm}^{2}\end{array}$ & WRS/8.4.3 \\
\hline Exterior Lawn & Class 2 & .025 & .025 & $140 \mathrm{~Bq} / \mathrm{kg}$ & $3.8 \mathrm{~Bq} / \mathrm{kg}$ & N/A & Sign/8.3.3 \\
\hline Exterior Lawn & Class 3 & .025 & .01 & $140 \mathrm{~Bq} / \mathrm{kg}$ & $3.8 \mathrm{~Bq} / \mathrm{kg}$ & N/A & Sign/8.3.4 \\
\hline
\end{tabular}


Interpretation of Survey Results

\subsection{Contaminant Not Present in Background}

The statistical test discussed in this section is used to compare each survey unit directly with the applicable release criterion. A reference area is not included because the measurement technique is radionuclide-specific and the radionuclide of concern is not present in background (see Section 8.2.6). In this case the contaminant levels are compared directly with the DCGL $_{\mathrm{W}}$. The method in this section should only be used if the contaminant is not present in background or is present at such a small fraction of the $\mathrm{DCGL}_{\mathrm{w}}$ value as to be considered insignificant. In addition, onesample tests are applicable only if radionuclide-specific measurements are made to determine the concentrations. Otherwise, the method in Section 8.4 is recommended.

Reference areas and reference samples are not needed when there is sufficient information to indicate there is essentially no background concentration for the radionuclide being considered. With only a single set of survey unit samples, the statistical test used here is called a one-sample test. See Section 5.5 for further information appropriate to following the example and discussion presented here.

\subsubsection{One-Sample Statistical Test}

The Sign test is designed to detect uniform failure of remedial action throughout the survey unit. This test does not assume that the data follow any particular distribution, such as normal or log-normal. In addition to the Sign Test, the DCGL ${ }_{\mathrm{EMC}}$ (see Section 5.5.2.4) is compared to each measurement to ensure none exceeds the DCGL ${ }_{\mathrm{EMC}}$. If a measurement exceeds this DCGL, then additional investigation is recommended, at least locally, to determine the actual areal extent of the elevated concentration.

The hypothesis tested by the Sign test is

Null Hypothesis

$\mathrm{H}_{0}$ : The median concentration of residual radioactivity in the survey unit is greater than the DCGL

versus

Alternative Hypothesis

$\mathrm{H}_{\mathrm{a}}$ : The median concentration of residual radioactivity in the survey unit is less than the DCGL $_{\mathrm{w}}$

The null hypothesis is assumed to be true unless the statistical test indicates that it should be rejected in favor of the alternative. The null hypothesis states that the probability of a measurement less than the $\mathrm{DCGL}_{\mathrm{w}}$ is less than one-half, i.e., the 50th percentile (or median) is 
Interpretation of Survey Results

greater than the $\mathrm{DCGL}_{\mathrm{w}}$. Note that some individual survey unit measurements may exceed the DCGL $_{w}$ even when the survey unit as a whole meets the release criterion. In fact, a survey unit average that is close to the DCGL $\mathrm{w}_{\mathrm{w}}$ might have almost half of its individual measurements greater than the $\mathrm{DCGL}_{\mathrm{w}}$. Such a survey unit may still not exceed the release criterion.

The assumption is that the survey unit measurements are independent random samples from a symmetric distribution. If the distribution of measurements is symmetric, the median and the mean are the same.

The hypothesis specifies a release criterion in terms of a DCGL $\mathrm{W}_{\mathrm{w}}$. The test should have sufficient power (1- $\beta$, as specified in the DQOs) to detect residual radioactivity concentrations at the Lower Boundary of the Gray Region (LBGR). If $\sigma$ is the standard deviation of the measurements in the survey unit, then $\Delta / \sigma$ expresses the size of the shift (i.e., $\Delta=\mathrm{DCGL}_{\mathrm{W}}$ - LBGR) as the number of standard deviations that would be considered "large" for the distribution of measurements in the survey unit. The procedure for determining $\Delta / \sigma$ is given in Section 5.5.2.3.

\subsubsection{Applying the Sign Test}

The Sign test is applied as outlined in the following five steps, and further illustrated by the examples in Sections 8.3.3 and 8.3.4.

1. List the survey unit measurements, $X_{i}, i=1,2,3 \ldots, N$.

2. Subtract each measurement, $X_{i}$, from the $\mathrm{DCGL}_{\mathrm{w}}$ to obtain the differences:

$$
D_{i}=D C G L_{W}-X_{i}, i=1,2,3 \ldots, N \text {. }
$$

3. Discard each difference that is exactly zero and reduce the sample size, $N$, by the number of such zero measurements.

4. Count the number of positive differences. The result is the test statistic S+. Note that a positive difference corresponds to a measurement below the $\mathrm{DCGL}_{\mathrm{W}}$ and contributes evidence that the survey unit meets the release criterion.

5. Large values of $\mathrm{S}+$ indicate that the null hypothesis (that the survey unit exceeds the release criterion) is false. The value of $\mathrm{S}+$ is compared to the critical values in Table I.3. If $\mathrm{S}+$ is greater than the critical value, $k$, in that table, the null hypothesis is rejected.

\subsubsection{Sign Test Example: Class 2 Exterior Soil Survey Unit}

For the Class 2 Exterior Soil survey unit, the one-sample nonparametric statistical test is appropriate since the radionuclide of concern does not appear in background and radionuclidespecific measurements were made. 
Table 8.3 shows that the DQOs for this survey unit include $\alpha=0.025$ and $\beta=0.025$. The $\mathrm{DCGL}_{\mathrm{W}}$ is $140 \mathrm{~Bq} / \mathrm{kg}(3.8 \mathrm{pCi} / \mathrm{g})$ and the estimated standard deviation of the measurements is $\sigma$ $=3.8 \mathrm{~Bq} / \mathrm{kg}(0.10 \mathrm{pCi} / \mathrm{g})$. Since the estimated standard deviation is much smaller than the DCGL $_{\mathrm{w}}$, the LBGR should be set so that $\Delta / \sigma$ is about 3 .

If $\Delta / \sigma=\left(\mathrm{DCGL}_{\mathrm{w}}-\mathrm{LBGR}\right) / \sigma$

$$
=3
$$

then

$$
\begin{aligned}
\mathrm{LBGR} & =\mathrm{DCGL}_{\mathrm{W}}-3 \sigma \\
& =140-(3 \times 3.8) \\
& =128 \mathrm{~Bq} / \mathrm{kg}(3.5 \mathrm{pCi} / \mathrm{g}) .
\end{aligned}
$$

Table 5.5 indicates the number of measurements estimated for the Sign Test, N, is $20(\alpha=0.025$, $\beta=0.025$, and $\Delta / \sigma=3$ ). (Table I.2a in Appendix I also lists the number of measurements estimated for the Sign test.) This survey unit is Class 2, so the 20 measurements needed were made on a random-start triangular grid. When laying out the grid, 22 measurement locations were identified.

The 22 measurements taken on the exterior lawn Class 2 survey unit are shown in the first column of Table 8.4. The mean of these data is $129 \mathrm{~Bq} / \mathrm{kg}(3.5 \mathrm{pCi} / \mathrm{g})$ and the standard deviation is $11 \mathrm{~Bq} / \mathrm{kg}(0.30 \mathrm{pCi} / \mathrm{g})$. Since the number of measurements is even, the median of the data is the average of the two middle values $(126+128) / 2=127 \mathrm{~Bq} / \mathrm{kg}(3.4 \mathrm{pCi} / \mathrm{g})$. A Quantile Plot of the data is shown in Appendix I.8, Figure I.3.

There are five measurements that exceed the DCGL $_{\mathrm{w}}$ value of $140 \mathrm{~Bq} / \mathrm{kg}: 142,143,145,148$, and 148. However, none exceed the mean of the data plus three standard deviations: $127+(3 \times 11)=160 \mathrm{~Bq} / \mathrm{kg}(4.3 \mathrm{pCi} / \mathrm{g})$. Thus, these values appear to reflect the overall variability of the concentration measurements rather than to indicate an area of elevated activity - provided that these measurements were scattered through the survey unit. However, if a posting plot demonstrates that the locations of these measurements are grouped together, then that portion of the survey unit containing these locations merits further investigation.

The middle column of Table 8.4 contains the differences, $D C G L_{W}-$ Data, and the last column contains the signs of the differences. The bottom row shows the number of measurements with positive differences, which is the test statistic $\mathrm{S}+$. In this case, $\mathrm{S}+=17$.

The value of $\mathrm{S}+$ is compared to the appropriate critical value in Table I.3. In this case, for $N=22$ and $\alpha=0.025$, the critical value is 16 . Since $S+=17$ exceeds this value, the null hypothesis that the survey unit exceeds the release criterion is rejected. 
Interpretation of Survey Results

Table 8.4 Example Sign Analysis: Class 2 Exterior Soil Survey Unit

\begin{tabular}{|c|c|c|}
\hline $\begin{array}{c}\text { Data } \\
(\mathrm{Bq} / \mathrm{kg})\end{array}$ & $\begin{array}{c}\text { DCGL }- \text { Data } \\
(\mathrm{Bq} / \mathrm{kg})\end{array}$ & Sign \\
\hline 121 & 19 & 1 \\
\hline 143 & -3 & -1 \\
\hline 145 & -5 & -1 \\
\hline 112 & 28 & 1 \\
\hline 125 & 15 & 1 \\
\hline 132 & 8 & 1 \\
\hline 122 & 18 & 1 \\
\hline 114 & 26 & 1 \\
\hline 123 & 17 & 1 \\
\hline 148 & -8 & -1 \\
\hline 115 & 25 & 1 \\
\hline 113 & 27 & 1 \\
\hline 126 & 14 & 1 \\
\hline 134 & 6 & 1 \\
\hline 148 & -8 & -1 \\
\hline 130 & 10 & 1 \\
\hline 119 & 21 & 1 \\
\hline 136 & 4 & 1 \\
\hline 128 & 12 & 1 \\
\hline 125 & 15 & 1 \\
\hline 142 & -2 & -1 \\
\hline 129 & 11 & 1 \\
\hline \multicolumn{3}{|c|}{ Number of positive differences $S+=17$} \\
\hline
\end{tabular}

\subsubsection{Sign Test Example: Class 3 Exterior Soil Survey Unit}

For the Class 3 exterior soil survey unit, the one-sample nonparametric statistical test is again appropriate since the radionuclide of concern does not appear in background and radionuclidespecific measurements were made.

Table 8.3 shows that the DQOs for this survey unit include $\alpha=0.025$ and $\beta=0.01$. The $\mathrm{DCGL}_{\mathrm{w}}$ is $140 \mathrm{~Bq} / \mathrm{kg}(3.8 \mathrm{pCi} / \mathrm{g})$ and the estimated standard deviation of the measurements is $\sigma=3.8$ $\mathrm{Bq} / \mathrm{kg}(0.10 \mathrm{pCi} / \mathrm{g})$. Since the estimated standard deviation is much smaller than the $\mathrm{DCGL}_{\mathrm{w}}$, the lower bound for the gray region should be set so that $\Delta / \sigma$ is about 3 . 


$$
\text { If } \quad \begin{aligned}
\Delta / \sigma & =\left(\mathrm{DCGL}_{\mathrm{w}}-\mathrm{LBGR}\right) / \sigma \\
\text { then } \quad \text { LBGR } & =3 \\
& =140-(3 \times 4) \\
& =128 \mathrm{~Bq} / \mathrm{kg}(3.5 \mathrm{pCi} / \mathrm{g}) .
\end{aligned}
$$

Table 5.5 indicates that the sample size estimated for the Sign Test, $N$, is $23(\alpha=0.025, \beta=0.01$, and $\Delta / \sigma=3$ ). This survey unit is Class 3 , so the measurements were made at random locations within the survey unit.

The 23 measurements taken on the exterior lawn are shown in the first column of Table 8.5. Notice that some of these measurements are negative $(-0.37$ in cell A6). This might occur if an analysis background (e.g., the Compton continuum under a spectrum peak) is subtracted to obtain the net concentration value. The data analysis is both easier and more accurate when numerical values are reported as obtained rather than reporting the results as "less than" or not detected. The mean of these data is $2.1 \mathrm{~Bq} / \mathrm{kg}(0.057 \mathrm{pCi} / \mathrm{g})$ and the standard deviation is 3.3 $\mathrm{Bq} / \mathrm{kg}(0.089 \mathrm{pCi} / \mathrm{g})$. None of the data exceed $2.1+(3 \times 3.3)=12.0 \mathrm{~Bq} / \mathrm{kg}(0.32 \mathrm{pCi} / \mathrm{g})$. Since $\mathrm{N}$ is odd, the median is the middle ( $12^{\text {th }}$ highest) value, namely $2.6 \mathrm{~Bq} / \mathrm{kg}(0.070 \mathrm{pCi} / \mathrm{g})$.

An initial review of the data reveals that every data point is below the DCGL $_{w}$, so the survey unit meets the release criterion specified in Table 8.3. For purely illustrative purposes, the Sign test analysis is performed. The middle column of Table 8.5 contains the quantity DCGL $\mathrm{W}_{\mathrm{W}}$ - Data. Since every data point is below the $\mathrm{DCGL}_{\mathrm{w}}$, the sign of $\mathrm{DCGL}_{\mathrm{w}}$ - Data is always positive. The number of positive differences is equal to the number of measurements, $\mathrm{N}$, and so the Sign test statistic $\mathrm{S}+$ is 23 . The null hypothesis will always be rejected at the maximum value of $\mathrm{S}+$ (which in this case is 23) and the survey unit passes. Thus, the application of the Sign test in such cases requires no calculations and one need not consult a table for a critical value. If the survey is properly designed, the critical value must always be less than $\mathrm{N}$.

Passing a survey unit without making a single calculation may seem an unconventional approach. However, the key is in the survey design which is intended to ensure enough measurements are made to satisfy the DQOs. As in the previous example, after the data are collected the conclusions and power of the test can be checked by constructing a retrospective power curve as outlined in Appendix I, Section I..9.

One final consideration remains regarding the survey unit classification: "Was any definite amount of residual radioactivity found in the survey unit?" This will depend on the MDC of the measurement method. Generally the MDC is at least 3 or 4 times the estimated measurement standard deviation. In the present case, the largest observation, $9.3 \mathrm{~Bq} / \mathrm{kg}(0.25 \mathrm{pCi} / \mathrm{g})$, is less than three times the estimated measurement standard deviation of $3.8 \mathrm{~Bq} / \mathrm{kg}(0.10 \mathrm{pCi} / \mathrm{g})$. Thus, it is unlikely that any of the measurements could be considered indicative of positive contamination. This means that the Class 3 survey unit classification was appropriate. 
Interpretation of Survey Results

Table 8.5 Sign Test Example Data for Class 3 Exterior Survey Unit

\begin{tabular}{|c||c|c|c|}
\hline & $\mathbf{A}$ & $\mathbf{B}$ & $\mathbf{C}$ \\
\hline \hline $\mathbf{1}$ & Data & DCGL $_{W}$ Data & Sign \\
\hline $\mathbf{2}$ & 3.0 & 137.0 & 1 \\
\hline $\mathbf{3}$ & 3.0 & 137.0 & 1 \\
\hline $\mathbf{4}$ & 1.9 & 138.1 & 1 \\
\hline $\mathbf{5}$ & 0.37 & 139.6 & 1 \\
\hline $\mathbf{6}$ & -0.37 & 140.4 & 1 \\
\hline $\mathbf{7}$ & 6.3 & 133.7 & 1 \\
\hline $\mathbf{8}$ & -3.7 & 143.7 & 1 \\
\hline $\mathbf{9}$ & 2.6 & 137.4 & 1 \\
\hline $\mathbf{1 0}$ & 3.0 & 137.0 & 1 \\
\hline $\mathbf{1 1}$ & -4.1 & 144.1 & 1 \\
\hline $\mathbf{1 2}$ & 3.0 & 137.0 & 1 \\
\hline $\mathbf{1 3}$ & 3.7 & 136.3 & 1 \\
\hline $\mathbf{1 4}$ & 2.6 & 137.4 & 1 \\
\hline $\mathbf{1 5}$ & 4.4 & 135.6 & 1 \\
\hline $\mathbf{1 6}$ & -3.3 & 143.3 & 1 \\
\hline $\mathbf{1 7}$ & 2.1 & 137.9 & 1 \\
\hline $\mathbf{1 8}$ & 6.3 & 133.7 & 1 \\
\hline $\mathbf{1 9}$ & 4.4 & 135.6 & 1 \\
\hline $\mathbf{2 0}$ & -0.37 & 140.4 & 1 \\
\hline $\mathbf{2 1}$ & 4.1 & 135.9 & 1 \\
\hline $\mathbf{2 2}$ & -1.1 & 141.1 & 1 \\
\hline $\mathbf{2 3}$ & 1.1 & 138.9 & 1 \\
\hline $\mathbf{2 4}$ & 9.3 & 130.7 & 1 \\
\hline $\mathbf{2 5}$ & Number of positive differences S+ & 23 \\
\hline & & & \\
\hline
\end{tabular}

If one determines that residual radioactivity is definitely present, this would indicate that the survey unit was initially mis-classified. Ordinarily, MARSSIM recommends a resurvey using a Class 1 or Class 2 design. If one determines that the survey unit is a Class 2, a resurvey might be avoided if the survey unit does not exceed the maximum size for such a classification. In this case, the only difference in survey design would be whether the measurements were obtained on a random or on a triangular grid. Provided that the initial survey's scanning methodology is sufficiently sensitive to detect areas at $\mathrm{DCGL}_{\mathrm{w}}$ without the use of an area factor, this difference in the survey grids alone would not affect the outcome of the statistical analysis. Therefore, if the above conditions were met, a resurvey might not be necessary. 


\subsection{Contaminant Present in Background}

The statistical tests discussed in this section will be used to compare each survey unit with an appropriately chosen, site-specific reference area. Each reference area should be selected on the basis of its similarity to the survey unit, as discussed in Section 4.5.

\subsubsection{Two-Sample Statistical Test}

The comparison of measurements from the reference area and survey unit is made using the Wilcoxon Rank Sum (WRS) test (also called the Mann-Whitney test). The WRS test should be conducted for each survey unit. In addition, the EMC is performed against each measurement to ensure that it does not exceed a specified investigation level. If any measurement in the remediated survey unit exceeds the specified investigation level, then additional investigation is recommended, at least locally, regardless of the outcome of the WRS test.

The WRS test is most effective when residual radioactivity is uniformly present throughout a survey unit. The test is designed to detect whether or not this activity exceeds the DCGL $\mathrm{w}_{\mathrm{w}}$. The advantage of the nonparametric WRS test is that it does not assume that the data are normally or log-normally distributed. The WRS test also allows for "less than" measurements to be present in the reference area and the survey units. As a general rule, the WRS test can be used with up to 40 percent "less than" measurements in either the reference area or the survey unit. However, the use of "less than" values in data reporting is not recommended as discussed in Section 2.3.5. When possible, report the actual result of a measurement together with its uncertainty.

The hypothesis tested by the WRS test is

Null Hypothesis

$\mathrm{H}_{0}$ : The median concentration in the survey unit exceeds that in the reference area by more than the DCGL $_{\mathrm{w}}$

versus

Alternative Hypothesis

$\mathrm{H}_{\mathrm{a}}$ : The median concentration in the survey unit exceeds that in the reference area by less than the DCGL $_{\mathrm{w}}$

The null hypothesis is assumed to be true unless the statistical test indicates that it should be rejected in favor of the alternative. One assumes that any difference between the reference area and survey unit concentration distributions is due to a shift in the survey unit concentrations to higher values (i.e., due to the presence of residual radioactivity in addition to background). Note that some or all of the survey unit measurements may be larger than some reference area 
measurements, while still meeting the release criterion. Indeed, some survey unit measurements may exceed some reference area measurements by more than the $\mathrm{DCGL}_{\mathrm{w}}$. The result of the hypothesis test determines whether or not the survey unit as a whole is deemed to meet the release criterion. The EMC is used to screen individual measurements.

Two assumptions underlying this test are: 1) samples from the reference area and survey unit are independent, identically distributed random samples, and 2) each measurement is independent of every other measurement, regardless of the set of samples from which it came.

\subsubsection{Applying the Wilcoxon Rank Sum Test}

The WRS test is applied as outlined in the following six steps and further illustrated by the examples in Section 8.4.3 and Appendix A.

1. Obtain the adjusted reference area measurements, $Z_{i}$, by adding the DCGL $\mathrm{w}_{\mathrm{w}}$ to each reference area measurement, $X_{i} . Z_{i}=X_{i}+D C G L_{W}$

2. The $m$ adjusted reference sample measurements, $Z_{i}$, from the reference area and the $n$ sample measurements, $Y_{i}$, from the survey unit are pooled and ranked in order of increasing size from 1 to $N$, where $N=m+n$.

3. If several measurements are tied (i.e., have the same value), they are all assigned the average rank of that group of tied measurements.

4. If there are $t$ "less than" values, they are all given the average of the ranks from 1 to $t$. Therefore, they are all assigned the rank $t(t+1) /(2 t)=(t+1) / 2$, which is the average of the first $t$ integers. If there is more than one detection limit, all observations below the largest detection limit should be treated as "less than" values. ${ }^{3}$

5. Sum the ranks of the adjusted measurements from the reference area, $W_{r}$. Note that since the sum of the first $N$ integers is $N(N+1) / 2$, one can equivalently sum the ranks of the measurements from the survey unit, $W_{s}$, and compute $W_{r}=N(N+1) / 2-W_{s}$.

6. Compare $W_{r}$ with the critical value given in Table $I .4$ for the appropriate values of $n, m$, and $\alpha$. If $W_{r}$ is greater than the tabulated value, reject the hypothesis that the survey unit exceeds the release criterion.

\footnotetext{
${ }^{3}$ If more than 40 percent of the data from either the reference area or survey unit are "less than," the WRS test cannot be used. Such a large proportion of non-detects suggest that the DQO process be re-visited for this survey to determine if the survey unit was properly classified or the appropriate measurement method was used. As stated previously, the use of "less than" values in data reporting is not recommended. Wherever possible, the actual result of a measurement, together with its uncertainty, should be reported.
} 


\subsubsection{Wilcoxon Rank Sum Test Example: Class 2 Interior Drywall Survey Unit}

In this example, the gas-flow proportional counter measures total beta-gamma activity (see Appendix $\mathrm{H}$ ) and the measurements are not radionuclide specific. The two-sample nonparametric test is appropriate for the Class 2 interior drywall survey unit because gross betagamma activity contributes to background even though the radionuclide of interest does not appear in background.

Table 8.3 shows that the DQOs for this survey unit include $\alpha=0.025$ and $\beta=0.05$. The $\mathrm{DCGL}_{\mathrm{W}}$ is $3,000 \mathrm{~Bq} / \mathrm{m}^{2}\left(5,000 \mathrm{dpm}\right.$ per $\left.100 \mathrm{~cm}^{2}\right)$ and the estimated standard deviation of the measurements is about $\sigma=375 \mathrm{~Bq} / \mathrm{m}^{2}\left(625 \mathrm{dpm}\right.$ per $\left.100 \mathrm{~cm}^{2}\right)$. The estimated standard deviation is 8 times less than the $D C G L_{W}$. With this level of precision, the width of the gray region can be made fairly narrow. As noted earlier, sample sizes do not decrease very much once $\Delta / \sigma$ exceeds 3 or 4 . In this example, the lower bound for the gray region was set so that $\Delta / \sigma$ is about 4 .

$$
\text { If } \quad \begin{aligned}
\Delta / \sigma & =\left(\mathrm{DCGL}_{\mathrm{w}}-\mathrm{LBGR}\right) / \sigma \\
& =4 \\
\text { then } \quad \text { LBGR } & =\mathrm{DCGL} \mathrm{w}_{\mathrm{w}}-4 \sigma \\
& =3,000-(4 \times 375) \\
& =1,500 \mathrm{~Bq} / \mathrm{m}^{2}\left(2,500 \mathrm{dpm} \text { per } 100 \mathrm{~cm}^{2}\right) .
\end{aligned}
$$

In Table 5.3, one finds that the number of measurements estimated for the WRS test is 11 in each survey unit and 11 in each reference area $(\alpha=0.025, \beta=0.05$, and $\Delta / \sigma=4)$. (Table I.2b in Appendix I also lists the number of measurements estimated for the WRS test.) This survey unit was classified as Class 2, so the 11 measurements needed in the survey unit and the 11 measurements needed in the reference area were made using a random-start triangular grid. ${ }^{4}$

Table 8.6 lists the data obtained from the gas-flow proportional counter in units of counts per minute. A reading of $160 \mathrm{cpm}$ with this instrument corresponds to the $\mathrm{DCGL}_{\mathrm{W}}$ of $3,000 \mathrm{~Bq} / \mathrm{m}^{2}$ $\left(5,000 \mathrm{dpm}\right.$ per $\left.100 \mathrm{~cm}^{2}\right)$. Column $\mathrm{A}$ lists the measurement results as they were obtained. The average and standard deviation of the reference area measurements are 44 and $4.4 \mathrm{cpm}$, respectively. The average and standard deviation of the survey unit measurements are 98 and 5.3 cpm, respectively.

\footnotetext{
${ }^{4}$ A random start systematic grid is used in Class 2 and 3 survey units primarily to limit the size of any potential elevated areas. Since areas of elevated activity are not an issue in the reference areas, the measurement locations can be either random or on a random start systematic grid (see Section 5.5.2.5).
} 
Interpretation of Survey Results

Table 8.6 WRS Test for Class 2 Interior Drywall Survey Unit

\begin{tabular}{||c||c|c|c|c|c||}
\hline & A & B & C & D & E \\
\hline \hline $\mathbf{1}$ & $\begin{array}{c}\text { Data } \\
\text { (cpm) }\end{array}$ & Arëa & $\begin{array}{c}\text { Adjusted } \\
\text { Data }\end{array}$ & Ranks & $\begin{array}{c}\text { Reference Area } \\
\text { Ranks }\end{array}$ \\
\hline $\mathbf{2}$ & 49 & R & 209 & 22 & 22 \\
\hline $\mathbf{3}$ & 35 & R & 195 & 12 & 12 \\
\hline $\mathbf{4}$ & 45 & R & 205 & 17.5 & 17.5 \\
\hline $\mathbf{5}$ & 45 & R & 205 & 17.5 & 17.5 \\
\hline $\mathbf{6}$ & 41 & R & 201 & 14 & 14 \\
\hline $\mathbf{7}$ & 44 & R & 204 & 16 & 16 \\
\hline $\mathbf{8}$ & 48 & R & 208 & 21 & 21 \\
\hline $\mathbf{9}$ & 37 & R & 197 & 13 & 13 \\
\hline $\mathbf{1 0}$ & 46 & R & 206 & 19 & 19 \\
\hline $\mathbf{1 1}$ & 42 & R & 202 & 15 & 15 \\
\hline $\mathbf{1 2}$ & 47 & R & 207 & 20 & 20 \\
\hline $\mathbf{1 3}$ & 104 & S & 104 & 9.5 & 0 \\
\hline $\mathbf{1 4}$ & 94 & S & 94 & 4 & 0 \\
\hline $\mathbf{1 5}$ & 98 & S & 98 & 6 & 0 \\
\hline $\mathbf{1 6}$ & 99 & S & 99 & 7 & 0 \\
\hline $\mathbf{1 7}$ & 90 & S & 90 & 1 & 0 \\
\hline $\mathbf{1 8}$ & 104 & S & 104 & 9.5 & 0 \\
\hline $\mathbf{1 9}$ & 95 & S & 95 & 5 & 0 \\
\hline $\mathbf{2 0}$ & 105 & S & 105 & 11 & 3 \\
\hline $\mathbf{2 1}$ & 93 & S & 93 & 3 & 0 \\
\hline $\mathbf{2 2}$ & 101 & S & 101 & 8 & 0 \\
\hline $\mathbf{2 3}$ & 92 & S & 92 & 253 & 0 \\
\hline $\mathbf{2 4}$ & & Sum & & & 0 \\
\hline & & & & 253 & 0 \\
\hline
\end{tabular}

In column B, the code " $R$ " denotes a reference area measurement, and " $S$ " denotes a survey unit measurement. Column $\mathrm{C}$ contains the Adjusted Data. The Adjusted Data are obtained by adding the $\mathrm{DCGL}_{\mathrm{W}}$ to the reference area measurements (see Section 8.4.2, Step 1). The ranks of the adjusted data appear in Column $\mathrm{D}$. They range from 1 to 22 , since there is a total of $11+11$ measurements (see Section 8.4.2, Step 2).

Note that there were two cases of measurements tied with the same value, at 104 and 209. Each tied measurement is always assigned the average of the ranks. Therefore, both measurements at 104, are assigned rank $(9+10) / 2=9.5$ (see Section 8.4.2, Step 3). Also note that the sum of all of the ranks is still $22(22+1) / 2=253$. Checking this value with the formula in Step 5 of Section 8.4.2 is recommended to guard against errors in the rankings. 
Column $\mathrm{E}$ contains only the ranks belonging to the reference area measurements. The total is 187. This is compared with the entry for the critical value of 156 in Table I.4 for $\alpha=0.025$, with $n=11$ and $m=11$. Since the sum of the reference area ranks is greater than the critical value, the null hypothesis (i.e., that the average survey unit concentration exceeds the $\mathrm{DCGL}_{\mathrm{w}}$ ) is rejected.

The analysis for the WRS test is very well suited to the use of a computer spreadsheet. The spreadsheet formulas used for the example above are given in Appendix I.10, Table I.11.

\subsubsection{Class 1 Interior Concrete Survey Unit}

As in the previous example, the gas-flow proportional counter measures total beta-gamma activity (see Appendix $\mathrm{H}$ ) and the measurements are not radionuclide specific. The two-sample nonparametric test is appropriate for the Class 1 interior concrete survey unit because gross betagamma activity contributes to background even though the radionuclide of interest does not appear in background.

Appendix A provides a detailed description of the calculations for the Class 1 interior concrete survey unit.

\subsubsection{Multiple Radionuclides}

The use of the unity rule when there is more than one radionuclide to be considered is discussed in Appendix I.11. An example application appears in Section I.11.4.

\subsection{Evaluating the Results: The Decision}

Once the data and the results of the tests are obtained, the specific steps required to achieve site release depend on the procedures instituted by the governing regulatory agency and site-specific ALARA considerations. The following suggested considerations are for the interpretation of the test results with respect to the release limit established for the site or survey unit. Note that the tests need not be performed in any particular order.

\subsubsection{Elevated Measurement Comparison}

The Elevated Measurement Comparison (EMC) consists of comparing each measurement from the survey unit with the investigation levels discussed in Section 5.5.2.6 and Section 8.2.5. The EMC is performed for both measurements obtained on the systematic-sampling grid and for locations flagged by scanning measurements. Any measurement from the survey unit that is equal to or greater than an investigation level indicates an area of relatively high concentrations that should be investigated-regardless of the outcome of the nonparametric statistical tests. 
Interpretation of Survey Results

The statistical tests may not reject $H_{0}$ when only a very few high measurements are obtained in the survey unit. The use of the EMC against the investigation levels may be viewed as assurance that unusually large measurements will receive proper attention regardless of the outcome of those tests and that any area having the potential for significant dose contributions will be identified. The EMC is intended to flag potential failures in the remediation process. This should not be considered the primary means to identify whether or not a site meets the release criterion.

The derived concentration guideline level for the EMC is:

$$
\dot{D C} G L_{E M C}=A_{m} \times D C G L_{W}
$$

where $A_{m}$ is the area factor for the area of the systematic grid area. Note that $D C G L_{E M C}$ is an $a$ priori limit, established both by the $\mathrm{DCGL}_{\mathrm{W}}$ and by the survey design (i.e., grid spacing and scanning MDC). The true extent of an area of elevated activity can only be determined after performing the survey and taking additional measurements. Upon the completion of further investigation, the a posteriori limit, $D C G L_{E M C}=A_{m} \times D C G L_{W}$, can be established using the value of $A_{m}$ appropriate for the actual area of elevated concentration. The area of elevated activity is generally bordered by concentration measurements below the $\mathrm{DCGL}_{\mathrm{w}}$. An individual elevated measurement on a systematic grid could conceivably represent an area four times as large as the systematic grid area used to define the $\mathrm{DCGL}_{\mathrm{EMC}}$. This is the area bounded by the nearest neighbors of the elevated measurement location. The results of the investigation should show that the appropriate $\mathrm{DCGL}_{\mathrm{EMC}}$ is not exceeded. Area factors are discussed in Section 5.5.2.4.

If measurements above the stated scanning MDC are found by sampling or by direct measurement at locations that were not flagged by the scanning survey, this may indicate that the scanning method did not meet the DQOs.

The preceding discussion primarily concerns Class 1 survey units. Measurements exceeding DCGL $_{\mathrm{W}}$ in Class 2 or Class 3 areas may indicate survey unit mis-classification. Scanning coverage for Class 2 and Class 3 survey units is less stringent than for Class 1 . If the investigation levels of Section 8.2.5 are exceeded, an investigation should: 1) ensure that the area of elevated activity discovered meets the release criterion, and 2) provide reasonable assurance that other undiscovered areas of elevated activity do not exist. If further investigation determines that the survey unit was mis-classified with regard to contamination potential, then a resurvey using the method appropriate for the new survey unit classification may be appropriate. 


\subsubsection{Interpretation of Statistical Test Results}

The result of the statistical test is the decision to reject or not to reject the null hypothesis. Provided that the results of investigations triggered by the EMC were resolved, a rejection of the null hypothesis leads to the decision that the survey unit meets the release criterion. However, estimating the average residual radioactivity in the survey unit may also be necessary so that dose or risk calculations can be made. This estimate is designated $\delta$ (see Appendix D, Section D.6). The average concentration is generally the best estimator for $\delta$ (EPA 1992g).

If residual radioactivity is found in an isolated area of elevated activity-in addition to residual radioactivity distributed relatively uniformly across the survey unit-the unity rule (Section 4.3.3) can be used to ensure that the total dose is within the release criterion:

$$
\frac{\delta}{D C G L_{W}}+\frac{(\text { average concentration in elevated area }-\delta)}{(\text { area factor for elevated area })\left(D C G L_{W}\right)}<1
$$

If there is more than one elevated area, a separate term should be included for each. As an alternative to the unity rule, the dose or risk due to the actual residual radioactivity distribution can be calculated if there is an appropriate exposure pathway model available. Note that these considerations generally apply only to Class 1 survey units, since areas of elevated activity should not exist in Class 2 or Class 3 survey units.

A retrospective power analysis for the test will often be useful, especially when the null hypothesis is not rejected (see Appendix 1.9). When the null hypothesis is not rejected, it may be because it is in fact true, or it may be because the test did not have sufficient power to detect that it is not true. The power of the test will be primarily affected by changes in the actual number of measurements obtained and their standard deviation. An effective survey design will slightly overestimate both the number of measurements and the standard deviation to ensure adequate power. This insures that a survey unit is not subjected to additional remediation simply because the final status survey is not sensitive enough to detect that residual radioactivity is below the guideline level. When the null hypothesis is rejected, the power of the test becomes a somewhat moot question. Nonetheless, even in this case, a retrospective power curve can be a useful diagnostic tool and an aid to designing future surveys.

\subsubsection{If the Survey Unit Fails}

The guidance provided in MARSSIM is fairly explicit concerning the steps that should be taken to show that a survey unit meets release criteria. Less has been said about the procedures that should be used if at any point the survey unit fails. This is primarily because there are many different ways that a survey unit may fail the final status survey. The overall level of residual 
Interpretation of Survey Results

radioactivity may not pass the nonparametric statistical tests. Further investigation following the elevated measurement comparison may show that there is a large enough area with a concentration too high to meet the release criterion. Investigation levels may have caused locations to be flagged during scanning that indicate unexpected levels of residual radioactivity for the survey unit classification. Site-specific information is needed to fully evaluate all of the possible reasons for failure, their causes, and their remedies.

When a survey unit fails to demonstrate compliance with the release criterion, the first step is to review and confirm the data that led to the decision. Once this is done, the DQO Process (Appendix D) can be used to identify and evaluate potential solutions to the problem. The level of residual radioactivity in the survey unit should be determined to help define the problem. Once the problem has been stated the decision concerning the survey unit should be developed into a decision rule. Next, determine the additional data, if any, needed to document that the survey unit demonstrates compliance with the release criterion. Alternatives to resolving the decision statement should be developed for each survey unit that fails the tests. These alternatives are evaluated against the DQOs, and a survey design that meets the objectives of the project is selected.

For example, a Class 2 survey unit passes the nonparametric statistical tests, but has several measurements on the sampling grid that exceed the $\mathrm{DCGL}_{\mathrm{w}}$. This is unexpected in a Class 2 area, and so these measurements are flagged for further investigation. Additional sampling confirms that there are several areas where the concentration exceeds the DCGL ${ }_{\mathrm{W}}$. This indicates that the survey unit was mis-classified. However, the scanning technique that was used was sufficient to detect residual radioactivity at the $\mathrm{DCGL}_{\mathrm{EMC}}$ calculated for the sample grid. No areas exceeding the DCGL ${ }_{\mathrm{EMC}}$ where found. Thus, the only difference between the final status survey actually done, and that which would be required for a Class 1 area, is that the scanning may not have covered $100 \%$ of the survey unit area. In this case, one might simply increase the scan coverage to $100 \%$. Reasons why the survey unit was misclassified should be noted. If no areas exceeding the $\mathrm{DCGL}_{\mathrm{EMC}}$ are found, the survey unit essentially demonstrates compliance with the release criterion as a Class 1 survey unit.

If, in the example above, the scanning technique was not sufficiently sensitive, it may be possible to re-classify as Class 1 only that portion of the survey unit containing the higher measurements. This portion would be re-sampled at the higher measurement density required for a Class 1 survey unit, with the rest of the survey unit remaining Class 2.

A second example might be a Class 1 Survey unit that passes the nonparametric statistical tests and contains some areas that were flagged for investigation during scanning. Further investigation, sampling and analysis indicates one area is truly elevated. This area has a concentration that exceeds the $\mathrm{DCGL}_{\mathrm{W}}$ by a factor greater than the area factor calculated for its actual size. This area is then remediated. Remediation control sampling shows that the residual 
radioactivity was removed, and no other areas were contaminated with removed material. In this case one may simply document the original final status survey, the fact that remediation was performed, the results of the remedial action support survey, and the additional remediation data. In some cases, additional final status survey data may not be needed to demonstrate compliance with the release criterion.

As a last example, consider a Class 1 area which fails the nonparametric statistical tests. Confirmatory data indicates that the average concentration in the survey unit does exceed the $\mathrm{DCGL}_{\mathrm{W}}$ over a majority of its area. This indicates remediation of the entire survey unit is necessary, followed by another final status survey. Reasons for performing a final status survey in a survey unit with significant levels of residual radioactivity should be noted.

These examples are meant to illustrate the actions that may be necessary to secure the release of a survey unit that has failed to meet the release criterion. The DQO Process should be revisited to plan how to attain the original objective, that is to safely release the survey unit by showing that it meets the release criterion. Whatever data are necessary to meet this objective will be in addition to the final status survey data already in hand.

\subsubsection{Removable Activity}

Some regulatory agencies may require that smear samples be taken at indoor grid locations as an indication of removable surface activity. The percentage of removable activity assumed in the exposure pathway models has a great impact on dose calculations. However, measurements of smears are very difficult to interpret quantitatively. Therefore, the results of smear samples should not be used for determining compliance. Rather, they should be used as a diagnostic tool to determine if further investigation is necessary.

\subsection{Documentation}

Documentation of the final status survey should provide a complete and unambiguous record of the radiological status of the survey unit relative to the established DCGLs. In addition, sufficient data and information should be provided to enable an independent evaluation of the results of the survey including repeating measurements at some future time. The documentation should comply with all applicable regulatory requirements. Additional information on documentation is provided in Chapter 3, Chapter 5, Chapter 9, and Appendix N.

Much of the information in the final status report will be available from other decommissioning documents. However, to the extent practicable, this report should be a stand-alone document with minimum information incorporated by reference. This document should describe the 
instrumentation or analytical methods used, how the data were converted to DCGL units, the process of comparing the results to the DCGLs, and the process of determining that the data quality objectives were met.

The results of actions taken as a consequence of individual measurements or sample concentrations in excess of the investigation levels should be reported together with any additional data, remediation, or re-surveys performed to demonstrate that issues concerning potential areas of elevated activity were resolved. The results of the data evaluation using statistical methods to determine if release criteria were satisfied should be described. If criteria were not met or if results indicate a need for additional data, appropriate further actions should be determined by the site management in consultation with the responsible regulatory agency. 


\section{EXAMPLE DATA INTERPRETATION CHECKLIST}

\section{CONVERT DATA TO STANDARD UNITS}

Structure activity in $\mathrm{Bq} / \mathrm{m}^{2}\left(\mathrm{dpm} / 100 \mathrm{~cm}^{2}\right)$
Solid media (soil, etc.) activity in $\mathrm{Bq} / \mathrm{kg}(\mathrm{pCi} / \mathrm{g})$

\section{EVALUATE ELEVATED MEASUREMENTS}

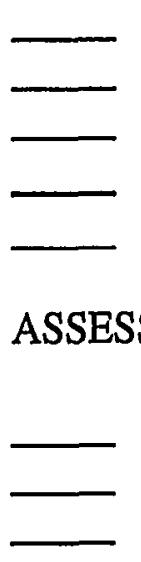

Identify elevated data

Compare data with derived elevated area criteria

Determine need to remediate and/or reinvestigate elevated condition

Compare data with survey unit classification criteria

Determine need to investigate and/or reclassify

\section{ASSESS SURVEY DATA}

Review DQOs and survey design

Verify that data of adequate quantity and quality were obtained

Perform preliminary assessments (graphical methods) for unusual or suspicious trends or results-investigate further as appropriate

\section{PERFORM STATISTICAL TESTS}

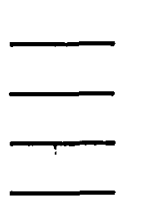

Select appropriate tests for category of contaminant

\section{Conduct tests}

Compare test results against hypotheses

Confirm power level of tests

\section{COMPARE RESULTS TO GUIDELINES}

Determine average or median concentrations

Confirm that residual activity satisfies guidelines

\section{COMPARE RESULTS WITH DQOs*}

Determine whether all DQOs are satisfied

Explain/describe deviations from design-basis DQOs

\footnotetext{
* ALARA may be included in the DQOs.
} 


\section{QUALITY ASSURANCE AND QUALITY CONTROL}

\subsection{Introduction}

The goal of quality assurance and quality control $(\mathrm{QA} / \mathrm{QC})$ is to identify and implement sampling and analytical methodologies which limit the introduction of error into analytical data. For MARSSIM data collection and evaluation, a system is needed to ensure that radiation surveys produce results that are of the type and quality needed and expected for their intended use. A quality system is a management system that describes the elements necessary to plan, implement, and assess the effectiveness of QA/QC activities. This system establishes many functions including: quality management policies and guidelines for the development of organization- and project-specific quality plans; criteria and guidelines for assessing data quality; assessments to ascertain effectiveness of QA/QC implementation; and training programs related to QA/QC implementation. A quality system ensures that MARSSIM decisions will be supported by sufficient data of adequate quality and usability for their intended purpose, and further ensures that such data are authentic, appropriately documented, and technically defensible.

Any organization collecting and evaluating data for a particular program must be concerned with the quality of results. The organization must have results that: meet a well-defined need, use, or purpose; comply with program requirements; and reflect consideration of cost and economics. To meet the objective, the organization should control the technical, administrative, and human factors affecting the quality of results. Control should be oriented toward the appraisal, reduction, elimination, and prevention of deficiencies that affect quality.

Quality systems already exist for many organizations involved in the use of radioactive materials. There are self-imposed internal quality management systems (e.g., DOE) or there are systems required by regulation by another entity (e.g., NRC) which require a quality system as a condition of the operating license. ${ }^{1}$ These systems are typically called Quality Assurance Programs. An organization may also obtain services from another organization that already has a quality system in place. When developing an organization-specific quality system, there is no need to develop new quality management systems, to the extent that a facility's current Quality Assurance Program can be used. Standard ANSI/ASQC E4-1994 (ASQC 1995) provides national consensus quality standards for environmental programs. It addresses both quality systems and the collection and evaluation of environmental data. Annex B of ANSI/ASQC E4-1994

\footnotetext{
${ }^{1}$ Numerous quality assurance and quality control $(Q A / Q C)$ requirements and guidance documents have been applied to environmental programs. Until now, each Federal agency has developed or chosen QAVCC requirements to fit its particular mission and needs. Some of these requirements include DOE Order 5700.6c (DOE 1991c); EPA QA/R-2 (EPA 1994f); EPA QA/R-5 (EPA 1994c); 10 CFR 50, App. B; NUREG-1293, Rev. 1 (NRC 1991); Reg Guide 4.15 (NRC 1979); and MIL-Q-9858A (DOD 1963). In addition, there are several consensus standards for QA/AC, including ASME NQA-1 (ASME 1989), and ISO 9000/ASQC Q9000 series (ISO 1987). ANSJ/ASQC E41994 (ASQC 1995) is a consensus standard specifically for environmental data collection.
} 
Quality Assurance and Quality Control

(ASQC 1995) and Appendix K of MARSSIM illustrate how existing quality system documents compare with organization- and project-specific environmental quality system documents.

Table 9.1 illustrates elements of a quality system as they relate to the Data Life Cycle. Applying a quality system to a project is typically done in three phases as described in Section 2.3: 1) the planning phase where the Data Quality Objectives (DQOs) are developed following the process described in Appendix D and documented in the Quality Assurance Project Plan (QAPP), ${ }^{2} 2$ ) the implementation phase involving the collection of environmental data in accordance with approved procedures and protocols, and 3) the assessment phase including the verification and validation of survey results as discussed in Section 9.3 and the evaluation of the environmental data using Data Quality Assessment (DQA) as discussed in Section 8.2 and Appendix E. Detailed guidance on quality systems is not provided in MARSSIM because a quality system should be in place and functioning prior to beginning environmental data collection activities.

Table 9.1 The Elements of a Quality System Related to the Data Life Cycle

\begin{tabular}{||l|l||}
\hline \hline Data Life Cycle & Quality System Elements \\
\hline Planning & $\begin{array}{l}\text { Data Quality Objectives (DQOs) } \\
\text { Quality Assurance Project Plans (QAPPs) } \\
\text { Standard Operating Procedures (SOPs) }\end{array}$ \\
\hline Implementation & $\begin{array}{l}\text { QAPPs } \\
\text { SOPs } \\
\text { Data collection } \\
\text { Assessments and audits }\end{array}$ \\
\hline Assessment & $\begin{array}{l}\text { Data validation and verification } \\
\text { Data Quality Assessment (DQA) }\end{array}$ \\
\hline
\end{tabular}

A graded approach bases the level of controls on the intended use of the results and the degree of confidence needed in their quality. Applying a graded approach may mean that some organizations (e.g., those using the simplified procedures in Appendix B) make use of existing plans and procedures to conduct surveys. For many other organizations, the need for cleanup and restoration of contaminated facilities may create the need for one or more QAPPs suitable to the special needs of environmental data gathering, especially as it relates to the demonstration of compliance with regulatory requirements. There may even be a need to update or revise an existing quality management system.

\footnotetext{
2 The quality assurance project plan is sometimes abbreviated QAPjP. MARSSIM adopts the terminology and abbreviations used in ANSI/ASQC E4-1994 (ASQC 1995) and EPA QA/R-5 (EPA 1994c).
} 


\subsection{Development of a Quality Assurance Project Plan}

The Quality Assurance Project Plan (QAPP) ${ }^{3}$ is the critical planning document for any environmental data collection operation because it documents how $\mathrm{QA} / \mathrm{QC}$ activities will be implemented during the life cycle of a project (EPA 1997). The QAPP is the blueprint for identifying how the quality system of the organization performing the work is reflected in a particular project and in associated technical goals. This section provides information on how to develop a QAPP based on the DQO process. The results of the DQO process provide key inputs to the QAPP and will largely determine the level of detail in the QAPP.

The consensus standard ANSI/ASQC E4-1994 (ASQC 1995) describes the minimum set of quality elements required to conduct programs involving environmental data collection and evaluation. Table 9.2 lists the quality elements for collection and evaluation of environmental data from ANSI/ASQC E4-1994. These quality elements are provided as examples that should be addressed when developing a QAPP. This table also includes references for obtaining additional information on each of these quality elements. Many of these elements will be addressed in existing documents, such as the organization's Quality Assurance Program or Quality Management Plan. Each of these quality elements should be considered during survey planning to determine the degree to which they will be addressed in the QAPP. Additional quality elements may need to be added to this list as a result of organizational preferences or requirements of Federal and State regulatory authorities. For example, safety and health or public participation may be included as elements to be considered during the development of a QAPP.

The QAPP should be developed using a graded approach as discussed in Section 9.1. In other words, existing procedures and survey designs can be included by reference. This is especially useful for sites using a simplified survey design process (e.g., surveys designed using Appendix B).

A QAPP should be developed to document the results of the planning phase of the Data Life Cycle (see Section 2.3). The level of detail provided in the QAPP for relevant quality elements is determined using the DQO process during survey planning activities. Information that is already provided in existing documents does not need to be repeated in the QAPP, and can be included by reference (EPA 1997).

${ }^{3}$ MARSSIM uses the term Quality Assurance Project Plan to describe a single document that incorporates all of the elements of the survey design. This term is consistent with ANSI/ASQC E4-1994 (ASQC 1995) and EPA guidance (EPA 1994c, EPA 1997), and is recommended to promote consistency. The use of the term QAPP in MARSSIM does not exclude the use of other terms (e.g., Decommissioning Plan, Sampling and Analysis Plan, Field Sampling Plan) to describe survey planning documentation as long as the information in the documentation supports the objectives of the survey. 
Table 9.2 Examples of QAPP Elements for Site Surveys and Investigations

\begin{tabular}{|c|c|c|}
\hline QAPP Element & 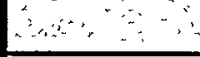 & Information Source \\
\hline $\begin{array}{l}\text { Planning and } \\
\text { Scoping (reference } \\
\text { the QA Manual for } \\
\text { information on the } \\
\text { quality system) }\end{array}$ & $\begin{array}{l}\text { ASQC } 1995 \\
\text { EPA } 1994 \mathrm{c} \\
\text { EPA } 1997 \\
\text { NRC } 1997 \mathrm{c} \\
\text { EPA } 1993 \mathrm{~d}\end{array}$ & $\begin{array}{l}\text { Part A, Sections } 2.1 \text { and } 2.7 ; \text { Part B, Section } 3.1 \\
\text { Sections A4, A5, A6 and A7 } \\
\text { Chapter W, Sections A4, A5, A6, and A7 } \\
\text { Chapter 14 } \\
\text { Project Objectives }\end{array}$ \\
\hline $\begin{array}{l}\text { Design of Data } \\
\text { Collection } \\
\text { Operations } \\
\text { (including training) }\end{array}$ & $\begin{array}{l}\text { ASQC } 1995 \\
\text { EPA } 1994 \mathrm{c} \\
\text { EPA } 1997 \\
\text { EPA 1993d }\end{array}$ & $\begin{array}{l}\text { Part A, Section 2.3; Part B, Section } 3.2 \\
\text { Sections A9 and B1 } \\
\text { Chapter III, Sections A9 and B1 } \\
\text { Sampling Design }\end{array}$ \\
\hline $\begin{array}{l}\text { Implementation of } \\
\text { Planned Operations } \\
\text { (including } \\
\text { documents and } \\
\text { records) }\end{array}$ & $\begin{array}{l}\text { ASQC } 1995 \\
\text { EPA } 1994 \mathrm{c} \\
\text { EPA } 1997 \\
\text { NRC } 1997 \mathrm{c} \\
\text { EPA 1993d }\end{array}$ & $\begin{array}{l}\text { Part A, Section 2.8; Part B, Section } 3.3 \\
\text { Sections A1, A2, A3, B2, B3, B4, B5, B6, B7, B8, B9, and B10 } \\
\text { Chapter III, Sections A1, A2, A3, B2, B3, B4, B5, B6, B7, B8, B9, and B10 } \\
\text { Chapter } 5 \\
\text { Sampling Execution, Sample Analysis }\end{array}$ \\
\hline $\begin{array}{l}\text { Assessment and } \\
\text { Response }\end{array}$ & $\begin{array}{l}\text { ASQC } 1995 \\
\text { EPA } 1994 \mathrm{c} \\
\text { EPA } 1997 \\
\text { EPA 1993d }\end{array}$ & $\begin{array}{l}\text { Part A, Section 2.9, Part B, Section } 3.4 \\
\text { Sections C1 and C2 } \\
\text { Chapter II, Sections C1 and C2 } \\
\text { Exhibit 3, Reference Box } 3\end{array}$ \\
\hline $\begin{array}{l}\text { Assessment and } \\
\text { Verification of } \\
\text { Data Usability }\end{array}$ & $\begin{array}{l}\text { ASQC } 1995 \\
\text { EPA } 1994 \mathrm{c} \\
\text { EPA } 1997 \\
\text { NRC } 1997 \mathrm{c} \\
\text { EPA } 1993 \mathrm{~d}\end{array}$ & $\begin{array}{l}\text { Part B, Section } 3.5 \\
\text { Sections D1, D2, and D3 } \\
\text { Chapter III, Sections D1, D2, and D3 } \\
\text { Chapter 20, Appendix J, Appendix Q } \\
\text { Assessment of Data Quality }\end{array}$ \\
\hline
\end{tabular}

For example, the quality system description, personnel qualifications and requirements, and Standard Operating Procedures (SOPs) for the laboratory analysis of samples may simply be references to existing documents (e.g., Quality Management Plan, Laboratory Procedure Manual). SOPs for performing direct measurements with a specific instrument may be attached to the QAPP because this information may not be readily available from other sources.

There is no particular format recommended for developing a QAPP. Figure 9.1 provides an example of a QAPP format presented in EPA QA/R-5 (EPA 1994c). Appendix K compares the quality elements presented in this example to the quality elements found in EPA QAMS-005-80 (EPA 1980d), ASME NQA-1 (ASME 1989), DOE Order 5700.6c (DOE 1991c), MIL-Q-9858A (DOD 1963), and ISO 9000 (ISO 1987). 


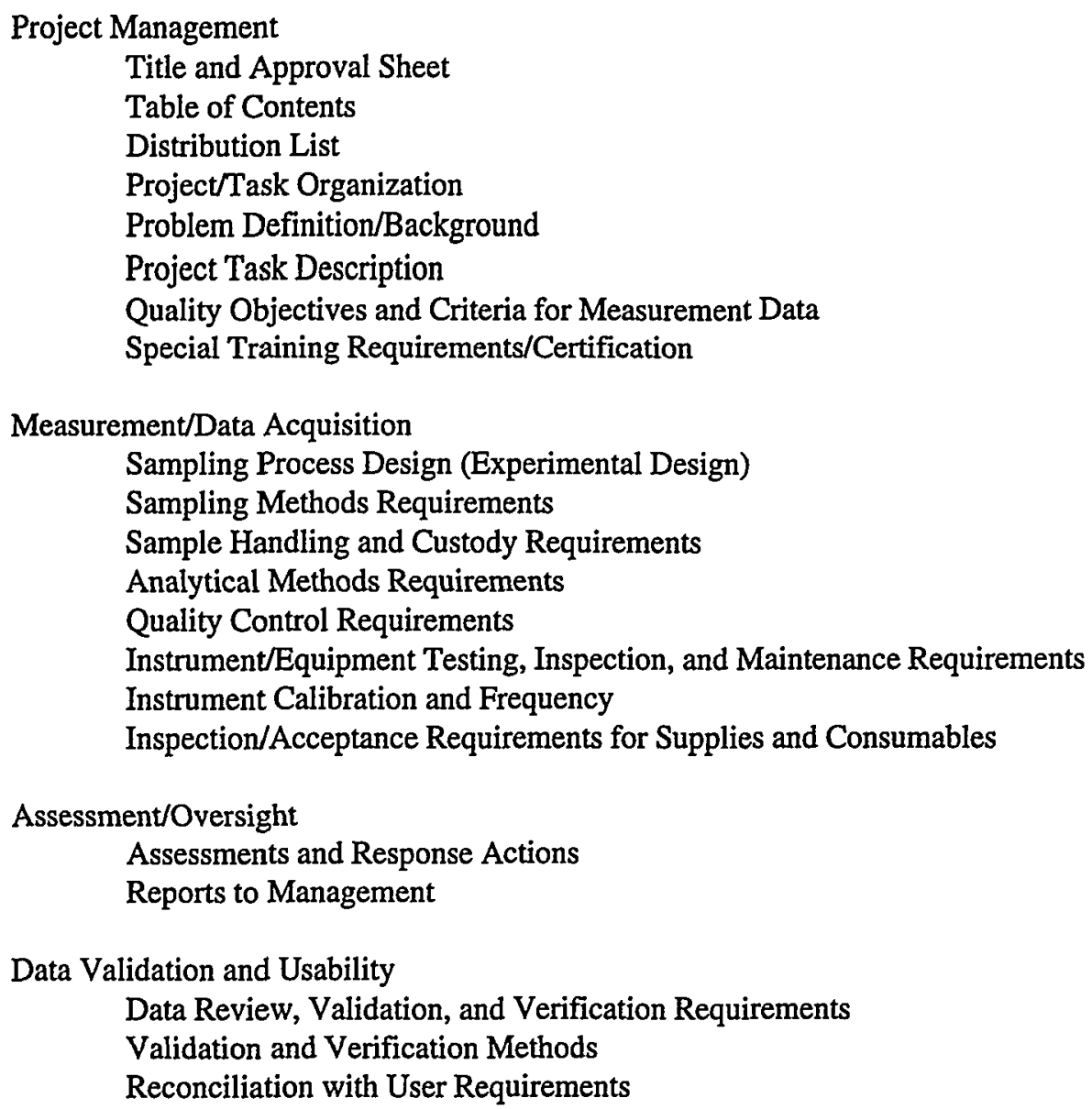

Data Validation and Usability

Data Review, Validation, and Verification Requirements

Validation and Verification Methods

Reconciliation with User Requirements

\section{Figure 9.1 Example of a QAPP Format}

\subsection{Data Assessment}

Assessment of environmental data is used to evaluate whether the data meet the objectives of the survey, and whether the data are sufficient to determine compliance with the DCGL (EPA 1992a, 1992b, 1996a). The assessment phase of the Data Life Cycle consists of three phases: data verification, data validation, and Data Quality Assessment (DQA). This section provides guidance on verifying and validating data collected during a final status survey designed to demonstrate compliance with a dose- or risk-based regulation. Guidance on DQA is provided in Chapter 8 and Appendix E. As with all components of a successful survey, the level of effort associated with the assessment of survey data should be consistent with the objectives of the survey (i.e., a graded approach). 
Quality Assurance and Quality Control

\subsubsection{Data Verification}

Data verification ensures that the requirements stated in the planning documents (e.g., Quality Assurance Project Plan, Standard Operating Procedures) are implemented as prescribed. This means that deficiencies or problems that occur during implementation should be documented and reported. This also means that activities performed during the implementation phase are assessed regularly with findings documented and reported to management. Corrective actions undertaken should be reviewed for adequacy and appropriateness and documented in response to the findings. Data verification activities should be planned and documented in the QAPP. These assessments may include but are not limited to inspections, QC checks, surveillance, technical reviews, performance evaluations, and audits.

To ensure that conditions requiring corrective actions are identified and addressed promptly, data verification activities should be initiated as part of data collection during the implementation phase of the survey. The performance of tasks by personnel is generally compared to a prescribed method documented in the SOPs, and is generally assessed using inspections, surveillance, or audits. Self-assessments and independent assessments may be planned, scheduled, and performed as part of the survey. Self-assessment also means that personnel doing work should document and report deficiencies or problems that they encounter to their supervisors or management.

The performance of equipment such as radiation detectors or measurement systems such as an instrument and human operator can be monitored using control charts. Control charts are used to record the results of quantitative QC checks such as background and daily calibration or performance checks. Control charts document instrument and measurement system performance on a regular basis and identify conditions requiring corrective actions on a real time basis. Control charts are especially useful for surveys that extend over a significant period of time (e.g., weeks instead of days) and for equipment that is owned by a company that is frequently used to collect survey data. Surveys that are accomplished in one or two days and use rented instruments may not benefit significantly from the preparation and use of control charts. The use of control charts is usually documented in the SOPs.

A technical review is an independent assessment that provides an in-depth analysis and evaluation of documents, activities, material, data, or items that require technical verification to ensure that established requirements are satisfied (ASQC 1995). A technical review typically requires a significant effort in time and resources and may not be necessary for all surveys. A complex survey using a combination of scanning, direct measurements, and sampling for multiple survey units is more likely to benefit from a detailed technical review than a simple survey design calling for relatively few measurements using one or two measurement techniques for a single survey unit. 
Quality Assurance and Quality Control

\subsubsection{Data Validation}

Data validation activities ensure that the results of data collection activities support the objectives of the survey as documented in the QAPP, or support a determination that these objectives should be modified. Data Usability is the process of ensuring or determining whether the quality of the data produced meets the intended use of the data (EPA 1992a, EPA 1997). Data verification compares the collected data with the prescribed activities documented in the SOPs; data validation compares the collected data to the DQOs documented in the QAPP. Corrective actions may improve data quality and reduce uncertainty, and may eliminate the need to qualify or reject data.

\subsubsection{Data Qualifiers}

Qualified data are any data that have been modified or adjusted as part of statistical or mathematical evaluation, data validation, or data verification operations (ASQC 1995). Data may be qualified or rejected as a result of data validation or data verification activities. Data qualifier codes or flags are often used to identify data that has been qualified. Any scheme used should be fully explained in the QAPP and survey documentation. The following are examples of data qualifier codes or flags derived from national qualifiers assigned to results in the contract laboratory program (CLP; EPA 1994g).

$\mathrm{U}$ or $\angle \mathrm{MDC}$ The radionuclide of interest was analyzed for, but the radionuclide concentration was below the minimum detectable concentration (MDC). Section 2.3.5 recommends that the actual result of the analysis be reported so this qualifier would inform the reader that the result reported is also below the MDC.

The associated value reported is a modified, adjusted, or estimated quantity. This qualifier might be used to identify results based on surrogate measurements (see Section 4.3.2) or gross activity measurements (e.g., gross alpha, gross beta). The implication of this qualifier is that the estimate may be inaccurate or imprecise which might mean the result is inappropriate for the statistical evaluation of the results. Surrogate measurements that are not inaccurate or imprecise may or may not be associated with this qualifier. It is recommended that the potential uncertainties associated with surrogate or gross measurements be quantified and included with the results.

$\mathrm{R} \quad$ The associated value reported is unusable. The result is rejected due to serious analytical deficiencies or quality control results. These data would be rejected because they do not meet the data quality objectives of the survey.

The associated value reported was determined to be an outlier. 
Quality Assurance and Quality Control

\subsubsection{Data Validation Descriptors}

Data validation is often defined by six data descriptors. These six data descriptors are summarized in Table 9.3 and discussed in detail in Appendix N. The decision maker or reviewer examines the data, documentation, and reports for each of the six data descriptors to determine if performance is within the limits specified in the DQOs during planning. The data validation process for each data descriptor should be conducted according to procedures documented in the QAPP.

Table 9.3 Suggested Content or Consideration, Impact if Not Met,
and Corrective Actions for Data Descriptors

\begin{tabular}{|c|c|c|c|}
\hline Data Descriptor & $\begin{array}{l}\text { Suggested Content } \\
\text { or Consideration }\end{array}$ & Impact if Not Met & Corrective Action \\
\hline $\begin{array}{l}\text { Reports to } \\
\text { Decision Maker }\end{array}$ & $\begin{array}{l}\text { - Site description } \\
\text { - Survey design with } \\
\text { measurement locations } \\
\text { - Analytical method and detection } \\
\text { limit } \\
\text { - Detection limits (MDCs) } \\
\text { - Background radiation data } \\
\text { - Results on per measurement } \\
\text { basis, qualified for analytical } \\
\text { limitations } \\
\text { - Field conditions for media and } \\
\text { environment } \\
\text { - Preliminary reports } \\
\text { - Meteorological data, if indicated } \\
\text { by DQOs } \\
\text { - Field reports }\end{array}$ & $\begin{array}{l}\text { - Unable to perform a } \\
\text { quantitative radiation } \\
\text { survey and site } \\
\text { investigation }\end{array}$ & $\begin{array}{l}\text { - Request missing } \\
\text { information } \\
\text { - Perform qualitative or } \\
\text { semi-quantitative site } \\
\text { investigation }\end{array}$ \\
\hline Documentation & $\begin{array}{l}\text { - Chain-of-custody records } \\
\text { - SOPs } \\
\text { - Field and analytical records } \\
\text { - Measurement results related to } \\
\text { geographic location }\end{array}$ & $\begin{array}{l}\text { - Unable to identify } \\
\text { appropriate concentration } \\
\text { for survey unit } \\
\text { measurements } \\
\text { - Unable to have } \\
\text { adequate assurance of } \\
\text { measurement results }\end{array}$ & $\begin{array}{l}\text { - Request that locations be } \\
\text { identified } \\
\text { - Resurveying or } \\
\text { resampling } \\
\text { - Correct deficiencies }\end{array}$ \\
\hline Data Sources & $\begin{array}{l}\text { - Historical data used meets } \\
\text { DQO's }\end{array}$ & $\begin{array}{l}\text { Potential for Type I } \\
\text { and Type II decision } \\
\text { errors } \\
\text { - Lower confidence of } \\
\text { data quality }\end{array}$ & $\begin{array}{l}\text { - Resurveying, resampling, } \\
\text { or reanalysis for unsuitable } \\
\text { or questionable } \\
\text { measurements }\end{array}$ \\
\hline
\end{tabular}


Table 9.3 (continued)

\begin{tabular}{|c|c|c|c|}
\hline Data Descriptor & $\begin{array}{l}\text { Suggested Content } \\
\text { "or Consideration }\end{array}$ & Impact if Not Met & Corrective Action \\
\hline $\begin{array}{l}\text { Analytical } \\
\text { Method and } \\
\text { Detection Limit }\end{array}$ & $\begin{array}{l}\text { - Routine methods used to } \\
\text { analyze radionuclides of potential } \\
\text { concern }\end{array}$ & $\begin{array}{l}\text { - Unquantified } \\
\text { precision and accuracy } \\
\text { - Potential for Type I } \\
\text { and Type II decision } \\
\text { errors }\end{array}$ & $\begin{array}{l}\text { - Reanalysis } \\
\text { - Resurveying, resampling, } \\
\text { or reanalysis } \\
\text { - Documented statements } \\
\text { of limitation }\end{array}$ \\
\hline Data Review & $\begin{array}{l}\text { - Defined level of data review for } \\
\text { all data }\end{array}$ & $\begin{array}{l}\text { - Potential for Type I } \\
\text { and Type II decision } \\
\text { errors } \\
\text { - Increased variability } \\
\text { and bias due to analytical } \\
\text { process, calculation } \\
\text { errors, or transcription } \\
\text { errors }\end{array}$ & - Perform data review \\
\hline $\begin{array}{l}\text { Data Quality } \\
\text { Indicators }\end{array}$ & $\begin{array}{l}\text { - Surveying and sampling } \\
\text { variability identified for each } \\
\text { radionuclide } \\
\text { - QC measurements to identify } \\
\text { and quantify precision and accuracy } \\
\text { - Surveying, sampling, and } \\
\text { analytical precision and accuracy } \\
\text { quantified }\end{array}$ & $\begin{array}{l}\text { Unable to quantify } \\
\text { levels for uncertainty } \\
\text { - Potential for Type I } \\
\text { and Type II decision } \\
\text { errors }\end{array}$ & $\begin{array}{l}\text { - Resurveying or } \\
\text { resampling } \\
\text { - Perform qualitative site } \\
\text { investigation } \\
\text { - Documented discussion } \\
\text { of potential limitations }\end{array}$ \\
\hline
\end{tabular}

Data collected should meet performance objectives for each data descriptor. If they do not, deviations should be noted and any necessary corrective action performed. Corrective action should be taken to improve data usability. when performance fails to meet objectives. 
$\ldots$ 


\section{REFERENCES, REGULATIONS, \& U. S. CODE}

\section{General References}

42 FR 60956. November 30, 1977. "Persons Exposed to Transuranium Elements in the Environment," Federal Register

46 FR 52601. October 1981. "Disposal or On-site Storage of Thorium or Uranium Wastes

From Past Operations," NRC Branch Technical Position, Federal Register

57 FR 13389. April 16, 1992. "Action Plan to Ensure Timely Cleanup of Site Decommissioning Management Plan Sites," Federal Register

57 FR 6136. February 20, 1992. "Order Establishing Criteria and Schedule for Decommissioning the Bloomberg Site." Federal Register

Agency for Toxic Substances and Disease Registry (ATSDR). 1992. ATSDR - Public Health Assessment Guidance Manual. ATSDR, Atlanta, GA. (PB92-147164)

Altshuler, B., and B. Pasternak. 1963. Statistical Measures of the Lower Limit of Detection of a Radioactivity Counter. Health Physics 9:293-298.

American National Standards Institute (ANSI). 1996a. Performance Criteria for Radiobioassay, N13.30.

American National Standards Institute (ANSI). 1996b. Radiation Protection Instrumentation Test and Calibration - Portable Survey Instruments, N323A.

American Nuclear Society (ANS). 1994. Mobile In Situ Gamma-Ray Spectroscopy System. Transactions of the American Nuclear Society 70:47.

American Nuclear Society (ANS). 1994. Large Area Proportional Counter for In Situ Transuranic Measurements. Transactions of the American Nuclear Society 70:47.

American Public Health Association (APHA). 1995. Standard Methods for the Examination of Water and Wastewater. $19^{\text {th }}$ Edition, APHA, Washington, DC.

American Society of Mechanical Engineers (ASME). 1989. Quality Assurance Program Requirements for Nuclear Facilities. NQA-1, ASME, New York, New York.

American Society for Quality Control (ASQC). 1995. Specifications and Guidelines for Quality Systems for Environmental Data Collection and Environmental Technology Programs. ANSI/ASQC E4-1994, ASQC, Milwaukee, Wisconsin. 
References

American Society of Testing and Materials (ASTM). 1993. Reducing Samples of Aggregate to Testing Size, C702-93. ASTM, West Conshohocken, PA.

American Society of Testing and Materials (ASTM). 1995. Soil Sample preparation for the Determination of Radionuclides, C999-90 (1995) e1. ASTM, West Conshohocken, PA.

American Society of Testing and Materials (ASTM). 1997. Annual Book of ASTM Standards, Water and Environmental Technology: Environmental Assessment; Hazardous Substances and Oil Spill Responses; Waste Management; Environmental Risk Assessment. Volume 11.04, ASTM, West Conshohocken, PA.

Bernabee, R., D. Percival, and D. Martin. 1980. Fractionation of Radionuclides in Liquid Samples from Nuclear Power Facilities. Health Physics 39:57-67.

Berven, B. A., W. D. Cottrell, R. W. Leggett, C. A. Little, T. E. Myrick, W. A. Goldsmith, and F. F. Haywood. 1986. Generic Radiological Characterization Protocol for Surveys Conducted for DOE Remedial Action Programs. ORNL/TM-7850, Martin Marietta Energy Systems, Inc., Oak Ridge National Laboratory. (DE86-011747)

Berven, B. A., W. D. Cottrell, R. W. Leggett, C. A. Little, T. E. Myrick, W. A. Goldsmith, and F. F. Haywood. 1987. Procedures Manual for the ORNL Radiological Survey Activities (RASA) Program. ORNL/TM-8600, Martin Marietta Energy Systems, Inc., Oak Ridge National Laboratory. (DE87-009089)

Brodsky, A. 1992. "Exact Calculation of Probabilities of False Positives and False Negatives for Low Background Counting," Health Physics 63(2):198-204.

Committee on the Biological Effects of Ionizing Radiations (BEIR). 1990. Health Effects of Exposure to Low Levels of Ionizing Radiation. BEIR V. National Academy of Sciences, National Academy Press, Washington D.C.

Conover. W. J. 1980. Practical Nonparametric Statistics, Second Edition. John Wiley \& Sons, New York.

Currie, L.A. 1968. Limits for Qualitative Detection and Quantitative Determination. Analytical Chemistry 40(3):586-693.

Davidson, J.R. 1995. ELIPGRID-PC: Upgraded Version. ORNL/TM-13103. Oak Ridge National Laboratory. 
Department of the Army. 1993. USAEHA Environmental Sampling Guide. Technical Guide No. 155, U.S. Army Environmental Hygiene Agency, Aberdeen Proving Ground, MD.

Department of Defense (DOD). 1963. Quality Program Requirements. Military Specification MIL-Q-9858A. DOD, Washington, D.C.

Department of Energy (DOE). 1982. Radiological and Environmental Sciences Laboratory Procedures, Analytical Chemistry Branch Procedures Manual. DOE/DDO-12096, DOE, Idaho Operations Office, Idaho Falls.

Department of Energy (DOE). 1985. Formerly Utilized Sites Remedial Action Program, Verification and Certification Protocol - Supplement No. 2 to the FUSRAP Summary Protocol, Revision 1. DOE, Division of Facility and Site Decommissioning Projects, Office of Nuclear Energy.

Department of Energy (DOE). 1986a. Formerly Utilized Sites Remedial Action Program, Summary Protocol, Identification - Characterization - Designation - Remedial Action Certification. DOE, Division of Facility and Site Decommissioning Projects, Office of Nuclear Energy.

Department of Energy (DOE). 1986b. Formerly Utilized Sites Remedial Action Program, Designation/Elimination Protocol Supplement No. 1 to the FUSRAP Summary Protocol. DOE, Division of Facility and Site Decommissioning Projects, Office of Nuclear Energy.

Department of Energy (DOE). 1987. The Environmental Survey Manual, Appendix A - Criteria for Data Evaluation. DOE/EH-0053, DOE, Office of Environmental Audit, Washington, D.C. (DE88-000254)

Department of Energy (DOE). 1990a. Environmental Protection, Safety, and Health Protection Information Reporting Requirements. DOE Order 5484.1, Change 7, DOE, Washington, DC.

Department of Energy (DOE). 1990b. EML Procedures Manual, HASL-300, 27th ed. HASL300-ED.27-Vol 1, DOE, Environmental Measurements Laboratory, New York. (DE91010178)

Department of Energy (DOE). 1991a. Environmental Regulatory Guide for Radiological Effluent Monitoring and Environmental Surveillance. DOE/EH-0173T, DOE, Washington, D.C. (DE91-013607) 
References

Department of Energy (DOE). 1991b. Safety and Health, Environmental Regulatory Guide for Radiological Effluent Monitoring and Environmental Surveillance. DOE/EH-0173, DOE, Assistant Secretary for Environment.

Department of Energy (DOE). 1991c. Quality Assurance. U.S. DOE Order 5700.6c.

Department of Energy (DOE). 1992. Environmental Implementation Guide for Radiological Survey Procedures Manual, DOE Report for Comment. Martin Marietta Energy Systems, Oak Ridge National Laboratory.

Department of Energy (DOE). 1994. Decommissioning Handbook. DOE/EM-0142P, DOE, Washington, D.C.. (DE94-008981)

Department of Energy (DOE). 1995. DOE Methods for Evaluating Environmental and Waste Management Samples. DOE/EM-0089T, Rev. 2. Prepared for the U.S. Department of Energy by Pacific Northwest Laboratory, Richland, WA.

Department of Energy (DOE). 1996. Statistical and Cost-Benefit Enhancements to the DQO Process for Characterization Decisions. DOE/EM-0316, U.S. Department of Energy, Washington, D.C.

Environmental Protection Agency (EPA). 1974. Methods for Chemical Analysis of Water and Wastes. EPA 625/6-74-003, (revised), EPA, Washington, D.C.

Environmental Protection Agency (EPA). 1979. Radiochemical Analytical Procedures for Analysis of Environmental Samples, EMSL-LV-0539-17, EPA, Office of Radiation and Indoor Air, Las Vegas. (EMSL-LV-0539-17)

Environmental Protection Agency (EPA). 1980a. Prescribed Procedures for Measurement of Radioactivity in Drinking Water. EPA-600/4-80-032, EPA, Environmental Monitoring and Support Laboratory, Cincinnati, Ohio. (PB80-224744)

Environmental Protection Agency (EPA). 1980b. Samplers and Sampling Procedures for Hazardous Waste Streams. EPA-600/2-80-018, EPA, Washington, D.C. (PB80-135353)

Environmental Protection Agency (EPA). 1980c. Upgrading Environmental Radiation Data, Health Physics Society Committee Report HPSR-1. EPA 520/1-80-012, EPA, Office of Radiation Programs, Washington, D.C. (PB81-100364) 
Environmental Protection Agency (EPA). 1980d. Interim Guidelines and Specifications for Preparing Quality Assurance Project Plans. QAMS-005/80, EPA, Washington, D.C.

Environmental Protection Agency (EPA). 1982. Handbook for Sampling and Sample Preservation of Water and Wastewater. EPA 600/4-82-029, EPA, Washington, D.C. (PB83-124503)

Environmental Protection Agency (EPA). 1983. Interim Guidelines and Specifications for Preparing Quality Assurance Project Plans. EPA, Washington, D.C. (PB83-170514)

Environmental Protection Agency (EPA). 1984a. Eastern Environmental Radiation Facility: Radiochemical Procedures Manual. EPA 520/5-84-006, EPA, Office of Radiation Programs, Eastern Environmental Radiation Facility [renamed the National Air and Radiation Environmental Laboratory (NAREL) in 1989], Montgomery, Alabama. (PB84215581)

Environmental Protection Agency (EPA). 1984b. Soil Sampling Quality Assurance User's Guide. EPA 600/4-84-0043, EPA, Washington, D.C. (PB84-198621)

Environmental Protection Agency (EPA). 1986. Preliminary Assessment Petition. Publication 9200.5-301FS, EPA, Office of Emergency and Remedial Response, Washington, D.C.

Environmental Protection Agency (EPA). 1987a. A Compendium of Superfund Field Operations Methods. EPA 540/P-87-001, EPA, Office of Emergency and Remedial Response, Washington, D.C. (PB88-181557)

Environmental Protection Agency (EPA). 1987b. Data Quality Objectives for Remedial Response Activities-Development Process. EPA/540/G-87/003, OSWER Directive 9355.07B, EPA, Washington, D.C. (PB88-131370)

Environmental Protection Agency (EPA). 1987c. DQOs for Remedial Response ActivitiesExample Scenario: RI/FS Activities at a Site with Contaminated Soils and Groundwater. EPA/540/G-87/004. OSWER Directive 9355.07B, EPA, Washington, D.C. (PB88131388)

Environmental Protection Agency (EPA). 1987d. Entry and Continued Access Under CERCLA. EPA, Washington, D.C. (PB91-138867) 
References

Environmental Protection Agency (EPA). 1988a. Field Screening Methods Catalog - User's Guide. EPA 540/2-88-005, EPA, Office of Emergency and Remedial Response, Washington, D.C. (PB89-134159)

Environmental Protection Agency (EPA). 1988b. Guidance for Conducting Remedial Investigations and Feasibility Studies Under CERCLA, Interim Final.. EPA/540/G89/004, OSWER Directive 9355.3-01, EPA, Washington, D.C. (PB 89-184626)

Environmental Protection Agency (EPA). 1988c. Superfund Removal Procedures. OSWER Directive 9360.0-03B, EPA, Office of Emergency and Remedial Response, Washington, D.C.

Environmental Protection Agency (EPA). 1989a. Methods for Evaluating the Attainment of Cleanup Standards, Volume 1: Soils and Solid Media. EPA-230/02-89-042, EPA, Office of Policy, Planning, and Evaluation, Washington, D.C. (PB89-234959)

Environmental Protection Agency (EPA). 1989b. Procedures for Completion And Deletion of National Priorities List Sites and (Update); Final Report. OSWER Directive 9320.2-03B EPA, Office of Solid Waste and Emergency Response, Washington, D.C. (PB90-274556)

Environmental Protection Agency (EPA). 1989c. Background Information Document on Procedures Approved for Demonstrating Compliance with 40 CFR Part 61, Subpart I. EPA/520/1-89-001, EPA, Washington, D.C.

Environmental Protection Agency (EPA). 1990. A Rationale for the Assessment of Errors in the Sampling of Soils. EPA 600/4-90/013.

Environmental Protection Agency (EPA). 1991a. Description and Sampling of Contaminated Soils. EPA 625/12-91-002, EPA, Office, Washington, D.C.

Environmental Protection Agency (EPA). 1991b. Compendium of ERT Soil Sampling and Surface Geophysics Procedures. EPA 540/P-91-006, EPA, Office, Washington, D.C. (PB91-921273/CCE)

Environmental Protection Agency (EPA). 1991c. Compendium of ERT Ground Water Sampling Procedures. EPA 540/P-91-007, EPA, Office, Washington, D.C. (PB91-921275/CCE) 
Environmental Protection Agency (EPA). 1991d. Compendium of ERT Surface Water and Sediment Sampling Procedures. EPA 540/P-91-005, EPA, Washington, D.C. (PB91921274/CCE)

Environmental Protection Agency (EPA). 1991e. Site Assessment Information Directory. EPA, Office of Emergency and Remedial Response, Washington, D.C.

Environmental Protection Agency (EPA). 1991f. Guidance for Performing Preliminary Assessments Under CERCLA. EPA/540/G-91/013, EPA, Office of Emergency and Remedial Response, Washington, D.C. (PB92-963303)

Environmental Protection Agency (EPA). 1991g. Removal Program Representative Sampling Guidance: Volume 1 - Soil. Publication 9360.4-10, EPA, Office of Emergency and Remedial Response, Washington, D.C. (PB92-963408)

Environmental Protection Agency (EPA). 1991h. Risk Assessment Guidance for Superfund. Volume 1, Human Health Evaluation Manual. Part B, Development of Risk Based Preliminary Remediation Goals. Interim Report, EPA/540/R-92/003, OSWER 9285.701B, Office of Solid Waste and Emergency Response, Washington, D.C. (PB92-963333)

Environmental Protection Agency (EPA). 1992a. Guidance for Data Useability in Risk Assessment, Part A. OSWER Directive 9285.7-09A, EPA, Office of Emergency and Remedial Response, Washington, D.C. (PB92-963356)

Environmental Protection Agency (EPA). 1992b. Guidance for Data Useability in Risk Assessment, Part B. OSWER Directive 9285.7-09B, EPA, Office of Emergency and Remedial Response, Washington, D.C. (PB92-963362)

Environmental Protection Agency (EPA). 1992c. Radon Measurement in Schools, Revised Edition. EPA 402-R-92-014, EPA, Office of Air and Radiation, Washington, D.C.

Environmental Protection Agency (EPA). 1992d. Indoor Radon and Radon Decay Product Measurement Device Protocols. EPA 402-R-92-004, EPA, Office of Air and Radiation, Washington, D.C.

Environmental Protection Agency (EPA). 1992e. Guidance for Performing Site Inspections Under CERCLA. EPA/540-R-92-021, EPA, Office of Solid Waste and Emergency Response, Washington, D.C. 
References

Environmental Protection Agency (EPA). 1992f. Guidance on Implementation of the Superfund Accelerated Cleanup Model (SACM) under CERCLA and the NCP. OSWER Directive 9203.1-03, EPA, Office of Solid Waste and Emergency Response, Washington, D.C.

Environmental Protection Agency (EPA). 1992g. Supplemental Guidance to RAGS:

Calculating the Concentration Term. Publication 9285.7-081, EPA, Office of Solid Waste and Emergency Response, Washington, DC. (PB92-963373)

Environmental Protection Agency (EPA). 1993a. Protocols for Radon and Radon Decay Product Measurements In Homes. EPA 402-R-93-003, EPA, Office of Air and Radiation, Washington, D.C.

Environmental Protection Agency (EPA). 1993b. RCRA Groundwater Monitoring: Draft Technical Guidance. EPA/530-R-93-001. EPA Office of Solid Waste, Washington, D.C. (PB93-139350)

Environmental Protection Agency (EPA). 1993c. Integrating Removal and Remedial Site Assessment Investigations. OSWER Directive 9345.1-16FS, EPA, Office of Solid Waste and Emergency Response, Washington, D.C. (PB93-963341)

Environmental Protection Agency (EPA). 1993d. Quality Assurance for Superfund Environmental Data Collection Activities. Publication 9200.2-16FS, EPA, Office of Solid Waste and Emergency Response, Washington, D.C.

Environmental Protection Agency (EPA). 1993e. Subsurface Characterization and Monitoring Techniques: A Desk Reference Guide, Volume 1. EPA/625/R-93/003A, U.S.

Environmental Protection Agency, Cincinnati, Ohio. (PB94-136272)

Environmental Protection Agency. 1993f. Description and Sampling of Contaminated Soils: A Field Pocket Guide, EPA/625/12-91/00.

Environmental Protection Agency (EPA). 1994a. Guidance for the Data Quality Objectives Process. EPA/600/R-96/055, EPA QA/G-4, Final, EPA, Quality Assurance Management Staff, Washington, D.C.

Environmental Protection Agency (EPA). 1994b. Statistical Methods for Evaluating the Attainment of Cleanup Standards, Volume 3: Reference Based Standards for Soils and Solid Media. EPA 230-R-94-004, EPA, Office of Policy, Planning, and Evaluation, Washington, D.C. (PB94-176831) 
Environmental Protection Agency (EPA). 1994c. EPA Requirements for Quality Assurance Project Plans for Environmental Data Operations. EPA QA/R-5, EPA, Draft Interim Final, Quality Assurance Management Staff, Washington, D.C.

Environmental Protection Agency (EPA). 1994d. An SAB Report: Review of EPA's Approach to Screening for Radioactive Waste Materials at a Superfund Site in Uniontown, Ohio. Prepared by the ad hoc Industrial Excess Landfill Panel of the Science Advisory Board (SAB). EPA-SAB-EC-94-010. EPA, SAB, Washington, D.C.

Environmental Protection Agency (EPA). 1994e. Methods for Monitoring Pump-and-Treat Performance. EPA/600/R-94/123, EPA, Office of Research and Development, Washington, D.C.

Environmental Protection Agency (EPA). 1994f. EPA Requirements for Quality Management Plans. EPA QA/R-2, Interim Draft. Quality Assurance Management Staff, Washington, D.C.

Environmental Protection Agency (EPA). 1995a. DEFT Software for Data Quality Objectives. EPA/600/R-96/056, EPA QA/G-4D. EPA, Washington, D.C.

Environmental Protection Agency (EPA). 1995b. Guidance for the Preparation of Standard Operating Procedures (SOPs) for Quality Related Documents. EPA QA/G-6, EPA, Quality Assurance Management Staff, Washington, D.C.

Environmental Protection Agency (EPA). 1996a. Guidance for Data Quality Assessment: Practical Methods for Data Analysis. EPA QA/G-9 QA96 Version, EPA/600/R-96/084, EPA, Quality Assurance Management Staff, Washington, D.C.

Environmental Protection Agency (EPA). 1996b. Soil Screening Guidance: User's Guide. EPA/540/R-96/018, EPA, Office of Emergency and Remedial Response, Washington, D.C.

Environmental Protection Agency (EPA). 1996c. Soil Screening Guidance: Technical Background Document. EPA/540/R-95/128, EPA, Office of Solid Waste and Emergency Response, Washington, D.C. (PB96-963502)

Environmental Protection Agency (EPA). 1997a. EPA Guidance for Quality Assurance Project Plans. Final, EPA QA/G-5, EPA, Office of Research and Development, Washington, D.C. 
References

Environmental Protection Agency (EPA). 1997b. Integrated Site Assessments may Expedite Cleanups. GAO/RCED-97-181. GAO, Washington, D.C.

Egan, J.P. 1975. Signal Detection Theory and ROC Analysis. Academic Press, Inc., New York.

Eisenbud, M. 1987. Environmental Radioactivity, 3rd ed. Academic Press, Inc., New York.

Friedman, G.M. and J.L. Sanders. 1978. Principles of Sedimentology. John Wiley and Sons, New York, NY.

Fritzsche, A.E. 1987. An Aerial Radiological Survey of the White Creek Floodplain, Oak Ridge Resrvation, Oak Ridge, Tennessee. EGG-10282-1136, Remote Sensing Laboratory, EG\&G/EM, Las Vegas, NV.

George, A.C. 1984. Passive, Integrated Measurement of Indoor Radon Using Activated Carbon. Health Physics 46:867.

Gilbert, R. O. 1987. Statistical Methods for Environmental Pollution Monitoring. Van Nostrand Reinhold, New York.

Hardin, J.W. and R.O. Gilbert. 1993. Comparing Statistical tests for Detecting Soil

Contamination Greater Than Background. PNL-8989, Pacific Northwest Laboratory, Richland, WA.

Harnett, D. L. 1975. Introduction to Statistical Methods, 2nd ed. Addison-Wesley, Reading, Massachusetts.

Health Physics Society (HPS). 1994a. Program handbook for the Accreditation of Calibration Laboratories by the Health Physics Society. HPS, McLean, VA.

Health Physics Society (HPS). 1994b. Criteria for Accreditation of Calibration Laboratories by the Health Physics Society. HPS, McLean, VA.

Hora, S. C. and R. L. Iman. 1989. Expert Opinion in Risk Analysis: The NUREG-1150 Methodology. Nuclear Science and Engineering. 102 (4):323-331.

International Atomic Energy Agency (IAEA). 1971. Handbook on Calibration of Radiation Protection Monitoring Instruments. IAEA, Technical Report Series 133, Vienna. 
International Organization for Standardization (ISO). 1987. ISO 9000/ASQC Q9000 Series. American Society for Quality Control, Milwaukee, Wisconsin. ISO 9000-1, Quality Management and Quality Assurance Standards - Guidelines for Selection and Use.

ISO 9001-1, Quality Systems - Model for Quality Assurance in Design/Development, Production, Installation and Servicing.

ISO 9002, Quality Systems - Model for Quality Assurance in Production and Installation, and Servicing.

ISO 9003, Quality Systems - Model for Quality Assurance in Final Inspection and Test. ISO 9004-1, Quality Management and Quality System Elements - Guidelines.

International Organization for Standardization (ISO). 1988. Evaluation of Surface Contamination - Part 1: Beta Emitters and Alpha Emitters. ISO-7503-1 (first edition), ISO, Geneva, Switzerland.

International Organization for Standardization (ISO). 1993. International Vocabulary of Basic and General Terms in Metrology. ISO, Geneva, Switzerland.

Jenkins, P .H. 1986. Radon Measurement Methods: An Overview. In Proceedings of Health Physics Society Meeting, 29 June 1986, Pittsburgh, PA. CONF-8606139-5, Monsanto Research Corporation, Miamisburg, Ohio, p. 38.

Kume, H. 1985. Statistical Methods for Quality Improvement. The Association of Overseas Technical Scholarship, Tokyo, Japan.

Lodge. J.P., Jr. (Ed). 1988. Methods of Air Sampling and Analysis. $3^{\text {rd }}$ Edition, American Chemical Society, American Institute of Chemical Engineers, American Public Works Association, American Society of Mechanical Engineers, Association of Official Analytical Chemists, Air and Waste Management Association, Health Physics Society, Instrument Society of America. CRC Press, Inc. Boca Raton, FL.

Macmillan, N.A., and C.D. Creelman. 1991. Detection Theory: A User's Guide. Cambridge University Press, Cambridge, England.

Miller, K. M., P. Shebell and G. A. Klemic. 1994. In Situ Gamma-Ray Spectrometry for the Measurement of Uranium in Surface Soils. Health Physics 67, 140-150.

Myrick, T.E. et al. 1981. State Background Radiation Levels: Results of Measurements Taken During 1975-1979. ORNL/TM 7343, Oak Ridge National Laboratory, Oak Ridge, Tennessee. 
References

National Council on Radiation Protection and Measurements (NCRP). 1976a. Environmental Radiation Measurements. NCRP Report No. 50, NCRP, Bethesda, Maryland.

National Council on Radiation Protection and Measurements (NCRP). 1976b Tritium Measurement Techniques. NCRP Report 47, NCRP, Bethesda, Maryland.

National Council on Radiation Protection and Measurements (NCRP). 1978. Instrumentation and Monitoring Methods for Radiation Protection. NCRP Report 57, NCRP, Bethesda, Maryland.

National Council on Radiation Protection and Measurements (NCRP). 1985. A Handbook of Radioactivity Measurement Procedures. NCRP Report 58, 2nd ed, NCRP, Bethesda, Maryland.

National Council on Radiation Protection and Measurements (NCRP). 1987. Exposure of the Population in the United States and Canada from Natural Radiation. NCRP Report 94, NCRP, Bethesda, Maryland.

National Council on Radiation Protection and Measurements (NCRP). 1991. Calibration of Survey Instruments used in Radiation Protection for the Assessment of Ionizing Radiation Fields and radioactive Surface Contamination. NCRP Report 112, NCRP, Bethesda, Maryland.

Nuclear Regulatory Commission (NRC). 1974. Termination of Operating Licenses for Nuclear Reactors. Regulatory Guide 1.86, NRC, Washington, D.C.

Nuclear Regulatory Commission (NRC). 1975. Programs for Monitoring Radioactivity in the Environs of Nuclear Power Plants. NRC Regulatory Guide 4.1, Rev. 1, NRC, Washington, D.C.

Nuclear Regulatory Commission (NRC). 1979. Quality Assurance for Radiological Monitoring Programs (Normal Operations) - Effluent Streams and the Environment. Regulatory Guide 4.15, NRC, Washington, D.C.

Nuclear Regulatory Commission (NRC). 1980. Radiological Effluent and Environmental Monitoring at Uranium Mills. NRC Regulatory Guide 4.14, Rev. 1, NRC, Washington, D.C.

Nuclear Regulatory Commission (NRC). 1982. NRC, Office of Nuclear Reactor Regulation Letter to Stanford University, NRC Docket No. 50-401, NRC, Washington, D.C. 
Nuclear Regulatory Commission (NRC). 1984. Lower Limit of Detection: Definition and Elaboration of a Proposed Position for Radiological Effluent and Environmental Measurements. NUREG/CR-4007, U.S. Nuclear Regulatory Commission, Washington D.C.

Nuclear Regulatory Commission (NRC). 1990. Severe Accident Risks: An Assessment for Five U.S. Nuclear Power Plants. NUREG-1150, Volume 1. Office of Nuclear Regulatory Research, NRC, Washington, D.C.

Nuclear Regulatory Commission (NRC). 1991. Quality Assurance Guidance for a Low-Level Radioactive Waste Disposal Facility. NUREG-1293, Revision 1. NRC, Washington, D.C.

Nuclear Regulatory Commission (NRC). 1992a. Manual for Conducting Radiological Surveys in Support of License Termination. NUREG/CR-5849, Draft Report for Comment, U.S. Nuclear Regulatory Commission, Washington, D.C. and Oak Ridge Associated Universities, Oak Ridge, TN.

Nuclear Regulatory Commission (NRC). 1992b. Residual Radioactive Contamination from Decommissioning. NUREG/CR-5512, Final Report. U.S. Nuclear Regulatory Commission, Washington, D.C. and Pacific Northwest Laboratory, Richland, WA.

Nuclear Regulatory Commission (NRC). 1994a. Draft Branch Technical Position on Site Characterization for Decommissioning. NRC, Washington, D.C.

Nuclear Regulatory Commission (NRC). 1994b. Background as a Residual Radioactivity Criterion for Decommissioning, Draft Report. NUREG-1501, U. S. Nuclear Regulatory Commission, Office of Nuclear Regulatory Research, Washington, D.C.

Nuclear Regulatory Commission (NRC). 1994c. Working Draft Regulatory Guide on Release Criteria for Decommissioning: NRC Staff's Draft for Comment. NUREG-1500, U. S. Nuclear Regulatory Commission, Office of Nuclear Regulatory Research, Washington, D.C.

Nuclear Regulatory Commission (NRC). 1995. Proposed Methodologies for Measuring Low Levels of Residual Radioactivity for Decommissioning. NUREG-1506, Draft Report for Comment, NRC, Washington, D.C. 
References

Nuclear Regulatory Commission (NRC). 1997a. A Proposed Nonparametric Statistical Methodology for the Design and Analysis of Final Status Decommissioning Surveys. NUREG-1505, Final, NRC, Washington, D.C.

Nuclear Regulatory Commission (NRC). 1997b. Minimum Detectable Concentrations with Typical Radiation Survey Instruments for Various Contaminants and Field Conditions. NUREG/CR-1507, Final, NRC, Washington, D.C.

Nuclear Regulatory Commission (NRC). 1997c. NMSS Handbook for Decommissioning Fuel Cycle and Materials Licensees. NUREG/BR-0241, NRC, Washington, D.C.

Perdue, P. A., R. W. Leggett, and F. F. Haywood. 1978. A Technique for Evaluating Airborne Concentrations of Daughters of Radon Isotopes. T. F. Gesell and W. M. Lowder, (eds). Third International Symposium on the Natural Radiation Environment, 23-28 April 1978, in Natural Radiation Environment III, Volume 1, pp. 347-356. CONF-780422, Houston, Texas.

Peter Gray \& Associates (PGA). 1997. The NORM Report. (P.O. Box 470932, Tulsa, Oklahoma 74147). Spring 1997, pp. 1-7.

Taylor, J.K. 1987. Quality Assurance of Chemical Measurements. Lewis Publishers, Inc., Chelsea, MI.

van der Leeden, F., F.L. Troise, and D.K. Todd. 1990. The Water Encyclopedia. $2^{\text {nd }}$ Edition, Lewis Publishers, Chelsea, MI.

Wallo, A., M. Moscovitch, J.E. Rodgers, D. Duffey, and C. Soares. 1994. "Investigations of Natural Variations of Cesium-137 Concentrations in Residential Soils." The Health Physics Society 39th Anual Meeting, June 28, 1994. McLean, Virginia: The Health Physics Society.

Yu, C., A. J. Zidan, J.-J. Cheng, Y. C. Yuan, L. G. Jones, D. J. LePoire, Y. Y. Wang, C. O. Loureiro, E. Gnanaprgusan, E. Faillace, A. Wallo III, W. A. Williams, and H. Peterson. 1993. Manual for Implementing Residual Radioactive Material Guidelines Using RESRAD, Version 5.0. ANL/EAD/LD-2, Argonne National Laboratory, Argonne, Illinois. (DE94-015594)

Walpole, R.E. and R.H. Myers. 1985. Probability and Statistics for Engineers and Scientists. $3^{\text {rd }}$ Edition, MacMillan Publishing Company, New York, NY. 


\section{U. S. Code of Federal Regulations}

10 CFR, Chapter 1. 1995. U.S. Nuclear Regulatory Commission. "Nuclear Regulatory Commission."

10 CFR 20. 1995. U.S. Nuclear Regulatory Commission. "Standards for Protection Against Radiation."

10 CFR 20.1001. 1995. U.S. Nuclear Regulatory Commission. "Standards for Protection Against Radiation-Subpart A-General Provisions: Purpose."

10 CFR 20.1301. 1995. U.S. Nuclear Regulatory Commission. "Dose limits for individual members of the public_Subpart D-Occupational Dose Limits: Dose Limits for Individual Members of the Public."

10 CFR 20.2002. 1995. U.S. Nuclear Regulatory Commission. "Method for obtaining approval of proposed disposal procedures."

10 CFR 30. 1995. U.S. Nuclear Regulatory Commission. "Rules of General Applicability to Domestic Licensing of Byproducts and Material."

10 CFR 30.36. 1995. U.S. Nuclear Regulatory Commission. "Licenses: Expiration and Termination of Licenses and Decommissioning of Sites and Separate Buildings or Outdoor Areas."

10 CFR 40. 1995. U.S. Nuclear Regulatory Commission. "Domestic Licensing of Source Material."

10 CFR 40.42. 1995. U.S. Nuclear Regulatory Commission. "Licenses: Expiration and Termination of Licenses and Decommissioning of Sites and Separate Buildings or Outdoor Areas."

10 CFR 40.65. 1995. U.S. Nuclear Regulatory Commission. "Domestic Licensing of Source Material: Effluent Monitoring Reporting Requirements."

10 CFR 40, Appendix A. 1995. U.S. Nuclear Regulatory Commission. "Criteria Relating to the Operation of Uranium Mills and the Disposition of Tailings or Wastes Produced by the Extraction or Concentration of Source Material From Ores Processed Primarily for Their Source Material Content"

10 CFR Part 50. 1995. U.S. Nuclear Regulatory Commission. "Domestic Licensing of Production and Utilization Facilities." 
10 CFR Part 50, Appendix I. 1995. U.S. Nuclear Regulatory Commission. "Numerical Guides for Design Objectives and Limiting Conditions for Operations to Meet the Criterion 'As Low as is Reasonably Achievable' For Radioactive Material in Light-Water-Cooled Nuclear Power Reactor Effluents."

10 CFR Part 50.82. 1995. U.S. Nuclear Regulatory Commission. "Domestic Licensing of Production and Utilization Facilities: US/IAEA Safeguards Agreement: Application for Termination of License."

10 CFR 70. 1995. U.S. Nuclear Regulatory Commission. "Domestic Licensing of Special Nuclear Material."

10 CFR 70.38. 1995. U.S. Nuclear Regulatory Commission. "Licenses: Expiration and Termination of Licenses and Decommissioning of Sites and Separate Buildings or Outdoor Areas."

10 CFR 70.59. 1995. U.S. Nuclear Regulatory Commission. "Special Nuclear Material Control, Records, Reports and Inspections: Effluent Monitoring Reporting Requirements."

10 CFR 71. 1996. U.S. Nuclear Regulatory Commission. "Packaging and Transportation of Radioactive Material."

10 CFR 71.4. 1996. U.S. Nuclear Regulatory Commission. "Packaging and Transportation of Radioactive Material-Subpart A-General Provisions: Definitions."

10 CFR 71.10. 1996. U.S. Nuclear Regulatory Commission. "Packaging and Transportation of Radioactive Material-Subpart B-Exemptions: Exemption for Low-level Materials."

10 CFR 71.88. 1996. U.S. Nuclear Regulatory Commission. "Packaging and Transportation of Radioactive Material-Subpart F-Operating Controls and Procedures: Air Transport of Plutonium."

10 CFR 72.54. 1995. U.S. Nuclear Regulatory Commission. "Licensing Requirements for the Independent Storage of Spent Nuclear Fuel and High-level Radioactive Waste-Subpart $\mathrm{C}$-Issuance and Conditions of License: Expiration and Termination of Licenses and Decommissioning of Sites and Separate Buildings or Outdoor Areas."

40 CFR 141. 1994. U.S. Environmental Protection Agency. "National Primary Drinking Water Regulations." 
40 CFR 141.15. 1994. U.S. Environmental Protection Agency. "National Primary Drinking Water Regulations-Subpart B-Maximum Contaminant Levels for Radium-226, Radium-228, and Gross Alpha Particle Radioactivity in Community Water Systems."

40 CFR 141.16. 1994. U.S. Environmental Protection Agency. "National Primary Drinking Water Regulations-Subpart C-Maximum Contaminant Levels for Beta Particle and Photon Radioactivity from Man-made Radionuclides in Community Water Systems."

40 CFR Part 190. 1995. U.S. Environmental Protection Agency. "Environmental Radiation Protection Standards for Nuclear Power Operations."

40 CFR 192, 30-34. 1994. U.S. Environmental Protection Agency. "Health and Environmental Protection Standards for Uranium and Thorium Mill Tailings-Subpart D-Standards for Management of Uranium Byproduct Materials Pursuant to Section 84 of the Atomic Energy Act of 1954, as Amended."

40 CFR 192, 40-43. 1994. U.S. Environmental Protection Agency. "Health and Environmental Protection Standards for Uranium and Thorium Mill Tailings-Subpart E-Standards for Management of Thorium Byproduct Materials Pursuant to Section 84 of the Atomic Energy Act of 1954, as Amended."

40 CFR 300. 1990. U.S. Environmental Protection Agency. "Hazard Ranking System."

49 CFR 107. 1996. U.S. Department of Transportation. "Registration of shipper/carrier-Subpart G-Registration of Persons Who Offer or Transport Hazardous Materials."

49 CFR 171. 1996. U.S. Department of Transportation. "Accident Reporting."

49 CFR 172. 1996. U.S. Department of Transportation. "Marking and Labeling Packages for Shipment."

49 CFR 173. 1996. U.S. Department of Transportation. "Packaging."

49 CFR 174. 1996. U.S. Department of Transportation. "Transport by Rail."

49 CFR 175. 1996. U.S. Department of Transportation. "Transport by Air."

49 CFR 176. 1996. U.S. Department of Transportation. "Transport by Vessel."

49 CFR 177. 1996. U.S. Department of Transportation. "Transport on Public Highway." 
References

\section{U.S. Federal Code}

Atomic Energy Act of 1954 (AEA), as Amended.

Clean Air Act of 1955 (CAA).

Diplomatic Security and Anti-Terrorism Act of 1986.

Energy Reorganization Act of 1974, as Amended.

Executive Order 10831, "Federal Compliance With Pollution Control Standards."

Energy Policy Act of 1992.

Federal Water Pollution Control Act of 1948 (FWPCA).

Comprehensive Environmental Response, Compensation, and Liability Act of 1980 (CERCLA), as Amended.

Low Level Radioactive Waste Policy Act (LLRWPA) of 1980, as amended.

Low-Level Radioactive Waste Policy Amendments Act of 1985.

Low-Level Radioactive Waste Policy Act of 1980.

Nuclear Non-Proliferation Act of 1982.

Nuclear Waste Policy Act of 1982 (NWPA).

Nuclear Waste Policy Amendments Act of 1987.

Resource Conservation and Recovery Act of 1976 (RCRA).

Safe Drinking Water Act of 1974 (SDWA).

Solar, Wind, Waste and Geothermal Power Production Incentives Act of 1990.

Toxic Substances Control Act of 1976 (TSCA).

Uranium Mill Tailings Radiation Control Act of 1978 (UMTRCA), as Amended.

West Valley Demonstration Project Act of 1980.

MARSSIM

Ref-18

December 1997 


\section{APPENDIX A \\ Example of MARSSIM Applied to a Final Status Survey}

\section{A.1 Introduction}

This appendix presents the final status survey for a relatively simple example of a radiation site. Portions of this example appear earlier in Chapter 5 and Chapter 8. This appendix highlights the major steps for implementing a final status survey and gathering information needed to prepare a report. The report's format will vary with the requirements of the responsible regulatory agency. The Final Status Survey Checklist given at the end of Section 5.5 serves as a general outline for this appendix -although not every point is discussed in detail. Chapters providing discussions on particular points are referenced at each step. This example presents detailed calculations for a single Class 1 survey unit. Section A.2 addresses the completion of steps 1-4 of the Data Quality Objectives (DQO) Process (see Appendix D, Sections D.1 to D.4). Section A.3 addresses the completion of steps 5-7 of the DQO Process (see Appendix D, Sections D.5 to D.7). Section A.4 covers survey performance. Section A.5 discusses evaluating the survey results using Data Quality Assessment (DQA, see Appendix E).

\section{A.2 Survey Preparations \\ (Chapter 3- Historical Site Assessment)}

The Specialty Source Manufacturing Company produced low-activity encapsulated sources of radioactive material for use in classroom educational projects, instrument calibration, and consumer products. The manufacturing process — conducted between 1978 and 1993-involved combining a liquid containing a known quantity of the radioactive material with a plastic binder. This mixture was poured into a metal form and allowed to solidify. After drying, the form and plastic were encapsulated in a metal holder which was pressure sealed. A variety of radionuclides were used in this operation, but the only one having a half-life greater than 60 days was ${ }^{60} \mathrm{Co}$. Licensed activities were terminated as of April 1993 and stock materials containing residual radioactivity were disposed using authorized procedures. Decontamination activities included the initial identification and removal of contaminated equipment and facilities. The site was then surveyed to demonstrate that the radiological conditions satisfy regulatory agency criteria for release.

\section{A.2.1 Identify the Radionuclides of Concern}

(Section 4.3)

More than 15 half-lives have passed for the materials with a half-life of 60 days or less. Based on radioactive decay and the initial quantities of the radionuclides, the quantities that could remain at the site are negligible. A characterization survey confirmed that no radioactive contaminants, other than ${ }^{60} \mathrm{Co}$, were present. 
Appendix A

\section{A.2.2 Determine Residual Radioactivity Limits (DCGLs)} (Section 4.3)

The objective of this survey is to demonstrate that residual contamination in excess of the release criterion is not present at the site. The $\mathrm{DCGL}_{\mathrm{w}}$ for ${ }^{60} \mathrm{Co}$ used for evaluating survey results is $3,000 \mathrm{~Bq} / \mathrm{m}^{2}\left(5,000 \mathrm{dpm} / 100 \mathrm{~cm}^{2}\right)$ for surface contamination of structures. The $\mathrm{DCGL}_{\mathrm{W}}$ for contamination in soil is $140 \mathrm{~Bq} / \mathrm{kg}(3.8 \mathrm{pCi} / \mathrm{g}){ }^{1}$

\section{A.2.3 Classify Areas Based on Contamination Potential.}

(Section 4.4)

This facility consists of one administration/manufacturing building situated on approximately 0.4 hectares (1.0 acres) of land as shown in Figure A.1. The building is a concrete block structure on a poured concrete slab with a poured concrete ceiling. The northern portion of the building housed the manufacturing operations, and consists of a high-bay area of approximately $20 \mathrm{~m} \times 20$ $\mathrm{m}$ with a $7 \mathrm{~m}$ high ceiling. The remainder of the building is single-story with numerous small rooms partitioned by drywall construction. This portion of the building, used for administration activities, occupies an area of approximately $600 \mathrm{~m}^{2}(20 \mathrm{~m} \mathrm{x} 30 \mathrm{~m})$. The license does not authorize use of radioactive materials in this area. Operating records and previous radiological surveys do not identify a potential for residual contamination in this section of the building. Figure A.2 is a drawing of the building.

The property is surrounded by a chain-link security fence. At the northern end of the property, the surface is paved and was used as a parking lot for employees and for truck access to the manufacturing and shipping/receiving areas. The remainder of the property is grass-covered. There are no indications of incidents or occurrences leading to radioactive material releases from the building. Previous surveys were reviewed and the results were determined to be appropriate for planning the final status survey. These surveys identified no radioactive contamination outside the building.

\section{A.2.4 Identify Survey Units}

(Section 4.6)

Based on the results of other decommissioning surveys at the site and the operating history, the following survey units were used to design the final status survey. All of the interior survey units consist of concrete surfaces (either poured concrete or cinder block) with the exception of the administration areas which are drywall. The results of previous surveys demonstrated that the same reference area could be used to represent the poured concrete and cinder block surfaces.

1 The DCGL values used in this appendix are meant to be illustrative examples and are not meant to be generally applied. 
Appendix A
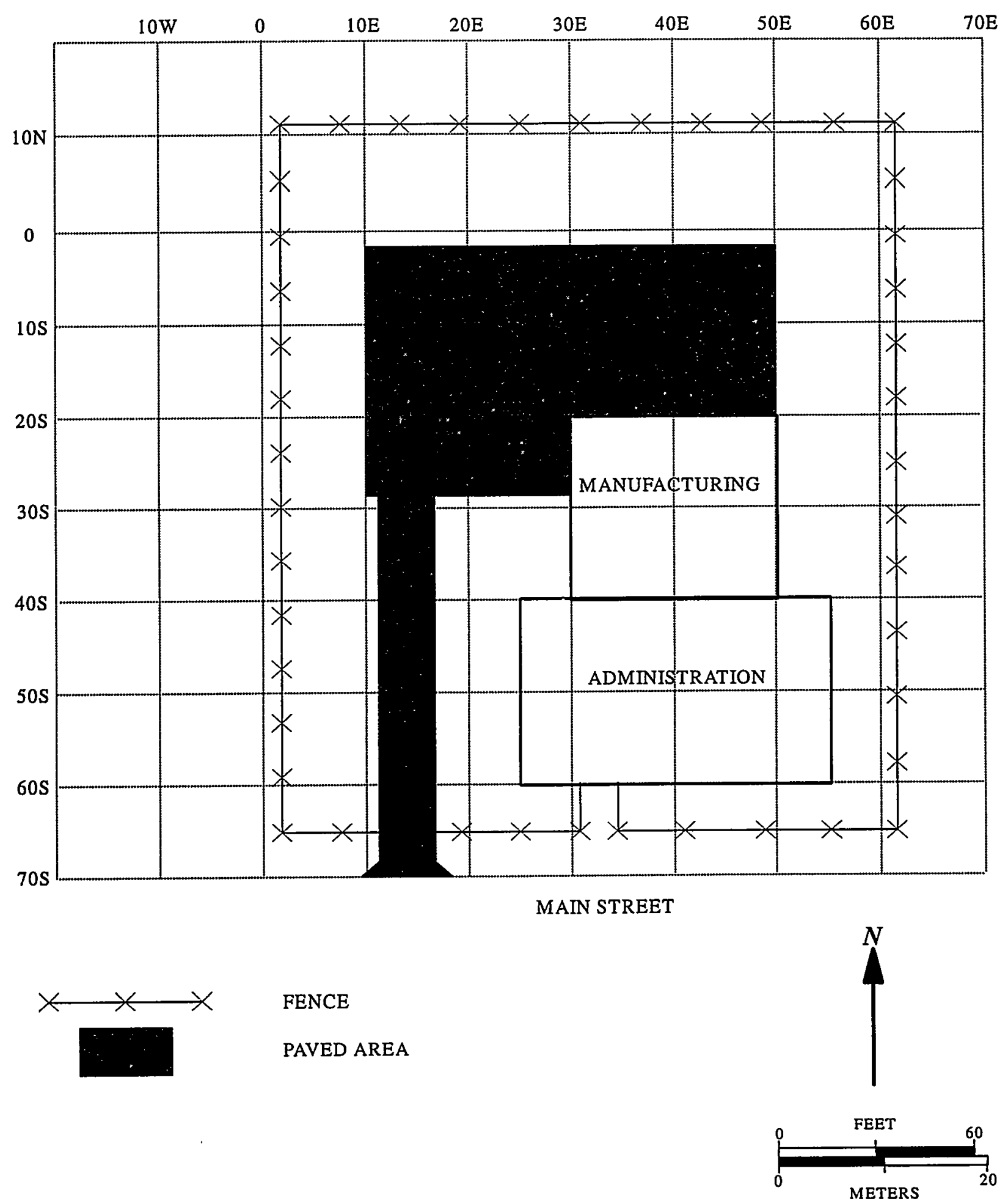

Figure A.1 Plot Plan of the Specialty Source Manufacturing Company 
Appendix A

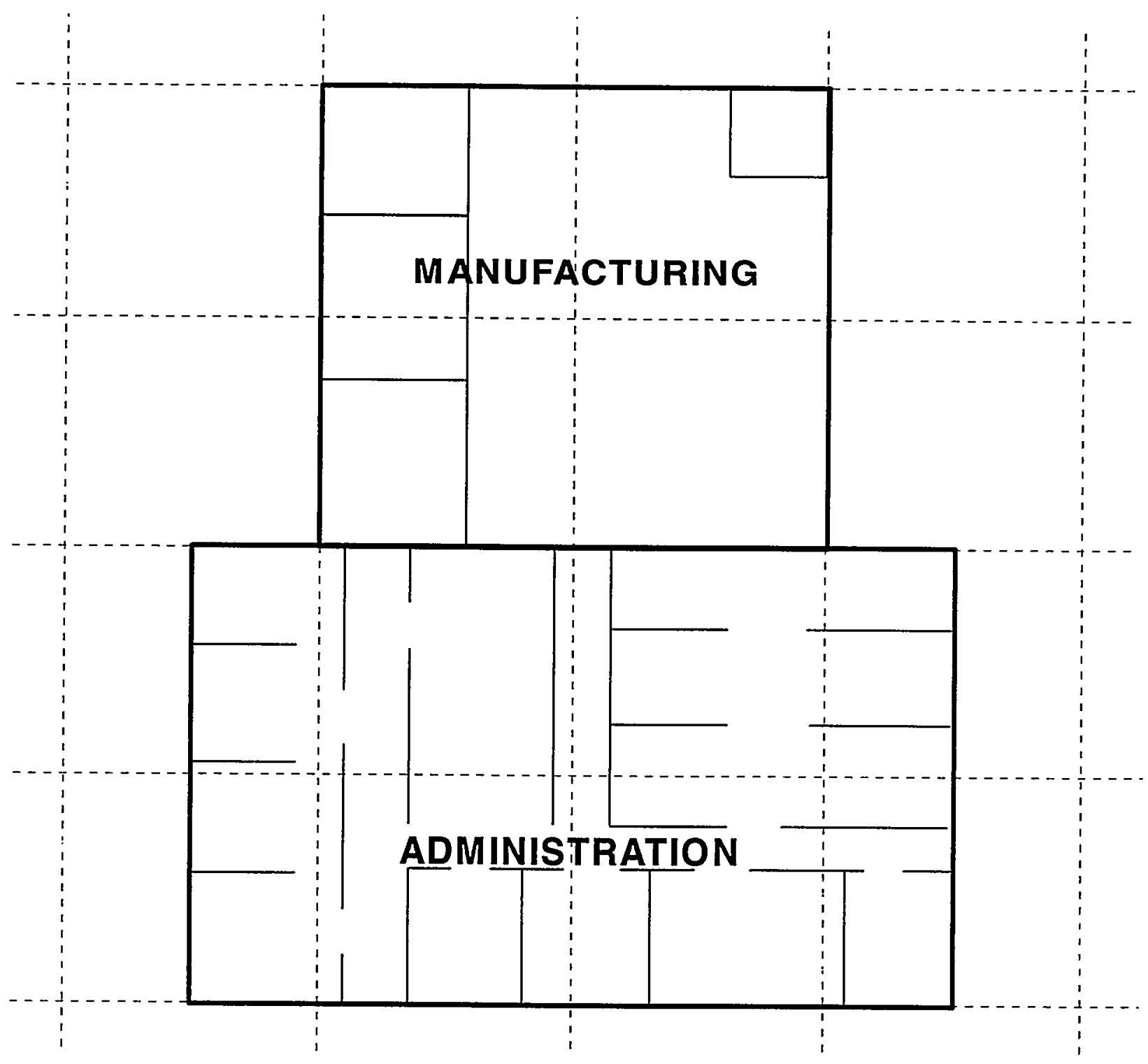

PARTITIONS (WALLS) REMOVED

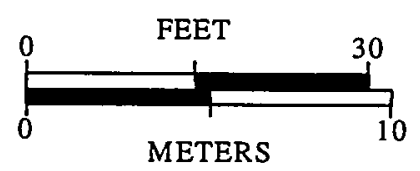

Figure A.2 Building Floor Plan 


\section{Structures}

Class 1 Floor and lower walls (up to 2 meters above the floor) of manufacturing area - 4 survey units of $140 \mathrm{~m}^{2}$ each.

Class 2 Upper walls (over 2 meters above the floor) of manufacturing area - 4 survey units of $100 \mathrm{~m}^{2}$ each.

Ceiling of manufacturing area - 4 survey units of $100 \mathrm{~m}^{2}$ each.

Paved area outside manufacturing area roll-up door - 1 survey unit of $60 \mathrm{~m}^{2}$.

Class 3 Floors and lower walls of administration areas - 1 survey unit. Remainder of paved surfaces -1 survey unit.

\section{Land Areas}

Class 3 Lawn areas - 1 survey unit.

\section{A.2.5 Select Survey Instrumentation and Survey Techniques}

(Section 4.7, Chapter 6, Chapter 7, Appendix H, and Appendix M)

For interior surfaces, direct measurements of gross beta activity were made using one minute counts on a gas flow proportional counter with an $\mathrm{MDC}$ of $255 \mathrm{~Bq} / \mathrm{m}^{2}\left(425 \mathrm{dpm} / 100 \mathrm{~cm}^{2}\right)$. This is actually less than $10 \%$ of the DCGL for ${ }^{60} \mathrm{Co}$. Surfaces were scanned using either a $573 \mathrm{~cm}^{2}$ floor monitor with an MDC of $2,200 \mathrm{~Bq} / \mathrm{m}^{2}\left(3,600 \mathrm{dpm} / 100 \mathrm{~cm}^{2}\right)$ or a $126 \mathrm{~cm}^{2}$ gas flow proportional counter with an MDC of $1,200 \mathrm{~Bq} / \mathrm{m}^{2}\left(2000 \mathrm{dpm} / 100 \mathrm{~cm}^{2}\right)$.

Exterior soil surfaces were sampled and counted in a laboratory using a Ge spectrometer with an MDC of $20 \mathrm{~Bq} / \mathrm{kg}(0.5 \mathrm{pCi} / \mathrm{g})$. This is actually slightly greater than $10 \%$ of the DCGL for ${ }^{60} \mathrm{Co}$. Soil surfaces were scanned using a $\mathrm{NaI}(\mathrm{Tl})$ scintillator with an $\mathrm{MDC}$ of $185 \mathrm{~Bq} / \mathrm{kg}(5.0 \mathrm{pCi} / \mathrm{g})$ of ${ }^{60} \mathrm{Co}$.

Examples of scanning patterns used in each of the Class 1, 2, and 3 areas are shown in Figure A.3.

\section{A.2.6 Select Representative Reference (Background) Areas} (Section 4.5)

For the purposes of evaluating gross beta activity on structure surfaces, a building of similar construction was identified on the property immediately east of the site. This building served as a reference for surface activity measurements. Two reference areas-one for concrete surfaces and one for drywall surfaces-were required. Because ${ }^{60} \mathrm{Co}$ is not a constituent of background and evaluation of the soil concentrations was radionuclide-specific, a reference area was not needed for the land area surveys. 
Appendix A

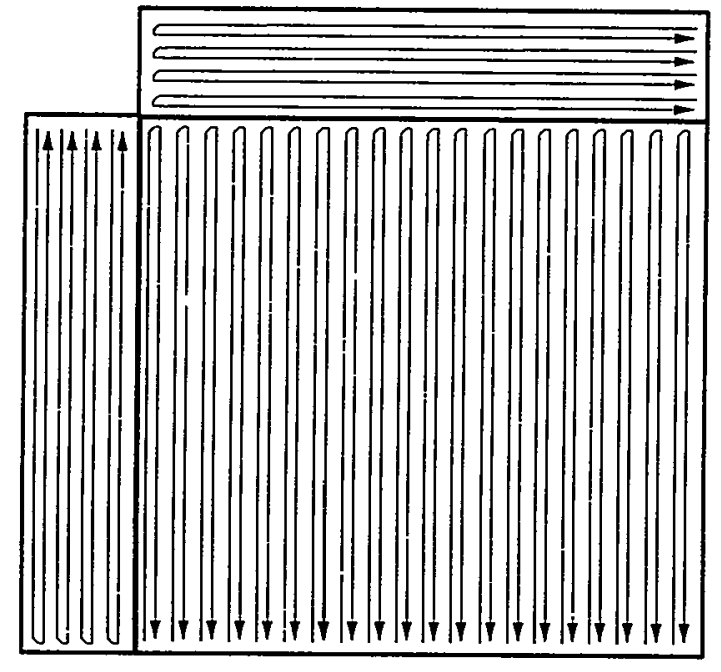

Interior Concrete Survey Units

Class 1 Floors - $100 \%$ Scan with Floor Monitor

Class 1 Walls - $100 \%$ Scans with Gas Flow Proportional Counter

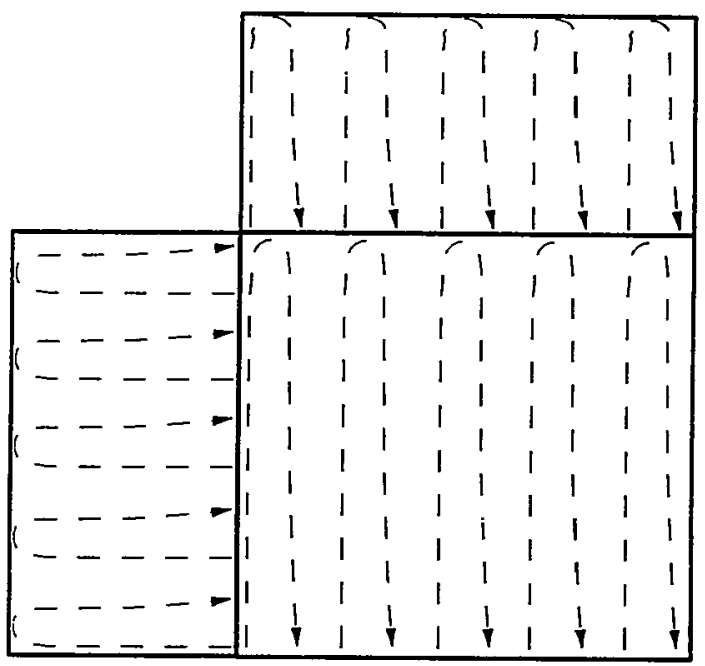

Manufacturing Area Upper Walls and Ceiling Class 2 Areas - 25\% Scans with Gas Flow Proportional Counter

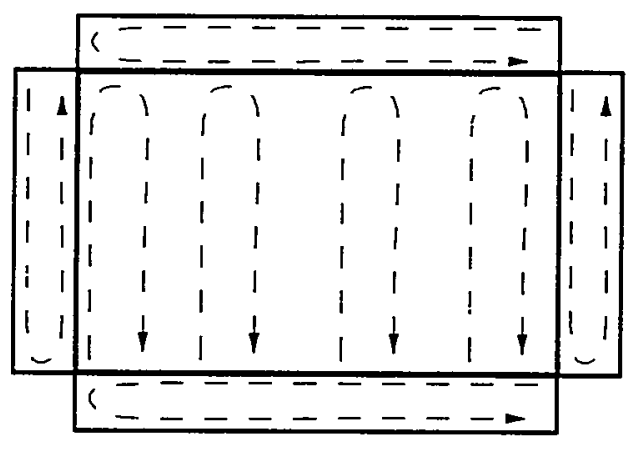

Administration/Office Areas

Class 3 Floors - $25 \%$ Scan with Floor Monitor

Class 3 Walls - $25 \%$ Scan with Gas Flow Proportional Counter

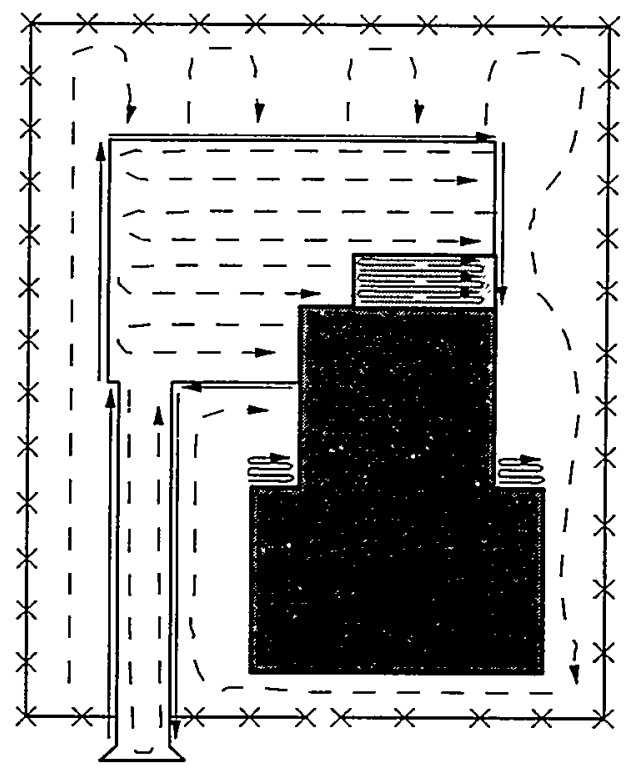

Class 2 Paved Area - $100 \%$ Scan with Floor Monitor Class 3 Paved Area - $25 \%$ Scan with Nal(TI)

Class 3 Lawn Area - $100 \%$ Scan with $\mathrm{Nal}(\mathrm{Tl})$ at Downspouts and Edge of Pavement (Runoff Areas) $10 \%$ Scan with Nal(TI) on Remaining Lawn Area

Figure A.3 Examples of Scanning Patterns for Each Survey Unit Classification 


\section{A.2.7 Prepare Area}

(Section 4.8)

Prior to the survey, and as part of the decommissioning process, all internal partitions were removed from the manufacturing area. Other items removed include the radioactive material control exhaust system, a liquid waste collection system, and other furnishings and fixtures not considered an integral part of the structure.

\section{A.2.8 Establish Reference Coordinate Systems}

(Section 4.8.5)

Land areas were gridded at $10 \mathrm{~m}$ intervals along north-south and east-west axes in preparation for the characterization survey as shown in Figure A.1. The grid was checked to verify its use for the final status survey.

Structure surfaces were already gridded at $2 \mathrm{~m}$ intervals, incorporating the floors and the lower 2 $\mathrm{m}$ of the walls. Figure A.4 is an example of the coordinate system installed for one of the Class 1 interior concrete survey units.

\section{A.3 Survey Design}

\section{A.3.1 Quantify DQOs}

(Section 2.3, Appendix D)

The null hypothesis for each survey unit is that the residual radioactivity concentrations exceed the release criterion (Scenario A, Figure D.5). Acceptable decision error probabilities for testing the hypothesis were determined to be $\alpha=0.05$ and $\beta=0.05$ for the Class 1 interior concrete survey units, and $\alpha=0.025$ and $\beta=0.05$ for all other survey units.

\section{A.3.2 Construct the Desired Power Curve}

(Section 2.3, Appendix D.6, Appendix I.9)

The desired power curve for the Class 1 interior concrete survey units is shown in Figure A.5. The gray region extends from 1,500 to $3,000 \mathrm{~Bq} / \mathrm{m}^{2}\left(2,500\right.$ to $\left.5,000 \mathrm{dpm} / 100 \mathrm{~cm}^{2}\right)$. The survey was designed for the statistical test to have $95 \%$ power to decide that a survey unit containing less than $1,500 \mathrm{~Bq} / \mathrm{m}^{2}\left(2,500 \mathrm{dpm} / 100 \mathrm{~cm}^{2}\right)$ above background meets the release criterion. For the same test, a survey unit containing over $6,000 \mathrm{~Bq} / \mathrm{m}^{2}\left(10,000 \mathrm{dpm} / 100 \mathrm{~cm}^{2}\right)$ above background had less than a $2.5 \%$ probability of being released. 
Appendix A
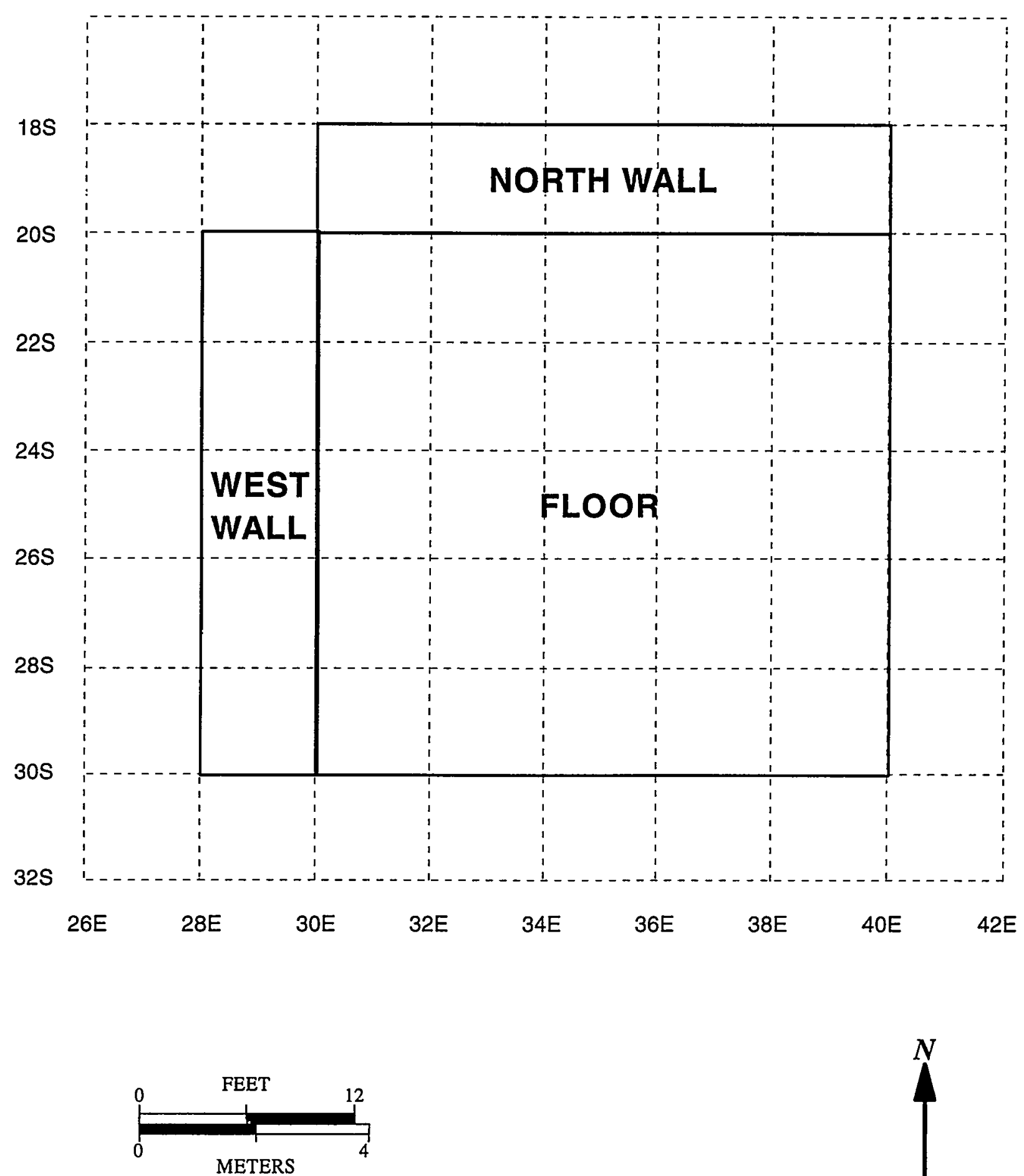

Figure A.4 Reference Coordinate System for the Class 1 Interior Concrete Survey Unit 


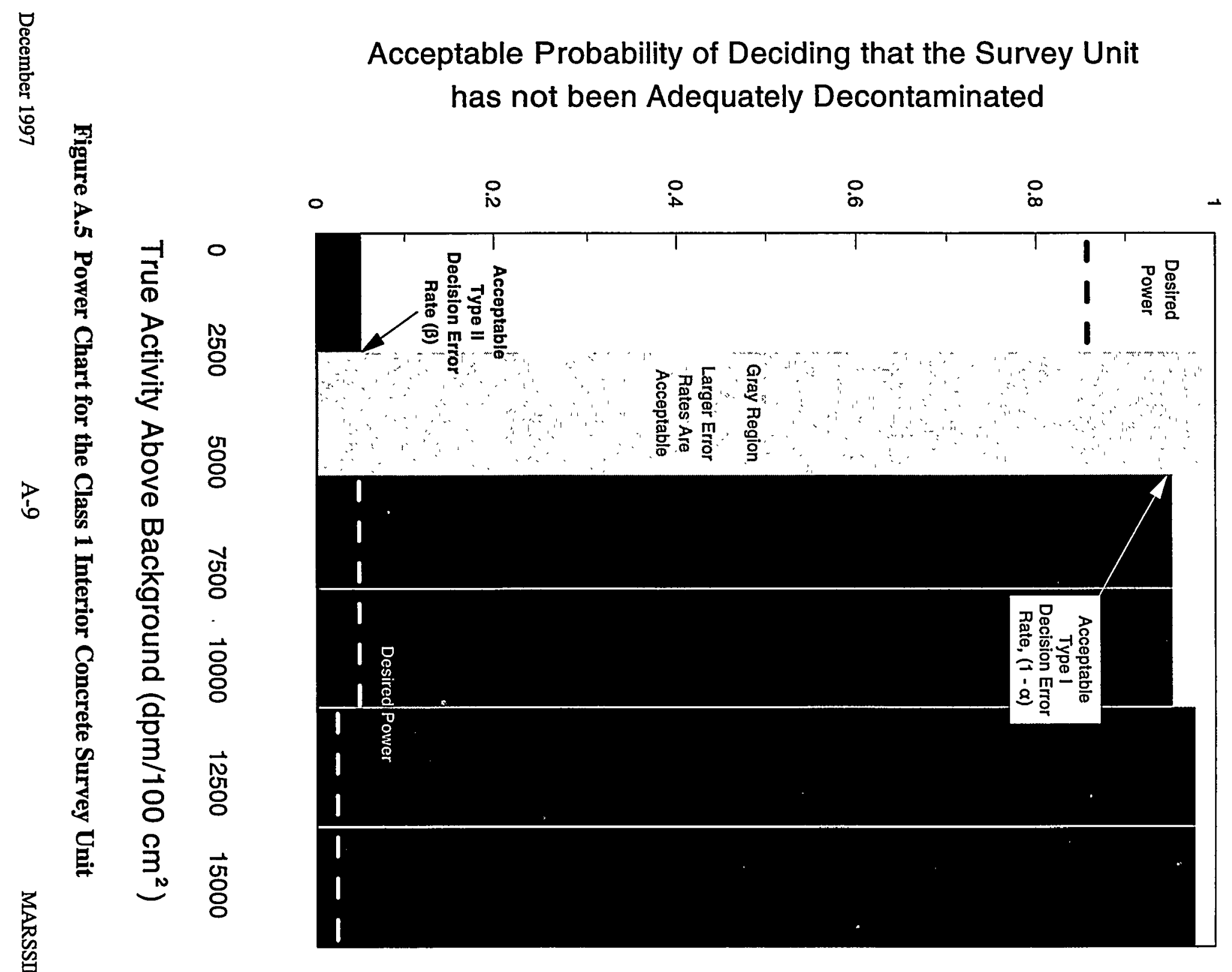


Appendix A

\section{A.3.3 Specify Sample Collection and Analysis Procedures (Chapter 7)}

In the Class 3 exterior survey unit soil cores were taken to a depth of $7.5 \mathrm{~cm}$ ( $3 \mathrm{in}$.) based on development of DQOs, the conceptual site model, and the assumptions used to develop the DCGLs. Each sample was labeled with the location code, date and time of sampling, sealed in a plastic bag, and weighed prior to shipment to the analytical laboratory. At the laboratory, the samples were weighed, dried, and weighed again. The samples were ground to a uniform particle size to homogenize the samples consistent with the modeling assumptions used to develop the DCGLs. One hundred gram (100 g) aliquots were gamma counted using a germanium detector with multichannel analyzer.

The decision to use radionuclide-specific measurements for soil means that the survey of the Class 3 exterior soil surface survey unit was designed for use with the one-sample Sign test.

\section{A.3.4 Provide Information on Survey Instrumentation and Techniques}

(Chapter 6)

A gas flow proportional counter with $20 \mathrm{~cm}^{2}$ probe area and $16 \% 4 \pi$ response was placed on the surface at each direct measurement location, and a one minute count taken. Calibration and background were checked before and after each series of measurements. The DCGL $\mathrm{W}_{\mathrm{W}}$ adjusted for the detector size and efficiency, is:

$$
\left(5,000 \mathrm{dpm} / 100 \mathrm{~cm}^{2}\right)(0.20)(0.16)=160 \mathrm{cpm}
$$

The decision to use total activity measurements for interior surfaces means that the survey of all the interior survey units was designed for use with the two-sample WRS test for comparison with an appropriate reference area.

\section{A.3.5 Determine Numbers of Data Points}

(Section 5.5.2.2)

This facility contains 15 survey units consisting of interior concrete surfaces, interior drywall surfaces, exterior surface soil, and exterior paved surfaces.

\section{Concrete Surfaces}

The site has 12 interior concrete survey units to be compared with 1 reference area. The same type of instrument and method were used to perform measurements in each area. 
The lower bound of the gray region is selected to be one-half the DCGL, and Type I and Type II error values ( $\alpha$ and $\beta$ ) of 0.05 were selected. The number of samples/measurements to be obtained, based on the requirements of the statistical tests, was determined using Equation 5-1 in Section 5.5.2.2:

$$
N=\frac{\left(Z_{1-\alpha}+Z_{1-\beta}\right)^{2}}{3\left(P_{r}-0.5\right)^{2}}
$$

From Table 5.2 it is found that $Z_{1-\alpha}=Z_{1-\beta}=1.645$ for $\alpha=\beta=0.05$.

The parameter $\mathrm{P}_{\mathrm{r}}$ depends on the relative shift, $\Delta / \sigma$. The width of the gray region, $\Delta$, in Figure A.5 is $1,500 \mathrm{~Bq} / \mathrm{m}^{2}\left(2,500 \mathrm{dpm} / 100 \mathrm{~cm}^{2}\right)$, which corresponds to $80 \mathrm{cpm}$. Data from previous scoping and characterization surveys indicate that the background level is $45 \pm 7(1 \sigma) \mathrm{cpm}$. The standard deviation of the contaminant in the survey unit $\left(\sigma_{s}\right)$ is estimated at $\pm 20 \mathrm{cpm}$. When the estimated standard deviation in the reference area and the survey units are different, the larger value should be used to calculate the relative shift. Thus, the value of the relative shift, $\Delta / \sigma$, is $(160-80) / 20$ or $4 .^{2}$ From Table 5.1, the value of $P_{r}$ is approximately 1.000 .

The number of data points for the WRS test of each combination of reference area and survey units according to the allocation formula was:

$$
N=\frac{(1.645+1.645)^{2}}{3(1.000-0.5)^{2}}=14.4
$$

Adding an additional $20 \%$ and rounding up yielded 18 data points total for the reference area and each survey unit combined. Note that the same result is obtained by simply using Table 5.3 or Table I. $2 \mathrm{~b}$ with $\alpha=\beta=0.05$ and $\Delta / \sigma=4$. Of this total number, 9 were planned from the reference area and 9 from each survey unit. The total number of measurements calculated based on the statistical tests was $9+(12)(9)=117$.

\section{A.3.6 Evaluate the power of the statistical tests against the DQOs. (Appendix 1.9.2)}

Using Equation I-8, the prospective power expected of the WRS test was calculated using the fact that 9 samples were planned in each of the survey units and the reference area. The value of $\sigma_{\mathrm{s}}$ was taken to be $20 \mathrm{cpm}$, the larger of the two values anticipated for the reference area $(7 \mathrm{cpm})$ and the survey unit $(20 \mathrm{cpm})$. This prospective power curve is shown in Figure A.6.

${ }^{2}$ Ordinarily $\Delta / \sigma$ would be adjusted to a value between 1 and 3 . For this example the adjustment was not made. 
Appendix A

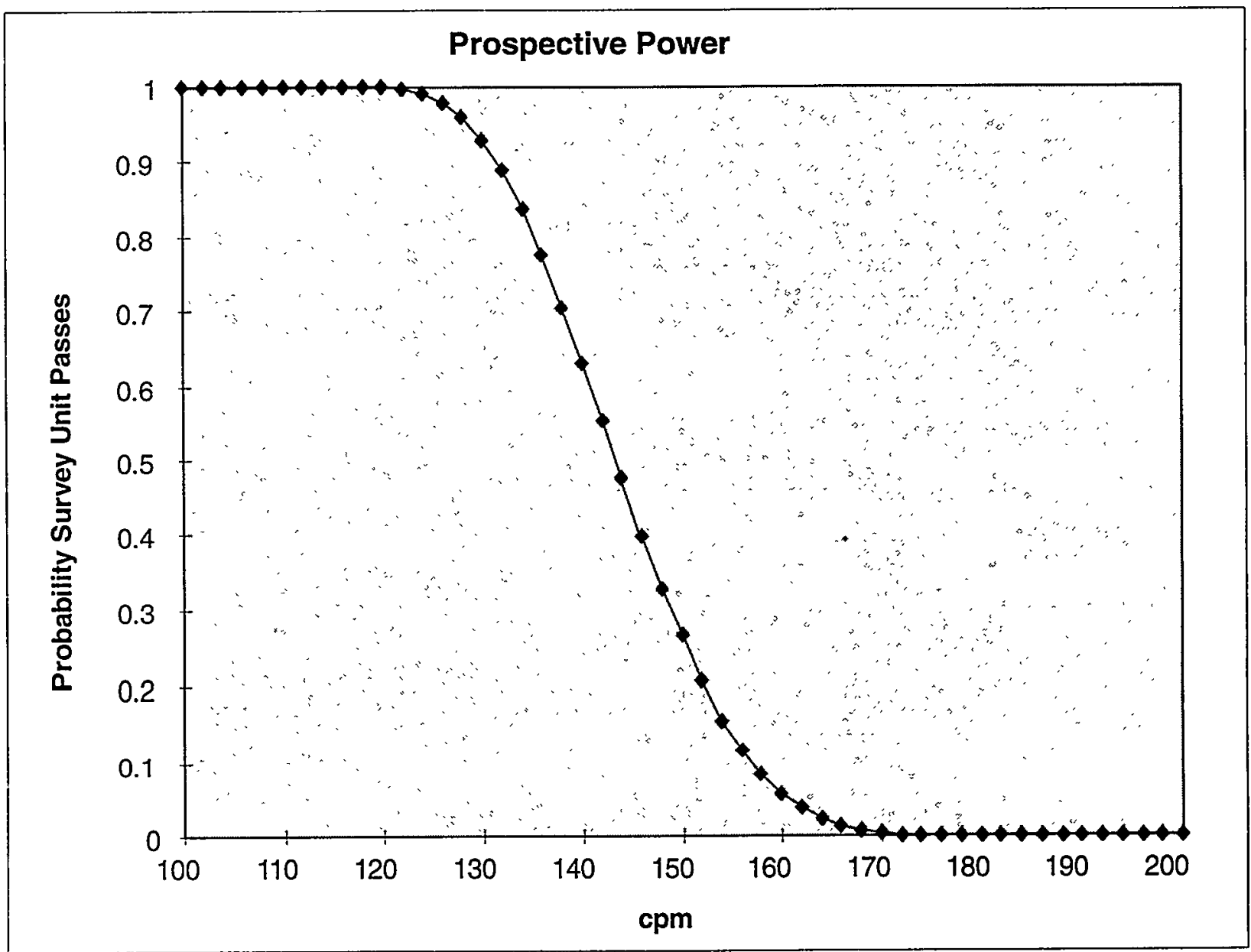

Figure A.6 Prospective Power Curve for the Class 1 Interior Concrete Survey Unit

\section{A.3.7 Ensure that the Sample Size is Sufficient for Detecting Areas of Elevated Activity} (Chapter 5.5.2.4)

The Class 1 concrete interior survey units each have an area of $140 \mathrm{~m}^{2}$ (Figure A.7). The distance between measurement locations in these survey units was:

$$
L=\sqrt{\frac{A}{0.866 n}}=\sqrt{\frac{140}{0.866(10)}}=4.2 \mathrm{~m}
$$


Appendix A

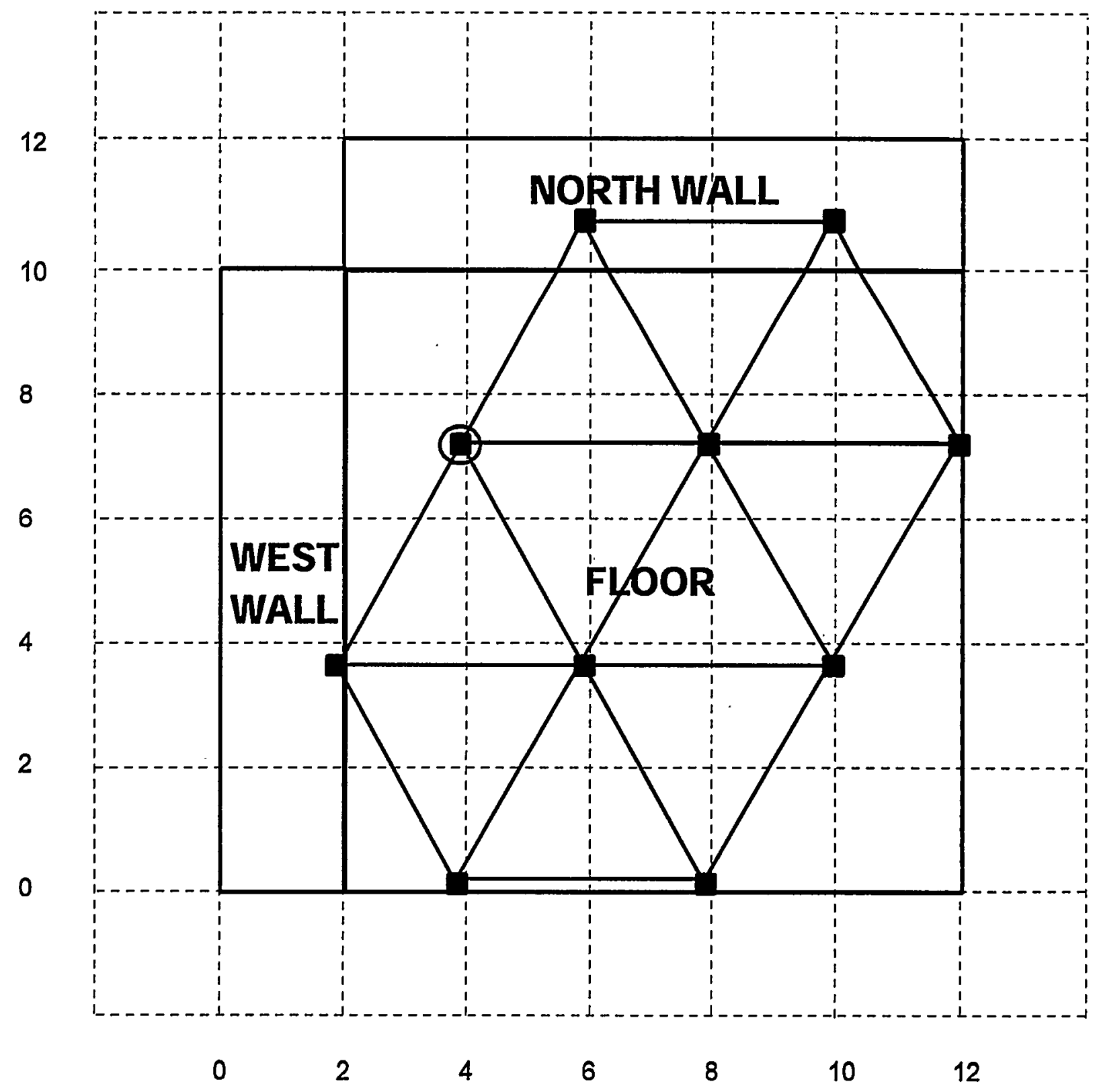

D DIRECT MEASUREMENT LOCATION

(OANDOM START LOCATION
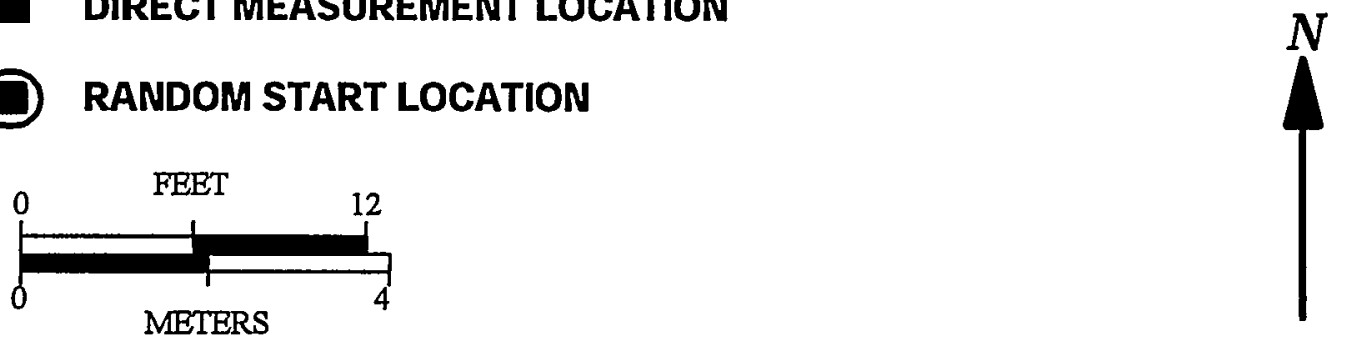

Figure A.7 Measurement Grid for the Class 1 Interior Concrete Survey Unit 
Appendix A

The result for $\mathrm{L}$ was rounded down to the nearest meter, giving $\mathrm{L}=4 \mathrm{~m}$. This resulted in an area between sampling points of $0.866 \mathrm{~L}^{2}=13.9 \mathrm{~m}^{2}$. The DCGL $\mathrm{DW}_{\mathrm{W}}$ of $3,000 \mathrm{~Bq} / \mathrm{m}^{2}(5,000 \mathrm{dpm} / 100$ $\left.\mathrm{cm}^{2}\right)$ was well above the scanning MDC of $2,200 \mathrm{~Bq} / \mathrm{m}^{2}\left(3,600 \mathrm{dpm} / 100 \mathrm{~m}^{2}\right)$ for the least sensitive of the two scanning instruments (the floor monitor). Therefore, no adjustment to the number of data points to account for areas of elevated activity was necessary.

\section{A.3.8 Specify Sampling Locations}

(Chapter 5.5.2.5)

Two random numbers between zero and one were generated to locate the random start for the sampling grid. Using Table I.6 in Appendix I, 0.322467 and 0.601951 were selected. The random start for triangular sampling pattern was found by multiplying these numbers by the length of the reference grid $\mathrm{X}$ and $\mathrm{Y}$ axes:

$$
\begin{aligned}
& \mathrm{X}=0.322467 \times 12 \mathrm{~m}=3.9 \\
& \mathrm{Y}=0.601951 \times 12 \mathrm{~m}=7.2
\end{aligned}
$$

The first row of measurement locations was laid out at $4 \mathrm{~m}$ intervals parallel to one axis of the reference grid. The second row was positioned $(0.866)(4)=3.5 \mathrm{~m}$ from the first row, with measurement locations offset by $2 \mathrm{~m}$ from those in the first row. The measurement grid is shown in Figure A.7. When the measurement grid was constructed it was found that 10 measurement locations were identified within the boundaries of the survey unit, which is greater than the 9 measurement locations calculated to be required for the statistical test. Because the spacing between the measurements $(\mathrm{L})$ is important for identifying areas of elevated activity, all of the identified sampling locations should be used.

\section{A.3.9 Develop Quality Control Procedures}

(Section 4.9)

\section{A.3.10 Document Results of Planning into a Quality Assurance Project Plan} (Section 9.2)

\section{A.4 Conducting Surveys}

\section{A.4.1 Perform Reference (Background) Area Measurements and Scanning (Chapter 6)}

\section{A.4.2 Collect and Analyze Samples (Chapter 7)}


Appendix A

\section{A.5 Evaluating Survey Results}

\section{A.5.1 Perform Data Quality Assessment} (Chapter 8.2)

The data from the one Class 1 interior concrete survey unit and its associated reference area are given in Table A.1. Since ten sampling locations were identified, ten results are listed for the survey unit. ${ }^{3}$ The average measurement in the survey unit is $206 \mathrm{cpm}$, and in the reference area the average is $46 \mathrm{cpm}$. The means and the medians are nearly equal in both cases. The standard deviations are also consistent with those estimated during the survey design. The survey unit clearly contains residual radioactivity close to the $D_{C G L}$ of $160 \mathrm{cpm}$ (calculated using Equation A-1).

Table A.1 Class 1 Interior Concrete Survey Unit and Reference Area Data

\begin{tabular}{||c|c|c|}
\hline & Reference Area & Survey Unit \\
\hline & (cpm) & (cpm) \\
\hline & 45 & 205 \\
\hline & 36 & 207 \\
\hline & 32 & 203 \\
\hline & 57 & 196 \\
\hline & 46 & 211 \\
\hline & 60 & 208 \\
\hline & 39 & 172 \\
\hline & 45 & 216 \\
\hline & 53 & 233 \\
\hline mean & 42 & 209 \\
\hline & 46 & 206 \\
\hline standard deviation & 9 & 15.4 \\
\hline median & 45 & 207.5 \\
\hline
\end{tabular}

${ }^{3}$ There are also ten results listed for the reference area. This is only because there were also ten locations identified there when the grid was laid out. Had nine locations been found, the survey would proceed using those nine locations. There is no requirement that the number of sampling locations in the survey unit and reference area be equal. It is only necessary that at least the minimum number of samples required for the statistical tests is obtained in each. 
The stem and leaf displays (see Appendix I.7) for the data appear in Table A.2. They indicate that the data distributions are unimodal with no notable asymmetry. There are two noticeably extreme values in the survey unit data set, at 172 and $233 \mathrm{cpm}$. These are both about 2 standard deviations from the mean. A check of the data logs indicated nothing unusual about these points, so there was no reason to conclude that these values were due to anything other than random measurement variability.

\section{Table A.2 Stem and Leaf Displays for Class 1 Interior Concrete Survey Unit}

\begin{tabular}{|l|l|l|l|l|}
\hline \multicolumn{5}{|c|}{ Refence Ared } \\
\hline 30 & 6 & 2 & 9 & \\
\hline 40 & 5 & 5 & 6 & 2 \\
\hline 50 & 7 & 3 & & \\
\hline 60 & 0 & & & \\
\hline
\end{tabular}

\begin{tabular}{|l|l|l|l|l|l|}
\hline \multicolumn{7}{|c|}{ Survey Unit } \\
\hline 170 & 2 & & & & \\
\hline 180 & & & & & \\
\hline 190 & 6 & & & & \\
\hline 200 & 5 & 7 & 3 & 8 & 9 \\
\hline 210 & 1 & 6 & & & \\
\hline 220 & & & & & \\
\hline 230 & 3 & & & & \\
\hline
\end{tabular}

A Quantile-Quantile plot (see Appendix I.8) of this data, shown in Figure A.8, is consistent with these conclusions. The median and spread of the survey unit data are clearly above those in the reference area. The middle part of the curve has no sharp rises. However, the lower and upper portion of the curve both show a steep rise due to the two extreme measurements in the survey unit data set.

\section{A.5.2 Conduct Elevated Measurement Comparison} (Section 8.5.1)

The DCGL $\mathrm{W}_{\mathrm{w}}$ is $160 \mathrm{cpm}$ above background. Based on an area between measurement locations $13.9 \mathrm{~m}^{2}$ for $\mathrm{L}=4 \mathrm{~m}$, the area factor (from Table 5.7 ) is approximately 1.5 . This means the $\mathrm{DCGL}_{\mathrm{EMC}}$ is $240 \mathrm{cpm}$ above background. Even without subtracting the average background value of 46 , there were no survey unit measurements exceeding this value. All of the survey unit measurements exceed the $\mathrm{DCGL}_{\mathrm{w}}$ and six exceed $206 \mathrm{cpm}$-the $\mathrm{DCGL}_{\mathrm{w}}$ plus the average background. If any of these data exceeded three standard deviations of the survey unit mean, they might have been considered unusual, but this was not the case. Thus, while the amount of residual radioactivity appeared to be near the release criterion, there was no evidence of smaller areas of elevated residual radioactivity. 


\section{Quantile-Quantile Plot: Class 1 Interior Concrete}

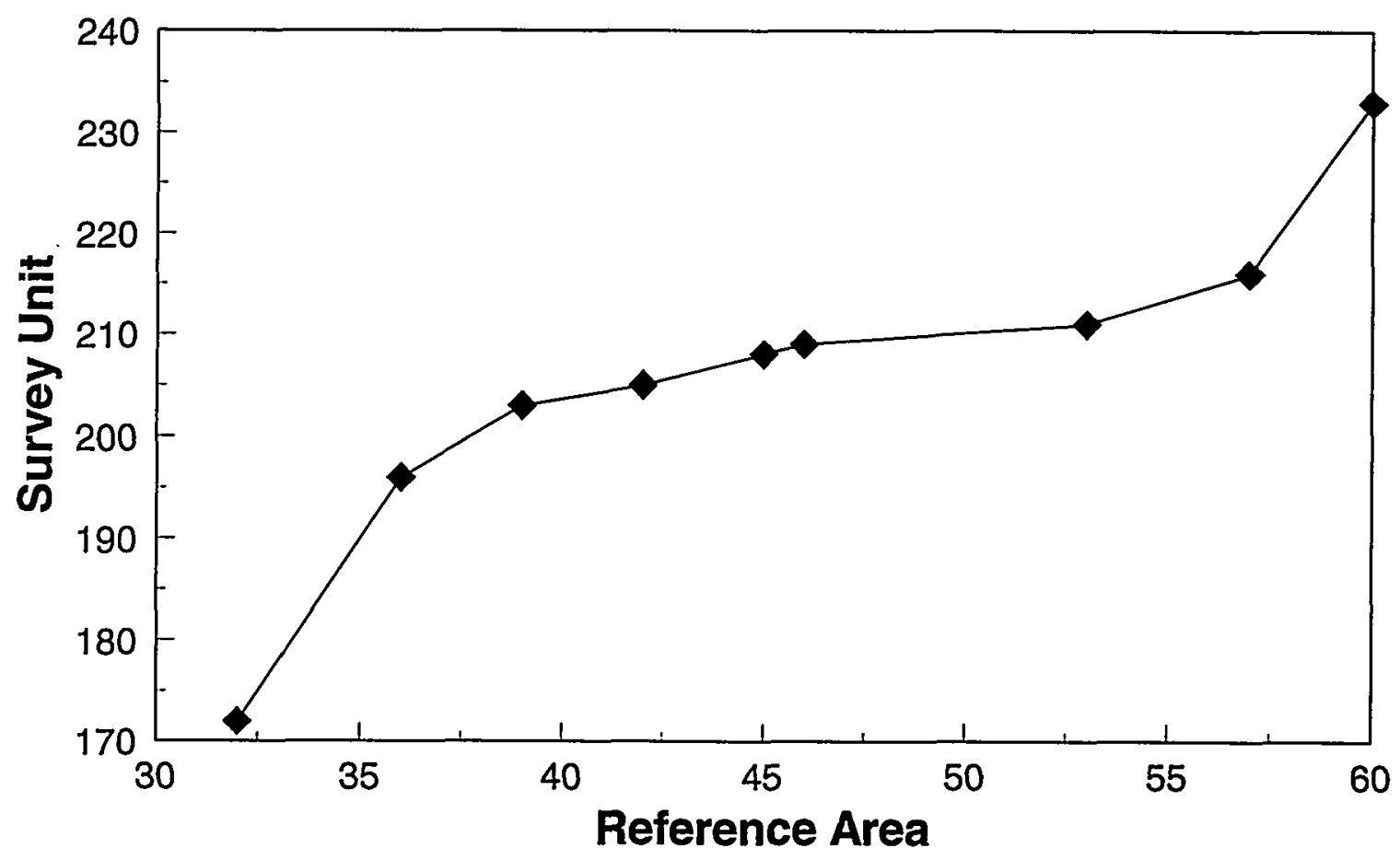

Figure A.8 Quantile-Quantile Plot for the Class 1 Interior Concrete Survey Unit

\section{A.5.3 Conduct Statistical Tests}

(Section 8.3, 8.4)

For the Class 1 interior concrete survey unit, the two-sample nonparametric statistical tests of Section 8.4 were appropriate since, although the radionuclide of concern does not appear in background, radionuclide specific measurements were not made. This survey unit was classified as Class 1 , so the 10 measurements performed in the reference area and the 10 measurements performed in the survey unit were made on random start triangular grids.

Table A.3 shows the results of the twenty measurements in the first column. The average and standard deviation of the reference area measurements were 46 and 9 , respectively. The average and standard deviation of the survey unit measurements were 206 and 15, respectively. 
Appendix A

Table A.3 WRS Test for Class 1 Interior Concrete Survey Unit

\begin{tabular}{|c|c|c|c|c|}
\hline Data & Area & $\begin{array}{c}\text { Adjusted } \\
\text { Data }\end{array}$ & Ranks & Refence Area \\
\hline 45 & R & 205 & 7.5 & Ranks \\
\hline 36 & R & 196 & 4 & 4 \\
\hline 32 & R & 192 & 3 & 3 \\
\hline 57 & R & 217 & 15 & 15 \\
\hline 46 & R & 206 & 9 & 9 \\
\hline 60 & R & 220 & 16 & 16 \\
\hline 39 & R & 199 & 5 & 5 \\
\hline 45 & R & 205 & 7.5 & 7.5 \\
\hline 53 & R & 213 & 13 & 13 \\
\hline 42 & R & 202 & 6 & 6 \\
\hline 211 & S & 211 & 12 & 0 \\
\hline 208 & S & 208 & 10 & 0 \\
\hline 172 & S & 172 & 1 & 0 \\
\hline 216 & S & 216 & 14 & 0 \\
\hline 233 & S & 233 & 18 & 0 \\
\hline 209 & S & 209 & 11 & 0 \\
\hline 237 & S & 237 & 19 & 0 \\
\hline 176 & S & 176 & 2 & 0 \\
\hline 253 & S & 253 & 20 & 0 \\
\hline 229 & S & 229 & 17 & 0 \\
\hline & Sum & & 210 & 86 \\
\hline
\end{tabular}

The analysis proceeded as described in Section 8.6.3. In the "Area" column, the code " $R$ " is inserted to denote a reference area measurement, and " $\mathrm{S}$ " to denote a survey unit measurement. In the "Data" column, the data were simply listed as obtained. The Adjusted Data were obtained by adding the $\mathrm{DCGL}_{\mathrm{W}}$ to the reference area measurements and leaving the survey unit measurements unchanged. The ranks of the Adjusted Data appear in the "Ranks" column. They range from 1 to 20 , since there is a total of $20(10+10)$ measurements. The sum of all of the ranks is $20(20+1) / 2=210$. It is recommended to check this value as a guard against errors in the rankings.

The "Reference Area Ranks" column contains only the ranks belonging to the reference area measurements. The total is 86 . This was compared with the entry in Table I.4 for $\alpha=0.05$, with $n=10$ and $m=10$. This critical value is 127 . Thus, the sum of the reference area ranks was less than the critical value and the null hypothesis-that the survey unit concentrations exceed the DCGL $_{w}$-was accepted. 
Again, as in Section 8.6.3, the retrospective power curve for the WRS test was constructed as described in Appendix I.9, using Equations I-8, I-9, and I-10, together with the actual number of concentration measurements obtained, $N$. The power as a function of $\Delta / \mathrm{s}$ was calculated using the observed standard deviation, $s=15.4$, in place of $\sigma$. The values of $\Delta / \sigma$ were converted to cpm using:

$$
\mathrm{cpm}=\mathrm{DCGL}_{\mathrm{w}}-(\Delta / \sigma)(\text { observed standard deviation })
$$

The results for this example are plotted in Figure A.9, showing the probability that the survey unit would have passed the release criterion using the WRS test versus cpm of residual radioactivity. This curve shows that the data quality objectives were easily met. The curve shows that a survey unit with less than about $130 \mathrm{cpm}$ above background would almost always pass and that a survey unit with more than about $170 \mathrm{cpm}$ above background would almost always fail.

\section{A.5.4 Estimate Amount of Residual Radioactivity} (Chapter 8.5.2.1)

The amount of residual radioactivity in the survey unit above background was estimated following the WRS test using the difference between the mean measurement in the survey unit and the mean measurement in the reference area: $\delta=206-46=160$. This was converted to a surface area activity concentration of $3,000 \mathrm{~Bq} / \mathrm{m}^{2}\left(5,000 \mathrm{dpm} / 100 \mathrm{~cm}^{2}\right)$, which is just at the limiting value, $\mathrm{DCGL}_{\mathrm{w}}$.

The difference in the median measurements $(207.5-45=162.5)$ was converted to a surface activity concentration of $3,060 \mathrm{~Bq} / \mathrm{m}^{2}\left(5,100 \mathrm{dpm} / 100 \mathrm{~cm}^{2}\right)$. This slightly exceeds the DCGL $\mathrm{w}_{\mathrm{w}}$. 
Appendix A

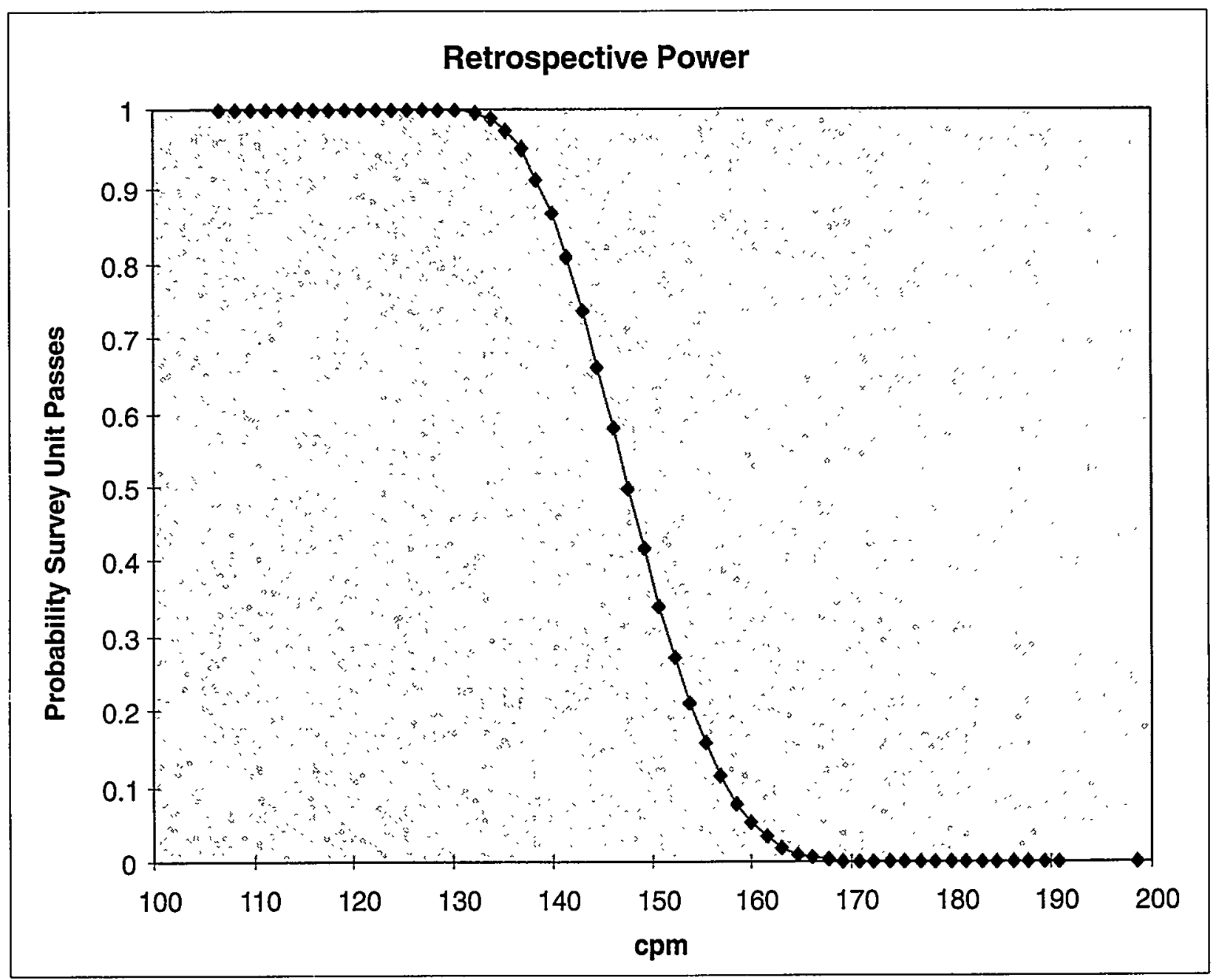

Figure A.9 Retrospective Power Curve for the Class 1 Interior Concrete Survey Unit 


\title{
APPENDIX B
}

\section{SIMPLIFIED PROCEDURE FOR CERTAIN USERS OF SEALED SOURCES, SHORT HALF-LIFE MATERIALS, AND SMALL QUANTITIES}

\begin{abstract}
A large number of users of radioactive materials may use a simplified procedure to demonstrate regulatory compliance for decommissioning, avoiding complex final status surveys. Sites that qualify for simplified decommissioning procedures are those where radioactive materials have been used or stored only in the form of: non-leaking, sealed sources; short half-life radioactive materials (e.g., $\mathrm{t}_{12} \leq 120$ days) that have since decayed to insignificant quantities; small quantities exempted or not requiring a specific license from a regulatory authority; or combinations of the above.
\end{abstract}

The user of a site that may qualify for implementation of a simplified procedure should provide the regulatory authority with a minimum of: (1) a certification that no residual radioactive contamination attributable to the user's activities is detectable by generally accepted survey methods for decommissioning; and (2) documentation on the disposal of nuclear materials, such as the information required in Form NRC-314 (Certification of Disposition of Materials). This minimum information may be used by the regulatory authority to document protection of both the public health and safety and the environment, based on the transfer, decay, or disposal of radioactive material in some authorized manner.

Normally, the absence of radioactive contamination can be demonstrated by: (1) documenting the amounts, kinds and uses of radionuclides as well as the processes involved; (2) conducting a radiation survey of the site; and (3) submitting a report on this survey. More specifically, a user of a qualified site should document from process knowledge and the nature of the use that either no or unmeasurable quantities of radioactive material remain onsite-whether on surfaces, buried, imbedded, submersed, or dissolved. The submittal to the regulatory authority should include possession history, use of the radioactive materials, and, if applicable, results of all leak tests. Where only small quantities or short half-life materials were handled, the regulatory authority may consider the documentation on a case-by-case basis.

For those sites where a simple final status survey is conducted to demonstrate compliance with the release criterion, the following information should be included in the final status survey report:

\footnotetext{
- basis for selecting the instrumentation used for the survey

- $\quad$ nature of the radionuclides surveyed

- measurement techniques and instruments used, including references for procedures and protocols used to perform the measurements
} 
Appendix B

- minimum detectable concentrations (MDCs) of the instruments and measurement systems used to perform the measurements

- calibration, field testing, and maintenance of the instrumentation

- qualifications of the personnel using the instrumentation

- methods used to interpret the survey measurements

- qualifications of the personnel interpreting the survey measurements

- measurement results and measurement locations including the operator's name, instrument model and serial number, date the measurement was performed, and traceability of the measurement location

The number of measurements in each survey unit and each reference area can be determined using Table 5.3 for sites where the radionuclide of potential interest is present in background. The number of measurements for each survey unit where the radionuclide is not present in background can be determined using Table 5.5. Values for acceptable decision error levels ( $\alpha$ and $\beta)$ and the relative shift $(\Delta / \sigma)$ can be determined as described in Section 5.5.2. For sites where the simplified approach in this appendix is appropriate, reasonably conservative values for these parameters would be $\alpha=0.05, \beta=0.05$, and $\Delta / \sigma=1$. After increasing the number of measurements by $20 \%$ to ensure adequate power for the statistical tests, Table 5.3 and Table 5.5 list a value of approximately 30 measurements for each survey unit and each reference.

Therefore, 30 measurements may be used in place of the guidance in Section 5.5.2 at sites that qualify for the simplified survey design process.

The results of the survey should be compared to derived concentration guideline levels (DCGLs) using an appropriate statistical test, such as the Student's $t$ test or Wilcoxon test. If all measurements are less than the DCGL ${ }_{W}$, then the statistics do not need to be addressed because the conclusions are obvious. If the mean of the measurements exceeds the $\mathrm{DCGL}_{\mathrm{W}}$, the survey unit obviously fails to demonstrate compliance and the statistics do not need to be addressed.

Radiation levels and concentrations should be reported as follows:

- $\quad$ For external dose rates, units of:

- milli-Sieverts (micro-rem) per hour at one meter from surfaces;

- For levels of radioactive materials, including alpha and beta measurements, units of:

- $\quad \mathrm{Bq} / \mathrm{m}^{2}\left(\mathrm{dpm} / 100 \mathrm{~cm}^{2}, \mathrm{pCi} / 100 \mathrm{~cm}^{2}\right.$ ) (removable and fixed) for surfaces;

- $\quad \mathrm{Bq} / \mathrm{L}(\mathrm{pCi} / \mathrm{mL})$ for water;

- $\quad \mathrm{Bq} / \mathrm{kg}(\mathrm{pCi} / \mathrm{g})$ for solids such as soils or concrete. 


\section{APPENDIX C \\ REGULATIONS AND REQUIREMENTS ASSOCIATED WITH RADIATION SURVEYS AND SITE INVESTIGATIONS ${ }^{1}$}

\section{C.1 EPA Statutory Authorities}

The U.S. Environmental Protection Agency administers several statutes that address various aspects of the cleanup of radioactively contaminated sites. Listed below are the statutes, the implementing regulations, and the responsible EPA offices.

\section{C.1.1 The Office of Air and Radiation (OAR) administers several statutes and implementing regulations:}

- Clean Air Act (CAA) as amended (42 U.S.C. 7401-7671 q.): The CAA protects and enhances the nation's air quality through national ambient air quality standards, new source performance standards, and other provisions. Radionuclides are a hazardous air pollutant regulated under Section 112 of the Act.

- National Emissions Standard for Hazardous Air Pollutants for Radionuclides (40 CFR Part 61, 10 CFR 20.101-20.108)

- Uranium Mill Tailings Radiation Control Act (UMTRCA) of 1978 (42 U.S.C. 2022): UMTRCA requires stabilization and control of byproduct materials (primarily mill tailings) at licensed commercial uranium and thorium processing sites. NRC and DOE implement standards under this Act.

- $\quad$ Health and Environmental Protection Standards for Uranium and Thorium Mill Tailings (40 CFR Part 192)

This regulation, along with "Criteria Relating to the Operation of Uranium Mills and the Disposition of Tailings or Wastes Produced by the Extraction or Concentration of Source Material From Ores Processed Primarily for Their Source Material Content" (10 CFR 40, Appendix A), issued by the NRC and EPA, establish technical criteria related to the operation, decontamination, decommissioning, and reclamation of uranium or thorium mills and mill tailings. Both regulations provide design requirements for closure of the mill's waste disposal area.

\footnotetext{
${ }^{1}$ The user of this manual should consult the text of the statutes and regulations listed in this Appendix to ensure compliance with all requirements applicable to a specific site and to ensure the use of current versions of applicable statutes and regulations.
} 
The principal radiological hazards from uranium milling operations and mill tailings disposal are due to radon gas emissions originating from uranium and thorium daughters. Release rates to the atmosphere are limited to an average rate of $0.7 \mathrm{~Bq}(20 \mathrm{pCi})$ per square meter per second. This rate is applicable to any portion of a licensed or disposal site unless land areas do not contain radium . concentrations-averaged over 100 square meters-greater than (i) $185 \mathrm{~Bq} / \mathrm{kg}$ ( $5 \mathrm{pCi} / \mathrm{g}$ ) of radium averaged over the first 15 centimeters below. the surface and (ii) $555 \mathrm{~Bq} / \mathrm{kg}(15 \mathrm{pCi} / \mathrm{g})$ of radium averaged over $15 \mathrm{~cm}$ thick layers more than 15 centimeters below the surface.

- $\quad$ Atomic Energy Act (AEA) as amended (42 U.S.C. 2011-2296): The AEA requires the management, processing, and utilization of radioactive materials in a manner that protects public health and the environment. This is the principal basis for EPA, NRC and DOE authorities.

The AEA requires that source, special nuclear, and byproduct materials be managed, processed, and used in a manner that protects public health and the environment. Under the AEA and Reorganization Plan No. 3 of 1970, EPA is authorized to issue federal guidance on radiation protection matters as deemed necessary by the Agency or as mandated by Congress. This guidance may be issued as regulations, given that EPA possesses the authority to promulgate generally applicable radiation protection standards under Reorganization Plan No. 3. For example, under AEA authority EPA promulgated its environmental radiation protection standards for nuclear power operations in $40 \mathrm{CFR}$ Part 190.

In conjunction with the AEA, EPA presently supports the following:

- $\quad$ Environmental Radiation Protection Standards for the Management and Disposal of Spent Nuclear, High-Level and Transuranic Radioactive Wastes (40 CFR 191)

- Nuclear Waste Policy Act (NWPA), as amended (Pub. L. 100-507, 42 U.S.C. 10101): The NWPA is intended to provide an orderly scheme for the selection and development of repositories for high-level radioactive waste and spent nuclear fuel.

- Low Level Radioactive Waste Policy Act (LLRWPA), as amended (Pub. L. 99-240, 42 U.S.C. 2021b): LLRWPA assigns States responsibility for ensuring adequate disposal capacity for low-level radioactive waste generated within their borders.

- Indoor Radon Abatement Act of 1988 (15 U.S.C. 2601 Sec. 301-311) 
C.1.2 The Office of Emergency and Remedial Response (OERR) administers the Comprehensive Environmental Response, Compensation, and Liability Act (CERCLA) of 1980, as amended (Pub. L. 99-499, 42 U.S.C. 9601-9657)

- CERCLA authorizes EPA, consistent with the National Oil and Hazardous Substances Contingency Plan (NCP, 40 CFR 300) to provide for remedial action in response to releases or substantial threats of releases of hazardous substances into the environment. Hazardous substances are defined as any substance designated or listed under the Clean Air Act, the Federal Water Pollution Control Act, the Toxic Substances Control Act, and the Resource Conservation and Recovery Act. Because the CAA designated radionuclides as a hazardous air pollutant, the provisions of CERCLA apply to radionuclides.

\section{C.1.3 The Office of Solid Waste (OSW) administers the Resource Conservation and} Recovery Act of 1976 (RCRA), as amended (Pub. L. 94-580, 42 U.S.C. 6901 et seq.)

- $\quad$ RCRA provides for detailed regulation of hazardous waste from generation to final disposal. Hazardous waste generators and transporters must comply with EPA standards. Owners and operators of treatment, storage, or disposal facilities must obtain RCRA permits. Materials defined in the AEA are expressly excluded from the definition of solid waste, and, thus from regulation under RCRA. Naturally occurring and accelerator produced radioactive materials, however, are not excluded.

\section{C.1.4 The Office of Water (OW) administers several statutes and implementing regulations:}

- Section 14.2 of the Public Health Service Act as amended by the Safe Drinking Water Act (SDWA) as amended (Pub. L. 93-523, 42 U.S.C. 300 f et seq.). As amended in 1986, SDWA seeks to protect public water supply systems through protection of groundwater. Any radioactive substance that may be found in water is regulated under the Act (although the current regulations only specify a limited number of individual substances).

- Maximum Contaminant Levels (includes certain radionuclides). (40 CFR 141.11141.16)

- Clean Water Act as amended (Pub. L. 92-500, 33 U.S.C. 1251 et seq.)

- $\quad$ Requirements (40 CFR Parts 131, 400-469) established pursuant to sections 301, 302, 303 (including State water quality standards), 306, 307, (including Federal Pretreatment requirements for discharge into a publicly owned treatment works), and 403 of the Clean Water Act. 
Appendix C

\section{C.1.5 The Office of Prevention, Pesticides and Toxic Substances administers the Toxic Substances and Control Act (TSCA; 15 U.S.C. 2601)}

- TSCA regulates the manufacture, distribution in commerce, processing, use, and disposal of chemical substances and mixtures. Materials defined in the AEA are expressly excluded from TSCA. However, naturally occurring and accelerator produced radionuclides are not excluded.

\section{C.2 DOE Regulations and Requirements}

\section{C.2.1 Authorities of the Department of Energy}

The Department of Energy Organization Act, which created DOE, the Energy Reorganization Act of 1974, which created the Energy Research and Development Administration, and the Atomic Energy Act of $1954^{2}$ provide the basic authorities of the Department of Energy. The principal DOE statutory authorities and regulations that pertain to radiation protection are shown in Table C.1.

\section{C.2.1.1 Atomic Energy Act of 1954, as amended}

The Atomic Energy Act of 1954 established a program of private ownership and use of nuclear materials and nuclear facilities, such as nuclear research reactors, and a program for government regulation of those applications. (Prior to 1954, all source, byproduct, and special nuclear materials were government owned). The Atomic Energy Commission was given both the regulatory authorities and the mission to develop both the peaceful and military uses of atomic energy. The Act also retained the Atomic Energy Commission as the civilian agency responsible for weapons programs production, development and research consistent with the Atomic Energy Act of 1946.

Under the Act, the Atomic Energy Commission was responsible for establishing regulations ensuring the safety of commercial facilities and establishing requirements that ensure public protection from radiation and radioactive materials resulting from or used in its research, development, and production activities.

\footnotetext{
${ }^{2}$ The Atomic Energy Commission was created by the Atomic Energy Act of 1946, not the 1954 act.
} 
Appendix C

Table C.1

\section{DOE AUTHORITIES, ORDERS AND REGULATIONS RELATED TO RADIATION PROTECTION}

\section{Statutes}

Atomic Energy Act of 1954, as amended

Energy Reorganization Act of 1974

Uranium Mill Tailings Radiation Control Act of 1978 , as amended

Nuclear Non-Proliferation Act of 1978

Department of Energy Organization Act of 1980

West Valley Demonstration Project Act of 1980

Nuclear Waste Policy Act of 1982

Low-Level Waste Policy Act of 1980

Low-Level Waste Policy Amendments Act of 1985

Energy Policy Act of 1992

Waste Isolation Pilot Plant Land Withdrawal Act

Price Anderson Act

\section{$\underline{\text { DOE Regulations }}$}

10 CFR Part 835, "Occupational Radiation Protection"

\section{Executive Orders}

\section{DOE Orders}

Order 5400.1, "General Environmental Protection Program"

Order 5400.2A, "Environmental Compliance Issue Coordination"

Order DOE 5400.5, "Radiation Protection of the

Public and the Environment"

Order DOE 5400.4, "Comprehensive Environmental, Response, Compensation and Liability Act Requirements"

Order DOE 5440.1E, "National Environmental Policy Act Compliance Program"

Order DOE 5480.1B, "Environment, Safety and

Health Program for Department of Energy Facilities" Order DOE 5480.3, "Safety Requirements for the Packaging and Transportation of Hazardous Materials, Hazardous Substances \& Hazardous Wastes"

Order DOE 5480.4, "Environment, Safety and Health Protection Standards"

Order DOE 5480.6, "Safety of Department of Energy Owned Nuclear Reactors"

Order DOE 5480.11, "Occupational Radiation Protection"

Order DOE 5480.24, "Nuclear Criticality Safety" Order DOE 5480.25, "Safety at Accelerator Facilities"

Order DOE 5484.1, "Environmental Protection, Safety and Health Protection Information Reporting Requirements"

Order DOE 5820.2A, "Radioactive Waste

Management"

Executive Order 12580 
Appendix C

\section{C.2.1.2 Energy Reorganization Act of 1974 (Public Law 93-438 (1974), as amended)}

The Energy Reorganization Act of 1974 divided the former Atomic Energy Commission and created the Energy Research and Development Administration (ERDA) and the Nuclear Regulatory Commission. The ERDA was responsible for radiation protection at its facilities, to provide for worker and public health, worker safety, and environmental protection. ERDA was abolished with the creation of the Department of Energy in 1980.

\section{C.2.1.3 Department of Energy Organization Act of 1977 Public Law 95-91}

The Department of Energy Organization Act created the Department of Energy (DOE) by combining the Energy Research \& Development Administration, the Federal Energy Administration, Federal Power Commission, and part of the Department of Interior.

The DOE was intended to identify potential environmental, health, safety, socioeconomic, institutional, and technological issues associated with the development and use of energy sources. Through this Act, DOE retained the responsibilities and authorities-held by its predecessor agencies - to take actions necessary to protect the public from radiation associated with radioactive materials production, research, and development. DOE established requirements through a directives system that largely used DOE Orders as its regulatory procedures. With the passage of the Price-Anderson Act Amendments of 1990, DOE began converting its health and safety Orders to rules.

\section{C.2.1.4 Uranium Mill Tailings Radiation Control Act of 1978, as amended}

The Uranium Mill Tailings Radiation Control Act (UMTRCA) provides a program of assessment and remedial action at active and inactive uranium mill sites to control their tailings in a safe and environmentally sound manner and to reduce radiation hazards to the public residing in the vicinity of these sites. The DOE was directed to complete remedial action at 21 sites of inactive uranium mills.

\section{C.2.1.5 West Valley Demonstration Project Act of 1980}

This act authorized DOE to carry out a project at West Valley, New York to demonstrate solidification techniques which could be used for preparing high level radioactive waste for disposal. The Act provides for informal review and project consultation by the NRC.

\section{C.2.1.6 Low-Level Waste Policy Act of 1980}

This act established the policy that each State is responsible for providing for the disposal of lowlevel radioactive waste generated within its borders, except for waste from defense activities of 
DOE or Federal research and development activities, and authorized States to enter into compacts to carry out this policy. DOE was required to take actions to assist the States in carrying out this policy.

\section{C.2.1.7 Nuclear Waste Policy Act of 1982 (Public Law 97-425, 1983)}

This Act gives DOE the responsibility to develop repositories and to establish a program of research, development, and demonstration for the disposal of high-level radioactive waste and spent nuclear fuel. Title to and custody of commercial low-level waste sites under certain conditions could be transferred to DOE.

\section{C.2.1.8 Low-Level Waste Policy Amendments Act of 1985}

This act amends the Low-Level Waste Policy Act of 1980 to improve the procedures for State compacts. It also assigns responsibility to the Federal government for the disposal of low-level waste generated or owned by the DOE, specific other Federally generated or owned wastes, and wastes with concentrations of radionuclides that exceed the limits established by the NRC for class $\mathrm{C}$ radioactive waste. The Act provides that all class $\mathrm{C}$ radioactive wastes designated as a Federal responsibility - those that result from activities licensed by the NRC - shall be disposed of in a facility licensed by the NRC. The Act also assigns responsibilities to DOE to provide financial and technical assistance to the States in carrying out the Act.

\section{C.2.1.9 Waste Isolation Pilot Plant Land Withdrawal Act}

The Waste Isolation Pilot Plant (WIPP) is a repository intended for the disposal of transuranic radioactive waste produced by defense activities. The Act establishes the following:

1) an isolated parcel of land for the WIPP

2) provisions concerning testing and limits on the quantities of waste which may be disposed at the WIPP

3) EPA certification of compliance with disposal standards

\section{C.2.1.10 Price Anderson Act}

\section{C.2.2 Executive Orders}

Executive Order (E.O.) 12580 delegates to various Federal officials the responsibilities vested in the President for implementing the Comprehensive Environmental Response, Compensation, and Liability Act of 1980 (CERCLA) as amended by the Superfund Amendments and Reauthorization Act of 1986 (SARA). 
Appendix C

\section{C.2.3 DOE Regulations and Orders}

\section{C.2.3.1 10 CFR Part 835, "Occupational Radiation Protection"}

This rule, which became effective on January 13, 1993, provides for the protection of radiation workers at DOE owned facilities. The requirements contained in Part 835 are generally similar to those in Order DOE 5480.11 and those used in NRC Regulations pertaining to the commercial nuclear industry. In addition to the rule, DOE issued a dozen implementation guides, including the "DOE Radiological Control Manual," (DOE/EH-0256T, Rv.1, April 1994).

\section{C.2.3.2 Order DOE 5400.5, "Radiation Protection of the Public and the Environment"}

This Order, issued in February 1990, contains DOE's requirements for ensuring the protection of the public from the hazards of radiation. This regulation includes dose limits for protection of the public and environment, plus requirements:

1) to apply the ALARA process-to reduce doses to the public as far below the release criterion as is practicable

2) to apply the best available control technology to liquid effluents

3) for control of property containing residual radioactive material

DOE 5400.5 is supported by numerous guidance documents, including those listed in this section.

DOE 5400.5 is the primary directive relating to the release of property subject to radiological contamination by DOE operations. DOE 5400.5 will be replaced by 10 CFR Part 834 and its guidance will be adopted for Part 834 when it is issued.

Under DOE 5400.5 and the guidance included in this section (C.2.3), DOE established requirements for a case-by-case review and approval for release of real or non-real property containing residual radioactive material. Authorized limits and measurement procedures must be developed by DOE before facilities can release property from their control. The principle requirement is to reduce doses to levels that are as low as practicable using the ALARA process and assuming realistic but conservative use scenarios that are not likely to underestimate dose. This requirement ensures that doses are as far below the primary dose limit ( $1 \mathrm{mSv} / \mathrm{y}$ [100 $\mathrm{mrem} / \mathrm{y}]$ ) as is reasonably achievable. Because the primary dose limit is for doses from all sources and pathways, authorized limits should be selected at levels below a DOE dose constraint of $0.3 \mathrm{mSv} / \mathrm{y}(30 \mathrm{mrem} / \mathrm{y})$. However, the goal is to reduce doses under likely-use scenarios to a few fractions of a $\mathrm{mSv} / \mathrm{year}$ or less. 
In addition to the requirement to apply ALARA and the dose constraint, DOE also utilizes surface contamination guidelines similar to those in NRC Regulatory Guide 1.86 and the 40 CFR Part 192 soil concentration limits for radium and thorium. The ALARA requirement ensures that the 40 CFR Part 192 limits are appropriately used. DOE also permits the use of supplemental limits for situations where cleanups to authorized limits are not practicable or where the scenarios used to develop the authorized limits are not appropriate. DOE 5400.5 permits the release of property for restricted use and requires procedures to ensure these restrictions are maintained.

Most DOE remedial action and restoration activities are also subject to CERCLA. In such cases, DOE requirements are integrated into the CERCLA process.

The following sections describe the scope and importance of several guidance documents.

A. Residual Radioactive Material Control:

DOE/CH-8901, Manual for Implementing Residual Radioactive Material Guidelines - A Supplement to the U.S. Department of Energy Guidelines for Residual Radioactive Material at FUSRAP and SFMP Sites, Department of Energy, June 1989.

DOE Guidance Memorandum, "Unrestricted Release of Radioactively Contaminated Personal Property," J. Maher, DOE Office of Nuclear Safety, Mar. 15, 1984.

ANL/EAD/LD-2, Manual for Implementing Residual Radioactive Material Guidelines Using RESRAD, Version 5.0, Published by Argonne National Laboratory and prepared by ANL and DOE staff, September 1993.

ANL/EAIS-8, Data Collection Handbook to Support Modeling the Impacts of Radioactive Material in Soil, Argonne National Laboratory, April 1993.

ANL/EAIS/TM-103, A Compilation of Radionuclide Transfer Factors for Plant, Meat, Milk and Aquatic Food Pathways and Suggested Default Values for the RESRAD Code, Argonne National Laboratory, August 1993.

PNL-8724, Radiation Dose Assessments to Support Evaluations of Radiological Control Levels for Recycling or Reuse of Material and Equipment, Pacific Northwest Laboratory, July 1995.

ANL/EAD.LD-3, RESRAD-Build: A Computer Model for Analyzing the Radiological Doses Resulting from the Remediation and Occupancy of Buildings Contaminated with Radioactive Material, Argonne National Laboratory, November 1994. 
Appendix C

B. ALARA

DOE Guidance: DOE Guidance on the Procedures in Applying the ALARA Process for Compliance with DOE 5400.5, Department of Energy, Office of Environmental Guidance, March 8, 1991.

ANL/EAD/LD-2, Manual for Implementing Residual Radioactive Material Guidelines Using RESRAD, Version 5.0, Chapters 1 and 5 and App. M, September 1993.

C. Measurement and Data Reporting

DOE Manual for use and Comment, Environmental Implementation Guide for Radiological Survey Procedures, Department of Energy, Office of Environmental Guidance, Nov. 1992.

DOE/EH-0173T, Environmental Regulatory Guide for Radiological Effluent Monitoring and Environmental Surveillance, Department of Energy, Jan. 1991.

D. Dose Factors

DOE/EH-0071, Internal Dose Conversion Factors for Calculation of Dose to the public, DOE, July 1988. DOE currently recommends use of EPA-520-1-88-020, Federal Guidance Report No. 11, Limiting Radionuclide Intake and Air Concentrations and Dose Conversion Factors for Inhalation, Submersion and Ingestion, Environmental Protection Agency, Sept. 1988, as an alternative to DOE/EH-0071.

DOE/EH-0070, External Dose-Rate Conversion Factors for Calculation of Dose to the Public, DOE, July 1988. DOE currently recommends use of EPA 402-R-93-081, Federal Guidance Report No. 12, External Exposure to Radionuclides in Air, Water and Soil, Environmental Protection Agency, Sept. 1993, as an alternative to DOE/EH-0070.

E. Liquid Effluents

Implementation Guidance for DOE 5400.5. Section II.3 (Management and Control of Radioactive Materials in Liquid Discharges and the Phaseout of Soil Columns), DOE Office of Environment, June 1992.

\section{C.2.3.3 Order DOE 5820.2A, "Radioactive Waste Management"}

Order DOE 5820.2A establishes the policies, guidelines, and requirements by which the DOE manages its radioactive and mixed waste and contaminated facilities. The Order implements DOE's responsibilities and authorities for prediction of public and worker health and safety and 
the environment under the Atomic Energy Act. It contains the requirements for management and disposal of high-level waste, transuranic waste, low-level waste, NARM waste, and for the decommissioning of radioactively contaminated facilities.

\section{A. High-level Waste}

The Order specifies: (1) requirements for storage operations including requirements for waste characterization, transfer operations, monitoring, surveillance, and leak detection, and (2) specifies that disposal shall be in accordance with the requirements of the Nuclear Waste Policy Act of 1982.

\section{B. Transuranic Waste}

The Order requires waste to be certified in compliance with the Waste Isolation Pilot PlantWaste Acceptance Criteria and sent to the WIPP. There are requirements for waste classification, waste generation and treatment, waste certification, waste packaging, temporary storage, transportation and shipping, and interim storage. There are provisions for use of the WIPP, and for assessing the disposition of previously buried transuranic-contaminated wastes.

\section{Low-level Waste}

The Order specifies performance objectives which assure that external exposure waste concentrations of radioactive material - which may be released into surface water, ground water, soil, plants, and animals-result in an effective dose equivalent that does not exceed $0.25 \mathrm{mSv} / \mathrm{y}$ ( $25 \mathrm{mrem} / \mathrm{y})$ to a member of the public. Releases to the atmosphere shall meet the requirements of 40 CFR Part 61. Reasonable efforts should be made to maintain releases of radioactivity in effluents to the general environment as low as is reasonably achievable. Radiological performance assessments are required for the disposal of waste for the purpose of demonstrating compliance with these performance objectives.

For low-level waste, there are also requirements on waste generation, waste characterization, waste acceptance criteria, waste treatment, and long term storage. The Order includes additional disposal requirements concerning disposal facility and disposal site design and waste characteristic, site selection, facility operations, site closure and post closure, and environmental monitoring.

\section{NARM Waste}

For management of Naturally-Occurring and Accelerator-Produced Radioactive Materials (NARM) and 11(e)(2) byproduct materials (the tailings or wastes resulting from the concentration of uranium or thorium), the order specifies that storage and disposal shall be 
Appendix C

consistent with the requirements of the residual radioactive material guidelines contained in 40 CFR 192.

E. Decommissioning of Radioactively Contaminated Facilities

For the decommissioning of contaminated facilities, the order requires DOE organizations to develop and document decommissioning programs which include provisions for surveillance and maintenance. There are requirements for facility design, post-operational activities, characterization, and environmental review.

\section{C.3 NRC Regulations and Requirements}

\section{C.3.1 NRC's Mission and Statutory Authority}

The mission of the U.S. Nuclear Regulatory Commission (NRC) is to ensure adequate protection of the public health and safety, the common defense and security, and the environment in the use of nuclear materials in the United States. The NRC's scope of responsibility includes regulation of commercial nuclear power reactors; nonpower research, test, and training reactors; fuel cycle facilities; medical, academic, and industrial uses of nuclear materials; and the storage and disposal of nuclear materials and waste.

The NRC is an independent agency created by the Energy Reorganization Act of 1974. This Act abolished the Atomic Energy Commission (AEC), moved the AEC's regulatory function to NRC, and, along with the Atomic Energy Act of 1954, as amended, provides the foundation for regulation of the nation's commercial nuclear power industry.

NRC regulations are issued under the United States Code of Federal Regulations (CFR) Title 10, Chapter 1. Principal statutory authorities that govern NRC's work are:

\footnotetext{
- Atomic Energy Act of 1954, as amended

- Energy Reorganization Act of 1974, as amended

- Uranium Mill Tailings Radiation Control Act of 1978, as amended

- Nuclear Non-Proliferation Act of 1978

- Low-Level Radioactive Waste Policy Act of 1980

- West Valley Demonstration Project Act of 1980

- $\quad$ Nuclear Waste Policy Act of 1982

- Low-Level Radioactive Waste Policy Amendments Act of 1985

- Diplomatic Security and Anti-Terrorism Act of 1986

- $\quad$ Nuclear Waste Policy Amendments Act of 1987

- Solar, Wind, Waste and Geothermal Power Production Incentives Act of 1990

- $\quad$ Energy Policy Act of 1992
} 
The Atomic Energy Act of 1954, as amended, allows the NRC to issue orders to both licensees and persons not licensed by the NRC. NRC orders may be a means of compelling decommissioning at sites where the license has been terminated or at sites that were not previously licensed but currently contain radioactive material that is under the jurisdiction of the NRC.

The NRC and its licensees share a common responsibility to protect the public health and safety. Federal regulations and the NRC regulatory program are important elements in the protection of the public. NRC licensees, however, have the primary responsibility for the safe use of nuclear materials.

\section{C.3.2 NRC Criteria for Decommissioning}

This section of the survey manual contains information on the existing cleanup criteria for decommissioning sites regulated by the NRC. Additional cleanup criteria established by State and local governments may also be applicable at NRC-licensed sites at the time of decommissioning.

NRC's requirements for decommissioning and license termination are contained in $10 \mathrm{CFR}$ $30.36,40.42,50.82,70.38$, and 72.54 . The radiological criteria for license termination are contained in 10 CFR 20.1401 through 1406 (62 FR 39058, July 21, 1997).

Prior to the adoption of the current regulations on radiological criteria for license termination, the Commission's position on residual contamination criteria, site characterization, and other related decommissioning issues was outlined in a NRC document entitled "Action Plan to Ensure Timely Cleanup of Site Decommissioning Management Plan Sites," which was published in the Federal Register on April 6, 1993 (57 FR 13389). Other documents that were used in the past and which may continue to have some applicability in special cases include:

"Criteria Relating to the Operation of Uranium Mills and the Disposition of Tailings or Wastes Produced by the Extraction or Concentration of Source Material From Ores Processed Primarily for Their Source Material Content" (10 CFR 40, Appendix A) and Health and Environmental Protection Standards for Uranium and Thorium Mill Tailings (40 CFR 192, Subparts D and E)

These regulations, issued by the NRC and EPA, establish technical criteria related to the operation, decontamination, decommissioning, and reclamation of uranium or thorium mills and mill tailings. Both regulations provide design requirements for closure of the mill's waste disposal area, which requires an earthen cover over tailings or waste piles to control radiological hazards from uranium and thorium tailings for 200 to 1,000 years, according to Technical Criterion 6 of Appendix A to 10 CFR Part 40. 
Appendix C

The principal radiological hazards from uranium milling operations and mill tailings disposal are radon from uranium and thorium daughters. The atmospheric release rates of these gaseous radionuclides to the atmosphere are limited to an average rate of $0.7 \mathrm{~Bq}(20$ $\mathrm{pCi})$ per square meter per second. This rate is applicable to any portion of a licensed or disposal site unless land areas do not contain radium concentrations-averaged over 100 square meters-greater than: (i) $0.2 \mathrm{~Bq} / \mathrm{g}$ ( $5 \mathrm{pCi} / \mathrm{g}$ ) of radium averaged over the first 15 centimeters below the surface, and (ii) $0.6 \mathrm{~Bq} / \mathrm{g}(15 \mathrm{pCi} / \mathrm{g})$ of radium averaged over 15 -centimeter thick layers more than 15 centimeters below the surface.

Criterion 6 allows radon release rates to be averaged over a period of at least 1 year (but much less than 100 years) to account for the wide variability in atmospheric radon concentrations over short time periods and seasons. In addition, this criterion applies only to emissions from uranium daughters and does not include radon emissions from earthen materials used to cover the tailings piles. If appropriate, radon emissions from cover materials are evaluated when developing a closure plan for each site to account for this additional contribution from naturally occurring radon. However, direct gamma exposure rates from tailings or wastes should be reduced to background levels according to this standard.

\section{C.3.3 NRC Decommissioning Process and Staff Plans for Implementing Survey Procedures in this Manual}

NRC licensees are required to conduct radiation surveys of the premises where the licensed activities were conducted and submit a report describing the survey results. The survey process follows requirements contained in 10 CFR $30.36,40.42,50.82,70.38$, and 72.54 , which pertain to decommissioning of a site and termination of a license. This process leads to the unrestricted release of a site; however, many of the requirements may not be necessary if the licensee demonstrates that the premises are suitable for release in some other manner. Each year, the $\mathrm{NRC}$ staff routinely evaluates licensee requests to discontinue licensed operations. The majority of these requests are straightforward, requiring little, if any, site remediation before radiological surveys are conducted and evaluated. However, some NRC sites require substantial remediation because buildings and lands contain nonroutine amounts of radiological contamination. Radiological surveys may also be performed by the NRC at sites where there is not a license.

The NRC decommissioning process for a site requiring substantial remediation can be described by the activities listed below:

- licensee notifies the NRC they intend to decommission all or part of the site

- site characterization, including preparation of the characterization plan and performance of site characterization

- development and submission of decommissioning plan 
- $\quad$ NRC review and approval of decommissioning plan

- performance of decommissioning actions described in the plan

- $\quad$ performance of termination survey and submittal of termination survey report

- $\quad$ NRC performance and documentation of confirmatory survey

- $\quad$ NRC termination of license

The NRC staff plans to use the information contained in this manual as primary guidance for conducting radiological surveys of routine licensee requests for license termination and nonroutine license termination requests that require more extensive decommissioning actions. Supplementary guidance may be used by the NRC staff to assist licensees in conducting such surveys or aid the NRC staff in evaluating licensee's survey plans and survey results to determine compliance with decommissioning criteria. Examples of supplementary guidance include NRC Information Notices, Bulletins, Generic Letters, Branch Technical Positions, NUREG reports, Regulatory Guides, and other regulatory documents that transmit NRC requirements and guidance.

\section{C.4 DOD Regulations and Requirements}

The Department of Defense (DOD) consists of four primary military services: the United States Air Force, the United States Army, the United States Navy, and the United States Marine Corps.

DOD installations use sources of ionizing radiation and support radiation protection programs for the control of these radioactive materials. As a Federal agency, the DOD complies with all applicable environmental regulations under the Federal Facilities Compliance Act of 1992.

\section{C.4.1 DOD Sources of Ionizing Radiation}

DOD's list of radioactive materials includes:

- Special nuclear material such as plutonium or enriched uranium

- Source material such as uranium or thorium

- Byproduct material such as any radioactive material yielded in or made radioactive by exposure to radiation incident to the process of producing special nuclear material

- Naturally occurring or accelerator-produced radioactive material (NARM), such as radium, and not classified as source material

- Materials containing induced or deposited radioactivity

Ionizing Radiation Producing Devices: Electronic devices that are capable of emitting ionizing radiation. Examples are linear accelerators, cyclotrons, radiofrequency generators that use klystrons or magnetrons, and other electron tubes that produce $\mathrm{x}$-rays. These devices may have 
Appendix C

components that contain radioactive material or they may induce radioactivity in certain other materials.

\section{C.4.2 Commodities Containing Radioactive Material Within the DOD System}

The DOD uses a variety of manufactured items (commodities) incorporating in whole or in part both sealed and unsealed radioactive material. A sealed source is any radioactive material that is permanently bound or fixed in a capsule or matrix designed to prevent the release or dispersal of such material under the most severe conditions encountered in normal use.

Ionizing radiation is used directly in DOD systems as calibration and check sources for RADIAC or other survey-type instruments, as a source of radioluminescence in meters and gauges, as an ionization source in various devices, and as radiographic sources.

Indirectly, ionizing radiation may be emitted from a DOD material system as natural radioactivity or induced radioactivity incorporated into material or a component of the system.

Specific examples of commodities include instrument calibration sources, luminescent compasses and exit signs, certain electron tubes and spark gaps, depleted uranium counterweights and munitions, and magnesium-thorium aircraft components.

\section{C.4.3 Licensed Radioactive Material}

Licensed radioactive material is source, special nuclear, or byproduct material received, stored, possessed, used, or transferred under a specific or general license issued by the NRC or an NRC Agreement State.

Radioactive material licensed or controlled by the individual military services:

- The Department of the Air Force has been designated by the NRC, through the issuance of a Master Materials License, regulatory authority for the receipt, possession, distribution, use, transportation, transfer, and disposal of radioactive material at Air Force activities. The Air Force Radioisotope Committee was established to provide administrative control of all radioactive material used in the Air Force except for reactors and associated radioactivity, nuclear weapons, and certain components of weapons delivery systems. Air Force Radioactive Material Permits are used to maintain this control.

- The Department of the Army, through the issuance of NRC specific licenses to Army installations and activity commanders, maintains the regulatory authority for the receipt, possession, distribution, use, transportation, transfer, and disposal of radioactive material 
at Army activities. In addition, within the Department of the Army, radioactive material classified as NARM may be used under a Department of the Army Radioactive Material Authorization (DARA) issued by the Army Material Command (AMC) or the Office of The Army Surgeon General. A Department of the Army Radiation Permit is required for use, storage, possession, and disposal of radiation sources by non-Army agencies (including contractors) on Army installations.

- The Department of the Navy is designated by the NRC to have-through the issuance of a Master Materials License-regulatory authority for the receipt, possession, distribution, use, transportation, transfer, and disposal of radioactive material at Navy and Marine Corps activities. The Navy Radiation Safety Committee was established to provide administrative control of all radioactive material used in the Navy and Marine Corps except for nuclear propulsion reactors and associated radioactivity, nuclear weapons, and certain components of weapons delivery systems. Navy Radioactive Material Permits are used to maintain this control.

\section{C.4.4 Other Controlled Radioactive Material}

Certain radioactive material on DOD installations may not be controlled or regulated by either the NRC or the DOE. However, during Base Realignment and Closure actions, DOD installation property which is identified to be returned to civilian use may have the potential for radioactive contamination by such material. The DOD complies with applicable State limits, guidelines, and procedures for this material. The methodologies and technical approaches for environmental radiological surveys outlined in this manual will provide guidance for dealing with issues concerning this material.

Naturally Occurring and Accelerator-Produced Radioactive Material

- Naturally occurring and accelerator-produced radioactive material (NARM) is controlled and regulated by the individual military services, as is similarly done by certain States for corporations and other users residing within their boundaries.

Special Nuclear Material Used in Military Applications

- Special nuclear material used in military applications is a unique category of radioactive material. This may be buried as radioactive waste on DOD installations, used in military weapons or utilization facilities, or used in nuclear reactors involving military applications on DOD installations. Radioactive material used or associated with weapons systems or reactors associated with such military applications is exempt from NRC and State regulations under Section 91b, Chapter 9, Military Application of Atomic Energy, Atomic Energy Act of 1954. 
Appendix C

\section{C.4.5 DOD Regulations Concerning Radiation and the Environment}

The DOD, with its global mission, supports several directives and instructions concerning environmental compliance. The individual military services have regulations implementing these directives and instructions. The documents describing these regulations are used as guidance in developing environmental radiological surveys within DOD.

The DOD and each military service also have specific regulations addressing the use of radioactive sources and the development of occupational health programs and radiation protection programs. These regulations may help in identifying potential locations and sources of radioactive contamination on DOD installations.

\section{C.4.6 DOD Regulations and Requirements}

Regulations and Requirements Concerning Development of Environmental Radiological Surveys

1. DOD Directive 4165.60, Solid and Hazardous Waste Management-Collection, Disposal, Resource Recovery, and Recycling Program.

2. DOD Directive 4210.15, Hazardous Material Pollution Prevention.

3. DOD Directive 5100.50, Protection and Enhancement of Environmental Quality.

4. DOD Directive 6050.1, Environmental Effects in the United States of Department of Defense Actions.

5. DOD Directive 6050.7, Environmental Effects Abroad of Major Department of Defense Actions.

6. DOD Directive 6050.8, Storage and Disposal of Non-DOD-Owned-Hazardous or Toxic Materials on DOD Installations.

7. DOD Instruction 4120.14, Environmental Pollution Prevention, Control, and Abatement.

8. DOD Instruction 5100.5, Protection and Enhancement of Environmental Quality.

Regulations and Requirements Concerning Use of Radioactive Sources and Development of Occupational Health Programs and Radiation Protection Programs:

1. DOD Instruction 6055.5-M, Occupational Health Surveillance Manual.

2. DOD Instruction 6055.8, Occupational Radiation Protection Program.

Examples of Air Force Instructions (AFIs):

1. AFI 40-201, Managing Radioactive Materials in the Air Force.

2. AFI 32-7020, Environmental Restoration Program.

3. AFI 32-7066, Environmental Baseline and Close-out Surveys in Real Estate Transactions. 
Examples of Army Regulations (ARs):

1. AR 40-5, Preventive Medicine.

2. AR 40-14, Occupational Ionizing Radiation Personnel Dosimetry.

3. AR 40-10, Health Hazard Assessment Program in Support of the Army Materiel Acquisition Decision Process.

4. AR 200-1, Environmental Protection and Enhancement.

5. AR 200-2, Environmental Effects of Army Actions.

6. AR 385-11, Ionizing Radiation Protection (Licensing, Control, Transportation, Disposal, and Radiation Safety).

7. AR 385-30, Safety Color Code Markings and Signs.

8. AR 700-64, Radioactive Commodities in the DOD Supply System.

9. AR 750-25, Army Test, Measurement, and Diagnostic Equipment (TMDE) Calibration and Repair Support Program.

10. TB MED 521, Management and Control of Diagnostic X-Ray, Therapeutic X-Ray, and Gamma Beam Equipment.

11. TB MED 522, Control of Health Hazards from Protective Material Used in SelfLuminous Devices.

12. TB MED 525, Control of Hazards to Health from Ionizing Radiation Used by the Army Medical Department.

13. TB 43-180, Calibration and Repair Requirements for the Maintenance of Army Materiel.

14. TB 43-0108, Handling, Storage, and Disposal of Army Aircraft Components Containing Radioactive Material.

15. TB 43-0116, Identification of Radioactive Items in the Army.

16. TB 43-0122, Identification of U.S. Army Communications-Electronic Command Managed Radioactive items in the Army.

17. TB 43-0141, Safe Handling, Maintenance, Storage, and Disposal of Radioactive Commodities Managed by U.S. Army Troop Support and Aviation Material Readiness Command (Including Aircraft Components).

18. TB 43-0197, Instructions for Safe Handling, Maintenance, Storage, and Disposal of Radioactive Items Managed by U.S. Army Armament Material Command.

19. TB 43-0216, Safety and Hazard Warnings for Operation and Maintenance of TACOM Equipment.

20. TM 3-261, Handling and Disposal of Unwanted Radioactive Material.

21. TM 55-315, Transportability Guidance for Safe Transport of Radioactive Materials.

Examples of Navy Regulations:

1. NAVMED P-5055, Radiation Health Protection Manual.

2. NAVSEA SO420-AA-RAD-010, Radiological Affairs Support Program (RASP) Manual.

3. OPNAV 6470.3, Navy Radiation Safety Committee. 
Appendix C

4. NAVSEA 5100.18A, Radiological Affairs Support Program.

5. OPNAV 5100.8G, Navy Safety and Occupational Safety and Health Program.

6. NAVMEDCOM 6470.10, Initial Management of Irradiated or Radioactively

Contaminated Personnel.

7. OPNAV 3710.31, Carrying Hazardous Materials; Operational Procedures.

8. NAVSUP 5101.11, Procedures for the Receipt, Storage, and Handling of Radioactive Material Shipments.

9. NAVSUP 5101.6, Procedures for the Requisitioning, Labeling, Handling, Storage, \& Disposal of Items Which Contain Radioactive By-Product Material.

10. NAVSUP 4000.34, Radioactive Commodities in the DOD Supply System.

11. NAVSEA 9639.1, Radioluminescent Sources and Radioactively Contaminated Equipment Aboard Inactive Naval Ships and Craft.

12. NAVSUP 4510.28, Special Restrictions on Issue and Disposal of Radiological Control Materials.

13. NAVMED 6470.7, Procedures and Responsibilities for Use of Radioactive Materials at NAVMED Activities.

\section{C.5 State and Local Regulations and Requirements}

An Agreement State is a state that has signed an agreement with the NRC allowing the State to regulate the use of radioactive materials-i.e., specifically Atomic Energy Act materials-within that state. Table C. 2 lists the Agreement States as of October 1, 1995 (see Appendix L for contacts and addresses). Each Agreement State provides regulations governing the use of radioactive materials that may relate to radiation site investigations. Table C.3 lists the states that regulate naturally occurring radioactive material (NORM) as of June 15, 1997 (PGA 1997). A number of other states are in the process of developing regulations governing the use of NORM. The decision maker should check with the state to ensure compliance with all applicable regulations. 


\begin{tabular}{||c|c|c|}
\hline & Table C2 Agreement States & \\
\hline Alabama & Kentucky & North Carolina \\
Arizona & Louisiana & North Dakota \\
Arkansas & Maine & Oregon \\
California & Maryland & Rhode Island \\
Colorado & Mississippi & South Carolina \\
Florida & Nebraska & Tennessee \\
Georgia & Nevada & Texas \\
Illinois & New Hampshire & Utah \\
Iowa & New Mexico & Washington \\
Kansas & New York & \\
\hline
\end{tabular}

\begin{tabular}{||c|c|c||}
\hline \multicolumn{2}{|c|}{} & Table C.3 States That Regulate Diffuse NORM \\
\hline Arkansas & Mississippi & Oklahoma (proposed) \\
Colorado (proposed) & New Jersey & Oregon \\
Georgia & New Mexico & South Carolina \\
Louisiana (proposed) & North Dakota & Texas \\
Michigan (proposed) & Ohio & Utah \\
\hline
\end{tabular}




\section{APPENDIX D}

\section{THE PLANNING PHASE OF THE DATA LIFE CYCLE}

The planning phase of the Data Life Cycle is carried out using the Data Quality Objectives (DQO) Process. The DQO Process is a series of planning steps based on the scientific method for establishing criteria for data quality and developing survey designs (EPA 1994a, 1987b, 1987c). The level of effort associated with planning is based on the complexity of the survey. Large, complicated sites generally receive a significant amount of effort during the planning phase, while smaller sites may not require as much planning effort.

Planning radiological surveys using the DQO Process can improve the survey effectiveness and efficiency, and thereby the defensibility of decisions. It also can minimize expenditures related to data collection by eliminating unnecessary, duplicative, or overly precise data. The use of the DQO Process assures that the type, quantity, and quality of environmental data used in decision making will be appropriate for the intended application. It provides systematic procedures for defining the criteria that the survey design should satisfy, including when and where to perform measurements, the level of decision errors for the survey, and how many measurements to perform.

The expected output of planning a survey using the DQO Process is a quality assurance project plan (QAPP). The QAPP integrates all technical and quality aspects of the Data Life Cycle, and defines in detail how specific quality assurance and quality control activities will be implemented during the survey.

The DQO Process provides for early involvement of the decision maker and uses a graded approach to data quality requirements. This graded approach defines data quality requirements according to the type of survey being designed, the risk of making a decision error based on the data collected, and the consequences of making such an error. This approach provides a more effective survey design combined with a basis for judging the usability of the data collected.

DQOs are qualitative and quantitative statements derived from the outputs of the DQO Process that:

- clarify the study objective

- define the most appropriate type of data to collect

- determine the most appropriate conditions for collecting the data

- $\quad$ specify limits on decision errors which will be used as the basis for establishing the quantity and quality of data needed to support the decision 
The DQO Process consists of seven steps, as shown in Figure D.1. The output from each step influences the choices that will be made later in the Process. Even though the DQO Process is depicted as a linear sequence of steps, in practice it is iterative; the outputs of one step may lead to reconsideration of prior steps as illustrated in Figure D.2. For example, defining the survey unit boundaries may lead to classification of the survey unit, with each area or survey unit having a different decision statement. This iteration is encouraged since it ultimately leads to a more efficient survey design. The first six steps of the DQO Process produce the decision performance criteria that are used to develop the survey design. The final step of the Process develops a survey design based on the DQOs. The first six steps should be completed before the final survey design is developed, and every step should be completed before data collection begins.

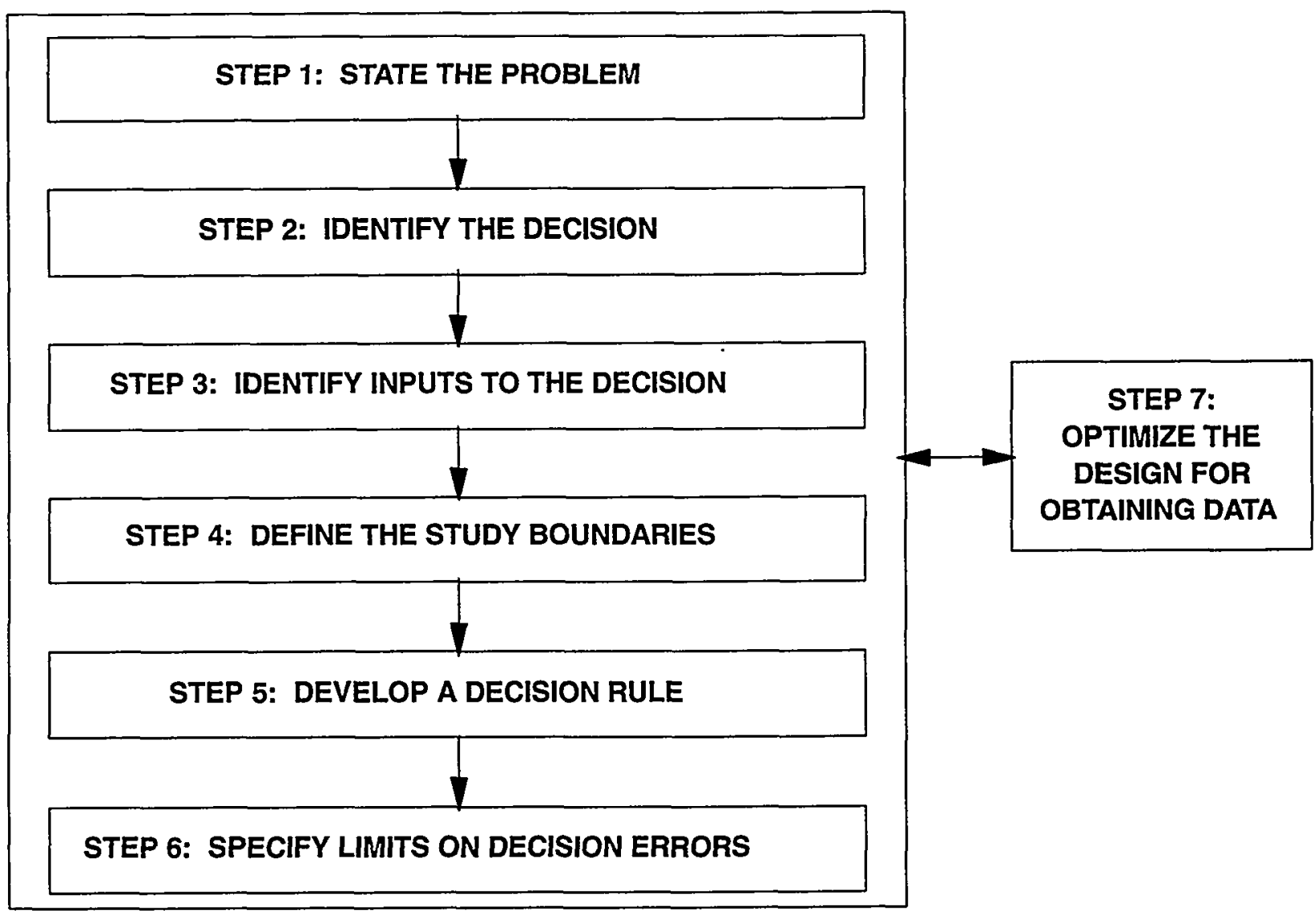

Figure D.1 The Data Quality Objectives Process

When the DQO Process is used to design a survey, it helps ensure that planning is performed properly the first time and establishes measures of performance for the data collector (implementation) and the decision maker (assessment) during subsequent phases of the Data Life Cycle. DQOs provide up-front planning and define decision maker/data collector relationships by presenting a clear statement of the decision maker's needs. This information is recorded in the QAPP. 
Iterate as

Needed

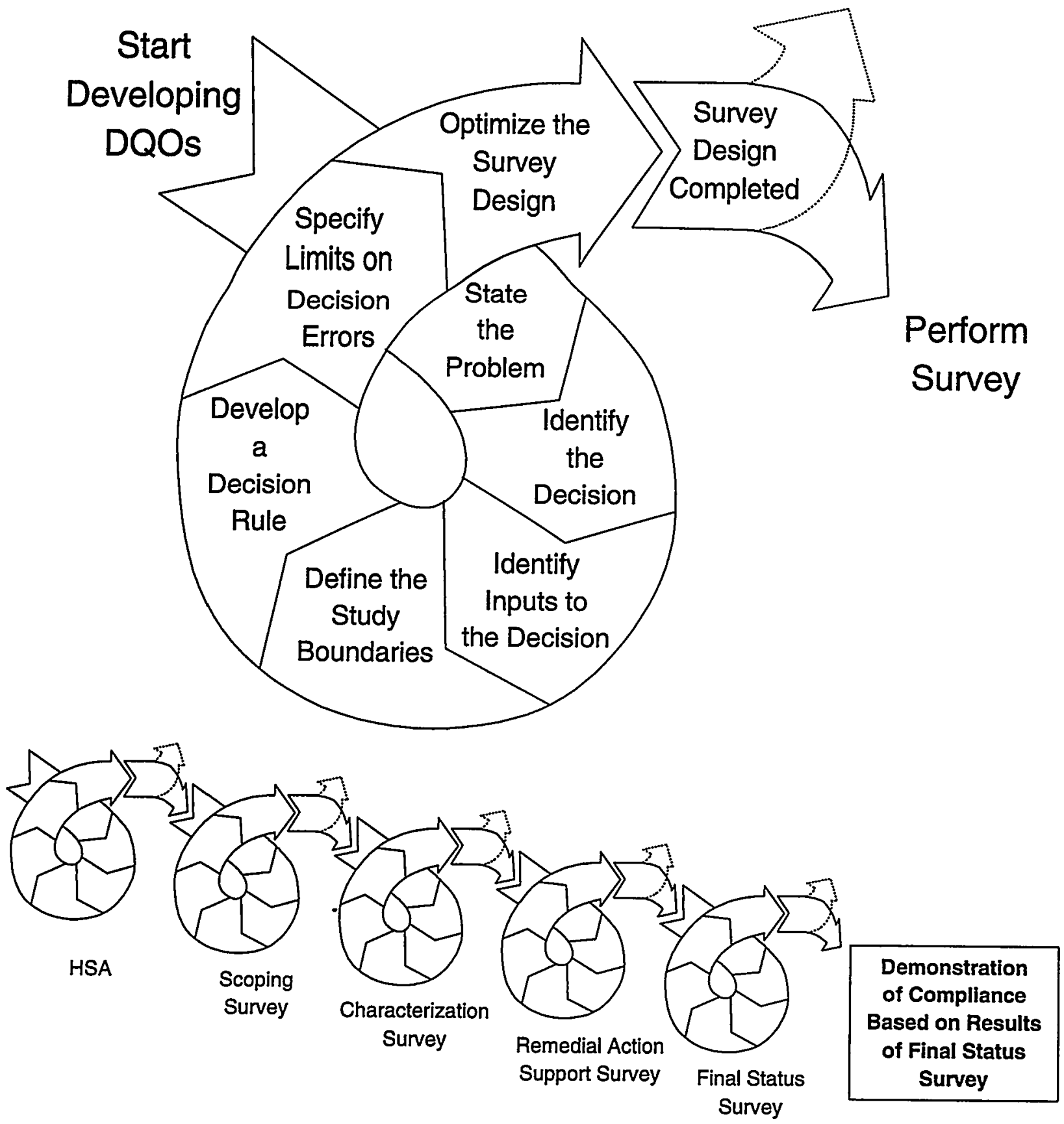

Figure D.2 Repeated Applications of the DQO Process Throughout the Radiation Survey and Site Investigation Process 
Appendix D

DQOs for data collection activities describe the overall level of uncertainty that a decision maker is willing to accept for survey results. This uncertainty is used to specify the quality of the measurement data required in terms of objectives for precision, accuracy, representativeness, comparability, and completeness. These objectives are presented in detail in Section 9.3.2 and Appendix N.

The DQO Process is a flexible planning tool that can be used more or less intensively as the situation requires. For surveys that have multiple decisions, such as characterization or final status surveys, the DQO Process can be used repeatedly throughout the performance of the survey. Decisions made early in decommissioning are often preliminary in nature. For this reason, a scoping survey may only require a limited planning and evaluation effort. As the site investigation process nears conclusion the necessity of avoiding a decision error becomes more critical.

The following sections briefly discuss the steps of the DQO Process, especially as they relate to final status survey planning, and list the outputs for each step in the process. The outputs from the DQO Process should be included in the documentation for the survey plan.

\section{D.1 State the Problem}

The first step in any decision making process is to define the problem so that the focus of the survey will be unambiguous. Since many sites or facilities present a complex interaction of technical, economic, social, and political factors, the success of a project is critically linked to a complete but uncomplicated definition of the problem .

There are four activities associated with this step:

- identifying members of the planning team and stakeholders

- identifying the primary decision maker or decision-making method

- developing a concise description of the problem

- specifying available resources and relevant deadlines for the study

The expected outputs of this step are:

- a list of the planning team members and identification of the decision maker

- a concise description of the problem

- a summary of available resources and relevant deadlines for the survey

For a final status survey, examples of planning team members and stakeholders are described in Section 3.2. A description of the problem would typically involve the release of all or some portion of a site to demonstrate compliance with a regulation. The resources and deadlines are typically identified on a site-specific basis. 


\section{D.2 Identify the Decision}

The goal of this step is to define the question that the survey will attempt to resolve and identify alternative actions that may be taken based on the outcome of the survey. The combination of these two elements is called the decision statement. The decision statement would be different for each type of survey in the Radiation Survey and Site Investigation Process, and would be developed based on the survey objectives described in Chapter 5 .

There are four activities associated with this step in the DQO Process:

- identifying the principal study question

- defining the alternative actions that could result from resolution of the principal study question

- combining the principal study question and the alternative actions into a decision statement

- $\quad$ organizing multiple decisions

The expected output from this step is a decision statement that links the principal study question to possible solutions to the problem.

For a final status survey, the principal study question could be: "Is the level of residual radioactivity in the survey units in this portion of the site below the release criterion?" Alternative actions may include further remediation, re-evaluation of the modeling assumptions used to develop the DCGLs, re-assessment of the survey unit to see if it can be released with passive controls, or a decision not to release the survey unit. The decision statement may be: "Determine whether or not all the survey units in this portion of the site satisfy the release criterion."

\section{D.3 Identify the Inputs to the Decision}

Collecting data or information is necessary to resolve most decision statements. In this step, the planning team focuses on the information needed for the decision and identifies the different types of information needed to resolve the decision statement.

The key activities for this step include:

- Identifying the information required to resolve the decision statement. Ask general questions such as: "Is information on the physical properties of the site required?" or: "Is information on the chemical characteristics of the radionuclide or the matrix required?" Determine which environmental variables or other information are needed to resolve the decision statement. 
Appendix D

- Determining the sources for each item of information. Identify and list the sources for the required information.

- Identifying the information needed to establish the action level or the derived concentration guideline level (DCGL) based on the release criterion. The actual numerical value will be determined in Step 5 (i.e., Section D.5).

- Confirming that appropriate measurement methods exist to provide the necessary data. A list of potentially appropriate measurement techniques should be prepared based on the information requirements determined previously in this step. Field and laboratory measurement techniques for radionuclides are discussed in Chapters 6 and 7 of this manual. Information on using field and laboratory equipment, their detection limits and analytical costs are listed in Appendix $\mathrm{H}$. This performance information will be used in Steps 5 and 7 of the DQO Process.

The expected outputs of this step are:

- a list of informational inputs needed to resolve the decision statement

- a list of environmental variables or characteristics that will be measured

For the final status survey, the list of information inputs generally involves measurements of the radioactive contaminants of concern in each survey unit. These inputs include identifying survey units, classifying survey units, identifying appropriate measurement techniques including measurement costs and detection limits, and whether or not background measurements from a reference area or areas need to be performed. The list of environmental variables measured during the final status survey is typically limited to the level of residual radioactivity in the affected media for each survey unit.

\section{D.4 Define the Boundaries of the Study}

During this step the planning team should develop a conceptual model of the site based on existing information collected in Step 1 of the DQO Process or during previous surveys. Conceptual models describe a site or facility and its environs, and present hypotheses regarding the radionuclides present and potential migration pathways. These models may include components from computer models, analytical models, graphic models, and other techniques. Additional data collected during decommissioning are used to expand the conceptual model.

The purpose of this step is to define the spatial and temporal boundaries that will be covered by the decision statement so data can be easily interpreted. These attributes include:

- spatial boundaries that define the physical area under consideration for release (site boundaries) 
- $\quad$ spatial boundaries that define the physical area to be studied and locations where measurements could be performed (actual or potential survey unit boundaries) temporal boundaries that describe the time frame the study data represents and when measurements should be performed

- $\quad$ spatial and temporal boundaries developed from modeling used to determine DCGLs

There are seven activities associated with this step:

- $\quad$ specifying characteristics that define the true but unknown value of the parameter of interest

- defining the geographic area within which all decisions must apply

- when appropriate, dividing the site into areas or survey units that have relatively homogeneous characteristics

- determining the time frame to which the decision applies

- determining when to collect data

- defining the scale of decision making

- identifying any practical constraints on data collection

The expected outputs of this step are:

- a detailed description of the spatial and temporal boundaries of the problem (a conceptual model)

- any practical constraints that may interfere with the full implementation of the survey design

Specifying the characteristics that define the true but unknown value of the parameter of interest for the final status survey typically involves identifying the radionuclides of concern. If possible, the physical and chemical form of the radionuclides should be described. For example, describing the residual radioactivity in terms of total uranium is not as specific or informative as describing a mixture of uraninite $\left(\mathrm{UO}_{2}\right)$ and uranium metaphosphate $\left(\mathrm{U}\left(\mathrm{PO}_{3}\right)_{4}\right)$ for natural abundances of ${ }^{234} \mathrm{U},{ }^{235} \mathrm{U}$, and ${ }^{238} \mathrm{U}$.

As an example, the study boundary may be defined as the property boundary of a facility or, if there is only surface contamination expected at the site, the soil within the property boundary to a depth of $15 \mathrm{~cm}$. When appropriate (typically during and always before final status survey design), the site is subdivided into survey units with relatively homogeneous characteristics based on information collected during previous surveys. The radiological characteristics are defined by the area classification (Class 1 , Class 2 , or Class 3 ) while the physical characteristics may include structures vs. land areas, transport routes vs. grassy areas, or soil types with different radionuclide transfer characteristics. 
Appendix D

The time frame to which the final status survey decision applies is typically defined by the regulation. For example: "The data are used to reflect the condition of radionuclides leaching into ground water over a period of 1,000 years." Temporal boundaries may also include seasonal conditions such as winter snow cover or summer drought that affect the accessibility of certain media for measurement.

For the final status survey, the smallest, most appropriate subsets of the site for which decisions will be made are defined as survey units. The size of the survey unit and the measurement frequency within a survey unit are based on classification, site-specific conditions, and relevant decisions used during modeling to determine the DCGLs.

\section{D.5 Develop a Decision Rule}

The purpose of this step is to define the parameter of interest, specify the action level (or DCGL), and integrate previous DQO outputs into a single statement that describes a logical basis for choosing among alternative actions.

There are three activities associated with this step:

- $\quad$ specifying the statistical parameter that characterizes the parameter of interest

- $\quad$ specifying the action level for the study

- combining the outputs of the previous DQO steps into an "if...then..." decision rule that defines the conditions that would cause the decision maker to choose among alternative actions

Certain aspects of the site investigation process, such as the HSA, are not so quantitative that a statistical parameter can be specified. Nevertheless, a decision rule should still be developed that defines the conditions that would cause the decision maker to choose among alternatives.

The expected outputs of this step are:

- the parameter of interest that characterizes the level of residual radioactivity

- the action level

- an "if...then..." statement that defines the conditions that would cause the decision maker to choose among alternative actions

The parameter of interest is a descriptive measure (such as a mean or median) that specifies the characteristic or attribute that the decision maker would like to know about the residual contamination in the survey unit. 
The mean is the value that corresponds to the "center" of the distribution in the sense of the "center of gravity" (EPA 1989a). Positive attributes of the mean include: 1) it is useful when the action level is based on long-term, average health effects, 2) it is useful when the population is uniform with relatively small spread, and 3) it generally requires fewer samples than other parameters of interest. Negative attributes include: 1) it is not a very representative measure of central tendency for highly skewed distributions, and 2) it is not useful when a large proportion of the measurements are reported as less than the detection limit (EPA 1994a).

The median is also a value that corresponds to the "center" of a distribution, but where the mean represents the center of gravity the median represents the "middle" value of a distribution. The median is that value such that there are the same number of measurements greater than the median as less than the median. The positive attributes of the median include: 1) it is useful when the action level is based on long-term, average health effects, 2) it provides a more representative measure of central tendency than the mean for skewed populations, 3) it is useful when a large proportion of the measurements are reported as less than the detection limit, and 4) it relies on few statistical assumptions. Negative attributes include: 1) it will not protect against the effects of extreme values, and 2) it is not a very representative measure of central tendency for highly skewed distributions (EPA 1994a).

The nonparametric statistical tests discussed in Chapter 8 are designed to determine whether or not the level of residual activity uniformly distributed throughout the survey unit exceeds the DCGL $_{\mathrm{w}}$. Since these methods are based on ranks, the results are generally expressed in terms of the median. When the underlying measurement distribution is symmetric, the mean is equal to the median. The assumption of symmetry is less restrictive than that of normality because the normal distribution is itself symmetric. If, however, the measurement distribution is skewed to the right, the average will generally be greater than the median. In severe cases, the average may exceed the DCGL ${ }_{\mathrm{w}}$ while the median does not. For this reason, MARSSIM recommends comparing the arithmetic mean of the survey unit data to the $D_{C G L}$ as a first step in the interpretation of the data (see Section 8.2.2.1).

The action level is a measurement threshold value of the parameter of interest that provides the criterion for choosing among alternative actions. MARSSIM uses the investigation level, a radionuclide-specific level of radioactivity based on the release criterion that results in additional investigation when it is exceeded, as an action level. Investigation levels are developed for both the Elevated Measurement Comparison (EMC) using scanning techniques and the statistical tests using direct measurements and samples. Section 5.5.2.6 provides information on investigation levels used in MARSSIM.

The mean concentration of residual radioactivity is the parameter of interest used for making decisions based on the final status survey. The definition of residual radioactivity depends on whether or not the contaminant appears as part of background radioactivity in the reference area. If the radionuclide is not present in background, residual radioactivity is defined as the mean 


\section{Appendix D}

concentration in the survey unit. If the radionuclide is present in background, residual radioactivity is defined as the difference between the mean concentration in the survey unit and the mean concentration in the reference area selected to represent background. The term 1-sample case is used when the radionuclide does not appear in background, because measurements are only made in the survey unit. The term 2-sample case is used when the radionuclide appears in background, because measurements are made in both the survey unit and the reference area.

Figure D. 3 contains a simple, hypothetical example of the 1-sample case. The upper portion of the figure shows a probability distribution of residual radionuclide concentrations in the surface soil of the survey unit. The parameter of interest is the location of the mean of this distribution, represented by the vertical dotted line and denoted by the symbol $\mathrm{D}$.

The decision rule for the 1-sample case is: "If the mean concentration in the survey unit is less than the investigation level, then the survey unit is in compliance with the release criterion." To implement the decision rule, an estimate of the mean concentration in the survey unit is required. An estimate of the mean of the survey unit distribution may be obtained by measuring radionuclide concentrations in soil at a set of $n$ randomly selected locations in the survey unit. A point estimate for the survey unit mean is obtained by calculating the simple arithmetic average of the $n$ measurements. Due to measurement variability, there is a distribution of possible values for the point estimate for the survey unit mean, $\delta$. This distribution is referred to as $f(\delta)$, and is shown in the lower graph of Figure D.3. The investigation level for the Sign test used in the 1-sample case is the DCGL $\mathrm{W}_{\mathrm{W}}$, shown on the horizontal axis of the graph.

If $f(\delta)$ lies far to the left (or to the right) of the $\mathrm{DCGL}_{\mathrm{w}}$, a decision of whether or not the survey unit demonstrates compliance can be easily made. However, if $f(\delta)$ overlaps the $D_{C G L}$, statistical decision rules are used to assist the decision maker. Note that the width of the distribution for the estimated mean may be reduced by increasing the number of measurements. Thus, a large number of samples will reduce the probability of making decision errors.

Figure D.4 shows a simple, hypothetical example of the 2-sample case. The upper portion of the figure shows one probability distribution representing background radionuclide concentrations in the surface soil of the reference area, and another probability distribution representing radionuclide concentrations in the surface soil of the survey unit. The graph in the middle portion of the figure shows the distributions of the estimated mean concentrations in the reference area and the survey unit. In this case, the parameter of interest is the difference between the means of these two distributions, $\mathrm{D}$, represented by the distance between the two vertical dotted lines.

The decision rule for the 2-sample case is: "If the difference between the mean concentration in the survey unit and the mean concentration in the reference area is less than the investigation level, then the survey unit is in compliance with the release criterion." To implement the 
Appendix D

\section{1-Sample Case}
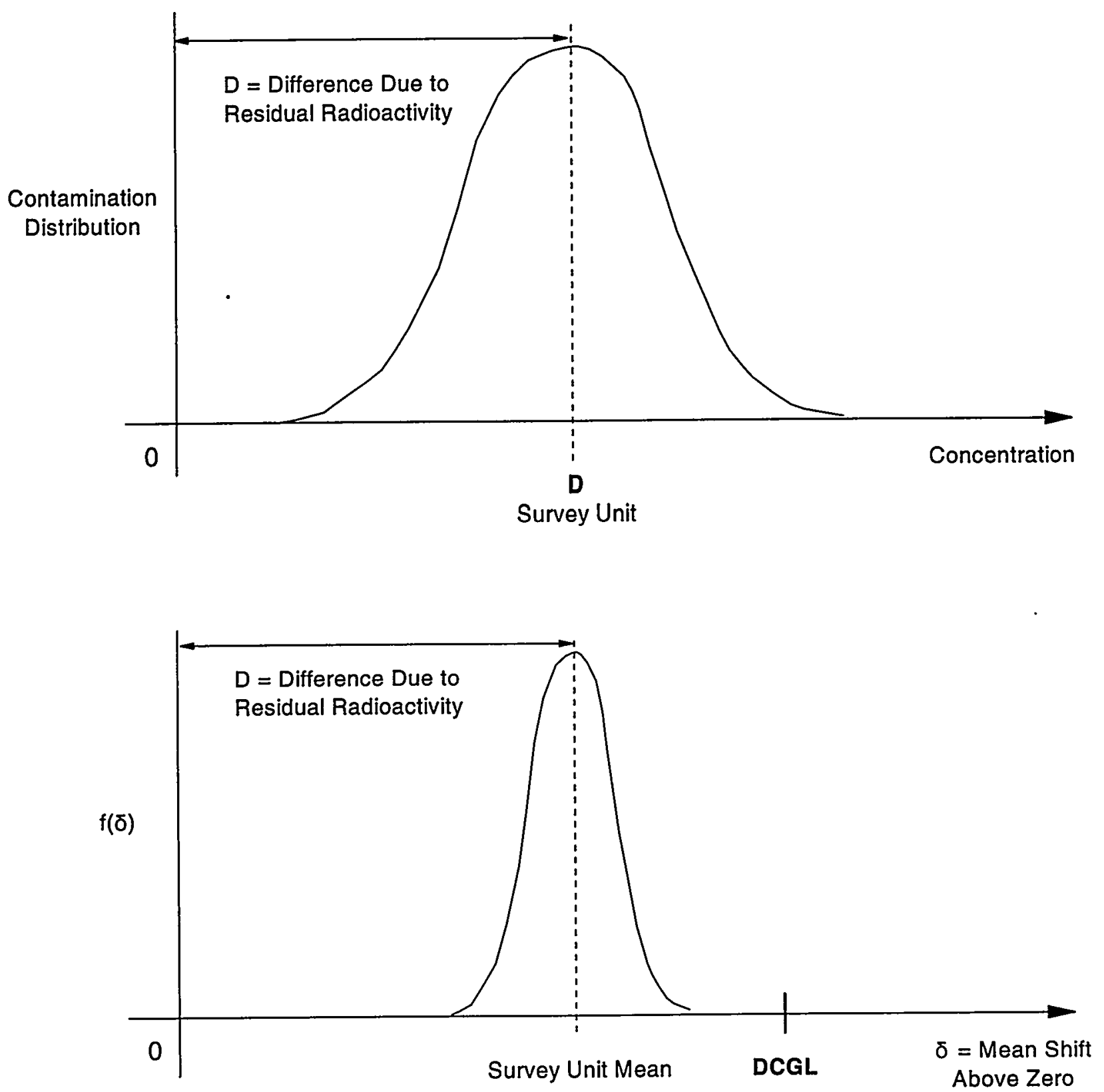

$f(\delta)$ is the sampling distribution of the estimated survey unit mean.

Figure D.3 Example of the Parameter of Interest for the 1-Sample Case 
Appendix D

\section{2-Sample Case}
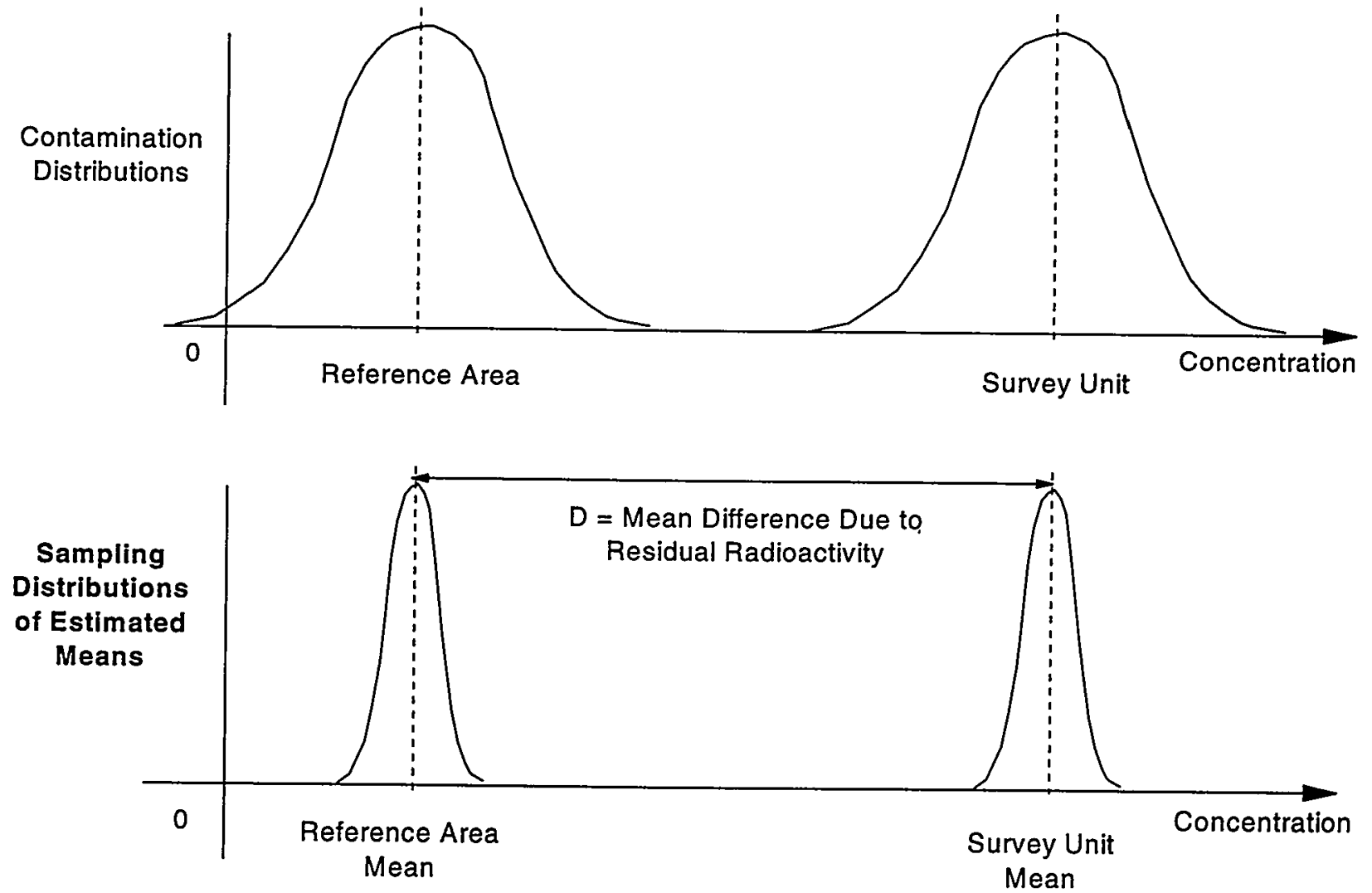

$f(\delta)$

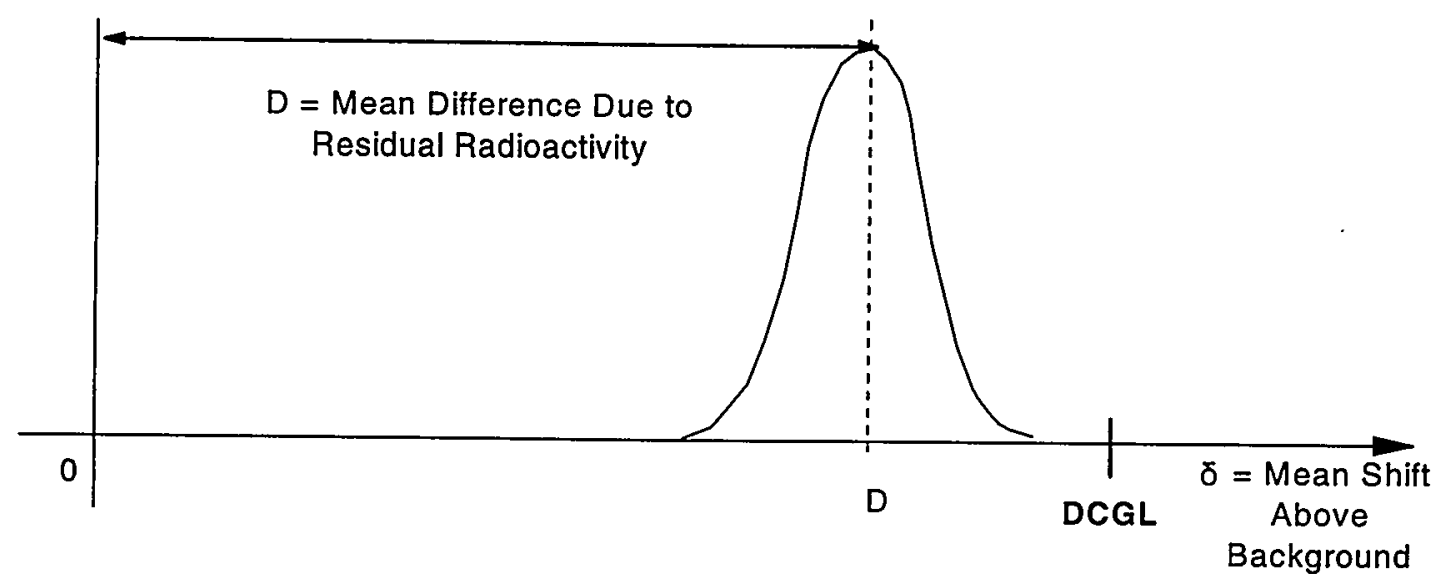

$f(\delta)$ is the sampling distribution of the difference between the survey unit mean and the reference area mean.

Figure D.4 Example of the Parameter of Interest for the 2-Sample Case 
decision rule, an estimate of the difference is required. This estimate may be obtained by measuring radionuclide concentrations at a set of " $n$ " randomly selected locations in the survey unit and " $m$ " randomly selected locations in the reference area. A point estimate of the survey unit mean is obtained by calculating the simple arithmetic average of the $n$ measurements in the survey unit. A point estimate of the reference area mean is similarly calculated. A point estimate of the difference between the two means is obtained by subtracting the reference area average from the survey unit average.

The measurement distribution of this difference, $f(\delta)$, is centered at $D$, the true value of the difference. This distribution is shown in the lower graph of Figure D.4.

Once again, if $f(\delta)$ lies far to the left (or to the right) of the DCGL $_{w}$, a decision of whether or not the survey unit demonstrates compliance can be easily made. However, if $f(\delta)$ overlaps the DCGL $_{\mathrm{W}}$, statistical decision rules are used to assist the decision maker.

\section{D.6 Specify Limits on Decision Errors}

Decisions based on survey results can often be reduced to a choice between "yes" or "no", such as determining whether or not a survey unit meets the release criterion. When viewed in this way, two types of incorrect decisions, or decision errors, are identified: 1) incorrectly deciding that the answer is "yes" when the true answer is "no", and 2) incorrectly deciding the answer is "no" when the true answer is "yes". The distinctions between these two types of errors are important for two reasons: 1) the consequences of making one type of error versus the other may be very different, and 2) the methods for controlling these errors are different and involve tradeoffs. For these reasons, the decision maker should specify levels for each type of decision error.

The purpose of this section is to specify the decision maker's limits on decision errors, which are used to establish performance goals for the data collection design. The goal of the planning team is to develop a survey design that reduces the chance of making a decision error.

While the possibility of a decision error can never be totally eliminated, it can be controlled. To control the possibility of making decision errors, the planning team attempts to control uncertainty in the survey results caused by sampling design error and measurement error. Sampling design error may be controlled by collecting a large number of samples. Using more precise measurement techniques or field duplicate analyses can reduce measurement error. Better sampling designs can also be developed to collect data that more accurately and efficiently represent the parameter of interest. Every survey will use a slightly different method of controlling decision errors, depending on the largest source of error and the ease of reducing those error components. 
Appendix D

The estimate of the standard deviation for the measurements performed in a survey unit $\left(\sigma_{s}\right)$ includes the individual measurement uncertainty as well as the spatial and temporal variations captured by the survey design. For this reason, individual measurement uncertainties are not used during the final status survey data assessment. However, individual measurement uncertainties may be useful for determining an a priori estimate of $\sigma_{s}$ during survey planning. Since a larger value of $\sigma_{\mathrm{s}}$ results in an increased number of measurements needed to demonstrate compliance during the final status survey, the decision maker may seek to reduce measurement uncertainty through various methods (e.g., different instrumentation). There are trade-offs that should be considered during survey planning. For example, the costs associated with performing additional measurements with an inexpensive measurement system may be less than the costs associated with a measurement system with better sensitivity (i.e., lower measurement uncertainty, lower minimum detectable concentration). However, the more expensive measurement system with better sensitivity may reduce $\sigma_{s}$ and the number of measurements used to demonstrate compliance to the point where it is more cost effective to use the more expensive measurement system. For surveys in the early stages of the Radiation Survey and Site Investigation Process, the measurement uncertainty and instrument sensitivity become even more important. During scoping, characterization, and remedial action support surveys, decisions about classification and remediation are made based on a limited number of measurements. When the measurement uncertainty or the instrument sensitivity values approach the value of the DCGL, it becomes more difficult to make these decisions. From an operational standpoint, when operators of a measurement system have an a priori understanding of the sensitivity and potential measurement uncertainties, they are able to recognize and respond to conditions that may warrant further investigation-e.g., changes in background radiation levels, the presence of areas of elevated activity, measurement system failure or degradation, etc.

The probability of making decision errors can be controlled by adopting a scientific approach, called hypothesis testing. In this approach, the survey results are used to select between one condition of the environment (the null hypothesis, $\mathrm{H}_{0}$ ) and an alternative condition (the alternative hypothesis, $\mathrm{H}_{\mathrm{a}}$ ). The null hypothesis is treated like a baseline condition that is assumed to be true in the absence of strong evidence to the contrary. Acceptance or rejection of the null hypothesis depends upon whether or not the particular survey results are consistent with the hypothesis.

A decision error occurs when the decision maker rejects the null hypothesis when it is true, or accepts the null hypothesis when it is false. These two types of decision errors are classified as Type I and Type II decision errors, and can be represented by a table as shown in Table D.1.

A Type I decision error occurs when the null hypothesis is rejected when it is true, and is sometimes referred to as a false positive error. The probability of making a Type I decision error, or the level of significance, is denoted by alpha $(\alpha)$. Alpha reflects the amount of evidence the decision maker would like to see before abandoning the null hypothesis, and is also referred to as the size of the test. 
Table D.1 Example Representation of Decision Errors for a Final Status Survey

\begin{tabular}{|c|c|c|c|}
\hline \multicolumn{4}{|c|}{$\mathrm{H}_{0}$ : The Residual Activity in the Survey Unit Exceeds the Release Criterion } \\
\hline \multirow{4}{*}{$\begin{array}{c}\text { TRUE } \\
\text { CONDITION } \\
\text { OF } \\
\text { SURVEY } \\
\text { UNIT }\end{array}$} & \multirow[b]{3}{*}{$\begin{array}{l}\text { Meets } \\
\text { Release } \\
\text { Criterion }\end{array}$} & \multicolumn{2}{|c|}{ DECISION } \\
\hline & & $\begin{array}{c}\text { Reject } \mathrm{H}_{0} \\
\text { (Meets Release Criterion) }\end{array}$ & $\begin{array}{l}\quad \text { Accept } \mathrm{H}_{0} \\
\text { (Exceeds Release Criterion) }\end{array}$ \\
\hline & & (No decision error) & $\begin{array}{c}\text { Incorrectly Fail to Release } \\
\text { Survey Unit } \\
\text { (Type II) }\end{array}$ \\
\hline & $\begin{array}{l}\text { Exceeds } \\
\text { Release } \\
\text { Criterion }\end{array}$ & $\begin{array}{l}\text { Incorrectly Release } \\
\text { Survey Unit } \\
\text { (Type I) }\end{array}$ & (No decision error) \\
\hline
\end{tabular}

A Type II decision error occurs when the null hypothesis is accepted when it is false. This is sometimes referred to as a false negative error. The probability of making a Type II decision error is denoted by beta $(\beta)$. The term (1- $\beta)$ is the probability of rejecting the null hypothesis when it is false, and is also referred to as the power of the test.

There is a relationship between $\alpha$ and $\beta$ that is used in developing a survey design. In general, increasing $\alpha$ decreases $\beta$ and vice versa, holding all other variables constant. Increasing the number of measurements typically results in a decrease in both $\alpha$ and $\beta$. The number of measurements that will produce the desired values of $\alpha$ and $\beta$ from the statistical test can be estimated from $\alpha, \beta$, the DCGL $L_{\mathrm{w}}$, and the estimated variance of the distribution of the parameter of interest.

There are five activities associated with specifying limits on decision errors:

- Determining the possible range of the parameter of interest. Establish the range by estimating the likely upper and lower bounds based on professional judgement.

- Identifying the decision errors and choosing the null hypothesis.

a. Define both types of decision errors (Type I and Type II) and establish the true condition of the survey unit for each decision error.

b. Specify and evaluate the potential consequences of each decision error.

c. Establish which decision error has more severe consequences near the action level. Consequences include health, ecological, political, social, and resource risks. 
Appendix D

d. Define the null hypothesis and the alternative hypothesis and assign the terms "Type I" and "Type II" to the appropriate decision error.

- Specifying a range of possible parameter values, a gray region, where the consequences of decision errors are relatively minor. It is necessary to specify a gray region because variability in the parameter of interest and unavoidable imprecision in the measurement system combine to produce variability in the data such that a decision may be "too close to call" when the true but unknown value of the parameter of interest is very near the action level. Additional guidance on specifying a gray region is available in Guidance for the Data Quality Objectives Process (EPA 1994a).

- Assigning probability limits to points above and below the gray region that reflect the probability for the occurrence of decision errors.

- Graphically representing the decision rule.

The expected outputs of this step are decision error rates based on the consequences of making an incorrect decision. Certain aspects of the site investigation process, such as the Historical Site Assessment (HSA), are not so quantitative that numerical values for decision errors can be specified. Nevertheless, a "comfort region" should be identified where the consequences of decision errors are relatively minor.

In Section D.5, the parameter of interest was defined as the difference between the survey unit mean concentration of residual radioactivity and the reference area mean concentration in the 2 -sample case, or simply the survey unit mean concentration in the 1-sample case. The possible range of values for the parameter of interest is determined based on existing information (such as the Historical Site Assessment or previous surveys) and best professional judgement. The likely lower bound for $f(\delta)$ is either background or zero. For a final status survey when the residual radioactivity is expected to meet the release criterion, and a conservative upper bound might be approximately three times $\mathrm{DCGL}_{\mathrm{W}}$.

Hypothesis testing is used to determine whether or not a statement concerning the parameter of interest should be verified. The statement about the parameter of interest is called the null hypothesis. The alternative hypothesis is the opposite of what is stated in the null hypothesis. The decision maker needs to choose between two courses of action, one associated with the null hypothesis and one associated with the alternative hypothesis.

To make a decision using hypothesis testing, a test statistic is compared to a critical value. The test statistic ${ }^{1}$ is a number calculated using data from the survey. The critical value of the test statistic defines a rejection region based on some assumptions about the true distribution of data in the survey unit. If the value of the test statistic falls within the rejection region, the null

1 The test statistic is not necessarily identical to the parameter of interest, but is functionally related to it through the statistical analysis. 
hypothesis is rejected. The decision rule, developed in Section D.5, is used to describe the relationship between the test statistic and the critical value.

MARSSIM considers two ways to state $\mathrm{H}_{0}$ for a final status survey. The primary consideration in most situations will be compliance with the release criterion. This is shown as Scenario A in Figure D.5. The null hypothesis is that the survey unit exceeds the release criterion. Using this statement of $\mathrm{H}_{0}$ means that significant evidence that the survey unit does not exceed the release criterion is required before the survey unit would be released.

In some situations, however, the primary consideration may be determining if any residual radioactivity at the site is distinguishable from background, shown as Scenario B in Figure D.6. In this manual, Scenario $\mathrm{A}$ is used as an illustration because it directly addresses the compliance issue and allows consideration of decision errors. More information on Scenario B can be found in the NRC draft report NUREG-1505 (NRC 1995a).

For Scenario A, the null hypothesis is that the survey unit does not meet the release criterion. A Type I decision error would result in the release of a survey unit containing residual radioactivity above the release criterion. The probability of making this error is $\alpha$. Setting a high value for $\alpha$ would result in a higher risk that survey units that might be somewhat in excess of the release criterion would be passed as meeting the release criterion. Setting a low value for $\alpha$ would result in fewer survey units where the null hypothesis is rejected. However, the cost of setting a low value for $\alpha$ is either a higher value for $\beta$ or an increased number of samples used to demonstrate compliance.

For Scenario A, the alternative hypothesis is that the survey unit does meet the release criterion. A Type II decision error would result in either unnecessary costs due to remediation of survey units that are truly below the release criterion or additional survey activities to demonstrate compliance. The probability of making a Type II error is $\beta$. Selecting a high value for $\beta$ (low power) would result in a higher risk that survey units that actually meet the release criterion are subject to further investigation. Selecting a low value for $\beta$ (high power) will minimize these investigations, but the tradeoff is either a higher value for $\alpha$ or an increased number of measurements used to demonstrate compliance. Setting acceptable values for $\alpha$ and $\beta$, as well as determining an appropriate gray region, is a crucial step in the DQO process.

In the MARSSIM framework, the gray region is always bounded from above by the DCGL corresponding to the release criterion. The Lower Bound of the Gray Region (LBGR) is selected during the DQO process along with the target values for $\alpha$ and $\beta$. The width of the gray region, equal to (DCGL - LBGR), is a parameter that is central to the nonparametric tests discussed in this manual. It is also referred to as the shift, $\Delta$. The absolute size of the shift is actually of less importance than the relative shift $\Delta / \sigma$, where $\sigma$ is an estimate of the standard deviation of the measured values in the survey unit. The estimated standard deviation, $\sigma$, includes both the real spatial variability in the quantity being measured, and the precision of the chosen measurement 


\section{SCENARIO A}

Assume as a null hypothesis that the survey unit exceeds the release criterion. This requires significant evidence that the residual radioactivity in the survey unit is less than the release criterion to reject the null hypothesis (and pass the survey unit). If the evidence is not significant at level $\alpha$, the null hypothesis of a non-complying survey unit is accepted (and the survey unit fails).

\section{HYPOTHESIS TEST}

$H_{0}$ : Survey unit does not meet release criterion

Survey unit passes if and

$H_{a}$ : Survey unit does meet the release criterion only if the test statistic falls in the rejection region.

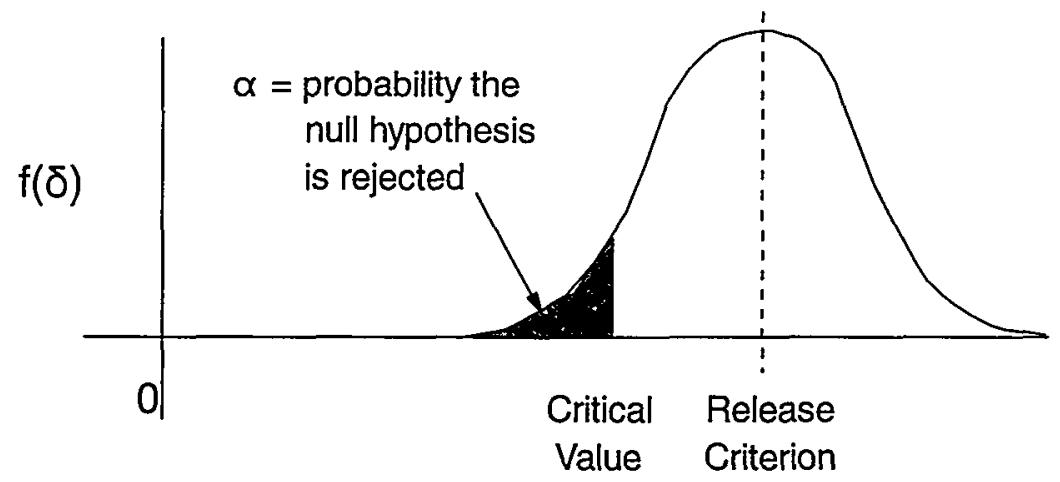

This test directly addresses the compliance question.

The mean shift for the survey unit must be significantly below the release criterion for the null hypothesis to be rejected.

With this test, site owners face a trade-off between additional sampling costs and unnecessary remediation costs. They may choose to increase the number of measurements in order to decrease the number of Type II decision errors (reduce the chance of remediating a clean survey unit for survey units at or near background levels.

Distinguishability from background is not directly addressed. However, sample sizes may be selected to provide adequate power at or near background levels, hence ensuring that most survey units near background would pass. Additional analyses, such as point estimates and/or confidence intervals, may be used to address this question.

A high percentage of survey units slightly below the release criterion may fail the release criterion, unless large numbers of measurements are used. This achieves a high degree of assurance that most survey units that are at or above the release criterion will not be improperly released.

Figure D.5 Possible Statement of the Null Hypothesis for the Final Status Survey Addressing the Issue of Compliance 


\section{SCENARIO B}

Assume as a null hypothesis that the survey unit is indistinguishable from background. This requires significant evidence that the survey unit residual radioactivity is greater than background to reject the null hypothesis (and fail the survey unit). If the evidence is not significant at level $\alpha$, the null hypothesis of a clean survey unit is accepted (and the survey unit passes).

\section{HYPOTHESIS TEST}

$\mathrm{H}_{0}$ : Survey unit is indistinguishable from background

$\mathrm{H}_{\mathrm{a}}$ : Survey unit is distinguishable from background
Survey unit passes if and only if the test statistic falls in the rejection region.

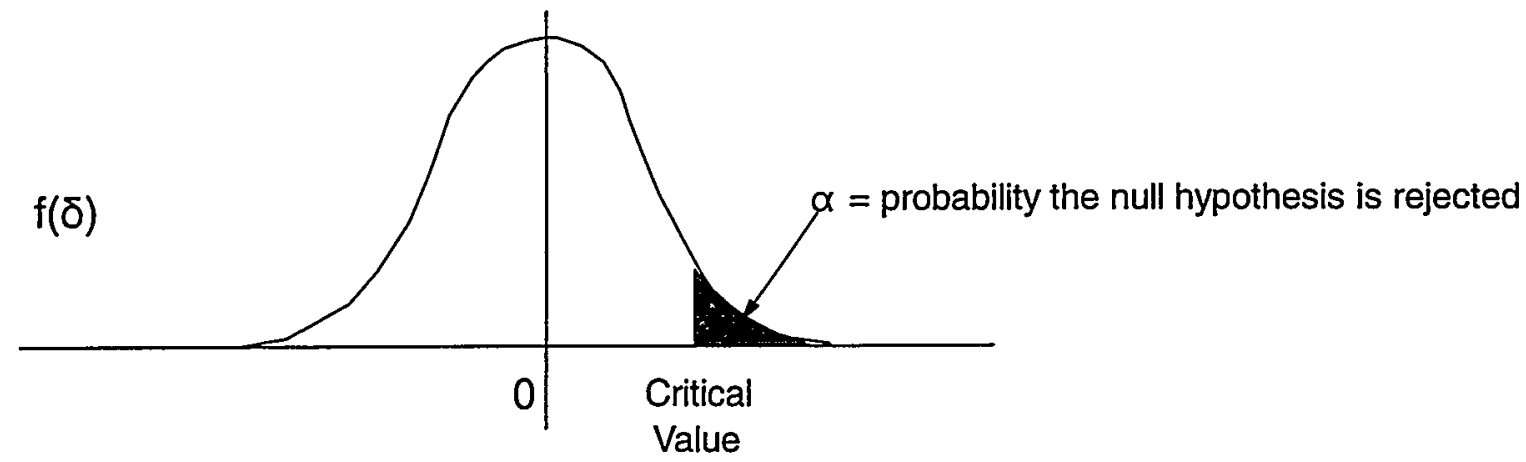

Distinguishability from background may be of primary importance to some stakeholders.

The residual radioactivity in the survey unit must be significantly above background for the null hypothesis to be rejected.

Compliance with the DCGLs is not directly addressed. However, the number of measurements may be selected to provide adequate power at or near the DCGL, hence ensuring that most survey units near the DCGL would not be improperly released. Additional analysis, based on point estimates and/or confidence intervals, is required to determine compliance if the null hypothesis is rejected by the test.

A high percentage of survey units slightly below the release criterion will fail unless large numbers of measurements are used. This is necessary to achieve a high degree of assurance that for most sites at or above the release criterion the null hypothesis will fail to be improperly released.

\section{Figure D.6 Possible Statement of the Null Hypothesis for the Final Status Survey} Addressing the Issue of Indistinguishability from Background 
method. The relative shift, $\Delta / \sigma$, is an expression of the resolution of the measurements in units of measurement uncertainty. Expressed in this way, it is easy to see that relative shifts of less than one standard deviation, $\Delta / \sigma<1$, will be difficult to detect. On the other hand, relative shifts of more than three standard deviations, $\Delta / \sigma>3$, are generally easier to detect. The number of measurements that will be required to achieve given error rates, $\alpha$ and $\beta$, depends almost entirely on the value of $\Delta / \sigma$ (see Chapter 5$)$.

Since small values of $\Delta / \sigma$ result in large numbers of samples, it is important to design for $\Delta / \sigma>1$ whenever possible. There are two obvious ways to increase $\Delta / \sigma$. The first is to increase the width of the gray region by making LBGR small. Only Type II decision errors occur in the gray region. The disadvantage of making this gray region larger is that the probability of incorrectly failing to release a survey unit will increase. The target false negative rate $\beta$ will be specified at lower residual radioactivity levels, i.e., a survey unit will generally have to be lower in residual radioactivity to have a high probability of being judged to meet the release criterion. The second way to increase $\Delta / \sigma$ is to make $\sigma$ smaller. One way to make $\sigma$ small is by having survey units that are relatively homogeneous in the amount of measured radioactivity. This is an important consideration in selecting survey units that have both relatively uniform levels of residual radioactivity and also have relatively uniform background radiation levels. Another way to make $\sigma$ small is by using more precise measurement methods. The more precise methods might be more expensive, but this may be compensated for by the decrease in the number of required measurements. One example would be in using a radionuclide specific method rather than gross radioactivity measurements for residual radioactivity that does not appear in background. This would eliminate the variability in background from $\sigma$, and would also eliminate the need for reference area measurements.

The effect of changing the width of the gray region and/or changing the measurement variability on the estimated number of measurements (and cost) can be investigated using the DEFT (Decision Error Feasibility Trials) software developed by EPA (EPA 1995a). This program can only give approximate sample sizes and costs since it assumes that the measurement data are normally distributed, that a Student's t test will be used to evaluate the data, and that there is currently no provision for comparison to a reference area. Nevertheless, as a rough rule of thumb, the sample sizes calculated by DEFT are about $85 \%$ of those required by the one-sample nonparametric tests recommended in this manual. This rule of thumb works better for large numbers of measurements than for smaller numbers of measurements, but can be very useful for estimating the relative impact on costs of decisions made during the planning process.

Generally, the design goal should be to achieve $\Delta / \sigma$ values between one and three. The number of samples needed rises dramatically when $\Delta / \sigma$ is smaller than one. Conversely, little is usually gained by making $\Delta / \sigma$ larger than about three. If $\Delta / \sigma$ is greater than three or four, one should take advantage of the measurement precision available by making the width of the gray region smaller. It is even more important, however, that overly optimistic estimates for $\sigma$ be avoided. The consequence of taking fewer samples than are needed given the actual measurement variations will be unnecessary remediations (increased Type $\Pi$ decision errors). 
Once the preliminary estimates of $\Delta$ and $\sigma$ are available, target values for $\alpha$ and $\beta$ can be selected. The values of $\alpha$ and $\beta$ should reflect the risks involved in making Type I and Type II decision errors, respectively.

One consideration in setting the false positive rate are the health risks associated with releasing a survey unit that might actually contain residual radioactivity in excess of the DCGL $\mathrm{W}_{\mathrm{W}}$. If a survey unit did exceed the DCGL ${ }_{\mathrm{w}}$, the first question that arises is "How much above the DCGL ${ }_{\mathrm{W}}$ is the residual radioactivity likely to be?" The DEFT software can be used to evaluate this.

For example, if the $\mathrm{DCGL}_{\mathrm{w}}$ is $100 \mathrm{~Bq} / \mathrm{kg}(2.7 \mathrm{pCi} / \mathrm{g})$, the $\mathrm{LBGR}$ is $50 \mathrm{~Bq} / \mathrm{kg}(1.4 \mathrm{pCi} / \mathrm{g}), \sigma$ is 50 $\mathrm{Bq} / \mathrm{kg}(1.4 \mathrm{pCi} / \mathrm{g}), \alpha=0.10$ and $\beta=0.05$, the DEFT calculations show that while a survey unit with residual radioactivity equal to the $\mathrm{DCGL}_{\mathrm{w}}$ has a $10 \%$ chance of being released, a survey unit at a level of $115 \mathrm{~Bq} / \mathrm{kg}(3.1 \mathrm{pCi} / \mathrm{g})$ has less than a $5 \%$ chance of being released, a survey unit at a level of $165 \mathrm{~Bq} / \mathrm{kg}(4.5 \mathrm{pCi} / \mathrm{g}$ ) has virtually no chance of being released. However, a survey unit with a residual radioactivity level of $65 \mathrm{~Bq} / \mathrm{kg}(1.8 \mathrm{pCi} / \mathrm{g})$ will have about an $80 \%$ chance of being released and a survey unit with a residual radioactivity level of $80 \mathrm{~Bq} / \mathrm{kg}(2.2 \mathrm{pCi} / \mathrm{g})$ will only have about a $40 \%$ chance of being released. Therefore, it is important to examine the probability of deciding that the survey unit does not meet the release criterion over the entire range of possible residual radioactivity values, and not only at the boundaries of the gray region. Of course, the gray region can be made narrower, but at the cost of additional sampling. Since the equations governing the process are not linear, small changes can lead to substantial changes in survey costs.

As stated earlier, the values of $\alpha$ and $\beta$ that are selected in the DQO process should reflect the risk involved in making a decision error. In setting values for $\alpha$, the following are important considerations:

- In radiation protection practice, public health risk is modeled as a linear function of dose (BEIR 1990). Therefore a 10\% change in dose, say from 15 to 16.5 , results in a $10 \%$ change in risk. This situation is quite different from one in which there is a threshold. In the latter case, the risk associated with a decision error can be quite high, and low values of $\alpha$ should be selected. When the risk is linear, much higher values of $\alpha$ at the release criterion might be considered adequately protective when the survey design results in smaller decision error rates at doses or risks greater than the release criterion. False positives will tend to be balanced by false negatives across sites and survey units, resulting in approximately equal human health risks.

- The DCGL itself is not free of error. The dose or risk cannot be measured directly, and many assumptions are made in converting doses or risks to derived concentrations. To be adequately protective of public health, these models are generally designed to over predict the dose or risk. Unfortunately, it is difficult to quantify this. Nonetheless, it is probably safe to say that most models have uncertainty sufficiently large such that the true dose or risk delivered by residual radioactivity at the DCGL is very likely to be lower than the 
Appendix D

release criterion. This is an additional consideration for setting the value of $\alpha$, that could support the use of larger values in some situations. In this case, one would prospectively address, as part of the DQO process, the magnitude, significance, and potential consequences of decision errors at values above the release criterion. The assumptions made in any model used to predict DCGLs for a site should be examined carefully to determine if the use of site specific parameters results in large changes in the DCGLs, or whether a site-specific model should be developed rather than designing a survey around DCGLs that may be too conservative.

- The risk of making the second type of decision error, $\beta$, is the risk of requiring additional remediation when a survey unit already meets the release criterion. Unlike the health risk, the cost associated with this type of error may be highly non-linear. The costs will depend on whether the survey unit has already had remediation work performed on it, and the type of residual radioactivity present. There may be a threshold below which the remediation cost rises very rapidly. If so, a low value for $\beta$ is appropriate at that threshold value. This is primarily an issue for survey units that have a substantial likelihood of falling at or above the gray region for residual radioactivity. For survey units that are very lightly contaminated, or have been so thoroughly remediated that any residual radioactivity is expected to be far below the DCGL, larger values of $\beta$ may be appropriate especially if final status survey sampling costs are a concern. Again, it is important to examine the probability of deciding that the survey unit does not meet the release criterion over the entire range of possible residual radioactivity values, below as well as above the gray region.

- Lower decision error rates may be possible if alternative sampling and analysis techniques can be used that result in higher precision. The same might be achieved with moderate increases in sample sizes. These alternatives should be explored before accepting higher design error rates. However, in some circumstances, such as high background variations, lack of a radionuclide specific technique, and/or radionuclides that are very difficult and expensive to quantify, error rates that are lower than the uncertainties in the dose or risk estimates may be neither cost effective nor necessary for adequate radiation protection.

None of the above discussion is meant to suggest that under any circumstances a less than rigorous, thorough, and professional approach to final status surveys would be satisfactory. The decisions made and the rationale for making these decisions should be thoroughly documented.

For Class 1 Survey Units, the number of samples may be driven more by the need to detect small areas of elevated activity than by the requirements of the statistical tests. This in turn will depend primarily on the sensitivity of available scanning instrumentation, the size of the area of elevated activity, and the dose or risk model. A given concentration of residual radioactivity spread over a smaller area will, in general, result in a smaller dose or risk. Thus, the DCGL $\mathrm{EMC}_{\mathrm{C}}$ used for the elevated measurement comparison is usually larger than the DCGL $\mathrm{W}_{\mathrm{w}}$ used for the statistical test. In some cases, especially radionuclides that deliver dose or risk primarily via internal pathways, 
dose or risk is approximately proportional to inventory, and so the difference in the DCGLs is approximately proportional to the areas.

However, this may not be the case for radionuclides that deliver a significant portion of the dose or risk via external exposure. The exact relationship between the $\mathrm{DCGL}_{\mathrm{EMC}}$ and the $\mathrm{DCGL}_{\mathrm{W}}$ is a complicated function of the dose or risk modeling pathways, but area factors to relate the two DCGLs can be tabulated for most radionuclides (see Chapter 5), and site-specific area factors can also be developed.

For many radionuclides, scanning instrumentation is readily available that is sensitive enough to detect residual radioactivity concentrations at the $\mathrm{DCGL}_{\mathrm{EMC}}$ derived for the sampling grid of direct measurements used in the statistical tests. Where instrumentation of sufficient sensitivity (MDC, see Chapter 6) is not available, the number of samples in the survey unit can be increased until the area between sampling points is small enough (and the resulting area factor is large enough) that $\mathrm{DCGL}_{\mathrm{EMC}}$ can be detected by scanning. The details of this process are discussed in Chapter 5. For some radionuclides (e.g., $\left.{ }^{3} \mathrm{H}\right)$ the scanning sensitivity is so low that this process would never terminate-i.e., the number of samples required could increase without limit. Thus, an important part of the DQO process is to determine the smallest size of an area of elevated activity that it is important to detect, $A_{\min }$, and an acceptable level of risk, $R_{A}$, that it may go undetected. Charts showing the geometric probability of sampling at least one point of an area of elevated activity as a function of sample density with either a square or triangular sampling pattern is shown in Figure D.7. The ELIPGRID-PC (Davidson 1995) computer code can also be used to calculate these probabilities.

In this part of the DQO process, the concern is less with areas of elevated activity that are found than with providing adequate assurance that negative scanning results truly demonstrate the absence of such areas. In selecting acceptable values for $A_{\min }$ and $R_{A}$, maximum use of information from the HSA and all surveys prior to the final status surveys should be used to determine what sort of areas of elevated activity could possibly exist, their potential size and shape, and how likely they are to exist. When the detection limit of the scanning technique is very large relative to the $\mathrm{DCGL}_{\mathrm{EMC}}$, the number of measurements estimated to demonstrate compliance using the statistical tests may become unreasonably large. In this situation an evaluation of the survey objectives and considerations be performed. These considerations may include the survey design and measurement methodology, exposure pathway modeling assumptions and parameter values used to determine the DCGLs, Historical Site Assessment conclusions concerning source terms and radionuclide distributions, and the results of scoping and characterization surveys. In most cases the results of this evaluation is not expected to justify an unreasonably large number of measurements.

A convenient method for visualizing the decision rule is to graph the probability of deciding that the survey unit does not meet the release criterion, i.e., that the null hypothesis of Scenario A is accepted. An example of such a chart is shown in Figure D.8. 
Appendix D
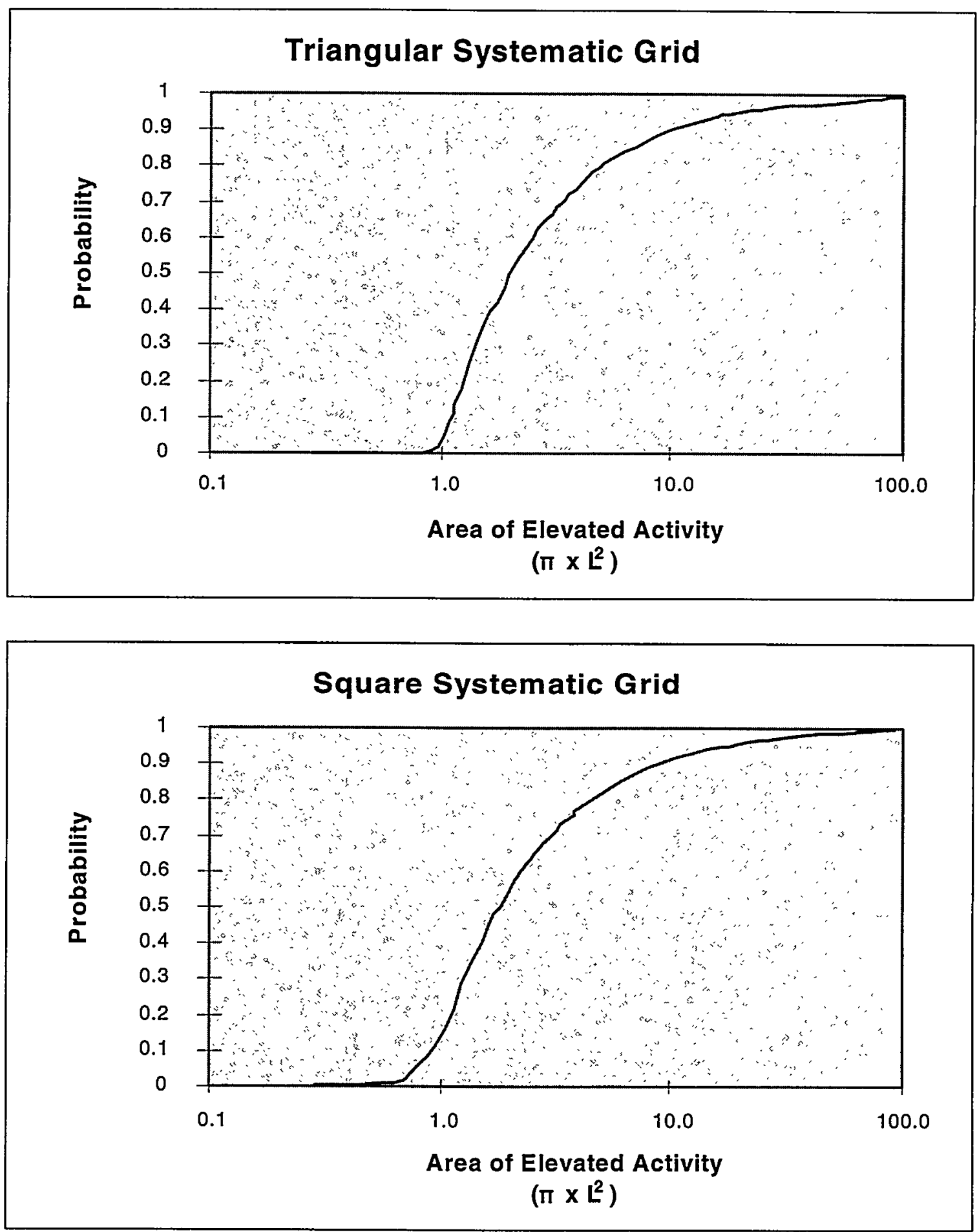

Figure D.7 Geometric Probability of Sampling at Least One Point of an Area of Elevated Activity as a Function of Sample Density with

Either a Square or Triangular Sampling Pattern 


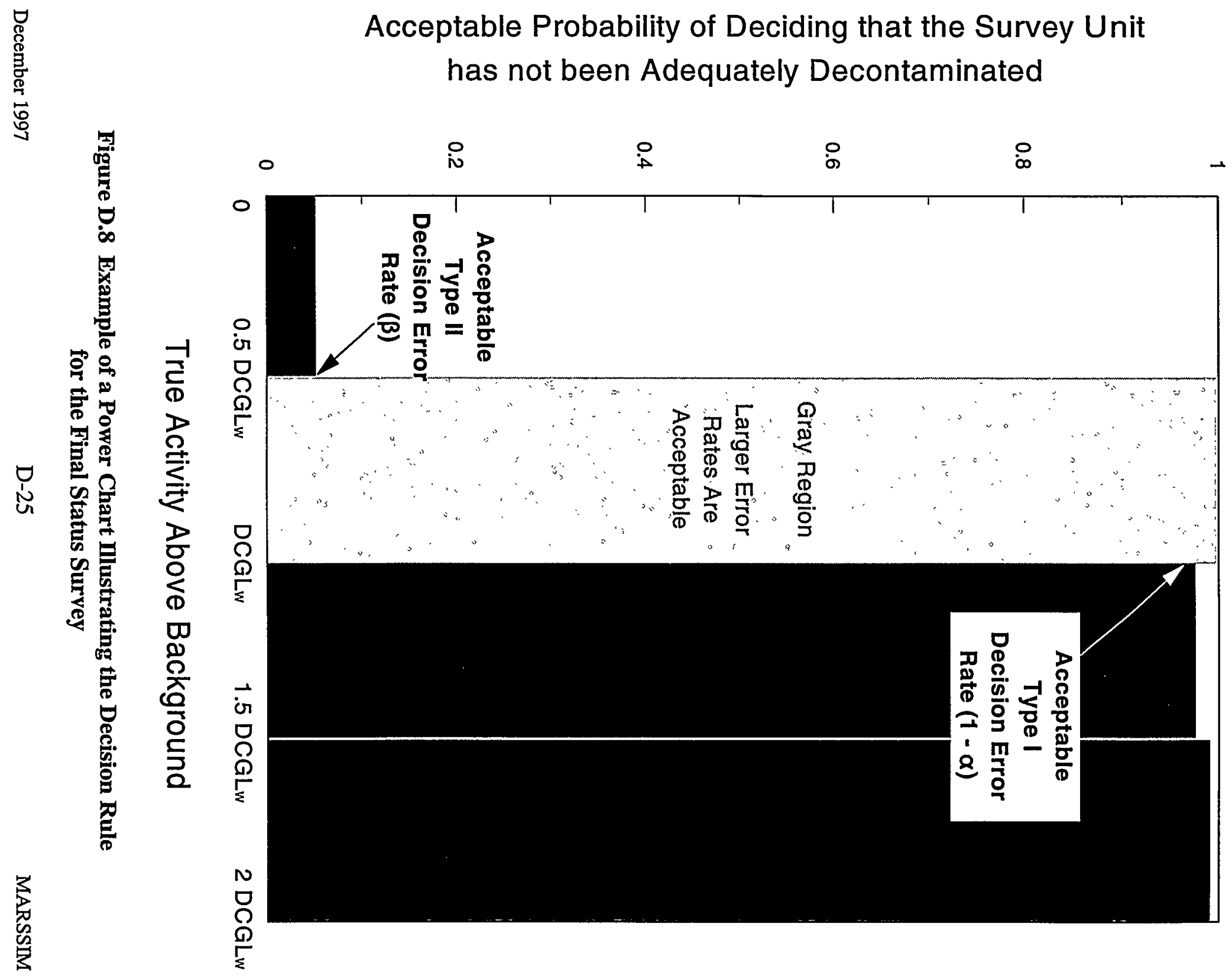


Appendix D

In this example $\alpha$ is 0.025 and $\beta$ is 0.05 , providing an expected power (1- $\beta$ ) of 0.95 for the test. A second method for presenting the information is shown in Figure D.9. This figure shows the probability of making a decision error for possible values of the parameter of interest, and is referred to as an error chart. In both examples a gray region, where the consequences of decision errors are deemed to be relatively minor, is shown. These charts are used in the final step of the DQO Process, combined with the outputs from the previous steps, to produce an efficient and cost-effective survey design. It is clear that setting acceptable values for $\alpha$ and $\beta$, as well as determining an appropriate gray region, is a crucial step in the DQO Process. Instructions for creating a prospective power curve, which can also be used to visualize the decision rule, are provided in Appendix I.

After the survey design is implemented, the expected values of $\alpha$ and $\beta$ determined in this step are compared to the actual significance level and power of the statistical test based on the measurement results during the assessment phase of the Data Life Cycle. This comparison is used to verify that the objectives of the survey have been achieved.

EPA QA/G-9 (EPA 1996a) discusses considerations for selecting a particular null hypothesis. Because of the basic hypothesis testing philosophy, the null hypothesis is generally specified in terms of the status quo (e.g., no change or action will take place if the null hypothesis is not rejected). Also, since the classical hypothesis testing approach exercises direct control over the Type I (false positive) error rate, this rate is generally associated with the error of most concern. In the case of the null hypothesis in which the residual radioactivity in the survey unit exceeds the release criterion, a Type I decision error would conclude that the residual activity was less than the release criterion when in fact it was above the release criterion. One difficulty, therefore, may be obtaining a consensus on which error should be of most concern (i.e., releasing a site where the residual activity exceeds the release criterion or failing to release a site where the residual activity is less than the release criterion). It is likely that the regulatory agency's public health-based protection viewpoint will differ from the viewpoint of the regulated party. The ideal approach is not only to define the null hypothesis in such a way that the Type I decision error protects human health and the environment but also in a way that encourages quality (high precision and accuracy) and minimizes expenditure of resources in situations where decisions are relatively "easy" (e.g., all observations are far below the threshold level of interest or DCGL).

To avoid excessive expense in performing measurements, compromises are sometimes necessary. For example, suppose that a significance level $(\alpha)$ of 0.05 is to be used. However, the affordable sample size may be expected to yield a test with power $(\beta)$ of only 0.40 at some specified parameter value chosen to have practical significance. One possible compromise may be to relax the Type I decision error rate $(\alpha)$ and use a value of $0.10,0.15$, or even 0.20 . By relaxing the Type I decision error rate, a higher power (i.e., a lower Type II decision error rate) can be achieved. An argument can be made that survey designs should be developed and number of measurements determined in such a way that both the Type $I(\alpha)$ and Type $\Pi(\beta)$ decision error rates are treated simultaneously and in a balanced manner (i.e., $\alpha=\beta=0.15$ ). This approach of 


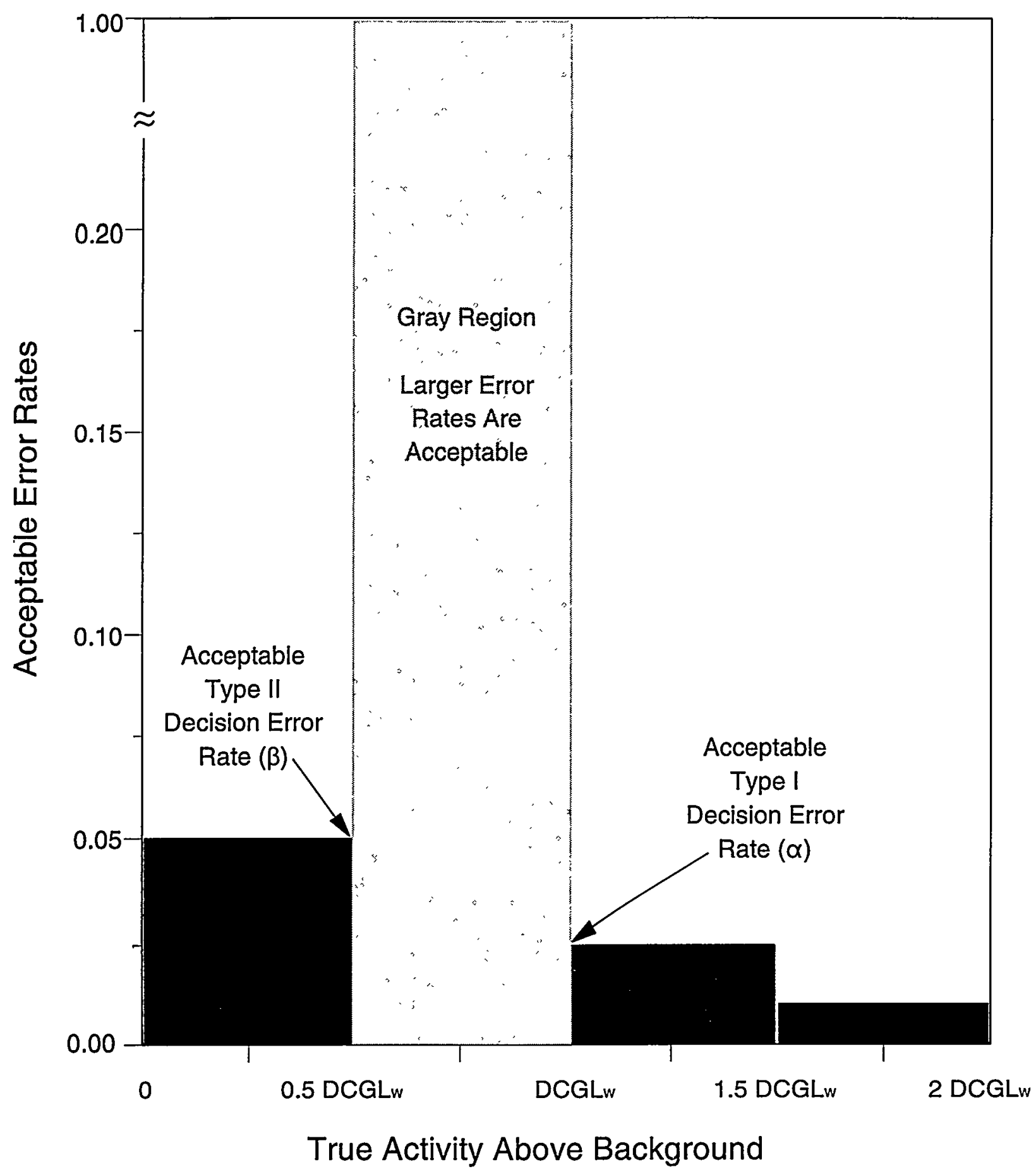

Figure D.9 Example of an Error Chart Illustrating the Decision Rule for the Final Status Survey 
Appendix D

treating the Type I and Type II decision error rates simultaneously is taken by the DQO Process. It is recommended that several different values for $\alpha$ and $\beta$ be investigated before specific values are selected.

\section{D.7 Optimize the Design for Collecting Data}

This step is designed to produce the most resource-effective survey design that is expected to meet the DQOs. It may be necessary to work through this step more than once after revisiting previous steps in the DQO Process.

There are six activities included in this step:

- Reviewing the DQO outputs and existing environmental data to ensure they are internally consistent.

- Developing general data collection design alternatives. Chapter 5 describes random and systematic sampling designs recommended for final status surveys based on survey unit classification.

- Formulating the mathematical expressions needed to solve the design problem for each data collection design alternative.

- Selecting the optimal design that satisfies the DQOs for each data collection design alternative. If the recommended design will not meet the limits on decision errors within the budget or other constraints, then the planning team will need to relax one or more constraints. Examples include:

a. increasing the budget for sampling and analysis

b. using exposure pathway modeling to develop site-specific DCGLs

c. increasing the decision error rates, not forgetting to consider the risks associated with making an incorrect decision

d. increasing the width of the gray region by decreasing the LBGR

e. relaxing other project constraints-e.g., schedule

f. changing the boundaries-it may be possible to reduce measurement costs by changing or eliminating survey units that will require different decisions

g. evaluating alternative measurement techniques with lower detection limits or

lower survey costs

h. considering the use of passive controls when releasing the survey unit rather than unrestricted release

- Selecting the most resource-effective survey design that satisfies all of the DQOs. Generally, the survey designs described in Chapter 5 will be acceptable for demonstrating compliance. Atypical sites (e.g., mixed-waste sites) may require the planning team to consider alternative survey designs on a site-specific basis. 
- Documenting the operational details and theoretical assumptions of the selected design in the QAPP, the field sampling plan, the sampling and analysis plan, or the decommissioning plan. All of the decisions that will be made based on the data collected during the survey should be specified along with the alternative actions that may be adopted based on the survey results.

Chapters 4 and 5 present a framework for a final status survey design. When this framework is combined with the site-specific DQOs developed using the guidance in this section, the survey design should be acceptable for most sites. The key inputs to Chapters 4 and 5 are:

- investigation levels and DCGLs for each radionuclide of interest

- acceptable measurement techniques for scanning, sampling, and direct measurements, including detection limits and estimated survey costs

- identification and classification of survey units

- an estimate of the variability in the distribution of residual radioactivity for each survey unit, and in the reference area if necessary

- the decision maker's acceptable $a$ priori values for decision error rates ( $\alpha$ and $\beta$ ) 


\section{APPENDIX E \\ THE ASSESSMENT PHASE OF THE DATA LIFE CYCLE}

The assessment phase of the Data Life Cycle includes verification and validation of the survey data and assessment of quality of the data. Data verification is used to ensure that the requirements stated in the planning documents are implemented as prescribed. Data validation is used to ensure that the results of the data collection activities support the objectives of the survey as documented in the Quality Assurance Project Plan (QAPP), or permit a determination that these objectives should be modified. Data Quality Assessment (DQA) is the scientific and statistical evaluation of data to determine if the data are of the right type, quality, and quantity to support their intended use (EPA 1996a). DQA helps complete the Data Life Cycle by providing the assessment needed to determine that the planning objectives are achieved. Figure E.1 illustrates where data verification, data validation and DQA fit into the Assessment Phase of the Data Life Cycle.

There are five steps in the DQA Process:

- Review the Data Quality Objectives (DQOs) and Survey Design

- Conduct a Preliminary Data Review

- $\quad$ Select the Statistical Test

- Verify the Assumptions of the Statistical Test

- Draw Conclusions from the Data

These five steps are presented in a linear sequence, but the DQA process is applied in an iterative fashion much like the DQO process. The strength of the DQA process is that it is designed to promote an understanding of how well the data will meet their intended use by progressing in a logical and efficient manner.

\section{E.1 Review DQOs and Survey Design}

The DQA process begins by reviewing the key outputs from the Planning phase of the Data Life Cycle that are recorded in the planning documents (e.g., the QAPP). The DQOs provide the context for understanding the purpose of the data collection effort. They also establish qualitative and quantitative criteria for assessing the quality of the data set for the intended use. The survey design (documented in the QAPP) provides important information about how to interpret the data. 

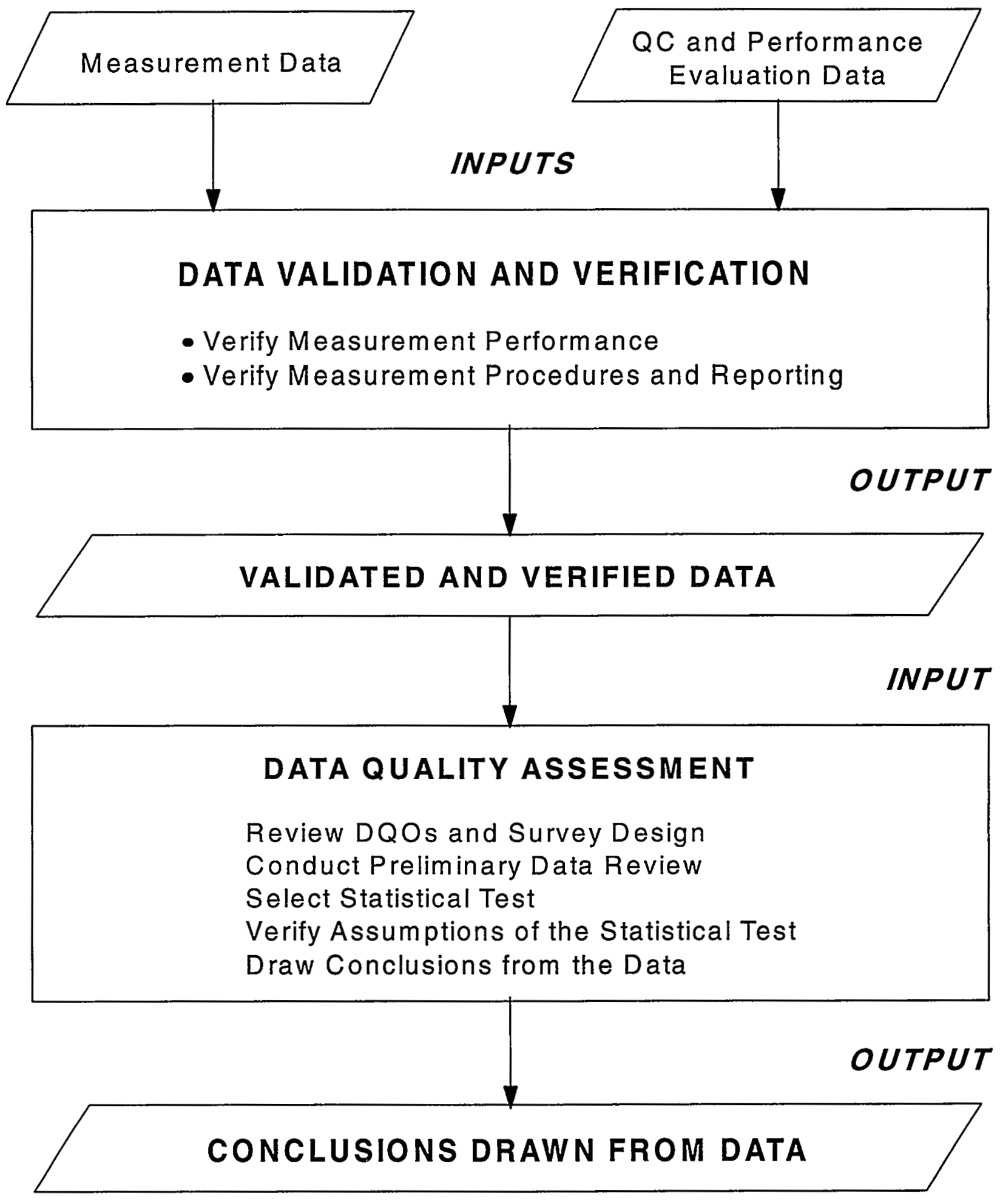

Figure E.1 The Assessment Phase of the Data Life Cycle 
There are three activities associated with this step in the DQA process:

- Translating the data user's objectives into a statement of the hypotheses to be tested using environmental data. These objectives should be documented as part of the DQO Process, and this activity is reduced to translating these objectives into the statement of hypotheses. If DQOs have not been developed, which may be the case for historical data, review Appendix $\mathrm{D}$ for assistance in developing these objectives.

- Translating the objectives into limits on the probability of committing Type I or Type II decision errors. Appendix D, Section D.6 provides guidance on specifying limits on decision errors as part of the DQO process.

- Reviewing the survey design and noting any special features or potential problems. The goal of this activity is to familiarize the analyst with the main features of the survey design used to generate the environmental data. Review the survey design documentation (e.g., the QAPP) with the data user's objectives in mind. Look for design features that support or contradict these objectives.

For the final status survey, this step would consist of a review of the DQOs developed using Appendix D and the QAPP developed in Chapter 9.

\section{E.2 Conduct a Preliminary Data Review}

In this step of the DQA process, the analyst conducts a preliminary evaluation of the data set, calculating some basic statistical quantities and looking at the data through graphical representations. By reviewing the data both numerically and graphically, the analyst can learn the "structure" of the data and thereby identify appropriate approaches and limitations for their use.

This step includes three activities:

- reviewing quality assurance reports

- calculating statistical quantities (e.g., relative standing, central tendency, dispersion, . shape, and association)

- graphing the data (e.g., histograms, scatter plots, confidence intervals, ranked data plots, quantile plots, stem-and-leaf diagrams, spatial or temporal plots)

Chapter 8 discusses the application of these activities to a final status survey. 
Appendix E

\section{E.3 Select the Statistical Test}

The statistical tests presented in Chapter 8 are applicable for most sites contaminated with radioactive material. Chapter 2 discusses the rationale for selecting the statistical methods recommended for the final status survey in more detail. Additional guidance on selecting alternate statistical methods can be found in Section 2.6 and in EPA's DQA guidance document (EPA 1995).

\section{E.4 Verify the Assumptions of the Statistical Test}

In this step, the analyst assesses the validity of the statistical test by examining the underlying assumptions in light of the environmental data. The key questions to be resolved are: "Do the data support the underlying assumptions of the test?", and: "Do the data suggest that modifications to the statistical analysis are warranted?"

The underlying assumptions for the statistical tests are discussed in Section 2.5. Graphical representations of the data, such as those described in Section 8.2 and Appendix I, can provide important qualitative information about the validity of the assumptions. Documentation of this step is always important, especially when professional judgement plays a role in accepting the results of the analysis.

There are three activities included in this step:

- Determining the approach for verifying assumptions. For this activity, determine how the assumptions of the hypothesis test will be verified, including assumptions about distributional form, independence, dispersion, type, and quantity of data. Chapter 8 discusses methods for verifying assumptions for the final status survey statistical test during the preliminary data review.

- Performing tests of the assumptions. Perform the calculations selected in the previous activity for the statistical tests. Guidance on performing the tests recommended for the final status survey are included in Chapter 8.

- Determining corrective actions (if any). Sometimes the assumptions underlying the hypothesis test will not be satisfied and some type of corrective action should be performed before proceeding. In some cases, the data for verifying some key assumption may not be available and existing data may not support the assumption. In this situation, it may be necessary to collect new data, transform the data to correct a problem with the distributional assumptions, or select an alternate hypothesis test. Section 9.3 discusses potential corrective actions. 
Appendix E

\section{E.5 Draw Conclusions from the Data}

The final step of the DQA process is performing the statistical test and drawing conclusions that address the data user's objectives. The procedure for implementing the statistical test is included in Chapter 8.

There are three activities associated with this final step:

- Performing the calculations for the statistical hypothesis test (see Chapter 8).

- Evaluating the statistical test results and drawing the study conclusions. The results of the statistical test will be either accept the null hypothesis, or reject the null hypothesis.

- Evaluating the performance of the survey design if the design is to be used again. If the survey design is to be used again, either in a later phase of the current study or in a similar study, the analyst will be interested in evaluating the overall performance of the design. To evaluate the survey design, the analyst performs a statistical power analysis that describes the estimated power of the test over the full range of possible parameter values. This helps the analyst evaluate the adequacy of the sampling design when the true parameter value lies in the vicinity of the action level (which may not have been the outcome of the current study). It is recommended that a statistician be consulted when evaluating the performance of a survey design for future use. 


\section{APPENDIX F}

\section{THE RELATIONSHIP BETWEEN THE RADIATION SURVEY AND SITE INVESTIGATION PROCESS, THE CERCLA REMEDIAL OR REMOVAL PROCESS, AND THE RCRA CORRECTIVE ACTION PROCESS}

This appendix presents a discussion of the relationship between the Radiation Survey and Site Investigation Process, the Comprehensive Environmental Response, Compensation, and Liability Act (CERCLA) Remedial or Removal Process, and the Resource Conservation and Recovery Act (RCRA) Corrective Action Process. Each of these processes has been designed to incorporate survey planning using the Data Quality Objectives (DQO) Process and data interpretation using Data Quality Assessment (DQA) using a series of surveys to accomplish the project objectives. At this basic level, MARSSIM is consistent with the other processes.

Figure F.1 illustrates the relationship between the major steps in each of these processes. As shown in Figure F.1, the scope of MARSSIM (Section 1.1) results in steps in the CERCLA Remedial or Removal Process and the RCRA Process that are not directly addressed by MARSSIM (e.g., Feasibility Study or Corrective Measure Study). MARSSIM's focus on the demonstration of compliance for sites with residual radioactivity using a final status survey integrates with the remedial design/remedial action (RD/RA) step of the CERCLA Remedial Process described in Sec. 300.435(b)(1) of Part 40 of the Code of Federal Regulations. However, MARSSIM's focus is not directly addressed by the major steps of the CERCLA Removal Process or the RCRA Corrective Action Process.

Much of the guidance presented in MARSSIM for designing surveys and assessing the survey results is taken directly from the corresponding CERCLA or RCRA guidance. MARSSIM users familiar with the Superfund Preliminary Assessment guidance (EPA 1991f) will recognize the guidance provided on performing the Historical Site Assessment (Chapter 3) for identifying potentially contaminated soil, water, or sediment. In addition, MARSSIM provides guidance for identifying potentially contaminated structures which is not covered in the original CERCLA guidance. The survey designs and statistical tests for relatively uniform distributions of residual radioactivity discussed in MARSSIM are also discussed in CERCLA guidance (EPA 1989a, EPA 1994b). However, MARSSIM includes scanning for radioactive materials which isn't discussed in the more general CERCLA guidance that doesn't specifically address radionuclides. MARSSIM is not designed to replace or conflict with existing CERCLA or RCRA guidance, it is designed to provide supplemental guidance for specific applications of the CERCLA Remedial or Removal Process or the RCRA Corrective Action Process. 
Appendix F

RADIATION SURVEY

AND SITE

INVESTIGATION PROCESS

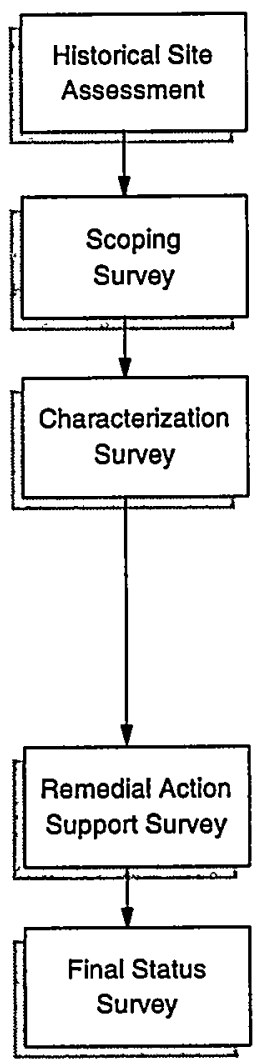

CERCLA

\begin{tabular}{lll}
\hline SOIL SCREENING & REMEDIAL & REMOVAL \\
LEVEL GUIDANCE & PROCESS & PROCESS
\end{tabular}
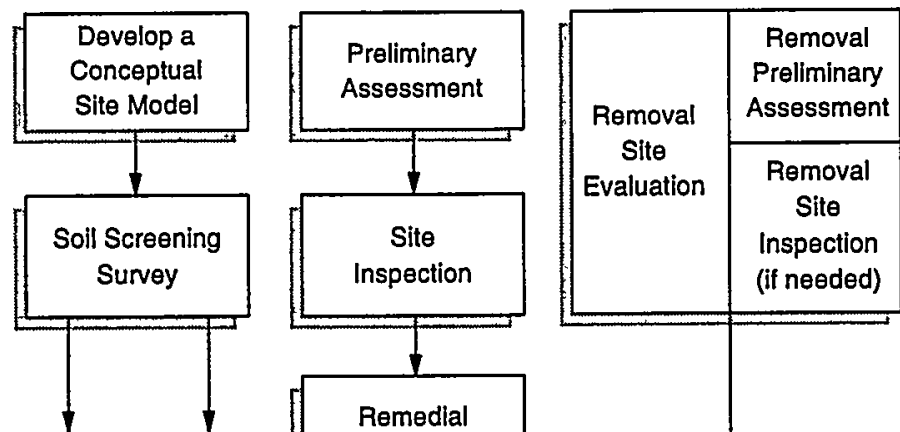

Inspection
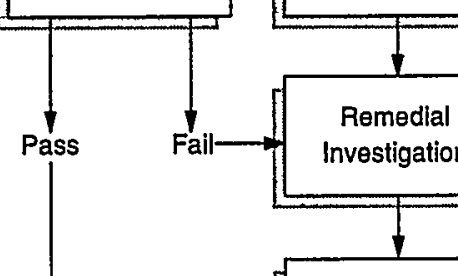

Remedial

Investigation

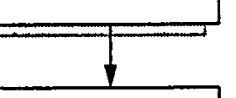

Feasibility Study

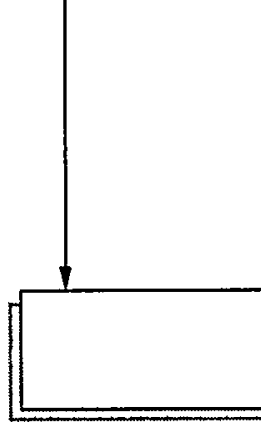

Closure/Post-Closure

Long-Term Remedial Assessment
RCRA CORRECTIVE

ACTION PROCESS

Facility

Assessment

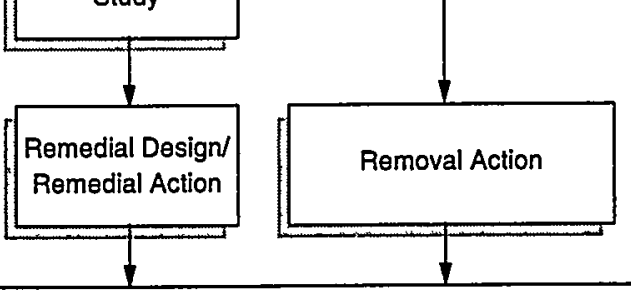

Figure F.1 Comparison of the Radiation Survey and Site Investigation Process with the CERCLA Superfund Process and the RCRA Corrective Action Process

Table F.1 lists the major steps in MARSSIM and other CERCLA and RCRA processes and describes the objectives of each step. This table provides a direct comparison of these processes, and it shows the correlation between the processes. This correlation is the result of carefully integrating CERCLA and RCRA guidance with guidance from other agencies participating in the development of MARSSIM to produce a multi-agency consensus document.

The first step in the CERCLA Remedial Process is the preliminary assessment to obtain existing information about the site and determine if there is a threat to human health and the environment. The next step is the site inspection which includes risk prioritization using the Hazard Ranking System-sites with a score above a certain level are put on the National Priorities List (NPL). Following the site assessment, the remedial investigation (RI) is performed to characterize the 
extent and type of release, and to evaluate the risk to human health and the environment. A Sampling and Analysis Plan is constructed as part of the remedial investigation which consists of a Quality Assurance Project Plan, a Field Sampling Plan, a Health and Safety Plan, and a Community Relations Plan. The site feasibility study (FS) is the next step in the CERCLA Remedial Process (although the RI and FS are intended to be done concurrently) which involves an evaluation of alternative remedial actions. For sites listed on the NPL the next action would be to obtain a Record of Decision (ROD) which provides the remedy selected for the site. The remedial design/remedial action (RD/RA), which includes the development of the selected remedy and its implementation, follows development of the ROD. After the RD/RA activities there is a period of operation and maintenance when the site is given a long term remedial assessment followed by closure/post-closure of the site (or removal from the NPL). A removal action may occur at any stage of the CERCLA Remedial Process.

The CERCLA Removal Process is similar to the Remedial Process for the first few steps. 40 CFR $\S 300.400$ (NCP Subpart E_Hazardous Substance Response) establishes methods and criteria for determining the extent of response when there is a release into the environment of a hazardous substance or any pollutant or contaminant that may present an imminent and substantial danger to the public health or welfare of the United States. The first step in the Removal Process is a removal site evaluation which includes a removal preliminary assessment and, if warranted, a removal site inspection. A removal preliminary assessment may be based on available information and should include an evaluation of the factors necessary to make the determination of whether a removal is necessary. A removal site inspection is performed, if warranted, in a similar manner as in the CERCLA Remedial Process. If environmental samples are to be collected, a sampling and analysis plan should be developed which consists of a field sampling plan and a quality assurance project plan. Post-removal site controls are those activities necessary to sustain the effectiveness and integrity of the removal action. In the case of all CERCLA removal actions taken pursuant to $\S 300.415$, a designated spokesperson will inform the community of actions taken, respond to inquiries, and provide information concerning the release-this may include a formal community relations plan specifying the community relations activities expected during the removal response.

Comparisons have been made between the CERCLA Remedial Process and CERCLA Removal Process (EPA, 1993c). Table F.2 presents the data elements that are common to both programs and those that are generally common to one program rather than the other. Table F.3 shows the emphasis placed on sampling for remedial site assessment versus removal site assessment.

Another guidance document that can be compared to MARSSIM is the Soil Screening Guidance (EPA 1996b, EPA 1996c), which facilitates removing sites from consideration early in the CERCLA Process. Although not written to specifically address radioactive contaminants, the Soil Screening Guidance leads the user from the initial site conceptualization and planning stages through data collection and evaluation to the final testing step. MARSSIM also leads the user through similar planning, evaluation, and testing stages, but the guidance focuses on the final compliance demonstration step. 
Appendix F

The Soil Screening Guidance provides a way to calculate risk-based, site-specific, soil screening levels (SSLs) for contaminants in soil. SSLs can be used as preliminary remediation goals (PRGs) if the conditions found at a specific site are similar to the conditions assumed in calculating the SSLs.

Both the Soil Screening Guidance and MARSSIM provide examples of acceptable sampling and analysis plans (SAP) for site contaminants. The Soil Screening Guidance recommended default survey design for surface soils is very specific_recommendations for the grid size for sampling, the number of soil samples collected from each subarea and composited, and data analysis and interpretation techniques are described in detail. MARSSIM provides guidance that is consistent and compatible with the Soil Screening Guidance with respect to the approaches, framework, tools, and overall objectives.

SSLs calculated using the CERCLA Soil Screening Guidance could also be used for RCRA Corrective Action sites as action levels. The RCRA Corrective Action program views action levels as generally fulfilling the same purpose as soil screening levels. Table F.1 shows other similarities between the RCRA Corrective Action Process, CERCLA Remedial or Removal Process, and MARSSIM.

The similarities between the CERCLA Remedial Process and Removal Process have led to a number of streamlined approaches to expedite site cleanups by reducing sampling and preventing duplication of effort. One example of these approaches is the Superfund Accelerated Cleanup Model (SACM) where the concept of integrating the removal and remedial site assessment was introduced (EPA, 1993c). A memorandum from EPA, DOE, and DOD (August 22,1994) discusses guidance on accelerating and developing streamlined approaches for the cleanup of hazardous waste at federal facility sites. 


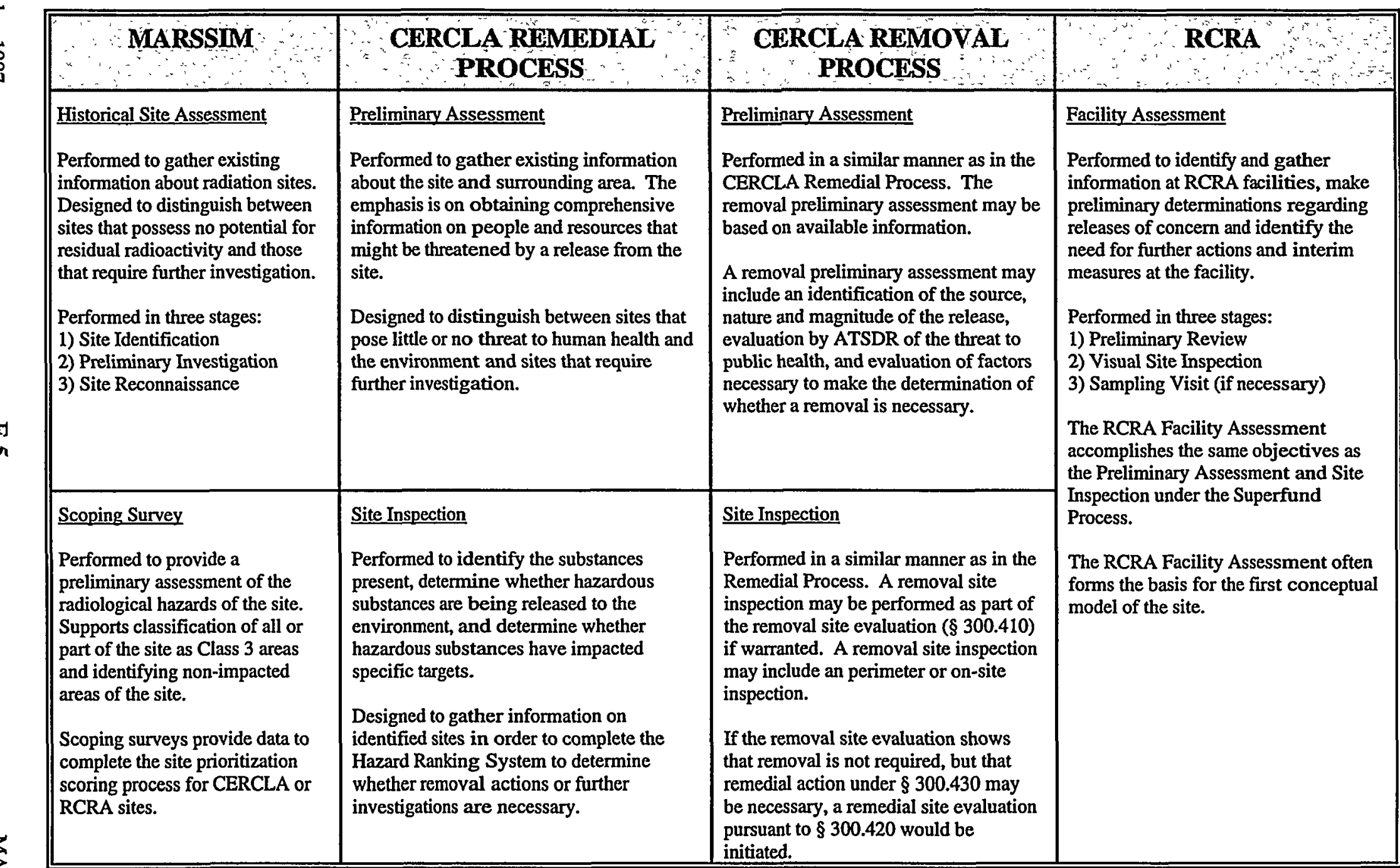




\begin{tabular}{|c|c|c|c|}
\hline MARSSIM & $\begin{array}{l}\text { CERCLA REMLDLAL } \\
\text { PROCESS }\end{array}$ & $\begin{array}{l}\text { CEROLA REMOVAL } \\
\text { PROCESS }\end{array}$ & RERA \\
\hline Characterization Survey & Remedial Investigation & Removal Action & Facility Investigation \\
\hline $\begin{array}{l}\text { Performed to support planning } \\
\text { for final status surveys to } \\
\text { demonstrate compliance with a } \\
\text { dose- or risk-based regulation. } \\
\text { Objectives include determining } \\
\text { the nature and extent of } \\
\text { contamination at the site, as well } \\
\text { as meeting the requirements of } \\
\text { RI/FS and FI/CMS. }\end{array}$ & $\begin{array}{l}\text { Performed to characterize the extent and } \\
\text { type of release of contaminants. The RI is } \\
\text { the mechanism for collecting data to } \\
\text { characterize site conditions, determine the } \\
\text { nature of the waste, assess risk to human } \\
\text { health and the environment, and conduct } \\
\text { treatability testing as necessary to evaluate } \\
\text { the potential performance and cost of the } \\
\text { treatment technologies that are being } \\
\text { considered. } \\
\text { EPA guidance presents a combined RI/FS } \\
\text { Model Statement of Work. The RI is } \\
\text { generally performed in seven tasks: } \\
\text { 1) project planning (scoping): } \\
\text { - summary of site location } \\
\text { - history and nature of problem } \\
\text { - history of regulatory and } \\
\text { response actions } \\
\text { - preliminary site boundary } \\
\text { - development of site operations } \\
\text { plans } \\
\text { 2) field investigations } \\
\text { 3) sample/analysis verification } \\
\text { 4) data evaluation } \\
\text { 5) assessment of risks } \\
\text { 6) treatability study/pilot testing } \\
\text { 7) RI reporting }\end{array}$ & $\begin{array}{l}\text { Performed once the decision has been } \\
\text { made to conduct a removal action at the } \\
\text { site (under } \S 300.415 \text { ). Whenever a } \\
\text { planning period of at least six months } \\
\text { exists before on-site activities must be } \\
\text { initiated, an engineering evaluation/cost } \\
\text { analysis or its equivalent is conducted. } \\
\text { If environmental samples are to be } \\
\text { collected, a sampling and analysis plan } \\
\text { is developed to provide a process for } \\
\text { obtaining data of sufficient quality and } \\
\text { quantity to satisfy data needs. The } \\
\text { sampling and analysis plan consists of: } \\
\text { 1) The field sampling plan, which } \\
\text { describes the number, type, and } \\
\text { location of samples and the type of } \\
\text { analysis } \\
\text { 2) The quality assurance project plan, } \\
\text { which describes policy, organization, } \\
\text { and functional activities and the data } \\
\text { quality objectives and measures } \\
\text { necessary to achieve adequate data for } \\
\text { use in removal actions. }\end{array}$ & $\begin{array}{l}\text { Defines the presence, magnitude, } \\
\text { extent, direction, and rate of movement } \\
\text { of any hazardous wastes and hazardous } \\
\text { constituents within and beyond the } \\
\text { facility boundary. } \\
\text { The scope is to : } \\
\text { 1) characterize the potential pathways } \\
\text { of contaminant migration } \\
\text { 2) characterize the source(s) of } \\
\text { contamination } \\
\text { 3) define the degree and extent of } \\
\text { contamination } \\
\text { 4) identify actual or potential receptors } \\
\text { 3) support the development of } \\
\text { alternatives from which a corrective } \\
\text { measure will be selected by the EPA } \\
\text { The Facility Investigation is performed } \\
\text { in seven tasks: } \\
\text { 1) description of current conditions } \\
\text { 2) identification of preliminary } \\
\text { remedial measures technologies } \\
\text { 3) FI work plan requirements } \\
\text { - project management plan } \\
\text { - data collection QAPP } \\
\text { - data management plan } \\
\text { - health and safety plan } \\
\text { - community relations plan } \\
\text { 4) facility investigation } \\
\text { 5) investigation analysis } \\
\text { 6) laboratory and bench-scale studies } \\
\text { 7) reports }\end{array}$ \\
\hline
\end{tabular}




\begin{tabular}{|c|c|c|c|}
\hline MARSSIM & $\begin{array}{l}\text { CERCLA REMEDIAL } \\
\text { PROCESS }\end{array}$ & $\begin{array}{l}\text { CERCLA REMOVAL } \\
\text { PROCESS }\end{array}$ & RCRA \\
\hline $\begin{array}{l}\text { DCGLs } \\
\text { Residual levels of radioactive } \\
\text { material that correspond to } \\
\text { allowable radiation dose } \\
\text { standards are calculated (derived } \\
\text { concentration guideline levels) } \\
\text { and provided to the user. The } \\
\text { survey unit is then evaluated } \\
\text { against this radionuclide-specific } \\
\text { DCGL. } \\
\text { The DCGLs in this manual are } \\
\text { for structure surfaces and soil } \\
\text { contamination. MARSSIM does } \\
\text { not provide equations or guidance } \\
\text { for calculating DCGLs. }\end{array}$ & $\begin{array}{l}\text { PRGs } \\
\text { Preliminary remediation goals are } \\
\text { developed early in the RI/FS process. } \\
\text { PRGs may then be used as the basis for } \\
\text { final cleanup levels based on the nine } \\
\text { criteria in the National Contingency Plan. } \\
\text { Soil Screening Levels (SSLs) can be used } \\
\text { as PRGs provided conditions at a specific } \\
\text { site are similar to those assumed in } \\
\text { calculating the SSLs. } \\
\text { SSLs are derived with exposure } \\
\text { assumptions for suburban residential land } \\
\text { use only. SSLs are based on a } \\
10^{-6} \text { risk for carcinogens, a hazard index } \\
\text { quotient of } 1 \text { for noncarcinogens (child } \\
\text { ingestion assumptions), or MCLGs, } \\
\text { MCLs, or HBLs for the migration to } \\
\text { groundwater. The User's Guide provides } \\
\text { equations and guidance for calculating } \\
\text { site-specific SSLs. }\end{array}$ & $\begin{array}{l}\text { Removal Levels } \\
\text { The removal level is established by } \\
\text { identification of applicable or relevant } \\
\text { and appropriate requirements (ARARs), } \\
\text { or by health assessments. Concern is } \\
\text { for protection of human health and the } \\
\text { environment from the immediate } \\
\text { hazard of a release rather than a } \\
\text { permanent remedy. }\end{array}$ & $\begin{array}{l}\text { Action Levels } \\
\text { At certain facilities subject to RCRA } \\
\text { corrective action, contamination will be } \\
\text { present at concentrations (action levels) } \\
\text { that may not justify further study or } \\
\text { remediation. Action levels are health- } \\
\text { or environmental-based concentrations } \\
\text { derived using chemical-specific } \\
\text { toxicity information and standardized } \\
\text { exposure assumptions. The SSLs } \\
\text { developed under CERCLA guidance } \\
\text { can be used as action levels since the } \\
\text { RCRA corrective action program } \\
\text { currently views them as serving the } \\
\text { same purpose. }\end{array}$ \\
\hline
\end{tabular}




\begin{tabular}{|c|c|c|c|}
\hline MARSSIM & $\begin{array}{l}\text { CERCLA REMEDIAL } \\
\text { PROCESS }\end{array}$ & $\begin{array}{l}\text { CERCLA REMOVAL } \\
\text { PROCESS }\end{array}$ & $\mathbf{R C R A}$ \\
\hline $\begin{array}{l}\text { No Direct Correlation } \\
\text { (MARSSIM characterization and } \\
\text { remedial action support surveys } \\
\text { may provide data to the } \\
\text { Feasibility Study or the } \\
\text { Corrective Measures Study) }\end{array}$ & $\begin{array}{l}\text { Feasibility Study } \\
\text { The FS serves as the mechanism for the } \\
\text { development, screening, and detailed } \\
\text { evaluation of alternative remedial actions. } \\
\text { As noted above, the RI and the FS are } \\
\text { intended to be performed concurrently. } \\
\text { However, the FS is generally considered to } \\
\text { be composed of four general tasks. } \\
\text { These tasks are: } \\
\text { 1) development and screening of remedial } \\
\text { alternatives } \\
\text { 2) detailed analysis of alternatives } \\
\text { 3) community relations } \\
\text { 4) FS reporting }\end{array}$ & No Direct Correlation & $\begin{array}{l}\text { Corrective Measures Study } \\
\text { The purpose of the CMS is to identify, } \\
\text { develop, and evaluate potentially } \\
\text { applicable corrective measures and to } \\
\text { recommend the corrective measures to } \\
\text { be taken. } \\
\text { The CMS is performed following an FI } \\
\text { and consists of the following four } \\
\text { tasks: } \\
\text { 1) identification and development of } \\
\text { the corrective measures alternatives } \\
\text { 2) evaluation of the corrective } \\
\text { measures alternatives } \\
\text { 3) justification and recommendations } \\
\text { of the corrective measures alternatives } \\
\text { 4) reports }\end{array}$ \\
\hline
\end{tabular}




\begin{tabular}{|c|c|c|c|}
\hline MARSSIM & $\begin{array}{c}\text { CERCLA REMEDIAL } \\
\text { PROCESS }\end{array}$ & $\begin{array}{c}\text { CERCLA REMOVAL } \\
\text { PROCESS }\end{array}$ & $\mathbf{R C R A}$ \\
\hline $\begin{array}{l}\text { Remedial Action Support Survey } \\
\text { Performed to support remediation } \\
\text { activities and determine when a } \\
\text { site or survey unit is ready for the } \\
\text { final status survey. These surveys } \\
\text { monitor the effectiveness of } \\
\text { decontamination efforts in } \\
\text { reducing residual radioactivity to } \\
\text { acceptable levels. } \\
\text { Remedial action support surveys } \\
\text { do not include routine operational } \\
\text { surveys conducted to support } \\
\text { remedial activities. }\end{array}$ & $\begin{array}{l}\text { Remedial Design/Remedial Action } \\
\text { This activity includes the development of } \\
\text { the selected remedy and implementation of } \\
\text { the remedy through construction. A } \\
\text { period of operation and maintenance may } \\
\text { follow the RD/RA activities. } \\
\text { Generally, the RD/RA includes: } \\
\text { 1) plans and specifications } \\
\text { - preliminary design } \\
\text { - intermediate design } \\
\text { - prefinal/final design } \\
\text { - estimated cost } \\
\text { - correlation of plans and specifications } \\
\text { - selection of appropriate RCRA facilities } \\
\text { - compliance with requirements of other } \\
\text { environmental laws } \\
\text { - equipment startup and operator training } \\
\text { 2) additional studies } \\
\text { 3) operation and maintenance plan } \\
\text { 4) QAPP } \\
\text { 5) site safety plan }\end{array}$ & No Direct Correlation & $\begin{array}{l}\text { Corrective Measures Implementation } \\
\text { The purpose of the CMI is to design, } \\
\text { construct, operate, maintain, and } \\
\text { monitor the performance of the } \\
\text { corrective measures selected in the } \\
\text { CMS. } \\
\text { The CMI consists of four activities: } \\
\text { 1) Corrective Measure Implementation } \\
\text { Program Plan } \\
\text { 2) corrective measure design } \\
\text { - design plans and specifications } \\
\text { - operation and maintenance plan } \\
\text { - cost estimate } \\
\text { - schedule } \\
\text { - construction QA objectives } \\
\text { - health and safety plan } \\
\text { - design phases } \\
\text { 3) corrective measures construction } \\
\text { (includes a construction QA program) } \\
\text { 4) reporting }\end{array}$ \\
\hline $\begin{array}{l}\text { Final Status Survey } \\
\text { Performed to demonstrate that } \\
\text { residual radioactivity in each } \\
\text { survey unit satisfies the release } \\
\text { criterion. }\end{array}$ & $\begin{array}{l}\text { Long Term Remedial Assessment } \\
\text { Closure/Post-Closure } \\
\text { NPL De-Listing }\end{array}$ & $\begin{array}{l}\text { Post-Removal Site Control } \\
\text { Those activities that are necessary to } \\
\text { sustain the integrity of a removal action } \\
\text { following its conclusion. }\end{array}$ & Closure/Post-Closure \\
\hline
\end{tabular}


Table F.2 Data Elements for Site Visits ${ }^{\mathrm{a}}$

\begin{tabular}{|c|c|c|}
\hline $\begin{array}{l}\text { Datta Elements Common } \\
\text { Both Remedial and Removal }\end{array}$ & $\begin{array}{l}\text { Geñerally Remedial Site } \\
\text { Assessment Only }\end{array}$ & Generally Removal \\
\hline $\begin{array}{l}\text {-Current human exposure identification } \\
\text {-Sources identification, including locations, } \\
\text { sizes, volumes } \\
\text {-Information on substances present } \\
\text {-Labels on drums and containers } \\
\text { - - } \text { - Entainment evaluation } \\
\text {-Lvidence of releases (e.g., stained soils) } \\
\text { immediate vicinity } \\
\text {-Nearby wetlands identification } \\
\text {-Nearby land uses } \\
\text {-Distance measurements or estimates for } \\
\text { wells, land uses (residences and schools), } \\
\text { surface waters, and wetlands } \\
\text {-Public accessibility } \\
\text {-Blowing soils and air contaminants } \\
\text {-Photodocumentation } \\
\text {-Site sketch }\end{array}$ & $\begin{array}{l}\text {-Perimeter survey } \\
\text {-Number of people within } 200 \\
\text { feet } \\
\text {-Some sensitive environments } \\
\text {-Review all pathways }\end{array}$ & $\begin{array}{l}\text {-Petroleum releases } \\
\text {-Fire and explosion threat } \\
\text {-Urgency of need for response } \\
\text {-Response and treatment } \\
\text { alternatives evaluation } \\
\text {-Greater emphasis on specific } \\
\text { pathways (e.g., direct contact) } \\
\text {-Sampling }\end{array}$ \\
\hline
\end{tabular}

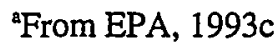

Table F.3 Comparison of Sampling Emphasis Between Remedial Site Assessment and Removal Assessment ${ }^{\mathrm{a}}$

\begin{tabular}{||l|l||}
\hline \hline Remedial Site Assessment Emphasis & \multicolumn{1}{|c|}{ Removal Assessment Emphasis } \\
\hline -Attribution to the site & -Sampling from containers \\
-Background samples & -Physical characteristics of wastes \\
-Ground water samples & -Treatability and other engineering concerns \\
-Grab samples from residential soils & -On-site contaminated soils \\
-Surface water sediment samples & -Composite and grid sampling \\
-HRS factors related to surface water sample locations & -Rapid turnaround on analytical services \\
-Fewer samples on average (10-30) than removal & -Field/screening analyses \\
assessment & -PRP-lead removal actions \\
-Strategic sampling for HRS & -Goal of characterizing site \\
-Contract Laboratory Program usage & -Focus on NCP removal action criteria \\
-Full screening organics and inorganics analyses & \\
-Definitive analyses & \\
-Documentation, including targets and receptors & \\
-Computing HRS scores & \\
-Standardized reports & \\
\hline
\end{tabular}

${ }^{\mathrm{a} F r o m ~ E P A, ~ 1993 c ~}$ 


\section{APPENDIX G \\ HISTORICAL SITE ASSESSMENT INFORMATION SOURCES}

This appendix provides lists of information sources often useful to site assessment. The lists are organized in two ways:

- Table G.1, beginning on page G-2, identifies information needs by category and lists appropriate information sources for each. The categories are:

-- $\quad$ General site information, p. G-2

-- $\quad$ Source and waste characteristics, p. G-2

-- Ground water use and characteristics, p. G-3

-- $\quad$ Surface water use and characteristics, p. G-4

-- $\quad$ Soil exposure characteristics, p. G-5

-- $\quad$ Air characteristics, p. G- 6

- The reverse approach is provided in Table G.2, beginning on page G-7. Categories of information sources are listed with a brief explanation of the information provided by each source. A contact is provided for additional information. The categories are:

-. $\quad$ Databases, p. G-7

-- $\quad$ Maps and aerial photographs, p. G-13

-- $\quad$ Files, p. G-17

-- $\quad$ Expert and other sources, p. G-19

More complete listings of site assessment information sources are available in the Site Assessment Information Directory (EPA91e). 
Appendix G

Table G.1 Site Assessment Information Sources

(Organized by Information Needed)

\begin{tabular}{||l|l||}
\hline \multicolumn{2}{|c||}{ General Site Information : } \\
\hline Site Location, Latitude/Longitude & Type of Operation and Site Status \\
CERCLIS & EPA Regional Libraries \\
USGS Topographic Maps & State Environmental Agency Files \\
State Department of Transportation Maps & Site Reconnaissance \\
Site Reconnaissance & \\
USGS Global Land Information System \\
U.S. Census Bureau Tiger Mapping Services & \\
\hline $\begin{array}{l}\text { Owner/Operator Information } \\
\text { EPA Regional Libraries }\end{array}$ & Environmental Setting, Size of Site \\
State Environmental Agency Files & USGS Topographic Maps \\
Local Tax Assessor & Aerial Photographs \\
\hline & Site Reconnaissance \\
\hline Source and Waste Characteristics \\
\hline Source Types, Locations, Sizes & Hazardous Substances Present \\
EPA Regional Libraries & EPA Regional Libraries \\
State Environmental Agency Files & State Environmental Agency Files \\
Aerial Photographs & RCRIS \\
Site Reconnaissance & Local Health Department \\
DOE Field Offices & Local Fire Department \\
& ERAMS \\
& Local Public Works Department \\
\hline Waste Types and Ouantities & \\
EPA Regional Office Files & \\
State Environmental Agency Files & \\
RCRIS & \\
Local Fire Department & \\
Aerial Photographs & \\
Site Reconnaissance & \\
Aerial Radiation Surveys & \\
\hline
\end{tabular}


Table G.1 Site Assessment Information Sources (continued) (Organized by Information Needed)

\begin{tabular}{||l|l||}
\hline \multicolumn{1}{|c||}{ General Stratigraphy } & Private and Municipal Wells \\
\hline USGS Topographic Maps & Local Water Authority \\
U.S. Geological Survey & Local Health Department \\
State Geological Surveys & Local Well Drillers \\
Geologic and Bedrock Maps & State Environmental Agency Files \\
Local Experts & WellFax \\
Local University or College & WATSTORE \\
\hline Karst Terrain & Distance to Nearest Drinking Water Well \\
\hline USGS Topographic Maps & USGS Topographic Maps \\
U.S. Geological Survey & Local Water Authority \\
State Geological Surveys & Local Well Drillers \\
Geologic and Bedrock Maps & Local Health Department \\
Local Experts & WellFax \\
Local University or College & WATSTORE \\
& Site Reconnaissance \\
\hline Depth to Aquifer & Wellhead Protection Areas \\
U.S. Geological Survey & State Environmental Agency \\
State Geological Surveys & Local Water Authority \\
Geologic and Bedrock Maps & Local Well Drillers \\
Local Experts & Local Health Department \\
Local Well Drillers & EPA Regional Water Officials \\
WATSTORE & \\
\hline
\end{tabular}


Table G.1 Site Assessment Information Sources (continued) (Organized by Information Needed)

\begin{tabular}{||l|l||}
\hline \multicolumn{1}{|c|}{ Surface Water Use and Characteristics } \\
\hline Surface Water Body Types & Drinking Water Intakes \\
USGS Topographic Maps & Local Water Authority \\
State Department of Transportation Maps & USGS Topographic Maps \\
Aerial Photographs & U.S. Army Corps of Engineers \\
Site Reconnaissance & State Environmental Agency \\
\hline Distance to Nearest Surface Water Body & Fisheries \\
USGS Topographic Maps & U.S. Fish and Wildlife Service \\
State Department of Transportation & State Environmental Agency \\
Aerial Photographs & Local Fish and Wildlife Officials \\
Site Reconnaissance & \\
\hline Surface Water Flow Characteristics & Sensitive Environments \\
\hline U.S. Geological Survey & USGS Topographic Maps \\
State Environmental Agency & State Department of Transportation Maps \\
U.S. Army Corps of Engineers & State Environmental Agency \\
STORET & U.S. Fish and Wildlife Service \\
WATSTORE & Local Fish and Wildlife Officials \\
& National Wetland Inventory Maps \\
& Ecological Inventory Maps \\
\hline Flood Frequency at the Site & Natural Heritage Program \\
\hline Federal Emergency Management Agency & \\
State Environmental Agency & \\
\hline
\end{tabular}


Table G.1 Site Assessment Information Sources (continued)

(Organized by Information Needed)

\begin{tabular}{|c|c|}
\hline \multicolumn{2}{|c|}{ Soil Exposure Characteristics } \\
\hline Number of People Living Within 200 Feet & Schools or Day Care Within 200 Feet \\
\hline $\begin{array}{l}\text { Site Reconnaissance } \\
\text { USGS Topographic Maps } \\
\text { Aerial Photographs } \\
\text { U.S. Census Bureau Tiger Mapping Service }\end{array}$ & $\begin{array}{l}\text { Site Reconnaissance } \\
\text { USGS Topographic Maps } \\
\text { Local Street Maps }\end{array}$ \\
\hline Number of Workers Onsite & Locations of Sensitive Environment \\
\hline $\begin{array}{l}\text { Site Reconnaissance } \\
\text { Owner/Operator Interviews }\end{array}$ & $\begin{array}{l}\text { USGS Topographic } \\
\text { State Department of Transportation Maps } \\
\text { State Environmental Agency } \\
\text { U.S. Fish and Wildlife Service } \\
\text { Ecological Inventory Maps } \\
\text { Natural heritage Program }\end{array}$ \\
\hline
\end{tabular}


Appendix G

Table G.1 Site Assessment Information Sources (continued)

(Organized by Information Needed)

\begin{tabular}{||l|l||}
\hline Populations Within Four Miles & $\frac{\text { Locations of Sensitive Environments, Acreage }}{\text { of Wetlands }}$ \\
& USGS Topographic Maps \\
GEMS & State Department of Transportation Maps \\
NPDC & State Environmental Agency \\
USGS Topographic Maps & U.S. Fish and Wildlife Service \\
Site Reconnaissance & National Wetland Inventory Maps \\
U.S. Census Bureau Tiger Mapping Services & Ecological Inventory Maps \\
& Natural Heritage Program \\
\hline Distance to Nearest Individual & \\
USGS Topographic Maps & \\
Site Reconnaissance & \\
\hline
\end{tabular}


Table G.2 Site Assessment Information Sources (Organized by Information Source)

\begin{tabular}{|c|c|}
\hline \multicolumn{2}{|r|}{ Databases } \\
\hline Source: & $\begin{array}{l}\text { CERCLIS (Comprehensive Environmental Response, Compensation, and } \\
\text { Liability Information System) }\end{array}$ \\
\hline Provides: & $\begin{array}{l}\text { EPA's inventory of potential hazardous waste sites. Provides site name, EPA } \\
\text { identification number, site address, and the date and types of previous } \\
\text { investigations }\end{array}$ \\
\hline Supports: & General Site Information \\
\hline Contact: & $\begin{array}{l}\text { U.S. Environmental Protection Agency } \\
\text { Office of Solid Waste and Emergency Response } \\
\text { Office of Emergency and Remedial Response } \\
\begin{array}{ll}\text { Mike Cullen } & 703 / 603-8881 \\
\text { Fax } & 703 / 603-9133\end{array}\end{array}$ \\
\hline Source: & RODS (Records of Decision System) \\
\hline Provides: & $\begin{array}{l}\text { Information on technology justification, site history, community participation, } \\
\text { enforcement activities, site characteristics, scope and role of response action, and } \\
\text { remedy. }\end{array}$ \\
\hline Supports: & General Site Information, Source and Waste Characteristics \\
\hline Contacts: & $\begin{array}{l}\text { U.S. Environmental Protection Agency } \\
\text { Office of Solid Waste and Emergency Response } \\
\text { Office of Emergency and Remedial Response } \\
\text { Mike Cullen } \\
\begin{array}{ll}703 / 603-8881 \\
\text { Fax } & 703 / 603-9133\end{array}\end{array}$ \\
\hline
\end{tabular}


Appendix G

Table G.2 Site Assessment Information Sources (continued)

(Organized by Information Source)

\begin{tabular}{|c|c|}
\hline & Databases \\
\hline Source: & RCRIS (Resource Conservation and Recovery Information System) \\
\hline Provides: & $\begin{array}{l}\text { EPA's inventory of hazardous waste generators. Contains facility name, address, } \\
\text { phone number, and contact name; EPA identification number; treatment, storage } \\
\text { and disposal history; and date of notification. }\end{array}$ \\
\hline Supports: & General Site Information, Source and Waste Characteristics \\
\hline Contacts: & $\begin{array}{l}\text { U.S. Environmental Protection Agency } \\
\text { Office of Solid Waste and Emergency Response } \\
\text { Office of Solid Waste } \\
\begin{array}{ll}\text { Kevin Phelps } & 202 / 260-4697 \\
\text { Fax } & 202 / 260-0284 \\
\end{array}\end{array}$ \\
\hline Source: & ODES (Ocean Data Evaluation System) \\
\hline Provides: & $\begin{array}{l}\text { Information associated with both marine and fresh water supplies with the } \\
\text { following programs: } \\
\text { - } 301(\mathrm{~h}) \text { sewage discharge } \\
\text {-National Pollutant Discharge Elimination System (NPDES) } \\
\text { - Ocean Dumping } \\
\text { - National Estuary Program } \\
\text {-403c Industrial Discharge } \\
\text { - Great Lakes Remedial Action Program } \\
\text { - National Coastal Waters Program } \\
\text { Houses a variety of data pertaining to water quality, oceanographic descriptions, } \\
\text { sediment pollutants, physical/chemical characteristics, biological characteristics, } \\
\text { and estuary information. }\end{array}$ \\
\hline Supports: & $\begin{array}{l}\text { General Site Information, Source and Waste Characteristics, } \\
\text { Surface Water Use and Characteristics }\end{array}$ \\
\hline Contact: & $\begin{array}{l}\text { U.S. Environmental Protection Agency } \\
\text { Office of Water } \\
\begin{array}{ll}\text { Robert King } & 202 / 260-7026 \\
\text { Fax } & 202 / 260-7024\end{array}\end{array}$ \\
\hline
\end{tabular}


Table G.2 Site Assessment Information Sources (continued) (Organized by Information Source)

\begin{tabular}{|c|c|}
\hline$\because$ & $\because \div \quad \therefore$ \\
\hline Source: & EMMI (Environmental Monitoring Methods Index) \\
\hline Provides: & $\begin{array}{l}\text { U.S. Environmental Protection Agency's official methods compendium. Serves } \\
\text { as a source of standard analytical methods. }\end{array}$ \\
\hline Supports: & General Site Information \\
\hline Contact: & $\begin{array}{l}\text { U.S. Environmental Protection Agency } \\
\text { User Support } 703 / 519-1222 \\
\text { Annual updates may be purchased from the National Technical Information } \\
\text { Service at } 703 / 487-4650\end{array}$ \\
\hline Source: & WellFax \\
\hline Provides: & $\begin{array}{l}\text { National Water Well Association's inventory of municipal and community water } \\
\text { supplies. Identifies public and private wells within specified distances around a } \\
\text { point location and the number of households served by each. }\end{array}$ \\
\hline Supports: & Ground Water Use and Characteristics \\
\hline Contact: & $\begin{array}{l}\text { National Water Well Association (NWWA) } \\
6375 \text { Riverside Drive } \\
\text { Dublin, OH } 43017\end{array}$ \\
\hline Source: & Geographic Resources Information Data System (GRIDS) \\
\hline Provides: & $\begin{array}{l}\text { National access to commonly requested geographic data products such as those } \\
\text { maintained by the U.S. Geologic Survey, the Bureau of the Census, and the U.S. } \\
\text { Fish and Wildlife Service. }\end{array}$ \\
\hline Supports: & $\begin{array}{l}\text { General Site Information, Ground Water Use and Characteristics, } \\
\text { Surface Water Use and Characteristics, Soil Exposure Characteristics, } \\
\text { Air Pathway Characteristics }\end{array}$ \\
\hline Contact: & $\begin{array}{l}\text { U.S. Environmental Protection Agency } \\
\text { Office of Administration and Resources Management } \\
\text { Office of Information Resources Management } \\
\begin{array}{ll}\text { Bob Pease } & 703 / 235-5587 \\
\text { Fax } & 703 / 557-3186\end{array}\end{array}$ \\
\hline
\end{tabular}


Appendix G

Table G.2 Site Assessment Information Sources (continued)

(Organized by Information Source)

\begin{tabular}{|c|c|}
\hline Source: & National Planning Data Corporation (NPDC) \\
\hline Provides: & $\begin{array}{l}\text { Commercial database of U.S. census data. Provides residential populations in } \\
\text { specified distance rings around a point location. }\end{array}$ \\
\hline Supports: & Soil Exposure Characteristics, Air Pathway Characteristics \\
\hline Contact: & $\begin{array}{l}\text { National Planning Data Corporation } \\
20 \text { Terrace Hill } \\
\text { Ithaca, NY } 14850-5686\end{array}$ \\
\hline Source: & STORET (Storage and Retrieval of U.S. Waterways Parametric Data) \\
\hline Provides: & $\begin{array}{l}\text { EPA's repository of water quality data for waterways within the U.S. The system } \\
\text { is capable of performing a broad range of reporting, statistical analysis, and } \\
\text { graphics functions. }\end{array}$ \\
\hline Supports: & $\begin{array}{l}\text { Geographic and descriptive information on various waterways; analytical data } \\
\text { from surface water, fish tissue, and sediment samples; stream flow data. }\end{array}$ \\
\hline Contact: & 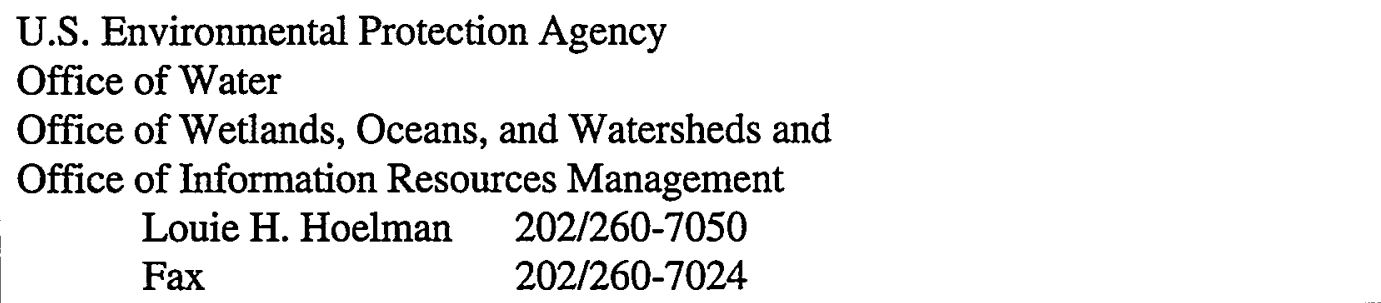 \\
\hline
\end{tabular}


Table G.2 Site Assessment Information Sources (continued) (Organized by Information Source)

\begin{tabular}{|c|c|}
\hline & Databases \\
\hline Source: & Federal Reporting Data System (FRDS) \\
\hline Provides: & $\begin{array}{l}\text { General information on public water supplies, including identification } \\
\text { information, noncompliance related events, violations of the State Drinking } \\
\text { Water Act, enforcement actions, identification of significant noncompliers, and } \\
\text { information on variances, exemptions, and waivers. }\end{array}$ \\
\hline Supports: & Ground Water Use and Characteristics, Surface Water Use and Characteristics \\
\hline Contact: & $\begin{array}{l}\text { U.S. Environmental Protection Agency } \\
\text { Office of Water } \\
\text { Office of Ground Water and Drinking Water } \\
\begin{array}{ll}\text { Abe Seigel } & 202 / 260-2804 \\
\text { Fax } & 202 / 260-3464\end{array}\end{array}$ \\
\hline Source: & WATSTORE \\
\hline Provides: & $\begin{array}{l}\text { U.S. Geological Survey's National Water Data Storage and Retrieval System. } \\
\text { Administered by the Water Resources Division and contains the Ground Water } \\
\text { Site Inventory file (GWSI). This provides physical, hydrologic, and geologic } \\
\text { data about test holes, springs, tunnels, drains, ponds, other excavations, and } \\
\text { outcrops. }\end{array}$ \\
\hline Supports: & $\begin{array}{l}\text { General Site Information, Ground Water Use and Characteristics, Surface Water } \\
\text { Use and Characteristics }\end{array}$ \\
\hline Contact: & $\begin{array}{l}\text { U.S. Geological Surgery or } \quad \text { USGS Regional Field Office } \\
12201 \text { Sunrise Valley Drive } \\
\text { Reston, VA } 22092\end{array}$ \\
\hline
\end{tabular}


Appendix G

Table G.2 Site Assessment Information Sources (continued) (Organized by Information Source)

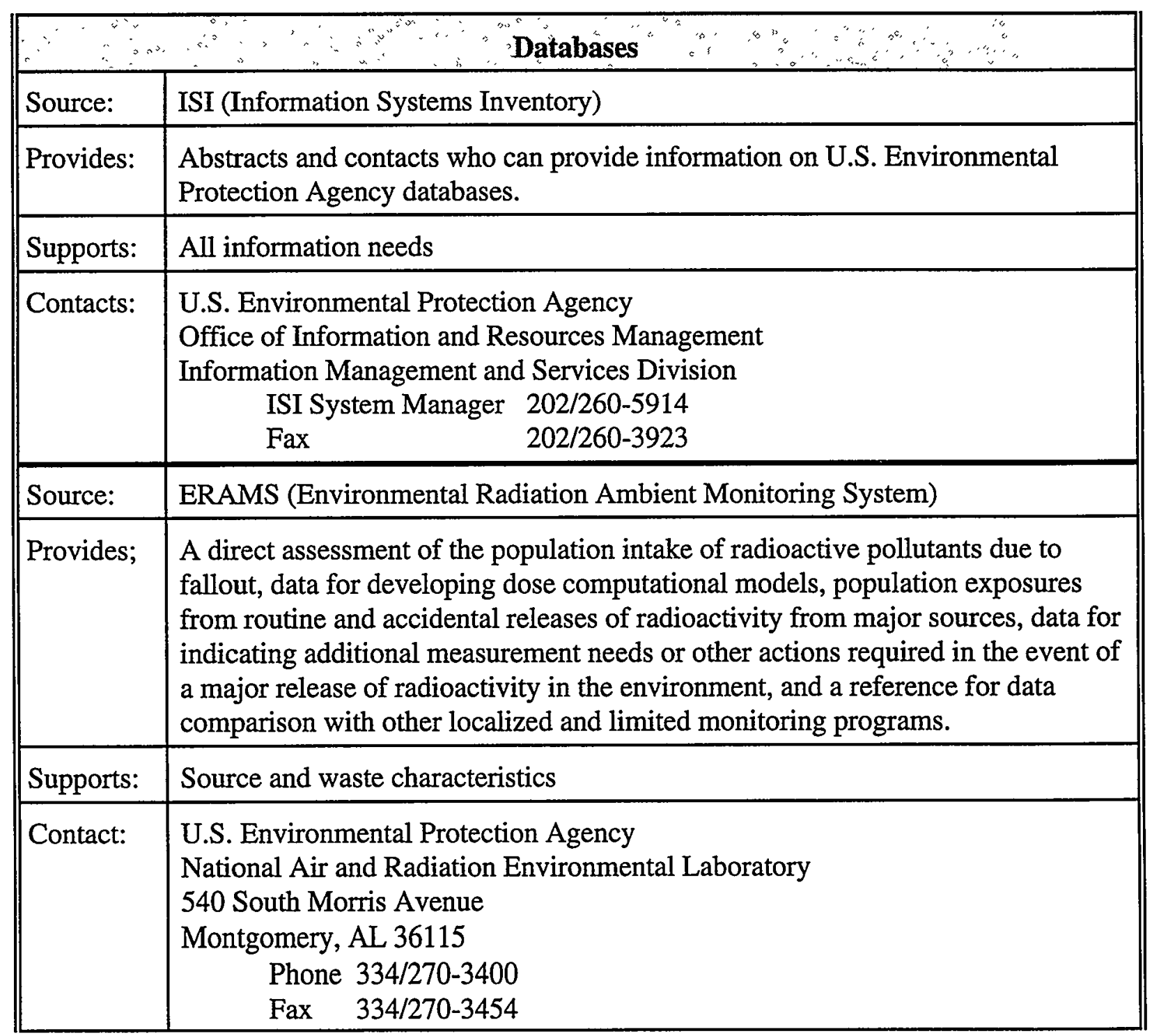


Table G.2 Site Assessment Information Sources (continued) (Organized by Information Source)

\begin{tabular}{|c|c|c|}
\hline & \multicolumn{2}{|c|}{ Maps and Aerial Photographs } \\
\hline Source: & \multicolumn{2}{|c|}{ U.S. Geological Survey (USGS) Topographic Quadrangles } \\
\hline Provides: & \multicolumn{2}{|c|}{$\begin{array}{l}\text { Maps detailing topographic, geographical, political, and cultural features. } \\
\text { Available in } 7.5 \text { - and 15-minutes series. }\end{array}$} \\
\hline Supports: & \multicolumn{2}{|c|}{$\begin{array}{l}\text { Site location and environmental setting; latitude/longitude; houses, schools, and } \\
\text { other buildings; distances to targets; surface water body types; drainage routes; } \\
\text { wetlands and sensitive environments; karst terrain features. }\end{array}$} \\
\hline Contacts: & $\begin{array}{l}\text { U.S. Geological Survey } \\
12201 \text { Sunrise Valley Drive } \\
\text { Reston, VA } 22092\end{array}$ & USGS Regional or Field Office \\
\hline Source: & \multicolumn{2}{|l|}{ National Wetland Inventory Maps } \\
\hline Provides; & \multicolumn{2}{|c|}{ Maps delineating boundaries and acreage of wetlands. } \\
\hline Supports: & \multicolumn{2}{|c|}{ Environmental setting and wetlands locations. } \\
\hline Contact: & $\begin{array}{l}\text { U.S. Geological Survey } \\
12201 \text { Sunrise Valley Drive } \\
\text { Reston, VA } 22092\end{array}$ & $\begin{array}{l}\text { U.S. Fish and Wildlife Service } \\
18 \text { th and C Street, NW } \\
\text { Washington, DC } 20240\end{array}$ \\
\hline Source: & \multicolumn{2}{|l|}{ Ecological Inventory Maps } \\
\hline Provides: & \multicolumn{2}{|c|}{$\begin{array}{l}\text { Maps delineating sensitive environments and habitats; including special land use } \\
\text { areas, wetlands, study areas, and native plant and animal species. }\end{array}$} \\
\hline Supports: & \multicolumn{2}{|c|}{ Environmental setting, sensitive environments, wetland locations and size. } \\
\hline Contact: & $\begin{array}{l}\text { U.S. Geological Survey } \\
12201 \text { Sunrise Valley Drive } \\
\text { Reston, VA } 22092\end{array}$ & $\begin{array}{l}\text { U.S. Fish and Wildlife Service } \\
\text { 18th and C Streets, NW } \\
\text { Washington, DC } 20240\end{array}$ \\
\hline
\end{tabular}


Table G.2 Site Assessment Information Sources (continued) (Organized by Information Source)

\begin{tabular}{||l|l||}
\hline \multicolumn{1}{||}{$\mid$\begin{tabular}{l} 
Maps and Aerial Photographs \\
\hline Source:
\end{tabular}} & Flood Insurance Rate Maps (FIRM) \\
\hline Provides: & Maps delineating flood hazard boundaries for flood insurance purposes. \\
\hline Supports: & Flood frequency. \\
\hline Contact: & $\begin{array}{l}\text { Federal Emergency Management Agency (FEMA) or Local Zoning and } \\
\text { Federal Insurance Administration } \\
\text { Office of Risk Assessment } \\
\text { 500 C Street, SW } \\
\text { Washington, DC 20472 }\end{array}$ \\
\hline Source: & State Department of Transportation Maps \\
\hline Provides: & $\begin{array}{l}\text { State maps detailing road systems, surface water systems, and other } \\
\text { geographical, cultural, and political features. }\end{array}$ \\
\hline Supports: & $\begin{array}{l}\text { Site location and environmental setting, distances to targets, wetlands, and } \\
\text { sensitive environments. }\end{array}$ \\
\hline Contact: & State or Local Government Agency \\
\hline Source: & Geologic and Bedrock Maps \\
\hline Provides: & $\begin{array}{l}\text { Maps detailing surficial exposure and outcrop of formations for interpreting } \\
\text { subsurface geology. Bedrock maps describe depth and lateral distribution of } \\
\text { bedrock. }\end{array}$ \\
\hline Supports: & General stratigraphy beneath and surrounding the site. \\
\hline Contact: & $\begin{array}{l}\text { U.S. Geological Survey or } \\
\text { 12201 Sunrise Valley Drive } \\
\text { Reston, VA 22092 }\end{array}$ \\
\hline
\end{tabular}




\section{Table G.2 Site Assessment Information Sources (continued) (Organized by Information Source)}

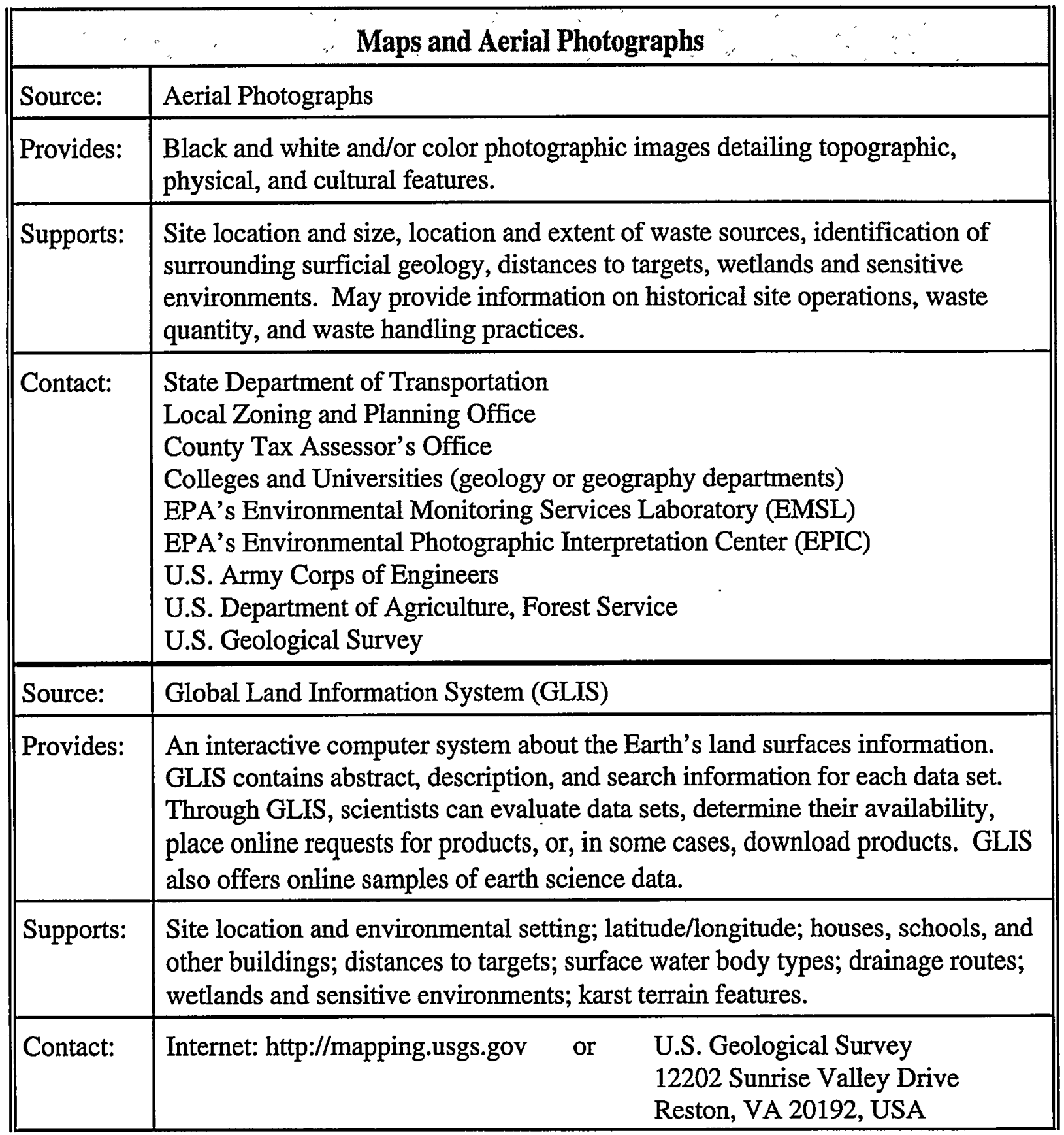


Appendix G

Table G.2 Site Assessment Information Sources (continued) (Organized by Information Source)

\begin{tabular}{|l|l||}
\hline \multicolumn{1}{|c|}{} & \multicolumn{1}{|c|}{ Maps and Aerial Photographs } \\
\hline Source: & Topologically Integrated Geographic Encoding and Referencing (TIGER) System \\
\hline Provides: & $\begin{array}{l}\text { Automates the mapping and related geographic activities required to support the } \\
\text { decennial census and sample survey programs of the U.S. Census Bureau starting } \\
\text { with the 1990 decennial census. The topological structure of the TIGER data } \\
\text { base defines the location and relationship of streets, rivers, railroads, and other } \\
\text { features to each other and to the numerous geographic entities for which the } \\
\text { Census Bureau tabulates data from its censuses and sample surveys. }\end{array}$ \\
\hline Supports: & $\begin{array}{l}\text { General Site Information, Soil Exposure Characteristics, Air Pathway } \\
\text { Characteristics }\end{array}$ \\
\hline Contacts: & $\begin{array}{l}\text { http://www.census.gov/geo/www/tiger } \\
\text { Public Information Office } \\
\text { Room 2705, FB-3 } \\
\text { Census Bureau } \\
\text { U.S. Department of Commerce } \\
\text { Washington, DC 20233 }\end{array}$ \\
\hline
\end{tabular}


Table G.2 Site Assessment Information Sources (continued) (Organized by Information Source)

\begin{tabular}{||l|l||}
\hline \multicolumn{2}{|l||}{} \\
\hline Source: & Office project files \\
\hline Provides: & Site investigation reports, logbooks, telecons, references, etc. \\
\hline Supports: & $\begin{array}{l}\text { Information on nearby sites such as town populations, public and private water } \\
\text { supplies, well locations, targets, and general stratigraphy descriptions. }\end{array}$ \\
\hline Source: & State Environmental Agency files \\
\hline Provides; & Historical site information, permits, violations, and notifications. \\
\hline Supports: & $\begin{array}{l}\text { General site information and operational history, source descriptions, waste } \\
\text { quantities and waste handling practices. May provide results of previous site } \\
\text { investigations. }\end{array}$ \\
\hline
\end{tabular}


Appendix G

Table G.2 Site Assessment Information Source (continued)

(Organized by Information Source)

\begin{tabular}{|c|c|c|}
\hline 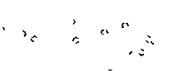 & 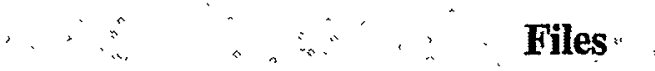 & $\because "$ \\
\hline Source: & \multicolumn{2}{|l|}{ EPA Regional Libraries } \\
\hline Provides: & \multicolumn{2}{|c|}{$\begin{array}{l}\text { Historical information on CERCLIS sites, permits, violations, and notification. } \\
\text { Additionally provides interlibrary loan services. }\end{array}$} \\
\hline Supports: & \multicolumn{2}{|c|}{$\begin{array}{l}\text { General site information and operational history, source descriptions, waste quantities } \\
\text { and waste handling practices. May provide results of previous site investigations. }\end{array}$} \\
\hline Contact: & 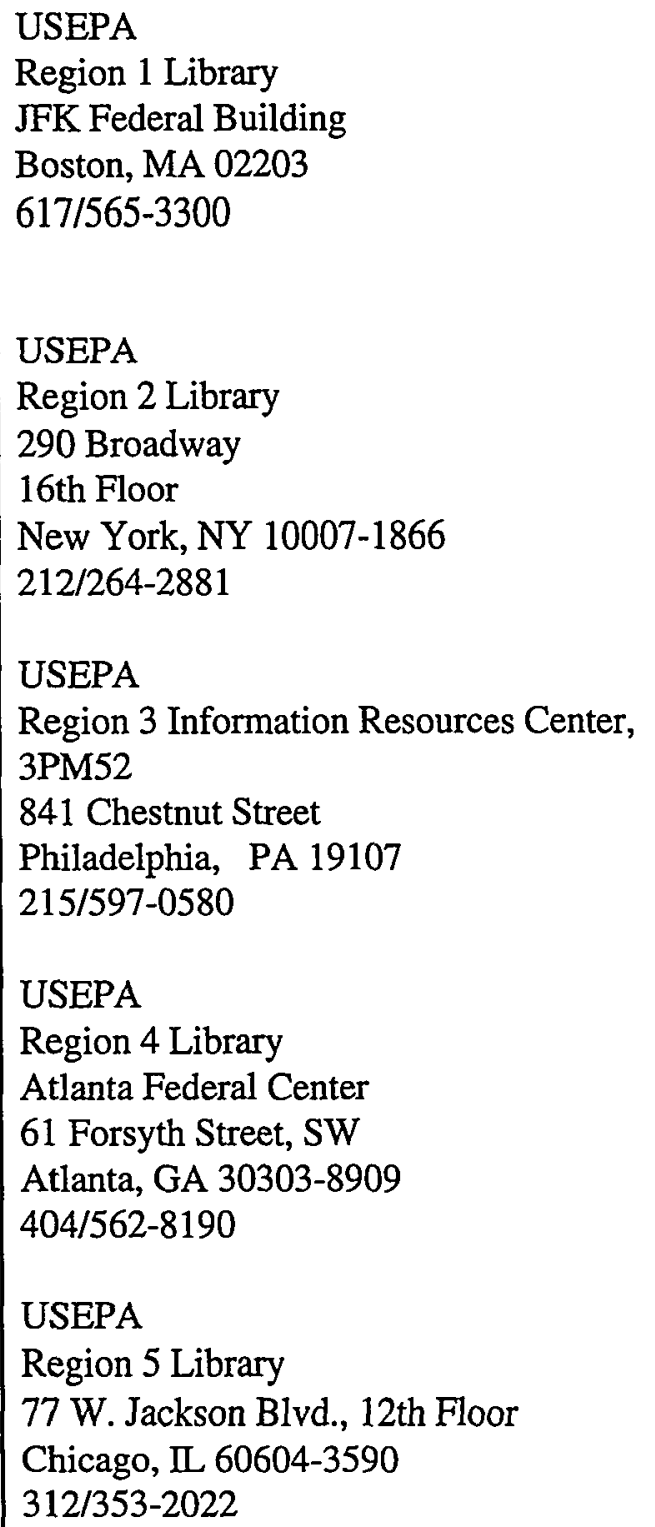 & $\begin{array}{l}\text { USEPA } \\
\text { Region } 6 \text { Library, 6M-A1 } \\
\text { 1445 Ross Avenue, Suite } 1200 \\
\text { First Interstate Bank Tower } \\
\text { Dallas, TX 75202-2733 } \\
\text { 214/655-6427 } \\
\text { USEPA } \\
\text { Region } 7 \text { Information Resources Center } \\
\text { 726 Minnesota Avenue } \\
\text { Kansas City, KS 66101 } \\
\text { 913/551-7358 } \\
\\
\text { USEPA } \\
\text { Region } 8 \text { Library, 8PM-IML } \\
\text { 999 18th Street Suite 500 } \\
\text { Denver, CO 80202-2405 } \\
\text { 303/293-1444 } \\
\text { USEPA } \\
\text { Region 9 Library, MS:P-5-3 } \\
75 \text { Hawthorne Street } \\
\text { San Francisco, CA 94105 } \\
\text { 415/744-1510 } \\
\text { 1200 Sixth Avenue } \\
\text { Seattle, WA 98101 } \\
\text { 206/553-1289 or 1259 } \\
\text { Region 10 Library, MD-108 }\end{array}$ \\
\hline
\end{tabular}


Table G.2 Site Assessment Information Sources (continued) (Organized by Information Source)

\begin{tabular}{|l|l||}
\hline \multicolumn{2}{|l|}{ Expert and Other Sources } \\
\hline Source: & U.S. Geological Survey \\
\hline Provides: & $\begin{array}{l}\text { Geologic, hydrogeologic, and hydraulic information including maps, reports, } \\
\text { studies, and databases. }\end{array}$ \\
\hline Supports: & $\begin{array}{l}\text { General stratigraphy descriptions, karst terrain, depth to aquifer, stream flow, } \\
\text { ground water and surface water use and characteristics. }\end{array}$ \\
\hline Contact: & $\begin{array}{l}\text { U.S. Geological Survey or } \\
\text { 12201 Sunrise Valley Drive } \\
\text { Reston, VA 22092 }\end{array}$ \\
\hline Source: & U.S. Army Corps of Engineers \\
\hline Provides: & Records and data surrounding engineering projects involving surface waters. \\
\hline Supports: & $\begin{array}{l}\text { Ground water and surface water characteristics, stream flow, locations of } \\
\text { wetlands and sensitive environments. }\end{array}$ \\
\hline Contact: & U.S. Army Corps of Engineers \\
\hline Source: & State Geological Survey \\
\hline Provides: & $\begin{array}{l}\text { State-specific geologic and hydrogeologic information including maps, reports, } \\
\text { studies, and databases. }\end{array}$ \\
\hline Supports: & $\begin{array}{l}\text { General stratigraphy descriptions, karst terrain, depth to aquifer, ground water } \\
\text { use and characteristics. }\end{array}$ \\
\hline Contact: & State Geological Survey (Local or Field Office) \\
\hline Source: & Natural Heritage Program \\
\hline Provides: & $\begin{array}{l}\text { Information on Federal and State designated endangered and threatened plants, } \\
\text { animals, and natural communities. Maps, lists and general information may be } \\
\text { available. }\end{array}$ \\
\hline Supports: & Location of sensitive environments and wetlands. \\
\hline Contact: & State Environmental Agency \\
\hline & \\
\hline
\end{tabular}


Appendix G

Table G.2 Site Assessment Information Sources (continued) (Organized by Information Source)

\begin{tabular}{||l|l||}
\hline \multicolumn{2}{|l||}{$\quad$ Expert and Other Sources } \\
\hline Source: & U.S. Fish and Wildlife Service \\
\hline Provides: & Environmental Information \\
\hline Supports: & $\begin{array}{l}\text { Locations of sensitive environments, wetlands, fisheries; surface water } \\
\text { characteristics and stream flow. }\end{array}$ \\
\hline Contact: & $\begin{array}{l}\text { U.S. Fish and Wildlife Service or } \\
\text { 18th and C Streets, NW } \\
\text { Washington, DC 20240 }\end{array}$ \\
\hline Source: & Local Fish and Wildlife Officials \\
\hline Provides: & Local Environmental Information \\
\hline Supports: & $\begin{array}{l}\text { Locations of sensitive environments, wetlands, fisheries; surface water } \\
\text { characteristics and stream flow. }\end{array}$ \\
\hline Contact: & $\begin{array}{l}\text { State or Local Environmental Agency } \\
\text { State or Local Game or Conservation Office }\end{array}$ \\
\hline Source: & Local Tax Assessor \\
\hline Provides: & $\begin{array}{l}\text { Past and present land ownership records, lot and building sizes, assessors maps. } \\
\text { May also provide historical aerial photographs. }\end{array}$ \\
\hline Supports: & $\begin{array}{l}\text { Name of present and past owners/operators, years of ownership, size of site, } \\
\text { and operational history. }\end{array}$ \\
\hline Contact: & \begin{tabular}{l} 
Local Town Government Office \\
\hline
\end{tabular} \\
\hline
\end{tabular}


Table G.2 Site Assessment Information Sources (continued)

(Organized by Information Source)

\begin{tabular}{||l|l||}
\hline \multicolumn{1}{|c||}{ Expert and Other Sources } \\
\hline Source: & Local Water Authority \\
\hline Provides: & $\begin{array}{l}\text { Public and private water supply information, including service area maps, well } \\
\text { locations and depths, well logs, surface water intake locations, information } \\
\text { regarding water supply contamination. }\end{array}$ \\
\hline Supports: & $\begin{array}{l}\text { Locations and populations served by municipal and private drinking water } \\
\text { sources (wells and surface water intakes), pumpage and production, blended } \\
\text { systems, depth to aquifer, general stratigraphic descriptions, ground water and } \\
\text { surface water characteristics, stream flow. }\end{array}$ \\
\hline Contact: & Local Town Government Office \\
\hline Source: & Local Health Department \\
\hline Provides: & $\begin{array}{l}\text { Information and reports regarding health-related problems that may be } \\
\text { associated with a site. Information on private and municipal water supplies, } \\
\text { and onsite monitoring wells. }\end{array}$ \\
\hline Supports: & $\begin{array}{l}\text { Primary/secondary targets differentiation, locations and characteristics of public } \\
\text { substances present at the site. }\end{array}$ \\
\hline Contact: & Local Town Government Office \\
\hline Source: & Local Zoning Board or Planning Commission \\
\hline Provides: & $\begin{array}{l}\text { Records of local land development, including historical land use and } \\
\text { ownership, and general stratigraphy descriptions. }\end{array}$ \\
\hline Supports: & General site description and history, previous ownership, and land use. \\
\hline Contact: & Local Town Government Office \\
\hline
\end{tabular}


Appendix G

Table G.2 Site Assessment Information Sources (continued)

(Organized by Information Source)

\begin{tabular}{|l|l||}
\hline & \multicolumn{1}{|c|}{$\quad$ Expert and Other Sources } \\
\hline Source: & Local Fire Department \\
\hline Provides: & $\begin{array}{l}\text { Records of underground storage tanks in the area, material safety data sheets } \\
\text { (MSDS) for local commercial and industrial businesses, and other information } \\
\text { on hazardous substances used by those businesses. }\end{array}$ \\
\hline Supports: & $\begin{array}{l}\text { Location and use of underground storage tanks and other potential sources of } \\
\text { hazardous substances, identification of hazardous substances present at the site. }\end{array}$ \\
\hline Contact: & Local Town Government Office \\
\hline Source: & Local Well Drillers \\
\hline Provides: & $\begin{array}{l}\text { Public and Private water supply information including well locations and } \\
\text { depths, well logs, pumpage and production. }\end{array}$ \\
\hline Supports: & $\begin{array}{l}\text { Populations served by private and municipal drinking water wells, depth to } \\
\text { aquifer, general stratigraphic information. }\end{array}$ \\
\hline Source: & Local University or College \\
\hline Provides: & $\begin{array}{l}\text { Geology/Environmental Studies departments may have relevant published } \\
\text { materials (reports, theses, dissertations) and faculty experts knowledgeable in } \\
\text { local geologic, hydrologic, and environmental conditions. }\end{array}$ \\
\hline Supports: & $\begin{array}{l}\text { General stratigraphic information, ground water and surface water use and } \\
\text { characteristics, stream flow. }\end{array}$ \\
\hline Source: & Site Reconnaissance \\
\hline Provides: & Onsite and /or offsite visual observation of the site and surrounding area. \\
\hline Supports: & $\begin{array}{l}\text { General site information; source identification and descriptions; general ground } \\
\text { water, surface water, soil, and air pathway characteristics; nearby targets; } \\
\text { probable point of entry to surface water. }\end{array}$ \\
\hline
\end{tabular}




\section{APPENDIX H \\ DESCRIPTION OF \\ FIELD SURVEY AND LABORATORY ANALYSIS EQUIPMENT}

H.1 INTRODUCTION $\ldots \ldots \ldots \ldots \ldots \ldots \ldots \ldots \ldots \ldots \ldots \ldots \ldots, \mathrm{H}-3$

H.2 FIELD SURVEY EQUIPMENT $\ldots \ldots \ldots \ldots \ldots \ldots \ldots \ldots \ldots \ldots \ldots \ldots$ H-5

H.2.1 Alpha Particle Detectors $\ldots \ldots \ldots \ldots \ldots \ldots \ldots \ldots \ldots \ldots \ldots$ H-5

ALPHA SCINTILLATION SURVEY METER $\ldots \ldots \ldots \ldots \ldots \ldots \ldots$ H-6

ALPHA TRACK DETECTOR $\ldots \ldots \ldots \ldots \ldots \ldots \ldots \ldots \ldots \ldots \ldots, \mathrm{H}-7$

ELECTRET ION CHAMBER $\ldots \ldots \ldots \ldots \ldots \ldots \ldots \ldots \ldots \ldots \ldots, \mathrm{H}-8$

GAS-FLOW PROPORTIONAL COUNTER $\ldots \ldots \ldots \ldots \ldots \ldots \ldots \ldots$ H-9

LONG RANGE ALPHA DETECTOR (LRAD) $\ldots \ldots \ldots \ldots \ldots \ldots \ldots, \mathrm{H}-10$

H.2.2 Beta Particle Detectors $\ldots \ldots \ldots \ldots \ldots \ldots \ldots \ldots \ldots \ldots \ldots \ldots \ldots \ldots \ldots, 11$

ELECTRET ION CHAMBER ........................

GAS-FLOW PROPORTIONAL COUNTER ............... H-13

GM SURVEY METER WITH BETA PANCAKE PROBE $\ldots \ldots \ldots \ldots \ldots$ H-14

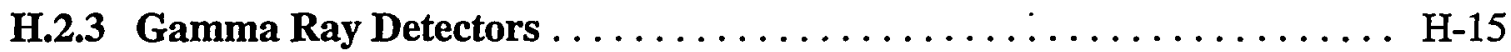

ELECTRET ION CHAMBER . . . . . . . . . . . . . . . . . . . H-16

GM SURVEY METER WITH GAMMA PROBE $\ldots \ldots \ldots \ldots \ldots \ldots \ldots$ H-17

HAND-HELD ION CHAMBER SURVEY METER ............ H-18

HAND-HELD PRESSURIZED ION CHAMBER SURVEY METER . . . . H-19

PORTABLE GERMANIUM MULTICHANNEL ANALYZER . ........ H-20

PRESSURIZED IONIZATION CHAMBER (PIC) $\ldots \ldots \ldots \ldots \ldots \ldots . . .6 .22$

SODIUM IODIDE SURVEY METER $\ldots \ldots \ldots \ldots \ldots \ldots \ldots \ldots, \mathrm{H}-23$

THERMOLUMINESCENCE DOSIMETER $\ldots \ldots \ldots \ldots \ldots \ldots \ldots, \mathrm{H}-24$

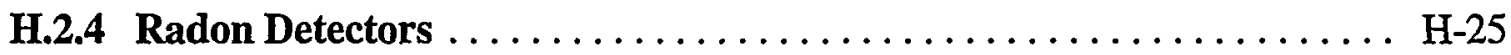

ACTIVATED CHARCOAL ADSORPTION $\ldots \ldots \ldots \ldots \ldots \ldots \ldots$ H-26

ALPHA TRACK DETECTION $\ldots \ldots \ldots \ldots \ldots \ldots \ldots \ldots \ldots \ldots, \mathrm{H}-27$

CONTINUOUS RADON MONITOR $\ldots \ldots \ldots \ldots \ldots \ldots \ldots \ldots \ldots$ H-28

ELECTRET ION CHAMBER . ........................ H-29

LARGE AREA ACTIVATED CHARCOAL COLLECTOR . . . . . . . . . H-30

H.2.5 X-Ray and Low Energy Gamma Detectors $\ldots \ldots \ldots \ldots \ldots \ldots \ldots$ H-31

FIDLER PROBE WITH SURVEY METER $\ldots \ldots \ldots \ldots \ldots \ldots \ldots \ldots, \mathrm{H}-32$

FIELD X-RAY FLUORESCENCE SPECTROMETER $\ldots \ldots \ldots \ldots \ldots \mathrm{H}-33$

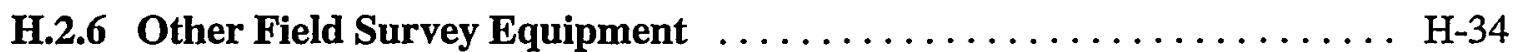

CHEMICAL SPECIES LASER ABLATION MASS SPECTROMETER .. H-35

LA-ICP-AES AND LA-ICP-MS $\ldots \ldots \ldots \ldots \ldots \ldots \ldots \ldots \ldots$ H-36 
Appendix $\mathrm{H}$

H.3 LABORATORY INSTRUMENTS $\ldots \ldots \ldots \ldots \ldots \ldots \ldots \ldots \ldots \ldots \ldots \ldots, \mathrm{H}-38$

H.3.1 Alpha Particle Analysis . . . ...................... H-38

ALPHA SPECTROSCOPY WITH MULTICHANNEL ANALYZER ..... H-39

GAS-FLOW PROPORTIONAL COUNTER $\ldots \ldots \ldots \ldots \ldots \ldots \ldots, \mathrm{H}-40$

LIQUID SCINTILLATION SPECTROMETER $\ldots \ldots \ldots \ldots \ldots \ldots \ldots$ H-41

LOW-RESOLUTION ALPHA SPECTROSCOPY $\ldots \ldots \ldots \ldots \ldots \ldots \mathrm{H}-42$

H.3.2 Beta Particle Analysis $\ldots \ldots \ldots \ldots \ldots \ldots \ldots \ldots \ldots \ldots \ldots \ldots . . .43$

GAS-FLOW PROPORTIONAL COUNTER $\ldots \ldots \ldots \ldots \ldots \ldots \ldots, \mathrm{H}-44$

LIQUID SCINTILLATION SPECTROMETER $\ldots \ldots \ldots \ldots \ldots \ldots \ldots \mathrm{H}-45$

H.3.3 Gamma Ray Analysis . ....................... H-46 GERMANIUM DETECTOR WITH MULTICHANNEL ANALYZER ....H-47 SODIUM IODIDE DETECTOR WITH MULTICHANNEL ANALYZER . H-48

EQUIPMENT SUMMARY TABLES $\ldots \ldots \ldots \ldots \ldots \ldots \ldots \ldots \ldots \ldots \ldots \ldots \ldots$ H-49

Table H.1 - Radiation Detectors with Applications to Alpha Surveys . .......... H-50

Table H.2 - Radiation Detectors with Applications to Beta Surveys ........... H-52

Table H.3 - Radiation Detectors with Applications to Gamma Surveys $\ldots \ldots \ldots \ldots$. . .

Table H.4 - Radiation Detectors with Applications to Radon Surveys $\ldots \ldots \ldots \ldots$ H-55

Table H.5 - Systems that Measure Atomic Mass or Emissions $\ldots \ldots \ldots \ldots \ldots$ H-56 


\section{H.1 INTRODUCTION}

This appendix provides information on various field and laboratory equipment used to measure radiation levels and radioactive material concentrations. The descriptions provide general guidance, and those interested in purchasing or using the equipment are encouraged to contact vendors and users of the equipment for specific information and recommendations. Although most of this equipment is in common use, a few specialty items are included to demonstrate promising developments.

The equipment is divided into two broad groupings of field survey and laboratory instruments, and each group is subdivided into equipment that measures alpha, beta, gamma, $\mathrm{x}$-rays, and radon. A single sheet provides information for each system and includes its type of use (field or lab), the primary and secondary radiation detected, applicability for site surveys, operation, specificity/sensitivity, and cost of the equipment and surveys performed.

The Applicability for Site Surveys section discusses how the equipment is most useful for performing site radiological surveys. The Operation section provides basic technical information on what the system includes, how it works, how to use it practically in the field, and its features. The Specificity/Sensitivity section addresses the system's strengths and weaknesses, and the levels of radioactivity it can measure. Information for the Cost section was obtained primarily from discussions with manufacturers, users, and reviews of product literature. The cost per measurement is an estimate of the cost of producing and documenting a single data point, generally as part of a multipoint survey. It assumes times for instrument calibration (primarily if conducted at the time of the survey), use, sample analysis, and report preparation and review. It should be recognized that these values will change over time due to factors like inflation and market expansion.

It is assumed that the user of this appendix has a basic familiarity with field and laboratory equipment. Some of the typical instrument features and terms are listed below and may not be described separately for the individual instruments:

- Field survey equipment consists of a detector, a survey meter, and interconnected cables, although these are sometimes packaged in a single container. The detector or probe is the portion which is sensitive to radiation. It is designed in such a manner, made of selected materials, and operated at a high voltage that makes it sensitive to one or more types of radiation. Some detectors feature a window or a shield whose construction material and thickness make the detector more or less sensitive to a particular radiation. The size of the detector can vary depending on the specific need, but is often limited by the characteristics of the construction materials and the physics of the detection process. The survey meter contains the electronics and provides high voltage to the detector, processes the detector's signal, and displays the readings in analog or digital fashion. An analog survey meter has a continuous swing needle and typically a manually operated 
Appendix $\mathrm{H}$

scale switch, used to keep the needle on scale. The scaling switch may not be required on a digital survey meter. The interconnecting cables serve to transfer the high voltage and detector signals in the proper direction. These cables may be inside those units which combine the meter and detector into a single box, but they are often external with connectors that allow the user to interchange detectors.

- Scanning and measuring surveys. In a scanning survey, the field survey meter is operated while moving the detector over an area to search for a change in readings. Since the meter's audible signal responds faster than the meter display, listening to the built-in speaker or using headphones allows the user to more quickly discern changes in radiation level. When a scanning survey detects a change, the meter can be held in place for a more accurate static measurement.

- Integrated readings. Where additional sensitivity is desired, the reading can be integrated using internal electronics or an external scaler to give total values over time. The degree to which the sensitivity can be improved depends largely on the integration time selected.

- Units of measure. Survey meters with conventional meter faces measure radiation levels in units of counts, microRoentgen $(\mu \mathrm{R})$, millirad (mrad), or millirem (mrem) in terms of unit time, e.g., cpm or $\mu \mathrm{R} / \mathrm{hr}$. Those with SI meter faces use units of microSievert $(\mu \mathrm{Sv})$ or milliGray per unit time, e.g., $\mu \mathrm{Sv} / \mathrm{hr}$ or $\mathrm{mGy} / \mathrm{hr}$. 
Appendix $\mathrm{H}$

\section{H.2 FIELD SURVEY EQUIPMENT}

\section{H.2.1 Alpha Particle Detectors}


Appendix $\mathrm{H}$

System:

Lab/Field:

ALPHA SCINTILLATION SURVEY METER

Radiation Detected: Primary: Alpha

Secondary: None (in relatively low gamma fields)

Applicability to Site Surveys: The alpha scintillation survey meter is useful for determining the presence or absence of alpha-emitting contamination on nonporous surfaces, swipes, and air filters, or on irregular surfaces if the degree of surface shielding is known.

Operation: This survey meter uses an alpha radiation detector with a sensitive area of approximately 50 to $100 \mathrm{~cm}^{2}$ (8 to $16 \mathrm{in}^{2}$ ). The detector has a thin, aluminized window of mylar that blocks ambient light but allows alpha radiation to pass through. The detecting medium is silver activated zinc sulfide, $\mathrm{ZnS}(\mathrm{Ag})$. When the discriminator is appropriately adjusted, the meter is sensitive only to alpha radiation. Light pulses are amplified by a photomultiplier tube and passed to the survey meter.

The probe is generally placed close to the surface due to the short range of alpha particles in air. A scanning survey is used to identify areas of elevated surface contamination and then a direct survey is performed to obtain actual measurements. Integrating the readings over time improves the sensitivity enough to make the instrument very useful for alpha surface contamination measurements for many isotopes. The readings are displayed in counts per minute, but factors can usually be obtained to convert readings from $\mathrm{cpm}$ to $\mathrm{dpm}$. Conversion factors, however, can be adversely affected by the short range of alpha particles which allows them to be shielded to often uncertain degrees if they are embedded in the surface. Systems typically use 2 to 6 "C" or "D" cells and will operate for 100-300 hours.

Specificity/Sensitivity: When the alpha discriminator is correctly adjusted, the alpha scintillation survey meter measures only alpha radiation, even if there are other radiations present. A scanning survey gives a quick indication of the presence or absence of surface contamination, while integrating the readings provides a measure of the activity on a surface, swipe, or filter. Alpha radiation is easily adsorbed by irregular, porous, moist, or over painted surfaces, and this should be carefully considered when converting count rate data to surface contamination levels. This also requires wet swipes and filters to be dried before counting. The minimum sensitivity is around $10 \mathrm{cpm}$ using the needle deflection or 1 to $2 \mathrm{cpm}$ when using headphones or a scaler. Some headphones or scalers give one click for every two counts, so the manual should be consulted to preclude underestimating the radioactivity by a factor of two.

\section{Cost of Equipment: $\$ 1000$}

Cost per Measurement: $\$ 5$ 
Appendix $\mathrm{H}$

System: $\quad$ ALPHA TRACK DETECTOR

Lab/Field: $\quad$ Field and Indoor Surfaces

Radiation Detected: Primary: Alpha Secondary: None

Applicability to Site Surveys: Alpha track detectors measure gross alpha surface contamination, soil activity levels, or the depth profile of contamination.

Operation: This is a passive integrating detector. It consists of a $1 \mathrm{~mm}$-thick sheet of polycarbonate material which is deployed directly on the soil surface or in close proximity to the contaminated surface. When alpha particles strike the detector surface, they cause microscopic damage centers to form in the plastic matrix. After deployment, the detector is etched in a caustic solution which preferentially attacks the damage centers. The etch pits may then be counted in an optical scanner. The density of etch pits, divided by the deployment time, is proportional to the soil or surface alpha activity. The measurement may be converted to isotopic concentration if the isotopes are known or measured separately. The area of a standard detector is $2 \mathrm{~cm}^{2}\left(0.3 \mathrm{in}^{2}\right)$, but it may be cut into a variety of shapes and sizes to suit particular needs.

Specificity/Sensitivity: Alpha track detectors are relatively inexpensive, simple, passive, and have no measurable response to beta/gamma radiation. They provide a gross alpha measurement where the lower limit of detection is a function of deployment time. For surface contamination it is $120 \mathrm{~Bq} / \mathrm{m}^{2}\left(200 \mathrm{dpm} / 100 \mathrm{~cm}^{2}\right)$ @ l hour, $18 \mathrm{~Bq} / \mathrm{m}^{2}\left(30 \mathrm{dpm} / 100 \mathrm{~cm}^{2}\right) @ 8$ hours, and $6 \mathrm{~Bq} / \mathrm{m}^{2}$ $\left(10 \mathrm{dpm} / 100 \mathrm{~cm}^{2}\right) @ 48$ hours. For soil contamination it is $11,000 \mathrm{~Bq} / \mathrm{kg}(300 \mathrm{pCi} / \mathrm{g}) @ 1$ hour, $3,700 \mathrm{~Bq} / \mathrm{kg}(100 \mathrm{pCi} / \mathrm{g}) @ 8$ hours, and $740 \mathrm{~Bq} / \mathrm{kg}(20 \mathrm{pCi} / \mathrm{g}) @ 96$ hours. High surface contamination or soil activity levels may be measured with deployment times of a few minutes, while activity down to background levels may require deployment times of 48-96 hours. When placed on a surface, they provide an estimate of alpha surface contamination or soil concentration. When deployed against the side of a trench, they can provide an estimate of the depth profile of contamination. They may also be used in pipes and under/inside of equipment.

For most applications, the devices are purchased for a fixed price per measurement, which includes readout. This requires that the detectors be returned to the vendor and the data are not immediately available. For programs having continuing needs and a large number of measurements, automated optical scanners may be purchased. The cost per measurement is then a function of the number of measurements required.

Cost of Equipment: $\$ 65,000$

Cost per Measurement: $\$ 5$ to $\$ 10$ 
Appendix $\mathrm{H}$

System:

Lab/Field:

ELECTRET ION CHAMBER

Radiation Detected: Primary: Alpha, beta, gamma, or radon . Secondary: None Applicability to Site Surveys: An electret is a passive integrating detector for measurements of alpha- or beta-emitting contaminants on surfaces and in soils, gamma radiation dose, or radon air concentration.

Operation: The system consists of a charged Teflon disk (electret), open-faced ionization chamber, and electret voltage reader/data logger. When the electret is screwed into the chamber, a static electric field is established and a passive ionization chamber is formed. For alpha or beta radiation, the chamber is opened and deployed directly on the surface or soil to be measured so the particles can enter the chamber. For gammas, however, the chamber is left closed and the gamma rays incident on the chamber penetrate the $2 \mathrm{~mm}$-thick plastic detector wall. These particles or rays ionize the air molecules, the ions are attracted to the cnarged electret, and the electret's charge is reduced. The electret charge is measured before and after deployment with the voltmeter, and the rate of change of the charge is proportional to the alpha or beta surface or soil activity, with appropriate compensation for background gamma levels. A thin Mylar window may be used to protect the electret from dust. In low-level gamma measurements, the electret is sealed inside a Mylar bag during deployment to minimize radon interference. For alpha and beta measurements, corrections must be made for background gamma radiation and radon response. This correction is accomplished by deploying additional gamma or radonsensitive detectors in parallel with the alpha or beta detector. Electrets are simple and can usually be reused several times before recharging by a vendor. Due to their small size $(3.8 \mathrm{~cm}$ tall by $7.6 \mathrm{~cm}$ diameter or $1.5 \mathrm{in}$. tall by $3 \mathrm{in}$. diameter), they may be deployed in hard-to-access locations.

Specificity/Sensitivity: This method gives a gross alpha, gross beta, gross gamma, or gross radon measurement. The lower limit of detection depends on the exposure time and the volume of the chamber used. High surface alpha or beta contamination levels or high gamma radiation levels may be measured with deployment times of a few minutes. Much lower levels can be measured by extending the deployment time to 24 hours or longer. For gamma radiation, the response of the detector is nearly independent of energy from 15 to $1200 \mathrm{keV}$, and fading corrections are not required. To quantify ambient gamma radiation fields of $10 \mu \mathrm{R} / \mathrm{hr}$, a 1000 $\mathrm{mL}$ chamber may be deployed for two days or a $50 \mathrm{~mL}$ chamber deployed for 30 days. The smallest chamber is particularly useful for long-term monitoring and reporting of monthly or quarterly measurements. For alpha and beta particles, the measurement may be converted to isotopic concentration if the isotopes are known or measured separately. The lower limit of detection for alpha radiation is $30 \mathrm{~Bq} / \mathrm{m}^{2}\left(50 \mathrm{dpm} / 100 \mathrm{~cm}^{2}\right) @ 1$ hour, $9 \mathrm{~Bq} / \mathrm{m}^{2}\left(15 \mathrm{dpm} / 100 \mathrm{~cm}^{2}\right)$ @ 8 hours, and $5 \mathrm{~Bq} / \mathrm{m}^{2}(8 \mathrm{dpm} / 100 \mathrm{~cm})$ @ 24 hours. For beta radiation from tritium it is 3,600 $\mathrm{Bq} / \mathrm{m}^{2}$ (6,000 dpm/ $\left.\mathrm{cm}^{2}\right)$ @ 1 hour and $180 \mathrm{~Bq} / \mathrm{m}^{2}$ (300 dpm/ $\left.\mathrm{cm}^{2}\right)$ @ 24 hours. For beta radiation from ${ }^{99} \mathrm{Tc}$ it is $300 \mathrm{~Bq} / \mathrm{m}^{2}$ (500 dpm/ $\left.\mathrm{cm}^{2}\right) @ 1$ hour and $12 \mathrm{~Bq} / \mathrm{m}^{2}\left(20 \mathrm{dpm} / \mathrm{cm}^{2}\right) @ 24$ hours.

Cost of Equipment: $\$ 4,000$ to $\$ 25,000$, for system if purchased.

Cost per Measurement: $\$ 8-\$ 25$, for use under service contract 
System:

Lab/Field:

Radiation Detected: Primary: Alpha, Beta Secondary: Gamma

Applicability to Site Surveys: This equipment measures gross alpha or gross beta/gamma surface contamination levels on relatively flat surfaces like the floors and walls of facilities. It also serves as a screen to determine whether or not more nuclide-specific analyses may be needed.

Operation: This system consists of a gas-flow proportional detector, gas supply, supporting electronics, and a scaler or rate meter. Small detectors $\left(\sim 100 \mathrm{~cm}^{2}\right)$ are hand-held and large detectors $\left(\sim 400-600 \mathrm{~cm}^{2}\right)$ are mounted on a rolling cart. The detector entrance window can be $<1$ to almost $10 \mathrm{mg} / \mathrm{cm}^{2}$ depending on whether alpha, alpha-beta, or gamma radiation is monitored. The gas used is normally $\mathrm{P}-10$, a mixture of $10 \%$ methane and $90 \%$ argon. The detector is positioned as close as practical to the surface being monitored for good counting efficiency without risking damage from the detector touching the surface. Quick disconnect fittings allow the system to be disconnected from the gas bottle for hours with little loss of counting efficiency. The detector operating voltage can be set to make it sensitive only to alpha radiation, to both alpha and beta radiation, or to beta and low energy gamma radiation. These voltages are determined for each system by placing either an alpha source, such as ${ }^{230} \mathrm{Th}$ or ${ }^{241} \mathrm{Am}$, or a beta source, such as ${ }^{90} \mathrm{Sr}$, facing and near the detector window, then increasing the high voltage in incremental steps until the count rate becomes constant. The alpha plateau, the region of constant count rate, will be almost flat. The beta plateau will have a slope of 5 to 15 percent per 100 volts. Operation on the beta plateau allows detection of some gamma radiation, but the efficiency is very low. Some systems use a spectrometer to separate alpha, and beta/gamma events, allowing simultaneous determination of both the alpha and beta/gamma surface contamination levels.

Specificity/Sensitivity: These systems do not identify the alpha or beta energies detected and cannot be used to identify specific radionuclides. Background for operation on the alpha plateau is very low, 2 to 3 counts per minute, which is higher than for laboratory detectors because of the larger detector size. Background for operation on the beta plateau is dependent on the ambient gamma and cosmic ray background, and typically ranges from several hundred to a thousand counts per minute. Typical efficiencies for unattenuated alpha sources are $15-20 \%$. Beta efficiency depends on the window thickness and the beta energy. For ${ }^{90} \mathrm{Sr} /{ }^{90} \mathrm{Y}$ in equilibrium, efficiencies range from $5 \%$ for highly attenuated to about $35 \%$ for unattenuated sources. Typical gamma ray efficiency is $<1 \%$. The presence of natural radionuclides in the surfaces could interfere with the detection of other contaminants. Unless the nature of the contaminant and any naturally-occurring radionuclides is well known, this system is better used for assessing gross surface contamination levels. The texture and porosity of the surface can hide or shield radioactive material from the detector, causing levels to be underestimated. Changes in temperature can affect the detectors's sensitivity. Incomplete flushing with gas can cause a nonuniform response over the detector's surface. Condensation in the gas lines or using the quick disconnect fittings can cause count rate instability.

Cost of Equipment: $\$ 2,000$ to $\$ 4,000$

Cost per Measurement: $\$ 2-\$ 10$ per $\mathrm{m}^{2}$

December 1997

H-9

MARSSIM 
Appendix H

System:

Lab/Field:

LONG RANGE ALPHA DETECTOR (LRAD)

Field

Radiation Detected: Primary: Alpha Secondary: None

Applicability to Site Surveys: The LRAD is a rugged field-type unit for measuring alpha surface soil concentration over a variety of dry, solid, flat terrains.

Operation: The LRAD system consists of a large $(1 \mathrm{~m} \mathrm{x} 1 \mathrm{~m})$ aluminum box, open on the bottom side, containing copper plates that collect ions produced in the soil or surface under the box, and used to measure alpha surface contamination or soil concentration. It is attached to a lifting device on the front of a tractor and can be readily moved to new locations. Bias power is supplied by a $300-\mathrm{V}$ dry cell battery, and the electrometer and computer are powered by an automobile battery and DC-to-AC inverter. A $50 \mathrm{~cm}$ grounding rod provides electrical grounding. A notebook computer is used for data logging and graphical interpretation of the data. Alpha particles emitted by radionuclides in soil travel only about $3 \mathrm{~cm}$ in air. However, these alpha particles interact with the air and produce ions that travel considerably farther. The LRAD detector box is lowered to the ground to form an enclosed ionization region. The copper detector plate is raised to $+300 \mathrm{~V}$ along with a guard detector mounted above the detector plate to control leakage current. The ions are then allowed to collect on the copper plate producing a current that is measured with a sensitive electrometer. The signal is then averaged and processed on a computer. The electric current produced is proportional to the ionization within the sensitive area of the detector and to the amount of alpha contamination present on the surface soil.

Due to its size and weight $(300 \mathrm{lb})$, the unit can be mounted on a tractor for ease of movement. All metal surfaces are covered with plastic to reduce the contribution from ion sources outside the detector box. At each site, a ground rod is driven into the ground. Each location is monitored for at least $5 \mathrm{~min}$. After each location is monitored, its data is fed into a notebook computer and an interpolative graph of alpha concentration produced. The unit is calibrated using standard alpha sources.

Sensitivity/Specificity: The terrain over which this system is used must be dry, to prevent the shielding of alpha particles by residual moisture, and flat, to prevent air infiltration from outside the detector, both of which can lead to large errors. The unit can detect a thin layer of alpha surface contamination at levels of $12-30 \mathrm{~Bq} / \mathrm{m}^{2}\left(20-50 \mathrm{dpm} / 100 \mathrm{~cm}^{2}\right)$, but does not measure alpha contamination of deeper layers. Alpha concentration errors are $\pm 74-740 \mathrm{~Bq} / \mathrm{kg}( \pm 2-20$ $\mathrm{pCi} / \mathrm{g}$ ), with daily repeat accuracies of $\pm 370-3,700 \mathrm{~Bq} / \mathrm{kg}( \pm 10-100 \mathrm{pCi} / \mathrm{g})$, depending on the contamination level. The dynamic measurement range appears to be $370-110,00 \mathrm{~Bq} / \mathrm{kg}$ $(10-3,000 \mathrm{pCi} / \mathrm{g})$.

Cost of Equipment: $\$ 25,000$ (est. for tractor, computer, software, electrometer, and detector) Cost per Measurement: $\$ 80$ (based on 30 min per point and a 2 person team) 
Appendix $\mathrm{H}$

\section{H.2 FIELD SURVEY EQUIPMENT}

\section{H.2.2 Beta Particle Detectors}


Appendix H

System:

Lab/Field:

\section{ELECTRET ION CHAMBER}

Field

Radiation Detected: Primary: Low energy beta (e.g. tritium, $\left.{ }^{99} \mathrm{Tc},{ }^{14} \mathrm{C},{ }^{90} \mathrm{Sr},{ }^{63} \mathrm{Ni}\right)$, alpha, gamma, or radon Secondary: None

Applicability to Site Surveys: This system measures alpha- or beta-emitting contaminants on surfaces and in soils, gamma radiation dose, or radon air concentration, depending on how it is configured.

Operation: The system consists of a charged Teflon disk (electret), open-faced ionization chamber, and electret voltage reader/data logger. When the electret is screwed into the chamber, a static electric field is established and a passive ionization chamber is formed. For alpha or beta radiation, the chamber is opened and deployed directly on the surface or soil to be measured so the particles can enter the chamber. For gammas, however, the chamber is left closed and the gamma rays incident on the chamber penetrate the $2 \mathrm{~mm}$-thick plastic detector wall. These particles or rays ionize the air molecules, the ions are attracted to the charged electret, and the electret's charge is reduced. The electret charge is measured before and after deployment with the voltmeter, and the rate of change of the charge is proportional to the alpha or beta surface or soil activity, with appropriate compensation for background gamma levels. A thin Mylar window may be used to protect the electret from dust. In low-level gamma measurements, the electret is sealed inside a Mylar bag during deployment to minimize radon interference. For alpha and beta measurements, corrections must be made for background gamma radiation and radon response. This correction is accomplished by deploying additional gamma or radon-sensitive detectors in parallel with the alpha or beta detector. Electrets are simple and can usually be reused several times before recharging by a vendor. Due to their small size $(3.8 \mathrm{~cm}$ tall by $7.6 \mathrm{~cm}$ diameter or 1.5 in. tall by 3 in. diameter), they may be deployed in hard-to-access locations.

Specificity/Sensitivity: This method gives a gross alpha, gross beta, gross gamma, or gross radon measurement. The lower limit of detection depends on the exposure time and the volume of the chamber used. High surface alpha or beta contamination levels or high gamma radiation levels may be measured with deployment times of a few minutes. Much lower levels can be measured by extending the deployment time to 24 hours or longer. For gamma radiation, the response of the detector is nearly independent of energy from 15 to $1200 \mathrm{keV}$, and fading corrections are not required. To quantify ambient gamma radiation fields of $10 \mu \mathrm{R} / \mathrm{hr}$, a 1000 $\mathrm{mL}$ chamber may be deployed for two days or a $50 \mathrm{~mL}$ chamber deployed for 30 days. The smallest chamber is particularly useful for long-term monitoring and reporting of monthly or quarterly measurements. For alpha and beta particles, the measurement may be converted to isotopic concentration if the isotopes are known or measured separately. The lower limit of detection for alpha radiation is $30 \mathrm{~Bq} / \mathrm{m}^{2}\left(50 \mathrm{dpm} / 100 \mathrm{~cm}^{2}\right) @ 1$ hour, $9 \mathrm{~Bq} / \mathrm{m}^{2}\left(15 \mathrm{dpm} / 100 \mathrm{~cm}^{2}\right)$ @ 8 hours, and $5 \mathrm{~Bq} / \mathrm{m}^{2}\left(8 \mathrm{dpm} / 100 \mathrm{~cm}^{2}\right) @ 24$ hours. For beta radiation from tritium it is 3,600 $\mathrm{Bq} / \mathrm{m}^{2}\left(6,000 \mathrm{dpm} / \mathrm{cm}^{2}\right) @ 1$ hour and $180 \mathrm{~Bq} / \mathrm{m}^{2}\left(300 \mathrm{dpm} / \mathrm{cm}^{2}\right) @ 24$ hours. For beta radiation from ${ }^{-99} \mathrm{Tc}$ it is $150 \mathrm{~Bq} / \mathrm{m}^{2}\left(500 \mathrm{dpm} / \mathrm{cm}^{2}\right) @ 1$ hour and $12 \mathrm{~Bq} / \mathrm{m}^{2}\left(20 \mathrm{dpm} / \mathrm{cm}^{2}\right) @ 24$ hours. Cost of Equipment: $\$ 4,000$ to $\$ 25,000$, for system if purchased.

Cost per Measurement: $\$ 8-\$ 25$, for use under service contract 
Appendix $\mathrm{H}$

System:

Lab/Field:

GAS-FLOW PROPORTIONAL COUNTER

Radiation Detected: Primary: Alpha, Beta Secondary: Gamma

Applicability to Site Surveys: This equipment measures gross alpha or gross beta/gamma surface contamination levels on relatively flat surfaces like the floors and walls of facilities. It would serve as a screen to determine whether or not more nuclide-specific analyses were needed. Operation: This system consists of a gas-flow proportional detector, gas supply, supporting electronics, and a scaler or rate meter. Small detectors $\left(-100 \mathrm{~cm}^{2}\right)$ are hand-held and large detectors $\left(-400-600 \mathrm{~cm}^{2}\right)$ are mounted on a rolling cart. The detector entrance window can be $<1$ to almost $10 \mathrm{mg} / \mathrm{cm}^{2}$ depending on whether alpha, alpha-beta, or gamma radiation is monitored. The gas used is normally P-10, a mixture of $10 \%$ methane and $90 \%$ argon. The detector is positioned as close as practical to the surface being monitored for good counting efficiency without risking damage from the detector touching the surface. Quick disconnect fittings allow the system to be disconnected from the gas bottle for hours with little loss of counting efficiency. The detector operating voltage can be set to make it sensitive only to alpha radiation, to both alpha and beta radiation, or to beta and low energy gamma radiation. These voltages are determined for each system by placing either an alpha source, such as ${ }^{230} \mathrm{Th}$ or ${ }^{241} \mathrm{Am}$, or a beta source, such as ${ }^{90} \mathrm{Sr}$, facing and near the detector window, then increasing the high voltage in incremental steps until the count rate becomes constant. The alpha plateau, the region of constant count rate, will be almost flat. The beta plateau will have a slope of 5 to 15 percent per 100 volts. Operation on the beta plateau allows detection of some gamma radiation, but the efficiency is very low. Some systems use a spectrometer to separate alpha, and beta/gamma events, allowing simultaneous determination of both the alpha and beta/gamma surface contamination levels.

Specificity/Sensitivity: These systems do not identify the alpha or beta energies detected and cannot be used to identify specific radionuclides. Background for operation on the alpha plateau is very low, 2 to 3 counts per minute, which is higher than for laboratory detectors because of the larger detector size. Background for operation on the beta plateau is dependent on the ambient gamma and cosmic ray background, and typically ranges from several hundred to a thousand counts per minute. Typical efficiencies for unattenuated alpha sources are 15-20\%. Beta efficiency depends on the window thickness and the beta energy. For ${ }^{90} \mathrm{Sr} /{ }^{90} \mathrm{Y}$ in equilibrium, efficiencies range from $5 \%$ for highly attenuated to about $35 \%$ for unattenuated sources. Typical gamma ray efficiency is $<1 \%$. The presence of natural radionuclides in the surfaces could interfere with the detection of other contaminants. Unless the nature of the contaminant and any naturally-occurring radionuclides is well known, this system is better used for assessing gross surface contamination levels. The texture and porosity of the surface can hide or shield radioactive material from the detector, causing levels to be underestimated. Changes in temperature can affect the detectors's sensitivity. Incomplete flushing with gas can cause a nonuniform response over the detector's surface. Condensation in the gas lines or using the quick disconnect fittings can cause count rate instability.

Cost of Equipment: $\$ 2,000$ to $\$ 4,000$

Cost per Measurement: $\$ 2-\$ 10$ per $\mathrm{m}^{2}$ 
Appendix $\mathrm{H}$

System:

Lab/Field:

GM SURVEY METER WITH BETA PANCAKE PROBE

Radiation Detected: Primary: Beta Secondary: Gamma and alpha

Applicability to Site Surveys: This instrument is used to find and measure low levels of beta/gamma contamination on relatively flat surfaces.

Operation: This instrument consists of a flat "pancake" type Geiger-Mueller detector connected to a survey meter which measures radiation response in counts per minute. The detector housing is typically a rigid metal on all sides except the radiation entrance face or window, which is made of Mylar, mica, or a similar material. A steel, aluminum, lead, or tungsten housing surrounds the detector on all sides except the window, giving the detector a directional response. The detector requires approximately 900 volts for operation. It is held within a few $\mathrm{cm}$ of the surface to minimize the thickness of air shielding in between the radioactive material and the detector. It is moved slowly to scan the surface in search of elevated readings, then held in place long enough to obtain a stable measurement. Radiation entering the detector ionizes the gas, causes a discharge throughout the entire tube, and results in a single count being sent to the meter. The counts per minute meter reading is converted to a beta surface contamination level in the range of $600 \mathrm{~Bq} / \mathrm{m}^{2}\left(1,000 \mathrm{pCi} / 100 \mathrm{~cm}^{2}\right)$ using isotope specific factors.

Specificity/Sensitivity: Pancake type GM detectors primarily measure beta count rate in close contact with surfaces to indicate the presence of contamination. They are sensitive to any alpha, beta, or gamma radiation that enters the detector and causes ionization. As a result, they cannot determine the type or energy of that radiation, except by using a set of absorbers. To be detected, beta particles must have enough energy to penetrate through any surface material that the contamination is absorbed in, plus the detector window, and the layer of air and other shielding materials in between. Low energy beta particles from emitters like ${ }^{3} \mathrm{H}(17 \mathrm{keV})$ that cannot penetrate the window alone are not detectable, while higher energy betas like those from ${ }^{60} \mathrm{Co}$ ( $314 \mathrm{keV}$ ) can be readily detected. The beta detection efficiency at a field site is primarily a function of the beta energy, window thickness, and the surface condition. The detection sensitivity can be improved by using headphones or the audible response during scans. By integrating the count rate over a longer period or by counting the removable radioactive material collected on a swipe , the ability to detect surface contamination can be improved. The nominal 2 in. diameter detector can measure an increase of around $100 \mathrm{cpm}$ above background, which equates to $1,500 \mathrm{~Bq} / \mathrm{m}^{2}\left(2,500 \mathrm{pCi} / 100 \mathrm{~cm}^{2}\right)$ of ${ }^{60} \mathrm{Co}$ on a surface under the detector or $20 \mathrm{~Bq}$ $(500 \mathrm{pCi})$ on a swipe. Larger $100 \mathrm{~cm}^{2}$ detectors improve sensitivity and eliminate the need to swipe. A swipe's collection efficiency may be below $100 \%$, and depends on the wiping technique, the actual surface area covered, the texture and porosity of the surface, the affinity of the contamination for the swipe material, and the dryness of the swipe. This will proportionately change the values above. The sensitivity to gamma radiation is around $10 \%$ or less of the beta sensitivity, while the alpha detection efficiency is difficult to evaluate.

Cost of equipment: $\$ 400$ to $\$ 1,500$

Cost per Measurement: $\$ 5$ to $\$ 10$ per location 
Appendix $\mathrm{H}$

\section{H.2 FIELD SURVEY EQUIPMENT}

\section{H.2.3 Gamma Ray Detectors}


Appendix $\mathrm{H}$

System:

ELECTRET ION CHAMBER

Lab/Field:

Field

Radiation Detected: Primary: Low energy beta (e.g. tritium, ${ }^{99} \mathrm{Tc},{ }^{14} \mathrm{C},{ }^{90} \mathrm{Sr},{ }^{63} \mathrm{Ni}$ ), alpha, gamma, or radon Secondary: None

Applicability to Site Surveys: This system measures alpha- or beta-emitting contaminants on surfaces and in soils, gamma radiation dose, or radon air concentration, depending on how it is configured.

Operation: The system consists of a charged Teflon disk (electret), open-faced ionization chamber, and electret voltage reader/data logger. When the electret is screwed into the chamber, a static electric field is established and a passive ionization chamber is formed. For alpha or beta radiation, the chamber is opened and deployed directly on the surface or soil to be measured so the particles can enter the chamber. For gammas, however, the chamber is left closed and the gamma rays incident on the chamber penetrate the $2 \mathrm{~mm}$-thick plastic detector wall. These particles or rays ionize the air molecules, the ions are attracted to the charged electret, and the electret's charge is reduced. The electret charge is measured before and after deployment with the voltmeter, and the rate of change of the charge is proportional to the alpha or beta surface or soil activity, with appropriate compensation for background gamma levels. A thin Mylar window may be used to protect the electret from dust. In low-level gamma measurements, the electret is sealed inside a Mylar bag during deployment to minimize radon interference. For alpha and beta measurements, corrections must be made for background gamma radiation and radon response. This correction is accomplished by deploying additional gamma or radon-sensitive detectors in parallel with the alpha or beta detector. Electrets are simple and can usually be reused several times before recharging by a vendor. Due to their small size $(3.8 \mathrm{~cm}$ tall by $7.6 \mathrm{~cm}$ diameter or 1.5 in. tall by 3 in. diameter), they may be deployed in hard-to-access locations.

Specificity/Sensitivity: This method gives a gross alpha, gross beta, gross gamma, or gross radon measurement. The lower limit of detection depends on the exposure time and the volume of the chamber used. High surface alpha or beta contamination levels or high gamma radiation levels may be measured with deployment times of a few minutes. Much lower levels can be measured by extending the deployment time to 24 hours or longer. For gamma radiation, the response of the detector is nearly independent of energy from 15 to $1200 \mathrm{keV}$, and fading corrections are not required. To quantify ambient gamma radiation fields of $10 \mu \mathrm{R} / \mathrm{hr}$, a 1000 $\mathrm{mL}$ chamber may be deployed for two days or a $50 \mathrm{~mL}$ chamber deployed for 30 days. The smallest chamber is particularly useful for long-term monitoring and reporting of monthly or quarterly measurements. For alpha and beta particles, the measurement may be converted to isotopic concentration if the isotopes are known or measured separately. The lower limit of detection for alpha radiation is $30 \mathrm{~Bq} / \mathrm{m}^{2}\left(50 \mathrm{dpm} / 100 \mathrm{~cm}^{2}\right) @ 1$ hour, $9 \mathrm{~Bq} / \mathrm{m}^{2}\left(15 \mathrm{dpm} / 100 \mathrm{~cm}^{2}\right)$ @ 8 hours, and $5 \mathrm{~Bq} / \mathrm{m}^{2}$ (8 dpm/100 $\left.\mathrm{cm}^{2}\right) @ 24$ hours. For beta radiation from tritium it is 3,600 $\mathrm{Bq} / \mathrm{m}^{2}\left(6,000 \mathrm{dpm} / \mathrm{cm}^{2}\right) @ 1$ hour and $180 \mathrm{~Bq} / \mathrm{m}^{2}\left(300 \mathrm{dpm} / \mathrm{cm}^{2}\right) @ 24$ hours. For beta radiation from ${ }^{99} \mathrm{Tc}$ it is $150 \mathrm{~Bq} / \mathrm{m}^{2}\left(500 \mathrm{dpm} / \mathrm{cm}^{2}\right)$ @ 1 hour and $12 \mathrm{~Bq} / \mathrm{m}^{2}\left(20 \mathrm{dpm} / \mathrm{cm}^{2}\right) @ 24$ hours. Cost of Equipment: $\$ 4,000$ to $\$ 25,000$, for system if purchased.

Cost per Measurement: $\$ 8-\$ 25$, for use under service contract 
System:

Lab/Field:
GM SURVEY METER WITH GAMMA PROBE

Field

\section{Radiation Detected: Primary: Gamma Secondary: Beta}

Applicability to Site Surveys: This instrument is used to give a quick indication of gammaradiation levels present at a site. Due to its high detection limit, the GM survey meter may be useful during characterization surveys but may not meet the needs of final status surveys.

Operation: This instrument consists of a cylindrical Geiger Mueller detector connected to a survey meter. It is calibrated to measure gamma exposure rate in $\mathrm{mR} / \mathrm{hr}$. The detector is surrounded on all sides by a protective rigid metal housing. Some units called end window or side window have a hinged door or rotating sleeve that opens to expose an entry window of Mylar, mica, or a similar material, allowing beta radiation to enter the sensitive volume. The detector requires approximately 900 volts for operation. It is normally held at waist height, but is sometimes placed in contact with an item be evaluated. It is moved slowly over the area to scan for elevated readings, observing the meter or, preferably, listening to the audible signal. Then it is held in place long enough to obtain a stable measurement. Radiation entering the detector ionizes the gas, causes a discharge throughout the entire tube, and results in a single count being sent to the meter. Conversion from count rate to exposure rate is accomplished at calibration by exposing the detector at discrete levels and adjusting the meter scale(s) to read accordingly. In the field, the exposure rate is read directly from the meter. If the detector housing has an entry window , an increase in "open-door" over "closed-door" reading indicates the presence of beta radiation in the radiation field, but the difference is not a direct measure of the beta radiation level.

Specificity/Sensitivity: GM meters measure gamma exposure rate, and those with an entry window can identify if the radiation field includes beta radiation. Since GM detectors are sensitive to any energy of alpha, beta, or gamma radiation that enters the detector, instruments that use these detectors cannot identify the type or energy of that radiation, or the specific radionuclide(s) present. The sensitivity can be improved by using headphones or the audible response during scans, or by integrating the exposure rate over time. The instrument has two primary limitations for environmental work. First, its minimum sensitivity is high, around 0.1 $\mathrm{mR} / \mathrm{hr}$ in rate meter mode or $0.01 \mathrm{mR} / \mathrm{hr}$ in integrate mode. Some instruments use a large detector to improve low end sensitivity. However, in many instances the instrument is not sensitive enough for site survey work. Second, the detector's energy response is nonlinear. Energy compensated survey meters are commercially available, but the instrument's sensitivity may be reduced.

Cost of Equipment: $\$ 400$ to $\$ 1,500$.

Cost per Measurement: $\$ 5$ per measurement for survey and report. 
Appendix $\mathrm{H}$

\section{System: $\quad$ HAND-HELD ION CHAMBER SURVEY METER \\ Lab/Field: \\ Field \\ Radiation Detected: Primary: Gamma Secondary: None}

Applicability to Site Surveys: The hand-held ion chamber survey meter measures true gamma radiation exposure rate, in contrast to most other survey meter/probe combinations which are calibrated to measure exposure rate at one energy and approximate the exposure rate at all other energies. Due to their high detection limit, these instruments are not applicable for many final status surveys.

Operation: This device uses an ion chamber operated at a bias voltage sufficient to collect all ion pairs created by the passage of ionizing radiation, but not sufficiently high to generate secondary ion pairs as a proportional counter does. The units of readout are $\mathrm{mR} / \mathrm{hr}$, or some multiple of $\mathrm{mR} / \mathrm{hr}$. If equipped with an integrating mode, the operator can measure the total exposure over a period of time. The instrument may operate on two " $D$ " cells or a 9 volt battery that will last for 100 to 200 hours of operation.

Specificity/Sensitivity: Ion chamber instruments respond only to gamma or x-radiation. They have no means to provide the identity of contaminants. Typical ion chamber instruments have a lower limit of detection of $0.5 \mathrm{mR} / \mathrm{hr}$. These instruments can display readings below this, but the readings may be erratic and have large errors associated with them. In integrate mode, the instrument sensitivity can be as low as $0.05 \mathrm{mR} / \mathrm{hr}$.

Cost of Equipment: $\$ 800$ to $\$ 1,200$

Cost per Measurement: \$5, or higher for making integrated exposure measurements. 
Appendix H

System:

Lab/Field:
HAND-HELD PRESSURIZED ION CHAMBER (PIC) SURVEY METER

Field

\section{Radiation Detected: $\quad$ Primary: Gamma Secondary: None}

Applicability to Site Surveys: The hand-held pressurized ion chamber survey meter measures true gamma radiation exposure rate, in contrast to most other survey meter/probe combinations which are calibrated to measure exposure rate at one energy and approximate the exposure rate at all other energies. Due to their high detection limit, these instruments are not applicable for many final status surveys.

Operation: This device uses a pressurized air ion chamber operated at a bias voltage sufficient to collect all ion pairs created by the passage of ionizing radiation, but not sufficiently high to cause secondary ionization.. The instrument is identical to the ion chamber meter on the previous page, except in this case the ion chamber is sealed and pressurized to 2 to 3 atmospheres to increase the sensitivity of the instrument by the same factors. The units of readout are $\mu \mathrm{R} / \mathrm{hr}$ or $\mathrm{mR} / \mathrm{hr}$. A digital meter will allow an operator to integrate the total exposure over a period of time. The unit may use two " $\mathrm{D}$ " cells or a 9-volt battery that will last for 100 to 200 hours of operation.

Specificity/Sensitivity: Since the ion chamber is sealed, pressurized ion chamber instruments respond only to gamma or X-radiation. They have no means to provide the identity of contaminants. Typical instruments have a lower limit of detection of $0.1 \mathrm{mR} / \mathrm{hr}$, or as low as $0.01 \mathrm{mR}$ in integrate mode. These instruments can display readings below this, but the readings may be erratic and have large errors associated with them.

Cost of Equipment: $\$ 1,000$ to $\$ 1,500$

Cost per Measurement: \$5, or higher for making integrated exposure measurements. 
Appendix $\mathrm{H}$

System: $\quad$ PORTABLE GERMANIUM MULTICHANNEL ANALYZER (MCA) SYSTEM Lab/Field: Field

Radiation Detected: $\quad$ Primary: Gamma Secondary: None

Applicability for Site Surveys: This system produces semi-quantitative estimates of concentration of uranium and plutonium in soil, water, air filters, and quantitative estimates of many other gamma-emitting isotopes. With an appropriate dewar, the detector may be used in a vertical orientation to determine, in situ, gamma isotopes concentrations in soil.

Operation: This system consists of a portable germanium detector connected to a dewar of liquid nitrogen, high voltage power supply, and multichannel analyzer. It is used to identify and quantify gamma-emitting isotopes in soil or other surfaces.

Germanium is a semiconductor material. When a gamma ray interacts with a germanium crystal, it produces electron-hole pairs. An electric field is applied which causes the electrons to move in the conduction band and the holes to pass the charge from atom to neighboring atoms. The charge is collected rapidly and is proportional to the deposited energy.

The typical system consists of a portable multichannel analyzer (MCA) weighing about 7-10 lbs with batteries, a special portable low energy germanium detector with a built-in shield, and the acquisition control and spectrum analysis software. The detector is integrally mounted to a liquid nitrogen dewar. The liquid nitrogen is added 2-4 hours before use and replenished every 4-24 hours based on capacity.

The MCA includes all required front end electronics, such as a high voltage power supply, an amplifier, a digital stabilizer, and an analog-to-digital converter (ADC), which are fully controllable from a laptop computer and software.

One method uses the $94-104 \mathrm{keV}$ peak region to analyze the plutonium isotopes from either "fresh" or aged materials. It requires virtually no user input or calibration. The source-todetector distance for this method does not need to be calibrated as long as there are enough counts in the spectrum to perform the analysis.

For in situ applications, a collimated detector is positioned at a fixed distance from a surface to provide multichannel spectral data for a defined surface area. It is especially useful for qualitative and (based on careful field calibration or appropriate algorithms) quantitative analysis of freshly deposited contamination. Additionally, with prior knowledge of the depth distribution of the primary radionuclides of interest, which is usually not known, or using algorithms that match the site, the in situ system can be used to estimate the content of radionuclides distributed below the surface (dependent, of course, on adequate detection capability.) 
Calibration based on Monte Carlo modeling of the assumed source-to-detector geometry or computation of fluence rates with analytical expressions is an important component to the accurate use of field spectrometry, when it is not feasible or desirable to use real radioactive sources. Such modeling used in conjunction with field spectrometry is becoming much more common recently, especially using the MCNP Monte Carlo computer software system.

Specificity/Sensitivity: With proper calibration or algorithms, field spectrometers can identify and quantify concentrations of gamma emitting radionuclides in the middle to upper energy range (i.e., $50 \mathrm{keV}$ with a P-type detector or $10 \mathrm{keV}$ with an $\mathrm{N}$-type detector).

For lower energy photons, as are important for plutonium and americium, an N-type detector or a planar crystal is preferred with a very thin beryllium $(\mathrm{Be})$ window. This configuration allows measurement of photons in the energy range 5 to $80 \mathrm{keV}$. The $\mathrm{Be}$ window is quite fragile and a target of corrosion, and should be protected accordingly.

The detector high voltage should only be applied when the cryostat has contained sufficient liquid nitrogen for several hours. These systems can accurately identify plutonium, uranium, and many gamma-emitting isotopes in environmental media, even if a mixture of radionuclides is present. Germanium has an advantage over sodium iodide because it can produce a quantitative estimate of concentrations of multiple radionuclides in samples like soil, water, and air filters.

A specially designed low energy germanium detector that exhibits very little deterioration in the resolution as a function of count rate may be used to analyze uranium and plutonium, or other gamma-emitting radionuclides. When equipped with a built-in shield, it is unnecessary to build complicated shielding arrangements while making field measurements. Tin filters can be used to reduce the count rate from the ${ }^{241} \mathrm{Am} 59 \mathrm{keV}$ line which allows the electronics to process more of the signal coming from $\mathrm{Pu}$ or $\mathrm{U}$.

A plutonium content of $10 \mathrm{mg}$ can be detected in a 55 gallon waste drum in about 30 minutes, although with high uncertainty. A uranium analysis can be performed for an enrichment range from depleted to $93 \%$ enrichment. The measurement time can be in the order of minutes depending on the enrichment and the attenuating materials.

Cost of Equipment: $\$ \$ 40,000$

Cost per Measurement: $\$ 100$ to $\$ 200$ 
Appendix $\mathrm{H}$

System:

Lab/Field:

PRESSURIZED IONIZATION CHAMBER (PIC)

Radiation Detected: $\quad$ Primary: Moderate $(>80 \mathrm{keV})$ to high energy photons

Secondary: None

Applicability to Site Surveys: The PIC is a highly accurate ionization chamber for measuring gamma exposure rate in air, and for correcting for the energy dependence of other instruments due to their energy sensitivities. It is excellent for characterizing and evaluating the effectiveness of remediation of contaminated sites based on exposure rate. However, most sites also require nuclide-specific identification of the contributing radionuclides. Under these circumstances, PICs must be used in conjunction with other soil sampling or spectrometry techniques to evaluate the success of remediation efforts.

Operation: The PIC detector is a large sphere of compressed argon-nitrogen gas at 10 to 40 atmospheres pressure surrounded by a protective box. The detector is normally mounted on a tripod and positioned to sit about three feet off the ground. It is connected to an electronics box in which a strip chart recorder or digital integrator measures instantaneous and integrated exposure rate. It operates at a bias voltage sufficient to collect all ion pairs created by the passage of ionizing radiation, but not sufficiently high to amplify or increase the number of ion pairs. The high pressure inside the detector and the integrate feature make the PIC much more sensitive and precise than other ion chambers for measuring low exposures. The average exposure rate is calculated from the integrated exposure and the operating time. Arrays of PIC systems can be linked by telecommunications so their data can be observed from a central and remote location.

Specificity/Sensitivity: The PIC measures gamma or $\mathrm{x}$-radiation and cosmic radiation. It is highly stable, relatively energy independent, and serves as an excellent tool to calibrate (in the field) other survey equipment to measure exposure rate. Since the PIC is normally uncollimated, it measures cosmic, terrestrial, and foreign source contributions without discrimination. Its rugged and stable behavior makes it an excellent choice for an unattended sensor where area monitors for gamma emitters are needed. PICs are highly sensitive, precise, and accurate to vast changes in exposure rate $(1 \mu \mathrm{R} / \mathrm{hr}$ up to $10 \mathrm{R} / \mathrm{hr})$. PICs lack any ability to distinguish either energy spectral characteristics or source type. If sufficient background information is obtained, the data can be processed using algorithms that employ time and frequency domain analysis of the recorded systems to effectively separate terrestrial, cosmic, and "foreign" source contributions. One major advantage of PIC systems is that they can record exposure rate over ranges of 1 to $10,000,000 \mu \mathrm{R}$ per hour (i.e., $\mu \mathrm{R} / \mathrm{hr}$ to $10 \mathrm{R} / \mathrm{hr}$ ) with good precision and accuracy.

Cost of Equipment: $\$ 15,000$ to $\$ 50,000$ depending on the associated electronics, data processing, and telecommunications equipment.

Cost per Measurement: $\$ 50$ to $\$ 500$ based on the operating time at each site and the number of measurements performed. 
System:

Lab/Field:

\section{SODIUM IODIDE SURVEY METER}

Field

\section{Radiation Detected: $\quad$ Primary: Gamma Secondary: None}

Applicability to Site Surveys: Sodium iodide survey meters can be response checked against a pressurized ionization chamber(PIC) and then used in its place so readings can be taken more quickly. This check should be performed often, possibly several times each day. They are useful for determining ambient radiation levels and for estimating the concentration of radioactive materials at a site.

Operation: The sodium iodide survey meter measures gamma radiation levels in $\mu \mathrm{R} / \mathrm{hr}\left(10^{-6}\right.$ $\mathrm{R} / \mathrm{hr}$ ) or counts per minute (cpm). Its response is energy and count rate dependent, so comparison with a pressurized ion chamber necessitates a conversion factor for adjusting the meter readings to true $\mu \mathrm{R} / \mathrm{hr}$ values. The conversion factor obtained from this comparison is valid only in locations where the radionuclide mix is identical to that where the comparison is performed, and over a moderate range of readings. The detector is held at waist level or suspended near the surface and walked through an area listening to the audio and watching the display for changes. It is held in place and the response allowed to stabilize before each measurement is taken, with longer times required for lower responses. Generally, the center of the needle swing or the integrated reading is recorded. The detector is a sodium iodide crystal inside an aluminum container with an optical glass window that is connected to a photomultiplier tube. A gamma ray that interacts with the crystal produces light that travels out of the crystal and into the photomultiplier tube. There, electrons are produced and multiplied to produce a readily measurable pulse whose magnitude is proportional to the energy the gamma ray incident on the crystal. Electronic filters accept the pulse as a count if certain discrimination height restrictions are met. This translates into a meter response. Instruments with pulse height discrimination circuitry can be calibrated to view the primary gamma decay energy of a particular isotope. If laboratory analysis has shown a particular isotope to be present, the discrimination circuitry can be adjusted to partially tune out other isotopes, but this also limits its ability to measure exposure rate.

Specificity/Sensitivity: Sodium iodide survey meters measure gamma radiation in $\mu \mathrm{R} / \mathrm{hr}$ or $\mathrm{cpm}$ with a minimum sensitivity of around $1-5 \mu \mathrm{R}$ per hour, or $200-1,000 \mathrm{cpm}$, or lower in digital integrate mode. The reading error of $50 \%$ can occur at low count rates because of a large needle swing, but this decreases with increased count rate. The instrument is quite energy sensitive, with the greatest response around $100-120 \mathrm{keV}$ and decreasing in either direction. Measuring the radiation level at a location with both a PIC and the survey meter gives a factor for converting subsequent readings to actual exposure rates. This ratio can change with location. Some meters have circuitry that looks at a few selected ranges of gamma energies, or one at a time with the aide of a single channel analyzer. This feature is used to determine if a particular isotope is present. The detector should be protected against thermal or mechanical shock which can break the sodium iodide crystal or the photomultiplier tube. Covering at least the crystal end with padding is often sufficient. The detector is heavy, so adding a carrying strap to the meter and a means of easily attaching and detaching the detector from the meter case helps the user endure long surveys.

Cost of Equipment: $\$ 2,000$

Cost per Measurement: $\$ 5$ 
Appendix $\mathrm{H}$

System:

Lab/Field:

THERMOLUMINESCENCE DOSIMETER (TLD)

Radiation Detected: $\quad$ Primary: Gamma Secondary: Neutron, beta, $x$-ray

Applicability to Site Surveys: TLDs can be used to measure such a low dose equivalent that they can identify gamma levels slightly above natural background. TLDs should be placed in areas outside the site but over similar media to determine the average natural background radiation level in the area. Other TLDs should be posted on site to determine the difference from background. Groups should be posted quarterly for days to quarters and compared to identify locations of increased onsite doses.

Operation: A TLD is a crystal that measures radiation dose. TLDs are semiconductor crystals that contain small amounts of added impurities. When radiation interacts with the crystal, electrons in the valence band are excited into the conduction band. Many lose their energy and return directly to the valence band, but some are trapped at an elevated energy state by the impurity atoms. This trapped energy can be stored for long periods, but the signal can fade with age, temperature, and light. Heating the TLD in a TLD reader releases the excess energy in the form of heat and light. The quantity or intensity of the light given off gives a measure of the radiation dose the TLD received. If the TLDs are processed at an off site location, the transit dose (from the location to the site and return) must be determined and subtracted from the net dose. The ability to determine this transit dose affects the net sensitivity of the measurements. The TLD is left in the field for a period of a day to a quarter and then removed from the field and read in the laboratory on a calibrated TLD reader. The reading is the total dose received by the TLD during the posting period. TLDs come in various shapes (thin-rectangles, rods, and powder), sizes $\left(0.08 \mathrm{~cm}\right.$ to $0.6 \mathrm{~cm}\left(1 / 32\right.$ in. to $1 / 4 \mathrm{in}$.) on a side), and materials $\left(\mathrm{CaF}_{2}: \mathrm{Mn}\right.$, $\mathrm{CaSO}_{4}: \mathrm{Dy},{ }^{6} \mathrm{LiF}: \mathrm{Mn},{ }^{7} \mathrm{LiF}: \mathrm{Mn}, \mathrm{LiBO}_{4}, \mathrm{LiF}: \mathrm{Mg}, \mathrm{Cu}, \mathrm{P}$ and $\left.\mathrm{Al}_{2} \mathrm{O}_{3}: \mathrm{C}\right)$. The TLD crystals can be held loosely inside a holder, sandwiched between layers of Teflon, affixed to a substrate, or attached to a heater strip and surrounded by a glass envelope. Most are surrounded by special thin shields to correct for an over response to low-energy radiation. Many have special radiation filters to allow the same type TLD to measure various types and energies of radiation.

Specificity/Sensitivity: TLDs are primarily sensitive to gamma radiation, but selected $\mathrm{TLD} /$ filter arrangements can be used to measure beta, $\mathrm{x}$-ray, and neutron radiation. They are posted both on site and off site in comparable areas. These readings are compared to determine if the site can cause personnel to receive more radiation exposure than would be received from background radiation. The low-end sensitivity can be reduced by specially calibrating each TLD and selecting those with high accuracy and good precision. The new $\mathrm{Al}_{2} \mathrm{O}_{3}$ TLD may be capable of measuring doses as low as $0.1 \mu \mathrm{Sv}(0.01 \mathrm{mrem})$ while specially calibrated $\mathrm{CaF}_{2}$ TLDs posted quarterly can measure dose differences as low as $0.05 \mathrm{mSv} / \mathrm{y}(5 \mathrm{mrem} / \mathrm{y})$. This is in contrast to standard TLDs that are posted monthly and may not measure doses below $1 \mathrm{mSv} / \mathrm{y}$ (100 $\mathrm{mrem} / \mathrm{y}$ ). TLDs should be protected from damage as the manufacturer recommends. Some are sensitive to visible light, direct sunlight, fluorescent light, excessive heat, or high humidity. Cost of Equipment: $\$ 5 \mathrm{~K}-\$ 100 \mathrm{~K}$ (reader), $\$ 25-\$ 40$ (TLD). TLDs cost $\$ 5$ to $\$ 40$ per rental. Cost per Measurement: $\$ 25$ to $\$ 125$ 
Appendix $\mathrm{H}$

\section{H.2 FIELD SURVEY EQUIPMENT}

\section{H.2.4 Radon Detectors}


Appendix $\mathrm{H}$

System:

Lab/Field:

Radiation Detected:
ACTIVATED CHARCOAL ADSORPTION

Field

Applicability to Site Surveys: Activated charcoal adsorption is a passive low cost screening method for measuring indoor air radon concentration. The charcoal adsorption method is not designed for outdoor measurements. For contaminated structures, charcoal is a good short-term indicator of radon contamination. Vendors provide measurement services which includes the detector and subsequent readout.

Operation: For this method, an airtight container with activated charcoal is opened in the area to be sampled and radon in the air adsorbs onto the charcoal. The detector, depending on its design, is deployed for 2 to 7 days. At the end of the sampling period, the container is sealed and sent to a laboratory for analysis. Proper deployment and analysis will yield accurate results.

Two analysis methods are commonly used in activated charcoal adsorption. The first method calculates the radon concentration based on the gamma decay from the radon progeny analyzed on a gamma scintillation or semiconductor detection system. The second method is liquid scintillation which employs a small vial containing activated charcoal for sampling. After exposure, scintillation fluid is added to the vial and the radon concentration is determined by the alpha and beta decay of the radon and progeny when counted in a liquid scintillation spectrometer.

Specificity/Sensitivity: Charcoal absorbers are designed to measure radon concentrations in indoor air. Some charcoal absorbers are sensitive to drafts, temperature and humidity. However, the use of a diffusion barrier over the charcoal reduces these effects. The minimum detectable concentration for this method ranges from $0.007-0.04 \mathrm{~Bq} / \mathrm{L}(0.2-1.0 \mathrm{pCi} / \mathrm{L})$.

Cost of Equipment: $\$ 10,000$ for a liquid scintillation counter, $\$ 10,000$ for a sodium iodide multichannel analyzer system, or $\$ 30,000+$ for a germanium multichannel analyzer system. The cost of the activated charcoal itself is minimal.

Cost per Measurement: $\$ 5$ to $\$ 30$ including canister. 
System:

Lab/Field:

\section{ALPHA TRACK DETECTOR}

Field

Radiation Detected: $\quad$ Primary: Radon Gas (Alpha Particles) Secondary: None Applicability to Site Surveys: An alpha track detector is a passive, low cost, long term method used for measuring radon. Alpha track detectors can be used for site assessments both indoors and outdoors (with adequate protection from the elements).

Operation: Alpha track detectors employ a small piece of special plastic or film inside a small container. Air being tested diffuses through a filtering mechanism into the container. When alpha particles from the decay of radon and its progeny strike the detector, they cause damage tracks. At the end of exposure, the container is sealed and returned to the laboratory for analysis.

The plastic or film detector is chemically treated to amplify the damage tracks and then the number of tracks over a predetermined area are counted using a microscope, optical reader, or spark counter. The radon concentration is determined by the number of tracks per unit area. Detectors are usually exposed for 3 to 12 months, although shorter time frames may be used when measuring high radon concentrations.

Specificity/Sensitivity: Alpha track detectors are primarily used for indoor air measurements but specially designed detectors are available for outdoor measurements. Alpha track results are usually expressed as the radon concentration over the exposure period (Bq/L-days). The sensitivity is a function of detector design and exposure duration, and is on the order of 0.04 $\mathrm{Bq} / \mathrm{L}-$ day (1 pCi/L-day).

Cost of Equipment: Not applicable when provided by a vendor

Cost per Measurement: $\$ 5$ to $\$ 25$ 
Appendix $\mathrm{H}$

System:

Lab/Field:

Radiation Detected: Primary: Radon gas Secondary: None

Applicability to Site Surveys: Continuous radon monitors are devices that measure and record real-time measurements of radon gas or variations in radon concentration on an hourly basis. Since continuous monitors display real-time hourly radon measurements, they are useful for short-term site investigation.

Operation: Continuous radon monitors are precision devices that track and record real-time measurements and variations in radon gas concentration on an hourly basis. Air either diffuses or is pumped into a counting chamber. The counting chamber is typically a scintillation cell or ionization chamber. Using a calibration factor, the counts are processed electronically, and radon concentrations for predetermined intervals are stored in memory or directly transmitted to a printer.

Most continuous monitors are used for a relatively short measurement period, usually 1 to 7 days. These devices do require some operator skills and often have a ramp-up period to equilibrate with the surrounding atmosphere. This ramp-up time can range from 1 to 4 hours depending on the size of the counting chamber and rate of air movement into the chamber.

Specificity/Sensitivity: Most continuous monitors are designed for both indoor and outdoor radon measurements. The limiting factor for outdoor usage is the need for electrical power. In locations where external power is unavailable, the available operating time depends on the battery lifetime of the monitor. The minimum detectable concentration for these detectors ranges from $0.004-0.04 \mathrm{~Bq} / \mathrm{L}(0.1-1.0 \mathrm{pCi} / \mathrm{L})$.

Cost of Equipment: $\$ 1,000$ to $\$ 5,000$.

Cost per Measurement: $\$ 80+$ based on duration of survey. 
Appendix $\mathrm{H}$

System:

Lab/Field:

ELECTRET ION CHAMBER

Radiation Detected: $\quad$ Primary: Radon gas (alpha, beta) Secondary: Gamma

Applicability to Site Surveys: Electrets are used to measure radon concentration in indoor environments. For contaminated structures, the electret ion chamber is a good indicator of shortterm and long-term radon concentrations.

Operation: For this method, an electrostatically charged disk (electret) is situated within a small container (ion chamber). During the measurement period, radon diffuses through a filter into the ion chamber, where the ionization produced by the decay of radon and its progeny reduces the charge on the electret. A calibration factor relates the voltage drop, due to the charge reduction, to the radon concentration. Variations in electret design enable the detector to make long-term or short-term measurements. Short-term detectors are deployed for 2 to 7 days, whereas long-term detectors may be deployed from 1 to 12 months.

Electrets are relatively inexpensive, passive, and can be used several times before discarding or recharging, except in areas of extreme radon concentrations. These detectors need to be corrected for the background gamma radiation during exposure since this ionization also discharges the electret.

Specificity/Sensitivity: Electrets are designed to make radon measurements primarily in indoor environments. Care must be taken to measure the background gamma radiation at the site during the exposure period. Extreme temperatures and humidity encountered outdoors may affect electret voltage. The minimum detectable concentration ranges from $0.007-0.02 \mathrm{~Bq} / \mathrm{L}(0.2$ to $0.5 \mathrm{pCi} / \mathrm{L})$.

Cost of Equipment: Included in rental price

Cost per Measurement: $\$ 8$ to $\$ 25$ rental for an electret supplied by a vendor 
Appendix $\mathrm{H}$

\section{System: \\ Lab/Field: \\ LARGE AREA ACTIVATED CHARCOAL COLLECTOR}

Radiation Detected: $\quad$ Primary: Radon gas Secondary: None

Applicability to Site Surveys: This method is used to make radon flux measurements (the surface emanation rate of radon gas) and involves the adsorption of radon on activated carbon in a large area collector.

Operation: The collector consists of a 10 inch diameter PVC end cap, spacer pads, charcoal distribution grid, retainer pad with screen, and a steel retainer spring. Between 170 and 200 grams of activated charcoal is spread in the distribution grid and held in place by the retainer pad and spring.

The collector is deployed by firmly twisting the end cap into the surface of the material to be measured. After 24 hours of exposure, the activated charcoal is removed and transferred to plastic containers. The amount of radon adsorbed on the activated charcoal is determined by gamma spectroscopy. This data is used to calculate the radon flux in units of $\mathrm{Bq} \mathrm{m} \mathrm{m}^{-2} \mathrm{~s}^{-1}$.

Specificity/Sensitivity: These collectors give an accurate short-term assessment of the radon gas surface emanation rate from a material. The minimum detectable concentration of this method is $0.007 \mathrm{~Bq} \mathrm{~m}^{-2} \mathrm{~s}^{-1}\left(0.2 \mathrm{pCi} \mathrm{m}^{-2} \mathrm{~s}^{-1}\right)$.

Exposures greater than 24 hours are not recommended due to atmospheric and surface moisture and temperature extremes which may affect charcoal efficiency.

Cost of Equipment: Not applicable

Cost per Measurement: $\$ 20$ - $\$ 50$ including canister 
Appendix $\mathrm{H}$

\section{H.2 FIELD SURVEY EQUIPMENT}

\section{H.2.5 X-Ray and Low Energy Gamma Detectors}


Appendix $\mathrm{H}$

System:

Lab/Field:

FIDLER PROBE WITH SURVEY METER

Radiation Detected: $\quad$ Primary: X-ray Secondary: Low Energy Gamma

Applicability to Site Surveys: The FIDLER (Field Instrument for the Detection of Low

Energy Radiation) probe is a specialized detector consisting of a thin layer of sodium or cesium iodide which is optimized to detect gamma and $\mathrm{x}$-radiation below $100 \mathrm{keV}$. It is most widely used for determining the presence of $\mathrm{Pu}$ and ${ }^{241} \mathrm{Am}$, and can be used for estimating radionuclide concentrations in the field.

Operation: The FIDLER consists of a thin beryllium or aluminum window, a thin crystal of sodium iodide, a quartz light pipe, and photomultiplier tube. The probe can have either a 3 in. or 5 in. crystal. The discussion below is applicable to 5 in. crystals. The survey meter requires electronics capable of setting a window about an $\mathrm{x}$-ray or gamma ray energy. This window allows the probe and meter to detect specific energies and, in most cases, provide information about a single element or radionuclide. The window also lowers the background count. Two types of survey meters are generally used with FIDLER probes. One type resembles those used with GM and alpha scintillation probes. They have an analog meter and range switch. The second type is a digital survey meter, which can display the count rate or accumulate counts in a scaler mode for a preset length of time. Both types have adjustable high voltage and window settings. The advantage of the digital meter is that both background and sample counts can be acquired in scaler mode, yielding a net count above background. The activity of a radionuclide can then be estimated in the field.

Specificity/Sensitivity: The FIDLER probe is quite sensitive to $\mathrm{x}$-ray and low energy gamma radiation. Since it has the ability to discriminate energies, an energy window can be set that makes it possible to determine the presence of specific radionuclides when the nature of the contamination is known. If the identity of a contaminant is known, the FIDLER can be used to quantitatively determine the concentration. However, interferences can cause erroneous results if other radionuclides are present. The FIDLER can also be used as a survey instrument to detect the presence of $x$-ray or low energy gamma contaminates, and to determine the extent of the contamination. FIDLER probes are most useful for determining the presence of $\mathrm{Pu}$ and ${ }^{241} \mathrm{Am}$. These isotopes have a complex of $\mathrm{x}$-rays and gamma rays from 13-21 keV that have energies centered around $17 \mathrm{keV}$, and ${ }^{241} \mathrm{Am}$ has a gamma at $59 \mathrm{keV}$. There is an interference at $13 \mathrm{keV}$ from both americium and uranium $\mathrm{x}$-rays. The FIDLER cannot distinguish which isotope of $\mathrm{Pu}$ is present. ${ }^{241} \mathrm{Am}$ can be identified based on the $59 \mathrm{keV}$ gamma. Typical sensitivities for ${ }^{238} \mathrm{Pu}$ and ${ }^{239} \mathrm{Pu}$ at one foot above the surface of a contaminated area are 500 to 700 and 250 to 350 counts per minute per $\mu \mathrm{Ci}$ per square meter $\left(\mathrm{cpm} / \mu \mathrm{Ci} / \mathrm{m}^{2}\right)$, respectively. Assuming a soil density of 1.5 , uniform contamination of the first $1 \mathrm{~mm}$ of soil, and a typical background of 400 counts per minute, the MDC for ${ }^{238} \mathrm{Pu}$ and ${ }^{239} \mathrm{Pu}$ would be 370 and $740 \mathrm{~Bq} / \mathrm{kg}$ (10 and $20 \mathrm{pCi} / \mathrm{g}$ ), or 550 and $1,100 \mathrm{~Bq} / \mathrm{m}^{2}$ (900 and $1,800 \mathrm{dpm} / 100 \mathrm{~cm}^{2}$ ). This MDC is for fresh deposition; and will be significantly less as the plutonium migrates into the soil. Because the window is fragile, most operations with a FIDLER probe require a low mass protective cover to prevent damaging the window. Styrofoam, cardboard, and other cushioning materials are common choices for a protective cover.

Cost of Equipment: $\$ 4,000$ to $\$ 7,000$

Cost per Measurement: $\$ 10$ to $\$ 20$ 
System: $\quad$ FIELD X-RAY FLUORESCENCE SPECTROMETER

Lab/Field: $\quad$ Field

Radiation Detected: $\quad$ Primary: X-ray and low energy gamma radiation Secondary: None

Applicability to Site Surveys: The system accurately measures relative concentrations of metal atoms in soil or water samples down to the ppm range.

Operation: This system is a rugged form of $x$-ray fluorescence system that measures the characteristic $x$-rays of metals as they are released from excited electron structures. The associated electronic and multi-channel analyzer systems are essentially identical to those used with germanium spectrometry systems. The spectra of characteristic $\mathrm{x}$-rays gives information for both quantitative and qualitative analysis; however, most frequently, the systems are only calibrated for relative atomic abundance or percent composition.

Specificity/Sensitivity: This is ideal for cases of contamination by metals that have strong $\mathrm{x}$-ray emissions within 5-100 keV. Application for quantification of the transition metals (in the periodic table) is most common because of the $\mathrm{x}$-ray emissions. Operation of this equipment is possible with only a moderate amount of training. The sensitivity ranges from a few percent to ppm depending on the particular atoms and their characteristic $\mathrm{X}$-rays. When converted to activity concentration, the minimum detectable concentration for ${ }^{238} \mathrm{U}$ is around $1,850 \mathrm{~Bq} / \mathrm{kg}$ $(50 \mathrm{pCi} / \mathrm{g})$ for typical soil matrices.

Cost of Equipment: $\$ 15,000$ - $\$ 75,000$ depending on size, speed of operation and auxiliary features employed for automatic analysis of the results.

Cost per Measurement: $\$ 200$ 
Appendix $\mathrm{H}$

\section{H.2 FIELD SURVEY EQUIPMENT \\ H.2.6 Other Field Survey Equipment}


Appendix H

System:

Lab/Field: CHEMICAL SPECIES LASER ABLATION MASS SPECTROMETER

Radiation Detected: None

Applicability to Site Surveys: Chemical Species Laser Ablation Mass Spectrometry has been successfully applied to the analysis of organic and inorganic molecular species in condensed material with high sensitivity and specificity.

Operation: Solids can be converted into aerosol particles which contain much of the molecular species information present in the original material. (One way this is done is by laser excitation of one component of a solid mixture which, when volatilized, carries along the other molecular species without fragmentation.) Aerosol particles can be carried hundreds of feet without significant loss in a confined or directed air stream before analysis by mass spectrometry. Some analytes of interest already exist in the form of aerosol particles. Laser ablation is also preferred over traditional means for the conversion of the aerosol particles into molecular ions for mass spectral analysis. Instrument manufacturers are working with scientists at national laboratories and universities in the development of compact portable laser ablation mass spectrometry instrumentation for field based analyses.

Specificity/Sensitivity: This system can analyze soils and surfaces for organic and inorganic molecular species, with extremely good sensitivity. Environmental concentrations in the range of $10^{-9}-10^{-14} \mathrm{~g} / \mathrm{g}$ can be determined, depending on environmental conditions. It is highly effective when used by a skilled operator, but of limited use due to high costs. It may be possible to quantify an individual radionuclide if no other nuclides of that isotope are present in the sample matrix. Potential MDC's are $4 \times 10^{-8} \mathrm{~Bq} / \mathrm{kg}\left(1 \times 10^{-9} \mathrm{pCi} / \mathrm{g}\right)$ for ${ }^{238} \mathrm{U}, 0.04 \mathrm{~Bq} / \mathrm{kg}\left(10^{-3} \mathrm{pCi} / \mathrm{g}\right)$ for ${ }^{239} \mathrm{Pu}, 4 \mathrm{~Bq} / \mathrm{kg}(1 \mathrm{pCi} / \mathrm{g})$ for ${ }^{137} \mathrm{Cs}$, and $37 \mathrm{~Bq} / \mathrm{kg}(10 \mathrm{pCi} / \mathrm{g})$ for ${ }^{60} \mathrm{Co}$.

Cost of Equipment: Very expensive (prototype)

Cost per Measurement: May be comparable to laser ablation inductively coupled plasma atomic emission spectrometry (LA-ICP-AES) and laser ablation inductively coupled plasma mass spectrometry (LA-ICP-MS). When using the Atomic Emission Spectrometer, the reported cost is $\$ 4,000$ per sample, or $80 \%$ of conventional sampling and analysis costs. This high cost for conventional samples is partly due to the 2-3 day time to analyze a sample for thorium by conventional methods. When using the mass spectrometer, the time required is about 30 minutes per sample. 
Appendix H

\section{System: $\quad$ LA-ICP-AES AND LA-ICP-MS \\ Lab/Field: $\quad$ Field \\ Radiation Detected: None}

Applicability to Site Surveys: LA-ICP-AES and LA-ICP-MS are acronyms for Laser AblationInductively Coupled Plasma-Atomic Emission Spectrometry or Mass Spectrometry. LA-ICPAES/MS techniques are used to screen/characterize very small samples of soils and concrete (non-destructively) in situ to determine the level of contamination. It is particularly suited to measuring the surface concentration of uranium and thorium. The unit can assess the concentrations at various depths when lower levels are exposed by some means. It has the advantages of not consuming surface material, providing real time response, reducing sampling and analysis time, and keeping personnel clear of the materials being sampled. The information developed can assist in identifying locations for excavation. It is currently being tested.

Operation: Components of the system include a sampling system, fiber optics cables, spectrometer, potable water supply, cryogenic and high-pressure gas supply, a robotics arm, control computers, inductively coupled plasma torch, and video monitor.

Sampling probes have been developed and prototyped that will screen/characterize surface soils, concrete floors or pads, and subsurface soils. The sampling probes, both surface and subsurface, contain the laser (a 50- $\mathrm{Hz} \mathrm{Nd/YAG} \mathrm{laser),} \mathrm{associated} \mathrm{optics,} \mathrm{and} \mathrm{control} \mathrm{circuitry} \mathrm{to} \mathrm{raster} \mathrm{the}$ laser (ablation) energy across one square inch of sample surface. Either sampling probe is connected by an umbilical, currently $20 \mathrm{~m}$ long, to the Mobile Demonstration Laboratory for Environmental Screening Technologies (MDLEST), a completely self-contained mobile laboratory containing the instrumentation to immediately analyze the samples generated by the laser ablation.

A fiber optic cable delivers laser light to the surface of interest. This ablates a small quantity of material that is carried away in a stream of argon gas. The material enters the plasma torch where it is vaporized, atomized, ionized, and electrically excited at about $8,000 \mathrm{~K}$. This produces an ionic emission spectrum that is analyzed on the atomic emission spectrometer.

The analysis instrumentation (ICP-AES/MS) in the MDLEST does not depend on radioactive decay for detection but looks directly at the atomic make up of the elements(s) of interest. A large number of metals including the longer half-life radioactive elements can be detected and quantified. The spectrometer is set up using either hardware, software, or both to simultaneously detect all elements of interest in each sample.

The MDLEST can be set up on site to monitor soil treatment processes. This function enables the remediation manager to monitor, in real time, the treatment processes removing the contaminants and ensure that satisfactory agreement with both regulatory agency and QC/QA requirements is attained. 
Specificity/Sensitivity: This system measures the surface or depth concentration of atomic species, and is particularly suited to uranium and thorium analysis. It is highly effective with skilled operators. Some advantages are no contact with the soil, real time results, and no samples to dispose of. The sample results are quickly available for field remediation decisions, with the LA-ICP-AES taking about 10 minutes and LA-ICP-MS taking about 30 minutes. The detection limits for the two spectrometers that have been used are as follows:

1) The AES (atomic emission spectrometer) can see ppm levels for some 70 elements and reportedly detects uranium and thorium concentrations at $1 \mathrm{ppm}$, or $10 \mathrm{~Bq} / \mathrm{kg}(0.3 \mathrm{pCi} / \mathrm{g})$ for ${ }^{238} \mathrm{U}$ and $4 \mathrm{~Bq} / \mathrm{kg}(0.1 \mathrm{pCi} / \mathrm{g})$ for ${ }^{232} \mathrm{Th}$. However, the technique is only sensitive to elements; it cannot discriminate between the different isotopes of uranium and thorium. This prevents it from being used for assessing lower $\mathrm{Z}$ elements that have stable isotopes, or from determining relative abundances of isotopes of any element. This may significantly limit its use at some sites.

2) The MS (mass spectrometer) can see sub-ppb levels and is capable of quantifying the uranium and thorium isotopes. This system has been used to search for ${ }^{230} \mathrm{Th}$ and ${ }^{226} \mathrm{Ra}$ and is reportedly useful in reaching $0.8 \mathrm{ppm}$ or $0.6 \mathrm{~Bq} / \mathrm{g}\left(15 \mathrm{pCi} / \mathrm{g}\right.$ ) for ${ }^{230} \mathrm{Th}$ content for remediated soil. It appears to measure uranium and thorium concentration of soil more sensitively than the LA-ICP-AES system.

Cost of Equipment: Very expensive, $>\$ 1 \mathrm{M}$.

Cost per Measurement: When using the Atomic Emission Spectrometer, the reported cost is $\$ 4,000$ per sample. When using the mass spectrometer, a dollar price was not provided. 
Appendix $\mathrm{H}$

\section{H.3 LABORATORY INSTRUMENTS}

\section{H.3.1 Alpha Particle Analysis}


Appendix $\mathrm{H}$

System:

Lab/Field:

\section{Radiation Detected: Primary: Alpha Secondary: None}

Applicability to Site: This is a very powerful tool for accurately identifying and quantifying the activity of multiple alpha-emitting radionuclides in a sample of soil, water, air filters, etc.

Methods exist for the analyses of most alpha emitting radionuclides including uranium, thorium, plutonium, polonium, and americium. Samples must first be prepared in a chemistry lab to isolate the radionuclides of interest from the environmental matrix.

Operation: This system consists of an alpha detector housed in a light-tight vacuum chamber, a bias supply, amplifier, analog-to-digital converter, multichannel analyzer, and computer. The bias is typically 25 to 100 volts. The vacuum is typically less than 10 microns ( 0.1 millitorr). The detector is a silicon diode that is reverse biased. Alpha particles which strike the diode create electron-hole pairs; the number of pairs is directly related to the energy of each alpha. These pairs cause a breakdown of the diode and a current pulse to flow. The charge is collected by a preamplifier and converted to a voltage pulse which is proportional to the alpha energy. It is amplified and shaped by an amplifier. The MCA stores the resultant pulses and displays a histogram of the number of counts vs. alpha energy. Since most alphas will loose all of their energy to the diode, peaks are seen on the MCA display that can be identified by specific alpha energies. Two system calibrations are necessary. A source with at least two known alpha energies is counted to correlate the voltage pulses with alpha energy. A standard source of known activity is analyzed to determine the system efficiency for detecting alphas. Since the sample and detector are in a vacuum, most commonly encountered alpha energies will be detected with approximately the same efficiency, provided there is no self-absorption in the sample. Samples are prepared in a chemistry lab. The sample is placed in solution and the element of interest (uranium, plutonium, etc.) separated. A tracer of known activity is added before separation to determine the overall recovery of the sample from the chemical procedures. The sample is converted to a particulate having very little mass and collected on a special filter, or it is collected from solution by electroplating onto a metal disk. It is then placed in the vacuum chamber at a fixed distance from the diode and analyzed. For environmental levels, samples are typically analyzed for 1000 minutes or more.

Specificity/Sensitivity: The system can accurately identify and quantify the various alpha emitting radioactive isotopes of each elemental species provided each has a different alpha energy that can be resolved by the system. For soils, a radionuclide can be measured below $0.004 \mathrm{~Bq} / \mathrm{g}(0.1 \mathrm{pCi} / \mathrm{g})$. The system is appropriate for all alphas except those from gaseous radionuclides.

Cost of Equipment: $\$ 10,000$ - $\$ 100,000$ based on the number of detectors and sophistication of the computer and data reduction software. This does not include the cost of equipment for the chemistry lab.

Cost per Measurement: $\$ 250-\$ 400$ for the first element, $\$ 100-200$ for each additional element per sample. The additional element cost depends on the separation chemistry involved and may not always be less. $\$ 200-\$ 300$ additional for a rush analysis. 
Appendix $\mathrm{H}$

\section{System: $\quad$ GAS-FLOW PROPORTIONAL COUNTER}

Lab/Field: $\mathrm{Lab}$

\section{Radiation Detected: Primary: Alpha, Beta Secondary: Gamma}

Applicability to Site Surveys: This system can determine the gross alpha or gross beta activity of water, soil, air filters, or swipes. Results can indicate if nuclide-specific analysis is needed. Operation: The system consists of a gas-flow detector, supporting electronics, and an optional guard detector for reducing background count rate. A thin window can be placed between the gas-flow detector and sample to protect the detector from contamination, or the sample can be placed directly into the detector. Systems with guard detectors operate sample and guard detectors in anticoincidence mode to reduce the background and MDC. The detector high voltage and discriminator are set to count alpha radiation, beta radiation, or both simultaneously. The alpha and beta operating voltages are determined for each system by placing an alpha source, like ${ }^{230} \mathrm{Th}$ or ${ }^{241} \mathrm{Am}$, in the detector and increasing the high voltage incrementally until the count rate becomes constant, then repeating with a beta source, like ${ }^{90} \mathrm{Sr}$. The alpha plateau, or region of constant count rate, should have a slope $<2 \% / 100 \mathrm{~V}$ and be $>800 \mathrm{~V}$ long. The beta plateau should have a slope of $<2.5 \% / 100 \mathrm{~V}$ and be $>200 \mathrm{~V}$ long. Operation on the beta plateau will also allow detection of some gamma radiation and bremsstrahlung (x-rays), but the efficiency is very low. Crosstalk between the $\alpha$-to- $\beta$ channels is typically around $10 \%$ while $\beta$-to- $\alpha$ channels should be $<1 \%$. The activity in soil samples is chemically extracted, separated if necessary, deposited in a thin layer in a planchet to minimize self absorption, and heated to dryness.

Liquids are deposited and dried, while air filters and swipes are placed directly in the planchet. After each sample is placed under the detector, P-10 counting gas constantly flows through the detector. Systems with automatic sample changers can analyze tens to hundreds of planchet samples in a single run.

Specificity/Sensitivity: Natural radionuclides present in soil samples can interfere with the detection of other contaminants. Unless the nature of the contaminant and any naturallyoccurring radionuclides is well known, this system is better used for screening samples. Although it is possible to use a proportional counter to roughly determine the energies of alpha and beta radiation, the normal mode of operation is to detect all alpha events or all alpha and beta events. Some systems use a discriminator to separate alpha and beta events, allowing simultaneous determination of both the alpha and beta activity in a sample. These systems do not identify the alpha or beta energies detected and cannot be used to identify specific radionuclides. The alpha channel background is very low, $<0.2 \mathrm{cpm}(<0.04 \mathrm{cpm}$ guarded), depending on detector size. Typical, 4-pi, efficiencies for very thin alpha sources are $35-45 \%$ (window) and $40-50 \%$ (windowless). Efficiency depends on window thickness, particle energy, source-detector geometry, backscatter from the sample and holder, and detector size. The beta channel background ranges from 2 to $15 \mathrm{cpm}\left(<0.5 \mathrm{cpm}\right.$ guarded). The 4-pi efficiency for a thin ${ }^{90} \mathrm{Sr} /{ }^{90} \mathrm{Y}$ source is $>50 \%$ (window) to $>60 \%$ (windowless), but can reduce to $<5 \%$ for a thick source.

MDA's for guarded gas-flow proportional counters are somewhat lower for beta emitters than for internal proportional counters because of the lower backgrounds. Analyzing a high radioactivity sample or flushing the detector with $\mathrm{P} 10$ gas at too high a flow rate can suspend fine particles and contaminate the detector.

Cost of Equipment: $\$ 4 \mathrm{~K}-\$ 5 \mathrm{~K}$ (manual), $\$ 25 \mathrm{~K}-\$ 30 \mathrm{~K}$ (automatic)

Cost per Measurement: $\$ 30$ to $\$ 50$ plus radiochemistry 
System:

Lab/Field:

Radiation De

LIQUID SCINTILLATION SPECTROMETER

Lab (primarily), field (secondarily)

\section{Primary: Alpha, beta Secondary: Gamma}

Applicability to Site Surveys: Liquid Scintillation can be a very effective tool for measuring the concentration of radionuclides in soil, water, air filters, and swipes. Liquid scintillation has historically been applied more to beta emitters, particularly the low energy beta emitters ${ }^{3} \mathrm{H}$ and ${ }^{14} \mathrm{C}$, but it can also apply to other radionuclides. More recently it has been used for measuring radon in air and water. Initial scoping surveys may be done (particularly for loose surface contamination) with surface swipes or air particulate filters. They may be counted directly in liquid scintillation cocktails with no paper dissolution or other sample preparation.

Operation: The liquid scintillation process involves detection of light pulses (usually in the near visible range) by photo-multiplier tubes (or conceptually similar devices). The detected light pulses originate from the re-structuring of previously excited molecular electron structures. The molecular species that first absorb and then re-admit the visible light are called "liquid scintillators" and the solutions in which they reside are called "liquid scintillation cocktails." For gross counting, samples may be placed directly into a LSC vial of cocktail, and counted with no preparation. Inaccuracies result when the sample itself absorbs the radiation before it can reach the LSC cocktail, or when the sample absorbs the light produced by the cocktail. For accurate results, these interferences are minimized. Interferences in liquid scintillation counting due to the inability of the solution to deliver the full energy pulse to the photo-multiplier detector, for a variety of reasons, are called "pulse quenching." Raw samples that cloud or color the LSC cocktail so the resulting scintillations are absorbed will "quench" the sample and result in underestimates of the activity. Such samples are first processed by ashing, radiochemical or solvent extraction, or pulverizing to place the sample in intimate contact with the LSC cocktail. Actions like bleaching the sample may also be necessary to make the cocktail solution transparent to the wavelength of light it emits. The analyst has several reliable computational or experimental procedures to account for "quenching." One is by exposing the sample and pure cocktail to an external radioactive standard and measuring the difference in response.

Specificity/Sensitivity: The method is extremely flexible and accurate when used with proper calibration and compensation for quenching effects. Energy spectra are 10 to 100 times broader than gamma spectrum photopeaks so that quantitative determination of complex multi-energy beta spectra is impossible. Sample preparation can range from none to complex chemical reactions. In some cases, liquid scintillation offers many unique advantages; no sample preparation before counting in contrast to conventional sample preparation for gas proportional counting. Recent advances in electronic stability and energy pulse shape discrimination has greatly expanded uses. Liquid scintillation counters are ideal instruments for moderate to high energy beta as well as alpha emitters, where the use of pulse shape discrimination has allowed dramatic increases in sensitivity by electronic discrimination against beta and gamma emitters. Additionally, very high energy beta emitters (above $1.5 \mathrm{MeV}$ ) may be counted using liquid scintillation equipment without "liquid scintillation cocktails" by use of the Cerenkov light pulse emitted as high energy charged particles move through water or similar substances.

Cost of Equipment: $\$ 20,000$ to $\$ 70,000$ based on the specific features and degree of automation Cost per Measurement: $\$ 50-200$ plus cost of chemical separation, if required 
Appendix H

System:

Lab/Field:

LOW-RESOLUTION ALPHA SPECTROSCOPY

Radiation Detected: Primary: Alpha Secondary:

Applicability to Site Surveys: Low-resolution alpha spectroscopy is a method for measuring alpha activity in soils with a minimum of sample preparation. Some isotopic information can be obtained.

Operation: The system consists of a 2 in. diameter silicon detector, small vacuum chamber, roughing pump, multichannel analyzer, laptop or benchtop computer, and analysis software. Soil samples are dried, milled to improve homogeneity, distributed into 2 in. planchets, loaded into the vacuum chamber, and counted. The accumulated alpha spectrum is displayed in real time. When sufficient counts have been accumulated, the spectrum is transferred to a data file and the operator inputs the known or suspected contaminant isotopes. The analysis software then fits the alpha spectrum with a set of trapezoidal peaks, one for each isotope, and outputs an estimate of the specific activity of each isotope.

Specificity/Sensitivity: This method fills the gap between gross alpha analysis and radiochemical separation/high-resolution alpha spectroscopy. Unlike gross alpha analysis, it does provide some isotopic information. Because this is a low-resolution technique, isotopes with energies closer than $\sim 0.2 \mathrm{MeV}$ cannot be separated. For example, ${ }^{238} \mathrm{U}(4.20 \mathrm{MeV})$ can be readily distinguished from ${ }^{234} \mathrm{U}(4.78 \mathrm{MeV})$, but ${ }^{230} \mathrm{Th}(4.69 \mathrm{MeV})$ cannot be distinguished from ${ }^{234} \mathrm{U}$.

Because no chemical separation of isotopes is involved, only modest MDC's can be achieved. Detection limits are determined by the background alpha activity in the region of interest of the contaminant of concern, and also by the counting time. Typical MDC's are $1,500 \mathrm{~Bq} / \mathrm{kg}$ (40 $\mathrm{pCi} / \mathrm{g}) @ 15 \mathrm{~min}$ counting time, $260 \mathrm{~Bq} / \mathrm{kg}$ (7 pCi/g) @ 8 hours, and $185 \mathrm{~Bq} / \mathrm{kg}(5 \mathrm{pCi} / \mathrm{g}) @ 24$ hours. The method does not generate any new waste streams and does not require a sophisticated laboratory or highly-trained personnel.

Cost of Equipment: $\$ 11,000$

Cost per Measurement: $\$ 25-\$ 100$ 
Appendix $\mathrm{H}$

\section{H.3 LABORATORY INSTRUMENTS}

H.3.2 Beta Particle Analysis 
Appendix $\mathrm{H}$

System:

Lab/Field:

GAS-FLOW PROPORTIONAL COUNTER

\section{Radiation Detected: Primary: Alpha, Beta Secondary: Gamma}

Applicability to Site Surveys: This system can determine the gross alpha or gross beta activity of water, soil, air filters, or swipes. Results can indicate if nuclide-specific analysis is needed.

Operation: The system consists of a gas-flow detector, supporting electronics, and an optional guard detector for reducing background count rate. A thin window can be placed between the gas-flow detector and sample to protect the detector from contamination, or the sample can be placed directly into the detector. Systems with guard detectors operate sample and guard detectors in anticoincidence mode to reduce the background and MDC. The detector high voltage and discriminator are set to count alpha radiation, beta radiation, or both simultaneously. The alpha and beta operating voltages are determined for each system by placing an alpha source, like ${ }^{230} \mathrm{Th}$ or ${ }^{241} \mathrm{Am}$, in the detector and increasing the high voltage incrementally until the count rate becomes constant, then repeating with a beta source, like ${ }^{90} \mathrm{Sr}$. The alpha plateau, or region of constant count rate, should have a slope $<2 \% / 100 \mathrm{~V}$ and be $>800 \mathrm{~V}$ long. The beta plateau should have a slope of $<2.5 \% / 100 \mathrm{~V}$ and be $>200 \mathrm{~V}$ long. Operation on the beta plateau will also allow detection of some gamma radiation and bremsstrahlung ( $\mathrm{x}$-rays), but the efficiency is very low. Crosstalk between the $\alpha$-to- $\beta$ channels is typically around $10 \%$ while $\beta$-to- $\alpha$ channels should be $<1 \%$. The activity in soil samples is chemically extracted, separated if necessary, deposited in a thin layer in a planchet to minimize self absorption, and heated to dryness. Liquids are deposited and dried, while air filters and swipes are placed directly in the planchet. After each sample is placed under the detector, P-10 counting gas constantly flows through the detector. Systems with automatic sample changers can analyze tens to hundreds of planchet samples in a single run.

Specificity/Sensitivity: Natural radionuclides present in soil samples can interfere with the detection of other contaminants. Unless the nature of the contaminant and any naturallyoccurring radionuclides is well known, this system is better used for screening samples. Although it is possible to use a proportional counter to roughly determine the energies of alpha and beta radiation, the normal mode of operation is to detect all alpha events or all alpha and beta events. Some systems use a discriminator to separate alpha and beta events, allowing simultaneous determination of both the alpha and beta activity in a sample. These systems do not identify the alpha or beta energies detected and cannot be used to identify specific radionuclides. The alpha channel background is very low, $<0.2 \mathrm{cpm}$ ( $<0.04 \mathrm{cpm}$ guarded), depending on detector size. Typical, 4-pi, efficiencies for very thin alpha sources are $35-45 \%$ (window) and $40-50 \%$ (windowless). Efficiency depends on window thickness, particle energy, source-detector geometry, backscatter from the sample and holder, and detector size. The beta channel background ranges from 2 to $15 \mathrm{cpm}\left(<0.5 \mathrm{cpm}\right.$ guarded). The 4-pi efficiency for a thin ${ }^{90} \mathrm{Sr} /{ }^{90} \mathrm{Y}$ source is $>50 \%$ (window) to $>60 \%$ (windowless), but can reduce to $<5 \%$ for a thick source. MDA's for guarded gas-flow proportional counters are somewhat lower for beta emitters than for internal proportional counters because of the lower backgrounds. Analyzing a high radioactivity sample or flushing the detector with $\mathrm{P} 10$ gas at too high a flow rate can suspend fine particles and contaminate the detector.

Cost of Equipment: $\$ 4 \mathrm{~K}-\$ 5 \mathrm{~K}$ (manual), $\$ 25 \mathrm{~K}-\$ 30 \mathrm{~K}$ (automatic)

Cost per Measurement: $\$ 30$ to $\$ 50$ plus radiochemistry 
System:

Lab/Field:
LIQUID SCINTILLATION SPECTROMETER

Lab (primarily), field (secondarily)

\section{Radiation Detected: Primary: Alpha, beta Secondary: Gamma}

Applicability to Site Surveys: Liquid Scintillation can be a very effective tool for measuring the concentration of radionuclides in soil, water, air filters, and swipes. Liquid scintillation has historically been applied more to beta emitters, particularly the low energy beta emitters ${ }^{3} \mathrm{H}$ and ${ }^{14} \mathrm{C}$, but it can also apply to other radionuclides. More recently it has been used for measuring radon in air and water. Initial scoping surveys may be done (particularly for loose surface contamination) with surface swipes or air particulate filters. They may be counted directly in liquid scintillation cocktails with no paper dissolution or other sample preparation.

Operation: The liquid scintillation process involves detection of light pulses (usually in the near visible range) by photo-multiplier tubes (or conceptually similar devices). The detected light pulses originate from the re-structuring of previously excited molecular electron structures. The molecular species that first absorb and then re-admit the visible light are called "liquid scintillators" and the solutions in which they reside are called "liquid scintillation cocktails." For gross counting, samples may be placed directly into a LSC vial of cocktail, and counted with no preparation. Inaccuracies result when the sample itself absorbs the radiation before it can reach the LSC cocktail, or when the sample absorbs the light produced by the cocktail. For accurate results, these interferences are minimized. Interferences in liquid scintillation counting due to the inability of the solution to deliver the full energy pulse to the photo-multiplier detector, for a variety of reasons, are called "pulse quenching." Raw samples that cloud or color the LSC cocktail so the resulting scintillations are absorbed will "quench" the sample and result in underestimates of the activity. Such samples are first processed by ashing, radiochemical or solvent extraction, or pulverizing to place the sample in intimate contact with the LSC cocktail. Actions like bleaching the sample may also be necessary to make the cocktail solution transparent to the wavelength of light it emits. The analyst has several reliable computational or experimental procedures to account for "quenching." One is by exposing the sample and pure cocktail to an external radioactive standard and measuring the difference in response.

Specificity/Sensitivity: The method is extremely flexible and accurate when used with proper calibration and compensation for quenching effects. Energy spectra are 10 to 100 times broader than gamma spectrum photopeaks so that quantitative determination of complex multi-energy beta spectra is impossible. Sample preparation can range from none to complex chemical reactions. In some cases, liquid scintillation offers many unique advantages such as no sample preparation before counting in contrast to conventional sample preparation for gas proportional counting. Recent advances in electronic stability and energy pulse shape discrimination has greatly expanded uses. Liquid scintillation counters are ideal instruments for moderate to high energy beta as well as alpha emitters, where the use of pulse shape discrimination has allowed dramatic increases in sensitivity by electronic discrimination against beta and gamma emitters. Additionally, very high energy beta emitters (above $1.5 \mathrm{MeV}$ ) may be counted using liquid scintillation equipment without "liquid scintillation cocktails" by use of the Cerenkov light pulse emitted as high energy charged particles move through water or similar substances.

Cost of Equipment: $\$ 20,000$ to $\$ 70,000$ based on the specific features and degree of automation Cost per Measurement: $\$ 50-200$ plus cost of chemical separation, if required 
Appendix $\mathrm{H}$

\section{H.3 LABORATORY INSTRUMENTS}

\section{H.3.3 Gamma Ray Analysis}


System:

Lab/Field: Radiation Detected:
GERMANIUM DETECTOR WITH MULTICHANNEL ANALYZER (MCA)

Applicability to Site: This system accurately measures the activity of gamma-emitting radionuclides in a variety of materials like soil, water, air filters, etc. with little preparation. Germanium is especially powerful in dealing with multiple radionuclides and complicated spectra.

Operation: This system consists of a germanium detector connected to a dewar of liquid nitrogen, high voltage power supply, spectroscopy grade amplifier, analog to digital converter, and a multichannel analyzer. P-type germanium detectors typically operate from +2000 to +5000 volts. N-type germanium detectors operate from -2000 to -5000 volts. Germanium is a semiconductor material. When a gamma ray interacts with a germanium crystal, it produces electron-hole pairs. An electric field is applied which causes the electrons to move in the conduction band and the holes to pass the charge from atom to neighboring atom. The charge is collected rapidly and is proportional to the deposited energy. The count rate/energy spectrum is displayed on the MCA screen with the full energy photopeaks providing more useful information than the general smear of Compton scattering events shown in between. The system is energy calibrated using isotopes that emit at least two known gamma ray energies, so the MCA data channels are given an energy equivalence. The MCA's display then becomes a display of intensity versus energy. Efficiency calibration is performed using known concentrations of mixed isotopes. A curve of gamma ray energy versus counting efficiency is generated, and it shows that P-type germanium is most sensitive at $120 \mathrm{keV}$ and trails off to either side. Since the counting efficiency depends on the distance from the sample to the detector, each geometry must be given a separate efficiency calibration curve. From that point the center of each gaussianshaped peak tells the gamma ray energy that produced it, the combination of peaks identifies each isotope, and the area under selected peaks is a measure of the amount of that isotope in the sample. Samples are placed in containers and tare weighed. Plastic petri dishes sit atop the detector and are useful for small volumes or low energies, while Marinelli beakers fit around the detector and provide exceptional counting efficiency for volume samples. Counting times of 1000 seconds to 1000 minutes are typical. Each peak is identified manually or by gamma spectrometry analysis software. The counts in each peak or energy band, the sample weight, the efficiency calibration curve, and the isotope's decay scheme are factored together to give the sample concentration.

Specificity/Sensitivity: The system accurately identifies and quantifies the concentrations of multiple gamma-emitting radionuclides in samples like soil, water, and air filters with minimum preparation. A P-type detector is good for energies over $50 \mathrm{keV}$. An N-type or P-type planar (thin crystal) detector with beryllium-end window is good for $5-80 \mathrm{keV}$ energies using a thinner sample placed over the window.

Cost of Equipment: $\$ 35,000$ to $\$ 150,000$ based on detector efficiency and sophistication of MCA/computer/software system

Cost per Measurement: $\$ 100$ to $\$ 200$ (rush requests can double or triple costs) 


\section{System:}

Lab/Field:

\section{Radiation Detected: $\quad$ Primary: Gamma Secondary: None}

Applicability to Site Surveys: This system accurately measures the activity of gamma-emitting radionuclides in a variety of materials like soil, water, air filters, etc. with little preparation. Sodium iodide is inherently more efficient for detecting gamma rays but has lower resolution than germanium, particularly if multiple radionuclides and complicated spectra are involved. Operation: This system consists of a sodium iodide detector, a high voltage power supply, an amplifier, an analog to digital converter, and a multichannel analyzer. The detector is a sodium iodide crystal connected to a photomultiplier tube (PMT). Crystal shapes can vary extensively and typical detector high voltage are $900-1,000 \mathrm{~V}$. Sodium iodide is a scintillation material. A gamma ray interacting with a sodium iodide crystal produces light which is passed to the PMT. This light ejects electrons which the PMT multiplies into a pulse that is proportional to the energy the gamma ray imparted to the crystal. The MCA assesses the pulse size and places a count in the corresponding channel. The count rate and energy spectrum is displayed on the MCA screen with the full energy photopeaks providing more useful information than the general smear of Compton scattering events shown in between. The system is energy calibrated using isotopes that emit at least two gamma ray energies, so the MCA data channels are given an energy equivalence. The MCA's CRT then becomes a display of intensity versus energy. A non-linear energy response and lower resolution make isotopic identification less precise than with a germanium detector. Efficiency calibration is performed using known concentrations of single or mixed isotopes. The single isotope method develops a count rate to activity factor. The mixed isotope method produces a gamma ray energy versus counting efficiency curve that shows that sodium iodide is most sensitive around $100-120 \mathrm{keV}$ and trails off to either side. Counting efficiency is a function of sample to detector distance, so each geometry must have a separate efficiency calibration curve. The center of each peak tells the gamma ray energy that produced it and the combination of peaks identifies each isotope. Although the area under a peak relates to that isotope's activity in the sample, integrating a band of channels often provides better sensitivity. Samples are placed in containers and tare weighed. Plastic petri dishes sit atop the detector and are useful for small volumes or low energies, while Marinelli beakers fit around the detector and provide exceptional counting efficiency for volume samples. Counting times of 60 seconds to 1,000 minutes are typical. The CRT display is scanned and each peak is identified by isotope. The counts in each peak or energy band, the sample weight, the efficiency calibration curve, and the isotope's decay scheme are factored together to give the sample concentration. Specificity/Sensitivity: This system analyzes gamma-emitting isotopes with minimum preparation, better efficiency, but lower resolution compared to most germanium detectors. Germanium detectors do reach efficiencies of $150 \%$ compared with a 3 in. by 3 in. sodium iodide detector, but the cost is around $\$ 100,000$ each compared with $\$ 3,000$. Sodium iodide measures energies over $80 \mathrm{keV}$. The instrument response is energy dependent, the resolution is not superb, and the energy calibration is not totally linear, so care should be taken when identifying or quantifying multiple isotopes. Computer software can help interpret complicated spectra. Sodium iodide is fragile and should be protected from shock and sudden temperature changes. Cost of Equipment: $\$ 6 \mathrm{~K}-\$ 20 \mathrm{~K}$ Cost per Measurement: $\$ 100-\$ 200$ per sample. 


\section{EQUIPMENT SUMMARY TABLES}

Table H.1 - Radiation Detectors with Applications to Alpha Surveys

Table H.2 - Radiation Detectors with Applications to Beta Surveys

Table H.3 - Radiation Detectors with Applications to Gamma Surveys

Table H.4 - Radiation Detectors with Applications to Radon Surveys

Table H.5 - Systems that Measure Atomic Mass or Emissions 


\begin{tabular}{|c|c|c|c|c|c|}
\hline$\therefore:$ & 20 & 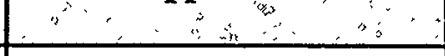 & 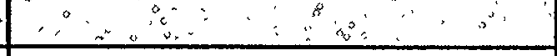 & Cost & $=$ Cost \\
\hline $\begin{array}{l}\text { Alpha } \\
\text { spectroscopy }\end{array}$ & $\begin{array}{l}\text { A system using silicon diode } \\
\text { surface barrier detectors for } \\
\text { alpha energy identification } \\
\text { and quantification }\end{array}$ & $\begin{array}{l}\text { Accurately identifies and } \\
\text { measures the activity of } \\
\text { multiple alpha radionuclides } \\
\text { in a thin extracted sample of } \\
\text { soil, water, or air filters. }\end{array}$ & $\begin{array}{l}\text { Sample requires radiochemical } \\
\text { separation or other preparation before } \\
\text { counting }\end{array}$ & $\$ 10 \mathrm{~K}-\$ 100 \mathrm{~K}$ & $\$ 250-\$ 400$ \\
\hline $\begin{array}{l}\text { Alpha } \\
\text { scintillation } \\
\text { survey meter }\end{array}$ & $\begin{array}{l}<1 \mathrm{mg} / \mathrm{cm}^{2} \text { window, probe } \\
\text { face area } 50 \text { to } 100 \mathrm{~cm}^{2} .\end{array}$ & $\begin{array}{l}\text { Field measurement of } \\
\text { presence or absence of alpha } \\
\text { contamination on nonporous } \\
\text { surfaces, swipes, and air } \\
\text { filters, or on irregular surfaces } \\
\text { if the degree of surface } \\
\text { shielding is known. }\end{array}$ & $\begin{array}{l}\text { Minimum sensitivity is } 10 \mathrm{cpm} \text {, or } 1 \\
\text { cpm with headphones }\end{array}$ & $\$ 1000$ & $\$ 5$ \\
\hline $\begin{array}{l}\text { Alpha Track } \\
\text { Detector }\end{array}$ & $\begin{array}{l}\text { Polycarbonate plastic sheet is } \\
\text { placed in contact with a } \\
\text { contaminated surface and kept } \\
\text { in place }\end{array}$ & $\begin{array}{l}\text { Measures gross alpha surface } \\
\text { contamination, soil activity } \\
\text { level, or the depth profile of } \\
\text { contamination }\end{array}$ & $\begin{array}{l}\text { Alpha radiation produces holes that } \\
\text { are enlarged chemically. Density of } \\
\text { holes gives a measure of the } \\
\text { radioactivity level. }\end{array}$ & & $\$ 5-\$ 25$ \\
\hline $\begin{array}{l}\text { Electret ion } \\
\text { chamber }\end{array}$ & $\begin{array}{l}\text { A charged Teflon disk in an } \\
\text { open-faced ion chamber }\end{array}$ & $\begin{array}{l}\text { Measures alpha or beta } \\
\text { contamination on surfaces and } \\
\text { in soils, plus gamma radiation } \\
\text { dose or radon concentration }\end{array}$ & $\begin{array}{l}\text { The type of radiation is determined by } \\
\text { how the electret is employed, e.g., the } \\
\text { unit is kept closed and bagged in } \\
\text { plastic to measure gammas }\end{array}$ & $\$ 4,000-\$ 5,000$ & $\$ 8-\$ 25$ \\
\hline $\begin{array}{l}\text { Long range } \\
\text { alpha detector } \\
\text { (LRAD) }\end{array}$ & $\begin{array}{l}1 \mathrm{~m} \times 1 \mathrm{~m} \text { detector measures } \\
\text { ionization inside the box. } \\
\text { Attached to tractor for } \\
\text { movement. Has location } \\
\text { finder and plots graph of } \\
\text { contamination. }\end{array}$ & $\begin{array}{l}\text { Measures surface } \\
\text { contamination or soil } \\
\text { concentration at grid points } \\
\text { and plots curves of constant } \\
\text { contamination. Intended for } \\
\text { large areas. }\end{array}$ & $\begin{array}{l}\text { Alpha detection limit is } 20-50 \\
\mathrm{dpm} / 100 \mathrm{~cm}^{2} \text { or } 0.4 \mathrm{~Bq} / \mathrm{g}(10 \mathrm{pCi} / \mathrm{g}) \text {. }\end{array}$ & $\$ 25,000$ & $\$ 80$ \\
\hline
\end{tabular}


Table H.1 Radiation Detectors with Applications to Alpha Surveys

\begin{tabular}{|c|c|c|c|c|c|}
\hline System & Description & Application & Remarks & $\begin{array}{l}\text { Equipment } \\
\text { Cost }\end{array}$ & $\begin{array}{c}\text { Measurement } \\
\text { Cost }\end{array}$ \\
\hline $\begin{array}{l}\text { Gas-flow } \\
\text { proportional } \\
\text { counter (field) }\end{array}$ & $\begin{array}{l}\text { A detector through which } \mathrm{P} 10 \\
\text { gas flows and which measures } \\
\text { alpha and beta radiation. }<1- \\
10 \mathrm{mg} / \mathrm{cm}^{2} \text { window, probe } \\
\text { face area } 50 \text { to } 100 \mathrm{~cm}^{2} \text { for } \\
\text { hand held detectors; up to } 600 \\
\mathrm{~cm}^{2} \text { if cart mounted }\end{array}$ & $\begin{array}{l}\text { Surface scanning, surface } \\
\text { activity measurement, or field } \\
\text { evaluation of swipes. Serves } \\
\text { as a screen to determine if } \\
\text { more nuclide-specific } \\
\text { analyses are needed. }\end{array}$ & $\begin{array}{l}\text { Natural radionuclides in samples can } \\
\text { interfere with the detection of other } \\
\text { contaminants. Requires } \mathrm{P} 10 \text { gas }\end{array}$ & $\$ 2 \mathrm{~K}-\$ 4 \mathrm{~K}$ & $\$ 2-\$ 10 / \mathrm{m}^{2}$ \\
\hline $\begin{array}{l}\text { Gas-flow } \\
\text { proportional } \\
\text { counter (lab) }\end{array}$ & $\begin{array}{l}\text { Windowless (internal } \\
\text { proportional) or window }<0.1 \\
\mathrm{mg} / \mathrm{cm}^{2} \text {, probe face area } 10 \text { to } \\
20 \mathrm{~cm}^{2} \text {. May have a second or } \\
\text { guard detector to reduce } \\
\text { background and MDA. } \\
\end{array}$ & $\begin{array}{l}\text { Laboratory measurement of } \\
\text { water, air, and swipe samples } \\
\end{array}$ & $\begin{array}{l}\text { Requires } \mathrm{P} 10 \text { gas. Windowless } \\
\text { detectors can be contaminated. }\end{array}$ & $\$ 4 \mathrm{~K}-\$ 30 \mathrm{~K}$ & $\$ 50$ \\
\hline $\begin{array}{l}\text { Liquid } \\
\text { scintillation } \\
\text { counter (LSC) }\end{array}$ & $\begin{array}{l}\text { Samples are mixed with LSC } \\
\text { cocktail and the radiation } \\
\text { emitted causes light pulses } \\
\text { with proportional intensity. }\end{array}$ & $\begin{array}{l}\text { Laboratory analysis of alpha } \\
\text { or beta emitters, including } \\
\text { spectrometry capabilities. }\end{array}$ & $\begin{array}{l}\text { Highly selective for alpha or beta } \\
\text { radiation by pulse shape } \\
\text { discrimination. Requires LSC } \\
\text { cocktail. }\end{array}$ & $\$ 20 \mathrm{~K}-\$ 70 \mathrm{~K}$ & $\$ 50-\$ 200$ \\
\hline
\end{tabular}


Table H.2 Radiation Detectors with Applications to Beta Surveys

\begin{tabular}{|c|c|c|c|c|c|}
\hline System & Description & Application & Remarks & $\begin{array}{l}\text { Equipment } \\
\text { Cost }\end{array}$ & $\begin{array}{l}\text { Measurement } \\
\text { Cost }\end{array}$ \\
\hline $\begin{array}{l}\text { GM survey meter } \\
\text { with beta } \\
\text { pancake probe }\end{array}$ & $\begin{array}{l}\text { Thin } 1.4 \mathrm{mg} / \mathrm{cm}^{2} \text { window } \\
\text { detector, probe area } 10 \text { to } 100 \\
\mathrm{~cm}^{2}\end{array}$ & $\begin{array}{l}\text { Surface scanning of } \\
\text { personnel, working areas, } \\
\text { equipment, and swipes for } \\
\text { beta contamination. } \\
\text { Laboratory measurement } \\
\text { of swipes when connected } \\
\text { to a scaler. }\end{array}$ & $\begin{array}{l}\text { Relatively high detection limit } \\
\text { making it of limited value in final } \\
\text { status surveys. }\end{array}$ & $\$ 400-\$ 1,500$ & $\$ 5-\$ 10$ \\
\hline $\begin{array}{l}\text { Gas-flow } \\
\text { proportional } \\
\text { counter (field) }\end{array}$ & $\begin{array}{l}\text { A detector through which P10 } \\
\text { gas flows and which measures } \\
\text { alpha and beta radiation. }<1- \\
10 \mathrm{mg} / \mathrm{cm}^{2} \text { window, probe } \\
\text { face area } 50 \text { to } 100 \mathrm{~cm}^{2}\end{array}$ & $\begin{array}{l}\text { Surface scanning, surface } \\
\text { activity measurement, or } \\
\text { field evaluation of swipes. } \\
\text { Serves as a screen to } \\
\text { determine if more nuclide- } \\
\text { specific analyses are } \\
\text { needed. }\end{array}$ & $\begin{array}{l}\text { Natural radionuclides in samples can } \\
\text { interfere with the detection of other } \\
\text { contaminants. Requires } P 10 \text { gas, but } \\
\text { can be disconnected for hours. }\end{array}$ & $\$ 2 \mathrm{~K}-\$ 4 \mathrm{~K}$ & $\$ 2-\$ 10 / \mathrm{m}^{2}$ \\
\hline $\begin{array}{l}\text { Gas-flow } \\
\text { proportional } \\
\text { counter (lab) }\end{array}$ & $\begin{array}{l}\text { Windowless (internal } \\
\text { proportional) or window }<0.1 \\
\mathrm{mg} / \mathrm{cm}^{2} \text {, probe face area } 10 \text { to } \\
20 \mathrm{~cm}^{2} \text {. May have a second or } \\
\text { guard detector to reduce } \\
\text { background and MDA. } \\
\end{array}$ & $\begin{array}{l}\text { Laboratory measurement } \\
\text { of water, air, and swipe } \\
\text { samples }\end{array}$ & $\begin{array}{l}\text { Requires } \mathrm{P} 10 \text { gas. Windowless } \\
\text { detectors can be contaminated. }\end{array}$ & $\$ 4 \mathrm{~K}-\$ 30 \mathrm{~K}$ & $\$ 50$ \\
\hline $\begin{array}{l}\text { Liquid } \\
\text { scintillation } \\
\text { counter (LSC) }\end{array}$ & $\begin{array}{l}\text { Samples are mixed with LSC } \\
\text { cocktail and the radiation } \\
\text { emitted causes light pulses } \\
\text { with proportional intensity. }\end{array}$ & $\begin{array}{l}\text { Laboratory analysis of } \\
\text { alpha and beta emitters, } \\
\text { including spectrometry } \\
\text { capabilities. }\end{array}$ & $\begin{array}{l}\text { Highly selective for alpha and beta } \\
\text { radiation by pulse shape } \\
\text { discrimination. Requires LSC } \\
\text { cocktail. }\end{array}$ & $\$ 20 \mathrm{~K}-\$ 70 \mathrm{~K}$ & $\$ 100-\$ 200$ \\
\hline
\end{tabular}




\begin{tabular}{|c|c|c|c|c|c|}
\hline System: & Description & $\therefore$ Application. $\because$ & $\begin{array}{l}\text { Remarks } \\
0\end{array}$ & Cost of Equipment & $\begin{array}{l}\text { Cost per } \\
\text { Measurement }\end{array}$ \\
\hline $\begin{array}{l}\text { GM survey meter } \\
\text { with gamma probe }\end{array}$ & $\begin{array}{l}\text { Thick-walled } 30 \mathrm{mg} / \mathrm{cm}^{2} \\
\text { detector }\end{array}$ & $\begin{array}{l}\text { Measure radiation levels } \\
\text { above } 0.1 \mathrm{mR} / \mathrm{hr} \text {. }\end{array}$ & $\begin{array}{l}\text { Its non-linear energy response can } \\
\text { be corrected by using an energy } \\
\text { compensated probe. }\end{array}$ & $\$ 400-\$ 1,000$ & $\$ 5$ \\
\hline $\begin{array}{l}\text { Pressurized ion } \\
\text { chamber (PIC) }\end{array}$ & $\begin{array}{l}\text { A highly accurate } \\
\text { ionization chamber that is } \\
\text { rugged and stable. }\end{array}$ & $\begin{array}{l}\text { Excellent for measuring } \\
\text { gamma exposure rate during } \\
\text { site remediation. }\end{array}$ & $\begin{array}{l}\text { Is used in conjunction with } \\
\text { radionuclide identification } \\
\text { equipment. }\end{array}$ & $\$ 15 \mathrm{~K}-\$ 50 \mathrm{~K}$ & $\$ 50-\$ 500$ \\
\hline $\begin{array}{l}\text { Electret ion } \\
\text { chamber }\end{array}$ & $\begin{array}{l}\text { Electrostatically charged } \\
\text { disk inside an ion } \\
\text { chamber }\end{array}$ & Gamma exposure rate & N/A, rented & $\begin{array}{l}\text { included in rental } \\
\text { price }\end{array}$ & $\$ 8-\$ 25$ \\
\hline $\begin{array}{l}\text { Hand-held ion } \\
\text { chamber survey } \\
\text { meter }\end{array}$ & $\begin{array}{l}\text { Ion chamber for } \\
\text { measuring higher } \\
\text { radiation levels than } \\
\text { typical background. }\end{array}$ & $\begin{array}{l}\text { Measures true gamma } \\
\text { exposure rate. }\end{array}$ & $\begin{array}{l}\text { Not very useful for site surveys } \\
\text { because of high detection limit } \\
\text { above background levels. }\end{array}$ & $\$ 800-\$ 1,200$ & $\$ 5$ \\
\hline $\begin{array}{l}\text { Hand-held } \\
\text { pressurized ion } \\
\text { chamber survey } \\
\text { meter }\end{array}$ & $\begin{array}{l}\text { Ion chamber for } \\
\text { measuring higher } \\
\text { radiation levels than } \\
\text { typical background. } \\
\end{array}$ & $\begin{array}{l}\text { Measures true gamma } \\
\text { exposure rate with more } \\
\text { sensitivity than the } \\
\text { unpressurized ion chamber. }\end{array}$ & $\begin{array}{l}\text { Not very useful for site surveys } \\
\text { because of high detection limit } \\
\text { above background levels. }\end{array}$ & $\$ 1,000-\$ 1,500$ & $\$ 5$ \\
\hline $\begin{array}{l}\text { Sodium Iodide } \\
\text { survey meter }\end{array}$ & $\begin{array}{l}\text { Detectors sizes up to } \\
8 " x 8 " . \text { Used in micro } R- \\
\text { meter in smaller sizes. }\end{array}$ & $\begin{array}{l}\text { Measures low levels of } \\
\text { environmental radiation. }\end{array}$ & $\begin{array}{l}\text { Its energy response is not linear, } \\
\text { so it should be calibrated for the } \\
\text { energy field it will measure or } \\
\text { have calibration factors developed } \\
\text { by comparison with a PIC for a } \\
\text { specific site. }\end{array}$ & $\$ 2 \mathrm{~K}$ & $\$ 5$ \\
\hline $\begin{array}{l}\text { FDLER (Field } \\
\text { Instrument for } \\
\text { Detection of Low } \\
\text { Energy Radiation) }\end{array}$ & $\begin{array}{l}\text { Thin crystals of } \mathrm{NaI} \text { or } \\
\text { CsI. }\end{array}$ & $\begin{array}{l}\text { Scanning of gamma/X } \\
\text { radiation from plutonium and } \\
\text { americium. }\end{array}$ & & $\$ 6 \mathrm{~K}-\$ 7 \mathrm{~K}$ & $\$ 10-\$ 20$ \\
\hline
\end{tabular}


Table H.3 Radiation Detectors with Applications to Gamma and X-Ray Surveys

\begin{tabular}{|c|c|c|c|c|c|}
\hline System & $\therefore$ Description & Application & $\therefore$ Remarks & Cost of Equipment & $\begin{array}{l}\text { Còst per } \\
\text { Measurement }\end{array}$ \\
\hline $\begin{array}{l}\text { Sodium iodide } \\
\text { detector with } \\
\text { multichannel } \\
\text { analyzer (MCA) }\end{array}$ & $\begin{array}{l}\text { Sodium iodide crystal } \\
\text { with a large range of sizes } \\
\text { and shapes, connected to } \\
\text { a photomultiplier tube and } \\
\text { MCA. }\end{array}$ & $\begin{array}{l}\text { Laboratory gamma } \\
\text { spectroscopy to determine the } \\
\text { identity and concentration of } \\
\text { gamma emitting radionuclides } \\
\text { in a sample. }\end{array}$ & $\begin{array}{l}\text { Sensitive for surface soil or } \\
\text { groundwater contamination. } \\
\text { Analysis programs have difficulty } \\
\text { if sample contains more than a few } \\
\text { isotopes. }\end{array}$ & $\$ 6 \mathrm{~K}-\$ 20 \mathrm{~K}$ & $\$ 100$ to $\$ 200$ \\
\hline $\begin{array}{l}\text { Germanium } \\
\text { detector with } \\
\text { multichannel } \\
\text { analyzer (MCA) }\end{array}$ & $\begin{array}{l}\text { Intrinsic germanium } \\
\text { semiconductor in } \mathrm{p} \text { - or } \mathrm{n}- \\
\text { type configuration and } \\
\text { without a beryllium } \\
\text { window. } \\
\end{array}$ & $\begin{array}{l}\text { Laboratory gamma } \\
\text { spectroscopy to determine the } \\
\text { identity and concentration of } \\
\text { gamma emitting radionuclides } \\
\text { in a sample. }\end{array}$ & $\begin{array}{l}\text { Very sensitive for surface soil or } \\
\text { groundwater contamination. Is } \\
\text { especially powerful when more } \\
\text { than one radionuclide is present in } \\
\text { a sample. }\end{array}$ & $\$ 35 \mathrm{~K}-\$ 150 \mathrm{~K}$ & $\$ 100$ to $\$ 200$ \\
\hline $\begin{array}{l}\text { Portable } \\
\text { Germanium } \\
\text { Multichannel } \\
\text { Analyzer (MCA) } \\
\text { System }\end{array}$ & $\begin{array}{l}\text { A portable version of a } \\
\text { laboratory based } \\
\text { germanium detector and } \\
\text { multichannel analyzer. }\end{array}$ & $\begin{array}{l}\text { Excellent during } \\
\text { characterization through final } \\
\text { status survey to identify and } \\
\text { quantify the concentration of } \\
\text { gamma ray emitting } \\
\text { radionuclides and in situ } \\
\text { concentrations of soil and } \\
\text { other media }\end{array}$ & $\begin{array}{l}\text { Requires a supply of liquid } \\
\text { nitrogen or a mechanical cooling } \\
\text { system, as well as highly trained } \\
\text { operators. }\end{array}$ & $\$ 40 \mathrm{~K}$ & $\$ 100$ \\
\hline $\begin{array}{l}\text { Field x-ray } \\
\text { fluorescence } \\
\text { spectrometer }\end{array}$ & $\begin{array}{l}\text { Uses silicon or } \\
\text { germanium } \\
\text { semiconductor }\end{array}$ & $\begin{array}{l}\text { Determining fractional } \\
\text { abundance of low percentage } \\
\text { metal atoms. }\end{array}$ & & $\$ 15 \mathrm{~K}-\$ 75 \mathrm{~K}$ & $\$ 200$ \\
\hline $\begin{array}{l}\text { Thermoluminesce } \\
\text { nce dosimeters } \\
\text { (TLDs) }\end{array}$ & \begin{tabular}{|l|} 
Crystals that are sensitive \\
to gamma radiation
\end{tabular} & $\begin{array}{l}\text { Measure cumulative radiation } \\
\text { dose over a period of days to } \\
\text { months. }\end{array}$ & $\begin{array}{l}\text { Requires special calibration to } \\
\text { achieve high accuracy and } \\
\text { reproducibility of results. }\end{array}$ & $\begin{array}{l}\$ 5 \mathrm{~K}-\$ 50 \mathrm{~K} \text { for } \\
\text { reader }+ \\
\$ 25-\$ 40 \text { per TLD }\end{array}$ & $\$ 25-\$ 125$ \\
\hline
\end{tabular}




\begin{tabular}{|c|c|c|c|c|c|}
\hline Systèm & Description & Application & Remarks & $\begin{array}{c}\text { Equipment } \\
\text { Cost }\end{array}$ & $\begin{array}{l}\text { Measurement } \\
\text { Cost } \\
\end{array}$ \\
\hline $\begin{array}{l}\text { Large area } \\
\text { activated charcoal } \\
\text { collector }\end{array}$ & $\begin{array}{l}\text { A canister containing activated } \\
\text { charcoal is twisted into the } \\
\text { surface and left for } 24 \text { hours. }\end{array}$ & $\begin{array}{l}\text { Short term radon flux } \\
\text { measurements }\end{array}$ & $\begin{array}{l}\text { The LLD is } 0.007 \mathrm{~Bq} \mathrm{~m}^{-2} \mathrm{~s}^{-1} \\
\left(0.2 \mathrm{pCi} \mathrm{m}^{-2} \mathrm{~s}^{-1}\right)\end{array}$ & N/A, rented & $\begin{array}{l}\$ 20-\$ 50 \\
\text { including } \\
\text { canister }\end{array}$ \\
\hline $\begin{array}{l}\text { Continuous radon } \\
\text { monitor }\end{array}$ & $\begin{array}{l}\text { Air pump and scintillation cell } \\
\text { or ionization chamber }\end{array}$ & $\begin{array}{l}\text { Track the real time } \\
\text { concentration of radon }\end{array}$ & $\begin{array}{l}\text { Takes } 1 \text { to } 4 \text { hours for system to } \\
\text { equilibrate before starting. The LLD is } \\
0.004-0.04 \mathrm{Bg} / \mathrm{L}(0.1-1.0 \mathrm{pCi} / \mathrm{L}) \text {. }\end{array}$ & $\$ 1 \mathrm{~K}-\$ 5 \mathrm{~K}$ & $\$ 80$ \\
\hline $\begin{array}{l}\text { Activated charcoal } \\
\text { adsorption }\end{array}$ & $\begin{array}{l}\text { Activated charcoal is opened } \\
\text { to the ambient air, then gamma } \\
\text { counted on a gamma } \\
\text { scintillator or in a liquid } \\
\text { scintillation counter. }\end{array}$ & $\begin{array}{l}\text { Measure radon } \\
\text { concentration in indoor } \\
\text { air }\end{array}$ & $\begin{array}{l}\text { Detector is deployed for } 2 \text { to } 7 \text { days. } \\
\text { The } L L D \text { is } 0.007-0.04 \mathrm{~Bq} / \mathrm{L}(0.2 \text { to } \\
1.0 \mathrm{pCi} / \mathrm{L}) \text {. }\end{array}$ & $\$ 10 \mathrm{~K}-\$ 30 \mathrm{~K}$ & $\begin{array}{l}\$ 5-\$ 30 \\
\text { including } \\
\text { canister if } \\
\text { outsourced. }\end{array}$ \\
\hline $\begin{array}{l}\text { Electret ion } \\
\text { chamber }\end{array}$ & $\begin{array}{l}\text { This is a charged plastic vessel } \\
\text { that can be opened for air to } \\
\text { pass into. }\end{array}$ & $\begin{array}{l}\text { Measure short-term or } \\
\text { long-term radon } \\
\text { concentration in indoor } \\
\text { air. }\end{array}$ & $\begin{array}{l}\text { Must correct reading for gamma } \\
\text { background concentration. Electret is } \\
\text { sensitive to extremes of temperature } \\
\text { and humidity. LLD is } 0.007-0.02 \mathrm{~Bq} / \mathrm{L} \\
(0.2-0.5 \mathrm{pCi} / \mathrm{L}) \text {. }\end{array}$ & N/A, rented & $\$ 8-\$ 25$ for rental \\
\hline $\begin{array}{l}\text { Alpha track } \\
\text { detection }\end{array}$ & $\begin{array}{l}\text { A small piece of special plastic } \\
\text { or film inside a small } \\
\text { container. Damage tracks from } \\
\text { alpha particles are chemically } \\
\text { etched and tracks counted. }\end{array}$ & $\begin{array}{l}\text { Measure indoor or } \\
\text { outdoor radon } \\
\text { concentration in air. }\end{array}$ & $\begin{array}{l}\mathrm{LLD} \text { is } 0.04 \mathrm{~Bq} \mathrm{~L}^{-1} \mathrm{~d}^{-1} \\
\left(1 \mathrm{pCi} \mathrm{L} \mathrm{L}^{-1} \mathrm{~d}^{-1}\right)\end{array}$ & & $\$ 5-\$ 25$ \\
\hline
\end{tabular}


Table H.5 Systems that Measure Atomic Mass or Emissions

\begin{tabular}{|c|c|c|c|c|c|}
\hline System & Description & Application & Remarks & $\begin{array}{c}\text { Cost of } \\
\text { Equipment }\end{array}$ & $\begin{array}{l}\text { Cost per } \\
\text { Measurement }\end{array}$ \\
\hline $\begin{array}{l}\text { LA-ICP-AES (Laser } \\
\text { Ablation Inductively } \\
\text { Coupled Plasma Atomic } \\
\text { Emissions Spectrometer) }\end{array}$ & $\begin{array}{l}\text { Vaporizes and ionizes the } \\
\text { surface material, and } \\
\text { measures emissions from } \\
\text { the resulting atoms. }\end{array}$ & $\begin{array}{l}\text { Live time analysis of } \\
\text { radioactive } U \text { and Th } \\
\text { contamination in the } \\
\text { field. }\end{array}$ & $\begin{array}{l}\text { Requires expensive equipment } \\
\text { and skilled operators. LLD is } \\
0.004 \mathrm{~Bq} / \mathrm{g}(0.1 \mathrm{pCi} / \mathrm{g}) \text { for }{ }^{232} \mathrm{Th} \\
\text { and } 0.01 \mathrm{~Bq} / \mathrm{g}(0.3 \mathrm{pCi} / \mathrm{g}) \text { for } \\
{ }^{238} \mathrm{U} \text {. }\end{array}$ & $>\$ 1,000,000$ & $\$ 4,000$ \\
\hline $\begin{array}{l}\text { LA-ICP-MS (Laser } \\
\text { Ablation Inductively } \\
\text { Coupled Plasma Mass } \\
\text { Spectrometer) }\end{array}$ & $\begin{array}{l}\text { Vaporizes and ionizes the } \\
\text { surface material, then } \\
\text { measures the mass of the } \\
\text { resulting atoms. }\end{array}$ & $\begin{array}{l}\text { Live time analysis of } \\
\text { radioactive U and Th } \\
\text { contamination in the } \\
\text { field. }\end{array}$ & $\begin{array}{l}\text { Requires expensive equipment } \\
\text { and skilled operators. More } \\
\text { sensitive than LA-ICP-AES. } \\
\text { LLD is } 0.6 \mathrm{~Bq} / \mathrm{g}(15 \mathrm{pCi} / \mathrm{g} \text { ) for } \\
{ }^{230} \mathrm{Th} \text {. }\end{array}$ & $>\$ 1,000,000$ & $>\$ 4,000$ \\
\hline $\begin{array}{l}\text { Chemical speciation laser } \\
\text { ablation/mass } \\
\text { spectrometer }\end{array}$ & $\begin{array}{l}\text { A laser changes the sample } \\
\text { into an aerosol that it } \\
\text { analyzed with a mass } \\
\text { spectrometer. }\end{array}$ & $\begin{array}{l}\text { Analyze organic and } \\
\text { inorganic species with } \\
\text { high sensitivity and } \\
\text { specificity. }\end{array}$ & $\begin{array}{l}\text { Volatilized samples can be } \\
\text { carried hundreds of feet to the } \\
\text { analysis area. }\end{array}$ & $>\$ 1,000,000$ & $>\$ 4,000$ \\
\hline
\end{tabular}




\section{APPENDIX I}

\section{STATISTICAL TABLES AND PROCEDURES}

\section{I.1 Normal Distribution}

Table I.1 Cumulative Normal Distribution Function $\Phi(\mathrm{z})$

\begin{tabular}{|c|c|c|c|c|c|c|c|c|c|c|}
\hline$z$ & 0.00 & 0.01 & 0.02 & 0.03 & 0.04 & 0.05 & 0.06 & 0.07 & 0.08 & 0.09 \\
\hline 0.00 & 0.5000 & 0.5040 & 0.5080 & 0.5120 & 0.5160 & 0.5199 & 0.5239 & 0.5279 & 0.5319 & 0.5359 \\
\hline 0.10 & 0.5398 & 0.5438 & 0.5478 & 0.5517 & 0.5557 & 0.5596 & 0.5636 & 0.5674 & 0.5714 & 0.5753 \\
\hline 0.20 & 0.5793 & 0.5832 & 0.5871 & 0.5910 & 0.5948 & 0.5987 & 0.6026 & 0.6064 & 0.6103 & 0.6141 \\
\hline 0.30 & 0.6179 & 0.6217 & 0.6255 & 0.6293 & 0.6331 & 0.6368 & 0.6406 & 0.6443 & 0.6480 & 0.6517 \\
\hline 0.40 & 0.6554 & 0.6591 & 0.6628 & 0.6664 & 0.6700 & 0.6736 & 0.6772 & 0.6808 & 0.6844 & 0.6879 \\
\hline 0.50 & 0.6915 & 0.6950 & 0.6985 & 0.7019 & 0.7054 & 0.7088 & 0.7123 & 0.7157 & 0.7190 & 0.7224 \\
\hline 0.60 & 0.7257 & 0.7291 & 0.7324 & 0.7357 & 0.7389 & 0.7422 & 0.7454 & 0.7486 & 0.7517 & 0.7549 \\
\hline 0.70 & 0.7580 & 0.7611 & 0.7642 & 0.7673 & 0.7704 & 0.7734 & 0.7764 & 0.7794 & 0.7823 & 0.7852 \\
\hline 0.80 & 0.7881 & 0.7910 & 0.7939 & 0.7967 & 0.7995 & 0.8023 & 0.8051 & 0.8078 & 0.8106 & 0.8133 \\
\hline 0.90 & 0.8159 & 0.8186 & 0.8212 & 0.8238 & 0.8264 & 0.8289 & 0.6315 & 0.8340 & 0.8365 & 0.8389 \\
\hline 1.00 & 0.8413 & 0.8438 & 0.8461 & 0.8485 & 0.8508 & 0.8531 & 0.8554 & 0.8577 & 0.8599 & 0.8621 \\
\hline 1.10 & 0.8643 & 0.8665 & 0.8686 & 0.8708 & 0.8729 & 0.8749 & 0.8770 & 0.8790 & 0.8810 & 0.8830 \\
\hline 1.20 & 0.8849 & 0.8869 & 0.8888 & 0.8907 & 0.8925 & 0.8944 & 0.8962 & 0.8980 & 0.8997 & 0.9015 \\
\hline 1.30 & 0.9032 & 0.9049 & 0.9066 & 0.9082 & 0.9099 & 0.9115 & 0.9131 & 0.9147 & 0.9162 & 0.9177 \\
\hline 1.40 & 0.9192 & 0.9207 & 0.9222 & 0.9236 & 0.9251 & 0.9265 & 0.9279 & 0.9292 & 0.9306 & 0.9319 \\
\hline 1.50 & 0.9332 & 0.9345 & 0.9357 & 0.9370 & 0.9382 & 0.9394 & 0.9406 & 0.9418 & 0.9429 & 0.9441 \\
\hline 1.60 & 0.9452 & 0.9463 & 0.9474 & 0.9484 & 0.9495 & 0.9505 & 0.9515 & 0.9525 & 0.9535 & 0.9545 \\
\hline 1.70 & 0.9554 & 0.9564 & 0.9573 & 0.9582 & 0.9591 & 0.9599 & 0.9608 & 0.9 & 0.9625 & 0.9633 \\
\hline 1.80 & 0.9641 & 0.9649 & 0.9656 & 0.9664 & 0.9671 & 0.9678 & 0.9686 & 0.9693 & 0.9699 & 0.9706 \\
\hline 1.90 & 0.9713 & 0.9719 & 0.9726 & 0.9732 & 0.9738 & 0.9744 & 0.9750 & 0.9756 & 0.9761 & 0.9767 \\
\hline 2.00 & 0.9772 & 0.9778 & 0.9783 & 0.9788 & 0.9793 & 0.9798 & 0.9803 & 0.9808 & 0.9812 & 0.9817 \\
\hline 2.10 & 0.9821 & 0.9826 & 0.9830 & 0.9834 & 0.9838 & 0.9842 & 0.9846 & 0.9850 & 0.9854 & 0.9857 \\
\hline 2.20 & 0.9861 & 0.9864 & 0.9868 & 0.9871 & 0.9875 & 0.9878 & 0.9881 & 0.9884 & 0.9887 & 0.9890 \\
\hline 2.30 & 0.9893 & 0.9896 & 0.9898 & 0.9901 & 0.9904 & 0.9906 & 0.9909 & 0.9911 & 0.9913 & 0.9916 \\
\hline 2.40 & 0.9918 & 0.9920 & 0.9922 & 0.9925 & 0.9927 & 0.9929 & 0.9931 & 0.9932 & 0.9934 & 0.9936 \\
\hline 2.50 & 0.9938 & 0.9940 & 0.9941 & 0.9943 & 0.9945 & 0.9946 & 0.9948 & 0.9949 & 0.9951 & 0.9952 \\
\hline 2.60 & 0.9953 & 0.9955 & 0.9956 & 0.9957 & 0.9959 & 0.9960 & 0.9961 & 0.9962 & 0.9963 & 0.9964 \\
\hline 2.70 & 0.9965 & 0.9966 & 0.9967 & 0.9968 & 0.9969 & 0.9970 & 0.9971 & 0.9972 & 0.9973 & 0.9974 \\
\hline 2.80 & 0.9974 & 0.9975 & 0.9976 & 0.9977 & 0.9977 & 0.9978 & 0.9979 & 0.9979 & 0.9980 & 0.9981 \\
\hline 2.90 & 0.9981 & 0.9982 & 0.9982 & 0.9983 & 0.9984 & 0.9984 & 0.9985 & 0.9985 & 0.9986 & 0.9986 \\
\hline 3.00 & 0.9987 & 0.9987 & 0.9987 & 0.9988 & 0.9988 & 0.9989 & 0.9989 & 0.9989 & 0.9990 & 0.9990 \\
\hline 3.10 & 0.9990 & 0.9991 & 0.9991 & 0.9991 & 0.9992 & 0.9992 & 0.9992 & 0.9992 & 0.9993 & 0.9993 \\
\hline 3.20 & 0.9993 & 0.9993 & 0.9994 & 0.9994 & 0.9994 & 0.9994 & 0.9994 & 0.9995 & 0.9995 & 0.9995 \\
\hline 3.30 & 0.9995 & 0.9995 & 0.9995 & 0.9996 & 0.9996 & 0.9996 & 0.9996 & 0.9996 & 0.9996 & 0.9997 \\
\hline 3.40 & 0.9997 & 0.9997 & 0.9997 & 0.9997 & 0.9997 & 0.9997 & 0.9997 & 0.9997 & 0.9997 & 0.9998 \\
\hline
\end{tabular}

Negative values of $\mathrm{z}$ can be obtained from the relationship $\Phi(-\mathrm{z})=1-\Phi(\mathrm{z})$. 


\section{I.2 Sample Sizes for Statistical Tests}

Table I.2a Sample Sizes for Sign Test

(Number of measurements to be performed in each survey unit)

\begin{tabular}{|c|c|c|c|c|c|c|c|c|c|c|c|c|c|c|c|}
\hline$\Delta / \sigma$ & $\begin{array}{l}0.01 \\
0.01\end{array}$ & $\begin{array}{l}0.01 \\
0.025\end{array}$ & $\begin{array}{l}0.01 \\
0.05\end{array}$ & $\begin{array}{l}0.01 \\
0.1\end{array}$ & $\begin{array}{l}0.01 \\
0.25\end{array}$ & $\left|\begin{array}{l}0.025 \\
0,025\end{array}\right|$ & $\mid \begin{array}{l}0.025 \\
0.05\end{array}$ & $\begin{array}{l}0.025 \\
0.1\end{array}$ & $\begin{array}{c}0.025 \\
0.25\end{array}$ & $\begin{array}{l}0.05 \\
0.05\end{array}$ & $\begin{array}{l}0.05 \\
0.1\end{array}$ & $\begin{array}{l}0.05 \\
0.25\end{array}$ & $\begin{array}{l}0.1 \\
0.1\end{array}$ & $\begin{array}{l}0.1 \\
0.25\end{array}$ & $\begin{array}{l}0.25 \\
0.25\end{array}$ \\
\hline 0.1 & 4095 & 3476 & 2984 & 2463 & 1704 & 2907 & 2459 & 1989 & 1313 & 2048 & 1620 & 1018 & 1244 & 725 & 345 \\
\hline 0.2 & 1035 & 879 & 754 & 623 & 431 & 735 & 622 & 503 & 333 & 518 & 410 & 258 & 315 & 184 & 88 \\
\hline 0.3 & 468 & 398 & 341 & 282 & 195 & 333 & 281 & 227 & 150 & 234 & 185 & 117 & 143 & 83 & 40 \\
\hline 0.4 & 270 & 230 & 197 & 162 & 113 & 192 & 162 & 131 & 87 & 136 & 107 & 68 & 82 & 48 & 23 \\
\hline 0.5 & 178 & 152 & 130 & 107 & 75 & 126 & 107 & 87 & 58 & 89 & 71 & 45 & 54 & 33 & 16 \\
\hline 0.6 & 129 & 110 & 94 & 77 & 54 & 92 & 77 & 63 & 42 & 65 & 52 & 33 & 40 & 23 & 11 \\
\hline 0.7 & 99 & 83 & 72 & 59 & 41 & 70 & 59 & 48 & 33 & 50 & 40 & 26 & 30 & 18 & 9 \\
\hline 0.8 & 80 & 68 & 58 & 48 & 34 & 57 & 48 & 39 & 26 & 40 & 32 & 21 & 24 & 15 & 8 \\
\hline 0.9 & 66 & 57 & 48 & 40 & 28 & 47 & 40 & 33 & 22 & 34 & 27 & 17 & 21 & 12 & 6 \\
\hline 1.0 & 57 & 48 & 41 & 34 & 24 & 40 & 34 & 28 & 18 & 29 & 23 & 15 & 18 & 11 & 5 \\
\hline 1.1 & 50 & 42 & 36 & 30 & 21 & 35 & 30 & 24 & 17 & 26 & 21 & 14 & 16 & 10 & 5 \\
\hline 1.2 & 45 & 38 & 33 & 27 & 20 & 32 & 27 & 22 & 15 & 23 & 18 & 12 & 15 & 9 & 5 \\
\hline 1.3 & 41 & 35 & 30 & 26 & 17 & 29 & 24 & 21 & 14 & 21 & 17 & 11 & 14 & 8 & 4 \\
\hline 1.4 & 38 & 33 & 28 & 23 & 16 & 27 & 23 & 18 & 12 & 20 & 16 & 10 & 12 & 8 & 4 \\
\hline 1.5 & 35 & 30 & 27 & 22 & 15 & 26 & 22 & 17 & 12 & 18 & 15 & 10 & 11 & 8 & 4 \\
\hline 1.6 & 34 & 29 & 24 & 21 & 15 & 24 & 21 & 17 & 11 & 17 & 14 & 9 & 11 & 6 & 4 \\
\hline 1.7 & 33 & 28 & 24 & 20 & 14 & 23 & 20 & 16 & 11 & 17 & 14 & 9 & 10 & 6 & 4 \\
\hline 1.8 & 32 & 27 & 23 & 20 & 14 & 22 & 20 & 16 & 11 & 16 & 12 & 9 & 10 & 6 & 4 \\
\hline 1.9 & 30 & 26 & 22 & 18 & 14 & 22 & 18 & 15 & 10 & 16 & 12 & 9 & 10 & 6 & 4 \\
\hline 2.0 & 29 & 26 & 22 & 18 & 12 & 21 & 18 & 15 & 10 & 15 & 12 & 8 & 10 & 6 & 3 \\
\hline 2.5 & 28 & 23 & 21 & 17 & 12 & 20 & 17 & 14 & 10 & 15 & 11 & 8 & 9 & 5 & 3 \\
\hline 3.0 & 27 & 23 & 20 & 17 & 12 & 20 & 17 & 14 & 9 & 14 & 11 & 8 & 9 & 5 & 3 \\
\hline
\end{tabular}


Appendix I

Table I.2b Sample Sizes for Wilcoxon Rank Sum Test

(Number of measurements to be performed in the reference area and in each survey unit)

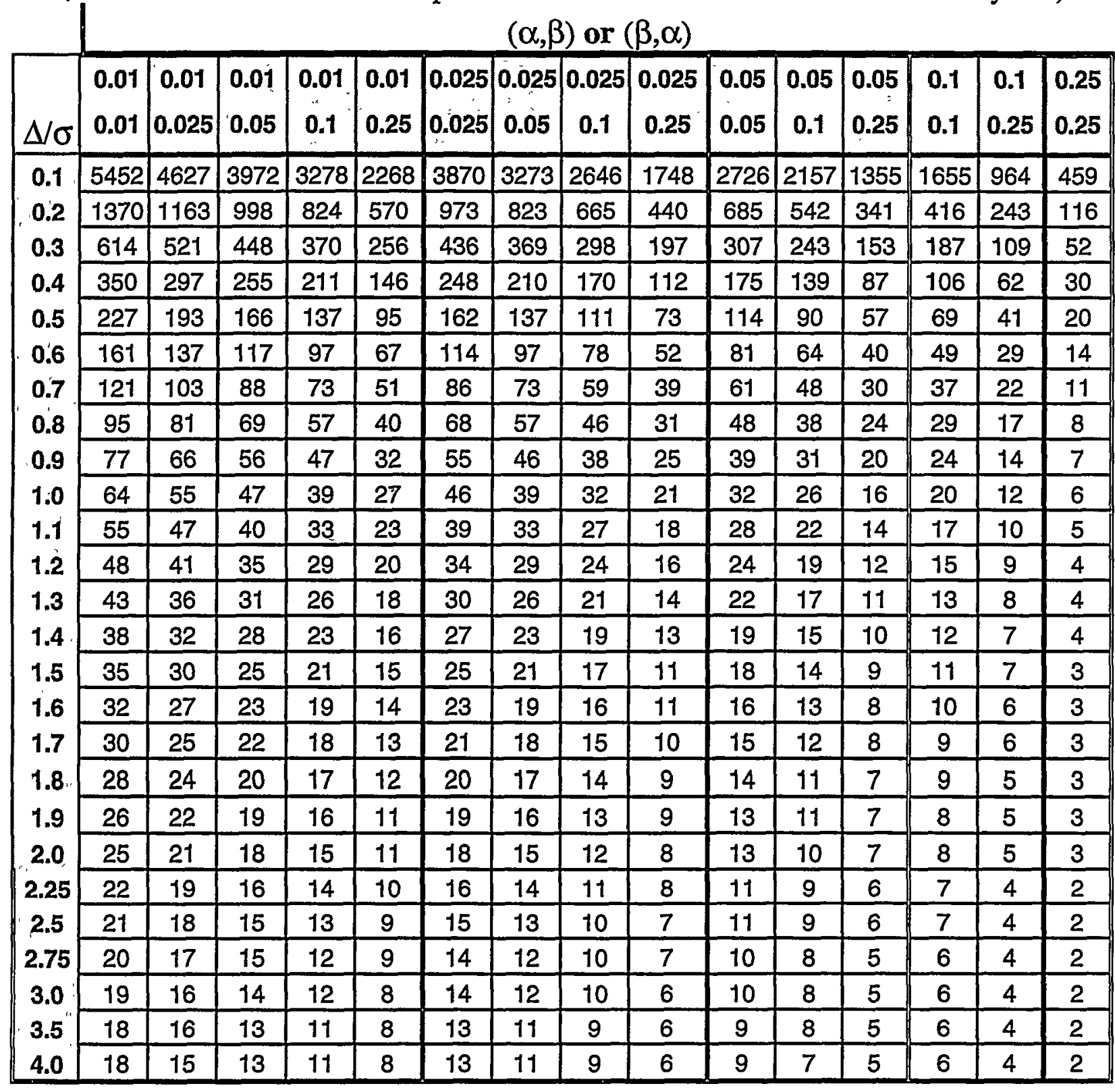


Appendix I

\section{I.3 Critical Values for the SignTest}

Table I.3 Critical Values for the Sign Test Statistic S+

\begin{tabular}{|c|c|c|c|c|c|c|c|c|c|}
\hline \multirow[b]{2}{*}{$N$} & \multicolumn{9}{|c|}{ Alpha } \\
\hline & 0.005 & 0.01 & 0.025 & 0.05 & 0.1 & 0.2 & 0.3 & 0.4 & 0.5 \\
\hline 4 & 4 & 4 & 4 & 4 & 3 & 3 & 3 & 2 & 2 \\
\hline 5 & 5 & 5 & 5 & 4 & 4 & 3 & 3 & 3 & 2 \\
\hline 6 & 6 & 6 & 5 & 5 & 5 & 4 & 4 & 3 & 3 \\
\hline 7 & 7 & 6 & 6 & 6 & 5 & 5 & 4 & 4 & 3 \\
\hline 8 & 7 & 7 & 7 & 6 & 6 & 5 & 5 & 4 & 4 \\
\hline 9 & 8 & 8 & 7 & 7 & 6 & 6 & 5 & 5 & 4 \\
\hline 10 & 9 & 9 & 8 & 8 & 7 & 6 & 6 & 5 & 5 \\
\hline 11 & 10 & 9 & 9 & 8 & 8 & 7 & 6 & 6 & 5 \\
\hline 12 & 10 & 10 & 9 & 9 & 8 & 7 & 7 & 6 & 6 \\
\hline 13 & 11 & 11 & 10 & 9 & 9 & 8 & 7 & 7 & 6 \\
\hline 14 & 12 & 11 & 11 & 10 & 9 & 9 & 8 & 7 & 7 \\
\hline 15 & 12 & 12 & 11 & 11 & 10 & 9 & 9 & 8 & 7 \\
\hline 16 & 13 & 13 & 12 & 11 & 11 & 10 & 9 & 9 & 8 \\
\hline 17 & 14 & 13 & 12 & 12 & 11 & 10 & 10 & 9 & 8 \\
\hline 18 & 14 & 14 & 13 & 12 & 12 & 11 & 10 & 10 & 9 \\
\hline 19 & 15 & 14 & 14 & 13 & 12 & 11 & 11 & 10 & 9 \\
\hline 20 & 16 & 15 & 14 & 14 & 13 & 12 & 11 & 11 & 10 \\
\hline 21 & 16 & 16 & 15 & 14 & 13 & 12 & 12 & 11 & 10 \\
\hline 22 & 17 & 16 & 16 & 15 & 14 & 13 & 12 & 12 & 11 \\
\hline 23 & 18 & 17 & 16 & 15 & 15 & 14 & 13 & 12 & 11 \\
\hline 24 & 18 & 18 & 17 & 16 & 15 & 14 & 13 & 13 & 12 \\
\hline 25 & 19 & 18 & 17 & 17 & 16 & 15 & 14 & 13 & 12 \\
\hline 26 & 19 & 19 & 18 & 17 & 16 & 15 & 14 & 14 & 13 \\
\hline 27 & 20 & 19 & 19 & 18 & 17 & 16 & 15 & 14 & 13 \\
\hline 28 & 21 & 20 & 19 & 18 & 17 & 16 & 15 & 15 & 14 \\
\hline 29 & 21 & 21 & 20 & 19 & 18 & 17 & 16 & 15 & 14 \\
\hline 30 & 22 & 21 & 20 & 19 & 19 & 17 & 16 & 16 & 15 \\
\hline
\end{tabular}


Table I.3 Critical Values for the Sign Test Statistic S+ (continued)

\begin{tabular}{|c|c|c|c|c|c|c|c|c|c|}
\hline \multirow[b]{2}{*}{$N$} & \multicolumn{9}{|c|}{ Alpha } \\
\hline & 0.005 & 0.01 & 0.025 & 0.05 & 0.1 & 0.2 & 0.3 & 0.4 & 0.5 \\
\hline 31 & 23 & 22 & 21 & 20 & 19 & 18 & 17 & 16 & 15 \\
\hline 32 & 23 & 23 & 22 & 21 & 20 & 18 & 17 & 17 & 16 \\
\hline 33 & 24 & 23 & 22 & 21 & 20 & 19 & 18 & 17 & 16 \\
\hline 34 & 24 & 24 & 23 & 22 & 21 & 19 & 19 & 18 & 17 \\
\hline 35 & 25 & 24 & 23 & 22 & 21 & 20 & 19 & 18 & 17 \\
\hline 36 & 26 & 25 & 24 & 23 & 22 & 21 & 20 & 19 & 18 \\
\hline 37 & 26 & 26 & 24 & 23 & 22 & 21 & 20 & 19 & 18 \\
\hline 38 & 27 & 26 & 25 & 24 & 23 & 22 & 21 & 20 & 19 \\
\hline 39 & 27 & 27 & 26 & 25 & 23 & 22 & 21 & 20 & 19 \\
\hline 40 & 28 & 27 & 26 & 25 & 24 & 23 & 22 & 21 & 20 \\
\hline 41 & 29 & 28 & 27 & 26 & 25 & 23 & 22 & 21 & 20 \\
\hline 42 & 29 & 28 & 27 & 26 & 25 & 24 & 23 & 22 & 21 \\
\hline 43 & 30 & 29 & 28 & 27 & 26 & 24 & 23 & 22 & 21 \\
\hline 44 & 30 & 30 & 28 & 27 & 26 & 25 & 24 & 23 & 22 \\
\hline 45 & 31 & 30 & 29 & 28 & 27 & 25 & 24 & 23 & 22 \\
\hline 46 & 32 & 31 & 30 & 29 & 27 & 26 & 25 & 24 & 23 \\
\hline 47 & 32 & 31 & 30 & 29 & 28 & 26 & 25 & 24 & 23 \\
\hline 48 & 33 & 32 & 31 & 30 & 28 & 27 & 26 & 25 & 24 \\
\hline 49 & 33 & 33 & 31 & 30 & 29 & 27 & 26 & 25 & 24 \\
\hline 50 & 34 & 33 & 32 & 31 & 30 & 28 & 27 & 26 & 25 \\
\hline
\end{tabular}


Appendix I

\section{I.4 Critical Values for the WRS Test}

Table I.4 Critical Values for the WRS test

$m$ is the number of reference area samples and $n$ is the number of survey unit samples.

\begin{tabular}{|c|c|c|c|c|c|c|c|c|c|c|c|c|c|c|c|c|c|c|c|c|}
\hline & $\mathrm{n}=$ & 2 & 3 & 4 & 5 & 6 & 7 & 8 & 9 & 10 & 11 & 12 & 13 & 14 & 15 & 16 & 17 & 18 & 19 & 20 \\
\hline \multirow[t]{6}{*}{$m=2$} & $\alpha=0.001$ & 7 & 9 & 11 & 13 & 15 & 17 & 19 & 21 & 23 & 25 & 27 & 29 & 31 & 33 & 35 & 37 & 39 & 41 & 43 \\
\hline & $\alpha=0.005$ & 7 & 9 & 11 & 13 & 15 & 17 & 19 & 21 & 23 & 25 & 27 & 29 & 31 & 33 & 35 & 37 & 39 & 40 & 42 \\
\hline & $\alpha=0.01$ & 7 & 9 & 11 & 13 & 15 & 17 & 19 & 21 & 23 & 25 & 27 & 28 & 30 & 32 & 34 & 36 & 38 & 39 & \\
\hline & $\alpha=0.025$ & 7 & 9 & 11 & 13 & 15 & 17 & 18 & 20 & 22 & 23 & 25 & 27 & 29 & 31 & 33 & 34 & 36 & 38 & \\
\hline & $\alpha=0.05$ & 7 & 9 & 11 & 12 & 14 & 16 & 17 & 19 & 21 & 23 & 24 & 26 & 27 & 29 & 31 & 33 & 34 & 36 & \\
\hline & $\alpha=0.1$ & 7 & 8 & 10 & 11 & 13 & 15 & 16 & 18 & 19 & 21 & 22 & 24 & 26 & 27 & 29 & 30 & 32 & 33 & \\
\hline & $n=$ & 2 & 3 & 4 & 5 & 6 & 7 & 8 & 9 & 10 & 11 & 12 & 13 & 14 & 15 & 16 & 17 & 18 & 19 & \\
\hline \multirow[t]{6}{*}{$m=3$} & $\alpha=0.001$ & 12 & 15 & 18 & 21 & 24 & 27 & 30 & 33 & 36 & 39 & 42 & 45 & 48 & 51 & 54 & 56 & 59 & 62 & \\
\hline & $\alpha=0.005$ & 12 & 15 & 18 & 21 & 24 & 27 & 30 & 32 & 35 & 38 & 40 & 43 & 46 & 48 & 51 & 54 & 57 & 59 & \\
\hline & $\alpha=0.01$ & 12 & 15 & 18 & 21 & 24 & 26 & 29 & 31 & 34 & 37 & 39 & 42 & 45 & 47 & 50 & 52 & 55 & 58 & \\
\hline & $\alpha=0.025$ & 12 & 15 & 18 & 20 & 22 & 25 & 27 & 30 & 32 & 35 & 37 & 40 & 42 & 45 & 47 & 50 & 52 & 55 & \\
\hline & $\alpha=0.05$ & 12 & 14 & 17 & 19 & 21 & 24 & 26 & 28 & 31 & 33 & 36 & 38 & 40 & 43 & 45 & 47 & 50 & 52 & \\
\hline & $\alpha=0.1$ & 11 & 13 & 16 & 18 & 20 & 22 & 24 & 27 & 29 & 31 & 33 & 35 & 37 & 40 & 42 & 44 & 46 & 48 & \\
\hline
\end{tabular}

$\begin{array}{lllllllllllllllllllll} & \mathrm{n}= & 2 & 3 & 4 & 5 & 6 & 7 & 8 & 9 & 10 & 11 & 12 & 13 & 14 & 15 & 16 & 17 & 18 & 19 & 20 \\ \mathrm{~m}=4 & \alpha=0.001 & 18 & 22 & 26 & 30 & 34 & 38 & 42 & 46 & 49 & 53 & 57 & 60 & 64 & 68 & 71 & 75 & 78 & 82 & 86 \\ & \alpha=0.005 & 18 & 22 & 26 & 30 & 33 & 37 & 40 & 44 & 47 & 51 & 54 & 58 & 61 & 64 & 68 & 71 & 75 & 78 & 81 \\ & \alpha=0.01 & 18 & 22 & 26 & 29 & 32 & 36 & 39 & 42 & 46 & 49 & 52 & 56 & 59 & 62 & 66 & 69 & 72 & 76 & 79 \\ & \alpha=0.025 & 18 & 22 & 25 & 28 & 31 & 34 & 37 & 41 & 44 & 47 & 50 & 53 & 56 & 59 & 62 & 66 & 69 & 72 & 75 \\ & \alpha=0.05 & 18 & 21 & 24 & 27 & 30 & 33 & 36 & 39 & 42 & 45 & 48 & 51 & 54 & 57 & 59 & 62 & 65 & 68 & 71 \\ & \alpha=0.1 & 17 & 20 & 22 & 25 & 28 & 31 & 34 & 36 & 39 & 42 & 45 & 48 & 50 & 53 & 56 & 59 & 61 & 64 & 67\end{array}$

$\begin{array}{lllllllllllllllllllll} & \mathrm{m}=5 & 2 & 3 & 4 & 5 & 6 & 7 & 8 & 9 & 10 & 11 & 12 & 13 & 14 & 15 & 16 & 17 & 18 & 19 & 20 \\ & \alpha=0.001 & 25 & 30 & 35 & 40 & 45 & 50 & 54 & 58 & 63 & 67 & 72 & 76 & 81 & 85 & 89 & 94 & 98 & 102 & 107 \\ & \alpha=0.005 & 25 & 30 & 35 & 39 & 43 & 48 & 52 & 56 & 60 & 64 & 68 & 72 & 77 & 81 & 85 & 89 & 93 & 97 & 101 \\ & \alpha=0.01 & 25 & 30 & 34 & 38 & 42 & 46 & 50 & 54 & 58 & 62 & 66 & 70 & 74 & 78 & 82 & 86 & 90 & 94 & 98 \\ & \alpha=0.025 & 25 & 29 & 33 & 37 & 41 & 44 & 48 & 52 & 56 & 60 & 63 & 67 & 71 & 75 & 79 & 82 & 86 & 90 & 94 \\ & \alpha=0.05 & 24 & 28 & 32 & 35 & 39 & 43 & 46 & 50 & 53 & 57 & 61 & 64 & 68 & 71 & 75 & 79 & 82 & 86 & 89 \\ & \alpha=0.1 & 23 & 27 & 30 & 34 & 37 & 41 & 44 & 47 & 51 & 54 & 57 & 61 & 64 & 67 & 71 & 74 & 77 & 81 & 84\end{array}$

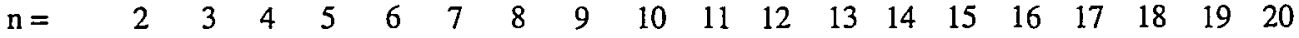

$\begin{array}{lllllllllllllllllllllll} & \mathrm{m}=6 & \mathrm{n}= & \alpha=0.001 & 33 & 39 & 45 & 51 & 57 & 63 & 67 & 72 & 77 & 82 & 88 & 93 & 98 & 103 & 108 & 113 & 118 & 123 & 128\end{array}$

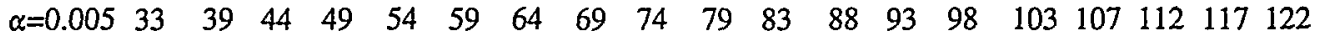
$\begin{array}{llllllllllllllllllll}\alpha=0.01 & 33 & 39 & 43 & 48 & 53 & 58 & 62 & 67 & 72 & 77 & 81 & 86 & 91 & 95 & 100 & 104 & 109 & 114 & 118\end{array}$ $\begin{array}{llllllllllllllllllll}\alpha=0.025 & 33 & 37 & 42 & 47 & 51 & 56 & 60 & 64 & 69 & 73 & 78 & 82 & 87 & 91 & 95 & 100 & 104 & 109 & 113\end{array}$ $\begin{array}{llllllllllllllllllll}\alpha=0.05 & 32 & 36 & 41 & 45 & 49 & 54 & 58 & 62 & 66 & 70 & 75 & 79 & 83 & 87 & 91 & 96 & 100 & 104 & 108\end{array}$ $\begin{array}{llllllllllllllllllll}\alpha=0.1 & 31 & 35 & 39 & 43 & 47 & 51 & 55 & 59 & 63 & 67 & 71 & 75 & 79 & 83 & 87 & 91 & 94 & 98 & 102\end{array}$ 


\section{Table I.4 Critical Values for the WRS Test (continued)}

\begin{tabular}{|c|c|c|c|c|c|c|c|c|c|c|c|c|c|c|c|c|c|c|c|}
\hline \multirow{7}{*}{$m=7$} & $\mathrm{n}=$ & 2 & 3 & 4 & 5 & 6 & 7 & 8 & 9 & 10 & 11 & 12 & 13 & 15 & 16 & 17 & 18 & 19 & 20 \\
\hline & $\alpha=0.001$ & 42 & 49 & 56 & 63 & 69 & 75 & 81 & 87 & 92 & 98 & 104 & 110116 & 122 & 128 & 133 & 139 & 145 & 151 \\
\hline & $\alpha=0.005$ & 42 & 49 & 55 & 61 & 66 & 72 & 77 & 83 & 88 & 94 & 99 & 105110 & 116 & 121 & 127 & 132 & 138 & 143 \\
\hline & $\alpha=0.01$ & 42 & 48 & 54 & 59 & 65 & 70 & 76 & 81 & 86 & 92 & 97 & 102108 & 113 & 118 & 123 & 129 & 134 & 139 \\
\hline & $\alpha=0.025$ & 42 & 47 & 52 & 57 & 63 & 68 & 73 & 78 & 83 & 88 & 93 & $98 \quad 103$ & 108 & 113 & 118 & 123 & 128 & 133 \\
\hline & $\alpha=0.05$ & 41 & 46 & 51 & 56 & 61 & 65 & 70 & 75 & 80 & 85 & 90 & 99 & 104 & 109 & 113 & 118 & 123 & \\
\hline & $\alpha=0.1$ & 40 & 44 & 49 & 54 & 58 & 63 & 67 & 72 & 76 & 81 & 85 & 90 & 99 & 103 & 108 & 112 & 117 & \\
\hline
\end{tabular}

$\begin{array}{llllllllllllllllllll}\mathrm{n}= & 2 & 3 & 4 & 5 & 6 & 7 & 8 & 9 & 10 & 11 & 12 & 13 & 14 & 15 & 16 & 17 & 18 & 19 & 20\end{array}$

$\begin{array}{llllllllllllllllllllllll}\mathrm{m}=8 & \alpha=0.001 & 52 & 60 & 68 & 75 & 82 & 89 & 95 & 102 & 109 & 115 & 122 & 128 & 135 & 141 & 148 & 154 & 161 & 167 & 174\end{array}$

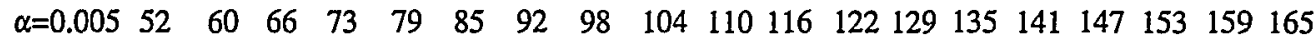

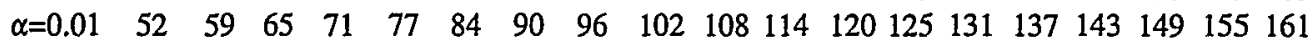

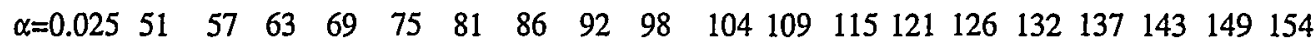
$\begin{array}{llllllllllllllllllll}\alpha=0.05 & 50 & 56 & 62 & 67 & 73 & 78 & 84 & 89 & 95 & 100 & 105 & 111 & 116 & 122 & 127 & 132 & 138 & 143 & 148\end{array}$ $\begin{array}{llllllllllllllllllll}\alpha=0.1 & 49 & 54 & 60 & 65 & 70 & 75 & 80 & 85 & 91 & 96 & 101 & 106 & 111 & 116 & 121 & 126 & 131 & 136 & 141\end{array}$

$\begin{array}{lllllllllllllllllllll} & \mathrm{n}= & 2 & 3 & 4 & 5 & 6 & 7 & 8 & 9 & 10 & 11 & 12 & 13 & 14 & 15 & 16 & 17 & 18 & 19 & 20 \\ \mathrm{~m}=9 & \alpha=0.001 & 63 & 72 & 81 & 88 & 96 & 104 & 111 & 118 & 126 & 133 & 140 & 147 & 155 & 162 & 169 & 176 & 183 & 190 & 198\end{array}$ $\begin{array}{llllllllllllllllllll}\alpha=0.005 & 63 & 71 & 79 & 86 & 93 & 100 & 107 & 114 & 121 & 127 & 134 & 141 & 148 & 155 & 161 & 168 & 175 & 182 & 188\end{array}$ $\begin{array}{llllllllllllllllllll}\alpha=0.01 & 63 & 70 & 77 & 84 & 91 & 98 & 105 & 111 & 118 & 125 & 131 & 138 & 144 & 151 & 157 & 164 & 170 & 177 & 184\end{array}$ $\begin{array}{llllllllllllllllllllll}\alpha=0.025 & 62 & 69 & 76 & 82 & 88 & 95 & 101 & 108 & 114 & 120 & 126 & 133 & 139 & 145 & 151 & 158 & 164 & 170 & 176\end{array}$ $\begin{array}{lllllllllllllllllllll}\alpha=0.05 & 61 & 67 & 74 & 80 & 86 & 92 & 98 & 104 & 110 & 116 & 122 & 128 & 134 & 140 & 146 & 152 & 158 & 164 & 170\end{array}$ $\begin{array}{llllllllllllllllllllll}\alpha=0.1 & 60 & 66 & 71 & 77 & 83 & 89 & 94 & 100 & 106 & 112 & 117 & 123 & 129 & 134 & 140 & 145 & 151 & 157 & 162\end{array}$

$\begin{array}{lllllllllllllllllllll} & \mathrm{n}= & 2 & 3 & 4 & 5 & 6 & 7 & 8 & 9 & 10 & 11 & 12 & 13 & 14 & 15 & 16 & 17 & 18 & 19 & 20 \\ \mathrm{~m}=10 & \alpha=0.001 & 75 & 85 & 94 & 103 & 111 & 119 & 128 & 136 & 144 & 152 & 160 & 167 & 175 & 183 & 191 & 199 & 207 & 215 & 222 \\ & \alpha=0.005 & 75 & 84 & 92 & 100 & 108 & 115 & 123 & 131 & 138 & 146 & 153 & 160 & 168 & 175 & 183 & 190 & 197 & 205 & 212 \\ & \alpha=0.01 & 75 & 83 & 91 & 98 & 106 & 113 & 121 & 128 & 135 & 142 & 150 & 157 & 164 & 171 & 178 & 186 & 193 & 200 & 207 \\ & \alpha=0.025 & 74 & 81 & 89 & 96 & 103 & 110 & 117 & 124 & 131 & 138 & 145 & 151 & 158 & 165 & 172 & 179 & 186 & 192 & 199 \\ & \alpha=0.05 & 73 & 80 & 87 & 93 & 100 & 107 & 114 & 120 & 127 & 133 & 140 & 147 & 153 & 160 & 166 & 173 & 179 & 186 & 192 \\ & \alpha=0.1 & 71 & 78 & 84 & 91 & 97 & 103 & 110 & 116 & 122 & 128 & 135 & 141 & 147 & 153 & 160 & 166 & 172 & 178 & 184\end{array}$

$\begin{array}{lllllllllllllllllllll} & \mathrm{n}= & 2 & 3 & 4 & 5 & 6 & 7 & 8 & 9 & 10 & 11 & 12 & 13 & 14 & 15 & 16 & 17 & 18 & 19 & 20 \\ \mathrm{~m}=11 & \alpha=0.001 & 88 & 99 & 109 & 118 & 127 & 136 & 145 & 154 & 163 & 171 & 180 & 188 & 197 & 206 & 214 & 223 & 231 & 240 & 248\end{array}$

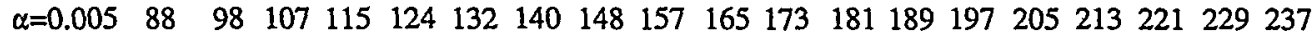

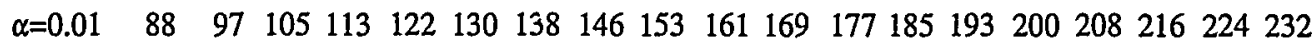

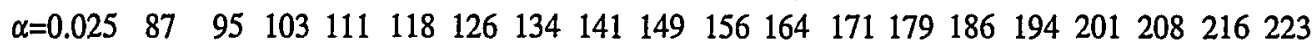

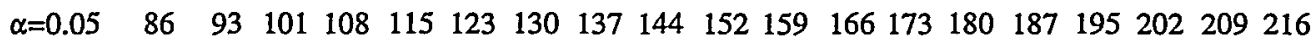

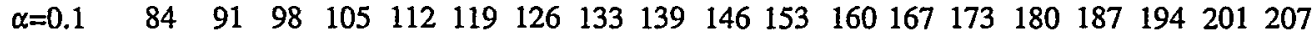


Appendix I

\section{Table I.4 Critical Values for the WRS Test (continued)}

\begin{abstract}
$\mathrm{n}=\begin{array}{llllllllllllllllllll}2 & 3 & 4 & 5 & 6 & 7 & 8 & 9 & 10 & 11 & 12 & 13 & 14 & 15 & 16 & 17 & 18 & 19 & 20\end{array}$

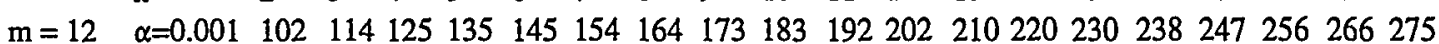

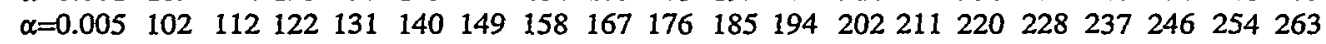
$\begin{array}{llllllllllllllllllll}\alpha=0.01 & 102 & 111 & 120 & 129 & 138 & 147 & 156 & 164 & 173 & 181 & 190 & 198 & 207 & 215 & 223 & 232 & 240 & 249 & 257\end{array}$ $\alpha=0.025100109118126 \quad 135143 \quad 151 \quad 159168 \quad 176 \quad 184 \quad 192200208216 \quad 224232 \quad 240248$ $\alpha=0.05 \quad 99 \quad 108116 \quad 124 \quad 132140 \quad 147 \quad 155165 \quad 171179186194202209217225233240$ $\alpha=0.1 \quad 97 \quad 105113 \quad 120128135143 \quad 150158 \quad 165172 \quad 180187194202209216224231$

$\mathrm{n}=\begin{array}{llllllllllllllllllll}2 & 3 & 4 & 5 & 6 & 7 & 8 & 9 & 10 & 11 & 12 & 13 & 14 & 15 & 16 & 17 & 18 & 19 & 20\end{array}$

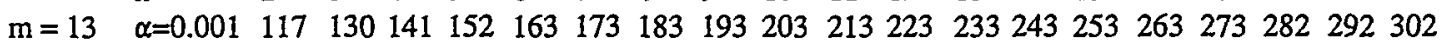

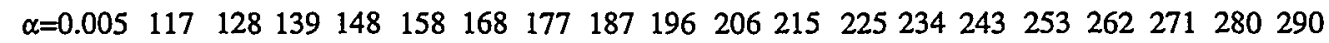
$\alpha=0.01 \quad 116 \quad 127137146 \quad 156165 \quad 174 \quad 184193 \quad 202211 \quad 220229238247256265 \quad 274283$

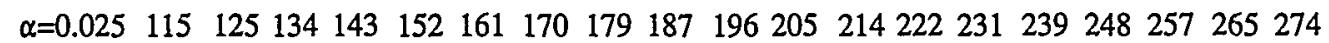

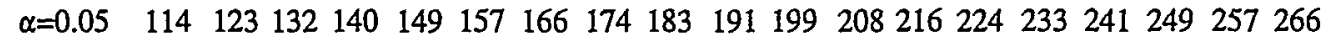
$\alpha=0.1 \quad 112 \quad 120129137 \quad 145153 \quad 161 \quad 169177 \quad 185193201209217224232240248256$ $\mathrm{m}=14 \quad \alpha=0.001 \quad 133 \quad 147 \quad 159171 \quad 182193204215225 \quad 236247 \quad 257268 \quad 278289299310320330$ $\alpha=0.005 \quad 133 \quad 145156 \quad 167 \quad 177 \quad 187 \quad 198 \quad 208218 \quad 228238 \quad 248258268 \quad 278288298 \quad 307 \quad 317$ $\alpha=0.01 \quad 132144154 \quad 164175185194204214224234 \quad 243253263272282291301311$ $\alpha=0.025 \quad 131 \quad 141151 \quad 161 \quad 171 \quad 180190199208218227 \quad 236245255264273282 \quad 292301$ $\alpha=0.05 \quad 129139149158167176 \quad 185194203 \quad 212221230239248257265274283292$ $\alpha=0.1 \quad 128 \quad 136145154163171 \quad 180189197206214223231240248257265273282$
\end{abstract}

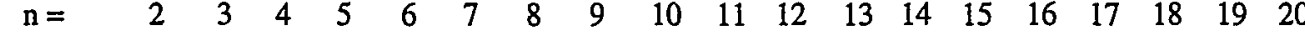

$\mathrm{m}=15 \quad \alpha=0.001 \quad 150 \quad 165178190202212225237248260271282293304316327338349360$ $\alpha=0.005 \quad 150 \quad 162174 \quad 186 \quad 197208 \quad 219230240 \quad 251262 \quad 272283293 \quad 304 \quad 314 \quad 325335346$ $\alpha=0.01 \quad 149 \quad 161 \quad 172183 \quad 194 \quad 205215 \quad 226236 \quad 247257 \quad 267278288298 \quad 308 \quad 319329339$ $\alpha=0.025 \quad 148 \quad 159169180 \quad 190 \quad 200210 \quad 220230 \quad 240250 \quad 260270280289299309319329$ $\alpha=0.05 \quad 146 \quad 157167176 \quad 186196206 \quad 215225 \quad 234244 \quad 253263272 \quad 282291301310319$ $\alpha=0.1 \quad 144 \quad 154163172 \quad 182191200209218 \quad 227236 \quad 246255264273282291300309$

$\mathrm{n}=\quad \begin{array}{llllllllllllllllllll}2 & 3 & 4 & 5 & 6 & 7 & 8 & 9 & 10 & 11 & 12 & 13 & 14 & 15 & 16 & 17 & 18 & 19 & 20\end{array}$

$\mathrm{m}=16 \quad \alpha=0.001 \quad 168 \quad 184197210223236248260272 \quad 284296 \quad 308320332343355367379390$ $\alpha=0.005 \quad 168 \quad 181194206218229241252264275286298309320331342353 \quad 365376$ $\alpha=0.01 \quad 167 \quad 180192203215226237248259270281292303 \quad 314325336347357368$ $\alpha=0.025 \quad 166 \quad 177 \quad 188200 \quad 210 \quad 221 \quad 232 \quad 242 \quad 253 \quad 264274 \quad 284295305 \quad 316 \quad 326337347357$ $\alpha=0.05 \quad 164 \quad 175185196206217227237247257267 \quad 278288298308 \quad 318328 \quad 338348$ $\alpha=0.1 \quad 162 \quad 172182192202211221231241250260269279289298308317327336$ 
Table I.4 Critical Values for the WRS Test (continued)

$\begin{array}{lllllllllllllllllllll}\mathrm{m}=17 & \mathrm{n}= & 2 & 3 & 4 & 5 & 6 & 7 & 8 & 9 & 10 & 11 & 12 & 13 & 14 & 15 & 16 & 17 & 18 & 19 & 20 \\ \alpha=0.001 & 187 & 203 & 218 & 232 & 245 & 258 & 271 & 284 & 297 & 310 & 322 & 335 & 347 & 360 & 372 & 384 & 397 & 409 & 422 \\ \alpha=0.005 & 187 & 201 & 214 & 227 & 239 & 252 & 264 & 276 & 288 & 300 & 312 & 324 & 336 & 347 & 359 & 371 & 383 & 394 & 406 \\ \alpha=0.01 & 186 & 199 & 212 & 224 & 236 & 248 & 260 & 272 & 284 & 295 & 307 & 318 & 330 & 341 & 353 & 364 & 376 & 387 & 399 \\ \alpha=0.025 & 184 & 197 & 209 & 220 & 232 & 243 & 254 & 266 & 277 & 288 & 299 & 310 & 321 & 332 & 343 & 354 & 365 & 376 & 387 \\ \alpha=0.05 & 183 & 194 & 205 & 217 & 228 & 238 & 249 & 260 & 271 & 282 & 292 & 303 & 313 & 324 & 335 & 345 & 356 & 366 & 377 \\ \alpha=0.1 & 180 & 191 & 202 & 212 & 223 & 233 & 243 & 253 & 264 & 274 & 284 & 294 & 305 & 315 & 325 & 335 & 345 & 355 & 365\end{array}$

$\mathrm{n}=\quad \begin{array}{lllllllllllllllllll}2 & 3 & 4 & 5 & 6 & 7 & 8 & 9 & 10 & 11 & 12 & 13 & 14 & 15 & 16 & 17 & 18 & 19 & 20\end{array}$

$m=18 \quad \alpha=0.001 \quad 207 \quad 224239254 \quad 268282296 \quad 309323 \quad 336349 \quad 362376 \quad 389402415428441454$ $\alpha=0.005207222236249262275288301313 \quad 326339351364376388401413425438$ $\alpha=0.01 \quad 206 \quad 220233246259272284296309321333345357370382394406418430$ $\alpha=0.025 \quad 204217230242254266278290302313325337348360372383 \quad 395406418$ $\alpha=0.05 \quad 202 \quad 215226238250261273 \quad 284295307318329340352363 \quad 374385396407$ $\alpha=0.1 \quad 200 \quad 211222233244255266277288299309320331342352363374384395$

$\begin{array}{llllllllllllllllllll}\mathrm{n}= & 2 & 3 & 4 & 5 & 6 & 7 & 8 & 9 & 10 & 11 & 12 & 13 & 14 & 15 & 16 & 17 & 18 & 19 & 20\end{array}$

$\mathrm{m}=19 \quad \alpha=0.001228 \quad 246262277292307321335350364377 \quad 391405419433446460473487$ $\alpha=0.005 \quad 227243258272286300313327340353366379392405419431444457470$ $\alpha=0.01 \quad 226 \quad 242256269283296309322335348361373386399411424437449462$ $\alpha=0.025225239252265278290303315327340352364377389401413425437450$ $\alpha=0.05 \quad 223 \quad 236248261273285297309321333345356368380392403415427439$ $\alpha=0.1 \quad 220232244256267279290302313325336347358370381392403415426$

$\mathrm{n}=\begin{array}{llllllllllllllllllll}2 & 2 & 3 & 4 & 5 & 6 & 7 & 8 & 9 & 10 & 11 & 12 & 13 & 14 & 15 & 16 & 17 & 18 & 19 & 20\end{array}$

$\mathrm{m}=20 \quad \alpha=0.001250 \quad 269286302317333348363377 \quad 392407421435450464479493507521$ $\alpha=0.005249266281296311325339353367381395409422436450463477490504$ $\alpha=0.01 \quad 248264279293307321335349362376389402416429442456469482495$ $\alpha=0.025247261275289302315329341354367380393406419431444457470482$ $\alpha=0.05 \quad 245258271284297310322335347360372385397409422434446459471$ $\alpha=0.1 \quad 242254267279291303315327339351363375387399410422434446458$ 
Appendix I

Reject the null hypothesis if the test statistic $\left(\mathrm{W}_{\mathrm{r}}\right)$ is greater than the table (critical) value.

For $n$ or $m$ greater than 20 , the table (critical) value can be calculated from:

$$
m(n+m+1) / 2+z \sqrt{n m(n+m+1) / 12}
$$

if there are few or no ties, and from

$$
m(n+m+1) / 2+z \sqrt{\frac{n m}{12}\left[(n+m+1)-\sum_{j=1}^{g} \frac{t_{j}\left(t_{j}^{2}-1\right)}{(n+m)(n+m-1)}\right]}
$$

if there are many ties, where $g$ is the number of groups of tied measurements and $t_{j}$ is the number of tied measurements in the jth group. $z$ is the $(1-\alpha)$ percentile of a standard normal distribution, which can be found in the following table:

\begin{tabular}{ll}
\multicolumn{1}{c}{$\boldsymbol{\alpha}$} & $\mathbf{z}$ \\
0.001 & 3.09 \\
0.005 & 2.575 \\
0.01 & 2.326 \\
0.025 & 1.960 \\
0.05 & 1.645 \\
0.1 & 1.282
\end{tabular}

Other values can be found in Table I-1. 
Appendix I

\section{I.5 Probability of Detecting an Elevated Area}

Table I.5 Risk that an Elevated Area with Length $\mathrm{L} / \mathrm{G}$ and Shape $S$ will not be Detected and the Area (\%) of the Elevated Area Relative to a Triangular Sample Grid Area of $0.866 \mathbf{G}^{2}$

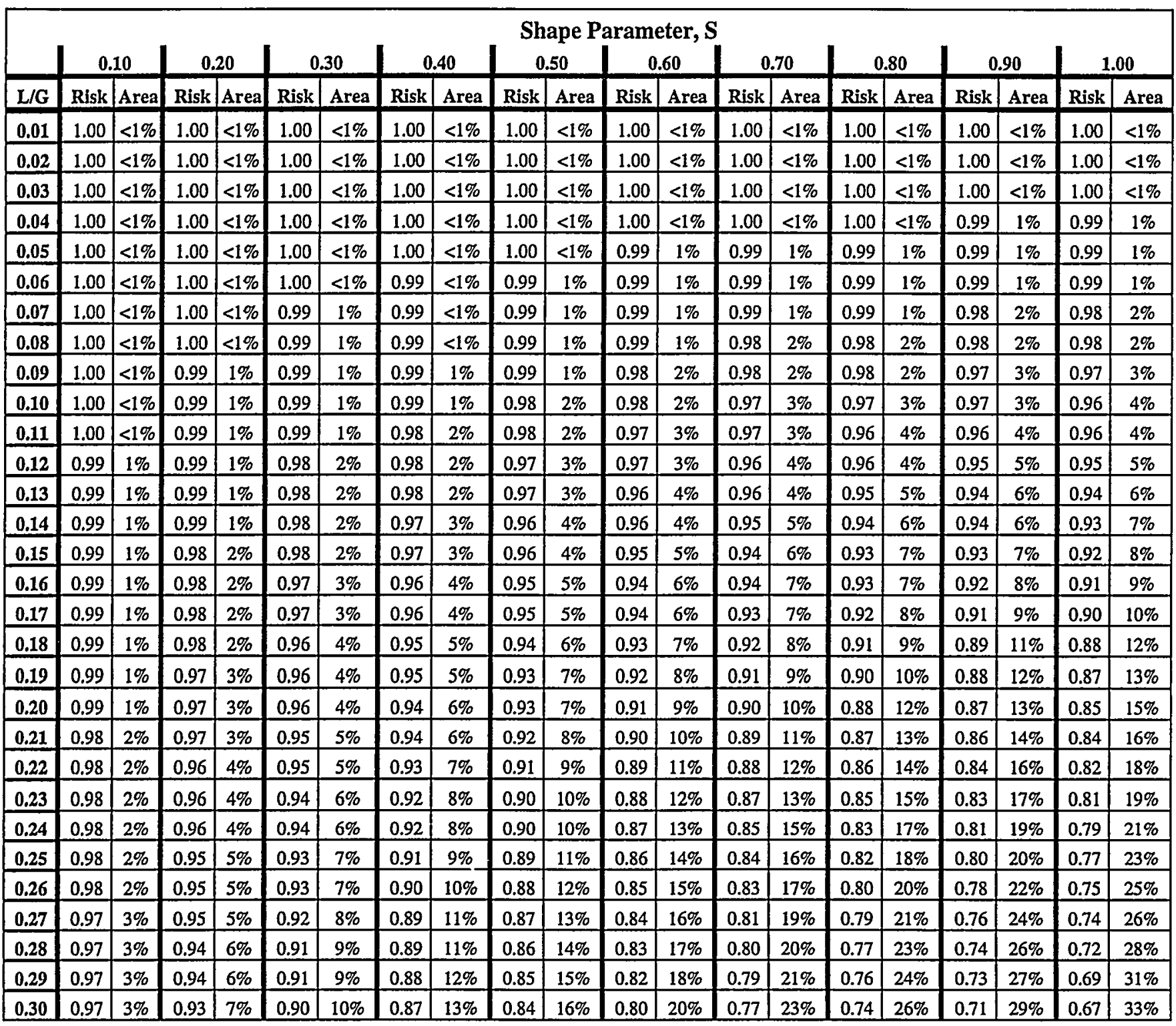

Guidance for using Table I.5 can be found in Gilbert 1987 and EPA 1989a. 
Appendix I

Table I.5 Risk that an Elevated Area with Length L/G and Shape $S$ will not be Detected and the Area (\%) of the Elevated Area Relative to a Triangular Sample Grid Area of $0.866 \mathbf{G}^{2}$ (continued)

\begin{tabular}{|c|c|c|c|c|c|c|c|c|c|c|c|c|c|c|c|c|c|c|c|c|}
\hline & \multicolumn{20}{|c|}{ Shape Parameter, S } \\
\hline$L / G$ & Risk & Area & Risk & Area & Risk & Area & Risk & Area & Risk & Area & Risk & Area & Risk & Area & Risk & Area & Risk & Area & Risk & Area \\
\hline & 0.97 & $3 \%$ & & $7 \%$ & & $10 \%$ & & $14 \%$ & & $7 \%$ & & $1 \%$ & 0.76 & $24 \%$ & .72 & $28 \%$ & 0.69 & $1 \%$ & .65 & $35 \%$ \\
\hline 32 & 0.96 & $4 \%$ & 0.93 & $7 \%$ & 0.89 & $11 \%$ & 0.85 & $15 \%$ & 0.81 & $19 \%$ & 0.78 & $22 \%$ & 0.74 & $26 \%$ & 0.70 & $30 \%$ & .67 & $33 \%$ & .63 & $37 \%$ \\
\hline 33 & 0.96 & $4 \%$ & 0.92 & $8 \%$ & 0.88 & $12 \%$ & 0.84 & $16 \%$ & 0.80 & $20 \%$ & 0.76 & $24 \%$ & 0.72 & $28 \%$ & 0.68 & $32 \%$ & 0.64 & $36 \%$ & .61 & $40 \%$ \\
\hline 0.34 & 0.96 & $4 \%$ & 0.92 & $8 \%$ & 0.87 & $13 \%$ & 0.83 & $17 \%$ & 0.79 & $21 \%$ & 0.75 & $25 \%$ & 0.71 & $29 \%$ & 0.66 & $34 \%$ & 0.62 & $38 \%$ & .58 & $42 \%$ \\
\hline .35 & 096 & $4 \%$ & 0.91 & $9 \%$ & 0.87 & $13 \%$ & 0.82 & $18 \%$ & 0.78 & (2) & 073 & 270 & 060 & $31 \%$ & 0.64 & $36 \%$ & 0.60 & $0 \%$ & & $44 \%$ \\
\hline & 0.95 & $5 \%$ & 0.91 & $9 \%$ & & $14 \%$ & 0.81 & $19 \%$ & 0.76 & 2410 & & 2001 & 0.67 & $33 \%$ & 0.62 & 5010 & & $42 \pi 0$ & & $47 \%$ \\
\hline & & $5 \%$ & 0.90 & $10 \%$ & & $15 \%$ & & $20 \%$ & 0.75 & 2010 & & 300 & 0.65 & $35 \%$ & 0.60 & $70 \pi$ & Nos & $3 \%$ & .50 & $50 \%$ \\
\hline & & $5 \%$ & 0.90 & $10 \%$ & & $16 \%$ & 0.79 & $21 \%$ & 0.74 & $20 \%$ & 0.09 & $31 \%$ & 0.05 & $37 \%$ & 0.58 & 720 & 0.03 & $47 \%$ & .48 & $52 \%$ \\
\hline & 0.94 & $6 \%$ & 0.89 & $11 \%$ & 0.02 & $17 \%$ & 0.78 & $22 \%$ & 0.72 & $28 \%$ & 0.67 & 3570 & 0.01 & $39 \%$ & 0.56 & $44 \%$ & 0.50 & $50 \%$ & 0.45 & $55 \%$ \\
\hline & 0.94 & $6 \%$ & 0.88 & $12 \%$ & 0.83 & $17 \%$ & 0.77 & $23 \%$ & 0.71 & $29 \%$ & 0.65 & $35 \%$ & 0.59 & $41 \%$ & 0.54 & $46 \%$ & 0.48 & $52 \%$ & 0.42 & $58 \%$ \\
\hline & 0.94 & $6 \%$ & 0.88 & $12 \%$ & 0.82 & $18 \%$ & 0.76 & $24 \%$ & 0.70 & $30 \%$ & 0.63 & $37 \%$ & 0.57 & $43 \%$ & 0.51 & $49 \%$ & 0.45 & $55 \%$ & 0.39 & $61 \%$ \\
\hline & 0.94 & $6 \%$ & 0.87 & $13 \%$ & 0.81 & $19 \%$ & 0.74 & $26 \%$ & 0.68 & $32 \%$ & 0.62 & $38 \%$ & 0.55 & $45 \%$ & 0.49 & $51 \%$ & 0.42 & $58 \%$ & .36 & $64 \%$ \\
\hline 0. & 0.93 & $7 \%$ & 0.87 & $13 \%$ & 0.80 & $20 \%$ & 0.73 & $27 \%$ & 0.66 & $34 \%$ & 0.60 & $40 \%$ & 0.53 & $47 \%$ & 0.46 & $54 \%$ & 0.40 & $60 \%$ & 0.33 & $67 \%$ \\
\hline 0.44 & 0.93 & $7 \%$ & 0.86 & $14 \%$ & 0.79 & $21 \%$ & 0.72 & $28 \%$ & 0.65 & $35 \%$ & 0.58 & $42 \%$ & 0.51 & $49 \%$ & 0.44 & $56 \%$ & 0.37 & $63 \%$ & .30 & $70 \%$ \\
\hline & 0.93 & $7 \%$ & 0.85 & $15 \%$ & 0.78 & $22 \%$ & 0.71 & $29 \%$ & 0.63 & $37 \%$ & 0.56 & $44 \%$ & 0.49 & $51 \%$ & 0.41 & $59 \%$ & 0.34 & $66 \%$ & 0.27 & $73 \%$ \\
\hline 46 & 0.92 & $8 \%$ & 0.85 & $15 \%$ & 0.77 & $23 \%$ & 0.69 & $31 \%$ & 0.62 & $38 \%$ & 0.54 & $46 \%$ & 0.46 & $54 \%$ & 0.39 & $61 \%$ & 0.31 & $69 \%$ & 0.23 & $77 \%$ \\
\hline 0.47 & 0.92 & $8 \%$ & 0.84 & $16 \%$ & 0.76 & $24 \%$ & 0.68 & $32 \%$ & 0.60 & $40 \%$ & 0.52 & $48 \%$ & 0.44 & $56 \%$ & 0.36 & $64 \%$ & 0.28 & $72 \%$ & .20 & $80 \%$ \\
\hline 0.48 & 0.92 & $8 \%$ & 0.83 & $17 \%$ & & $25 \%$ & & $33 \%$ & & $42 \%$ & & $50 \%$ & 0.41 & $59 \%$ & 0.33 & & & $75 \%$ & .16 & $84 \%$ \\
\hline & & $9 \%$ & & $17 \%$ & & $26 \%$ & & $35 \%$ & 0.56 & $44 \%$ & 0.48 & $52 \%$ & 0.39 & $61 \%$ & 0.30 & $70 \%$ & 0.22 & $78 \%$ & 0.13 & $87 \%$ \\
\hline & 0.91 & $9 \%$ & 0.82 & $18 \%$ & .73 & $27 \%$ & 0.64 & $36 \%$ & 0.55 & $45 \%$ & 0.46 & $54 \%$ & 0.37 & $63 \%$ & 0.27 & $73 \%$ & 0.18 & $82 \%$ & 0.09 & $91 \%$ \\
\hline 0.51 & 0.91 & $9 \%$ & 0.81 & $19 \%$ & 0.72 & $28 \%$ & 0.62 & $38 \%$ & 0.53 & $47 \%$ & 0.43 & $57 \%$ & 0.34 & $66 \%$ & 0.25 & $75 \%$ & 0.15 & $85 \%$ & .07 & $94 \%$ \\
\hline 0.52 & 0.90 & $10 \%$ & 0.80 & $20 \%$ & 0.71 & $29 \%$ & 0.61 & $39 \%$ & 0.51 & $49 \%$ & 0.41 & $59 \%$ & 0.32 & $69 \%$ & 0.22 & $78 \%$ & 0.13 & $38 \%$ & .05 & $98 \%$ \\
\hline 0.53 & 0.90 & $10 \%$ & 0.80 & $20 \%$ & 0.70 & $31 \%$ & 0.59 & $41 \%$ & 0.49 & $51 \%$ & 0.39 & $61 \%$ & 0.29 & $71 \%$ & 0.19 & $82 \%$ & 0.10 & $92 \%$ & 0.03 & $102 \%$ \\
\hline 0.54 & 0.89 & $11 \%$ & 0.79 & $21 \%$ & 0.68 & $32 \%$ & 0.58 & $42 \%$ & 0.47 & $53 \%$ & 0.37 & $63 \%$ & 0.27 & $74 \%$ & 0.17 & $85 \%$ & 0.08 & $95 \%$ & 0.02 & $106 \%$ \\
\hline 0.55 & 0.89 & $11 \%$ & 0.78 & $22 \%$ & 0.67 & $33 \%$ & 0.56 & $44 \%$ & 0.46 & $55 \%$ & 0.35 & $66 \%$ & 0.24 & $77 \%$ & 0.14 & $88 \%$ & 0.06 & $99 \%$ & 0.01 & $110 \%$ \\
\hline & 0.89 & $11 \%$ & 0.77 & $23 \%$ & 0.66 & $34 \%$ & 0.55 & $46 \%$ & 0.44 & $57 \%$ & & $68 \%$ & 0.22 & $80 \%$ & 0.12 & $91 \%$ & 0.04 & $102 \%$ & 0.00 & $114 \%$ \\
\hline & 0.88 & $12 \%$ & 0.77 & $24 \%$ & 0.65 & $35 \%$ & & $47 \%$ & 0.42 & $59 \%$ & 0.21 & $71 \%$ & 0.20 & $83 \%$ & 0.10 & $94 \%$ & 0.02 & $106 \%$ & 0.00 & $118 \%$ \\
\hline & 0.88 & $12 \%$ & 0.76 & $24 \%$ & 0.64 & $37 \%$ & 0.52 & $49 \%$ & 0.40 & $61 \%$ & 0.29 & $73 \%$ & 0.18 & $85 \%$ & 0.08 & $98 \%$ & 0.01 & $110 \%$ & 0.00 & $122 \%$ \\
\hline & 0.87 & $13 \%$ & 0.75 & $25 \%$ & 0.63 & $38 \%$ & 0.51 & $51 \%$ & 0.39 & $63 \%$ & 0.27 & $76 \%$ & 0.16 & $88 \%$ & 0.06 & $101 \%$ & 0.00 & $114 \%$ & 0.00 & $126 \%$ \\
\hline 0.60 & 0.87 & $13 \%$ & 0.74 & $26 \%$ & 0.62 & $39 \%$ & 0.49 & $52 \%$ & 0.37 & $65 \%$ & 0.25 & $78 \%$ & 0.14 & $91 \%$ & 0.04 & $104 \%$ & 0.00 & $118 \%$ & 0.00 & $131 \%$ \\
\hline 0.61 & 0.87 & $13 \%$ & 0.73 & $27 \%$ & 0.60 & $40 \%$ & 0.48 & $54 \%$ & 0.35 & $67 \%$ & 0.23 & $81 \%$ & 0.12 & $94 \%$ & 0.03 & $108 \%$ & 0.00 & $121 \%$ & 0.00 & $135 \%$ \\
\hline 0.62 & 0.86 & $14 \%$ & 0.73 & $28 \%$ & 0.59 & $42 \%$ & 0.46 & $56 \%$ & 0.34 & $70 \%$ & 0.21 & $84 \%$ & 0.10 & $98 \%$ & 0.02 & $112 \%$ & 0.00 & $126 \%$ & 0.00 & $139 \%$ \\
\hline & 0.86 & $14 \%$ & 0.72 & $29 \%$ & 0.58 & $43 \%$ & 0.45 & $58 \%$ & 0.32 & $72 \%$ & 0.20 & $86 \%$ & 0.09 & $101 \%$ & 0.01 & $115 \%$ & 0.00 & $130 \%$ & 0.00 & $144 \%$ \\
\hline & 0.85 & $15 \%$ & 0.71 & $30 \%$ & 0.57 & $45 \%$ & 0.43 & $59 \%$ & 0.30 & $74 \%$ & 0.18 & $89 \%$ & 0.07 & $104 \%$ & 0.00 & $119 \%$ & 0.00 & $134 \%$ & 0.00 & $149 \%$ \\
\hline 0.65 & 0.85 & $15 \%$ & 0.70 & $31 \%$ & 0.56 & $46 \%$ & 0.42 & $61 \%$ & 0.29 & $77 \%$ & 0.16 & $92 \%$ & 0.06 & $107 \%$ & 0.00 & $123 \%$ & 0.00 & $138 \%$ & 0.00 & $153 \%$ \\
\hline
\end{tabular}


Appendix I

Table I.5 Risk that an Elevated Area with Length $\mathrm{L} / \mathrm{G}$ and Shape $S$ will not be Detected and the Area (\%) of the Elevated Area Relative to a Triangular Sample Grid Area of $0.866 G^{2}$ (continued)

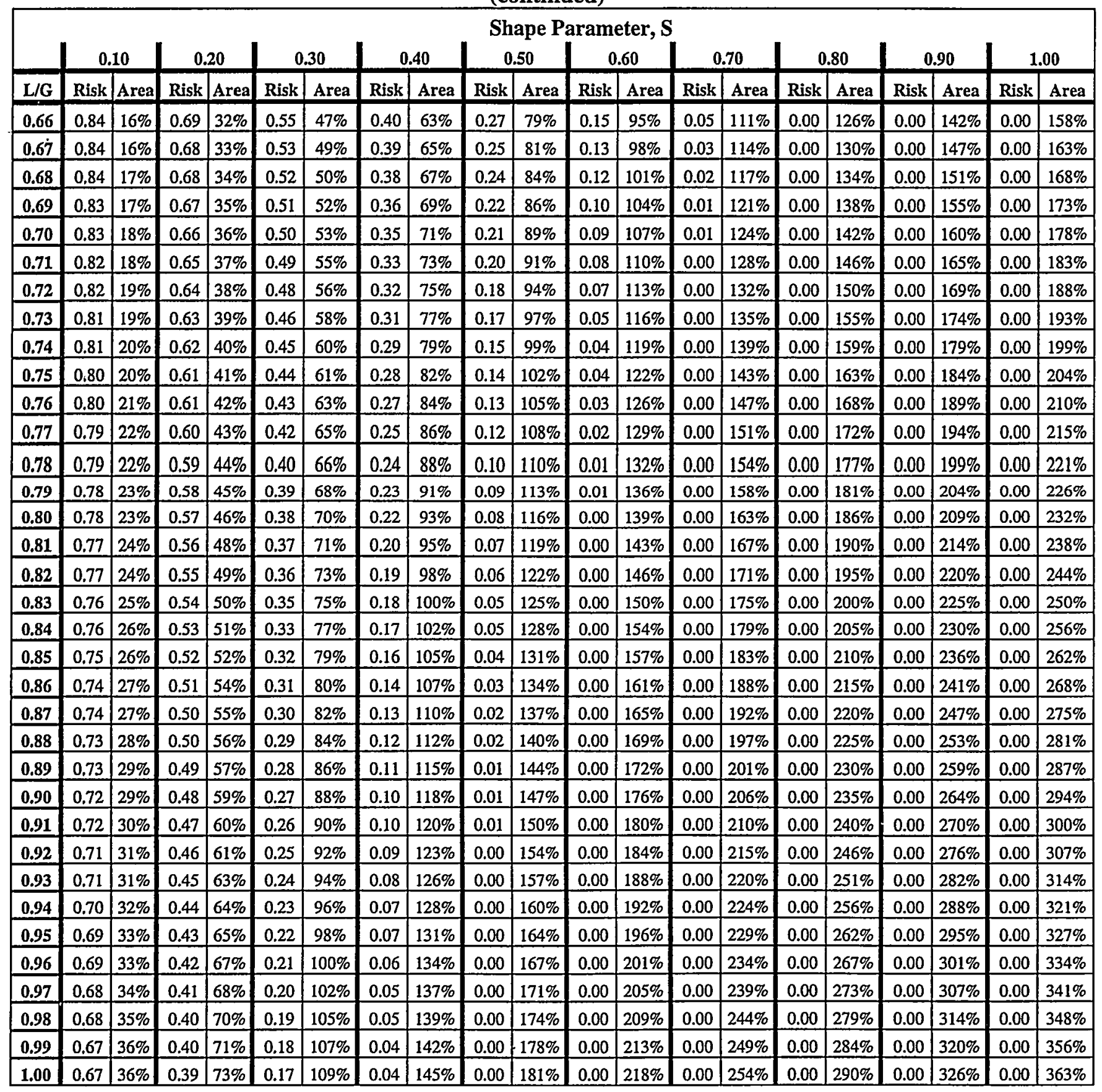


Appendix I

\section{I.6 Random Numbers}

Table I.6 1,000 Random Numbers Uniformly Distributed between Zero and One

\begin{tabular}{|c|c|c|c|c|c|c|c|c|c|}
\hline 0.163601 & 0.647423 & 0.555548 & 0.248859 & 0.259801 & 0.718368 & 0.305020 & 0.812482 & 0.601951 & 0.973160 \\
\hline 0.934196 & 0.951102 & 0.979831 & 0.132364 & 0.157808 & 0.040605 & 0.997626 & 0.896462 & 0.360578 & \\
\hline 0.054552 & 0.965257 & 0.999181 & 0.172627 & 0.583713 & 0.852958 & 0.116336 & 0.748483 & 0.058602 & 0.738495 \\
\hline 0.972409 & 0.241889 & 0.799991 & 0.926726 & 0.585505 & 0.453993 & 0.877990 & 0.947022 & 0.910821 & 0.388081 \\
\hline 0.556401 & 0.621126 & 0.293328 & 0.984335 & 0.366531 & 0.912588 & 0.733824 & 0.092405 & 0.717362 & 0.423421 \\
\hline 0.625153 & 0.838711 & 0.196153 & 0.630553 & 0.867808 & 0.957094 & 0.830218 & 0.783518 & 0.141557 & 0.444997 \\
\hline 0.527330 & 0.124034 & 0.351792 & 0.161947 & 0.688925 & 0.140346 & 0.553577 & 0.890058 & 0.470457 & 0.566196 \\
\hline 0.826643 & 0.673286 & 0.550827 & & 0.690781 & & 0.108632 & 0.090765 & & 0.937184 \\
\hline 0.296068 & 0.891272 & 0.392367 & 0.649633 & 0.261410 & 0.523221 & 0.769081 & 0.358794 & 4341 & 7665 \\
\hline 0.848882 & 0.083603 & 0.274621 & 0.268003 & 0.272254 & 0.017727 & 0.309463 & 5986 & 4653 & 4564 \\
\hline 0.779276 & 0.484461 & 0.101393 & 0.995100 & 0.085164 & 0.611426 & 0.030270 & 4982 & 5236 & 0.270225 \\
\hline 0.095038 & 0.577943 & 0.18 & $0.26^{\prime}$ & 0.786070 & 0.208937 & 0.184565 & 0.826397 & 6825 & 0.489034 \\
\hline 0.011672 & 0.844846 & 0.443407 & 0.91 & 0.275906 & 009 & 7728 & 552 & 6671 & 4429 \\
\hline 0.215993 & 0.476035 & 0.354717 & 0.883172 & 0.840666 & 0.393867 & 0.374810 & 2167 & 4691 & 0.596046 \\
\hline 0.982374 & 0.101973 & 0.68 & 0.730612 & 0.548200 & 0.08 & 0.14 & 680 & & 0.592776 \\
\hline 0.860 & 0.794 & 0.81 & 0.75 & 956 & 0.3 & 0.0 & & & 8967 \\
\hline 0.718917 & 0.696798 & 0.463655 & 0.762408 & 3097 & 0.84 & 0.36 & 266 & 048 & 3842 \\
\hline 0.800735 & 0.225556 & 0.39 & 0.437067 & 2698 & 0.14 & 0.10 & 095 & 3953 & 0.648478 \\
\hline 0.91 & 0.71 & & & & & & & & \\
\hline 0.97 & 0.65 & 0.928348 & 0.513444 & 0.744095 & 0.972031 & 0.527368 & 0.494287 & 0.602829 & 0.592834 \\
\hline 0.435196 & 0.272 & 0.45 & $\overline{0.79}$ & 291 & 0.8 & $\overline{0.4}$ & 518 & 966 & 9741 \\
\hline 0.692512 & 0.368151 & 0.82 & 0.583707 & 354 & 0.13 & 0.5 & 516 & 608 & 1559 \\
\hline 0.678823 & 0.930602 & 0.657348 & 0.025057 & 093 & 0.49 & 0.00 & & 204 & 1439 \\
\hline 0.642075 & 0.02 & 0.289042 & 0.891009 & & 0.97 & 0.95 & & & 5955 \\
\hline 0.174285 & 0.863244 & 0.133649 & & & 0.2 & 0.272407 & 7658 & 2225 & 5514 \\
\hline 0.951401 & 0.921291 & 0.210993 & 0.369411 & 6909 & 0.05 & 0.36 & 718 & 6843 & 8418 \\
\hline 0.186824 & 0.005407 & 0.310843 & 0.998118 & 0.725887 & 0.14 & 721 & 0.8 & 969 & 9622 \\
\hline 0.105673 & 0.026 & 0.878006 & 0.105936 & & 0.124601 & 0.922558 & 8985 & 6805 & 0.737256 \\
\hline 0.801 & 0.61 & 0.933720 & 0.275881 & & 0.64 & 0.713379 & 0.302687 & 4515 & 0.457172 \\
\hline 0.101214 & 0.236405 & 0.945199 & 0.005975 & 0.893786 & 0.082317 & 0.648743 & 871 & 3942 & 1573 \\
\hline 0.177754 & 0.930066 & 0.390527 & 0.575622 & 0.390428 & 0.600575 & 0.460949 & 0.191600 & 0.910079 & 0.099444 \\
\hline 0.846157 & 0.322467 & 0.156607 & 0.253388 & 0.739021 & 0.133498 & 0.293141 & 0.144834 & 0.626600 & 0.045169 \\
\hline 0.812147 & 0.306383 & 0.201517 & 0.306651 & 0.827112 & 0.277716 & 0.660224 & 0.268538 & 0.518416 & 0.579216 \\
\hline 0.691055 & 0.059046 & 0.104390 & 0.427038 & 0.148688 & 0.480788 & 0.026511 & 0.572705 & 0.745522 & 0.986078 \\
\hline 0.483819 & 0.797573 & 0.174899 & 0.892670 & 0.118990 & 0.813221 & 0.857964 & 0.279164 & 0.883509 & 0.154562 \\
\hline 0.165133 & 0.985134 & 0.214681 & 0.595309 & 0.741697 & 0.418602 & 0.301917 & 0.338913 & 0.680062 & 0.097350 \\
\hline 0.281668 & 0.476899 & 0.839512 & 0.057760 & 0.474156 & 0.898409 & 0.482638 & 0.198725 & 0.888281 & 0.018872 \\
\hline 0.554337 & 0.350955 & 0.942401 & 0.526759 & 0.509846 & 0.408165 & 0.800079 & 0.789263 & 0.564192 & 0.140684 \\
\hline
\end{tabular}


Appendix I

\section{Table I.6 1,000 Random Numbers Uniformly Distributed between Zero and One (continued)}

\begin{tabular}{|c|c|c|c|c|c|c|c|c|c|}
\hline 0.873143 & 0.349662 & 0.238282 & 0.383195 & 0.568383 & 0.298471 & 0.490431 & 0.731405 & 0.339906 & 0.431645 \\
\hline 0.401675 & 0.061151 & 0.771468 & 0.795760 & 0.365952 & & & 0.375686 & 0.828215 & \\
\hline 0.574987 & 0.154831 & 0.808117 & 0.723544 & 0.134014 & 0.360957 & 0.166572 & 0.112314 & 0.242857 & 0.309290 \\
\hline 0.745415 & 0.929459 & 0.425406 & 0.118845 & 0.386382 & 0.867386 & 0.808757 & 0.009573 & 0.229879 & 0.849242 \\
\hline 0.613554 & 0.926550 & 0.857632 & 0.014438 & 0.004214 & 0.592513 & 0.280223 & 0.283447 & 0.943793 & 0.205750 \\
\hline 0.880368 & 0.303 & & 0.341580 & 0.867155 & & 0.473418 & 0.650251 & 0.326222 & \\
\hline 0.567556 & 0.183534 & 0.696381 & 0.373333 & 0.716762 & 0.526636 & & 0.904790 & 1931 & \\
\hline 0.280015 & 0.237361 & 0.336240 & 0.424191 & 0.192603 & 0.770194 & 0.284572 & 0.992475 & 3979 & 3329 \\
\hline 0.502862 & 0.818555 & 0.238758 & 0.057148 & 0.461531 & 0.904929 & 0.521982 & 0.599127 & 5509 & \\
\hline & 0.79 & & & 0.021104 & & & & & \\
\hline 0.366209 & 0.749763 & & & 0.869115 & & & & & \\
\hline 0.739267 & 0.554299 & 0.979969 & 0.48 & 0.545130 & 0.931869 & 0.096443 & & 070 & 0563 \\
\hline 0.375690 & 0.86 & 0.256930 & 0.51 & 0.21 & & & & & \\
\hline & 0.17 & & & 0.556232 & & & & & \\
\hline 0.668 & 0.29 & & & 0.799426 & & & & & 722 \\
\hline 0.470107 & 0.13 & 0.2 & 0.4 & 0.485610 & & & & & 8847 \\
\hline 0.047 & 0.69 & 0.3 & 0.2 & 0.008978 & & 858 & & 796 & 072 \\
\hline & 0.07 & & & 0.17 & & & & & \\
\hline 0.83 & 0.33 & & & 0.87 & & & & & \\
\hline 0.488 & 0.26 & & & 0.30 & & & & & 217 \\
\hline 0.488369 & 0.48 & 0.3 & 0.8 & 0.781546 & 0.7 & 400 & & 609 & 580 \\
\hline & & & & 0.17 & & & & & \\
\hline 0.028 & 0.07 & & & 0.77 & & & & & 087 \\
\hline 0.466 & 0.603 & & & 0.487552 & & & & & 620 \\
\hline 0.720 & 0.57 & 0.9 & & 0.767389 & & & & 615 & 732 \\
\hline & $0.77 \varepsilon$ & & & 0.64 & & & & & 273 \\
\hline 0.849 & 0.917789 & 0.8 & 0.57 & 0.753757 & 324 & & & & 1997 \\
\hline 0.989999 & 0.994007 & 0.349735 & 0.9 & 0.74 & 852 & & & & 3725 \\
\hline 0.337214 & 0.987184 & & & 0.549 & & & & & 447 \\
\hline & 0.082 & & & 0.031334 & & & & & \\
\hline 0.417239 & 0.916556 & 0.707773 & & 0.169301 & 0.914420 & 0.732687 & 4912 & 5594 & 0.726957 \\
\hline 0.653 & 0.529996 & 0.305465 & 0.181747 & 0.153359 & 3168 & 377 & 3970 & 347 & 5438 \\
\hline 0.099373 & 0.156385 & 0.067157 & 0.755573 & 0.689979 & 0.494021 & & & & 5525 \\
\hline 0.860299 & 0.210143 & 0.026232 & 0.838499 & 0.108975 & 0.455260 & 0.320633 & 0619 & 0.445073 & 5619 \\
\hline 0.067160 & 0.791992 & 0.36 & 0.825052 & 0.047561 & 194 & 47486 & 659 & 6616 & 5018 \\
\hline 0.944317 & 0.348844 & 0.210015 & 0.769274 & 0.253032 & & & & & \\
\hline 0.917419 & 0.185575 & 0.743859 & 0.655124 & 0.185320 & 0.237660 & 0.271534 & 0.949825 & 0.441666 & 0.811135 \\
\hline 0.365705 & 0.800723 & 0.116707 & 0.386073 & 0.837800 & 0.244896 & 0.337304 & 0.869528 & 0.845737 & 0.194553 \\
\hline 0.911453 & 0.591254 & 0.920222 & 0.707522 & 0.782902 & 0.092884 & 0.426444 & 0.320336 & 0.226369 & 0.377845 \\
\hline
\end{tabular}


Appendix I

Table I.6 1,000 Random Numbers Uniformly Distributed between Zero and One (continued)

\begin{tabular}{|c|c|c|c|c|c|c|c|c|c|}
\hline 0.027171 & 0.058193 & 0.726183 & 0.057705 & 0.935493 & 0.688071 & 0.752543 & 0.932781 & 0.048914 & 0.591035 \\
\hline 0.768066 & 0.387888 & 0.655990 & 0.690208 & 0.746739 & 0.936409 & 0.685458 & 0.090931 & 0.242120 & 0.067899 \\
\hline 0.052305 & 0.899285 & 0.092643 & 0.058916 & 0.826653 & 0.772790 & 0.785028 & 0.967761 & 0.588503 & 0.896590 \\
\hline 0.623285 & 0.492051 & 0.644294 & 0.821341 & 0.600824 & 0.901289 & 0.774379 & 0.391874 & 0.810022 & 0.437879 \\
\hline 0.624284 & 0.308522 & 0.208541 & 0.297156 & 0.576129 & 0.373705 & 0.370345 & 0.372748 & 0.965550 & 0.874416 \\
\hline 0.853117 & 0.671602 & 0.018316 & 0.095780 & 0.871263 & 0.885420 & 0.919787 & 0.439594 & 0.460586 & 0.629443 \\
\hline 0.967796 & 0.933631 & 0.397054 & 0.682343 & 0.505977 & 0.406611 & 0.539543 & 0.066152 & 0.885414 & 0.857606 \\
\hline 0.759450 & 0.768853 & 0.115419 & 0.744466 & 0.607572 & 0.179839 & 0.413809 & 0.228607 & 0.362857 & 0.826932 \\
\hline 0.514703 & 0.108915 & 0.864053 & 0.076280 & 0.352557 & 0.674917 & 0.572689 & 0.588574 & 0.596215 & 0.639101 \\
\hline 0.826 & 0.264540 & 0.255775 & 0.180449 & 0.405715 & 0.740170 & 0.423514 & & 0.877436 & 0.512284 \\
\hline 0.354198 & 0.792775 & 0.051583 & 0.806962 & 0.385851 & 0.655314 & 0.046701 & 0.860466 & 0.848112 & 0.515684 \\
\hline 0.744807 & 0.960789 & 0.123099 & 0.163569 & 0.621969 & 0.571558 & 0.482449 & 0.346358 & 0.795845 & 0.207558 \\
\hline 0.642312 & 0.356643 & 0.797708 & 0.505570 & 0.418534 & 0.634642 & 0.033111 & 0.393330 & 0.105093 & 0.328848 \\
\hline 0.824625 & 0.855876 & 0.770743 & 0.678619 & 0.927298 & 0.204828 & 0.831460 & 0.979875 & 0.566627 & 0.056160 \\
\hline 0.755877 & 0.679791 & 0.442388 & 0.899944 & 0.563383 & 0.197074 & 0.679568 & 0.244433 & 0.786084 & 0.337991 \\
\hline 0.625370 & 0.967123 & 0.321605 & 0.697578 & 0.122418 & 0.475395 & 0.068207 & 0.070374 & 0.353248 & 0.461960 \\
\hline 0.124012 & 0.133851 & 0.761154 & 0.501578 & 0.204221 & 0.866481 & 0.925783 & 0.329001 & 0.327832 & 0.844681 \\
\hline 0.825392 & 0.382001 & 0.847909 & 0.520741 & 0.404959 & 0.308849 & 0.418976 & 0.972838 & 0.452438 & 0.600528 \\
\hline 0.999194 & 0.297058 & 0.617183 & 0.570478 & 0.875712 & 0.581618 & 0.284410 & 0.405575 & 0.362205 & 0.427077 \\
\hline 0.536855 & 0.667083 & 0.636883 & 0.043774 & 0.113509 & 0.980045 & 0.237797 & 0.618925 & 0.670767 & 0.814902 \\
\hline 0.361632 & 0.797162 & 0.136063 & 0.487575 & 0.682796 & 0.952708 & 0.759989 & 0.058556 & 0.292400 & 0.871674 \\
\hline 0.923253 & 0.479871 & 0.022855 & 0.673915 & 0.733795 & 0.811955 & 0.417970 & 0.095675 & 0.831670 & 0.043950 \\
\hline 0.845432 & 0.202336 & 0.348421 & 0.050704 & 0.171916 & 0.600557 & 0.284838 & 0.606715 & 0.758190 & 0.394811 \\
\hline
\end{tabular}


Appendix I

\subsection{Stem and Leaf Display}

The construction of a stem and leaf display is a simple way to generate a crude histogram of the data quickly. The "stems" of such a display are the most significant digits of the data. Consider the sample data of Section 8.2.2.2:

$90.7,83.5,86.4,88.5,84.4,74.2,84.1,87.6,78.2,77.6$, $86.4,76.3,86.5,77.4,90.3,90.1,79.1,92.4,75.5,80.5$.

Here the data span three decades, so one might consider using the stems 70,80 and 90 . However, three is too few stems to be informative, just as three intervals would be too few for constructing a histogram. Therefore, for this example, each decade is divided into two parts. This results in the six stems $70,75,80,85,90,95$. The leaves are the least significant digits, so 90.7 has the stem 90 and the leaf 0.7.77.4 has the stem 75 and the leaf 7.4. Note that even though the stem is 75 , the leaf is not 2.4 . The leaf is kept as 7.4 so that the data can be read directly from the display without any calculations.

As shown in the top part of Figure I.1, simply arrange the leaves of the data into rows, one stem per row. The result is a quick histogram of the data. In order to ensure this, the same number of digits should be used for each leaf, so that each occupies the same amount of horizontal space.

If the stems are arranged in increasing order, as shown in the bottom half of Figure I.1, it is easy to pick out the minimum (74.2), the maximum (92.4), and the median (between 84.1 and 84.4).

A stem and leaf display (or histogram) with two peaks may indicate that residual radioactivity is distributed over only a portion of the survey unit. Further information on the construction and interpretation of data plots is given in EPA QA/G-9 (EPA 1996a). 
Appendix I

\begin{tabular}{|ll|}
\hline \multicolumn{2}{l}{ Stem Leaves } \\
70 & 4.2 \\
75 & $8.2,7.6,6.3,7.4,9.1,5.5$ \\
80 & $3.5,4.4,4.1,0.5$ \\
85 & $6.4,8.5,7.6,6.4,6.5$ \\
90 & $0.7,0.3,0.1,2.4$ \\
95 & \\
& \\
Stem & Sorted Leaves \\
70 & 4.2 \\
75 & $5.5,6.3,7.4,7.6,8.2,9.1$ \\
80 & $0.5,3.5,4.1,4.4$ \\
85 & $6.4,6.4,6.5,7.6,8.5$ \\
90 & $0.1,0.3,0.7,2.4$ \\
95 & \\
\hline
\end{tabular}

\section{Figure I.1 Example of a Stem and Leaf Display}

\section{I.8 Quantile Plots}

A Quantile plot is constructed by first ranking the data from smallest to largest. Sorting the data is easy once the stem and leaf display has been constructed. Then, each data value is simply plotted against the percentage of the samples with that value or less. This percentage is computed from:

$$
\text { Percent }=\frac{100(\text { rank }-0.5)}{(\text { number of data points })}
$$

The results for the example data of Section I.7 are shown in Table I.7. The Quantile plot for this example is shown in Figure I.2.

The slope of the curve in the Quantile plot is an indication of the amount of data in a given range of values. A small amount of data in a range will result in a large slope. A large amount of data in a range of values will result in a more horizonal slope. A sharp rise near the bottom or the top is an indication of asymmetry. Sudden changes in slope, or notably flat or notably steep areas may indicate peculiarities in the survey unit data needing further investigation. 
Table I.7 Data for Quantile Plot

\begin{tabular}{|lcccccccccc|}
\hline Data: & 74.2 & 75.5 & 76.3 & 77.4 & 77.6 & 78.2 & 79.1 & 80.5 & 83.5 & 84.1 \\
Rank: & 1 & 2 & 3 & 4 & 5 & 6 & 7 & 8 & 9 & 10 \\
Percent: & 2.5 & 7.5 & 12.5 & 17.5 & 22.5 & 27.5 & 32.5 & 37.5 & 42.5 & 47.5 \\
& & & & & & & & & & \\
Data: & 84.4 & 86.4 & 86.4 & 86.5 & 87.6 & 88.5 & 90.1 & 90.3 & 90.7 & 92.4 \\
Rank: & 11 & 12.5 & 12.5 & 14 & 15 & 16 & 17 & 18 & 19 & 20 \\
Percent: & 52.5 & 60.0 & 60.0 & 67.5 & 72.5 & 77.5 & 82.5 & 87.5 & 92.5 & 97.5 \\
\hline
\end{tabular}

A useful aid to interpreting the quantile plot is the addition of boxes containing the middle $50 \%$ and middle $75 \%$ of the data. These are shown as the dashed lines in Figure I.2. The 50\% box has its upper right corner at the 75th percentile and its lower left corner at the 25th percentile. These points are also called the Quartiles. These are $\sim 78$ and $\sim 88$, respectively, as indicated by the dashed lines. They bracket the middle half of the data values. The $75 \%$ box has its upper right corner at the 87.5th percentile and its lower left corner at the 12.5th percentile. A sharp increase within the $50 \%$ box can indicate two or more modes in the data. Outside the $75 \%$ box, sharp increases can indicate outliers. The median (50th percentile) is indicated by the heavy solid line at the value $\sim 84$, and can be used as an aid to judging the symmetry of the data distribution. There are no especially unusual features in the example Quantile plot shown in Figure I.2, other than the possibility of slight asymmetry around the median.

Another Quantile plot, for the example data of Section 8.3.3, is shown in Figure I.3. 
Appendix I

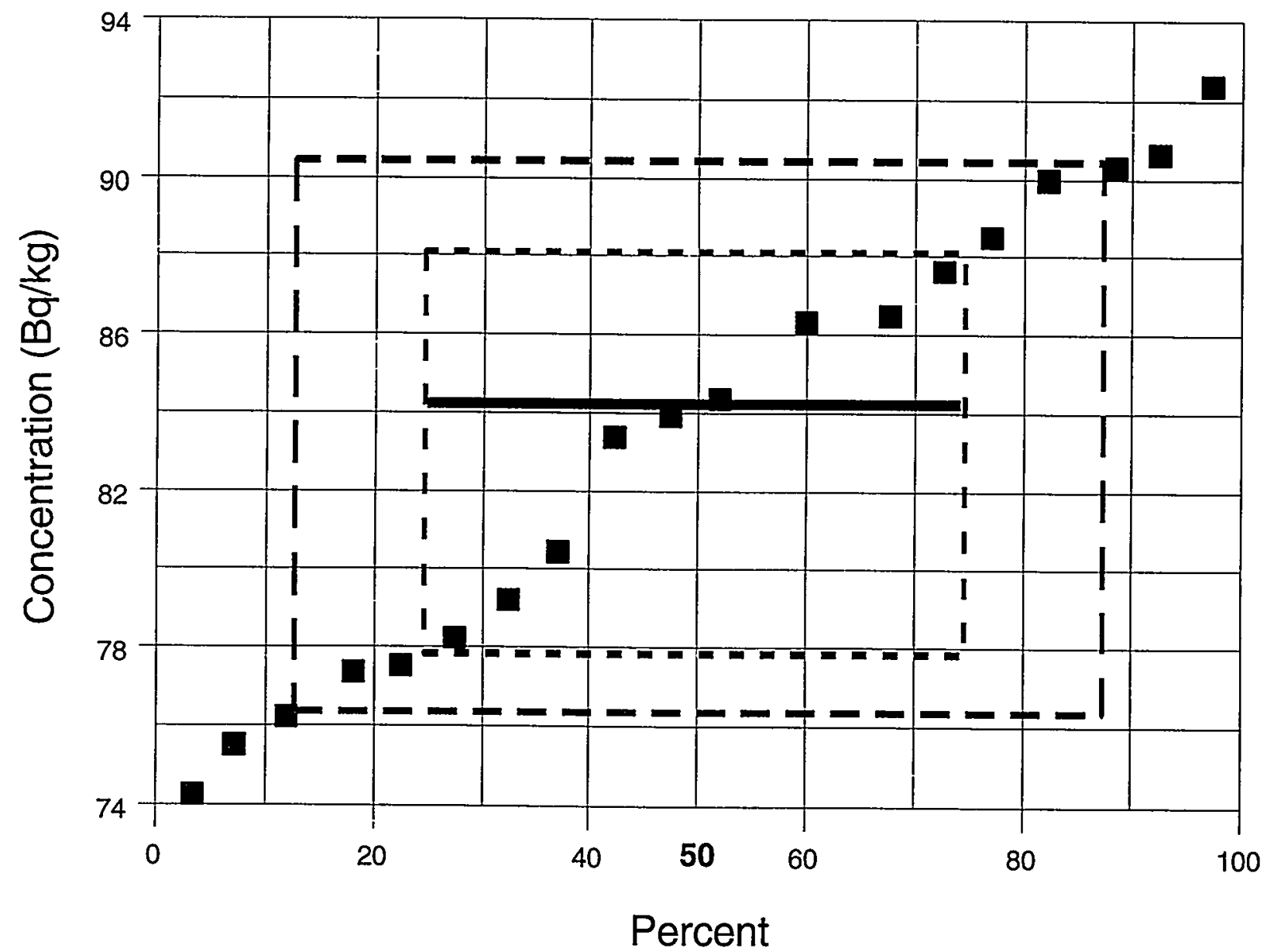

Figure I.2 Example of a Quantile Plot 


\section{Class 2 Exterior Survey Unit}

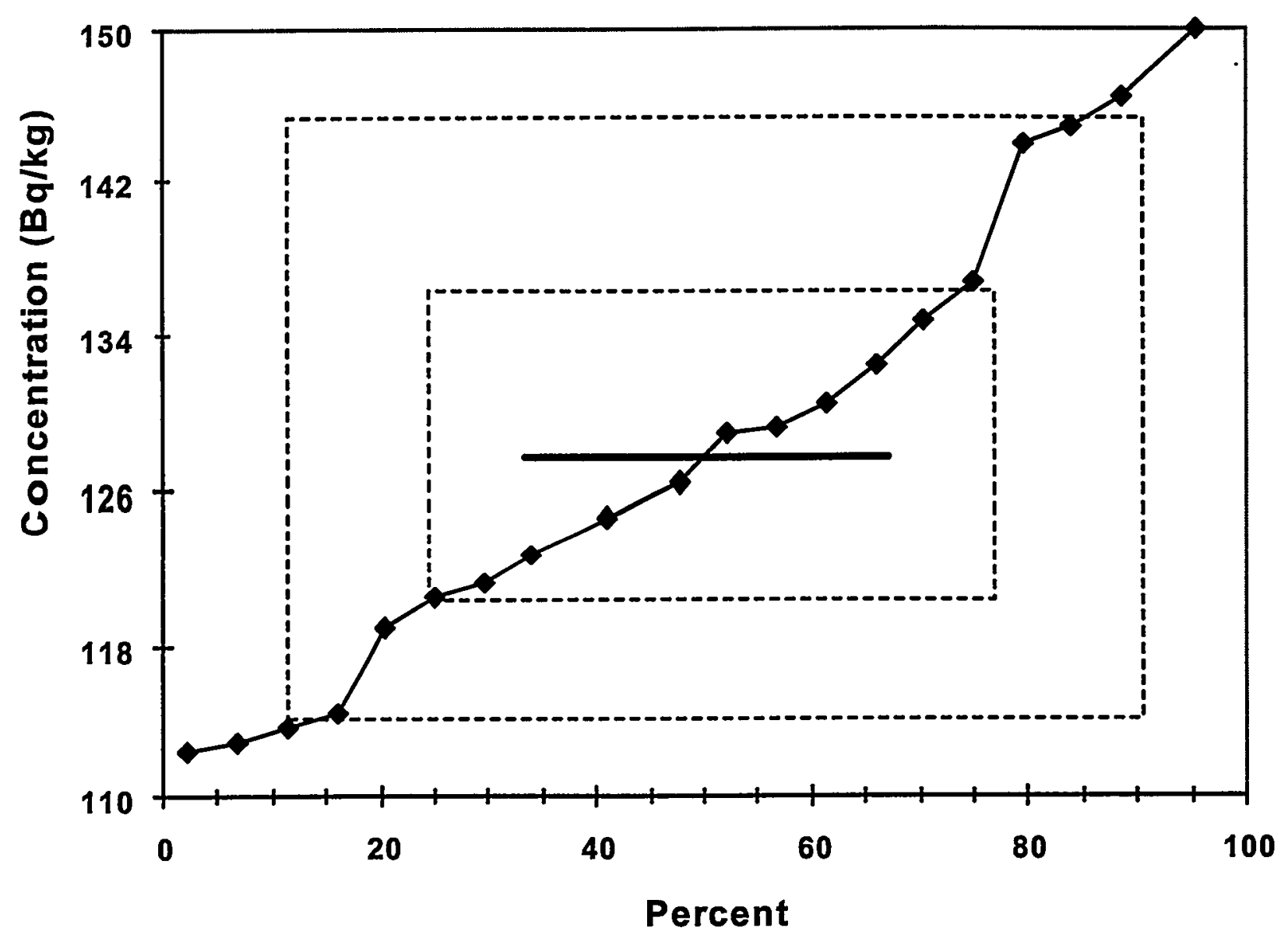

Figure I.3 Quantile Plot for Example Class 2 Exterior Survey Unit of Section 8.3.3. 
A Quantile-Quantile plot is extremely useful for comparing two sets of data. Suppose the following 17 concentration values were obtained in a reference area corresponding to the example survey unit data of Section I.7:

$92.1,83.2,81.7,81.8,88.5,82.4,81.5,69.7,82.4,89.7$, $81.4,79.4,82.0,79.9,81.1,59.4,75.3$.

A Quantile-Quantile plot can be constructed to compare the distribution of the survey unit data, $Y_{j}, j=1, \ldots n$, with the distribution of the reference area data $X_{i}, i=1, \ldots m$. (If the reference area data set were the larger, the roles of $X$ and $Y$ would be reversed.) The data from each set are ranked separately from smallest to largest. This has already been done for the survey unit data in Table I.7. For the reference area data, we obtain the results in Table I.8.

Table I.8 Ranked Reference Area Concentrations

\begin{tabular}{|lrrrrrrrrrr||}
\hline Data: & 59.4 & 69.7 & 75.3 & 79.4 & 79.9 & 81.1 & 81.4 & 81.5 & 81.7 & 81.8 \\
Rank: & 1 & 2 & 3 & 4 & 5 & 6 & 7 & 8 & 9 & 10 \\
Data: & 82.0 & 82.4 & 82.4 & 83.2 & 88.5 & 89.7 & 92.1 & & & \\
Rank: & 11 & 12.5 & 12.5 & 14 & 15 & 16 & 17 & & & \\
\hline
\end{tabular}

The median for the reference area data is 81.7 , the sample mean is 80.7 , and the sample standard deviation is 7.5 .

For the larger data set, the data must be interpolated to match the number of points in the smaller data set. This is done by computing

$$
v_{1}=0.5(n / m)+0.5 \text { and } v_{i+1}=v_{i}+(n / m) \text { for } i=1, \ldots m-1 \text {, }
$$

where $m$ is the number of points in the smaller data set and $n$ is the number of points in the larger data set. For each of the ranks, $i$, in the smaller data set, a corresponding value in the larger data set is found by first decomposing $v_{i}$ into its integer part, $j$, and its fractional part, $g$.

Then the interpolated values are computed from the relationship: 


$$
Z_{i}=(1-g) Y_{j}+g Y_{j+l} .
$$

The results of these calculations are shown in Table I.9.

Table I.9 Interpolated Ranks for Survey Unit Concentrations

\begin{tabular}{|lllllllllll||}
\hline Rank & 1 & 2 & 3 & 4 & 5 & 6 & 7 & 8 & 9 & 10 \\
$v_{\mathrm{i}}$ & 1.09 & 2.26 & 3.44 & 4.62 & 5.79 & 6.97 & 8.15 & 9.33 & 10.50 & 11.68 \\
$\mathrm{Z}_{\mathrm{i}}$ & 74.3 & 75.7 & 76.8 & 77.5 & 78.1 & 79.1 & 80.9 & 83.7 & 84.3 & 85.8 \\
$\mathrm{X}_{\mathrm{i}}$ & 59.4 & 69.7 & 75.3 & 79.4 & 79.7 & 81.1 & 81.4 & 81.5 & 81.7 & 81.8 \\
& & & & & & & & & & \\
Rank & 11 & 12.5 & 12.5 & 14 & 15 & 16 & 17 & & \\
$v_{\mathrm{i}}$ & 12.85 & 14.03 & 15.21 & 16.38 & 17.56 & 18.74 & 19.91 & & \\
$\mathrm{Z}_{\mathrm{i}}$ & 86.4 & 86.5 & 87.8 & 89.1 & 90.2 & 90.6 & 92.3 & & \\
$\mathrm{X}_{\mathrm{i}}$ & 82.0 & 82.4 & 82.4 & 83.2 & 88.5 & 89.7 & 92.1 & & \\
\hline
\end{tabular}

Finally, $Z_{\mathrm{i}}$ is plotted against $X_{i}$ to obtain the Quantile-Quantile plot. This example is shown in Figure I.4.

The Quantile-Quantile Plot is valuable because it provides a direct visual comparison of the two data sets. If the two data distributions differ only in location (e.g. mean) or scale (e.g. standard deviation), the points will lie on a straight line. If the two data distributions being compared are identical, all of the plotted points will lie on the line $Y=X$. Any deviations from this would point to possible differences in these distributions. The middle data point plots the median of $Y$ against the median of $X$. That this point lies above the line $Y=X$, in the example of Figure 8.4, shows that the median of $Y$ is larger than the median of $X$. Indeed, the cluster of points above the line $Y=X$ in the region of the plot where the data points are dense, is an indication that the central portion of the survey unit distribution is shifted toward higher values than the reference area distribution. This could imply that there is residual radioactivity in the survey unit. This should be tested using the nonparametric statistical tests described in Chapter 8.

Another Quantile-Quantile plot, for the Class 1 Interior Survey Unit example data, is shown in Figure A.8.

Further information on the interpretation of Quantile and Quantile-Quantile plots are given in EPA QA/G-9 (EPA 1996a). 


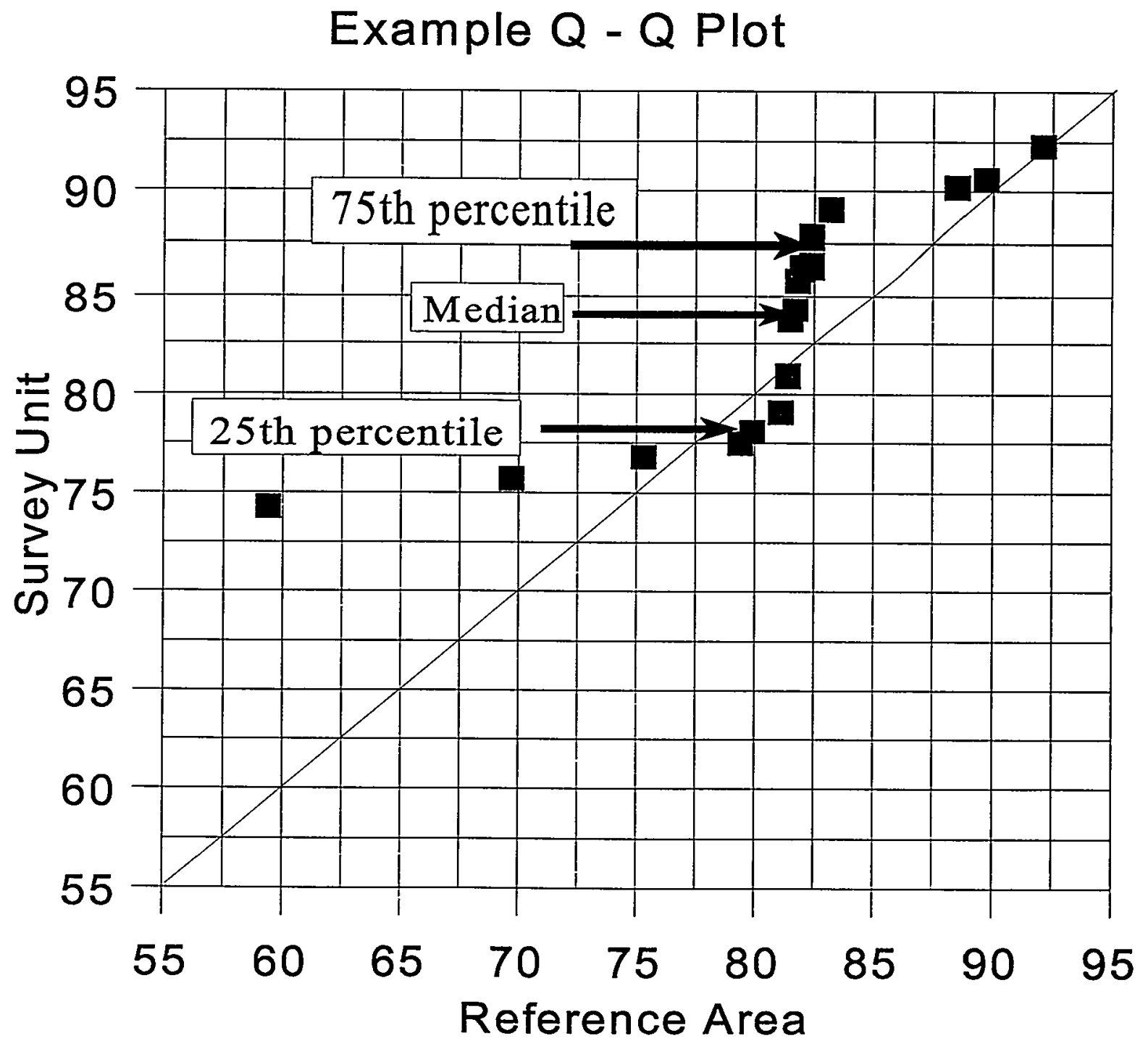

Figure I.4 Example Quantile-Quantile Plot 


\section{I.9 Power Calculations for the Statistical Tests}

\section{I.9.1 Power of the Sign Test}

The power of the Sign test for detecting residual radioactivity at the concentration level LBGR = DGCL - $\Delta$, may be found using equation I-6.

$$
1-\beta=1-\sum_{i=0}^{k}\left(\begin{array}{c}
N \\
i
\end{array}\right)\left[q^{*}\right]^{i} \cdot\left[1-q^{*}\right]^{N-i} \approx 1-\Phi\left(\frac{k-N q^{*}}{\sqrt{N q^{*}\left(1-q^{*}\right)}}\right)
$$

with

$$
q^{*}=\Phi(\Delta / \sigma)
$$

The function $\Phi(z)$ is the standard normal cumulative distribution function tabulated in Table I.1. Note that if $\Delta / \sigma$ is large, $q^{*}$ approaches one, and the power also approaches one. This calculation can be performed for other values, $\Delta^{*}$, in order to construct a power curve for the test. These calculations can also be performed using the standard deviation of the actual measurement data, $s$, in order to construct a retrospective power curve for the test. This is an important step when the null hypothesis is not rejected, since it demonstrates whether the DQOs have been met.

The retrospective power curve for the Sign test can be constructed using Equations I-6 and I-7, together with the actual number of concentration measurements obtained, $N$. The power as a function of $\Delta / \sigma$ is calculated. The values of $\Delta / \sigma$ are converted to concentration using:

$$
\text { Concentration }=\mathrm{DCGL}_{\mathrm{W}}-(\Delta / \sigma) \text { (observed standard deviation). }
$$

The results for the Class 3 Exterior Survey Unit example of Section 8.3.4 are plotted in Figure I.5. This figure shows the probability that the survey unit would have passed the release criterion using the Sign test versus concentration of residual radioactivity. This curve shows that the data quality objectives were met, despite the fact that the actual standard deviation was larger than that used in designing the survey. This is primarily due to the additional $20 \%$ that was added to the sample size, and also that sample sizes were always rounded up. The curve shows that a survey unit with less than $135 \mathrm{~Bq} / \mathrm{kg}$ would almost always pass, and that a survey unit with more than $145 \mathrm{~Bq} / \mathrm{kg}$ would almost always fail. 
Appendix I

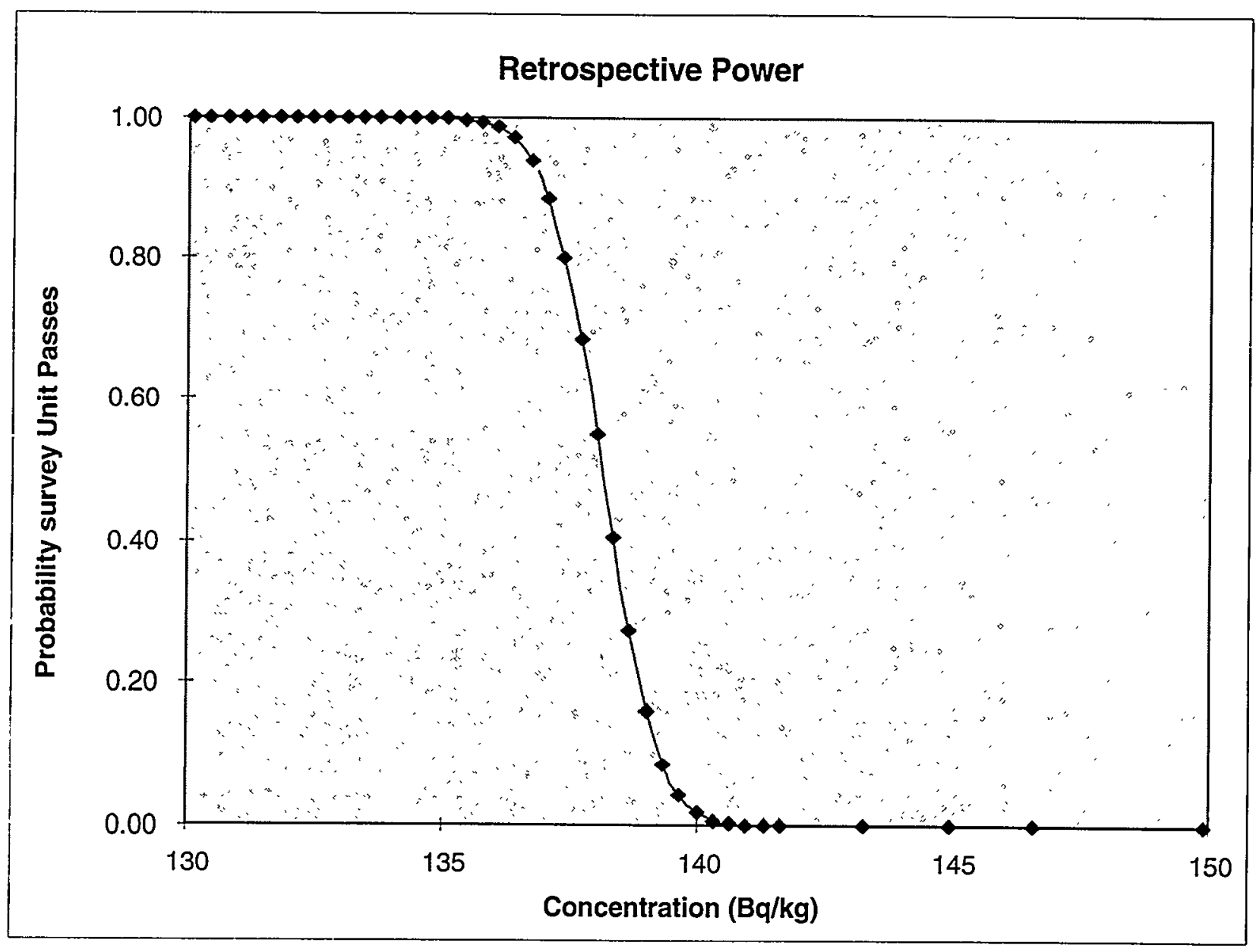

Figure I.5 Retrospective Power Curve for Class 3 Exterior Survey Unit 


\section{I.9.2 Power of the Wilcoxon Rank Sum Test}

The power of the WRS test is computed from

$$
\text { Power }=1-\Phi\left[\frac{W_{c}-0.5-0.5 m(m+1)-E\left(W_{M W}\right)}{\sqrt{\operatorname{Var}\left(W_{M W}\right)}}\right]
$$

where $W_{c}$ is the critical value found in Table I.4 for the appropriate vales of $\alpha, n$ and $m$. Values of $\Phi(z)$, the standard normal cumulative distribution function, are given in Table I.1.

$W_{M W}=W_{r}-0.5 m(m+1)$ is the Mann-Whitney form of the WRS test statistic. Its mean is

$$
E\left(W_{M W}\right)=m n P_{r}
$$

and its variance is

$$
\operatorname{Var}\left(W_{M W}\right)=m n P_{r}\left(1-P_{r}\right)+m n(n+m-2)\left(p_{2}-P_{r}^{2}\right)
$$

Values of $P_{r}$ and $p_{2}$ as a function of $\Delta / \sigma$ are given in Table I.10.

The power calculated in Equation I-8 is an approximation, but the results are generally accurate enough to be used to determine if the sample design achieves the DQOs.

The retrospective power curve for the WRS test can be constructed using Equations I-8, I-9, and I-10, together with the actual number of concentration measurements obtained, $N$. The power as a function of $\Delta / \sigma$ is calculated. The values of $\Delta / \sigma$ are converted to $\mathrm{dpm} / 100 \mathrm{~cm}^{2}$ using:

$$
\mathrm{dpm} / 100 \mathrm{~cm}^{2}=\mathrm{DCGL}-(\Delta / \sigma) \text { (observed standard deviation). }
$$

The results for this example are plotted in Figure I.6, showing the probability that the survey unit would have passed the release criterion using the WRS test versus dpm of residual radioactivity. This curve shows that the data quality objectives were easily achieved. The curve shows that a survey unit with less than $4,500 \mathrm{dpm} / 100 \mathrm{~cm}^{2}$ above background would almost always pass, and that one with more than $5,100 \mathrm{dpm} / 100 \mathrm{~cm}^{2}$ above background would almost always fail. 
Appendix I

Table I.10 Values of $\boldsymbol{P}_{r}$ and $p_{2}$ for Computing the Mean and Variance of $W_{M W}$

\begin{tabular}{|c|c|c||c|c|c||}
\hline$\Delta / \sigma$ & $P_{\mathrm{r}}$ & $p_{2}$ & $\Delta / \sigma$ & $P_{\mathrm{r}}$ & $p_{2}$ \\
\hline-6.0 & $1.11 \mathrm{E}-05$ & $1.16 \mathrm{E}-07$ & 0.7 & 0.689691 & 0.544073 \\
-5.0 & 0.000204 & $6.14 \mathrm{E}-06$ & 0.8 & 0.714196 & 0.574469 \\
-4.0 & 0.002339 & 0.000174 & 0.9 & 0.737741 & 0.604402 \\
-3.5 & 0.006664 & 0.000738 & 1.0 & 0.760250 & 0.633702 \\
-3.0 & 0.016947 & 0.002690 & 1.1 & 0.781662 & 0.662216 \\
-2.5 & 0.038550 & 0.008465 & 1.2 & 0.801928 & 0.689800 \\
-2.0 & 0.078650 & 0.023066 & 1.3 & 0.821015 & 0.716331 \\
-1.9 & 0.089555 & 0.027714 & 1.4 & 0.838901 & 0.741698 \\
-1.8 & 0.101546 & 0.033114 & 1.5 & 0.855578 & 0.765812 \\
-1.7 & 0.114666 & 0.039348 & 1.6 & 0.871050 & 0.788602 \\
-1.6 & 0.128950 & 0.046501 & 1.7 & 0.885334 & 0.810016 \\
-1.5 & 0.144422 & 0.054656 & 1.8 & 0.898454 & 0.830022 \\
-1.4 & 0.161099 & 0.063897 & 1.9 & 0.910445 & 0.848605 \\
-1.3 & 0.178985 & 0.074301 & 2.0 & 0.921350 & 0.865767 \\
-1.2 & 0.198072 & 0.085944 & 2.1 & 0.931218 & 0.881527 \\
-1.1 & 0.218338 & 0.098892 & 2.2 & 0.940103 & 0.895917 \\
-1.0 & 0.239750 & 0.113202 & 2.3 & 0.948062 & 0.908982 \\
-0.9 & 0.262259 & 0.128920 & 2.4 & 0.955157 & 0.920777 \\
-0.8 & 0.285804 & 0.146077 & 2.5 & 0.961450 & 0.931365 \\
-0.7 & 0.310309 & 0.164691 & 2.6 & 0.967004 & 0.940817 \\
-0.6 & 0.335687 & 0.184760 & 2.7 & 0.971881 & 0.949208 \\
-0.5 & 0.361837 & 0.206266 & 2.8 & 0.976143 & 0.956616 \\
-0.4 & 0.388649 & 0.229172 & 2.9 & 0.979848 & 0.963118 \\
-0.3 & 0.416002 & 0.253419 & 3.0 & 0.983053 & 0.968795 \\
-0.2 & 0.443769 & 0.278930 & 3.1 & 0.985811 & 0.973725 \\
-0.1 & 0.471814 & 0.305606 & 3.2 & 0.988174 & 0.977981 \\
0.0 & 0.500000 & 0.333333 & 3.3 & 0.990188 & 0.981636 \\
0.1 & 0.528186 & 0.361978 & 3.4 & 0.991895 & 0.984758 \\
0.2 & 0.556231 & 0.391392 & 3.5 & 0.993336 & 0.987410 \\
0.3 & 0.583998 & 0.421415 & 4.0 & 0.997661 & 0.995497 \\
0.4 & 0.611351 & 0.451875 & 5.0 & 0.999796 & 0.999599 \\
0.5 & 0.638163 & 0.482593 & 6.0 & 0.999989 & 0.999978 \\
0.6 & 0.664313 & 0.513387 & & & \\
\hline & & & & & \\
\hline
\end{tabular}




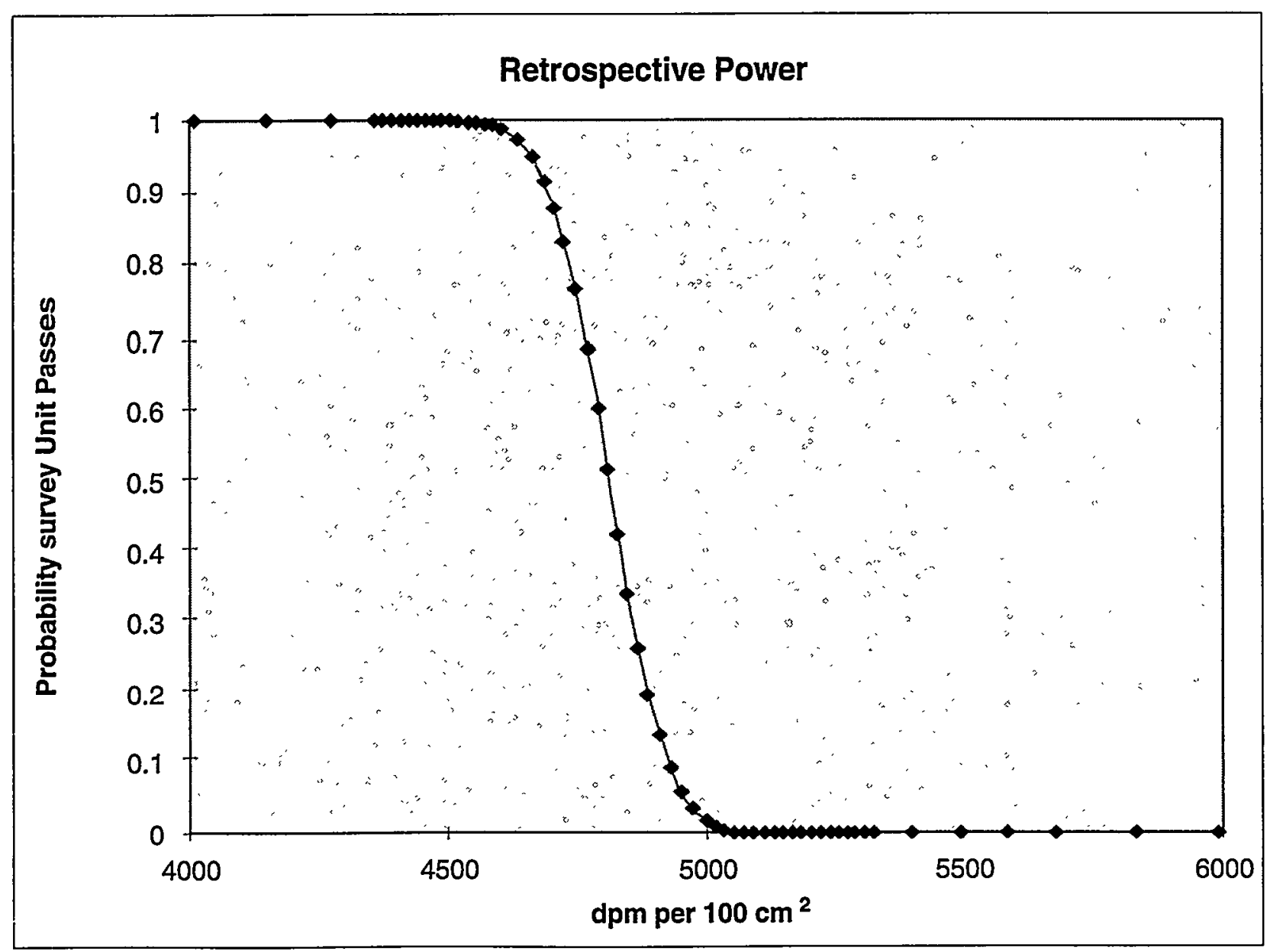

Figure I.6 Retrospective Power Curve for Class 2 Interior Drywall Survey Unit 
Appendix I

\section{I.10 Spreadsheet Formulas for the Wilcoxon Rank Sum Test}

The analysis for the WRS test is very well suited for calculation on a spreadsheet. This is how the analysis discussed above was done. This particular example was constructed using Excel 5.0 $0^{\mathrm{TM}}$. The formula sheet corresponding to Table 8.7 is given in Table I.11. The function in Column D of Table I.11 calculates the ranks of the data. The RANK function in Excel ${ }^{\mathrm{TM}}$ does not return tied ranks in the way needed for the WRS. The COUNTIF function is used to correct for this. Column $\mathrm{E}$ simply picks out the reference area ranks from Column D.

\section{Table I.11 Spreadsheet Formulas Used in Table 8.7}

\begin{tabular}{|c|c|c|c|c|c|}
\hline & $\mathbf{A}$ & B & $\mathrm{C}$ & D & $\mathbf{E}$ \\
\hline 1 & Data & Area & Adjusted Data & Ranks & $\begin{array}{c}\text { Reference Area } \\
\text { Ranks }\end{array}$ \\
\hline 2 & 49 & $\mathrm{R}$ & $=\mathrm{IF}(\mathrm{B} 2=$ & $=\operatorname{RANK}(C 2, \$ C \$ 2: \$ C \$ 23,1)+(\mathrm{COU}$ & $=\mathrm{IF}(\mathrm{B} 2=" \mathrm{R} " \mathrm{E} 2,0)$ \\
\hline 3 & 35 & $\mathrm{R}$ & $=I F(B 3=" R ", A 3+160, A 3)$ & $=\operatorname{RANK}(\mathrm{C} 3, \$ C \$ 2: \$ C \$ 23,1)+(\mathrm{COUNTTF}(\$ \mathrm{C} \$ 2: \$ C \$ 23, \mathrm{C} 3)-1) / 2$ & $=\mathrm{IF}(\mathrm{B} 3=" \mathrm{R} ", \mathrm{E} 3,0)$ \\
\hline 4 & 45 & $\mathrm{R}$ & $=\mathrm{IF}(\mathrm{B} 4=" \mathrm{R} ", \mathrm{~A} 4+160, \mathrm{~A} 4)$ & $=\operatorname{RANK}(\mathrm{C} 4, \$ \mathrm{C} \$ 2: \$ \mathrm{C} \$ 23,1)+(\mathrm{COUNTIF}(\$ \mathrm{C} \$ 2: \$ \mathrm{C} \$ 23, \mathrm{C} 4)-1) / 2$ & $=I F(B 4=" R " . E 4,0)$ \\
\hline 5 & 45 & $\mathrm{R}$ & $=\mathrm{IF}(\mathrm{B} 5=" \mathrm{R} ", \mathrm{~A} 5+160, \mathrm{~A} 5)$ & $=$ RANK $(\mathrm{C} 5, \$ C \$ 2: \$ C \$ 23,1)+(\mathrm{COUNTIF}(\$ C \$ 2: \$ C \$ 23, \mathrm{C} 5)-1) / 2$ & $=\mathrm{IF}(\mathrm{B} 5=" \mathrm{R} ", \mathrm{E} 5,0)$ \\
\hline 6 & 41 & $\underline{R}$ & ",A6+160,A6) & $6, \$ C \$ 2: \$ C \$ 23,1)+($ COUNTIF $(\$ C \$ 2: \$ C \$ 23$ & $=\mathrm{IF}(\mathrm{B} 6=" \mathrm{R} ", \mathrm{E} 6,0)$ \\
\hline 7 & 44 & $\mathrm{R}$ & $=\mathrm{IF}(\mathrm{B} 7=" \mathrm{R} ", \mathrm{~A} 7+160, \mathrm{~A} 7)$ & $=\operatorname{RANK}(C 7, \$ C \$ 2: \$ C \$ 23,1)+(\operatorname{COUNTIF}(\$ C \$ 2: \$ C \$ 23, C 7)-1) / 2$ & $=\mathrm{IF}(\mathrm{B} 7=" \mathrm{R} ", \mathrm{E} 7,0)$ \\
\hline 8 & 48 & $\mathrm{R}$ & $=\mathrm{IF}(\mathrm{B} 8=" \mathrm{R} ", \mathrm{~A} 8+160, \mathrm{~A} 8)$ & $=$ RANK $(\mathrm{C} 8, \$ C \$ 2: \$ C \$ 23,1)+(\mathrm{COUNTTF}(\$ \mathrm{C} \$ 2: \$ C \$ 23, \mathrm{C} 8)-1) / 2$ & $=\mathrm{IF}(\mathrm{B} 8=" \mathrm{R} ", \mathrm{E} 8,0)$ \\
\hline 9 & 37 & $\mathrm{R}$ & $=\mathrm{IF}(\mathrm{B} 9=" \mathrm{R} ", \mathrm{~A} 9+160, \mathrm{~A} 9)$ & $=$ RANK $(C 9, \$ C \$ 2: \$ C \$ 23,1)+(\operatorname{COUNTIF}(\$ C \$ 2: \$ C \$ 23, \mathrm{C} 9)-1) / 2$ & $=\mathrm{IF}(\mathrm{B} 9=" \mathrm{R} ", \mathrm{E} 9,0)$ \\
\hline & 46 & $\mathrm{R}$ & $=\mathrm{IF}(\mathrm{B} 10=" \mathrm{R} ", \mathrm{~A} 10+160, \mathrm{~A} 10)$ & $=\operatorname{RANK}(\mathrm{C} 10, \$ \mathrm{C} \$ 2: \$ C \$ 23,1)+(\mathrm{COUNTIF}(\$ \mathrm{C} \$ 2: \$ \mathrm{C} \$ 23, \mathrm{C} 10)-1) / 2$ & $=I F(B 10=" R ", E 10,0)$ \\
\hline 11 & 42 & $\mathrm{R}$ & $=\mathrm{IF}(\mathrm{B} 11=" \mathrm{R} ", \mathrm{~A} 11+160, \mathrm{~A} 11)$ & $=\operatorname{RANK}(\mathrm{C} 11, \$ \mathrm{C} \$ 2: \$ C \$ 23,1)+(\operatorname{COUNTIF}(\$ C \$ 2: \$ C \$ 23, \mathrm{C} 11)-1) / 2$ & $=\mathrm{IF}(\mathrm{B} 11=" \mathrm{R} ", \mathrm{E} 11,0)$ \\
\hline 12 & 47 & $\mathrm{R}$ & $=\mathrm{IF}(\mathrm{B} 12=" \mathrm{R} ", \mathrm{~A} 12+160, \mathrm{~A} 12)$ & $=\operatorname{RANK}(\mathrm{C} 12, \$ \mathrm{C} \$ 2: \$ \mathrm{C} \$ 23,1)+(\mathrm{COUNTIF}(\$ \mathrm{C} \$ 2: \$ \mathrm{C} \$ 23, \mathrm{Cl} 2)-1) / 2$ & $=\mathrm{IF}(\mathrm{B} 12=" \mathrm{R} ", \mathrm{E} 12,0)$ \\
\hline 13 & 104 & S & $=I F(B 13=" R ", A 13+160, A 13)$ & $=\operatorname{RANK}(\mathrm{C} 13, \$ C \$ 2: \$ C \$ 23,1)+(\operatorname{COUNTIF}(\$ C \$ 2: \$ C \$ 23, \mathrm{Cl} 3)-1) / 2$ & $=\mathrm{IF}(\mathrm{B} 13=" \mathrm{R} ", \mathrm{E} 13,0)$ \\
\hline 14 & 94 & $S$ & $=\mathrm{IF}(\mathrm{B} 14=" \mathrm{R} ", \mathrm{~A} 14+160, \mathrm{~A} 14)$ & $=\operatorname{RANK}(\mathrm{C} 14, \$ C \$ 2: \$ C \$ 23,1)+(\operatorname{COUNTIF}(\$ C \$ 2: \$ C \$ 23, \mathrm{C1} 14)-1) / 2$ & $=\mathrm{IF}(\mathrm{B} 14=" \mathrm{R} ", \mathrm{E} 14,0)$ \\
\hline 15 & 98 & $S$ & $=\mathrm{IF}(\mathrm{B} 15=" \mathrm{R} ", \mathrm{~A} 15+160, \mathrm{~A} 15)$ & $=\operatorname{RANK}(\mathrm{C} 15, \$ C \$ 2: \$ C \$ 23,1)+(\operatorname{COUNTIF}(\$ C \$ 2: \$ C \$ 23, \mathrm{C15})-1) / 2$ & $=\mathrm{IF}(\mathrm{B} 15=" \mathrm{R} ", \mathrm{E} 15,0)$ \\
\hline 16 & 99 & $S$ & $=\mathrm{IF}(\mathrm{B} 16=" \mathrm{R} ", \mathrm{~A} 16+160, \mathrm{~A} 16)$ & $=\operatorname{RANK}(\mathrm{C} 16, \$ \mathrm{C} \$ 2: \$ C \$ 23,1)+(\mathrm{COUNTIF}(\$ C \$ 2: \$ C \$ 23, \mathrm{C} 16)-1) / 2$ & $=\mathrm{IF}(\mathrm{B} 16=" \mathrm{R} ", \mathrm{E} 16,0)$ \\
\hline 17 & 90 & $s$ & $=\mathrm{IF}(\mathrm{B} 17=" \mathrm{R} ", \mathrm{~A} 17+160, \mathrm{~A} 17)$ & $=\operatorname{RANK}(\mathrm{C} 17, \$ C \$ 2: \$ C \$ 23,1)+(\operatorname{COUNTIF}(\$ C \$ 2: \$ C \$ 23, \mathrm{C} 17)-1) / 2$ & $=\mathrm{IF}(\mathrm{B} 17=" \mathrm{R} ", \mathrm{E} 17,0)$ \\
\hline 18 & 104 & $S$ & $=I F(B 18=" R ", A 18+160, A 18)$ & $=\operatorname{RANK}(\mathrm{C} 18, \$ \mathrm{C} \$ 2: \$ C \$ 23,1)+(\mathrm{COUNTIF}(\$ C \$ 2: \$ C \$ 23, \mathrm{C1} 18)-1) / 2$ & $=\mathrm{IF}(\mathrm{B} 18=" \mathrm{R} ", \mathrm{E} 18,0)$ \\
\hline 19 & 95 & $S$ & $=\mathrm{IF}(\mathrm{B} 19=" \mathrm{R} ", \mathrm{~A} 19+160, \mathrm{~A} 19)$ & $=\operatorname{RANK}(\mathrm{C} 19, \$ \mathrm{C} \$ 2: \$ C \$ 23,1)+(\mathrm{COUNTIF}(\$ C \$ 2: \$ C \$ 23, \mathrm{C} 19)-1) / 2$ & $=\mathrm{IF}(\mathrm{B} 19=" \mathrm{R} ", \mathrm{E} 19,0)$ \\
\hline 20 & 105 & $s$ & $=\mathrm{F}(\mathrm{B} 20=" \mathrm{R} ", \mathrm{~A} 20+160, \mathrm{~A} 20)$ & $=\operatorname{RANK}(\mathrm{C} 20, \$ \mathrm{C} \$ 2: \$ C \$ 23,1)+(\mathrm{COUNTIF}(\$ C \$ 2: \$ C \$ 23, \mathrm{C} 20)-1) / 2$ & $=\mathrm{IF}(\mathrm{B} 20=" \mathrm{R} ", \mathrm{E} 20,0)$ \\
\hline 21 & 93 & $S$ & $=\mathrm{IF}(\mathrm{B} 2 \mathrm{l}=\mathrm{R} \mathrm{R} ", \mathrm{~A} 2 \mathrm{I}+160, \mathrm{~A} 21)$ & $=\operatorname{RANK}(\mathrm{C} 21, \$ \mathrm{C} \$ 2: \$ C \$ 23,1)+(\mathrm{COUNTIF}(\$ C \$ 2: \$ C \$ 23, \mathrm{C} 21)-1) / 2$ & $=\mathrm{IF}(\mathrm{B} 21=" \mathrm{R} ", \mathrm{E} 21,0)$ \\
\hline 22 & 101 & $\mathbf{S}$ & $=\mathrm{IF}(\mathrm{B} 22=" \mathrm{R} ", \mathrm{~A} 22+160, \mathrm{~A} 22)$ & $=\operatorname{RANK}(\mathrm{C} 22, \$ \mathrm{C} \$ 2: \$ \mathrm{C} \$ 23,1)+(\mathrm{COUNTIF}(\$ \mathrm{C} \$ 2: \$ \mathrm{C} \$ 23, \mathrm{C} 22)-1) / 2$ & $=\mathrm{IF}(\mathrm{B} 22=" \mathrm{R} ", \mathrm{E} 22,0)$ \\
\hline 23 & 92 & $\mathrm{~s}$ & $=\mathrm{IF}(\mathrm{B} 23=" \mathrm{R} ", \mathrm{~A} 23+160, \mathrm{~A} 23)$ & $=\operatorname{RANK}(\mathrm{C} 23, \$ \mathrm{C} \$ 2: \$ \mathrm{C} \$ 23,1)+(\mathrm{COUNTTF}(\$ \mathrm{C} \$ 2: \$ \mathrm{C} \$ 23, \mathrm{C} 23)-1) / 2$ & $=\operatorname{IF}(B 23=" \mathrm{R} ", \mathrm{E} 23,0)$ \\
\hline & & & Sum $=$ & $=$ SUM(D2:D23) & $=\mathrm{SUM}(\mathrm{E} 2: \mathrm{E} 23)$ \\
\hline
\end{tabular}


Appendix I

\section{I.11 Multiple Radionuclides}

There are two cases to be considered when dealing with multiple radionuclides, namely 1) the radionuclide concentrations have a fairly constant ratio throughout the survey unit, or 2) the concentrations of the different radionuclides appear to be unrelated in the survey unit. In statistical terms, we are concerned about whether the concentrations of the different radionuclides are correlated or not. A simple way to judge this would be to make a scatter plot of the concentrations against each other, and see if the points appear to have an underlying linear pattern. The correlation coefficient can also be computed to see if it lies nearer to zero than to one. One could also perform a curve fit and test the significance of the result. Ultimately, however, sound judgement must be used in interpreting the results of such calculations. If there is no physical reason for the concentrations to be related, they probably are not. Conversely, if there is sound evidence that the radionuclide concentrations should be related because of how they were treated, processed or released, this information should be used.

\section{I.11.1 Using the Unity Rule}

In either of the two above cases, the unity rule described in Section 4.3.3 is applied. The difference is in how it is applied. Suppose there are $n$ radionuclides. If the concentration of radionuclide $i$ is denoted by $C_{i}$, and its $\mathrm{DCGL}_{\mathrm{W}}$ is denoted by $D_{i}$, then the unity rule for the $n$ radionuclides states that:

$$
\mathrm{C}_{1} / D_{1}+C_{2} / D_{2}+C_{3} / D_{3}+\cdots+C_{n} / D_{n} \leq 1
$$

This will ensure that the total dose or risk due to the sum of all the radionuclides does not exceed the release criterion. Note that if $D_{\min }$ is the smallest of the DCGLs, then

$$
\left(C_{1}+C_{2}+C_{3}+\cdots+C_{n}\right) / D_{\min } \leq C_{1} / D_{1}+C_{2} / D_{2}+C_{3} / D_{3}+\cdots+C_{n} / D_{n}
$$

so that the smallest DCGL may be applied to the total activity concentration, rather than using the unity rule. While this option may be considered, in many cases it will be too conservative to be useful.

\section{I.11.2 Radionuclide Concentrations with Fixed Ratios}

If there is an established ratio among the concentrations of the $n$ radionuclides in a survey unit, then the concentration of every radionuclide can be expressed in terms of any one of them, e.g., radionuclide \#1. The measured radionuclide is often called a surrogate radionuclide for the others. 


$$
C_{2}=R_{2} C_{1}, C_{3}=R_{3} C_{1}, \ldots, C_{i}=R_{i} C_{l}, \ldots, C_{n}=R_{n} C_{l}
$$

then

$$
\begin{gathered}
C_{1} / D_{1}+C_{2} / D_{2}+C_{3} / D_{3}+\cdots+C_{n} / D_{n} \\
=C_{1} / D_{1}+R_{2} C_{1} / D_{2}+R_{3} C_{1} / D_{3}+\cdots+R_{n} C_{1} / D_{n} \\
=C_{1}\left[1 / D_{1}+R_{2} / D_{2}+R_{3} / D_{3}+\cdots+R_{n} / D_{n}\right] \\
=C_{1} / D_{\text {total }}
\end{gathered}
$$

where

$$
D_{\text {total }}=1 /\left[1 / D_{1}+R_{2} / D_{2}+R_{3} / D_{3}+\cdots+R_{n} / D_{n}\right]
$$

Thus, $D_{\text {total }}$ is the DCGL for the surrogate radionuclide when the concentration of that radionuclide represents all radionuclides that are present in the survey unit. Clearly, this scheme is applicable only when radionuclide specific measurements of the surrogate radionuclide are made. It is unlikely to apply in situations where the surrogate radionuclide appears in background, since background variations would tend to obscure the relationships between it and the other radionuclides.

Thus, in the case where there are constant ratios among radionuclide concentrations, the statistical tests are applied as if only the surrogate radionuclide were contributing to the residual radioactivity, with the $D C G L_{\mathrm{W}}$ for that radionuclide replaced by $D_{\text {total }}$. For example, in planning the final status survey, only the expected standard deviation of the concentration measurements for the surrogate radionuclide is needed to calculate the sample size.

For the elevated measurement comparison, the $\mathrm{DCGL}_{\mathrm{EMC}}$ for the surrogate radionuclide is replaced by

$$
E_{\text {total }}=1 /\left[1 / E_{1}+R_{2} / E_{2}+R_{3} / E_{3}+\cdots+R_{n} / E_{n}\right]
$$

where $E_{i}$ is the DCGL $L_{\mathrm{EMC}}$ for radionuclide $i$.

\section{I.11.3 Unrelated Radionuclide Concentrations}

If the concentrations of the different radionuclides appear to be unrelated in the survey unit, there is little alternative but to measure the concentration of each radionuclide and use the unity rule. The exception would be in applying the most restrictive $\mathrm{DCGL}_{\mathrm{w}}$ to all of the radionuclides, as mentioned later in this section.

Since the release criterion is

$$
\mathrm{C}_{1} / D_{1}+C_{2} / D_{2}+C_{3} / D_{3}+\cdots+C_{n} / D_{n} \leq 1
$$


Appendix I

the quantity to be measured is the weighted sum, $T=C_{1} / D_{1}+C_{2} / D_{2}+C_{3} / D_{3}+\cdots+C_{n} / D_{n}$. The $D C G L_{w}$ for $T$ is one. In planning the final status survey, the measurement standard deviation of the weighted sum, $T$, is estimated by

$$
\sigma^{2}(T)=\left[\sigma\left(C_{1}\right) / D_{1}\right]^{2}+\left[\sigma\left(C_{2}\right) / D_{2}\right]^{2}+\left[\sigma\left(C_{3}\right) / D_{3}\right]^{2}+\cdots+\left[\sigma\left(C_{n}\right) / D_{n}\right]^{2}
$$

since the measured concentrations of the various radionuclides are assumed to be uncorrelated.

For the elevated measurement comparison, the inequality

$$
C_{1} / E_{1}+C_{2} / E_{2}+C_{3} / E_{3}+\cdots+C_{n} / E_{n} \leq 1
$$

is used, where $E_{i}$ is the $\mathrm{DCGL}_{\mathrm{EMC}}$ for radionuclide $i$. For scanning, the most restrictive $\mathrm{DCGL}_{\mathrm{EMC}}$ should generally be used.

When some of the radionuclides also appear in background, the quantity $T=C_{l} / D_{1}+C_{2} / D_{2}+$ $C_{3} / D_{3}+\cdots+C_{n} / D_{n}$ must also be measured in an appropriate reference area. If radionuclide $i$ does not appear in background, set $C_{i}=0$ in the calculation of $T$ for the reference area.

Note that if there is a fixed ratio between the concentrations of some radionuclides, but not others, a combination of the method of this section with that of the previous section may be used. The appropriate value of $D_{\text {total }}$ with the concentration of the measured surrogate radionuclide should replace the corresponding terms in equation $\mathrm{I}-17$.

\section{I.11.4 Example Application of WRS Test to multiple radionuclides}

This section contains an example application of the nonparametric statistical methods in this report to sites that have residual radioactivity from more than one radionuclide. Consider a site with both ${ }^{60} \mathrm{Co}$ and ${ }^{137} \mathrm{Cs}$ contamination. ${ }^{137} \mathrm{Cs}$ appears in background from global atmospheric weapons tests at a typical concentration of about $1 \mathrm{pCi} / \mathrm{g}$. Assume that the $\mathrm{DCGL}_{\mathrm{W}}$ for ${ }^{60} \mathrm{Co}$ is 2 $\mathrm{pCi} / \mathrm{g}$ and for ${ }^{137} \mathrm{Cs}$ is $1.4 \mathrm{pCi} / \mathrm{g}$. In disturbed areas, the background concentration of ${ }^{137} \mathrm{Cs}$ can vary considerably. An estimated spatial standard deviation of $0.5 \mathrm{pCi} / \mathrm{g}$ for ${ }^{137} \mathrm{Cs}$ will be assumed. During remediation, it was found that the concentrations of the two radionuclides were not well correlated in the survey unit. ${ }^{60} \mathrm{Co}$ concentrations were more variable than the ${ }^{137} \mathrm{Cs}$ concentrations, and $0.7 \mathrm{pCi} / \mathrm{g}$ is estimated for its standard deviation. Measurement errors for both ${ }^{60} \mathrm{Co}$ and ${ }^{137} \mathrm{Cs}$ using gamma spectrometry will be small compared to this. For the comparison to the release criteria, the weighted sum of the concentrations of these radionuclides is computed from:

Weighted sum $=\left({ }^{60} \mathrm{Co}\right.$ concentration $) /\left({ }^{60} \mathrm{Co} \mathrm{DCGL} \mathrm{W}_{\mathrm{W}}\right)+\left({ }^{137} \mathrm{Cs}\right.$ Concentration $) /\left({ }^{137} \mathrm{Cs}^{\mathrm{DCG}} \mathrm{L}_{\mathrm{W}}\right)$ $=\left({ }^{60} \mathrm{Co}\right.$ concentration $) /(2)+\left({ }^{137} \mathrm{Cs}\right.$ Concentration $) /(1.4)$ 
The variance of the weighted sum, assuming that the ${ }^{60} \mathrm{Co}$ and ${ }^{137} \mathrm{Cs}$ concentrations are spatially unrelated is

$$
\begin{aligned}
\sigma^{2} & =\left[\left({ }^{60} \mathrm{Co} \mathrm{Standard} \mathrm{deviation}\right) /\left({ }^{60} \mathrm{Co} \mathrm{DCGL}\right.\right. \\
& =[(0.7) /(2)]^{2}+[(0.5) /(1.4)]^{2}=0.25 .
\end{aligned}
$$

Thus $\sigma=0.5$. The DCGL for the weighted sum is one. The null hypothesis is that the survey unit exceeds the release criterion. During the DQO process, the LBGR was set at 0.5 for the weighted sum, so that $\Delta=\mathrm{DCGL}_{\mathrm{W}}-\mathrm{LBGR}=1.0-0.5=0.5$, and $\Delta / \sigma=0.5 / 0.5=1.0$. The acceptable error rates chosen were $\alpha=\beta=0.05$. To achieve this, 32 samples each are required in the survey unit and the reference area.

The weighted sums are computed for each measurement location in both the reference area and the survey unit. The WRS test is then performed on the weighted sum. The calculations for this example are shown in Table I.12. The DCGL $\mathrm{w}_{\mathrm{w}}$ (i.e., 1.0) is added to the weighted sum for each location in the reference area. The ranks of the combined survey unit and adjusted reference area weighted sums are then computed. The sum of the ranks of the adjusted reference area weighted sums is then compared to the critical value for $n=m=32, \alpha=0.05$, which is 1162 (see formula following Table I.4). In Table I.12, the sum of the ranks of the adjusted reference area weighted sums is 1281 . This exceeds the critical value, so the null hypothesis is rejected. The survey unit meets the release criterion. The difference between the mean of the weighted sums in the survey unit and the reference area is $1.86-1.16=0.7$. Thus, the estimated dose or risk due to residual radioactivity in the survey unit is $70 \%$ of the release criterion. 
Appendix I

Table I.12 Example WRS Test for Two Radionuclides

\begin{tabular}{|c|c|c|c|c|c|c|c|c|c|}
\hline & \multicolumn{2}{|c|}{ Reference Area } & \multicolumn{2}{|c|}{ Survey Unit } & \multicolumn{3}{|c|}{ Weighted Sum } & \multicolumn{2}{|c|}{ Ranks } \\
\hline & ${ }^{137} \mathrm{Cs}$ & ${ }^{60} \mathrm{Co}$ & ${ }^{137} \mathrm{Cs}$ & ${ }^{60} \mathrm{Co}$ & Ref & Survey & Adj Ref & Survey & AdjRef \\
\hline 1 & 2.00 & 0 & 1.12 & 0.06 & 1.43 & 0.83 & 2.43 & 1 & 56 \\
\hline 2 & 1.23 & 0 & 1.66 & 1.99 & 0.88 & 2.18 & 1.88 & 43 & 21 \\
\hline 3 & 0.99 & 0 & 3.02 & 0.56 & 0.71 & 2.44 & 1.71 & 57 & 14 \\
\hline 4 & 1.98 & 0 & 2.47 & 0.26 & 1.41 & 1.89 & 2.41 & 23 & 55 \\
\hline 5 & 1.78 & 0 & 2.08 & 0.21 & 1.27 & 1.59 & 2.27 & 9 & 50 \\
\hline 6 & 1.93 & 0 & 2.96 & 0.00 & 1.38 & 2.11 & 2.38 & 37 & 54 \\
\hline 7 & 1.73 & 0 & 2.05 & 0.20 & 1.23 & 1.56 & 2.23 & 7 & 46 \\
\hline 8 & 1.83 & 0 & 2.41 & 0.00 & 1.30 & 1.72 & 2.30 & 16 & 52 \\
\hline 9 & 1.27 & 0 & 1.74 & 0.00 & 0.91 & 1.24 & 1.91 & 2 & 24 \\
\hline 10 & 0.74 & 0 & 2.65 & 0.16 & 0.53 & 1.97 & 1.53 & 27 & 6 \\
\hline 11 & 1.17 & 0 & 1.92 & 0.63 & 0.83 & 1.68 & 1.83 & 13 & 18 \\
\hline 12 & 1.51 & 0 & 1.91 & 0.69 & 1.08 & 1.71 & 2.08 & 15 & 32 \\
\hline 13 & 2.25 & 0 & 3.06 & 0.13 & 1.61 & 2.25 & 2.61 & 47 & 63 \\
\hline 14 & 1.36 & 0 & 2.18 & 0.98 & 0.97 & 2.05 & 1.97 & 30 & 28 \\
\hline 15 & 2.05 & 0 & 2.08 & 1.26 & 1.46 & 2.12 & 2.46 & 39 & 58 \\
\hline 16 & 1.61 & 0 & 2.30 & 1.16 & 1.15 & 2.22 & 2.15 & 45 & 41 \\
\hline 17 & 1.29 & 0 & 2.20 & 0.00 & 0.92 & 1.57 & 1.92 & 8 & 25 \\
\hline 18 & 1.55 & 0 & 3.11 & 0.50 & 1.11 & 2.47 & 2.11 & 59 & 35 \\
\hline 19 & 1.82 & 0 & 2.31 & 0.00 & 1.30 & 1.65 & 2.30 & 11 & 51 \\
\hline 20 & 1.17 & 0 & 2.82 & 0.41 & 0.84 & 2.22 & 1.84 & 44 & 19 \\
\hline 21 & 1.76 & 0 & 1.81 & 1.18 & 1.26 & 1.88 & 2.26 & 22 & 48 \\
\hline 22 & 2.21 & 0 & 2.71 & 0.17 & 1.58 & 2.02 & 2.58 & 29 & 62 \\
\hline 23 & 2.35 & 0 & 1.89 & 0.00 & 1.68 & 1.35 & 2.68 & 3 & 64 \\
\hline 24 & 1.51 & 0 & 2.12 & 0.34 & 1.08 & 1.68 & 2.08 & 12 & 33 \\
\hline 25 & 0.66 & 0 & 2.59 & 0.14 & 0.47 & 1.92 & 1.47 & 26 & 5 \\
\hline 26 & 1.56 & 0 & 1.75 & 0.71 & 1.12 & 1.60 & 2.12 & 10 & 38 \\
\hline 27 & 1.93 & 0 & 2.35 & 0.85 & 1.38 & 2.10 & 2.38 & 34 & 53 \\
\hline 28 & 2.15 & 0 & 2.28 & 0.87 & 1.54 & 2.06 & 2.54 & 31 & 61 \\
\hline 29 & 2.07 & 0 & 2.56 & 0.56 & 1.48 & 2.11 & 2.48 & 36 & 60 \\
\hline 30 & 1.77 & 0 & 2.50 & 0.00 & 1.27 & 1.78 & 2.27 & 17 & 49 \\
\hline 31 & 1.19 & 0 & 1.79 & 0.30 & 0.85 & 1.43 & 1.85 & 4 & 20 \\
\hline 32 & 1.57 & 0 & 2.55 & 0.70 & 1.12 & 2.17 & 2.12 & 42 & 40 \\
\hline Avg & 1.62 & 0 & 2.28 & 0.47 & 1.16 & 1.86 & 2.16 & sum $=$ & sum $=$ \\
\hline Std Dev & 0.43 & 0 & 0.46 & 0.48 & 0.31 & 0.36 & 0.31 & 799 & 1281 \\
\hline
\end{tabular}




\section{APPENDIX J \\ DERIVATION OF ALPHA SCANNING EQUATIONS PRESENTED IN SECTION 6.7.2.2}

For alpha survey instrumentation with a background around one to three counts per minute, a single count will give a surveyor sufficient cause to stop and investigate further. Assuming this to be true, the probability of detecting given levels of alpha emitting radionuclides can be calculated by use of Poisson summation statistics.

\section{Discussion}

Experiments yielding numerical values for a random variable $\mathrm{X}$, where $\mathrm{X}$ represents the number of events occurring during a given time interval or a specified region in space, are often called Poisson experiments (Walpole and Myers 1985). The probability distribution of the Poisson random variable $\mathrm{X}$, representing the number of events occurring in a given time interval $t$, is given by:

$$
P(x ; \lambda t)=\frac{e^{-\lambda t}(\lambda t)^{x}}{x !}, \quad x=0,1,2, \ldots
$$

where:

$\mathrm{P}(\mathrm{x} ; \lambda \mathrm{t})=\quad$ probability of $\mathrm{x}$ events in time interval $\mathrm{t}$

$\lambda=$ Average number of events per unit time

$\lambda \mathrm{t}=$ Average value expected

To define this distribution for an alpha scanning system, substitutions may be made giving:

$$
P(n ; m)=\frac{e^{-m} m^{n}}{n !}
$$

where:

$$
\begin{aligned}
& P(n ; m)=\quad \text { probability of getting } n \text { counts when the average number expected is } m \\
& \mathrm{~m} \quad=\quad \lambda \mathrm{t} \text {, average number of counts expected } \\
& \mathrm{n}=\mathrm{x} \text {, number of counts actually detected }
\end{aligned}
$$

For a given detector size, source activity, and scanning rate, the probability of getting $n$ counts while passing over the source activity with the detector can be written as: 
Appendix J

$$
P(n ; m)=\frac{e^{\frac{-G E d}{60 v}}\left[\frac{G E d}{60 v}\right]^{n}}{n !}=\frac{e^{\frac{-G E t}{60}\left[\frac{G E t}{60}\right]^{n}}}{n !}
$$

where:

$$
\begin{array}{lll}
\mathrm{G} & = & \text { source activity }(\mathrm{dpm}) \\
\mathrm{E} & = & \text { detector efficiency }(4 \pi) \\
\mathrm{d} & = & \text { width of the detector in the direction of } \mathrm{scan}(\mathrm{cm}) \\
\mathrm{v} & = & \text { scan speed }(\mathrm{cm} / \mathrm{s}) \\
\mathrm{t} & =\mathrm{d} / \mathrm{v}, \text { dwell time over source }(\mathrm{s})
\end{array}
$$

If it is assumed that the detector background is equal to zero, then the probability of observing greater than or equal to 1 count, $P(n \geq 1)$, within a time interval $t$ is:

$$
P(n \geq 1)=1-P(n=0)
$$

If it is also assumed that a single count is sufficient to cause a surveyor to stop and investigate further, then:

$$
P(n \geq 1)=1-P(n=0)=1-e^{-\frac{G E d}{60 v}}
$$

Figures J.1 through J.3 show this function plotted for three different detector sizes and four different source activity levels. Note that the source activity levels are given in terms of areal activity values $\left(\mathrm{dpm}\right.$ per $\left.100 \mathrm{~cm}^{2}\right)$, the probe sizes are the dimensions of the probes in line with the direction of scanning, and the detection efficiency has been assumed to be $15 \%$. The assumption is made that the areal activity is contained within a $100 \mathrm{~cm}^{2}$ area and that the detector completely passes over the area either in one or multiple passes.

Once a count has been recorded and the surveyor stops, the surveyor should wait a sufficient period of time such that if the guideline level of contamination is present, the probability of getting another count is at least $90 \%$. This minimum time interval can be calculated for given contamination guideline values by substituting the following parameters into Equation $\mathrm{J}-5$ and solving: 


$$
\begin{aligned}
& \mathrm{P}(\geq 1)=0.9 \\
& \mathrm{~d} / \mathrm{v}=\mathrm{t} \\
& \mathrm{G}=\frac{C A}{100}
\end{aligned}
$$

where:

$$
\begin{array}{lll}
\mathrm{C} & =\text { contamination guideline }\left(\mathrm{dpm} / 100 \mathrm{~cm}^{2}\right) \\
\mathrm{A} & =\text { Detector area }\left(\mathrm{cm}^{2}\right)
\end{array}
$$

Giving:

$$
t=\frac{13800}{C A E}
$$

Equation J-3 can be solved to give the probability of getting any number of counts while passing over the source area, although the solutions can become long and complex. Many portable proportional counters have background count rates on the order of 5 to 10 counts per minute and a single count will not give a surveyor cause to stop and investigate further. If a surveyor did stop for every count, and subsequently waited a sufficiently long period to make sure that the previous count either was or wasn't caused by an elevated contamination level, little or no progress would be made. For these types of instruments, the surveyor usually will need to get at least 2 counts while passing over the source area before stopping for further investigation. Assuming this to be a valid assumption, Equation $J-3$ can be solved for $\mathrm{n} \geq 2$ as follows:

$$
\begin{aligned}
P(n \geq 2) & =1-P(n=0)-P(n=1) \\
& =1-e^{-\frac{(G E+B) t}{60}}-\frac{(G E+B) t}{60} e^{-\frac{(G E+B) t}{60}} \\
& =1-e^{-\frac{(G E+B) t}{60}}\left(1+\frac{(G E+B) t}{60}\right)
\end{aligned}
$$

Where:

$$
\begin{aligned}
& \mathrm{P}(\mathrm{n} \geq 2)=\text { probability of getting } 2 \text { or more counts during the time interval } \mathrm{t} \\
& \mathrm{P}(\mathrm{n}=0)=\text { probability of not getting any counts during the time interval } \mathrm{t} \\
& \mathrm{P}(\mathrm{n}=1)=\text { probability of getting } 1 \text { count during the time interval } \mathrm{t} \\
& \mathrm{B}
\end{aligned}
$$

All other variables are the same as in Equation J-3. 
Appendix J

Figures J-4 through J-7 show this function plotted for three different probe sizes and three different source activity levels. The same assumptions were made when calculating these curves as were made for Figures J-1 through J-3 except that the background was assumed to be 7 counts per minute. 


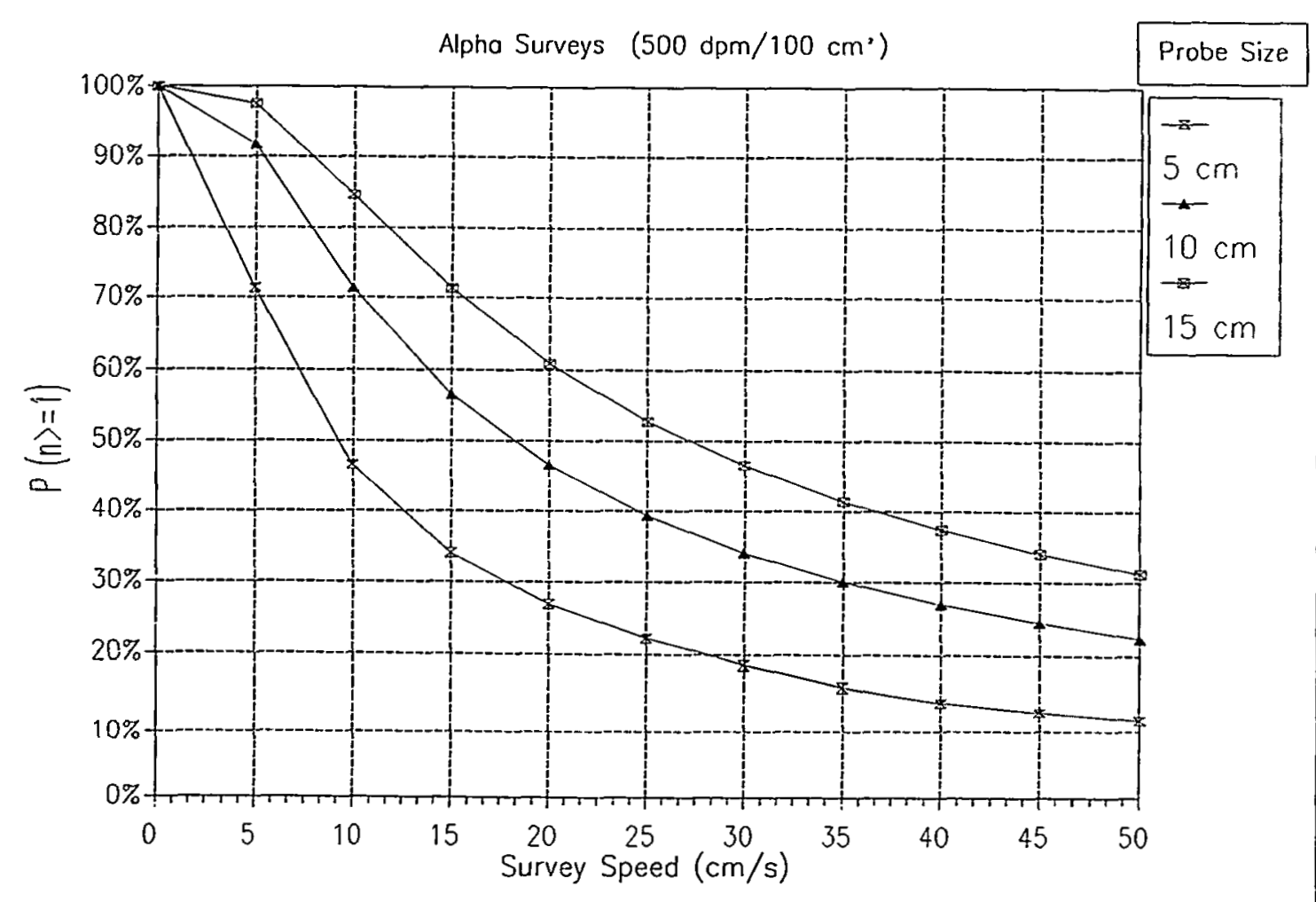

Figure J.1 Probability (P) of getting one or more counts when passing over a $100 \mathrm{~cm}^{2}$ area contaminated at $500 \mathrm{dpm} / 100 \mathrm{~cm}^{2}$ alpha. The chart shows the probability versus scanning speed for three different probe sizes. The probe size denotes the dimensions of the probes which are in line with the direction of scanning. A detection efficiency of $15 \%(4 \pi)$ is assumed. 


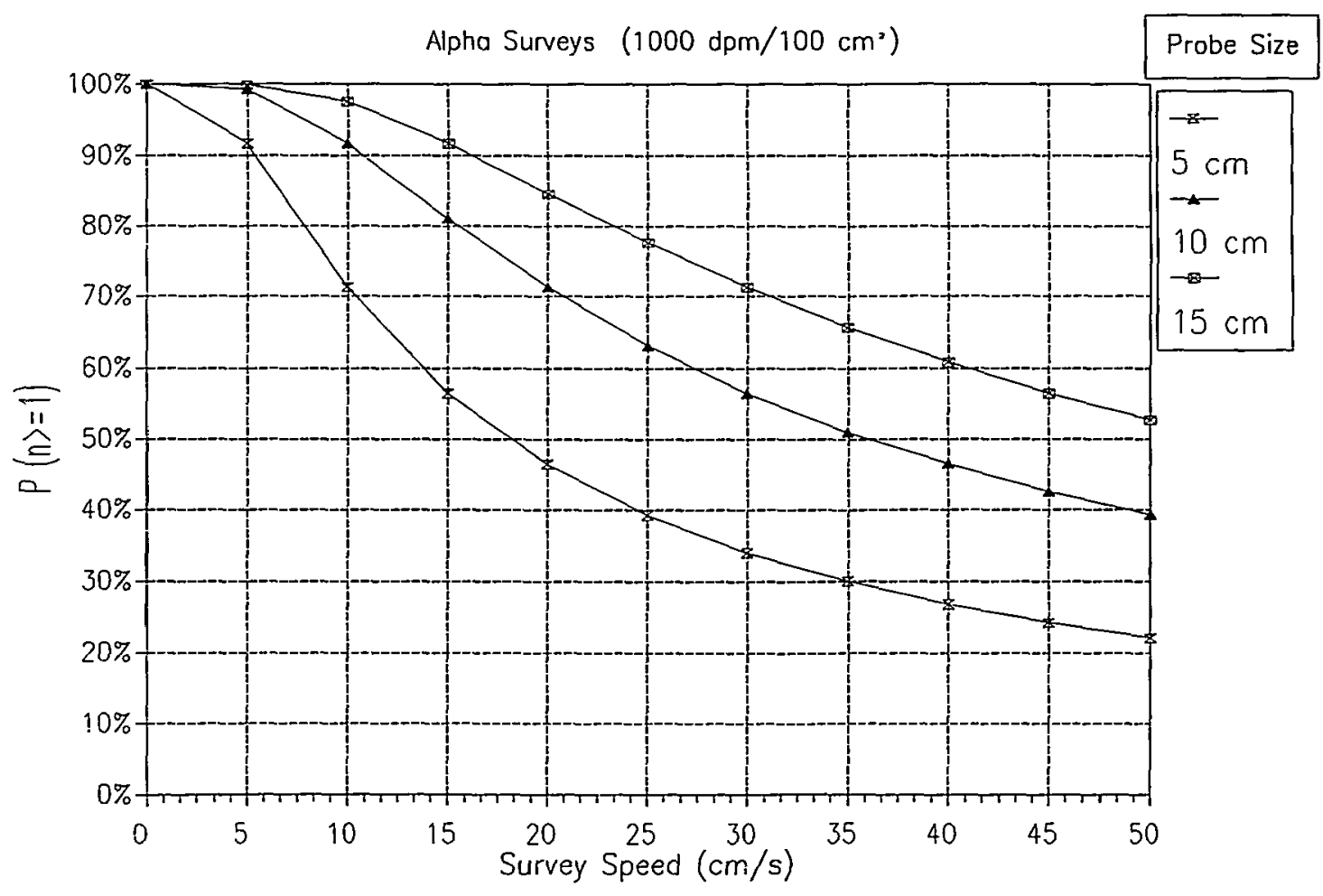

Figure J.2 Probability (P) of getting one or more counts when passing over a $100 \mathrm{~cm}^{2}$ area contaminated at $1,000 \mathrm{dpm} / 100 \mathrm{~cm}^{2}$ alpha. The chart shows the probability versus scanning speed for three different probe sizes. The probe size denotes the dimensions of the probes which are in line with the direction of scanning. A detection efficiency of $15 \%(4 \pi)$ is assumed. 
Appendix J

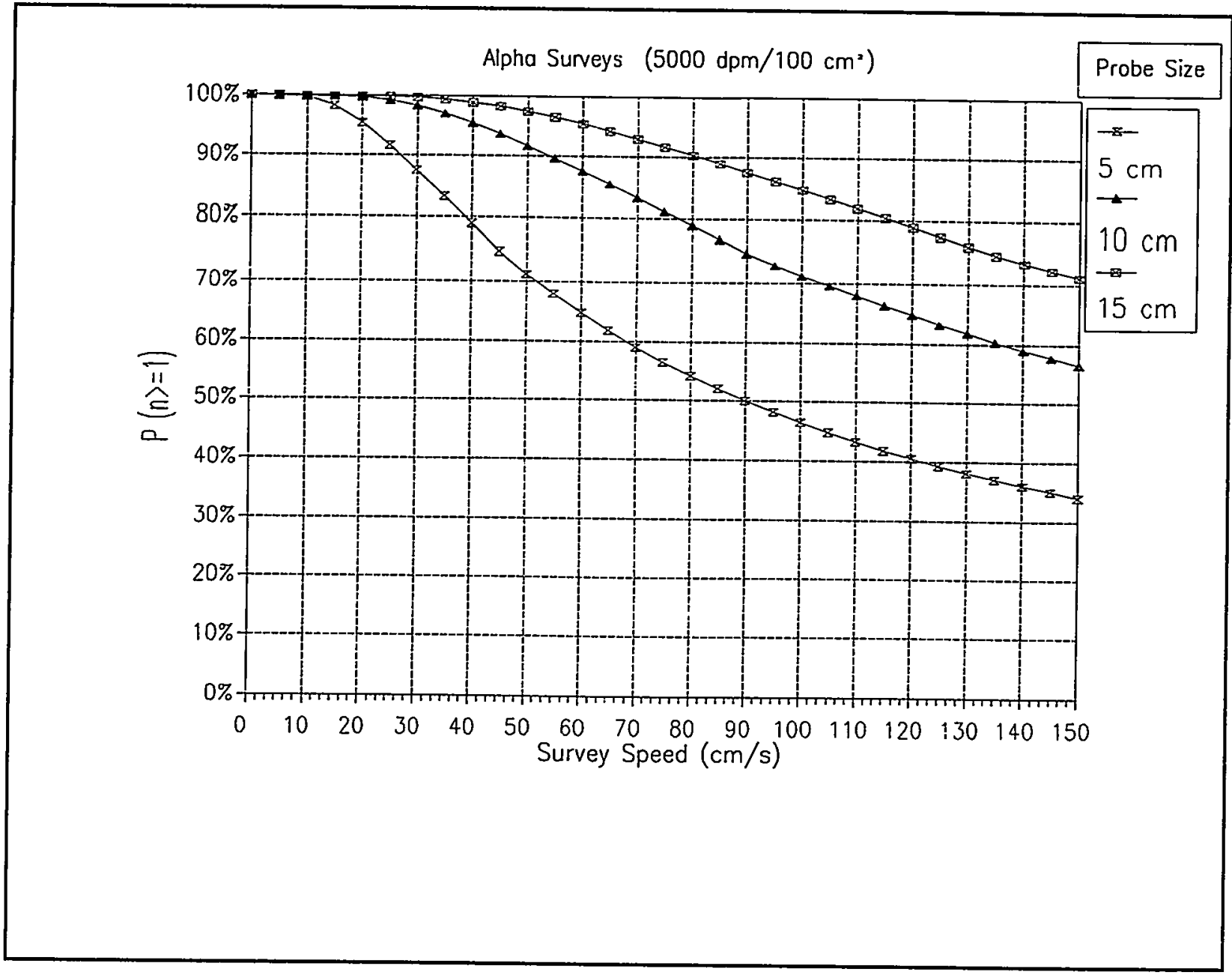

Figure J.3 Probability (P) of getting one or more counts when passing over a $100 \mathrm{~cm}^{2}$ area contaminated at $5,000 \mathrm{dpm} / 100 \mathrm{~cm}^{2}$ alpha. The chart shows the probability versus scanning speed for three different probe sizes. The probe size denotes the dimensions of the probes which are in line with the direction of scanning. A detection efficiency of $15 \%(4 \pi)$ is assumed. 


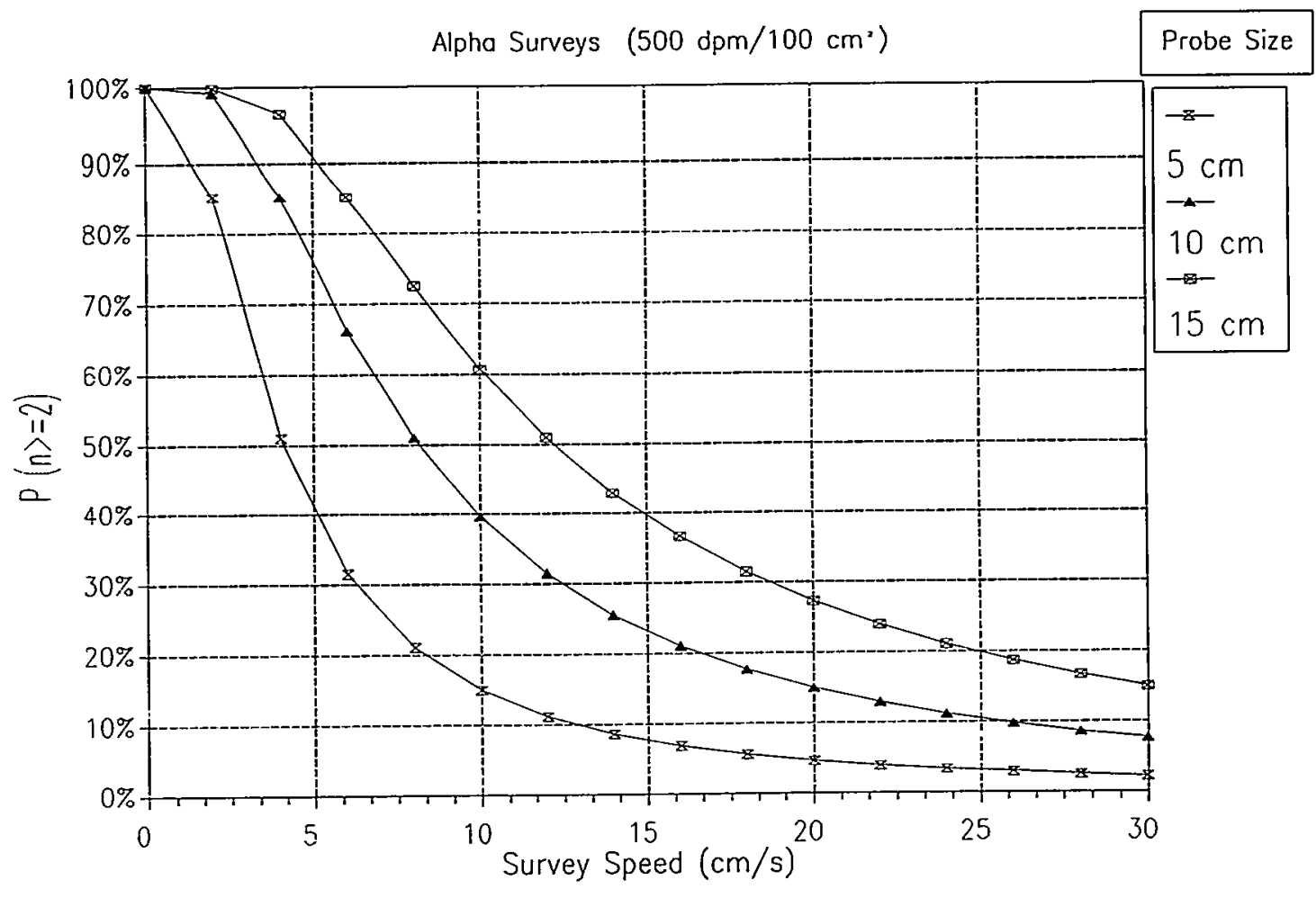

Figure J.4 Probability (P) of getting two or more counts when passing over a $100 \mathrm{~cm}^{2}$ area contaminated at $500 \mathrm{dpm} / 100 \mathrm{~cm}^{2}$ alpha. The chart shows the probability versus scanning speed for three different probe sizes. The probe size denotes the dimensions of the probes which are in line with the direction of scanning. A detection efficiency of $15 \%(4 \pi)$ is assumed. 
Appendix J

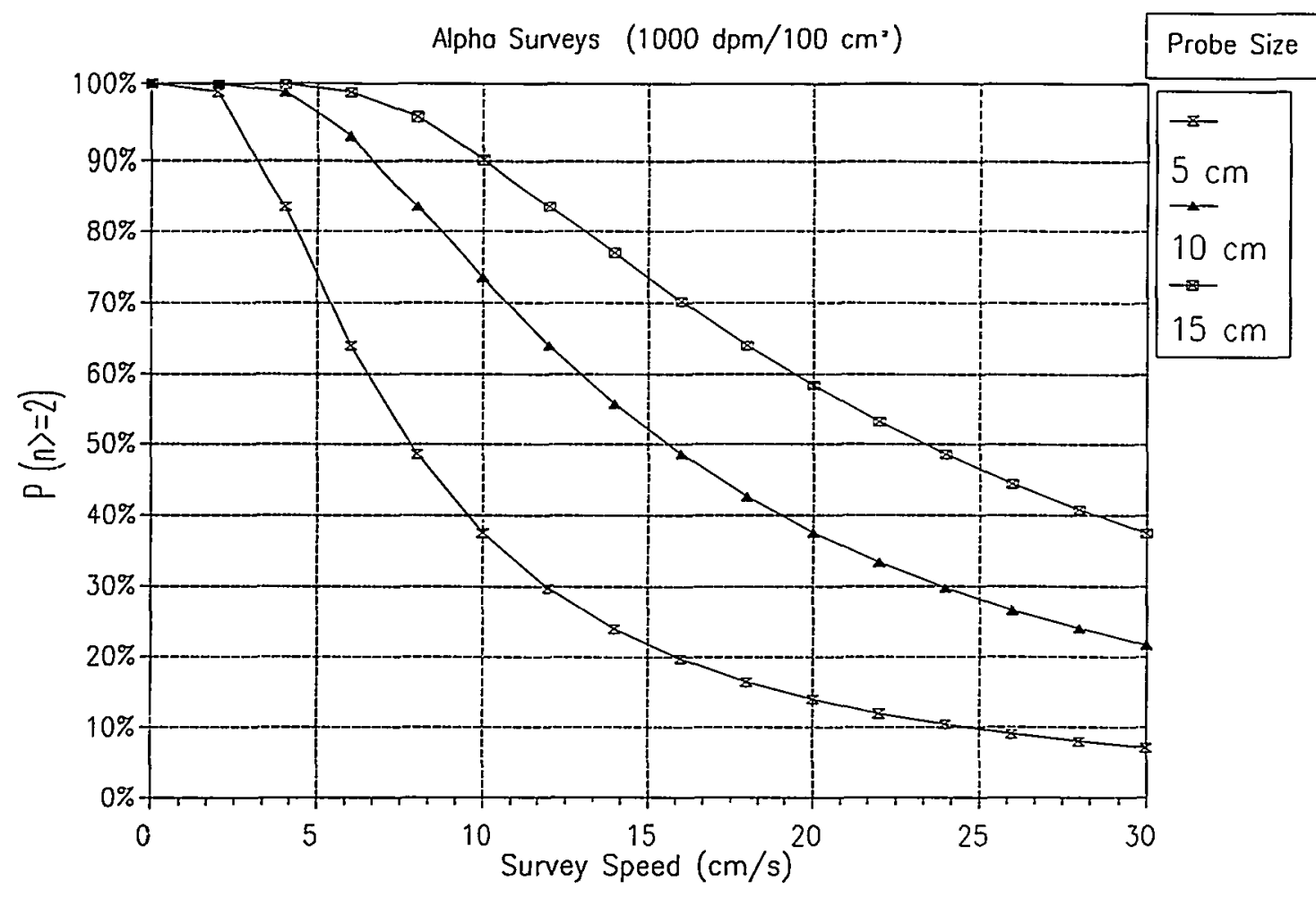

Figure J.5 Probability (P) of getting two or more counts when passing over a $100 \mathrm{~cm}^{2}$ area contaminated at $1,000 \mathrm{dpm} / 100 \mathrm{~cm}^{2}$ alpha. The chart shows the probability versus scanning speed for three different probe sizes. The probe size denotes the dimensions of the probes which are in line with the direction of scanning. A detection efficiency of $15 \%(4 \pi)$ is assumed. 


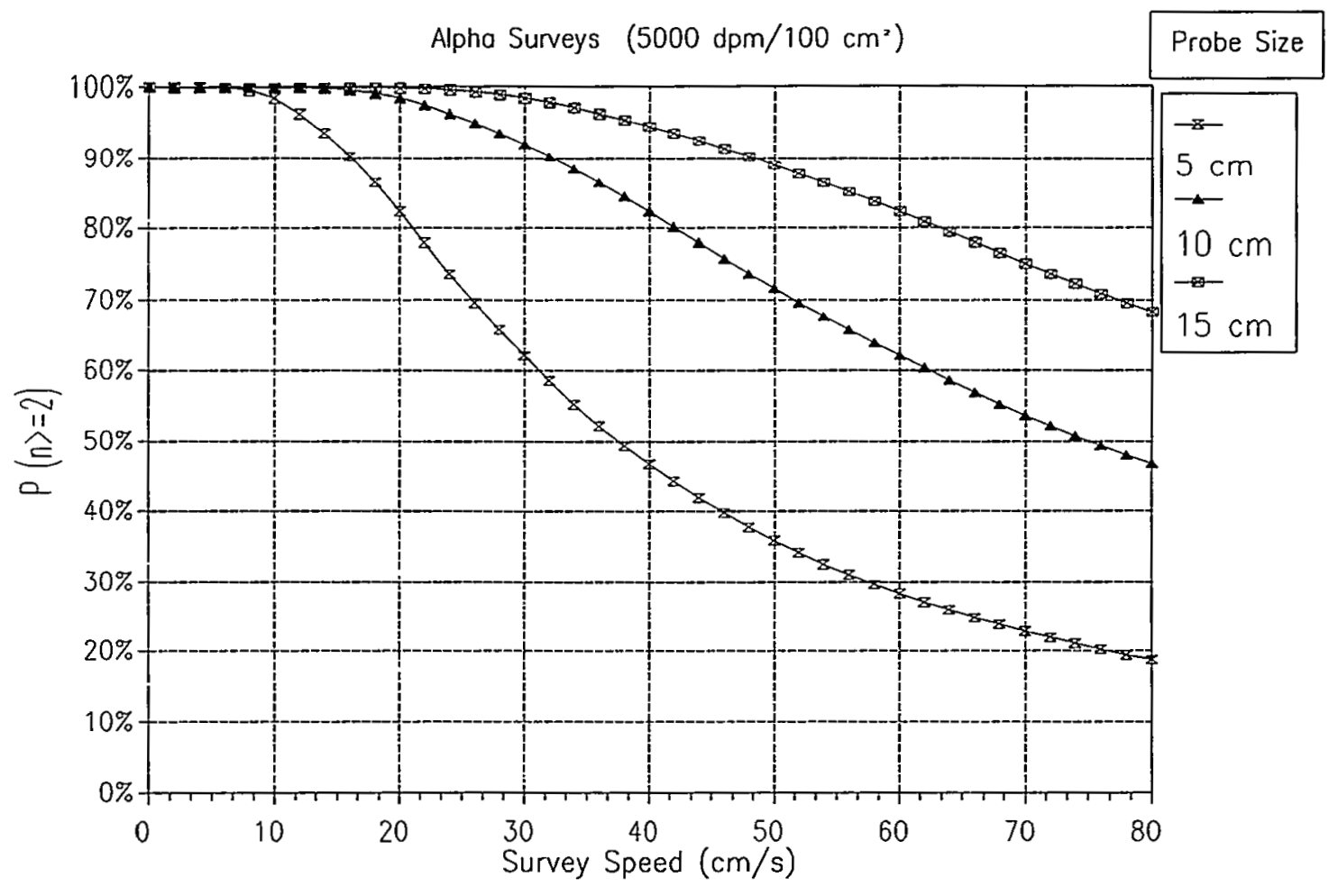

Figure J.6 Probability (P) of getting two or more counts when passing over a $100 \mathrm{~cm}^{2}$ area contaminated at $5,000 \mathrm{dpm} / 100 \mathrm{~cm}^{2}$ alpha. The chart shows the probability versus scanning speed for three different probe sizes. The probe size denotes the dimensions of the probes which are in line with the direction of scanning. A detection efficiency of $15 \%(4 \pi)$ is assumed. 


\section{APPENDIX K \\ COMPARISON TABLES BETWEEN QUALITY ASSURANCE DOCUMENTS}

The comparison tables in this appendix provide a reference for the MARSSIM user who may not be familiar with developing a QAPP based on EPA QA/R-5 (EPA 1994c). The tables relate the basic recommendations and requirements of EPA QA/R-5 and other quality assurance documents the reader may be more familiar with.

Each of the quality assurance documents compared in these tables was developed for a specific industry and scope. For this reason, there is not a direct comparison from one document to another. Rather, the tables are designed to show similarities between different quality assurance documents. In addition, there are topics specific to certain quality assurance documents that do not have a counterpart in these comparison tables.

If there is no section listed as being comparable with a section of EPA QA/R-5, this does not necessarily mean that the topic is not covered by the quality assurance document. In some cases the topic may have been divided up into several subtopics that are distributed between other sections of the particular document.

This appendix is not meant to provide a thorough cross-reference between different quality assurance documents. The purpose of these comparison tables is to demonstrate how the content of QAPPs might be arranged differently and show a user the location of important information concerning radiation surveys and site investigations. This might occur if the QAPP is developed using guidance the reviewer is unfamiliar with.

EPA QA/R-5 is compared with five quality assurance documents in the following tables:

$\begin{array}{ll}- & \text { EPA QAMS-005/80 (EPA 1980d) } \\ - & \text { ASME NQA-1 (ASME 1989) } \\ - & \text { DOE Order 5700.6c (DOE 1991c) } \\ - & \text { MIL-Q-9858A (DOD 1963) } \\ \text { ISO } 9000 \text { (ISO 1987) }\end{array}$


Appendix $\mathrm{K}$

Table K.1 Comparison of EPA QA/R-5 and EPA QAMS-005/80

\begin{tabular}{|c|c|c|c|}
\hline \multicolumn{2}{|r|}{ EPA QA/R-5 Elements } & \multicolumn{2}{|r|}{ EPA QAMS $-005 / 80$} \\
\hline $\mathrm{A} 1$ & Title and Approval Sheet & 1.0 & $\begin{array}{l}\text { Title Page with Provision for Approval } \\
\text { Signatures }\end{array}$ \\
\hline A2 & Table of Contents & 2.0 & Table of Contents \\
\hline $\mathrm{A} 3$ & Distribution List & & \\
\hline A4 & Project/Task Organization & 4.0 & Project Organization and Responsibility \\
\hline A5 & Problem Definition/Background & 3.0 & Project Description \\
\hline A6 & Project/Task Description & 3.0 & Project Description \\
\hline A7 & $\begin{array}{l}\text { Quality Objectives and Criteria for } \\
\text { Measurement Data }\end{array}$ & 5.0 & $\begin{array}{l}\text { Quality Assurance Objectives for } \\
\text { Measurement Data }\end{array}$ \\
\hline A8 & Project Narrative & & \\
\hline A9 & Special Training Requirements/Certification & & \\
\hline $\mathrm{A} 10$ & Documentation and Records & & \\
\hline B1 & Sampling Process Design & 6.0 & Sampling Procedures \\
\hline B2 & Sampling Methods Requirements & 6.0 & Sampling Procedures \\
\hline B3 & Sample Handling and Custody Requirements & 7.0 & Sample Custody \\
\hline$\overline{\mathrm{B} 4}$ & Analytical Methods Requirements & 9.0 & Analytical Methods \\
\hline B5 & Quality Control Requirements & 11.0 & $\begin{array}{l}\text { Internal Quality Control Checks and } \\
\text { Frequency }\end{array}$ \\
\hline B6 & $\begin{array}{l}\text { Instrument/Equipment Testing, Inspection, } \\
\text { and Maintenance Requirements }\end{array}$ & 13.0 & $\begin{array}{l}\text { Preventive Maintenance Procedures and } \\
\text { Schedules }\end{array}$ \\
\hline B7 & Instrument Calibration and Frequency & 8.0 & Calibration Procedures and Frequency \\
\hline$\overline{B 8}$ & $\begin{array}{l}\text { Inspection/Acceptance Requirements for } \\
\text { Supplies and Consumables }\end{array}$ & & \\
\hline B9 & Data Acquisition Requirements & & \\
\hline $\mathrm{B} 10$ & Data Quality Management & & \\
\hline $\mathrm{C} 1$ & Assessments and Response Actions & $\begin{array}{l}12.0 \\
15.0\end{array}$ & $\begin{array}{l}\text { Assessment and Response Actions } \\
\text { Corrective Actions }\end{array}$ \\
\hline $\mathrm{C} 2$ & Reports to Management & 16.0 & Quality Assurance Reports to Management \\
\hline D1 & $\begin{array}{l}\text { Data Review, Validation, and Verification } \\
\text { Requirements }\end{array}$ & 10.0 & Data Reduction, Validation, and Reporting \\
\hline $\mathrm{D} 2$ & Validation and Verification Methods & 10.0 & Data Reduction, Validation, and Reporting \\
\hline D3 & Reconciliation with User Requirements & & \\
\hline
\end{tabular}


Table K.2 Comparison of EPA QA/R-5 and ASME NQA-1

\begin{tabular}{|c|c|c|c|}
\hline & EPA QA/R-5 Elements & & ASME NQA-1 Elements \\
\hline A1 & Title and Approval Sheet & & \\
\hline A2 & Table of Contents & & \\
\hline A3 & Distribution List & & \\
\hline A4 & Project/Task Organization & 1. & Organization \\
\hline A5 & Problem Definition/Background & & \\
\hline A6 & Project/Task Description & 3. & Design Control \\
\hline$\overline{\mathrm{A} 7}$ & $\begin{array}{l}\text { Quality Objectives and Criteria for } \\
\text { Measurement Data }\end{array}$ & 2. & Quality Assurance Program \\
\hline A8 & Project Narrative & 8. & Identification and Control of Items \\
\hline A9 & Special Training Requirements/Certification & & \\
\hline A10 & Documentation and Records & & $\begin{array}{l}\text { Procurement Document Control } \\
\text { Document Control }\end{array}$ \\
\hline B1 & Sampling Process Design & 3. & Design Control \\
\hline B2 & Sampling Methods Requirements & 5. & Instructions, Procedures, and Drawings \\
\hline B3 & Sample Handling and Custody Requirements & 13. & Handling, Storage, and Shipping \\
\hline B4 & Analytical Methods Requirements & 5. & Instructions, Procedures, and Drawings \\
\hline B5 & Quality Control Requirements & & $\begin{array}{l}\text { Control of Processes } \\
\text { Test Control }\end{array}$ \\
\hline B6 & $\begin{array}{l}\text { Instrument/Equipment Testing, Inspection, } \\
\text { and Maintenance Requirements }\end{array}$ & $\begin{array}{l}10 . \\
12 .\end{array}$ & $\begin{array}{l}\text { Inspection } \\
\text { Control of Measuring and Test Equipment }\end{array}$ \\
\hline B7 & Instrument Calibration and Frequency & 14. & Inspection, Test, and Operating Status \\
\hline B8 & $\begin{array}{l}\text { Inspection/Acceptance Requirements for } \\
\text { Supplies and Consumables }\end{array}$ & & $\begin{array}{l}\text { Control of Purchased Items and Services } \\
\text { Identification and Control of Items }\end{array}$ \\
\hline$\overline{B 9}$ & Data Acquisition Requirements & & \\
\hline B10 & Data Quality Management & & \\
\hline $\mathrm{C1}$ & Assessments and Response Actions & & $\begin{array}{l}\text { Control of Nonconforming Items } \\
\text { Corrective Action } \\
\text { Audits }\end{array}$ \\
\hline $\mathrm{C} 2$ & Reports to Management & 17. & Quality Assurance Records \\
\hline $\bar{D} 1$ & $\begin{array}{l}\text { Data Review, Validation, and Verification } \\
\text { Requirements }\end{array}$ & & \\
\hline D2 & Validation and Verification Methods & & \\
\hline D3 & Reconciliation with User Requirements & & \\
\hline
\end{tabular}


Appendix K

Table K.3 Comparison of EPA QA/R-5 and DOE Order 5700.6c

\begin{tabular}{|c|c|c|}
\hline & EPA QA/R-5 Elements & DOE Order $5700.6 \mathrm{C}$ Elements \\
\hline $\mathrm{Al}$ & Title and Approval Sheet & \\
\hline A2 & Table of Contents & \\
\hline A3 & Distribution List & \\
\hline A4 & Project/Task Organization & Personnel Training and Qualification \\
\hline A5 & Problem Definition/Background & Program \\
\hline A6 & Project/Task Description & \\
\hline A7 & $\begin{array}{l}\text { Quality Objectives and Criteria for } \\
\text { Measurement Data }\end{array}$ & Program \\
\hline A8 & Project Narrative & \\
\hline A9 & Special Training Requirements/Certification & Personnel Training and Qualification \\
\hline A10 & Documentation and Records & Documents and Records \\
\hline $\mathrm{B} 1$ & Sampling Process Design & Design \\
\hline B2 & Sampling Methods Requirements & Work Processes \\
\hline B3 & Sample Handling and Custody Requirements & \\
\hline B4 & Analytical Methods Requirements & Work Processes \\
\hline B5 & Quality Control Requirements & \\
\hline B6 & $\begin{array}{l}\text { Instrument/Equipment Testing, Inspection, } \\
\text { and Maintenance Requirements }\end{array}$ & Inspection and Acceptance Testing \\
\hline B7 & Instrument Calibration and Frequency & \\
\hline B8 & $\begin{array}{l}\text { Inspection/Acceptance Requirements for } \\
\text { Supplies and Consumables }\end{array}$ & $\begin{array}{ll}7 & \text { Procurement } \\
8 & \text { Inspection and Acceptance Testing }\end{array}$ \\
\hline B9 & Data Acquisition Requirements & \\
\hline $\mathrm{B} 10$ & Data Quality Management & \\
\hline $\mathrm{C} 1$ & Assessments and Response Actions & Independent Assessment \\
\hline $\mathrm{C} 2$ & Reports to Management & Management Assessment \\
\hline D1 & $\begin{array}{l}\text { Data Review, Validation, and Verification } \\
\text { Requirements }\end{array}$ & \\
\hline $\mathrm{D} 2$ & Validation and Verification Methods & \\
\hline D3 & Reconciliation with User Requirements & Quality Improvement \\
\hline
\end{tabular}


Table K.4 Comparison of EPA QA/R-5 and MIL-Q-9858A

\begin{tabular}{|c|c|c|c|}
\hline & EPA QA/R-5 Elements & & MIL-Q-9858A Elements \\
\hline $\mathrm{A} 1$ & Title and Approval Sheet & & \\
\hline $\mathrm{A2}$ & Table of Contents & & \\
\hline$\overline{\mathrm{A} 3}$ & Distribution List & & \\
\hline$\overline{\mathrm{A} 4}$ & Project/Task Organization & 3.1 & Organization \\
\hline A5 & Problem Definition/Background & & \\
\hline A6 & Project/Task Description & & \\
\hline A7 & $\begin{array}{l}\text { Quality Objectives and Criteria for } \\
\text { Measurement Data }\end{array}$ & 3.2 & Initial Quality Planning \\
\hline A8 & Project Narrative & & \\
\hline A9 & Special Training Requirements/Certification & & \\
\hline A10 & Documentation and Records & $\begin{array}{l}3.4 \\
4.1\end{array}$ & $\begin{array}{l}\text { Records } \\
\text { Drawings, Documentation, and Changes }\end{array}$ \\
\hline B1 & Sampling Process Design & & \\
\hline B2 & Sampling Methods Requirements & 3.3 & Work Instructions \\
\hline B3 & Sample Handling and Custody Requirements & 6.4 & Handling, Storage, and Delivery \\
\hline B4 & Analytical Methods Requirements & 3.3 & Work Instructions \\
\hline B5 & Quality Control Requirements & 6.7 & Identification of Inspection Status \\
\hline B6 & $\begin{array}{l}\text { Instrument/Equipment Testing, Inspection, } \\
\text { and Maintenance Requirements }\end{array}$ & 4.2 & Measuring and Test Equipment \\
\hline B7 & Instrument Calibration and Frequency & 4.2 & Measuring and Test Equipment \\
\hline B8 & $\begin{array}{l}\text { Inspection/Acceptance Requirements for } \\
\text { Supplies and Consumables }\end{array}$ & & $\begin{array}{l}\text { Control of Purchases } \\
\text { Materials and Material Control }\end{array}$ \\
\hline B9 & Data Acquisition Requirements & & \\
\hline $\mathrm{B} 10$ & Data Quality Management & 3.4 & Records \\
\hline $\mathbf{C 1}$ & Assessments and Response Actions & & $\begin{array}{l}\text { Corrective Action } \\
\text { Nonconforming Material }\end{array}$ \\
\hline $\mathrm{C} 2$ & Reports to Management & 3.6 & Costs Related to Quality \\
\hline $\mathrm{D} 1$ & $\begin{array}{l}\text { Data Review, Validation, and Verification } \\
\text { Requirements }\end{array}$ & & \\
\hline $\mathrm{D} 2$ & Validation and Verification Methods & 6.6 & Statistical Quality Control \\
\hline \multirow[t]{3}{*}{ D3 } & Reconciliation with User Requirements & & \\
\hline & & 6.2 & Production Processing and Fabrication \\
\hline & & 6.3 & Completed Item Inspection and Test \\
\hline
\end{tabular}


Appendix K

Table K.5 Comparison of EPA QA/R-5 and ISO 9000

\begin{tabular}{|c|c|c|c|}
\hline \multicolumn{2}{|r|}{ EPA QA/R-5 Elements } & \multicolumn{2}{|r|}{ ISO 9000 Elements } \\
\hline A1 & Title and Approval Sheet & & \\
\hline A2 & Table of Contents & & \\
\hline A3 & Distribution List & & \\
\hline A4 & Project/Task Organization & 4 & Management Responsibility \\
\hline A5 & Problem Definition/Background & & \\
\hline A6 & Project/Task Description & & \\
\hline A7 & $\begin{array}{l}\text { Quality Objectives and Criteria for } \\
\text { Measurement Data }\end{array}$ & & $\begin{array}{l}\text { Quality System Principles } \\
\text { Structure of the Quality System }\end{array}$ \\
\hline A8 & Project Narrative & & \\
\hline A9 & Special Training Requirements/Certification & & \\
\hline A10 & Documentation and Records & & \\
\hline$\overline{B 1}$ & Sampling Process Design & 8 & Quality in Specification and Design \\
\hline$\overline{\mathrm{B} 2}$ & Sampling Methods Requirements & 10 & Quality in Production \\
\hline B3 & Sample Handling and Custody Requirements & 16 & Handling and Post Production Functions \\
\hline B4 & Analytical Methods Requirements & 10 & Quality in Production \\
\hline B5 & Quality Control Requirements & 11 & Control of Production \\
\hline B6 & $\begin{array}{l}\text { Instrument/Equipment Testing, Inspection, } \\
\text { and Maintenance Requirements }\end{array}$ & 13 & Control of Measuring and Test Equipment \\
\hline B7 & Instrument Calibration and Frequency & & \\
\hline B8 & $\begin{array}{l}\text { Inspection/Acceptance Requirements for } \\
\text { Supplies and Consumables }\end{array}$ & $\begin{array}{l}9 \\
11.2\end{array}$ & $\begin{array}{l}\text { Quality in Procurement } \\
\text { Material Control and Traceability }\end{array}$ \\
\hline B9 & Data Acquisition Requirements & & \\
\hline B10 & Data Quality Management & & \\
\hline $\mathrm{C} 1$ & Assessments and Response Actions & & $\begin{array}{l}\text { Auditing the Quality System } \\
\text { Nonconformity } \\
\text { Corrective Action }\end{array}$ \\
\hline $\mathrm{C} 2$ & Reports to Management & $\begin{array}{l}5.3 \\
6\end{array}$ & $\begin{array}{l}\text { Documentation of the Quality System } \\
\text { Economics-Quality Related Costs }\end{array}$ \\
\hline D1 & $\begin{array}{l}\text { Data Review, Validation, and Verification } \\
\text { Requirements }\end{array}$ & 11.7 & Control of Verification Status \\
\hline D2 & Validation and Verification Methods & 12 & Verification Status \\
\hline D3 & Reconciliation with User Requirements & & \\
\hline & & 7 & Quality in Marketing \\
\hline
\end{tabular}




\section{APPENDIX L}

\section{REGIONAL RADIATION PROGRAM MANAGERS}

The following is a directory list of regional program managers in Federal agencies who administer radiation control activities and have responsibility for certain radiation protection activities. The telephone numbers and addresses in this appendix are subject to change without notice. A more complete directory list of professional personnel in state and local government agencies is available from the Conference of Radiation Control Program Directors, Inc. (CRCPD). This directory is updated and distributed yearly. To obtain a copy of this annual publication please write to:

\section{CRCPD}

Attn: Ellen Steinberg

205 Capital Avenue

Frankfort, KY 40601

(502) 227-4543 
Appendix L

\section{L.1 Department of Energy (DOE)}

Oak Ridge Operations Office

Department of Energy (EOC.)

Post Office Box 2001

Oak Ridge, Tennessee 37831

Savannah River Operations Office

Department of Energy

Post Office Box A

Aiken, South Carolina 29801

Albuquerque Operations Office

Department of Energy

Post Office Box 5400

Albuquerque, New Mexico 87115-5400

Chicago Operations Office

Department of Energy

9800 South Cass Avenue

Argonne, Illinois 60439

Idaho Operations Office

Department of Energy

850 Energy Drive

Idaho Falls, Idaho 83401

Oakland Operations Office

Department of Energy

1303 Clay Street, $700 \mathrm{~N}$

Oakland, California 94612-5208

Richland Operations Office

Department of Energy

Post Office Box 550

Richland, Washington 99352

Nevada Operations Office

Department of Energy

PO Box 98518

Las Vegas, NV 89193-8518
Telephone: (615) 576-1005

(615) 525-7885

Telephone: (803) 725-3333

Telephone: (505) 844-4667

Telephone: (708) 252-4800

(708) $252-5731$

Telephone: (208) 526-1515

Telephone: (510) 637-1589

Telephone: (509) 373-3800

Telephone: (702) 295-7063 


\section{L.2 Environmental Protection Agency (EPA)}

Region 1 (CT, MA, ME, NH, RI, VT)

Radiation Program Manager

Telephone: (617) 565-4502

Environmental Protection Agency

(617) $565-3420$

John F. Kennedy Federal Building (ATR)

One Congress Street

Boston, Massachusetts 02203

Region 2 (NJ, NY, PR, VD)

Chief, Radiation and Indoor Air Branch (2AWM:RAD) Telephone: (212) 637-4010

Division of Environmental Planning and Protection

(212) $637-3000$

Environmental Protection Agency

290 Broadway

New York, New York 10007-1866

Region 3 (DC, DE, MD, PA, VA, WV)

Radiation Program Manager

Radiation Program Section (3AT-12)

Telephone: (215) 597-8326

Environmental Protection Agency

(215) $597-9800$

841 Chestnut Building

Philadelphia, Pennsylvania 19107

Region 4 (AL, FL, GA, KY, MS, NC, SC, TN)

Radiation Program Manager

Telephone: (404) 562-9139

Environmental Protection Agency

Atlanta Federal Center

61 Forsyth Street, SW

Atlanta, Georgia 30303-3104

Region $5 \quad(\mathrm{I}, \mathbb{I N}, \mathrm{MI}, \mathrm{MN}, \mathrm{OH}, \mathrm{WI})$

Radiation Program Manager

Telephone: (312) 886-6175

Environmental Protection Agency

(312) $353-2000$

77 West Jackson Boulevard (AT-18J)

Chicago, Illinois 60604-3507 
Appendix L

Region 6 (AR, LA, NM, OK, TX)

Radiation Program Manager

Telephone: (214) 665-7224

Environmental Protection Agency

(214) 665-6444

Air Enforcement Branch (6T-E)

Air, Pesticides and Toxics Division

1445 Ross Avenue

12th Floor, Suite 1200

Dallas, Texas 75202-2733

Region 7 (LA, KS, MO, NE)

Radiation Program Manager

Telephone: (913) 551-7605

Environmental Protection Agency

(913) $551-7000$

726 Minnesota Avenue

Kansas City, Kansas 66101

Region 8 (CO, MT, ND, SD, UT, WY)

Radiation Program Manager

Telephone:(303) 293-1440

Radiation and Indoor Air Programs Branch (8ART-RP)

(303) 293-1603

Environmental Protection Agency

999 18th Street, Suite 500

Denver, Colorado 80202-2466

Region 9 (AZ, CA, HI, NV, American Samoa, Guam, and North Mariana Islands)

Radiation Program Manager

Telephone: (415) 744-1048

Environmental Protection Agency

(415) 744-1305

75 Hawthorne Street, A-1-1

San Francisco, California 94105

Region 10 (AK, ID, OR, WA)

Radiation Program Manager

Telephone: (206) 553-7660

Environmental Protection Agency

(206) 553-1200

1200 Sixth Avenue, Mail Stop AT-082

Seattle, Washington 98101 


\section{L.3 Nuclear Regulatory Commission (NRC)}

Region I (CT, DC, DE, MA, MD, ME, NH, NJ, NY, PA, RI, VT)

Administrator

Telephone: (610) 337-5299

U.S. Nuclear Regulatory Commission

(610) $337-5000$

475 Allendale Road

King of Prussia, Pennsylvania 19406-1415

Region II (AL, FL, GA, KY, MS, NC, PR, SC, TN, VA, VI, WV, Panama Canal)

Administrator

Telephone: (404) 331-5500

U.S. Nuclear Regulatory Commission

(404) $331-4503$

Atlanta Federal Center

61 Forsyth Street, SW

Atlanta, Georgia 30303

Region III $\quad$ (IA, IL, IN, MI, MN, MO, OH, WI)

Administrator

U.S. Nuclear Regulatory Commission

Telephone: (708) 829-9657

801 Warrenville Road

Lisle, Illinois 60532-4351

Region IV (AR, CO, ID, KS, LA, MT, NE, ND, NM, OK, SD, TX, UT, WY)

Administrator

Telephone: (817) 860-8225

U.S. Nuclear Regulatory Commission

(817) $860-8100$

611 Ryan Plaza Drive, Suite 400

Arlington, Texas 76011-8064

(AK, AZ, CA, HI, NV, OR, WA, Pacific Trust Territories)

U.S. Nuclear Regulatory Commission

Telephone: (817) 860-8115

Walnut Creek Field Office*

1450 Maria Lane

Walnut Creek, California 94596-5368

* Scheduled for closure October 1, 1998. Thereafter, functions will be transferred to Region IV. 
Appendix L

\section{L.4 Department of the Army}

The following is a list of key personnel within the Department of the Army who administer radiation control activities and have responsibilities for certain radiation protection activities.

Deputy for Environmental Safety \& Occupational Health

Office of the Assistant Secretary of the Army (Installations, Logistics, \& Environment)

110 Army Pentagon

Washington, DC 20310-0110

Director of Army Radiation Safety

Army Safety Office

DACS-SF

Chief of Staff

200 Army Pentagon

Washington, DC 20310-0200

Radiological Hygiene Consultant

Office of The Surgeon General

Walter Reed Army Medical Center

Attn: MCHL-HP

Washington, DC 20307-5001
Telephone: (703) 695-7824

Telephone: (703) 695-7291

Telephone: (301) 427-5107 


\section{L.5 Department of the Navy}

The following is a list of key personnel within the Department of the Navy who administer radiation control activities and have responsibilities for certain radiation protection activities.

Navy Radiation Safety Committee

Chief of Naval Operations (N455)

Telephone: (703) 602-2582

2211 Jefferson Davis Highway

Crystal Plaza \#5, Room 678

Arlington, VA 22244-5108

Commander (SEA-07R)

Telephone: (703) 602-1252

Radiological Controls Program

Naval Sea Systems Command

2531 Jefferson Davis Highway

Arlington, VA 22242-5160

Officer in Charge

Telephone: (757) 887-4692

Radiological Affairs Support Office

P.O. Drawer 260

Yorktown, VA 23691-0260 
Appendix L

\section{L.6 Department of the Air Force}

The following is a list of key personnel within the Department of the Air Force who administer radiation control activities and have responsibilities for certain radiation protection activities.

Associate Corps Chief, Health Physics

Telephone: (202) 767-0621

Office of the USAF Surgeon General

HQ AFMOA/SGPA

170 Luke Avenue, Suite 400

Bolling AFB, DC 20332-5133

Chairperson, USAF Radioisotope Committee (RIC) Telephone: (210) 536-3331 AFMOA/SGPR

8901 18th Street

Brooks AFB, TX 78235-5217

Chief, Consultant Branch

Telephone: (210) 536-3486

Radiation Services Division, Armstrong Laboratory

AL/OEBZ

2402 E Street

Brooks AFB, TX 78235-5114 


\section{APPENDIX M}

\section{SAMPLING METHODS: A LIST OF SOURCES}

\section{M.1 Introduction}

Planning activities associated with field survey work include developing new and compiling or adopting existing sampling methods. The following listing includes documents that represent examples for the types of information one encounters when searching for sampling methods. This listing initially presents references that appear with brief annotations that characterize the information found in each document.

Journal articles and books may list references that lead to still other types of useful information. Depending on survey needs, media being sampled, or site-specific requirements, one may follow these references to resources that describe other types of methods found in original papers or documents that appeared even as specific sampling techniques were first introduced.

The present listing is not exhaustive. Other titles or resources for sampling methods are available through online literature databases; Federal, State, and university libraries; the internet; and other sources.

\section{M.2 List of Sources}

Department of Energy (DOE). 1987. The Environmental Survey Manual. DOE/EH-0053, Vol. 1 of 4. DOE, Office of the Assistant Secretary for Environment, Safety, and Health, Office of Environmental Audit, Washington, D.C.

- General Description of Document: Size: Approximately 188 pages (single sided)—This is the first of a four volume set that amounts to over 4 ins. (total thickness) of documentation related to environmental surveys. The first volume represents the main document, with the remaining three volumes contain eleven appendices.

- $\quad$ Key Features of This Document: Unlike a number of other references listed here, this document does include information related to radionuclides and considers biota (animal, plant, and related sample types). Flow charts, checklists, planning diagrams, and figures help the reader to visualize a number of topics described in the text of all four volumes. Section 2 of this volume entertains topics related to a survey team's activities and survey reports. Section 3 considers the use of existing data, followed by technical checklists in Section 4 and health and safety issues described in Section 5. 
Appendix $M$

A quick review of this first volume reveals a limited amount of depth to the information presented. There is little descriptive How To Sample information given here. However, as an overview, the document is quite comprehensive and this may encourage a survey team to consider obtaining additional information relevant to a particular project need.

Department of Energy (DOE). 1987. The Environmental Survey Manual: Appendices A, B, and C. DOE/EH-0053, Vol. 2 of 4. DOE, Office of the Assistant Secretary for Environment, Safety, and Health, Office of Environmental Audit, Washington, D.C.

- General Description of Document: Size: Approximately 188 pages (double sided)—This second volume contains three of eleven appendices.

- $\quad$ Key Features of This Document: The appendices include: A) Criteria for Data Evaluation, B) Checklists and Lines of Inquiry, and C) Health and Safety Plan for On-Site Survey Activities.

Department of Energy (DOE). 1987. The Environmental Survey Manual: Appendix D. DOE/EH-0053, Vol. 3 of 4. DOE, Office of the Assistant Secretary for Environment, Safety, and Health, Office of Environmental Audit, Washington, D.C.

- $\quad$ General Description of Document: Size: Approximately 438 pages (double sided)—This single volume is the largest part of the four part set and contains only one appendix: Appendix D - Analytical Methods.

- Key Features of This Document: The topics presented here have little to do with sample collection and are mostly concerned with the types of compounds or constituents within a sample. A radiological section covers a number of radionuclides that one may encounter in a number of sample matrices-including in water, air, soil, and sediments. Again, this is an appendix dedicated to sample analysis.

Department of Energy (DOE). 1987. The Environmental Survey Manual: Appendices E, F, G, $H, I, J$, and K. DOE/EH-0053, Vol. 4 of 4. DOE, Office of the Assistant Secretary for Environment, Safety, and Health, Office of Environmental Audit, Washington, D.C.

- General Description of Document: Size: Approximately 312 pages (double sided)-This fourth and final volume includes seven appendices. 
- Key Features of This Document: Appendix E is entitled Field Sampling Protocols and Guidance-which offers a number of site scenarios to describe an approach to sampling under varied conditions. Each scenario is followed by a set of sampling procedures appropriate for a particular sample matrix. This appendix is 216 pages in length making this the largest part of Volume 4. Diagrams are included to illustrate scenarios and the appearance of sampling equipment.

The remaining appendices cover: F) guidelines for preparation of quality assurance plans, $\mathrm{G})$ decontamination guidance, $\mathrm{H}$ ) data management and analysis, $\mathrm{I}$ ) sample and document management guidance, $\mathrm{J}$ ) health and safety guidance for sampling and analysis teams, and $\mathrm{K})$ documents for sampling and analysis program.

Department of Energy (DOE). 1991. Environmental Regulatory Guide for Radiological Effluent Monitoring and Environmental Surveillance. DOE/EH-0173T, DOE, Assistant Secretary for Environment, Safety, and Health, Washington, D.C. (DE91-013607)

- General Description of Document: Size: approximately 90 pages - This guide covers a number of topics related to radiation and environmental surveillance.

- Key Features of This Document: To accomplish environmental surveillance, various sample types - from biotic (animal and plant) to abiotic (air, water, soil, etc.) -are considered in Chapter 5 (title: Environmental Surveillance). The basis for taking certain samples appears along with information on sample location and frequency. A brief statement on sampling methods completes each section but procedures or techniques are not given in detail. References to other guidance documents on sampling are cited. The reader is directed to other sources to obtain additional regulatory information or descriptions of specific procedures.

Chapter 6 provides information on laboratory procedures. Other chapters cover: liquid effluent monitoring, airborne effluent monitoring, meteorological monitoring, data analysis and statistical treatment, dose calculations, records and reports, quality assurance (QA), and reports.

Department of Energy (DOE). 1994. Decommissioning Handbook. DOE/EM-0142P. DOE, Office of Environmental Restoration, Germantown, MD

- General Description of Document: Size: Approximately 312 pages-The manual is essentially written for those involved in decommissioning a nuclear power facility. While not specifically focused on radiation sampling methods, this document may play a role in 
Appendix M

identifying activities or sampling needs related to survey work before or during remediation at some Federal facilities.

- $\quad$ Key Features of This Document: Chapter 6 presents information on final project configuration based on planning and as such speaks of site boundaries. Chapter 7 presents topics related to characterization including on-site measurements.

This document includes discussion and illustrations of robotic devices used in sampling operations. Perhaps only appropriate in extreme situations, the use of a robot for obtaining a sample may apply where radiation levels are high, dust or air quality pose problems, or where technical staff cannot physically reach a sample location due to structural limitations.

Environmental Protection Agency (EPA). 1980. Samplers and Sampling Procedures for Hazardous Waste Streams. EPA-600/2-80-018, EPA, Municipal Environmental Research Laboratory, Cincinnati, $\mathrm{OH}$.

- General Description of Document: Size: 67 pages-the procedures listed here cover different types of media and include helpful diagrams of sampling devices.

- Key Features of This Document: While not specifically geared to radioactive samples, this short manual outlines and presents information in a logical sequence-starting with descriptions of sampling devices, followed by discussion of selecting an appropriate device for various media (including samples taken from various sources; e.g., drum, barrel, waste pile), container types, labels, seals, use of a log book, chain of custody, sample receipt and logging, preservation and storage of samples, and references. The document includes five appendices, covering development of the composite liquid waste sampler, parts for constructing the sampler, checklist of items required in the field for sampling hazardous waste, random sampling, and systematic errors in using the composite liquid waste sampler.

Environmental Protection Agency (EPA). 1982. Test Methods For Evaluating Solid Waste, Physical / Chemical Methods, 2nd Edition. EPA, Office of Solid Waste, Washington, D.C. (PB87-120291)

- $\quad$ General Description of Document: Size: Approximately 375 pages-composed of chapters and methods that update the first edition of this volume. 
- Key Features of This Document: Chapter 1 of this manual pulls together information from the first three chapters of the first edition. This includes a Sampling Methodology section that addresses statistics, sampling strategies and examples, implementing a sampling plan, plus tables and figures of sampling devices, etc. The main focus is on solid waste including metals and organics. Methods are described with the same format as indicated above in reference 1 . As above, the methods include some information relevant to the field component of sampling work, but the remainder of each method essentially is most useful to laboratory personnel.

Environmental Protection Agency (EPA). 1982. Handbook for Sampling and Sample Preservation of Water and Wastewater. EPA-600/4-82-029, EPA, Environmental Monitoring and Support Laboratory, Cincinnati, OH. (PB83-124503)

- $\quad$ General Description of Document: Size: Approximately 500 pages-composed of information specifically focused on sample collection and preservation. While the document concerns only water sampling, this volume is comprehensive and even includes a chapter on Sampling Radioactive Materials.

- $\quad$ Key Features of This Document: The handbook is geared to address sampling issues. The scope of the document covers all types or sources of water, including: municipal, industrial, surface, agricultural, ground, and drinking waters. Types of samples are defined and discussed, including grab and composite samples. Diagrams, tables, and forms are provided to illustrate key points raised in the text. Statistical methods and related tables are provided. Each topic is accompanied by references. The chapter on radioactive samples is brief but touches on: background, radioactive decay, detection capability, frequency of sampling, sampling location, sample volume, containers, filtration, preservation, general procedures, radiation safety, and references.

Environmental Protection Agency (EPA). 1984. Soil Sampling Quality Assurance User's Guide. EPA 600/4-84-043, EPA, Environmental Monitoring Systems Laboratory, Office of Research and Development, Las Vegas, NV.

- General Description of Document: Size: 102 pages-The introduction to this document starts with: "An adequate quality assurance/quality control (QA/QC) program requires the identification and quantification of all sources of error associated with each step of a monitoring program so that the resulting data will be of known quality. the components of error, or variance, include those associated with sampling, sample preparation, extraction, analysis, and residual error." 
Appendix M

- Key Features of This Document: Because of potential inhomogeneity in soil samples, the authors state this QA/QC document is specifically concerned with soil sampling. The general outline of the document includes: objectives of QA/QC, statistics, exploratory studies, sample number and sample sites, sample collection, sample handling and documentation, analysis and interpretation of QA/QC data, and systems audits and training. References are provided followed by two appendices covering sample number precision and confidence plus tables for use in calculating confidence tolerance limits and judging validity of measurements.

The sample collection chapter is very brief and does not specifically outline methods or types of equipment. This and the following chapter on sample handling and documentation mention relevant topics in light of QA/QC.

Environmental Protection Agency (EPA). 1986. Engineering Support Branch Standard Operating Procedures and Quality Assurance Manual. EPA, Region IV, Environmental Services Division, Athens, GA. (Sections 3 to 5 reviewed)

- General Description of Document: Size: approximately 90 pages (single sided)—The introduction states: "The objectives of this section are to present the Branch standard operating procedures for sample identification, sample control and chain of custody, maintenance of field records, and document control.

- Key Features of This Document: The basic format of the document is that of a compendium of standard operating procedures bound in one volume. Each Standard Operating Procedure (SOP) is several pages and is dedicated to a specific topic. A five page outline pertaining to sampling procedures presents a brief overview that is a relatively typical treatment of this topic. Sample preservation, for example, is summarized with five bullet points. The next section offers a three page listing of definitions covering grab, composite, split, duplicate, reference or control, and background samples, plus a very brief definition for sample aliquot.

The document lacks figures but does include descriptive notes for equipment and methods related to taking samples of waste water, surface water (fresh and salt water), ground water, potable water supply, soil, samples from landfills and hazardous waste sites, followed by references. The last part of the guide include information on making flow measurements.

The document does not appear to focus on radioactive materials, but as with other documents the information can in part be used in conjunction with obtaining radioactive samples. 
Environmental Protection Agency (EPA). 1987. A Compendium of Superfund Field Operations Methods. EPA/540/P-87/001, EPA, Office of Emergency and Remedial Response, Washington, D.C.

- General Description of Document: Size: Approximately 375 pages-the size and title of this document is a clue to the comprehensive nature of this volume. In brief, the text of this document provides a potentially valuable resource to field workers involved with Multi-Agency Radiation Survey and Site Investigation Manual (MARSSIM) surveys. While relatively complete-in that the document covers a broad range of topics-some readers may desire additional depth to the information provided here. Conversely, planners and field personnel might gain added insight by considering the broad range of topics included here before approaching the survey process.

- $\quad$ Key Features of This Document: Perhaps the best summary of this compendium is provided by a listing of sections, as follows: 1) Use of the Compendium, 2) Preparation of Project Description and Statement of Objectives, 3) Implementing Field Objectives, 4) Sample Control, Including Chain of Custody, 5) Laboratory Interface, 6) Sample Containers, Preservation, and Shipping, 7) Field Methods for Screening Hazardous Material, 8) Earth Sciences (i.e., drilling, excavations, reconnaissance, geophysics, and ground water), 9) Earth Sciences Laboratory Procedures, 10) Surface Hydrology, 11) Meteorology and Air Quality, 12) Specialized Sampling Techniques (e.g., wipes, human habitation sampling, TCDD, and container sampling), 14) Land Surveying, Aerial Photography, and Mapping, 15) Field Instrumentation (a comprehensive treatment including radiation monitors), 16) data handling, 17) Document Control, 18) Corrective Action, 19) QA Audit Procedures, and 20) QA Reporting.

That this document serves objectives set forth by Superfund-and is not specifically focused on radionuclide sampling - in no way diminishes the importance of the compendium's complete overview of field sampling equipment and activities.

Environmental Protection Agency (EPA). 1989. Test Methods For Evaluating Solid Waste Physical/Chemical Methods - Third Edition Proposed Update Package. EPA, Office of Solid Waste, Washington, D.C. (PB89-148076)

- General Description of Document: Size Approximately 500 pages-composed of several updated chapters and 46 methods that are described by text and graphics. Only methods that are updated from 2nd Edition appear in this volume. 
Appendix M

- Key Features of This Document: Chapters 1, 2, 4, and 7 describe QC, Choosing the Correct Procedure, Organic Analytes, and Regulatory Definitions, respectively. Of primary interest are the 46 methods that are described in what constitutes the bulk of this document. However, as is evident from some of the first methods listed for organics, sample collection techniques are only briefly touched on by a section of Chapter Four. This essentially makes the methods laboratory oriented protocols and the only reference to field methods appears in the text of a short chapter as opposed to part of each method. Some methods do list Sample Collection, Preservation, and Handling information with emphasis on use of containers, acidification or refrigeration, or a brief set of points to consider when preparing to go out to the field.

Each method includes a method number and a title, plus the following information: 1) Scope and Application, 2) Summary of Method, 3) Interferences, 4) Apparatus and Materials, 5) Reagents, 6) Sample Collection, Preservation, and Handling, 7) Procedure, 8) QC, 9) Method Performance, and 10) References. Diagrams, flow charts, and tables follow the initial sequence of sections.

The listing of methods include Method 9320 for Radium-228, Method 9310 for Gross Alpha \& Gross Beta, and Method 9315 for Alpha-Emitting Radium Isotopes. These methods do not appear in the bound volume used for this review and thus no further comment is offered here.

Environmental Protection Agency (EPA). 1991. Compendium of ERT Surface Water and Sediment Sampling Procedures. OSWER Directive 9360.4-03, EPA, Office of Emergency and Remedial Response, Washington, D.C. (PB91-921274)

- General Description of Document: Size: 31 pages-this document includes three standard operating procedures (SOPs), the first of which is the same as the first SOP listed in the document described below.

- Key Features of This Document: The three SOPs included in this document include: 1) Sampling Equipment Decontamination, 2) Surface Water Sampling, and 3) Sediment Sampling. Each SOP is similar in content with sections that cover: scope, method summary, preservation, containers, equipment, apparatus, etc.

Environmental Protection Agency (EPA). 1991. Compendium of ERT Ground water Sampling Procedures. OSWER Directive 9360.4-06, EPA, Office of Emergency and Remedial Response, Washington, D.C. (PB91-921275) 
- General Description of Document: Size: 71 pages—this document embodies eight standard operating procedures (SOPs) with a similar format as that described above.

- Key Features of This Document: The SOPs covered in this document include sampling equipment decontamination, ground water well sampling, soil gas samples, installing monitor wells, water level measurements, and other topics related to ground water and wells.

Environmental Protection Agency (EPA). 1991. Compendium of ERT Soil Sampling and Surface Geophysics Procedures. OSWER Directive 9360.4-02, EPA, Office of Emergency and Remedial Response, Washington, D.C. (PB91-921273)

- General Description of Document: Size: 39 pages-this document lists four standard operating procedures (SOPs) for soil sampling - with a similar format as that described above.

- $\quad$ Key Features of This Document: The SOPs covered in this document include sampling equipment decontamination, soil sampling, soil gas sampling, and soil sampling and surface geophysics. The SOP for soil sampling is five pages in length. This treatment essentially covers samples collected from the soil surface, to use of augers and tube samplers, a trier, split-spoon (barrel) sampler, and excavation techniques.

Environmental Protection Agency (EPA). 1991. Environmental Compliance Branch Standard Operating Procedures and Quality Assurance Manual. EPA, Region IV, Environmental Services Division, Athens, GA.

- General Description of Document: Size: Approximately 500 pages (single sided)-This document is presented with seven sections and eleven appendices. The main sections cover standard operating polices and procedures which relates to the Region IV laboratory's administrative functions to SOPs that are specifically focused on sampling activities.

- $\quad$ Key Features of This Document: Sections 3 and 4 are of primary importance when thinking of sample control, field record keeping, document control and sampling procedures. Section 4 on sampling procedures is descriptive--without diagrams or figures-and quite comprehensive in that this section touches on a multitude of topics not mentioned in a number of other guides, including: selection of parameters to be measured, holding time, cross contamination, and Data Quality Objectives (DQOs) (described as Level I to V). The sampling of soil, water, and air are covered in this 
Appendix $\mathrm{M}$

section with many of the subsections covering topics that are common to other documents reviewed here. A number of example forms are presented, including several that relate to State programs. Section 6 covers field analytical methods and Section 7 describes field physical measurements.

The appendices include helpful information relevant to sampling, including: A) sample containers, preservation, holding times, and permissible sample type, B) standard cleaning procedures, C) shipping procedures, D) standard field analytical methods, E) monitoring wells, F) pump operation procedures, $G$ ) air monitoring, $H$ ) wastewater field methods, I) saturation monitoring, and K) safety protocols.

Environmental Protection Agency (EPA). 1992. Characterizing Heterogeneous Waste: Methods and Recommendations. EPA/600/R92/033, EPA, Environmental Monitoring Systems Laboratory, Office of Research and Development, Las Vegas, NV. (PB92-216894)

- General Description of Document: Size: 144 pages-the focus of this document is on all types of waste materials that one might encounter. The base scenario appears to be one where a drum is encountered and the objective is to work to a point when the drum contents are understood. Because a drum may include more than one type of waste, this document provides a review of a wide variety of materials one might expect when surveying a site.

- Key Features of This Document: The table of contents reveals that the text attempts to provide a complete picture, from definitions of terms, to planning studies, QA/QC and data assessment, to sample acquisition, and steps that follow to the lab and what makes the characterization process a success. Radioactive waste materials, along with organics, solids, liquids, etc., are covered, but in a relatively brief fashion. The model scenario of dealing with wastes in a drum is incorporated into a hypothetical example in an appendix. 


\section{APPENDIX N}

\section{Data Validation Using Data Descriptors}

Data validation is often defined by six data descriptors:

1) reports to decision maker

2) documentation

3) data sources

4) analytical method and detection limit

5) data review

6) data quality indicators

The decision maker or reviewer examines the data, documentation, and reports for each of the six data descriptors to determine if performance is within the limits specified in the DQOs developed during survey planning. The data validation process should be conducted according to procedures documented in the QAPP.

\section{N.1 Reports to Decision Maker}

Data and documentation supplied to the decision maker should be evaluated for completeness and appropriateness and to determine if any changes were made to the survey plan during the course of work. The survey plan discusses the surveying, sampling, and analytical design and contains the QAPP and DQOs. The decision maker should receive all data as collected plus preliminary and final data reports. The final decision on qualifying or rejecting data will be made during the assessment of environmental data. All data, including qualified or rejected data, should be documented and recorded even if the data are not included in the final report.

Preliminary analytical data reports allow the decision maker to begin the assessment process as soon as the surveying effort has begun. These initial reports have three functions.

1) For scoping or characterization survey data, they allow the decision maker to begin to characterize the site on the basis of actual data. Radionuclides of interest will be identified and the variability in concentration can be estimated.

2) They allow potential measurement problems to be identified and the need for corrective action can be assessed.

3) Schedules are more likely to be met if the planning of subsequent survey activities can begin before the final data reports are produced. 
Appendix N

\section{N.2 Documentation}

Three types of documentation should be assessed: (1) field operation records; (2) laboratory records; and (3) data handling records (EPA 1997).

\section{N.2.1 Field Operation Records}

The information contained in these records documents overall field operations and generally consists of the following:

- Field measurement records. These records show that the proper measurement protocol was performed in the field. At a minimum, this documentation should include the names of the persons conducting the activity, measurement identification, measurement locations, measurement results, maps and diagrams, equipment and SOP used, and unusual observations. Bound field notebooks are generally used to record raw data and make references to prescribed procedures and changes in planned activities. Data recording forms might also be used. A document control system should be used for these records to control attributes such as formatting to include pre-numbered pages with date and signature lines.

- Sample tracking records. Sample tracking records (e.g., chain-of-custody) document the progression of samples as they travel from the original sampling location to the laboratory and finally to disposal (see Section 7.7).

- $Q C$ measurement records. QC measurement records document the performance of QC measurements in the field. These records should include calibration and standards' traceability documentation that can be used to provide a reproducible reference point to which all similar measurements can be correlated. QC measurement records should contain information on the frequency, conditions, level of standards, and instrument calibration history.

- Personnel files. Personnel files record the names and training certificates of the staff collecting the data.

- General field procedures. General field procedures (e.g., SOPs) record the procedures used in the field to collect data and outline potential areas of difficulty in performing measurements.

- Deficiency and problem identification reports. These reports document problems and deficiencies encountered as well as suggestions for process improvement. 
- Corrective action reports. Corrective action reports show what methods were used in cases where general field practices or other standard procedures were violated and include the methods used to resolve noncompliance.

\section{N.2.2 Laboratory Records}

The following list describes some of the laboratory-specific records that should be compiled if available and appropriate:

- Laboratory measurement results and sample data. These records contain information on the sample analysis used to verify that prescribed analytical methods were followed. The overall number of samples, sample identification, sample measurement results, any deviations from the SOPs, time of day, and date should be included. Sample location information might also be provided.

- $\quad$ Sample management records. Sample management records should document sample receipt, handling and storage, and scheduling of analyses. The records will verify that sample tracking requirements were maintained, reflect any anomalies in the samples (e.g., receipt of damaged samples), and note proper log-in of samples into the laboratory.

- Test methods. Unless analyses were performed exactly as prescribed by SOPs, this documentation will describe how the analyses were carried out in the laboratory. This documentation includes sample preparation and analysis, instrument standardization, detection and reporting limits, and method-specific QC requirements. Documentation demonstrating laboratory proficiency with each method used could also be a part of the data reporting package, particularly for subcontracted work.

- $\quad Q C$ measurement records. These include the general $\mathrm{QC}$ records, such as initial demonstration of capability, instrument calibration, routine monitoring of analytical performance, calibration verification, etc., considered in Section 7.3 for selecting a radioanalytical laboratory. Project-specific information from the QC checks such as blanks, spikes, calibration check samples, replicates, splits, and so on should be included in these reports to facilitate data quality analysis.

- Deficiency and problem identification reports. These reports document problems and deficiencies encountered as well as suggestions for process improvement.

- Corrective action reports. Corrective action reports show what methods were used in cases where general laboratory practices or other standard procedures were violated and include the methods used to resolve noncompliance. Corrective action procedures to replace samples violating the SOP also should be noted. 
Appendix N

\section{N.2.3 Data Handling Records}

Data handling records document protocols used in data reduction, verification, and validation. Data reduction addresses data transformation operations such as converting raw data into reportable quantities and units, using significant figures, calculating measurement uncertainties, etc. The records document procedures for handling data corrections.

\section{N.3 Data Sources}

Data source assessment involves the evaluation and use of historical analytical data. Historical analytical data should be evaluated according to data quality indicators and not the source of the data (e.g., analytical protocols may have changed significantly over time). Data quality indicators are qualitative and quantitative descriptors used in interpreting the degree of acceptability or utility of data. Historical data sources are addressed during the Historical Site Assessment, and are discussed in Section 3.4.1.

\section{N.4 Analytical Method and Detection Limit}

The selection of appropriate analytical methods based on detection limits is important to survey planning. The detection limit of the method directly affects the usability of the data because results near the detection limit have a greater possibility of false negatives and false positives. Results near the detection limit have increased measurement uncertainty. When the measurement uncertainty becomes large compared to the variability in the radionuclide concentration, it becomes more difficult to demonstrate compliance using the guidance provided in MARSSIM.

The decision maker compares detection limits (i.e., minimum detectable concentrations; MDCs) with radionuclide-specific results to determine their effectiveness in relation to the DCGL. Assessment of preliminary data reports provides an opportunity to review the detection limits early and resolve any detection sensitivity problems. When a radionuclide is reported as not detected, the result can only be used with confidence if the MDCs reported are lower than the DCGL.

If the DCGL is less than or equal to the MDC, and the radionuclide is not detected, report the actual result of the analysis. Do not report data as "less than the detection limit." Even negative results and results with large uncertainties can be used in the statistical tests described in Chapter 8. Results reported as "<MDC" cannot be fully used and, for example, complicate even such simple analyses as calculating an average. When the MDC reported for a radionuclide is near the DCGL, the confidence in both identification and quantitation may be low. Information 
Appendix N

concerning non-detects or detections at or near MDCs should be qualified according to the degree of acceptable uncertainty.

\section{N.5 Data Review}

Data review begins with an assessment of the quality of analytical results and is performed by a professional with knowledge of the analytical procedures. Only data that are reviewed according to a specified level or plan should be used in the quantitative site investigation. Any analytical errors, or limitations in the data that are identified by the review, should be noted. An explanation of data qualifiers should be included with the review report.

All data should receive some level of review. Data that have not been reviewed should be identified, because the lack of review increases the uncertainty in the data. Unreviewed data may lead to Type I and Type II decision errors, and may also contain transcription errors and calculation errors. Data may be used in the preliminary assessment before review, but should be reviewed at a predetermined level before use in the final survey report.

Depending on the survey objectives, the level and depth of the data review varies. The level and depth of the data review may be determined during the planning process and should include an examination of laboratory and method performance for the measurements and radionuclides involved. This examination includes

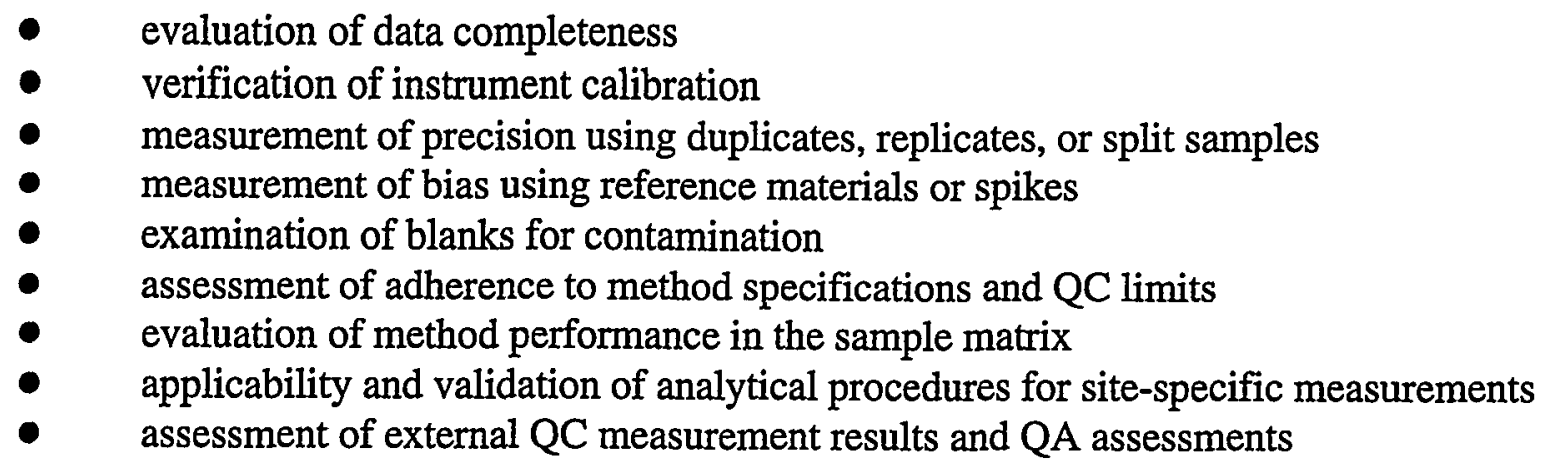

A different level or depth of data review may be indicated by the results of this evaluation. Specific data review procedures are dependent upon the survey objectives and should be documented in the QAPP. 
Appendix N

\section{N.6 Data Quality Indicators}

The assessment of data quality indicators presented in this section is significant to determine data usability. The principal data quality indicators are precision, bias, representativeness, comparability, and completeness (EPA 1997). Other data quality indicators affecting the RSSI process include the selection and classification of survey units, Type I and Type II decision error rates, the variability in the radionuclide concentration measured within the survey unit, and the lower bound of the gray region (see Section 2.3.1).

Of the six principal data quality indicators, precision and bias are quantitative measures, representativeness and comparability are qualitative, completeness is a combination of both qualitative and quantitative measures, and accuracy is a combination of precision and bias. The selection and classification of survey units is qualitative, while decision error rates, variability, and the lower bound of the gray region are quantitative measures.

The major activity in determining the usability of data based on survey activities is assessing the effectiveness of measurements. Scanning and direct measurements taken during survey activities and samples collected for analysis should meet site-specific objectives based on scoping and planning decisions.

Determining the usability of analytical results begins with the review of QC measurements and qualifiers to assess the measurement result and the performance of the analytical method. If an error in the data is discovered, it is more important to evaluate the effect of the error on the data than to determine the source of the error. The documentation described in Section N.2 is reviewed as a whole for some criteria. Data are reviewed at the measurement level for other criteria.

Factors affecting the accuracy of identification and the precision and bias of quantitation of individual radionuclides, such as calibration and recoveries, should be examined radionuclide by radionuclide. Table N.1 presents a summary of the QC measurements and the data use implications.

\section{N.6.1 Precision}

Precision is a measure of agreement among replicate measurements of the same property under prescribed similar conditions. This agreement is calculated as either the range or the standard deviation. It may also be expressed as a percentage of the mean of the measurements such as relative range (for duplicates) or coefficient of variation. 
Table N.1 Use of Quality Control Data

\begin{tabular}{|c|c|c|c|}
\hline $\begin{array}{l}\text { Quality Control } \\
\text { Criterion }\end{array}$ & $\begin{array}{l}\text { Effect on Identification When } \\
\text { Criterion is Not Met }\end{array}$ & $\begin{array}{c}\text { Quantitative } \\
\text { Bỉas }\end{array}$ & Use \\
\hline $\begin{array}{l}\text { Spikes (Higher than } \\
\text { expected result) }\end{array}$ & $\begin{array}{l}\text { Potential for incorrectly } \\
\text { deciding a survey unit does not } \\
\text { meet the release criterion } \\
\text { (Type II decision error) }\end{array}$ & High & Use data as upper limit \\
\hline $\begin{array}{l}\text { Spikes (Lower than } \\
\text { expected result) }\end{array}$ & $\begin{array}{l}\text { Potential for incorrectly } \\
\text { deciding a survey unit does } \\
\text { meet the release criterion } \\
\text { (Type I decision error) }\end{array}$ & Low & Use data as lower limit \\
\hline $\begin{array}{l}\text { Replicates } \\
\text { (Inconsistent) }\end{array}$ & $\begin{array}{l}\text { None, unless analyte found in } \\
\text { one duplicate and not the } \\
\text { other - then either Type I or } \\
\text { Type II decision error }\end{array}$ & High or Low ${ }^{b}$ & $\begin{array}{l}\text { Use data as } \\
\text { estimate-poor precision }\end{array}$ \\
\hline Blanks (Contaminated) & $\begin{array}{l}\text { Potential for incorrectly } \\
\text { deciding a survey unit does not } \\
\text { meet the release criterion } \\
\text { (Type II decision error) }\end{array}$ & High & $\begin{array}{l}\text { Check for gross } \\
\text { contamination or } \\
\text { instrument malfunction }\end{array}$ \\
\hline Calibration (Bias) & $\begin{array}{l}\text { Potential for Type I or Type II } \\
\text { decision errors }\end{array}$ & High or Low & $\begin{array}{l}\text { Use data as estimate } \\
\text { unless problem is } \\
\text { extreme }\end{array}$ \\
\hline
\end{tabular}

a Only likely if recovery is near zero.

b Effect on bias determined by examination of data for each radionuclide.

For scanning and direct measurements, precision may be specified for a single person performing the measurement or as a comparison between people performing the same measurement. For laboratory analyses, precision may be specified as either intralaboratory (within a laboratory) or interlaboratory (between laboratories). Precision estimates based on a single surveyor or laboratory represent the agreement expected when the same person or laboratory uses the same method to perform multiple measurements of the same location. Precision estimates based on two or more surveyors or laboratories refer to the agreement expected when different people or laboratories perform the same measurement using the same method.

The two basic activities performed in the assessment of precision are estimating the radionuclide concentration variability from the measurement locations and estimating the measurement error attributable to the data collection process. The level for each of these performance measures 
Appendix $N$

should be specified during development of DQOs. If the statistical performance objectives are not met, additional measurements should be taken or one (or more) of the performance parameters changed.

Measurement error is estimated using the results of replicate measurements, as discussed in Chapter 6 for field measurements and Chapter 7 for laboratory measurements. When collocated measurements are performed (in the field or in the laboratory) an estimate of total precision is obtained. When collocated samples are not available for laboratory analysis, a sample subdivided in the field and preserved separately can be used to assess the variability of sample handling, preservation, and storage along with the variability in the analytical process, but variability in sample acquisition is not included. When only variability in the analytical process is desired, a sample can be subdivided in the laboratory prior to analysis.

Summary statistics such as sample mean and sample variance can provide as assessment of the precision of a measurement system or component thereof for a project. These statistics may be used to estimate precision at discrete concentration levels, average estimated precision over applicable concentration ranges, or provide the basis for a continual assessment of precision for future measurements. Methods for calculating and reporting precision are provided in $E P A$ Guidance for Quality Assurance Project Plans (EPA 1997).

Table N.2 presents the minimum considerations, impacts if the considerations are not met, and corrective actions for precision.

\section{N.6.2 Bias}

Bias is the systematic or persistent distortion of a measurement process that causes errors in one direction. Bias assessments for radioanalytical measurements should be made using personnel, equipment, and spiking materials or reference materials as independent as possible from those used in the calibration of the measurement system. When possible, bias assessments should be based on certified reference materials rather than matrix spikes or water spikes so that the effect of the matrix and the chemical composition of the contamination is incorporated into the assessment. While matrix spikes include matrix effects, the addition of a small amount of liquid spike does not always reflect the chemical composition of the contamination in the sample matrix. Water spikes do not account for either matrix effects or chemical composition of the contamination. When spikes are used to assess bias, a documented spiking protocol and consistency in following that protocol are important to obtaining meaningful data quality estimates. 


\section{Table N.2 Minimum Considerations for Precision, Impact if Not Met, and Corrective Actions}

\begin{tabular}{|c|c|c|}
\hline $\begin{array}{l}\text { Minimum Considerations for } \\
\text { Precision }\end{array}$ & $\begin{array}{l}\text { Impact When Minimum } \\
\text { Considerations Are Not Met }\end{array}$ & Corrective Action \\
\hline $\begin{array}{l}\text { Confidence level as specified } \\
\text { in DQOs. } \\
\text { Power as specified in DQOs. } \\
\text { Minimum detectable relative } \\
\text { differences specified in the } \\
\text { survey design and modified } \\
\text { after analysis of background } \\
\text { measurements if necessary } \\
\text { One set of field duplicates or } \\
\text { more as specified in the survey } \\
\text { design. } \\
\text { Analytical duplicates and splits } \\
\text { as specified in the survey } \\
\text { design. } \\
\text { Measurement error specified. }\end{array}$ & $\begin{array}{l}\text { Errors in decisions to act or not } \\
\text { to act based on analytical data. } \\
\text { Unacceptable level of } \\
\text { uncertainty. } \\
\text { Increased variability of } \\
\text { quantitative results. } \\
\text { Potential for incorrectly } \\
\text { deciding a survey unit does } \\
\text { meet the release criterion for } \\
\text { measurements near the } \\
\text { detection limits (Type I } \\
\text { decision error). }\end{array}$ & $\begin{array}{l}\text { For Surveying and Sampling: } \\
\text { Add survey or sample locations based } \\
\text { on information from available data that } \\
\text { are known to be representative. } \\
\text { Adjust performance objectives. } \\
\text { For Analysis: } \\
\text { Analysis of new duplicate samples. } \\
\text { Review laboratory protocols to ensure } \\
\text { comparability. } \\
\text { Use precision measurements to } \\
\text { determine confidence limits for the } \\
\text { effects on the data. } \\
\text { The investigator can use the maximum } \\
\text { measurement results to set an upper } \\
\text { bound on the uncertainty if there is too } \\
\text { much variability in the analyses. }\end{array}$ \\
\hline
\end{tabular}

Activity levels for bias assessment measurements should cover the range of expected contaminant concentrations, although the minimum activity is usually at least five times the MDC. For many final status surveys, the expected contaminant concentration is zero or background, so the highest activity will be associated with the bias assessment measurements. The minimum and maximum concentrations allowable in bias assessment samples should be agreed on during survey planning activities to prevent accidental contamination of the environment or an environmental level radioanalytical laboratory.

For scanning and direct measurements there are a limited number of options available for performing bias assessment measurements. Perhaps the best estimate of bias for scanning and direct measurements is to collect samples from locations where scans or direct measurements were performed, analyze the samples in a laboratory, and compare the results. Problems associated with this method include the time required to obtain the results and the difficulty in 
Appendix N

obtaining samples that are representative of the field measurement to provide comparable results. A simple method of demonstrating that analytical bias is not a significant problem for scanning or direct measurements is to use the instrument performance checks to demonstrate the lack of analytical bias. A control chart can be used to determine the variability of a specific instrument and track the instrument performance throughout the course of the survey. Field background measurements can also be plotted on a control chart to estimate bias caused by contamination of the instrument.

There are several types of bias assessment samples available for laboratory analyses as discussed in Chapter 7. Field blanks can be evaluated to estimate the potential bias caused by contamination from sample collection, preparation, shipping, and storage.

Table N.3 presents the minimum considerations, impacts if the considerations are not met, and corrective actions for bias.

\section{Table N.3 Minimum Considerations for Bias, Impact if Not Met, and Corrective Actions}

\begin{tabular}{|c|c|c|}
\hline $\begin{array}{c}\text { Minimum Considerations for } \\
\text { Bias }\end{array}$ & $\begin{array}{l}\text { Impact When Minimum } \\
\text { Considerations Are Not Met }\end{array}$ & Corrective Action \\
\hline $\begin{array}{l}\text { Matrix spikes to assess bias of } \\
\text { non-detects and positive sample } \\
\text { results if specified in the survey } \\
\text { design. } \\
\text { Analytical spikes as specified in } \\
\text { the survey design. } \\
\text { Use analytical methods (routine } \\
\text { methods whenever possible) that } \\
\text { specify expected or required } \\
\text { recovery ranges using spikes or } \\
\text { other QC measures. } \\
\text { No radionuclides of potential } \\
\text { concern detected in the blanks. }\end{array}$ & $\begin{array}{l}\text { Potential for incorrectly deciding a } \\
\text { survey unit does meet the release } \\
\text { criterion (Type I decision error): if } \\
\text { spike recovery is low, it is } \\
\text { probable that the method or } \\
\text { analysis is biased low for that } \\
\text { radionuclide and values of all } \\
\text { related samples may underestimate } \\
\text { the actual concentration. } \\
\text { Potential for incorrectly deciding a } \\
\text { survey unit does not meet the } \\
\text { release criterion (Type II decision } \\
\text { error): if spike recovery exceeds } \\
\text { 100\%, interferences may be } \\
\text { present, and it is probable that the } \\
\text { method or analysis is biased high. } \\
\text { Analytical results overestimate the } \\
\text { true concentration of the spiked } \\
\text { radionuclide. }\end{array}$ & $\begin{array}{l}\text { Consider resampling at affected } \\
\text { locations. } \\
\text { If recoveries are extremely low or } \\
\text { extremely high, the investigator } \\
\text { should consult with a } \\
\text { radiochemist or health physicist } \\
\text { to identify a more appropriate } \\
\text { method for reanalysis of the } \\
\text { samples. }\end{array}$ \\
\hline
\end{tabular}


Appendix N

\section{N.6.3 Accuracy}

Accuracy is a measure of the closeness of an individual measurement or the average of a number of measurements to the true value (EPA 1997). Accuracy includes a combination of random error (precision) and systematic error (bias) components that result from performing measurements. Systematic and random uncertainties (or errors) are discussed in more detail in Section 6.8.1.

Accuracy is determined by analyzing a reference material of known contaminant concentration or by reanalyzing material to which a known concentration of contaminant has been added. To be accurate, data must be both precise and unbiased. Using the analogy of archery, to be accurate one's arrows must land close together and, on average, at the spot where they are aimed. That is, the arrows must all land near the bull's eye (see Figure N.1).

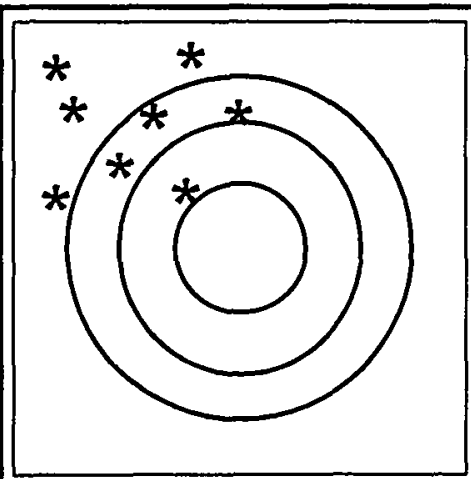

(a) high bias + low precision $=$ low accuracy

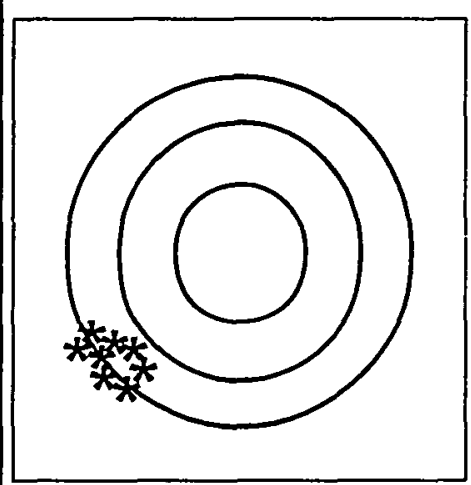

(c) high bias + high precision $=$ low accuracy

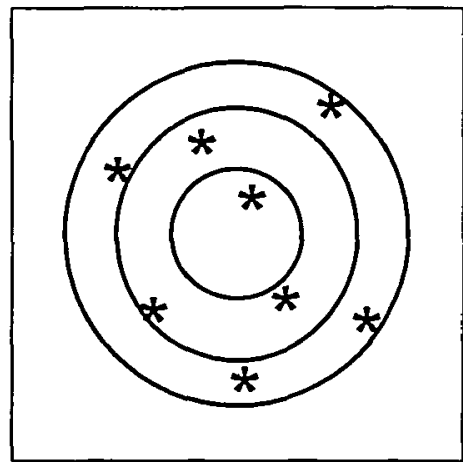

(b) low bias + low precision = low accuracy

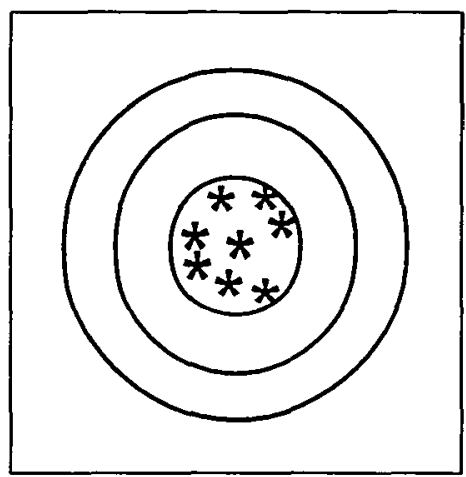

(d) low bias + high precision $=$ high accuracy

Figure N.1 Measurement Bias and Random Measurement Uncertainty 
Accuracy is usually expressed either as a percent recovery or as a percent bias. Determination of accuracy always includes the effects of variability (precision); therefore, accuracy is used as a combination of bias and precision. The combination is known statistically as mean square error. Mean square error is the quantitative term for overall quality of individual measurements or estimators.

Mean square error is the sum of the variance plus the square of the bias. (The bias is squared to eliminate concern over whether the bias is positive or negative.) Frequently it is impossible to quantify all of the components of the mean square error-especially the biases-but it is important to attempt to quantify the magnitude of such potential biases, often by comparison with auxiliary data.

\section{N.6.4 Representativeness}

Representativeness is a measure of the degree to which data accurately and precisely represent a characteristic of a population parameter at a sampling point or for a process condition or environmental condition. Representativeness is a qualitative term that should be evaluated to determine whether in situ and other measurements are made and physical samples collected in such a manner that the resulting data appropriately reflect the media and contamination measured or studied.

Representativeness of data is critical to data usability assessments. The results of the environmental radiological survey will be biased to the degree that the data do not reflect the radionuclides and concentrations present at the site. Non-representative radionuclide identification may result in false negatives. Non-representative estimates of concentrations may be higher or lower than the true concentration. With few exceptions, non-representative measurements are only resolved by additional measurements.

Representativeness is primarily a planning concern. The solution to enhancing representativeness is in the design of the survey plan. Representativeness is determined by examining the survey plan. Analytical data quality affects representativeness since data of low quality may be rejected for use.

Table N.4 presents the minimum considerations, impacts if the considerations are not met, and corrective actions for representativeness.

\section{N.6.5 Comparability}

Comparability is the qualitative term that expresses the confidence that two data sets can contribute to a common analysis and interpolation. Comparability should be carefully evaluated to establish whether two data sets can be considered equivalent in regard to the measurement of a specific variable or groups of variables. 
Table N.4 Minimum Considerations for Representativeness, Impact if Not Met, and Corrective Actions

\begin{tabular}{|c|c|c|}
\hline $\begin{array}{l}\text { Minimum Considerations for } \\
\text { Representativeness }\end{array}$ & $\begin{array}{l}\text { Impact When Minimum } \\
\text { Considerations Are Not Met }\end{array}$ & Corrective Action \\
\hline $\begin{array}{l}\text { Survey data representative of } \\
\text { survey unit. } \\
\text { Documented sample preparation } \\
\text { procedures. Filtering, } \\
\text { compositing, and sample } \\
\text { preservation may affect } \\
\text { representativeness. } \\
\text { Documented analytical data as } \\
\text { specified in the survey design. }\end{array}$ & $\begin{array}{l}\text { Bias high or low in estimate of } \\
\text { extent and quantity of } \\
\text { contaminated material. } \\
\text { Potential for incorrectly deciding a } \\
\text { survey unit does meet the release } \\
\text { criterion (Type I decision error). } \\
\text { Inaccurate identification or } \\
\text { estimate of concentration of a } \\
\text { radionuclide. } \\
\text { Remaining data may no longer } \\
\text { sufficiently represent the site if a } \\
\text { large portion of the data are } \\
\text { rejected, or if all data from } \\
\text { measurements at a specific } \\
\text { location are rejected. }\end{array}$ & $\begin{array}{l}\text { Additional surveying or sampling. } \\
\text { Examination of effects of sample } \\
\text { preparation procedures. } \\
\text { Reanalysis of samples, or } \\
\text { resurveying or resampling of the } \\
\text { affected site areas. } \\
\text { If the resurveying, resampling, or } \\
\text { reanalyses cannot be performed, } \\
\text { document in the site } \\
\text { environmental radiological survey } \\
\text { report what areas of the site are } \\
\text { not represented due to poor } \\
\text { quality of analytical data. }\end{array}$ \\
\hline
\end{tabular}

Comparability is not compromised provided that the survey design is unbiased, and the survey design or analytical methods are not changed over time. Comparability is a very important qualitative data indicator for analytical assessment and is a critical parameter when considering the combination of data sets from different analyses for the same radionuclides. The assessment of data quality indicators determines if analytical results being reported are equivalent to data obtained from similar analyses. Only comparable data sets can be readily combined.

The use of routine methods (as defined in Section 7.6) simplifies the determination of comparability because all laboratories use the same standardized procedures and reporting parameters. In other cases, the decision maker may have to consult with a health physicist and/or radiochemist to evaluate whether different methods are sufficiently comparable to combine data sets.

There are a number of issues that can make two data sets comparable, and the presence of each of the following items enhances their comparability (EPA 1997). 
Appendix $\mathrm{N}$

- two data sets should contain the same set of variables of interest.

- units in which these variables were measured should be convertible to a common metric.

- similar analytic procedures and quality assurance should be used to collect data for both data sets

- time of measurements of certain characteristics (variables) should be similar for both data sets

- measuring devices used for both data sets should have approximately similar detection levels

- rules for excluding certain types of observations from both samples should be similar

- samples within data sets should be selected in a similar manner

- sampling frames from which the samples were selected should be similar

- number of observations in both data sets should be of the same order of magnitude

These characteristics vary in importance depending on the final use of the data. The closer two data sets are with regard to these characteristics, the more appropriate it will be to compare them. Large differences between characteristics may be of only minor importance depending on the decision that is to be made from the data.

Table N.5 presents the minimum considerations, impacts if they are not met, and corrective actions for comparability.

\section{N.6.6 Completeness}

Completeness is a measure of the amount of valid data obtained from the measurement system, expressed as a percentage of the number of valid measurements that should have been collected (i.e., measurements that were planned to be collected).

Completeness for measurements is calculated by the following formula:

$$
\text { \%Completeness }=\frac{\text { (Number of Valid Measurements) } \times 100}{\text { Total Number of Measurements Planned }}
$$

Completeness is not intended to be a measure of representativeness; that is, it does not describe how closely the measured results reflect the actual concentration or distribution of the contaminant in the media being measured. A project could produce $100 \%$ data completeness (i.e., all planned measurements were actually performed and found valid), but the results may not be representative of the actual contaminant concentration. 
Table N.5 Minimum Considerations for Comparability, Impact if Not Met, and Corrective Actions

\begin{tabular}{||l|l|l||}
\hline \multicolumn{1}{|c|}{$\begin{array}{c}\text { Minimum Considerations for } \\
\text { Comparability }\end{array}$} & \multicolumn{1}{|c|}{$\begin{array}{c}\text { Impact When Minimum } \\
\text { Considerations Are Not Met }\end{array}$} & \multicolumn{1}{c|}{ Corrective Action } \\
\hline \hline $\begin{array}{l}\text { Unbiased survey design or } \\
\text { documented reasons for selecting } \\
\text { another survey design. }\end{array}$ & Non-additivity of survey results. \\
$\begin{array}{l}\text { The analytical methods used should } \\
\text { have common analytical parameters. } \\
\text { Reduced confidence, power, and } \\
\text { ability to detect differences, } \\
\text { given the number of } \\
\text { measurements available. }\end{array}$ & $\begin{array}{l}\text { For Surveying and Sampling: } \\
\text { Statistical analysis of effects of } \\
\text { bias. }\end{array}$ \\
$\begin{array}{l}\text { Same units of measure used in } \\
\text { reporting. }\end{array}$ & Increased overall error. \\
$\begin{array}{l}\text { Similar detection limits. } \\
\begin{array}{l}\text { Equivalent sample preparation } \\
\text { techniques. }\end{array}\end{array}$ & $\begin{array}{l}\text { For Analytical Data: } \\
\text { Preferentially use those data that } \\
\text { provide the most definitive } \\
\text { identification and quantitation of } \\
\text { the radionuclides of potential } \\
\text { concern. For quantitation, } \\
\text { examine the precision and } \\
\text { accuracy data along with the } \\
\text { reported detection limits. }\end{array}$ \\
$\begin{array}{l}\text { Analytical equipment with similar } \\
\text { should be factored into the results. }\end{array}$ & & $\begin{array}{l}\text { Reanalysis using comparable } \\
\text { methods. }\end{array}$ \\
\hline
\end{tabular}

Alternatively, there could be only $70 \%$ data completeness ( $30 \%$ lost or found invalid), but, due to the nature of the survey design, the results could still be representative of the target population and yield valid estimates. The degree to which lack of completeness affects the outcome of the survey is a function of many variables ranging from deficiencies in the number of measurements to failure to analyze as many replications as deemed necessary by the QAPP and DQOs. The intensity of effect due to incompleteness of data is sometimes best expressed as a qualitative measure and not just as a quantitative percentage.

Completeness can have an effect on the $\mathrm{DQO}$ parameters. Lack of completeness may require reconsideration of the limits for decision error rates because insufficient completeness will decrease the power of the statistical tests described in Chapter 8.

For most final status surveys, the issue of completeness only arises when the survey unit demonstrates compliance with the release criterion and less than $100 \%$ of the measurements are determined to be acceptable. The question now becomes whether the number of measurements is sufficient to support the decision to release the survey unit. This question can be answered by constructing a power curve as described in Appendix I and evaluating the results. An alternative 
method is to consider that the number of measurements estimated to demonstrate compliance in Chapter 5 was increased by $20 \%$ to account for lost or rejected data and uncertainty in the calculation of the number of measurements. This means a survey with $80 \%$ completeness may still have sufficient power to support a decision to release the survey unit.

Table N.6 presents the minimum considerations, impacts if the considerations are not met, and corrective actions for completeness.

\section{Table N.6 Minimum Considerations for Completeness, Impact if Not Met, and Corrective Actions}

\begin{tabular}{|c|c|c|}
\hline $\begin{array}{l}\text { Minimum Considerations for } \\
\text { Completeness }\end{array}$ & $\begin{array}{l}\text { Impact When Minimum } \\
\text { Considerations Are Not Met }\end{array}$ & Corrective Action \\
\hline $\begin{array}{l}\text { Percentage of measurement } \\
\text { completeness determined during } \\
\text { planning to meet specified } \\
\text { performance measures. }\end{array}$ & $\begin{array}{l}\text { Higher potential for incorrectly } \\
\text { deciding a survey unit does not meet } \\
\text { the release criterion (Type II decision } \\
\text { error). } \\
\text { Reduction in power. } \\
\text { A reduction in the number of } \\
\text { measurements reduces site coverage } \\
\text { and may affect representativeness. } \\
\text { Reduced ability to differentiate site } \\
\text { levels from background. } \\
\text { Impact of incompleteness generally } \\
\text { decreases as the number of } \\
\text { measurements increases. }\end{array}$ & $\begin{array}{l}\text { Resurveying, resampling, or } \\
\text { reanalysis to fill data gaps. } \\
\text { Additional analysis of samples } \\
\text { already in laboratory. } \\
\text { Determine whether the missing } \\
\text { data are crucial to the survey. }\end{array}$ \\
\hline
\end{tabular}

\section{N.6.7 Selection and Classification of Survey Units}

Selection and classification of survey units is a qualitative measure of the assumptions used to develop the survey plan. The level of survey effort, measurement locations (i.e., random vs. systematic and density of measurements), and the integrated survey design are based on the survey unit classification. The results of the survey should be reviewed to determine whether the classification used to plan the survey is supported by the results of the survey. 
If a Class 3 survey unit is found to contain areas of contamination (even if the survey unit passes the statistical tests), the survey unit may be divided into several survey units with appropriate classifications, and additional surveys planned as necessary for these new survey units.

Class 3 areas may only require additional randomly located measurements to provide sufficient power to release the new survey units. Class 2 and Class 1 areas will usually require a new survey design based on systematic measurement locations, and Class 1 areas may require remediation before a new final status survey is performed.

If a Class 2 survey unit is determined to be a Class 1 survey unit following the final status survey and remediation is not required, it may not be necessary to plan a new survey. The scan MDC should be compared to the DCGL ${ }_{\mathrm{EMC}}$ to determine if the measurement spacing is adequate to meet the survey objectives. If the scan MDC is too high, a new scan survey using a more sensitive measurement technique may be available. Alternatively, a new survey may be planned using a new measurement spacing or a stratified survey design may be implemented to use as much of the existing data as possible.

\section{N.6.8 Decision Error Rates}

The decision error rates developed during survey planning are related to completeness. A low level of completeness will affect the power of the statistical test. It is recommended that a power curve be constructed as described in Appendix I, and the expected decision error rates compared to the actual decision error rates to determine if the survey objectives have been accomplished.

\section{N.6.9 Variability in Contaminant Concentration}

The variability in the contaminant concentration (both in the survey unit and the reference area) is a key parameter in survey planning, and is related to the precision of the measurements. Statistical simulations show that underestimating the value of $\sigma$ (the standard deviation of the survey unit measurements) can greatly increase the probability that a survey unit will fail to demonstrate compliance with the release criterion.

If a survey unit fails to demonstrate compliance and the actual $\sigma$ is greater than the $\sigma$ used during survey planning, there are several options available to the project manager. If the major component of variability is measurement uncertainty, a new survey can be designed using a measurement technique with higher precision or a lower MDC to reduce variability. If samples were collected as part of the survey design, it may only be necessary to reanalyze the samples using a method with higher precision rather than collect additional samples. Alternatively, the number of measurements can be increased to reduce the variability. 
Appendix N

If the variability is due to actual variations in the contaminant concentration, there are still options available. If there is a high variability in the reference area, it may be appropriate to demonstrate the survey unit is indistinguishable from background. NUREG 1505 (NRC 1997b) provides guidance on determining whether this test is appropriate and performing the statistical tests. If the variability is caused by different contaminant distributions in different parts of the site (i.e., changing soil types influences contaminant concentrations), it may be appropriate to redefine the survey unit boundaries to provide a more homogeneous set of survey units.

\section{N.6.10 Lower Bound of the Gray Region}

The lower bound of the gray region (LBGR) is used to calculate the relative shift, which in turn is used to estimate the number of measurements required to demonstrate compliance. The LBGR is initially set arbitrarily to one half the DCGL ${ }_{\mathrm{w}}$. If this initial selection is used to design the survey, there is no technical basis for the selection of this value. This becomes important because the Type II decision error rate $(\beta)$ is calculated at the LBGR.

For survey units that pass the statistical tests, the value selected for the LBGR is generally not a concern. If the survey unit fails to demonstrate compliance, it may be caused by improper selection of the LBGR. Because the number of measurements estimated during survey planning is based on the relative shift (which includes both $\sigma$ and the LBGR), MARSSIM recommends that a power curve be constructed as described in Appendix I. If the survey unit failed to demonstrate compliance because of a lack of statistical power, an adjustment of the LBGR may be necessary when planning subsequent surveys. 


\section{GLOSSARY}

91b material: Any material identified under Section 91b of the Atomic Energy Act of 1954 (42 U.S.C. Section 2121).

$\mathbf{A}_{\mathrm{mn}}$ : The smallest area of elevated activity identified using the DQO Process that is important to identify.

action level: The numerical value that will cause the decision maker to choose one of the alternative actions. It may be a regulatory threshold standard (e.g., Maximum Contaminant Level for drinking water), a dose- or risk-based concentration level (e.g., DCGL), or a reference-based standard. See investigation level.

activity: See radioactivity.

ALARA (acronym for As Low As Reasonably Achievable): A basic concept of radiation protection which specifies that exposure to ionizing radiation and releases of radioactive materials should be managed to reduce collective doses as far below regulatory limits as is reasonably achievable considering economic, technological, and societal factors, among others. Reducing exposure at a site to ALARA strikes a balance between what is possible through additional planning and management, remediation, and the use of additional resources to achieve a lower collective dose level. A determination of ALARA is a site-specific analysis that is open to interpretation, because it depends on approaches or circumstances that may differ between regulatory agencies. An ALARA recommendation should not be interpreted as a set limit or level.

alpha $(\alpha)$ : The specified maximum probability of a Type I error. In other words, the maximum probability of rejecting the null hypothesis when it is true. Alpha is also referred to as the size of the test. Alpha reflects the amount of evidence the decision maker would like to see before abandoning the null hypothesis.

alpha particle: A positively charged particle emitted by some radioactive materials undergoing radioactive decay.

alternative hypothesis $\left(\mathbf{H}_{\mathbf{a}}\right)$ : See hypothesis.

area: A general term referring to any portion of a site, up to and including the entire site.

area of elevated activity: An area over which residual radioactivity exceeds a specified value $D C G L_{E M C}$. 
Glossary

area factor $\left(\mathbf{A}_{\mathfrak{m}}\right):$ A factor used to adjust $D C G L_{W}$ to estimate $D C G L_{E M C}$ and the minimum detectable concentration for scanning surveys in Class 1 survey units $-D C G L_{E M C}=D C G L_{W} A_{m}$. $A_{m}$ is the magnitude by which the residual radioactivity in a small area of elevated activity can exceed the $D C G L_{W}$ while maintaining compliance with the release criterion. Examples of area factors are provided in Chapter 5 of this manual.

arithmetic mean: The average value obtained when the sum of individual values is divided by the number of values.

arithmetic standard deviation: A statistic used to quantify the variability of a set of data. It is calculated in the following manner: 1) subtracting the arithmetic mean from each data value individually, 2) squaring the differences, 3) summing the squares of the differences, 4) dividing the sum of the squared differences by the total number of data values less one, and 5) taking the square root of the quotient. The calculation process produces the Root Mean Square Deviation (RMSD).

assessment: The evaluation process used to measure the performance or effectiveness of a system and its elements. As used in MARSSIM, assessment is an all-inclusive term used to denote any of the following: audit, performance evaluation, management systems review, peer review, inspection, or surveillance.

attainment objectives: Objectives that specify the design and scope of the sampling study including the radionuclides to be tested, the cleanup standards to be attained, the measure or parameter to be compared to the cleanup standard, and the Type I and Type II error rates for the selected statistical tests.

audit (quality): A systematic and independent examination to determine whether quality activities and related results comply with planned arrangements and whether these arrangements are implemented effectively and are suitable to achieve objectives.

\section{background reference area: See reference area.}

background radiation: Radiation from cosmic sources, naturally occurring radioactive material, including radon (except as a decay product of source or special nuclear material), and global fallout as it exists in the environment from the testing of nuclear explosive devices or from nuclear accidents like Chernobyl which contribute to background radiation and are not under the control of the cognizant organization. Background radiation does not include radiation from source, byproduct, or special nuclear materials regulated by the cognizant Federal or State agency. Different definitions may exist for this term. The definition provided in regulations or regulatory program being used for a site release should always be used if it differs from the definition provided here. 
Becquerel (Bq): The International System (SI) unit of activity equal to one nuclear transformation (disintegration) per second. $1 \mathrm{~Bq}=2.7 \times 10^{-11}$ Curies $(\mathrm{Ci})=27.03$ picocuries (pCi).

beta ( $\beta$ ): The probability of a Type II error, i.e., the probability of accepting the null hypothesis when it is false. The complement of beta $(1-\beta)$ is referred to as the power of the test.

beta particle: An electron emitted from the nucleus during radioactive decay.

bias: The systematic or persistent distortion of a measurement process which causes errors in one direction (i.e., the expected sample measurement is different from the sample's true value).

biased sample or measurement: See judgement measurement.

byproduct material: Any radioactive material (except special nuclear material) yielded in or made radioactive by exposure to the radiation incident to the process of producing or utilizing special nuclear material.

calibration: Comparison of a measurement standard, instrument, or item with a standard or instrument of higher accuracy to detect and quantify inaccuracies and to report or eliminate those inaccuracies by adjustments.

CDE (committed dose equivalent): The dose equivalent calculated to be received by a tissue or organ over a 50-year period after the intake into the body. It dose not include contributions from radiation sources external to the body. CDE is expressed in units of Sv or rem.

CEDE (committed effective dose equivalent): The sum of the committed dose equivalent to various tissues in the body, each multiplied by the appropriate weighting factor $\left(W_{t}\right) . \operatorname{CEDE}$ is expressed in units of Sv or rem. See TEDE.

chain of custody: An unbroken trail of accountability that ensures the physical security of samples, data, and records.

characterization survey: A type of survey that includes facility or site sampling, monitoring, and analysis activities to determine the extent and nature of contamination. Characterization surveys provide the basis for acquiring necessary technical information to develop, analyze, and select appropriate cleanup techniques.

Class 1 area: An area that is projected to require a Class 1 final status survey. 
Glossary

Class 1 survey: A type of final status survey that applies to areas with the highest potential for contamination, and meet the following criteria: (1) impacted; (2) potential for delivering a dose above the release criterion; (3) potential for small areas of elevated activity; and (4) insufficient evidence to support reclassification as Class 2 or Class 3.

Class 2 area: An area that is projected to require a Class 2 final status survey.

Class 2 survey: A type of final status survey that applies to areas that meet the following criteria: (1) impacted; (2) low potential for delivering a dose above the release criterion; and (3) little or no potential for small areas of elevated activity.

Class 3 area: An area that is projected to require a Class 3 final status survey.

Class 3 survey: A type of final status survey that applies to areas that meet the following criteria: (1) impacted; (2) little or no potential for delivering a dose above the release criterion; and (3) little or no potential for small areas of elevated activity.

classification: The act or result of separating areas or survey units into one of three designated classes: Class 1 area, Class 2 area, or Class 3 area.

cleanup: Actions taken to deal with a release or threatened release of hazardous substances that could affect public health or the environment. The term is often used broadly to describe various Superfund response actions or phases of remedial responses, such as remedial investigation/ feasibility study. Cleanup is sometimes used interchangeably with the terms remedial action, response action, or corrective action.

cleanup standard: A numerical limit set by a regulatory agency as a requirement for releasing a site after cleanup. See release criterion.

cleanup (survey) unit: A geographical area of specified size and shape defined for the purpose of survey design and compliance testing.

coefficient of variation: A unitless measure that allows the comparison of dispersion across several sets of data. It is often used in environmental applications because variability (expressed as a standard deviation) is often proportional to the mean. See relative standard deviation.

comparability: A measure of the confidence with which one data set can be compared to another.

completeness: A measure of the amount of valid data obtained from a measurement system compared to the amount that was expected to be obtained under correct, normal conditions. 
composite sample: A sample formed by collecting several samples and combining them (or selected portions of them) into a new sample which is then thoroughly mixed.

conceptual site model: A description of a site and its environs and presentation of hypotheses regarding the contaminants present, their routes of migration, and their potential impact on sensitive receptors.

confidence interval: A range of values for which there is a specified probability (e.g., 80\%, $90 \%, 95 \%$ ) that this set contains the true value of an estimated parameter.

confirmatory survey: A type of survey that includes limited independent (third-party) measurements, sampling, and analyses to verify the findings of a final status survey.

consensus standard: A standard established by a group representing a cross section of a particular industry or trade, or a part thereof.

contamination: The presence of residual radioactivity in excess of levels which are acceptable for release of a site or facility for unrestricted use.

control chart: A graphic representation of a process, showing plotted values of some statistic gathered from that characteristic, and one or two control limits. It has two basic uses: 1) as a judgement to determine if a process was in control, and 2) as an aid in achieving and maintaining statistical control.

core sample: A soil sample taken by core drilling.

corrective action: An action taken to eliminate the causes of an existing nonconformance, deficiency, or other undesirable situation in order to prevent recurrence.

criterion: See release criterion.

critical group: The group of individuals reasonably expected to receive the greatest exposure to residual radioactivity for any applicable set of circumstances.

critical level $\left(\mathbf{L}_{\mathbf{c}}\right)$ : A fixed value of the test statistic corresponding to a given probability level, as determined from the sampling distribution of the test statistic. $L_{c}$ is the level at which there is a statistical probability (with a predetermined confidence) of correctly identifying a background value as "greater than background." 
Glossary

critical value: The value of a statistic $(t)$ corresponding to a given significance level as determined from its sampling distribution; e.g., if $\operatorname{Pr}\left(t>t_{0}\right)=0.05$, $t_{0}$ is the critical value of $t$ at the 5 percent level.

curie (Ci): The customary unit of radioactivity. One curie $(\mathrm{Ci})$ is equal to 37 billion disintegrations per second $\left(3.7 \times 10^{10} \mathrm{dps}=3.7 \times 10^{10} \mathrm{~Bq}\right)$, which is approximately equal to the decay rate of one gram of ${ }^{226} \mathrm{Ra}$. Fractions of a curie, e.g. picocurie (pCi) or $10^{-12} \mathrm{Ci}$ and microcurie $(\mu \mathrm{Ci})$ or $10^{-6} \mathrm{Ci}$, are levels typically encountered in decommissioning.

cyclotron: A device used to impart high energy to charged particles, of atomic weight one or greater, which can be used to initiate nuclear transformations upon collision with a suitable target.

D: The true, but unknown, value of the difference between the mean concentration of residual radioactivity in the survey unit and the reference area.

DQA (Data Quality Assessment): The scientific and statistical evaluation of data to determine if the data are of the right type, quality, and quantity to support their intended use.

DQOs (Data Quality Objectives): Qualitative and quantitative statements derived from the DQO process that clarify study technical and quality objectives, define the appropriate type of data, and specify tolerable levels of potential decision errors that will be used as the basis for establishing the quality and quantity of data needed to support decisions.

Data Quality Objectives Process: A systematic strategic planning tool based on the scientific method that identifies and defines the type, quality, and quantity of data needed to satisfy a specified use. The key elements of the process include:

- concisely defining the problem

- identifying the decision to be made

- identifying the inputs to that decision

- defining the boundaries of the study

- developing the decision rule

- $\quad$ specifying tolerate limits on potential decision errors

- selecting the most resource efficient data collection design

DQOs are the qualitative and quantitative outputs from the DQO process. The DQO process was developed originally by the U.S. Environmental Protection Agency, but has been adapted for use by other organizations to meet their specific planning requirement. See also graded approach. 
data quality indicators: Measurable attributes of the attainment of the necessary quality for a particular decision. Data quality indicators include precision, bias, completeness, representativeness, reproducibility, comparability, and statistical confidence.

data usability: The process of ensuring or determining whether the quality of the data produced meets the intended use of the data.

DCGL (derived concentration guideline level): A derived, radionuclide-specific activity concentration within a survey unit corresponding to the release criterion. The DCGL is based on the spatial distribution of the contaminant and hence is derived differently for the nonparametric statistical test $\left(\mathrm{DCGL}_{\mathrm{w}}\right.$ ) and the Elevated Measurement Comparison (DCGL $\mathrm{EMC}_{\mathrm{EC}}$. DCGLs are derived from activity/dose relationships through various exposure pathway scenarios.

decay: See radioactive decay.

decision maker: The person, team, board, or committee responsible for the final decision regarding disposition of the survey unit.

decision rule: A statement that describes a logical basis for choosing among alternative actions.

decommission: To remove a facility or site safely from service and reduce residual radioactivity to a level that permits release of the property and termination of the license and other authorization for site operation.

decommissioning: The process of removing a facility or site from operation, followed by decontamination, and license termination (or termination of authorization for operation) if appropriate. The objective of decommissioning is to reduce the residual radioactivity in structures, materials, soils, groundwater, and other media at the site so that the concentration of each radionuclide contaminant that contributes to residual radioactivity is indistinguishable from the background radiation concentration for that radionuclide.

decontamination: The removal of radiological contaminants from, or their neutralization on, a person, object or area to within levels established by governing regulatory agencies. Decontamination is sometimes used interchangeably with remediation, remedial action, and cleanup.

delta ( $\delta$ ): The amount that the distribution of measurements for a survey unit is shifted to the right of the distribution of measurements of the reference area. 
Glossary

delta $(\Delta)$ : The width of the gray region. $\Delta$ divided by $\sigma$, the arithmetic standard deviation of the measurements, is the relative shift expressed in multiples of standard deviations. See relative shift, gray region.

derived concentration guideline level: See $D C G L$.

design specification process: The process of determining the sampling and analysis procedures that are needed to demonstrate that the attainment objectives are achieved.

detection limit: The net response level that can be expected to be seen with a detector with a fixed level of certainty.

detection sensitivity: The minimum level of ability to identify the presence of radiation or radioactivity.

direct measurement: Radioactivity measurement obtained by placing the detector near the surface or media being surveyed. An indication of the resulting radioactivity level is read out directly.

distribution coefficient $\left(\mathbf{K}_{\mathrm{d}}\right)$ : The ratio of elemental (i.e., radionuclide) concentration in soil to that in water in a soil-water system at equilibrium. $\mathrm{K}_{\mathrm{d}}$ is generally measured in terms of gram weights of soil and volumes of water $\left(\mathrm{g} / \mathrm{cm}^{3}\right.$ or $\left.\mathrm{g} / \mathrm{ml}\right)$.

dose commitment: The dose that an organ or tissue would receive during a specified period of time (e.g., 50 or 70 years) as a result of intake (as by ingestion or inhalation) of one or more radionuclides from a given release.

dose equivalent (dose): A quantity that expresses all radiations on a common scale for calculating the effective absorbed dose. This quantity is the product of absorbed dose (rads) multiplied by a quality factor and any other modifying factors. Dose is measured in $S v$ or rem.

double-blind measurement: Measurements that cannot be distinguished from routine measurements by the individual performing the measurement. See non-blind measurement and single-blind measurement.

effective probe area: The physical probe area corrected for the amount of the probe area covered by a protective screen.

elevated area: See area of elevated activity. 
elevated measurement: A measurement that exceeds a specified value $D C G L_{E M C}$

Elevated Measurement Comparison (EMC): This comparison is used in conjunction with the Wilcoxon test to determine if there are any measurements that exceed a specified value $D C G L_{E M C}$.

exposure pathway: The route by which radioactivity travels through the environment to eventually cause radiation exposure to a person or group.

exposure rate: The amount of ionization produced per unit time in air by X-rays or gamma rays. The unit of exposure rate is Roentgens/hour $(\mathrm{R} / \mathrm{h})$; for decommissioning activities the typical units are microRoentgens per hour $(\mu \mathrm{R} / \mathrm{h})$, i.e., $10^{-6} \mathrm{R} / \mathrm{h}$.

external radiation: Radiation from a source outside the body.

false negative decision error: The error that occurs when the null hypothesis $\left(\mathrm{H}_{0}\right)$ is not rejected when it is false. For example, the false negative decision error occurs when the decision maker concludes that the waste is hazardous when it truly is not hazardous. A statistician usually refers to a false negative error as a Type II decision error. The measure of the size of this error is called beta, and is also known as the complement of the power of a hypothesis test.

false positive decision error: A false positive decision error occurs when the null hypothesis $\left(\mathrm{H}_{0}\right)$ is rejected when it is true. Consider an example where the decision maker presumes that a certain waste is hazardous (i.e., the null hypothesis or baseline condition is "the waste is hazardous"). If the decision maker concludes that there is insufficient evidence to classify the waste as hazardous when it truly is hazardous, the decision maker would make a false positive decision error. A statistician usually refers to the false positive error as a Type I decision error. The measure of the size of this error is called alpha, the level of significance, or the size of the critical region.

Field Sampling Plan: As defined for Superfund in the Code of Federal Regulations 40 CFR 300.430 , a document which describes the number, type, and location of samples and the type of analyses to be performed. It is part of the Sampling and Analysis Plan.

final status survey: Measurements and sampling to describe the radiological conditions of a site, following completion of decontamination activities (if any) in preparation for release. 
Glossary

fluence rate: A fundamental parameter for assessing the level of radiation at a measurement site. In the case of in situ spectrometric measurements, a calibrated detector provides a measure of the fluence rate of primary photons at specific energies that are characteristic of a particular radionuclide.

gamma $(\gamma)$ radiation: Penetrating high-energy, short-wavelength electromagnetic radiation (similar to X-rays) emitted during radioactive decay. Gamma rays are very penetrating and require dense materials (such as lead or steel) for shielding.

graded approach: The process of basing the level of application of managerial controls applied to an item or work according to the intended use of the results and the degree of confidence needed in the quality of the results. See data quality objectives process.

gray region: A range of values of the parameter of interest for a survey unit where the consequences of making a decision error are relatively minor. The upper bound of the gray region in MARSSIM is set equal to the $D C G L_{W}$, and the lower bound of the gray region (LBGR) is a site-specific variable.

grid: A network of parallel horizontal and vertical lines forming squares on a map that may be overlaid on a property parcel for the purpose of identification of exact locations. See reference coordinate system.

grid block: A square defined by two adjacent vertical and two adjacent horizontal reference grid lines.

half-life $\left(t_{1 / 2}\right)$ : The time required for one-half of the atoms of a particular radionuclide present to disintegrate.

Historical Site Assessment (HSA): A detailed investigation to collect existing information, primarily historical, on a site and its surroundings.

hot measurement: See elevated measurement.

hot spot: See area of elevated activity.

hypothesis: An assumption about a property or characteristic of a set of data under study. The goal of statistical inference is to decide which of two complementary hypotheses is likely to be true. The null hypothesis $\left(\mathrm{H}_{0}\right)$ describes what is assumed to be the true state of nature and the alternative hypothesis $\left(\mathrm{H}_{\mathrm{a}}\right)$ describes the opposite situation. 
impacted area: Any area that is not classified as non-impacted. Areas with a possibility of containing residual radioactivity in excess of natural background or fallout levels.

independent assessment: An assessment performed by a qualified individual, group, or organization that is not part of the organization directly performing and accountable for the work being assessed.

indistinguishable from background: The term indistinguishable from background means that the detectable concentration distribution of a radionuclide is not statistically different from the background concentration distribution of that radionuclide in the vicinity of the site or, in the case of structures, in similar materials using adequate measurement technology, survey, and statistical techniques.

infiltration rate: The rate at which a quantity of a hazardous substance moves from one environmental medium to another-e.g., the rate at which a quantity of a radionuclide moves from a source into and through a volume of soil or solution.

inspection: An activity such as measuring, examining, testing, or gauging one or more characteristics of an entity and comparing the results with specified requirements in order to establish whether conformance is achieved for each characteristic.

inventory: Total residual quantity of formerly licensed radioactive material at a site.

investigation level: A derived media-specific, radionuclide-specific concentration or activity level of radioactivity that: 1) is based on the release criterion, and 2) triggers a response, such as further investigation or cleanup, if exceeded. See action level.

isopleth: A line drawn through points on a graph or plot at which a given quantity has the same numerical value or occurs with the same frequency.

judgment measurement: Measurements performed at locations selected using professional judgment based on unusual appearance, location relative to known contaminated areas, high potential for residual radioactivity, general supplemental information, etc. Judgment measurements are not included in the statistical evaluation of the survey unit data because they violate the assumption of randomly selected, independent measurements. Instead, judgment measurements are individually compared to the $D C G L_{w}$. 
Glossary

karst terrain: A kind of terrain with characteristics of relief and drainage arising from a high degree of rock solubility. The majority of karst conditions occur in limestone areas, but karst may also occur in areas of dolomite, gypsum, or salt deposits. Features associated with karst terrain may include irregular topography, abrupt ridges, sink holes, caverns, abundant springs, and disappearing streams. Well developed or well integrated drainage systems of streams and tributaries are generally not present.

klystron: An electron tube used in television, etc., for converting a stream of electrons into ultra high-frequency waves that are transmitted as a pencil-like radio beam.

less-than data: Measurements that are less than the minimum detectable concentration.

license: A license issued under the regulations in parts 30 through $35,39,40,60,61,70$ or part 72 of 10 CFR Chapter I.

licensee: The holder of a license.

license termination: Discontinuation of a license, the eventual conclusion to decommissioning.

lower bound of the gray region (LBGR): The minimum value of the gray region. The width of the gray region ( $D C G L-L B G R$ ) is also referred to as the shift, $\Delta$.

lower limit of detection $\left(\mathbf{L}_{\mathrm{D}}\right)$ : The smallest amount of radiation or radioactivity that statistically yields a net result above the method background. The critical detection level, $L_{C}$ is the lower bound of the $95 \%$ detection interval defined for $L_{D}$ and is the level at which there is a $5 \%$ chance of calling a background value "greater than background." This value should be used when actually counting samples or making direct radiation measurements. Any response above this level should be considered as above background; i.e., a net positive result. This will ensure $95 \%$ detection capability for $L_{D}$. A 95\% confidence interval should be calculated for all responses greater than $L_{C}$.

m: The number of measurements from the reference area used to conduct a statistical test.

magnetron: A vacuum tube in which the flow of ions from the heated cathode to the anode is controlled by a magnetic field externally applied and perpendicular to the electric field by which they are propelled. Magnetrons are used to produce very short radio waves.

measurement: For the purpose of MARSSIM, it is used interchangeably to mean: 1) the act of using a detector to determine the level or quantity of radioactivity on a surface or in a sample of material removed from a media being evaluated, or 2) the quantity obtained by the act of measuring. 
micrometeorology: The study of weather conditions in a local or very small area, such as immediately around a tree or building, that can affect meteorological conditions.

minimum detectable concentration (MDC): The minimum detectable concentration (MDC) is the a priori activity level that a specific instrument and technique can be expected to detect $95 \%$ of the time. When stating the detection capability of an instrument, this value should be used. The $M D C$ is the detection limit, $L_{D}$, multiplied by an appropriate conversion factor to give units of activity.

minimum detectable count rate (MDCR): The minimum detectable count rate (MDCR) is the a priori count rate that a specific instrument and technique can be expected to detect.

missing or unusable data: Data (measurements) that are mislabeled, lost, or do not meet quality control standards. Less-than data are not considered to be missing or unusable data. See $R$.

munitions: Military supplies, especially weapons and ammunition.

$\mathrm{N}: N=m+n$, is the total number of measurements required from the reference area and a survey unit. See $m$ and $n$.

n: Number of measurements from a survey unit used to conduct a statistical test.

$\mathbf{n}_{\mathfrak{p}}$ : The number of samples that should be collected in an area to assure that the required number of measurements from that area for conducting statistical tests is obtained. $n_{f}=n /(1-R)$.

NARM: Naturally occurring or accelerator-produced radioactive material, such as radium, and not classified as source material.

naturally occurring radionuclides: Radionuclides and their associated progeny produced during the formation of the earth or by interactions of terrestrial matter with cosmic rays.

non-blind measurement: Non-blind measurements are measurements that have a concentration and origin that are known to the individual performing the measurement. See single-blind measurement and double-blind measurement.

nonconformance: A deficiency in characteristic, documentation, or procedure that renders the quality of an item or activity unacceptable or indeterminate; nonfulfillment of a specified requirements. 
Glossary

non-impacted area: Areas where there is no reasonable possibility (extremely low probability) of residual contamination. Non-impacted areas are typically located off-site and may be used as background reference areas.

nonparametric test: A test based on relatively few assumptions about the exact form of the underlying probability distributions of the measurements. As a consequence, nonparametric tests are generally valid for a fairly broad class of distributions. The Wilcoxon Rank Sum test and the Sign test are examples of nonparametric tests.

normal (gaussian) distribution: A family of bell shaped distributions described by the mean and variance.

organization: a company, corporation, firm, government unit, enterprise, facility, or institution, or part thereof, whether incorporated or not, public or private, that has its own functions and administration.

outlier: Measurements that are unusually large or small relative to the rest and therefore are suspected of misrepresenting the population from which they were collected.

p: The probability that a random measurement from the survey unit is less than $\Delta$.

$\mathbf{p}^{\prime}$ : The probability that the sum of two independent random measurements from the survey unit is less than $2 \Delta$.

$\mathbf{P}_{\mathbf{r}}$ : The probability that a measurement performed at a random location in the survey unit is greater than a measurement performed at a random location in the reference area.

peer review: A documented critical review of work generally beyond the state of the art or characterized by the existence of potential uncertainty. The peer review is conducted by qualified individuals (or organization) who are independent of those who performed the work, but are collectively equivalent in technical expertise (i.e., peers) to those who performed the original work. The peer review is conducted to ensure that activities are technically adequate, competently performed, properly documented, and satisfy established technical and quality requirements. The peer review is an in-depth assessment of the assumptions, calculations, extrapolations, alternate interpretations, methodology, acceptance criteria, and conclusions pertaining to specific work and of the documentation that supports them. Peer reviews provide an evaluation of a subject where quantitative methods of analysis or measures of success are unavailable or undefined, such as in research and development. 
performance evaluation: A type of audit in which the quantitative data generated in a measurement system are obtained independently and compared with routinely obtained data to evaluate the proficiency of an analyst or laboratory.

physical probe area: The physical surface area assessed by a detector. The physical probe area is used to make probe area corrections in the activity calculations.

Pitman efficiency: A measure of performance for statistical tests. It is equal to the reciprocal of the ratio of the sample sizes required by each of two tests to achieve the same power, as these sample sizes become large.

power (1- $\beta)$ : The probability of rejecting the null hypothesis when it is false. The power is equal to one minus the Type II error rate, i.e. (1- $\beta$ ).

precision: A measure of mutual agreement among individual measurements of the same property, usually under prescribed similar conditions, expressed generally in terms of the standard deviation.

process: A combination of people, machine and equipment, methods, and the environment in which they operate to produce a given product or service.

professional judgement: An expression of opinion, based on technical knowledge and professional experience, assumptions, algorithms, and definitions, as stated by an expert in response to technical problems.

qualified data: Any data that have been modified or adjusted as part of statistical or mathematical evaluation, data validation, or data verification operations.

quality: The totality of features and characteristics of a product or service that bear on its ability to meet the stated or implied needs and expectations of the user.

quality assurance (QA): An integrated system of management activities involving planning, implementation, assessment, reporting, and quality improvement to ensure that a process, item, or service is of the type and quality needed and expected by the customer.

Quality Assurance Project Plan (QAPP): A formal document describing in comprehensive detail the necessary $Q A, Q C$, and other technical activities that must be implemented to ensure that the results of the work performed will satisfy the stated performance criteria. As defined for Superfund in the Code of Federal Regulations 40 CFR 300.430, the Quality Assurance Project Plan describes policy, organization, and functional activities and the Data Quality Objectives and measures necessary to achieve adequate data for use in selecting the appropriate remedy. The 
Glossary

QAPP is a plan that provides a process for obtaining data of sufficient quality and quantity to satisfy data needs. It is a part of the Sampling and Analysis Plan.

quality control (QC): The overall system of technical activities that measure the attributes and performance of a process, item, or service against defined standards to verify that they meet the stated requirements established by the customer, operational techniques and activities that are used to fulfill requirements for quality.

quality indicators: Measurable attributes of the attainment of the necessary quality for a particular environmental decision. Indicators of quality include precision, bias, completeness, representativeness, reproducibility, comparability, and statistical confidence.

Quality Management Plan (QMP): A formal document that describes the quality system in terms of the organizational structure, functional responsibilities of management and staff, lines of authority, and required interfaces for those planning, implementing, and assessing all activities conducted.

quality system: A structured and documented management system describing the policies, objectives, principles, organizational authority, responsibilities, accountability, and implementation plan of an organization for ensuring quality in its work processes, products (items), and services. The quality system provides the framework for planning, implementing, and assessing work performed by the organization and for carrying out required QA and QC.

R: The rate of missing or unusable measurements expected to occur for samples collected in reference areas or survey units. See missing or unusable data. See $n_{f}$. (Not to be confused with the symbol for the radiation exposure unit Roentgen.)

$\mathbf{R}_{\mathbf{A}}$ : The acceptable level of risk associated with not detecting an area of elevated activity of area $A_{\text {min }}$.

radiation survey: Measurements of radiation levels associated with a site together with appropriate documentation and data evaluation.

radioactive decay: The spontaneous transformation of an unstable atom into one or more different nuclides accompanied by either the emission of energy and/or particles from the nucleus, nuclear capture or ejection of orbital electrons, or fission. Unstable atoms decay into a more stable state, eventually reaching a form that does not decay further or has a very long halflife. 
radioactivity: The mean number of nuclear transformations occurring in a given quantity of radioactive material per unit time. The International System (SD) unit of radioactivity is the Becquerel $(B q)$. The customary unit is the Curie (Ci).

radiological survey: Measurements of radiation levels and radioactivity associated with a site together with appropriate documentation and data evaluation.

radioluminescence: Light produced by the absorption of energy from ionizing radiation.

radionuclide: An unstable nuclide that undergoes radioactive decay.

random error: The deviation of an observed value from the true value is called the error of observation. If the error of observation behaves like a random variable (i.e., its value occurs as though chosen at random from a probability distribution of such errors) it is called a random error. See systematic error.

readily removable: A qualitative statement of the extent to which a radionuclide can be removed from a surface or medium using non-destructive, common, housekeeping techniques (e.g., washing with moderate amounts of detergent and water) that do not generate large volumes of radioactive waste requiring subsequent disposal or produce chemical wastes that are expected to adversely affect public health or the environment.

reference area: Geographical area from which representative reference measurements are performed for comparison with measurements performed in specific survey units at remediation site. A site radiological reference area (background area) is defined as an area that has similar physical, chemical, radiological, and biological characteristics as the site area being remediated, but which has not been contaminated by site activities. The distribution and concentration of background radiation in the reference area should be the same as that which would be expected on the site if that site had never been contaminated. More than one reference area may be necessary for valid comparisons if a site exhibits considerable physical, chemical, radiological, or biological variability.

reference coordinate system: A grid of intersecting lines referenced to a fixed site location or benchmark. Typically the lines are arranged in a perpendicular pattern dividing the survey location into squares or blocks of equal areas. Other patterns include three-dimensional and polar coordinate systems.

reference region: The geographical region from which reference areas will be selected for comparison with survey units. 
Glossary

regulation: A rule, law, order, or direction from federal or state governments regulating action or conduct. Regulations concerning radioisotopes in the environment in the United States are shared by the Environmental Protection Agency (EPA), the U.S. Nuclear Regulatory Commission (NRC), the U.S. Department of Energy (DOE), and many State governments. Federal regulations and certain directives issued by the U.S. Department of Defense(DOD) are enforced within the DOD.

relative shift $(\Delta / \sigma): \Delta$ divided by $\sigma$, the standard deviation of the measurements. See delta.

relative standard deviation: See coefficient of variation.

release criterion: A regulatory limit expressed in terms of dose or risk.

rem (radiation equivalent man): The conventional unit of dose equivalent. The corresponding International System (SI) unit is the Sievert $(S v): 1 \mathrm{~Sv}=100 \mathrm{rem}$.

remedial action: Those actions that are consistent with a permanent remedy taken instead of, or in addition to, removal action in the event of a release or threatened release of a hazardous substance into the environment, to prevent or minimize the release of hazardous substances so that they do not migrate to cause substantial danger to present or future public health or welfare or the environment. See remedy.

remediation: Cleanup or other methods used to remove or contain a toxic spill or hazardous materials from a Superfund site.

remediation control survey: A type of survey that includes monitoring the progress of remedial action by real time measurement of areas being decontaminated to determine whether or not efforts are effective and to guide further decontamination activities.

remedy: See remedial action.

removable activity: Surface activity that is readily removable by wiping the surface with moderate pressure and can be assessed with standard radiation detectors. It is usually expressed in units of $\mathrm{dpm} / 100 \mathrm{~cm}^{2}$.

removal: The cleanup or removal of released hazardous substances, or pollutants or contaminants which may present an imminent and substantial danger; such actions as may be necessary taken in the event of the threat of release of hazardous substances into the environment; such actions as may be necessary to monitor, assess, and evaluate the threat of release of hazardous substances; the removal and disposal of material, or the taking of other such actions as may be necessary to prevent, minimize or mitigate damage to the public health or welfare or the environment. 
replicate: A repeated analysis of the same sample or repeated measurement at the same location.

representative measurement: A measurement that is selected using a procedure in such a way that it, in combination with other representative measurements, will give an accurate representation of the phenomenon being studied.

representativeness: A measure of the degree to which data accurately and precisely represent a characteristic of a population, parameter variations at a sampling point, a process condition, or an environmental condition.

reproducibility: The precision, usually expressed as a standard deviation, that measures the variability among the results of measurement of the same sample at different laboratories.

residual radioactivity: Radioactivity in structures, materials, soils, groundwater, and other media at a site resulting from activities under the cognizant organization's control. This includes radioactivity from all sources used by the cognizant organization, but excludes background radioactivity as specified by the applicable regulation or standard. It also includes radioactive materials remaining at the site as a result of routine or accidental releases of radioactive material at the site and previous burials at the site, even if those burials were made in accordance with the provisions of $10 \mathrm{CFR}$ Part 20.

restoration: Actions to return a remediated area to a usable state following decontamination.

restricted use: A designation following remediation requiring radiological controls.

robust: A statistical test or method that is approximately valid under a wide range of conditions.

run chart: A chart used to visually represent data. Run charts are used to monitor a process to see whether or not the long range average is changing. Run charts are points plotted on a graph in the order in which they become available, such as parameters plotted versus time.

s: The arithmetic standard deviation of the mean.

S+: The test statistic used for the Sign test.

sample: (As used in MARSSIM) A part or selection from a medium located in a survey unit or reference area that represents the quality or quantity of a given parameter or nature of the whole area or unit; a portion serving as a specimen.

sample: (As used in statistics) A set of individual samples or measurements drawn from a population whose properties are studied to gain information about the entire population. 
Sampling and Analysis Plan (SAP): As defined for Superfund in the Code of Federal Regulations 40 CFR 300.430 , a plan that provide a process for obtaining data of sufficient quality and quantity to satisfy data needs. The sampling and analysis plans consists of two parts: 1) the Field Sampling Plan, which describes the number, type, and location of samples and the type of analyses; and 2) the Quality Assurance Project Plan, which describes policy, organization, functional activities, the Data Quality Objectives, and measures necessary to achieve adequate data for use in selecting the appropriate remedy.

scanning: An evaluation technique performed by moving a detection device over a surface at a specified speed and distance above the surface to detect radiation.

scoping survey: A type of survey that is conducted to identify: 1) radionuclide contaminants, 2) relative radionuclide ratios, and 3 ) general levels and extent of contamination.

self-assessment: Assessments of work conducted by individuals, groups, or organizations directly responsible for overseeing and/or performing the work.

shape parameter (S): For an elliptical area of elevated activity, the ratio of the semi-minor axis length to the semi-major axis length. For a circle, the shape parameter is one. A small shape parameter corresponds to a flat ellipse.

shift: See delta $(\Delta)$.

Sievert (Sv): The special name for the International System (SI) unit of dose equivalent. $1 \mathrm{~Sv}=100 \mathrm{rem}=1$ Joule per kilogram.

Sign test: A nonparametric statistical test used to demonstrate compliance with the release criterion when the radionuclide of interest is not present in background and the distribution of data is not symmetric. See also Wilcoxon Rank Sum test.

single-blind measurement: A measurement that can be distinguished from routine measurements but are of unknown concentration. See non-blind measurement and double-blind measurement.

site: Any installation, facility, or discrete, physically separate parcel of land, or any building or structure or portion thereof, that is being considered for survey and investigation.

site reconnaissance: A visit to the site to gather sufficient information to support a site decision regarding the need for further action, or to verify existing site data. Site reconnaissance is not a study of the full extent of contamination at a facility or site, or a risk assessment. 
size (of a test): See alpha.

soil: The top layer of the earth's surface, consisting of rock and mineral particles mixed with organic matter. A particular kind of earth or ground-e.g., sandy soil.

soil activity (soil concentration): The level of radioactivity present in soil and expressed in units of activity per soil mass (typically $\mathrm{Bq} / \mathrm{kg}$ or $\mathrm{pCi} / \mathrm{g}$ ).

source material: Uranium and/or Thorium other than that classified as special nuclear material.

source term: All residual radioactivity remaining at the site, including material released during normal operations, inadvertent releases, or accidents, and that which may have been buried at the site in accordance with 10 CFR Part 20.

special nuclear material: Plutonium, ${ }^{233} \mathrm{U}$, and Uranium enriched in ${ }^{235} \mathrm{U}$; material capable of undergoing a fission reaction.

split: A sample that has been homogenized and divided into two or more aliquots for subsequent analysis.

standard normal distribution: A normal (Gaussian) distribution with mean zero and variance one.

standard operating procedure (SOP): A written document that details the method for an operation, analysis, or action with thoroughly prescribed techniques and steps, and that is officially approved as the method for performing certain routine or repetitive tasks.

statistical control: The condition describing a process from which all special causes have been removed, evidenced on control chart by the absence of points beyond the control limits and by the absence of non-random patterns or trends within the control limits. A special cause is a source of variation that is intermittent, unpredictable, or unstable.

stratification: The act or result of separating an area into two or more sub-areas so as each subarea has relatively homogeneous characteristics such as contamination level, topology, surface soil type, vegetation cover, etc.

subsurface soil sample: A soil sample that reflects the modeling assumptions used to develop the DCGL for subsurface soil activity. An example would be soil taken deeper than $15 \mathrm{~cm}$ below the soil surface to support surveys performed to demonstrate compliance with 40 CFR 192. 
Glossary

surface contamination: Residual radioactivity found on building or equipment surfaces and expressed in units of activity per surface area $\left(\mathrm{Bq} / \mathrm{m}^{2}\right.$ or $\left.\mathrm{dpm} / 100 \mathrm{~cm}^{2}\right)$.

surface soil sample: A soil sample that reflects the modeling assumptions used to develop the $D C G L$ for surface soil activity. An example would be soil taken from the first $15 \mathrm{~cm}$ of surface soil to support surveys performed to demonstrate compliance with 40 CFR 192.

surveillance (quality): Continual or frequent monitoring and verification of the status of an entity and the analysis of records to ensure that specified requirements are being fulfilled.

survey: A systematic evaluation and documentation of radiological measurements with a correctly calibrated instrument or instruments that meet the sensitivity required by the objective of the evaluation.

survey plan: A plan for determining the radiological characteristics of a site.

survey unit: A geographical area consisting of structures or land areas of specified size and shape at a remediated site for which a separate decision will be made whether the unit attains the site-specific reference-based cleanup standard for the designated pollution parameter. Survey units are generally formed by grouping contiguous site areas with a similar use history and the same classification of contamination potential. Survey units are established to facilitate the survey process and the statistical analysis of survey data.

systematic error: An error of observation based on system faults which are biased in one or more ways, e.g., tending to be on one side of the true value more than the other.

T+: The test statistic for the Wilcoxon Signed Rank test.

tandem testing: Two or more statistical tests conducted using the same data set.

technical review: A documented critical review of work that has been performed within the state of the art. The review is accomplished by one or more qualified reviewers who are independent of those who performed the work, but are collectively equivalent in technical expertise to those who performed the original work. The review is an in-depth analysis and evaluation of documents, activities, material, data, or items that require technical verification or validation for applicability, correctness, adequacy, completeness, and assurance that established requirements are satisfied.

technical systems audit (TSA): A thorough, systematic, on-site, qualitative audit of facilities, equipment, personnel, training, procedures, recordkeeping, data validation, data management, and reporting aspects of a system. 
TEDE (total effective dose equivalent): The sum of the effective dose equivalent (for external exposure) and the committed effective dose equivalent (for internal exposure). TEDE is expressed in units of Sv or rem. See CEDE.

test statistic: A function of the measurements (or their ranks) that has a known distribution if the null hypothesis is true. This is compared to the critical level to determine if the null hypothesis should be accepted or rejected. See $S+, T+$, and $W_{r}$

tied measurements: Two or more measurements that have the same value.

traceability: The ability to trace the history, application, or location of an entity by means of recorded identifications. In a calibration sense, traceability relates measuring equipment to national or international standards, primary standards, basic physical constants or properties, or reference materials. In a data collection sense, it relates calculations and data generated throughput the project back to the requirements for quality for the project.

triangular sampling grid: A grid of sampling locations that is arranged in a triangular pattern. See grid.

two-sample $\mathbf{t}$ test: A parametric statistical test used in place of the Wilcoxon Rank Sum (WRS) test if the reference area and survey unit measurements are known to be normally (Gaussian) distributed and there are no less-than measurements in either data set.

Type I decision error: A decision error that occurs when the null hypothesis is rejected when it is true. The probability of making a Type I decision error is called alpha $(\alpha)$.

Type II decision error: A decision error that occurs when the null hypothesis is accepted when it is false. The probability of making a Type II decision error is called beta ( $\beta)$.

unity rule (mixture rule): A rule applied when more than one radionuclide is present at a concentration that is distinguishable from background and where a single concentration comparison does not apply. In this case, the mixture of radionuclides is compared against default concentrations by applying the unity rule. This is accomplished by determining: 1) the ratio between the concentration of each radionuclide in the mixture, and 2) the concentration for that radionuclide in an appropriate listing of default values. The sum of the ratios for all radionuclides in the mixture should not exceed 1.

unrestricted area: Any area where access is not controlled by a licensee for purposes of protection of individuals from exposure to radiation and radioactive materials-including areas used for residential purposes. 
unrestricted release: Release of a site from regulatory control without requirements for future radiological restrictions. Also known as unrestricted use.

validation: Confirmation by examination and provision of objective evidence that the particular requirements for a specific intended use are fulfilled. In design and development, validation concerns the process of examining a product or result to determine conformance to user needs.

verification: Confirmation by examination and provision of objective evidence that the specified requirements have been fulfilled. In design and development, verification concerns the process of examining a result of given activity to determine conformance to the stated requirements for that activity.

$\mathrm{W}_{\mathrm{r}}$ : The sum of the ranks of the adjusted measurements from the reference area, used as the test statistic for the Wilcoxon Rank Sum test.

$\mathrm{W}_{s}$ : The sum of the ranks of the measurements from the survey unit, used with the Wilcoxon Rank Sum test.

weighting factor $\left(\mathbf{W}_{t}\right)$ : The fraction of the overall health risk, resulting from uniform, wholebody radiation, attributable to specific tissue. The dose equivalent to tissue is multiplied by the appropriate weighting factor to obtain the effective dose equivalent to the tissue.

Wilcoxon Rank Sum (WRS) test: A nonparametric statistical test used to determine compliance with the release criterion when the radionuclide of concern is present in background. See also Sign test.

working level: A special unit of radon exposure defined as any combination of short-lived radon daughters in 1 liter of air that will result in the ultimate emission of $1.3 \times 10^{5} \mathrm{MeV}$ of potential alpha energy. This value is approximately equal to the alpha energy released from the decay of progeny in equilibrium with $100 \mathrm{pCi}$ of ${ }^{222} \mathrm{Ra}$.

$Z_{1-\phi}:$ The value from the standard normal distribution that cuts off $100 \phi \%$ of the upper tail of the standard normal distribution. See standard normal distribution. 


\section{INDEX}

$$
\begin{array}{lr}
\alpha & \\
\beta & \text { see Type I decision error } \\
& \text { see Type II decision error }
\end{array}
$$

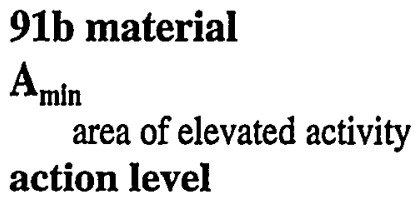

\begin{tabular}{|c|c|}
\hline ALARA & $\begin{array}{l}2-5 ; 5-52 ; 8-21 \\
27 ; C-8 \text { to } 10\end{array}$ \\
\hline $\begin{array}{l}\text { alpha }(\alpha) \text { radiation } \\
\text { analysis }\end{array}$ & $\begin{array}{l}4-6,7 ; 7-15 \\
7-22\end{array}$ \\
\hline $\begin{array}{l}\text { detection sensitivity } \\
\text { direct measurement } \\
\text { scanning }\end{array}$ & $\begin{array}{l}6-32 \text { to } 37 \\
2-14 ; 5-48 \\
6-47 \text { to } 49\end{array}$ \\
\hline detectors & $6-15$ to 17,20 \\
\hline attenuation & $4-23,25$ \\
\hline measurement & $\begin{array}{l}5-12,13 \\
6-13,14\end{array}$ \\
\hline radon & $6-55$ to 59 \\
\hline alternative hypothesis & $\begin{array}{l}2-39 ; 5-25 \\
8-11,17\end{array}$ \\
\hline \multicolumn{2}{|l|}{ area } \\
\hline evaluation \& HSA & $3-11$ \\
\hline classification & $\begin{array}{l}2-4,5,17,28 \\
4-11\end{array}$ \\
\hline contaminated & $2-3$ \\
\hline land & $4-26$ \\
\hline reference coordinate system & $4-27$ \\
\hline scanning & $2-31 ; 5-46$ to 48 \\
\hline site & $4-17$ \\
\hline site diagram & $3-21$ \\
\hline structures & $4-23,25$ \\
\hline survey unit & $2-4 ; 4-15$ \\
\hline
\end{tabular}

4-8

$2-14 ; 4-1$

$3-19 ; 5-10,14$, $18 ; 6-11,13$, 55 to $60 ; 7-13$, 16, 27; App. M $2-5 ; 5-52 ; 8-21$, $27 ; \mathrm{C}-8$ to 10

4-6, 7; 7-15

6-32 to 37

$2-14 ; 5-48$;

$6-47$ to 49

$6-15$ to 17,20

$4-23,25$

$5-12,13$

$6-13,14$

$6-55$ to 59

2-39; 5-25; area of elevated activity $\quad 2-3,4,27,28$,

30 ; 5-35 to 39 ;

6-42 to 45 ;

$8-22,23,27$

demonstrating compliance $\quad 2-27$

determining data points $\quad 5-35$

flagging $\quad 5-44$

investigation level $\quad 5-44$ to 46

final status survey design $\quad 2-29,32$;

5-46 to 52

area factor

2-27; 5-36 to 39 ;

$8-16,22,24$

\section{arithmetic mean}

see mean

arithmetic standard deviation

see standard deviation kground (radiation)

activity

$5-10,11$

decommissioning

4-13

detection sensitivity

$6-37,39$ to 49

ground water

$5-13$

indistinguishable from

$2-39$

samples

$5-10,11 ; 7-2,5$

statistical tests

$2-26 ; 4-9 ; 5-28$

see background reference area

background reference area $2-6,28 ; 4-13$ to

$16 ; 7-5 ; 8-3$ to

11,17 to $21 ; A-5$

background radiation

4-13

data points

$5-25$ to 31

$\mathrm{P}_{\mathrm{r}}$

$5-27$

relative shift WRS test $\quad 5-26$

survey

Becquerel (Bq)

see conversion table

beta $(\beta)$ radiation $\quad 4-6$

analysis

detection sensitivity

$7-21,22$

direct measurement

scanning

6-32 to 37

$2-14 ; 5-48$;

6-37 to 47

detectors

6-15 to 17,21

attenuation

$4-23,25$

measurement

$5-12,13$

radon

$6-55,58,59$

bias

field measurements

$2-11 ; 4-32$ to 38

6-4 to 6

laboratory measurements 
biased sample measurement see judgement measurement

$\begin{array}{ll}\begin{array}{c}\text { byproduct material } \\ \text { byproducts }\end{array} & \mathrm{C}-15,16 \\ \text { calibration } & 3-5 \\ & 4-17 ; 6-20 \text { to } 28 ; \\ & 7-4,13 ; 9-5,6\end{array}$

CEDE (committed effective dose

equivalent)
CERCLA
compared to MARSS
Chain of Custody
characterization sur
checklist
DCGLs
checklist(s)
see survey checklist

Class 1 area

investigation level scanning

Class 2 area

investigation level scanning

Class 3 area investigation level scanning classification

areas

$\mathrm{HSA} /$ scoping

see Class 1,2, and 3 area

cleanup

regulations

release criterion

cleanup standard

cleanup (survey) unit see survey unit

coefficient of variation
2-2

2-22, 39; 3-1, 2;

5-1, 7

App. F

5-3, 17;

7-23 to $25 ; 9-8$

$2-15,16,22,23$;

3-24; 4-21;

5-7 to $17 ; \mathrm{A}-17$

$5-16,17$

4-4

$2-5 ; 4-11 ; 5-48$;

$8-24,25$

5-45

2-32; 5-46

2-5; 4-12; 5-49;

$8-24$

$5-45$

$2-32 ; 5-47$

$2-5 ; 4-12 ; 5-49$

$5-45$

2-33; 5-48

$2-4,10,17,28$;

3-1, 12, 22; 4-11;

5-46 to $51 ; 7-7$;

$8-1,2,15,16,22$,

24,$27 ; \mathrm{A}-5 ; \mathrm{N}-16$

2-5

2-23

$1-1,4 ; 5-18,19$

1-3

2-2

2-2

5-26

\begin{tabular}{|c|c|}
\hline comparability & $\begin{array}{l}2-11 ; 6-6 ; 7-6 \\
12 ; \mathrm{N}-12 \text { to } 15\end{array}$ \\
\hline completeness & $\begin{array}{l}2-11 ; 6-6,7 ; 7-6 \\
7 ; N-14 \text { to } 16\end{array}$ \\
\hline \multicolumn{2}{|l|}{ computer code } \\
\hline DEFT & D-20, 21 \\
\hline ELIPGRID & D-23 \\
\hline RESRAD & $5-36$ \\
\hline RESRAD-BUILD & $5-36$ \\
\hline conceptual site model & $\begin{array}{l}3-21,22 ; 4-21 ; \\
5-8,47 ; 7-11,13, \\
15 ; \mathrm{A}-10\end{array}$ \\
\hline & $6-53$ to 55 \\
\hline $\begin{array}{l}\text { alternate null hypothesis } \\
\text { confirmatory survey }\end{array}$ & $2-36$ \\
\hline $\begin{array}{l}\text { survey design } \\
\text { see final status survey }\end{array}$ & $5-21$ \\
\hline contamination & $1-1,2,3,6$ \\
\hline characterization survey & $5-7$ to 15 \\
\hline classification & $\begin{array}{l}2-4,5,28 ; 3-3 \\
4-11\end{array}$ \\
\hline DCGLs & $2-2,3 ; 4-3$ \\
\hline decommissioning criteria & $5-25$ \\
\hline field measurements & $6-5,6$ \\
\hline final status survey & $5-25$ to 52 \\
\hline HSA & $2-22$ \\
\hline historical data & $3-7,10$ \\
\hline reconnaissance & $3-9$ \\
\hline identifying & $3-11$ \\
\hline in soil & $3-13,14$ \\
\hline in water & $3-15,17$ \\
\hline in structures & $3-20$ \\
\hline in air & $3-19$ \\
\hline remedial action & $2-23 ; 5-18,19$ \\
\hline sampling & $\begin{array}{l}7-11 \text { to } 16 \\
\text { App. } \mathrm{M}\end{array}$ \\
\hline $\begin{array}{l}\text { surrogate measurements } \\
\text { see area of elevated activity } \\
\text { see impacted area }\end{array}$ & $4-4$ \\
\hline control chart & $\begin{array}{l}4-33,37 \\
6-5,7,8\end{array}$ \\
\hline corrective action & $\begin{array}{l}2-23 ; 6-28 ; 7-11 ; \\
9-8,9\end{array}$ \\
\hline bias & $\mathrm{N}-10$ \\
\hline comparability & N-15 \\
\hline completeness & $\mathrm{N}-16$ \\
\hline precision & N-9 \\
\hline representativeness & N-13 \\
\hline
\end{tabular}

December 1997 


\section{criterion}

alternate hypothesis

compliance

DCGLs

FSS

measurement

QC

release criterion

statistical tests

null hypothesis

critical level $\left(\mathbf{L}_{\mathbf{c}}\right)$

critical value

\section{curie (Ci)}

see conversion table

data

conversion

data interpretation checklist

distribution

number of points needed

EMC

Sign test

WRS test

preliminary review (DQA)

review

skewness

spatial dependency

see mean, median, standard deviation

see posting plot

see ranked data

see stem and leaf display

\section{Data Life Cycle}

figure

steps:
1. planning
2. implementation
3. assessment
4. decision making
2-8; App. D
2-11
2-11; App. E
$2-7$
2-16

table

2-6 to $12 ; 4-35$;

$5-46 ; 9-2,3,5$

2-7
$2-25$

4-3

$2-24$

4-32 to 38

-1 to $3 ; 3-24$

22,34

6-32 to 37

$8-12,13,15,18$,

21; A-18;

D-16, 17
6-28 to 31

$8-4,5$

2-10

5-31 to

5-25 to 31

$\mathrm{E}-3$

$\mathrm{N}-5$

ation

\section{Data Quality Assessment (DQA)}

$1-4 ; 2-6 ; 5-46$;

$8-1,2 ; 9-2,5$;

App. E

assessment phase 2-8, 11 ; App. E

historical data

3-7

\section{Data Quality Objectives (DQOs)}

$1-3,4 ; 2-7,9$;

$4-4,19 ; 5-2,8$,

21,$52 ; 6-2$;

7-1, 2; 8-1, 2;

9-2, 7, 8; App.D

DQO Process

iterations (figure)

state problem

2-10; App. D

identify decision

D-3

D-4

inputs

D-5

study boundaries

D-5, 6

develop decision rule

D-6 to 8

decision errors

D-8 to 13

optimize design

D-13 to 28

HSA

D-28, 29

preliminary review (DQA) E-1

measurement uncertainty $\quad 6-50$

QAPP

$9-2,3$

data quality indicators $2-11 ; 6-3,7 ; 7-2$,

$7 ; 9-9 ; \mathrm{N}-6$ to 18

Derived Concentration Guideline Level

(DCGL)

$2-2,11,33$;

4-3 to $11 ; 6-1,2$,

$7,19,32,50$;

$7-2,7,9 ; 8-2,6$,

$11,22,26 ; 9-5$

DCGL $_{W} \quad 2-3 ; A-2 ; D-9$

DCGL

HSA

$3-1,12$

gross activity $\quad 4-8$

sampling $\quad 7-2,7,9$

surveys $\quad 5-1$

decay

see radioactive decay

decision error

D-13 to 17 , 20 to 22,26 to $29 ; \mathrm{N}-17$

error chart

D-27

false positive

D-14, 21, 26

see Type I error

false negative

D-15, 20

see Type II error

feasibility trials

DEFT

D-20, 21

specifying limits

D-15

table 
Index

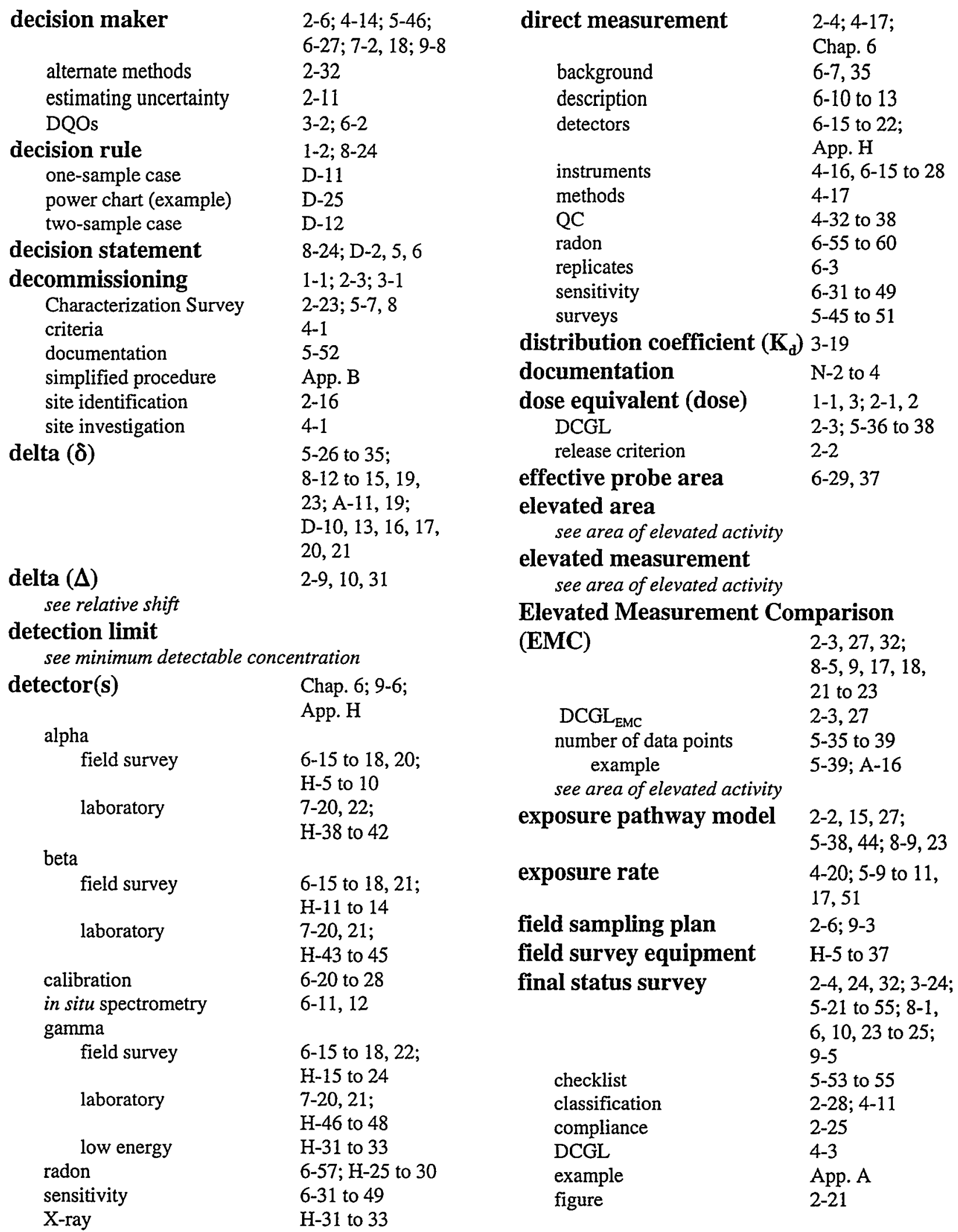


final status survey (continued)

health and safety

integrated design

investigation process

planning

sampling

survey units

fluence rate

frequency plot

gamma $(\gamma)$ radiation

analysis

detection sensitivity

direct measurement

scanning

detectors

measurement

radon

scanning

spectrometry

surface measurement

graded approach

graphical data review

see frequency plot

see posting plot

see stem and leaf display

gray region

example

see decision error

see lower bound (LBGR)

grid

example

positioning systems

random start example

reference coordinate system

example(s)
4-38

2-32

$2-16$

2-9; 5-21 to 55

7-7 to 16 ;

App. $M$

4-14

$6-11,12,44$

8-4, 5

$7-21$

6-31

6-32 to 37

6-37 to 47

6-15 to 18,22 ;

$7-20,21 ; \mathrm{H}-15$ to

24,46 to 48

4-16

$6-55,57,60$

6-14

4-16

6-11, 12

$1-5 ; 2-4,5,8$;

$3-1 ; 6-8 ; 8-1$;

9-2, 3, 5

8-4; E-3

$2-9,31 ; 5-25$ to

$27,32,33 ; 6-7$;

$7-7,8$ to 12,14 ,

19; D-16, 17,

20 to $22,26,28$

A-7, 11

2-31; 4-27 to 31 ;

$5-3,16,40$ to 43 ;

7-7

A-7, 13, 14, 15

6-61, 62

$5-40,41 ; \mathrm{A}-14$

2-23; 4-27;

6-61, 66

$4-28,29,30$ grid (continued)

sample/scan

$2-32 ; 5-40$

spacing

$5-42$

triangular grid

figure

5-40 to 43

$5-43$

half-life $\left(t_{1 / 2}\right)$

$1-5 ; 4-6 ; 6-55$;

A-1; B-1

histogram

see frequency plot

see stem and leaf display

\section{Historical Site Assessment (HSA)}

$1-3,4 ; 2-16,22$;

Chap. $3 ; 5-1,16$,

$39 ; 6-14 ; 7-12$;

data sources

$8-9 ; \mathrm{A}-1$

figure

information sources

survey planning

App. G

2-18

App. G

4-11

hot measurement see area of elevated activity

hot spot

see area of elevated activity

hypothesis

alternative hypothesis

null hypothesis

$2-26 ; 8-8,12,18$

$2-39 ; \mathrm{D}-14,15$

2-9, 26; 8-11, 15, 17,$23 ; \mathrm{D}-14,15$

statistical testing

$1-3 ; 2-13,26$

approach explained $\quad 2-26$

Sign test

WRS test

$2-28 ; 8-11$

$2-28 ; 8-17$

impacted area 2-4

classification 4-11

DQO

3-2

HSA

non-impacted

2-23; Chap. 3

Scoping Survey

$2-4$

$2-23$

$\begin{array}{ll}\text { site diagram } & 3-23 \\ \text { survey design } & 2-25\end{array}$

see residual radioactivity

indistinguishable from background

2-39; D-19

infiltration rate

$3-14,16,18$

inventory 
Index

investigation level

example (table)

scanning

survey strategy

see release criterion

see action level

judgment measurement

\begin{tabular}{|c|c|}
\hline & \\
\hline karst terrain & 3-19 \\
\hline laboratory equipment & $4-16 ; H-38$ to 48 \\
\hline less-than data & $2-13$ \\
\hline license & $\begin{array}{l}2-16 ; 3-4,5,7,8 \\
7-11\end{array}$ \\
\hline $\begin{array}{l}\text { license termination } \\
\text { see decommissioning }\end{array}$ & \\
\hline lower bound of the gra & gion (LBGR) \\
\hline & $\begin{array}{l}2-9,31 ; 5-25 \text { to } \\
27,31 \text { to } 33 ; 6-7 \\
7-7 ; 8-12,13,15, \\
19 ; \mathrm{D}-17,20 \\
21,28 ; \mathrm{N}-18\end{array}$ \\
\hline $\begin{array}{l}\text { example } \\
\text { see gray region }\end{array}$ & A-11 \\
\hline
\end{tabular}

$m$ (number of data points in the reference area)

mean

of data (example)

measurement techniques

median
$5-29,39,42$;

$8-18,21$

$2-2,32 ; 4-1$

$5-18,44$ to 46 ;

6-14, 15;

$8-9,17,21$

$5-45$

$6-3$

$5-46$

$2-22,23,30,33$

$5-2,3,44,48$,

51,55

4-16; $\mathrm{H}-38$ to 48

$2-16 ; 3-4,5,7,8$;

$2-27,28 ; 4-33$;

$5-49,50 ; 8-2,3$,

5 to $7,12,13,15$;

D-9

8-3

$1-2,4 ; 2-4 ; 3-7$;

4-16, 17;

$7-20$ to 22

2-28; 5-27, 32, $45 ; 8-2,3,5$ to 7 , $12,13,15 ; \mathrm{D}-9$ minimum detectable concentration

(MDC)

$2-10,34 ; 4-16$,

$17,34,35$;

5-36, 37, 48;

6-31 to 49 ;

8-15, 18, 22;

9-7 to 9

direct measurement $\quad 6-32$ to 37

elevated activity $\quad 5-39$

reporting 2-13

scan

6-37 to 49

minimum detectable count rate

(MDCR) 6-40 to 45

missing or unusable data $5-29,31,33,35$

model(s)

conceptual site model

defining study boundaries

$3-3,22 ; 5-8,47$

exposure pathway

D-6, 7

$1-4 ; 2-2,15,27$;

$6-10,28$

area factor (example) $\quad 5-36$

determining DCGLs 4-3,6

$\mathbf{N}$ (number of data points) $2-10 ; 5-25$ to 39 ;

$8-12,13,15,18$

QC measurements

4-32 to 38

Sign test

5-31 to 35

example

table

5-33, 35; B-2

$5-34$

WRS test

5-25 to 31

example

5-29, 31;

A-11; B-2

table

5-30

n (number of data points in survey unit)

$5-29,38,42$;

$8-18,21$

NARM

3-4

naturally occurring radionuclides

\section{non-impacted area}

$1-4 ; 3-3 ; 6-5 ; 7-5$

background (reference area) 4-13

classification

2-28; 4-11

DQO

3-2

HSA

2-17;

3-10 to 12

survey design

$2-31$ 


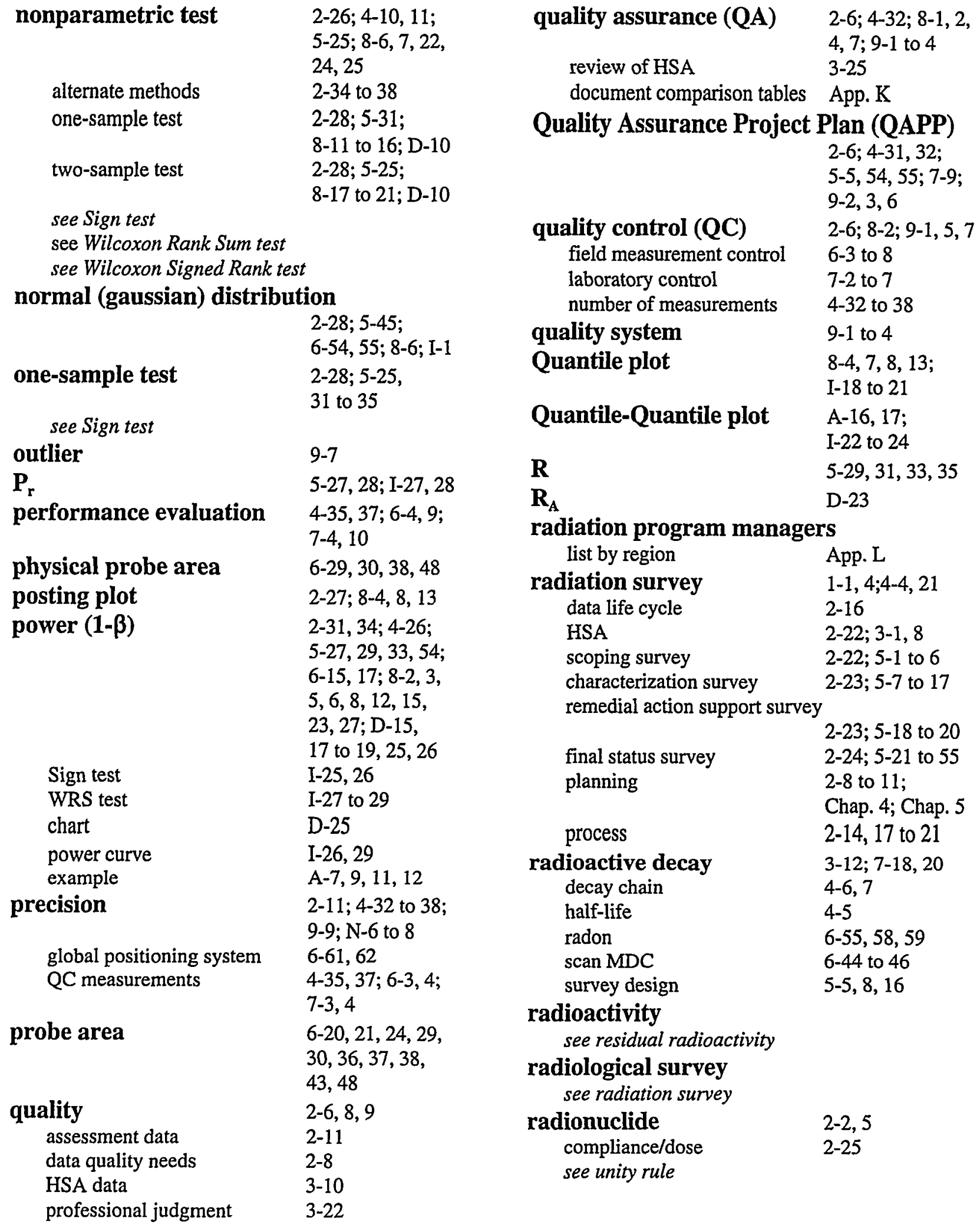


Index

radon

$3-20 ; 5-14$

$6-55$ to 60

random uncertainty

$2-14 ; 6-50$ to 52

ranked data

I-22

interpolated ranks

RCRA

I-23

$2-22,23,39 ; 3-1$

$5-1,7$

compared to MARSSIM

App. F

reference coordinate system see grid

regulations \& requirements App. C

DOD

DOE

EPA

NRC

States

relative shift $(\Delta / \sigma)$

calculate example

DQO process

number of data points

$P_{r}$

Sign $\mathrm{p}$

tables

$\mathrm{N}$ (Sign test)

N/2 (WRS test)

$\mathrm{P}_{\mathrm{r}}$

Sign $p$

release criterion

alternate null hypothesis

compliance

DCGLs

final status survey

null hypothesis

statistical tests

survey planning

rem (radiation equivalent man)

see conversion table

remedial action support survey

$2-15,23 ; 5-18$ to
$20 ; 6-12 ; 8-25$
$5-20$

checklist

figure

table
$2-15,23 ; 5-18$
$20 ; 6-12 ; 8-25$
$5-20$

$5-20$

2-20

C- 15 to 20

C-4 to 12

C-1 to 4

C- 12 to 15

C-20, 21

5-26 to 35,40 ,

42 ; $8-12$ to 15 ,

19; D-17, 20

5-26, 5-32

5-29, 5-33;

A- 11,19

$2-9,10,31$

$5-28,33$

5-27

$5-32$

5-34

5-30

$5-28$

5-32

$1-1,2,5 ; 2-2$

2-39

$2-25$

4-3

$2-24$

$2-9,26$

2-25

5-1

$2-16$ remediation

$1-1,3,4 ; 8-9,11$

see remedial action support survey

\begin{tabular}{|c|c|}
\hline removable activity & $\begin{array}{l}5-17,52 \\
6-20,21\end{array}$ \\
\hline \multicolumn{2}{|l|}{ see surface contamination } \\
\hline removal & $2-5 ; 5-2$ \\
\hline criteria & 2-23; App. F \\
\hline of structures/equipment & $4-24$ to 26 \\
\hline Superfund & App. F \\
\hline HSA & $3-1$ \\
\hline scoping survey & $5-2$ \\
\hline replicate & $4-35,37$ \\
\hline sample & $7-3$ \\
\hline measurement & $6-3$ \\
\hline
\end{tabular}

\section{representativeness}

$2-11,24 ; 4-34$

6-6; 7-3;

$\mathrm{N}-12,13$

\section{reproducibility \\ residual radioactivity}

$4-27 ; 6-61$

analytical procedures

characterization surveys land areas structures

final status survey land areas structures

remedial action design see surface contamination

restricted use

$2-3,26 ; 3-24$;

$4-1,24$

7-17 to 23

5-11

$5-10$

$5-40,50,51$

$5-44,48$ to 50

$5-18$

$1-1 ; 5-7$

see unrestricted release

robust

$2-35,37 ; 8-6$

$5-45,49 ; 8-2$

8-12 to 16

see test statistic

sample(s)

$2-4$

alternate survey design

background

blanks

Chain of Custody

characterization

land

structures

2-33

4-13

$7-5$

$7-23$ to 25

5-11

$5-10$

confirmation/verification $\quad 2-25$

criteria

DCGLs
4-19, 21

4-4 
sample(s) (continued)

documentation

final status survey

locations

number of data points

matrix spikes

packing/transport

preservation of

QC

remedial action

sampling

scoping

soil

surrogate

water \& sediments
$5-52$

5-40 to 44

5-25 to 39

$7-4$

$7-25$ to 28

7-16, 17

4-32 to 38

5-19

$2-4$

5-2, 3

$7-11$ to 14

4-4

$5-12,13$

Sampling and Analysis Plan

scanning

alpha

alpha scanning sensitivity equations - derivations beta

demonstrating compliance

detectors

elevated activity

gamma

MDCs

pattern (example)

sensitivity

survey techniques

scanning surveys

scoping

characterization

land areas

structures

remedial action

final status

Class 1 areas

Class 2 areas

Class 3 areas

scoping survey

area classification

checklist

figure

HSA \& planning

table

sealed source

final status survey example

App.

2-31

2-29

6-14

6-37 to 49

A-6

6-37 to 49

$5-3,6$

5-11

5-10

5-19

$2-32 ; 5-46$

$2-32 ; 5-47$

$2-33 ; 5-48$

4-11

$5-5,6$

2-19

3-1, 2

2-16

App. B sigma $(\sigma)$

see standard deviation

Sievert (Sv)

see conversion table

Sign test

applying test

example(s)

hypothesis

number of data points example

power

Sign $\mathrm{p}$

site(s)

clearing for access

decommissioning

definition

historical assessment

identification

investigation process

site preparation

6-15 to 18,20 to

22, 57; App. H

$4-17 ; 6-13$ to 15

$2-15,22 ; 5-1$ to 6

site reconnaissance

identify contamination

site model

$2-3,27,28 ; 5-25$;

$8-11$ to 16

8-12

8-12, 14

8-11

5-31 to 35

$5-33,35$

I $-25,26$

5-32

Chap. 1

4-24

4-1

2-3

Chap. 3

2-16; 3-4

2-14

4-22

3-9

3-13

3-22

smear (swipe)

see removable activity

soil

analysis

background

sampling

surveys

survey coverage

source term

split

$\begin{array}{cl}\text { regulatory verification } & 2-25 \\ \text { sample } & 4-35 ; 7-3,14 \\ \text { standard deviation } & 2-9,31 ; 4-16 ; \\ & 5-26,29,31,32, \\ & 45,49 ; 8-2,10, \\ & 12 \text { to } 15,19,23 ; \\ & \mathrm{A}-11,19 ; \mathrm{N}-17 \\ \text { standard operating procedure (SOP) } & 6-3,51 ; \\ & 7-9,19,25\end{array}$

3-13 to 15

7-17 to 23

4-13

$7-11$ to 14

$5-33,9$ to 11,19 , $33,47,50,51$

2-32; 5-47

4-21

2-25

4-35; 7-3, 14

$5-26,29,31,32$, 45,$49 ; 8-2,10$,

A to $15,19,23$

re (SOP)

$7-9,19,25$ 


$\begin{array}{cl}\text { statistical tests } & 2-25 ; 4-11 ; 5-25 \text {; } \\ & \text { Chap. } 8 ; \text { App. I } \\ \text { alternate methods } & 2-34 \text { to } 38 \\ \text { documenting } & 8-25,26 \\ \text { interpreting results } & 8-21 \text { to } 25 \\ \text { selecting a test } & 8-6,7 ; \mathrm{E}-4 \\ \text { summary (table) } & 8-9 \\ \text { verify assumptions } & 8-7,8 ; \mathrm{E}-4 \\ \text { stem \& leaf display } & 8-5,7 ; \mathrm{I}-17,18 \\ \text { structures } & 3-20 \\ \text { access } & 4-25 \\ \text { HSA site plots } & 3-8 \\ \text { measurements } & 4-20 \\ \text { reference coordinate system } & 4-27 \text { to } 31 \\ \text { surface activity } & 5-10 \\ \text { surveys } & 5-7 \text { to } 10,46,47 \\ \text { survey coverage } & 5-47 \\ \text { survey example } & \text { App. A } \\ \text { survey unit } & 2-4 ; 4-14,15 \\ \text { WRS test (example) } & \\ \quad \text { Class 1 } & 8-21, \text { App. A } \\ \text { Class 2 } & 8-19 \\ \text { Student's t test } & 2-35,37 \\ \text { subsurface soil (sample) } & 1-9 ; 4-24 \\ \text { characterization survey } & 5-9,5,11 \\ \text { HSA } & 3-11,13,14 \\ \text { sampling } & 7-16 ; \text { App. M } \\ \text { surface contamination } & 1-3,4 \\ \text { detectors } & \\ \text { alpha } & 6-20 \\ \text { beta } & 6-21 \\ \text { gamma } & 6-22 \\ \text { direct measurements } & 6-10 \text { to } 13 \\ \text { identification } & 3-12 \\ \text { in situ spectrometry } & 6-11,12 \\ \text { land areas } & 4-24 \\ \text { scanning } & 6-13 \text { to } 15 \\ \text { soil } & 3-14 \\ \text { structures } & 4-23 ; 5-10 \\ \text { surface activity DCGLs } & 4-4 \\ \text { surrogates/DCGLs } & 4-4 \\ \text { surface soil } & 1-3,1-4 ; 3-13 \\ \text { background } & 4-13 \\ \text { sampling } & 7-9,12 \text { to } 14,16, \\ \text { surrogate measurements } & 4-4 \text { to } 7 ; 5-12 ; \\ & 6-7 \\ & \\ & \end{array}$

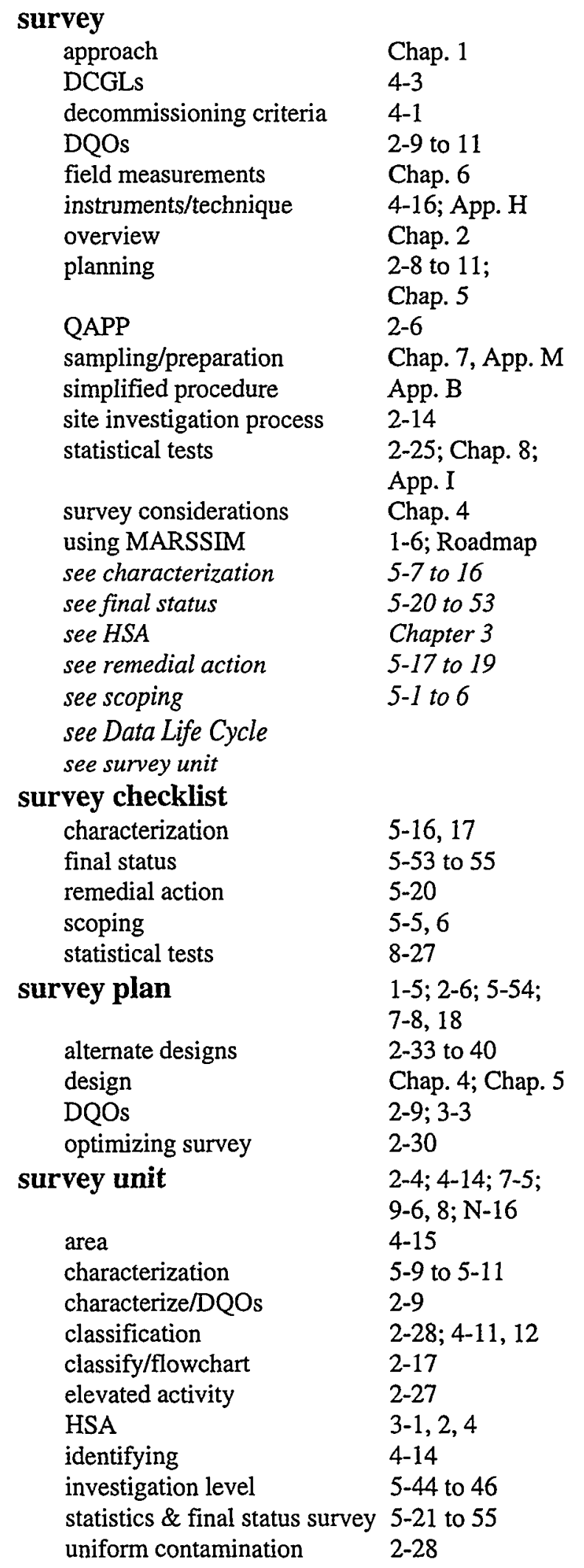

\section{survey}

4-3

2-9 to 11

Chap. 6

4-16; App. H

Chap. 2

2-8 to 11

Chap. 5

2-6

App. B

2-14

; Chap. 8

Chap 4

1-6; Roadmap

5-7 to 16

5-20 to 53

Chapter 3

5-17 to 19

5-1 to 6

$5-16,17$

$5-53$ to 55

$5-20$

$5-5,6$

1-5; 2-6; 5-54;

$7-8,18$

Chap. 4; Chap. 5

$2-9 ; 3-3$

$2-4 ; 4-14 ; 7-5$

$9-6,8 ; \mathrm{N}-16$

5-9 to $5-11$

2-17

$2-27$

4-14 


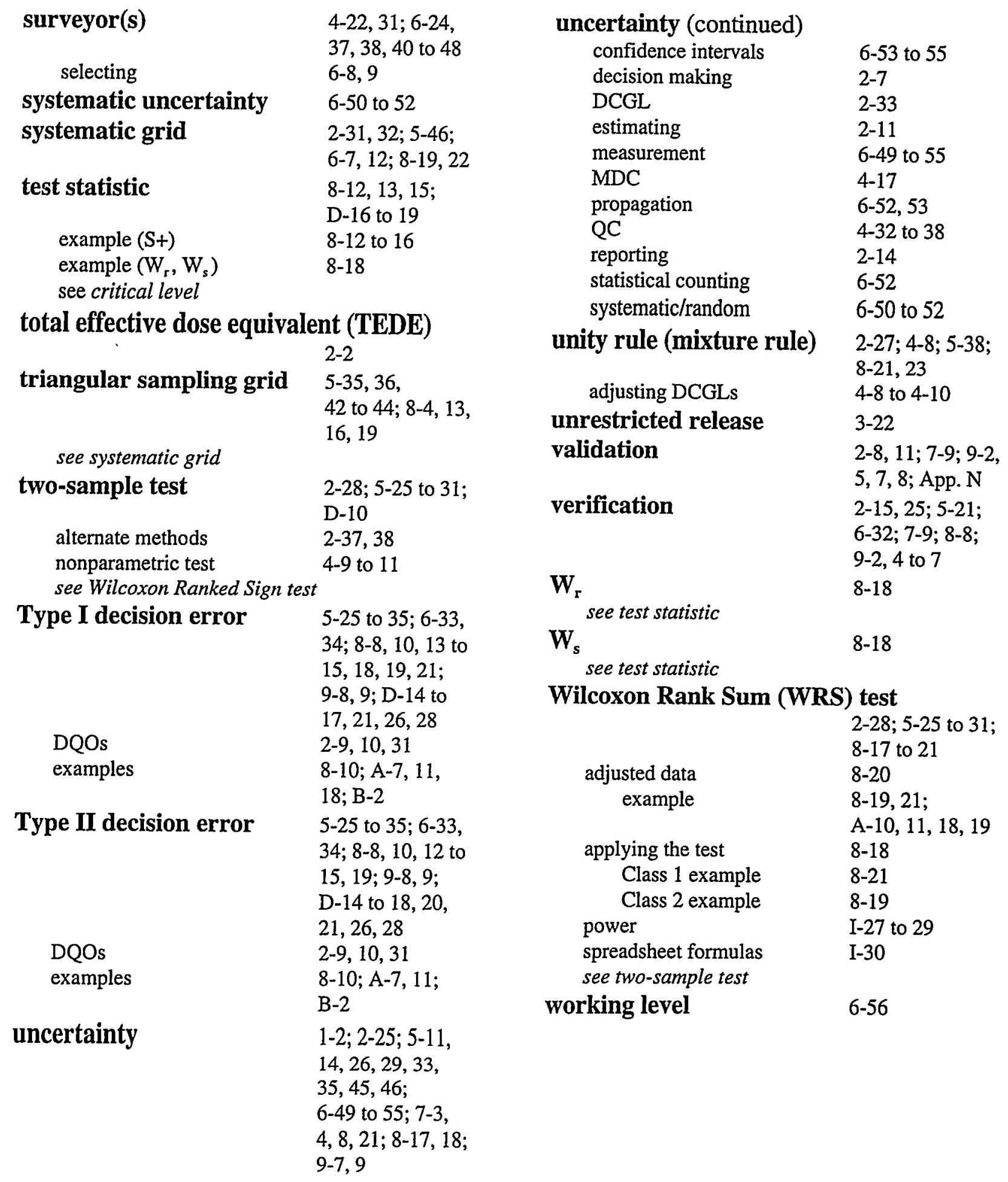

